


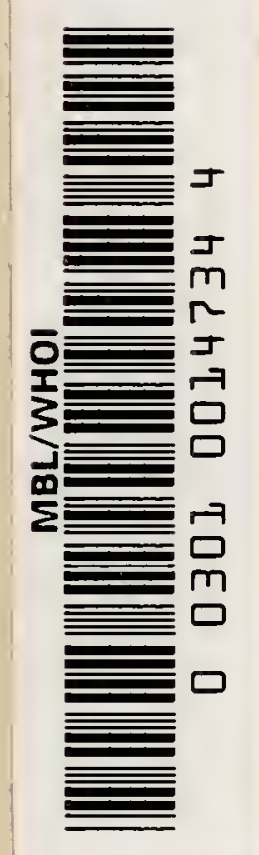





\section{LEHRBUCH}

DER

\section{Z O O L O G I E,}

EINE MORPHOLOGISCHE ÜBERSICHT DES THIERREICHES ZUR EINFÜHRUNG IN DAS STUDIUM DIESER

WISSENSCHAFT

VON

\section{DR. BERTHOLD HATSCHEK,}

O. O. PROFESSOR DER ZOOLOGIE AY DER DEUTSCHEN CARL-FERDINANDS-UNIVERSITÄT IN PRAG.

ERSTE LIEFERUNG.

MIT I55 ABBILDUNGEN IM TEXT.

J E N A,

VERLAG VON GUSTAV FISCHER.

1888.

Die zweite Lieferung ist in Vorbereitung und wird demnächst erscheinen. 


$$
\text { 7久多1 }
$$




\section{Vorwort zur ersten Lieferung.}

Das Lehrbuch der Zoologie, dessen erste Lieferung hier vorliegt, wird nach folgendem Plane sich entwickeln: Vorwiegend morphologische Behandlung des Stoffes, ausführliche Berücksichtigung der Entwicklungsgeschichte und Einschränkung des systematischen Theiles.

Ich beabsichtige demnach eine "morphologische Uebersicht des Thierreiches" zu geben. Wenn auch der physiologischen Betrachtung ganze Capitel gewidmet sind, so bildet dieselbe hier doch nur ein Hilfsmittel der Morphologie. Die vergleichende Physiologie der Thiere ist ein Sondergebiet, das sowohl in der Literatur - welcher seit Berganann-Leuckart ein zusammenfassendes Werk fehlt - als auch an unseren Universitäten, wie wir hoffen dürfen bald auch eine besondere Vertretung finden wird. Unsere grössten Universitäten werden sich wohl nicht lange mehr der Verpflichtung entziehen können, Lehrkanzelı der physiologischen Zoologie zil schaffen. Die physiologischen Lehrkanzeln der medicinischen Facultäten werden die Arbeitskräfte liefern.

Den herkömmlichen Darstellungen gegenüber wurden in dem vorliegenden Buche manche bedeutende Verïnderungen, namentlich in Bezug auf das zoologische System, vorgenommeu; doch habe ich dabei mir es zur Pflicht gemacht, nur solche Veränderungen aufzustellen, die nach dem gegenwärtigen Stande der Wissenschaft mit einiger Sicherheit begründet werden körmen und Dauer versprechen.

Ferner bitte ich, folgenden Satz Huxley's für dieses Buch in Anspruch nehmen zu dürfen: „Mit Ausnahme einiger wenigen Fälle habe ich es vermieden, verweisende Noten anzubringen und wenn daher der Leser mich mit Recht für jeden Irrthum verantwortlich halten wird, den er finden sollte, wird er auf der anderen Seite doch wohl 
thun, das, was etwa originale Ansicht zu sein scheint, mir nicht zuzuschreiben, wenn seine Kenntnisse nicht so eindringend sind, um ihn zu richtiger Beurtheilung in dieser Richtung zu befähigen." - Ein Verzeichnis der wichtigsten Literatur folgt am Schlusse des Buches.

In der nächsten Lieferung kömmt das Capitel „Histologie der Metazoen" zum Abschluss und es folgt das Capitel über die Functionen des Metazoenkörpers (Stoffivechsel, Bewegung, Empfindung, Arten der Fortpflanzung, Theorie der Vererbung) und ferner die speciellen Capitel über Spongien, Cnidarier etc.

Meinen besonderen Dank spreche ich meinem verehrten Collegen Herrn Prof. Herrng aus, der das erste Capitel durchgesehen und zu meiner grossen Beruhigung gebilligt hat.

Prag, November 1888.

Der Verfasser,

Sinnstörender Druckfehler: pag. 61 , Z. 6 v. unten ist nach dem Worte "Kernsubstanz" einzuschalten: ,zwischen beiden Individuen“. 


\section{ERSTES CAPITEL.}

\section{Plasma und Lebenserscheinungen.}

\section{Das Plasma.}

Wenn wir die Organismen im Allgemeinen betrachten und nach dem Gemeinsamen, dem Charakteristischen derselben fragen, so wird uns als wesentlich an ihnen die eigenthümliche lebendige Substanz, die als Plasma oder Protoplasma bezeichnet wird, erscheinen.

Bei den niedrigsten, einfachsten Organismen ist der gesammte Körper nichts anderes, als ein Klümpchen von Plasma. Bei allen nur einigermaassen complicirten Organismen unterscheiden wir Bestandtheile, die aus Plasma bestehen, und solche, die aus einer Umwandlung von Plasma hervorgegangen sind. In beiden Fällen sind alle Lebenserscheinungen in letzter Instanz auf das Plasma zurückführbar.

\section{Mannigfaltigkeit der Plasmaarten.}

Schon die Mannigfaltigkeit der Funktion deutet uns an, dass es sehr zahlreiche Plasmaarten giebt. Die Verschiedenartigkeit der Organismen ist auf die Verschiedenartigkeit ihres Plasmas zurückzuführen. Das Plasma ist aber nicht nur verschiedenartig je nach der Art des Organismus, sondern auch verschiedenartig in einzelıen Theilen desselben Organismus. Nur allereinfachste Organismen, z. B. Mikroben (Bakterien etc.) bestehen aus gleichartigem Plasma. Schon an den elementaren Gebilden, den Zellen, die bei den meisten Organismen in Ein- oder Mehrzahl den Körper zusammensetzen, findet sich an und für sich das Plasma verschieden im Zellleib und im Zellkern; und die Kellen der verschiedenen Körpertheile sind wieder in Bezug auf ihre Plasmabeschaffenheit einander gegenüberzustellen.

Physikalische und chemische Beschaffenheit des Plasma.

Das Plasma ist von zäh-weicher Consistenz (dies beruht, wie wir sehen werden, auf seinem mechanisch gebundenen Wassergehalt). Mit dieser Consistenz hängen gewisse Erscheinungen in der Formgestaltung der Organismen zusammen. Denn bei all der grossen Mannigfaltigkeit der Formgestaltung, mit deren Problem wir uns noch ausführlich beschäftigen werden, können wir eine Eigenthümlichkeit hervorheben, die in der Natur des Plasma begründet und daher von ursprünglicher Bedeutung und gemeinsam für alle Organismen ist: Die Organismen besitzen soge- 
nannte, "weiche ${ }^{6}$ Formen, d. h. Formen, die nicht von geraden Linien und ebenen Flächen begrenzt und die in gewissem Grade veränderlich sind. - Wir können im Plasma mit den stärksten Vergrösserungen meist noch Structuren, nämlich Körnchen und feine Fäden beobachten. Wir dürfen also das Plasma nicht als ei ne chemische Snbstanz, sondern wir mïssen es als ein Gemenge betrachten. Welche chemische Substanzen sind nun in diesem Gemenge nachweisbar?

Im Körper der Organismen kommt eine grosse Zahl von chemischen Elementen in mannigfachen Verbindungen vor (Sauerstoff, Wasserstoff, Kohlenstoff, Stickstoff, Schwefel, Phosphor, Chlor, Fluor, Kiesel, Kalium, Natrium, Magnesium, Eisen, Mangan und noch andere für die Organismen weniger wesentliche Elemente).

Gewisse chemische Verbindungen sind besonders wichtig als charakteristische Bestandtheile des Plasma. Es sind dies die kohlenstoffhaltigen oder ,organischen" Verbindungen und unter diesen vor allem gewisse stickstoffhaltige Verbindungen, die Eiweisskörper, ferner die stickstofflosen Kohlehydrate und Fette. Die Gruppe der Fiweisskörpel' ist chemisch sehr mannigfaltig, alle bestehen aus: Kohlenstoff, Wasserstoff, Sauerstoff, Stickstoff, Schwefel, und zwar stets in ähnlicher procentischer Zusammensetzung. Die A rtt und Weise dieser' Zusammensetzung aber, die chemische Constitution der verschiedenen Eiweisskörper, ist uns noch gänzlich unbekannt, wir wissen nur, dass sie zu den complicirtesten gehört. Die uns bekannten Eiweisskörper sind meist nur Zerfallsprodukte oder Leichenprodukte des Plasnia. Diese hochzusammengesetzten Verbindungen selbst gehen in der lebendigen Substanz noch höhere Verbindungen ein, die sich der chemischen Beurtheilung umsomehr entziehen. - Die Eiweisshörper und ihre Terbindungen kommen in Körper der Organismen stets in gequollenem Zustande vor; d. d. sie haben mechanisch Wasser gebunden, welches zudem Salze gelöst enthält.

Auch gewisse stickstofflose Verbindungen, nämlich die Ko hlehydrate (Stärke, Zuckerarten, Cellulose) und die Fet te spielen theils im pflanzlichen, theils im thierischen Organismus eine wesentliche Rolle. Die Kohlehydrate sind Körper, die aus Kohlenstoff, Wasserstoff und Sauerstoff bestehen, und zwar sind die beiden letz.teren in solchem Verhältniss enthalten, wie dieselben das Wasser zusammensetzen; durch Oxydation zerfallen die Kohlehydrate in Kohlensäure und Wasser. - Die Fette sind ebenfalls niedrig oxydirte stickst of flos e Kohlenstoffverbindungen.

\section{Assimilation (Entstehung neuer Plasmatheilchen).}

Die wesentlichste - und wohl auch urspriunglichste - Lebenselscheinung der Organismen ist die As similation. Das Plasma besitzt die Fähigkeit, gewisse fremde Substanzen von ander's gearteter chemischer Zusammensetzung in seine eigene Substanz umzusetzen, sie zu assimiliren. Durch die Assimilation wird neues Plasma, neue lebendige, d. h. selbst wieder assimilirende Substanz erzeugt; die lebendige Substanz wächst also durch die Assimilation. Als lebendiges Theilchen oder Plasmatheilchen können wir das kleinste Partikelchen bezeichnen, welches selbst noch die wesentliche Eigenschaft des Assimilationsvermögens besitzt, — möge man sich dieses Theilchen, wic viele es thun, als eigenartiges chemisches Molekel (Eiweissmolekel) 
vor'stellen, oder, was wahl'scheinlicher ist, als ein pliysikalisch wirkendes System verschiedenartiger Molekel. Durch die Assimilation werden also neue „Plasmatheilclien" erzeugt.

Man hat den Assimilationsprocess mit dem Wachsthum der Kristalle verglichen. Der Kristall wird durch Anziehnug vou Molekeln aus der Mutterlauge vergrössert und zwar solcher Molekel, die seinen eigenen gleichartig sind. Der Assimilationsprocess unterscheidet sich davon und zwar dadurch, dass bei demselben eine Umsetzung des molekularen Baues der aufgenommenen Nahrung erfolgt.

\section{Assimilationsprocess bei Pflanzen.}

Um die Natur des Assimilationsprocesses näher kennen zu lernen, wollen wir zuerst die Assimilation bei den Pflanzen betrachten, welcle die einfachere und über'sichtlichere ist. Der Process tritt hier auch mehr in den Vordergrund der Lebenserscheinungen als bei den Thieren.

Die Nahrung der Pflanzen ist Wasser, Kohlensäure, Salze und Ammoniak oder ammoniakalische Verbindungen. Aus diesen Körperı entstelıt in der Pflanze zuuächst Plasma, welches die Eiweisskörper entliält. In der Pflanze entstehen ferner unter dem Einflusse des Plasma in grosser Menge andere organische Substanzen, nämlich Kohleliydrate, sowie auch Fette, Harze und ätherische Oele. - Während die Nahrumg der Pflanze aus niedrig zusammengesetzten und dabei hoch oxydirten Substanzen bestelıt (wie Kohlensäure, Wasser und Salze) sind die daraus eutstehenden Stoffe sehr hocl zusammengesetzt und niedrig oxydirt. Bei einem derartigen chemischen Processe, einer clemischen Synthese, wird lebendige Kraft oder Wärme in Spannkraft umgewandelt. Die Wälme, die bei dem Assimilationsprocesse der Pflanzen gebunden wird, ist die Sonnenwärme. Wir können die von den Pflanzen verbrauchte Wärme wieder gewinnen, indem wir die Substanz der Pflanze oxydiren, indem wir die Pflanze verbremnen. - Die Zerfällung der Kohlensäure - wobei Sauerstoff frei wird, den die Pflanzen ausathmen und die Umsetzung des Kohlenstoffs derselben in Eiweisskörper und Kohleliydrate findet nur in den grüneu chlorophyllhaltigen Pflanzentheilen unter dem Einfluss der Sonnenstrahlen statt. Die chlorophyllfreien Pflanzentheile assimiliren auf Kosten von Reservestoffen, die von ersteren Theilen geliefert werden. Ebenso assimiliren die gänzlich chlorophyllfreien Humusflanzen und Schmarotzerpflanzen nur bereits von anderen Pflanzen vorbereitete Stoffe.

Viele Botaniker, welche nur den Process in den chlorophyllhaltigen Pflanzentheilen als Assimilation bezeichnen, kommen consequenter Weise zu dem Ausspruch, dass die Humuspflanzen und Schmarotzerpflanzen nicht assimiliren. Man müsste dann, wie aus den folgenden Ausführungen ersichtlich wird, auch den Thieren Assimilation absprechen. In beiden Fällen handelt es sich aber um Verwandlung andersgearteter Substanzen in die Substanzen des Plasma, also um Assimilation in unserem Sinne; es wird hier nur eine bereits höher zusammengesetzte Nahrung assimilirt.

\section{Assimilationsprocess bei Thielen.}

Die Nahrung der Thiere bilden Eiweisskörper, Kohlehydrate und Fette, die entweder dem Körper einer Pflanze oder eilles anderen Thieres entstammen. Da das fleischfressende Thier das pflanzenfressende. 
verzehrt, so stammt die organische Nahrung des Thieres in letzter Instanz immer vom Pflanzenreiche. Die Thiere sind also in ihrer Existenz vom Pflanzenreich abhängig.

Bei den Thieren finden gewisse Processe statt, durch welche die Nahrung noch für den Assimilationsprocess vorbereitet wird. So sehen wir bei den löheren Thieren, dass die Nahrung, nachdem sie etwa zerkleinert wurde, gewissen Secreten, den Verdauungssecreten, ausgesetzt und verflüssigt wild. Dieser ,Verdauungsprocess" findet in der Darmhöhle statt, welche ihrem Wesen nach nur eine Vertiefung der Körperoberfläche ist. Von hier aus erfolgt die Resorption, d. i. die Aufnahme der verflüssigten Nahrung in das Blut, während unbrauchbare Reste der Nahrung (durch den After oder bei afterlosell Thieren durch dell Mund) wieder entleert werden. Das Blut befördert nun die Nalirung zu dem Plasma der verschiedenen Gewele des Körpers; dies erst ist der Ort, wo die Assimilation selbst stattfindet. Bei den niederen Thieren mit einfachen Plasmakörper wird die feste Nahrung direkt in das Plasnı aufgenommen, es finden in diesem Falle auch die vorbereitenden Verdauungsprocesse im Plasma selbst statt.

Zweifellos werden die aufgenommenen Fiweisssubstanzen im Plasma, nachdem sie gewisse Veränderungen erfaliren haben, wieder in zusammengesetztere Verbindungen iibergeführt; anch die thierische Assimilation ist eine Synthese, bei welcher Wärue in Spannkraft umgesetzt wird. Da alser die Nahrungsstoffe sellst schon hoch zusammengesetzt sind, so wird eine viel geringere Wärmemenge gebunden, als liei der pflanzlichen Assimilation. Die hier in Frage kommende Wärme ist wahrscbeinliclı Athmungswärme (siehe unten).

Arbeitsleistung und Wärmeproduktion der Thiere durch Athmung.

Bei den 'Thieren spielen auch noch andere chemische Processe eine hervorragende Rolle, welche zunächst mit den Bewegungserscheinungen der Thiere zusammenhälgen. Das Thier muss sich bewegen, zunächst um seine Nahrung aufzusuchen und aufzumehmen. Es bewegt dabei seinen Körper, um den Ort zu verändern, oder es erzengt Strömungen im umgebenden Wasser, um dasselbe zu wechseln, oder es zieht die Nahrung sonstwie mechanisch heran. Die Bewegungsarbeit wird durch chemische Processe aufgebracht, bei welchen Spannkraft in lebendige Kraft ungewandelt wird, indem höher zusammengesetzte, niedrig oxydirte Substanzen in niedrig zusammengesetzte hoch oxydirte umgewandelt werden. Dies geschieht, indem im arbeitenden Plasma Eiweisskörper oder auch stickstofflose Verbindungen oxydirt werden. Eine besondere Rolle spielen die Kohlehydrate, welche unter Verbrauch von Sauerstoff in Kiohlensäure und Wasser zerfallen. Das ist wohl nur die ungefälure Ausdrucksweise; man stellt sicl gegenwärtig diese chemischen Processe complicirter vor, aber mit demselben Endergebniss. '/un 'Zwecke der Apleitsleistung miissen die Thiere demnach Sauerstoff aufnehmen und als Folge derselben scheiden sie Kohlensäure aus. Dies ist der durch die Arbeit bedingte Athmungsprocess der Thiere.

Die Athmungsorgane der Thiere dienen nur zur Aufnahme und Abgabe dieser Gase; das Blut führt dieselben dann $z u$ den arbeitenden Geweben, die letzteren selbst sind der Ort der chemischen Veränderungen. Bei den niedrigen Thieren findet der Gasaustausch zwischen Plasma und äusserem Medium unmittelbar statt. 
Neben der Arbeitsploduction wird durch Oxydation anch Wärme wohl bei allen Thielen erzcugt (Oxydation von Fetten pflegt hier eine besondere Rolle zu spielen). Bei ten warmblütigen 'J'hieren hat der Athnumgsprocess in dieser Bezichung cinc hervorragente Bedeutung, es wird bei ilnen durch die Oxydation vormelnnlich stickstoffloser Snlstanzen (Kohlehydrate, Fette) auch die Wälme er\%eugt, durch welche die für die Lebensplocesse dieser 'Thiere wichtige constante Temperatur erhalten wird. Wir sehen also, dass die Thiere Naln'ungsmittel aufnehmen nicht nur zum Zwecke der Assimilation, sonrlern anch zum /Wwecke der Arbeitsleistung und Wärmeproduktion.

Die Verwendung der. Nahrunguittel der. Tliele können wir kurz folgendermaassen zusammenfassen: Die Eiw e isskörper werden erstens zum Aufbau von Plasma verwendet, dienen also vor allem der eigentlichen Assimilation; sie können ferner auch als Respirationsmittel dienen, d. h. der Oxydation unterliegen; wenn sie aber im Ueberschuss zugeführt werden, wird die Oxydation nicht beendigt und es bleiben noch branchbare Reservestoffe, die später weiter oxydirt werden könmen, im Körper zurück, nämlich die Köorperfette. Die Kohlehydrate sind Arbeits- und Respirationsmittel. Die Nalru ugfette werden als Respirationsmittel verbraucht oder sie könne» auch zunächst direkt als Körperfett im Organismus abgelagert werden. Die letzteren beiden Arten von Körperu kömnen demnach als Nahrung das Eiweiss nur in Bezug auf gewisse Zwecke (Arbeits- und Wärmeproduktion) ersetzen und den Eiweissbedarf daher lierabmindern. Voll gänzlich eiweissloser Nahrung kann aber kein 'Thicr seine Lebensprocesse unterhalten und vor allem nicht assimiliren.

\section{Excretionsprocess der Thiere.}

Unbrauchbare Stoffe oder schädliche Substanzen, die bereits in die Körpersäfte (bei den lö̈lıeren Thieren in das Blut) aufgenommen sind, können durch den Harn wieder aus dem Körper entfernt werden. Von wesentlicher Bedeutung ist es aber, dass durch den Harn gewisse Stoffe, die im Körper selbst entstelien und deren Verbleiben giftig wirken würde, ausgeschieden werden. Die wichtigste dieser Substanzen ist der Harnstoff, ein durch '/ersetzung der Eiweisskörper gebildeter, bereits höher oxydirter stickstofflualtiger Körper. - Die Menge von Harnstoff, die ein Thier ausscheidet, ist mabhängig von der geleisteten Arbeit; in der Ruhe, ja selbst im Schlafe wird cbensoviel Harnstoff ausgeschieden, als bei oder nach der Arbeit; dagegen steht sic in bestimmtem Verhältniss zu der Menge der aufgenommencu Eiweisskörper'. Auffallend ist es aber', dass nicht nur ein humgerndes 'Thier, sondern auch ein solches, das nur mit eiweissloser Nahrung gefüttert wird, noch inmer bis zu ciner bestimmten Menge Harnstoff ausscheidet, und zwar' auf Kosten seiner Gewebe, wobei das 'Thier' natürlich au Körper verliert, abmagert. Die Eiweisszufuhr muss eine gewisse Höhe erreichen, um den Körper im Gleichmaasse zu erhalten, erst darüber hinaus findet ein Zunehmen desselben statt ${ }^{1}$ ).

Die Ausscheidung des Harns geschieht vornehmlich durch Excretionsorgane (Nieren), bei einfacheren Thieren kann sie aber nnmittelbar vom Plasma ansgehen.

1) Wir können daraus schliessen, entweder dass es auch ausser der Assimilation Functionen des thierischen Organismus giebt, bei welchen notwendig Eiweiss verbraucht wird, oder dass gewisse Assimilationsprocesse stets vor sich gehen - wenn nicht anders so auf Kosten der übrigen Körpertheile. 
A thum ug bei Pflanzen.

Auch die Pflanzen rerlurauchen bei gewissen Processen Sauerstoff; sie brauchen den Sauerstoff zum '/wecke der inneren Bewegungsleistungen, fermer bei der Assimilation innerhalb der chlorophyllfreien Theile und iiberhaupt bei Abschluss des Lichtes. Besonders auffallend ist die Sauerstoffathmung und Tärmeerzeugung bei den keimenden Pflanzen.

Wemm wir den Gesamm tstoffwechsel der Thiere und Pflanzen im Grossen und Ganzen vergleichen, so sehen wir, dass bei den Pflanzen Kohlensäure (als Nahrung) aufgenommen und ein Bestandtheil derselben, der Sauerstoff, ausgeschieden wird, dass dabei Wärme in Spannkraft ungewandelt wird. Bei den Thieren dagegen wird nebst hochzusammengesetzter Nahrung Sauerstoff aufgenommen und Kohlensäure ausgeschieden und es wird Spannkraft in bewegende Kraft mod Wärme ungesetzt. Dieser Gegensatz folgt daraus, dass bei den synthetischen Processen der Pflanze durch Desoxydation Sauerstoff frei wird und dabei sehr viel Wärme verbraucht wird, wälrend bei ihren geringfügigen inneren Bewegungserscheinungen der Verbrauch von Sanerstoff nur gering ist. Bei den Thieren dagegen wird viel Sauerstoff verbraucht zum Zwecke der bedeutenden Bewegungsleistungen und auch um Wärme zu erzengen, während bei der Synthese nur wenig Wärme verbraucht wird, da die Nahrungsstoffe schon hoch zusammengesetzt sind, es wird ferner in Zusammenhang mit der Arbeits- und Värmeproduction Kohlensäure ausgeschieden.

\section{Wachsthum und Fortpflanzung.}

Assimilation ist die einzige bekannte Bildungweise von Plasma.

Bei näherem Eingehen auf die Lebenserscheinungen finden wir, dass die Assimilation ïberhaupt die einzige Art der Entstehung neuer Plasmateikchen ist, welche wir aus der Erfahrung kennen. Durch die Fortphanzung wird kein neues Plasma erzeugt, denn die Fortpflanzung an und für sich ist nichts anderes als ein Theilungsprocess. Wir werden nur theoretisch zur Ammahme noch einer anderen Art der Eutstehumg von assimilirender Substanz oder Plasma reranlasst, wenn wir das erste Auftreten der Organismen erklären wollen. Es ist dies die Urzeugung (Generatio a quivoca oder spontanea).

\section{Ur z e u gung.}

Aristoteles liess selbst höhere Organismen durch Urzeugung: entstehen, so Aale und Frösche ans dem Schlamme, Insecten aus Pflanzentheilen, Maden aus faulendem Fleische u. s. w. Schon durch PeDr wurde diese Lehre ron der Urzeugnng wirksan bekämpft. Nachdem aber vermittelst des Nikroskopes eine neue Telt von Organismen entdeckt worden war, vertheidigte man wieder die Generatio aequivoca der Infusorien. Erst in unserem Jahrhunderte wurde endgiltig nachgewiesen, dass auch für die Infusorien und Eingeweidewürmer die Generatio aequivoca keine Geltung habe. In Bezug auf die fäulnisserregenden Organismen, Bacterien etc., hat sich die Discussion der Frage noch bis in die juingste Zeit (PAsteur gegen Poucher) fort- 
gesetzt. Gegenwärtig ist man durch vielfache Untersuchungen zu der Ueberzeugung gekommen, dass kein uns bekannter Organisnıus durch Urzeugung entsteht.

Auch theoretisch kommen wir zu einer ähulichen Anschanumg. ITil finden selbst die niedersten uns bekannten Organismen in ihren Lebenserscheinnngen in so bestimmter Weise an besondere Lebensbedingungen angepasst, dass wir, um diese Anpassung zu erklären, eine lange Reihe rorhergehender Generationen annehmen müssen. Wir sind der Ansicht, dass durch Urzeugung nur solche Organismen entstanden sind oder entstehen, deren assimilire nde Substanz oder Plasma viel einfacher war, als diejenige aller uns bekannten Organismen (NAEGELT).

\section{Begrenztleit des Wachstlums. Individualitït.}

Eine unmittelbare Folge der Assimilation ist das Wachsthum. Das Wachstlum der Organismen ist ein individuell begrenztes. Die bestimmte Grösse eines Organismus ist durch die Art seiner Organisation, durch seinen Bau, bedingt. Je einfacher die Organisation, un so geringer ist - innerhalb gewisser Grenzen — die Grösse des Organisnus. Man lat die Ansicht aufgestellt, dass die ursprünglichsten Organismen nicht ron begrenzter Grösse gewesen seicn, dass sie mmegehmässig zusammenhängende Plasmamassen von beliebiger', vom //ufall abhängender Ausdehnung gebildet hätten (HAEckeL's Bathybius). Fs ist aber nach Analogie der bekannten Verhältnisse walıscheinlicher, dass die ursprünglichsten Organismen von sehr geringer Grösse waren. Es ist auch möglich, dass es Organismen gibt, die sich durch ihre geringe Grösse jetzt noch unserer Beobachtung trotz aller optischen Hilfsmittel entriehen. (Manche Bakterien stehen an der Grenze der Walınehmbarkeit.)

Fortpflanzungoder. Vervielfältgung de Individualität.

Wenn das Individum die Grenze seines Wachsthums erreicht hat, wächst es als Individum nicht weiter. Aber es ist eine Fortsetzung des Wachsthums durch Tervielfältigung der Individualität möglich. Die Grösse des Organismus wird dnch 'Theilung herabgesetzt und es folgt cin erneutes IVachsthum der Theilstïcke. Ilan hat daher dic Vervielfältigung der Individuen, die Fortpflanzung, auch als , Wachsthmm über das individuelle Maass himaus", definirt (K. E. V. BAER).

Die Theilstücke sind entweder amnähernd gleich gross und wachsen beide in gleicher Weise wieder heran (Fortpflanzung durch Theilung im engeren Sinne), oder es werden von dem ursprünglichen Individumm verhältnissmässig kleine Theile abgestossen (Knospen, Kieime, Fortpflanzungskörper'), so dass dadurch die urspliüngliche Individualität nicht wesentlich beeinträchtigt wird, - und in diesem Falle erfolgt das wesentliche Waclistlum an jenen als neue Individuen abgestossenen Theilen.

Nur bei den einfachsten Organismen, die eine geringe Differenzirung des Körpers besitzen, bei denen demnach die Theilstücke (Theile, Knospen, Keime) im Wesentlichen dem Ganzen gleichen, beruht die Fortpflanzung nur auf Theilung und Wiederheranwachsen der Theilstücke. In allen anderen Fällen, wo die Theilstücke dem Ganzen nicht gleichen, kommen Differenzirungs- oder Entwicklungsvorgänge hinzu. 


\section{Vererbung.}

Hier tritt uns nun die Frage der Vererbung entgegen. Die Erscheinnugen der Organisnen wiederholen sich von Generation zu Generation oder auch im Rhythmus mehrerer Generationen. Wir nemnen die Ursache dieser Wiederholung "Vererbung", oder genauer gesagt - rla die Ursache keine einfache, sonder'n meist eine sehr complicirte Kette von Ursachen und Folgen ist - : Wir fassen unter dem Namen Vererbung die ganze Kette von Ursachen und Folgen zusammen, welche die Eischeinungen der aufeinanderfolgenden Generationen verbindet. Die Vererbungserscheinungen eines Organismus erklären, heisst diese ganze Kette voll Ursachen und Folgen klar legen.

Bei jenen einfachsten Organismen, die sehr geringe Differenzirungen besitzen, überblicken wir leicht den Zusammenhang der Erscheinungen und eliminiren die Vererbungsfrage, indem wir sagen: Die Theilstücke besitzen die wesentlichen Eigenschaften des Ganzen und gleichen demselben durch Wiederheranwachsen. Die Schwierigkeit der Erklärung beginnt erst dort, wo bei der Fortpflanzung die Theilstïcke dem Ganzen nicht gleichen, wo complicirte Eigenschaften verschwinden und wieder erscheinen. Die Vererbungsfrage beginnt für uns also erst dort, wo Differenzirungs- oder Entwicklungsvorgänge bei den Organismen auftreten.

Vermischung der Individualitaten ( $\mathrm{C}$ on jugat i o n, B efruch tung).

Von ganz allgemeiner Bedeutung ist die bei allen Arten von Organismen auftretende Erscheinung, dass getrennte Individuen sich unter Vermischung ihres Plasmas zu einem Individuun vereinigen (Vermischung der Individualitäten). Diese Vermischung der Individualitäten steht meist in einem gewissen Connex mit der Vermehrung der Individualitäten, d. i. der Fortpflanzung, wenn auch die beiden Processe ursprïinglich von einander unabhängig sind. Bei den nierlrigen Organismen verschnelzen entwickelte Individuen nit einander zu einem Individuum (Conjugatiou) und dieses rermehrt sich sodam durch eigentliche Theilung. Bei jenen höheren Organismen, wo besondere Fortpflanzungskörper (Ei, Sperma) als neue Individualitäten gebildet werden, sind es diese, welche zur Verschmelzung kommen (Befruchtumgsprocess, wohl zu unterscheiden von der vermittehnden Begattung). Die Verschmelzung geht also an den Fortpflanzungsörpern (das ist an dem einfachsten Zustande der Individualität) vor sich ${ }^{1}$ ). Wir bezeichnen eine Fortpflanzung, welche mit Vermischung der Individualitäten combinirt ist, als geschlechtliche Fortpflanzung. Neben derselben kommt bei vielen Organismen in rhythmischer Abwechslung ungeschlechtliche Fortpflanzung vor, bei keinem Organismus aber, wenigstens von den Einzelligen angefangen, fehlt die geschlechtliche Fortpflanzung.

1) Der verschiedenartige Bau der weiblichen und männlichen Fortpflanzungskörper ist fiir das Wesen der Befruchtung nur von secundärer Bedeutung. Diese Verschiedenheit beruht auf einer Theilung der Arbeit. Der weibliche Fortpflanzungskörper, die Eizelle, ist von bedeutenderem Volumen und liefert die ïberwiegende Menge von Substanz für das neue Individuum Der männliche Fortpflanzungskörper, die Samenzelle, ist klein, sehr beweglich und wird in sehr grosser Zahl erzeugt, alles Eigenthümlichkeiten, die zur Sicherheit des Zusammentreffens von $\mathrm{Ei}$ und Samen dienen (O. HerTwrG). 
Wir werden uns die Frage stellen: welche Bedeutung hat die geschlechtliche Fortpflanzung für den Organismus? Dass ein wesentlicher Vortheil für den Organismus daraus erwächst, beweist schon das allgemeine, gesetzmässige Auftreten dieser Erscheinung; um diesen Vortheil zu erforschen, wollen wir zunächst die verschiedenen Erfolge der geschlechtlichen Fortpflanzung oder Kreuzung ins Auge fassen.

Es wurde besonders von DABWIN auf zahlreiche Thatsachen hingewiesen, aus welchen hervorgeht, dass allzu nahe Verwandtschaft der Eltern ungünstig auf die Natur der Nachkommen einwirkt. Selbstbefruchtung ist bei vielen (zwitterigen) Pflanzen entweder resultatlos oder führt zu schwächlicher Nachkommenschaft; bei zahlreichen Pflanzen sind auch Einrichtungen vorhanden, welche diesen Vorgang iberhaupt verhüten. Aus einer grossen Anzahl von Thatsachen ist ferner ersichtlich, dass auch allzu nahe Verwandtschaft der Eltern („Inzucht") ganz allgemein schwächliche Nachkommenschaft zur Folge hat, besonders wenn die Inzucht durch mehrere Generationen fortgesetzt wurde. Das günstigste Resultat erfolgt bei einem gewissen Grade von Verschiedenheit der Eltern. Bei einem grösseren Unterschiede aber, wie er zwischen verschiedenen Rassen oder Arten besteht, machen sich wieder Störungen bemerkbar (Unfruchtbarkeit der Bastarde etc.), welche sich mit dem Grade der Verschiedenheit so weit steigern, dass die Befruchtung endlich wieder resultatlos erscheint. Das Gesetzmässige dieser Erscheinungen lässt sich dahin zusammenfassen, dass ein gewisser Grad von Verschiedenheit der Eltern für die Lebensfähigkeit der Nachkommen günstig ist.

Die erblichen Unterschiede zwischen den Individuen einer Art beruhen auf der Verschiedenartigkeit der äusseren Einfliisse (Lebensbedingungen), welche Generationen hindurch auf dieselben einwirkten. Diese Einflisse können auch ungünstige Veränderungen hervorrufen. Es ist besonders hervorzuheben, dass ein Organismus, der zahlreiche Generationen hindurch allzu gleichartigen Lebensbedingungen ausgesetzt bleibt, ungünstig beeinflusst erscheint (erbliche Häufung der Schädlichkeiten). Dagegen wirken geringe Veränderungen der Lebensbedingungen günstig anf den Organismus ein. Ein ähnlicher Erfolg kann aber auch (für die Nachkommen) erzielt werden durch Kreuzung von Individuen, die in gewissem Grade verschieden sind (d. h. Generationen hindurch in gewissem Grade verschiedenartigen Bedingungen ausgesetzt waren). Die Kreuzung erscheint daher als eine Correcturgegendie ungïstige und erblicheWirkung einseitiger Lebensbedingungen. Es wird der Einfluss mannigfacher Lebensbedingungen hierdurch ausgenützt, d. h. von verschiedenen Individuen auf eines übertragen ${ }^{1}$ ).

1) In ähnlicher Weise hat sich schon DARwin geäussert, indem er darauf hinweist, dass ein ,Parallelismus zwischen den Wirkungen der veränderten Lebenshedingungen und der Kreuzung" bestehe: ,Es scheint mir, dass einerseits geringe Veränderungen in den Lebensbedingungen aller organischen Wesen vortheilhaft sind, und dass andererseits schwache Kreuzungen, nämlich zwischen Männchen und Weibchen derselben Art, welche unbedeutend verschicdenen Bedingungen ausgesetzt gewesen sind und unbedeutend variirt haben, der Nachkommenschaft Kraft und Stärke verleihen. Dagegen haben wir aber gesehen, dass bedeutendere Veränderungen der Verhältnisse die Organismen, welche lange Zeit an gewisse gleichförmige Lebensbedingungen im Naturzustande gewöhnt waren, oft in gewissem Grade unfruchtbar machen, wie wir auch wissen, dass Kreuzungen zwischen sehr weit oder specifisch verschieden gewordenen Männchen und Weibchen Bastarde hervorbringen, die beinahe immer einigermaassen unfruchtbar sind. Ich bin vollständig iiberzeugt, dass dieser Parallelismus durchaus nicht auf einem blossen Zufalle oder eincr Täuschung beruht." 
Wir können nun die vorhin erwähnten verschiedenen Erfolge der Kreuzung folgendermaassen erklären. Wenn gleichartige Individualitäten (Fortpflanzungskörper, die von ein und demselben elterlichen Individuum oder von nahe Verwandten herruhren) miteinander verschmelzen, so ist damit keine direkte Schädlichkeit gegeben, sondern es ist nur die nützliche Correctur in Wegfall gekommen (wie bei ungeschlechtlicher Vermehrung). Ein gewisser Grad von Verschiedenheit ist günstig, da die Wahrscheinlichkeit der Correctur hier grösser ist. Der Misserfolg aber, der bei einem noch grösseren Betrage von Verschiedenheit eintritt, beruht auf Gründen ganz anderer Art; das Plasma der beiden Individuen ist nämlich hier schon derart verschieden, dass die Mechanik der Lebensprocesse, wenn wir uns so ausdrücken dürfen, hier durch die Vermischung gestört wird ${ }^{1}$ ).

Man wird hier die Frage aufwerfen, ob nicht jede Veränderung, also auch eine neu auftretende, dem Organismus nützliche Eigenthümlichkeit, durch die wiederholte Kreuzung aufgehoben werden müsse?

Diese Frage ist vom Standpunkte der später zu erörternden Descendenztheorie besonders wichtig.

Die fortgesetzte Kreuzung würde in der That zur Wiederaufhebung aller neu auftretenden Eigenthümlichkeiten führen, wenn nicht die "n a tiu rli che Zuchtwahl" als ein selbständiger Faktor einwirken würde.

So wird eine Veränderung der Art in der Richtung der von der Zuchtwahl begünstigten Eigenschaften immerhin stattfinden, wenn auch oin Theil der Veränderungen durch Kreuzung wieder aufgehoben wird. Die Wirksamkeit der natürlichen Zuchtwahl wird demnach durch die Kreuzung verlangsamt, aber nicht aufgehoben.

\section{Contractilität und Irritabilität des Plasmas.}

Als allgemeine Eigenschaften des Plasmas werden ferner die Contractilität und Ir roitabilität betraclitet.

Trir sehen am Plasma Gestaltsveränderungen vor sich gehen, welche walnscheinlich stets auf einer abwechselnden Verkür Zullg und Verlängerung seiner fürligen Bestandtheile beruhen, während die flïssigen Bestantlheile mit den Köruchen dabei sehr auffallende, aber wahrscheinlich passive. Strömung serscheiuungen zeigen. Alle Bewegungsarten der Organisnen sind von dieser Grunderscheinung abzuleiten.

Auf ïussere Einflïsse (, Reize*), z. B. chemische, mechanische, Licht-, Wärmereize ctc, schen wir an Plasn1a Veränderungen, zumeist Contractionserscheinumgen, erfolgen. Es ist zul vermuthen, dass die verschiedenintigen Reize innerhall, des Plasmas immer zunächst in gewisse chemisch-pliysikalische Verïnderungen des Plasmas („Er re gung $g^{6)}$ ) migesetzt werden, die mmittelhar orlel mittelbar (Fortleitung

1) WEISMAN hat eine ganz andere Ansicht über die Bedeutung der geschlechtlicheu Fortpflanzung aufgestellt. Sie soll selbst die Ursache der Variabilität sein (welche das substrat für die phylogeuetisclı e Vervollkommung der Organismen bildet). Diese Theorie des geistreichen Forschers gründet sich auf falsche Voraussetzungen. Erstens ist die Aunahme nicht richtig, dass ein Organismus, der sich längere Zeit nur ungeschlechtlich vermehrt, nicht der Variabilität unterliegt (DARwiN hat darauf hingewiesen, dass Zweige eines Baumes oder durch stecklinge fortgepflanzte Gewächse variiren); zweitens ist die Kreuzung, nach ganz allgemeiner und gut begründeter Anschauung, wohl geeignet, Verschiedenheiten zu verwischen und Mischcharaktere zu erzeugen, nicht aber neue Charaktere entstehen zu lassen. Drittens ist noch einzuwenden: da viele Organismen innerhalb sehr langer Zeitperioden keine merkbare phylogenetische V'ervollkommung erfahren, so ist der etwaige Nutzen der Variabilität ein viel zu indirekter (zeitlich entfernter), um eine so allgemeine und gesetzmässige Eimrichtung zu bedingen, wie es die Vermischung der Individuen ist. 
(ler Erregung) den Anstoss zur Contraction etc. gehen, letztere ist aber meist mechanisch viel mächtiger, als der Anstoss sellost.

Wir können im Thierreiche eine Stnfenreihe beohachten von dem einfachen Folgevorgang (Abfolge) von Reiz, Erregme nnd Bowromm bis zu jenen complicirten Vorgängen, wo das 'Thier anf die lindriicke der Anssenwelt mit complicirten zweckrlienlichen Handlungen antwortet, unter Vermittlung complicirter Erregungsurocesse. Wir Wollen hier in kurzem andeuten, worin diese complicirten Processe hestehen. Fs treten besondere Organe auf, dic als Vermittler der Frognmg dienen (Nervensystem). Die rurch einen Reiz bewirkte Erregung wird rlurch das Nervensystem fortgeleitet, sie läuft aber nicht einfach mit der Inslösung einel Thätigkeit in der ohen angerleuteten ITeise al), sondern sic linterlässt in einen entsprechenden Theile des Nervensystens (nämlich in den ,Ganglienzellen") eine dauernde Nacherregnug. Der einfachste Vortheil, der hieraus erwächst, ist, dass eine nachfolgende gleichartige Frregung schon bei geringerer Intensität die entsprechenrle Folgebewegung veranlasst. Da aber die verschiedenen Theile des Nervensystens mit einander in mamnigfachster Weise in physiologischer Verbindumg stehen, so kommt es, dass eine duch einen Reiz bewirkte Erregung auf dem Wege dieser mamnigfachen Verbindungen anch mit einer ganzen Summe vou Tacherregungen zul Interferenz kommen kamn und das Resultat dieses complicirten Processes ist oft eine combinirte Hamrllmm. Die Nacherregungen werden auch, ohne dass ein neuer Reiz hinznkoumnt, in Wechselwirkung treten; es wird dies zu veründerten Erregungszuständen führen; es können aus dieser letzten Wechsolwirkung auch Handlungen erfolgen, die also das Resultat weit zuriickliegender, frïher stattgefundener, Reize sind.

$$
\text { Ueber die, geistigen Vorgänge". }
$$

Wir haben im Vorhergehenden kurz angedeutet, welcher Art dic complicirten Vorgänge sind, die im Centralnervensystem rler Thiere nurd des Menschen ablaufen. So odler ähnlich werden dieselben von allen Naturforschern aufgefasst.

Die materialistische Schule betrachtet nun diese Vorgïnge als irlentisch mit den sogenannten geistigen Vorgängen. Anrlere Philosophen wollen diese Vorgänge, als materielle, streng unterschierlen wissen ron dem geistigen Leben, welches eine parallel einhergehende Begleit ersche in u $\mathrm{ng}$ rieser materiellen Vorginge sein soll. Wierler andere wollen das Materielle und Geistige auf die verscliciedene Betrachtungweis e eines und desselben Dinges zuliickfuihren.

Wir kïnnen auf eine nähere Erörterung dieser Anschaumgen hier nicht eingehen. Wir wollen $11 u r$ eines hervorhehen. Voull Stan alpunkte der mechan is chen Weltanschanung (der sogenannten naturwissenschaftlichen) hahen wir nichts anderes zu erklären, als den mechanischen Zusanmenhang del Eischeinumgen. So werden wil z. B. auch rlie Thätigkeit des Nervensystems als vollständig erklärt hetrachten, wenn wir den /busammenlang von Reiz, Erregming und Handlumg in allen seinen Complicationen mechanisch erklärt haben. Fs gilt ries aucli, wenn wir uns sellst als Object betrachten ${ }^{1}$ ).

1) Bei dieser Betrachtungsweise ist die mechanische Bewegung unser Rechungselement; wenn wir aber die Empfindung jals Rechnungselement einsetzen (MACH), dann haben wir die Welt als reine Empfindungswelt zu betracliten, denn das, was wir Bewegung nennen, ist selbst nur Folgerung aus (oder entspricht) einem Conplex von Empfindungen. 


\section{ZWEITES (APITEL.}

\section{Descendenzle hre.}

\section{Constanzlehre und Descendenzlehre (LشARCk, DARWN)' ${ }^{\text {) }}$.}

Die Lehre yon der Constanz der A rten war bis in die jüngste Keit die her'rschende; die Arten galten als muveränderlich; jede Art sollte einzeln für sich erschaffen rorden sein. Nach der Descendenzlehre, die gegenwärtig von beinahe allen Naturforschern anerkannt wird, halten wir dafür, dass die Arten veränderlich und dengemaiss ron anderen Arten abzuleiten seien. Wir betrachten alles Leben anf nnserem Planeten als einen einheitlichen, durch die Abstamnung mechanisch zusammenhängenden Process - von den einfachsten Lebenserscheinungen der ersten, durch Urzengung entstandenen Organismen heginnend und innerhalb, ungehenrer Zeiträume zu den üheraus mannigfaltigen und complicirten Erscheinungen der Gegenwart hinführend. Der Z/usinmmenhang dieses Processes in seinen grossen Kü̈gen wird durch den Stammbaum der Organismen dargestellt.

Die Ideen der Descendenzlehre sind in ihren ersten Anfängen bis in das classisehe Altertlum zurückzuverfolgen. Die ausführliche Darlegung und Begriürdung der Descendenzlehre gehört aber unserem Jahrhunderte an. Die Geschichte dieser Theorie bildet einen wichtigen Theil der Geschichte der geistigen Bewegung unseres Jahrhundertes.

LAMAlick hatte in Jalre 1801 und damn bedeutend erweitert 1809 in seiner Philosophie zoologique die Lehre anfgestellt, dass alle Arten, den Menschen eingeschlossen, von anderen Arten abstammen. Er nahn ein Gesetz der fortschreitenden Entwicklung an. Als Ursachender Umwandlung der Arten stellte er hanptsächlich die directe Einwirkung äusserer Einflüsse, ferner den Gebrauch oder Nichtgebrauch der Organe auf, da er die hiedurch hervorgerufenen Veränderungen irriger Weise - für erblich hielt. Wir können LAMARck's Theorie als die Theorie der direkten Anpassung bezeichnen.

1) Die Selectionstheorie DARwins, welche den wesentlichen Inhalt dieses Capitels bildet, ist schon vielfach auszugsweise behandelt worden. In keiner dieser Darstellungen ist die treffende Ausdrucksweise für den Gegenstand in so bewunderungswuirdiger Weise gefunden, wie in dem classischen Originalwerke. Dieser Einsicht folgend habe ich mich hier in diesem kurzen Auszuge beinahe ausschliesslich an die Worte des Originals gehalten (nach der Uebersetzung von Brove, revidirt von V. Carus, 5. Auflage, Stuttgart 1872 ) und war nur bestrebt, die demselben entnommenen Sätze sinngemäss aneinanderzureihen und zu verbinden. Ich hoffe dadurch die Jünger der Wissenschaft am besten dazu anzuregen, das Originalwerk selbst zur Hand zu nehmen. 
Wenn auch sein denkwïdiger Versuch an der Unrichtigkeit dieses erklärenden Principes scheiterte und die Descendenzlchre nicht zu allgemeiner Anerkennung brachte, so ist dennoch LAulick stets als der erste zu nennen, rer die Descendenzlehre in wisscnschaftlicher und consequenter Weise vertrat.

In der Folgezeit wiederholen sich immer zahlreichere Versuche und Andeutungen, die sich auf dic Abstammungstheorie beziehen, dem der Boden ward immer mehr fiur dieselbe vorbereitet: Die fortgeschrittene Physiologie lehrte, dass die Organismen denselben allgemeinen physikalischen Gesetzen unterworfen seien, wie die anorganischen Körper — und die morpholngische Forschung, nämlich die vergleichende Anatomic und Entwicklungsgeschichte, hatte eine Summe von Thatsachen zusammengetragen, durch welche das allgeneine wissenschaftliche Bewusstsein sich mvermerkt jencr 'Theorie immer mehr näherte.

Als nun DAlwis mit rler fundamentalen Entdeckung des Selections princips hervortrat und damit die Descendenzlehre aufs neue begriundete, gelangte dieselhe in kürzester '/eit zu allgemeiner Anerkennung.

\section{Darwin's Selectionstheorie.}

DAkwrs hat seine 'Theoric zunächst im /ansammenhang dargestellt in seinem Hauptwerk: "Ueber die Entstehung der Arten durch natürliche Kuchtwahloder die Erhaltung der begünstigten Rassen im Kímpf ums Dasein" (1859) ${ }^{1}$ ). In einer ganzen Reihe nachfolgender Werke werden viele wichtige hierhergehörige Fragen noch ausführlicher erörtert.

DARwin geht von der Betrachtung der Bildung von Rassen unter dem Einflusse des Züichters (Abänderung im Zustande der Domestication) aus. Das Mittel, durch welches der Züchter seine Erfolge er:zielt, ist die Kuchtwahl. Der Züchter kann seine 'Thiere nicht direkt verändern, sondern er benutzt die ohne sein Zuthun auftretenden Veränderungen. Es sind also folgende 2 Hauptpunkte hervorzuheben: 1) Bei den einzelnen Individuen treten mannigfache erbliche Veränderungen auf. 2) Der Küchter wählt diejenigen Individuen zur Nachzucht aus, welche ihm zusagende Eigenthümlichkeiten besitzen. Durch fortgesetzte Zuchtwahl können geringe Veränderungen zu einem lucdeutenden Betrage gehäuft werden (accumulatives Wahlvermögen). Dic durch den Züchter erzielten Rassen zeigen daher Eigenthümlichkeiten, welche nicht dem eigenen Nutzen der Pflanze oder des Thieres dienen, sondern dem Nutzen und der Liebhaberei des Menschen.

Die Umwandlung der Arten in Naturzustande beruht auf folgenden analogen Principien: 1) A uftreten mannigfacher erblicher ind i vidueller A bänderungen. 2) Natürliche Kuchtwahl oder Ueberleben der bevorzugten (passendsten) Individueu im Kampfe ums Daseill.

Die individuelle Abändelung der Organismen im Naturzustande ist allerdings weniger häufig und weniger auffallend, als im Kustande der Domestication; sie besitzen, wie man sich ausdrickt, einen weniger biegsamen Charakter. Die Gesetze der Abänderung sind noch wenig erforscht. 
I a m p u u s Dasein.

Der Kampf uns Dasein unter den organischen Wesen der ganzen Welt geht unvermeidlich aus dem hohen ge ometrischen Verhältnisse ilmer Vermehrung hervor. Es ist dies die socialwissenschaftliche Lehre von MaLthus auf das ganze Thier- und Pflanzenreich angewendet. Es giebt keine Ausnahme von der Regel, dass jedes organische Wesen sich auf natürliche Weise in einem so hohen Maasse vermehrt, dass, wenn nicht Zerstörung einträte, die Erde bald vol der Nachkommenschaft eines einzigen Paares bedeckt sein wiirde. Sellost der Mensch, welcher sich doch nur langsan vermehrt, verdoppelt seine Anzahl in fünfundzwanzig Jahren, und bei so fortschreitender Vervielfältigung würde die Welt schon in weniger als tausend Jahren buchstäblich keinen Raum mehr für seine Nachkommenschaft haben. Lissé hat schon berechnet, dass, wenn eine einjährige Pflanze nur zwei Samen erzeugte (und es giebt keine Pflanze, die so wenig productiv wäre) und ihre Sämlinge im nächsten Jahre wieder zwei gäben u. S. w., sie in zwanzig Jahren schon eine Million Pflanzen liefern würde. Wird eine Baumart durchschnittlich tausend Jalne alt, so würde es zmr Erhaltung ihrer vollen Anzahl genügen. wenn sie in tausend Jahren nur einen Samen hervorbrächte, vorausgesetzt, dass diesem einen die Sicherheit der Entwicklung und Existenz gegeben wäre.

Der Ausdruck Kampfums Dasein wird von DARwin im weitesten Sinne gebraucht. Vor allem ist hervorzuheben, dass dabei nicht nur das Leben des Individuums, sonder'n was noch wichtiger ist, der Erfolg in Bezug auf das Hinterlassen der Nachkommenschaft einbegriffen wird. Es ist ferner nicht nu ein unmittelbarer Kampf, soutlern überhanpt die Wechselbeziehungen der Wesen zu einander hiermit bezeichnet. Man kann mit Recht sagen, dass zwei hundeartige Raubthiere in Zeiten des Mangels um Nalıung und Leben mit einander kämpfen. Von einer Pflanze, welche alljährlich tausend Samen erzengt, unter welchen im Durchschnitt nur einer zur Entwicklung kommt, kann man sagen, sie kämpfe ums Dasein mit anderen Pflanzen derselben oder anderer Arten, welche bereits den Boden bekleiden. Die Mistel ist abhängig vom Apfelbaum und wenigen anderen Baumarten. Wachsen nehrere Simlinge derselben dicht auf einem Aste beisammen, so kann man in zutreffender Weise sagen, sie kämpfen mit einander. Da die Samen der Mistel von Vögeln ausgestreut werden, so hängt ihr Dasein mit von dem der Vögel ab und man kann metaphorisch sagen, sie kämpfen mit anderen beerentragenden Pflanzen, damit sie die Vögel veranlassen, eher ilıre Früchte zu verzehren und ihre Samen auszustreuen, als die der andern. - Es bestehen complicirte Beziehungen aller Pflanzen und 'Thiere zu einander im Kampfe ums Dasein. - Der Kampf ums Dasein ist am heftigsten zwischen Individuen und Varietäten derselben $\mathrm{Art}^{1}$ ).

1) DARWIN schreibt an einer Stelle: "Wir sehen das Antlitz der Natur in Heiterkeit strahlen, wir sehen oft Ueberfluss an Nahrung, aber wir sehen nicht oder vergessen, dass die Vögel, welche um uns her sorglos ihren Gesang erschallen lassen, meistens von Insecten oder Samen leben und mithin beständig Leben zerstören; oder wir vergessen, wie viele dieser Sänger oder ihrer Eier oder ihrer Nestlinge unaufhörlich von Raubvögeln und Raubthieren zerstört werden; wir behalten nicht immer im Sinne, dass, wenn auch das Futter jetzt im Ueberfluss vorhanden sein mag, dies doch nicht zu allen Zeiten jedes umlaufenden Jahres der Fall ist. 


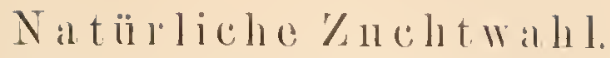

Wenn wir uns daran erinnern, dass oftenbar viel nehr Individuen geboren werden, als möglicherwoise fortlehen kïmuen, so ist nicht zu bezweifoln, dass diejenigen Individuen, welche irwend einen, wenn anch noch so geringen Vortheil ror anderen vorans hositzen, die meiste Wahrscheinlichkeit haben, die ander'n zn ïberdaner'n nnd wieder ihnesgleichen hervorzubringen. Andererseits können wir sicher sein, llass eine in geringsten Grade nachtheilige Abändernug nunachsichtlich der 'serstörung anhein fillt. Diese Erhaltung gïnstiger individueller Verschiedenheiten und Abändermugen und die Kerstörung jener, welche nachtheilig sind, ist es was, Datwin natiurliche /uchtwall nennt orlen Ueberleben des Passendsten ${ }^{1}$ ).

Da der Mensch dnuch nethoulisch orler mbewnsst ausgeführte Wahl zum Zwecke der Nachzucht so grosse Erfolge erzielen kanı unm! gewiss erzielt lat, was mag nicht die natïrliche Znchtwalıl leisten kïnnen ? Der Meusch kamn nur auf äusserliche nuld sichtbare Charaktere wirken; die Natur (wenu es gestattet ist, so die matürliche Erhaltung oder das Ueberleben des Passendsten zu personiticiren) fragt nicht nach ilon Anssehen, ausser wo es irgend einen Wesen niitzlich sein kann. Sic kann auf jerles innere Organ, auf jerle Schattirung einer constitntionellon Verschierlenheit, auf die ganze Maschinerie des Lebens virken. Dor Mensch wälılt nur zu seinem eigenen Nutzen; die Natul umr zum Nutzen des Wesens, das sie erzielt.

Die natuirliche '/uchtwahl wirkt nur durch und für den Vortheil eines jeden Wesens. Was die natürliche Zuchtwahl nicht bewirken kilnn, ras ist: Unänderung der Structul einer Species ohne Vortheil fïr sic zn Gunsten einer anderen Spocies ${ }^{2}$ ).

Man kanu figürlich sagen, die natürliche Zuchtwahl sei täglich und stiindlich durch rlie ganze Welt besclıäftigt, eine jerle, auch die geringste Abänderung zu prïfen, sie zu verwerfen, wem sie schlecht, und sie zu erhalten nnd zul vermehren, wenn sie gut ist. Still mud unmerkbal ist sie überall und allezeit, wo sicle di e Gelegenleit dabietet, mit der Vervollkommnung eines jerlen organischen Wesens in Bezug anf dessen organische und nuorganische Lebenshedingungen beschäftigt.

Die nat ï rliche Kuchtwahl wirkt immer mit äusserstel. La $\mathrm{n}$ gs a m keit. Sie kamn nur damn wirken, wenu in dem Naturhaushalte eines Gebietes Stellen vorhanden sind, welche dadnch besser bosetzt werden können, dass einige seiner Bewohner irgend welche Abändermug erfahren. Durch diese Wirknug in Verlaufe langer Zeitrïume ist der Umfang der Veränderungen, die Schönheit und endlose Verflechtumg der Anpassumgen alle1 organischen Nesen an einander und natïrlichen Lebensberlingungen ermöglicht.3).

1) In jünster Zeit hat Weismann, einer der verdienstvollsten Fortbilder der Descendenzlehre, es wahrscheinlich gemacht, dass selbst auch zur Erhaltung des Organismus auf gleicher Stufe, die Thätigkeit der Zuchtwalıl nöthig sei. Theile eines Organismus, die dem Einfluss der Zuchtwahl entrückt werden (z. B. Augen der Höhlenthiere) sollen nach dem Prin cip der ,Panm y $\mathrm{x}$ i e" der Degeneration anheimfallen.

2) Doch können zwei Organismen zu wechselseitigem Nutzen angepasst sein.

3) Der blosse Verlauf der Zeit an und für sich thut nichts für und nichts gegen die natürliche Zuchtwahl. DARWIN bemerkt dies ausdrücklich, weil man irrig behauptet laat, dass er dem Zeitelement einen allmächtigen Antheil bei der Modifikation der Arten zugestehe. 
Ein specieller Fall der natürlichen rouchtwahl ist die gesch le ch t lich e Z nch twall, d. i. der Kampf der Individuen eines Geschlechtes, meistens der Männchen, um den Besitz des anderen Geschlechtes. Ein geweihloser Hirsch nud spornloser Hahn haben wenig Aussicht, zahlreiche Erhen zu linterlassen. Durch die sexnelle /uchtwahl sind viele Eigenthümlichkeiten entstanden: so das prächtige Gefieder der mämnlichın Tögel, der Gesang derselben etc. und in ähnlicher Weise bei vielen anderen Thierklassen besonder's secundäre Geschlechts-Charactere, die nur dem einen Geschlechte znkommen (Schmnck, Waffen, Vertheidigungsmittel).

Divergenz des Charakers. Artenzahl der Organismen.

Wir müsscn uns num die Frage stellen, ans welchem Grunde bei den organischen Wesen eine so mamnigfaltige und bedeutende Verschiedenheit der Organisation zu finden ist. Um hierin einen Eimblick zu gewimmen, gehen wir zunïchst von der specielleren Frage aus: Anf welche IVeise wächst die kleinere Verschiedenheit der Varietäten zu grösseren specifischen Verschiertenheit an?

DARWI ist anch hier von der Retrachtung der Züichtungserzengnisse ansgegangen. Die Bildung so weit anseinanderlatufendel Rassen, wie die des Rem- und Karrenpferdes, der verschichlenen Taubenrassen 11. s. W. sind dadurch zu Stande gekommen, dass die Züchter Mittelformen nicht bewundern, sondern Fxtrene lieben, und weil durch die grössere Verschiedenheit der Rassen dem Menschen ein mannigfaltigerer Nutzen erwächst.

Auch die Natur begïnstigt, wenn man so sagen will, die Extreme, denn je weiter die Abkömmlinge einer Species im Ban, Constitution und Lebensweise anseinandergehen, un so besser werden sie geeignet sein, viele und sehr verschiedene Stellen in Haushalte der Natureinzunelnen und somit befähigt werden, a $11 \%$ a h l zuzunelimen.

Es ist durch Versuche dargethan worden, dass, wemn man eine Strecke Landes mit Gräser'n verschiedener Gattungen besäet, nan eine grössere Anzalıl von Pflanzen erzielen mul ein grösseres Gewicht ron Heu einbringen kann, als wemn man eine gleiche Strecke nur mit einer Grasart aussiet. - Die Landwirthe wissen, dass sie bei einer Funchtfolge mit Pflanzenarten aus den verschiedensten Ordmungen an meisten Fntter erziehen kömnen, und die Natur bietet, was man eine simultane Fuchtfolge nemnen könnte.

Die Wahrheit des Princips, dass die grösste Summe von Leben durch die grösste Differenzirung der Structur vermittelt werden kann, lässt sich unter vielerlei natürlichen Verhältnissen erkennen. Je verschiedenel die Wesen sind, eine um so grössere Kahl derselben kann an einer gegebenen Oertlichkeit neben einander bestehen. Der' Vortheil einer Diflerenzirung der Structur der Bewohner einer' und derselben Gegend ist in der 'That der'selbe, wie er für einen individuellen Organismms ans der' physiologischen 'Theilung der Arbeit unter seine Organe

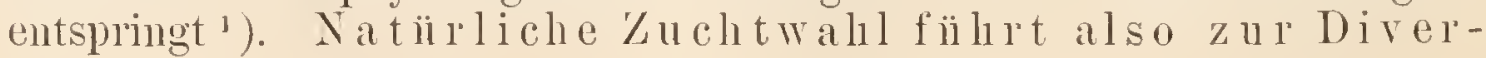

1) Daraus ist auch zu erklären, wie es kommt, dass die einen Formen viel höher als die anderen entwickelt sind. Warum haben diese höher ausgebildeten Formen nicht schon überall die minder vollkommenen ersetzt und vertilgt? Weil sie verschiedene Stellen im 
genz der Charaktere und zu starker Austilgung der minder vollkommenen und der mittleren Lebens formen.

Wir müssen andererseits fragen: Was ist es num, das die uncudliche Zunahme der Artenzahl beeinträchtigt? Da nur eine bestimmte Anzahl von Individuen auf der Erdoberfläclıe existiren kinn, so würde bei einer sehr grossen Artenzahl jede Art aus einer geringen Individuenzahl bestehen. Eine durch wenige Individuen vertretene Form unterliegt aber der Gefahr des Aussterbens durch vorkommende Schwankungen der Lebensbedingungen. Trird eine Art sehr selten, so muss auch die Parung unter nahen Verwandten, die nahe Inzucht, zu ihrer Vertilgung mitwirken ${ }^{1}$ ). Auf diese Teise kommen auch stets noch Arten zum Erlöschen.

DARwin hat gezeigt, dass die Fauna nud Flora einer bestimmten Oertlichkeit von bestimmten Bedingungen geregelt sei. Wenu wir Büsche und Pflanzen betrachten, welche ein dicht bewachsenes Ufer überziehen, so werden wir versucht, ihre Arten und deren Zahlenverhältnisse dem zuzuschreiben, was wir Zufall nennen. Doch wie falsch ist diese Ansicht! Jedermann hat gehört, dass, wemn in Amerika ein Tald niedergehauen wird, eine ganz verschiedene Pflanzenwelt zum Vorschein lommt, und doch ist beobachtet worden, dass die Bäume, welche jetzt auf den alten Indianerıunen im Sürlen der Vereinigten 'Staaten wachsen, deren fiüherer' Baumbestand abgetrieben worden sein musste, jetzt wieder eben dieselbe bunte Mamnigfaltigkeit und dasselbe Artenverhältniss wie die umgebenden unberïhrten Wälder darbieten,

In ähnlicher Weise ist auch die Artenzahl der gesammten olganischen Welt in jedeu Zeitabschnitte als ein nothwendiges Resultat der mannigfachen Wechselbeziehungen der Organismen und der Lebensbediugungen aufzufasseu.

\section{Allgemeine Bedeutung des Nützlichkeitsprincips.}

Darwin sagt in der Einleitung seines Hauptwerkes: „Wenn ein Naturfor'scher über den Ursprung der Arten nachdenkt, so ist es wohl begreiflich, dass el' in Erwägung der gegenseitigen Verwandtschaftsverhältnisse der Organismen, ihrer embryonalen Beziehungen, ihrer geographischen Verbreitung, ihrer geologischen Aufeinanderfolge und anderer solcher Thatsachen zu dem Schlusse gelangt, die Arten seien nicht selbständig erschaffen, sonder'n stammen wie Varietäten von anderen Arten ab. Demungeachtet dürfte eine solche Schlussfolgerung, selbst wenn sie wohl begründet wäre, liein Genüge leisten, so lange nicht nachgewiesen werden kömnte, auf welche Teise die zahllosen Arten, welche jetzt unsere Erde bewohnen, so abgeändert worden sind, dass sie die jetzige Vollkommenheit des Baues und der gegenseitigen Anpassung innerhalb ihrer jedesmaligen Lebensver-

Haushalte der Natur einnahmen. Unter sehr einfachen Lebensbedingungen ist eine holie Organisation ohne Nutzen, ja sogar von wirklichem Nachtheil. Es gibt Fälle, wo auch das eingetreten ist, was wir einen Rückschritt in der Organisation nennen müssen. (Man hat in letzter Zeit diese Fälle in viel grösserer Ausdehnung constatirt und es wird daher bei Betrachtung der Verwandtschaftsverhältnisse stets auch die Frage der Rückbildung erwogen; besonders zahlreiche Beispiele liefern die festsitzenden Thiere und die Parasiten.)

1) Man kann behaupten, dass die geschlcchtliche Fortpflanzung eine Hauptursache davon ist, dass es abgegrenzte Arten gibt. Ich habe diesen Satz in präciser Weise zuerst von Prof. Hering aussprechen gchört.

$\mathrm{H}$ a t s che ki, Lehrbuch der Zoologie. 
hältnisse erlangten, welche nit Recht unsere Bewunderung erregen."

In der 'Tlat erfuillt Darwin's Theorie diese Bedingming. Durch ihn ist die teleologische Weltanschauung, die Anerkennung eines vorbedachten 'Zweckes, widerlegt, dabei aber das Nützlichkeitsprincip in verschärfter Weise begrïndet worden. Wir selıen, dass alle Eigentlümlichkeiten der Orgamismen nur durch ihren eigenen Nutzen bestehen. Darin erblicken wir einen der Hauptgrundsätze der gegenwärtigen Philosophie der Organismen.

Dieses allgemeine Princip hat auch weit über das Gebiet der Naturwissenschaften in den verschiedensten historischen Disciplinen Anwendung: gefunden.

Für die Descendenztheorie liefern noch eine Reihe von Beweisen:

1) Die Palaeontologie (geologische Aufeinanderfolge der Wesen).

2) Die Thier- und Pflanzen-Geographie (geographische Verbreitung der Wesen).

3) Die Morphologic (vergleichende Anatomie und Embryologie der Thiere und Pflanzen).

Irir können auf die grosse Menge der diesbezüglichen Thatsachen hier nicht nälıer eingehen. Nur' auf die 'Thatsachen der thierischen Morphologie werden wir noch vielfach zurückkommen, da dieser Gegenstand dē̄ Hauptinhalt dieses Buches bildet.

Fortscluritte der Selectionstheorie seit Darwin.

Von grösster Bedeutung für die Selectionstheorie ist die Frage, welche Veränder'ungen erblich sind, demn nur diese kommen für die Veränderung der Art in Betracht, nicht erbliche Veränderungen sind olne Bedeutung.

Nach DARWIN können die Lebensbedingungen auf •zweierlei Weise auf den Organisnus verändernd wirken: direkt auf den ganzen Organismus oder seine Körppertleile - und indirekt durch Affection der Reproductionsorgane. Letzteres äussert sich zumeist als Wirkung auf die Nachkonmmen, indenn erst an diesen die Verïnderung sichtbar wird. Schon Darwin hielt diese Art ron Veränderungen (mit welchen auch die an Knospen auftretenden verwandt sind) für besonders wichtig, doch wollte er in einzelnen Fällen auch dem Einfluss der Gewohnheit und des Gebrauchs und Nichtgebrauchs der Organe (also direkten Wirkungen auf (len Organismus) erbliche Veränderungen zuschreiben.

Da gegenwärtig diese letzteren Fälle mit Recht in Zwweifel gezogen werden, so hat das Selectionsprincip noch wesentlich verschärfte und ausschliesslichere Bedeutung gewomnen (Weisunavs).

Im Einzelnen wurden ferner manche phylogenetische Entwicklungsgesetze neu aufgedeckt oder auch schärfcr präcisirt, so die Lehre vom "Kampf ums Dasein der Organe" innerhalb des Organismus (Rovx), das ,Princip des Functionswechsels" (Domrs), die "Substitution der Organe" (KLeinenberg). 


\section{DRITTES CAPITEL.}

\section{Principien der Morphologie.}

Die Biologie, oder Wissenschaft von den Organismen, zerfällt in zwei Wissensgruppen: die Physiologie, welche sich mit den Lebenserscheinungen beschäftigt, nud die Morphologie, oder Lehre von den Formen (änsserer und innerer Formgestaltung) der Organismen.

Die Phys i ologi e beschäftigt sich mit der Bewegung, Empfindung, dem Stoffwechsel, der Fortpflanzung, kur' mit allen Lebenserscheinumgen; sie beschäftigt sich auch mit den Formen, insofern sie nach ihrer Beziehung zu den physiologischen Leistungen frägt. Dieselbe kann ganz in speziellen die Beziehungen zwischen der Form eines Organes und seiner physiologischen Leistung erfor'schen - diesen besonderen Wissenszweig nement wir "physiologische Anatomie" -- oder anch die allgemeinsten Formgesetze nach demselben Prinzipe begründen, indem sie z. B. die Leistungen des bilateralen, des radiären Baues erklärt (,physiologische Morphologie $e^{6)}$. Die Physiologie frägt ferner nach der Mechanik, der Ernährung, dem Wachsthmm etc. bei der Entwicklung der Form (physiologische Embryologie).

Als Morphologie im engeren Sinne, oder genealogische Morphologie, bezeichnen wir jene Wissenschaft, welche sichmit den Formen an und für sich beschäfigt, um ilre Verwand tschaft $\mathrm{zu}$ ergründen. Der Ausdruck Verwandtschaft wurde in früherer Zeit metaphorisch gebraucht; gegenwärtig wird die Erforschung der Stammesgeschichte (Phylogenie) der Organismen als klares Ziel der Morphologie betrachtet.

Die Morphologie zerfällt in die vergleichende Anatomie und in die vergleichende Entwicklungsgeschichte (vergl. () nt ogenie).

\section{Principien der vergleichenden Anatomie.}

Die Principien der vergleichenden Anatomie wurden wohl auch schon früher in folgerichtiger Weise angewendet; dennoch sind sie erst durch die Descendenztheorie mit viel schärferer Klarheit festgestellt worden. Von besonderer "Wichtigkeit ist hier die Unterscheidung von Homologie und Analogie.

Homologie nemen wir eine Uebereinstimmung, die auf gemeinsamer Abstammung der betreffenden Organismen berult. Der Ausdruck Homologie wird demnach vollkommen im Simne der Ho moph ylie gebraucht. A n a logie nennen wir eine Uebereinstimmung, die bei einer verschiedenen Abstammung der Organismen in gleichartigen physiologischen Verhältnissen ihren Grund hat. Z. B.: Homolog sind die vorderen Extremitäten aller Wirbelthiere, mögen sie auch physiologisch 
verschiedenartig als Flossen, Füsse, Flügel fungiren. Homolog sind ferner die Schwimmblase der Fische und die Lunge der höheren Wirbelthiere. Analog dagegen sind die Fïsse eines IVirbelthieres und die eines Insectes odler die Flügel eines Vogels und die eines Insectes; auclı die Flügel der Fledermaus und des Vogels sind nur als vordere Extremitäten homolog, in Bezug auf ihre Ausbildung als Flïgel sind sie analog. Ferner sind analog die Lungen eimes Wirbelthieres und die Luftgefässe (Tracheen) eines Insectes; ebenso das hochentwickelte Auge eines Cephalopoden und das der Virbelthiere.

Als homodynam werden gleichartige Organe, die sich am Körper ein und desselben Thieres in gewisser Art wiederholen, bezeichnet. So z. B. die vorderen und hinteren Extremitäten eines Wirbelthieres, die aufeinanderfolgenden Beinpaare eines Krebses. Als homotyp werden Organe bezeichnet, die sich als Gegenstïcke zu einander verhalten, z. B. die gleichartigen Organe der beiderseitigen Körperhälften eines bilateralen Thieres, oder die in Mehrzahl um die Achse angeordneten Organe eines radiären Thieres.

\section{Principien der vergleichenden Entwicklungsgeschichte (biogenetisches Grundgesetz).}

Auch bei der vergleichenden Entwicklungsgeschichte handelt es sich im wesentlichen un die Unterscheidung von Homologien und Analogien. Doch gewinut die Frage hier eine grössere Vielseitigkeit.

Mit Ausnahme der allereinfachsten unter den einzelligen Organismen gilt es für alle übrigen (Pflanzen und Thiere), dass sie nicht durch einen einzigen Formzustand repräsentirt werden, sondern dass dieselben während ihrer individuellen Lebensperiode von einem einfachen Zustande aus zu höherer Ausbildung sich entwickeln und demnach eine bestimmte Reihe von Formzuständen durchlaufen, - wenn sie auch meist auf einem dieser Formzustände (in der Regel auf demjenigen, in welchem sie sich fortpflanzen) viel längere Zeit verweilen, als auf (len übrigen.

Besonder's scharf ausgeprägt ist diese Erscheinung bei den vielzelligen Organismen, wo von dem einzelligen Ei ausgehend bei steter Vermehrung der Zellen vielzellige Stadien folgen, die durch ein sich schrittweise complicirendes Lagerungsverlältniss der Zellen, mit welchem zugleich eine histologische Differenzirung der verschiedenen Zellgruppen einhergeht, zu dem Endstadium hinführen, welches den zusammengesetztesten Bau hat.

Bei der vergleichenden Embryologie handelt es sich daher nicht ıur um die Vergleichung von Einzelformen, sondern un die Vergleichung von Formenreihen.

Schon zu Anfang dieses Jahrhunderts findet sich in vielen zoologischen Schriften die Bemerkung, dass die höheren Thier e bei ihrer Entwicklung Stadien durchlaufen, welche ihrem Baue nach gewissen niedrigeren Thierformen entsprechen.

Karl Ernst v. Baer weist auf diesen Satz schon als auf einen allgemein bekannten hin ${ }^{1}$; er bekümpft aber diese Meinung in ge-

1) Karl Ersst v. BaEr, Ueber Entwicklungsgeschichte der Thiere, 1828, p. 199 etc. Das Capitel, welches betitelt ist: „Die herrschende Vorstellung, dass der Embryo höherer Thiere die bleibenden Formen der niederen Thiere durchlaufe" gibt uns ein Bild der damaligen Auffassung dieser Frage. Diese Lehre ist nach BAER ,mehr eine Entwicklungsstufe der Wissenschaft als das Eigenthum eines einzelnen Mannes"6. — ,Diese Idee, lebendig geworden zu einer Zeit, wo ausser MALPIGII und WoLFF noch keine zusammenhängenden Untersuchungen iiber die friheren Perioden der Entwicklungsgeschichte irgend eines Thieres 
wissem Sinne, indem er anführt, dass ein Embryo niemals einem entwickelten 'Thiere gleiche und daher immer' wieder nur mit einem anderen Embryo verglichen werden könne. Von der Vergleichung der Fmbryonen lehrt er: „Je verschiedener zwei Thierformen sind, um desto mehr muss man in der Entwicklungsgeschichte zurückgehen, um eine Uebereinstimmung zu finden." Er kömmt endlich zu dem Schlusse, dass die Anfangsstadien der Entwicklung bei allen Thieren sehr ähnlich seien (,bein ersten Auftreten sind vielleicht alle Thiere gleich und nur hohle Kugeln"6) und mit der weiteren Entwicklung immer speciellere Unterschiede, zunäclıst typische, dann Classen-, Ordnungs-, Familien- und Speciesmerkmale hervorträten; so dass bei näher verwandten 'Thieren die Uebereinstimmung sich bis auf entsprechend spätere Stadien erstrecke. (,Die individuelle Entwicklung ist ein Fortschreiten aus einer allgemeineren Form in eine mehr specielle ${ }^{66}$.)

Wenn auch in den Ausführungen V. BAER's manche Frage noch nicht aufgeklärt erscheint und im einzelnen auch einige Widersprüche sich finden, so sind doch durch seine Sätze die thatsächlichen Erscheinungen klar formulirt.

Durch die Erneuerung der Descendenztheorie mussten diese Beziehungen der embryonalen Formen wieder erhöhtes Interesse gewinnen. Schon bei Vorgängern BAER's findet sich ja die Ansicht deutlich ausgesprochen, dass bei der Entwicklung des Individuums die historische Entwicklung der Thierreihe wiederholt würde. Dieser Ansicht mussten die Anhänger der Descendenztheorie naturgemäss sich wieder zuwenden. DARwis selbst hat darauf hingewiesen, dass in den Erscheinungen de ${ }^{\circ}$ Embryonalentwicklung eine Stütze der Descendenztheorie zu finden sei, und hat dieselben so gedeutet, dass bei der individuellen Entwicklung die Zustände der Ahnenformen wiederholt würden.

Im Jahre 1864 hat FRITz MüLLER in einer geistreichen Schrift diesem Gegenstande eine eingehendere Erörterung gewidmet und besonders seine Ausführungen, die sich auf Abkürzung und Veränderung der Embryonalentwicklung im Verlaufe der historischen Descendenz beziehen, sind als ein bleibender Fortschritt unserer Anschauungen zu betrachten:

„Die in der Entwicklungsgeschichte (der Individuen) erhaltene geschichtliche Urkunde (von der Entwicklung der Vorfahren) wird allmählich verwischt, indem die Entwicklung einen immer geraderen Weg: vom Ei zum fertigen Thiere einschlägt, und sie wìd häufig gefälscht durch den Kampf ums Dasein, den die freilebenden Larven zu bestehen haben. Die Urgeschichte der Art (Phylogenesis) wird in ihrer Entwicklungsgeschichte (Ontogenesis) um so vollständiger enthalten sein, je länger die Reihe der Jugendzustände ist, die sie gleichmässigen Schrittes durchläuft, und um so treuer, je weniger sich die Lebensweise der Jungen von der der Alten entfernt, und je weniger die Eigen-

\footnotetext{
angestellt waren und vorzüglich durchgeführt von einem Manne, der iiber die Entwicklungsgeschichte der höheren Organismen wohl die meisten Kenntnisse besass [damit ist wohl MEckel gemeint], konnte nicht umhin, grosse Theilnahme zu erregen, da sie von einer Menge specieller Beweise unterstützt wurde". Eine Bemerkung, die sich an dieser Stelle findet, mag auch heute noch interessant scheinen: „Einige Vertheidiger wurden so eifrig, dass sie nicht mehr von Aehnlichkeit, sondern von völliger Gleichheit sprachen, und thaten, als ob die Uebereinstimmung überall und in jeder Einzelheit nachgewiesen wäre. Noch kürzlich lasen wir in einer Schrift iiber den Blutlauf des Embryo, nicht eine Thierform lasse der Embryo des Menschen aus."
} 
thümlichkeiten der einzelnen Jugendzustände als aus späteren in frühere Lebensabschnitte zurückverlegt orler als selbstständig erworben sich auffassen lassen". (Für DARwis. Leipzig 1864. S. 77, 81). Jetzt erst erscheint der Finwand vor BAER's entkräftet, dass ein Embryo niemals einer entwickelten Form gleichen könne, denn diese Verschiedenheit ist nach FRITz MǗLLER ein Resultat der Anpassung an das verschiedenartige Lebensverhältniss; wir können hinzufügen, dass gewisse Eigenthümlichkeiten des Embryo, seine „embryonale Beschaffenheit", speciell mit seiner Fähigkeit der Weiterentwicklung zusammenhängen.

Als einer der erfolgreichsten Vertreter der durch F. MÜLLER weiterentwickelten Theorie ist ERxst Hakkel zu nennen, der dieselbe in zahlreichen wissenschaftlichen und populären Schriften mit vielem Nachdruck vertreten hat und dadurch die allgemeine Aufmerksamkeit wieder auf diesen Gegenstand lenkte. HaEcket hat den von F. Mǘlter aufgestellten Sätzen wohl keine neuen theoretischen Gesichtspunkte hinzugefügt, doch war er der erste, der diese Theorie in ausgedehntester und erfolgreicher Weise in der Wissenschaft methodisch angewendet hat, wie z. B. in der ,Gastraeatheorie", wo er die ersten Entwickelungsvorgänge, die Furchung und Keimblätterbildung, phylogenetisch zu erklären suchte und die Zurückführung aller Metazoen auf eine gemeinschaftliche Stammform, die "Gastraea", darlegte.

Die Theorie von dem Parallelismus der individuellen Entwicklung mit der historischen Entwicklung der Art, welche wir schon von den Vorgängern v. BAER's ausgesprochen, dain von V. BAER kritisch beleuchtet und von F. MÜLLER weiter entwickelt finden, wurde von HaEckes mit dem Namen, bi o gen e tisches Grundgesetz"1) bezeichnet und in dem Satze zusammengefasst: ,Die Ontogenie (Keimesgeschichte) ist eine kurze Wiederholung der Phylogenie (Stammesgeschich te) $)^{6}$. Die Ausführungen FRITZ MƯLLER's über die Modificationen der Entwicklungsgeschichte finden bei HAECKEL ihren Ausdruck darin, dass er die ontogenetischen Erscheinungen in "palingenetische", welche die Erscheinungen einer ehemaligen entwickelten Stammform wiederholen, und "cenogenetische", welche durch Anpassung an das Embryo- oder Larvenleben entstanden sind, eintheilt.

Kritische Begründung der morphogenetischen Theorie.

Wir können die Hauptsätze unserer gegenwärtigen morphogenetischen Theorie (oder des biogenetischen Grundgesetzes) mit einiger Aenderung der HAECKEL'schen Sätze folgendermaassen formuliren:

1) Die ontogenetische Formenreihe ist auf die phylogenetische Reiheder Endstadien zurückführbar. [DieOntogenie (Keimesgeschichte) ist eine kurze Wiederholung der Phylogenie (Stammesgeschichte), Haeckel].

2) Bei jeder ontogenetischen Formenreihe sind, „palingenetische Charaktere", welcheden Eigenthümlichkeiten der phylogenetischen Endstadien entsprechen, und „cenogenetische Charaktere", die als larvale oder embryonale Modificationen a ufgetreten sind, zu unterscheiden ${ }^{2}$ ). Der

1) Diese HAEckEL'sche Bezeichnung wurde oft als nicht ganz passend erklärt, sie wäre vielleicht besser durch den Ausdruck, morphogenetische Theorie"zu ersetzen.

2) Für das Verständniss der primären oder palingenetischen zu den secundären oder cenogenetischen Charakteren ist folgendes in Betrachtung zu ziehen: ,W ir m üs en es 
erste dieser Sätze stützt sich zunächst auf die Thats a chen des morphogenetischen Parallelismus, die wir in folgonden Sätzen zusammenfassen :

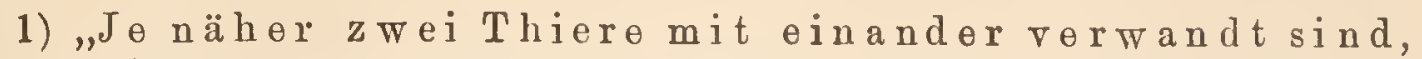
bis zu $\theta$ in $\theta$ m um so späteren Stadium lässt sich in ihrer Entwick lung Uebereinstimmung nachweisen" (C. E. v. Baer).

2) Die Embryonen höherer Thiere zeigen morphologische Uebereinstimmung mit den Endstadion niederer Th i $\theta$ re (Ergänzungssatz).

Wir werden nun noch weiter nach den Ursachen dieser thatsächlichen Erscheinungen selbst zu fragen haben, aus welchen das „biogenetische Grundgesetz" abgeleitet ist.

Sie sind nicht so ohne weiteres aus sich selbst erklärt, wie HaEckel glaubt, indem er den Satz ausspricht: „Die Ontogenesis ist unmittelbar bedingt durch die Phjlogenesis" (Generelle Morphologie II) oder : „Die Phylogenesis ist die mechanische Ursache der Ontogenesis" (Gastraeatheorie p. 7).

Aus dem Vorhergehen einer phylogenetischen Formenreihe soll nach HAECKEL mit Nothwendigkeit eine entsprechende ontogenetische Reihe sich ergeben. Es ist erweislich, dass auch ein anderer Hall möglich wäre. Gehen wir beispielsweise von einem Organismus aus, der in seiner Ontogenie die Stadion A-B-C durchläuft. Es wäre nun ganz wohl denkbar, dass oine phylogenetische Veränderung stattfände, welche folgendem Schema entspräche:

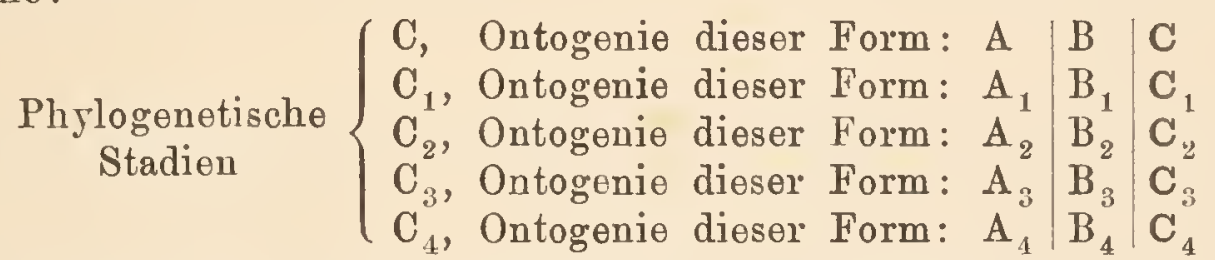

Es hätte also die phylogenetische Formenreihe $\mathrm{C}-\mathrm{C}_{1}-\mathrm{C}_{2}-\mathrm{C}_{3}-\mathrm{C}_{4}$ stattgehabt, ohne dass sie in der Ontogenie der Form $\mathrm{C}_{4}$ zum Ausdruck käme.

Die phylogenetische Veränderung erfolgt aber thatsächlieh meist in einer anderen Weise, welche dem hier folgenden Schema entspricht.

Gehen wir wieder von demselben Ausgangspunkte der ontogenetischen Reihe ABC aus:

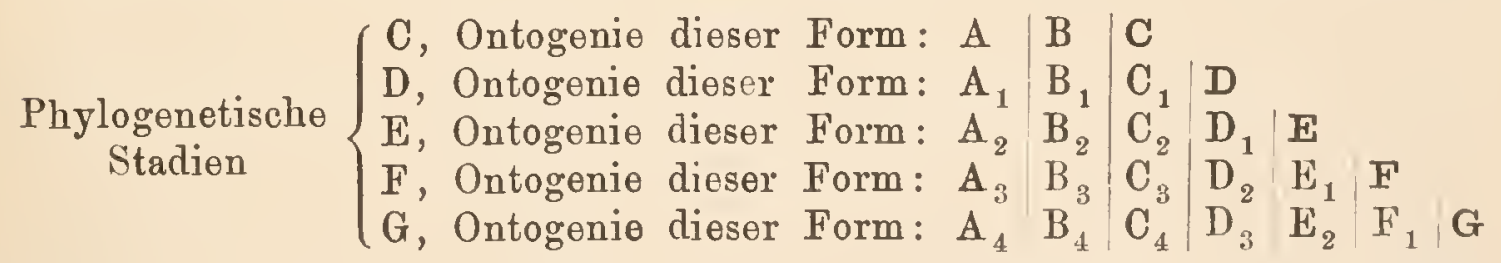

Dies scheint die häufigste Art der phylogenetischen Veränderung zu sein. Die phylogenetische Veränderung geht also in den

als ein ans dem Causalitätsprineip ableitbares Gesetzbetrachten, dassbei der phylogenetischen Veränderung einer Thierform niemals allein das Endstadium verändert wird, sondern immer die ganze Reihevouder Eizelle bis z m Endstadium. - Jede Veränderung des Endstadiums oder das Hinzukommen neuer Stadien wird cine Veränderung der Eizelle selbst zur Bedingung haben." Dieser Satz, den jeh früher schon (Entw. v. TEREdo, Wien 1880, p. 26) aufgestellt hatte, wurde mit Riicksicht auf Anpassungsveränderungen der Larvenoder Embryonalformen von GötTE dahin schärfer gefasst: ,j e de e r b li che A b änderung innerhalb einer einzelgesehiehtliehen Reihe setzt diejenige aller vorangehenden Gliedervoraus nd bewirkt eine solehealler folgenden Gli eder." (GötTE, Abhandl. z. Entwieklungsgeseh. d. Tiere, 2. Heft.) 
meisten Fällen so vor sich, dass eine Hinzufügung neuer Stadien an das Ende der ontogenetischen Formenreihe erfolgt.

Wir werden auch hier noch weitergehen und die Frage stellen: Warum ist diese Art der phylogenetischen Veränderung die häufigste?

Wenn man (wie HAECKEL) annimmt, dass die Veränderungen, welchedas entwickelte Individuum direct durch äussere Einflüsse und Uebung erwirbt, sich auf seine $\mathrm{Nachkommen}$ vererben, so gestaltet sich die Erklärung sehr einfach. Die neuen Erwerbungen der Eltern bewirken unmittelbar eine (im einzelnen sehr geringfügige, im Verlaufe der Generationen aber sich summirende) Verlängerung der ontogenetischen Formenreihe bei den Descendenten.

Wenn man aber an der Ansicht festhäl, dass nurdiejenigen neu auftretenden Charakteresich $\nabla \theta r e r b \theta n$, welche durch Variiren der Fortpflanzungszellen (Variirendurch Einfluss a uf die Generationsorgane, nach DanwiN) entstanden sind, so erscheint eine andere Erklärung nothwendig. Man wird „überschreitende Varietäten" annehmen müssen. Mit diesem Namen möchte ich solche Variäteten bezeichnen, welche in einer Verlängerung der ontogenetischen Formenreihe bestehen. (Dieselben werden am häufigsten bei besonders lebenskräftigem Plasma auftreten und auch durch ihre besondere Eigenthümlichkeit oft Nutzen gewähren und deher vorzugsweise erhalten werden).

\section{Die Bedeutung der Ontogenie für die Erforschung der Phylogenie.}

Es wurde oftmals die Frage aufgeworfen, ob der vergleichenden Anatomie oder der vergleichenden Embryologie grössere Wichtigkeit für die Erforschung des verwandtschaftlichen Zusammenhanges, d. i. der Phylogenie, der Thiere zukomme. Die Frage ist gewiss eine müssige, denn es ist nothwendig, beide Forschungsweisen zu verbinden und gleichmässig zu berücksichtigen. Da der individuelle Organismus nicht durch einen einzigen Formzustand, sondern durch eine Formenreihe repräsentirt ist, die er während seines individuellen Lebens durchläuft, so kann es auch nicht genügen, allein die Endformen zu vergleichen, sondern es muss die ganze Formenreihe berücksichtigt werden. Die vergleichende Anatomie verfügt über die grosse Menge der Details, die der Bau des entwickelten Thieres darbietet; sie wird in der Beurtheilung derselben durch die vergleichende Ontogenie unterstuitzt, die oft ein Hilfsmittel ist, um den verschiedengradigen Werth der Einzelheiten besser zu erkennen, und in vielen Fällen die letzte Entscheidung abgibt, ob bei einer auatomischen Uebereinstimmung Homologie oder blosse Analogie vorliege. Alle ontogenetischen Erscheinungen können zur Erforschung der Verwandtschaft wichtig werden. Auch specielle embryologische oder larvale Charaktere ('Typus der Furchung, Embryonalhüllen, secundäre Larvenformen etc.) sind oft für einen Thierkreis charakteristisch und ebenso wie die anatomischen Charaktere für die verwandtschaftliche Zusammengehörigkeit dieser Gruppe beweisend. Eine Anzahl Beispiele hierfür bieten die Wirbelthiere, bei welchen nach secundären Embryonal-Organen die Gruppen der Anamnia und Amniota, Aplacentalia und Placentalia unterschieden werden; so spielen auch bei der Charakteristik der Insectengruppen secundäre Larvencharaktere eine Rolle und in noch höherem Maasse bei den Crustaceen (Nauplius, Zoëa). 
Es liegt etwas irrthümliche Auffassung in den dicsbezüglichen Ausführungen HAECKEL's, die wir hier citiren wollen :

„Für dic Palingencsis oder „Auszugs-Entwicklung“ sind von hervorragender Bedeutung die Gesetze der ununterbrochenen (continuirlichen), der befestigten (constituirten), der glcichörtlichen (homotopen) und der glcichzeitlichen (homochronen) Vercrbung (Gencrelle Morphologie, Vol. II. p. 180 bis 190). Diese höchst wichtigen Vererbungsgesetze gestatten uns noch heute, aus den vorliegenden Thatsachen der Keimesgeschichte ganz positive Schlüsse auf den ursprünglichen Gang der Stammesgeschichte zu thum. Hingegen sind für die Cenogenesis oder die „Fälschungsentwicklung" ganz besonders wichtig die Gesetze der abgckürtcn (abbreviirten) und der gefälschten (modificirten), ganz besonders aber der ungleichörtlichen (heterotopen) und der ungleichzeitlichen (hoterochronen) Vererbung. Diese Vcrerbungsgesetze haben für dic Phylogenic nur einen negativen Werth. Für die gesammte Morphologie, und spcciell für die Phylogenie, ist selbstverständlich die Palingenesis von ganz anderer Bedcutung als dic Cenogenesis. Die Morphologie, welche ihre Aufgabe richtig begriffen hat, wird den versteckten Pfad der Phylogenie in dem schwierigen Gebietc der Ontogenie nur dann finden, wenn sic die palingenetischen Processe möglichst hervorsucht, die cenogenetischen möglichst eliminirt". (Gastraeatheorie II. p. 70, 71). Insofern als die Unterscheidung von Palingenie und Cenogenie überhaubt hervorgehoben wird, müssen wir HaEckeL bcipflichten. Wir haben aber darauf hingewiesen, dass nicht nur die primären (palingenetischen [HАEcKEL]), sondern auch diu secundären (cenogenetischen [HAECKEL]) Charaktere der Ontogenie für die Erforschung des verwandtschaftlichen Zusammenhanges der Thiere von Bedeutung sind. Es wird auch am Platzc sein, noch einige Ausführungen über die Beurtheilung ontogenetischer Erscheinungen hinzuzufügen.

Wenn wir eine Larven-oder Embryonalformals charakteristisch für einen ganzen Thierkreis erkennen, so dïren wir daraus nicht folgern, dass nothwendigerweise durch dieselbe ein ähnliches phylogenetisches Stadium repräsentirt werde. Wir sind nurzu dem Schlusseberechtigt, dass die Stammform dieses Thierkreises bereits jenes charakteristische Entwicklungsstadium besessen habe. Fritz Müller, der scharfsinnige Begründer der Lehre von den Modificationen der Ontogenie, hat gerade an dem Beispicl, an welchem or die Theorie erläuterte (Entwicklung der Crustaceen), den crwähnten Fehlschluss begangen. Wenn die $\mathrm{Naupli}$ us larve als charakteristisch für den Kreis der Krebsthiere (Crustaceen) nachgewiesen ist, so folgert daraus nur, dass bereits die Stammform der Crustaceen in ihrer Ontogenie jenes charakteristische Stadium besass; es ist aber nicht erwiesen, dass der Nauplius selbst eine Stammform repräsentire, wie MöLler glaubte; und in der That hat sich diese Ansicht als irrig erwicsen. - Ebenso ist für die höheren Crustaceen (die Malakostraken) cin späteres Larvenstadium, die $Z_{0} \ddot{e}$ a-Larve charakteristisch; daraus folgt nur, dass die Larve bereits der Stammform der Malakostraken eigenthümlich war; MÜLLER hielt sie cbenfalls für die Wiederholung dicser Stammform selbst, was ebenfalls später als irrig erwiesen wurde.

Wennaber cine Larven-oder Embryonalform höhcrer Thierc eine grosse Uebereinstimmung it dem cntwickclten Zustande niederer Thiere zcigt, dann kann man mit grosser Wahrscheinlichkeit schliessen, dass dieselbe einer ähnlichen Stammform entsprechc. - So sehen wir, dass 
die 'Troch ophora-Larve der Anneliden und Mollusken eine grosse Uebereinstimmung mit den entwickelten Räderthieren zeigt und wir schliessen daraus, dass wahrscheinlich eine ähnliche Ahnenform existirt habe. - Bei sämmtlichen Metazoen können wir ein charakteristisches zweischichtiges Entwicklungsstadium, die Gastrula, nachweisen. Daraus allein könnte man aber noch nicht auf ein ähnliches Ahnenstudium schliessen, sondern diese Ansicht stützt sich auch darauf, dass viele niedere Metazoen (z. B. die Hydroiden) in ihrem Bau der Gastrula noch sehr nahe stehen.

Aber auch dieser Schluss kann nicht mit vollkommener Sicherheit gezogen werden. Denn eine niedrere Thierform kann durch Unterdrückung der Endstadien aus einer höheren hervorgegangen sein. Es können z. B. manche Salamandrinen, welche einen kiementragenden $J u g e n d z u s t a n d$ durchlaufen, in welchem sie den niedrigeren Kiemenmolchen gleichen, ausnahmsweise auf diesem Stadium geschlechtsreif werden. In gewissen Fällen (z. B. beim Axolotl) wird das Endstadium in der Regel unterdrückt und tritt nur ausnahmsweise wieder auf. Wir mïssen uns daher auch bei der Betrachtung anderer (echter) Kiemenlurche in jedem Falle die Frage vorlegen, ob die betreffende Art ihrer Abstammung nach wirklich tiefer stehe als die Salamandrinen, oder ob sie etwa durch Unterdrüclsung des Endstadiums erst ron einer Salamandrimenform aus entstanden sei. - Unter den Ascillien kennen wir eine Gruppe, die Copelalen, welche den Larven der anderen Ascidien ähnlich ist, wie diese freischwimmend, geschwänzt und sonst auch niedrig organisirt ist. Wenn es nun auch wahrscheinlich ist, dass die Copelaten der Stammform nahe stehen, so ist doch auch die Möglichkeit nicht vollkommen widerlegt, dass sie ron festsitzenden Ascidien durch Unterdrückung der Endstadien abstammen. - In derselben Weise könnte a u ch eine secundäre Larvenform Uebereiustimmung mit einer niedreren Thierform zeigen, weche phylogenetisch durch Unterdrückung der Endstadien aus einer höheren Form hervorgegangen wäre.

Diese typischen Beispiele lehren uns, dass eine unmittelbare Construction der Phylogenio eines Thieres aus seinen ontogenetischen Stadien allein, ohne Kenntniss der niedreren Thierformen, nicht möglich ist. Die Erfahrung lehrt, dass bei der vergleicheuden Ontogenio überhaupt keine andere Methode anwendbar ist, als bei der vergleichenden Anatomie: durch Vergleichung das Gemeinsame herrorzuheben, und bei möglichster Berücksichtigung aller Umstände daraus Schlüsse auf die Verwandtschaft der Formen zu ziehen. Doch wendet die vergleichende Ontogenie diese Methode zur Vergleichung von Formenreihen an und erzielt daher grössere Erfolge. Die Methode der vergleichenden Ontogenie ist eine Erweiterung der rergleichend anatomischen Methode (Feststellung ron Homologie und Analogie) durch Anwendung derselben auf Formenreihen.

Die Ergebnisse der vergleichenden Ontogenie haben stets nur den Werth von Wahrscheinlichkeitsschlüssen, genau in demselben Grade wie die der vergleichenden Anatomie. Die relative Sicherheit hängt in beiden Fällen nur von der Menge der Praemissen und von der Schärfe des Schliessens ab. 


\title{
VIER'TES CAPITEL.
}

\author{
S y s t e m.
}

\section{Begriff des Systems. Categorien des Systems.}

Es ist leicht einzusehen, dass das System sich auf die vers ch i ed engra d i ge A e hnli chkeit der Organismen stützt. I)a man die Ursache dieser Aehnlichkeit früher nicht kannte, so wurde oftmals die Ansicht ausgesprochen, das System sei mur das Resultat einer abstrahirenden menschlichen Anschaumgsweise; man erklärte den Ausdruck ,natürliches System" als an und für sich widersinnig. Gegenwärtig, da wir als Ursache der Aehnlichkeit die Abstammmng erkannt haben, sind wir zu der Ansicht gekommen, dass dem System ein thatsächliches Verhältniss zu Grunde liege, nämlich der Stammbaum der Organismen. Das System bildet den Ausdruck unserer Anschaungen über die Verwandtschaft der Organismen, und zwar haben wir, vom Standpunkte der Descendenztheorie, eine reale, auf Abstammung beruhende Verwandtschaft im Sinne. Die Anordnung des Systems nach übergeordneten grösseren und darin enthaltenen kleineren Abtheilungen entspricht den Aesten und Zweigen des Stammbaumes. Die "gebrïuchlichsten ') Abtheilungen oder (Categorien des Systems sind:

\section{Reich (Regnum).}

Unterreich (Subregnum) auch Kreis, Typus oder Phylum genannt. Klasse (Classis).

Orinung (Ordo).

Familie (Familia).

Gattung (Genus).

Art (Species).

Um die Stellung eines Organismus im System vollständig zu determiniren, müsste man seine Zugehörigkeit nach allen diesen Categorien des Systems angeben. Nach der von Linné eingeführten binären Nomenclatur wird Art und Gattung schon in der Namensbezeichnung jedes Organismus angegeben.

1) Es erweist sich im einzclnen das Beduirniss mannigfacher Zwischenstufen. 


\section{Begriff der Species.}

Alle Categorien stützen sich auf den Aehnlichkeitsgrad der ()1ganismen; zu je tieferer Categorie wir herabsteigen, desto grösser ist die Aelınlichkeit, und sie ist am grössten bei den Individuen, die zu ein und derselben Species gehören.

Der Begriff der Species stützt sich aber nicht uur, wie der Begriff der anderen Categorien, auf die Aehnlichkeit der Form, sondern es kömnit hier auch noch ein anderes Moment in Betracht, nämlich das Verhältniss der geschlecht lichen Verm is chung, welches innerhalb der Species statt hat.

1) Aehnlichkeit der Individuen einer Species.

Wir müssen zunächst hervorheben, dass es sich bei der Species nicht nur um die Übereinstimmung eines einzelnen Formzustandes, sondern um die eines Formencyclus handelt. Denn wir wissen, dass die meisten Organismen nicht durch einen Formzustand repräsentirt werden, sondern durch eine Reihe von Formen, welche bei der Ontogenie (individuellen Entwicklung) durchlaufen werden. Der Formencyclus wird oft noch complicirter durch die Erscheinung des Generationswechsels, welche wir später genauer kennen lernen werden; es wiederholt sich nämlich die Einzelform nicht im Cyclus jeder Generation, sondern im Cyclus zweier oder mehrerer Generationen. Eine fermere Complication kennen wir in dem Polymorphismus; unter den Gesichtspunkt des Polymorphismus fällt erstens der geschlechtliche Dimorphismus und Polymorphismus; es können zu einer männlichen Form nicht nur eine, sondern auch zwei, ja drei verschiedene weibliche Formen gelıören, oder umgekehrt zu einer weiblichen $z$ wei verschiedene männliche Formen; zweitens der functionelle Polymorphismus, wie er z. B. bei den Bienen ausgeprägt ist, wo neben den Weibchen und Männchen noch Arbeiter vorkommen, oder bei Ameisen und 'Termiten, wo es sogar mehrere Arbeiterformen gibt.

Wenn wir num den Aehnlichkeitsgrad untersuchen, welcher zwischen Individuen des aräquaten Formzustandes bei einer und derselben Species herrscht, so müssen wir zunächst jene Unterschiede als unwesentliche (oder zufällige) bezeichnen, die nicht erblich sind, sondern nur von den jeweiligen äusseren Verhältnissen abhängen. So sehen wir, dass bei Pflanzen Veränderungen je nach dem Standorte auftreten, bei Insecten je mach der Nährpflanze; durch entsprechenden Techsel der Verhältnisse wird ein Individuum oder seine Nachkommen verändert, und es können diese Veränderungen ebenso wieder aufgehoben werden. Derartige Verändermmgen bezeichnen wir nach N̈̈GEL als V ariationen.

Wir finden ferner, dass die Individuen einer und derselben Species auch erbliche Verschiedenheiten zeigen; wir nemnen solche Veränderungen Varietäten. Wenn die Varietät veremzelt auftritt, so wird sie als ,individuelle Varietät" bezeichnet; wenn aber die gleichartige Varietät in eimer grossen Anzahl von Individuen vorkömmt, so wird sie „Rassenvarietät" oder kurz "Rasse" oder "Unterart" genannt. Die Rassen werden nach der Descendenzlehre als Anfänge der Bildung neuer Arten betrachtet.

Die Breite der Veränderlichkeit ist bei verschiedenen Arten eine sehr verschiedene; es gibt Arten, deren Charaktere mehr constante sind, während andere grössere Schwankungen zeigen. Die 
Erscheinumg kann aber, wie wir nun einsehen, iuf zwei wesentliclı verschiedenen Ursachen beruhen. Eimmal kann dieselbe darauf zurückgefüln't werden, dass die Art eine besondere Fäligkeit hat, V a r i a t i o n e n zu bilden, d. h. je nach Standort, Ermährungsverhältnissen etc. zeitliche Veränderungen zu erleiden; dies scheint bei vielen niederen Organismen, z. B. den Spongien, der Fall zu sein. Das andere Mal kann es der Fall sein, dass die Art die Neigung besitzt zu variiren, d. h. individuelle (erbliche) Varietäten zu bilden; bei solchen Arten sind nreist aucl bereits ausgeprägte Rassenvarie tät en aufgetreten. Es kanı auch bei einer Art die Fähigkeit der Variation und die Neigung zum Variiren gleichzeitig vorhanden sein.

Wir sehen also, dass die Breite der Veränderlichkeit einer Art in jedem einzelnen Falle erst Gegenstand genauer Untersuchung und des Züchtungsexperimentes sein nüsste, $1 \mathrm{~m}$ ihren Wesen naclı verstanden $\mathrm{zu}$ werden. Es ist begreiflich, dass wir über diesen Gegenstand nur erst spärliche Erfahrung besitzen ${ }^{1}$ ).

2) Vollkom mene Fruclitbarkeit innerhalb der Species.

Cuvien war der erste, der als ein wichtiges Criterium der Species die vollkommene Fruchtbarkeit bei Kreuzung ihrer Individuen liervorgehoben hat.

Als vollkom mene Fruch tbarkeit bezeichnen wir diejenige, welche bei fortgesetzter Kreuzung sich durch viele Generationen gleichmässig erhält. Die Individuen ein und derselben Specics sind stets untereinander volkommen fruchtbar - vorausgesetzt, dass ihre Geschlechtsorgane durchaus functionsfähig sind. (Durch fortgesetzte Inzucht wird die Fruchtbarkeit beeinträchtigt.)

Die Individuen verschiedener Arten derselben Gattung sind nur u nvollkom men fruch tbar, d. li. die Fruchtbarkeit erlischt innerhalb der näclisten oder innerhalb weniger Generationen; meist sind schon die Bastarde erster Generation, wenn auch vollkonumen lebenskräftig, doch nicht mehr fortpflanzungsfähig (Maulesel, Maulthier.)

Bei noch entfernterer Verwandtschaft (Individuen verschiedener Ordnungen etc.) findet eine fruchtbare Kreuzung überhaupt nicht mehr statt.

Es sind einige Ausnahmen bekannt, dass die Individuen verschiedener Species doch untereinander vollkommen fruchtbar sill. Der bestverbürgte Fall ist die Kreuzung von Hase und Kaninchen, deren Bastarde durch viele Generationen weitergezüchtet, sich als vollkommen fruchtbar erwiesen. Während wir also im Allgemeinen nit dem Grade der Aehnlichkeit auch den Grad der Kreuzungsfähigkeit in gleichem Maasse abnehmen sehen, so finden wir in derartigen einzelnen Fällen, dass der Aehnlichkeitsgrad schneller abnimmt als die Kreuzungsfähigkeit.

Wenn wir die Thatsache der geschlechtlichen Vermischung innerlialb der Species ins Auge fassen, so kommen wir zu der Anschauung, dass die Species nicht bloss eine Summe von Individuen ist, sondern

1) DARIVIN hat folgende allgemeine Gesetze aufgefunden: ,Weit verbreitete und gemeine Arten variiren am meisten. - Arten der grösseren Genera variiren häufiger als die der kleineren Genera. - Viele Arten der grossen Genera gleichen den Varietäten darin, dass sie sehr nahe, aber ungleich mit einander verwandt sind und beschränte Ver"breitungsbezirke haben."6 
eine von denselben gebildete physiologische Einheit. Wie etwa - um ein Bild zu gebrauchen - ein Fluss nicht eine blosse Summe von Tropfen ist, sondem auch insofern eine Einheit, als die Tropfen in ilm sich fortwährend miteinander vermischen. Wir müssen hier auch in Betracht ziehen, dass für den dauernden Bestand der Art eine gewisse Anzahl von Individuen physiologisch nothwendig ist (zur Hintanhaltung der Inzucht etc.).

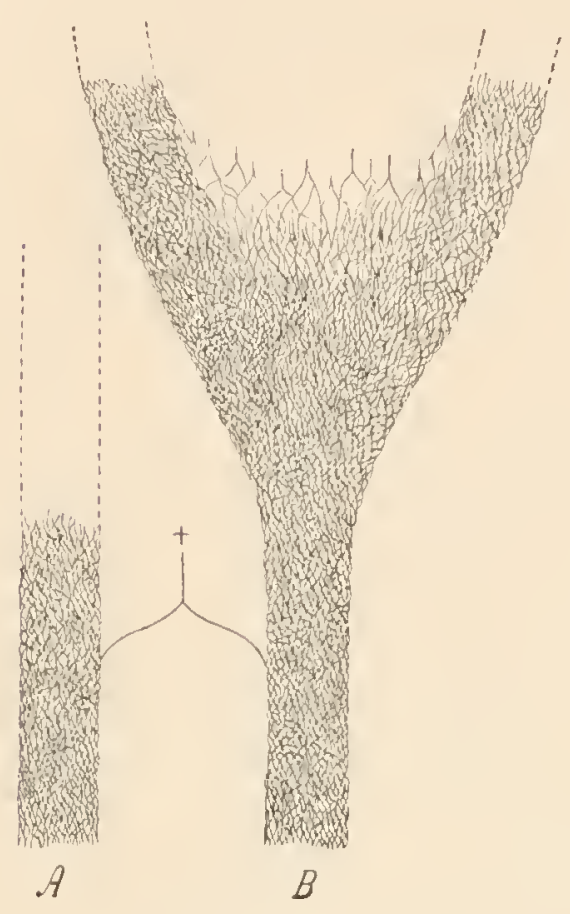

Fig. 1.

Wir können uns die Verhältnisse der Species graphisch in einem vereinfachten Schema darzustellen versuchen, indem wir sie als ein bandförmiges System von anastomosirenden Linien zeichnen. Die Kreuzung zwischen verwandten Arten $A$ und $B$, die kein dauerndes Produkt liefert, stellen wir als Anastomose dar, die bei $\dagger$ endigt. Bei der Entstelung zweier neuer Arten aus einer alten ${ }^{1}$ ) müssen wir uns das Netzwerk in zwei Aeste gespalten denken $(B)$, welche Anfangs durch Anastomosen verbunden sind, die immer spärlicher werden und endlich ganz verschwinden. Durch diese Anastomosen sind die Zwischenformen, die durch die Zuchtwahl ausgerottet werden, und die Kreuzungsprodukte der Rassen dargestellt, die allmählich erlöschen. Denn die Kreuzungsfähigkeit hört nicht plötzlich auf, sondern nimmt allmählich $a b$.

\section{Thierreich und Pfanzenreich.}

Die Eintheilung der gesammten Organismenwelt ist eine systematische Frage, also eine Frage der Abstammung. Thierreich und Pflanzenreich sind in ihren höler entwickelten Typen (den vielzelligen) scharf von einander unterschieden, bei den niedersten Formen dagegen (den einzelligen) ist der Gegensatz nur ein geringer. Dies rührt daher, dass diese beiden Hauptstänme an der Basis aus gemeinsamer Wurzel entspringen. Der '/usammenhang ist dadurch gegeben, dass sowohl die Pflanzen als auch die Thiere auf den Elementarorganismus der Zelle zиrückzuführen sind.

Es gilst auch Organismen, die noch tiefer stehen als die Zelle, da ihı Körper ein gleichartiger ist, ohne die Differenzirung von Zellkern und Zellleil,, durch welchen die Zelle sich auszeichnet. Solche Organismen sind z. B. die Spaltpilze und andere Organismen, die meist zum Pflanzenreich gezogen werden. Die Kernlosigkeit gewisser amöbenartiger Organismen (Moneren HAECKEL's) ist nicht endgiltig festgestellt.

Die Zelle zeigt bestimmte Differenzirungen, an welche sich bestimnte Vorgänge bei der Fortptlanzung und Conjugation der Zelle

1) Vereinzelt auftretende individuelle Varietäten haben für die Bildung neuer Arten in Naturzustande keine wesentliche Bedeutung, sondern es ist das häufige wiederholte Anftreten gleichartiger (wenn auch unbedeutender) individueller Varietïten nothwendig. 
knüpfen; und alle diese Erscheinungen sind ilır sowohl im 'J'hierreich als auch in Pflanzenreich eigenthümlich. Fs tritt nun die Frage auf, in welcher Weise schon innerhalb des Kreises der einzelligen Wesen Thier'reich und Pflanzenreich auseinandergehen. Da hiel' die Verwandtschaftsverhältnisse oft schwer zu beurtheilen sind, so ist diese Frage noch keineswegs endgiltig beantwortet.

E. HAEKeL machte den Vorschlag, die einzelligen Wesen als Protistenreich zusammenzufassen und sie als drittes Reich den vielzelligen Pflanzen und vielzelligen Thieren gegenüberzustellen. Doch hat man bisher meist daran festgehalten, einen Theil der Einzelligen dem Pflanzenreich, einen andern Theil dem Thierreich zuzuordnen. Man stuitzt sich bei der Unterscheidnng zumeist anf die physiologischen Charaktere, dic aber von der Anschauung der liöleren Pflanzen und Thiere abgeleitet sind, und bei den einzelligen nicht immer mit gleicher Schärfe sich geltend machen.

1) Als wichtigster Unterschied wird der Gegensatz des Stoffwe chsels hervorgehoben (vergl. pag. 3). Daran knüpft sich anch das Vorhandensein von Clilorophyll in den die Kohlensäure assimilirenden Pflanzentlieilen. Doch gibt es sowohl chlorophyllfreie Pflanzen (Schmarotzer -, Humuspflanzen) und Pflanzen, die gelegentlich Eiweissnahrung aufnehmen (,fleischfressende Pflanzen"), als auch andererseits Thiere mit Chlorophyll (Vortex, Hydra, Stentor). Letztere betreffend wird in jüngster Zeit vielfach die Ansicht aufgestellt, dass ihr Chlorophyll auf Algen zurïickzuführen sei, die in den Geweben dieser Thiere leben (Symbiose).

2) Es ist bei den Thieren Empfindung und Bewegung in höherem Grade ausgebildet. Diese Functionen sind aber auf die Irritabilität und Contractilität zurückzuführen, die wir als allgemeine Eigenschaften des Plasma kennen. Es ist daher der Gegensatz namentlich bei niedrigen Formen weniger ausgeprägt. Bei niederen Pflanzen kommen vielfach bewegliche 'Lustände vor' (Schwärmsporen, Plasmodien) ${ }^{\mathbf{1}}$ ).

3) Die Ausbildung einer Cellulosemembran ist für die Pflanzenzelle charakteristisch. Damit steht auch in Zusammenliang die eigenthümliche Anordnumg des Plasmas und die grossen Flüssigkeitsräume in der Pflanzenzelle. Eine ähnliche Anordnung des Plasma kommt aber auch häufig in thierischen Zellen vor; und auch Cellulose ist im Thierreich nachgewiesen (im Gewebe des Mantels bei den Ascidien).

Bei den höheren (vielzelligen) Thieren und Pflanzen treten nichit nur diese Gegensätze schärfer hervor, sondern es hat aucl die gesammte Organisation sich in verschiedenartiger Richtung entwickelt. Es wird besonders hervorgehoben, dass die Organe der Pflanzen einer Flächenentwicklung durch äussere Entfaltung zustreben, während bei den Thieren eine innere Flächenentwicklung durch Einstülpungsprocesse vorherrscht.

Die Thiere sind zu definiren als Organismen, die organische Nahrung aufnehmen, Sauerstoff verblauclien und Kohlensäure abgeben, bei denendie Functionen der Bewegung und Empfindung ingesteigerter Weise auftreten.

1) Intensivere Bewegungen höherer Pflanzen, z. B. der Mimosen beruhen nicht auf Contractilität des Plasma, sondern auf plötzlichen Schwankungen des Wasserinhaltes der Pflanzentheile (BRǘCKE). 
Die Pflanzen sind Organismen, die im Allgemeinen Kohlensäure als Nahrung aufnehmen und Sauerstoff abgeben, und bei welchen die Functionen der Bewegung und Empfindung von sehr geringer Intensität sind.

\section{Das zoologische System.}

\section{Grundanschaungen des zoologischen Systems.}

Linné, dessen System als der Ausgangspunkt der modernen Systeme angesehen wird, betrachtete die ganze Thierwelt als eine einzige aufsteigende Reihe von Formen, er fasste alle Arten und daher auch die grösseren Abtheilungen als einander in einer Reihe übergeordnet auf. Wir bezeichnen daher Lisxé's Lehre als die Lehre von der einreihigen Anordnung des Thierreichs.

Cuvier's Auffassung von den verschiedenen Bauplänen der Thiere bahnte eine neue Epoche des zoologischen Systems an. Er sah in jedem seiner typischen $\mathrm{Kre}$ ise eine selbstständig aufsteigende Reihe von Thieren. Wir kömnen Cuvier's Lehre als die Lehre von den parallelen Reihen bezeichnen. Einen sehr präcisen Ausdruck findet diese Lelne in den Worten CARL ERxst v. BAER's: „Vor allen Dingen muss man, um eine richtige Einsicht in die gegenseitige Verwandtschaft der Thiere zu erlangen, die verschiedenen Organisationstypen von den verschiedenen Stufen der Ausbildung stets unterscheiden."

Die Lehre Curier's bildet eine Vorstufe für die Lehre Darwin's. Wohl war auch früher schon vielfach die Idee eines gewissen 'Lusammenhanges der Typen ausgesprochen ${ }^{1}$ ) und unter mannigfachen Versuchen der Anordnung sogar auch die Verwandtschaft der Thiere nach dem Schema eines Stammbaums angedeutet. Dennoch kann man die neue Epoche in der Auffassung des Systems erst auf DARIvis zurückführen, der die Lehre von den verschiedenen Graden der Verwandtschaft von ïberaus erweiterten Gesichtspunkten betrachtet und dieselbe in erklärendes Licht gerückt hat. Wir können diese Lehre nach ihrem allgemeinsten systematischen Resultate als die Lehre von rler stammbaunförmigen Anordnung des Systems benennen. Man betrachtet das zoologische System seit DARwiN als einen Ausdruck für die reale Verwandtschaft der Thiere. Bei der Unvollkommenheit unserer Kenntnisse können wir kaum erst Bruchstuicke des zoologischen Stammbaumes aufstellen; man hat daher (und auch aus Gründen der Uebersichtlichkeit) allgemein die Anordnung in Form der systematischen Eintheilung beibehalten und es werden nur erklärende Stammbäume, nach unseren Vorstellungen, hinzugefügt. Wir betrachten nun die Typen nicht mehr als parallele Reihen, sondern als verzweigte Aeste, die selbst wieder an ihrer Basis mit dem gemeinsamen Stamme, entweder unmittelbar oder mittelbar, zusammenhängen.

Durch DARwis's Lehre wurde nicht nur eine veränderte allgemeine Anschaumng über das System begründet, sondern es wurde dadurch

1) R. I,EUCKAR'T, „Ueber die Morphologie und die Verwandtschaftsverhältnisse der wirbellosen Thiere", 1848, p. 3. Vou LEUCKART wurde auch eine bestimmte Aufeinanderfolge der Typen, cntsprechend der allmählichen Vervollkommnung der organischen Baustilc ausgesprochen. Wie weit aber die damaligen Anschauungen noch von den heutigen entfernt waren, zeigen die Anfüln'ungen LELCKART's auf p. 10-13. 
auch eime bedeutende Verbesserung in der Methode der Systematik angebahnt. Denn da man eine reale Verwandtschaft als Grundlage des Systems erkannte, wurden die Kriterien der Systematik in viel schärferer und klarerer Weise festgestellt.

\section{Specielle systematische Eintheilung des 'Thierreichs} (Geschichte des Systems).

Alle Systeme (mit scheimbaren Ausnahmen) grïndeten sich auf die Kenntniss der Formen und veränderten sich stetig mit der Erweiterung der morphologischen Erkenntnis. In der Geschichte des zoologischen Systems spiegelt sich daher die Geschichte der morphologischen Forschung wieder.

Da die morphologische Erkemntnis der höheren Thiere schon frülızeitig bis zu einem gewissen Grade gediehen war, zu einer '/eit, da die Kenntnis der niederen Thierformen noch in den ersten Anfüngen sich befand, so sehen wir in den älteren Systemen die höheren 'Thiere in eine Anzahl ron Classen geordnet, während die niederen 'Thierformen in eine grosse Sammelgruppe vereinigt erscheinen. Später erkannte man, daß die unterschiedenen einzelnen Gruppen der höheren Thiere eine gewisse Zusammengehörigkeit zeigen und man vereinigte sie inmer weiter in grössere gemeinsame Kreise, während man in den grossen Sanmelgruppen der niederen 'Thiere allmählich den heterogenen Inhalt unterscheiden lernte und daher dieselben in immer zahlreichere Kreise auflöste. Dies ist ein Hauptzug, welcher trotz mancher Schwankungen in der Geschichte des zoologischen Systems sich stetig verfolgen lässt. Wir werden sehen, dass auch die hier darzulegenden Veränderungen des Systens, die sich gegenwärtig als angemessen erweisen, noch diesem Zuge unterwolfen sind. Ja es lässt sich vielleicht schon jetzt vermuthen, dass unser hier anfgestelltes System in einiger Zeit in manchen Punkten wieder in ähnlichem Sinne modificirt werden wird.

\section{Sy s tem des Aristoteles.}

Aristoteles theilte die Thiere ein in A. Blutth i ere: 1) Lebendig gebärende Vierfüsser (Säugethiere), 2) Vögel, 3) eierlegende Vierfüsser (Reptilien mod Amphibien), 4) Walthiere, 5) Fische; B. Blutlose: 6) Weichthiere (Cephalopoden), 7) Weichschalthiere (Kruster), 8) Kerfe, 9) Schalthiere (Schnecken, Muscheln und einige andere Formen). Bis zum Ende des Mittelalter's fanden diese Anschanungen dognatische Anerkennung, und auf diesem System fussen auch die neueren Systeme seit Ray und Linné.

\section{Sys t e m Linné's und Cuvier's.}

Den Ausgangspunkt der neueren Systeme bildet das System Linner's. Vergleichen wil das System Linvé's (1707-1778) mit dem fortgeschrittenen CurieR'schen Systeme (1812), welches auf ausgedehnte anatomische Kenntnisse sich gründete (pag. 34), so sehen wir die vier ersten Classen Linxé's bei Curien schon zum Kreise der Vertebraten vereinigt ${ }^{1}$ ), auch Lixsé's Insecta (unseren jetzigen Arthropoden entsprechend) sind mit den Ammeliden zu dem grösseren Kreise der Articulaten vereinigt. Von den aufgelösten Lisséschen Vermes sind

1) Die Trennung der Amphibien und Reptilien geschah erst später durch BuarnviLLE 
ansserdem die Mollusken als selbstständiger Kreis gesondert. Der Rest ron Linvé's Vermes bleibt aber als "Radiata" beisammen und erscheint späteren For'schern ebenso als eine Sammelgrupe heterogener Formen, wie wohl der Auschaung Cuvier's Linné's Vermes erschienen.

Auch im einzehnen wiederloolt sich derselbe Vorgang. So z. B. bilden die ersten sechs Ordnungen von Linsés Insecta (die Coleoptera, Hemiptera, lepidoptera, Nemroptera, Hymenoptera, Diptera) noch mit Hinzuzielung der Myriopoden den Inlalt vou Cuvier's Classe der Insects, die siebente Ordnung aber, die Aptera, ist aufgelöst in die Arachnida und Crustacea, die nun als selbstständige Classen neben den Insects stehen und selbst in eine grössere Anzalıl von Ordnuugen eingetheilt sind.

\section{Stebold's (1845) und Laeuckart's (1848) S y s te mt.}

Die Fortschritte, welche das System seit Cuvier erfahren hat, bestehen, wie schon angedentet, vor allem wieder in der fortgesetzten Auflösung des untersten Kreises, nämlich der Radiaten. Wir wollen

\section{Linné's S y s te m :}

1. Cl. Nammalia. Ord. Primates, Bruta, Ferae, Glires, Pecora, Belluae, Cete.

2. Cl. Aves. Ord. Accipitres, Picae, Anseres, Grallae, Gallinae, Passeres.

3. Cl. Amphibia. Ord. Reptiles, Serpentes, Nantes.

4. Cl. Pisces. Ord. A podes Jugulares, Thoracici, Abdominales.

5. Cl. Insecta. Órd. Coleoptera, Hemiptera, Lepidoptera, Neuroptera, Hymenoptera, Diptera, A p tera.

6. Cl. Vermes. Ord. Intestina, Mollusca, Testacea, I ithophyta, Zoophyta.

\section{Cuvier's S y s tem:}

1. Kreis: Vertebrata.

1. Cl. Mammalia. (Ord.....)

2. Cl. Aves. (Ord......)

3. Cl. Reptilia. (Ord......)

4. Cl. Pisces. (Ord. .....)

2. Kreis: Mollusca.

1. Cl. Cephalopoda. (Ord.....)

2. Cl. Pteropoda. (Ord......)

3. Cl. Gasteropoda. (Ord......)

4. Cl. Acephala. (Ord.....)

5. Cl. Brachiopoda. (Ord......)

6. Cl. Cirrhopoda. (Ord......)

3. Kreis: Articulata.

1. Cl. Annelides. (Ord......)

2. Cl. Crustacea. 1. Sect. Malacostraca. (Ord.......) 2. Sect. Entomostraca. (Ord......)

3. Cl. Arachmides. (Ord.....)

4. Cl. Insecla. (Ord. Myriapoda, Thysanura etc. . . Diptera).

4. Kreis: Radiata.

1. Cl. Echinodermata. (Ord......)

2. Cl. Intestina. Ord. Nematoidea, (Parenchymatosa......)

3. Cl. Acalephae. (Ord. Simplices, Hydrostaticae).

4. Cl. Polypi. (Ord......)

5. Cl. Infusoria. (Ord. Porifera, Homogenea). 
hier besonders die Systeme von SiEBOLD (1845) und LatckarT (1848) betrachten (die in vielen Punkten schon durch Burans'ler, 1843, volbereitet waren).

Der Lreis der Radiaten enthielt bei Currer die Classen der Echinodermata, Acalepha, Entozoa, Polypi, Infusoria. Die blosse 'T'rennung dieses ummaturlichen Verbandes (und damit die Erhebnng der einzelnen Classen zu 'Typen) brachte schon das System Cuvirl's jenen Systemen nahe, welche mit einigen Modificationen bis in die jüngste Zeit (Anfang der $70 \mathrm{er}$ Jahre) allgemein anerkannt waren. In dev T'lat beruhen die wesentlichen Verbesserungen des Systems durch v. Siebold und Leuckar'T in einer solchen Auflösung. Doch war eine grosse Summe neuer morplologischer Erkenntnis nöthig, mu dieselbe zu begründen. Auch ward die Stellung einzelner kleinerer Abtheilungen (Rotatoria, Bryozoa) wesentlich berichtigt, wogegen andere Veränderungen (Stellung der Himdinei, Nematodes) sich nicht stichhaltig erweisen.

จ. Siebold's S y stem (1845):

\section{Protozoa.}

1. Cl. Infusoria.

2. Cl. Rhizopoda.

II. Zoophyta.

3. Cl. Polypi (Anthozoa, Bryozoa).

4. Cl. A calephae.

5. Cl. Echinodermata.

III. Vermes.

6. Cl. Helminthes.

7. Cl. Turbellarii.

8. Cl. Rotatorii.

9. Cl. Annulati.

IV. Mollusca.

10. Cl. Acephala (Tunicata, Brachiopoda u. Lammellibranchiata).

11. Cl. Cephalophora.

12. Cl. Cephalopoda.

V. Arthropoda.

13. Cl. Crustacea.

14. Cl. Arachnida.

15. Cl. Insecta.

VI. Vertebrata.
Leuckati's Sy st e m (1848):

a. Protozoa (von den übrigen Thieren zu sondern!).

I. Coelenterata.

1. Cl. Polypi.

2. Cl. Acalephae.

II. Echinodermata.

3. Cl. Pelmatozoa (Ord. Cystidea, Crinoidea).

4. Cl. Actinozoa (Ord. Echinida, Asterida).

5. Cl. Scytodermata (Ord. Holothuriae u. Sipunculida).

III. Vermes.

6. Cl. Anenterati (Ord. Cestodes, Acanthocephali).

7. Cl. Apodes (Ord. Nemertini, Turbellarii, Trematodes, Hirudinei).

8. Cl. Ciliati (Ord. Bryozoa, Rotiferi).

9. Cl. Annelides (Ord. Nematodes, Lumbricini, Branchiati).

IV. Arthropoda.

10. Cl. Crustacea.

11. Cl. Insecta.

V. Mollusca.

12. Cl. Tunicata (vielleicht selbständiger Typus!).

13. Cl. Acephala.

14. Cl. Gasteropoda.

15. Cl. Cephalopoda.

VI. Vertebrata. 
So sehen wir bei Srebold (auch schon bei früheren Autoren z. B. Carus) aus der Auflösung der Covien'schen Radiata die Aufstellung der Protozoa, Zoopleyta und Vermes erfolgen. Die Aufstellung der Protozoa hat sich in der Folge als ein überaus bedeutungsvoller Schritt erwiesen. Die Vermes in neuerem Sinne nach dem Vorgange Grapenhorst's, Berthold's und Burnerster's aufgestellt (und verschieden von den Vermes Linnés) sind aus Cuvier's Entozoa bervorgegangem, zu welchen die Rotatorien und T'urbellarien und auch die Anneliden zugezogen wurden, welche letztere dadurch von den "Arthropoden" (mit welchen sie bei Cuvier als Articulata vereinigt waren) entfernt wurden. So ward die Cuvien'sche Abtheilung der Articulaten wieder aufgelöst, ein Vorgang, der lange allgemein anerkannt blieb und erst in allerjüngster Zeit sich als unberechtigt erwies, so dass wir gegenwärtig auf dem Punkte stehen, zur Restitution von Cuvien's Articulaten zu schreiten.

Leuckart ging noch weiter, indem or die bei $\nabla$. Siebold noch als Zoophyten vereinigte Gruppe auflöste. Sein grosses Verdienst ist es, den Gegensatz der Coelenteraten und Echinodermen in richtiges Licht gesetzt zu haben. Diese Trennung hat die allgemeinste Anerkennung gefunden, und Versuche einer Wiedervereinigung sind vereinzelt geblieben (z. B. AGAssiz). Auch fügte LedcKart den Vermes noch die Bryozoen hinzu, indem er sie in die unmittelbare Nähe der Rotatorien stellte (nach dem Vorgange ron Farre und $\nabla$. Baer). Früher schon hatte Ehrenberg die Bryozoen den eigentlichon Polypen gegenübergestellt, und dann Milne-Edwards sie von denselben ganz entfernt und den Mollusken zugeordnet. Bis in die neueste Zeit schwanken die Ansichten über die Stellung der Bryozoen zwischen der Auffassung LeucKart's und MiLne-EDwards', wenn es auch nicht an verfehlten Versuchen mangelt, dieselben wieder den Polypen zu nähern.

Es bilden die Abtheilungen der Protozoen, Coelenteraten, Echinodermen, Vermes, Arthropoden, Mollusken, Vertebraten, wie sie nach ihrem Inhalt und typischen Charakter besonders von LEUCKART abgegrenzt wurden, den Hauptzïgen nach die Grundlage aller allgemeiner anerkannten Systeme bis zu Anfang der siebziger Jahre.

In speciellen Punkten erfuhr das System in dieser Zeit durch neuere morphologische Entdeckungen wohl noch wichtige Veränderungen.

Die wesentlichste Aenderung wurde durch die Entdeckung KowaLEVSKY's angebahnt, dass die Ascidien dem Vertebratentypus nahestünden. Man glaubte eine Zeit lang dadurch ein Verbindungsglied zwischen den Vertebraten und anderen Typen erwiesen zu sehen, doch ist man allmällich zur Ansicht geliommen, dass die früher angenommenen Beziehungen der Tunicaten zu den Mollusken oder Würmeln ganz unklar seien und dass diese Thiere eben nur einen veränderten Platz im Anschluss an die Wirbelthiere finden, ohne aber als Uebergangsform zu anderen Typen gelten zu können (DoHRs). Der oberste Typus ist nun zu der Abtheilung der ,Chord on $\mathrm{ii}^{6}$ erweitert.

Die Sipunculiden wurden von den Holothurien entfernt und, mit den Echiniden vereinigt, als „Gephyreen" in die Nähe der Anneliden gestellt. Auch die Stellung der Hirudineen bei den Trematoden (LEUCKART) erwies sich als nicht stichhaltig und sie wurden zu den Ammeliden zurückversetzt.

Die Spongien, iiber deren Natur man lange Zeit im Unklaren war, wurden in jüngster Zeit, namentlich durch HAECKEL's For'schungen, zu den Coelenteraten gezogen. 
Die auch gegenwärtig an meisten gebrauchten Systeme entsprechen also noch dem System LEUCKART's mit einigen Modificationen. Als Beispiel wollen wir das System von CiaUs (vergl. Tehrbuch der \%oologie 4. Auflage 1887) auführen:

1. Protozoa.

2. Coelenterata (Spongiaria, Cnidaria, Ctenophora.)

3. Echinodermata, Anh. Enteropneusta.

4. Vermes (Platyhelminthes, Nemathelminthes $[\mathrm{mit}$ den Chaetognathen], Annelides, Rotatoria).

5. Arthropoda (Crustacea, Arachnoidea, Onychophora, Myriopoda, 6. Mollusca. Hexapoda).

7. Molluscoidea (Bryozoa [endoprocta u. ectoprocta], Brachiopoda).

8. Tunicata.

9. Vertebrata.

Wenn wir den Einfluss der Descendenztheorie auf das specielle System während dieser Jahrzehnte (von DARwin [1859] bis in die 70er Jahre) ins Auge fassen, so sehen wir, dass durch diese Lehre nicht unmittelbar eine Aenderung des zoologischen Systems bewirkt wurde. Und dies ist leicht begreiflich. Die Principien der Systematik waren früher wohl weniger klar und deutlich erkannt, aber dennoch soweit richtig angewendet, dass sich nach vielfacher Durcharbeitung oin System ergab, dessen Zusammenhang durch die Descendenztheorie wohl ganz überraschend erhellt, aber nicht verändert wurde, denn die morphologischen Erkenntnisse, deren Ausdruck das System auch friiher schon war, wurden durch die Descendenztheorie an und für sich nicht vermehrt.

Die Versuche, das System unter dem Einflusse der neuen Ideen sofort umzugestalten, mussten daher verfehlte sein. In der That bringen HaEcKEL's erste systematische Versuche in der "generellen Morpholouie“, welche den neuen Ideen Rechnung tragen sollen, eigentlich nur von den herrschenden Ansichten abweichende, zum grossen Theil aber irrige Auffassungen der speciellen morphologischen Verhältnisse zum Ausdruck.

Ungleich fruchtbarer waren in nächster Zeit die Bestrebungen GeGENBADR's, das Verhältniss der Typen zu einander durch stete Vertiefung der morphologischen Erkenntnis zu ergründen. So ist durch ihn die Anschauung eines näheren verwandtschaftlichen Zusammenhanges zwischen den Würmern einerseits und den Arthropoden und Mollusken immer mehr gefördert worden, was uns endlich dahin führen musste, diese Gruppen in einem vereinigten Stamme den anderen Stämmen gegenüberstellen, wio wir es hier (vergl, pag. 40) ausgeführt haben.

Diese Fortschritte hängen aber auch wesentlich damit zusammen, dass der Begriff des Typus selbst verändert erschien. Gegenbaur betonte, „dass die starre Auffassung der Stämme, wie sie von der ersten Typenlehre her bestand, bedeutend nachgiebiger werden müsse, indem wir die Beziehung der Typen zu einander in keiner anderen Weise treffen, als die Abtheilungen innerhalb der Typen: in genealogischer Gliederung" (Grundziige d. vergl. Anat. 1872, p. 77). Sehr zutreffend bemerkt auch Hafckes: „Der "Typus" hat danach seine frühere Bedeutung vollständig vorloren und besitzt als $\mathrm{Kateg}$ orie des Systems keine andere philosophische Bedeutung als die niederen Kategorien der Klasse, Ordnung, Genus, Species, 
u. s. w.; er ist nur relati $\nabla$ (durch seine Höhe), nicht absolut von letzteren verschieden"(1874).

Von HAEckel's Gastraeatheorie (1874) bis zur Gegenwart.

Mit den siebziger Jalnen beginnt eiu neuer Abschnitt der Morphologie, welcher dadurch cliarakterisirt ist, dass die embryologische Forschung bedeutend in den Vordergrund tritt. Dieser Abschnitt wird eingeleitet durch die epochemachenden embryologischen Untersuchungen Kowalevsky's, welche nach dem Ziele hinsteuerten, den noch vielfach anerkannten Gegensatz der 'Iypen auf embryologischem Wege zu widerlegen und zwar durch den Nachweis der Homologie der Keimblätter in allen Typen. Dieselben embryonalen Keimblätter sollten überall die Grundlage des Körperbaues bilden.

Die Entdeckungen KowaLEvskY's waren nur von ganz allgemeinen theoretischen Bemerkungen und Andeutungen begleitet. Erst HAEckes, lat die KowaLEYsKY'schen Entdeckungen in ihrer vollen Tragweite gewürdigt und die systematisclien Schlussfolgerungen daraus gezogen. Seine Ausführungen sind von grösster Bedeutung für die Weiterbildung des Systems geworden. Die systematische Bedeutung der Gastraeatheorie gipfelt ill folgendem wichtigsten Punkte: „Das ganze Thierreich zerfällt zunächst in zwei grosse Hauptgruppen, deren scheidende Grenzmarke die Gastrula bildet: einerseits die Stammgruppe der Urthiere (Protozoa), andererseits die sechs höheren Thierstämme, die wir jenen als Keimblatt thiere (Metazoa oder B lastozoa)gegeniuberstellen." So geringfügig im System diese Zusammenfassung der Metazoa und ihre Gegenüberstellung zu den Protozoen (übrigens schon von LEUCKART hervorgehoben) erscheinen mag, so ist sie doch von der grössten Bedeutung für das Verständnis der allgemeinen verwandtschaftlichen Beziehungen der Thierstämme und es findet eine grosse Summe neuerer morphologischer Erkenntnisse darin ihren Ausdruck. Sie sind in den einfachen Worten zusammengefasst: dass alle löheren Thierstämme von der gemeinsamen Stammform der Gastrae a abstammen, welche einen einachsigen Körper besitzt, dessen Höhle an einem Pole durch den Urmund sich öffnet und dessen Körperwand aus zwei Zellenschichten, dem Exoderm und Endoderm besteht.

HAEckes versuchte auch innerhalb der Metazoen die Beziehungen der einzelnen Gruppen zu einander aufzuklären. Er sah ganz richtig, naclı welchen Principien das System nun weiter entwickelt werden müsse, da er als oberstes Classificationsprincip die Homologie der Keimblätter und des Urdarms und demnächst die Differenzirung der Kreuzachsen und des Coeloms hervorhob; dafür hat die Folgezeit die Bestätigung geliefert. In der Anwendung dieser Principien war er aber weniger glücklich. So erscheint die Eintheilung der Metazoa in Anaemaria und Haemataria als ein Missgriff, und ebenso die Art, wie HaEcker die Trennung der Vermes in Acoelomi und Coelomati im speciellen durchführte. Die Fehler, welche Hacckes in diesen Punkten beging, wurden besonders von CLAUs in zutreffender Weise nacligewiesen.

Die kritische Schrift von Clads, wenn auch in Bezug auf die Negation der HaEckes'schen Fortschritte viel zu weit gehend, hat doch vielfach die Anschauungen gefördert. Hier ward zuerst auf die Bedeutung des der Gastrula vorhergehenden einfachen blasenförmigen Stadiums hingewiesen. Wenn auch Claus selbst die älteren diesbezüglichen Andeutungen C. E. v. 
BAER's citirt, so hat doch or zuorst klar erkannt, dass in dieser einfachsten epithelartigen Anordnung der Zellen die Grundbedingung des Körperbaues der Metazoon vorliege. HácKel hat sich dieser Anschauung auch sogleich angeschlossen, und so selbst den Beweis geführt, dass die Bedeutung der „Blastula“ ganz wohl mit der Gastraeatheorie vereinbar sei.

Auch auf den bedeutungsvollen Gegensatz von primärer und secundärer Leibeshöhle wird von Craus hingewiesen und dadurch HaEckeL's Coelombegriff corrigirt.

Die Ableitung der Bilaternlthiere von einer „kriechenden Gastraea“ wird zurückgewiesen und auf die grosse Bedeutung, welche den freischwimmenden, pelagischen Thierformen für die Phylogenio des Thierreichs zukömmt, hingewiesen.

Wenn auch die Ver'suche HAEcksL's, die Beziehungen zwischen den eiuzelnen Typen noch weiter aufzuklïlen zum Theil verfehlt waren, so haben sie doch weiter Veranlassung gegeben zu einer Reihe ähnlicher Versuche, welche die systematischen Bestrebungen der nächstfolgenden Zeit kennzeichnen. Es wurde aufs eifrigste nach Homologieen zwischen den verschiedenen 'Typen gesucht und hierbei eine grosse Zahl von Hypothesen aufgestellt. Einige derselben werden vielleicht, wem auch mit wesentlicheu Abänderungen, bleibenden Werth behalten; zu den bedeutendsten dieser Hypothesen zählt die Ableitung der Wirbelthiere von den Anneliden, welche von SEMPER begrïndet wurde (Entdeckung der Segmentalorgane bei Wirbelthieren; vergl. auch die Arbeiten von Domrs, BALFour u. a.). Wenn auch manche dieser Hypothesen für den Fortschritt der Wissenschaft von grosser Wichtigkeit sind, so ist es doch geboten, bei den gegenwärtig so schrankenlos geübten Vergleichungen den verschiedengradigen Werth derselben nicht ausser Acht zu lassen. Wir können bei den Metazoen eine Anzahl von Gruppen, sei es als Typenoder Phylen, a ustellen; innerla $1 \mathrm{~b}$ dieser Typen ist die Vergleichung auch speciellerer Organe durchführbar, während derartigenspecielleren Vergleichungen zwiscllen diesen Typen derzeit nur ein weitaus geringerer Wahrscheinlichkeitsgrad (nurein hypothetischer oder heuristischer Werth) zuerkannt werden kann. Mit anderen Worten: Die Abstammung dieser Typen (oder Phylen) von der Gastraea ist anzuerkennen, die specielleren Verwandtschaftsverhältnisse derselben $\mathrm{zu}$ einander sind noch unsicher ${ }^{\mathbf{1}}$ ). In der nachfolgenden Tabelle sind unsere Anschauungen iiber das System zum Ausdruck gebracht. Unsere Typen sind abweichend von denjenigen der üblichen Systeme, indem einerseits der Kreis der Coelenteraten in 3 Typen aufgelöst wurde (aus später zu erörternden Gründen) wogegen die anderen Typen aus der Zusammenziehung bisher getrennter Gruppen resultiren. Als nächste Unterab-

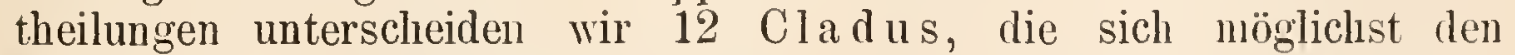
gebräuchlichen Abtheilungen anlehnen, zum 'Theil aber zeitgemässen Veränderungen Rechnung tragen.

1) Die Her'wig'sche Coelomtheorie, die (wie wir später noch erörtern), viele ïberaus wichtige Fragen angeregt hat, ist in Bezug auf die systematische Frage zu keinem befricdigenden Resultat gekommen; von einem einzigen Gesichtspunkte aus lassen sich eben diese complicirten Fragen nicht lösen. 


\section{A. Protozoa.}

\section{B. Metazoa.}

a) Protaxonia (= Coelenterata) *1)

\begin{tabular}{|c|c|c|}
\hline & I. Typ. Spongiaria & 1. Clad. Spongiaria \\
\hline & II. Typ. Cnidaria & $\begin{array}{l}\text { 2. Clad. Cniduria } \\
\text { 1. Class. Hydrozod } \\
\text { 2. Class. Scyphozoa } \\
\text { Anh. Planuloidea (Dyciemidae, } \\
\text { Orthonectidae). }\end{array}$ \\
\hline & III. Typ. Ctenophora & 3. Clad. Ctenophora \\
\hline \multicolumn{3}{|c|}{ Heteraxonia (= Bilateria) } \\
\hline & $\begin{array}{c}\text { IV. Typ. Zygoneura } * 2) \\
\text { 1. Subtyp. Autoscolecida } \\
\left.(=\text { Protonephridozoa })^{* 3}\right)\end{array}$ & $\begin{array}{l}\text { 4. Clad. Scolecida } \\
\text { 1. Class. Platodes } \\
\text { 2. Class. Rotifera } \\
\text { 3. Class. Endoprocta } \\
\text { 4. Class. Nematodes } \\
\text { 5. Class. Acanthocephali } \\
\text { Anh. Nemertini }\end{array}$ \\
\hline & $\begin{array}{l}\text { 2. Subtyp. Aposcolecida } \\
\left.(=\text { Metanephridozoa })^{* 4}\right)\end{array}$ & $\begin{array}{l}\text { 5. Ciad. Articulata } \\
\text { 1. Class. Annelida } \\
\text { Anh. Sipunculoidea } \\
\text { Anh. Chaetognathi } \\
\text { 2. Class. Onjchophora } \\
\text { 3. Class. Arthropoda } \\
\text { 6. Clad. Tentaculata (= Molluscoi- } \\
\text { dea) *5) } \\
\text { 1. Class. Phoronida } \\
\text { 2. Class. Bryozoa (ectoprocta) } \\
\text { 3. Class. Brachiopoda } \\
\text { 7. Clad. Mollusca } \\
\text { 1. Subclad. Amphineura } \\
\text { 2. Subclad. Conchifera }\end{array}$ \\
\hline & V. Typ. Ambulacralia ${ }^{*}{ }^{(j}$ ) & $\begin{array}{l}\text { 8. Clad. Echinodermata } \\
\text { 9. Clad. Enteropneusta }\end{array}$ \\
\hline & VI. Typ. Chordonii ${ }^{*}$ ) & $\begin{array}{l}\text { 10. Clad. Tunicala } \\
\text { 11. Clad. Leptocardii } \\
\text { 12. Clad. Vertebrata } \\
\text { 1. Subclad. Cyclostomata } \\
\text { 2. Subclad. Gnathostomata }\end{array}$ \\
\hline
\end{tabular}

1) Protaxonia und Heteraxonia werden von uns nur als zusammenfassende Bezeichnungen, nicht als sichere systematische Begriffe gebraucht. - Ueber die Auflösung der 
Coelenteraten vergl. Carl Heider, Metamorphose der Oscarella lobularis, Arb. zool. Iust. Wien 1885.

2) Die Zygoneura sind eine Gruppe, welche dureh zahlreiche Homologien sieher begründet erscheint. Sie ist zurückführbar auf die Grundform der Troehophora und der Protrochophora (Platodes). Die Zusanmenfassung der hier vereinigten Classen ist durch zahlleiche Ausfiihrungen Gegenisuur's vorbereitet. Der Name Zygoneura, Paarnervige, ist nach den parigen Längsnerven gewählt. die entweder in ganzer Länge oder wenigstcns im Bereich der Schlundkommissur zeitlebens getrennt bleiben.

3) Der Name Protonepliridozoa (seiner Länge wegen nur als Synonym gebraucht) bezieht sieh auf den dauernden Besitz des Protonephridinms; die ausführlichere Begründung dieser Gruppe folgt im speciellen Theile.

4) Zur Erklärung des Namens Metanephridozoa ist zu bemerken: das Protonephridium tritt hier nur als Larvenorgan auf; dafiir ist das characteristische Metanephridium aufgetreten und nur bei einigen Gruppen secundär wieder unterdriickt. Damit ist aus der grossen Zahl von Merkmalen nur eines betont.

5) Die Gruppe der Tentaculata ist provisorisch aufgestellt und bedarf noch einer besseren Erforschung (man vergl, die äluliehen Aufstellungen von CALdwelt und RAYIANKester). Es ist namentlich die Stellung der Bryozoa (eetoproeta) hier noch sicherer zul begruinden.

6) Im Sinne Metschnikoffs.

7) Die Gruppe der Chordonii wird gegenwärtig von zahlreiehen Autoren anerkannt. Sachlich ist sie zuerst begriudet durch die Untersuchungen KowaLevsky's. 


\section{FÜNFTES CAPITEL. \\ Zelle und Zelltheilung.}

\section{Zelle.}

Sowohl der thierische als auch der pflanzliche Körper besteht aus elementaren Gebilden, welche wir Zellen nemnen.

Gegenwärtig wissen wir, dass es, wie unter den Pflanzen so unter den Thieren, einzellige Formen giebt, deren Körper auf den Bau e in e r Zelle zurückführbar ist, und vielzellige Formen, die aus zahlreichen derartigen Zellen bestehen, welche die sogenannten Gewebe des Körpers zusammensetzen.

Die Form der Zelle ist im einfachsten Falle kugelig, in anderen Fällen - in Zusammenhang mit der Function und dem Lagerungsverhältnis - mannigfach verändert.

Die wesentlichen Theile der Zelle sind: 1) der Zellleib oder das Plasma (auch Protoplasma genannt) und 2) der darin eingeschlossene Zellkern.

Die Zusammensetzung des Körpers aus Zellen wurde zuerst bei den Pflanzen nachgewiesen. Man hatte schon früher mikroskopisch kleine Hohlräume in denselben bemerkt; da zeigte Dutrocaet, dass diese Hohlräume von eigenen Wänden begrenzt sind, dass kleine bläschen- oder schlauchförmige Gebilde vorliegen, aus welchen der ganze Pflanzenkörper aufgebaut ist. Dies bildete die Grundlage der von Schleinen ausgebildeten Zellentheorie. Der Botaniker RoвERT BRown entdeckte ein innerhalb der Zelle liegendes Gebilde, den Zellkern. Man betrachtete damals als typische Theile der Zelle die Zellwand, den flüssigen Inhalt und den Zellkern. Darnach erst wurde durch Th. Schwann die Lehre begründet, dass der thierische Körper, ähnlich wie derjenige der Pflanzen, aus Zellen bestünde. Schwann glaubte aber, dass die thierische Zelle gleich der pflanzlichen bläschenförmig sei, eine irrige Vorstellung, die später corrigirt wurde. Erst nachdem Hugo v. MoHL als einen wesentlichen Bestandtheil der Pflanzenzelle den plasmatischen Primordialschlauch, welcher der Zellwand innen anliegt, entdeckte, ward ein richtiger Vergleich der compacten thierischen und der bläschenförmigen Pflanzenzelle ermöglicht. Die Zellwand, welche aus Cellulose besteht, ist eine besondere, der Pflanzenzelle eigenthümliche Bildung. Auch der Flüssigkeitshohlraum, der in der Pflanzenzelle sich findet, kömmt der thierischen Zelle in der Regel nicht zu. Der der Zellwand anliegende plasmatische Primordialschlauch der Pflanzenzelle ist es, welcher dem Zellleib der thierischen Zelle entspricht. Der Zellkern der thierischen und pflanzlichen Zelle sind gleichwerthige Gebilde. Die jugendliche compacte und membranlose Pflanzenzelle gleicht vollkommen der thierischen Zelle, 
Das Plas ma der Zellen ist von zähflüssiger Consistenz und zeigt in mehr oder weniger deutlicher Weise die Fähigkeit der Contractilität. Es ist kein gleichartiger, homogener Körper, sonderu lässt stets verschiedene Structuren erkenmen. Man unterscheidet nach neueren Beobachtungen (KupfFen, Flemming u. a.) feinste Fäden, die sich viclleicht zu einem Netzwerk verbinden, als Filarsubst a $\mathrm{z}$ ides Plasma, und eine hellere, weiche (wasserreiche) Masse, in welche diese Fïden eingebettet sind, die Interfilarsubstanz. Die Fäden machen, wenn man sie im optischen Querschnitt sieht, den Eindruck von Körnchen; ausser diesen falschen Köınchen finden sich in Plasma wohl in allen Fällen auch wirkliche feinere oder gröbere Plasmakörnchen.

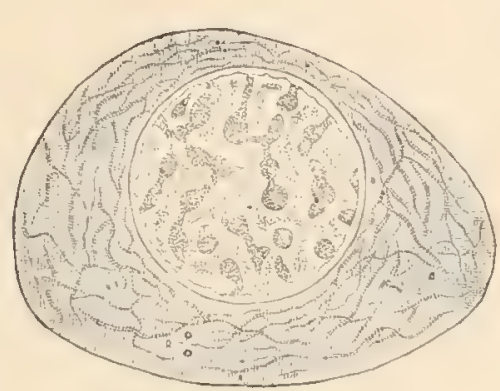

Fig. 2.

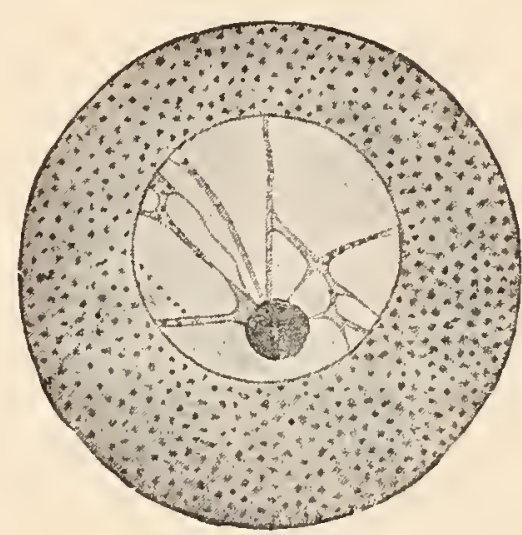

Fig. 3.

Fig. 2. Lebende Knorpelzelle der Salamanderlarve, stark vergrössert, mit dentlicher Filarsubstanz (nach FLEMMNG).

Fig. 3. Unreife Eizelle aus dem Eierstock eines Echinodermen. Dic Structur des Kernes ist hier sehr deutlich (nach HerTwIG).

Der Zellkern ( $\mathrm{Nucleus)} \mathrm{findet} \mathrm{sich} \mathrm{in} \mathrm{der} \mathrm{Zelle} \mathrm{in} \mathrm{einfacher,}$ seltener in mehrfacher $/ \mathrm{sahl}$.

Der häufigste typische Bau des Zellkernes ist folgender: Der Kern besitzt die Form eines runden Bläschens und besteht aus 1) der K e r 1 membran, einer dünnen Membran, welche die äusserc Begrenzun: des Kernes bildet, 2) dem Kernsaft, welcher den flüssigel Inhalt des Bläschens bildet und 3) dem Kerngerüst, einem Netzwerk von derberen Fäden, welches zum Theil der Kernmembran innen anliegt, zum Theil durch deu Hohlraum des Kerns ausgespannt ist; dem Netzwerk sind ein oder mehrere derbere Körnchen eingefügt, oft in der Mitte des Kernhohlraumes liegend, als sogen. Nucleoli; sie sind von der Substanz des Kerngerüstes kaum verschieden.

Das Kerngerüst und die Nucleoli bestehen aus sogenannter chromat is cher Substanz oder Clrom a tin. Diese Bezeichnung gründet sich auf eine eigenthümliche Reaction, welche diese Substanz, wemn die Zelle durch geeignete Mittel getödtet worden ist, vielen organischen Farbstoffen (Carmin, Haematoxylin, Anilinfarben etc.) gegenüber zeigt; sie imbibirt nämlich lebhaft den Farbstoff und hebt sich dadurch optisch sehr auffallend von den übrigen 'Theilen der Zelle ab. — In übrigen zeigen diese festeren Theile des Kernes eine ähnliche zähflüssige Beschaffenheit wie das Plasma der Zelle.

In den Zellen der vielzelligen Organismen zeigt der Kern zumeist den hier beschriebenen typischen Bau, oder er weicht nur wenig von dieser Form 
$\mathrm{ab}$; so ist er oft im Zusammenhang mit der Gestalt der Zelle gestreckt oder abgeplattet. Selten sind bedeutendere Formveränderungen $\mathrm{zu}$ beobachten (z. B. verästelte Kerne in den Zellen der Spinndrüsen der Seidenraupe). Bei den einzelligen Thieren, besonders den Infusorien, zeigt der Kern häufiger eine abweichende mannigfaltige Form und Structur; so erscheint er langgestreckt, perlschnurförmig, wurstförmig, rerästelt etc.; auch ist er oft compact, was wohl darauf beruht, dass hier der Kernsaft durch eine spärlichere und zugleich zähere Substanz ersetzt ist.

Bei Betrachtung der zahlreichen secundären Einrichtungen (D ifferenzirungen), die im Zusammenhang mit der mannigfachen Function der Zellen auftreten und die wir später an vielen Beispielen kennen lernen werden, sehen wir, dass alle die auffallenden functionellen Differenzirungen nur vom Plasma ausgehen, während der Bau des Kernes nur geringfügige, aber bestimmte Veränderungen zeigt. Es ist auch hervorzuheben, dass wir zahlreiche Lebenserscheinungen nur an Plasma beobachten, wällrend der Kern sich relativ indifferent verlält. Es ist daher begreiflich, dass uns die Function des Kernes noch sehr dunkel ist. - Dass diese aber zweifellos ron grösster Wichtigkeit für das Leben der Zelle ist, wird sowohl aus seinem constanten Vorkommen, als auch besonders aus den Vorgängen, die wir bei der 'Kelltheilung kennen, ersichtlich. - In jüngster Zeit wurde auch aus der wechselnden Lagebeziehung des Kermes auf sein Verhältıis zur 'Thätigkeit der \%elle geschlossen (HABERLANDT).

Bewegungserscheinungen werden an der chromatischen Substanz nicht wahrgenommen, ausser bei dem Theilungsprocesse. Feste Nahrungstheilchen gelangen nie in das Innere des Kerns; er scheint in Bezug auf seine Ernährung in einem Abhängigkeitsverhältnis zum Plasma zu stehen; ob er vom Plasma vorbereitete Nahrung assimilirt, oder ob sogar Theilchen von Kernsubstanz im Plasma entstehen und zum Kerne hinzutreten, ist gegenwärtig kaum zu entscheiden.

\section{Zelltheilung.}

Die Zelltheilung ist die einzige Vermehrungsart der Zellen. Die frïher vermuthete, freie Zellbildung" im Körper der Organismen hat sich als Irrthum erwiesen. Die Zelltheilung wird stets durch eine Theilung des Kerns eingeleitet. Dem früher schon aufgestellten Satze , omuis cellula e cellula" lässt sich nach den gegenwärtigen Forschungsergebnissen der Satz hinzufügen: , o mnis nucleus e nu cleo".

Die Theilungsvorgänge des Zellkerns sind in den letzten Jahren Gegenstand der eingehendsten Studien gewesen. - Früher schilderte man den Vorgang allgemein so, dass sich der Zellkeln einfach einschnüre und in zwei Theile zerfalle, worauf die Theilung des Zellleibes folge. - Es hat sich nun gezeigt, dass ein solcher Vorgang nur in wenigen Fällen, z. B. bei den einfachsten einzelligen Organismen, stattfindet. Wir nennen diese Art der Theilung direkte Zelltheilung.

Im Gegensatz hierzu steht die indirekte Zelltheilung (auch karyokinetische oder mitotische genannt). Bei dieser Art der Theilung unterliegt der Kern einer Reihe charakteristischer Veränderungen. 
Man kam erst allmählich zur Erkicnntnis dicser Vorgänge. Der erste Fortschritt gegenüber der ältern Ansicht von der allgemeinen direkten Theilung des Kernes war die Behauptung, dass bei der Kelltheilung der Mutterkern verschwinde und die Tochterkerne neu entstünden. Diese Ansicht war nur auf die Beobachtung des lebenden Objectes gestuitzt, an welchem der Kern während seiner Veränderungen undeutlich wird. Bald entdeckte man abcr, dass der Kern nicht verschwindet, sondern sich in einen hellen spindelförmigen Körper, die Kernspiudel, verwandelt, welche eine feine Längsstreifung und einc mittlerc Anhäufung von festerer Substanz, die Axenplatte erkennen lïsst. Die Axenplatte theilt sich, und ihre Hälften riucken als Polplatten an die Enden der Spindel. Im Zellplasma sind in diesem Stadium von den Polen ausgehende Strahlenfiguren, als Ausdruck von Bewegungserscheinungen, zu beobachten. Die Polplatten geben die Grundlage zur Bildung der neuen Kerne (Bürschlr).

Die Veränderungen des Kernes bei der mitotischen Theilung sind nach den neueren Forschungen folgende:

a) Ruhender Kerı. Bei den Vorgängen der karyokinetischen oder mitotischen 'Theilung; wie sie besonders FLemmsg aufgedeckt hat, können wir eine Reihe von Stadien unterscheiden. Bei der Betrachtung derselben gehen wir von der oben beschriebenen form des ru lien d e n Kernes aus.

b) Knäuelform des Hermes (Spirem). Die erste Veränderung ist das Schwinden der Kírnmembran und die Umwand ung des Ḱ erng e rü stes (chronatische Substanz) in einen gewundenen, an der Kermperipherie gelagerten Faden.

c) Steruform des Kermes (Aster). Sodann wandelt sich der Knäuel in eine Hache, sternförmige Figur um, welche senkrecht zur späteren 'Iheilungsebene gestellt ist; der clromatische Faden zerfällt nämlich in einzelne Stücke, die schleifenfö r mig geknickt sind (K e rns chleife n), deren Umbiegungsstelle gegen das Centrun, deren freie Enden gegen die Peripherie des Sternes liegen. Zugleich tritt im Bereiche des Kernes die, ach romatische Figur "6 auf, eine aus hellen, zarten, achromatischen Fäden zusanmengesetzte Spindel, deren Enden (oft mit hellen sogenannten Polarkör perchen zusammenhängend ${ }^{1}$ )) nach den 'Theilungspolen der Zelle gerichtet sind, und deren Mitte von der chromatischen Sternfigur eingenommen wird; hier stehen die zarten Fäden mit den einzelnen Kernschleifen in Zusammenhang. Im Zellleib ist in der Regel cine Plas as trah lung um zwei Centren, nämlich um die Pole der Spindel, zu beobachten, eine Erscheinumg, welche wahrscheinlich auf Bewegungsvorgänge des Plasnı zurückzuführen ist.

d) Stadium der Un-0rdnung (Metakinesis), Die Kiernschleifen erfahren nun eine Spaltung in der Längsriclitung des Fadens, so dass 11 m Doppelfäden vorliegen (die Spaltung ist nach neueren Beobachtungen selbst schon im Knäuelstadium vorbereitet). Die Spalthälften der einzehnen Schleifen werden danln - bei allen gleichzeitig - auf eigenthümliche Weise von einander getrennt, nämlich so, dass die Spalt-

1) Diese Polarkürperchen sind besonders in den nenesten Arbeiten hervorgehoben; sie werden als die Attractionscentren betrachtet, dic für die Mechanik der Zelltheilung von wesentlicher Bedeutung sein sollen. 
hälften je einer Schleife anseinanderrücken und nach den ungleichnamigen Polen der Spindel wandern; es geschieht dies durch active Zusammenziehung der achromatischen Spindelfäden. Das Wesentliche dieses Processes, die Vertheilung von Spalthälften, wurde hesonders durch die Untersuchungen von VAx BENEDEx und Rabl aufgeklärt.

e) Tochtersterne (Dyaster). So entstehen aus dem früheren einfachen Sterne zwei parallel gelagerte Sternfiguren, die Tochtersterne. Die zawischen denselben ausgespannten Theile der Spindelfüden schwinden; ebenso später anch die ïbrige Spindelfigur und die Plasmastrahlung.

f) Tochterknäuel (Dispirem). Die Tochtersterne gehen den umgekehrten Weg der Verwandlung; sie gehen zmnächst in 'Tochterkuäuel und sodann in

g) Buhende Tochterkerne iiber. '/ugleich mit diesen letzten Stanlien

a.

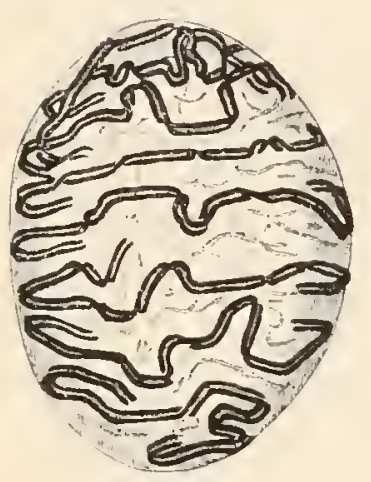

d.

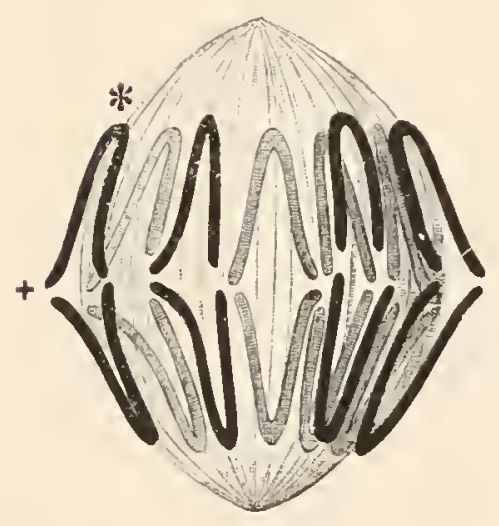

b.

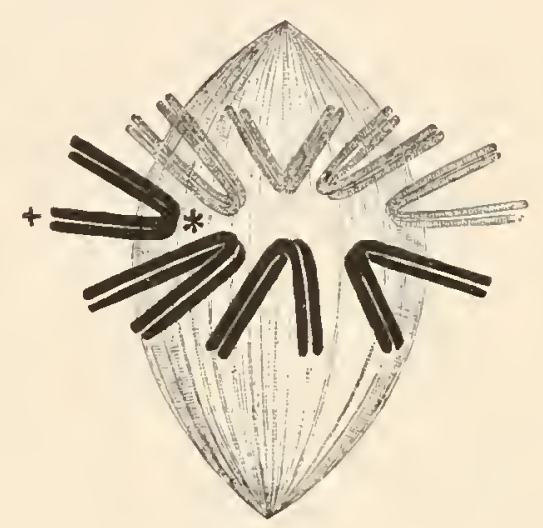

e.

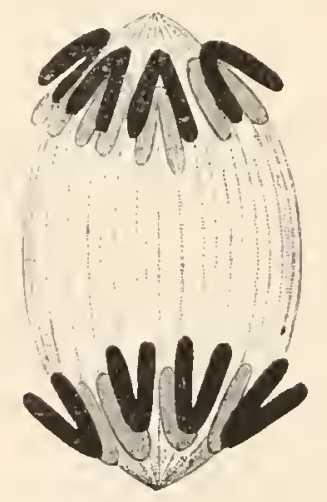

c.

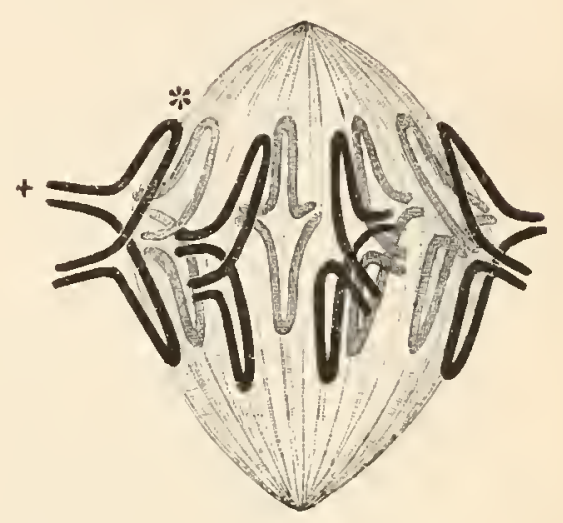

f.

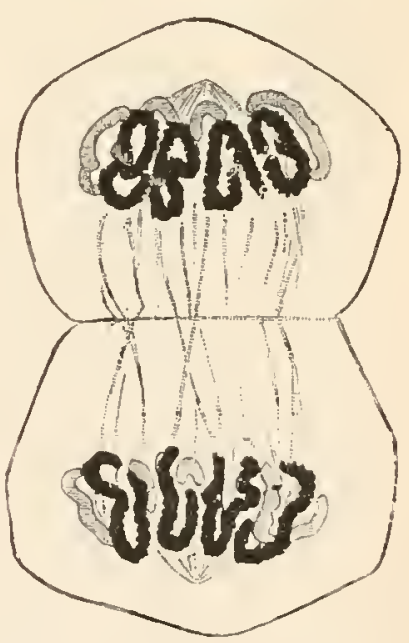

Fig. 4. Schematische Darstellung der Mitose (nach Fleming). Die Spaltung des chromatischen Fadens ist schon im Knäuelstadium vorbereitet.

a. Knäuel, b. Aster, c. und d. Metakinese, e. Dyaster, f. Die Tochterzellen mit den Tochterknäueln.

der Kerne erfolgt auch die Theilung des Zellleibes durch eine von Aussen nach Innen vordringende Einschnürung (wenn eine solche Einschnürung unterbleibt, entstehen vielkernige Zellen). 
Flemming stellt folgendes Schema für die Verwandlungsstadien des Kernes auf:

$\begin{array}{cc}\begin{array}{c}\text { Mutterkern } \\ \text { (progressiv) }\end{array} & \text { Tochterkern } \\ \text { (regressiv) } \\ \text { Ruhe (Gerïst) } & \text { Ruhe (Gerüst) } \\ \begin{array}{ll}\text { 1. Knäuel } & \text { 5. Kü̈uel } \\ \text { 2. Sterıl. } & \text { 4. Stern }\end{array}\end{array}$

Van Beneden und Rabi, haben gezeigt, dass in bestimnten Zellen die Anzahl der Kernschleifen eine bestimmte ist. Auch wurde von RABL wahrscheinlich gemacht, dass schon in r'uhenden Kerne die Anordnung des Kinäuels vorbereitet sei.

Wenn wir so complicirte Vorgänge in gesetzmässiger Weise an den thierischen und auch an den pflanzlichen Zellen auftreten sehen, so werden wir zu der Frage gedrängt, welche Bedeutung, welcher Zweck denselben zu Grunde liege. Roux hat in scharfsinniger Weise hierfür eine Erklärung angebahnt: Wemn das Kerngerïst vou durchwegs gleichartiger Beschaffenheit wäre, so könnten wir kaum den Zweck so complicirter Vorgänge bei der Zerlegung desselben in zwei 'Theile einsehen. Wir sind zu der Ammahme gedrängt, dass das Kerngerüst verschiedenartige, für die Lebensthätigkeit

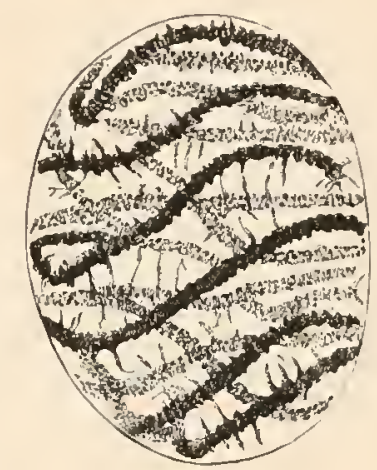

Fig. 5. Ruhender Zellkern aus dem Hoden des Salamanders (nach FLFMIING). der Zelle nothwendige Qualitäten besitze. Die Umwandlung des Geruistes in einen Faden und die L ängspaltung des F a d en s (oder seiner Schleifenstiucke) erscheint uns nun als ein äusserst zweckentsprechender Mechanismus, um die nach der Länge des Fadens aneinandergereihten, verschieden qualificirten Bestandtheile in gleicher "Weise auf beide Tochterkerne zu vertheilen. - Es ist hier zu erwähnen, dass der Kernfaden nach melıfachen Beobachtungen aus aneinandergereihten Körnchen besteht, so dass bei der Längsspaltung jedes Körnchen getheilt wird. 


\section{SECHSTES CAPITEL.}

\section{Protozoa.}

Die Protozoa sind einzellige (solitäre oder zu gleichartigen Zellcormen vereinigte) Organismen mit thierischem Stoffwechsel. Die Fortpflanzung erfolgt durch Theilung der differenzirten oder rückdifferenzirten Kelle. Vor übergehende oder dauernde Verschmelzung entweder gleichartiger oder heteromorpher t/allindividuen (Conjugation) kömmt überall gesetzmässig vor.

\section{Grundform und Haupttypen.}

Die Protozoen sind meist von mikroskopischer Grösse; bedeutend überschreiten sie dieselbe nur in wenigen Fällen (einige Foraminiferen). Ihr Körper ist auf den Grundtypus der einfachen Zelle zurückzutühren. Die morphologisch wichtigste Sonderung ist daher die von Zellleib und Zellkern.

Der Kern ist meist in Einzahl, oft aber auch mehrfach vorhanden. Die Vielkernigkeit kann jedoch in manchen Fällen als eine lang andauernde Vorbereitung zur Theilung aufgefasst werden, demn die vielkernigen Individuen zerfallen schliesslich in Stücke, die nur je einen Kern besitzen (z. B. Actinosphaerium Eichhomii, Opalina ranarum) ${ }^{1}$ ). Die moisten Infusorien (Ciliaten) aber besitzen neben dem .Grosskern" einen oder mehrere „Ersatzkerne" (mpassenderweise auch als "Nilcleoli" bezeichnet); letztere sind hier die eigentlichen Dauerkerne. Dei den sogenannten Moneren (amöbenähnlichen Organismen) wurden keine Kerne gefunden, doch hofft man solche noch nachweisen zu können. Meist ist der Zellkern der Protozoen compact und aus zahlreichen Chromatinkörnchen bestehend, die durch eine hellere Substanz verbunden werden; er ist rundlich oder langgestreckt, gewunden, perlschnurförmig, ja sogar verästelt. In vielen Fällen ist der Kern aber auch von typischbläschenförmiger Gestalt.

Die wesentlichen Differenzirungen des Protozoenkörpers betreffen stets das Plasma als den arbeitenden Theil der Zelle, wie dies ja ein allgemeines histologisches Gesetz fiir alle Arten von Zellen ist. Bei den niedersten Protozoenformen kann das Plasma wohl auch gleichartig sein in der Regel ist aber selbst bei niederen Formen ein äusseres,

1) Neuerdings wurde besonders bei einigen Rhizopodenformen das Vorhandensein zahIreicher sehr kleiner Kerne beobachtet; man vermuthet, dass dieses Verhalten von urspriinglicher Bedeutung sei (GRUBER). 
helleres, körnchenarmes Ectoplas ma und ein inneres, dunkleres, grobkörniges End op lasma zu unterscheiden. Bei höher entwickelten Protozoenformen finden wir in Plasma die mannigfaltigsten und complicirtesten Differenzirungen. Wir sehen äussere Wimpern, Muskelfibrillen, Haken, Borsten, Skeletbildungen, Trichocysten etc. auftreten. Die Zelle erreicht hier einen complicirteren Bau, eine grössere Summe von Differenzirungen, als bei vielzelligen Organismen, da sie bei letzteren in Folge der Arbeitstheilung nur im Sinne einer oder einiger bestimmter Functionen differenzirt ist.

Wir unterscheiden folgende Haupttypen der Protozoen: Erstens die Rhizopoden, deren zähflüssiger Plasmakörper seine Form und die Lage seiner Theilchen bedeutend $\mathrm{zu}$ verändern im Stande ist, indem er lappenförmige oder fadenförmige verästelte Fortsätze (Pseudopodien) an beliebigen Punkten der Oberfläche unter Strömungserscheinungen des Plasma aussendet und dieselben ebenso wieder einzieht, wir finden, dass er ver-

Fig. 6. Zwei nackte Rhizopoden mit $N$ Kern; cv Contractile Vacuole.

A. Amoeba guttula (nach AuerBacH).

B. Amoeba proteus (nach LEIDY).

$N$ Kern, $c v$ contractile Vacuole.

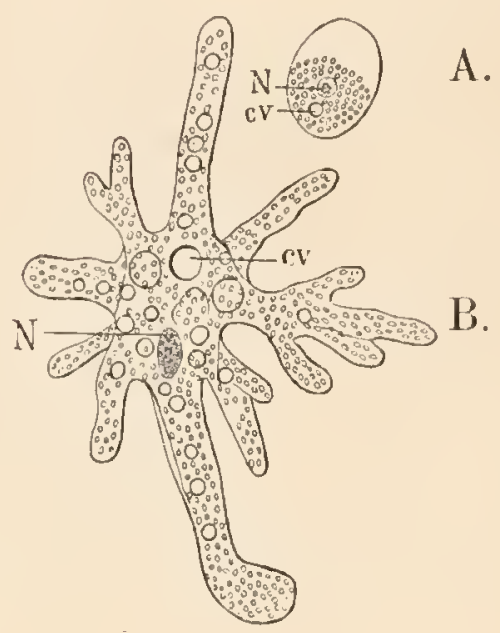

C.
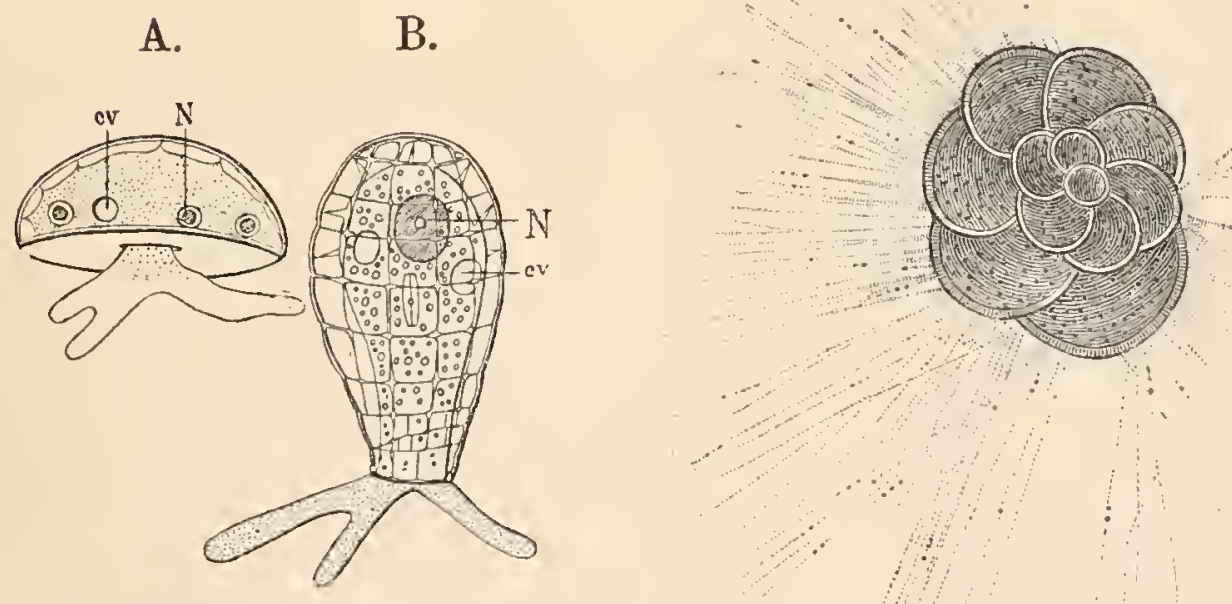

Fig. 7. Gehäusebildende Rhizopoden.

A. Arcella vulgaris (nach BüTSCHLI). Chitingehäusc Brodlaib-förmig mit unterer Oeffinung.

B. Quadrula symmetrica (nach F. E. ScHULzE). Chitingehäuse aus viereckigen Platten zusammengesetzt.

U. Rotalia venata (nach M. SchULTze), eine reticulate Rhizopodenform mit kalkigem, vielkammerigem Gehäuse, welches von zahlreichen Poren durchsetzt ist (daher Foraminijeren).

H at schek, Lehbuch der Zoologie. 
mittelst derselben sich forthewegt nud auch durch ïhnliehe Vorgänge - Umfliessen mittelst der Pseudopodien — an beliebiger Stelle der Obertläche feste Nahrungstheilchen in das Innere des Plasma aufnimmt. Trotz der unbeständigen Form des Weichkörpers bilden viele Rhizopoden Kalk-, Kíesel- oder Chitinskelete vou sehr regelmässiger nach

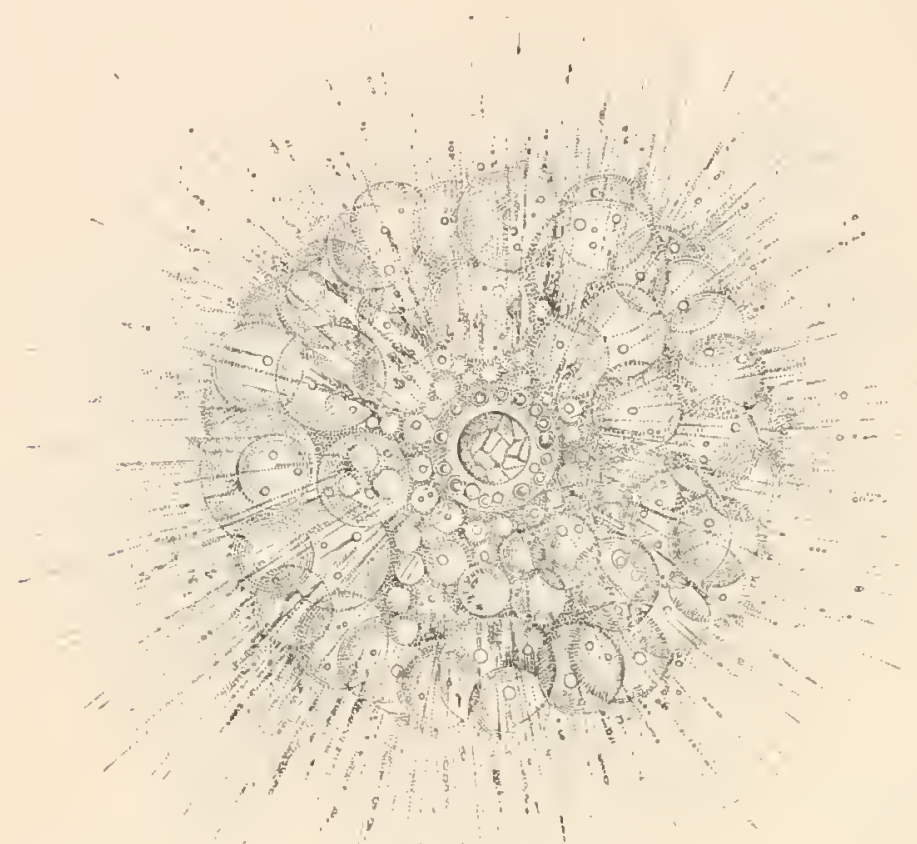

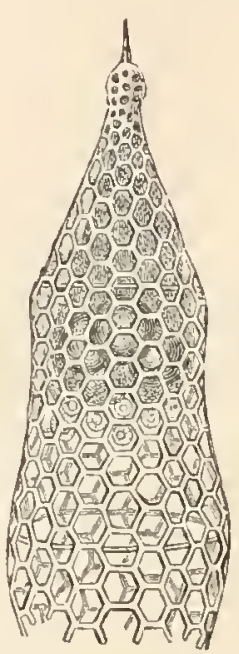

lig. 8 a.

Fig. 8.

Fig. 8. Thalassicolla pelagica, eine unbeschalte Radiolarie (nach HaEckez).

Fig 8 a. Eucyrtidium lagena, Radiolarie mit heteropolem Skelet (nach HAECKEL).

den Arten überaus mannigfacher Gestaltung. Den niedriger stehenden Foraminiferen, die aber trotz ihrer Einfachheit schon durch die Mannigfaltigkeit ilhrer Skeletbildungen (Kalk, Chitin) auffallen, stehen die Radiolarien als löehstentwickelter Rhizopodentypus gegenüber, da sie

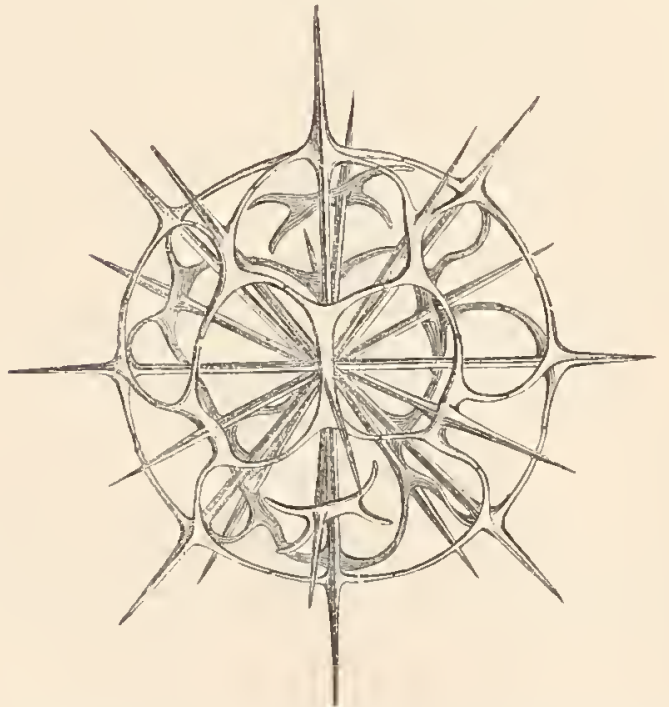

F'ig. 9. Skelett einer regulären Radiolarie, Dorataspis bipennis (nach HAECKEL). sowohl durch die complicirteren Skelettbildungen (Kiesel) sich auszeichnen, als auch durch das Vorhandensein einer häutigen, porösen Kapsel (Centralkapsel), welche das, ,intracapsuläre" Plasma mit dem Kern voln dem ,extracapsulären" Plasma mit den Pseudopodien abgrenzt.

Ein ganz anders gearteter 'Typus ist in der überaus mannigfaltigen Gruppe der Ciliaten (oder Infusorien) ausgeprägt. Der Körper ist hier vou einem festeren Ectoplasma, oft auch von einer äusseren Zellmembran (Cuticula) begrenzt und es ist dadurch trotz einer gewissen Contractilität eine best i m m tere (formbeständige) Gestalt bedingt. Stets ist ein Vorder- und Hinter- 


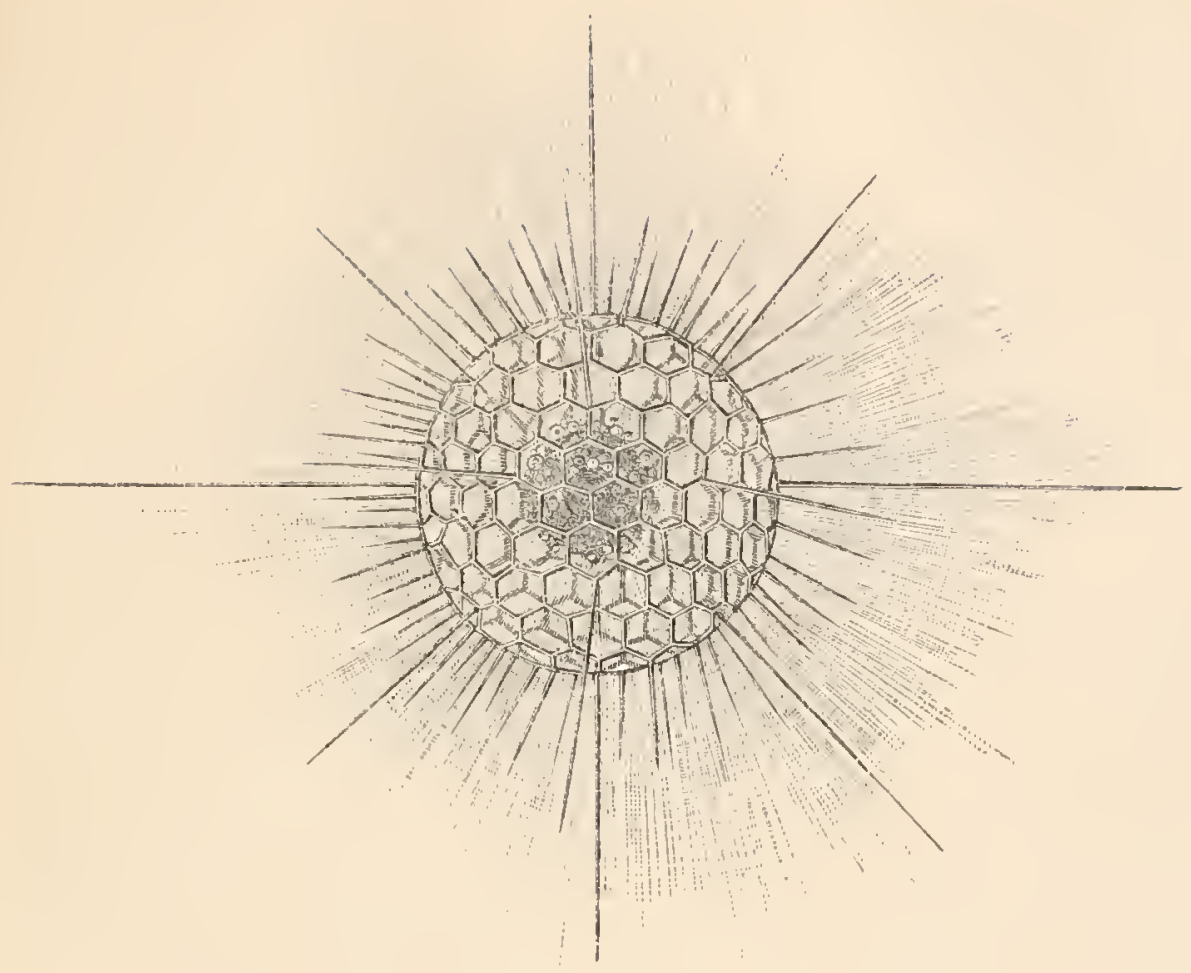

Fig. 10.

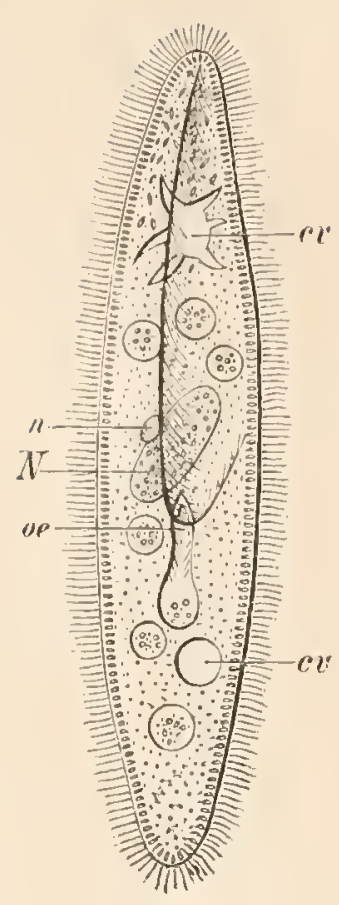

Fig. 11.

Fig. 10. Heliosphaera actinota, Radiolarie mit regulärem Skelet (nach HAECKEL).

Fig. 11. Paramaecium aurelia (nach BLochмans), eine gleichmässig bewimperte $C_{i-}$ liatenform.

$N$ Grosskern; $n$ Ersatzkern; $c v$ contractile Vacuolen, die vordere im Zustand der Diastole; oe Mund in den Schlund übergehend; im Ectoplasma liegen Trichocysten (vorschnellbare Nesselfäden).

ende, meist auch eine Baucliund Rückenseite ausgeprïgt; dabei ist merkwürdiger Weise zumeist die reclite und linke Körperseite asymmetrisch ausgebildet. Die Bervegung, welche in bestimmter Richtung erfolgt, wird durch schwingende Cilien, oft auch durch bewegliche Haken und Borsten vermittelt. Feste Nahrung wird in der Regel durch eine bestimmte Mundöffuung aufgenommen. Das con-

Fig. 12. Ciliophris infusionum (nach BÜTSCHLI) in ihren beiden Zuständen.

A. Amöboider Zustand.

B. Flagellaten-Zustand.

Fig. 13. Peranema trichophorum (nach BüTSCHLI).

$N$ Kern; $c v$ contractile Vacuole; oe Mund und Schlund.

Fig. 14. Actinocephalus oligacanthus (nach STEIN) aus dem Darme eines Insects, mit Hackenkranz am Epimerit $(E p)$.

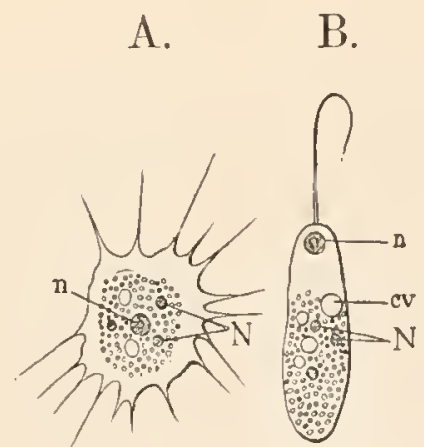

Fig. 12.

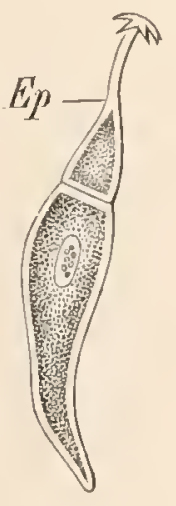

Fig. 14.

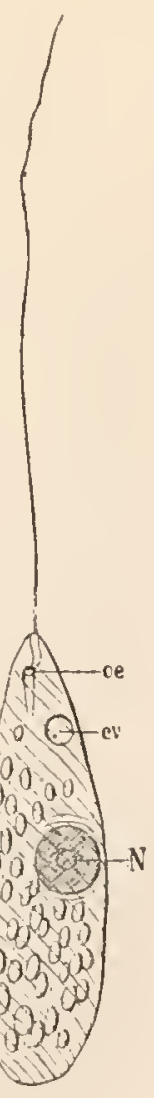

Fig 13. 
sistentere Ectoplasma ist oft mit Muskelfibrillen ausgestattet. Nur das Endoplasma zeigt eine gewisse Plasmaströmung.

Ein Typus, der den Rhizopoden trotz der auffallenden äusseren Verschiedenheit sehr nahe steht, sind die Flagellaten (oder Mastigophora). Es gibt Uebergänge zwischen beiden Typen; ferner ist hervorzulıeben, dass sowohl die Rhizopoden (z. B. die Radiolarien) vorübergehend Flagellaten ähnliche Lebenszustände besitzen, als auch die Flagellaten amöboide (d. h. Rhizopoden ähnliche). Der Kör'per der Flagellaten ist formbeständig und zeigt ein bestimmtes Vorder- und Hinterende und besitzt meist eine Mundöffinung, alles wie bei den Infusorien, er ist aber nur mit einer oder wenigen Geisseln als Bewegungsapparaten versehen. Die niedrigsten Formen dieser Gruppe schliessen sich unmittelbar an die Rhizopoden an (da sie amöboide Formzustände durchlaufen), während andere durch ihre complicirte Gestaltung (Noctiluca) oder durch die weit entwickelte Cormenbildung (Volvox) die höchste Stufe unter den Protozoen einnehmen.

Die parasitischen Gregarinen (Sporozoa) sind ebenfalls formbeständig, mit bestimmtem Vorder- und Hinterende; sie haben weder Cilien noch Psendopodien und bewegen sich durch wurmförmige Contractionen; sie ernähren sich endosmotisch; clarakteristisch ist eine Scheidewandbildung in der Zelle.

Die Verwandtschaft dieser 'Typen ist aus folgendem Schema elsichtlich:

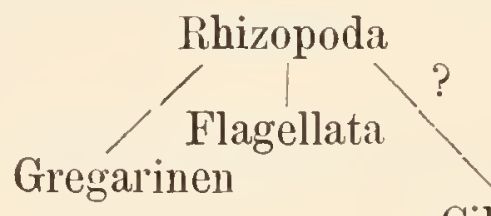

Ciliata

\section{Lebenserscheinungen (Functionen) des Protozoenkörpers.}

\section{Stoffwechsel.}

a) Ernährung. Bei den Protozoen werden allgemein feste Nahrungstheilchen iu das Innere des Körpers aufgenommen. Eine Ausnahme machen gewisse parasitische Protozoen (Gregarinen, Opalina), die ähnlich wie auch höhere parasitisch lebende Thiere - durch Endosmose fliissige Nahrung aufnehmen. Die Rhizopoden können die Nahrung an jeder Stelle der Oberfläche in den Körper aufnelumen, inden sie dieselbe mittelst der Pseudopodien umfliessen und durch die Plasmaströmung nach Innen befördern. Ebenso werden die unbrauchbaren Reste an beliebiger Stelle ausgestossen. Bei den marinen Rhizopodenformen, den Reticulaten und ähnlich auch bei den Radiolarien, findet die Verdauung hauptsächlich in den peripleren Plasmanetzen statt. Die Ciliaten, die in der Regel eine feste äussere Membran besitzen, zeigen an einer bestimmten Stelle dieser Membran eine Oeffnung, den Mund (Z ell en mund), der oft nach Innen schlundartig vertieft und mit besonderen Structureigenthïmlichkeiten ausgestattet ist. Auch die Ungebung dieses Mundes zeigt oft besondere Gestaltung (Peristom) und ist mit besonderen Wimpereinrichtungen ausgestattet (adorale Wimperreihe). Durch den Mund gelangen die Nahrungskörper in das Endoplasma, in welchem sie durch die Plasmaströmung umhergetrieben und wo sie verdaut werden. Anch die Ausstossung der unbranchbaren Reste erfolgt bei vielen Infusorieu 


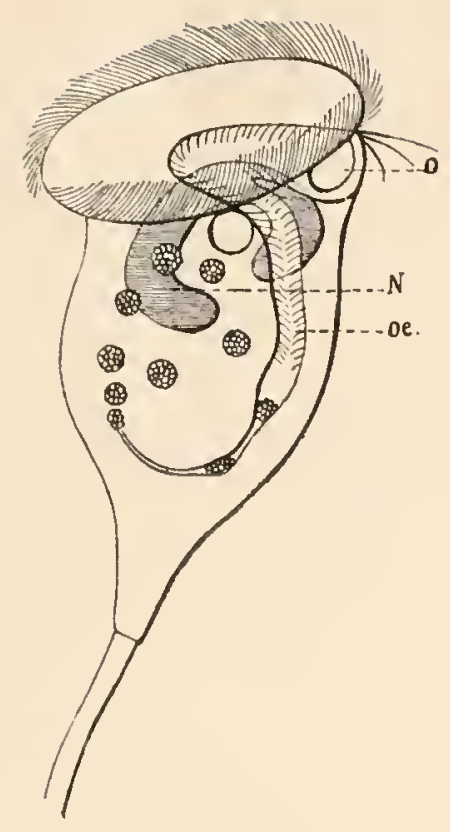

Fig. 15.

Fig. 15. Vorticella (nach GreerF).

Eine gestielte Ciliate mit adoraler Wimperzone und mit wurstförmigem $\operatorname{Kerne}(N)$, die Mundöffnung (o) führt in eine sehlundartige Vertiefung (oe), welehe sich in eine enge Speiseröhre fortsetzt, von dort gelangen die Nahrungsballen in das innere Plasma.

Fig. 16. Gestielte Acinete mit vior Büscheln von Saugtentakeln (nach STEIN).

$N$ Kern, $c v$ eontractile Vacuole.

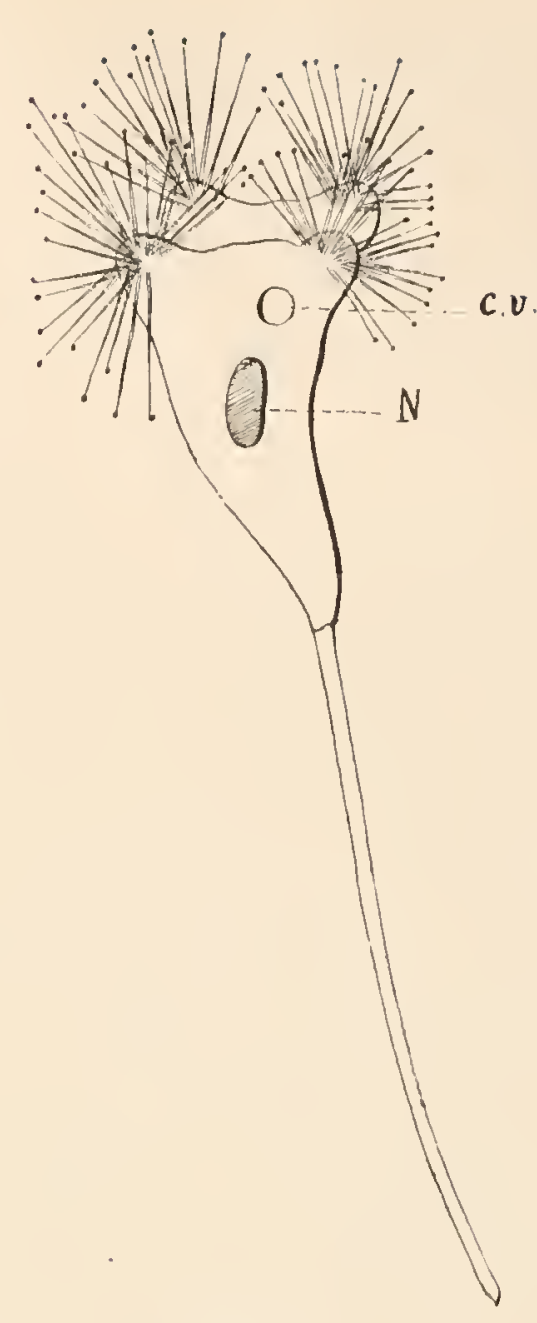

Fig. 16.

an bestimmter Stelle durch eine ,Afteröffnung", dieselbe ist meist nur im Momente der Ausstossung der Fäces wahrnehmbar. Aehnlich wie bei den Ciliaten verhält sich die Nahrungsaufnahme bei den meisten Flagellaten. Die Acineten nehmen mittelst einer Mehrzahl von Saugtentakeln ihre Nahrung auf.

b) Die Excretion wird in vielen Fällen (bei marinen Protozoen) wohl einfach durch die Körperoberfläche vermittelt; bei den Protozoen, die das Süsswass er bewohnen, bei Rhizopoden, Infusorien und Flagellaten findet sich aber eine besondere, in Beziehung zur Excretion stehende Einrichtung als ,pulsirende Vacuole“. Die mit Flüssigkeit erfüllte Vacuole zieht sich energisch zusammen (Systole) bis zum vollkommnen Verschwinden, wobei die Fliissigkeit durch eine sich bildende Oeffnung nach Aussen entleert wird; die Vacuole erscheint dann an derselben Stelle wieder, sich langsam vergrössernd (Diastole); diese Veränderungen wiederholen sich in regelmässigem Rhythmus. Oft steht die Vacuole mit gefässartigen Lacunen im Zusammenhang. Die solchermassen fortwährend aus dem Körper entleerte Flüssigkeit wird durch stetige, allseitige Wasseraufnahme aus dem umgebenden Medium erneuert und führt wahrscheinlich Excretionsprodukte in gelöster Form aus dem Körper aus.

c) Die Athmung erfolgt allgemein durch Vermittlung der gesammten Körperoberfläche. Bei der geringen Grösse der Protozoen ist 
das Verhältnis von Oberfläche zur Körpermasse ein so günstiges, dass dies zur Sauerstoffaufnahme vollkommen ausreicht.

Bewegung, Jede Massenbewegung oder Bewegung des Gesammtkörpers ist durch eine Bewegung kleinerer Theilchen verursacht. Wenn wir diese in Betracht ziehen, so erkennen wir im ganzen Thierreich eine Anzahl verschiedener Phänomene als Grunderscheinungen der Bewegung. Innerhali) des Kreises der Protozoen kommen schon alle Grunderscheinungen vor, die wir überlıaupt kennen.

1. Die Plasmaströmung oder amöboide Bewegung. Die ursprünglichste Bewegungserscheinung ist die Plasmaströmung, sie spielt die grösste Rolle bei den Rhizopoden. Wir sehen das zähflüssige, von Körnchen durchsetzte Plasma einer Amöbe bald in Ruhe, bald wieder in lebhafter Strömung begriffen; dabei sendet der Körper an beliebigen Stellen lappige Fortsätze (die Psendopodien) aus und zieht dieselben wieder ein; unter diesem steten Wechsel der äusseren Form erfolgt die Fortbewegung. - Bei den marinen Rhizopodenformen, den Reticulaten und Radiolarien, sind die Pseudopodien dünn und lang und haben die Neigung, zu Netzen und Platten zusammenzufliessen; an diesen fadenförmigen Pseudopodien ist das Phänomen der „Körnchenströmung" überaus lebhaft. Die Körnchen bewegen sich an der einen Seite des Fadens in centrifugaler, an der anderen Seite in centripetaler Richtung; die Strömung erfolgt immer in beiden Richtungen, ob nun das Pseudopodium dabei sich verlängert oder verkürzt; es wird aber in dem einen Falle die Menge des zufliessenden Plasmas, in dem anderen die des abfliessenden grösser sein. - Bei den formbeständigen Protozoen findet Plasmaströmung nur im Inneren, z. B. bei den Ciliaten im Endoplasma statt. - (Auch im Pflanzenreich ist die Plasmaströmung eine allgemein verbreitete Lebenserscheinung; sie ist an dem inneren Plasmanetz der Pflanzenzellen zu beobachten.)

2. Die Flimmerbewegung. Die Flimmerbewegung wird entweder durch Geisseln oder durch Cilien vermittelt. Die ersteren sind längere, peitschenförmig schwingende Plasmahärchen, die immer nur vereinzelt oder in geringer Anzahl an der Zelle vorhanden sind. Die Cilien (Wimperhaare) sind kürzere Plasmahärchen, die stets zahlreicl, oft in regelmässigen Reihen angeordnet sind und in den meisten Fällen nach einer bestimmten Richtung schwingen; beide Formen können willkürlich in Ruhe oder in Thätigkeit gesetzt werden, Bei den hypotrichen Ciliaten ist die adorale Wimperzone von eigenthümlichen Wimperp latten (Membranellen) gebildet, die Büscheln von verklebten Wimpern entsprechen. Die Geisseln sind für die Flagellaten charakteristisch, finden sich aber auch schon bei einigen Rhizopoden (nämlich bei Hetiozoen und auch bei den Schwärmsporen der Heliozoen sowie der Radiolarien)

Von F. E. Schulze und BÜtschli wurde zuerst die Beobachtung gemacht, dass bei Rhizopoden ähnlichen Organismen (Rhizomastiginen) ein dünnes Pseudopodium plötzlich eine erhöhte Beweglichkeit zeigt und zu einer Geissel sich umwandelt; dieselbe kann wieder zum Pseudopodiun rückgebildet und eingezogen werden. - Diese Beobachtung ist für die Auffassung der phylogenetischen Entstehung der Geissel- und Flimmerhaare von grösster Wichtigkeit. Wir betrachten dieselben als umgewandelte Pseudopodien. 
3. Contractilität des Plasmas. Dies ist eine überaus verbreitete Erscheinnng und findet sich iberall, wo das Plasma schon eine etwas festcre, zähere Consistenz zeigt. Sic besteht darin, dass cin Plasmakörper sich in irgend einer beliebigen Richtung verkürzt und senkrecht zu derselben entsprechend dicker wird; wem die Contraction aufhört, nimmt der Körper wieder seinc ursprüngliche Form an. Bei dicsem Processe findet also eine Verschiebung der Massentheilchen statt. Dic Verschiebung ist nur enger begrenzt als bei der Plasmaströmung und von bestimmterer Natur, wenn auch die Richtung der Contractilität noch eine beliebige ist. Die Contractilität des Plasmas ist daher wahrscheinlich auf die Plasmaströmnng zurückführbar.

4. Differenzirung von contractiler Muskelsubstanz. Ueberall, wo bei den Protozoen die Contractilität eine raschere Fnergie zeigt, und namentlich wo dieselbe in einer bestimmten Richtung erfolgt, sind es gewisse Differenzirungen im Plasma, an welche dieselbe gebunden ist; es sind dies die Muskelfibrillen, fadenförmige Gebilde, die in der Richtung ihrer Längsachse contractil sind; sie sind von stärker lichtbrechender Beschaffenheit als das Plasma und sind (wie eine Untersuchung in polarisirtem Lichte zeigt) doppelt brechend. Muskelfibrillen sind bei vielen Infusorien im Ectoplasma als parallele, incist der Längsachse nach, oft auch spiral verlaufende Streifen zu beobachten. Dic Vorticellinen besitzen einen kräftigen Stielmuskel. Oft werden dic Haken und Borsten der hypotrichen Ciliaten durch besondere Muskelfibrillen bewegt. Auch bei manchen Gregarinen finden sich älnnliche Muskelstreifen. Selbst bei cinigen Radiolarien wurden Muskelfibrillen gefunden. Die Bildung von Muskelsubstanz, die in Form von Fibrillen auftritt, ist als eine höhere Differenzirung von dem niedreren Zustande der Plasmacontractilität abzuleiten.

Die phylogenetische Beziehung der verschiedenen Grunderscheinungen der Bewegung können wir folgendermaassen darstellen:

A nıöboide Bewegung(od. Plasmaströmung)

Flimmerbewegung Plasmacontractilität

Muskelcontractilität.

Je nachdem die Bewegung des Gesammtkörpers auf einer oder der anderen der hier geschilderten Grunderscheinungen beruht, sehen wir dieselbe entweder als ein Kriechen mittelst fliessender Pseudopodien (Rhizopoden) oder als ein Fortgleiten (od. Schwimmen) durch Vermittlung schwingender Wimpern oder Geisseln (Citiaten, Flagellaten) oder als eine durch Contraction (Plasmacontraction, Muskelcontraction) vermittelte wurmförmige Bewegung des Körpers; letztere kann neben der Wimperbewegung bestehen (Ciliaten, Flagellaten) oder auch allein für sich (Gregarinen).

Empfindung, Beobachtung und Experiment lehren, dass selbst die niedrigsten Protozoen (Rhizopoden und ähnliche Organismen) auf mechanische und chemische Reize mit Bewegungserscheinungen antworten. Bei den Infusorien ist die 'Tastempfindung oft sehr entwickelt (Empfindung mechanischer Reize) und es sind ferner Geschmacksempfindung, Wärmeempfindung und Lichtempfindung nachweisbar, die wohl auf der chemischen Reizbarkeit des Plasmas beruhen.

Wenn auch gewisse Theile des Körpers besonders empfindlich el- 
scheinen, wie z. B. das Vorderende gewisser Infusorien, so kömmt es doch nicht zur Entwicklung eigentlicher Sinnesorgane. Die Deutung gewisser Pigmentflecke als Augen (bei Euglena) ist zweifelhaft. Nur bei einem acinetenähnlichen Wesen wurde von $R$. HerTwig ein Auge beobachtet. Die Fortleitung der Erregung scheint durch das Plasma überhaupt zu erfolgen. Nervenfibrillen sind nicht beobachtet.

Fortpflanzung, Die Fortpflanzung des einzelligen Protozoenkörpers beruht stets auf Zelltheilung. Dabei wurde sowohl mitotische als auch direkte Theilung beobachtet. Wenn nun auch alle Fortpflanzung der Protozoen auf Zelltheilung zurückzuführen ist, so lassen sich doclı verschiedene Modificationen dieses Processes, die auf anderell Momenten beruhen, beobachten. - So sehen wir z. B., dlass eine Amöbe ohne sonstige Veränderungen sich theilt, indem zunächst der Zellkern und sodann auch der umgebende Zelleib in zwei Stücke zerfällt. Die Theilung kann aber auch von besonderen Umständen begleitet sein, indem die Amöbe ihre Fortsätze einzieht und als ruhende Zelle sich mit einel Cyste umgibt und sodann in zwei oder auch successive in mehrere /sellen sich theilt. Mit Rücksicht auf ähnliche Umstände können wir die Fortpflanzungserscheinungen der Protozoen überhaupt eintheilen in:

a) Theilungsvorgänge am differenzirten Organismus, und

b) Theilungsvorgänge am rückdifferenzirten Organismus, der die Form der ruhenden Zelle angenommen hat.

Betrachten wir zunächst den ersten 'Typus, die 'Theilungsvorgänge, welche am differenzirten Organismus vor sich gehen. Hier können wir wieder zwischen ,eigentlicher Theilung"6 nnd „Knospung" unterscheiden. Bei der eigentlichen Theilung (oder Spaltung) wird der Körper in zwei beiläufig gleich grosse Stücke zerfällt, wobei dann beide Theilstücke die ihnen nun fehlenden Abschnitte durch Reproduktion ersetzen. Von Knospung sprechen wir, wenn eine beschränkte Stelle des Körpers zur Billung eines neuen Individuums herangezogen wird, ohne dass dabei die Individualität des alten Körpers bedeutend beeinträchtigt wird. Die Neubildungen treten dann hauptsächlich nur an der Knospe auf.

Theilung. Man hat versucht, Infusorien künstlich zu theilen. Wenn man z. B. einen Stentol', ein grosses Infusor mit perlschnurartigem Nucleus und vorderer Wimperspirale, der Quere nach in zwei Hälften schneidet, so kann jedes Stück sich zu einem vollkommenen Individuum ergänzen, wenn darin nur ein Theil des Nucleus enthalten war. Das vordere Stück muss einen Hinterkörper regeneriren, das hintere Stück muss eine neue Wimperspirale und Mundöffnung erhalten. Wir sehen hier eine Theilung mit nachfolgender Reproduktion. - Bei den meisten Infusorien kömmt nun eine Quertheilung als normaler Fortpflanzungsprocess und in gewissem Sinne in vervollkommneter Weise vor. Wir sehen z. B. bei demselben Stentor die Theilung normaler Weise so vor sich gehen, dass in der Mitte der Bauchseite eine neue Wimperspirale entsteht, bevor noch die Theilung erfolgt. Nachdem auch der Kern unter gewissen Veränderungen sich getheilt hat, erfolgt erst die Spaltung in zwei neue Individuen. Betrachten wir ferner z. B. eine Stylonichia mit ihren verschiedentlichen bestimmten Differenzirungen: der adoralen Wimperzone, der Mundöffnung, den gesetzmässig angeordneten Griffeln und Haken, dem Nucleus und den Nucleolen. Letztere Bildungen spielen nun wie bei jeder Zelltheilung eine wichtige Rolle, indem sie für jede Hälfte ein Theilstück 
abgeben. Aber auch an der Oberfläche des Körpers beobachten wir wichtige Erscheinungen: eine adorale Wimperzone wird für die hintere Körperhälfte neugebildet, und ebenso werden die Apparate der Griffel und Haken durch neu auftretende Bildungen für zwei Individuen ergänzt. Dies alles geschieht, bevor noch die Trennung der beiden Theile wirklich erfolgt ist. Wir können diesen Vorgang a Is TheiI ung mit vorzeitiger Reprod uction bezeichnen. Die Theilung ist bei den Infusorien

Fig. 17. Stentor polymorphus (nach STEIN).

A. Im gewöhnlichen Zustande.

B. In Theilung begriffen.

(Längs der Streifen sind feine Flimmerhaare angeordnet, die in dieser $\mathrm{Ab}$ bildung nicht ersichtlich sind.)

A.

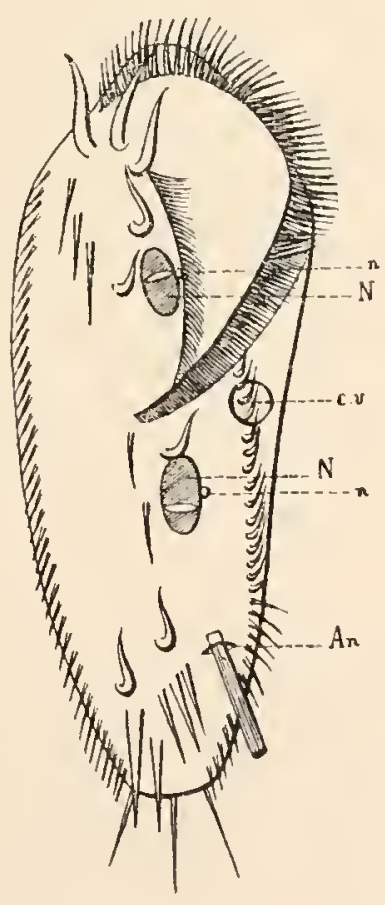

A.

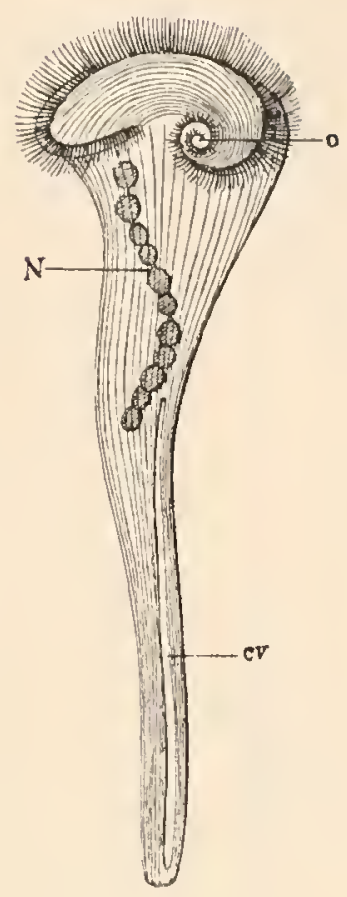

B.

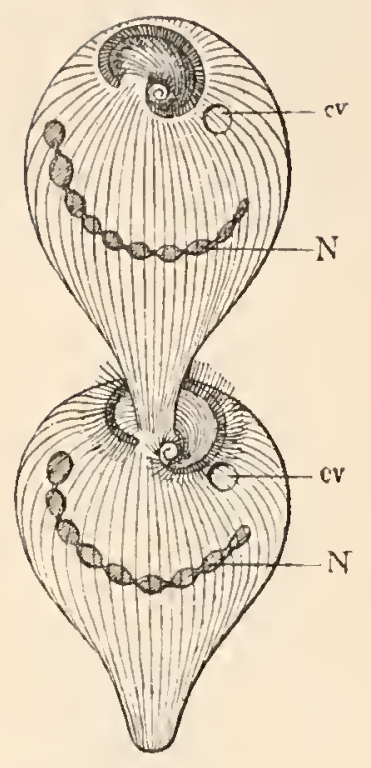

B.

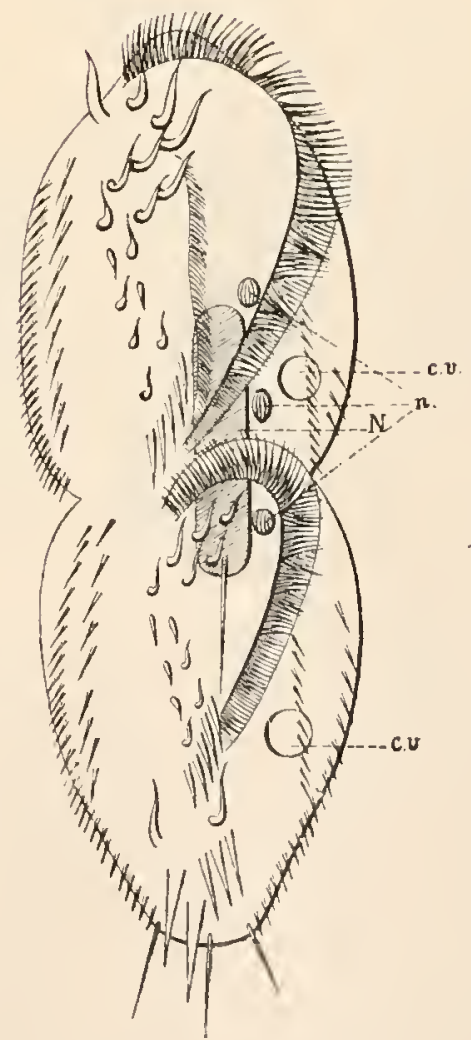

Fig. 17 a. Stylonichia mytilus (nach SterN).

A. Gewöhnliches Individuun mit zwei Kernen $(N)$, zwei Ersatzkernen $(n)$ und einer contractilen Vacuole $(c v)$. An After, aus dem ein Fremdkörper entleert wird.

B. In Vorbereitung zur Theilung. Die beiden Grosskerne sind zunächst verschmolzen, um sich später zu theilen. Drei spindelförmige Ersatzkerne. Die contractile Vacuole ist bereits verdoppelt u. S. w. 
sehr verbreitet. Meist ist es Quertheilung, seltener, z. B. bei den Vorticellinen, eine Theilung nach der Längsachse.

Knospung. Wir betrachten hier als Beispiel die Knospung der Spirochona gemmipara. Es ist dies ein festsitzendes Infusor, dessen keulenförmiger Kö̈rper einen eigenthümlichen trichterförmigen Aufsatz trägt, welcher ungefähr die Form einer zusammengerollten Papierdiute hat, deren Windungen etwas von einander abstehen. In der Tiefe des innen bewimperten Trichter's liegt die Mundöffnung. Spirochona besitzt einen Grosskern und zwei Ersatzkerne. Die Knnospe tritt an der Basis des Trichters auf und bildet anfangs einen kleinen Höcker.

A.

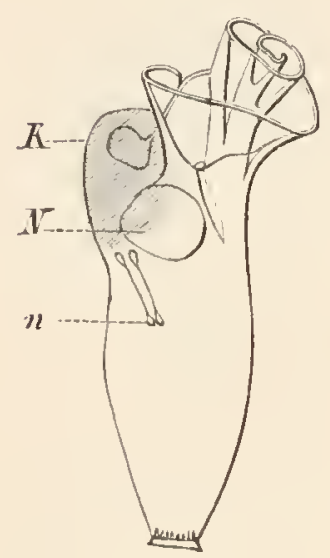

Fig. 18. Spirochona gemmipara (nach Hertwig).

A. Ein Individuum nit Knospe $(K)$, Nucleus $(N)$ und zwei in Theiluug begriffenen Ersatzkemen (n)

B Eine freigewordene Knospe.

Der Gesammtorganismus wird durch die Bildung der Knospe nur unbedeutend beeinträchtigt. Trotzdem gehen Theile der wesentlichsten Differenzirungen auf die Knospe über. Der Grosskern sowohl als B. auch die Nebenkerne geben je einen Theil für die Knospe ab. An dem Wimperorgan bildet sich eine kleine Ausbuchtung, die sich auf die Knospe fortsetzt und sich mit dieser abschnürt. Die Knospe erhält demnach einen Theil des Zellleibes, ferner einen Nucleus, drei Nucleoli und ein Wimperorgan; nach ihrer Abschnürung wird sie als sogenannter Schwärmsprössling frei. Wenn wir die Knospe mit dem ursprünglichen Organismus vergleichen, so sehen wir, dass wohl die wichtigsten Differenzirungen in dieselbe aufgenommen s ind, dass aber die Gestalt von der des entwickelten Organismus noch sehr verschieden ist, während der mütterliche Or'ranismus in seiner Gestalt kaum verändert erscheint. Es müssen daher noch wesentliche Veränderıngen an der abgelösten Knospe erfolgen, um dieselbe zur definitiven Form überzuführen. - Ein anderes Beispiel bietet uns Podophrya gemmipara, eine Acinete mit verästeltem Kern, die zahlreiche Knospen auf einmal erzeugt, in die je ein Kernstück aufgenommen wird.

Fortpflanzung am rückdifferenzirten Organismus. Ein einzelliger Organismus, beispielsweise ein Infusor, das eine Anzahl bestimmter Differenzirungen besitzt, kann sich so umbilden, dass er die äusseren Differeuzirungen aufgibt und die Form einer ruhenden Zelle annimmt, an der nur der Gegensat\% von Ker'l und Plasma zu beobachten ist. Diesen Vorgang, durch welchen eine complicirter organisirte Zelle zur ruhenden Zelle wird, bezeichnen wir als Rückdifferenzirung (Kataplasis). Eine solche ruhende Zelle scheidet in der Regel eine schïtzende Hülle, eine Cyste aus. Innerhalb der Cyste zerfällt die einfache Zelle durch fortgesetzte lebhafte Theilung in eine grosse Anzahl von Tochterzellen. Die Anzahl dieser Tochterzellen ist sehr verschieden; bei den Gregarinen beläuft sie sich auf viele hundert, bei manchen Infusorien beträgt sie 4-8. Jede einzelne Tochterzelle ist eine ruhende Zelle und unterscheidet sich nur durch die Grösse von der Mutterzelle. 
An jeder dieser 'Lellen wird num der Differenzirungsprocess fiir sich von neuem eingeleitet und es wird, oft nach einer Reilhe von Verwand lungen, jene Differenzirung erreicht, die der mütterliche Organismus vor der Rückdifferenzirung besessen latte (Aufdifferenzirung, Anaplasis). Bei (ler Aufdifferenzirung durchläuft das neue Individuum oft eine Reihe von Formzuständen, die von dem definitiven '/ustand auffallend verschieden sind. So sehen wir, dass bei den $R a-$ diolarien aus dem in die Centralkapsel zurückgezogenen Zellleib eine grosse Zahl von Geisselschwärmern entstehen. Auch bei Noctiluca sehen wir mach einer (eigenthümlichen unvollkommenen) Rückdifferenzirumg den Zellleib in Geisselschwälner sich theilen. Merkwürdige Stadien der Aufdifferenzirung durchlaufen die Gregarinen (Pseudonavicellenstadien).

Fig. 19. Sporenbildung vion Coccidium oviforme, aus der Leber des Kaninchens (nach LeuckART). Es werden nur 4 Sporen gebildet.

Fig. 20. Conjugation und Sporenbildung von Gregarina polymorpha (nach KOELLIKER). Die Conjugation scheint einer vorübergehenden zu cntsprechen, da die Individuen auch innerhalb der gemeinsamen Cyste wohl gesondert erscheinen. Die Anzahl der „Sporen" ist eine bedeutende.

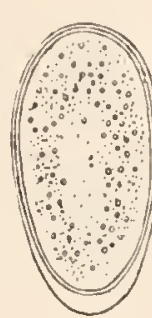

A

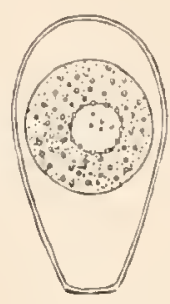

$\mathrm{B}$

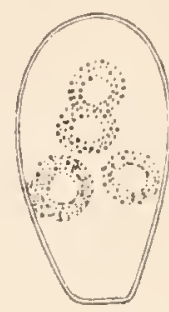

C

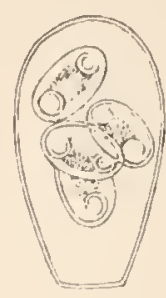

D)
Fig. 19.
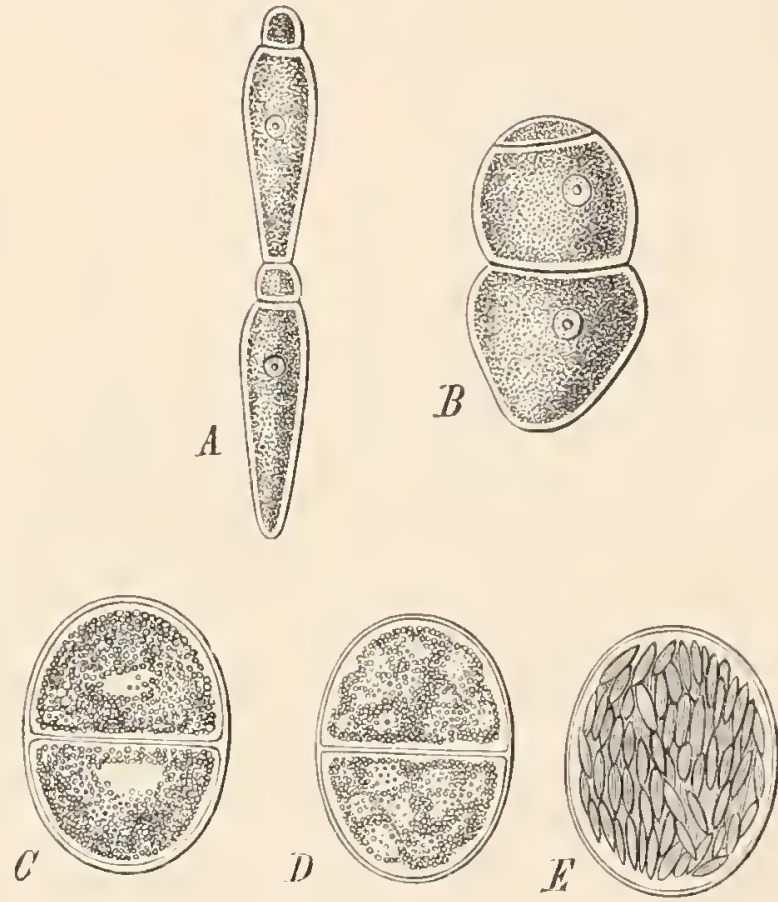

Fig. 20.

Blicken wir auf die Arten der Fortpflanzung bei den Protozoen zurück, so finden wir:

I. Fortpflanzung am differenzirten Organismus beruht auf den Vorgängen 1. der' Theilung und 2. Reproduction. Man unterscheidet :

a) Eigentliche Theilung (Spaltung), d. i. Theilumg nit Reproductionserscheinumgen an beiden Theilstücken.

b) Knos p ung, d. i. 'Theilung mit einseitigen Reproductionserscheinungen, nur an der Knospe.

II. Fortpflanzung am rückdifferenzirten Organismus beruht auf der Aufeinanderfolge von 1. Rückdifferenzirung (Kataplasis), 2. Theilung, und 3. Aufdifferenzirung (Anaplasis) der einzelnen 'Tochterzellen.

Es gibt vielfache Modificationen der hier betrachteten typischen Fälle. Die Theilung der rückdifferenzirten Zelle hat für uns besonderes 
Interesse, da wir später sehen werden, dass dieser Vorgang den Ausgangspunkt bildet für die Fortpflanzungs- und Entwicklungserscheinungen der Metazoen.

Conjugation. Die Conjugation ist ein Vorgang, der so vielfach bei allen genauer erforschten Protozoen beobachtet wurde, dass man zur Annahme eines allgemeinen, gesetzmässigen Vorkommens desselben berechtigt ist. Die Conjugation ist der Verschmelzungsprocess zweier oder mehrerer Protozoen-Individuen, die zusammentreten und ihre Substanz mit einander vermischen. In der Regel sehen wir auf eine Conjugation eine Reihe von Theilungen folgen; doch folgt nicht immer auf eine bestimmte Anzabl von Theilungsprocessen die Conjugation, sondern die letztere ist auch von anderen Umständen (Lebensbedingungen) abhängig, so dass dieser Vorgang ursprünglich gewissermassen als ein selbstständiger zu betrachten ist. In anderen Fällen aber sehen wir die Conjugation in regelmässiger Weise den Ausgangspunkt lebhafter fortgesetzter Theilungsprocesse bilden und so in einem bestimmten Verhältnis zum Fortpflanzungsprocess stehen. Wir unterscheiden:

a) Dauernde Conjugation, bei welcher die Individuen thatsächlich zu einem einzigen verschmelzen, und

b) Vor übergehende Conjugation, wobei zwei Individuen mit einander verschmelzen und Theile ihrer Substanz austauschen, aber nach a ufgehobener Conjugation doch wieder zwei Individualitäten repräsentiren; dieser Fall ist nur bei den Ciliaten beobachtet, vielleicht ist auch die Conjugation der Gregarinen so aufzufassen.

Von dem überaus wichtigen Vorgang der dauernden Conjugation besitzen wir nur spärlich genauere Beobachtungen. Doch ist aus diesen zu ersehen, dass hierbei Zellleib mit Zellleib und Zellkern mit Zellkern verschmilzt (Spirochona gemmipara, Vorticellen). Bei amöbenähnlichen Organismen ist beobachtet worden, dass auch eine Mehrzahl von Individuen $\mathrm{zu}$ einem sogenannten Plasmodium verschmelzen. Das Plasmodium nimmt die Form einer ruhenden Zelle an, scheidet eine Cyste aus und zerfällt innerhalb derselben durch fortgesetzte Theilung in eine grosse Anzahl von Individuen. Die Conjugation der Ciliaten wurde schon von Leuwenhoeck und O. Fr. Mǘt.er beobachtet, aber irrthümlich für einen Begattungsprocess gehalten. Diese Ansicht erhielt sich lange aufrecht; die eigenthümlichen Veränderungen von Nucleus und Nucleolus gaben Anlass, dieselben als Ovarien und Hoden zu deuten. Erst Bütschur hat die wahre Bedeutung dieser Vorgänge aufgedeckt. Viele Infusorien verschmelzen bei der Conjugation mit ihren Bauchflächen (Paramaecium, Stentor, Spirostomum), manche mit ihren Seitenflächen (laterale Conjugation bei den Oxytrichinen, Chilodonten), andere wieder vereinigen sich in der Längsachse (Enchelis, Halteria, Coleps). Bei der Conjugation mischt sich sowohl das Plasma, welches man von einem Individuum in das andere überströmen sieht, aber auch die Kernsubstanz. Der Ersatzkern nimmt nämlich die streifige Spindelform an und theilt sich wiederholt. Zwei dieser Theilstücke legen sich - wie neuerdings Prof. Gruber beobachtet hat - an der Berührungsfläche der Individuen innig an einander (Austausch von Kernsubstanz?). Nach einer Anzahl von Stunden trennen sich die Individuen und es erfolgt nun nach aufgehobener Conjugation ein Zerfall und Zugrundegehen des Grosskerns. Aus den Kernspindeln (Theilstücken des Ersatzkernes) 
A.

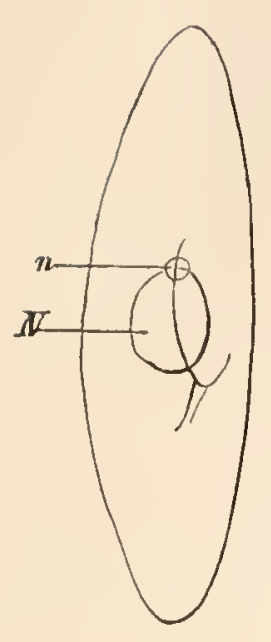

D.

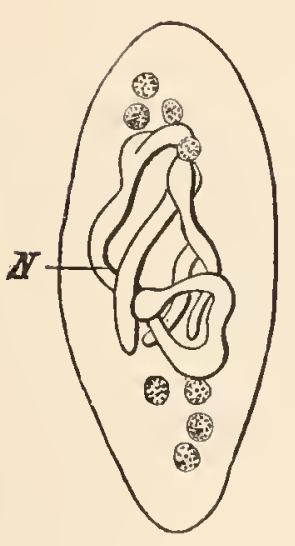

B.

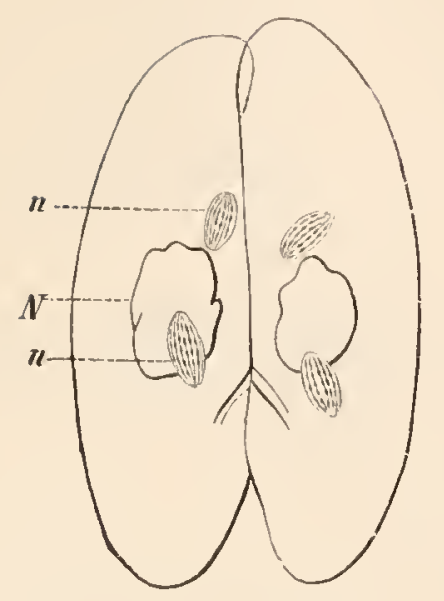

E.

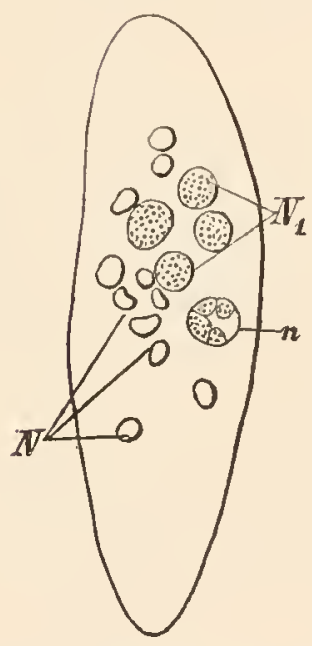

C.

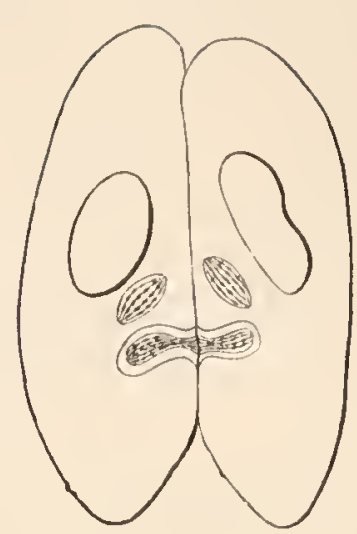

F.

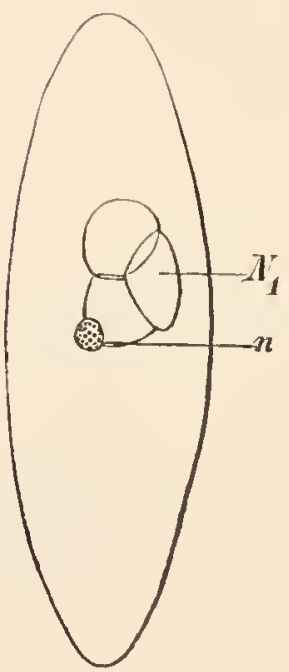

Fig. 21. Conjugationsprocess bei Paramaecium aurelia (nach Gruber). $N$ Grosskern, $n$ Ersatzkerne.

A. Ein Individuum im gewöhulichen Zustande.

B. Erstes Stadium der Conjugation, die Ersatzkerne haben sich getheilt und jedes Stiick ist in einen spindelförmigen Körper umgewandelt.

C. Zwei spindelförmige Körper haben sich bis zur Berührung genähert.

D. Stadium nach aufgehobener Conjugation. Der Grosskern wurstförmig gewunden. Die Ersatzkerne auf acht vermehrt.

E. Weiteres Stadium. Der alte Grosskern in Zerfall begriffen. $N_{1}$ Vier Ersatzkerne, welche zur Bildung des neuen Grosskerns zusammentreten. Bildung des neuen Ersatzkerns nahezu beendet.

F. Auch der neue Grosskern nahezu vollendet.

entsteht sowohl der neue Grosskern als auch der neue Ersatzkern. Wir können das Wesentliche des Conjugationsprocesses dahin zusammenfassen, dass dabei eine Vermischung der Kellsubstanz und Kernsubstanz stattfindet und dass darauf eine Regeneration des Grosskerns erfolgt.

Dimorphismus der conjugirenden Individuen. Von grossem Interesse ist es, dass in vielen Fällen von dauernder Conjugation grössere Individuen ( $\mathrm{Makrogonidien)} \mathrm{mit} \mathrm{besonders}$ gestalteten kleineren Individuen (Mikrogonidien) sich verbinden 
(knospenförmige Conjugation der Vorticellen). Oft sind diese conjugirenden Individuen von dem daueruden Formzustande auffallend verschieden (Schwärmsprösslinge der Radiolarien). Bei der coloniebildenden Flagellate Volvox haben die Makrogonidien die Form der ruhenden Zelle, während die Mikrogonidien (Spermatogonidien) be-

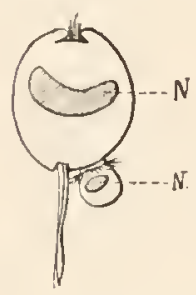
weglich und den übrigen Individuen dieser Flagellatencolonie in gewissem Grade ähnlich sind. (Vergl. p. 67.)

Fig. 22. Conjugationsprocess von Vorticella (nach (ExGELMANN). Ein gestieltes Makrogonidium (der Stiel nur theilweise dargestellt) verschmilzt mit dem freischwärmenden Mikrogonidium.

$N$ Die Kerne des Makrogonidiums und des Mikrogonidiums.

Cormenbildung der Protozoen. Die Vermehrung du r ch Spaltung (besonders Längsspaltung) und Knospung führt bei festsitzenden Protozoen sehr oft zur Cormenbildung, indem die Individuen durch verzweigte Stiele mit einander in Verbindung bleiben; so entstehen die Stöckchen von Epistylis und Carchesium, sowie die mannigfaltigen Cormen der Flagellaten. Auch bei den flottirenden Radiolarien gibt es cormenbildende Formen (Polycyttaria).

A.

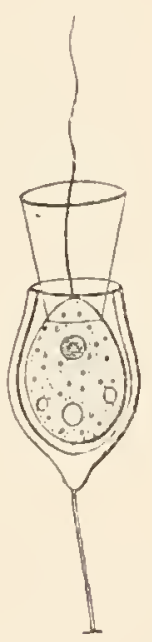

C.

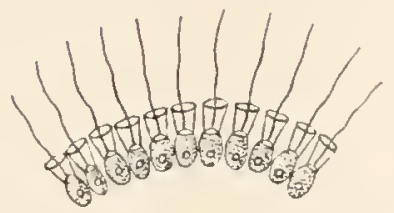

B.

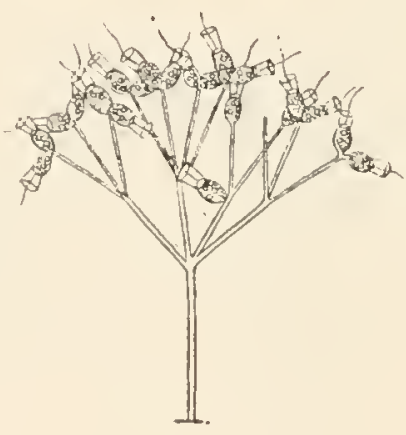

D.

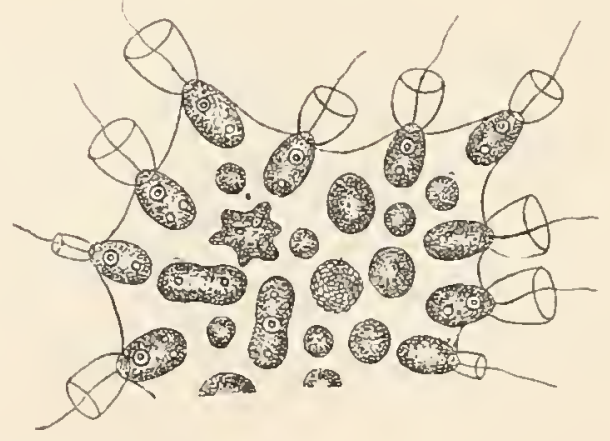

Fig. 23. Verschiedene Cormen von Choanofiagellaten.

A. Salpingoeca convallaria. Gestielte solitäre Forın mit Gehäuse (nach StEıN).

B. Codonocladium umbellatum, ein baumförniger Cormus (nach STEIN).

C. Codonodesmus phalanx, reihenförmiger Cormus (nach STEIN).

D. Protospongia Haeckelii (nach KExT) Theil eines Cormus. Zahlreiche Individuen in eine gemeinsame flache Gallertmasse eingebettet; dieselben sind theils im differenzirten, theils im ruhenden Zustande. 
Auch durch Vermelirum aus der ruhenden Zelle kön $n$ en Cormen entstelıen, inden die Theilstücke auch nach ihrer Aufdifferenzirung noch mit einander verbunden bleiben. Diese (mit Riicksicht auf die Metazoen besonders interessante) Cormenbildung kemen wir bei den Catallacten und den Volvocinen. Diese, welche oft die Form von Kingelcormen haben, zerfallen zum Kwecke der Fortpflanzung in die Einzelindividuen, die (eventuell nach erfolgter Conjugation) zur ruhenden Zelle werden und damn wieder durch Theilungsprocesse je einen neuen Cormus liefern (Gonium [Plattencormus], Eudorina). Bei Volvox aber ist eine weitere Differenzirung des Cormus aufgetreten, indem nur bestinmte /ellen zur Fortpflanzung befälngt erscheinen, während die übrigen Zellen, die im Verbande bleiben, steril sind und nach Ablösung de r Fortpflanzungszellen zu Grunde gehen. In diesem einen Falle kömmt also innerhalb des Cormus schon der Unterschied zwischen Arbeitszellen und Fortpflanzungszellen zur Erscheinung. (Vergl. pag. 67.)

\section{Systematische Uebersicht der Protozoen.}

\section{a) Cytomorpha.}

I. Cl. Die Rhizopoda (Sarcodina) sind Protozoen, deren zähflüssiges Plasma Pseudopodien bildet und an beliebigen Stellen der Oberfläche feste Nahrungskörper in das Innere aufnimmt.

1. Ord. Die Foraminifera (Rhizopoda s. str.) sind einfache Rhizopoden, meist mit Gehäusebildung (Kalk, Chitin) von überaus mannigfaltiger Form.

Lo b o sa. Meist Süsswasserbewohner, mit lappigen Pseudopodien, meist mit pulsirender Vacuole. Amoeba, Arcella, Difflugia, Euglypha.

Reticularia. Meist Meeresbewohner, mit fadenförmigen, Netze bildenden Pseudopodien. Gromia, Miliola, Rolalia.

2. Ord. Die Heliozoa sind Rhizopoden (zumeist des Süsswassers) mit radiären, wenig beweglichen Pseudopodien, mit contractilen Vacuolen, oft mit radiären Skeletbildungen.

Actionosphaerium, Clathrulina (bildet aus der ruhenden Zelle Geisselschwärmer).

3. Ord. Die Radiolaria, sind pelagische Rhizopoden mit Centralkapsel und meist mit complicirtem radiären Kieselskelet. Bei Fortpflanzung aus der ruhenden Zelle bilden sie Geisselschwärmer, welche den Conjugationsprocess eingehen.

IIo nozoa, Einzelthiere: Thallassicolla, Acanthomelra, Eucyrtidium.

Polycyllaria cormenbildend: Collozoum inerme.

Fig. 24. Clathrulina elegans, eine Heliozoë mit Stiel und kieseliger Gitterkugel (nach Greeff).

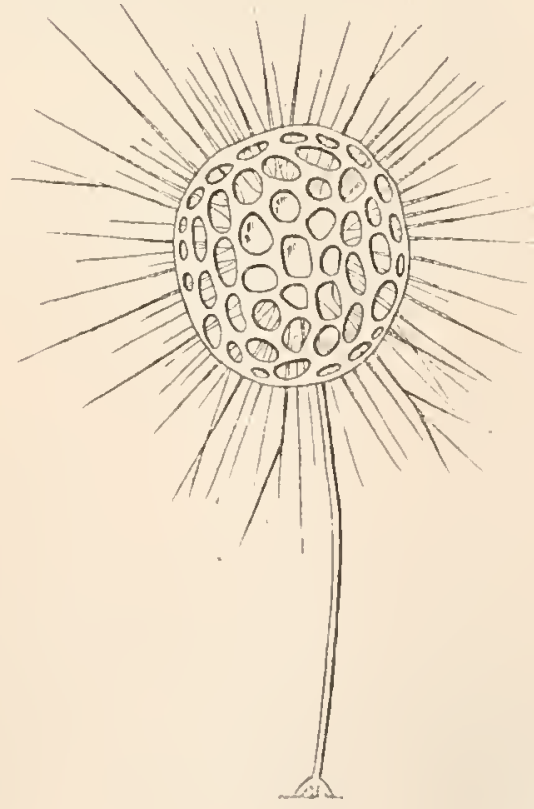


II. Cl. Die Flagellata (Mastigophora) sind Protozoen, deren Körper meist formbeständig von einem festeren Ectoplasma begrenzt ist, sie sind in der Regel mit Mundöffnung versehen und besitzen eine einzige oder eine geringe Zahl von Geisseln.

1. Ord. Nud of lagellat a mit einer oder mehreren Geisseln.

Rhizomastigina: Mastigamoeba, Ciliophris infusionum.

Cercomonas intestinalis, Euglena viridis, Trichomonas vaginalis, Peranema, Bodo, Hexamitus.

Fig. 25 .
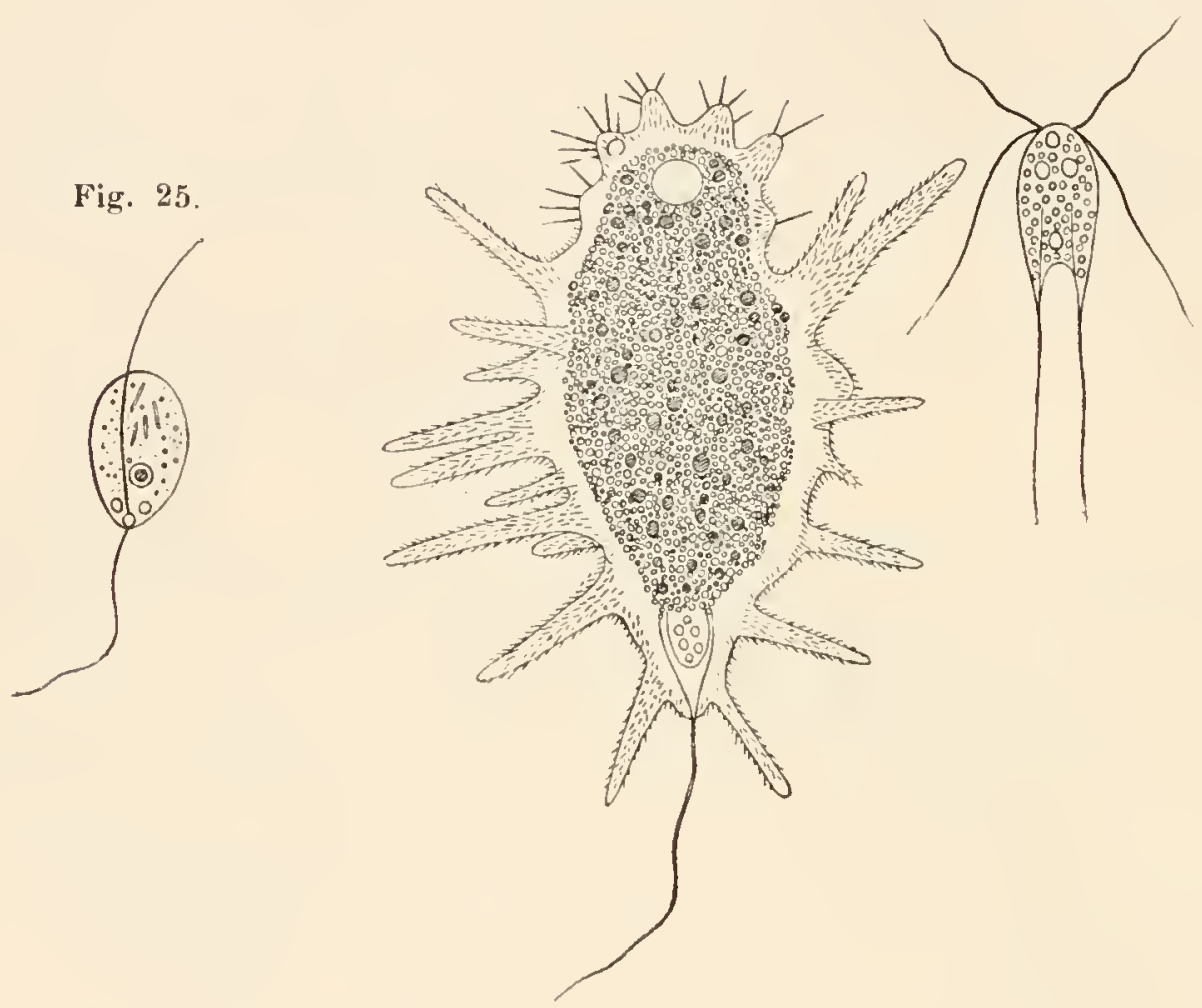

Fig. 25. Bodo caudatus (nach BüTSCHLI).

Fig. 26. Mastigamoeba aspera (nach F. E. Schulze).

Fig. 27. Hexamitus inflatus (nach BütschLI).

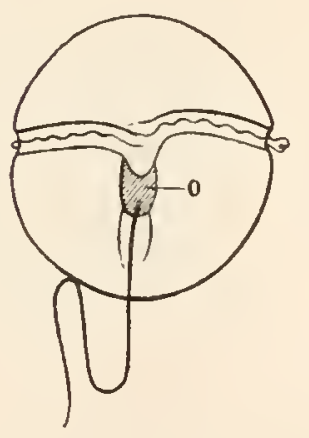

Fig. 28.

Fig. 28. Panzer von Peridinium divergens (nach STEIN)

Fig. 29. Die beiden Geisseln einer einfachen Cilioflagellatenform (nach BüTSCHLI).

o Mundöffnung.

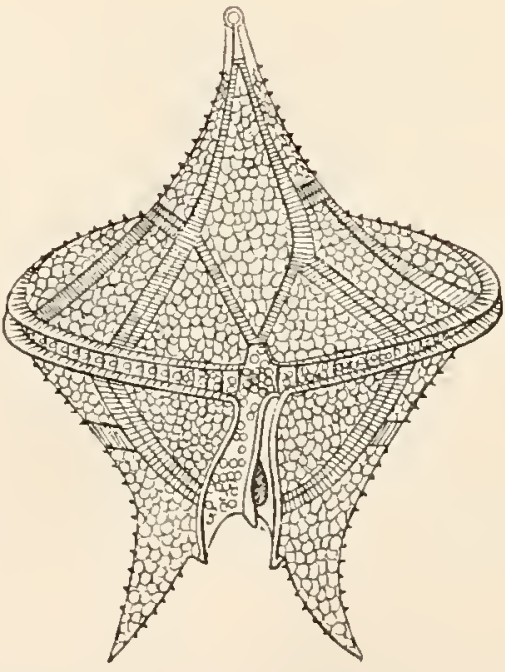

Fig. 29. 
2. Ord. Cho anoflagellata, mit einer, an ihrer Basis von einem trichterförmigen Kragen umgebenen Geissel.

Salpingoeca convallaria, Codosiga botrylis, Codonocladium, Codonodesmus, Protospongia Haeclielii.

3. Ord. Cilioflage lla la, mit einer freien Geissel und einer zweiten, die einen scheinbaren Wimperkranz bildet, mit kieseligem Panzerskelet.

Peridinium, Glenodinium, Ceratium.

4. Ord. Cystoflagellata, mit netzförmig angeordnetem Endoplasma, mit contractilem Tentakel und einer mundständigen Geissel; von ansehnlicher Grösse.

Nocticula miliaris, bläschenförmig; ist häufig Ursache des Meerleuchtens.

III. Cl. Die Sporozoa sind parasitische Protozoen, deren formbeständiger Körper von einer Cuticula und festerem Ectoplasma begrenzt ist; Mundöffnung fehlt, Ernährung endosmotisch; sie besitzen weder Cilien noch Pseudopodien, Körper meist contractil; nach erfolgter Conjugation zerfällt die encystirte, ruhende Zelle in spindelförmige Sporen (Pseudonavicellencyste).

Gregarina polymorpha, Stylorhynchus. Psorospermien, Sarcorystis.

\section{b) Cytoidea.}

IV. Cl. Die Ciliata (Infusoria) sind Protozoen, deren formbeständiger Körper von einer Cuticula und festerem Ectoplasma begrenzt ist, sind in der Regel mit Mund und After versehen, bewegen sich mittelst zahlreicher Cilien. In der Regel mit Grosskern (Nucleus) und Ersatzkern (Nucleoli).

1. Ord. Holotricha. Körper gleichmässig mit Wimpern bedeckt. opalina ranarum, Paramaecium.

2. Ord. Heterotricha. Körper gleichmässig mit reihenweise angeordneten Wimpern bedeckt und mit adoraler Wimperzone.

Spirostomum ambiguum, Bursuria truncatella, Balantidium coli, Stentor coeruleus.

3. Ord. Hypotricha. Nur die Bauchfläche bewimpert und mit Griffeln und Stielen besetzt; mit adoraler Wimperzone.

Stylonichia mytilus. Chilodon cucullulus, Euplotes.

4. Ord. Peritricha. Körper drehrund, oft gestielt. Mit adoraler Wimperzone und oft auch einem hinteren Wimperkranz.

Vorticella, Epistylis, Spirochona gemmipara.

5. Ord. Suctoria. Körper meist drehrund und gestielt, mit Saugtentakeln; nur im Jugendzustand mit einem Wimperkranz versehen.

Acinela, Podophrya gemmipara.

\section{Anhang. Volvocin a.}

Die Volvocin a gehören zu der den Flagellaten sich anschliessenden Gruppe der Phytomastigoda; es sind dies Flagellaten-ähnliche Protozoen mit zwei bis vier Geisseln, die sich durch pflanzlichen (holophytischen) Stoffwechsel auszeichnen und von den meisten Botanikeru zu den einzelligen Algen (Protococcoideae) gezogen werden. Doch zeigen unter denselben namentlich die Volvocinen in ihrer Cormenbildung und ihrer Fortpflanzung solche Erscheinungen, die geradezu als eine Vorstufe der bei den Metazoen vorliegenden Verhältnisse betrachtet 
worden mïssen. Vielleicht haben sowohl die höheren Pflanzen als auch die Metazoen ron derartigen Formen ihren Ausgang genommen (Bü tschur). Die rerschiedenen Fälle, die wir bei rlen Tolvocinen kennen, sind von grösstem Interesse, da sie eine successive Stufenreihe darstellen.

Gonium pectorale. Die Colonien sind in der Regel aus 16 tafelförmig vereinigten Individuen zusammengesetzt. Zum //wecke der Fortpflanzung zerfällt die Colonie in die Einzelindividuen, welche (durch successive Theilnng aus der' ruhenden \%elle) je eine nene Colonie bilden.

Aehnlich verhalten sich die mit einer Colonialliülle versehener Kungelcormen von Pandorina (Conjugation nahezu gleichartige r

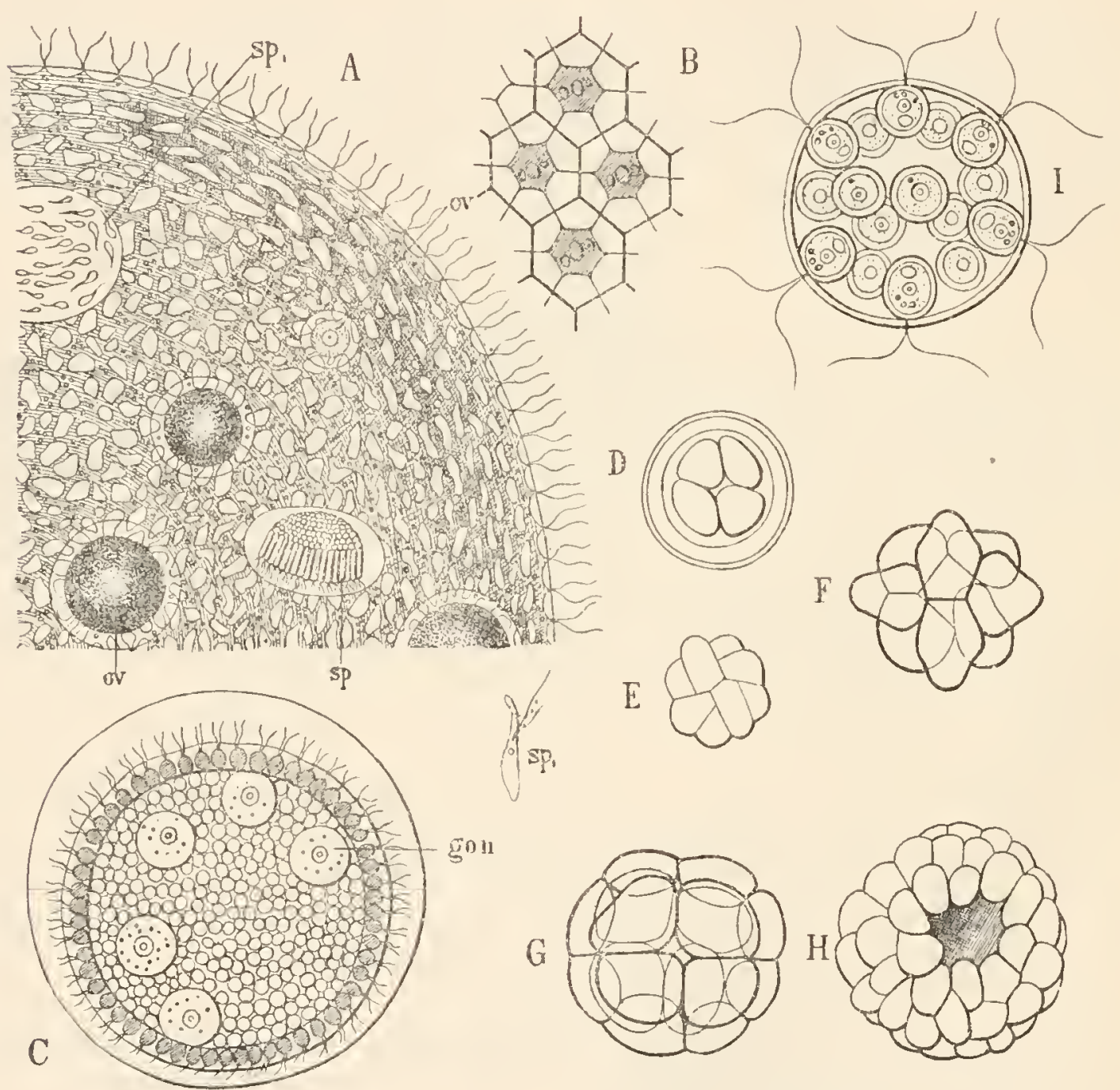
Сону).

Fig. 30. A. Volvox globator. Quadrant eines hermaphroditischen Individums (nach gelöst.

ov Ovogonidien; $S p$ Spermatozoenbündel, bei $S p_{1}$ in die einzelnen Spermatozoen auf-

B. Volvox globator. Theil der Oberfäche; zeigt die hexagonalen Grenzen der Separathiillén, sowie die plasmatischen Verbindungsfäden zwischen den Individuen (nach BÜTSCHLI).

C. Tochterindividuum (aus der Colonie entnommen) noch von der Separathülle umschlossen, von Volvox minor (nach Stein).

gon die jungen Fortpflanzungszellen.

D. E. F. G. H. Furchungsstadien von Volvox (nach Kirchner ete.).

1. Eudorina elegans (nach StEIN). 
Individuen wurde beobachtet) und Eudorina (di e conjuginenden Individuen sind verschieden |Makro- nnd Mikrogonidien|).

Volvox. Die grossen Kugelcolonien von Volvox sind von sehr zahlreichen Individnen gebildet (bis 1200), die, ähnlich wic bei Eudorina, an der Inmenfläche einer Coloniallıülle in gleichen Abstïnden von einander liegen, aber in diesem Falle durch feine Plasmafüiden verbunden sind. Ueberdies kommen den einzelnen Individnen Separathïllen zu, welche durch) gegenseitigen Druck die Form ron sechsseitigen Wraben annehmen und miteinander rerwachsen. Zwischen den zweigeisseligen Individuen finden sich geissellose Fortpflanzmnssellen, rie allmählich dnrch Wachsthum die übrigen Kellen an Grösse vielfach übertreften mnd mittelst ilner Separathüille in die Centrallöhle hineinhïngen. Diese Fortpflanzungszellen bilden sich zu Ovogonidien und Spermatogoniclien aus (entweder in einer Colonie oder auf zwei Colonien vertheilt, monöcisch - diöcisch). Die ()vogonidien, welche die Form einer ruhenden 'zelle haben, entstehen aus einer indifferenten Fortpflanzungszelle durch einfaches Wachsthun, die Spermatogonidien, welche als viel kileinere, schlanke, zweigeisselige Zellen mit Angenfleck und zwei kleinen contractilen Vacuolen sich erweisen, entstehen dadurch, dass eine indifferente Fortpflamznmgszelle zunächst erst durch successive Theilung eine bündelartige Spermatogonidienplatte liefert, welche in die zahlreichen Spermatogonidien zerfällt. Nicht alle Cormen liefern geschlechtliche Fortpflanzungszellen, denn anf eine geschlechtlich sich fortpflanzende Generation folgen eine Anzahl parthenogenetischer; bei letzteren bilden sich nämlich Parthenogonidien, das sind Fortpflanzungszellen, die den Ovogonidien gleichen, sich aber olne vorhergegangene Conjugation (parthenogenetisch) entwickehn. Bei der Entwicklung liefern die Parthenogonidien oder die befruchteten Ovogonidien durch fortgesetzte Theilung (,Furchung $\left.{ }^{66}\right)$ je eine junge Volvoxcolonie, die in die Centralhöhle der Muttercolonie gelangt und dort weiter wächst, bis sic endlich ansgestossen wird. Durch diese Theilung („Furchung6) entsteht zunächst eine Zellplatte, die schon auf dem achtzelligen Stadium sich zur Kugelgestalt zusammenzukrümmen begimnt; die Kugelgestalt vervollkommmet sich allmählich, doch bleibt eine Ocffnumg, welche gegen die Oberfläche der Muttercolonie gewendet ist, noch bis zum Ende der Entwickelung sichtbar. Die Fortpflanzungszellen sind an der jungen Colonie schon sehr frühzeitig wieder nachweisbar.

Nach Ablösung sämmtlicher Fortpflanznngszellen geht die ïbrige Colonie zu Grunde. Bei Volvox ist demnach eine wirkliche Differenzirung zwischen Arbeitszellen (Körperzellen) und Fortpflanzungszellen vorhand en. 


\section{SIEBENTES CAPITEL.}

\section{M e t a z o a. \\ (I. Grundform, Entwicklung der Grundform.)}

Die Metazoen sind rielzellige Tliere, die auf die Grund form der Gastrula zur ü ckführbar sind; mit localisirten Keimlagern, in welchen die lieteromorphen Fortpflanzungszellen (Fi-nud Samenzellen) siclbilden, welche beim Befruchtungsvorgang rerschmelzen. - An der reifen Eizelle sind zwei differente Pole a s gebildet (animaler und vegetativer Pol). - Die Entwicklung wird durcle die Furchung eingeleitet und es wird das Stadium der Blastnla und Gastrula durclula fent.

Del. Ball des ausgebildeten Thieles ist inl einfachsten Falle der Gastrula selpr ualuestelend-oder er erlebt sich durch mannigfache Complicationen weit über diese Grundform.

\section{Grundform der Metazoen.}

Der vielzellige Körper aller Metazoen ist seinem Ban und seiner Entwicklung nach anf die Grimdform der Gastrula zurückführbar (Haeckel 1873); diese Form ist bei der Entwicklung aller Metazoen, wemn anch unter mancherlei Modificationen, nachweisbar.

Die Gastrula, Fig. 31, hat die Form eines

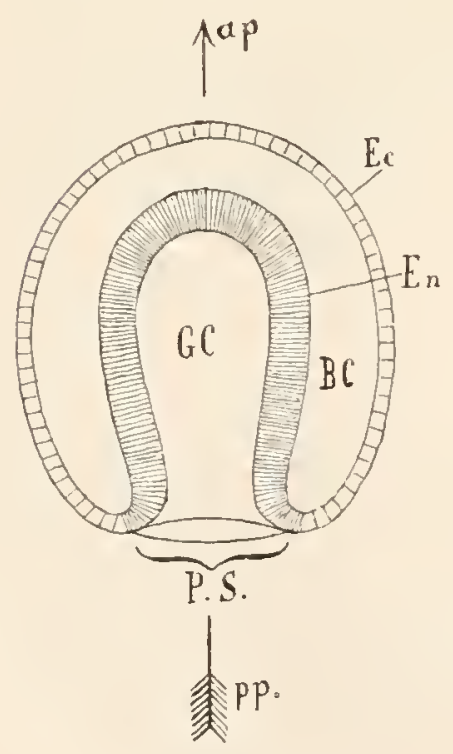
doppelschichtigen, aus einer äusseren und einer imneren Zellschichte bestehenden Sackes. Tir nemen solche Zellschichten, welche freie Flächen — sei es an der äusseren Oberfläche orler an inneren Höllen des Körpers - begrenzen, Epith elien.

Das äussere Epithel, welches die OberHäche der Gastruli bildet, wird als Ectoderm (Ur-Hant), das imnere Epithel, welches den centralen Holnlraum begrenzt, wird als End o d erm (Ur-Darmin) bezeichnet. Die centrale Hölle (Urdarm liölı le oder Gastrocoel) ist an dem einen Pole durch den Ur-

Fig. 31. Diagramm der Gastrula.

Ec Ectoderm; En Endoderm; PS Protostoma; $G C$ Gastrocoel; $B C$ Blastocoel; ap Apicalpol; $p p$ Protostompol. 
mund (P lotostom a) nach aussen geöfhet. Dort gehen die beiden Schichten, das Fctoderm nuld Fndoderm, ineinander iiber. '/wischen Ectoderm mud Endoderm findet sich oft ein Spaltraum, der als B la s tocoel oder primäre Leibeshöhle bezeichnet wird. - Dic Gastrula ist in allen ursprïnglichen Fällen (vor Allem bei den Protaxoniern) eine einachsige, lieteropole Form; wir unterscheiden einen A p i cal pol und einen Protostompol; die Achse, welche wir durch diese beiden Pole zichen, nennen wir die Primärachse.

Die Theorie einer gemeinsamen Grundform aller Metazoen entwickelte sich aus der Lehre von der „Homologie der Keimblätter", d. i. der embryonalen Körperschichten bei den verschiedenen Typen. Die erste Anregung ging von Hoxnex aus, welcher die zwei Körperschichten niederer Thiere (Polypen und Quallon) mit den embryonalen Schichten oder Keimblättern der Wirbelthiere, die durch C. F. WolfF und besonders durch C. E. v. BaEk bekannt geworden waren, verglich (1849). Eine weitere Begründung erfuhr diese Idee durch die bahnbrechenden Untersuchungen Kowalevskr's, welcher den exacten Nachweis führte, dass bei den verschiedenen Typen die frühesten Embryonalstadien in ihrem Bau im wesentlichen übereinstimmen (1870). Von grösster Bedeutung wurden dann die theoretischen Erörterungen HaEckel's, der den Unterschied zwischen den primären und secundären Charakteren bei den ersten Entwicklungserscheinungen besonders hervorhob, und den Grundtypus der zweischichtigen Sacklarve, der "Gastrula", mit Hinweis auf die verschiedenen Modificationen derselben, aufstellte; die Gastrula wird als Wiederholung eines entsprechenden phylogenetischen Stadiums, der ,Gasträa“, betrachtet, welche als hypothetische Stammform der Metazoen angenommen wird. Dadurch wurde die „Homologie der primären Keimblätter und die Uebereinstimmung der primären Achse bei allen Metazoen nicht nur bestimmter formulirt, sondern auch erklärend begründet" (Gastraeatheorie 1874).

Die einfachsten Metazoenformen sind sowohl in Bezug auf die Schichtung, als auch in Bezug auf die Achsenverhältnisse ihres Körpers der Gastrulaform noch sehr nahe verwandt (Hydroidpolypen), Fig. 33. Bei den höheren 'Typen aber' erfährt der Körper, nachdem er das Gastrulastadium durchlaufen hat, noch bedeutende Complicationen und Umgestaltungen. Hierbei sind zwei wesentliche Punkte besonders zu berücksichtigen: 1) Veräıderungen der Primärachse und des Protostoma und 2) Complicirung der Körperschichten.

Bei den Protaxoniern ist die Primäraxe auch die bleibende Hauptachse res Körpers. In Bezug auf das Protostoma zeigen zunächst die Spongien ein eigenthümliches Verhältnis, indem das Proto-

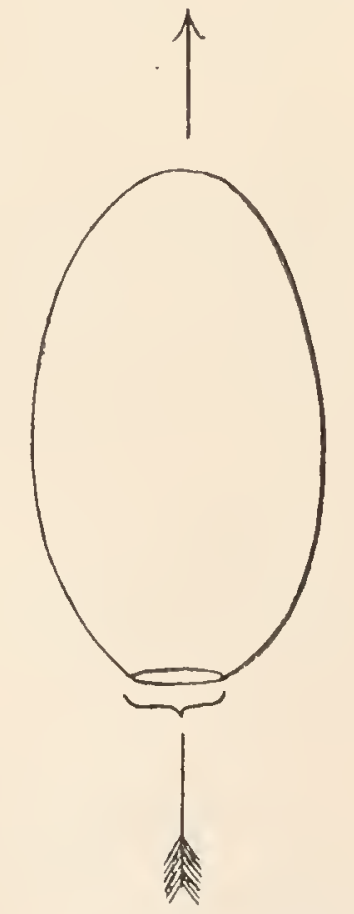

Fig. 32. Diagramm der Gastrulaachse und des Protostoma. stoma im Verlaufe der Eutwicklung sich schliesst und durch secundäre Oeffnungen ersetzt wird. Die Hydrozoen zeigen die ursprünglichsten Verhältnisse, da bei denselben das Protostoma der dauernden Mundöffinung entspricht, Fig. 33. Auch bei den Scyphozoen und den Ctenophoren persistirt das Protostoma, doch wird es hier 


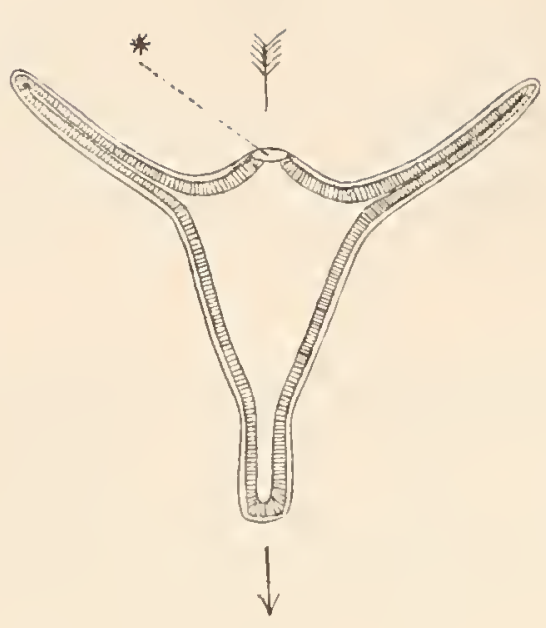

Fig. 33.

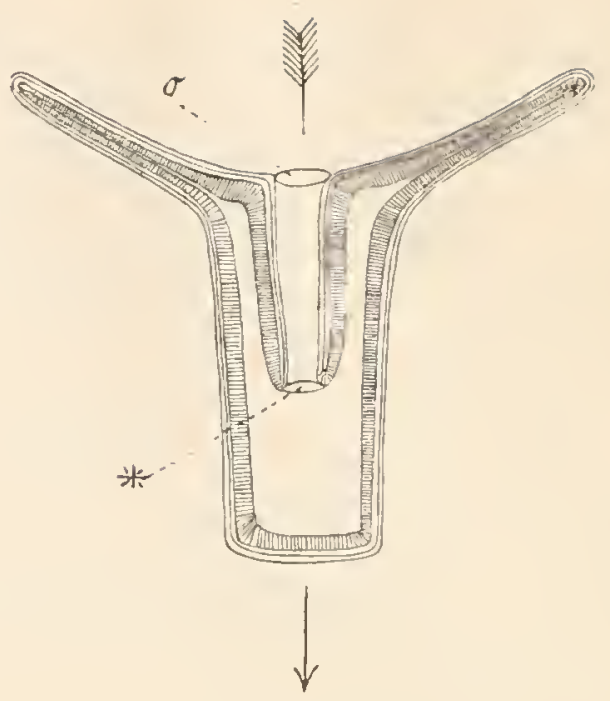

Fig. 34 .

Fig. 33. Diagramm eines Hydroidpolypen mit Tentakeln in der Ungebung der Mundôffnung, im übrigen aber den einfachen Schichtenbau einer Gastrula zeigend. Das Protostoma $\left(^{*}\right)$ fällt hier mit der Mundöffnung zusammen.

Fig. 34. Diagramm eines Scyphopolypen. Die Mundöfnung (o) führt in eine Schlundröhre. Die innere Schlundpforte (*) entspricht dem Protostoma.

durch die Bildung eines ectodermalen Schlundes mehr in die 'Tiefe des Körpers verlegt, es persistirt als Schlund p for te, * Fig. 34.

Bei den Heteraxonier'l oder Bilaterien zeigt sowohl die Primärachse als auch das Protostoma meist bedeutend veränderte Verlaältnisse. So ist z. B. bei den Annetiden (Fig. 35) nachgewiesen, dass das bleibende Vorderende des Thieres woll mit dem Apicalpole der Gastrula iibereinstimnit; das Hinterende aber entspricht nicht dem Protostoma, da letzteres während der Entwicklung nach der Banchseite sich verschiebt und dort der Länge nach verwächst; es schliesst sich bis auf einen kleinen vorderen Rest, der, durch die Bildung eines ectodermalen Schlundes in die Tiefe verlegt, zur Schlundpforte wird. - Bei den Chordoniern, Fig. 36, ist es dagegen die Rückenseite, nach welcher das Protostoma verschoben wird; es schliesst sich bis auf einen kleinen hinteren Rest, der durch einen eigenthümlichen Process auf die Bauchseite gelangt. Es ist nicht unwahrscheinlich, dass dieser Protostomrest zur Afteröffnung in Beziehung steht. Durch die Verschiebung des Protostoma erfährt in diesen beiden Fällen die Primärachse eine Knickung.

In Bezug auf die Complicirung des Schichtenbaues bei dell Metazoen ist von besonderer Wichtigkeit das Auftreten einer M e so d e r m s c h i ch te.

Bei allen Metazoen, mit Ausnahme der Hydrozoa, wird nämlich del Schichtenban des Körpers über das Gastrulastadium hinaus ein complicirterer, indem zunächst eine mittlere Schichte, ein Mesoder'm auftritt. Wir unterscheiden dann drei secundäre Blätter: das (secundäre) Ectoderm, das (secundäre) Endoderm und das Mesoderm. Das Mesoderm ist durchans nicht in allen Phylen von homologer Bedeutung, obzwar es überall durch Sollderung vom primären Endoderm entsteht.

Bei den niedrigeren Metazoen, den Spongien, den Scyphozoen und den Ctenophoren beobachten wir ein mesencly martiges Mesoderm, Fig. 37. Als Mesenchym bezeichnen wir nämlich nach dem Vorgange 


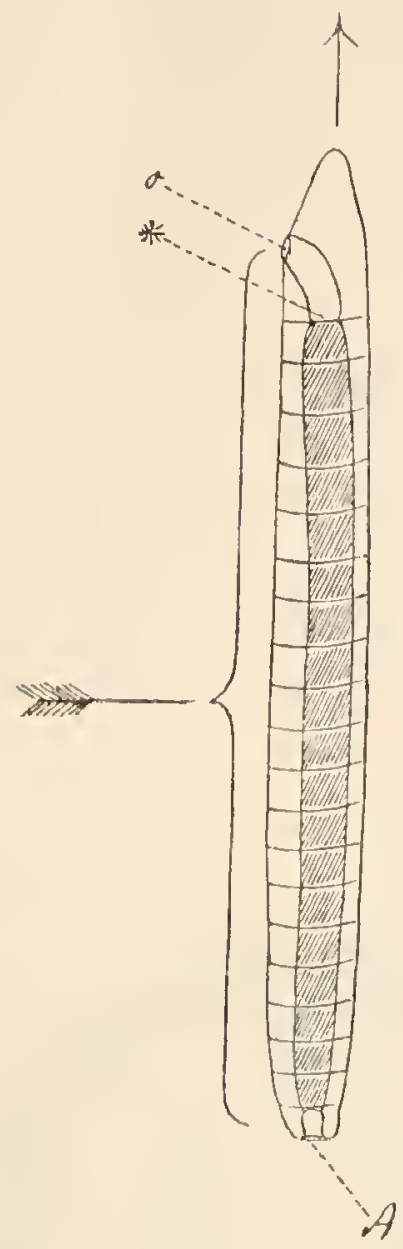

Fig. 35 .

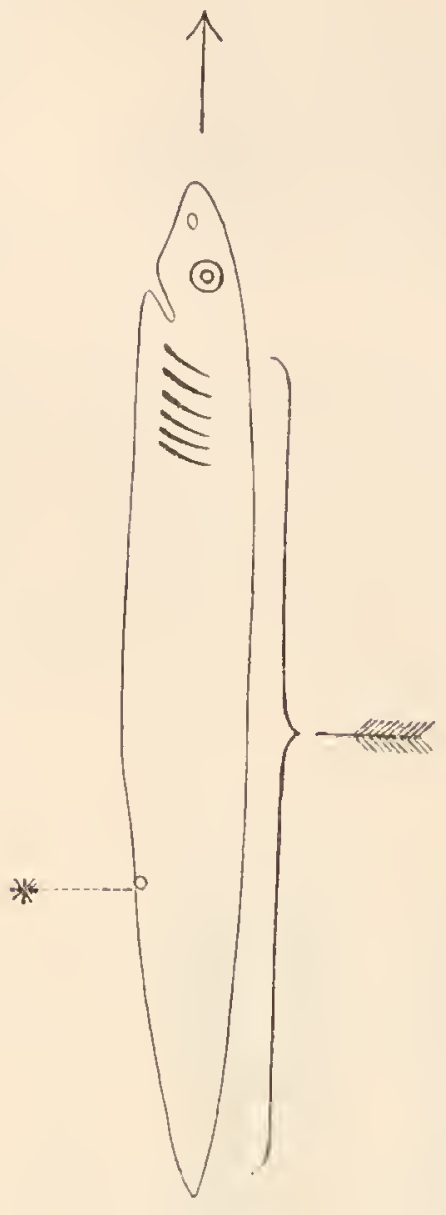

Fig. 36 .

Fig. 35. Diagramm eines Anneliden. Die Region zwischen Mund $(o)$ und After $(A)$, welche auf der Bauchseite liegt, entspricht dem verwachsenen Theile des Protostoma. Die Mundöffnung führt in ein ectodermales Schlundrohr; die innere Schlundpforte $\left({ }^{*}\right)$ entspricht einem Rest des Protostoma.

Fig. 36. Diagramm eines Wirbelthieres. Der grösste Theil des Rückens entspricht der Region des verwachsenen Protostoma. Der After (*) ist wahrscheinlich ein Rest des Protostoma.

von O. und R. Hertwig Zellen, die aus den Epithelien in das Blastocoel einwandern, und dnrch ihre Isolinnng eine gewisse grössere Selbststïndigkeit gewinnen, als die Epithelzellen. Die amöboide Form der Zelle tritt lier typisch auf.

Bei allen höheren Metazoen, die wir als Heteraxonier orler Bilaterien bezeichnen, besteht das Mesoderm aus zweierlei Gebilden, die aus einer g emein s a me 11 A nlage entstehen: 1.) aus paarigen Epithelsäcken und 2.) aus Mesenchym.

Bei den Scoleciden sind die Epithelsäcke nur durch die parigen Sackgonaden

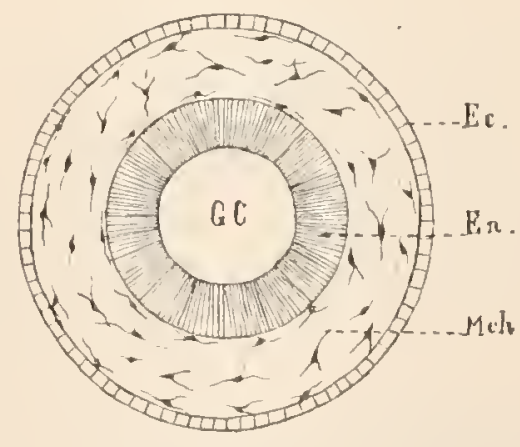

vig. 37. Diagramm des Schichtenbaues bei spongien, Scyphozoen und Ctenophoren (Querschnitt).

Ec Ectoderm; En Endoderm; Mch Mesenchym; $G_{C} C$ Gastrococl. 


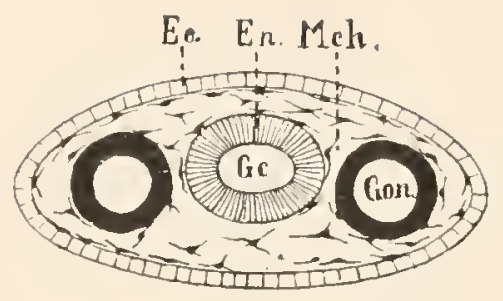

(d. i. sackförmige Keimlager) repräsentirt. Das Mesenchym ist sehr ansgebildet und spielt eine wichtige Rolle im Orgauismus rlieser 'Thiere, Fig. 38.

Fig. 38. Diagramm des Schichtenbaues bei Scoleciden (Querschnitt).

Ec Ectoderm; En Endoderm; Hch Mesenchym; $G C$ Gastrocoel; Gon Sackgonade.

Bei deu Anneliden, die wir lier als Repräsentanten der Aposcoleciden in Betracht zielıen wollen, sehen wir den epithelialen Theil des Mesoderms in For'm parriger Co e lo 111 s ä c li e auftreten. DDie Coelomsäcke sind bei den gegliederten Formen - und davon sind die Anneliden ein ausgeprägtes Beispiel — in zahlreichen hintereinander liegenden Paaren vorlianden, bei ungegliederten Aposcoleciden (Mollusca, Phoronis) dagegen nur in einem Pare.] Die eine Wand des Coelomsackes legt

A.

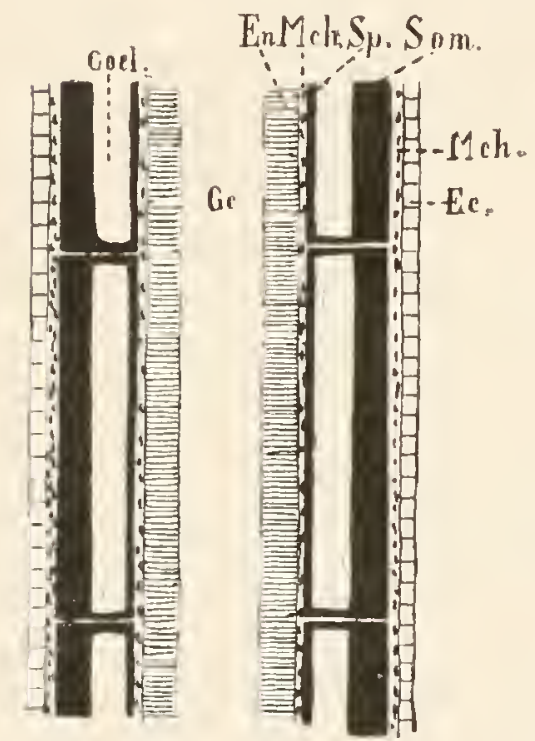

B.

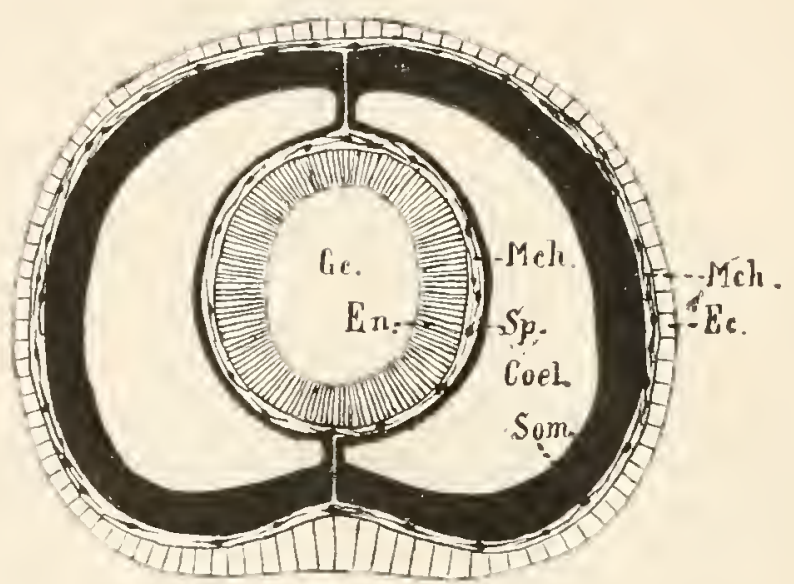

Fig. 39. Diagramm des Schichtenbaues der Anneliden.

A. Längsschnitt durch einen Abschnitt (Segment) des Körpers.

$B$. Querschnitt des Körpers.

Von aussen nach innen folgen: Ec Ectoderm; Mch Mesenchym; Som somatisches Blatt; Coel Coelomhöhle; Sp splanchnisches Blatt; MIch Mesenchym; En Endoderm; GC Gastrococl.

sich als somatisches Blatt an das Ectoderm, die andere als splanchnisclies Bilatt an das Endoderm; in der dorsalen und ventralen Mittellinie gehen diese Blätter in einander uiber und bilden die Aufhängebänder des Darmes, die sogenannten Mesenterieu (Fig. 39 B). Zwischen somatischem Blatt und Ectoderm, sowie zwischen splanchnischem Blatt und Endodern finden wir Mesenchym, welches hier eine viel untergeordnetere Rolle spielt, als bei den Scolociden.

Bei einer Gruppe der Aposcoleciden, bei den Mollusken, erlangt das Mesenchym eine mächtigere Ausbildung, so dass es hier im Gesammtorganismus wieder eine grössere Bedeutung erlangt. Bei anderen Formen aber ist das Mesenchym sehr reducirt, z. B. bei Sagilla, sowie bei Polygordius. 
Wir haben hier das Grundsehema des Schichtenlaues der Aposcoleciden dargelegt; im Bau des entwickelten Thieres kommen aber nocln mancherlei Complicationen linzu.

Der Schichtenbau der Ambulacralier ist dem Grundtypus nach ähnlich demjenigen der Aposcoleciden.

Auch bei den Chordoniern besteht das Mesoderm aus paarigen Coelomsäcken und Mesenchym. Die Coelonssïcke erfahren hier zahlreiche typische Complicationen, so dass der Schichtenbau der Chordonier nur in den frïhesten Stadien, nicht aber an entwickelten Thiere mit jenem der Metascoleciden und Ambulacralier verglichen werden kann.

Entstehuly des Mesoderms. Bei den Spongien, Scyphozoen und Ctenophoren entstelit das mesenchymartige Mesoder'm wohl allgemein (Actinozoen?) vom primären Endodern aus, aber in jeder dieser Gruppen auf besondere Art.

Die Entwicklung des Mesoderms bei den Heteraxoniern ist auf zwei Haupttypen zurückzuführen, die selbst bei nahe verwandten 'Thieren vorkommen können. So ist zum Beispiel der eine Bildungsmodus bei den Anneliden, der andere bei der den Anneliden nahestehenden Sagitta, sowie bei den Brachiopoden zu beobachten. Wir vermuthen daher, dass beide Modificationen von einem gemeinsamen Grundtypus abzuleiten seien. Wir werden erst später die Frage erörtern, welche von diesen beiden Entstehungsweisen des Mesoderms die urspriinglichere sei und wollen zunïchst dieselben in ihren Hauptrïgen kennen lernen.

In dem einen Falle, z. B. bei den Anneliden, entsteht das Mesoderm dadurch, dass zwei Endodermzellen, die am Protostomrande paarig, die eine rechts, die andere links von der Medianebene gelegen sind,

A.

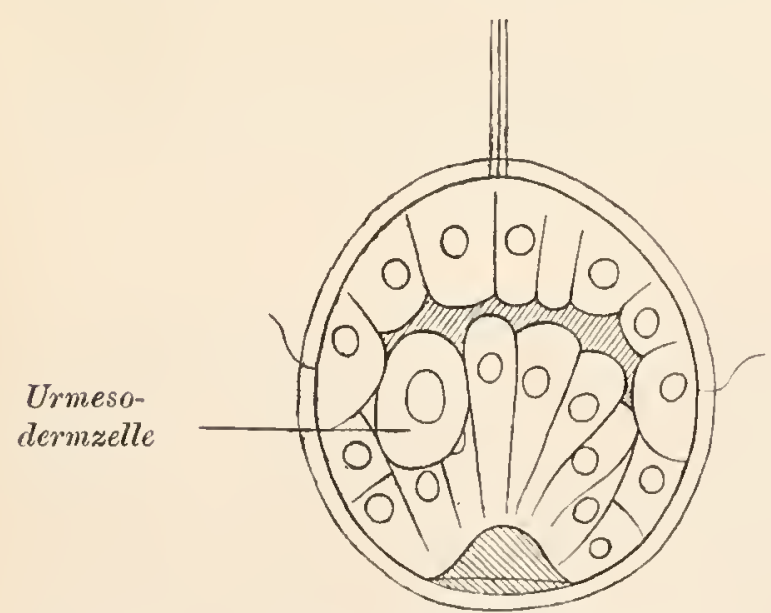

B.

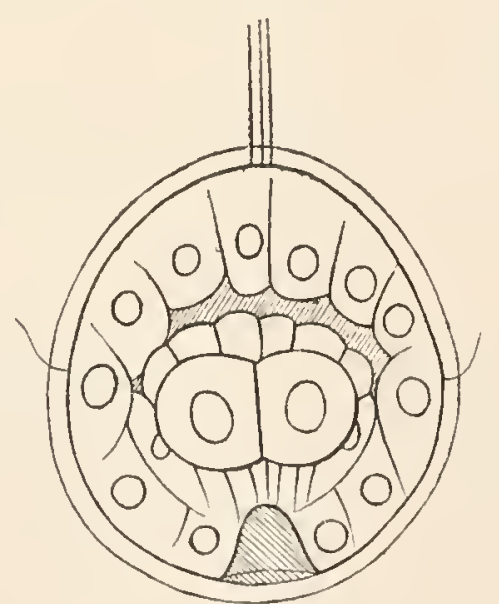

Fig. 40. Gastrula einer Serpulide, noch von der Eihülle umgeben, die von Wimperbildungen durchsetzt ist.

A. Längsschnitt, median. Eine Urmesodermzelle sichtbar.

B. Längsschnitt, frontal. Beide Urmesodermzellen sichtbar.

aus dem Verbande des Endoder'ms sich sondern und zwischen die beiden primären Blätter als parige Urmesodermzellen hineinrücken (Fig. 40). Aus diesen beiden Zellen entstehen durch Zellvermehrung sowohl Mesenchymzellen, als auch jederseits eine bandförmige Zellmasse, die 
Mesodermstreifen, welche durch Aushöhlung in die parigen Coelomsäcke sich verwandeln (und zwar bei den Anneliden in eine Mehrzahl hintereinanderliegender Paare), Fig. 41.

A.

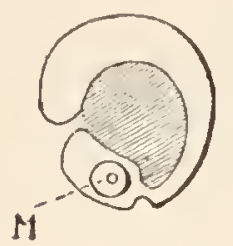

B.

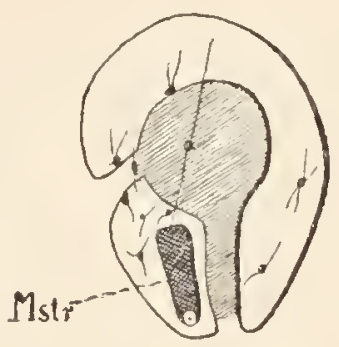

C.

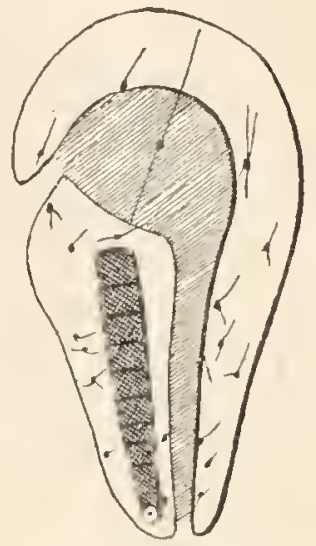

Fig. 41. Diagramm der weiteren Mesodermentwicklung bei Anneliden, drei Profilansichten.

A. Urmesodermzelle $(M)$, an der Bauchseite zwischen Mund und After liegend.

B. Die Urmesodermzelle hat auf jeder Körperseite einen Mesodermstreifen (IIstr) und ferner Mesenchymzellen geliefert. säcke).

C. Jeder Mesodermstreifen zerfällt in eine Anzahl Ursegmente (= segmentale Coelom-

Wir können diesen Vorgang als „Mesodermbildung a us pararigen Urmesodermzell e 1 " bezeichnen. Nach diesem Typus erfolgt die Mesodermbildung bei den meisten Zygoneuren, nur dass bei den Scoleciden ans den Urmesodermzellen die paarigen Sackgonarlen und das Nesenchym entsteht, während bei den Aposcoleciden (Anneliden, Mollusken etc.) die Coelonsäcke und das Mesenchym sich darans bilden.

Bei gewissen Plattwürmern, den Tricladen, werden vier regelmässig um das Protostoma angeordnete Urmesodermzellen beschrieben, aus welchen vier Mesodermstreifen sich bilden.

Den anderen Modus der Mesodermbildung finden wir beispielsweise bei Sagitta. Durch Längsfalten werden vom Urdarm unmittelbar die paarigen Coelomsäcke abgeschnürt (Fig. 42). Die Coelomsäcke erweisen sich hier als Absackungen des Urdarmes; ihre Höhlen stehen ursprünglich mit der Urdarmhöhle in Zusammenhang. Das Mesenchym ${ }^{1}$ ) tritt meist erst später auf, wahrscheinlich durch Auswanderming von Zellen des Coelomepithels. Wir können diesen Modus als, ,Mes odermbildu d u rch Abfaltung" bezeichnen. - Bei gegliederten Thieren, wo eine Mehrzahl von Coelomsackpaaren entsteht, kömmt es vor, dass jedes Paar gesondert vom Urdarm sich abfaltet, z. B. bei Amphioxus.

Die Verbreitung dieser beiden Typen der Mesodermbildung ist folgende. Unter den Zygoneuren ist die Bildung des Mesoderms aus zwei Urzellen der häufigere Fall, doch kömmt auch die Abfaltung in ausgeprägter Weise vor, nämlich bei Sagitta und Brachiopoden (Argiope), und ferner in etwas modificirter For'm bei den Tracheaten.

1) Speciell bei Sagitta äusserst spärlich entwickelt. 
A.

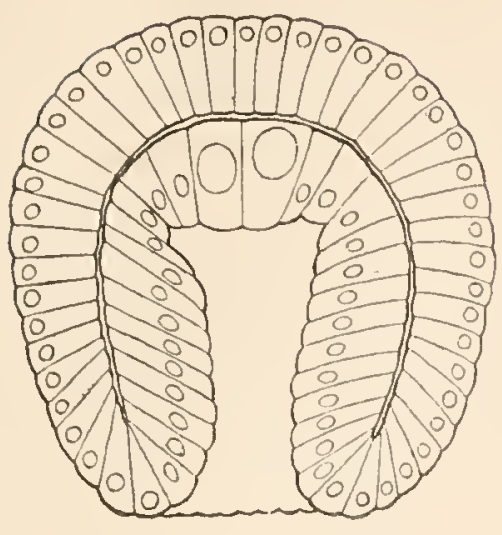

C.

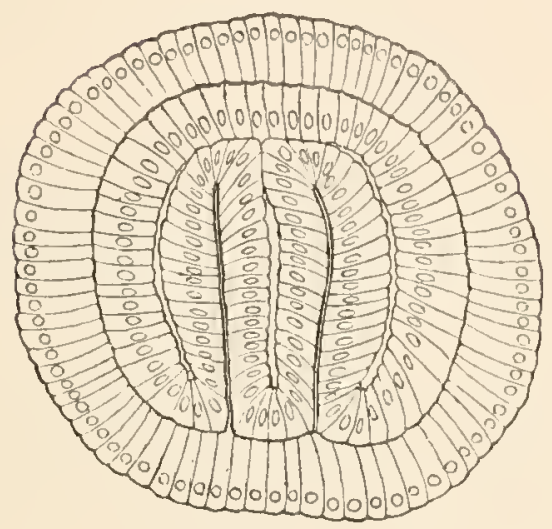

B.

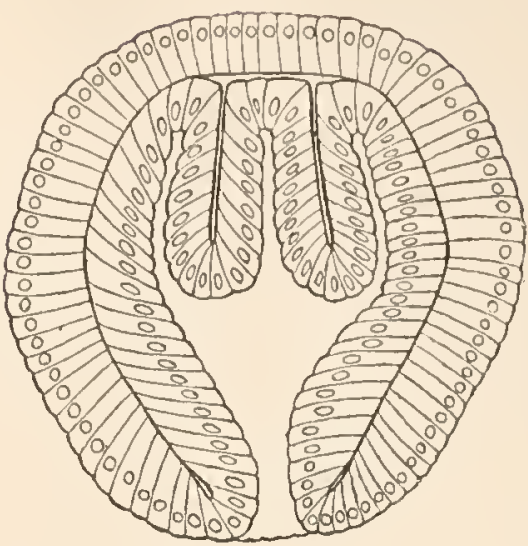

D.

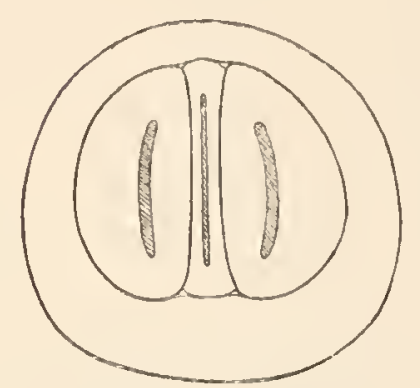

Fig. 42. Bildung der Coelomsäcke bei Sagitta (nach HerTwig).

A. Gastrula im frontalen Längsschnitt.

B. Im vorderen Theile ist am Endoderm eine unpare Falte als Epitliel des Darmes und paurige Falten als Coelomsäcke gebildet.

C. Querschnitt durch das Vorderende desselben Stadiums. Man sicht den Zusammenhang des Darmsackes und der Coelomsäcke.

D. Coelomsäcke und Darmsack sind vollkommen voneinander gesondert (Querschnitt).

A.

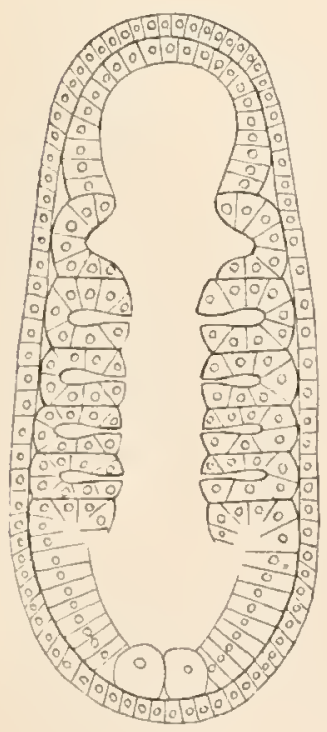

B.

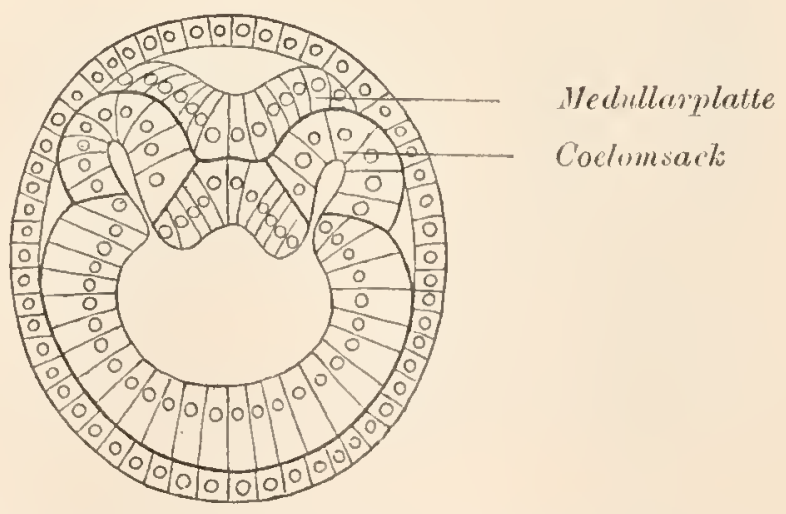

Fig. 43. Bildung der Coelomsäcke am Embryo von Amphioxus.

A. Frontaler Längsschnitt, um die Vielzahl der Coelomsackpaare zu zeigen.

B. Querschnitt. Die Medullarplatte (Anlage des Rückenmarkes) hat sich vom Ectoderm gesondert; die Coelomsäcke entstehels als Falten des Entoderms. 
Rei Ambulacraliern ist die Mesodermbildung durch Abfaltung die Regel. Bei den Chordoniern ist die Abfaltung der Grundtypus; sie findet sich ill sehr ausgeprägter Weise bei Amphioxus und alle Vorgänge der llesodermbildung bei den Wirbelthieren sind als Modificationen des bei Amphioxus vorliegenden Processes zu betrachten. Die Frage, welcher Bildungsmodus des Mesoderms bei den Heteraxoniern der ursprünglichere sei, lässt sich noch nicht mit Sicherheit beantworten. Doch ist es in hohem Grade walırscheinlich, dass die Abfaltung der ursprünglichere Fall sei. Die zwei Urmesodermzellen würden den Coelomsäcken entsprechen, von welchen sie durch Reducirung der Anzahl der Zellen abgeleitet wären. In der That findet sich dieser Bildungsmodus nu r dort, wo die Allzahl der Zellen des Embryo eine geringe is t. Und es ist lehrreich, dass in solchen Fällen bei sehr geringer Zellenzahl des Embryo auch das Endoderm, der Urdarm, in ganz analoger Weise durch wenige,

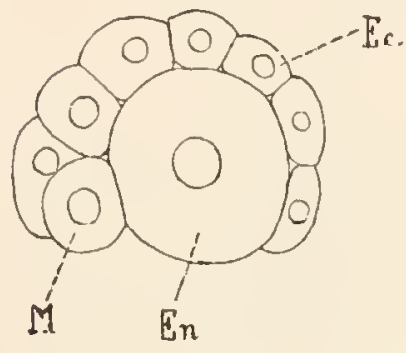
z. B. durch zwei Zellen vertreten sein kann, die erst später durch Zellvermehrung zu einem Epithelsack sich umwandeln.

Fig. 44. Medianschnitt durch die Gastrula einer Muschel (Teredo), sie ist aus einer geringen Zahl von Zellen zusammengesetzt. Mlan sieht eine von den zwei Endodermzellen $(E n)$ und eine von den zwei Mesodermzellen $(M T)$.

Vielleicht waren es im ursprünglichen Bildungsmodus ein paar kleine durch Abfaltung entstehende Cölomsäcke mit je einer hinteren Polzelle, die den Wachsthumspunkt der Cölomsäcke bildete. Davon hätte sich secundär die excessir grosse Abfaltung bei Sagitta und andererseits durch Reducirung die Bildung des Mesoderms aus zwei Urzellen abgeleitet.

\section{Geschlechtliche Fortpflanzung der Metazoen.}

\section{Die Fortpflanzungszellen.}

Der Metazoenkörper hat die Bedeutung eines Zellencormus. Die '/ellen sind in demselben nicht gleichartig, sondern in höherem oder greringerem Grade polymorph, denn in Zusammenhang mit der vielfachen Arbeitstheilung der einzelnen Zellen (z. B. als Muskelzellen, Sinneszellen, Nervenzellen, Drüsenzellen) zeigen dieselben auch verschiedenartige Differenzirungen ihres Plasma (,histologische Differenzirung der Zellen"). Nur bestimmte Zellen in diesem Zellencormus dienen zur Fortpflanzung, indem sie befähigt sind, aus dem Verbande des Zellcormus auszutreten und wieder einen gleichartigen Cormus aus sich hervorgehen zu lassen ${ }^{1}$ ). Diese Zellen, die wir als F ortpflanzungszellen bezeichmen, haben den Charakter ruhender (d. h. undifferenzirter) Zellen (Eizelle, Samenmutterzelle). Sie verhalten sich

1) Es ist bei den höheren, vielzelligen Organismen eine Theilung der Arbeit eingetreten, der zufolge nur einige wenige Zellen die Fortpflanzung des Individuums besorgen, während alle übrigen weit differenzirten Zellen, welche die complicirtesten Organe zusammensetzen, nur dienstbare Arbeiter im Zellenstaate sind; indem sie die Existenz des Gesammtorganismus of durch die complicirtesten Functionen ermöglichen, bewirken sie in letzter Instanz eigentlich nư die Existenz (den Schutz und die Ernährung) und Entwicklung der Fortpflanzungszellen. 
ihrem Bau nach (wahrscheinlich anch in Bezug auf ihre wesentliche Structur') zu den Arbeitszellen ähnlich, wie die rulıende (rückdifferenzirte) Protozocnzelle zn der thätigen (diflerenzirten) Protozoenzelle sich verhält. Nach Abstossung der Fortpflanzmngszellen gehen die Arbcitszellen des Cormus zu Grunde (beschränlite Jebensdaner der Metazoenperson [WEISMANN]).

Wir werden nun fragen: Ist es ähnlich wie bei den Protozoen der Fall, dass eine Arbeitszelle, die gewisse histologische Differenzirungen zeigt, sich durch Rückdifferenzirung zur ruhenden Zelle verwandelt und Fortpflanzungszelle wird? Es scheint dies thatsächlich, besonders bei den niedersten Metazoen (Spongien, Cnidarier) volzukommen. Wenn auch nicht alle Zellen des Körper's diesen Process cingehen können, so ist das doch bei gewissen in cincm bestimmten Grade differenzirten Zellen möglich. In anderen Fällen sehen wir aber, dass die Fortpflanzungszellen aus dem Kreise der Differenzirungen von Anfang an ausgeschlossen sind. Es kam da keine Muskelzelle, Nervenzelle, Drüsenzelle etc. znr Fortpflanzungszelle werden oder eine solche durch Theilung liefern; wenn wir zurïckgreifen und dic Entstehung cines Organismus aus der Fortpflanzungszelle verfolgen, so sehen wir, dass durch 'Theilung rlerselben zahlreiche rellen entstehen, welche die verschiedensten Differenzirnngen erfahren, dass aber auch undifferenzirte Zellen zurückbleiben, die wieder zu Fortpflanzungszellen werden. Diese Zellen haben gewissermassen in direkter Desccndenz von der Fortpflanzungszelle die Structur derselben beibehalten und zeigen auch, nachdem sie wieder herangewachsen sind, dieselbe Fähigkeit wie jene. Diese Erscheinung, die auch schon bei niederen Formen (sellost bei Volvox) auftritt und bei den höheren Metazoen Regel ist, bezeiclnen wir als Continu ität der Keimzellen.

Kcimepithel und Gonaden. Bei den Spongien sind dic Fortpflanzungszellen durch vereinzelte (in Mesenchym zerstreute) Zellen repräsentirt. Bei allen übrigen Metazoen finden wir begrenzte Keimlager (Gonaden), die auf die Grundform des ein- oder mehrschichtigen Epithels zurückzufiilıren sind (K e im e p ithel).

Wir können die Gonaden im Allgemeinen in Flachengonaden und S a ckgon ade $n$ ein theilen. Im ersteren Falle ist das Keimepithel mur eine besonders entwickelte Stelle an einer grösseren Epithelfläche (es bildet oft einen volspringenden Wulst), sei es nun die äussere ectodermale Fläche (Hydrozoa), odel die endodermale Fläche (Scyphozoa) oder die mesodermale Fläche des Coeloms (Anneliden, Eierstöcke der Vertebraten). Im anderen Falle bildet das Keim-

A.

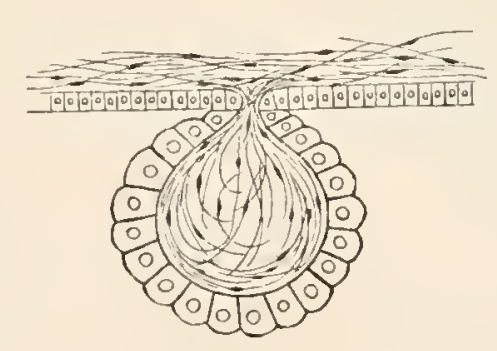

Fig. 45. A. Diagramm der Flächengonade mit innerem Stroma und äusserem Epithel.

B. Diagramm der Sack-
gonade, mit äusserem Stroma
und innerem Epithel.

B.

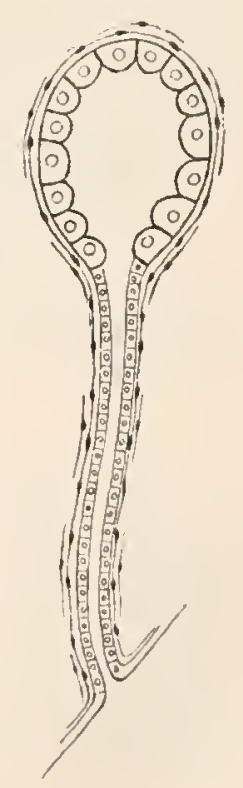
epithel die innere Aus- 
kleidung abgesonderter sackförmiger Organe (Sackgonaden), die stets mit eigenen Ausführungsgängen versehen sind. Als eine Modification dieser letzteren Form finden sich oft compacte, aber doch mit Ausführungsgängen versehene Gonaden. Das Kieimepithel bildet den wesentlichen Theil der Gonaden; es kommen aber meist noch als sogenanntes „S troma“ accessorische Gewebe (Bindegewebe, Muskeln, Blutgefässe) hinzu (Fig. 45. A, B).

Eizelle und Samenzelle. Die Gonaden liefern entweder weibliche Zellen (Eier, Ova) und werden als Ov a ri e $n$ bezeichnet, oder mämmliche Zellen (Spermatozoen) und werden dann Hod en genannt. Die Eier sind in der Riegel die grössten, die Spermatozoen die kleinsten Zellen des Metazoenkörpers. Ovarien nnd Hoden sind entweder auf verschiedene Individuen vertheilt (getremtgeschlechtliche Thiere) oder in einem Individnum vereinigt (Zwitter). In seltenen Fällen werden beiderlei Geschlechtsprodukte an gemeinschaftlicher Keimstätte erzeugt (Zwitterdrüse bei gewissen Mollusken). Besonders in diesem Falle erfolgt oft die Reifung der einen Art von Keimzelleu früher als die der anderen.

\section{Jas Ei. A.) Bau des Eies.}

Am thierischen Ei können wir zweierlei Bestandtheile unterscheiden. Erstens als wesentlichen Theil der stets und oft allein vorhanden ist, die Eizelle, und zweitens secundäre Theile, die aucl fehlen können, nämlich Hüllenbildungen, äussere Eiweissmassen etc.

1. Die Eizelle. Der wesentliche Theil des Eies (auch „Dotter" genannt) hat morphologisch die Bedeutung einer Zelle. Die reifen Eizellen sind in der Regel die grössten Zellen des Metazoenkörpers. Wir

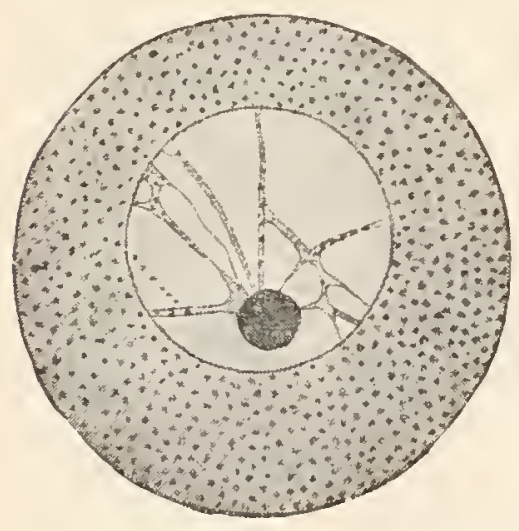

Fig. 46. Unreifes Ei aus dem Eierstock eines Echinodermen (nach HertwiG). unterscheiden an der Eizelle einen Zellkern, einen Zellleib und meist auch eine Zellmenbrall.

Der Z ellkern des Eies, der auch Ke imbläschen genannt wird, zeigt den typischen Bau, welchen wir in allgemeinen an Zellkernen kennen; wir unterscheiden eine Kernmembran, ein Kerngerüst meist mit einem (oder auch mehreren) ansehnlichen lícrnkörperchen, welches hier als Keimfleck bezeichnet wird, und den Kernsaft. Der Kiern liegt am reifen Ei stets etwas excentrisch, dem , an i imal en Pole" genähert; besonders auffallend ist diese Lagerung meist bei dotterreichen Eiern; der gegenüberliegende $\mathrm{Pol}$ wird als ,vegetativer Pol" bezeichnet.

Der Zellleib des Eies besteht aus Plasma und in dasselbe eingelagerten Dottersubstanzen. Es sind dies Reservenahrungsstoffe, welche später während der Embryonalentwicklung wieder resorbirt werden; sie finden sich entweder als flüssigere e iwe iss artige oder fettartige Tropfen, zumeist aber als festere eiweissartige Substanzen, sogenannte Dotterkörnchen. Dies sind meist kleine rundliche Körnchen, oft sind sie aber aucl unregelmässig gestaltet, 
selbst von der Form eckiger Plättchen (Anıphibicnei). Im Hiilnerei finden sich zweierlei Dotterkörnchen, die gelben und weissen, erstere in den peripheren Theilen der Zolle (des, Dotter's"), letztere melır in
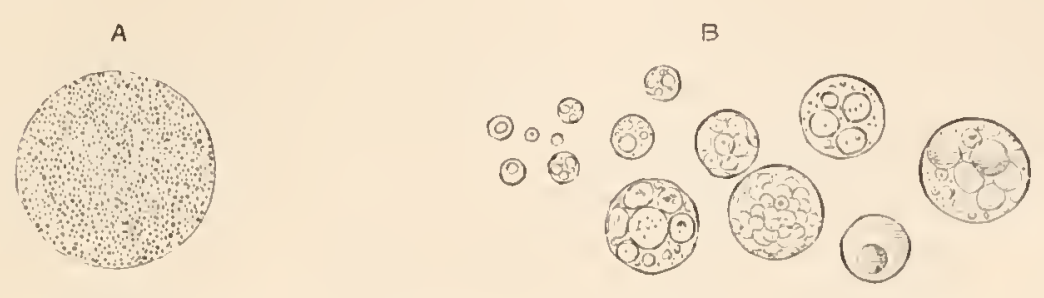

Fig. 47. Dotterelemente aus dem Ei des Huhnes. A gelber Dotter. B weisser Dotter (nach BALFOUR).

Centrım angehäuft. Von eigenthümlicher Form sind die Dotterkörnchen im Ei von Hydra (sog. Pseudozellen). Die Menge der Dottersubstanzen ist sehr verschieden; dotterarme Eizellen sind stets von geringer, oft nahezu mikroskopischer Grösse (z. B. bei vielen niederen Thieren Cnidarier, Scoleciden etc. und auch bei den Säugethieren); durclı mächtige Anhäufung von Dotterkörnchen erreicht die Eizelle bedentende, oft colossale Grösse (bei zahlreichen Wirbellosen, z. B. bei Krebsen, Insecten, Cephalopoden, ferner bei Wirbeltlieren, nämlich Fischen, Amphibien, Reptilien und Vïgeln).

Bei den meisten rotterreichen Eiern, wie z. B. beim Vogelei, ist das Plasma mit dem darin eingeschlossenen Kerne nach dem animalen Pole zusammengedrängt (telolecithaler' 'Typus) und in extremen Falle enthält der iulrige grösste Theil des Eies beinahe nur Dotterkörnchen, zwischen die sich wahrscheinlich ein feines Plasmanetz erstreckt. Speciell bei den A r th ropoden findet sich aber selbst bei berleutender Menge von Dottersubstanz der Kierı mit Plasmaanlıänfung nahezu im Centrum des Fies (man könnte diesen Typus des Eies, der auch ganz unpassender Treise, centrolecithal' genannt wird, besser als, perilecith alen T ypus" bezeichuen).

Das Ei bleibt in allen diesen Fällen eine einfache $/ \mathrm{selle}$; renn wenl sogar andere Zellen in dasselle aufgenommen werden, wie z. P. bei $H y d r a$, so gehen dieselben als Zellen zu Grunde und ihre Substanzen werden zu integrirenden Be-

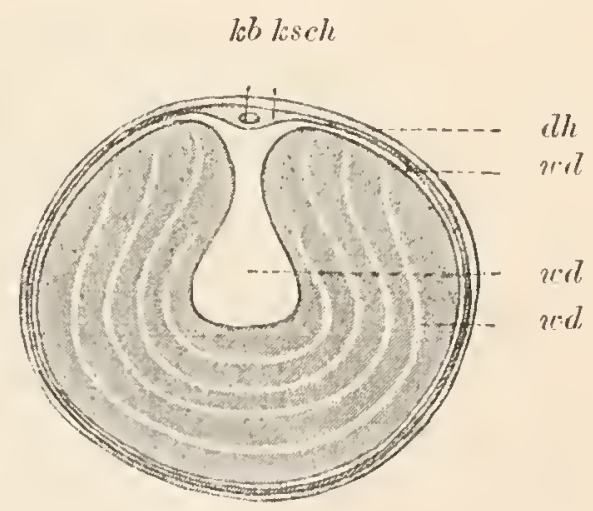

Fig. 48. Eizelle (Eidotter) des Huhns aus dem Eierstock (naclı HeRTwiG).

ksch Keimscheibe (Plasma); lit Keimbläschen; $u d$ weisser Dotter, im Centrum und in concentrischen Lagen angeordnet; $d$.h Dotterhaut. staudtheilen der Eizelle ungewandelt.

Eine $\mathrm{Z}$ ell mem bran, rlas ist cine Membran, welche von der Eizelle selbst ausgeschierlen wird, kommt beinahe allen Eieru zu; wir bezeichnen dieselbe als Dot te r me mb l'a $n$. Wir kennen nur wenige Fälle von ganz nackten Eiern (bei manchen Hydromedusen und Spongien), ferner fehlt die Dottermembran manchmal in solchen Fällen, wo ein Chorion vorhanden ist; bei sogenannter folliculärer Eibildung konmmt nämlich meist noch eine zweite, vom angrenzenden Follikelepithel 
ausgeschiedene Membran, das sogenannte Ch o ri o n zur Ausbildung. Die Dottermembran ist oft nur ein sehr zartes Häutchen, oft ist sie aber auch voll ansehnlicher Dicke; sie ist entweder von weicher, ja sogar schleimiger oder auch von derberer Consistenz, oft ist sie von radiären Poren durchsetzt. Das Chorion kann in vielen Fällen eine ganz ähnliche Structur zeigen und es ist daher manchmal zweifelhaft, ob eine Membran als Dottermembran oder als Clorion aufzufassen ist. In anderen Fällen erscheint das Chorion von derberer Consistenz, oft sogar mit besonderen Skulpturen und Anhängen ansgestattet (Insecten). Diese beiden Arten von Hüllen, die in den Ovarien selbst entstehen, von welchen aber nur die erstere als Zellmembran aufzufassen ist, werden als primäre Hüllen bezeichnet.

Es sind nicht nur beiderlei primäre Hüllen von zalılreichen radiären Poren durchsetzt, sondern es kimn anch an denselben eine besondere Oeffinumg vorkommen, die man als Mikropyle bezcichnet. Diese Oeffnung kann aber verschiedenartige Bedeutung haben; sie kaun einerseits mit der Nahrmmgszufuhr des kies während seiner Reifung im Zusammenhang stelen, oft dient dieselbe iber als Weg, durch welchen das Spermatozoon in das Ei cintritt. Vielleicht dient die Mikropyle in einigen Fïllen auch beiden Zwecken (?).

2.) Secundäre Hüllen nnd Nährnaterialien. Bei vielen Eiern kommen secundäre Hüllen und auch secundäre Nahr-

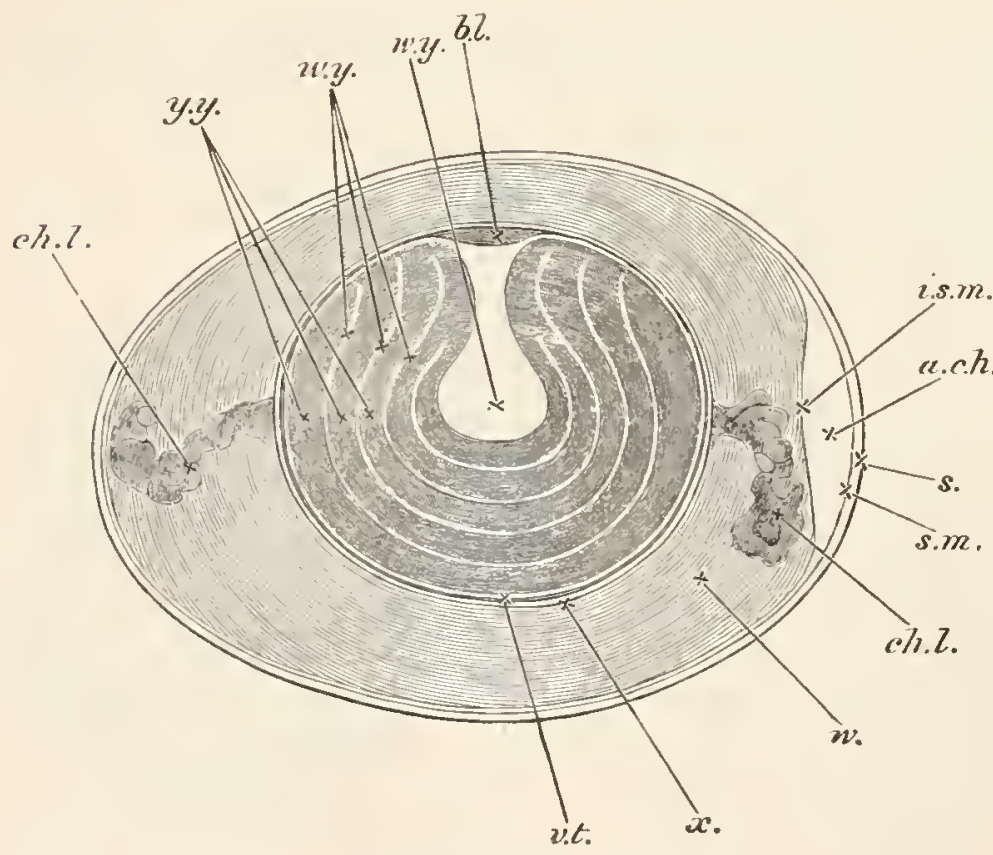

Fig. 49 .

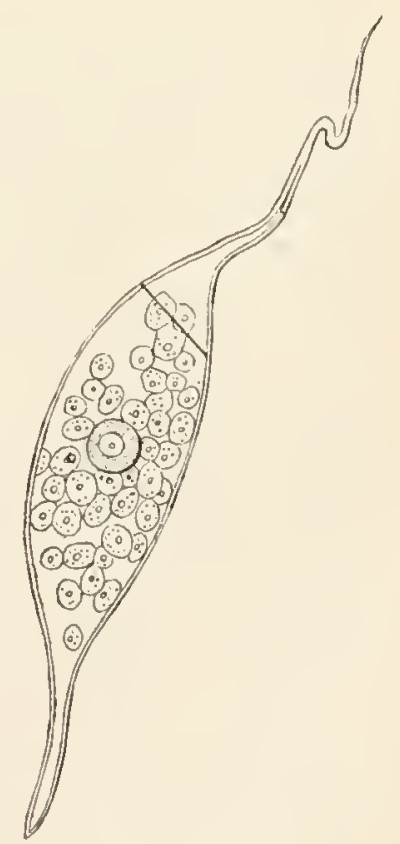

Fig. 50.

Fig. 49. Schematischer Längsschnitt eines unbebrüteten Hühnereies. (Nach ALLEN Thomson, etwas verändert, aus Hertwig).

bl. Keimscheibe; $v . y$. weisser Dotter, derselbe besteht aus einer centralen flaschenförmigen Masse und einer Anzahl concentrisch den gelben Dotter $y \cdot y$. umgebender Schichten; v.t. Dotterhaut; $x$. etwas fliussige Eiweissschicht, welche den Dotter unmittelbar umgiebt; $w$. Eiweiss aus abwechselnd dichteren und flüsigeren Lagen zusammengesetzt; ch.l. Chalazen (Hagelschnüre); a.ch. Luftkammer am stumpfen Ende des Eies. Sie ist einfach ein Zwischenraum zwischen den beiden Schichten der Schalenhaut; i.s.m. innere, s.m. äussere Schicht der Schalenhaut; s. Schale.

Fig. 50. Ei von Microcotyle mit secundärer Hülle, die sich deckelartig öffnen kann und mit secundären Dotteizellen (nach LUDw. Lorenz). 
un gs st offe zul Eizelle hinzu, die den Leitungswegen und ancessorischen Drüsen des Geschlechtsapparates oder anch anderen 'Theilen des Mutterthieres ilne Entstehung verdanken. Wir können als Beispiel das Vogel-Ei betrachten, dessen Dotter zunächst von spiralig geschichteten Eiweissmassen nit zusammengedrehten, festeren Eiweissschnüren (Hagelschnüre oder Chalazen), ferner von äusseren lı̈̈utigen und kalkigen Schalenschichten ungeben ist. Lin anderes sehr interessantes Beispiel bieten die meisten Plattwïrmer; bei diesen wird ein secundäles Nahrungsmaterial in Fornl einer Anzalıl von Dotterzellen, die sich von den sogenannten Dotterstöcken ablösen, zusammen nit der Eizelle von einer secundären Hiille eingeschlossen, welche an einer bestimmten Stelle der Leitmmgswege (dem sogenannten Ootyp) gebildet wird; der aus der Eizelle sich entwickelnde Embryo verbraucht diese Dotterzellen als seine erste Nahrung. - Bei vielen Thieren (z. B. Otigochacten, Hirudineen) werden mehrere Eier gemeinschaftlich von einer secundären Hülle eingeschlossen.

\section{B. Eibildung.}

1.) Eibildung im Allgemeinen. Das jugendliche Ei hat den Ban einer einfachen undifferenzirten Zelle, die dem Keimlager der Ovarien angehört. Die Reifung des Eies beruht vormehmlich auf der allmählichen Isolirung der jugendlichen Eizelle vonı Keimlager, dem Heranwachsen derselben zu bedentenderer Grösse und der Bildung der primären Eihüllen.

Das K eim lager der Ovarien erscheint in vielen Fällen als eine Plasmamasse mit zahlreichen darin eingeschlossenen Zellkernen; erst almählich grenzt sich um je einen leranwachsenden Zellkern, die Plasmamasse je einer Zelle ab. Dies ist wohl so aufzufassen, dass die Zellgrenzen zwischen den dichtgedrängten membranlosen Zellen anfangs nicht waln'nehmbar waren. Man hat diesem Verhalten früher eine gewisse Bedentung zugeschrieben. Doch bestelit wohl kein prinzipieller Unterschied zwischen diesen, vielkelnigen Plasmamassen" und solchen Keimlagern, wo man von Anfang an die Zellgrenzen zwischen den einzelnen Zellkernen deutlich sehen kamn.

Die Is o lirung der Eizelle wird dadurch eingeleitet, dass dieselbe eine sphärische Form anzunehmen beginnt. Die vollkommene Loslösung vom Keimlager erfolgt meist erst, nachdem das Wachsthum der Eizelle vollendet ist, in anderen Fällen aber auch früher, so dass die frei in der Ovarialhöhle oder im Coelom liegende Eizelle noch bedeutend wä chst.

Das Tralısthum spielt in allen Fällen eine bedentende Rolle. An den jumgen Eizellen ist in der Regel der Zellkern relativ sehr gross und das Plasma spärlich. Bein späteren Wachsthum nimmt daher das Plasma mehr zu als der Kern. In die Periode des Wachsthmms fällt auch die Bildung der Dottersubstanzen. Dieselben entstehen in den meisten Fällen als Ausscheidungsprodukte der Zelle selbst. In einigen Fällen aber scheint es, dass bereits geformte Dotterkörnchen von den benachbarten Follikelzellen an die Eizelle abgegeben werden.

II iillenbildung. In der Regel entstehen erst zu Ende der Wachsthminsperiode die Hüllen, und zwar wird, wie schon erwähnt, die Dottermembran von der Eizelle selbst gebildet, wälnend das Chorion, 
welches nur bei follicularer Eibildung vorkommt, wohl im Ovarium selbst ontsteht, aber von den die Eizelle nmhiillenden Follikelzellen ausgeschieden wird.

2.) Modificationen der Eibildung (Solitäre und follicula le Eibil d ung). Die überaus mannigfachen Modificationen, welche bei der Bildung des Eies vom Keimlager aus vorkonmen, kamn man in zwei Hamptabtheilungen bringen: 1. die solitäre Eibildung und 2. die folliculare Eibildung.

\section{Solitäre Eibildung.}

Bei der solitären Eibildung löst sich je eine einzelne \%elle vom Keimepithel oder Keimlager und wandelt sich zur Eizelle um. In vielen Fällen ist die junge Eizelle vor ihrer vollständigen Ablösung noch mit ihrer Basis wie mit einem Stiele am Keimlager befestigt, und meist wird von dieser Stelle aus die Ernährung derselben vermittelt (Echiniden, Lamellibranchiaten etc.). Bei den Nematoden bildet das Kieinepithel eine strangförmige, von den blinden Ende des Ovarialschlauches

B.
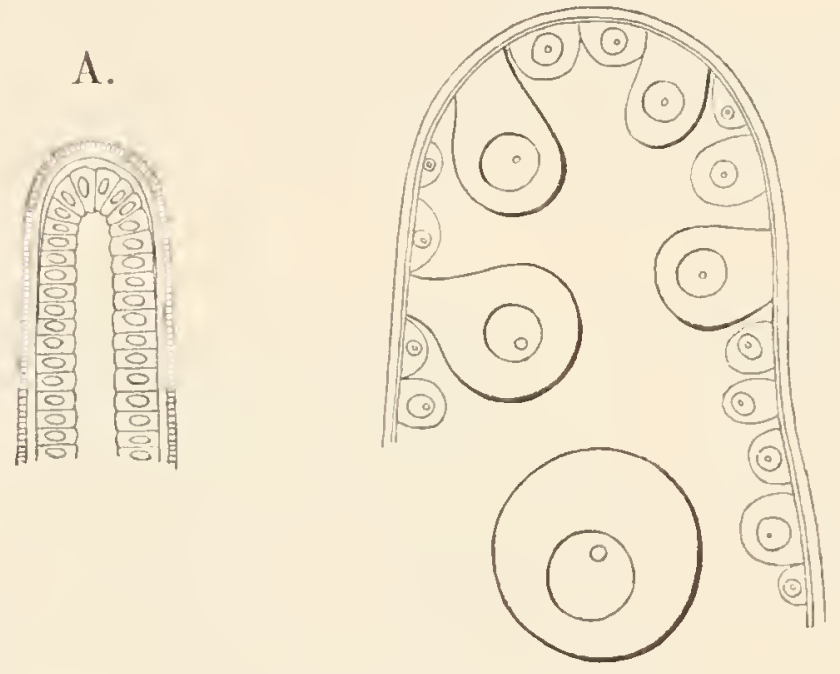

Fig. 51

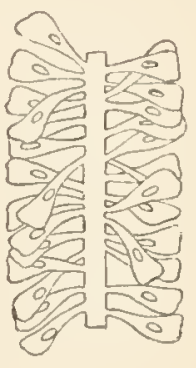

Fig. 52.

Fig. 51. Eibildung eines Seeigels (nach H. LodwiG).

A. Stïck eines jungen Ovarialschlauches, mit inmerem Keimepithel und zwei äusseren Hiillschichten (Durchschnitt).

B. Stïck eines älteren Ovarialschlauches mit Eizellen in verschiedenen Bildungsstadien (Durchschnitt).

Fig. 52. Eizellen, an einer gemeinsamen Rhachis befestigt, aus dem Ovarium des Spulwurmes (nach LeUCKART).

ausgehende Zellennasse (die sogenamnte Phachis); an dem freien Ende der Phachis sondern sich die reifen Eier; vor ihrer Ablösung sind die gestielten Eier rings um die Achse des Stranges mit ihren Stielen befestigt.

Die solitäre Eibildung ist an meisten bei den niedrigen Typen verbreitet; sie findet sich nit wenigen Ausnahmen bei (den Spongien) den Cnidariern, Ctenophoren, bei den Echinodermen (nit Ausnahme (der Holothurien?), bei den Scoleciden, ferner bei vielen Amneliden, den Tentaculaten, bei den meisten Mollusken (mit Ausnahne der Cephalopoden) und bei einigen niedrigeren Tracheaten (?). 
Folliculare Eibildung.

Die folliculare Eibildung ist ein complicirterer Process, der voln dem erstgenannten Modus abgeleitet zu denken ist. Ls wandeln sich in diesem Falle nicht alle Zellen des Keimepithels in Eizellen un, sondern es ist in Keimepithel selbst eine Theilung rler Arbeit eingetreten. Es bilden sich nämlich Gruppen von ursprünglich gleichartigen Keimzellen; in jeder Zellgruppe hat aber nur je eine '/elle die Bestinnmumg Eizelle zu werden, während die iibrigen die Enıährung dieser heranwachsenden Eizelle vermittehı und oft auch eine Hülle für dieselbe (das sogenannte Cliorion) secerniren.

In Bezug auf die Gruppirung der Zellen und ihre Funktion giebt es mannigfache Arten der Follikelbildung. In manchen Fällen sind die Follikelzellen der Fizelle nur angelagert. In sehr vielen Fällen sind die Follikelzellen epithelartig rings un die central gelegene junge Lizelle angeordnet; oft ist die Theilung der Arbeit eine mehrfache, so dass wir nebst dem Follikelepithel noch specielle Nährzellen finden.

Wir wollen die Mannigfaltigkeit der Follikelbildungen an einigen Beispielen betrachten.

Cnidarier. Als eine Art der follicularen Bildung ist die Eibildung bei Hydra aufzufassen; das Ovarium wird von einer Anhäufung gleichartiger Zellen gebildet, aber nur eine einzige dieser Zellen wird zur Eizelle, die übrigen dienen ihr zur Nahrung; sie werden von derselben geradezu auf amöboide Weise gefressen (Kleistanbergi). Aelmliche Verhältnisse finden sich, wie BALFour gezeigt hat, bei Tubularia.

Bei Anneliden kommen mancherlei Follikelbildungen vor. Bei Bonellia sitzt eine eigenthümlich angeordnete Gruppe von Nährzellen an dem einen Pole der jungen Eizelle. - Als Beispiel einer "freien Follikelbildung" ist Piscicola (zu den Hirudineen gehörig) anzuführen; hier liefert nämlich je eine vom Keimepithel bereits losgelöste Zelle durch Theilung einen Zellenhaufen; dieser sondert sich in Hüllzellen, Nährzellen und eine Eizelle, die zuletzt allein als Product des Follikels übrig bleibt.

Fig. 53. Folliculare Eibildung von Bonellia (nach SPENGEL). ov Eizelle, über derselben eine eigenthümliche Gruppe von Follikelzellen; fe platte Hüllzellen des Ovariums.

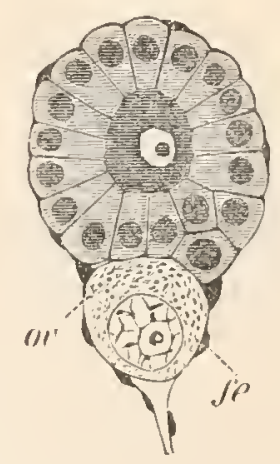

a. b.

C.

d.

e.

f.
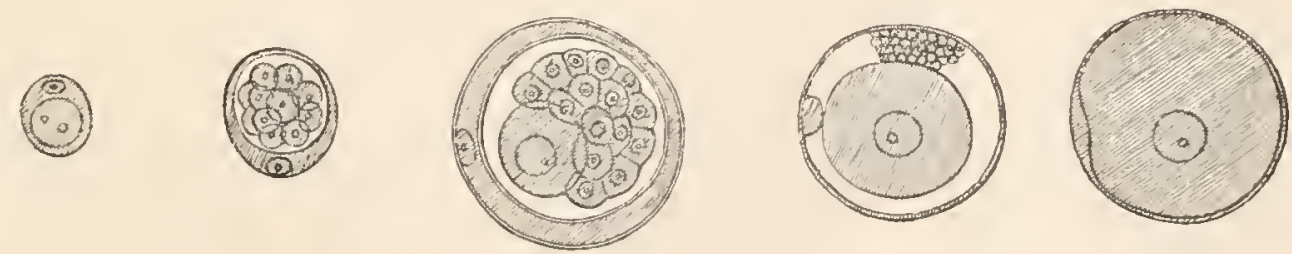

Fig. 54. Freie Follikelbildung bei Piscicola (nach H. IJowiG).

a. Freie Zelle aus der Orarialhöhle.

b. Hüllzelle und Inhaltszelle.

c. Letztere in einen Zellhanfen verwandelt.

d. Sonderung des Inlalts in kleinere Nälırzellen und eine grösserc Eizelle.

e. Die Nährzellen degeneriren.

f. Die Eizelle füllt allein die Hiille ans. 
Unter den Crustaceen wollen wir Apus betrachten; hier bilden sich aus dem regelmässigen einschichtigen Keimepithel Follikel von je vier Zellen; die drei anfangs grösseren Nährzellen werden allmählich

a.

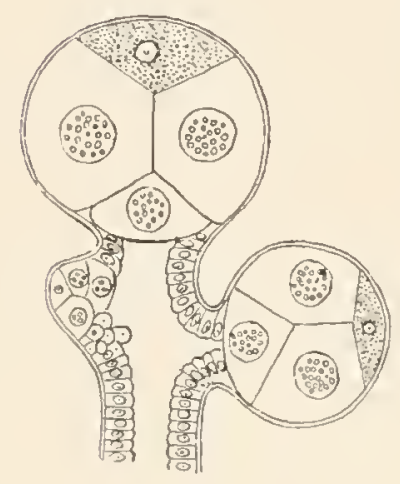

b.

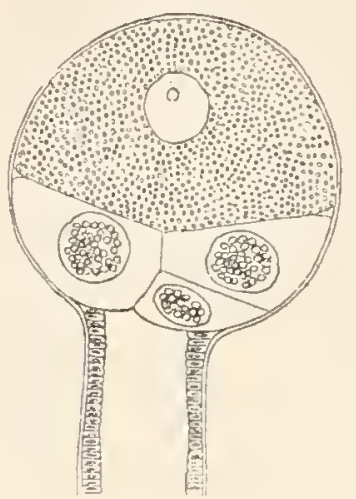

c.

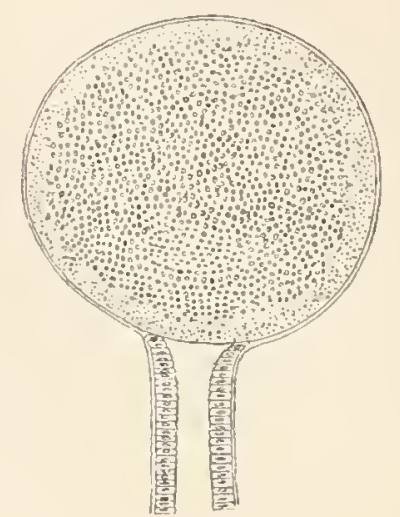

Fig. 55. Eibildung von Apus cancriformis (nach H. LudvIG).

a. Stiick eines Ovarialschlauches mit einem sehr jungen und zwei etwas älteren Follikeln, die Eizelle ist stets die kleinste von den vier Zellen.

b. Die Eizelle ist schon grösser als die Nährzellen.

c. Die Nährzellen sind ganz aufgebraucht.

resorbirt. Bei den Daphnien finden sich „freie Follikel" von je rier in einer Reihe liegenden Zellen, von welchen stets die dritte zur Eizelle wird. Bei Sacculina ist mit der Eizelle nur eine Nährzelle (Follikelzelle) verbunden.

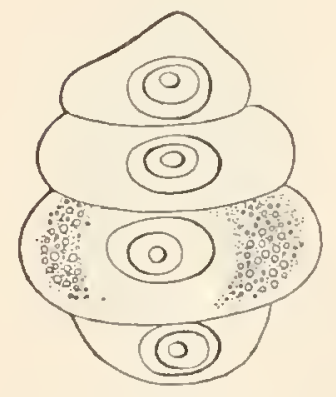

Fig. 56.

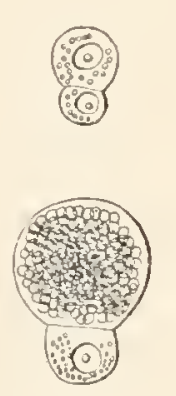

Fig. 57.

Fig. 56. Eibildung einer Daphnienform ; die dritte Zelle des freien Follikels wird zur

A. Eizelle (nach WeismanN).

Fig. 57. Eibildung von Sacculina (nach H. LUDWIG).

B.

A. Freier Follikel aus zwei Zellen bestehend.

B. Eizelle, bereits viel grösser als die Follikelzelle.

Bei allen Insecten liömmt eine eigentliümliche Form der Follikelbildung vor. Das Ovarium zerfällt in eine Anzahl Gebilde, die mit einem nicht ganz passenden Namen als "Eiröhren" bezeichnet werden; dieselben hängen mit dem gemeinschaftlichen Ausführungsgang (Eileiter) zusammen. Die einzelne Eiröhre besteht aus einer Reihe hintereinanderliegender Follikel („Eifächer"). An dem blinden Ende der Eiröhre in der "Endkammer" findet sich das Keimepithel, welches immer neue Follikel bildet; an dieser Stelle wächst also die Eiröhre in die Länge. Jeder Follikel enthïlt eine Eizelle, die von Follikelepithel umgeben ist, welches die Ernährung der Eizelle vermittelt und eine derbe Membran, das Cliorion, für dieselbe absondert. Das reife Ei wird in den Eileiter ausgestossen, 
das Follikelepithel geht sodann zugrunde und das nächste Eifach rückt, durch Schrumpfung der äusseren Bindegewebshülle der Eiröhre, bis an den Eileiter heran. - Dies ist die einfachere Form der Eiröhren, die bei den Orthopteren, Libellulinen und Puliciden vorkömmt. Bei den auderen Insecten wird der Bau der Eiröhre darlurch complicirt, dass
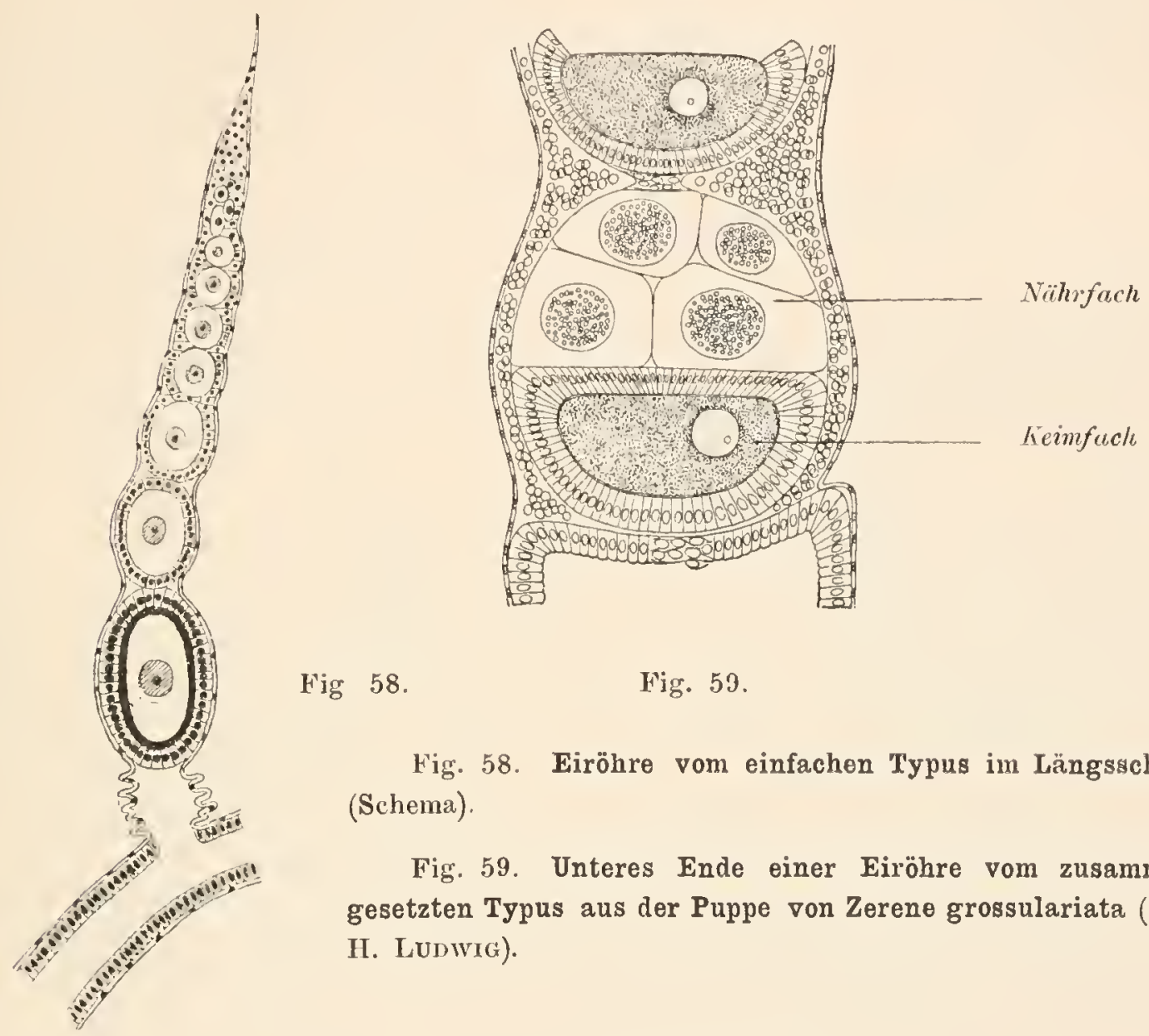

Fig 58.

Fig. 59.

Fig. 58. Eiröhre vom einfachon Typus in Längsschnitt (Schema).

Fig. 59. Unteres Ende einer Eiröhre vom zusammengesetzten Typus aus der Puppe von Zerene grossulariata (naclı H. LUDWIG).

auf jedes Eifach noch eine Gruppe „specieller Nährzellen" folgt (sog. Dotterfach), welche während des Wachsthums der Eizelle resorbirt werden; oft ist die Eizelle durch einen plasmatischen Strang mit diesen Nährzellen verbunden.

Wirbelthiere. Das Keimepithel des Wirbelthierovariums wird von einem besonderen Theil des allgemeinen Coelomepithels gebildet. Diese Ovarien sind daher, ihrem 'Typus nach, Flächenovarien. Sie bestehen aus einer bindegewebigen Stiutzsubstanz (dem ,Stroma“), in welchem auch die Gefässe und Muskelfasern liegen, und dem an der Oberfläche des Ovariums gelegenen Keimepithel. Von diesem Keimepithel aus wuchern die Follikel in das Stroma ein; in der Regel werden alle Follikel schon während des embryonalen Zustandes angelegt und es ist damit die Funktion des Keimepithels beendigt. Sehr übersichtlich ist der Process der Follikelbildung bei Raja batis, wo je eine einzelne Eizelle mit umgebenden Zellen in die Tiefe rückt. - In den meisten Fällen wuchern grössere Zellenmassen in die 'Tiefe (PFıüGER'sche Scliläuche, Zellennester [BALFOUR]), welche in eine Anzahl von Follikeln zerfallen. - Die Follikelzellen ordnen sich epithelartig um die centrale 
Eizelle. - Am heranreifenden Ei bildet sich eine von senkrechten Poren durchsetzte Membran, die Zona radiata, die wahrscheinlich (in den meisten Fällen) als Chorion zu deuten ist. - Bei den Säugethieren tritt

A.

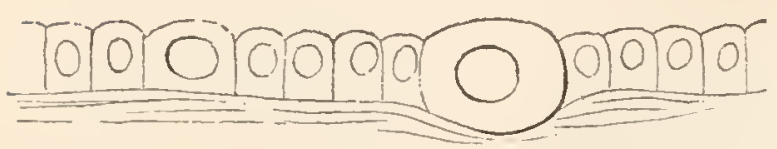

C.

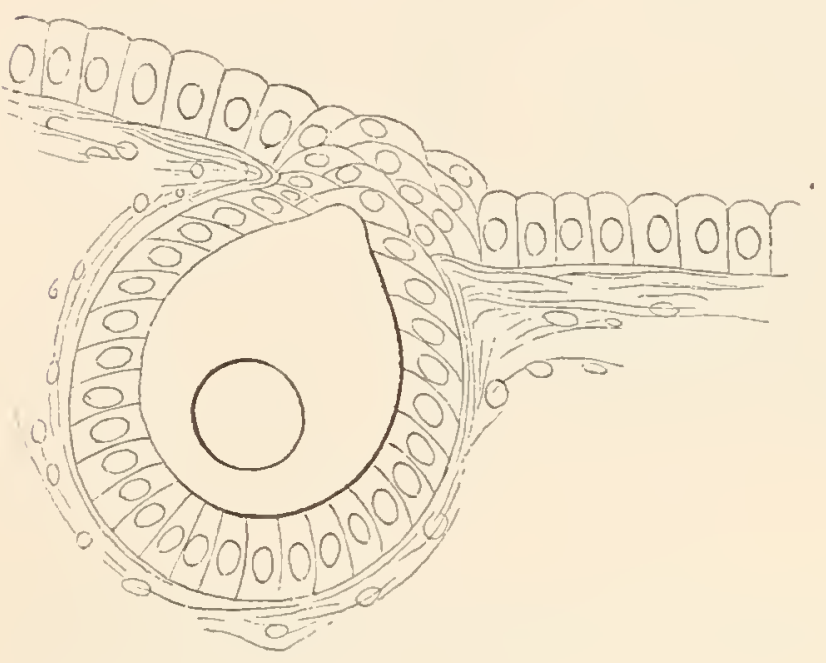

B.

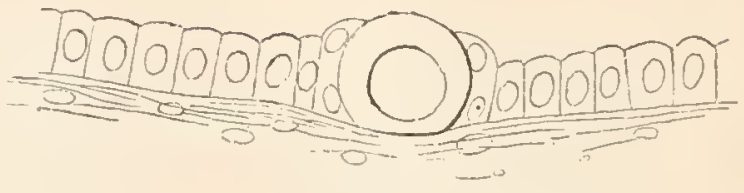

D.

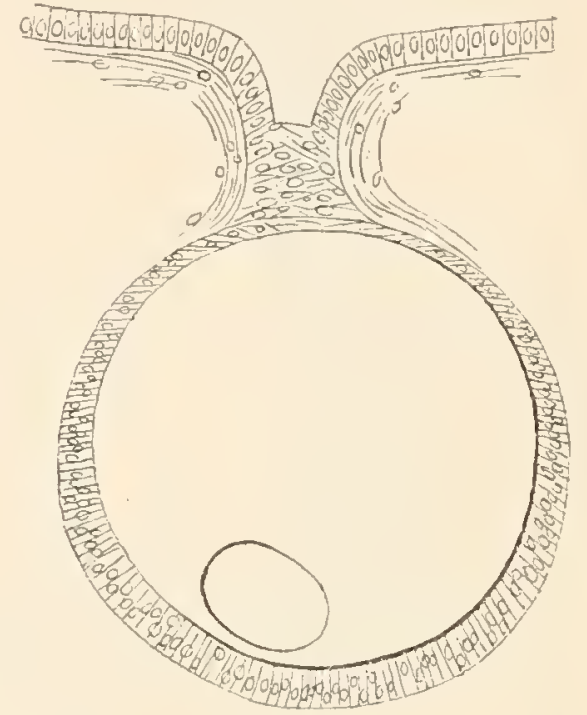

Fig. 60. Follikelbildung bei Selachiern (nach H. LodwiG).

A. Keimepithel mit einzelnen grösseren Zellen (von Acanthias) im Durchschnitt.

B. C. D. Die verschiedenen Stadien der Follikelbildung von Raja an Durchschnitten dargestell.

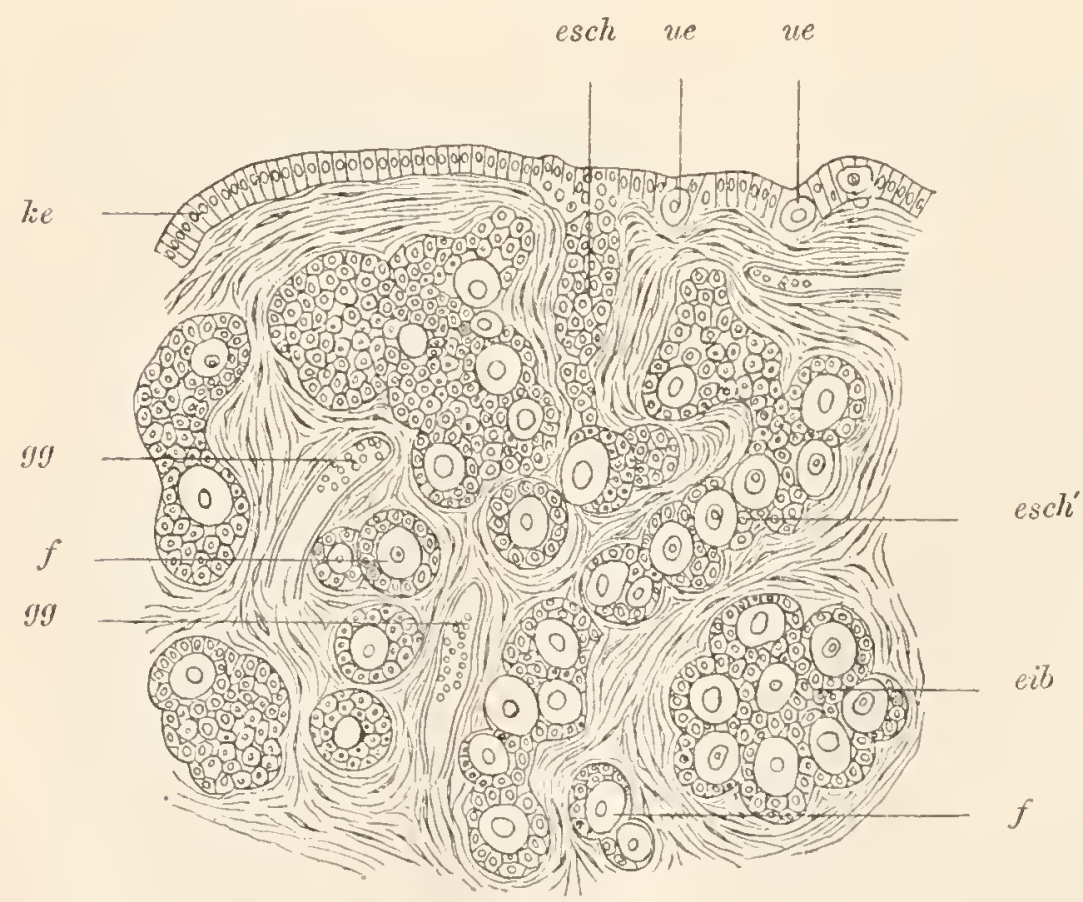

Fig. 61. Theil eines sagittalen Durchschnittes vom Eierstock eines neugeborenen Kindes. Stark vergr. (nach WALDEYER)

ke Keimepithel; esch PrLüGer'sche Schläuche; ue im Keimepithel gelegene Ureier ; esch' langer in Follikelbildung begriffener PFLÜGER'scher Schlaucli ; eib Eiballen, ebenfalls in der Zerlegung in Follikel begriffen ; $f$ juingste, bereits isolirte Follikel; gy Gefässe.

In den Schläuchen und Eiballen sind die Primordialeier und die kleineren Epithelzellen, das spätere Follikelepithel, zu unterscheiden. 
in reifen Follikel durch Flüssigkeitsabsonderung eine Höhle auf. Das Ei bleibt anfangs an einer Stelle der Follikelwandung (Discus proligerus) befestigt; bei der Loslösung fällt es damn in die Follikelhöhle, und wird von dort in die Coelomhöhle wie bei den Wirbelthieren im allgemeinen entleert (bei Knochenfischen hat das Ovarium eine imnere Höhle, die durch einen Eileiter direkt naclı Aussen führt).

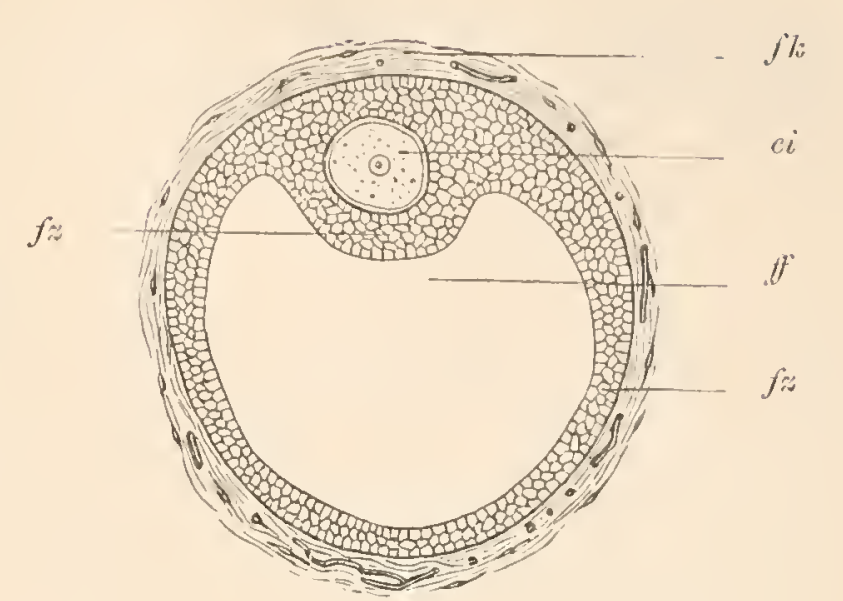

Fig. 62. Follikel vom Säugethier (Graaf'sches Bläschen) mit grösserer Ansammlung von Flüssigkeit $\mathrm{zwischen} \mathrm{den} \mathrm{Follikelzellen} \mathrm{(aus} \mathrm{HERTwIG).}$

ei Ei; $f z$ Follikelzellen; $f z^{\prime}$ Follikelzellen, welche das Ei einhüllen und den Discus proligerus bilden; ff Follikelflüssigkeit (Liquor folliculi); $f k$ Follikelkapsel (Theca folliculi).

Bau und Entwicklung der Spermatozoen.

Die Hoden sind ihrer Anlage nach den Ovarien gleichwerthig. Bei vielen Thieren ist es nicht möglich, an den jugend lichen Gonaden Ovarien von IIoden zu unterscheiden. Auch hat man bei manchen Thieren die interessante Beobachtung gemacht, dass zuweilen in dem Hoden sich einzelne Eier bilden, deren Entwicklungsfähigkeit allerdings nicht constatirt ist. - So mannigfaltig der Bau der Hoden in den verschiedenen Fällen sich gestaltet, so ist es meist doch nur ein gleichartiges Keimepithel, von welchem die Entwicklung der männlichen Fortpflanzungszellen, der Spermatozoen, ausgeht.

Bau der Spermatozoen. Die gewöhnliche Form, welche die Spermatozoen besitzen, ist die einer kleinen Geisselzelle, sie gehören meist zu den kleinsten Zellen des Körpers; in ihrer Grösse stehen dieselben stets weit hinter der Eizelle zurück. Der Zellkörper oder sogenannte ,Spermatozoen k opf " besteht aus der Kernsubstanz und einer sehr spärlichen Plasmaschichte; daram schliesst sich oft unter Vermittlung eines sogenannten Halses oder Zwischenstückes die bewegliche Geissel oder der sogenannte "Spermatozoen schwanz". Bei den verschiedenen Thieren finden sich vielfache Variationen in Bezug auf die Grösse und die speciellen Eigenthümlichkeiten der Spermatozoen. Bei einigen Thierformen, die in ihrem ganzen Organismus keine Flimmeroder Geisselzellen besitzen, haben merkwürdiger Weise auch die Spermatozoen nicht die normale Form der Geisselzelle; so sind sie bei den Nematoden kegelförmig und amöboid beweglich; bei den Crustaceen finden sich sternförnige Spermatozoen (bei den Insecten aber zeigen sie den normalen Typus).

Entwicklung der Spermatozoen. Die Keimepithelzelle des Hodens wandelt sich nicht unmittelbar in ein Spermatozoon um, sondern in eine sogenannte Samenmutterzelle (Spermatoblast, Spermatogonie). Aus dieser entstehen durch Theilung in der Regel sehr zahlreiche (oft maulbeerförmig angeordnete) Spermatocyten, die sich in je eim Spermatozoon umwandeln. Gewöhnlich häugen die Sper- 
matocyten anfangs alle gemeinschaftlich mit der Mutterzelle zusammen (Maulbeerform der Spermatogonie) und erst nach ihrer Verwandlung in Spermatozoen fallen sie auseinander.

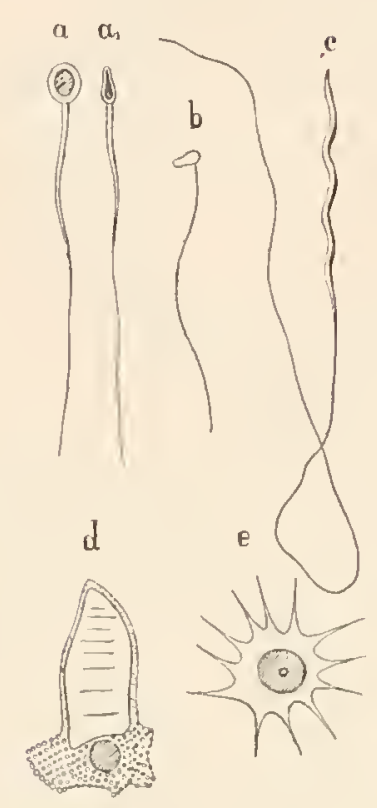

Fig. 63.

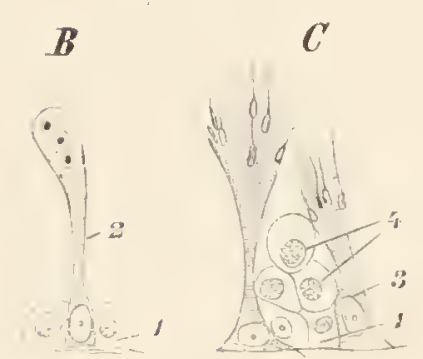

Fig. 65 .

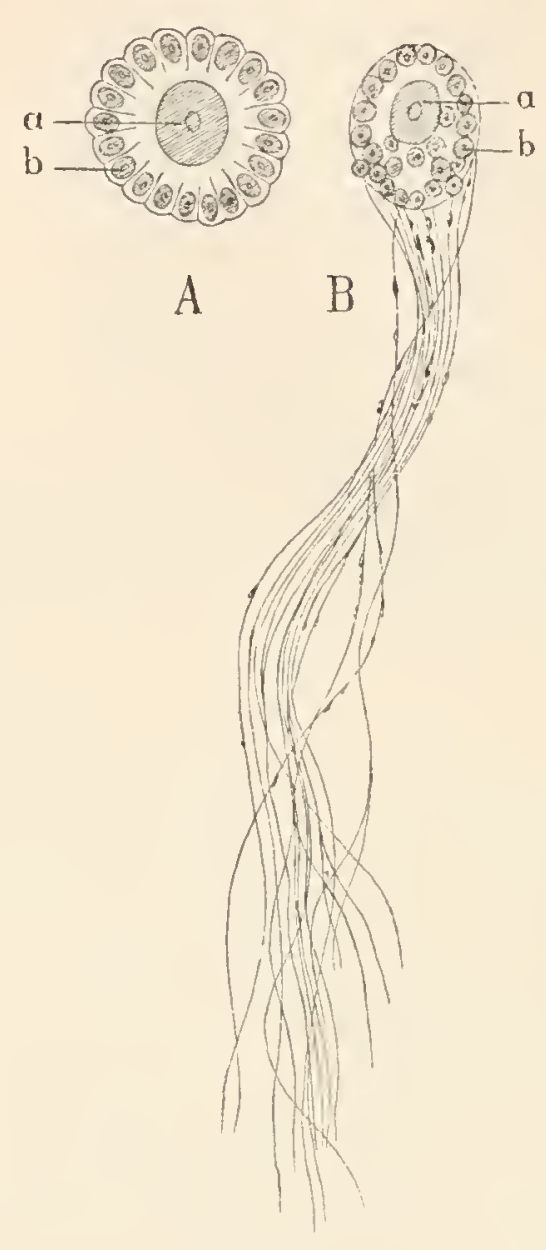

Fig. 64 .

Fig. 63. Spermatozoen. a. vom Menschen, Köpfchen von der Breitseite; a . Köpfchcn von der Schmalseite; b. ron einer Spongie; c. von cinem Rochen; d. vom Spulwurm; c. von einer Krabbe (nach verschiedenen Autoren).

Fig. 64. Spermatogenese eines Plattwurmes (Axine) (nach L. Lorenz).

A. Maulbeerform; B. Spermatozoen beginnen sich loszulösen. a. Zellkern der Spermatogonie; b. Zellkern der Spermatocyten.

Fig. 65. Spermatogenese des Stieres (nach SтöнR).

B. 1. Junge Spermatogonie; 2. ältere Spermatogonie mit Spermatocyten am freien Ende.

C. 1. und 4. junge Spermatogonien; 3. ältere Spermatogonie mit weit entwickelten Spermatocyten.

In einer grossen Zahl von Fällen wurde beobachtet, dass der Zellkern der Spermatogonie bei der Spermatocytenbildung nicht ganz aufgebraucht wird, sondern dass ein Theil unverbraucht übrig bleibt und dann zu Grunde geht.

Als Aequivalent des Eies wird nach der herrschenden Anschauung nicht das Spermatozoon oder die Spermatocyte betrachtet, sondern die

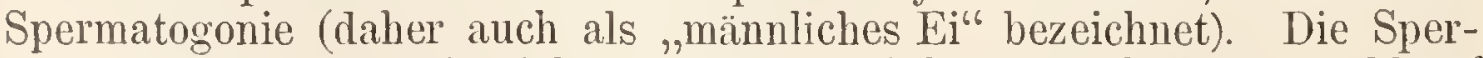
matozoen treten stets in viel bedeutenderer (oft tausendfacher) Anzahl auf als die Eier. Oft werden die Spermatozoen durch secundäre (meist in den Leitungswegen gebildete) Secrete zu eigenthümlichen Gebilden ver- 
einigt, die man als Spermatophoren bezeiclmet. In einfachsten Falle sind es nur verklebte Samenmassen (z. B. bein Flusslirebs), in anderen Fällen sind es complicirte Bildungen mit zweckdienlichen Einrichtungen (z. B. die patronenähnlichen Spermatophoren der Cephalopoden).

So auffallend auch die Verschiedenheit in Grösse und in Gestalt zwischen weiblicher Eizelle und männlicher Samenzelle erscheint, so ist sie doch nur von untergeordneter Bedeutung, denn wir wissen, dass in Bezug auf die wesentliche Leistung, nämlich die Verursachung: der Eigenschaften des neuen Individuums, die Eizelle und Samenzelle sich gleichartig verhalten; die väterlichen und mütterlichen Eigenschaften werden in gleichem Ausmasse vererbt. Die Verschiedenlieit von Eizelle und Samenzelle beruht in einer Arbeitstheilung in Bezug auf gervisse Nebenleistungen. Die Eizelle bringt den weitaus grösseren Antheil von Substanz für das nene Individuum mit, während das Spermatozoon sowohl durch seine grosse Anzahl als auch durch seine Beweglichkeit die Wahrscheinlichkeit des Zusammentreffens bewirkt. Es ist leicht einzusehen, dass durch die einseitige Vermehrung der Anzahl bei gleicher Wahrscheinlichkeit des Zusammentreffens ein vielfaches an Substanz erspart wird.

\section{Bildung der Richtungskörper und Befruchtung,}

Nachdem das reife Ei das Ovarium verlassen hat (nur in wenigen Fällen schon innerhalb des Ovariums) erfährt dasselbe gewisse Veränderungen, die eine nothwendige Vorbedingung der Befruchtung sind. Es wird nämlich ein Theil des Keimbläschens aus dem Ei ausgestossen (dieser Process wird oft auch als letztes Stadium der Eireifung bezeichnet). - Der Vorgang ist folgender: das Keimbläschen wandelt sich in eine Kernspindel um - von derselben Beschaffenheit, wie sie bei einer karyokinetischen Zelltheilung zu beobachten ist - und diese riickt an die Oberfläche des animalen Eipoles. Unter Strahlungserscheinungen des Plasmas wird ein Theil der Spindel, umgeben von einer geringen Plasmamenge, in Form eines hellen Kügelchens („Richtungskörper"6) ausgestossen. In den meisten Fiillen folgt noch die Ausstossung eines zweiten Richtungskörper's. Der Rest der Kernspindel nimmt wieder die Form eines ruhenden Kernes an und rückt in die Tiefe, wobei auch die Strahlenfigur im Plasma verschwindet. Dicsen Rest des Keimbläschens bezeichnen wir nach O. HerTwig als, Eiken" uder ,weiblicher Pronucleus". Die Richtungskörper gelıen später durch 'Lerfall zu Grunde.

Die Bildung der Richtungskörper wird mit Rücksicht auf die karyokinetischen Erscheinungen von manchen Forschern als Zelltheilumg aufgefasst; dieselben werden als Zellen betrachtet und „Polzellen" genannt. Die Richtigkeit dieser Auffassung ist nicht sichergestellt. Das Wesentliche des Processes ist die Ausstossung eines Theils des Keimbläschens.

Auch bei parthenogenetisch sich entwickelnden Eiern (vergl. Cap. IX) hat man die Ausstossung eines Richtungskörper's beobachtet (und wie WeISuAnN hervorhebt, stets nur eines einzigen, während nach demselben Autor sonst gesetzmässig zwei Richtungskörper auftreten sollen). 
I.
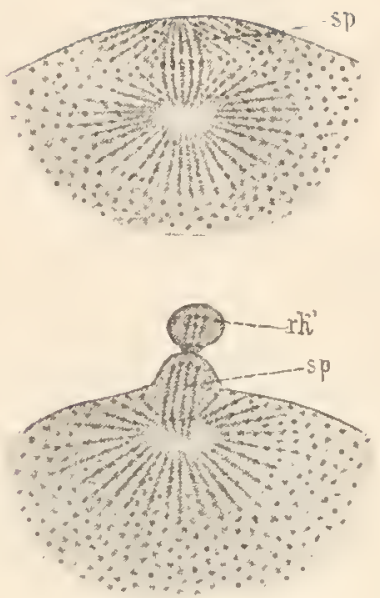

IV.
II.
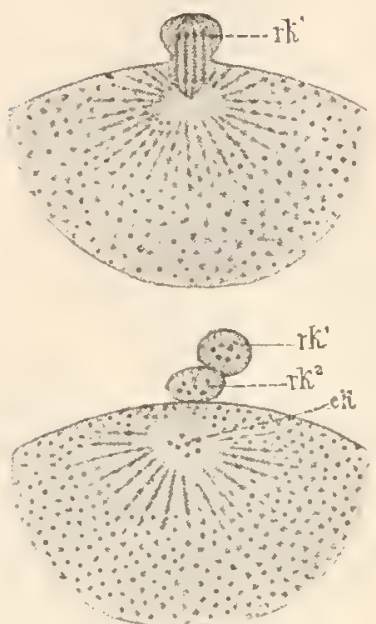

V.
III.
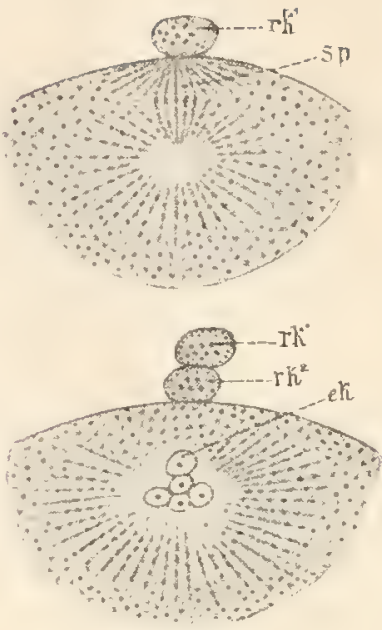

VI.

Fig. 66. Bildung der Richtungskörper bei Asterias glacialis (nach HERTwIG).

$s p$ Kernspindel; $k^{1} \vartheta^{2}$ erster und zweiter Richtungskörper; ek Eikern aus dem Rest der Spindel sich bildend.

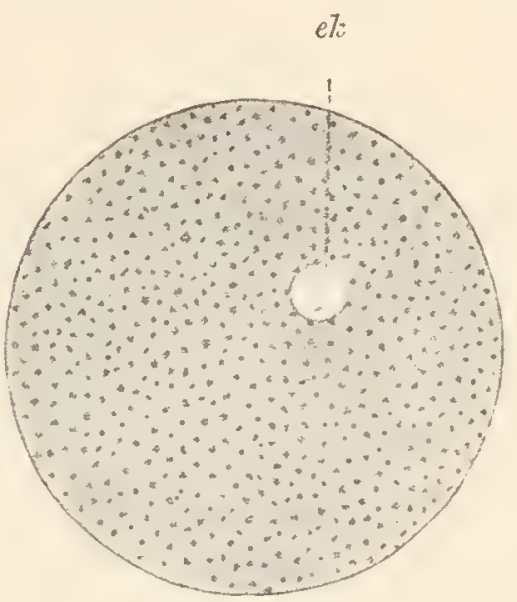

Fig. 6i.

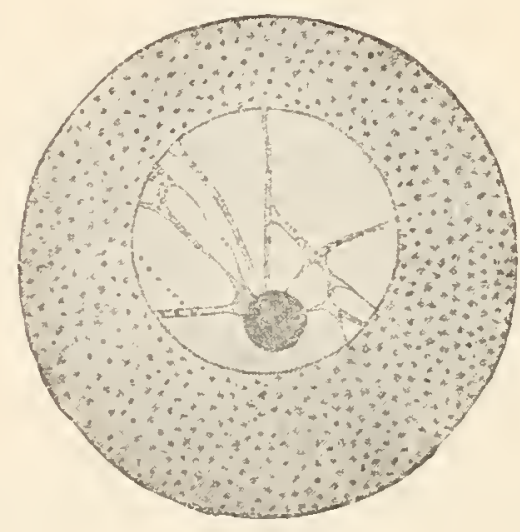

Fig. 68

Fig. 67. Reifes Ei mit Eikern (ek) eines Echinodermen (nach HERTwIG).

Fig. 68. Unreifes Ei mit Keimbläschen eines Echinodermen (nach HerTwiG).

Die Kenntnis de1 eigentlichen Befruchtungsvorgänge ist erst in den letzten Jahren besonders durch die Untersuchungen von Bütschu, o. Hertwig und Fol begründet worden. Am genauesten sind die Vorgänge an den Eiern von Seeigeln und Seesternen studirt, welche ein überaus günstiges Object bilden. weil sie klein und durchsichtig sind, so dass man mit starken Vergrösserungen die inneren Veränderungen beobachten kann, und weil man durch Mischung von Eiern und Sperma, die den reifen Geschlechtsorganen entnommen werden, jederzeit die sogenannte künstliche Befruchtung einleiten kann. - Zahlreiche Untersuchungen an anderen Objecten haben aber anch gezeigt, dass der Befruchtungsvorgang bei allen Metazoen typische Uebereinstimmung zeigt.

Bei Toxopneustes sieht man am lebenden Ei folgende Erscheinungen: die Spermatozoen sammeln sich an der Oberflaiche der galler- 
tigen Dottermenbran, und mittelst activer Bewegung beginnen sie dieselbe zu durchbohren; eines derselben wird, sobald es mit dem Köpfchen die Dottermembran passirt lat, von einem an der Eizelle sich bildenden Plasmalıöckel (,Empfängnisshügel ${ }^{6}$ ) aufgenommen. Im Plasma der Eizelle entstehen nun Strahlungen um zwei helle Centren (sog. Sonnenfiguren), nämlich um den Eikern und den eben aufgenommenen noch

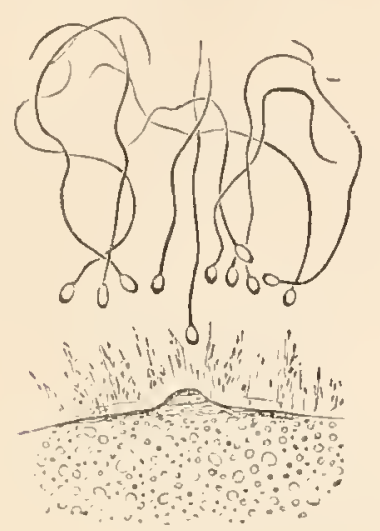

Fig. 69 .

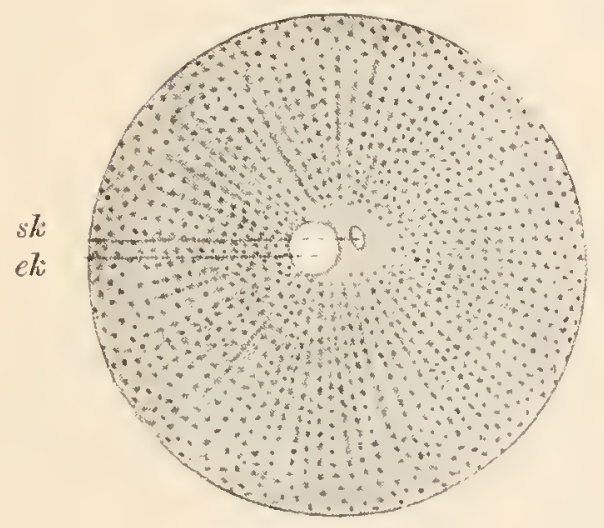

Fig. $70 \mathrm{~B}$.

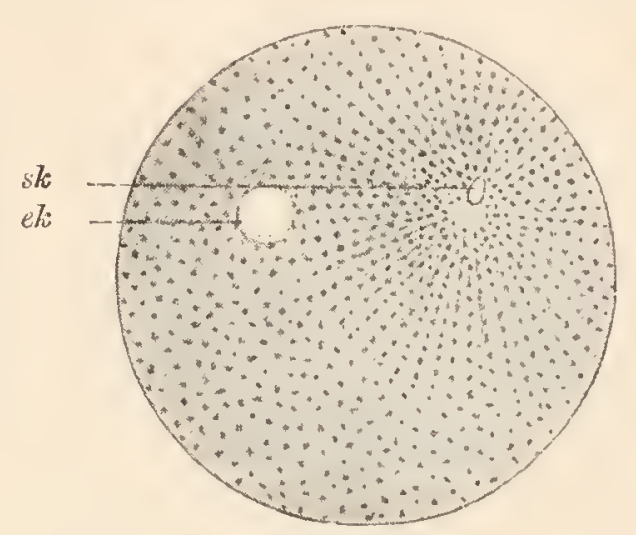

Fig. $70 \mathrm{~A}$.

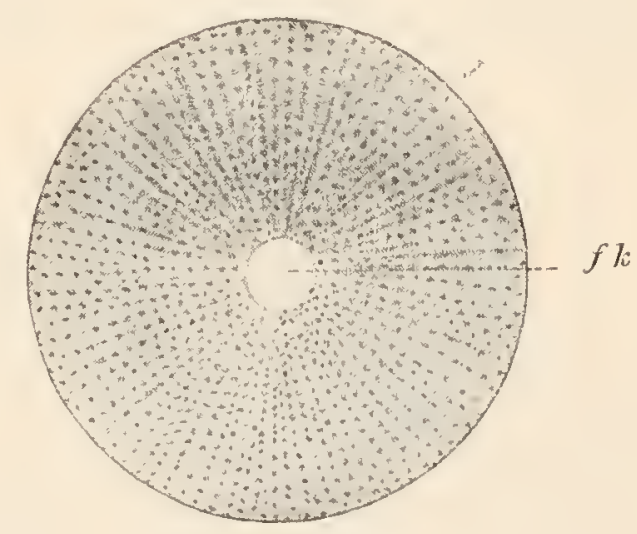

Fig. $70 \mathrm{C}$.

Fig. 69. Rand des Eies von Asterias glacialis, während der Befruchtung (nach FoL).

Fig. 70. Befruchtung des Seeigeleies (nach HertwiG).

A. Der Kopf des eingedrungenen Samenfadens hat sich in den von ciner Protoplasma. strahlung eingeschlossenen Samenkern ( $s k$ ) ungewandelt und ist dem Eikern (ek) entgegengerückt.

B. Der Samenkern sk und der Eikern ek sind nahe zusammengerückt und sind beidc von eincr Protoplasmastrahlung umgeben.

C. Ei- und Samenkern sind zum Furchungskern verschmolzen, der in Centrun einer Protoplasmastrahlung liegt.

peripher gelegenen Spermaker'n (oft auch nur um letzteren). Diese hellen Centren beginnen gegen cinander zu riicken, bis sie sich zum Centrum einer cinzigen Strahlenfigur vereinigen. Die Strahlenfigur verschwindet und das helle Centrum erscheint als der primäre Zellkern (sog. "Kern der ersten Furchungskugel"). Durch Fixirung und Kernfärbung ist genaner nachgewiesen worden, dass thatsächlich eine Vereinigung der chromatischen Substanz von Eikern und Spermakern stattfindet. Das blosse Eindringen des Spermatozoon in das Ei wirkt noch 
nicht als Befruchtung, dieselbe ist erst durch die Vereinigung der beiden Kerne vollzogen. (Die allgemeine Giltigkeit des letzteren Satzes wird in nenerer Zeit angefochten [VAN Beneden]).

Die wichtigsten Sätze der Hertwig'schen Befruchtungslehre sind:

1) Die Befruchtung beruht auf einer Vereinigung von Eikern (weiblicher Pronucleus) und Spermakern.

2) Es wird nur ein einziges Spermatozoon vom Ei aufgenommen.

Nach Untersuchungen an Ascaris megalocephala betrachtet VAN BENEDEN das Ei nach Ausstossung der Richtungskörperchen nicht als vollständige Zelle, sondern gleichsam als Theil einer Zelle. Da bei der Entstehung des Spermatozoons aus der Samenmutterzelle ebenfalls Theile der Zelle abgestossen werden, so wird auch das Spermatozoon ähnlich als Zelltheil aufgefasst. Bei der Befruchtung vereinigen sich diese Theile mit einander zu einem Zellganzen.

Es erfolgt ferner die eigentliche Vereinigung von Eikern und Spermakern erst nach Ablauf der ersten Theilung der Eizelle (wobei Eikern und Spermakern die Theilung mitmachen); auch ist der männliche und weibliche Antheil der Kerne noch weiter nachweisbar, ja es erstreckt sich dieser Nachwois auf alle Zellen des entwickelten Thieres, so dass eigentlich nur eine Aneinanderlagerung, nicht aber eine Vermischung der beiden Antheile statt hat.

\section{Entwicklung der Gastrula aus dem Ei.}

\section{Fu r ch u ng.}

Die Entwicklung der Metazoen beginnt mit einem fortgesetzten Zelltheilungsprocess, den wir als $\mathrm{Fur}$ chung bezeichnen. Es herrscht dabei eine gesetzmässige Richtung und zeitliche Folge der Theilungsebenen, wodurch eine gesetzmässige Anordnung der Zellen bedingt ist.

Für die bestimmte Gestaltung eines vielzelligen Körpers ist die Richtung auch schon der ersten Zelltheilungsebenen von Bedeutung. Wenn z. B. die Theilungsebenen alle parallel zu einander liegen, so entsteht eine fadenförmige Zellreihe (Fadenalgen, Diatomeenketten); wenn die Theilungsebenen in wechselnder Richtung aber alle senkrecht auf einer gemeinschaftlichen Ebene stehen, so bildet sich eine Zellplatte wie z. B. bei Gonium pectorale.

Die Furchung der Metazoen aber ist dadurch charakterisirt, dass meridionale (durch die Hauptachse gehende) und sogenannte, ,äquatoriale" (eigentlich Parallelkreisen entsprechende), Furchen" (Zelltheilungsebenen) in gewisser Reihenfolge auftreten, woraus eine Anordnung der Zellen in allseitiger einfacher Schichte rings um ein gemeinsames Centrum resultirt. Im Centrum bildet sich in der Regel durch Auseinanderweichen der Zellen ein Hohlraum, die Furchungshöhle oder BAER'sche Höhle (Blastocoel). Aus dem Verhalten der Theilungsebenen ist ersichtlich, dass die Primärachse, welche schon an der Eizelle nachweisbar war, bei der Furchıng ausgeprägt bleibt. Auch die Pole sind verschieden, demn am animalen Pole sind die Zellen stets kleiner und ärmer an Dotterkörnchen, als am vegetativen Pole. Der Grössenunterschied der Zellen beruht meist auf einer ungleichen Theilung 
beim Auftreten schon der ersten äquatorialen Furcle, wozu in späteren Stadien noch ein 'Lurückbleiben des Theilungsprocesses (geringere Zahl von 'Theilungen) an der vegetativen Seite kömmt. Fine, äquale“6 Furchung, bei welcher alle Theilstücke gleich gross sind, ist in keinem Falle mit Sicherheit beobachtet. Die Furchungszellen lraben in der Regel eine sphärische Form, doch sind sie an den gegenseitigen Beriihrungsstellen in einem gewissen Grade abgeplattet und zeigen dadurch schon von allem Anfang an einen Zusammenhang als beginnende Tendenz zur Gewebsbildung. Sie haben nicht die Neigung sich zu isoliren, wie dies bei dem ähnlichen Vermehrungsprocess aus der undifferenzirten Zelle bei den Protozoen der Fall ist.

Wir kemnen mannigfache Modificationen der Furchung, welche vornehmlich auf folgenden Punkten beruhen:

a) Menge und Lagerungsverhältnis des Nahrungsdotters und davon abhängiges Grössenverhältnis der Furchungszellen. (Das Grössenverhältnis der Furchungszellen kann aber auch von anderen Ursachen abhängen.)

b) Richtung, Zeitfolge und 'Lahl der 'Theilungen.

c) Verschiedene Ausdelmung orler Fehlen der Furchungshöhle.

E. Hacckes liat mit besonderer Berücksichtigung des ersten Punktes eine vortreffliche Eintheilung der Furchungsarten begründet, die bis auf geringe Aenderungen noch immel aufrecht zu lialten ist. Wir wollen dieselbe zunächst an einigen Beispielen kennen lernen.

I. Adäquale Furchung (= Reguläre Furchung = Primordiale Furchung [Ernst Hatckel]). Dies ist der einfachste und wahrscheinlich ursprünglichste Typus der Furchung bei den Metazoen, der nur in solchen Fällen vorkömmt, wo das Ei klein ist und eine relativ geringe Menge von Nahrungsdotter entlält, der Kern solcher Eier liegt nahezu central. Die Furchungszellen sind in Bezug auf Grösse und Beschaffenheit nur in geringern Grade von einander velschieden. Die Furchungshöhle ist in der Regel wohl ausgebildet. Beispiel: Furchung von Amplioxus. Wir sehen zunächst eine meridionale Theilungsebene vom animalen Pole ausgehen, daun eine zweite meridionale Furche senkrecht zur ersten auftreten. So entstehen 4 regelmässig um die Hauptachse angeordnete Zellen. Die el'ste äquatoriale Furche theilt die Zellen in ungleiche Theile, so dass damn die vier Zellen am animalen Pole etwas kleiner sind als die vier entgegengesetzten; letztere enthalten die reichlichere Menge von Dotterkörnchen. Dann folgen wieder meridionale Furchen, so dass 8 obere und 8 untere Zellen entstehen. Durch weitere äquatoriale Furchen kömmt es zum 32zelligen Stadium, das aus vier Kreisen zu je acht Zellen aufgebaut ist. Die Furchungshöhle, die schon in vierzelligen Stadium sichtbar war, hat sich vergrössert und dehnt sich später noch mehr aus. Bei den weiteren Furchungsstadien ist ein Zuruickbleiben des Theilungsprocesses an der vegetativen Hälfte zu beobachten, wodurch der Grössenunterschied der Zellen an den beiden Polen noch ausgeprägter wird.

II. Inäquale Furchung kömmt meist dort vor, wo reichlichere Mengen von Nalurungsdotter in der vegetativen Hälfte des Eies angehäuft sind; der Kern solcher Eier liegt stark excentrisch gegen den animalen Pol zu (telolecithaler Typus). - Der Unterschied der Furchungs- 
A.

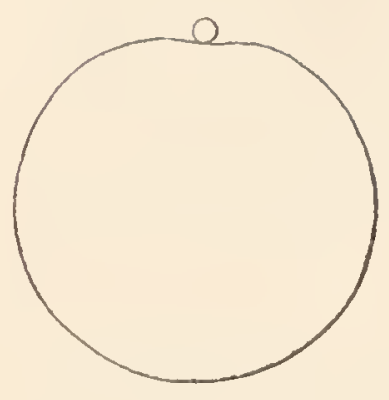

D.

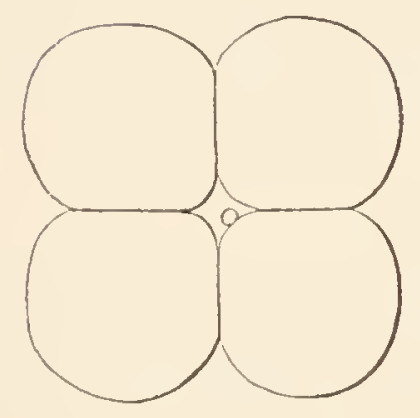

G.

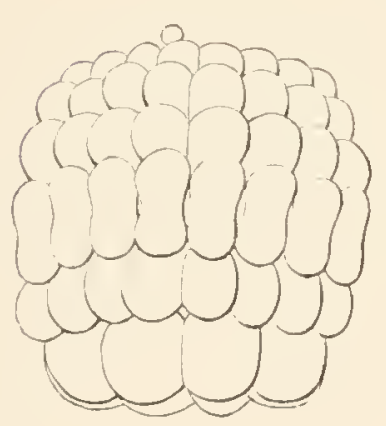

Ii.

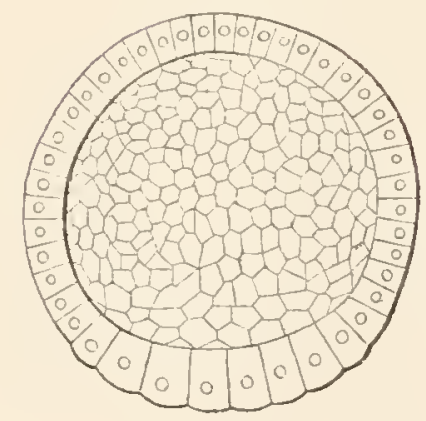

B.

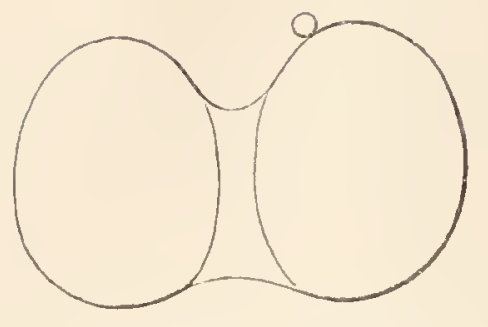

E.

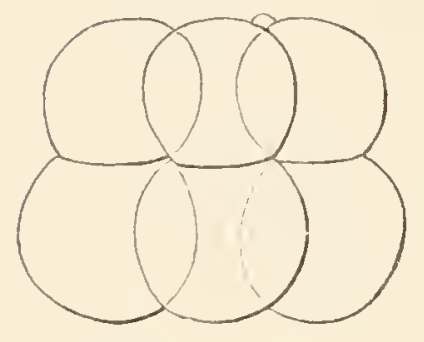

II.

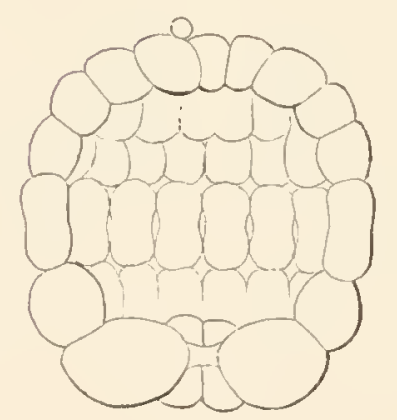

C.

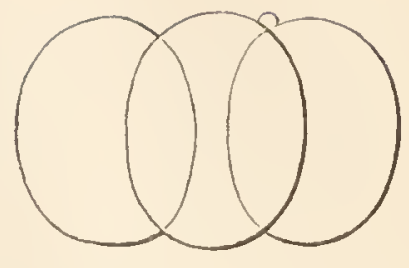

F.

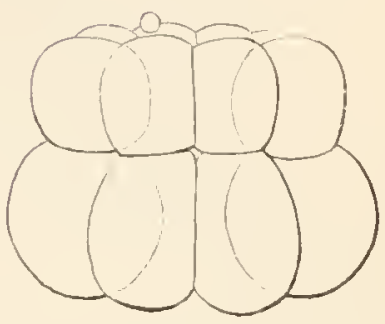

I.

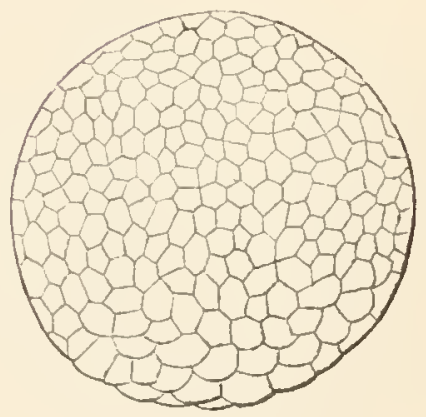

Fig. 71. Furchung von Amphioxus.

A. Ungefurchtes Ei mit Richtungskörper.

B. Zweitheilung, die beiden Zellen sind eben noch durch cine Plasmabrïcke verbunden.

C. Vierzelliges stadium.

D. Dasselbe vom Pole gesehen.

E. Achtzelliges Stadium.

F. Sechzehnzelliges Stadium.

G. Zurückbleiben des Theilungsprocesses am vegetativen Pole. Einer ron den Zellkreisen ist eben in Theilung begriffen.

H. Dasselbe Stadium, halbirt und innere Ansiclit.

I. Blastula, von der Fläche gesehen.

$\mathrm{K}$ Dieselbe halbirt und von Innen gesehen.

zellen in Bezug auf Grösse und Beschaffenheit ist bedeutend; und zwar liegen kleinere dotterarme Zellen nach dem animalen Pol, grössere mit Dotter beladene Zellen mach dem vegetativen Pole zu. Die Furchungslöhle ist verkleinert und ist stark excentrisch gegen den animalen Pol verschoben. (Auch bei sehr kleinen dotterarmen Eiern von „oligomerem“ 
F'nrchungstypus zeigt sich oft ein inäqualer Charakter der Furchung, welcher meist mit vollkommenem Nangel der Furchungshöhle einhergeht.)

Als Beispiel wollen wir die Furchung von Petromyzon betrachten. Am Ei mnterscheidet sich schon vor der Furchmg die animale Seite, welche reicher an Plasma erscheint, in auffallender W'eise von der vegetativen Seite, welche von Dotterkörnchen erfiillt ist. Der Furchungsprocess selbst begimnt auch hier mit dem Auftreten einer ersten und

A.

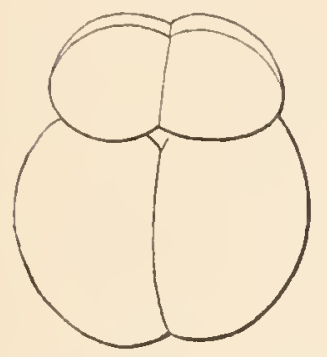

B.

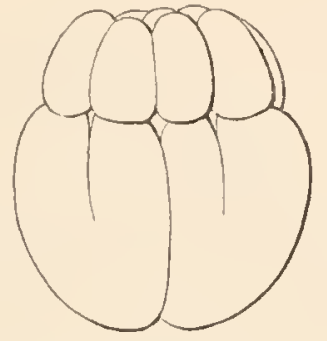

C.

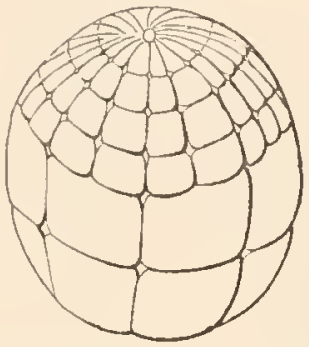

D.

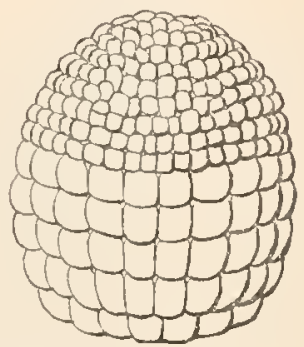

Fig. 72. Vier Furchungsstadien von Petromyzon (A. und B. nach ShIPLEY, C. und D. nach M. ScHULt7E).

zweiten meridionalen Furche. Erst bei der dritten, äquatorialen, Furche tritt hier der inäquale Charakter auf, indem durch dieselbe vier kleinere obere und vier grössere nntere Zellen entstehen. Bei den späteren Stadien steigert sich die Ungleichleit der Zellen, indem die Kellen der animalen Hälfte sich viel rascher theilen. Bei den Wirbelthieren sind die Zellen rings um das Blastocoel oft mehrschichtig angeordnet; doch ist dies für das Wesen der Furchung nur voll untergeordneter Bedeutung.

Fig. 73. Meridionalschnitt durch ein Furchungsstadium von Petromyzon (nach SHIPLEY).

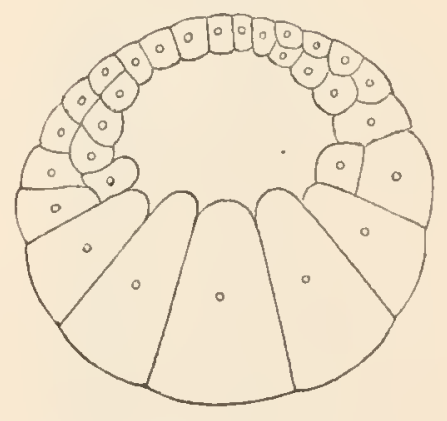

III. Discoidale Furchung findet ebenfalls an Eiern von telolecithalem Typus statt, und zwar in solchen liällen, wo sehr berleu-

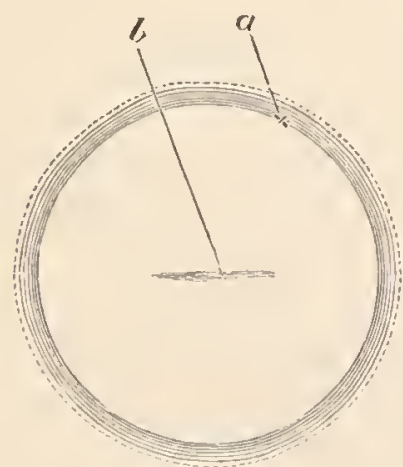

$A$

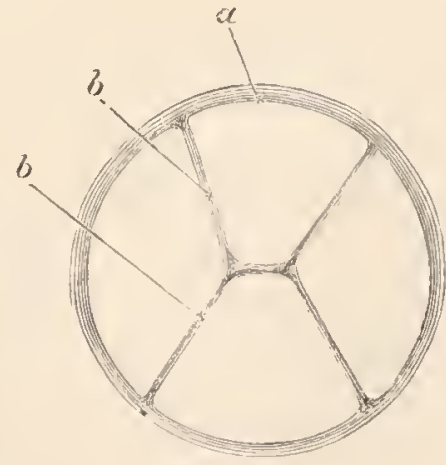

I

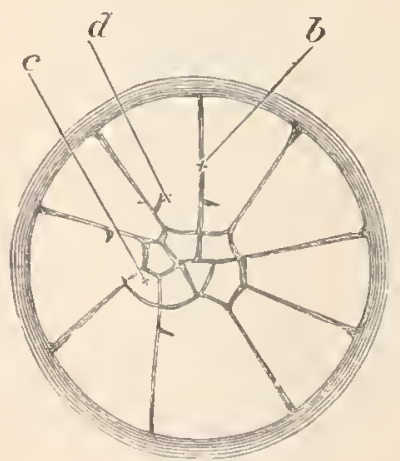

C

Fig. 74. Oberflächenansichten der ersten Furchungsstadien der Keimscheibe des Hühnchens (nach CostE).

a Rand der Keimscheibe, b radiäre Furche, $c$ kleines centrales, $d$ grosses peripheres Segment. 
tende Massen von Nahrungsdotter vorhanden sind und das Plasma mit den Kerne in noch schürferer Weise schon vor der Furchung am animalen Pole concentrirt ist. Dasselbe soudert sich schon vor der Furchung von dem Nahrungsdotter vollständig ab (bei Wirbelthieren) oder erst während der Furchung (bei den Cephalopoden.)

Nur der plasmatische Theil, der ,Bildungsdotter“", wird von der Furchung betroffen, während der Nahrungsdoter" zunächst als nichtzellige Masse von den Fur-

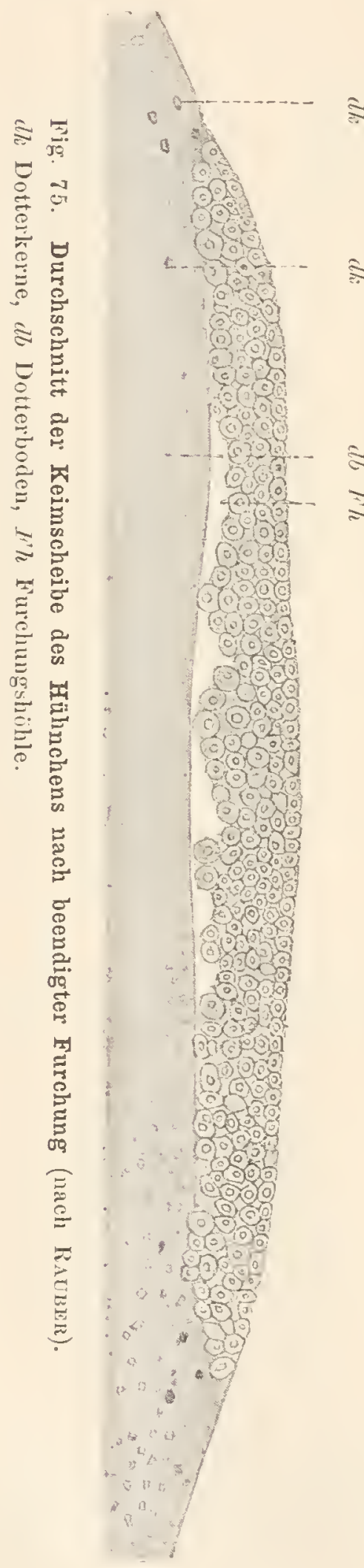
chungszellen gesondert ist. Bei der Furchung unterscheiden wir radiäre und circuläre Furchen, welche den meridionalen und äquatorialen der anderen Furchungsarten entsprechen. - Während der Furchung wandern secundär Zellen in den Nahrungsdotter ein (Dotterzellen). Das Resultat der Furchung ist daher: 1. Eine scheibenförmige Zellmasse (Keimscheibe), die am Rande dem Dotter direkt aufliegt, in der Mitte durch die Furchungshöhle von demselben getrennt ist, und 2. die in den Dotter eingewanderten ¿ Dotterzellen. Die Bedeutung dieser Dotter¿ zellen für dell Aufbau der Keimblätter ist noch nicht sichergestellt (und auch ihre Herkunft ist noch nicht ganz zweifellos).

Die discoidale Furchung ist aus der inäqualen abzuleiteu. Der gesonderte Nahrungsdotter und die Dotterzellen entsprechen Theilen, die bei der inäqualen Furchung in der vegetativen Hälfte der Keimblase enthalten sind.

Als Typus betrachten wir die Furchung des Vogel-Eies. Die discoidale I'urchung findet sich ferner bei den Reptitien und bei vielen Fischen. Unter den wirbellosen Thieren kömmt discoidale Furchung nur bei den Cephalopoden und bei den Assetn ror.

IV. Superficiale Furchung. Dieser' Furchungstypus ist ebenfalls durch Auläufung grösserer Dottermengen bedingt; doch liegt hier der Ker'u mit Plasmaanhäufung nahezu in Centrum des Eies. (Die Eier sind daher nicht „,centrolecithal ${ }^{6}$, wie sie einige Forscher nennen.) Auch hier sondern sich die Furchungszellen während des Furchungsprocesses von dem Nahrungsdotter. Die Zellen kommen an die ganze Peripherie zu liegen, wälırend der Nalılungsdotter jetzt erst eine centrale Lagerung gewinnt und die Stelle der Furchungshöhle eimimmt. Dieser Furchungstypus findet sich nur bei Arthropoden; er ist sowohl bei den Crustaceen als auch bei den Tracheaten selnr verbreitet. 
Bei den Crustaceen, z. B. bei dem Flusskrebs, ist die Furchung äusserlich einer adäqualen Furchung sehr ähnlich. An Durchschnitten ist aber der wesentliche Unterschied bemerkbar. Dic Furchen greifen nicht durch und die Furchungszellen bleiben daher mittelst einer gemeinsamen Dottermasse im Centrum in Zusammenlang und es kömmt nicht zur Bildung einer Furchungshöhle; die Kerne mit Plasmaanhäufung rücken gegen die Oberfläche der Furchungszellen; diese haben bei vorgeschrittener Furchung (Fig. 76 A) 'die Gestalt hoher dümer Pyramiden.

A.

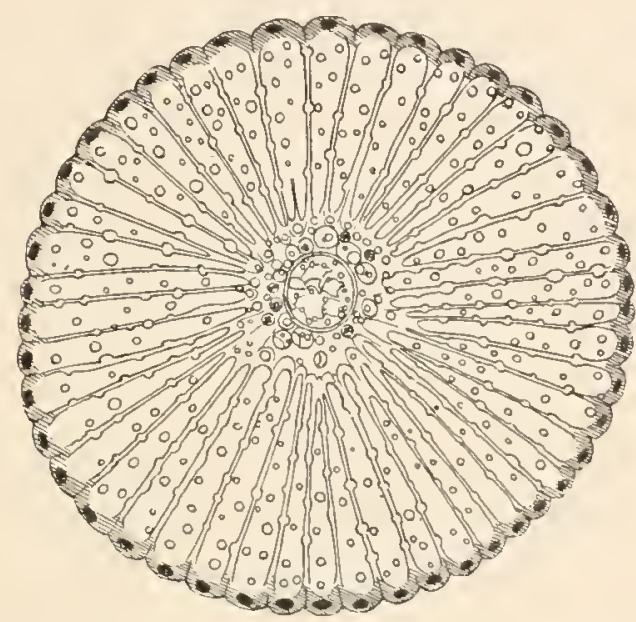

B.

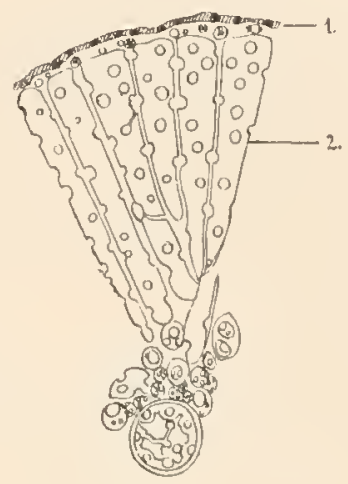

I'ig. 76. Furchung vom Flusskrebs (nach ReichenвacH).

A. Durchschnitt eines Furchungsstadiums. Die Furchungszellen sind pyramideuförmig. Das Plasma mit dem Zellkern ist gegen das äussere Ende der Zelle gedrängt, im Centrum findet sich eine ungefurchte Dottermasse mit eigenthümlichen Dottergebilden.

B. Die äusseren Enden der Zellen lraben sich als Blastoderm (1) von den „Dotterpyramiden" (2) gesondert.

Der periphere Theil derselben, welcher das Plasma und den Kern enthält, sondert sich nun in Form von cubischen oder platten Zellen als Blastoderm von dem centralen Theil, der die sogenannten Dotterpyramiden darstellt (Fig. $76 \mathrm{~B}$ ).

Noch weiter modificirt erscheint die Furchung der Insecten, Spinnen etc. Wir vermissen hier ganz die äusserlichen Furchen und sehen an der Oberfläche unvermittelt eine Zellenschichte, das Blastoderm, auftreten. Querschnitte lehren, dass anfangs im Inneren durch 'Theilung: des primären Kernes sich zahlreiche Kerne bilden, um welche amöboide Plasmamassen concentrirt sind; diese Gebilde wander'n allmählich gegen die Oberfläche und treten, dort angelangt, als zusammenhängende, epithelartige Zellschichte auf. Es bleiben aber Zellen (Dotterzellen) im Nahrungsdotter zurück, die denselben in sich aufnehmen, so dass er dann in Form von grossen dottererfüllten'/ellen, sogenannten D o t t e r s c holl e n, erscheint. Wir unterscheiden daher bei den Insecten ausser dem Zellmateriale des Blastoderms, aus welchem die Keimblätter hervorgehen, noch besondere Dotterzellen, die den Dotter zur Assimilation vorbereiten und dann im Verlanfe der Entwicklung zu Grunde gehen.

Die beiden ersten Furchungsarten, die adäquale und inäquale, fassen wir unter dem Namen der totalen Furchung zusammen, während die beiden anderen Modificationen, die discoidale und superficiale, als partielle Furchungsarten bezeichnet werden; dem bei letzteren wird 
nur ein Theil des Eies, der sogenannte Bildungsdotter, in Furchungszellen umgewandelt, während der Nahrungsdotter als nicht zelliges Material sich sondert (allerdings kann derselbe auch secundär in das Innere von Zellen gelangen [Insecten] und dadurch zelligen Charakter erhalten).

Wir haben demnach folgende Eintheilung der Furchungsarten:
A. Totale Furchung. $\{$ 1. Adäquale Furchung.
B. Partielle Furchung.
2. Inäquale Furchung.
3. Discoidale Furchung.
4. Superficiale Furchung.

Die adäquale Furchung findet sich häufiger bei den niedrigen Thierformen, während die höheren Thierformen meist die modificirteren Furchungsarten zeigen; in jenen Fällen aber, wo in einem Phylum sehr verschiedene Furchungsarten vorkommen (wie z. B. bei den Chordoniern adäquale, inäquale, discoidale Furchung), sehen wir im allgemeinen, dass die niedrigsten Formen den ursprünglichsten Modus zeigen, und in einzelnen höheren Reihen die secundären Furchungsarten auftreten, dies wird am besten aus nachfolgender tabellarischer Uebersicht ${ }^{1}$ ) ersichtlich:

\begin{tabular}{|c|c|c|c|c|c|}
\hline Adäqual: & $\begin{array}{l}\text { Spongien } \\
\text { Cnidarier }\end{array}$ & Scolecida & $\begin{array}{l}\text { Anneliden } \\
\text { Crustaceen } \\
\text { Mollusken }\end{array}$ & $\begin{array}{l}\text { Echino- } \\
\text { dermen }\end{array}$ & $\begin{array}{l}\text { Tumicaten } \\
\text { Amphioxus } \\
\text { (bei Säugethieren } \\
\text { in secundärer } \\
\text { Form) }\end{array}$ \\
\hline Inäqual: & $\begin{array}{l}\text { Spongien } \\
\text { Cnidarier } \\
\text { Ctenophore }\end{array}$ & Scolecida & $\begin{array}{l}\text { Anneliden } \\
\text { Crustaceen } \\
\text { Mollusken }\end{array}$ & $\begin{array}{l}\text { Echino- } \\
\text { dermen }\end{array}$ & $\begin{array}{l}\text { Petromyzonten } \\
\text { Ganoiden } \\
\text { Amphibien }\end{array}$ \\
\hline Discoidal: & & & $\begin{array}{c}\text { Cephalo- } \\
\text { poda }\end{array}$ & & $\begin{array}{l}\text { Selachier } \\
\text { Teleostier } \\
\text { Reptilien } \\
\text { Vögel } \\
\text { Monotremen (!) }\end{array}$ \\
\hline Superficial: & & & $\begin{array}{l}\text { Arthro- } \\
\text { poden }\end{array}$ & & \\
\hline
\end{tabular}

Blastula, Als Resultat der Furchung sehen wir die Keimblase oder Blastula entstehen, die je nach der Furclungsart gewisse Modificationen zeigt, die sich denmach auf die Menge und Vertheilung des Nahrungsdotters, die Anzalıl der Zellen, die Grösse der Furchungshöhle beziehen. Wir köunen als Grundtypus jene Blastula betrachten, die in der Regel nach adäqualer Furchung auftritt, und sich besonders durch den Besitz einer grossen Furchungshöhle anszeichnet.

1) Der fette Druck zeigt an, dass die Furchungsart für diese Abtheilung die vorherrschende ist. 
In diesem Falle besteht bie Blastula aus einer Schichte von Zellen (dem Blas toderm), die eng an einander schliessen mod in Folge dessen die Form polygonaler Prismen besitzen. Im allgemeinen nenmen wir eine solche Schichte flächenhaft angeordneter Zellen ein Epithel. Das Blastoderm umschliesst den centralen als Blastocoel (oder primäre Leibeshöhle) bezeichneten Hohlraum. Wir unterscheiden an der Blastula einen a $\mathrm{nimalen} \mathrm{Pol} \mathrm{mit} \mathrm{in} \mathrm{der} \mathrm{Regel} \mathrm{kleineren,} \mathrm{cinen} \mathrm{vege-}$ tativen Pol mit grösseren Zellen.

Man hat mit Recht darauf hingewiesen, dass in dieser einfachen Zellblase der Grundtypus des Metazoenkörpers in seiner grössten Vereinfachung vorliege (Claus, Haeckel). Halckel, der für dieses ontogenetische Stadium den Namen "Blastula" eingeführt lat, bezeiclmet das entsprechende phylogenetische Stadium (welches wir theoretisch annehmen) als ,Blastaea". Die Uebereinstimmung aller" Metazoen erstreckt sich aber auch noch auf ein späteres Stadium, niimlich die Gastrula.

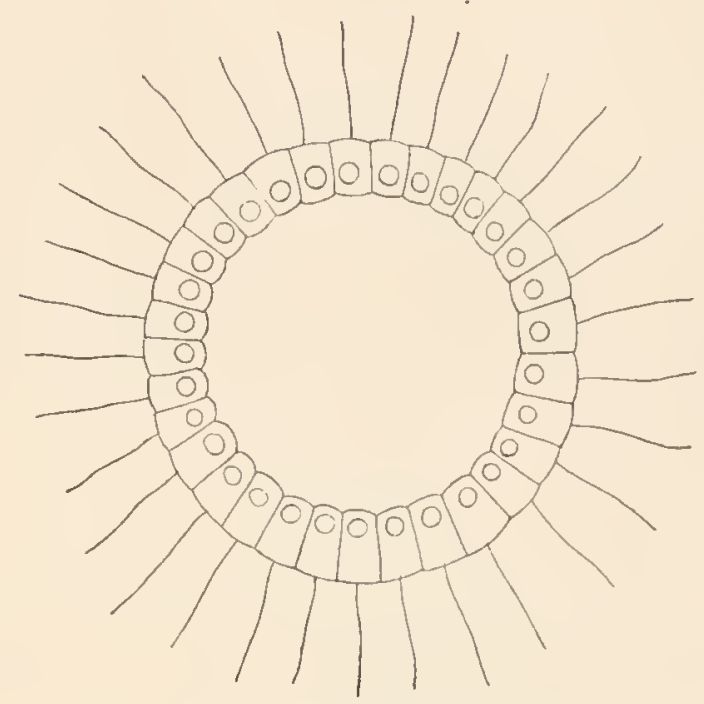

Fig. 77. Keimblasenstadium eines Seeigels (nach SELENKA). Die Blastodermzellen sind mit Geisseln versehen, mittelst welcher die Keimblase frei umherschwimmt.

\section{Gastrulation,}

Den Vorgang, durch welchen die einschichtige Blastula in die zweischichtige Gastrulaform verwandelt wird, bezeichnen wir als Gastrulat i 0 11. Bei adäqualer Furchung, wo eine Blastula mit grosser Furchungshöhle vorliegt, findet in sehr zahlreichen Fällen die Gastrulation derart

A.

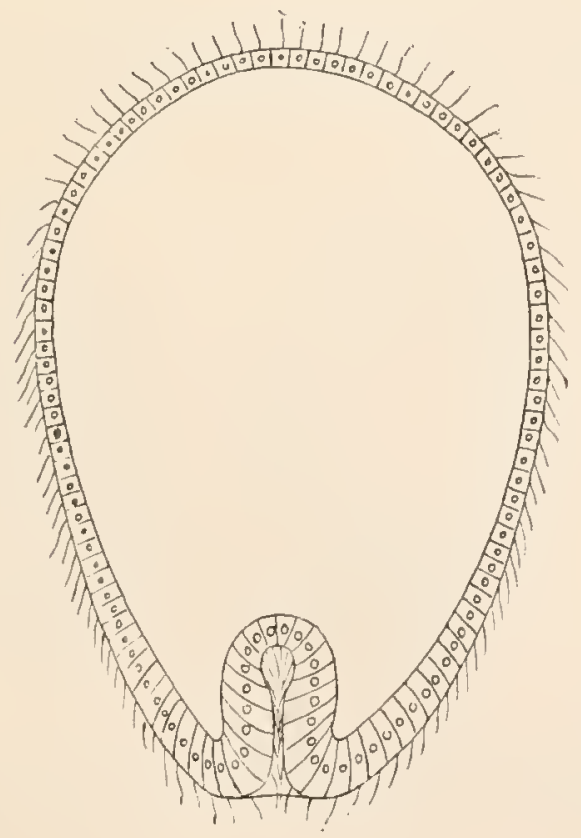

B.

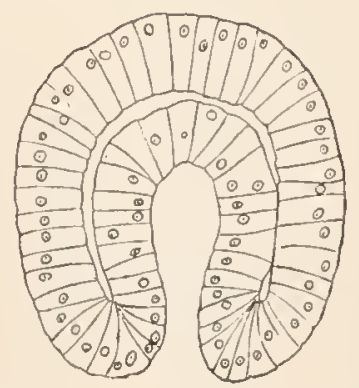

Fig. 78. A. Gastrula einer Holothurie (Synapta).

B. Gastrula einer Qualle (Aurelia) (nach GoetT:). 
statt, dass ein 'Theil des Blastoderms und zwar jener Bezirk, welcher' an der vegetativen Seite liegt, gegen die Furchungshöhle sich einstülpt und clas Entodern bildet (Invaginat ion), während der ibrige 'l'heil, also die animale Hälfte der Blastula, aussen bleibt und das Ectoderm repräsentirt. Das Blastocoel wird durch das eingestiilpte Entoderm entweder theilweise verdrängt oder auch gänzlich, so dass es damn nur einen Spaltraum zwischen den beiden Blättern bildet. Die durch Einstiilpung (Invagination) entstandene Höhle ist die Urdarmhöhle (Gastrocoel). Der Umschlagsiand, wo rlas Endoderm und Ectoderm zusammenhängen, bildet den Rand des Protostoma. - Wir beobachten in anderen Fällen zahlreiche Modificationen der Gastrulation, welche von der Verschiedenartigkeit der Keimblasen und daher auch von der vorausgehenden Furchung abhängig sind und in letzter Instanz meist auf der verschiedenartigen Aulıäufung von Dotter im Eie beruhen. Es gibt aber anclı Modificationen, die unabhängig von der Menge des Nalırumgsdotters sind, da sie nach adäqualer Furchung auftreten. Wir finden solche Modificationen bei den Hydrozoen, einer Thiergruppe, die in Bezng auf den Schichtenbau ihres Körpers danernd der Gastrulaform sehr nahe steht; diese Modificationen sind dalıer von besonderer Wichtigkeit fïı die Entscheidung der Frage, welche Art der Gastrulation der urspriingliche 'Typus sei.

Gastrulation bei den Hydrozoen. Wir kömen die Modificationen, welche die Gastrulation bei den Hydrozoen zeigt, in zwei Ilauptgruppen eintheilen.

I. Die polare Gastrulation. Jener' 'Typus der polaren Gastrulation, welcher sonst bei den Metazoen so allgemein verbreitet ist, mämlich die I $n$ vaginat i o 1 , ist bei den Hydrozoen noch nirgends mit Sicherheit beobachtet worden, dagegen finden wir hier zumeist einen Prozess, welchen wir als pola re Einw uc lo e r ung bezeichnen wollen. An der Blastula, welche deutlich zwei verschiedene Pole erkennen lässt, wandern nämlich am vegetativen Pole Zellen aus dem Blastoderm in das Blastocoel ein, indem sie dabei rmdliche oder amöboide Form annehmen, und zwar findet diese Einwucherung entweder in zusammenhängenden Massen statt, oder es wandern einzelne Zellen ein. Diese Zellen erfüllen allmählich das gesammte Blastocoel und bilden eine centrale Entodermmasse. Erst secundär entsteht inner'halb dieser Zellmasse ein Spaltraum (das Gastrocoel), um welchen sich die Endodermzellen epithelartig anordnen.
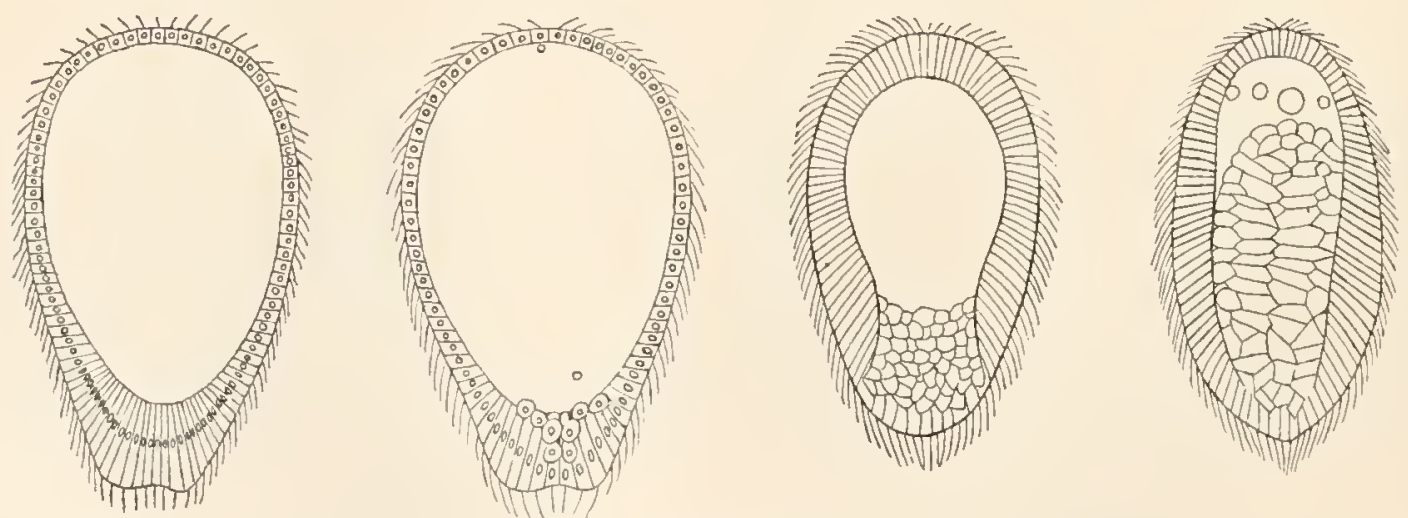

Fig. 79. Gastrulation durch polare Einwucherung bei einer Hydroidqualle (Aequorea) (11ach Cl.Avs). 
II. Die apolare Gastrulation oder allseitige Entodermbildung. Es werden zweierlei Processe beschrieben, die hier zu betrachten sind.

a. Die multiloculäre (allseitige) Einwucherung. Die 'Lellen, welche die centralen Entodermmassen bilden, wandern nicht allein vom vegetativen Pol, sondern einzelweise von den verschiedensten Stellen des Blastoderms in das Blastocoel ein (Eucope etc.). (MetscirnikofF glaubt diesen Vorgang mit genügender Sicherheit festgestellt zu haben.)

b. Di e Delamination. Die Delamination wurde früher als ein sehr allgemein verbreiteter Modus der Gastrulation nicht nur bei den Cnidariern, sondern auch bei vielen anderen 'Thieren betrachtet, es hat sich dies aber in den meisten Fällen als ein Irrthum herausgestellt; nur für Geryonia, eine Hydromedusenform (also in einer einzigen Gattung unter. allen Metazoen), wird dieser Vorgang von mehreren Forschem angegeben (Fol, Metschniroff). Das einschichtige Blastoderm soll hier, indem jede Zelle sich parallel zur Oberfläche theilt, in zwei Schichten zerfallen, von welchen die äussere das Ectoderm, die innere das Entoderm bildet.

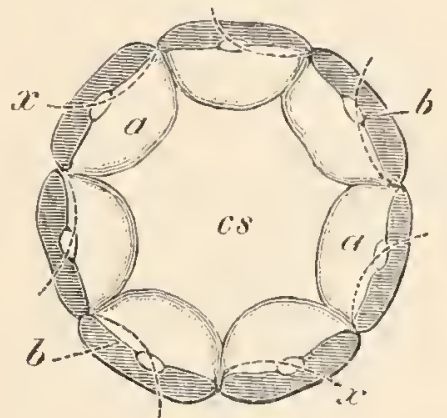

Fig. 80 .

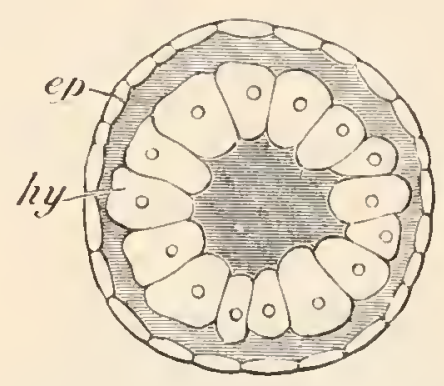

Fig. 81 .

Fig. 80. Blastula von Geryonia (nach FoL).

$c_{1}$ Blastocoel, $a$ helles inneres Plasma, $b$ äusseres dunkles Plasma der Blastodernzellen, die punktirten Linien deuten die nächsten Theilungsebenen alı.

Fig. 81. Embryo von Geryonia nach der Delamination (nach FOL).

ep Ectoderm, hy Endoderm.

(So wie FoL den Vorgang darstellt (schiefe Theilung), würde er übrigens eine gewisse Verwandtschaft mit der multiloculären Einwucherung zeigen). Die Höhle, welche von dem delaminirten Entoderm eingeschlossen wird, nämlich das ursprüngliche Blastocoel, wird hier zur Urdarmhöhle. Das Protostoma bricht erst secundär durch.

Mit Beziehung auf die hier geschilderten Verhältnisse wird von einigen Forschern die Delamination (RAY-LANkester) oder die multiloculäre Einwucherung (MErscchnikorf) als der phylogenetisch ursprüngliche Vorgang der Gastrulation überhaupt erklärt. Msтschnikoff hebt hervor, dass dieser Vorgang gerade bei den Hydrozoen sich findet, die unter allen Metazoen in ihrem entwickelten Zustande der Gastrula noch am nächsten stehen und zu den ursprünglichsten Metazoen gehören. Er betrachtet die polare Einwucherung nur als einen speciellen Fall, von welchem dann weiter die Invagination abzuleiten sei.

Nach den Ausführungen HaEckel's aber, welchen die meisten Zoologen sich anschliessen, wird die Invagination als ursprünglicher Modus der Gastrulabildung betrachtet. Diese Ansicht wird dadurch sehr ge- 
stützt, dass wir bei den Metazoen eine Oberflächenvergrösserung der Epithelien durch Faltung auch bei der weiteren Complication des Organismus und der Bildung neuer Organe die grösste Rolle spielen sehen. Auch mit anderen allgemeinen Erscheinungen der Epithelien steht diese Lehre im Einklang, so dass sie vorläufig als die bestbegründete angesehen werden kann.

Gastrulation bei den übrigen Metazoen. Bei allen übrigen Metazoen ist die Gastrulation durchweg als eine polare zu bezeichnen. Die Modificationen dieses Processes stehen zumeist im Zusammenhang mit der Furchungsart.

1. Die Invagination findet sich, wie schon früher erwähnt, am deutlichsten ausgeprägt in jenen Fällen, wo nach einer adäqualen Furchung eine Blastula mit grosser Furchungshöhle auftritt, also bei Thieren aus den verschiedensten Abtheilungen. (Scyphomedusen, Actinien, Sagitta, Echinodermen, Amphioxus u. s. w.) Die Invagination kömmt aber auch nach allen anderen Furchungsarten vor, z. B. bei den Wirbelthieren sowohl nach inäqualer als auch nach discoidaler Furchung; ferner tritt die Invagination regelmässig auf nach superficialer Furchung bei den Arthropoden. Die Modificationen, unter welchen sich die Invagination in diesen Fällen vollzieht, werden wir weiterhin an einigen Beispielen noch genauer kennen lernen.

2. Die Epibolie. Während besonders bei den Wirbelthieren selbst bei reichlichstem Nahrungsdotter noch Invagination nachweisbar

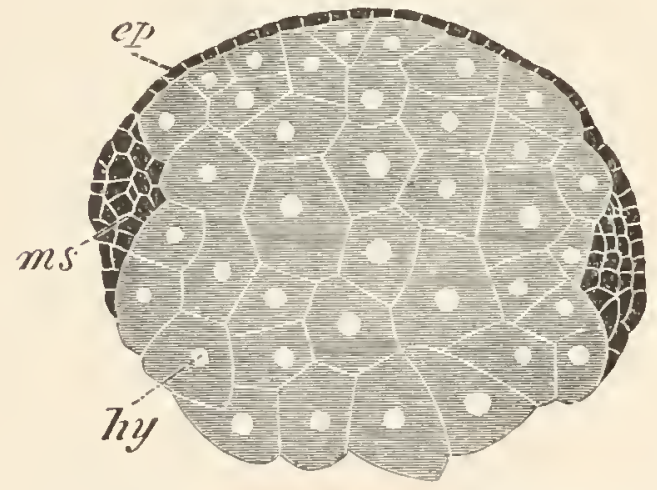

Fig. 82. Epibolie von einem Ringelwurme (Euaxes), Querschnitt (nach KowaLEVSKT). derm.

ep Ectoderm, hy Entoderm, ms Mesozwischen Blastulastadium und Beginn der Gastrulation ist hier nicht zu ziehen aus dem Grunde, weil die Furchungshöhle meist schon von Anfang an sehr reducirt ist. Die Urdarmhöhle fehlt selbst nach Beendigung des Umwachsungsprocesses; das Entoderm ist eine solide Zellmasse, die oft erst viel später (zu Ende der Embryonalentwicklung) eine secundäre Aushöhlung gewinnt. Während des Umwachsungsprocesses ist die Grenze des sich ausbreitenden Ectoderms als Protostomrand $\mathrm{zu}$ betrachten, sie entspricht dem Umschlagsrande einer Invaginationsgastrula. (Anders ist dies aber in jenen Fällen, wo von den unteren grossen Zellen fortwährend neue Zellen abgegeben werden, die sich dem Rande der Ectodermscheibe anschliessen.) 


\section{Ueber einige besondere Modificationen der Gastrulabildung.}

Die mannigfachen Modificationen der Gastrulabildung beruhen z. Th. wohl auf dem verschiedenen Verhalten des Nahrungsdotters und der daraus resultirenden verschiedenartigen Furchung und Blastulabildung, zum Theil beruhen sie aber auch darauf, dass gewisse anderweitige Entwicklungserscheinungen vorzeitig auftreten und die Gastrulabildung beeinflussen. Wir werden diese Modificationen nur an einigen Beispielen betrachten.

Gastrulation des Flusskrebses. Die Invagination findet an einer beschränkten Stelle des Blastoderms (die später zur Bauchseite des Thieres auswächst) statt. Das spätere Vorderende des Thieres geht nicht aus jenem Theile des Blastoderms hervor, welcher dem Gastrulamunde diametral gegenïberliegt - solches ist bei nahe verwandten, ursprünglicheren Thieren (bei vielen Anneliden) der Fall - sondern aus einem Theile, der dem Gastrulamunde (seinem vorderen Rande) ganz nahe liegt. Diese Verschiebung ist aus der Anhäufung des Nahrungsdotters zu erklären. Es ist ferner von Interesse zu sehen, wie die ursprünglich im Blastocoel gelegene Dottermasse (vergl. pag. 97) in das Gastrocoel gelangt. Die Entodermeinstülpung

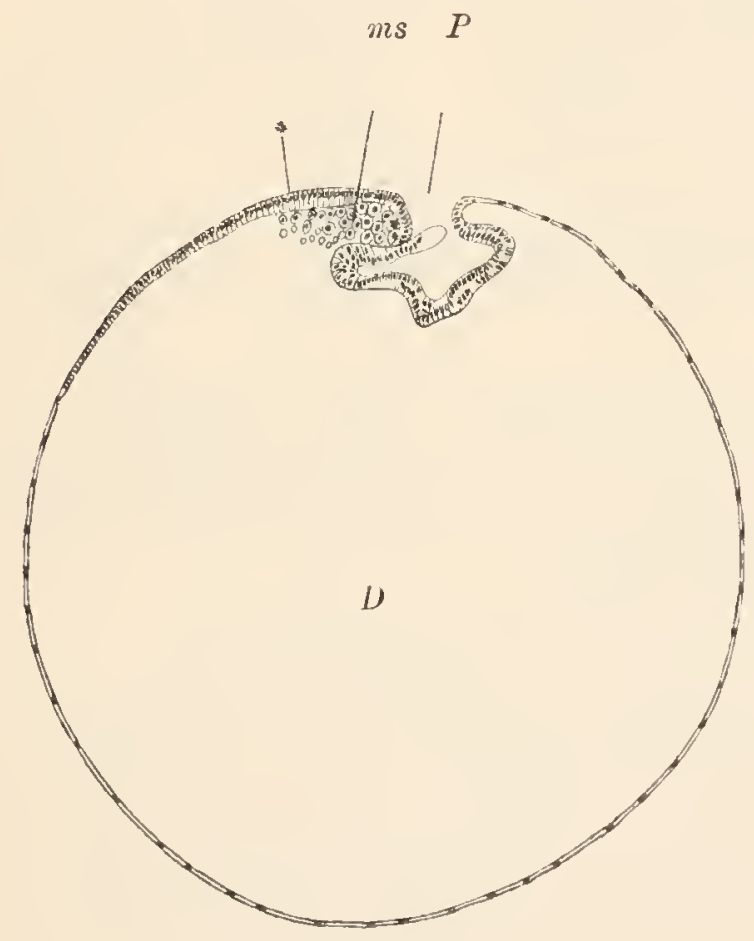

Fig. 83.

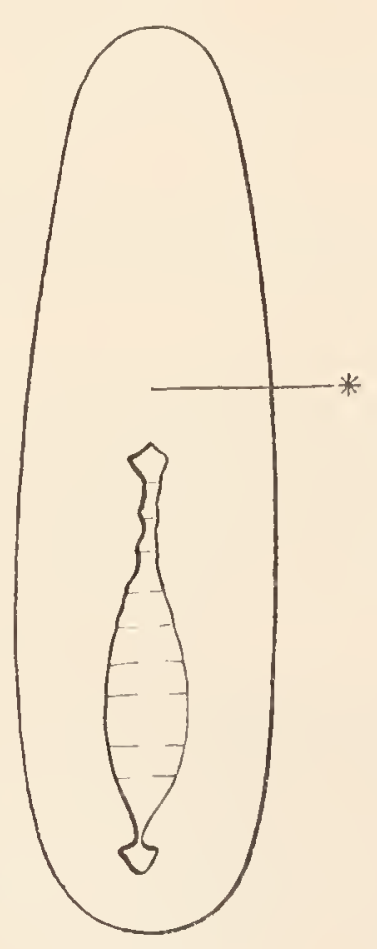

Fig. 84 .

Fig. 83. Gastrulastadium vom Flusskrebs im Längsschnitt (nach REICHENBACu).

$P$ Protostoma, ms Mesoderm, * bezeichnet die Stelle, an welcher das Vorderende des Körpers sich entwickelt, $D$ Dotter.

Fig. 84. Flächenansicht จom Embryo eines Käfers (Hydrophitus) im Gastrulastadium (nach HEIDER).

* bezeichnet die Stelle, an welcher das Vorderende des Körpers sich entwickelt.

senkt sich in die centrale Dottermasse ein; der Dotter liegt also ausserhalb des Urdarmes im Blastocoel. Die Entodermzellen beginnen sodann an ihrer Basalfläche mittelst amöboider Fortsätze den Dotter aufzunehmen und wachsen in Folge dessen zu hohen pyramidenförmigen dottererfüllten Zellen an. Die Kerne dieser Zellen mit einem sie umgebenden Plasmakörper sind der 
Basis des Epithels genähert. Diese Zellen stossen, nachdem sie den Dotter ganz aufgenommen haben, denselben wieder ab und zwar gegen die Darmhöhle $\mathrm{zu}$, und er findet sich nun innerhalb derselben in Form der sogenannten secundären Dotterpyramiden (zu unterscheiden von den primären Dotterpyramiden, die aus der Furchung hervorgegangen sind), und diese werden sodann allmählich resorbirt.

Gastrulation bei Insecten. Die Gastrulaeinstülpung erscheint hier in Form einer langgestreckten Rinne. Nahe dem Vorderende dieser Rinne entwickelt sich das spätere Vorderende des Thieres. Der Gastrulamund schliesst sich in Form eines langgestreckten Spaltes, und dementsprechend wird die Bauchseite des Thieres sofort langgestreckt angelegt (während sie bei den meisten Anneliden und beim Flusskrebs erst secundär in die Länge wuchs). Auch hier liegen die „Dotterschollen“ (vergl. pag. 97)

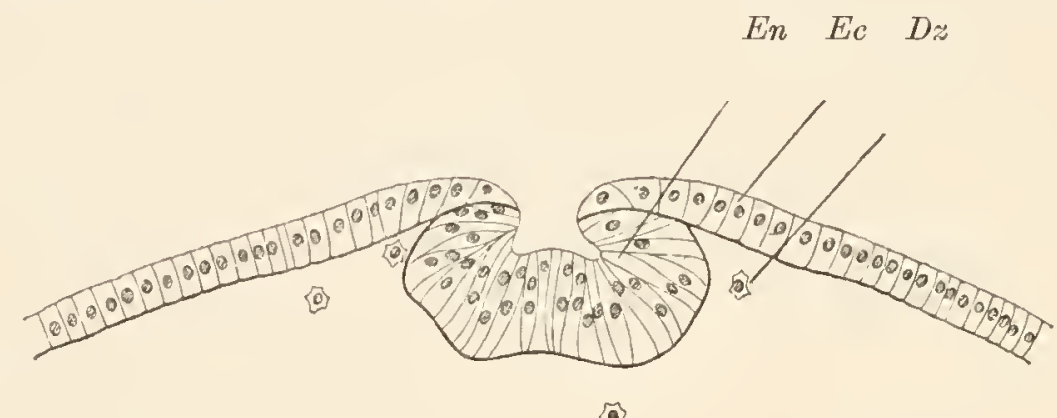

Fig. 85. Stück eines Querschnittes der Gastrula von Hydrophilus (nach HEIDER). bleiben.

Ec Ectoderm, En Entoderm, Dz Dotterzellen, die in der centralen Dottermasse ver-

anfangs ausserhalb des Urdarmes; das Endoderm verliert dann seinen ursprünglichen Zusammenhang und breitet sich in Form einer lockeren Zellschicht um den Dotter aus, diese ordnet sich secundär wieder zum Darmepithel, welches nun den Dotter umschliesst.

\section{Gastrulation der Wirbelthiere.}

Bei Amphioxus erfolgt eine reine Invagination, wobei sich eine mützenförmige Gastrula mit weitem Protostoma bildet. Sodann folgt ein Process, den wir als Schliessung des Gastrulamundes bezeichnen. Die Gastrula streckt sich, wobei der Gastrulamund enger wird und nach der abgeflachten Rückenseite verschoben erscheint. Wahrscheinlich ist diese Verengerung so aufzufassen, dass eine spaltförmige, von vorn nach hinten fortschreitende Schliessung des Gastrulamundes längs der so entstehenden Rückenseite stattfindet. (Nach dieser Auffassung würde das spätere Vorderende nicht aus dem animalen Pol des Blastoderms entstehen; diese Verschiebung wäre aber ähnlich wie bei den Arthropoden als cenogenetisch zu betrachten.) - Wir haben hier also zwei Processe aus einander zu halten, die Invagination und die Gastrulaschliessung.

Bei den Amphibien (sowie bei Petromyzon und den Ganoiden) finden wir als Resultat der inäqualen Furchung eine Blastula mit excentrischem Blastocoel und mit dünner animaler und bedeutend verdickter dotterreicher vegetativer Hälfte (Fig. 87 A). Während der Gastrulation und Gastrulaschliessung behält der Embryo, der dicht von der Dotterhaut eingeschlossen ist, die Kugelgestalt; die Wände der Blastula, die ursprünglich sehr dick sind, breiten sich, dünner werdend, zu grösserer Fläche aus, indem das Ectodem, 
welches ursprünglich die animale Hälfte der Keimblase einnahm, allmählich bis zum vegetativen Pole herabreicht, während das ebenfalls flächenhaft ausgedehnte Entoderm dadurch nach Innen gedrängt wird (Fig. 88). Wenn wir den Invaginationsprocess selbst genauer ins Auge fassen, so sehen wir, dass die Einstülpung nicht concentrisch erfolgt, sondern von der einen Seite,

A.

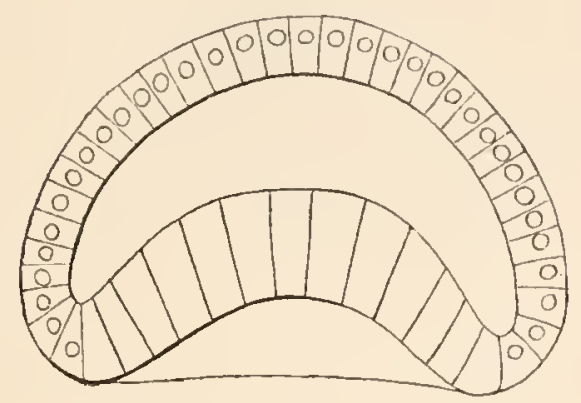

C.

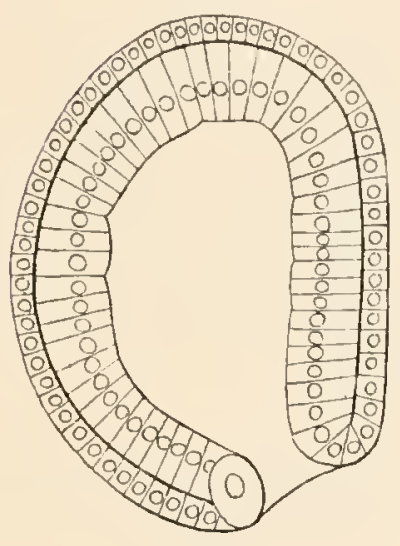

A.

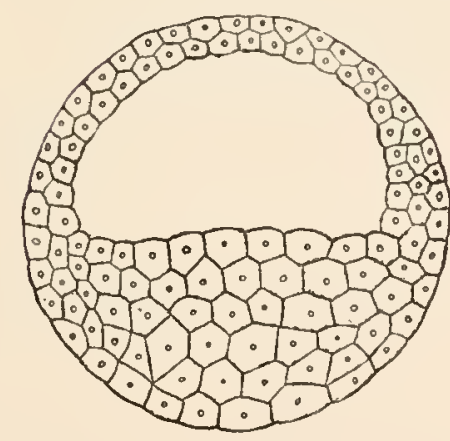

B.

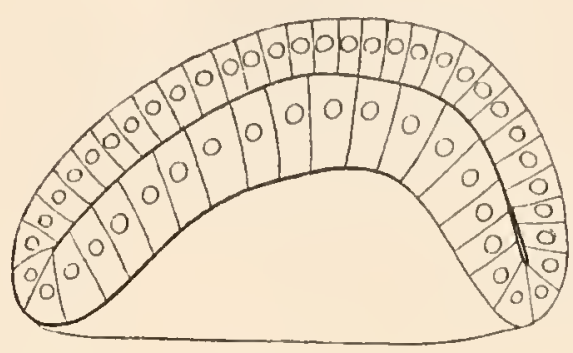

Fig. 86. Drei Entwicklungsstadien von Amphioxus im Längsschnitt.

A. Während der Invagination.

B. Invagination vollendet.

C. Mit verengertem Protostoma.

Fig. 87. Zwei Entwicklungsstadien von Petromyzon im Längsschnitt (nach SHIPLE).

A. Blastula.

B. Beginn der Invagination.

(NB. In dieser Figur ist die spätere Rückenseite des Thieres links gelegen, während sie in den Figuren $88-91$ rechts zu liegen kommt).

der dorsalen, des Aequators der Keimblase ausgeht und nach der entgegengesetzten Seite des Aequators fortschreitet (Fig. 90). Der dorsale Theil des Entoderms, der zuerst zur Einstülpung gelangt, ist bedeutend dünner und ärmer an Dottermasse, während der ventrale Theil, der zuletzt eingestülpt wird, aus einer geschichteten Masse grosser, dotterreich or Zellen besteht (Fig. 87 B). 
A.

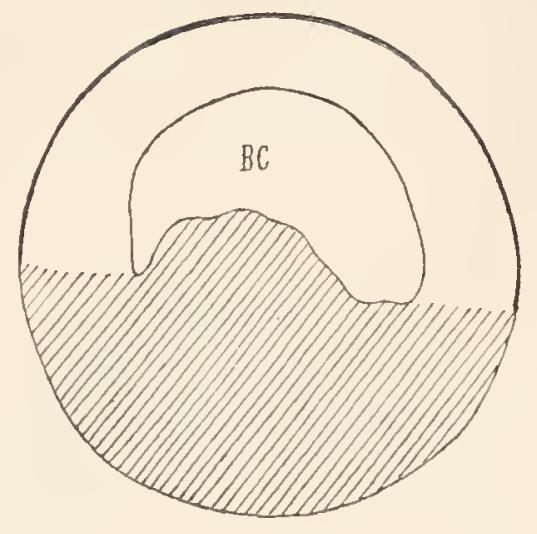

C.

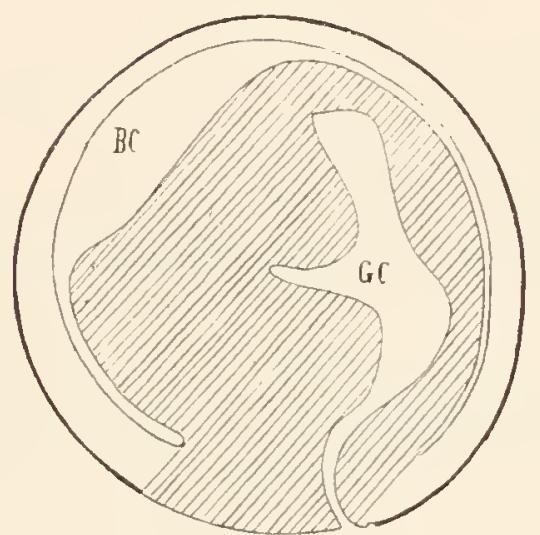

B.

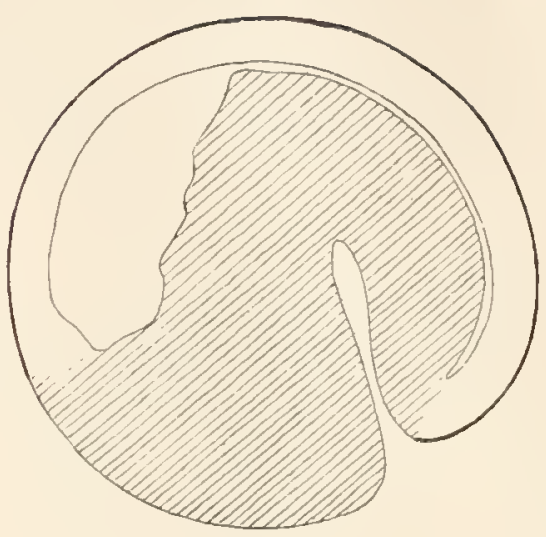

D.

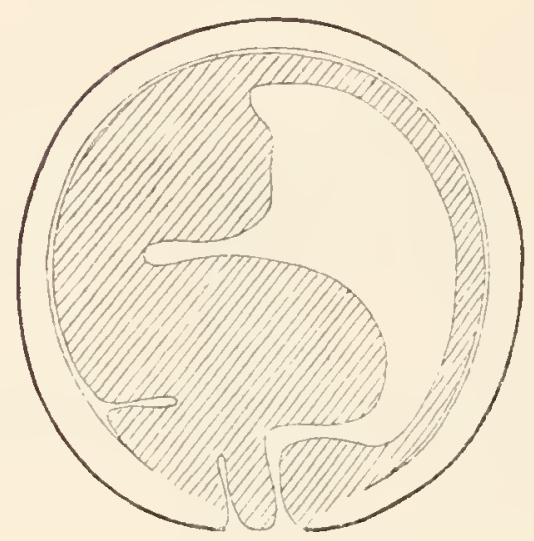

Fig. 88. Vier Stadien der Gastrulation von Triton im Längsschnitt (nach HERTwIG) (schematisch).

$B C$ Blastocoel, $G C$ Gastrocoel.

Zum Verständnis dieses Processes ist es auch wichtig, die Configuration des Gastrulamundes bei Oberflächenansicht zu betrachten (Fig. 89). Wir sehen, dass sich zuerst an der dorsalen Seite in der Nähe des Aequators eine halbmondförmige Rinne bildet ( $\mathrm{Sichelrinne),} \mathrm{diese} \mathrm{bildet} \mathrm{den} \mathrm{Eingang} \mathrm{in}$ das Einstülpungslumen. Erst während des Herabwachsens vervollständigt

A.

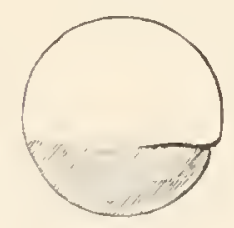

B.

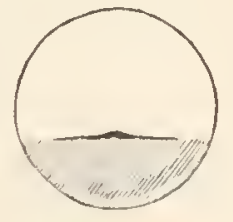

Fig. 89.
C.

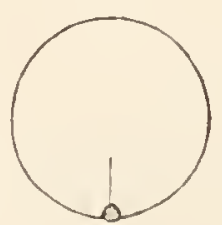

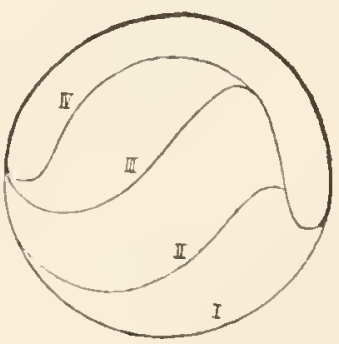

Fig. 90.

Fig. 89. Flächenansicht der Gastrulation von Amphibien, schematisch.

A. Stadium der Sichelrinne von der Seite.

B. Dasselbe Stadium vom Rücken gesehen.

C. Schliessung des Protostoma.

Fig. 90. Schema der excentrischen Invagination bei den Amphibien; der Nahrungsdotter und die gleichzeitig mit der Invagination erfolgende Schliessung des Protostoma sind eliminirt gedacht. 
sich die Sichelrinne zu einer kreisförmigen Falte (sog. Ruscon is cher After); man findet hier noch eine kleine Oeffnung des Urdarmes (Rest des Protostoma, der bei den Wirbelthieren meist zum neurenterischen Porus wird), und hinter derselben sieht man grosse dotterreiche Entodermzellen noch in Form eines Pfropfes vorragen (Dotterpfropf). - Wir müssen auch hier im Auge behalten, dass neben der Invagination eine Verengerung des Gastrulamundes einhergeht. Wahrscheinlich erfolgt die Verengerung nicht ron allen Seiten her in gleicher Weise, sondern so, dass längs der Rückenlinie die Ränder des Protostoma mit einander verwachsen. Die Stelle dieser Nathlinie (Gastrularaphe) ist durch eine Rinne (die Primitivrinne) gekennzeichnet; dort erfolgen dann wichtige Entwicklungsprocesse (zunächst die Mesodermbildung).

Gastrulation nach discoidaler Furchung (bei Selachiern, Finochenfischen und Amnioten). In allen Fällen handelt es sich erstens darum, dass die einschichtige Keimscheibe zu einer zweischichtigen wird und zweitens um die Umwachsung des Dotters.

a) Bei den Selachicrn wird ebenfalls ein excentrischer Invaginationsvorgang beobachtet, indem von dem hinteren Rande der Keimscheibe eine Epithellamelle unter die oberflächliche Schichte hineinwuchert. Zwischen dieser Schichte und dem Dotter ist eine Höhle zu beobachten, die am hinteren Rande der Keimscheibe sich nach aussen öffnet. In Betreff der Herkunft dieses Entodermblattes herrscht noch nicht vollkommene Uebereinstimmung; während die einen dasselbe für einen Umschlagsrand der Keimscheibe halten, wird von anderen dargelegt, dass es "Dotterzellen" (vergl. pag. 96) sind, welche dem Rande der Keimscheibe sich anschliessend, eine

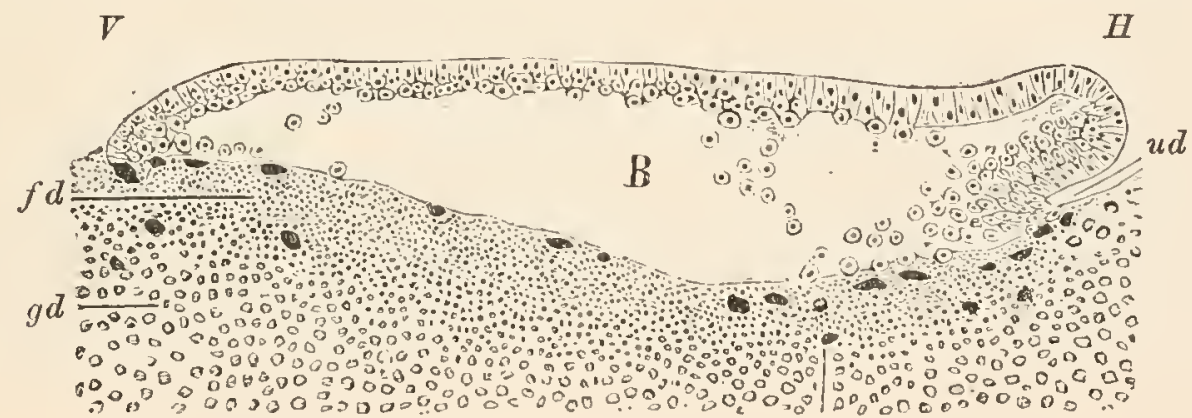

$d k$

Fig. 91. Medianschnitt durch eine Keimscheibe von Pristiurus, an welcher die Gastrulaeinstülpung beginnt (nach RüCKERT).

$u d$ erste Anlage des Urdarms, $B$ Furchungshöhle, $d k$ Dotterkerne, $f d$ feinkörniger Dotter, $g d$ grobkörniger Dotter, $\nabla, H$ vorderer, hinterer Rand der Keimscheibe.

epithelartige Anordnung gewinnen und so das Entoderm bilden. Die Uebereinstimmung dieser Entodermbildung mit dem Beginn der Invagination bei den Amphibien etc. (Fig. 88 B) ist unverkennbar. Diese Entodermschichte breitet sich sodann unterhalb der gesammten Keimscheibe aus, so dass dieselbe zweischichtig wird.

Wenn wir die Keimscheibe im Stadium der Gastrula von der Fläche betrachten, so finden wir, dass der ganze Rand der Keimscheibe dem Protostoma entspricht. Nur der hintere Theil dieses Randes erscheint als "Sichelrinne", und bildet den Eingang in die Höhle des Urdarmes. Im weiteren Verlaufe der Entwicklung erweisen sich die Theile des Protostoma als von wesentlich verschiedener Bedeutung. Die Sichelrinne, die wir als Gastroporus bezeichnen wollen, verengert sich bis auf eine kleine 
Oeffnung (Rest des Gastroporus, welcher sodann zum neurenterischen Porus wird). Vor dieser Oeffnung ensteht in der Mittellinie die Primitivrinne, wahrscheinlich durch spaltförmige Verwachsung des Protostomrandes (bei

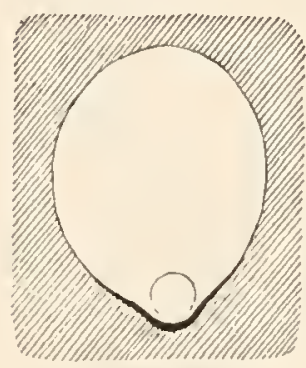

Fig. 92.
A.

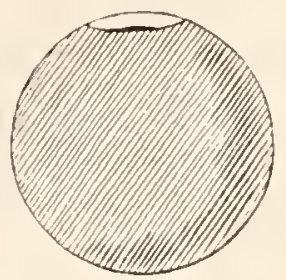

B.

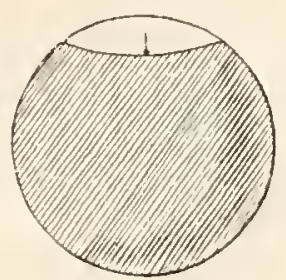

C.

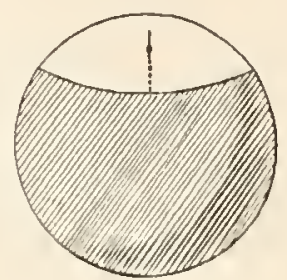

Fig. 93.

Fig. 92. Keimscheibe mit Embryonalschild eines Haies (Pristiurus) (nach Batfour).

Fig. 93. Ausbreitung der Keimscheibe schematisch dargestellt.

A. Stadium der Sichelrinne.

B. Stadium mit Primitivrinne und Gastroporusrest.

C. Diese Gebilde haben sich vom Rande der Keimscheibe entfernt.

den Selachiern ist sie allerdings wenig ausgeprägt). Auch der übrige Theil des Protostoma, den wir als Lecithoporus bezeichnen wollen, schliesst sich allmählich, indem die Keimscheibe den Dotter umwächst. Bei diesem Processe ist zunächst zu bemerken, dass der Primitivstreif mit dem Rest des Gastroporus, die anfangs randständig an der Keimscheibe sich fanden, nun vom Rande entfernt werden und mittelständig erscheinen, wahrscheinlich in Folge von spaltförmiger Schliessung des Lecithoporus (BALFovR).

Gastrulation nach discoidaler Furchung bei den Amn i oten (Reptilien, Vögel). Auch hier, z. B. beim Hühnchen, sehen wir die Sichelrinne als Ausdruck des Einstïlpungsprocesses auftreten. Die Sichelrinne liegt aber nicht am Keimscheibenrande, sondern in einiger Entfernung von demselben. Auch hier wird die Sichelrinne bis auf einen kleinen Rest verengert und vor diesem entsteht die Primitivrinne. Primitivrinne

A.

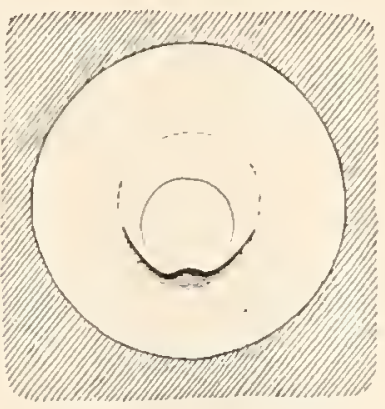

B.

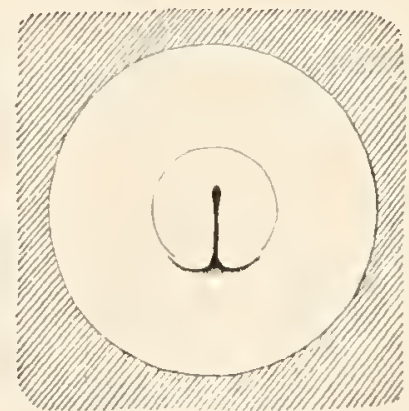

Fig. 94. Zwei Stadien der Keimscheibe des Hühnchens (nach KoLlE1).

A. Mit Sichelrinne und Embryonalschild.

B. Sichelrinne verkleinert, davor die Primitivrinne.

und Gastroporus erscheinen hier also, schon von Anfang, an der Keimscheibe mittelständig. Wenn wir dies mit dem Verhalten bei den Selachiern vergleichen, so kommen wir zu der Vorstellung, dass 
von der entgegengesetzten Seite des Blastoderms sich schon sehr frühzeitig Theile vorgeschoben haben, durch welche das Bildungsmaterial der Sichelrinne vom Blastodermrande abgedrängt wurde, oder mit anderen Worten, es haben die Wachsthumserscheinungen am Lecithoporus schon sehr frühzeitig begonnen, bevor noch die Invagination sich bemerkbar machte.

Gastrulation der Säugethiere. Nach der übereinstimmenden Meinung der Forscher sind die Entwicklungsvorgänge der Säugethiere von denjenigen der anderen Amnioten ableitbar, aber durch den Verlust des Nahrungsdotters wieder in eigenthümlicher Weise modificirt. Eine Aufklärung der Vorgänge im Speciellen verdanken wir namentlich deu neuesteu Untersuchungen vaN BenEDEN's. Aus der adäqualen Furchung

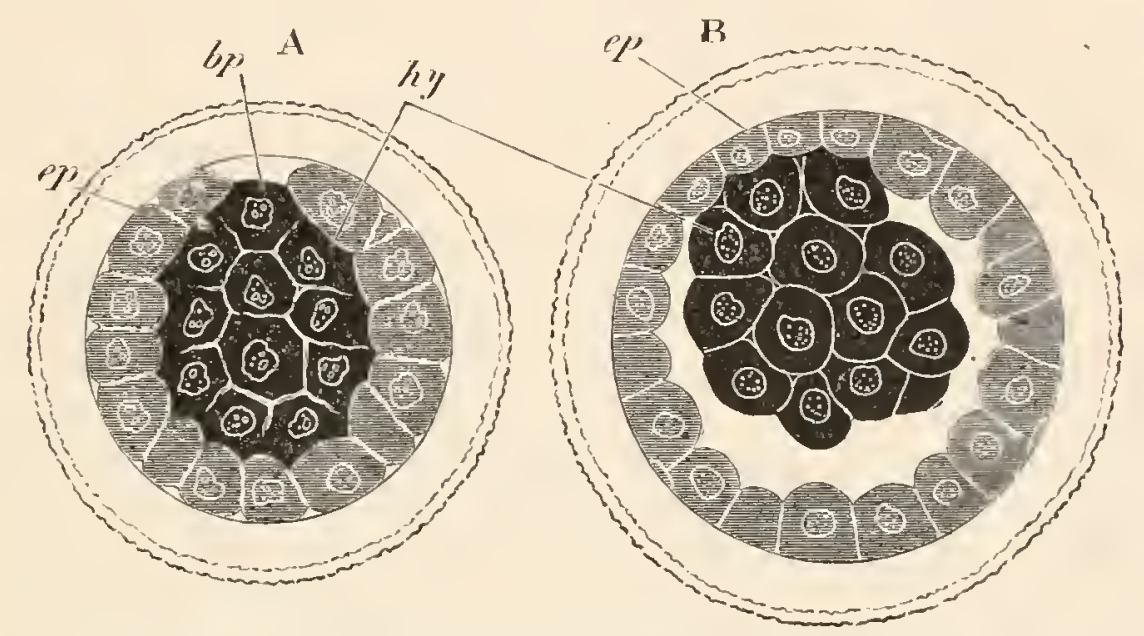

Fig. 95. Entwicklungsstadien des Kaninchens im Durchschnitt (nach VAN BENEDEN). ep Blastoderm, hy erstes Entoderm.

geht eine epibolische Pseudogastrula hervor, die sich vollkommen schliesst. Diejenigen Zellen, welche an der Obertläche liegen, bezeichnen wir als Blastoderm, die inneren Zellen wollen wir erstes Entoderm nennen (dasselbe entspricht wohl den „Dotterzellen“ der anderen Wirbelthiere). Dieser Keim dehnt sich dann zur Form einer Blase aus (Keim b las e); das Blastoderm umschliesst die geräumige Höhle, während das „,erste Entoderm" als eine Anhäufung von dunklen Zellen an einer beschränkten Stelle liegt; es breitet sich dann aber allmählich an der Innenfläche der Blase aus. Jetzt erst entsteht eine Einwucherung des Blastoderms, die sich als $\mathrm{z}$ we ites Entoderm zwischen die

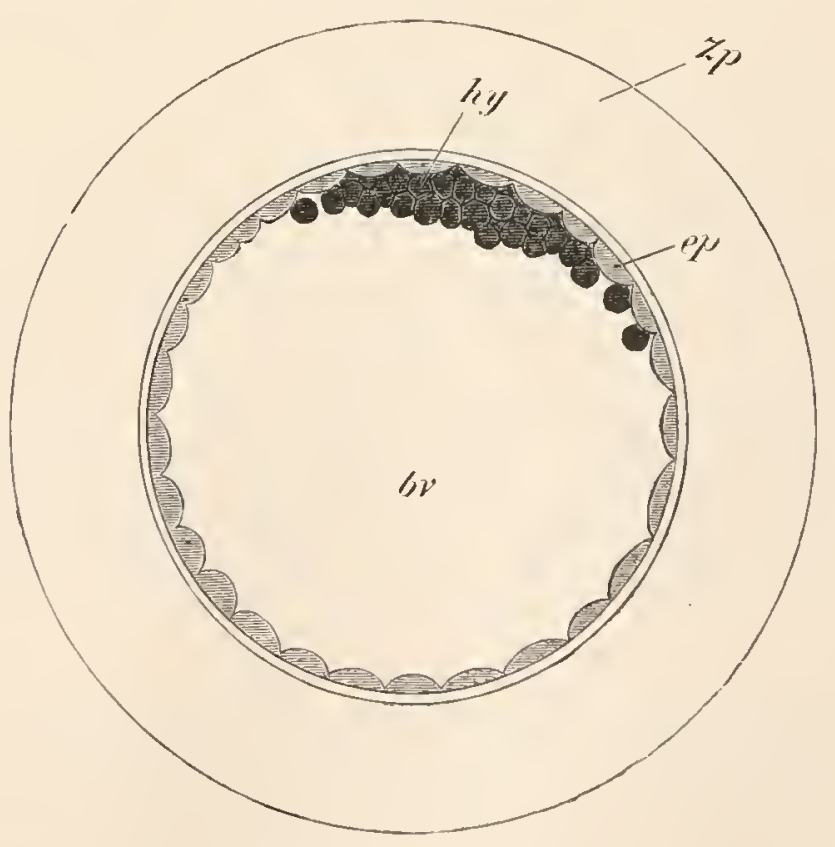

Fig. 96. Keimblase des Kaninchens (nach van Beneuen). ep Blastoderm, $h y$ erstes Entoderm. 
Zellen des ,ersten“ drängt. Dieses zweite Entoderm liefert alle wichtigeren Gebilde, die bei den anderen Amnioten vom Entoderm aus entstehen. An der Stelle der Einwucherung tritt auch die Primitivrinne und der Gastroporusrest auf, so dass die Uebereinstimmung mit den Entwicklungsstadien anderer Wirbelthiere hergestellt ist ${ }^{1}$ ).

A n m. Wir haben in unserer ganzen Darstellung angenommen, dass der Gastroporusrest (der zum neurenterischen Porus wird) stets am Hinterende der Primitivrinne gelegen sei. Einige Autoren geben aber an, dass in mancheu Fällen der erst spät nachweisbare neurenterische Porus am Vorderende der Primitivrinne liege. Wenn man in Erwägung zieht, dass die Umgebung der Primitivrinne (der Primitivstreif) vorn stetig durch Weiterbildung aufgebraucht wird, während sich dieselbe hinten durch Wachsthum fortwährend erneuert, so ergibt sich, dass es in diesem späten Stadium etwa nur ein abortiver $R$ est der Primitivrinne sein kann, der hinter dem neurenterischen Porus liegt, während der grössere bereits aufgebrauchte Theil derselben vor dieser Stelle lag. (Aehnlich fasst dies auch O. HERTwIG auf.)

\section{Erste Differenzirungserscheinungen der primären Ke i m blät ter.}

In den meisten Fällen, wo der Nahrungsdotter in der Eizelle nur einigermaassen beträchtlich ist, geht bei der Furchung die überwiegende Nenge von Nahrungsdotter in die zukünftigen Entodermzellen iiber; die Entodermzellen sind reicher an Nahrungsdotter und sie haben die Aufgabe, denselben zur Assimilation (d. i. zur Umwandlung in Plasma) und zwar für das Wachsthum des gesammten Embryo rorzubereiten. Der functionelle Charakter, der den Entodermzellen zukömmt, ist demnach schon frühzeitig in ihrem Verhältnis zum ersten Nahrungsmateriale, den Dotterkörnchen ausgeprägt. Aber auch in jenen Fällen, wo wenig Dotterkörnchen vorhanden sind, ist eine Verschiedenartigkeit von Ectodermund Entodermzellen in Bezug auf Grösse und Plasmabeschaffenheit vorhanden. In der Regel sind die Ectodermzellen kleiner und besitzen ein dichteres, durchsichtiges Plasma, während die Entodermzellen grösser und deren Plasma lockerer und wenig durchsichtig ist. Es findet demnach eine verschiedenartige Differenzirung der anfangs meist gleichartigen Furchungszellen statt.

Dieses Entwicklungsgesetz der Differenzirung, welches sich schon bei der Entstehung der primären Keimblätter geltend macht, indem das einfache Blastoderm in zwei durch Lage und Structur verschiedenartige Theile, Ectoderm und Entoderm sich sondert, ist dasselbe, welches auch dort sich ausprägt, wo in dem weiteren Entwicklungsgange ein viel complicirterer Bau erreicht wird. Ursprünglich einfach erscheinende Anlagen sondern sich in verschiedenartige 'Theile, so dass der Bau allmählich vom Einfachen zum Zusammengesetzteren fortschreitet. „Die individuelle Entwickelung ist ein Fortschreiten aus einer allgemeineren Form in eine mehr specielle" (C. E. V. BAER).

1) Obige Darstellung folgt einem Vortrage, den VAN BENEDEN bei der anatomischen Versammlung in Würzburg kürzlich gehalten hat; erst während der Correctur dieses Buches liegt uns die ausfübrlichere gedruckte Mittheilung vor, deren Nomenclatur daher hier noch nicht berücksichtigt werden konnte. 


\section{ACHTES CAPITEL.}

\section{Metazoa (II. Histologie).}

Bei den Metazoen zeigen die Zellen in verschiedenen Körpertheilen eincn verschiedenartigen Ban, welcher mit ilner verschiedenturtigen Function zusammenliungt. Es ist darin die Arbeitstheilung des \%ellenstaates (Zellencormus) ausgeprägt. In bestimmter Weise verbundene Zellen und deren Unwandlungsprodukte bilden die sogenamuten G e w e b e. Je höher ein Thier (Metazoon) organisirt ist, nm so mannigfaltiger erscheinen seine Gewebe und nmso mellraber sind diese Gewebe in Bezug anf illre Beschaffenleit nud physiologiscle Leistung specialisirt, und es ist daher jedes einzelne dieser mannigfaltigen Gewebe in sich gleichartiger. - Aus den Geweben sind die Organe des Körpers zusammengesetzt. Ein Organ kamn aus einerlei orler ans melrerlei Geweben bestehen.

Wir haben bei Betrachtung der Gewebe zwei Hauptpunkte zu berüicksichtigen: 1) das Lagerungsverhältnis der Zellen und 2) die Structur der Zellen und ilner Produlkte.

\section{Grundformen der Zelliagerung.}

1. Das Epithel (epitheliales Gewebe).

Die älteste und wichtigste Grundform des Metazoengewebes finden wir schon im Blastoderm der Blastula, welches von einer einfachen Zellenlage gebildet wird, ansgeprägt. Solche flächenhaft angeordnete Zellmassen werden als Epithel bezeichnet und wemn die Zellen, wie in dem vorliegenden Falle, in einfacher Schichte liegen, nennen wir das Epithel ein e in s ch ic htiges. Wir unterscheiden am Blastoderm zweierlei Flächen, eine freie Fläche, welche der Anssenwelt und eine Ba salflä c h e, die dem Blastocoel zugewendet ist. Dementsprechend unterscheiden wir an der einzelnen Zelle des epithelialen Mosaiks einen freien Pol und einen basalen $\mathrm{Pol}^{1}$ ). Diese beiden Flächen des Epithels zeigen einen verschiedenartigen Charakter. So können z. B. an der

1) Wir wollen hier darauf hinweisen, dass man die Blastula auf ein entsprechendes phylogenetisches Stadium, die Blasta e (HAECkEL, Claus) zuriickführt, welches als eine volvoxähnliche Flagellatencolonie dargestellt wird. Die einzelligen Vorfahren der Metazoen sollen Flagellaten gewesen sein (BÜTSCHLI). Die polare Differenzirung des Flagellatenindividuums wäre also in der entsprechenden Eigenthümlichkeit der Epithelzelle erhalten. Das geisseltragende Ende des Flagellatenkörpers würde dem freien Pol der 
freien Fläche Geissel- oder Flimmerhaare (selbst schon im Blastulistadium) sich bilden, niemals aber an der Basalfläche; und in ähnlicher Weise kommt - wie sich im speciellen erweisen wird - der urspringliche typische Gegensatz der Flii-

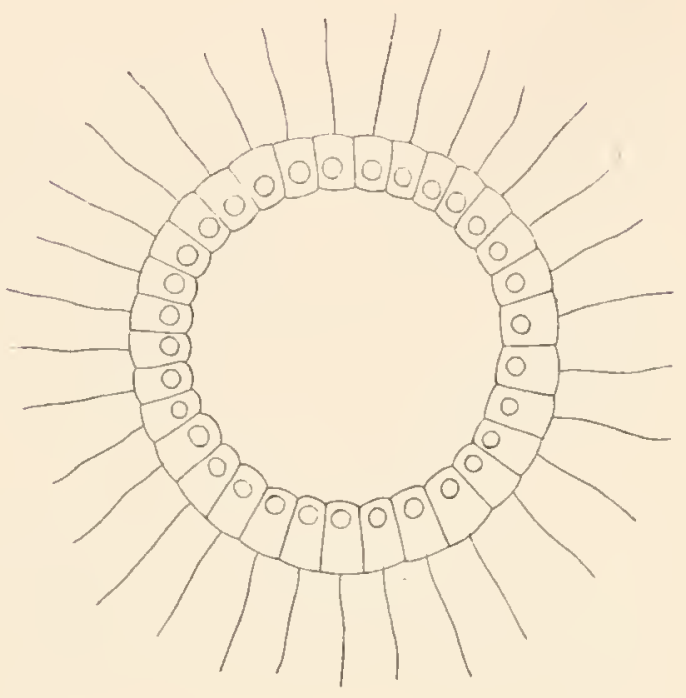
then bei sehr zahlreichen Differenzirungen der Epithelzellen zur Erscheinung. Wenn von dem primären Blastoderm noch so mannigfache Faltungen ausgehen, so hleibt doch immer, selbst an den complicirtesten Bildungen, dieser gegensätzliche Charakter der beiden Flächen in gesetzmässiger Weise gewahrt.

Fig. 97. Blastulastadium eines Echinodermen (nach Selenka). Im Durchschnitt gesehen. Das einfache Epithel trägt an seiner freien Fläche Geisselhaare (welche den Embryo im Meerwasser schwebend erhalten).

Die einschichtigen Epithelien werden je nach der Form ihrer Zellen als Cylinderepithel, kubisches Epithel, Plattenepithel bezeichnet.

a.

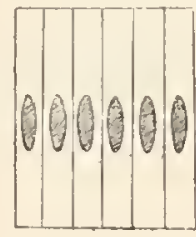

d.

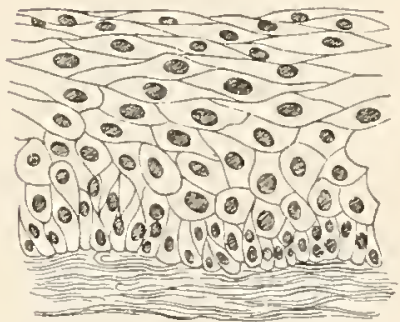

b.

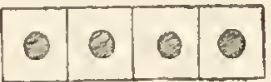

$\mathrm{e}_{1}$.

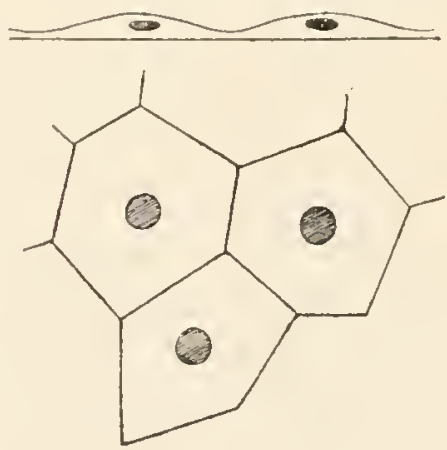

Fig. 98. Verschiedene Epithelformen.

a. Cylinderepithel, Durchschnitt. b. Kubisches Epithel, Durchschnitt. $c_{1}$. Plattenepithel, Durchschnitt. $c_{2}$. Dasselbe, Flächenansicht. d. Geschichtetes Epithel, Durchschnitt.

Epithelzelle entsprechen. - Von grossem Interesse wäre nun die Frage, ob die Polarität der Fortpflanzungszellen, die sowohl an der reifen Eizelle, als auch an der reifen Samenzelle sich bemerkbar macht, in einem bestimmten Verhältnis zu den Flächen des Keimepithels stehe. In Bezug auf die Spermatozoen kann man schon jetzt, auf cine grosse Reihe von Thatsachen gestuitzt, den Satz aussprechen, dass ihre Geisselanhänge der freien Fläche des Keimepithels entsprechen. Die Eizelle betreffend ist eine Anzahl von Fällen bekannt, in welchen der animale Pol des Eies mit der freien Fläche des Keimepithels übereinstimmt (z. B. Lamellibranchiaten). Es ist aber noch zu untersuchen, ob dieses Verhalten durch die ganze Thierreihe sich gleichartig wiederholt. 
Es gibt auch meln rechichtige (od. gesclichtete) Epithelien, z. B. in der Oberhant der Wirbelthiere. Die geschichteten Zellen sind nicht in der ganzen Dicke des Epithels gleichartig; in der Regel sind die oberflächlichen '/ellen mehr abgeplattet. In der inittleren und unteren Schichte des Epithels ist die Polarität der Zellen oft wenig ausgeprägt.

In seltenen Fällen leitet sich aus der Schichtumg des Epithels eine vollkonmene Spaltung in gesonderte Lamellen (Delam in a t i o n) ab. (vergl. pag. 122 und 134.)

\section{Epithelogenes Gewebe.}

Wir kennen Gewebe, welche a us zusammenlı̈̈ngenden Epithelstücken sich bilden, dabei aber entweder ihre Lagerung oder ihren flächenhaften Charakter so weit veränder'n, dass wir sie nicht mehr schlechtweg Epithelien nennen können. Wir werden sie als epithelogene Gewebe bezeichnen.

\section{Mesenchymgew ebe.}

Von der Basis des Epithels aus können einzelne Zellen in das Blastocoel (oder in demselben entsprechende Räume) einwandern, indem sic zunächst amöboide Beschaffenheit annelimen und daher in der Regel mit einfachen oder verästelten Fortsätzen ausgestattet sind. Sie büssen dabei ihre frühere polare Differenzirung ein und sinkeu so secundär zum Charakter von apolaren Zellen herab. Wir nennen diese Zellen Mesench y m zellen (O. mind R. Hertwig). Die Mesenchymzellen könuen wieder zur Bildung von Geweben in bestimmten Formen zusammentreten mol mancherlei Differenzirungen annehmen. Wir bezeichnen solche Gewebe als Mesenchymgewebe. Der Charakter der Mesenchyuzelle kann dabei wieder in höherem oder geringerem Grade verwischt werden, ja sie können sich sogar wieder epithelartig zur Begrenzung von Hohlränmen (oder

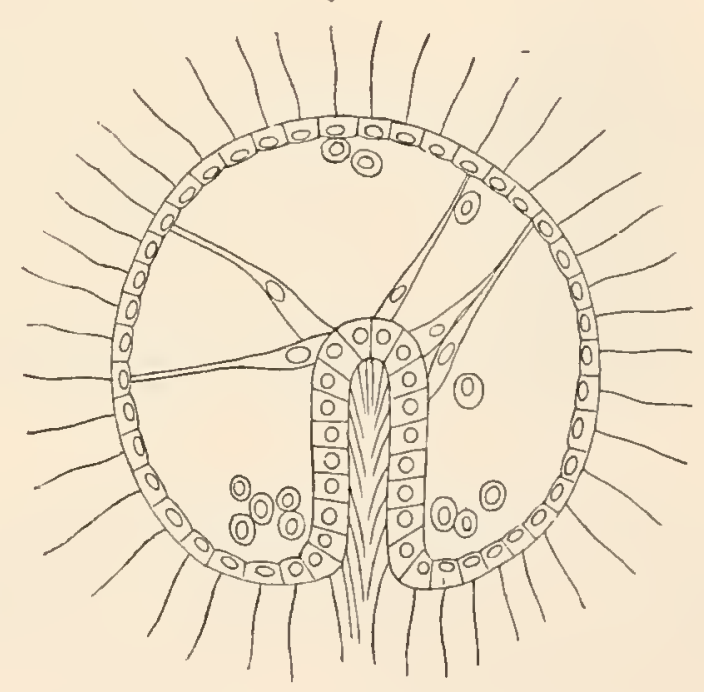

Fig. 99. Frühes Entwicklungsstadium eines Echinodermen (nach SELENKA).

Nebst ectorlermalem und entodermalem Epithel sind im Blastocoel liegende M esench y $\mathrm{mzellen}$ vorhanden. ron Gewebsmassen) anordnen; wir wollen derartige Bildungen als Pseud oepith eli en (oder besser Epitheloide) bezeichnen ${ }^{1}$ ).

1) His war der Erste, der die Entstehung derartiger Bildungen ins Auge fasste und hiefuir den Namen Endothel eingefiihrt hat; da aber von ihm die Auskleidung des Coeloms, die jetzt als echtes Epithel anerkannt wird, besonders unter den Begriff des Endothels gestellt wurde, so möchte die Beibehaltung dieses Terminus zu Missverständnissen führen, und nur aus diesem Grunde möchte ich einen neuen Terminus vorziehen.

Gewisse maskirte Invaginationsprocesse - z. B. die Entodermbildung durch Einwanderung von Zellen in das Blastocoel mit späterer Anordnung derselben zu einem Epithel - haben grosse Aehnlichkeit mit der Bildung von Pseudoepithelien, so dass die Beurtheilung solcher Vorgänge in jedem einzelnen Falle noch mancherlei Schwierigkeiten darbietet.

II a t s che k, Lehrbuch der Zoologie. 
Wir müssen hier hervorheben, dass wir mesenchymähnliche Zellen auch in der Inhaltsflüssigkeit solcher geschlossener Körperhöhlen finden, die von echten Epithelien ausgekleidet sind (z. B. in den Cölomhöhlen). Derartige isolirte, in Flüssigkeit suspendirte Zellen haben sich in vielen Fällen gewiss auch von der freien Fläche des Epithels abgelöst; sie stimmen also mit dem oben erörterten Wesen der Mesenchymzellen nicht ganz überein und man möchte sie daher mit besonderem Namen bezeichnen. Es ist aber die Entstehung dieser Zellen an und für sich schwer zu beobachten (Mesenchymzellen wandern auch durch Epithelien hindurch) und andererseits sind Blastocoelhöhlen mit coelomatösen Höhlen oft secundär in Verbindung getreten, so dass ihr Inhalt sich mischt; zur Zeit ist daher ein Gegensatz nur in einzelnen Fällen nachweisbar.

\section{Grundformen der Structur.}

So wie bei den Protozoen gehen auch bei den Metazoen alle histologischen Differenzirungen vom Zellplasma aus. Der Ker'n zeigt selbst bei hochdifferenzirten Zellen meist unverändert seine typische Beschaffenheit und in anderen Fällen nur unbedeutende Verändernngen.

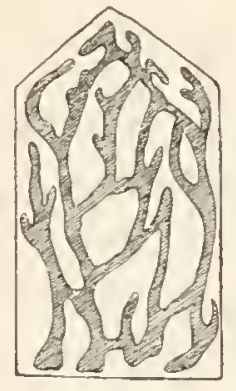

Bei stark abgeplatteten Zellen erscheint auch der Kern abgeplattet, bei gestreckten Zellen verlängert. Seltener sind andere Formveränderungen; so besitzen z. B. die grossen Zellen in den Spinndrüsen der Seidenraupe Kerne von verästelter Form; in den rothen Blutkörperchen der Säugethiere ist der Kern geschwunden.

Fig. 100. Epithelzelle mit verästeltem Zellkern von der Fläche gesehen, aus der Spinndrüse der Seidenraupe (nach HELM).

Untel den Differenzirungen, die vom Plasma aus entstehen, kennen wir solche, die nur als besondere Plasmaarten gelten kömnen, an welchen gewisse Plasmafunktionen (Contractilität, Reizbarkeit etc.) in erlöhtem Masse zur Erscheinumg kommen (Muskelsubstanz, Nervensubstanz).

Andere Differenzirungen wieder erweisen sich vom Plasma selbst so verschieden, dass sie nur als Produkte desselben betrachtet werden können. Wir wollen die ersteren als a u toplas m a t is che, die letzteren als a poplasmatische Structuren bezeichnen.

\section{Autoplasmatische Structuren.}

A. Aeussere plasmoide Bildungen der Zelle.

Pseudopodien. Die Pseudopodien spielen eine ähnliche Rolle, wie bei der Protozoenzelle. Sie ermöglichen eine Gestaltveränderung und Forthewegung der Zelle (amöboide Zellen, Wanderzellen) und sie dienen ferner dazu, feste Nahrungskörper in das Imere der Zelle aufzunehmen.

1) Amöboide Epithelzellen. An embryonalen Epithelien kömmt Pseudopodienbildung vielfach vor, namentlich zum Zweck der Dotteraufnahme, - ebenso bei pathologischen Processen (Entzïndungsprozess). Bei dem entwickelten Thiere finden wir Pseudo- 
podienbildung am ectodermalen Epithel nur bei den niedersten Metazoen, den Spongien. Am Endodernepithel aber ist Psendopodienbildung an der freien Epithelfläclı, zun Zwecke der Nallirungsaufualme, bei Thieren aus den verschiedensten Classen (selbst bei Wirbelthieren) beobachtet worden; besonders häufig ist diese Ersclieinumg bei niedligeren Metazoen (Cnidarier, Turbellarien).

2) A möboide Mesencliymzellen. Hier ist die Pseudopodienbildung schon füi die Grundform der Mesenchymzelle, die als anöboide Zelle erscheint, typisch, und es bleibt diese Eigenthïmlichkeit auch bei vielen Modificationen der Mesenchymzelle erhalten; wir wollen als wichtigste Beispiele anführen: zunächst die e m b r y ou a l e Mesen chy mz elle, welcher ganz allgenein die amöboide Beweglichkeit zukömmt, ferner die , fre i e Bind egew ebszelle" (Fig. 101), die noch einen älnulichen ursprünglichen Charakter besitzt und oft als "Wanderzelle" imerhalb des Organismus ihren Ort wecliselt. Dieser Zellenart nalıe verwandt sind die amöboiden Pigmentzellen (Fig. 102), die iı vielen Fällen durch abwechselnde Ausbreitung und Zusammenziehumg der Psendopodien die Erscheinung des Farbenwechsels

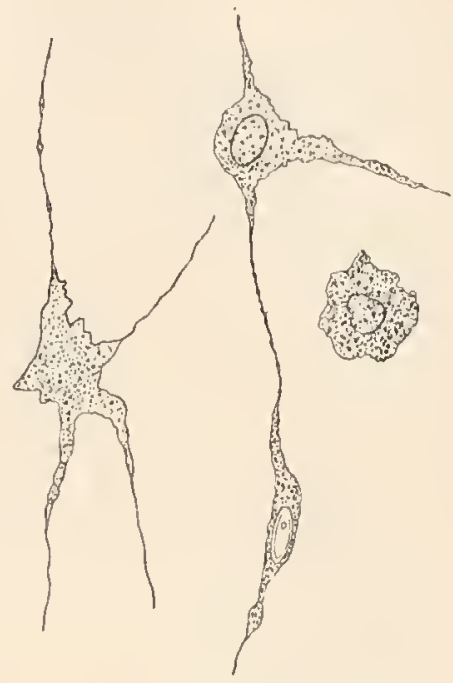

Fig. 101. Freie Bindegewebszellen vom Frosche (nach FREY). der Thiere hervorrufen. Sie liegen als Mesenchymgebilde ursprïnglich unterhalb der Epithelien, wandern aber oft secundär wieder in dieselben ein. Endlich finden wir amöboide Zelleu als, a möboide Blutkörperchen" in der Blutflüssigkeit

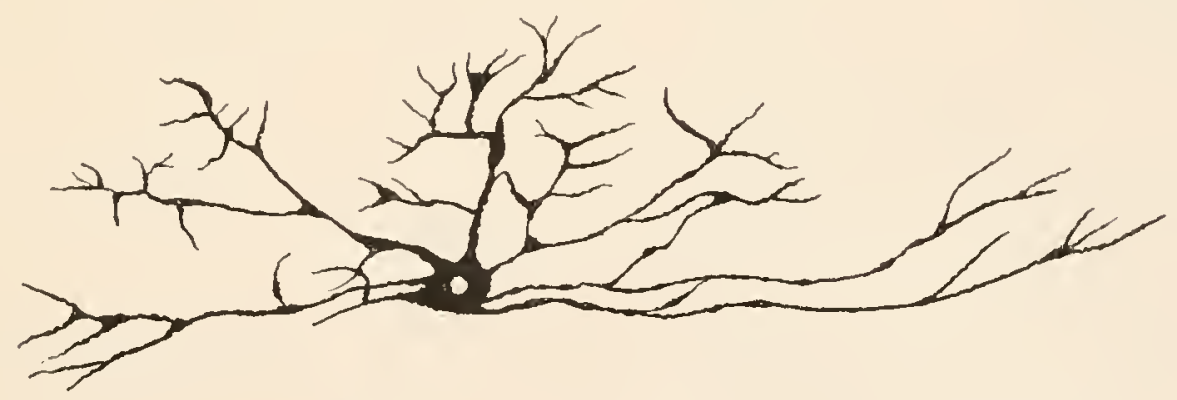

Fig. 102. Pigmentzelle aus dem Eierstock von Piscicola (nach I_EYDIG).

vieler Thiere (z. B. bei Arthropoden, Mollusken; bei den Wirbelthieren sind sie als ,weisse Blutkörperchen" (Fig. 103) neben den nicht amöboiden sog. ,rothen Blutkörperchen" vorhanden) und als ,Lymphkörperchen“6 in der Coelonıhöhle und in Gewebsliicken. In jenen Fällen, wo Blutgefässsystem und Coelomhöhle in Communication stehen, sind amöboide Blıtkörperchen und Lymphzellen identisch.

Fig. 103. Weisse Blutkörperchen vom Menschen in verschiedenon Bewegungszuständen (nach FreY).

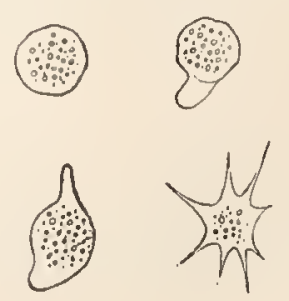


Flimmerhare. Flimmerhane finden wir nur an der freien Fläche von Epithelien, und zwar sowoln an geschichtetem Epithel, als auch an Cylinder-, cubischem und Plattenepithel. [Eine Ausuahme bilden die Kanälchen des Protonephridiums bei den Scoleciden nurd den Larven der Metascoleciden, die ihrer Entstehung nach auf ausgehöhlte Mesenchymzellen zurïckznführen sind (?), und dennoch in ihrem Lmmen Flimmerbildmengen zeigen.]

Wir unterscheiden Geisseln, das sind Flimmerhare, die einzeh auf je einer Zelle sitzen, und meist von ansehnlicher Länge sind (dies scheint die phylogenetisch älteste Form der Flimmerhare bei den Metazoen zu sein) nnd IV impern, die zahlreich die freie Fläche je einer Zelle bedecken mnd meist kürzer sind; wir kemnen auch Zwischenstufen,

a.

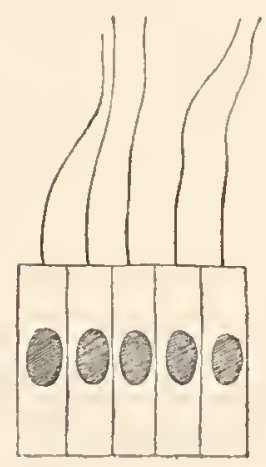

c.

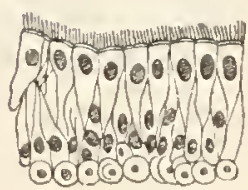

b.

1.
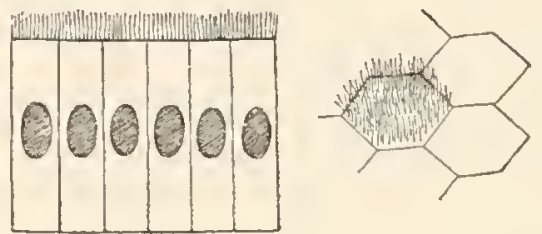

d.

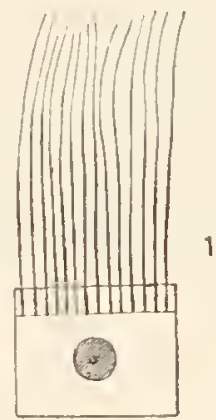

e.

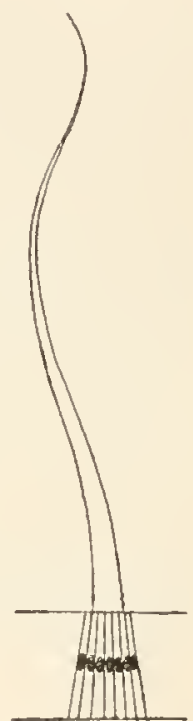

Fig. 104. Verschiedene Flimmerhaare.

a. Geisselepithel, Durchschnitt.

b. Wimperepithel. 1) Durchschnitt. 2) Flächenansicht; die Wimpern sind nur an einer Zelle dargestellt.

c. Geschichtetes Wimperepithel, Durchschnitt.

d. Zellen mit reihenweis gestellten Wimpern aus dem Wimperkranz einer Annelidenlarve. 1) Zelle von der Seite gesehen. 2) Zwei Zellen von der freien Fläche gesehen, mit den Ansatzstellen der Wimpern.

e. Zusammengesetzte Geissel von einer Mehrzahl von Zellen getragen.

da wir z. B. je eine einfache Reihe von Wimpern an einer Zelle finden. Es giebt anch zusammengesetzte Flimmerharbildungen: zahlreiche Geisseln (oder Wimpern) können zn einer dickeren z u s a m m en gesetzten Geissel verschmelzen. Durch Verschmelznng reihenweis gestellter Wimpern entstehen die eigenthümlichen schwingenden W i m p e r' platten der Ctenophoren.

In einigen Thiergruppen fehlen die Flimmerhaare nicht nur in der Organisation des ausgebildeten Thieres, sondern auch in der Entwicklung. Es sind dies die Arthropoden, Nematoden (und Acanthocephalen). Es ist auffallend, dass bei diesen Thieren zugleich cuticulare Bildungen in hohem 
Grade ausgebildet sind. Interessant ist es ferner, dass bei der Mehrzahl dieser 'Thiere, wie schon früher erwähnt, selbst die Spermatazoen ihre Geissel eingebüsst haben.

Sinneshare (Stifte, Stäbchen). Wir bezeichnen als Sinneszelle n epitheliale Zellen, die in der Regel an ihrem freien Ende mit S inn e shärchen (Stiften, Stäbchen) versehen sind und an ihren basalen Ende mit Nerven in Verbindung stehen.

(Es gibt auch Gebilde die man als Zwischenstufe von Geissel und Simneshaar ansehen könnte; es ist daher die Anreihung dieser Gebilde an die Wimpergebilde eine naturgenässe.)

Wir unterscheiden: 1) Sinneshärchen; das sind starre feine Härchen von ansehnlicher Länge, die einzeln oder auch in Mehrzahl auf dem freien Ende je einer Sinneszelle sitzen. Diese Gebilde haben namentlich bei den Wirbellosen die weiteste Verbreitung, sie finden sich an der Körperoberfläche der Tastwerkzeuge, sowie in den Gehörorganen etc.

2) Ganz ähnliche Bildungen, die aber kürzer und dicker als die Simneshärchen sind, werden als $\mathrm{S}$ tif te bezeichnet.

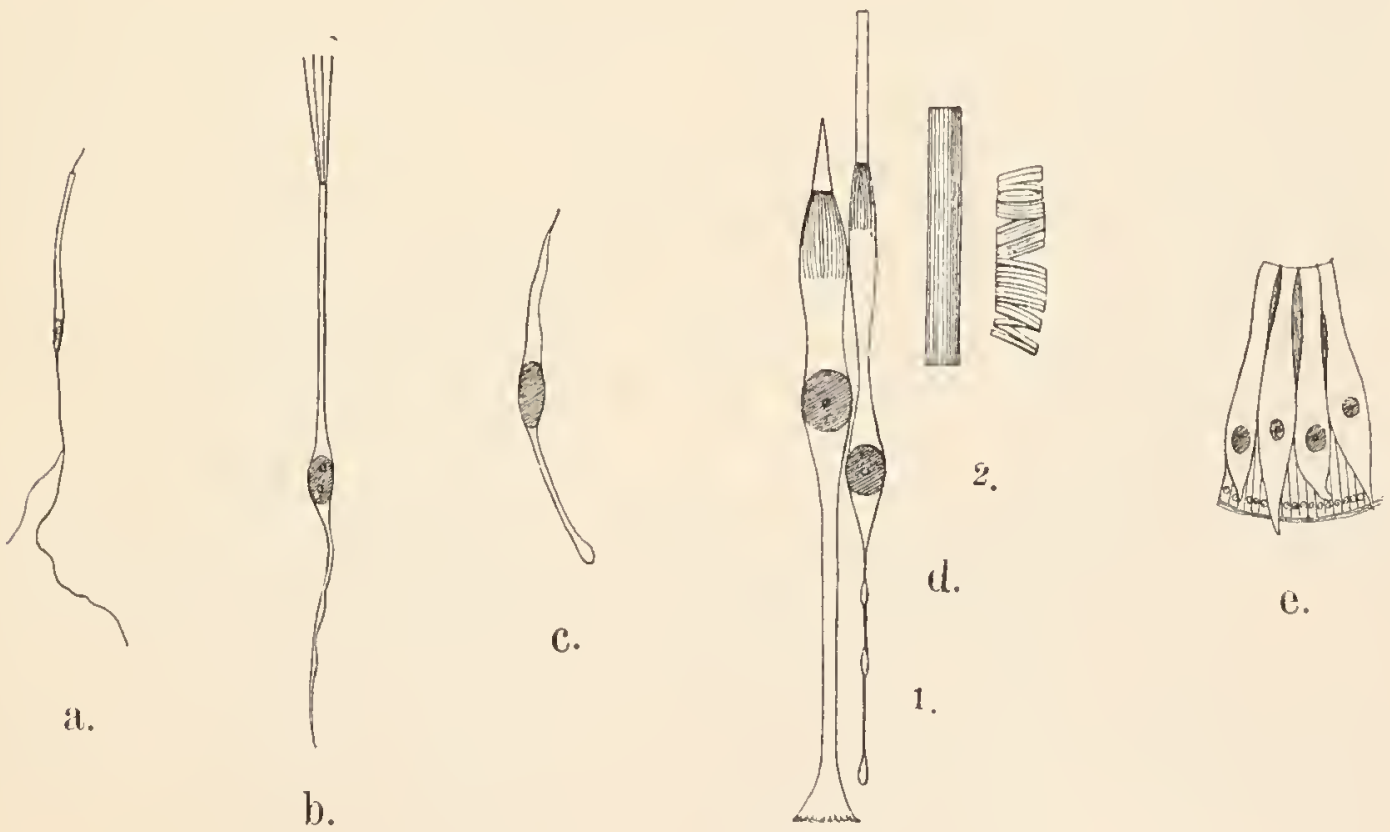

Fig. 105. Verschiedene Sinneszellen.

a. Sinneszelle einer Actinie, mit e in em Sinneshärchen am freien Ende der Zelle und mit zwei Ausläufern an der Basis, von welchen der eine nervöser Natur ist (nach HER'TwIG).

b. Sinneszelle aus dem Riechepithel des Frosches (nach M. Schultze).

c. Sinneszelle aus dem Geschmacksorgan des Kaninchens (nach ENGELMANN).

d. 1) Stäbchen- und Zapfen tragende Zellen aus der Retina des Menschen, 2) Stäbchen aus der Retina des Frosches im frischen und im macerirten Zustande (nach M. ScHULTZE).

e. Durchschnitt aus der Retina des Sloorpions. Zwischen den grossen Sehzellen liegen die Rhabdome (nach RAY.LANKESTER).

3) Endlich gehören hierhei die sogenannten Stäbchen, welche sich am freien Ende der Sehzellen (Sinneszellen des Auges) finden. Diese ansehnlichen Bildungen lassen oft besondere Structuren (Querschichtung, Längsfaserung) erkennen. Hier gibt es auch vom Grund- 
typus weiter abweichende Bildungen. So können die Stäbchen benachbarter Sehzellen miteinander verschmelzen („Rhabdome“, z. B. bei Arthropoden). Derartige Rhabdome haben ihre Lage meist zwischen den Seitenflächen der Sehzellen. Endlich sind auch stäbchenartige Gebilde sogar im Inneren des Plasmas der Sehzellen gelagert (Skorpion, Kreuzspinne).

Cnidocil. Cnidocils sind den Sinneshaaren ähnliche, starre Fortsätze, die an der freien Fläche der N e ss elzellen (bei den Cnidariern) sitzen und zu der Entladung dieser Zellen in Beziehung stehen.

Fig. 106. Nesselzelle von Hydra (nach F. E. Schulze).

Im Inneren die Nesselkapsel, welche den Zellkern zur Seite gedrängt hat; an der freien Fläche das Cnidocil.

\section{B. Innere plasmoide Bildungen der Zelle.}

\section{Muskelfibrille und Muskelgewebe.}

S tructure le ment. Die Muskelfibrille ist das contractile Element, welches innerhalb des Plasmas der Muskelzellen (Myoblasten) entsteht. Sie ist in der Regel fadenförmig, mit zugespitzten oder stumpfen Enden (sehr selten gegabelt oder gar netzförmig). Ihre Länge ist sehr mannigfach; es gibt kurze, beinahe spindelförmige Fibrillen; andererseits gibt es sehr lange Fibrillen, da sie selbst in grossen Muskeln continuirlich durch die ganze Länge desselben sich erstrecken. Sie sind von derber, stark lichtbrechender Substanz. Die Fibrillen bilden, parallel in Bündeln oder in einer einfachen oder mehrfachen Schichte angeordnet, den Inhalt einer einzelnen oder einer Summe von Zellen.

Die Muskelfibrillen sind entweder glatte oder quergestreifte.

Die glatte Muskelfibrille besteht aus gleichmässiger contractiler Substanz.

Bei der quergestreiften Muskelfibrille ist die contractile Substanz in einzelne Theilchen getrennt - Sarcous elements von

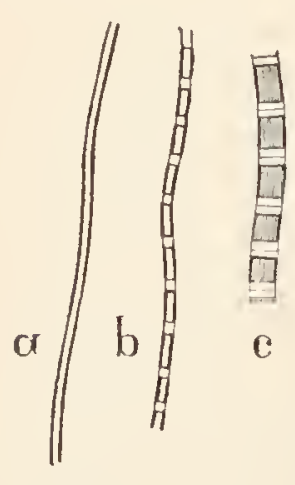
doppelt-lichtbrechender Beschaffenheit - welche durch nicht contractile $\mathrm{Zw}$ is chen s cheiben unterbrochen sind. Diese Querstreifung betrifft eine Summe von Fibrillen (z. B. die in einer "Muskelfaser" vereinigten) in der Regel in derartig übereinstimmender Neise, dass die Sarcous elements in gleichen Ebenen aneinandergereiht sind und dementsprechend die Zwischenscheiben zusammenhängende Platten bilden (Fig. $107 b . c$ und Fig. 110).

Fig. 107. Muskelfibrillen. a. glatte Fibrille, b. quergestreifte Fibrille, c. eine solche sehr stark vergrössert mit den KraUsE'schen Linien in den $Z$ wischenscheibchen.

Muskeln von lebhafter und kräftiger Function besitzen in der Regel quergestreifte Fibrillen. Wir finden solche selbst schon bei Protozoen, ferner bei Cnidariern, Rotatorien etc.'; bei den Arthropoden ist typischer Weise alles Muskelgewebe (Leibesmuskeln und Eingeweidemuskeln) quergestreift; bei den Wirbelthieren enthalten die willkürlichen Körpermuskeln und die des Herzens quergestreifte, die Muskeln des Darmes, der Eingeweide, der Blutgefässe etc. glatte Fibrillen. 
Zellelement. Die Muskelfibrillen entstehen in den Muskelzellen (Myoblasten). Wir unterscheiden hiervon: 1) Epithelmuslielzellen (bei den Cnidariern). Das sind Zellen, welche ihrer Lagerung nach Epithelzellen sind, und an ihrer Basis einen queren Fortsatz, den Muskelfortsatz besitzen; neben der Function als Muskelzellen haben diese Zellen zugleich auch noch die Function von Deckzellen (oder auch eine andere den Epithelzellen eigenthümliche Function). 2) Zellen, die ausschliesslich die Function von Muskelzellen versehen; diese bilden die sogenannten Muskelfasern und sind stets meln im Inneren des Körpers gelegen. Die Muskelfasern sind meist einfach strangförmige (spindelförmige, faden- oder bandförmige), seltener verästelte Gebilde. Wir

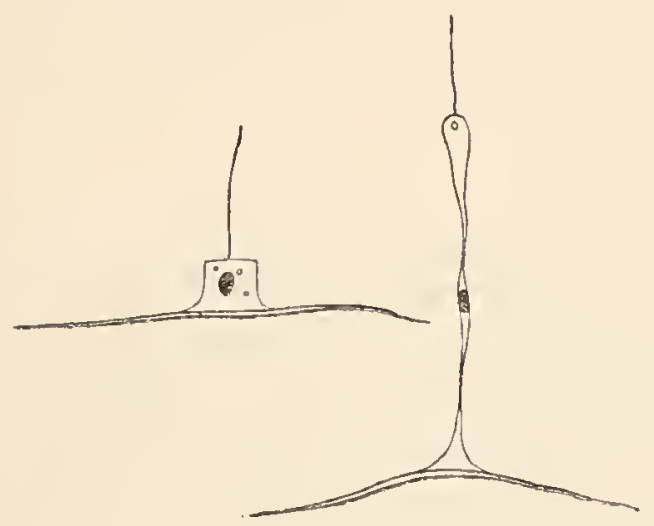

Fig. 108.

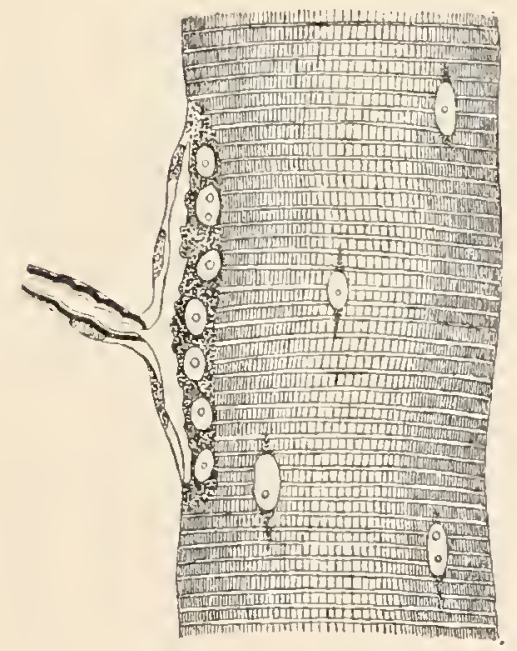

Fig. 110.

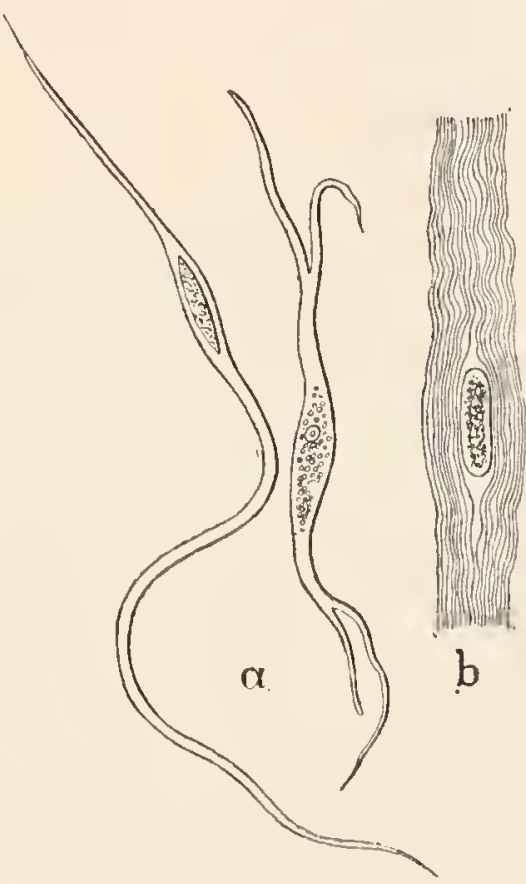

Fig. 109.

Fig. 108. Epithelmuskelzellen, die zugleich mit Geisselhaaren versehen sind, aus dem Endoderm einer Actinie (nach Hertwig).

Fig. 109. a. Glatte Muskelfaser vom Menschen (nach ARNOLD), b. die fibrilläre Structur durch Maceration dargestellt (nach ENGELMANN).

Fig. 110. Quergestreifte Muskelfaser der Eidechse (nach KÜHNE), mit zahlreichen Zellkernen; links an derselben eine Nervenendplatte.

unterscheiden an der Muskelfaser eine äussere Membran (S a r colemna), welche die Bedeutung einer Zellmembran hat, ferner den fibrillären Inhalt und endlich einen Rest von unverändertem Plasma mit dem Zellkern (das sog. Muskelkörperchen). Es gibt auch Muskelfasern mit zahlreichen Muskelkörperchen (quergestreifte Muskelfaser der Wirbelthiere und Arthropoden, glatte, zugleich verästelte Muskelfaser der Ctenophoren); in vielen dieser Fälle (z. B. Wirbelthiere) ist es nachgewiesen, dass eine solche vielkernige Muskelfaser aus einer Zelle durch Vermehrung der Kerne sich bildet (dagegen ist eine Concrescenz von Zellen bis jetzt nirgends beobachtet). 


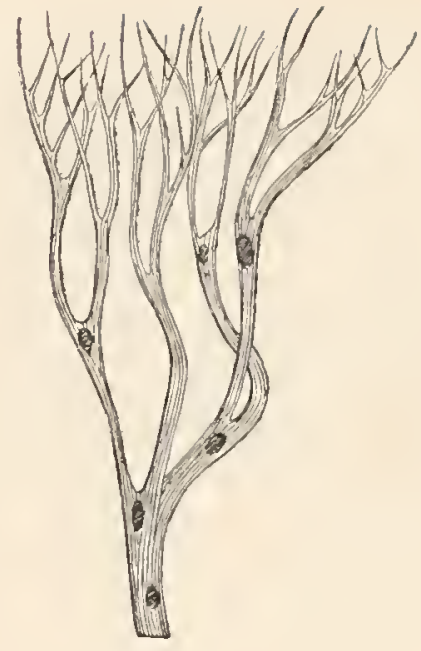

Fig. 111.

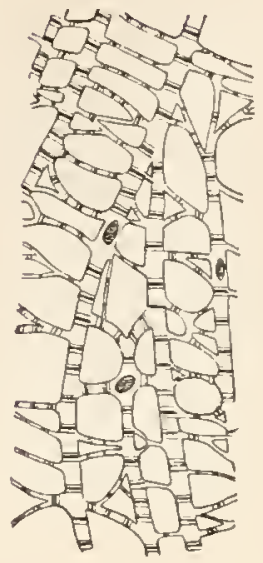

Fig. 112.
Fig. 111. Theil einer glatten Muskelfaser einer Ctenophore, verästelt mit zahlreichen Zellkernen (nach Hertwig).

Fig. 112. Quergestreifte Muskelfasern von der Darmdrüse einer Assel, netzartig mit zahlreichen Kernen (nach WEBER).

Man hat bisher die Muskelfasern nach der Beschaffenheit ihrer Fibrillen in glatte und quergestreifte eingetheilt, doch haben $O$. und R. Hertwig neuerdings darauf hingewiesen, dass dieser Charakter morphologisch von untergeordneter Bedeutung ist. Sie unterscheiden dagegen von genetischem Gesichtspunkte eine Art von Muskelfasern, welche dem epithelialen Muskel näher verwandt ist, während die andere Art mesenchymatösen Ursprungs ist. Da aber in Bezug auf den Bau der Muskelfaser selbst ein Unterschied nicht in allen Fällen nachweisbar ist - wenn auch z. B. die verästelte Form nur bei der Mesenchymmuskelfaser vorkömmt - so ist der Gegensatz vornehmlich durch die Genese und die gewebliche Anordnung der Muskelfasern begründet.

II u skelgewebe. O. und R. Hertwig haben also hervorgehoben, dass gewisse Muskelgewebe, die vom Cölomepithel abstammen, dem echten epithelialen Muskel der Cnidarier verwandt sind und haben beide als „Epithelmuskel" zusammengefasst und dem „Mesenchymmuskel $^{\text {" }}$ gegenübergestellt. Im Epithelmuskel sind die Muskelfasern stets in Massen und zwar parallel verlaufend angeordnet. Die Mesenchymmuskelfaser tritt vereinzelt auf oder auch in Massen; in letzterem Falle können die Fasern mannigfach verflochten und gekreuzt verlaufen od er a u ch parallel angeordnet sein. Wir sehen also, dass auch in Bezug auf die Anordnung der Fasern der Unterschied verschwinden kann. Es gibt dann die Genese des Muskels allein das Criterium $a b^{1}$ ).

Wir werden demnach folgende Arten von Muskelgewebe unterscheiden: 1) Epithelialer Muskel,2) Epithelogener Muskel (diese beiden sind von HeRTwig als „Epithelmuskel" zusammengefasst) und 3) M esenchymmuskel.

Epithelialer Muskel bei den Cnidariern.

Epithelialer Muskel kommt ausschliesslich bei den Cnidariern vor und zwar sowohl am ectodermalen als auch am endodermalen Epithel. Die Muskelfibrillen entstehen stets an der Basalfläche der

1) Die Gegner dieser Eintheilung werden die grosse Schwierigkeit hervorheben, auf welche die Unterscheidung von Mesenchymmuskel und Epithelmuskel in manchen Fällen stösst; doch ist dagegen einzuwenden, dass hier nicht eine ursprüngliche Uebereinstimmung vorliegt, sondern eine Convergenz der Erscheinungen in den extremen Fällen. 
Epithelzellen und verlaufen längs dieser Fläche in bestimmter Richtung zu einander parallel.

In den meisten Fällen findet siclt an jeder Epithelzelle je eine Muskelfibrille, die einen queren Fortsatz bildet, welcher von der Basis der Zelle ausgeht ${ }^{1}$ ).

Fig. 113. Muskelepithel aus dem Endoderm einer Actinie, die Zellen durch Maceration isolirt. Jede Zelle mit einer Fibrille versehen (nach Hertwig).

Fig. 114. Muskelepithel einer Meduse. Die Fibrillen sind gemeinsames Product der Epithelzellen(?). Sehematisch.

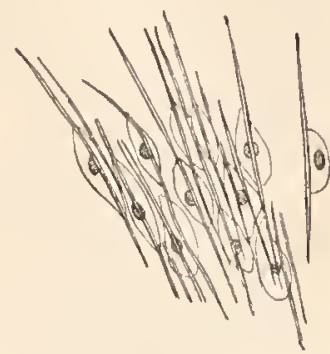

Fig. 113.

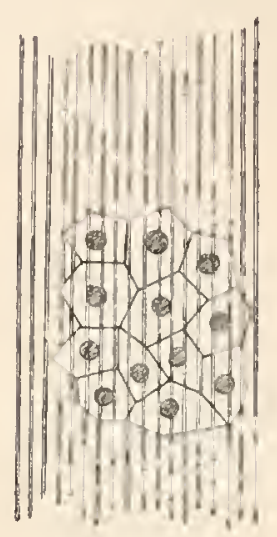

Fig. 114.

In manchen Fällen hat es den Anschein, als ob sich eine Mehr-zahl von Zellen gemeinschaftlich an der Bildung einer Mehrzahl von Fibrillen betheiligte; jede Fibrille durchzieht zahlreiche Zellen und dabei kommen auf die Breite einer Zelle mehrere Fibrillen nebeneinander zu liegen; die Fibrillen durchziehen also die Basis der Zellen, ohne von den Zellgrenzen abhängig zu sein. Dieses Verhalten scheint aber nicht genügend sichergestellt $\mathrm{zu}$ sein.

Massenzunahme der Fibrillen erfolgt beim epithelialen Muskel selten durch Schichtung der Fibrillen, sondern zumeist durch Faltenbildung einer einfachen Fibrillenschichte. Die fibrillenerzeugende Basis des Epithels, an welcher die Fibrillen in einfacher Schichte aneinandergereiht sind, bildet nämlich $\mathrm{L}_{\text {än }} \mathrm{g} \mathrm{s}$ falten (d. h. Falten parallel zur Längsrichtung der Fibrillen), welche unter Umständen eine sehr bedeutende Höhe erreichen und so eine bedeutende Mächtigkeit der Fibrillenschichte bedingen. Die Myoblasten bilden dann häufig eine besondere tiefe Schichte des (geschichteten) Epithels und kommen innerhalb der Fibrillenfalteı zu liegen.

a.

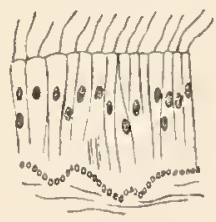

b.

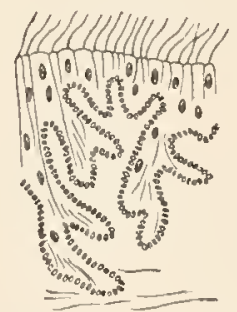

c.

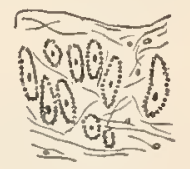

Fig. 115. Faltung des Muskelepithels vom Endoderm einer Actinie, Durehschnitte (nach Hertivig).

a. Faltung angedeutet, b. stärker entwickelt, e. abgelöste, epithelogene Muskelstränge.

\section{Epithelogener Muskel bei den Cnidariern.}

Wenn solche Fibrillenfalten mit ihren Myoblasten vom Epithel sich abschnüren, so entstehen subepitheliale, strangförmige Gebilde, die an der Peripherie eine einfache Schichte von Fibrillen, in der Achse die

1) $\mathrm{Ob}$ dieses Gebilde wirklich eine einfaclie Fibrille ist (wie allgemein angenommen wird), dies mag dahingestellt bleiben; wir wollen nur hervorheben, dass sonst stets eine Summe von Fibrillen je einer Muskelzelle (Muskelfaser) angehört. 
Myoblasten zeigen. An ein und derselben Körperstelle können alle Uebergänge zwischen epithelialem Muskel und derartigen epithelogenen Muskelsträngen vorkommen.

In seltenen Fällen findet einfache Delamination statt, wodurch

a.

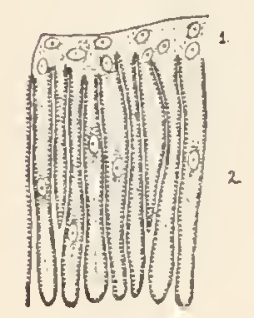
eine oberflächliche Deckschichte und eine tiefere Myoblastschichte scharf von einander gesondert werden.

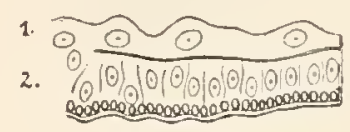

Fig. 116. a) Muskelepithel einer Meduse im Durchschnitte mit 1. Deckschichte und 2. gefalteter Muskelschichte (nach HerTwig).

b) Muskelepithel einer Meduse im Durchschnitte mit 1. Deckschichte und 2. durch Delamination gesonderter Muskelschichte (nach HERTwIG).

Epithelogener Muskel bei Coelomaten.

Bei den meisten Coelomaten (den Articulaten, Ambulacraliern und Chordoniern) entsteht ein bedeutender Theil der Körpermuskulatur (in der Regel Längsinuskeln) aus dem Coelomepithel. Die Art und Weise, wie diese Muskeln vom Epithel sich sonderm, ist im allgemeinen auf dieselben Gesetze zurückzuführen, die bei den ectodermalen und endodermalen Muskeln der Cnidarier sich zeigen. Wir finden die verschiedensten Stufen der Sonderung; in den ursprünglichsten Fällen könnte man die Muskeln sogar noch als epitheliale bezeichnen. Wir wollen einige typische Beispiele hier kennen lernen.

\section{Reihe der Articulaten.}

A nneliden. Die Längsmuskeln der Leibeswand sind Differenzirungen des Coelomepithels, und $\mathrm{zwar}$ des somatischen Blattes. - Im einfachsten Falle schon tritt eine Sonderung dieses ursprünglich einfachen Epithels in Zwei Schichten ein, nämlich in eine Deckschichte (gegen die Coelomhöhle gewendet), welche wir als Peritonealschichte (oder Somatopleura) bezeichnen, und eine basale Schichte, welche aus Muskelfasern besteht (M uskelschichte). Die Muskelfasern sind bandförmige Gebilde, welche wie die Blätter eines Buches aneinandergereiht sind; ihre Muskelkörperchen liegen nach der Deckschichte zu.

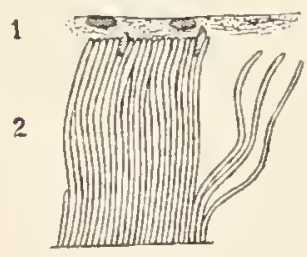

Fig. 117. Längsmuskelschichte aus der Leibeswand von Polygordius. Querschnitt.

1. Deckschichte (Peritoncalschichte), 2. Muskelschichtc.

Dieses Verhalten bildet den Ausgangspunkt für sehr verschiedenartige Modificationen. Um dieselben zu verstehen, müssen wir zunächst den Bau der Muskelfaser in den verschiedenen Fällen genauer betrachten. Die Muskelfaser ist in den meisten Fällen bandförmig, kann aber auch einen rundlichen Querschnitt zeigen; sio lässt in der Regel keine Querstreifung erkennen. Der fibrilläre Bau ist oft schwer nachweisbar, so dass die Fibrillenmasse wie eine einzige, sehr grosse Fibrille erscheint; genauere Untersuchung lehrt aber die Fibrillen unterscheiden (RHODE), die in einfacher Schichte rings um einen von Plasma erfüllten Centralraum angeordnet sind; derselbe ist meist sehr eng und spaltförmig; von ansehnlicher Ausdehnung ist er bei den rundlichen Muskelfasern der Hirudineen. Der Zell- 
kern liegt entweder an der einen Kante der bandförmigen Muskelfaser, und zwar an derjenigen, welche der Deckschichte zugewendet ist (wie oben beschrieben wurde), oder or liegt an der Fläche des Bandes, und er kann endlich auch im centralen Hohlraum gelegen sein (besonders auffallend bei den Jirudineen). In ein und demselben Muskel kann verschiedene Lage der Kerne an den Muskelfasern beobachtet werden.

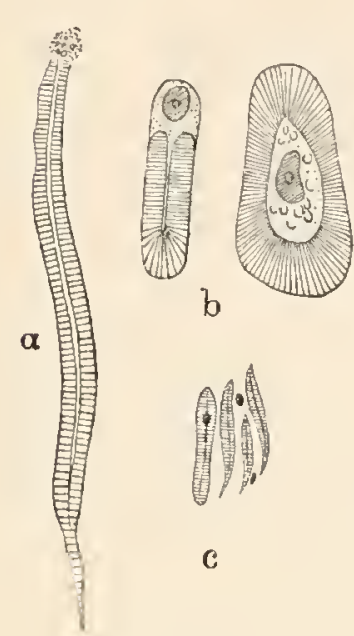

Fig. 118.

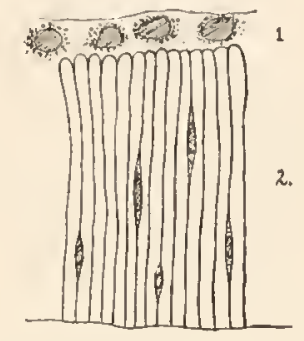

Fig. 119.

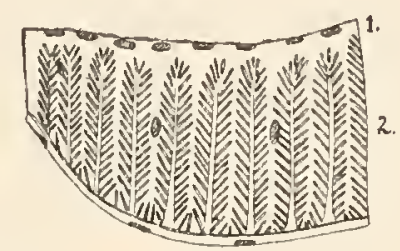

Fig. 120.

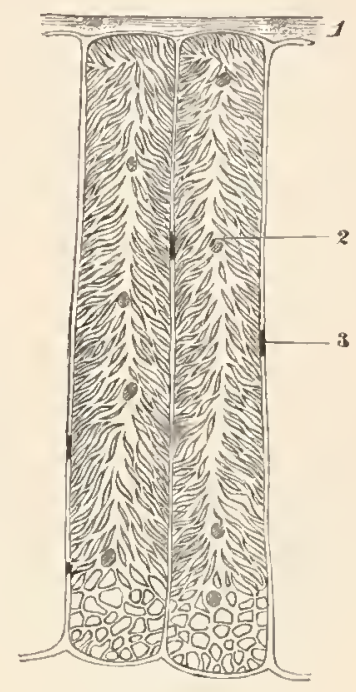

Fig. 121.

Fig. 118. Muskelfasern von Anneliden im Querschnitt gesehen (nach RHoDE).

a. von Lumbriculus, b. von Branchiobdella, c. von Polynoe, bei letzterer liegen die Kerne bald im Centrum, bald an der Peripherie der Muskelfasern.

Fig. 119. Längsmuskelschichte aus der Leibeswand von Lumbriculus im Querschnitt. 1. Deckschichte (Peritonealschichte), 2. Muskelschichte.

Fig. 120. Längsmuskelschichte von Sagitta im Querschnitt (nach HerTwig).

1. Deckschichte, 2. gefaltete Muskelschichte, unterhalb derselben ectodermales Epithel.

Fig. 121. Längsmuskelschichte eines Regenwurmes im Querschnitt.

1. Deckschichte (Peritonealschichte), 2. Muskelkästchen mit rundlichen Zellkernen (Muskelkörperchen) zwischen den Muskelfasern, 3. Bindcgewebshülle der Muskelkästchen mit platten Zellkernen.

Unterhalb der Peritonealschichte können die Muskelfasern sich zu einer geschichteten Masse häufen. Es kann aber auch der Bau des gesammten Muskels sich über den obenerwähnten einfachen Typus zunächst dadurch orheben, dass er eine Massenzunahmedurch Faltung erfährt (boi zahlreichen Polychaeten, bei Sagitta etc.) Die Deckschichte kann über die Falten der Muskelschichte glatt hinweggehen, oder sie betheiligt sich an der Faltung. - Bei den regenwurmartigen (Lumbriciden) haben sich die Falten von einander isolirt, so dass sio gesonderte, aneinandergereihte Muskelstränge (Muskelkästchen, Vөjdovsky) bilden. Sie sind durch bindegewebige Scheidewände (längs welcher auch Blutgefässe eindringen) von einander getrennt; diese sind Differenzirungen der Peritonealschichte. Bei manchen Arten sind die Muskelfasern in jedem Muskelstrang noch regelmässig in einfacher Schichte um einen centralen Spaltraum (dem Hohlraum der Falten entsprechend) angeordnet, bei anderen Arten ist der einzelne Muskelstrang aus einer regelloser geschichteten Masse von Muskelfasern zusammengesetzt. - Aehnlich diesen letzteren Falle verhalten sich auch die Hirudineen; da abor hier die Peritonealschichte (Deckschichte) bedeutende Veränderungen erfahren hat, forner die Bindegewobsscheide- 
wände reicher ausgebildet sind und endlich längs derselben nebst Blutgefässen auch heterogene Muskelfasern (die Transversalmuskeln) hineingewachsen sind, so ist in dem Bau dieser Längsmuskeln der ursprüngliche epitheliale Charakter kaum mehr ersichtlich. Analoge Verhältnisse finden wir auch schon bei manchen Chaetopoden ${ }^{1}$ ).

Arthropoden. Die somatische Muskulatur der Arthropoden (vor allem die Längsmuskelzüge) ist zweifellos von dem Hautmuskelschlauch der Anneliden abzuleiten; hier ist aber die Zerfällung des Muskelblattes in strangförmige Gebilde weiter gediehen und typisch geworden. Auch in der Längsrichtung ist die Muskulatur in kürzere Stücke gegliedert, die nur mittelst ihrer Enden an die Körperwand angeheftet sind. Im Einzelnen ist die Vergleichung des Anneliden- und Arthropodenmuskels noch wenig durchgeführt, so ist $\mathrm{z}$. B. das Verhalten der Peritonealschichte noch kaum erforscht.

Die somatischen Muskelfasern der Arthropoden ähneln in hohem Grade den ,quergestreiften Muskelfasern" der Wirbelthiere. Sie haben quergestreifte Fibrillen, ein deutliches Sarcolemm und zahlreiche Muskelkörperchen, die entweder an der Oberfläche oder in der Achse der Muskelfaser liegen. Ueber ihre Entwicklung (ob aus einer Zelle entstehend?) ist wenig bekannt.

\section{Reihe der Chordonier.}

Wir wollen uns hier speciell auf die Betrachtung des Seitenrumpfin uskels des Amphioxus und der Wirbelthiere beschränken, da derselbe den Ausgangspunkt für die Verhältnisse der somatischen, quergestreifte n Muskulatur dieses Typus bietet. Der segmentirte (in Myomeren getheilte) Seitenrumpfmuskel geht aus dem Coelomepithel herror. Es sind

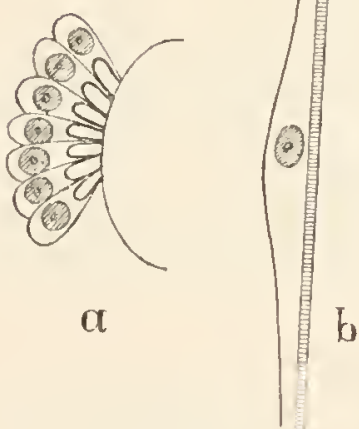
eigenthümlich ausgezogene Epithelzellen, die durch die ganze Länge je eines Körpersegmentes sich erstrecken, welche denselben bilden. Aus jeder dieser Zellen entsteht eine ursprïnglich einkernige Muskelfaser.

Fig. 122. Entwicklung der Muskelfaser von Amphioxus.

a. Querschnitt durch mehrere Myoblasten, welche an der Chorda liegen; in der Basis der Zellen sind die Querschnitte der Fibrillen zu sehen. b. Myoblast der Länge nach gesehen.

Amphiox.us. Der Seitenrumpfmuskel, der aus dem einschichtigen Coelomepithel hervorgeht, ist auch im entwickelten Zustande noch auf ein solches einschichtiges Epithel zurückführbar. An der freien Fläche des Epithels finden sich die Zellkerne mit Plasmaresten, die übrige Masse ist von Muskelfibrillen mit spärlicher Zwischensubstanz gebildet. Die Fibrillen sind derartig geschichtet, dass sie reihenweise übereinanderliegen; die dadurch zusammengesetzten bandförmigen Gebilde (S y m fibrien) liegen wie die Blätter eines Buches nebeneinander; die Breite der Bänder entspricht der Dicke des Muskels. Mehrere Symfibrien kommen auf je eine Muskelfaser; die Abgrenzung der Muskelfasern ist nicht deutlich (leichter nachweisbar in jüngeren Stadien und im lebenden Zustande). Ein Sarcolemm

1) Für die Auffassung der epithelogenen Natur der Anneliden-Längsmuskeln ist es besonders wichtig, dass die Muskelfibrillen ontogenetisch zu einer Zeit entstehen, wo das somatische Blatt noch einschichtig ist. Die weitere Sonderung desselben in Muskelschichte und Deckschichte ist aber ontogenetisch noch nicht genïgend klargestellt. 
wurde nicht beobachtet. Die Basalfläche dieses Epithelmuskels ist von einem secundär angelagerten Plattenepithel, dem Fascienblatte, überzogen.

Fig. 123. Querschnitt durch den Seitenrumpfmuskel eines jungen Amphioxus. Die hohen bandförmigen Symfibrien, wie die Blätter eines Buches aneinandergereilıt; in der Nähe der freien Fläche sind Zellkerne zwischen denselben gelegen, der Basalfläche ist die platte Fascienschichte angelagert.

Bei den Wirbelthieren s. str. (Cranioten) ist der Seitentumpfmuskel in gewissem Sinne einem geschichteten Epithel zu vergleichen; die Muskelfasern liegen zahlreich übereinander. Die ursprünglich einkernigen Muskelfasern werden vielkernig; die Kerne liegen meist an der Oberfläche der Fibrillenmasse; es ist ein Sarcolemma vorhanden. Die Muskelfasern sind hier ferner durch eingewuchertes Fasciengewebe einzelweise eingehiillt und so ron einander gesondert. Dadurch ist die ursprüngliche epitheliale Anlage in ihre Zellelemente aufgelöst. - Die Verhältnisse bei den Cyclostomen bilden einen Uebergang zwischen denjenigen des Amphioxus und der Cranioten.

Fig. 124. Querschnitt durch die Muskulatur einer Salamanderlarve. $b z$ Bindegewebszellen, welche die Hüllen der einzelnen Muskelfasern bilden.

\section{Mesenchy m m us kel.}

Die Mesenchymmuskelfasern sind phylogenetisch walıscheinlich aus den Bindegewebszellen der Gallerte abzuleiten, welche bei den niedersten Metazoen das Blastocoel erfüllt ${ }^{\mathbf{1}}$ ). Die vereinzelt verlaufende Muskelfaser ist hier der Grundtypus, während das 'Lusammentreten zu Gewebsmassen das secundäre Verhältnis ist.

Schon bei den Spongien sind vereinzelte Mesenchymmuskelfaseln beobachtet worden. Bei den Cnidariern scheinen sie zu fehlen. Bei den Ctenophoren durchsetzen sie in grosser Anzahl die Gallerte. Den Scoleciden kommen ausschliesslich Mesenchymmuskelfasern $\mathrm{zu}$; sie bilden hier oft schon regelmässig angeordnete Schichten, besonders an der Leibeswand (Ringmuskelschicht und Längsmuskelschicht), deren Anordnung derjenigen von epithelogenem Muskel sell ähnlich ist.

Fig. 125. Querschnitt durch die Muskelschichte des gemeinen Spulwurmes. An ciner der Muskelfasern ist das riesige Muskelkörperchen getroffen, in der Rindenschichte derselben liegt der

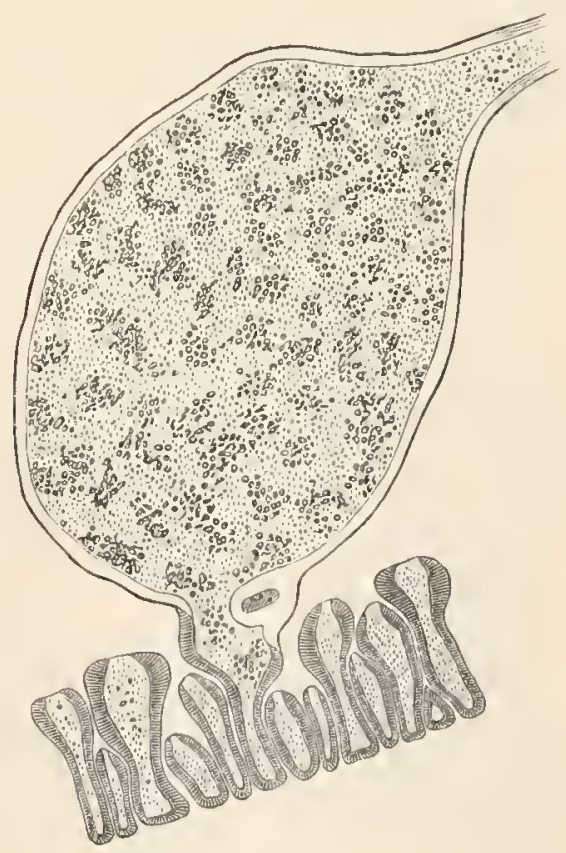
Zellkern.

1) Nach dieser Auffassung hätten die Zellen auf Grund einer anderen Function sich vom Epithel isolirt, und wären erst durch $\mathbf{F}$ uctionswechsel zu Muskelzellen geworden (HERTwIG). 
Bei den Nematoden (deren systematische Stellung überhaupt noch zweifelhaft ist), hat die Längsinuskelschicht der Leibeswand grosse Aehnlichkeit mit Epithelmuskeln, und wird anch von HerTwı dafür

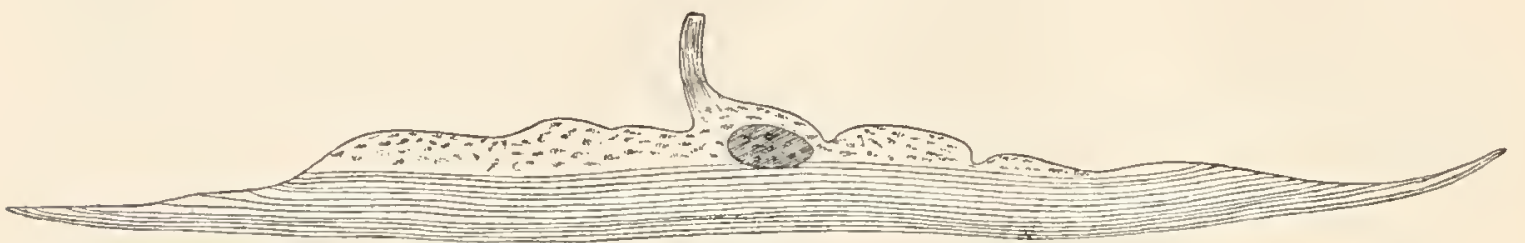

Fig. 126. Isolirte Muskelfaser eines Spulwurmes (nach Hertwig).

gehalten; gegen diese Auffassung spricht aber der Umstand, dass die Terven an die freie Fläche dieses epitheloiden Muskels herantreten (im Gegensatz zu dem Verhalten jedes echten epithelogenen Muskels).

Bei den Aposcoleciden ist der Mesenchymmuskel durch den epithelogenen mehr in den Hintergrund gedrängt. Im Allgemeinen scheint die Muskulatur des Darmes, der Blutgefässe, der Geschlechtsorgane etc. und die Ringmuskeln der Leibeswand mesenchymatösen Ursprungs zu sein (z. B. Amneliden). Bei den Mollusken erreicht der Mesenchymmuskel wieder erhöhte (vielleicht ausschliessliche) Bedleutung und bildet namentlich im „Fusse“" mächtige Muskelmassen.

Auch bei den Ambulacraliern und Chordoniern ist die Muskulatur der Eingeweide und ein kleiner Thlıil der äusseren Muskehn mesenchymatöser Natur.

\section{Nerrengewebe.}

Durch das Nervensystem sind bei den Metazoen (mit Ausnahme der Spongien?) die einzelnen Theile des Körpers derart in Verbindung gesetzt, dass die Erregung, die durch einen Reiz an irgend einer Stelle des Körper's bewirkt wird, auch anderen Theilen des Körpers mitgetheilt wird. Es wird z. B. ein Reiz, der ein Sinnesorgan trifft, in Erregung ungesetzt und als solche durch das Nervensystem auf einen Muskel fortgepflanzt, der dadurch zur Thätigkeit veranlasst wird. Es ist so eine Beziehung zwischen den einzelnen Körpertheilen hergestellt; das Nervensystem wird daher auch als Beziehungsapparat bezeichnet.

Die für das Nervensystem wesentlichen Gewebselemente sind die Ganglienzellen und die Nervenfasern. Die letzteren sind die eigentlichen Leitungsbahmen der Erregung, den ersteren wird ein gewisser Einfluss auf die Erregung (Regulirung derselben) zugeschrieben.

Das Nervensystem tritt nicht in allen Fällen als ein gesondertes Organsystem auf. In seinem niedrigsten (uns bekannten) Zustande breitet es sich als ein Ganglienplexus (Ganglien-Nerven-Netz) über grosse Körperstrecken nahezu gleichartig aus, und zwar innerhalb der Epithelien selbst, als ein Bestandtheil derselben (Actinien). Bei höherer Entwicklung des Nervensystems treten die Ganglienzellen in Massen gehäuft auf, als sogenannte "Ganglien", und die Nervenfasern, welche von ihnen ausgehen, sind zu Bündeln vereinigt, die als "N erven" bezeichnet werden; die Nerven verzweigen sich derart, dass sie gegen die Peripherie in immer kleinere Bündel sich auseinanderlegen, so dass sie zuletzt nur eine Nervenfaser enthalten. Die Nervenfasem 


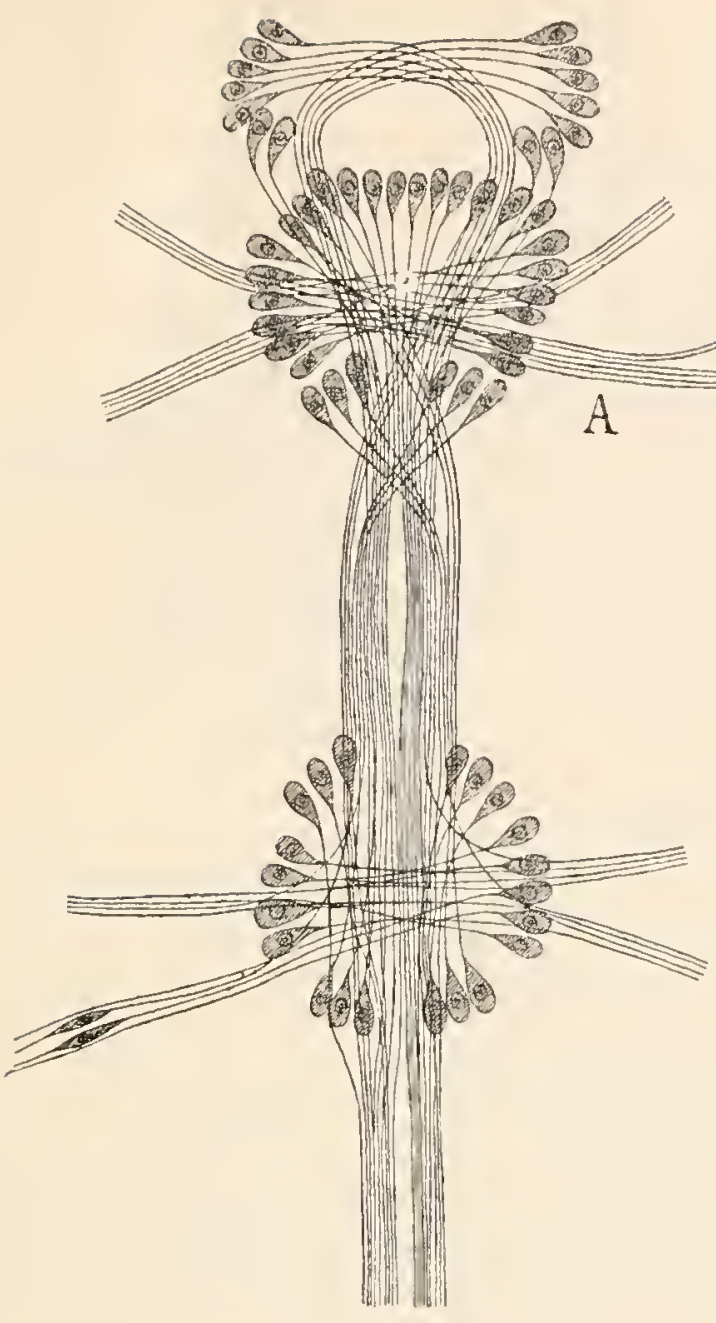

Fig. 127

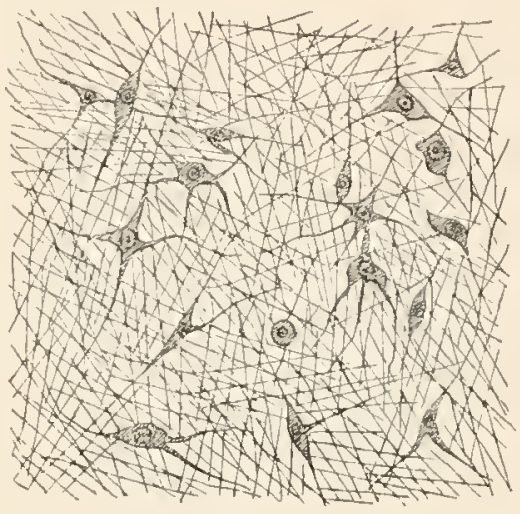

Fig. 128.

Fig. 127. Vorderer Abschnitt des centralisirten Nervensystems eines Anneliden. Schema zur Demonstrirung des Faserverlaufes (nach LEYDig, mit einigen Veränderungen).

Von den abgehenden Nerven ist nur einer (bei A) weiter verfolgt, um die Art der Verästelung zu zeigen; zuletzt geht auch die Nervenfaser eine Verästelung ein; bei + ist eine direkte Endigung der Endästchen, bei \# eine solche durch Vermittlung eines Nervenplexus schematisch dargestellt.

Fig. 128. Eine Stelle aus dem acentrischen Nervensystem einer Actinie (nach HERTWIG).

selbst verästehn sich nur in der Nähe der Ganglienzellen und in der Nälıe der Peripherie. Hier schliessen sich oft auch periphere Ganglienplexus' an.

Als das Structurelement des Nervengewebes wird besonders seit Max Schutate die Nervenfibrille (Nervenprimitivfibrille) betrachtet. Die Nervenfibrillen sind überaus feine, unverästelte Fäden, die oft charakteristische Varicositäten (Knı̈tchen) zeigen. Sie finden sich als Inhalt (1) der Ganglienzelle, in welcher sie concentrisch den Kern umkreisen und auch radiär verlaufend in ( 2 ) den Inhalt der Nervenfaser sich fortsetzen, welche bei ihrer peripheren Verästelung in die einzelnen Fibrillen sich auflöst. Und endlich können wir sie auch (3) bis in das Innere der peripheren Zellen, z. B. der Sinneszelle oder' der Muskelfaser, verfolgen.

Neuerdings wurde die nervöse Natur der Primitivfibrille bestritten. Die zwischen den Fibrillen gelagerte helle, schleimige (ja sogar als flüssig 


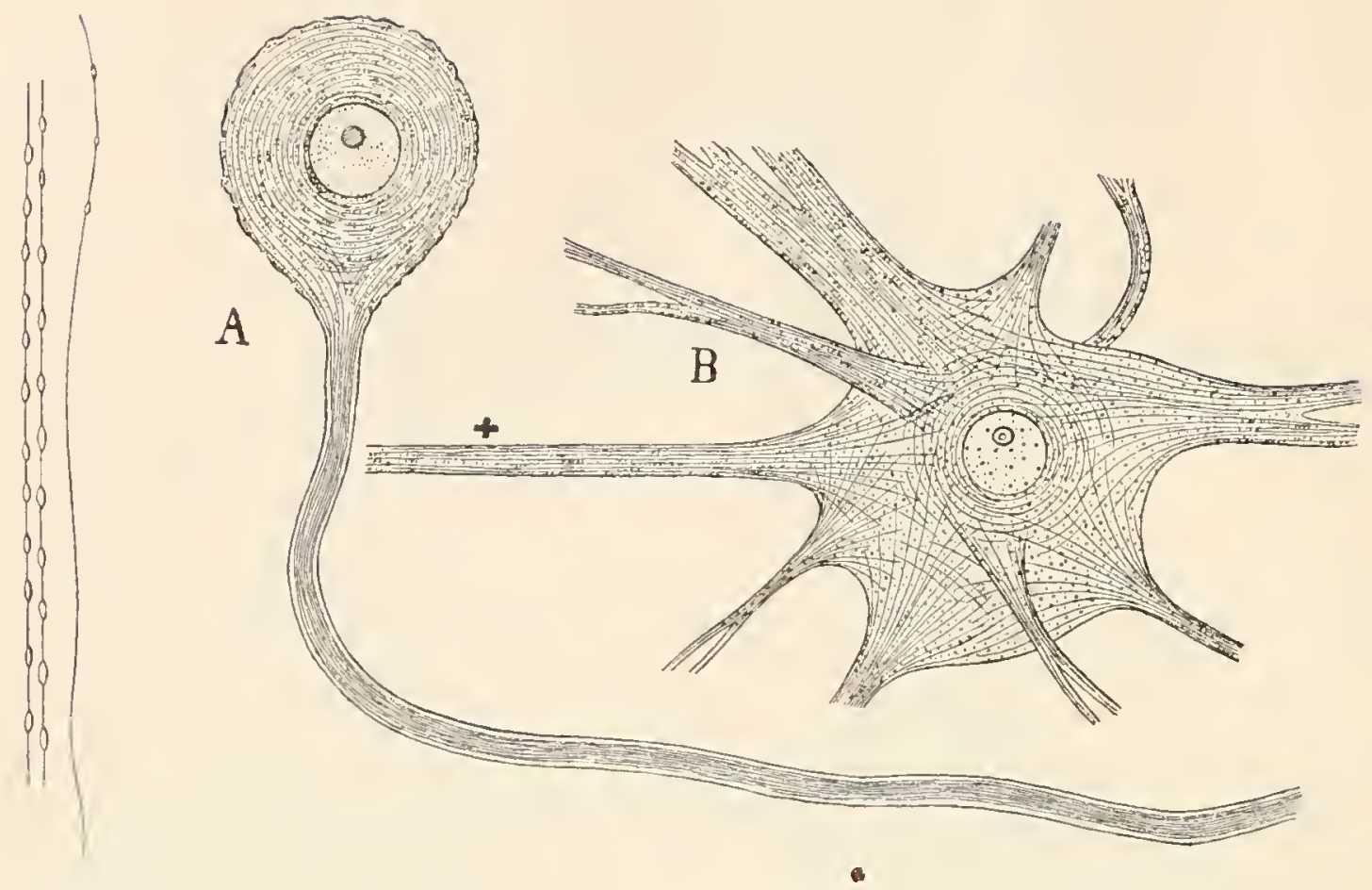

Fig. 129.

Fig. 130 .

Fig. 129. Nervenprimitivfibrillen (nach MAx Schultze).

Fig. 130. Fibrilläre Structur von Ganglienzellen und Nervenfasern

A Ganglienzelle mit Nervenfortsatz aus dem Nervensystem eines Anneliden [Sthenelais] (nach RHODE).

B. Ganglienzelle aus dem, electrischen Lappen des Gehirn des Zitterrochens; der mit + bezeichnete Fortsatz ist der Nervenfortsatz (,Achsencylinderfortsatz ${ }^{6}$ ), alle anderen sind sogen. Plasmafortsätze (nach M. Schultze).

bezeichnete) Substanz soll die eigentliche Nervensubstanz sein, auch sollen die „Primitivfibrillen" nicht selbständige Fäden sein, sondern im Querschnitt netzförmig zusammenhängen und dementsprechend im Längsschnitt als Wände von Röhren sich erweisen, in welcho die eigentliche Nervensubstanz eingelagert wäre (LEYDIG, NANSEN).

Gewebselemente. 1) Die Ganglienzellen sind von rundlicher Gestalt und mit einem oder mehreren Fortsätzen verselıen; nit Rücksicht anf die Anzahl der Fortsätze unterscheidet man unipolare, bipolare, multipolare Ganglienzellen. Die Forsätze können entweder in einen Nerven übergehen (,Nervenfortsatz oder A ch sen cylinderfortsatz") oder in ein feines Netzwerk sich verästeln, dessen nervöse Natır zweifelhaft ist („Plas mafortsatz oder verïstelter Fortsatz").

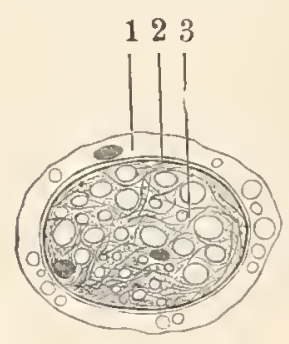

Naclı der Meinung einiger Autoren soll der Achsencylinderfortsatz stets nur in Einzahl vorhanden sein (das gilt aber sicherlich nicht ausnahmslos). Die Ganglienzelle besitzt in der Regel einen grossen runden Zellkern und reichliches Plasma, dessen fibrilläre Structur bereits erwälnnt wurde. 2) Nervenfaser. Der wesentliche Bestandtheil der Nervenfaser ist der Achsencylinder. Die Achsencylinder

Fig. 131. Querschnitt durch einen peripheren Nerven eines Regenwurmes.

1. Peritonaeum, 2. Membrana propria, 3. Gliasubstanz, in welche die hellen Achsencylinder eingebettet sind. 


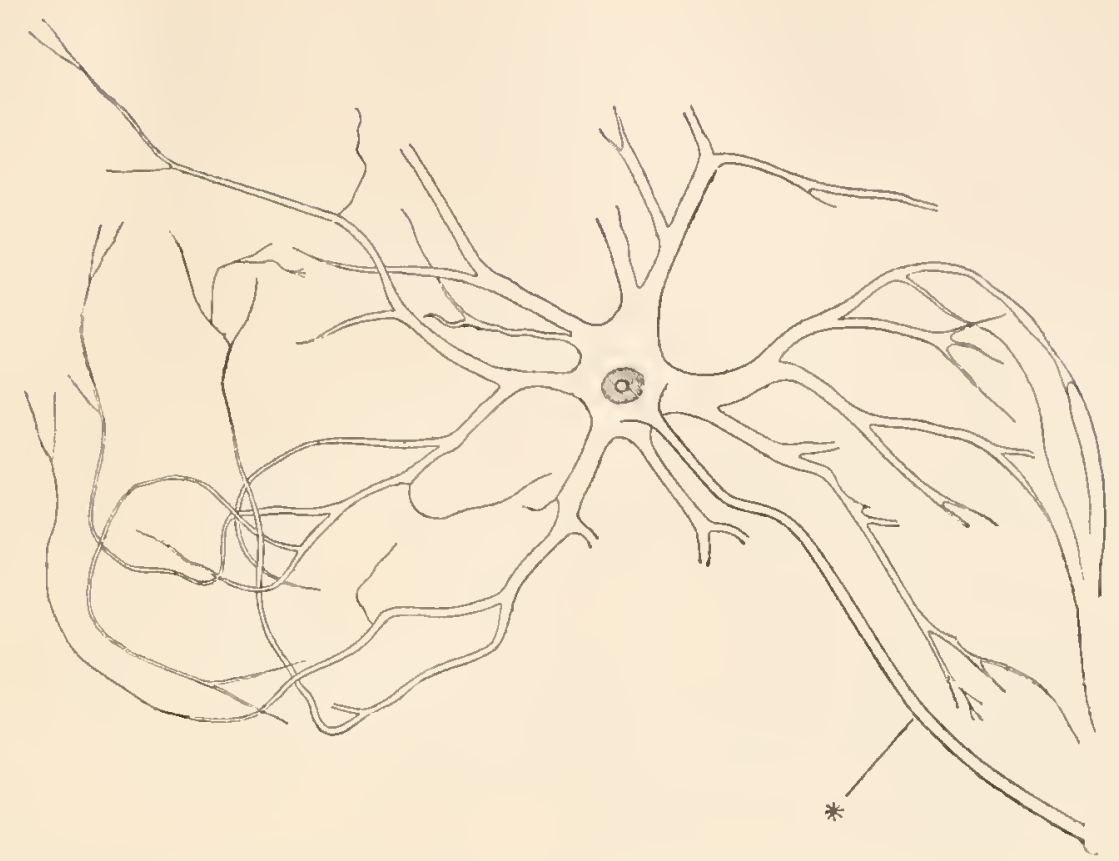

Fig. 132. Multipolare Ganglienzelle aus dem Rïckenmark des Rindes (nach DEITERS). Bei * ist der Nervenfortsatz zu sehen, alle anderen Fortsätze sind Plasmafortsätze.

sind von verschiedenen Durchmesser, von ansehnlicher Dicke bis zu kaum messbarer Feinheit. Thre Beschaffenheit ist zart, schleimig, dabei hell und von blassen Contouren (in Folge des geringen Lichtbrechumgsvermögens); unter starken Vergrösserungen ist eine iiberaus feine Längsstreifung als Ausdruck der schon erwälmten fibrillären Structur zu beobachten. - Zu den Aclisencylinder kann noch eine Hiille von fettartiger Substanz (Markscheide) hinzukommen, das sogenamnte Nervenmark oder Myelin. Die erstere Art von Achsencylindern nemnen wir marklose orler einfach contourirte, die letztere Art markhaltige oder doppeltcontourirte Achsencylinder. - Markhaltige Nervenfasern finden sich nur bei den Wirbelthieren, doch sind auch bei diesen die Nerven des sympathischen Systems (die Eingeweidenerven) und der Olfactorius (Riechnerv) mit marklosen Fasern versehen. Die Cyclostomen und Amphioxus, sowie alle Wirbellose haben nur einfach contourirte Nervenfasern. faser.

Fig. 133. A. Einfach contourirte Nerven-

B. Doppelt contourirte Nervenfaser.

Fig. 134. A. Einfach contourirte Nervenfaser mit Schwann'scher Scheide.

B. Doppeltcontourirte Nervenfaser mit Schwann'scher Scheide.

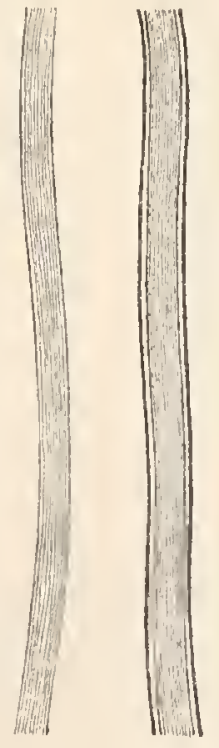

A B

Fig. 133.

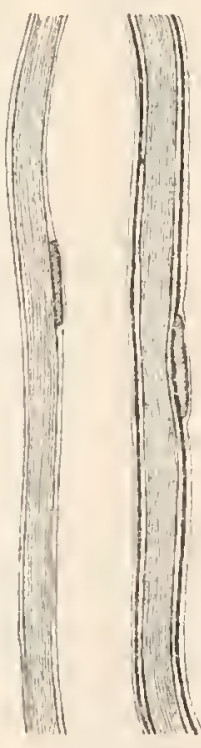

A B

Fig. 134.

Die Achsencylinder stehe» in den meisten Fällen in bestimmter Beziehung zu eigenthümlichen Stütz- oder Hüllgeweben. In den peripheren Nerven sowohl der Wirbelthiere als auch vieler Wirbelloser (Arthro- 
poden) finden wir die (einfach oder doppeltcontourirten) Aclisencylinder noch umgeben ron je einer bindegewebeähnlichen (manchmal deutlich geschichteten), mit Zellkernen verseheren Hülle, welche wir als Schwaxsche Scheide bezeichnen. Innerhalb des centralen Nervensystems dagegeu sind die Achsencylinder in ein zusamm enhängeudes Gewebe von faserig structurirten Zellen, (Gliazellen oder Neuroglia) eingebettet. In älnnlicher Weise aber simd bei wirbellosen Thieren (AnneTiden, Mollustien) auch in den peripheren Nerven die Achsencylinder nicht mit besonderen Scrwaxy'schen Scheiden ausgestattet, sondern mit cinem gemeinsamen Hüllgerrebe versehen. - In der Regel finden wir anch die Ganglienzellen in Gliasubstanz eingebettet. - Auf die Bedentung dieser Hüll- orler Stïtzsubstanzen werden wir noch zurückkonnnen.

In Bezug auf die Frage nach dem zelligen Charakter der Achsencylinder wollen wir zunächst diejenige Anschaumg vortragen, welche von der Mehrzahl der Autoren vertreten wird. Die Achsencylinder der peripheren Nerven sind trotz ihrer bedentenden Ausdelmung zumeist nur verlïngerte Fortsätze der centralen Ganglienzellen. Wir nüssen uns daran erimern, dass beim Embryo die Dimensionen viel geringer sind, und die oft enorme Länge der Nervenfaser erst durch späteres Wachsthum crreicht wird. Bei manchen Nerven sind bipolare Ganglienzellen in den Verlauf der Faser eingeschaltet und sie werden vielfach nur als zellige Verdickungen der Nervenfaser betrachtet; es gibt auchl alle Abstufinngen von rundlichen bis zu spindelförmig gestreckten Zellen und dies füilnt uns linüber zn jenen Formen ron

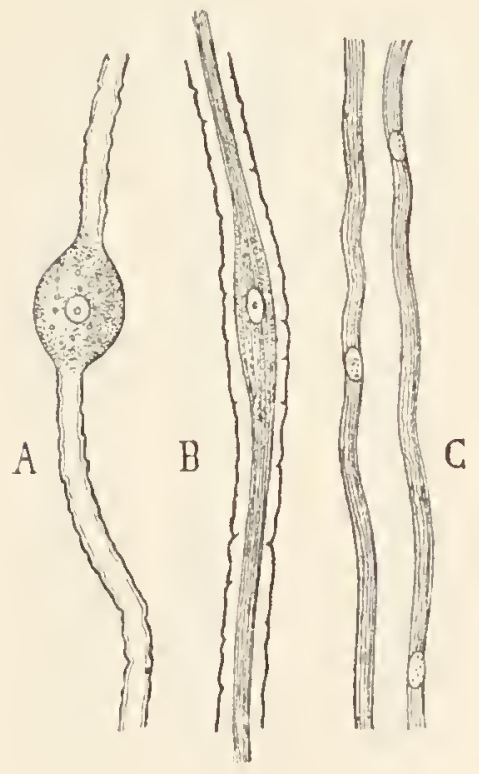
Achsencylindern, die zahlreiche Zellkerne enthalten und vielleicht aus aneimandergereilıten, gestreckten Ganglienzellen abzuleiten sind, wie z. B. die Nerven des sympathischen Systems bei den Wirbelthieren. Auch bei Wirbellosen sind derartige Tervenfasern, besonders in den Nervenplexus' vielfach zu beobachten.

Fig. 135. A. Bipolare Ganglienzelle in den Verlauf eines markhaltigen Nerven eingeschaltet, aus dem Ganglion Gasseri vom Hecht (nach BIDDER).

B. Bipolare Ganglienzelle in den Verlauf eines markhaltigen Nerven eingeschaltet, sie ist von spindelförmiger Gestalt und nur als kernhaltige Anschwellung des Achsencylinders zu betracliten, aus dem Nervus acusticus vom Hecht (nach M. SichuLTzE).

C. Nervenfasern aus dem Sympathicus des Rindes mit zahlreichen liernen (nach M. Schultze).

In der vorhergehenden Darstellung über das Verhältnis der Nervenfaser zur Zelle habe ich die herrschenden Anschauungen berücksichtigt, wenn ich auch einer anderen Ansicht die Möglichkeit offen halten will, welche ich besonders bei GeGenbaUR, wenn ich ihn richtig verstehe, wenigstens angedeutet finde. - Wir wollen von der Thatsache ausgehen, dass wir die Achsencylinder zumeist in Gliasubstanz eingebettet sehen; in den Nervenmassen der Centraltheile sind es zusammenhängende Gliamassen (sowohl bei Wirbelthieren als bei Wirhellosen), und ebenso auch in den peripheren Nerven niederer Wirbelloser (Anneliden, Mollustien); nur in den peripheren Nerven der Arthropoden und der Wirbelthiere ist die Gliasubstanz derart gesondert, dass sie für jeden Achsencylinder eine eigene 
Hülle, die Schwan'sche Scheide, bildet; ich betrachto diese als den Gliasubstanzen gleichwerthig. Es ist nun denkbar, dass die Gliazellen nicht nur als Bildner der Stützsubstanz aufzufassen wären, sondern auch als Nervenkörperchen, auf deren Kosten die Achsencylinder entstanden wären Diese Neuroblasten hätten demnach sowohl Stützsubstanz (Glia), als auch Nervensubstanz (Aclisencylinder) differenzirt. - Wir würden nun unterscheiden: 1) Achsencylinder, die von Neuroblasten gebildet worden sind, und daher stets in Begleitung ron Gliasubstanz auftreten (centrale und periphere Nerrenmassen); 2) Achsencylinder, die ron Ganglienzellen gebildet worden sind, entweder als Ausläufer derselben oder durch bedeutendere Streckung von ganglienähnlichen Zellen (Nervennetze, Nerven des Sympathicus). - Gegen obige Ausführungen könnte man einwenden, dass auch die Ganglienzellen ron faserigem, mit Zellkernen versehenen Gliagewebe eingehïllt werden; darauf ist zu erwidern, dass wir in Consequenz der erörterten Ansicht diese Zellen als solche, welche nur Stïtzsubstanz bilden, von jenen unterscheiden müssten, die zugleich auch Nervensubstanz liefern. Zur Entscheidung dieser hypothetischen Fragen sind noch eingehende Untersuchungen nöthig. Nach den vorliegenden Beobachtungen über Entwicklung ist es kaum zu entscheiden, ob die Achsencylinder als Ausläufer der Ganglienzellen in die Gliasubstanz hineinwachsen (nach der herrschenden Ansicht) oder ob sie auf Kosten der letzteren bei ihrer fortschreitenden Verlängerung entstehen.

Die peripheren Nervenenden verbinden sich mit Zellen verschiedenster Function, Sinneszellen, Muskelzellen, Drisenzellen etc. Oft ist ein peripherer Ganglienplexus zwischen die Nervenendigmng eingeschoben. Für die Wirbelthiere rerden auch vielfach freie Nervenendigungen zwischen den Epithelzellen angegeben.

Von besonderer Wichtigkeit ist für unsere Betrachtung die Nenvenendigmy an den Simneszellen mud Muskelzellen. Die Sinneszelle, welche in ihrer einfachsten typischen Form als cine schmale, lohe, an ihren freien Ende nit Simneshïrchen rersehene Zelle erscheint, ist stets an illrem ba sal eu Pole mit einem Nervenende in Verbindung, oft ist in ihren Imneren eine aufsteigende Nervenfibrille zur verfolgen.

Fig. 136. Schema der Nervenendigung. a. an der Muskelfaser und b. an der Sinneszelle.

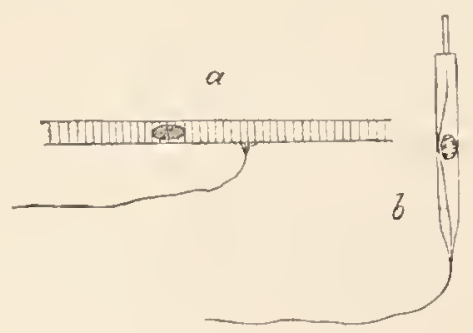

Die Innervirung des Muskels ist besonders bei der quergestreiften Muskelfaser der Wirbelthiere und Arthropoden genauer bekannt. Der Nerv tritt stets andic Längs seite der Muskelfaser und endet hier mit einer eigenthümlichen Nerveneudplatte. Auch bei der glatten Muskelfaser der Tirbelthiere und hei den Mesenchymmuskeln der Wirbellosen sieht man den Nerven stets seitlich an die Muskelfaser herantreten. (Die glatten Muskelfasern rer Wirbelthiere sind vou einem feinsten Nervennetz umsponnen.)

Nervengewebe. Ihrer Lagerung nach kömnen wir die Gewebe des Nervensystems in epitheliale und epithelogene cintheilen; es wurde wohl auch vermuthet, dass das gesammte Nervensystem gewisser 'Thiere mesenchymatöser' Natur sei, doch liat diese Ansicht bis jetzt keine Bestätigung erfahren. 
Epitheliales Nervensystem der Cnid arier.

Für dic Phylogenie des Nervensystems ïberhaupt und zunächst für das Verständnis der epithelialen Nervengewebe sind die Zustände, die bei den Cnidariern nachgewiesen wurden (O. und R. HerTwiG), vou besonderer Wichtigkeit.

1) Bei den Actinozoen finden sich Gewebe des Nervensystems sowohl im ectodermalen als auch im endodermalen Epithel, aber in ersterem in viel reicherem Masse; und dieses wollen wir hier eingehender betrachten. Das Ectorlermepithel der Actinien hat einen gemischten Charakter; wir finden in demselben nebeneinander Myoblasten, Drüsenzellen, Nesselzellen, Deck-Stïitzzellen (welche letzter'e die ganze Höhe des Epithels durchsetzen und mit einer Geissel versehen sind) und ferner die

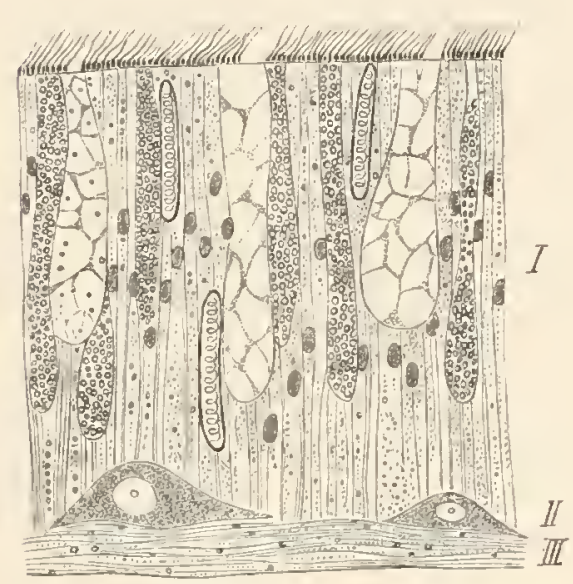

Fig. 137.

Fig. 137. Querschnitt vom Ectoderm einer Actinie (nach Hentwig).

I Deckschichte, II Ganglienschichte, III Nervenschichte.

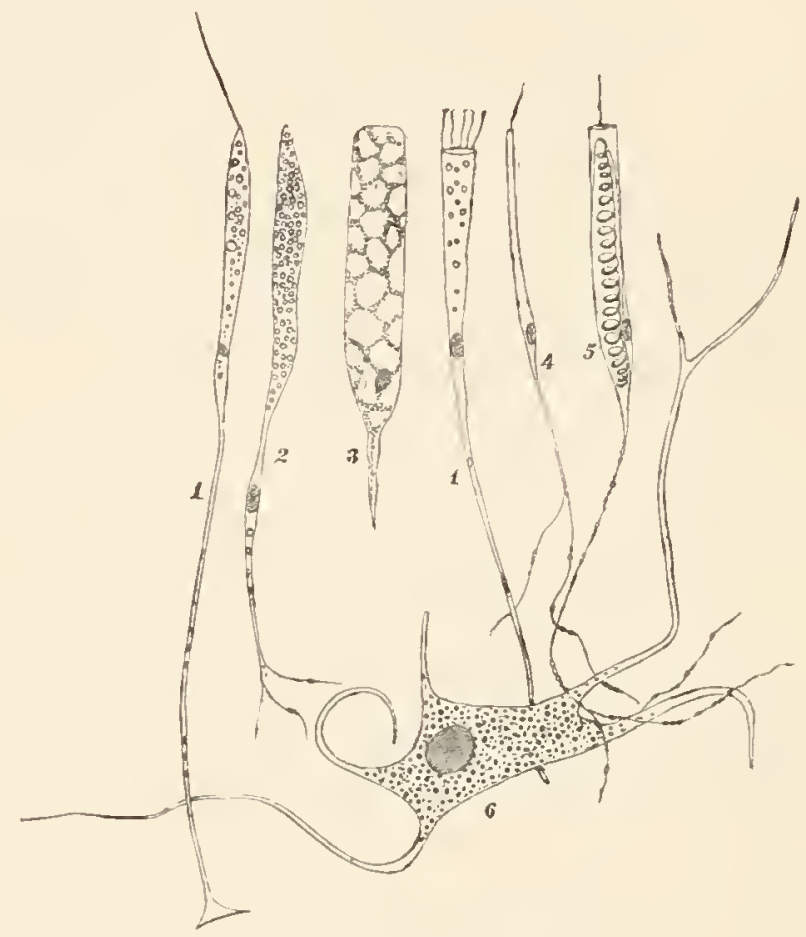

Fig. 138

Fig. 138. Isolirte Elemente eines ebensolchen Epithels (nach HERTwig).

1. Stützzellen, 2. und 3. Drüsenzellen (Körnchenzelle, Becherzelle), 4. Sinneszelle, 5. Nesselzelle, 6 Ganglienzelle.

uns hier speciell interessirenden Simnes- und nervösen Elemente. Diese sind: I) Sinneszellen, II) Ganglienzellen und III) Nervenmassen. Das Lagerungsverhältnis dieser drei verschiedenen Elemente ist stets ein derartiges, dass die Sinneszellen die oberste Lage, an der freien Fläche des Epithels einnehmen, dabei reichen sie in die Tiefe bis nahezu an die Basis des Epithels (ähnlich wie die Deck-Stützzellen); dlarauf folgen in der mittleren Schichte des Epithels vereinzelte oder dichter angeorlnete Ganglienzellen und endlich zu unterst, nächst der Basalfläche des Epithels, jene Schichte, die wir als Nervenmasse bezeichnen (weun das Epithel auch Muskelfibrillen besitzt, so bilden diese die tiefste Schichte noch unterhalb der Nervenmasse). Diese Nerven bilden eine netzförmige Verbindung zwischen den Ganglienzellen, den Sinneszellen und wohl auch den Muskelzellen. 
2) Centralisirtes Nervensystem bei Medusen. Bei anderen Cnidarieru und zwar bei den Hydroidmedusen und Scyphomedusen finden wir schon die Eimrichtung eines centralisirten Nervensystems. Dic Centralisirumg des Nervensystems steht immer im inn igsten Zusammenhang mit dem Auftreten von Sinnesorganen. Bei Bildung eines Simnesorganes finden sich an der betreffenden Stelle des ectodermalen Epithels die Sinneszellen und die nervösen Elemente gehäuft, und zwar in dem schon bei den Actinien beobachteten Schichtungsverhältnis; es finden sich dazwischen auch Stützzellen; die anderen /ellenarten des Epithels (Muskel-, Drüsell-, Nesselzellen) fehlen aber an dieser Stelle. Wir werden ein solches, functionell in höherem Grade specialisirtes Epithel als NervenSinnesepithel bezeichnen.

Bei rlen Scyphomedusen finden wir aclıt radiär vertleilte Gangliencentra in Zusanmenhang mit aclit Simnesorgangruppen. - Bei den Hydroidmedusen hat das Centralnervensystem die Form eines an Rande rer Scheibe rellaufenden, doppelten gangliösen Ringes, welchen in grösserer oder geringerer Anzahl Sinnesorgane angelagert sind. Einzelne Sinneszellen finden sich aher anch in der ganzen Ausdehnung des Ganglienringes zwischen den mit Geisselhaaren versehenen Deck-Stiitzzellen zerstreut. - Die Verbindung dieser Nervencentren nit den anderen Körpertheilen wirr durch einen spärlicheren, im Epithel gelogenen Ganglien-Nervenplexus liergestellt, also nicht durch regelmässig verzweigte periphere Nerven, wie solche bei den höheren Thieren rorliommen.

\section{Epitheliales Nervensystem bei Heteraxoniern.}

Bei den Heteraxoniem ist das Nervensystem stets ein centralisirtes, dabei kann es aber seine epitheliale Lage noch vollkommen hewahren. kíwalevsky, der zuel'st naclggewiesen lat, dass die Entwicklung des Centralnervensystems aus dem Ectoderm auch fïr die Wirbellosen Geltung hahe, liat auch die damals iiherraschende Thatsache festgestellt, flass bei Sagitta das Centralnervensysten zeitlebens eine ectorlermale Lage beibehält. Seither wurde ein ähnliches Verhalten bei vielen anderen Thiergruppen nachgewiesen. Wil führen hier an : Zahlreiche Anneliden, Sagitta, Phoronis, manche Brachiopoden, viele Echinodermen, Balanoglossus. Nicht nur das Centralnervensysten und die Simnesorgane, sondern auch die peripheren Nerven liegen innerhall, des Epithels. Nur die Furlzweige, welche zu den Muskeln ziehen, müssen das ectorlemale Epithel rerlassen, da die Mnskeln bei diesen Thieren einem anderen Blatte (dem somatisclien Blatte) angelı̈ren; roch liegen iiber das Verlialten rlieser Endzweige nul sehr spärliche Angaben vor. Die Verhältnisse dieses epithelialen Nervensystems lassen sich auf diejenigen 'ler Cnidarier zurïckfïlı'en, doch hat die Specialisirung hier einen höheren Grad erreicht. So finden wir in den Sinnesorganen die sin nesep ithelien, welche vorwiegend aus Simneszellen, Ganglienzellen und Nervenfaser'n und dameben aus Stütrzellen bestehen. Ferner in Bereich des centralen Nervensystems $\mathrm{N}$ ervenepithelien, welche Ganglienzellen, Nervenfaserı nebst Deckstiitzzellen entlalten, und endlich in Bereicl des peripheren Nervensystems solche Nervenepithelien, die nur aus Nervenfasern und Deckstützzellen zusamnengesetzt sind, Das S chichtungsgesetz ist dasselbe wie bei den Cnidariern: Die 
A

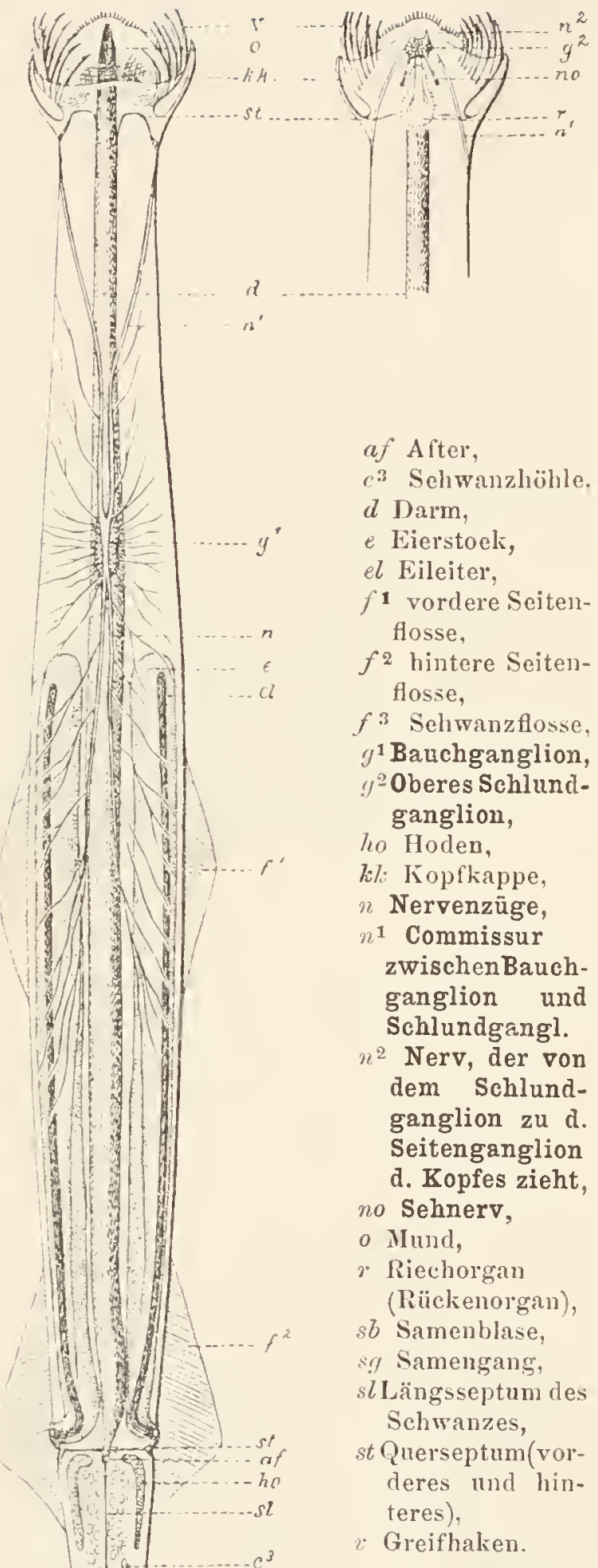

Das gesammte Nervensystem dieses Thieres liegt epithelial.
Deckstützzellen (unıl rie Simneszellen) nehmen in rer Regel rie ganze Höhe rles Epithels ein, rlie Ganglienzellen sind auf eine tiefere Lage beschränlit und dic Fasermassen liegen an der Basis des Epithels.

Fig. 139. A. Sagitta hexaptera, von der Bauchseite gesehen (nach O. HERTWIG). Vergr $\frac{4}{1}$.

1). Vorderende desselben Thieres, von der Rückenseite gesehen (combinirt nach Detailzeichnungen von O. HeITwig)

Epithelogenes Nervensystem bei Heteraxoniern.

Bei rlen höheren 'Thieren hat das Nervensystem seine nisprüngliche epitheliale Lage aufgegeben nnd eine geschütztere Stelle in Inneren des Körpers erhalten. Dadurch hat die anatomische Sonderung rlesselben einen vollkommeneren Grad erreicht.

Fiir rlie Vergleichung von epithelialen und epithelogenem Nervensystem sind jene Thiclgruppen voll besonderem Interesse, wo bei verwandten Gattungen und Arten, ja sogar innerhalb eines und desselben Thierkörpers alle Tebergänge von epithelialen zum epithelogenen Nervensystem zin beobachten sind. Hier sehen wil dentlich, rlass die Gliasubstanzen des Nervensystems unmittelbar auf die epithelialen Stiitzgewebe zur ü ckführbar sind. Es zeigt sich, dass in rem epithelial gelagerten Nervensysten schon die charakteristische Ausbildung nicht nur anatomisch, sondern auch histologisch rorbereitet ist. 


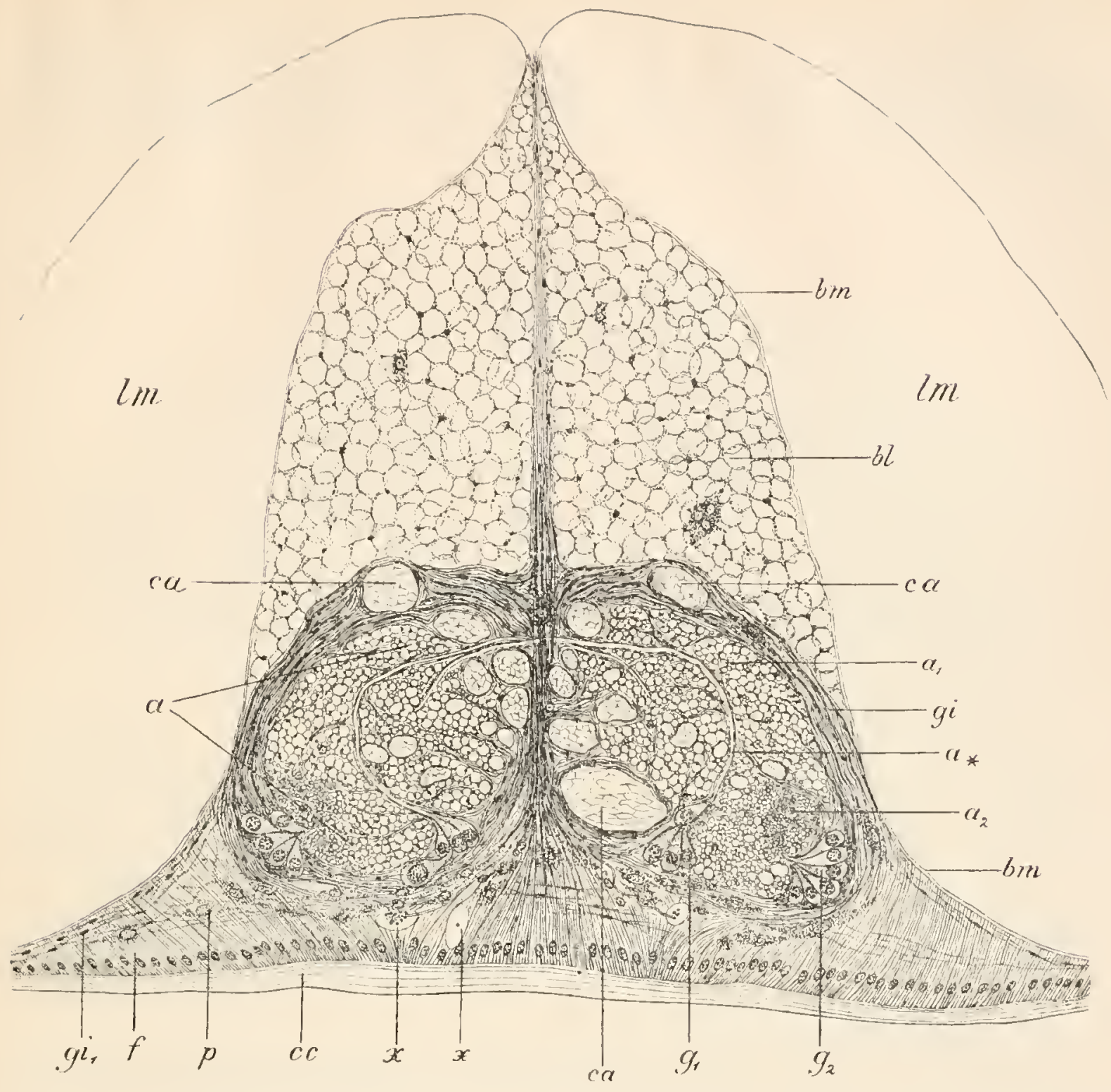

Fig. 140. Querschnitt durch das epithelial gelagerte Centralnervensystem, und zwar durch das Bauchmark eines Anneliden (Sigalion squamatum).

a Aehsencylinder, welche die eentrale Nervenmasse zusammensetzen.

$a_{1}$ Aelisencylinder von mittlerer Dieke.

$a_{2}$ Achseneylinder von geringer Dieke.

$a_{\not \rightarrow}$ Aehseneylinder, welcher der Länge naeh und in Zusammenhang mit einer Ganglienzelle getroffen ist. bm Basalmembran.

bl Blasiges epithcliales Stiitzgewebe; es sind regelmässig zerstreute, kleine, dunkle Zellkeme von je einer Gruppe von Bläselıen umgeben, und ausserdem sind grössere Kellkerne, einzeln oder zu melıeren von dunkelkörnigem Plasma umgeben, zu finden.

ca Colossale Aclisencylinder; dieselben sind aus kleineren Strängen zusammengesetzt, denn sie zeigen im Quersehnitt eine netzartige Zeiehnung, welehe der Ausdruck eines längsverlaufenden Fachwerkes ist. cc Aeussere Cutieula, Schichtungslinien zeigend.

$f$ Epitheliale Matrix der Cutienla; die Zellen haben ovale, helle Kerne und zeigen eine deutlielse Faserstruetur, welehe stellenweise direct in diejenigen der Gliazellen übergeht.

/ Mediane Gruppe von Ganglienzellen.

$g_{2}$ Laterale Gruppe von Ganglienzellen.

gi Gliasubstanz von faseriger Struetur mit längliclıen dunklen Zellkernen. Sie umgibt in cireulären Zügen die Masse des Banchmarks, und ein senkrechter Zug bildet eine mediane Scheidewand in demsellen; sie dringt ferner auch $\mathrm{z}$ wischen die Masse der Achseneylinder ein und umgibt die colossalen Aclisencylinder in Form vou derberen Hïllen, die auch Glia-Zellkerne enthalten, zwischen den kleineren Aehseneylindern erscheint sie auf dem Quersehnitte als ein Netzwerk mit derberen Knotenpunkten (dieses Querschmittsbild ist der Ausdruck eines Faehwerks mit derberen Längsfasern). Zwisehen den Aehseneylindern sind aueh einige wenige rundliche Zellkerne eingestreut.

$g_{1}$ Gliazellen seitlieh vom Nervensystem gelegen (die Nähe eines abzweigenden Nerven anzeigend).

lm Längsmuskelmassen des Körpers (nieht nälıer ausgeführt).

$p$ Verästelte, gelbliehe Pigmentzellen, welehe besonders häufig zwischen äusseren Matrixzellen und Gliahülle eingesehaltet sind, aber auel vereinzelt in der ganzen Cireumferenz des Nervensystems in der Gliasubstanz sieh finden.

$x$ IIelle Gebilde (Zellen?) oft mit einer hellen Faser (Nervenfaser?) verbunden, von unbekamnter Bedeutung. 
Die Sonderung des Centralnervensystems wollen wir zunächst in Betrachtung ziehen. Sie geschieht nach den zwei Haupttypen der D elamination und Invagination.

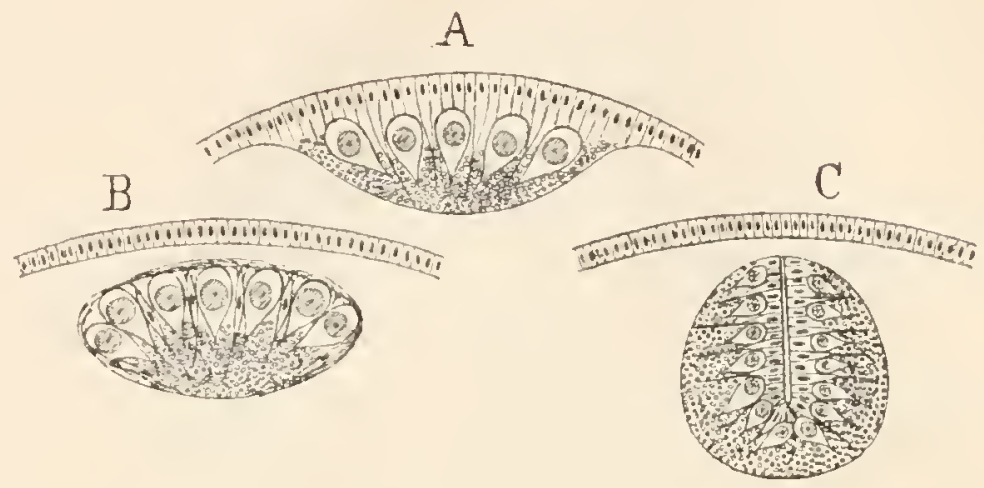

Fig. 141. Schematische Querschnitte durch das centrale Nervensystem.

A. Epithelialer Typus. B. Delaminations-Typus. C. Invaginations-Typus.

1. Delamination. Dieser Modus spielt bei den Wirbellosen cine grosse Rolle. Die Ganglien und Nervenschichte nit einer tieferen Lage von Stützzellen löst isich durch Spaltung des Epithels von der oberen oder Deckschichte ab, welche als dauernder epithelialer Theil an der Oberfliche bleibt. Auch an einem solchen durch Delamination entstandenen Centrahervensystem ist das bekannte Schichtungsgesetz 'zu beobachten, inden die Ganglienschiclıte stets dem äusseren Körperepithel zugewendet ist, während die Nervenmasse an der entgegengesetzten Seite liegt.

An dieser Stelle wollen wir eine Erörterung einschieben über den histologischen Bau der Nervenfasermasse im Centralnerrensystem der Wirbellosen. Es ist dies eine Frage, die gegenwärtig zu zahlreichen Meinungsverschiedenheiten der Autoren geführt hat.

In der centralen Nervenmasse finden wir Achsencylinder von verschiedener Dicke, meist in längsverlaufenden Zügen; diese werden von anderen Zügen gekreuzt, die theils von den Ganglienzellen, theils zu den peripheren Nerven ziehen. Die Achsencylinder sind in eine Substanz eingebettet, welche als ein dichtes Netzwcrk feinster Fädchen sich erweist (Gliasubstanz); dazu gehören kleine, meist längliche Zellkerne mit Plasmaresten (Gliakörperchen oder Gliazellen), welche am häufigsten rings um die centrale Nervenmasse angeordnet sind, aber auch einzeln innerhalb derselben sich finden. Von einem ähnlichen Gewebe sind auch die Ganglienzellen eingehüllt. Denselben Bau wie die centrale Nervenmasse (Achsencylinder in zusammenhängendem Gliafachwerk) zeigen auch die peripheren Nerren bei vielen Wirbellosen (Anneliden etc.).

Diese feinfaserige Substanz, welche wir als Gliasubstanz bezeichnet haben, ist der Ausgangspunkt der Controverse. Lerdig, der Altmeister der vergleichenden Histologie, war es, der schon vor Jahren jenes Netzwerk feinster Fäserchen für die nervöse Substanz hielt, wobei die zwischenliegenden Achsencylinder von ihm übersehen wurden. Er bezeichnete dieses feine Netzwerk nach dem Querschnittsbilde als „fibrilläre Punktsubstanz" (man pflegte sie dann auch als "Lerpig'sche Substanz" oder Fibrillenmasse zu bezeichnen). Dieselbe soll einerseits mit den Ausläufern 
der Ganglienzellen, andererseits mit den peripheren Nerven asern $2 \mathrm{R}$ sammenhängen. - Lexdrg hat in jüngster Zeit diesen Standpunlat vera rantic.y. und das Faserwerk als Stuitzsubstanz erkannt und NANSEN ist GAB RATORY

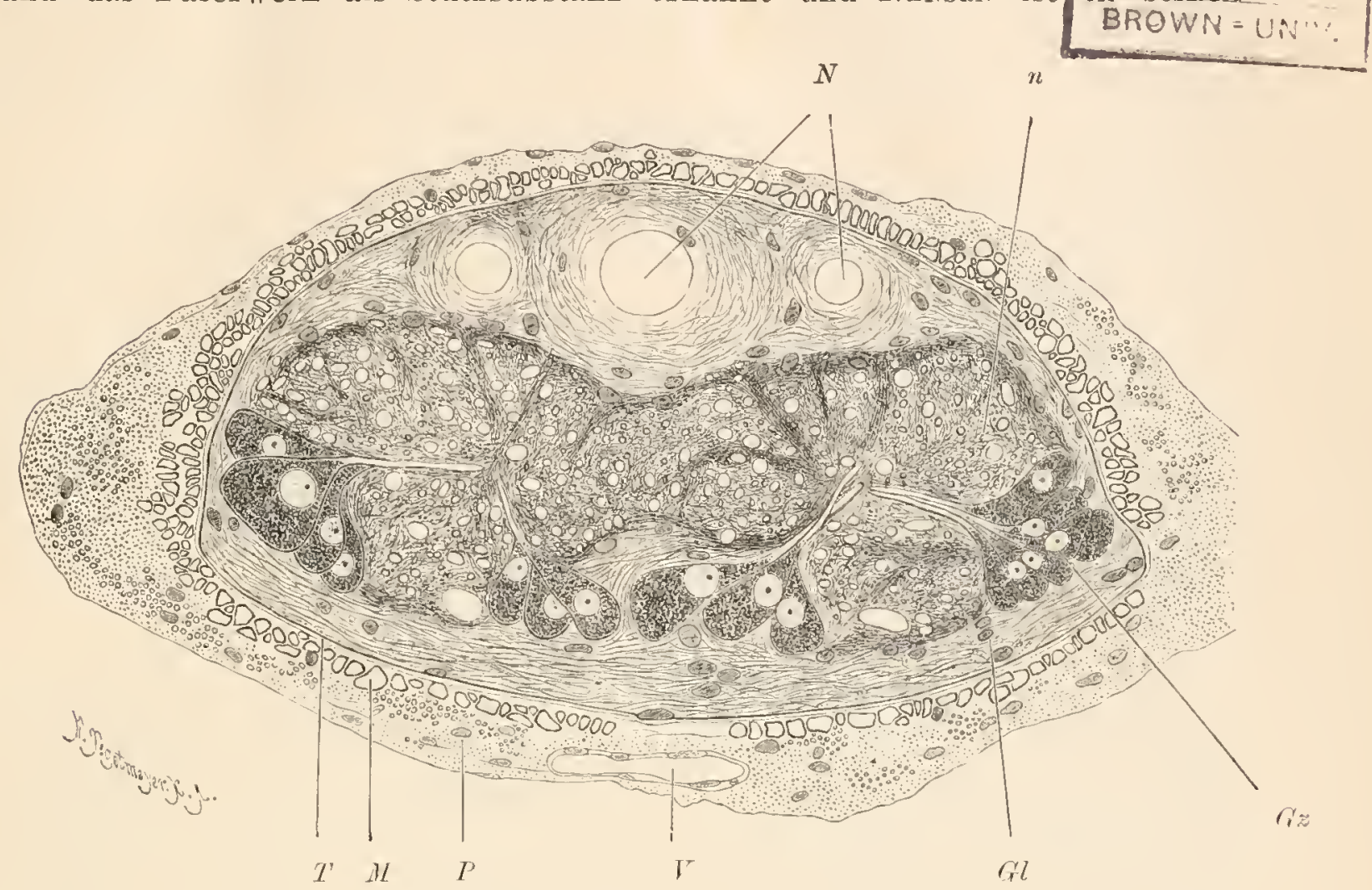

Fig. 142. Querschnitt durch das Bauchmark eines Regenwurmes (Allolobophora).

Das Bauehnark ist von Hüllen umgeben, nämlich: T eine strueturlose Tunica propria; $M$ Muskelsehiehte und $l$ Peritonealschichte, in letzterer das Gefäss $V$; $N$ colossale Axencyliuder; $n$ Nervenmasse, von verschieden dicken Axencylinderu zusammengesetzt, die in Gliasubstanz eingebettet sind; $G$ s Ganglienzellen in zwei seitlichen und zwei mittleren Paketen angeordnet; $G$ l änssere Schiehte von Gliasubstanz.

NB. Die Aehseneylinder wurden im Holzschnitt hell gelassen, um das Bild nicht zu eompliciren.

ausgezeichneten Untersuchungen auf diesem Wege fortgeschritten. Andere Forscher aber halten an der alten Lerbig'schen Ansicht fest und vertheidigen sie nun gegen ihn selbst. Im einzelnen sind die Meinungen noch mannigfach verschieden. Viele Forscher haben die eigentlichen Achsencylinder zum grössten Theil überseheı, die Gliasubstanz als feinst verästeltes Nervennetz und die Gliakörperchen als „kleinere Ganglienzellen“ betrachtet ${ }^{1}$ ).

An Stelle der Anschauung eines relativ einfachen Faserverlaufes, der schon vor vielen Jahren am lebenden Gewebe annähernd richtig beurtheilt wurde, hat die Vorstellung eines Netzwerks ron Millionen Fäserchen Platz gegriffen, welches wohl auch physiologisch kaum verständlich wäre.

Für die Auffassung der Nervenmasse im centralen Nervensystem der Wirbellosen ward auch noch ein anderer Irrthum verhängnissvoll. Es bezieht sich nämlich eine ähnliche Controverse auch auf das Nervensystem der Wirbelthiere und zwar auf ein feinstes "Nervennetz", welches in diesem Falle nicht in der Nervenmasse (,weissen Substanz"), sondern in

1) Einen Standpunkt, der sieh immerhin vertheidigen lässt, vertritt RноDE, indem er nebst den Achsencylindern noch ein Fibrillennetz annimmt; älnnlich wie es viele Histologen für die Wirbelthiere angeben. 
der Ganglienmasse (,grauen Substanz") des Rückenmarkes sich findet. Dies veranlasste LeYnig, die Fasermasse der wirbellosen Thiere mit der Ganglienmasse oder ,grauen Substanz" der Wirbelthiere zu vergleichen; ein Vergleich, der allgemein üblich wurde und stets einer richtigen $\mathrm{Be}$ urtheilung im Wege stand. In Wirklichkeit entspricht die Fasermasse der Wirbellosen del "Woissen Substanz", die Ganglienmasse derselben der "grauen Substanz" im Rückenmark der Wirbelthiere.

Diese Erörterungen haben für das Centralnervensystem der meisten Wirbellosen gleiche Geltung. Speciell für die Amneliden kommt noch die Controverse über die Natur der sogenannten ,colossalen Nervenfasern“ hinzu. Lexpig hat diese Gebilde seit vielen Jahren für Nerven erklärt und seine Ansicht ist kaum mehr zu bezweifeln, seitdem Spevgel gezeigt hat, dass sie mit zahlreichen grossen Gauglienzellen zusammenhängen (was ich für den Regenwurm aus eigener Anschauung bestätige) ${ }^{1}$ ); ihre Structur stimmt mit derjenigen der anderen Achsencylinder rollkommen uiberein; durch ihre mächtige Gliahülle setzen sie sich von der übrigen Fasermasse schärfer ab. Von vielen Forschern wird dennoch ihre Nervennatur bestritten.

2) Invagination. Beispie 1: Chordonier. Bei den Clordonier'n stiilpt sich ein 'Theil des Ectoderms an der Rïckenfläche des Embryo in Form einer Rinne gegen das Innere des Körpers ein und diese komnt sodaun zul Ablösung, so dass sie ein selbstiundiges Epithelrohr (das Medullarrolor) bildet. Dasselbe zewinut durch histologische Differenzirung den Charakter eines Nervenepitlıels. (In der ontogenetischen Fntwicklung folgt die histologische Differenzirung der Sonderung, während es in der phylogenetischen Entwicklnng zweifellos umgekehrt der Fall war" dasselbe ist oft anch beim Delaminationstypus zu beobachten). Im Medullarrohr ist die Schichtung der histologischen Elemente genan dieselhe, wie wir sie schon im Nervenepithel der Cnidarier fanden. An ïhersichtlichsten ist diese Anordnumg bei den einfachen Verhältuissen des A mp h i o x 1 s. Wir finden hier auf dem Querschnitte des Medullarrohres 1) nächst der freien Fläche des Fpithels (d. i. gegen das Lumen des Medullarrohres) Geisselzellen, welche nach der Basis

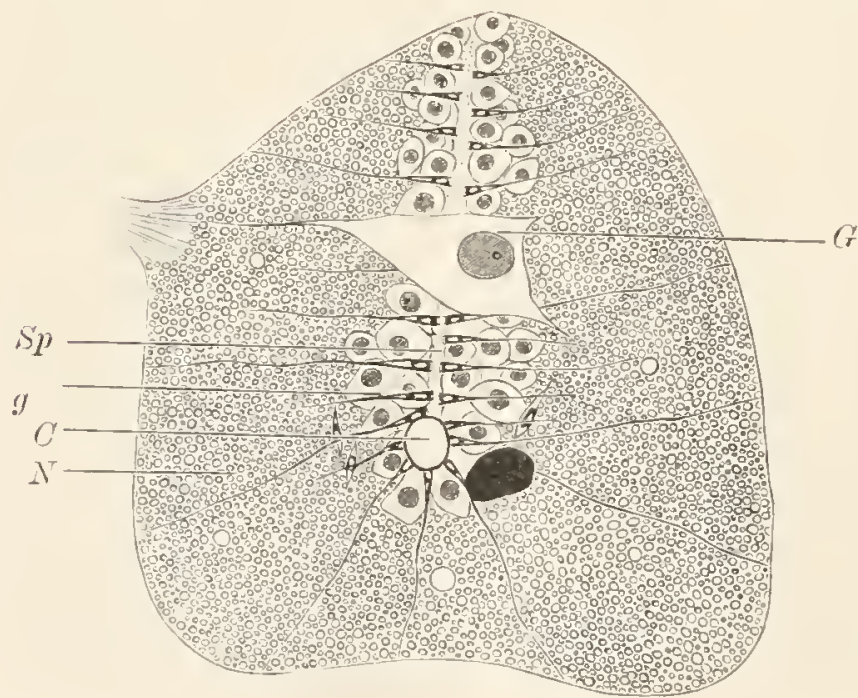
des Epithels (d. i. die äussere Fläche rles Medullarrohres) strangförmige, derbe Fortsätze aussenden. Diese Zellen repräsentiren die Deckstiitzzellen; läings des Verwachsungsspaltes finden sic

Fig. 143. Querschnitt durch das Medullarrohr eines jungen Amphioxus.

$C$ Centralcanal, unterhalb dessclben einc Pigmentmasse; Sp Verwachsungsspalt; beide von Stïtzzellen umgebeu; $C_{r}^{r}$ grosse Ganglienzelle, welche aus der Reihc der anderen Ganglienzellen heraustritt; ") Ganglienschichte (graue Substanz); $N$ Nervenschichte (weisse Substanz).

1) Wälurend des Druckes dieses Buches crschien eine Arbeit von B. FRIEDLAENDER, deren gleich lantende Angaben ich hiermit bcstiitige, während ich in Bezug auf die Structur der ccntralen Fasermasse nicht ganz mit jencm Antor iibereinstimmc. 
sich in mehr modificirter form. 2) Unterhalh der Deckzellen findet sieh die Ganglienschichte. nur einzehe 'bellon ilurchbrechen die lieihe; und 3) sehen wir in der basis des Epithels die sehr beträthtliche Nervenmasse. Ausser den Deckstiitzzellen ist nur äusserst spärliche Gliasubstanz vorhanden, während sic hei den liöheren Wirbelthieren hedeutendo Entwicklung zeigt.

Sonderung der Simnesepithelien, Die Simnesepithelien liegen entweder dauernd in derselben Eläche mit dem anderen ectodermalen Epithel. oder sic bilden vertiefte binstiilpungen, was nicht mm eine geschiitztere Lage lezweekt, sondern oft auch nit der kunction der Sinnesorgane zusimmenhängt, orler aher schniinen sich diese Einstül)ungen vollständig ab, meist in Fonn von Blasen, und stellen num gesonderte Derivate des cctodermalen Epithels dar (Augenblasen, Gehörblasen, 'Tastkörperchen). Fs gibt geschichtete Sinnesepithelien, das sind solche, die unterhalb der Simneszellen eine Crang-

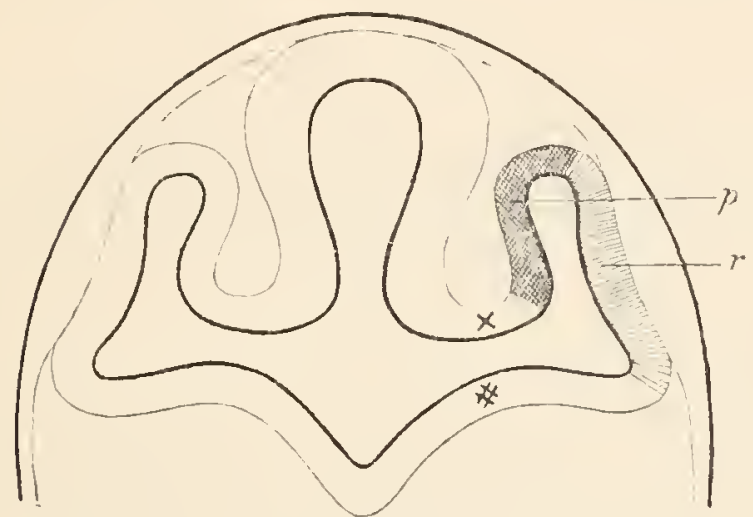

Fig. 144

Fig. 144. Querschnitt durch den Stirntheil eines Fisch-Embryos (Jepidosteus), schematisch (nach 13ALFOUR).

Von den Seiten des Medullarrohres gliedern sich die Augenblasen ab. $r$ ist derjenige Theil der Augenblase, der zur Retina wird; $p$ ist der Theil, der dic Pigmentschichte liefert; + und Stiel der Augenblase, der theilweise zum Sehnerven wird. - Sowohl die freie Fläche des äusseren Epithels, als auch die freie Fläche des Medullarrohres, die nach innen gewendet ist, sind in der Zeichnung durch eine kräftigere Contour hervorgehoben.

Fig. 145. Zellelemente und Schichtung der menschlichen Retina, schematisch (nach M. SchuLtze).

1. Sehzellen; $2 \mathrm{a}$ und $2 \mathrm{~b}$ erste und zweite Ganglienschichte (Ganglion retinae und Ganglion nervi optici); 3. Nervenschichte; 4. Stützellen, dic ganze Höle des Epithels einnehmend.

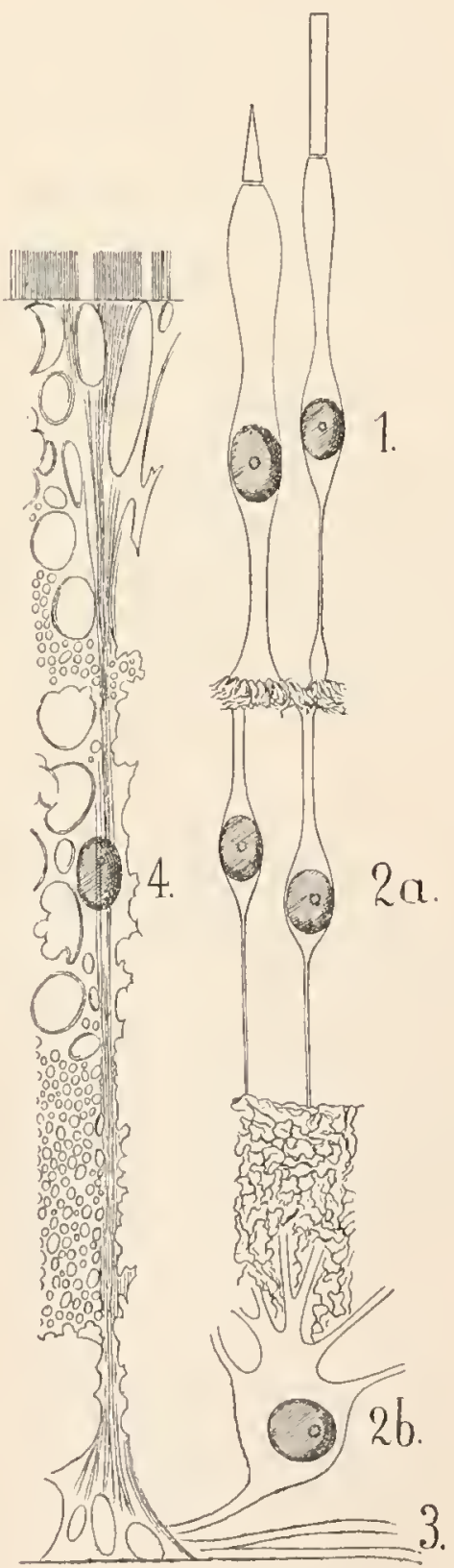

kig. 145. 
lienschichte und eine basale Nervenschichte besitzen, und einfache Sinnesepithelien, die bloss Sinneszellen enthalten, an deren basales Ende Nerven herantreten. Oft liegt aber in der Nähe des einfachen Sinnesepithels ein sogenamntes peripheres oder Sinnesganglion, welches als abgelöster tieferer Theil des Epithels aufzufassen ist.

Als ein interessantes Beispiel für die gesetzmässige Schichtung der Sinnesepithelien ist der Vergleich zwischen der Retina des Wirbelthierauges und des Cephalopodenauges hervorzuheben. Wenn wir bei den Wirbelthieren die Entwicklungsgeschichte der epithelartigen Retina (als Derivat des Medullarrohres) verfolgen, so finden wir, dass ihre der Oberfläche des Körpers zugekehrte Seite die basale ist, während die entgegengesetzte — dem Körperinneren zngekehrte — der freien Fläche entspricht. Es finden sich daher die Sinneszellen an dieser hinteren Fläche, während die Nervenmasse nach rorne liegt. Die Lichtstrahlen müssen, um die Sinneszellen zn treffen, die durchsichtige Nerven- und Ganglienschichte passiren. (Die Stiitzzellen. welche die ganze Höhe des Epithels durchsetzen, sind interessant in Iiezug auf die Frage der epithelialen Natur der Retina).

Im Cephalopodenauge, das in seinem ganzen Baue dem Wirbelthierauge scheinbar selır ihnlich ist. finden wir eine entgegengesetzte Schichtung der Retina (nacll Grkxacuer ist der Schichtenbau einfacher als man bisher glaubte), und die Entwicklung des Auges lehrt uns, dass es hier die freie Fuithelfliche des Simnesepithels ist, welche der Kürperobertläche zugewendet ist.

Die Entwicklung der peripheren Nerven ist nur l,ei den Wirbelthicreu bekannt: diesellyen entstehen als Answiichse des Centralnervensystems und treten secundär mit ihren Fndorganen in Verbindung. Die phylogenetisclı Deutung dieser Vorgänge ist noch kanm klargelegt und ist un so schwieriger, "la ja in rielen Fällen primäre Nervenbahmen zu Grunde gegangen and durch secundäre Nervenverbindungen ursetzt sein könllen.

\section{Apoplasmatische Structuren.}

\section{A) Innere Abscheidungen der Zellen:}

1) Flïssigkeitsvacuolen können sich in den verschiedensten zellen (sowohl in epithelialen als anch in Mesenchymzellen) bilden. Als Beispiel ist hier anzutüren. dass die Endodermzellen der $C n i$ darier meist ansehnliche Flüssigkeitsvacuolen enthalten (Fig. 146). Fine besondere Rolle spielen die Flïssigkeitsvacuolen in den Zellen gewisser Stiitzgewebe (oft auch als "Bindegewebe" bezeichnet); die Zellen gewinnen durch die Vacuolenlildung eine bedentendere Ausdehnung und ilıre strafferen peripheren Theile fungiren als Stützsul)-
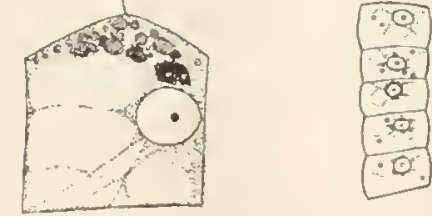

Fig. 146

Fig. 146. Eine Endodermzelle von Hydra fusca mit grossen Flüssigkeitsvacuolen, ausserdem finden sich pigmentirte und unpigmentirte Körner, welche als Producte der Assimilation zu betrachten sind (nach F. E. Schulze).

Fig. 147. Endodermale Stützzellen aus der Tentakelachse von Cordylophora (uacls F. E. SCHULZE). 
stanz. Derartige Gewebe sind: die endodermalen T e nt a kelach se n der Hydroidpolypen und der Medusen, ferner rie ebenfalls rom Endoderm abstanmende Chorda dorsalis (das primärc A chse 11 skelet) der Wirbelthiere; von Mesenchymbildungen ist das sogenannte, blasige $\mathrm{B}$ ind ege w e be $\mathrm{e}^{6} \mathrm{zu}$ crwähnen, welches besonder's bei den Plattwionmern und Mollusken eine weite Verbreitung besitzt. Aucl knorpelähnliche Bildungen sind bei Mollnsken mitunter (Zungenknorpel) woll auf Modificationen des blasigen Bindegewebes zur'ückzuführen, doch kömmt auch echtes Knorpelgewebe vor.

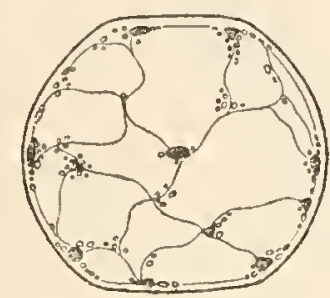

Fig. 148.

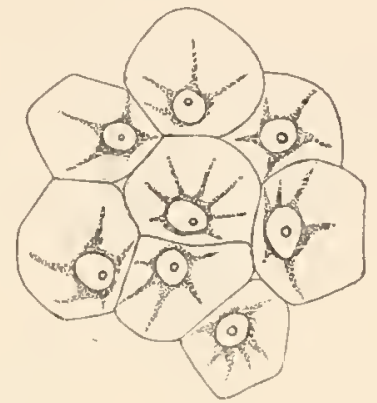

Fig. 149

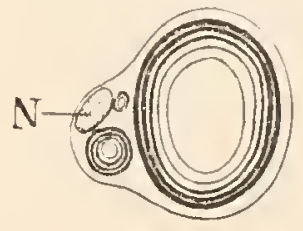

Fig. 150 .

Fig. 148. Querschnitt durch die Chorda dorsalis der Unkenlarve (nach GöTtE).

Das blasige Gewebe ist von einer structurlosen Membran (Chordascheide) cingehiillt, welche die Bedeutung einer Basalmembran hat.

Fig. 149. Blasiges Bindegewebe eines Plattwurmes (Axine) (nach Lonevz).

Fig. 150. Fettzelle vom Weissfisch (nach LEYDig) mit einem Zellkern $(N)$ und einem grossen und zwei kleineren Fetttropfen.

2) Fetttropfen finden sich in den verschichensten zelligen Gebilden, namentlich in den Endodermzellen niederer. Thierc (Cnidarier, Turbellarien etc.) meist in Fol'n von zahl'eichen kleinen Tröpfchen. Specielle Ablagerungsorte fïr diese Reservestoffe des Körpers bilden dic Fettzellen, welche in sogenamuten Fettgewche besonder's bei den Insekten und Wirbelthieren ganz allgenein vorkonmen. Das sind Kellen, die einen ähnlichen Ban hesitzen wie etwa dic oben elwähnten Zellen des blasigen Bindegewebes; nul' enthält der Hohlraum der /elle hier nicht eine wässrige Flüssigkeit, sondern einen oder mehrere grosse Fettropfen. Te nach dem Frnähnungsustande des 'Thieres kann der' Inhalt dieser' 'Lellen schwinden oder' zunchmen.

3) Pigmentkörnel. Bei viclen Thieren ist sowoll dic äusserc Färbung, als auch dic Färbung manclier immerer Organe anf das Volhandensein specieller Pigmentkörnchen in Plasma der '/ellen zuriickzuführen. Diese Körnchen sind wohl mannigfaltiger Natur, gewiss sind sie aber in vielen Fällen der eigentlichen Plasmasubstanz als sccundäre andersartige Bildungen gegenïberzustellen. Pigmentköınel können in allen Arten von 'sellen rorkommen. Von besonderem Interesse ist ihr Vorkommen: 1) In den Augen der verschicdensten Thiere, wo sie dazn dienen, von dem percipirenden 'Theil der Simneszellen solches Licht abzuhalten, welches aus anderer hichtung als aus derjenigen des Sehens kömmt; die Pigmentkörner können innerhall) der Sinnoszollen selbst gelegen sein, oder in henachbarten \%ollen. Manchmal bilden die Pigmentzellen sinc zusanmmenlä̈ngende Schichte an der Peripherie des Auges. 2) Wie schon an anderer Stelle ervähnt wurde, gibt es bei vielen 'Thieren amöhoide Pignentzellen, die unterhalh des Körperepi- 
thels liegen. Das Vermögen des Farbenweclisels bernht neist anf der selbständigen Contractilitit solcher Kellen; bei den Cephalopoden dagegen bedingen radiär an die \%elle herantretende Muskelfasern die Gestaltreränderung derselben zun Zwecke des Farbenvechsels; wem die Zellen ihı Fortsätze ausstrecken, erscheint die Gesanmtfärbung des Thieres dunkler, und mmgekehrt bei Contraction aler '/ellen heller.

t) Intracelluläre Skeletbildungen. Aelnnlicl wie bei vielen Protozoen (Foraminiferen, Radiolarien) kam anch die Metazoenzelle in ihren Inmeren Skelettbildungen ausscheiden. An häufigsten sind es Mesenchymzellen, welche diese Erscheinung zeigen. Derartige Skeletbildnngen sind die Kalknarleln und Kieselkörper, die wir bei deu Spongien in sehr mannigfaltiger Gestaltung vorfinden; sie liegen nur in ihren ersten Entwicklmugstadien in Inneren der /elle nnd dnrchbrechen bei ihrem bedentenden Heranwachsen rlie Contimuität derselben. lis ist daher keine scharfe Grenze zwischen diesen intracellulären mud anderen in ter cellulären Gebilden zu zichen. Vielleicht sind auch die Kalkskelette der Echinod e r'menlarven und anch die der erwachsenen Echinodermen auf cinen ähnlichen 'Typus zuriickzuführen; es sind aber hier die netzartigen Kalkmassen das Prodnkt zahl'eicher Zellen.
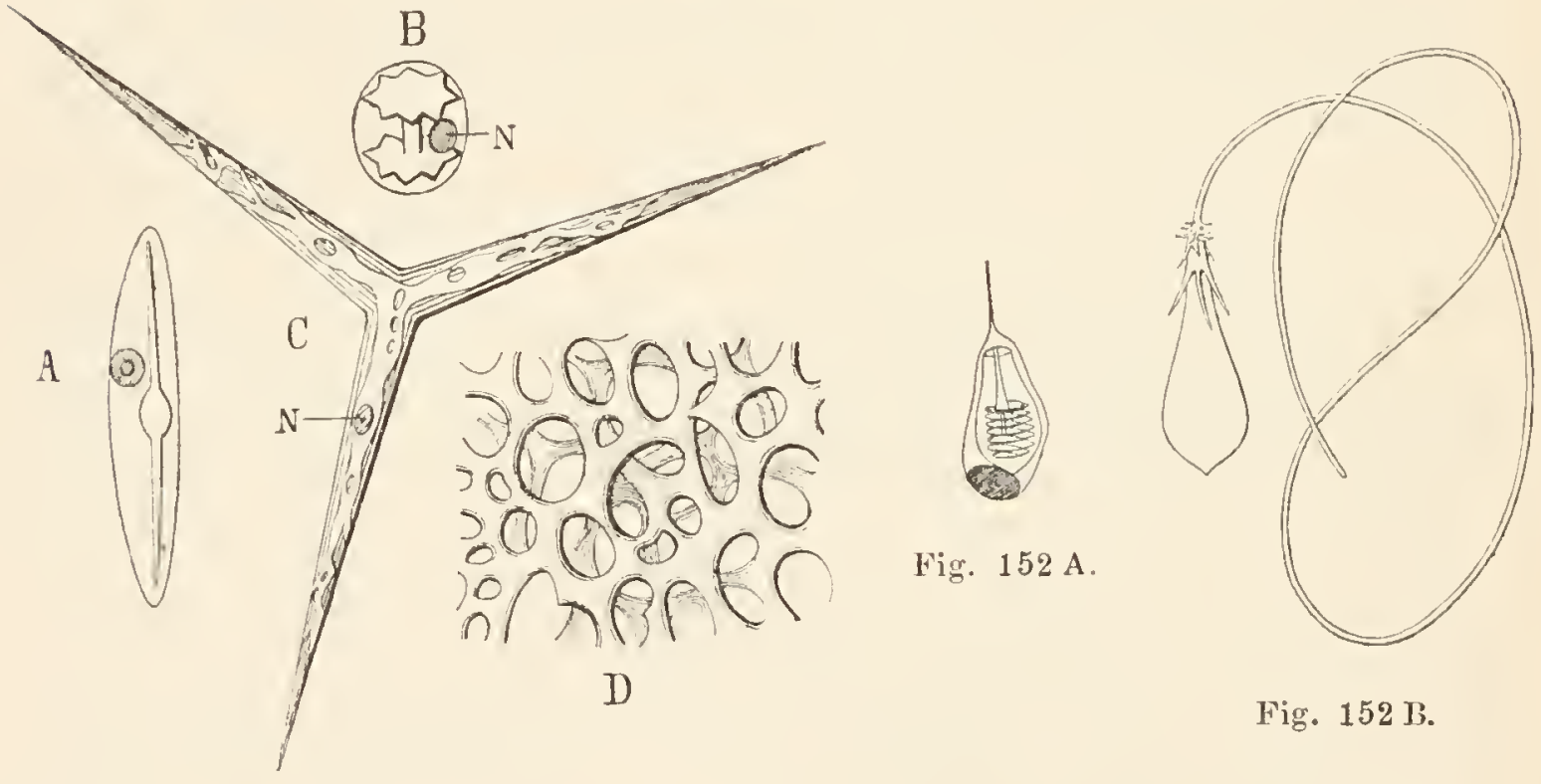

Fig. 151

Fig. 151. A. Kieselnadel von Sponyille mit der Bildungszelle.

B. Skeletbildung (Amphidiscus) aus cinem Winterkeime v. Spongilla mit der Bildungszelle.

C. Dreistrahlige Kalknadel eines Kalkschwammes mit der Bildungszelle, welche verzweigte Ausläufer besitzt. $N$ Zellkern (bei A, B u. C).

D. Kalknetz aus dem Skelet eines Seeigels (nach verschiedenen Autoren).

Fig. 152. A Cnidoblast mit eingeschlossener Nesselkapsel.

13. Eine explodirte Nesselkapsel noch stärker vergrössert.

Beides von IIydra fusce (nach F E. ScHurze).

In Anschhiss daran kömnen wir die Erscheinung betrachten, dass Zellen in ihrer anzen Ausrehmmg einer Chitinisirung (z. B. bei Arthropoden) odler einum Vorliorumgsprocess unterliegen: letzteres ist namentlich bei den epidermoirlalen Bildungen der höheren Wirbelthere (hornige Oberhaut, Nägel, Schuppen, Haare, Federn) der Fall.

5) Die Nesselkapseln sind eigenthïmliche complicirte Einschlüsse 
gewisser Zellen; sie bestchen ans einem derlwandigen Bläschen, welches nebst einem Flüssigkeitsinhalt noch einen spiralig eingerollten, vorstülpharen, an seiner Basis nit Widerhaken versehenen Nusselfaden enthält. Derartige Nesselzellen sind typisclı für dlie Epithelien der Cnidarier; sie finden sich aber auch bei einigen anderen 'Thierformen, z. B. bei Turbellarien (Prostomum) und marinen Nachtschnecken (Aeolidia).

\section{B) Secrete der Zellen. \\ Driisengewebe.}

In ähnlicher Weise wie die vorlinı erwähnten Einschlüsse, entstehen in Zellen auch Secrete, das sind solche Einschlüsse, die nicht in Inneren der Zelle verbleiben, sondern zunächst ans derselben, und in tler Regel aus dem thierischen Körper überhaupt, entleert werden. Die secernirenden Zellen bezeichnen wir als Drüsenzellen, sie sind stets Epithel-

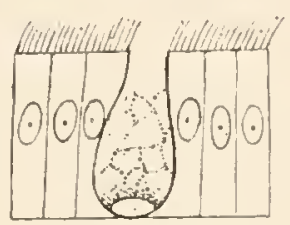

Fig. 153.

A

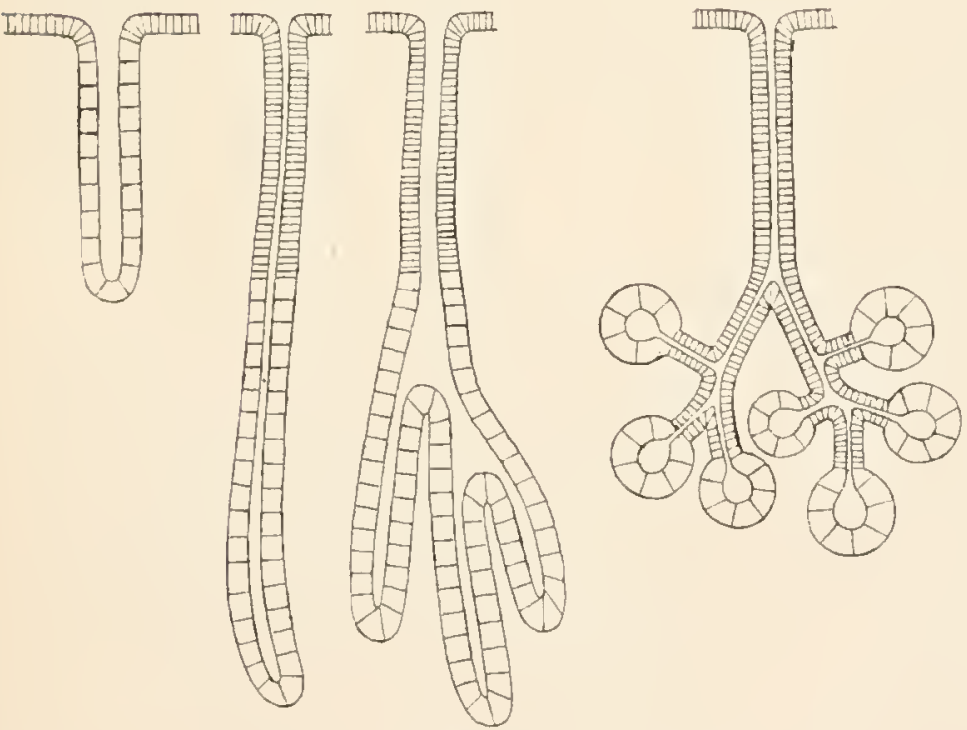

Fig. 155

Fig. 153. Epithel mit Becherzelle, im Querschnitt (nach Grobien).

Fig. 154. Drüsen eines Krebses (Poluceros) (nach Nebeski).

A. Eine einzellige Drïse. Benachbarte Zellen sind dicht bei der Ausmündungsstelle abgeschnitten.

B. Modification des einzelligen Drüsentypus, bei derselben Krebsart vorkommend. Hier sind zahlreiche einzellige Drisen an cinem gemeinsamen Ausfülnungsgang befestigt.

Fig. 155. Schema dor vielzelligen Drüsen.

A. Tubulöse Drïse. $B_{1}$. Driisiger Theil und Ausführungsgang sind differenzirt. $B_{2}$. Verzweigte tubulöse Driise. C. Acinöse Drüise.

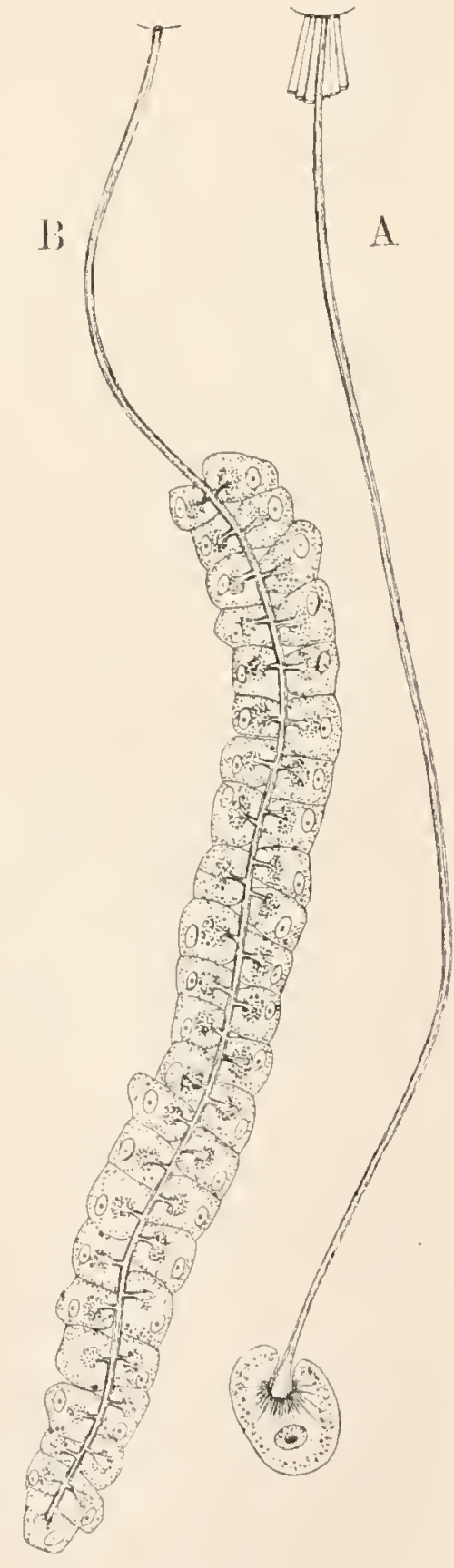

Eig. 154. 
zellen [vielleicht mit Ausnahme des Protonephridiums der Zygoneura]. Wir unterscheiden: 1) einzellige Drüsen; im einfachsten Falle liegen solche drïsige Zellen innerhall, der Reihe der anderen Epithelzellen (Becherzellen, Körnchenzellen etc.); es gibt aber auch einzellige Drüsen, welche aus der Reilı der angrenzenden Epithelzellen herausgetreten sind und, minterhalb des Epithels liegend, nnr mit ihrem freien Fnde zwischen die Epithelzellen lineinnagen; bei diesen ist die \%elle in der Regel in einen clïisigen Abschnitt und in einen Ausführungsgang differenzirt; solche einzellige Drüsen kömnen auch in Büschelı angeordnet sein. 2) Viel'zulligg D lius en entstehen darlurch, dass an einer Ejpithelstelle sämmutliclıe \%ellen drüsige Beschattenheit annehmen; neist geht dies mit einer Einstülpung der betreffenden Stelle einher. In der Regel differenzirt sich die Drüseneinstiulpung in einen eigentlich driisigen Endabschnitt 11nd einen Ausfühıungsgang, dessen Zellen nicht secretorisch fungiren. Dic Drüsen kömen schlauchförmig, nuld zwar einfach oder verästelt sein (tubulöse Drüsen), oder die Drüse liat eine traubige Form, wobei die Drüsenepithelien auf die bläschenförmigen Endabschnitte beschränkt sind (a cinös e D r ii s e n).

Dic Secrete haben nicht immer die Bedeutung von Auswurfsstoffen des Körpers, sondern sie können anch bestimmten Zwecken dienen, z. B. Verdaumossecrete, Secrete ron Giftcliusen etr. - Die Secrete können auch eine schützende Hülle für den körper bilden: so liefern sie bei zahlreichen $W^{2}$ ürmern schleimige orler auch derbere membranöse Gebilde, als eine Irt Gehäuse: oft werden aucl zu diesem Zwecke Fremalkörper (Steinchen u. dgl.) durch die Seclete zusammengekittet. Hier schliessen sich endlich auch die typischen G ehä usebildungen der Mollusken mol Brachiopoden und die Ectocyste de $B$ ryozoen, welche trotz ilner oft complicirten Structur nur als Secrete der darunter liegenden Epithelien zn hetrachten simd.

\section{C) Aeussere Abscheidungen der Zelle.}

Hierher gehören zunächst jenc festeren Abscheidungen, die an der Peripherie der Zellen entstehen und zumeist den eigentlichen Bindesubstanzen des Körpers den Ursprumg geben. Als primitivste Form derselben haben wil die $\%$ a $11 \mathrm{me} \mathrm{mbla} 11$ zn betrachten, die häufig als ein dümnes Häutchen an der Oberfläche der einzelnen \%ellen nachweisbar ist: die Dottermembran der Eizellen, das Sarcolemma der Muskelfaser'n ist einc solche Bildung. Wir finden ferner ähnliche Abscheidungen an Zellverbänden und zwall:

1) Ibscheidungen an Epithelien. a) Kittsubstanz del Epithelien nennen wir jene nucist spärliche Substanz, welche zwischen den Epithelzellen nachweisbar ist; nur selten gewinnt dieselbe eine beträchtlicho Mächtigkeit, wodurch die Zellen des Epithels weit auseinander gerlängt werden und dabei dic Charaktere isolirter 'Zellen (sternförmige Gestalt) gewimuell können (Mantel der Tunicaten). b) Als Basaluembra n bezeichnen wir eine an der Basis der Epithelien sehr allgemein vorfindliche Membran, die meist nur voll geringer Dicke, aber beträchtlicher Festigkeit ist: sic ist als eine gemeinsame Abscheidung des darüber liegenden Fpithels zu betracliten; meist erscheint sie structmolos, manchmal aber ist eine faserige Structur an derselben zu erkennen. c) Cuticula. Membranen, die an der freien Fläche der Epithelien sich hilden, hezeichnen wir als c'uticulanbihdungen; bei eingen 
Thiergruppen sind sie nicht entwickelt (z. B. Spongien, Wirbelthiere), bei anderen gewinnen sie aber einc typische Bedentnng, ja sie können sogar durch ihre mächtige Ausbildmg eine wichtige Rolle in der Gesammtorganisation des 'Thieres spielen. Eine Cuticula an der äusseren Kö̈rperoberfläche ist für die meisten Scoleciden charakteristisch; während sie aber in vielen Fällen nur ein zartes, schwer nachweisbares Häutchen bildet, erreicht sie in anderen Fällen, z. B. bei den Nematoden eine berleutende Dicke, sie ist hier geschichtet, zeigt eine bestimnte faserige Structur und trägt oft mannigfaltige äussere Sculpturen und Anhänge, während des Wachsthums des T'lieres wird sie mehrmals abgeworfen und wieder ernenert (cuticulare Häutung). Aelnnliche Gegensätze finden wir bei den Articulaten; während nämlich die Cuticula der Anneliden nur von geringer Mächtigkeit ist, erreicht sie bei den Arthropoden eine bedeutende Dicke und Festigkeit (Einlagerung von Kalksalzen bei den Crustaceen); sie zeigt auch hier charakteristische Structureigenthümlichkeiten und wird durch Häutung gewechselt. Die Einrichtung beeinflusst hier aufs tiefste die gesammte Organisation. - An den endodermalen Epithelien kommt bei den verschiedensten Thieren eine sogenannte Stäbchencuticula vor, d. i. ein cuticularer Saum, der von senkrechten Poren durchsetzt wird und manchmal in prismatische Theilchen zerfällbar ist.

Zwischen Cuticularbildungen und Secreten ist nicht in allen Fällen eine scharfe Unterscheidung möglich.

2. Grundsubstanz der Bindege websarten. Eine reichliche Zwischensubstanz wird auch von mesenchymartigen Zellen ausgeschieden und bildet die sogenannten echten Bindesubstanzen, besonders bei den Wirbelthieren. Die verschiedenen Arten von Bindegewebe zeigen verschiedene Structur der Grundsubstanz: 1) Der Hyalinknorpel besitzt eine homogene Grundsubstanz von elastischer, aber ziemlich festel' Beschaffenheit; auch sind für das Knorpelgewebe die r'undlichen Knorpelzellen charakteristisch; in das Knorpelgewebe dringen keine Blutgefüsse ein. Der Faserknorpel ist ein verwandtes Gewebe, bei welchem

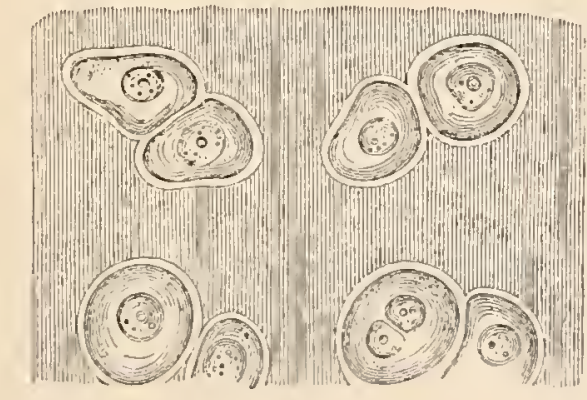

Fig. 156.

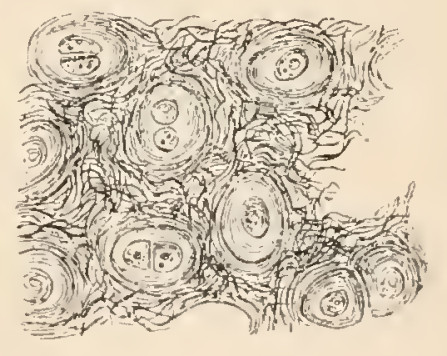

Fig. 157 .

Nig. 156. Hyalinknorpel eines Säugethieres.

Fig. 157. Faserknorpel eines Säugethieres.

auch faserige Structuren in der Grundsubstanz auftreten. 2) Das fibrilläre B ind egewebe ist von weicher Beschaffenheit, jedoch gewinnt es durch die parallelfaserige Structur seiner Grundsubstanz eine bedeutende Zugfestigkeit; hier sind die Zellen („Bindegewebskörperchen“) klein und von spindelförmig gestreckter Gestalt. Als eine verwandte Gewebsform ist das elastische Gewebe zu erwähnen. 3) Das 
Kr nochengewebe gewinnt durch Ablagerung von Kalksalzen in der Grundsubstanz eine bedentende Festigkeit und Härte; es ist dem fibrillären Bindegewebe am nächsten verwandt; ausser seiner Consistenz ist dasselbe durch seine charakteristische Schichtung (in der Regel rings um blutgefüissfülırende Hohlräume) und durch die charakteristische, verästelte Form und Anordnung seiner Knochenkörperchen ausgezeichnet. - Man hat daher wohl zu unterscheiden zwischen incrustirtem Knorpel, d. i.

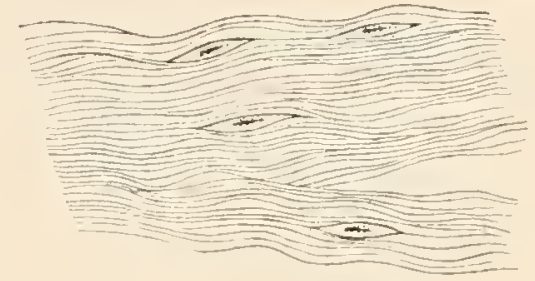

Fig 158.

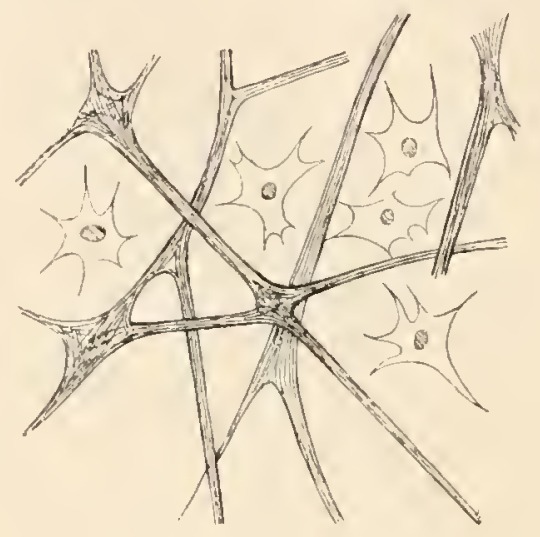

Fig. 160 .

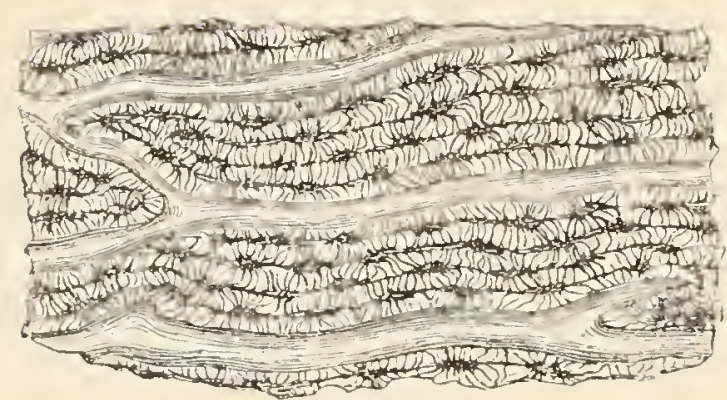

Fig. 159. A.

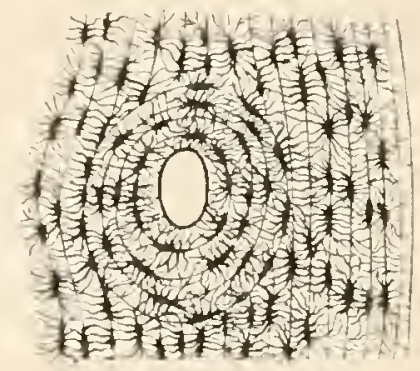

Fig. 159. B.

Fig. 158. Fibrilläres Bindegewebe eines Säugethieres.

Nig. 159. Knochenstructur.

A. aus dem Längsschnitt eines Röhrenknochens vom Säugethiere.

B. aus dem Querschnitte desselben.

Fig. 160. Gallertgewebe oiner Scyphomeduse (nach Claus). Man sieht in der Grundsubstanz verästelte faserige Structuren und Zelleı.

Knnorpel, dessen Grundsubstanz durch Ablagerung von Kalksalzen verhärtet ist und dem ganz anders gearteten Knochengewebe. Denn dort wo knorpelig präfor'mirte Skelettleile wirklich ossificiren, geschieht dies derart, dass das eine Gewebe (Knorpel) zerstört wird und das andere Gewebe (nämlich das Knochengewebe) an dessen Stelle eindringt.

Das Gallertgewebe der Cnidarier, welches besonders bei den Medusenformen eine so bedeutende Entwicklung erreicht, dass es den grössten Theil der Körpermasse bildet, nimmt den Raum zwischen den beiden primären Blättern ein. Bei den Hydromedusen ist es meist vollkommen zellenfrei und seine Structur kann nur auf den Einfluss der angrenzenden Blätter zurïckgeführt werden ${ }^{1}$ ). Bei den Scyphomedusen

1) Auch das Bindegewebe von Amphioxus zeigt ursprünglich ein derartiges Verhalten, da es als Ausscheidung einer epithelialen Lamelle (,Grenzlamelle des Bindegewebes") auftritt. 
enthält es mesenchymartige Zellen und in der Gallerte sellost finden sich meist viel deutlichere Faserstructuren; in diesen Falle zeigt es daher schon eine gewisse Verwandtschaft nit den fibrillären Bindegeweloe. Dieses Gallertgewebe repräsentirt eine Zwischenstufe zwischen Bindegewebe und zellenfühı'enden Kö̈rperflüssigkeiten (vielleicht den phylogenetischen Ansgangspunkt nach beiden Richtungen).

\section{D) Körperfluida.}

Drei morphologisch verschiedenartig ungrenzte Hohlraumsysteme enthalten Körperflüssigkeiten, diese sind: 1) die primäre Leibeshöhle; 2) die Coelomlı̈hle und 3) das Blutgefässsystem ${ }^{1}$ ). Anch die zelligen freien Inhaltsköryer dieser Flüssigkeiten können morphologisch sehr rerschiedenartiger Abkunft sein, da sie von den Wänden dieser Hohlrïume abgelöst sind. Es ist aber nicht immer eine scharfe Unterscheidung zwischen den verschiedenen Inhaltskörpern möglich, da in vielen Fällen, wie z. B. Mollusken, Arthropoden, die Hohlräume conflniren.

Die Flüssigkeit, die sich in der primären Leibeshöhle oder in Gewebslücken befindet, nemnen wir $\mathrm{Ly} \mathrm{mp}$ h e, die Inhaltsfluissigkeit des Coeloms wird ebenfalls als Lymphe oder auch speciell als Leibeshöhleuflüssigkeit bezeichnet und endlich heisst jene Fliissigkeit, die innerhalb der Blntgefüsse circulirt, Blut. - Diese Flïssigkeiten bestehen aus Wasser, das aber stets Eiweisskörper und Salze gelist enthält; das Wasser ist von aussen in den Körper aufgenommen, gelangt aber nicht direkt in diese Höhlen, sondern durch Vermittlung der ungebenden Gewebe, a uf deren Thätigkeit auch die specielle chemische Beschaffenleit dieser Flïssigkeiten zur ückzu$f u ̈ h r e n$ is t; oft kommen aber hiefür noch besondere Zellen in Betracht, nämlich f r e i e (mesenchymartige) Z ell en, welche von den Wänden der Hohl'äume abgelöst, in diesen Fliissigkeiten enthalten sind; am weitesten verbreitet sind amöboide Zellen (sogenannte weisse Blutkörperchen oder Lymphkörperchen). In Blnte finden wir in vielen Fällen daneben auch rothe Blutkörperchen, deren Farbstoff, das H a e m o g lobin, zum Gasaustausch, welcher durch das Blut vermittelt wird, in Beziehung steht; sie kommen bei wenigen Wirbellosen (einigen Anneliden, bei Phoronis) und bei allen Wirbelthieren vor, mit Ausnahme des Amphioxus, dessen Blut keine '/sellen enthält. Viele Wirbellose, besonders Anneliden, laben gefärbtes Blnt, dessen Farbe an die Blutflïssigkeit gebunden ist.

2 von der Kante gesehen. $c$ Weisse Blutkörperchen des Menschen. d Blutkörperchen eines Krebses (nach verschiedenen Autoren.)

1) Viele Forscher neigen gegenwärtig zu der Ansicht, dass das Blutgefässsystem auf die primäre Leibeshöhle zurückzuführen sei, indem es als Rest jener Höhle bei den Coelom- 
Phylogenetische und outogenetische Entwicklung der Gewebe.

In der phylogenetischen Entwicklung der Gewebe kömnen wir folgenden Gang nachweisen:

1) Ursprünglich finden wir einfache Gewebe, die aus gleichartigen Zellen zusanmengesetzt sind. Jede \%elle verlült sich anatomisch und physiologisch wie die benachbarte. Wenn auch die Zellen der hiden Blätter eine gewisse Verschiedenheit zeigen, so sind doch innerhilll) jedes Blattes die Zellen gleichartig, da jede derselben an den mannigfachen Functionen ihres Blattes gleichen Antheil nimmt.

2) Der nächste Schritt ist eine 'T' h e il ung der A r b e it z w is chen den einzelnen Zellen, die nebeneinander imerhalb eines Epithelgewebes sich finden. Wir haben dam gemischte Gew eb e vor mns. Diese Gewebe sind aus Zellen zusammengesetzt, die ilrem Bau und ihrer Function nach verschieden sind.

3) Sodamn wird ein weiteres Stadium der Differenzirung erreicht, indem die eimzelnen Gewebstheile sich in der Mamnigfaltigkeit ihrer Leistung beschränken und dafür sich in einer Richtung speciell ausbilden. Es ist num auch eine Theilung der A r beit $\mathrm{z}$ wisch en den Z ellc omplexen, den Geweben, eingetreten.

Tährend wir früher gemischte Gewebe fanden, die sich nur insofer'n von einander unterschieden, als der eine oder der andere Charakter iileerwiegend wurde, finden wir jetzt wieder einfache und zwar specialisirte Gewebe. Es hat sich aber eine Mannigfaltigkeit der Gewebe herausgebildet; demn jedes einzelne dieser Gewebe ist, indem es in Bezug auf seinen Bau und seine physiologisehe Leistmug specialisirt erscheint, in sich gleichartiger.

4) Endlich kommt es auch vor, dass verschiedenartige specialisirte Gewebe einander secundär durchwachsen. Hierher gehört die Durchwachsung vou Muskel und Bindegewebe bei Wirbelthieren und manchen Wirbellosen, die wir an auderer Stelle erörtert haben (pag. 123-125) und auch die Vascularisirung der Gewebe. So entstehen die z usam mengesetzten Gewebe ${ }^{1}$ ).

Diese phylogenetischen Stufen sind nicht nur für die epithelialen, sondern auch für die Mesenchymbildungen anzunehmen. Auch das Mesenchymgewebe tritt phylogenetisch ursprünglich als einfaches Gewebe auf. Das Mesenchym nimmt sodann einen gemischten Charakter an und liefert endlich auch specialisirte Gewebe. Hier müssen wir aber besonders hervorheben, dass der Process der Mesenchymbildung in der Phylogenie sich wohl mehrfach wiederholt hat, so dass z. B. das dermale und axiale Bindegewebe der Wirbelthiere wahrscheinlich eine erst innerhalb des Typus entwickelte Bildung ist, während das Bindegewebe und die Mesenchymmuskeln im Bereiche der Splanchnopleura ältere Bildungen sind.

In der Ontogenie der Gewebe (Histogenese) ist der Process im einzehen sehr abgekürzt, indem aus dem einfachen embryonalen Gewebe nicht etwa erst ein Gewebe gemischten Charakters entsteht und

thieren persistire. Andere halten das Gefässsystem fiir eine Endodermbildung (RABL). Es ist auch nicht feststehend, dass das Gefässsystem bei allen Phylen von gleicher morphologischer Bedeutung sei.

1) His war wohl der erste, der diesen Vorgängen speciell bei den Wirbelthieren grïssere Aufnerksamkeit zngewendet hat, indem er das Hineinwachsen nicht nur des Bindegewelses, sondern auch der Blutgefässe in andere Gewebe beobachtete. Die eigenthümliche Parablastheorie, die er daran knüpfte, hat aber hente wohl nur historische Bedeutung. 
dieses erst in specialisirte Gewebe sich verwandelt, sondern an den Geweben direkt die specifischen Charaktere sich lıerausbilden. Dagegen können wir im Allgemeinen eine graduelle Ausbildung der Verschiedenheit beobachten, z. B. zeigt zunächst das gesammte Ectorlerm einen gemeinsamen Charakter, es tritt dam eine Verschiedenleit zwischen Epitlel und Centralnervensystem auf und in letzterem können ursprünglich gleichartige 'Theile sich wieder verschieden ausbilden. In diesem graduellen Auftreten der Verschiedenheit (dem graduellen Differenzirmugprocesse) der Gewebe ist eine Wiederholung phylogenetischer Processe zu erkennen.

\section{Ueber das Verluältniss der Keimblätter zu den Geweben.}

Die Frage, ob die verschiedenen Gewebe der Metazoen gesetzmässig aus verschiedenen Keimblättem entstünden, bildete stets einen wichtigen 'Theil der Keimblättertheorie und war seit Jahrzehnten der Gegenstand eingehender Erörterungen.

Zunächst wurde nur die Histogenese der Wirbelthiere in Betrachtung gezogen und es grïndete sich darauf die Ansclauung, dass die drei Keimblätter einen besonderen, sich gegenseitig ausschliessenden histogenetischen Charakter besässen. Das ïussere oder Hautsinnesblatt (Ectoderm) sollte nur Deckepithelien (Epidermoidalbildungen) und Drüsenepithelien, ferner Nerven- und Simnesgewebe liefern, das innere oder Darmdriusenblatt (Endoderm) nur Epithelien des Darmes und der Darmdriisen, das mittlere Blatt oder Hautmuskel- und Darmfaserblatt nur Muskel, Bindesubstanzen und Blut.

Wir müssen nun mit Rïcksicht anf die neneren Forschungen fragen: 1) Ob für den Kreis der Wirbelthiere dieses Gesetz eines besonderen histogenetischen Charakter's der drei Keimblätter seine Bestätigung gefunden hat, 2) ob es gelumgen ist, dieses Gesetz auch auf die Metazoen im Allgemeinen auszudehmen?

In Bezug auf den ersteren Plunt ist hervorzuheben, dass neue Thatsachen bekannt wurden, welche den früher betonten histogenetischen Gegensatz der drei Blätter weniger scharf ausgeprägt erscheinen lassen. Es ist zunächst von Wichtigkeit, dass das Mesoderm seiner Anlage nach als epitheliale Bildung erkannt wurde; und es wurde auch sichergestellt, dass die Driisenepithelien der Niere und die Keimepithelien vom Mesoderm abstammen. Andererseits sind Bildungen, die man früher fïr mesodermal hielt, als heterogen erwiesen worden; so wurde gezeigt, dass die Chorda eine selbständige Endodermbildung sei, und in neuester 'Leit wurde sogar' die Abkunft der zelligen Gefässauskleidung (Gefässendothelien) und des Blutes vom Endoderm vahrscheinlich gemacht.

Wenn nun auch unsere Anschaumg in manchen Punkten verändert erscheint, indem wir z. B. sehen, dass Drüsenepithelien von allen drei Blättern abstammen, so bleibt doch bei Uebersicht der gesammten Histogenese der Sondercharakter der Keimblätter anzuerkennen, der sich in der Beschränkung gewisser wichtiger geweblicher Leistungen auf ein Blatt ausprägt (es werden z. B. Muskel und Bindesubstanzen nur vom Mesoderm, Nervengewebe nur vom Ectoderm geliefert).

Wir geben beispielsweise eine Uebersicht der histogenetischen Leistung der Keimblätter beiden Wirbelthieren: 
Ectoderm: Aeussere Epithelgebilde und Epithel der Hautdrüsen, Ner venge $\mathrm{w}$ e be, Sinneszellen.

Endoderm: Epithel des Darmes, seiner Anhänge und der Darmdrüsen, Chorda, Blutgefässepithel und Blut (?).

M esoderm: Epithel der Leibeshöhle, Keimepithel, Drüsenepithel der Niere, Muskelgewebe, Bindesubstanzen.

Das Beispiel der Wirbelthiere lehrt uns, dass die Keimblätter als Gewebebildner in wichtigen Punkten einen besonderen, gegensätzlichen Charakter zeigen und dass sich derselbe gesetzmässig in dieser ganzen grossen Thiergruppe wiederholt.

In Bezug auf den zweiten Punkt kömnell wir Folgendes hervolheben. Nachdem die Keimblätterlehre auf die gesammten Metazoen ausgedehnt worden war, glaubte man zuerst, dass auch die histogenetischen Gesetze eine gleiche Verallgemeinerung erfalıen wïrden. Diese Anschauung hat eine wesentliche Verbesserung erfahren, indem man nachwies, dass der histogenetische Sondercharakter der Keimblätter nicht ron Anfang an in gleicher Weise bestand, sondern sich phylogenetisch erst allmählich herausbildete.

Mit der Sonderung der Keimblätter sind auch gewisse Functionen (z. B. Nahrungsaufnahme durch das Endoderm) localisirt worden. Im '/usammenhang damit stehen besondere histologische Eigenthünlichkeiten der Blätter (z. B. die vacuolenreiche Beschaffenheit der Endoder'nzellen). Im übrigen finden wir aber bei den Cnirlariern jene Gewebe, deren Localisirung auf gewisse Keimblätter später so bedeutungsvoll wird, nämlich das Nervengewebe und Nuskelgewebe noch in beirlen Blätter'll vor'. Dabei haben die Gewebe der Cnidarier einen vorherrschend gemischten Charakter.

Nach dem Princip der Localisirung der Differenzirungen sehen wir dann bei den Heteraxoniern das Centralnervensystem ausschliesslich vom Ectoder'm aus sich bilden. Ebenso beruht darauf die Muskelbildung derselben. Während bei den Cnidarier'n typischer Weise Epithelmuskeln im Ectoder'm und Endoder'm auftreten, haben bei allen Heteraxoniern die äusseren Epithelien und die des Darmes die Fähigkeit der Muskelbildung verloren. Es hat zunächst das Mesenchym die Bildung der Muskeln übernommen, später aber wird seine Leistung in überwiegendem Maasse ersetzt durch die Bildung von Muskeln aus dem epithelialen Theile des Mesoderms (den Coelomsäcken).

Trotz der grossen Summe von Beobachtungen, die früher schon vorlagen, hat doch erst in jüngster Zeit die Histologie auch für die Erforschung der Phylogenie eine grössere Bedeutung gewonnen. Andererseits hat nun die phylogenetische Betrachtung auch zurückgewirkt auf unsere Auffassung von den Geweben. Diese Tendenz findet sich schon in Klemenenbrg's Neuromuskeltheorie und verschiedenen Schriften HaEckel's. Als bahnbrechender Versuch in dieser Richtung ist die "Coelomtheorie" der Brüder Hertwig zu nennen, wo auch der Gegensatz von Epithel und Nesenchym zum erstenmale aufgestellt wurde. Ob dort (so wie auch in unserer, mehrfache Modificationen enthaltenden Darstellung) im einzelnen das Richtige getroffen ist, mag dahingestellt bleiben; es ist aber als nächstes Ziel der vergleichenden Histologie erkannt: die phylogenetische Entwicklung der Gewebe $z u$ erforschen. 


\section{NEUNTES CAPITEL.}

\section{Functionen des Metazoenkörpers.}

Die Functionen des Metazoenkörpers sind stets nach dem Princip der Arbeitstheilung auf seine verschieden ausgebildeten Organe und in letzter Instanz auf die verschieden ausgebildeten Zellen vertheilt. Der Grad, bis zu welchem die Arbeitstheilung gediehen ist, erscheint je nach der Höhe der Organisation überaus verschieden. Der phylogenetisch ursprünglichste Gegensatz ist, sowie morphologisch, so auch functionell, derjenige von Ectoderm und Endoderm (Prinitivorgane der Gastraea). Je höhere Metazoen wir betrachten, um so mehr finden wir die speciellen Leistungen auf mannigfaltige Organe vertheilt; diese Verhältnisse werden wir in nachfolgendem eingehender erörtern.

Die Arbeitstheilung zwischen Ectoderm und Endoderm bezog sich zunächst nur auf gewisse Functionen. Die Fortbewegung des Körpers (durch Flimmerhaare) und die Empfindung waren besonders dem Ectoderm, die Nahrungsaufnahme dem Endoderm eigenthümlich. Andere Functionen aber kamen beiden Blättern in gleicher Weise zu (HAECKEL). Bei der weiteren phylogenetischen Entwicklung kam es 1) zu einer Steigerung des Gegensatzes zwischen beiden Blättern; 2) zu weiterer Arbeitstheilung innerhalb jedes derselben. Das Problem der allmählichen Ausbildung der Arbeitstheilung ist an und für sich ein schwieriges und es ist ferner dadurch noch schwieriger und verwickelter, dass hierbei auch die Erscheinungen des „Functionswechsels" und der "Substitution" vielfach in Frage kommen.

\section{Stoffiwechsel.}

a) Ernährung.

Der wesentliche Vorgang der Assimilation findet in allen Fällen in den Geweben selbst statt. Jedes Gewebe hat seine charakteristische Assimilation, indem es die für seinen Aufbau nothwendigen Substanzen der Nahrung entnimmt. Eine weitere Frage aber ist es, wie die Nahrung zu den Geweben gelangt und in welcher Weise sie für die Assimilation vorbereitet wird? In der Regel spielen hierbei die endodermalen Epithelzellen des Darmkanales die wichtigste Rolle, indem sie erstens Verdauungssecrete liefern, welche die in die Darmhöhle aufgenommene Nahrung verändern (verflüssigen) - d. i. die verda u ende 
Thätigkeit des Darmes - und zweitens, indem sie die veränderte Nahrung aufsangen, um sie sodann zunächst an die Körperflüssigkeiten abzugeben - d. i. die resorbirende Thätigkeit desselben. Es sind somit gewisse Functionen, welche ursprünglich bei den

Protozoen und Blastaeaden

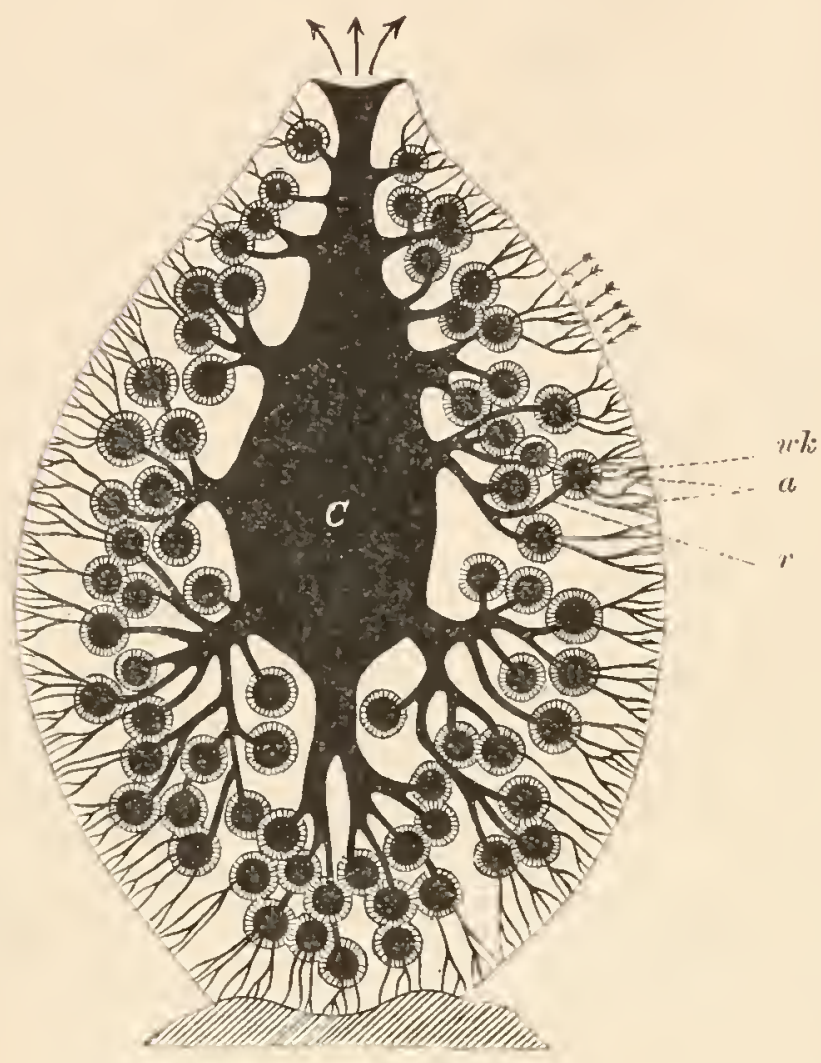
allgemeine Functionen der Zellen waren, speciell auf die Endodermzellen übertragen worden; doch ist diese Arbeitstheilung bei den niedersten Metazoen noch keineswegs so vollkommen durchgeführt, als bei den höheren Typen.

Bei den Spongien gelangt die Nahrung, welche aus mikroskopisch kleinen Körperchen besteht, in das innere Hohlraumsystem des Spongienkörpers und wird von den dort befindlichen endodermalen Epithelzellen aufgenommen, und zwar in unverändertem, festem $\mathrm{Zu}$ stande, und sie wird ferner in eben demselben Zustande an die anderen Gewebe des Köorpers weiter gegeben.

Fig. 162. Hohlraumsystem einer Kalkspongie vom Leucontypus, nach E. HAECKEL. Das Wasser strömt (wie dies durclı die Pfeile angedeutet wird) in die zahlreichen Poren des Körpers ein und durch die endständige Auswurfsöffnung aus. $C$ centraler Hohlraum, u Wimperkammern mit Geisselzellen, $a$ zufuihrende Kanäle, $r$ abführende Kanäle

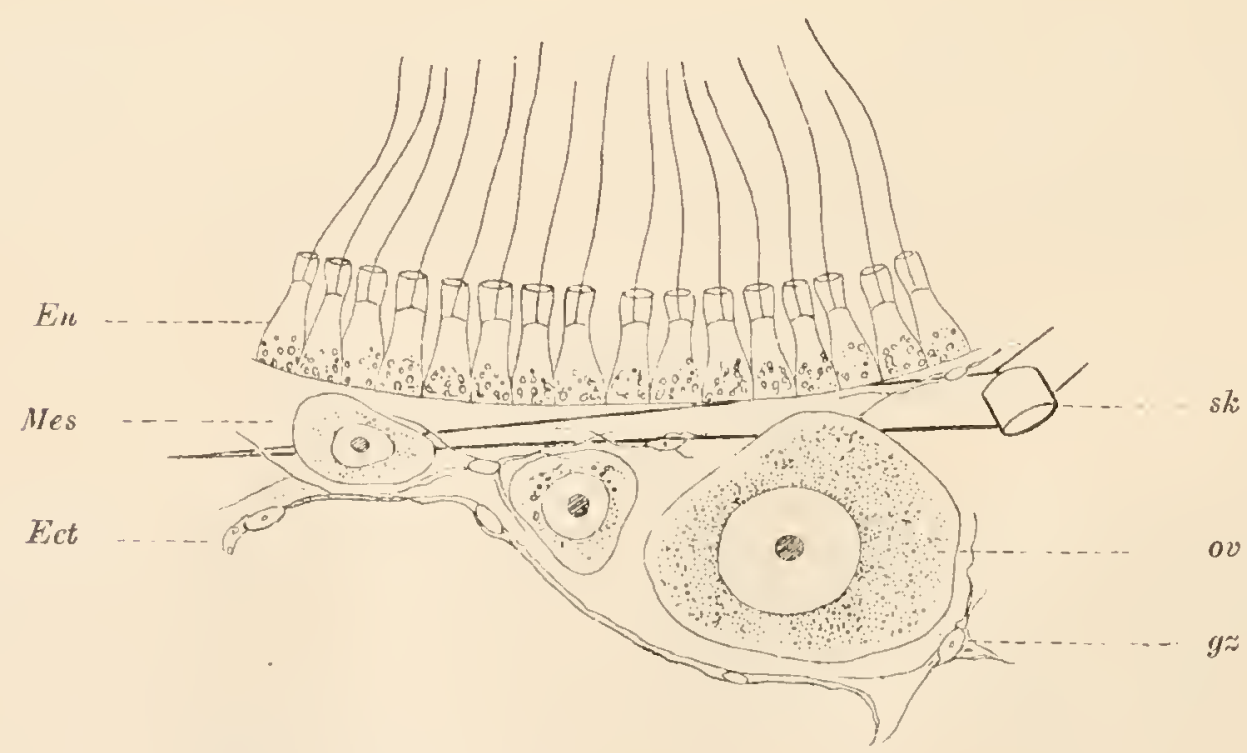

Fig. 163. Körperschichten einer Spongie (Sycon raphanus) nach F. E. SchultzE. Ect Ectoderm, Mes Mesoderm, En Endoderm (Geisselzellen finden sich nur in den Geisselkammern), g Bindegewebszellen der Gallertschichte, ov junge Eizellen, sk Theil einer dreistrahligen Kalkskelettuadel. 
Es gelangen die festen Nalnungstlieilchen in das Innere der Gevebezellen, um dort erst dem Verdauungsprocess unterworfen zu werden; derselbe ist also nicht auf die Endodermzellen beschränkt, sondern elscheint hier noch als eine allgemeine Thätigkeit der Köryerzellen (allgemeine intracelluläre Verdaung).

Von vielen Forschern wird behauptet, dass die Nahrung bei den Spongien auch nicht einmal auf dem Wege der Endodermzellen in die Gewebe gelangt, sondern an beliebigen Stellen der Körperoberfläche aufgenommen werde. Nach der Anschauung anderer Forscher ist es wohl nicht zu bezweifeln, dass Fremdkörper auch auf anderem Wege in die Gewebe eindringen, fürr die Nahrungsaufnahme wird aber doch den Endodermzellen (und zwar den sogenannten Kragenzellen) die weitaus überwiegende Hauptrolle zugeschrieben; ich schliesse mich dieser Ansicht an und erinnere mich hierbei der Fütterungsversuche von Spongien mittelst Carmin, welche mir vor einigen Jahren von meinem Freunde, Herrn Dr. C. Herder demonstrirt wurden.

Die Aufnahme fester Nahrungstheilchen in die Endodermzellen und ihre Verflüssigung innerhalb derselben, welche als (s p e ci e ll e n d o d e rmale) in tracelluläre Verda u u g bezeichnet wird, finden wir besonders bei den Cnidariern und Turbellarien und in geringerem Maasse selbst auch bei höheren Thieren; bei allen diesen 'Thierformen werden daher' feste Nahrungstheilchen niemals mehr vom Endoderm an die anderen Gewebe weitergegeben, sondern nur verfliissigte Nahrung (emulgirte Fette, lösliches Eiweiss); die elste Umwandlung (Verflüssigung der Nahrung) ist hier also schon eine specielle Leistung des Darmepithels.

Fig. 164. Darmepithel des Leberegels nach SOMMER.

Die Epithelzellen sind an ihrer freien Flächc mit amöboiden Fortsätzen ausgestattet. $a$ rothe Blutkörperchen des Schafes, die vom Leberegel als Nahrung aufgenommen wurden, $b$ derartige Blutkörperchen etwas gequollen, $c$ Chylustropfeu.

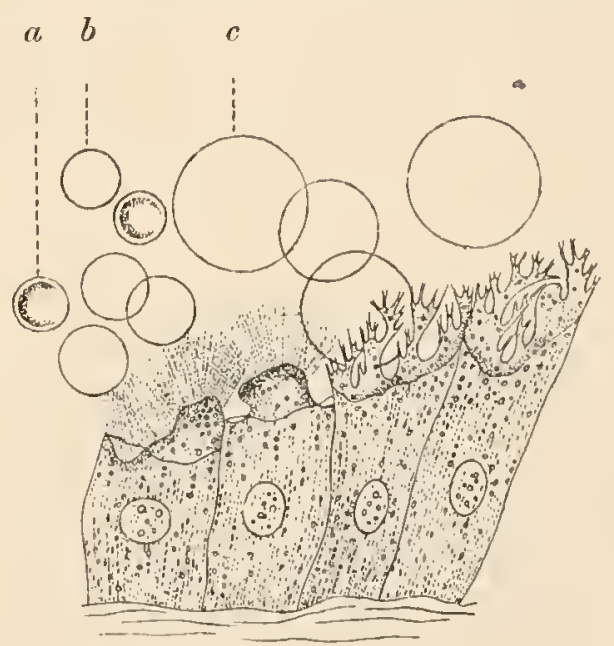

Bei den höheren Thieren wird die Nahrung schon innerhalb der Höhlung des Darmkanales der Eilwwirkung der Verdauungssecrete ausgesetzt (extracelluläre Verdauung) und sie wird von den Darmepithelien selbst nur in verflïssigter Form aufgesaugt (resorbirt).

An den Verdauungsorganen kommt es ferner noch zu mehrfacher Arbeitstheilung. Schon bei den Cnidariern hat ein Theil des Darmapparates in iiberwiegendem Maasse die Bildung von Verdauungssecreten iibernommen; derselbe wird als Magen bezeichnet. - Bei den höheren Thieren ist die Arbeitstheilung im Darmkanal meist noch viel weiter ausgebildet, indem der Anfangstheil des Darmes (Mundhöhle und Speiseröhre) meist nur zum Verschlingen der Nahrung dient, indem ferner ver'schieden beschaffene Verdaungssecrete von den Speicheldrüsen, Magendrüsen (Labdrüsen), Leber ${ }^{1}$ ), Bauchspeicheldrüsen geliefert wer-

1) Seitdem nachgewiesen wurde, dass die Function der Leber bei den Wirbelthieren weniger zur Verdauung als vielmehr zu weiteren vorbereitenden Processen der Assimilation 
den, sodann auch ein besonderer Darmabschnitt vorwiegend resorbirend fungirt (Chylusdarm); die nnbrauchbaren Reste der Nahruing, welche bei niederen Thieren (Cnidarier, Ctenophoren, Platoden) durch den Mnnd wieder entlecrt werden, sammeln sich bei den höheren 'Thicren im Enddarm und werden dnrch einen besonderen After entleert. - Es ist hervorzuheben, dass auch secundäre, von ectodermalen Epithelien ausgekleidete Theile (Vorderdarm, Hinterdarm) an diesem Aufbau des Darmes sich betheiligen und seine Functionen oft sogar in bedeutendem Maasse unterstïtzen.

Die Vertheilung der Nahrung im Körper erfolgt bei den verschiedenen Thiergruppen auf sehr verschiedenartige Weise.

Bei den Spongien geschalı dies, wie wir sahen, unmittelbar durch amöboide Thätigkeit aller Körperzellen.

Bei den Cnidariern herrscht das Princip der allseitigen Verbreitung des Darmes. Derselbe sendet röhrenförmige Ausläufer aus, die nach Art eines Gefässsystems in alle Körpertheile sich erstrecken (sie sind, dem allgemeinen Bau des Körpers folgend, radiär angeordnet). Jedes Organ, welches seiner Leistnng nach reichlicher Ernährung bedarf, wird von einem Ausläufer des Darmapparates versorgt. So ist z. B. jeder Fangfaden bei vielen Polypen mnd Medusen von einem gefässartigen Ausläufer des Darmapparates durchzogen etc. - Der Speisebrei wird in allen diesen gefässartigen Räumen durch Flimmerhaare fortbewegt. - Bei den Cnidariern kommt demnach jedem Körpertheil ein besonderer resorbirender Darmantheil zu und die Nahrung wird je nach Bedürfniss an Ort und Stelle resorbirt. O. und R. HERTwig haben anch die wichtige Thatsache dargethan, dass in der Nachbarschaft nahruugsbedürftiger Organe (z. B. der Gona(len) die resorbirenden Darmepithelieu eine bedeutendere Dicke zeigen. Früher hat man diese peripheren Darmverästelungen vielfach mit dem Blntgefässsystem höherer Thiere physiologisch verglichen. In der That dienen dieselben, da den Cnidariern sowohl Leibeshöhlen- als auch Blutflüssigkeit fehlt, in gewissem Sinne einer ähnlichen Function wic das Blutgefässsystem, ja es ist sogar möglich, dass letzteres sich phylogenetisch aus einer ähnlichen Einrichtnng entwickelt hat. Wir duirfeu aber nicht vergessen, dass die Art der Leistung beider Organe im Speciellen doch bedeutende Verschiedenheit zeigt, da die Blutgefässe nicmals activ resorbirende Epithelien besitzen. Physiologisch ähnliche Verhältnisse des Verdaunngsorganes wie bei den Cnidariern finden wir ferner auch bei den Ctenophoren.

Bei den Turbellarien (den Dendrocoelen) und bei manchen Trematoden (Distomum hepaticum) ist der Darmtractus (Fig. 166) ebenfalls mit zahlreichen Verästelungen versehen, und dieses Verhalten trägt wohl auch hier zur unmittelbaren Vertheilung der Nahrung an die verschiedenen Körpertheile bei; da aber diese Thiere eine primäre Leibeshöhle (in Form von Gewebslücken) besitzen, so ist wohl die Leibeshöhlenflüssigkeit, welcher vom Darme lösliche Nahrungssubstanzen überliefert wer-

und Vorgängen des Stoffwechsels in Beziehung steht, pflegt man mit der Bezeichnung „Leber" für Anhangsdrüsen des Darmes bei Wirbellosen zurïckhaltender vorzugeben und äbnliche Organe derselben als Mitteldarmdrüsen oder Hepatopankreas zu bezeichnen. Unsere physiologisch chemischen Kenntnisse über die Verdaungssecrete bei Wirbellosen sind aber überhaupt noch sehr unvollständig. 


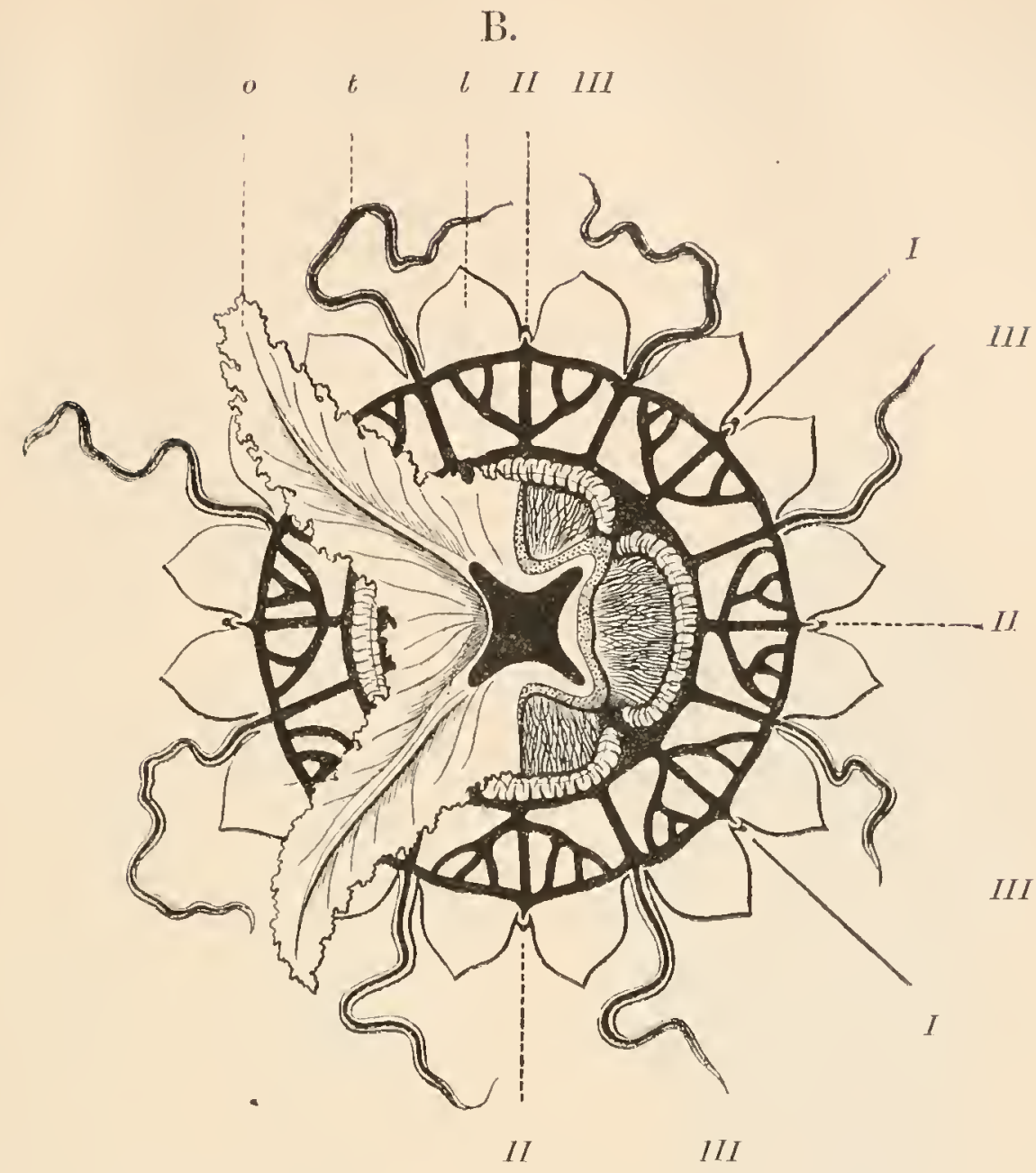

Fig. 165. Eine Schoibenqualle, Ulmaris prototypus, nach E. HAECKEl.. Von unten gesehen.

O Mundarme (zwei derselben sind abgeschnitten), die sich von der centralen Mundöffnung aus erstrecken, diese fïhrt in den Centralmagen, der sich in das periphere Gastrovascularsystem fortsetzt. $t$ Tentakel, $l$ Randlappen. $l$ Radien erster Ordnung, II Radien zweiter Ordnung, III Radien dritter Ordnung.

den, und ihre Inhaltszellen bei der Verbreitung derselben in Körper mit betlleiligt. Anderelseits mögen die Darmverästelungen hier ihre Bedeutung nebenbei darin finden, dass durch dieselben eine Vergrösserung der inneren, secernirenden und resorbirenden Fläche des Darmes bedingt ist. Und dies ist wohl ihre ausschliessliche Bedeutung, wenn sie bei höheren Thieren sich finden, die zugleich eine vollkommene Leibeshöhle oder sogar Blutcirculation besitzen, wie z. B. bei manchen Annetiden, den Hirulineen, sowie bei den Aeolidien (marine Nacktschnecken); sie erfüllen dann nur denselben Zweck, der z. B. bei anderen Thieren durch eine bedeutende Länge und vielfache Windungen des Darmkanales erreicht wird (Fig. 167).

Während bei vielen Plattwïrmern die Darmverästelungen noch mit eine Rolle bei der Vertheilung der resorbirenden Nahrung spielen mögen, ist bei den übrigen Scoleciden die Flïssigkeit der primären Teibeshöhle hiefür von grösserer Bedeutung; wenn auch diese Flüssigkeit keinem regelmässigen Kreislauf unterliegt, so ist sie doch bei der geringen Grösse der betreffenden Organismen im Stande, den Stoffwechsel der von ihr umspülten Körperorgane zu vermitteln. 
Bei den nächsthöheren Thicren, die schon eine bedeutendere Grösse crreichen, ist zur Vermittlung des Stoffiwechsels eine viel vollkommenere Einrichtung durch das Auftreten des Blutgefässsystems getroffen. Es

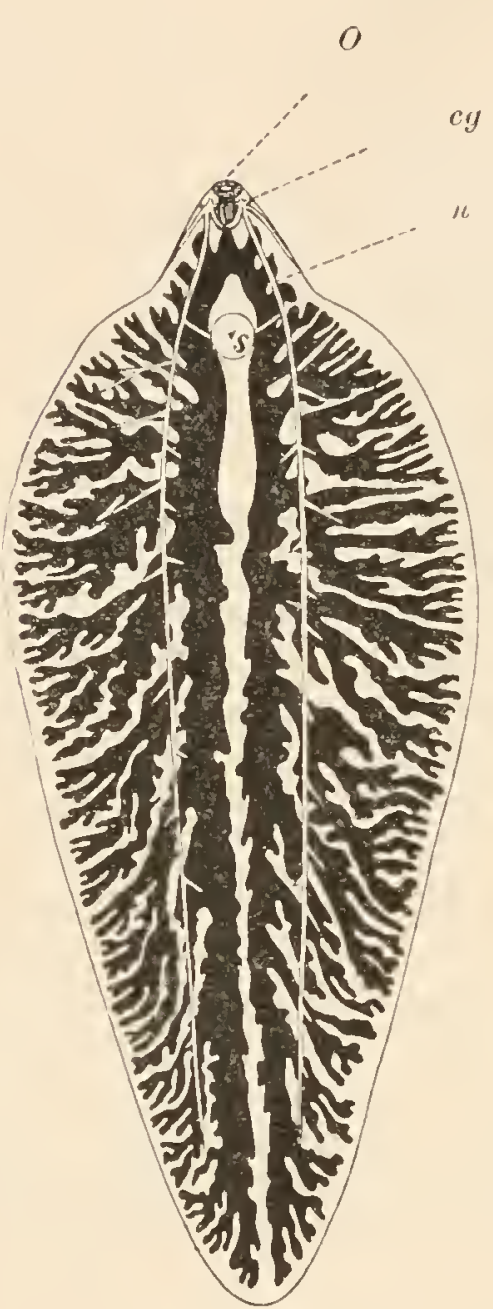

Fig. 166.

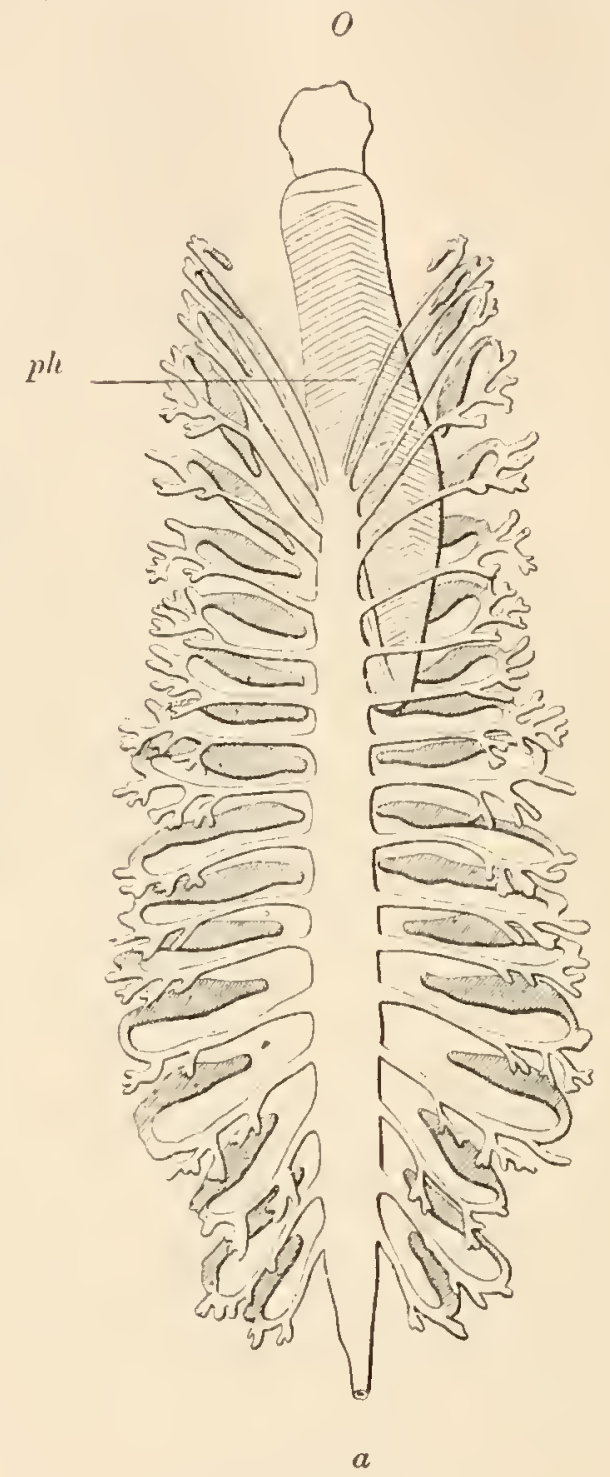

Fig. 167.

Fig. 166. Darmkanal und Nervensystem vom Leberegel (Distomum hepaticum) nach SOMMER.

O Mundsaugnapf mit der Mundöfnung, welche vermittelst einer kurzen Speiseröhre in den gabeltheiligen, reich verästelten Chylusdarm führt, $s$ Bauchsaugnapf, cg Cerebralganglien, welche dorsal und ventral vom Schlunde durch Commissuren verbunden sind und nebst kleineren Nerven besonders je einen starken Längsnerven nach rückwärts senden.

Fig. 167. Darmkanal von Aphrodite aculeata nach MilnE-Edwards.

0 Mundöffnung, $p h$ Pharynx, der mittelst einer aufsteigendeu Speiseröhre in den Mitteldarm führt, der mit zahlreichen blinddarmartigen Anhängen versehen ist, $a$ After.

ist dies ein in sich zurücklaufendes Röhrensystem, dessen Inhaltsflüssigkeit mit ihren Zellkörperchen durch die Contractilität entweder längerer Gefässstrecken oder eines localen, als Herz ausgebildeten Gefässtheiles in regelmässige Circulation versetzt wird. Das Blut übernimmt die Nahrung vom Darme und gibt sie an die Körperorgane ab. - Wir finden ein Blutgefässsystem bei den Aposcoleciden, den Ambulacraliern und Chordoniern, bei welchen Thiergruppen zugleich auch die primäre 
Leibeshöhle durch das Coelom verdrängt erscheint. Bei vielen dahingehörigen Thieren sehen wir aber das Blutgefässsystem in secundärer Weise wieder bedeutenden Umwandlungen unterliegen (Arthropoden, Mollusken), ja sogar zum Theil oder ganz der Rückbildung unterliegen.

Speciell bei den Wirbelthieren ist noch ein besonderes Saugadersystem (Lymphgefässsystem) genauer erforscht, welches sowohl Flüssigkeit aus den Gewebslücken als auch besonder's die resorbirte Nahrung vom Darme her dem Blutgefässsystem zuführt.

IV ir haben hier die Vervollkommnung der die Nahrung aufnehmenden und im Körper verbreitenden Organe in phylogenetischer Reihenfolge betrachtet. Eine Sonderstellung aber nehmen gewisse parasitische 'Thiere ein; so finden wir, dass manche Endoparasiten bei vollkommenem Mangel des Darmes mittelst ihrer äusseren Körperoberfläche flüssige Nahrung resorbiren, welche sie von ihrem "Wirthe" entuehmen; es silud hier besonders zu nennen die Cestoden und Acanthocephaten, sowie die Distomeen in gewissen Lebenszuständen. Die Sacculinen (parasitische Krebse) sangen flüssige Nahrung mittelst wurzelförmiger Organe aus ihrem Wirthe. In allen diesen Fällen handelt es sich um phylogenetisclic Rückbildung des ursprünglichen Darmapparates.

\section{b) A thmung.}

Als Atlmung bezeichnen wir den Gasaustausch des Körpers und zwar vornehmlich die Aufnahme von Sauerstoff und die Abgabe von Kohlensäure. Diese Processe stehen bekanntlich in Beziehung zur Arbeitsleistung und Wärmeproduction des gesammten Körpers. Der eigentliche Ort des Sauerstoffverbrauches und der Kohlensäurebildung sind daher alle Gewebe, wenn auch die einzelnen Gewebe sich hierin quantitativ verschieden verhalten mögen.

Der Austausch der Gase zwischen dem Körper und dem ihn umgebenden Medium erfolgt stets durch Diffusion an äusseren oder inneren Körperflächen. Die Art und Weise aber, wie der Sauerstoff 1) in den Körper übergeführt und 2) in demselbenvertheilt und ebenso die Kohlensäure ausgeschieden wird, ist bei den verschiedenen Thieren sehr mannigfaltig.

Jene Körpertheile, durch welche der Sauerstoff in den Körper aufgenommen und die Kohlensäure abgegeben wird, nennen wir A thmungsorgane. Bei sehr kleinen Thieren - oder bei solchen, die wohl etwas grösser sind, aber einen langsamen Stoffwechsel haben - wird der Gasaustausch durch die gesammte Körperoberfläche vermittelt, es fungiren demnach die gesammten Körperbedeckungen als Athmungsorgane. Bei grösseren Thieren kann die Körperoberfläche als Athmungsorgan nicht genügen, da die Masse in kubischem, die Fläche nur in quadratischem Verhältnisse wächst. Dieselben haben besondere Athmungsorgane in Form von Ausstülpungen oder Einstïlpungen der Körperwand. Die erstere Form findet sich vorwiegend als $\mathrm{Kiemen}$ bei den wasserathmenden Thieren, die andere als L ungen und 'T' r a clieen (d. s. die Luftgefässe bei Insecten etc.) bei den luftathmenden Thieren; bei diesen ist eine innere Lage der Athmungsorgane nothwendig, un allzugrosse Wasserverdunstung zu vermeiden. - Durch diese Localisirung der Athmung ist einerseits eine Theilung der Arbeit eingetreten, so daiss die Körperbedeckungen jetzt für ihre anderen Functionen eine grössere Vollkommenheit erlialten und ebenso die Athmungsorgane eine geeignete 
Beschaffenheit für die Diffusion der Gase annehmen - und andererseits ist eine Obertlächenvergrösserung in der reichen Entfaltung dieser Organe gegeben.

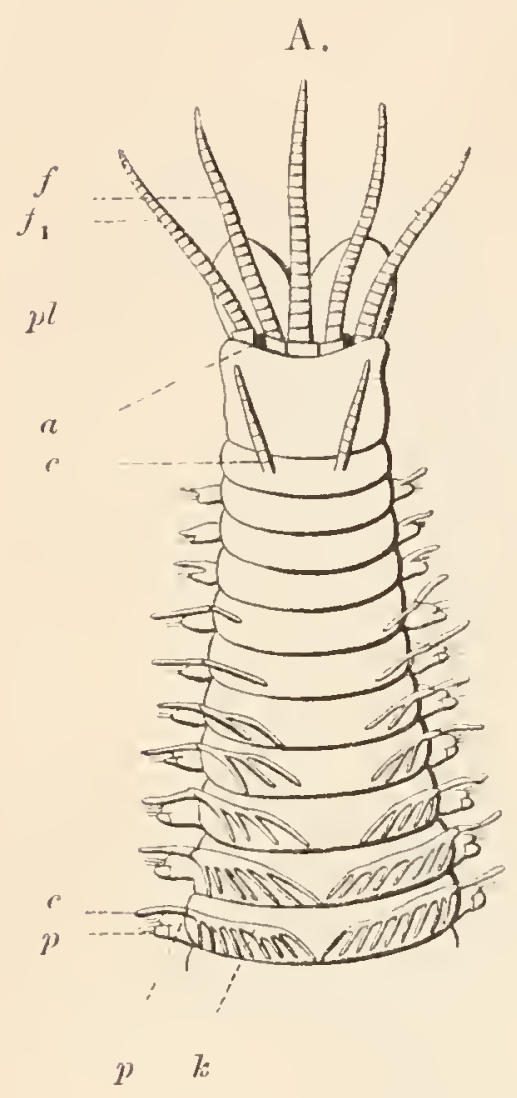

B.
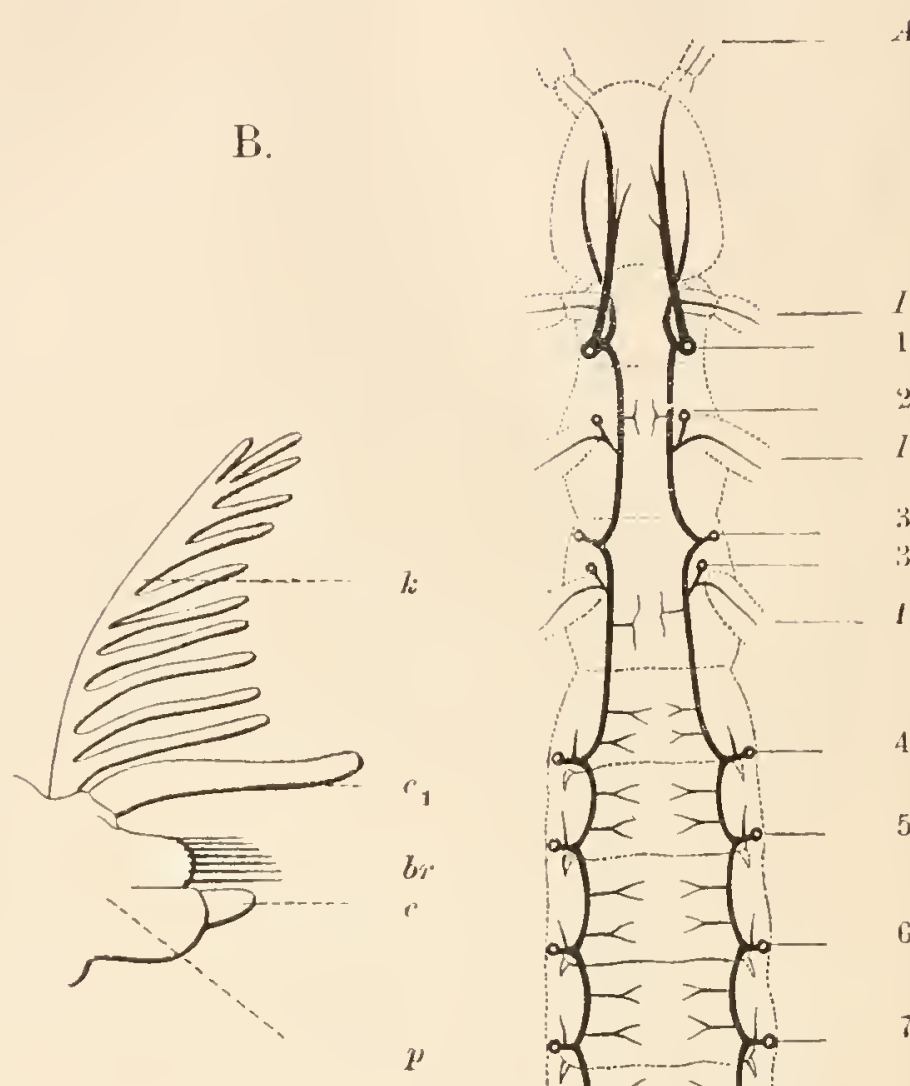

Fig. 168.

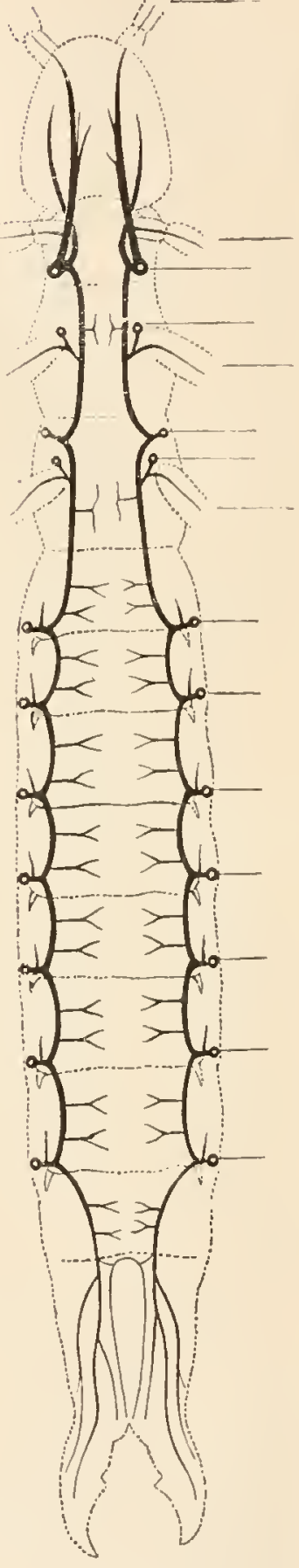

Fig. 169 .

Fig. 168. Kiemenbildung eines Anneliden nach MiLNEEDWARDS

A. Vorderes Körperende von Eunice vom Rücken gesehen; am Kopfe finden sich: $f f_{1}$ Fühler, $p l$ polsterförmige Taster, a Augen; am zweiten Segmente $c$ Rückencirren; an den nachfolgenden Segmenten wiederholen sich die $\mathrm{k}$ i em entragenden Parapodien.

B. Ein einzelnes Parapodium stärker vergrössert; $p$ stummelfürmiger Körper des Parapodiums, $b r$ Borstenbüschel, $c$ Bauchcirre, $c$, Rückencirre, $k \mathrm{~K}$ i e $\mathrm{m}$ e.

Fig. 169. Das Tracheensystem von Japyx mit seinen hauptsächlichen Verzweigungen (nach Grassi).

At Antennen; I, II, III die drei Paar Thorakalfüsse; $1-10$ die Stigmenöffnungen, welche in die seitlichen Hauptstämme des 'Tracheensystems führen.

Die Vertheilung des Sa u e r stoffesim Körper geschieht im einfachsten Falle auf dem Wege von Gewebe zu Gewebe oder durch die Leibeshöhlenflüssigkeit. Eine weit vollkommenere Eimrichtung wird aber dort erreicht, wo die Blutcirculation hiefür verwendet wird. Kiemen und Lungen bedürfen zu ihrer Function nicht nur eines entsprechenden Wechsels des respiratorischen Mediums, sondern ebenso eines raschen Blutwechsels, wodurch die Gase vom oder zum Körper weitergefülıtt werden. Ohne diese Einrichtung wäre auch die Flächenausdehnumg dieser Athmungsorgane noch ganz unzureichend für das Athmungsbedürfniss des Körpers. Die Blutgefässe bilden daher an dieseu Athmungsorganen einen physiologisch hervorragenden Bestandtheil. 
Diesem Verhalten gegenüber nehmen die Tracheen der Insecten u. s. w. eine Sonderstellung ein. Obzwar die Insecten einen Blutkreisliuf besitzen, übernimmt derselbe hier doch nicht die Vertheilung des Sauerstoffes, sondern die nit äusseren Oeffinungen (,Stigmen") beginnenden Tracheen erstrecken sich mit überaus reichen Verästelungen in alle 'Theile des Körpers, wo jedes Organ, ja sogar jedes kleine Gewebsstückchen von den dünnen Endästchen des Tracheensystems umsponnen und so direct mit Sauerstoff versehen wird. Wir können diese Einrichtung als allseitige Verbreitung des Athmungsorganes bezeichnen. Jedes Organ des Körpers hat seinen Antheil am Athmungsorgane.

Eine eigenthümliche Modification sind die ,Tracheenkiemen", die bei einigen wasserbewohnenden Insectenlarven, nämlich bei Ephemeridenlarven als äussere Anhänge des Hinterkörpers und bei Libellulidenlarven (Aeschna) als innere, in das Lumen des Enddarmes hineinragende Anhänge sich finden. In diese kiemenartigen Bildungen erstrecken sich Aeste eines geschlossenen (äusserer Oeffnungen entbehrenden) Tracheensystems. Dasselbe ist hier nur als Verbreitungsapparat des von den Kiemen aufgenommenen Sauerstoffes zu betrachten.

Fig. 170. Larve einer Eintagsfliege (nach CLAUS).

Am Abdomen finden sich 7 Paar Tracheenkiemen, welche in rasche schwingende Bewegung versetzt werden. Von den Hauptstämmen des geschlossenen Tracheensystems gehen Verästelungen in die Tracheenkiemen.

\section{c) Excretion.}

Als Excretionsprocess bezeiclnen wir die Ausscheidung von Harnstoff und verwandten Substanzen (z. B. Harnsäure); dieselbe steht - wie früher schon erörtert wurde - in Beziehung zur Assimilation der Eiweissnahrung. Da diese in allen Geweben stattfindet, so ist die Annalime berechtigt, dass auch die Bildung jener stickstoffhaltigen Excrete in allen Geweben erfolgt. Von da

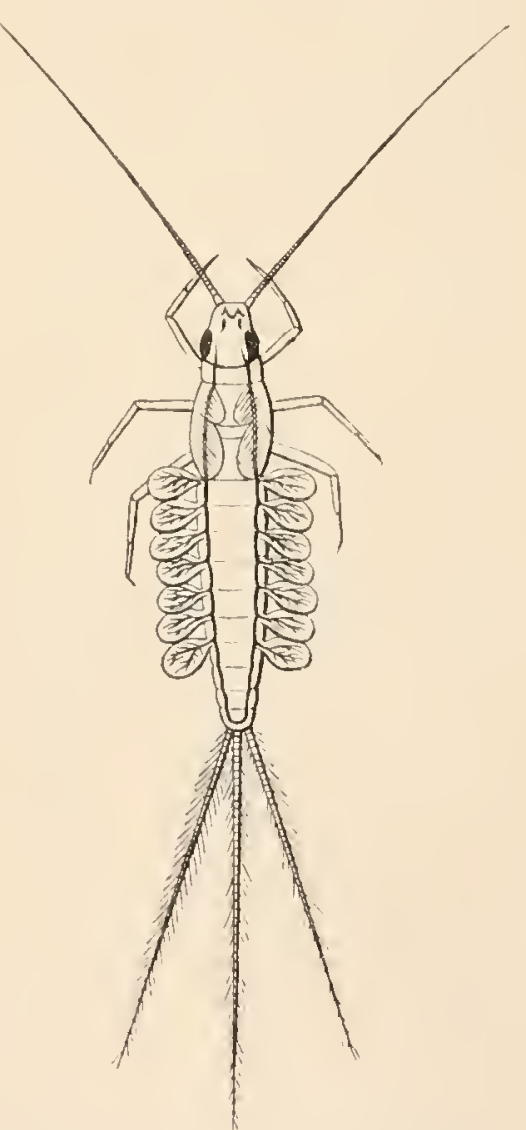
werden sie auf verschiedene Weise zu den Excretionsorganen geführt, welchen nur die Function zukommt, diese Producte aufzumehmeu und nach aussen zu befördern.

Viele physiologische Chemiker neigen gegenwärtig der Meinung zu, dass in den Geweben kohlensaures Ammoniak gebildet werde, aus welchem an zweitem Orte (in der Leber!) Harnstoff entsteht, welcher von da erst zur Niere geführt wird. Dies kommt aber für unsere weiteren Ausfïhrungen nicht unmittelbar in Betracht.

Bei Protaxoniern ist ein einheitliches Excretionsorgan nicht vorhanden; bei den Spongien sind vielleicht alle Gewebezellen nahezu gleichmässig an der Excretion betheiligt, bei den Cnidariern und Ctenophoren haben zahlreiche einzellige Drüsen des Ectoderms oder Endo- 
derms dieser Function zu dienen ${ }^{1}$ ). Bei Hydroidmedusen wurden Oeffnungen an den peripheren Aesten des Darmapparates beobachtet, die zur Entleerung der Excretionsproducte in Beziehung stehen sollen.

Den Scoleciden kommt ein eigenthümlicher Excretionsapparat zu, welcher meist als "Wassergefässsyste $\mathrm{m}^{\text {" }}$ bezeichnet wird und den wir im allgemeinen (vom morphologischen Gesichtspunkte) Protonephridi um nennen wollen. Es sind dies paarig vorhandene röhrenartige Gebilde, die entweder einfach oder reich verzweigt erscheinen; der Hauptstamm des Rohres mündet mit einer Oeffnung nach aussen; am entgegengesetzten Ende des Rohres oder seiner zahlreichen Aeste finden sich sogenannte T e rm in a l z e lle n (Terminalapparate), die mit einer zusammengesetzten Geissel (sog. Wimperflamme) versehen sind, welche in das Lumen des Rohres hineinragt. Die Wände des darauffolgenden Excretionskanales sind von einer geringen Anzahl grosser, drü siger Z ellen gebildet; oft sind es in einer einzigen Reihe angeordnete „, durchbohrte" Zellen. Auch diese tragen dem Lumen des Rohres zugewendete Geisseln. So findet in den Röhren eine kräftige Wimperbewegung statt, welche contimuirlich einen Flïssigkeitsstrom gegen die äussere Oeffnung des Organes treibt. Zweifellos sind es die umgebenden

A.

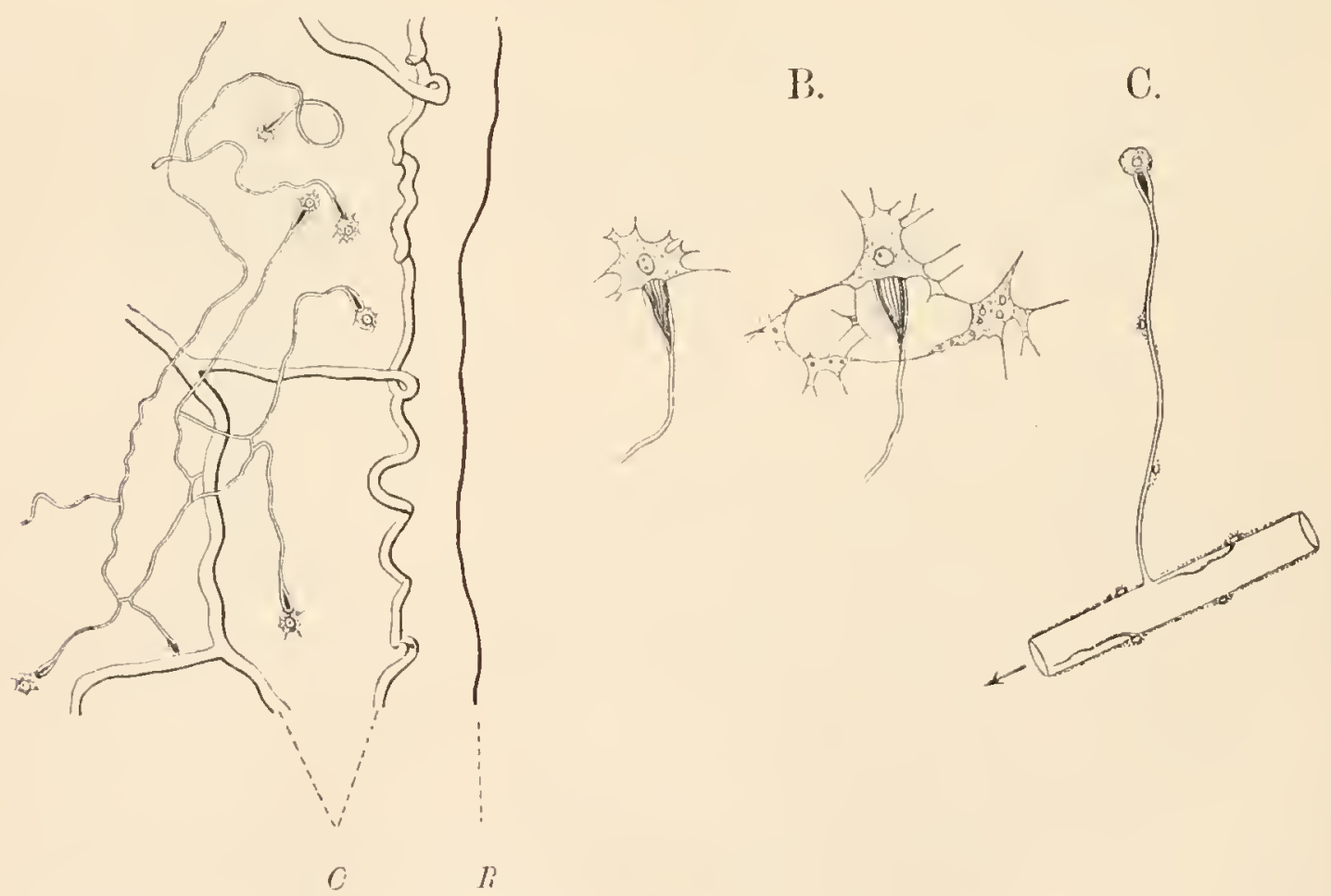

Fig. 171. Bau des Protonephridiums.

A. Ein kleiner Theil des Excretionsapparates einer Taenie (nach PIntner). Ii Rand des Körpers, $C$ grössere Sammelkanäle, in welche die capillaren Kanäle einmiinden.

B. Terminalzellen mit Wimperflammen vom Excretionsapparat einer Taenie (nach PintNer).

C. Schematische Darstellung von Terminalzelle, Exeretionseapillare und Exeretionscanal.

Gewebefliussigkeiten, welche besonders durch die 'Thätigkeit der T'erminalzellen in das Excretionsorgan transfundirt werden. Die driisi-

1) Selbst bei den höchsten Organismen (Säugethiere) werden kleine Mengen von Harnstoff von Hautdrïsen (Schweissdrüsen) ausgeschieden, die hier also die Function der Niere wenigstens unterstiitzen. 
gen Wandungen der Kanäle aber liefern die eigentlichen Excretionsstoffe, die sie direkt den umgebenden Gewebsflüssigkeiten entziehen '); die Stoffe werden von dem Flüssigkeitsstrome innerhalb der Canäle fortwährend gelöst und rasch weggeführt. Oft schliesst sich eine muskulöse Endblase (Harnblase) dem Protonephridium an.

Das Protonephridium besitzt bei den Platodes überaus reiche Verästelungen, mit welchen es durch den ganzen Körper sich erstreckt und alle Orgale umspinnt. In diesem Falle bezieht das Excretionsorgan die Excretionsstoffe unmittelbar aus allen Körpertheilen; ja wir können hier wieder sagen, dass jedem Körperorgan ein Antheil des Excretionsorganes zukommt (GROBBEN). In anderen Fällen, wo das

Protonephridium weniger reich entwickelt ist, spielt die Leibeshöhlenflüssigkeit auch für die Zufuhr der Excretionsstoffe von den Geweben her eine grössere Rolle.

Bei den Aposcoleciden findet sich
0

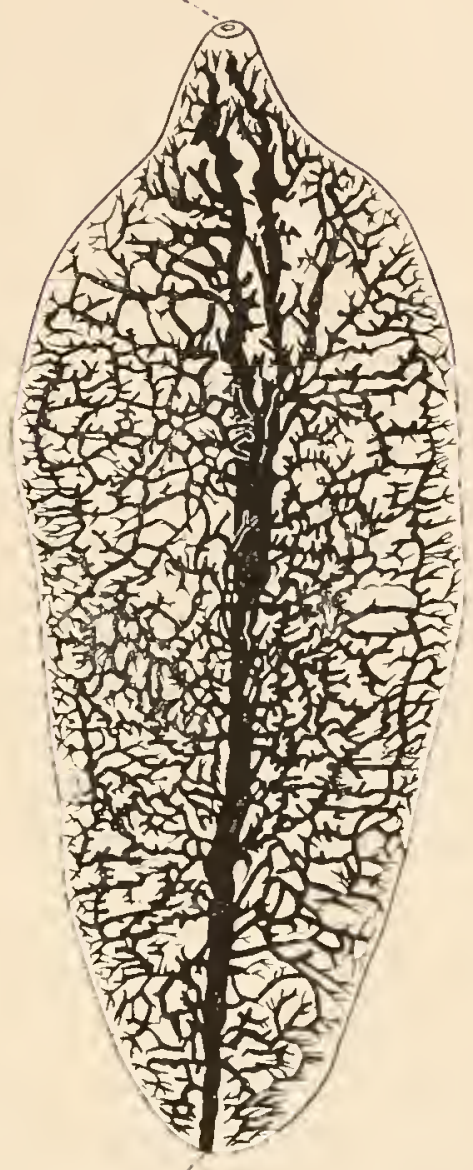

Fig. 172. Excretionsapparat des Leberegels (Distomum hepaticum) in seinen Hauptverzweigungen dargestellt (nach SомMER).

$p$ Mündung des Excretions«pparates, o Mundsaugnapf.

Fig. 173. Metanephridium (Segmentalorgan) in seinem Lageverhältniss zur Leibeswand bei Anneliden (schematisch).

A. Innerhalb der Leibeswand liegendes Organ. $l$ Leibeswand, aus Epitlelschicht, Muskelschicht und Peritonealschicht gebildet; zwischen letzteren Schichten liegt das Excretionsorgan; $i$ dessenTrichteröffnung; $e$ äussere Oeffnung ; $d$ Dissepiment, welches die Höhlen der aufeinanderfolgenden Körpersegmente von einander scheidet.

B. Innerhalb der Leibeshöhle liegendes Organ. Das mittlere Kanalstück des Excretionsorganes ist schleifenförmig verlängert und kommt, die Peritonealschichte vor sich stülpend, in die Leibeshöhle zu liegen.

Fig. 172.

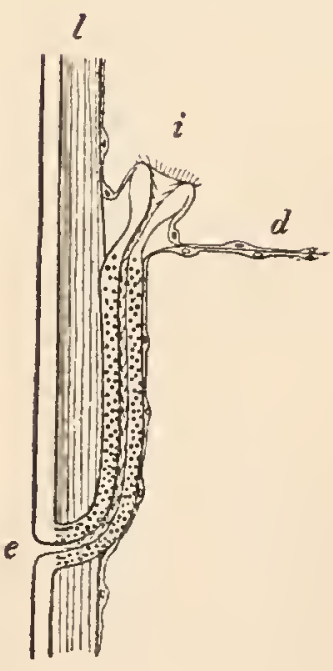

A.

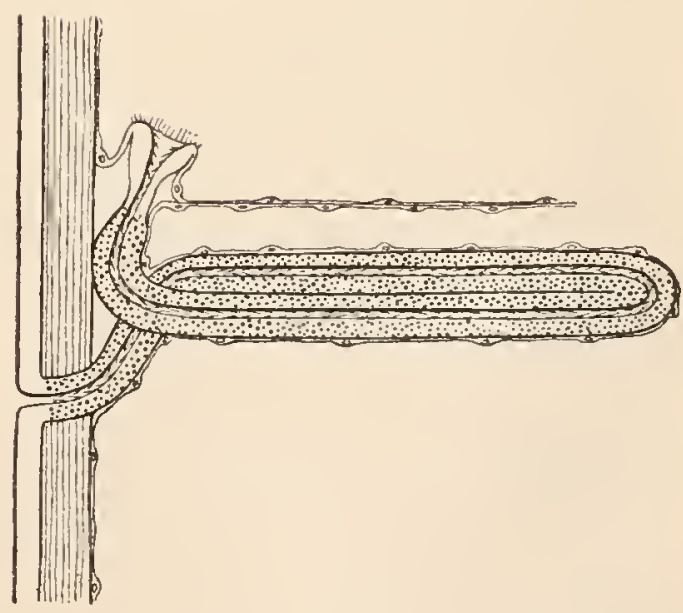

B.

Fig. 173.

1) Es ist hervorzuheben, dass die Stoffe, welche die Nierenepithelien an sich ziehen, schon als solche in den umgebenden Flüssigkeiten (oder im Blute) enthalten waren, während die Sekrete anderer Drüsen wohl meist dem Chemismus der Drïsenzellen selbst erst ihre chemische Zusammensetzung verdanken. 
das Protonephridium nur noch als embryonales Organ und wird im erwachsenen Thiere durch ein anderes Organ ersetzt, welches wir als Metanephridium bezeichnen.

Die parrig vorhandenen Metanephridien haben den Bau von drïsigen, wimpernden Röhren, welche durch eine innere Oeffnung mit der Coelomliöhle in Verbindung treten und durch eine äussere Oeffnung an der Oberfläche des Körpers münden. Wir unterscheiden an dem Organe erstens den sogenannten II i m p e r tr i c h t e r, ein trichterförmiges Gebilde, dessen Lumen mit weiter Oeftnung in der Coelomhölle beginnt und mit kräftigen Wimpern versehen ist; zweitens den drüsigen Flimmerkanal; derselbe liegt ursprünglich ausserhalb der Coelomhöhle, in vielen Fällen aber bildet er eine Sclıleife, die sich in die Coelomhöllle hineinstiilpt und dabei einen Ueberzug von Coelomepithel (Peritonealüberzug) erhält. Als dritter Abschnitt kommt häufig, aber nicht typisch, eine muskulös e Endblas e hinzu, die als secundäre Eiustülpung von der äusseren Haut her entsteht. Der Flimmertrichter nimmt Flïssigkeit direct aus der Coelomhöhle auf, der drüsige Flimmerkanal liefert die eigentlichen Excretionsstoffe, die muskulöse Endblase fungirt als Reservoir (Harnblase). - In jüngster Zeit wurde von mehreren Forschern (besonders Eisig) darauf hingewiesen, dass mit Concretionen beladene Zellen aus den Coelomlöhlen durch Vermittlung der Metanephridien direct nach aussen geschafft werden. Diese Zellen stammen von drüsigen Wandungen der Coelomlıölle her.

Die Mollusken besitzen ein Paar von Metanephridien, oft auch nur ein einseitig ausgebildetes Organ.

Bei den Anneliden wiederholen sich die Metanephridienpaare in den aufeinanderfolgenden Körpersegmenten und werden daher auch Segmentalorgane genannt. Der Flimmertrichter jedes Organes ist in der Regel in dem nächstvorderen Körpersegmente gelegen.

Bei den Crustaceen sind die Metaneplnidien in ihrem Bau bedeutend modificirt; dies ist schon dadurch bedingt, dass bei diesen Thieren Flimmerhaare in der Gesammtorganisation fehlen. - Bei den Tracheaten fehlt das Metanephridium (als Excretionsorgan) vollständig und ist durch zahlreiche, sehr lange fadenförmige Drüsenschläuche ersetzt, die als Differenzirungen des Hinterdarmes auftreten.

Organe von ähnlichem Baue wie die Metanephridien kennen wir auch bei den höheren Phylen, welche ebenfalls Coelomhöhlen besitzen, nämlich bei den Ambulacraliern und Chordoniern. Bei ersteren ist die Function der verschiedenen Nephridien-ähnlichen Gebilde noch nicht genügend aufgeklärt.

Bei den Wirbelthieren setzt sich der Apparat, welchen wir als Urni e re bezeichnen, aus zweierlei Theilen zusammen: 1) Aus den Segmentalcanälchen, welche ähnlich gebaut sind wie die Segmentalorgane der Anneliden und 2) einem wahrscheinlich von dem äusseren Epithel (Ectoderm) abstammenden Sammelgang (U r n i er en ga n g oder WoLFF's c hen Grang), welcher jederseits in der Längsrichtung des Körpers verläuft, mit allen Segmentalröhren der Körperseite in Verbindung steht und selbst mit seinem hinteren Ende in die Kloake sich öftnet. - Das ganze Organ liegt jederseits unterhalb der Wirbelsäule in der Nähe der Leibeshölle (,Splanchnocoel"), jedoch stets ausserhalb derselben („retroperitoneal ${ }^{6}$ ) und zwar in mehr oder weniger reichliches Bindegewebe (,Stroma ${ }^{6}$ ) eingebettet. Die Segmentalcanälchen sind ursprünglich nach der Zahl der Körpersegmente angeordnet; secundär ist aber ihre Anzahl oft bedeutend 
vermehrt; ihr Lumen steht mittelst einer mit Wimpern versehenen Oeffnung (Nephrostoma) mit der Leibeshöhle in Verbindung. Es konmt aber stets noch eine zweite characteristische Einrichtung hinzu, welche die Flüssigkeitszufuhr mit übernimmt. An den Drüsenkanälen finden sich nämlich seitliche bläschenförmige Erweiterungen, in welche ein netzartiges Blutgefässknäuel mit zuführendem und abführendem Blutgefäss (ein sog. Wundernetz) hineingestïlpt ist. MaLPigh's ch e Kör p er ch e n bezeichnet. Durch die Blutstauung in dem Gefässknäuel kommt es dazu, dass Flïssigkeit durch die dünnen Wände der Ampulle hindurchfiltrirt und demSegmen talcanälchen zugeführt wird.

Nur die niederen Wirbelthiere mit Einschluss der Amphibien besitzen zeitlebens eine Urniere; bei den Amnioten entwickelt sich im Embryo an einem Theil der Urniere secundär die definitive Niere und erstere unterliegt sodann der Rückbildung. Wenn schon bei der Urniere der Anamnia die Function der Nephrostomen durch die Thätigkeit der MaLPIGH'schen Körperchen in den Hintergrund gedrängt war, so sehen wir, dass nun bei der definitiven Niere der Amniotendie Nephrostomen mit dem Anfangsstück der Kanälchen.ganz in Wegfall gekommen sind; die Flüssigkeitszufuhr geschieht nun ausschliesslich durch die terminal liegenden MaLPigu'schen Körperchen. Nephrostomen sind also bei den Amnioten nur an der Urniere des Embryo zu finden. Bei der AmniotenNiere ist auch die grosse Menge der Harnkanälchen zu einer concentrirteren drüsenartigen Masse zusammengedrängt, die in den Harnleitern einheitliche Ausführungsgänge besitzt und diese münden hier direct in die als Reservoir fungirende Harnblase. Letztere ist noch bei den Amphibien von den Harnleitern getrennt, als ein Anhang der Cloake ausgebildet ${ }^{1}$ ).

Die Segmentalorgane der Anneliden und die ähnlichen Organe verwandter Diese Bildungen werden als

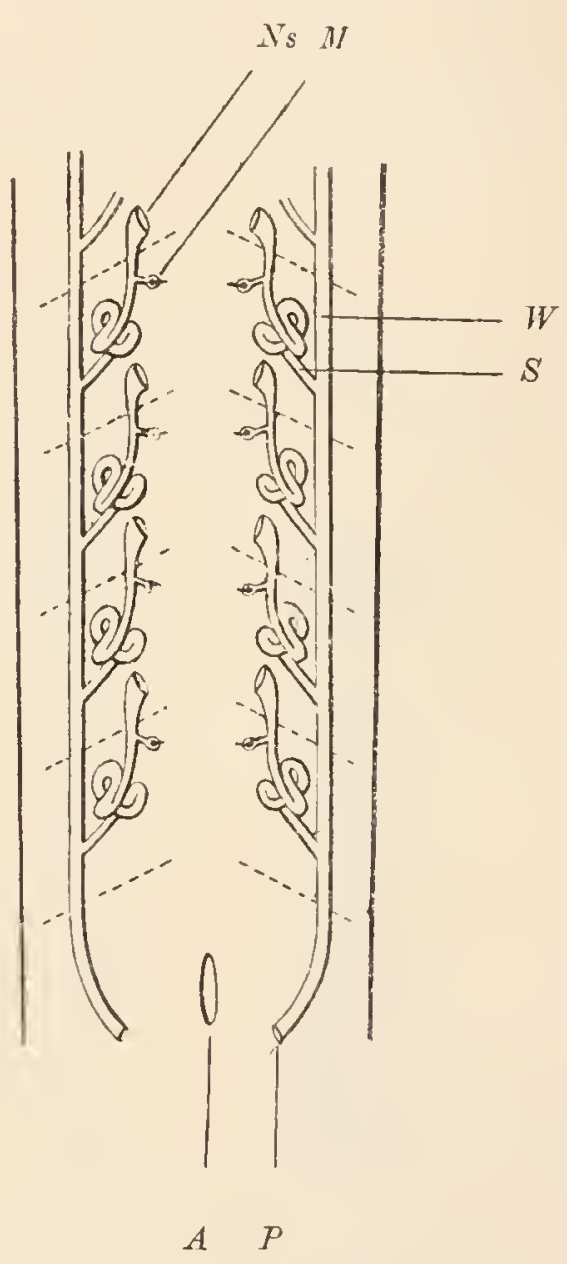

Fig. 174. Schematische Darstellung der Urnieren eines Wirbelthieres.

Die punktirten Linien bedeuten die Grenzen der Muskelsegmente des Körpers. $A$ primäre Afteröffnung, $W$ WolfF'sche Gänge, $P$ Mündung derselben, $S$ Segmentalröhren (Segmentalcanälchen), $N s$ Nephrostom, $M$ Malpigul'sches Körperchen.

Thierformen (Phoronis, Brachiopoden) haben in vielen Fällen neben ihrer excretorischen Thätigkeit auch die Function, die Geschlechtsproducte, welche von den Gonaden in die Leibeshöhle entleert werden, nach aussen zu befördern. In anderen Fällen sind es den Segmentalorganen ähnliche Gebilde mit innerer und änsserer Oeffnung, welche hierzu dienen, und die man für umgewan-

1) Die morphologische Beziehung von Vorniere, Urniere und definitiver Niere wird an anderer Stelle erörtert werden. 
delte Segmeutalorgane hält, wenn auch in manchen Fällen daneben noch echte Segmentalorgane in denselben Körpersegmenten vorkommen (Lumbricus). Es wird gegenwärtig als eine wichtige Aufgabe der Morphologie betrachtet, $\mathrm{zu}$ entscheiden, inwiefern auch die direct mit den Gonaden verbundenen Ausführungsgänge bei Hirudineen, Arthropoden etc. etwa auf Segmentalorgane zurückführbar seien. - Auch bei den Wirbelthieren wiederholen sich ähnliche Beziehungen zwischen Excretionsapparat und Geschlechtsorganen. Am auffallendsten erhält sich dies in dem Bau der Eileiter, welche typisch (mit wenigen Ausnahmen) mit einer inneren Wimperöffnung (Tuba) versehen sind, welche die in die Leibeshöhle entleerten Eier auffängt.

\section{d) Blutcirculation.}

Wir finden ein Blutgefässsystem nur bei jenen Thieren, die eine secundäre Leibeshöhle (Coelomhöhle) besitzen, das sind die Aposcoleciden, Ambulacralier und Chordonier. Es fehlt dagegen bei den niedrigeren Thieren (unterhalb der

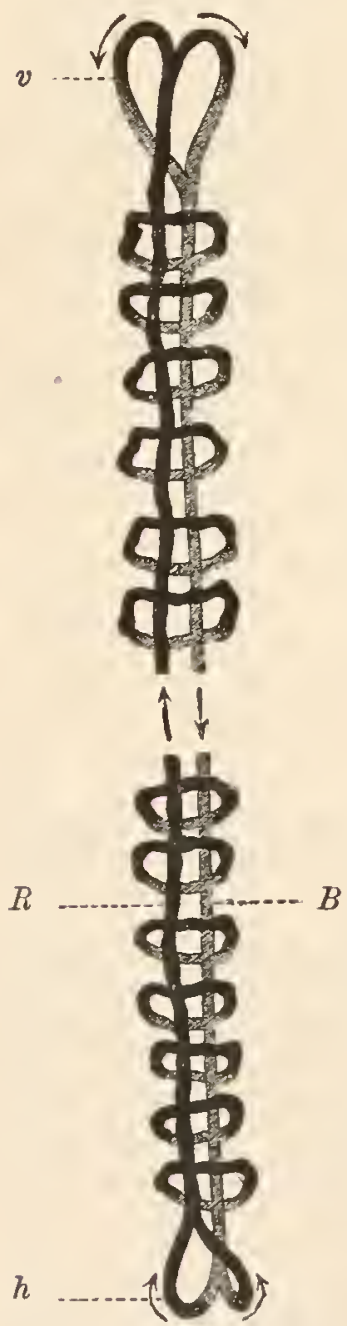
Anneliden); nur die Nemertinen, deren systematische Stellung übrigens noch nicht endgiltig aufgeklärt ist, besitzen schon ein Blutgefässsystem. Dagegen fehlt es wieder bei manchen Aposcoleciden, nämlich bei einigen Anneliden (Aphrodite, Capitelliden, Glyceriden) und Sagitta; bei gewissen kleineren Arthropodenformen, nämlich bei den meisten Copepoden, den meisten Milben, Linguatuliden und Tardigraden; endlich fehlt es auch den Bryozoen; wir sind der Ansicht, dass es in diesen Fällen durch Rückbildung secundär unterdrückt ist.

Die Blutgefässe sind Röhren mit eigenen Wandungen, welche aus zwei Schichten bestehen: einer inneren epithelialen Schichte (Gefässepithel, nach His als Endothel bezeichnet) und einer äusseren Muskelschichte; diese beiden Schichten können sich noch in untergeordnete Differenzirungen gliedern, auch können noch secundäre Schichten aussen sich anlagern. Den Inhalt der Gefässe bildet die Blutflüssigkeit mit oder ohne Blutkörperchen (vergl. p. 147).

Der ursprüngliche Typus ist ein geschlossenes Blutgefässsystem; wir finden ein solches bei den Anneliden. Die Hauptstämme sind hier ein Rücken- und ein Bauchgefäss, in welchen das Blut in entgegengesetzter Richtung strömt ${ }^{1}$ ); nämlich im ersteren von hinten nach vorne, in letzterem von vorne nach hinten; an ihren Enden gehen sie durch paarige Gefässschlingen in einander über, sie sind

Fig. 175. Schema des Blutgefässsystems bei einem Anneliden. $R$ Rückengefäss, $B$ Bauchgefäss, welche durch quere Gefässe verbunden sind und überdies durch $v$ vordere Gefässbogen und $h$ hintere Gefässbogen in einander übergehen. Die Pfeile zeigen die Richtung des Blutstromes an.

1) Eine unregelmässig wechselnde Richtung des Blutstromes kommt bei Phoronis vor, sowie bei den Salpen. 
ferner durch zahlreiche Quergefässe verbunden, in welchen letzteren die Riclitung des Blutstromes nicht bei allen Anneliden dieselbe zu sein scheint. Das Rückengefäss ist meist in seiner ganzen Länge contractil, es fungirt als „Herz", d. i. als Fortbewegungsapparat des Blutes; in manchen Fällen wird es in seiner Function durch die Contractilität verschiedener anderer Gefässe (z. B. einzelner Quergefässe, selten des Bauchgefässes) unterstiitzt.

Bei den Arthropoden und Mollusken zeigt das Blutgefässsystem in gewisser Beziehung eine löhere Ausbildung, in auderer Hinsicht aber eine Reduction. Das Rückengefäss hat sich nämlich zu einem vollkommeneren propulsatorischen Centralapparat ausgebildet; bei den $A r$ thropoden ist es meist vielkammerig, den Segmenten entsprechend, und mit einer entsprechenden Anzahl von paarigen, mit Klappenapparaten ausgestatteten Einströmungsöffnungen versehen; bei den Mollusken besteht es aus einer Kanmer mit unpaarer oder paarigen Vorkammern. Dagegen sind die peripheren Gefässe oft reducirt und das Blutgefässsystem ist mit anderen Höhlen, nämlich Coelomhöhlen und Gewebslücken zusammengeflossen, es ist demnach kein geschlos senes System. Bei den meisten Arthropoden bleibt nur noch das Herz übrig (bei kleineren Formen, Copepoden, Milben, fällt auch dieses hinweg), bei den Mollusken dagegen sind nur die peripheren Theile des Gefässsystems darch lacunäre Räume ersetzt. Physiologisch ist der Kreislauf bei diesen Thieren aber doch meist vollkommener als bei den Anneliden, denn der Blutstrom hält, obzwar er nur in den Zwischenräumen der Organe fliesst, doch ziemlich regelmässige Bahnen ein und bei der vollkommeneren Ausbildung des Herzens und der rascheren Pulsation desselben ist die Circulation eine viel lebhaftere, und dies ist ein physiologisch sehr bedeutsames Moment.

Die Ambulacralier besitzen ein ähnliches geschlossenes Gefässsystem wie die Anneliden.

Bei den Wirbelthieren ist das Blutgefässsystem ein geschlossenes und bei allen (mit Ausschluss des Amphioxus) ist ein Abschnitt desselben zu einem sehr vollkommenen Herzen differenzirt, welches aus mehreren Abtheilungen besteht und mit mehrfachen Klappenapparaten ausgestattet ist. Mit der Ausbildung eines sogenannten doppelten Kreislaufes - bei den luftathmenden Wirbelthieren - wird auch das Herz durch eine Scheidewandbildung in ein doppeltes verwandelt (vgl. unten). An dem Blutgefässsystem sind ferner in viel regelmässigerer Weise als bei Wirbellosen dreierlei Abschnitte ausgeprägt: Arterien, welche das Blut vom Herzen zu den Organen führen, Capillaren, welche das feinste Blutgefässnetz innerhalb der Organe bilden, und Venen, die das Blut sammeln und zum Herzen zurückführen. lusken.

Fig. 176. Schema des Blutkreislaufs bei Mol-

$h$ Herz aus Vorkammer (eine oder auch zwei) und Kammer bestehend, $k$ Körpergefässe, $b r$ Kiemengefässe.

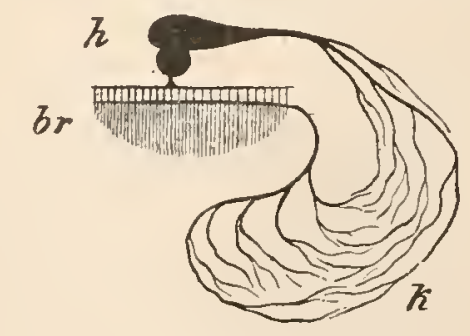

Das Verhältniss der Blutgefässe zu den Athmungsorganen ist von besonderem physiologischem Interesse. In der Regel

1) Nach neueren Angaben sollen in dem ursprünglichsten Gefässsystem, nämlich bei Anneliden, Gefässepithelien fehlen; meine eigenen Erfahrungen stehen damit in Widerspruch; die Gefässe von Phoronis besitzen ein inneres Epithel (Cori); auch in der Herzröhre von Arthropoden ist eine innere Epithelschichte nachzuweisen. 
finden wir bei den Wirbellosen ein sogenanntes Körperherz, d. h. das Blut geht vom Herzen zum Körper, von da in die Kiemen und von diesen wieder zum Herzen (Fig. 176). Bei den Cephalopoden finden sich neben dem Körperherzen noch besondere Kiemenherzen (der Anzahl der Kiemen entsprechend), welche das Blut mit neuer Kraft in die Kiemen treiben. - Die Anneliden bilden unter den Wirbellosen eine Ausnahme, da bei denselben das Blut vom Rückengefässe direkt entweder durch die Quergefässe zu den seitlichen Kiemen ${ }^{1}$ ) oder durch die Kopfgefässe zu den Kopfkiemen geführt wird, und von da in das Bauchgefïss gelangt.

Bei den kiementragenden Wirbelthieren, den Fischen, ist das Herz ein Kiemenherz; es sind die Kiemen nach dem Herzen in den Kreislauf eingeschaltet; das Blut, welches sich aus den Kiemen sammelt,

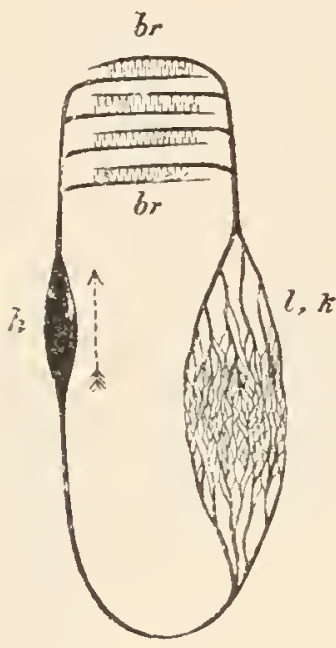

A.

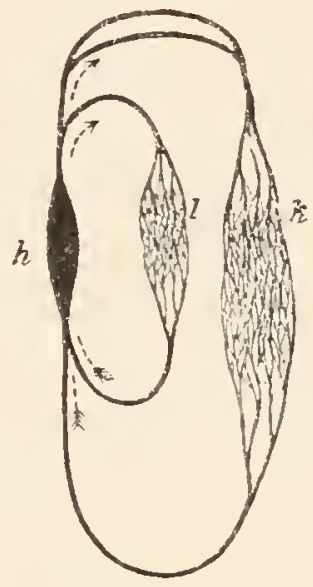

B.

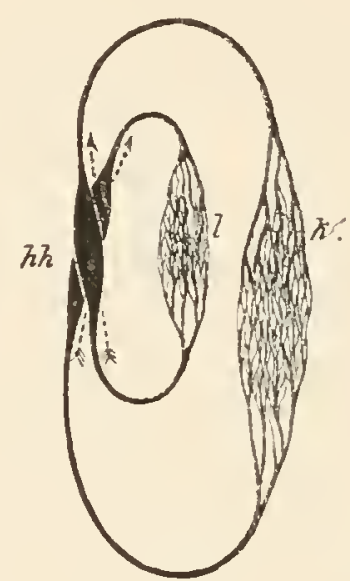

C.

Fig. 177. Schema des Blutkreislaufes bei Wirbelthieren

A. Kreislauf bei Fischen. $h$ Herz, br Kiemengefässe, $l, k$ Gefässe der Schwimmblase und des übrigen Körpers.

B. Kreislauf bei Amphibien. $l$ Lungengefässnetz, $k$ Körpergefässnetz.

C. Kreislauf bei Vögeln und Säugethieren. hh Das in zwei Theile gesonderte Herz

strömt dann zum Körper, um von da wieder zum Herzen zu gelangen. Mit dem Auftreten der Lungen gehen die Kiemen allmählich ein; durch Sonderung der Blutbahn der Lunge von der des Körpers wird der Kr reislauf nun ein doppelter, indem ein Theil des Blutes vom Herzen zur Lunge und wieder zum Herzen zurïck, ein anderer Theil vom Herzen zum Körper und wieder zum Herzen zurück führt; er ist so zunächst bei den Amphibien nur unvollkommen verdoppelt, insofern, als das Herz selbst ungetheilt ist und das Blut beider Bahnen in demselben sich mischt; gemischtes Blut geht somit durch die Lungenarterien zu den Lungen und kehrt sauerstoffreich als Lungenblut durch die Lungenvenen zurïck; es geht auch gemischtes Blut durch die Körperarterien zum Körper und kehrt als sauerstoffarmes Körperblut durch die Venen zum Helzen zurück. Das Herz ist hier zugleich Körperherz und Lungenherz (Amphibien, die meisten Reptilien). - In-

1) Aeltere Autoren haben dies Verhältniss anders dargestellt; es wären darnach die Verhältnisse der Arthropoden leichter von jenen der Anneliden ableitbar als nach den neueren Angaben. Daher verdient die Frage noch eingehende Untersuchung. 
dem die Scheidung des Kreislaufes endlich auch auf das Herz sich ausdehnt, ist der Kreislauf ein voll kommen doppelter geworden (Crocodilier, Vögel, Säugethiere). Wir können den gesammten Kreislauf einer Achtertour $[\infty]$ vergleichen, oder besser noch einer solchen, bei welcher der kleinere Kreis in den grösseren hineingelegt ist (Fig. 177 C.). Das Blut geht vom Körperherzen in den Körper, von diesem in das Lungenherz, durch dieses in die Lungen und von diesen wieder zum Körperherzen.

Um das Schema des Kreislaufes bei den verschiedenen Wirbelthieren zu vervollständigen, müssen wir auch die Form des Herzens berück-

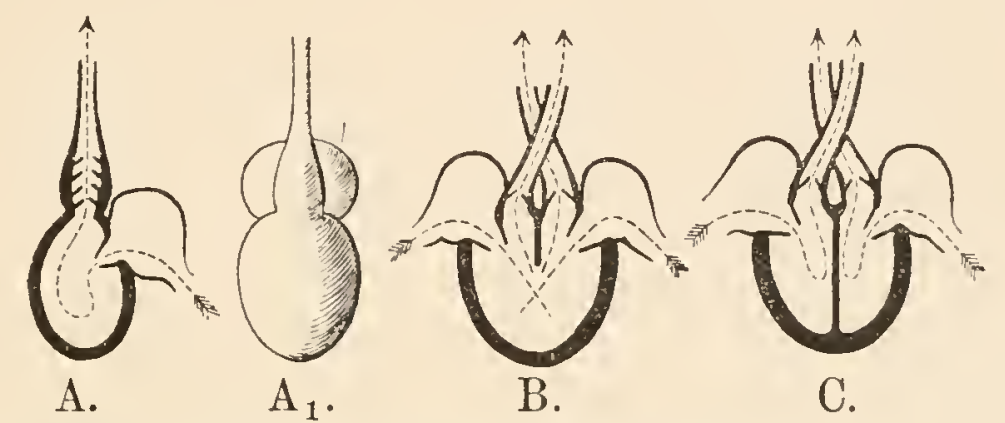

Fig. 178. Schema des Herzens bei den Wirbelthieren.

A. Herz der Fische von der Seite (Durchschnitt).

$A_{1}$. dasselbe von vorne gesehen.

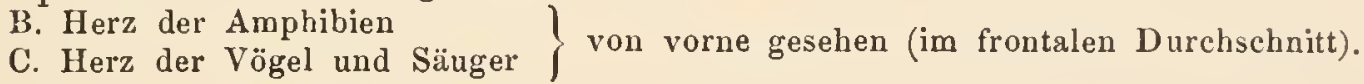

sichtigen. Das Blut strömt nicht am Hinterende des Herzens ein und am Vorderende aus, sondern beiderlei Oeffnungen befinden sich vorne. Das Herz ist nämlich schon bei den Fischen auf die Form eines schlingenförmig geknickten Schlauches zurückzuführen, der in mehrere Abtheilungen, die Vorkammer, Kammer und den Arterienstiel sich gliedert. Die Theilung des Herzens schreitet von der Peripherie nach dem Centrum fort, es werden zunächst die Vorkammern und der Arterienstiel getheilt, während die Kammer noch mehr oder weniger einheitlich erscheint (Amphibien, Reptilien). Erst durch die Entstehung einer Scheidewand innerhalb der Herzkammer wird das Herz zu einem vollkommenen Doppelherzen. Es entspricht nun zwei nebeneinander liegenden geknickten Schläuchen, deren Endtheile sich überkreuzen.

\section{Bewegung.}

Die Grunderscheinungen, auf welche alle Bewegung bei den Metazoen zurückzuführen ist, sind dieselben, welche wir schon bei den Protozoen kennen gelernt haben, nämlich: a möboide B ewegung; Plasmacontractilität, Wimperbewegung und Muskelcontractilität. Sie kommen nebeneinander in ein und demselben Thierkörper bei den meisten Metazoen und selbst bei den höheren Formen derselben vor; da aber die Bewegung grösserer Massen, wie wir sehen werden, nur durch Muskelcontractilität möglich ist, so spielt diese bei allen höheren Thieren, die ja eine bedeutende Grösse erreichen, die weitaus überwiegende Hauptrolle - und zwar nicht nur 
bei der Fortbewegung des Gesammtkörpers, sondern auch bei den inneren Bewegungsleistungen der Eingeweide.

D ie a möboide Bewegung ist zunächst bei den Spongien den meisten Gewebezellen eigenthümlich; sie dient aber auch hier nicht zur Fortbewegung des Körpers, sondern steht wohl zumeist in Beziehung zu der besonderen Ar't und Weise, durch welche die Verbreitung der Nahrung im Körper geschieht. Interessanter Weise sind es auch im Körper der höheren Thiere speciell solche Zellen, welche die Function der Nahrungsverbreitung übernommen haben, die eine amöboide Beschaffenheit zeigen, nämlich die amöboiden Wanderzellen, Lymphzellen und weissen Blutkörperchen ${ }^{1}$ ). Diese Zellen dienen nicht nur zur Verbreitung der Nahrung im Körper, sondern sie haben - wie Metschnikoff's schöne Entdeckungen gezeigt haben - auch die Aufgabe, schädliche Theilchen (eingedrungene Fremdkörper, parasitische Mikroorganismen [und auch Excretionsprodukte]) aufzunehmen und sie zu zerstören oder aus dem Körper zu entfernen; sie repräsentiren eine Art Sanitätspolizei im Körper.

Es ist hervorzuheben, dass auch der Resorptionsprocess im Darm vielleicht allgemein auf amöboide Vorgänge der Epithelzellen zurïckzuführen ist.

Die amöboide Beweglichkeit der sternförmigen Pigmentzellen, welche schon mehrfach erwähnt wurde, ist deshalb von hervorragendem Interesse, weil hier eine Abhängigkeit der Bewegung vom Nervensystem vorliegt (wie zuerst BRÜCKE am Chamaeleon nachwies), wahrscheinlich verhalten sich in ähnlicher Weise auch viele andere amöboide Zellen; ein solches Verhältniss ist begreiflicher Weise bei manchen der früher erwähnten Zellen (Blutzellen etc.) nicht vorhanden, weil sie innerhalb des Organismus eine gewisse Selbständigkeit erlangt haben.

Bei embryonalen Zellen ist die amöboide Beweglichkeit eine sehr häufige Erscheinung; manchmal spielt auch eine Wanderung von Zellen bei dem Aufbau des Embryos eine gewisse Rolle (Aufbau des Mitteldarmes bei Insecten etc.); eine Verlagerung von Zellen aus einem Keimblatt in das andere kommt aber kaum so bäufig vor, wie manche Forscher es vermuthen. Genauere Angaben besitzen wir nur über die Wanderung von Fortpflanzungszellen aus einem Keimblatt in das andere, die bei Hydroiden vorkommt (Kleinenberg, Weismans).

Die Plasmacontractilität, welche, wie schon früher erörtert, der amöboiden Bewegung ihrer Natur nach sehr nahe verwandt ist (vergl. pag. 55), kommt in gewissem Grade allen Gewebezellen zu, welche noch Plasma enthalten.

Ich möchte hervorheben, dass sie bei den niederen Metazoen mehr als man gegenwärtig anzunehmen pflegt, auch für die Bewegungserscheinungen des Körpers in Betracht kommt. Man nahm z. B. früher an, dass die Gestaltsveränderungen, deren der Körper bei Hydra fähig ist, nur auf Plasmacontractilität beruhen; nach der Entdeckung von Muskelfibrillen an der Basis der Epithelzellen hat man dagegen diesen allein die Bewegungsleistung zuerkannt; wenn wir uns aber vor Augen halten, in welch hohem Grade z. B. ein Tentakel verkürzt werden kann, und dabei beobachten, wie die früher flachen Deckepithelien sich bedentend verdicken, so kommen wir zu

1) Diese Verhältnisse sind auch für die phylogenetische Betrachtung der Gewele bedeutsam; wir verweisen besonders auf die Betrachtungen METschnikoff's, wenn wir auch nicht allen (morphologischen) Schlussfolgerungen dieses Forschers zustimmen können. 
dem Schlusse, dass deren Plasma nicht nur passiv zusammengedrïckt wird, sondern auch durch active Zusammenziehnng die Function der Muskelfibrillen unterstiutzt.

Die Flim erbewegung kommt bei den niedrigeren Metazoen sehr häufig auch an der Körperoberfläche vor und dient vielfach zur Fortbewegung des Körpers (Ctenophoren, Turbellarien, Rotatorien) oder auch bei vielen festsitzenden Formen zur Erzeugung eines Wasserstromes, um Nahrung herbeizuschaffen (Spongien, Rotatorien, Endoprocta, Tentaculata). Sehr häufig sind auch zum Zwecke des Wasserwechsels die Kiemen bewimpert. Die Fortbewegung des Körpers durch Wimperbewegung ist ferner sehr verbreitet bei den Larven der Wirbellosen, auch solcher, die im ausgebildeten Zustande andere Bewegungsart besitzen wie Mollusken, Anneliden, Echinodermen; es machen hiervon nur die Nematoden und Arthropoden eine Ausnahme.

Die Beschränkung dieser Art von Bewegung auf niedere Thiere und Larvenformen beruht vornehmlich auf zwei physiologischen Gründen. Erstens ist eine äussere Flimmerbedeckung nur bei Wasserthieren möglich oder bei solchen, die in einer beständig feuchten Atmosphäre leben (wie die Landplanarien in den tropischen Wäldern) und zweitens was noch bedeutsamer ist - kamn die an der Fläche wirkende Flimmerung nur kleinere Körper in Bewegung setzen, da bei grösseren Organismen das Verhältniss von äusserer Fläche zur Masse ein viel ungünstigeres ist. Die Vergrösserung der Wimpern selbst ist nur bis zu einem beschränkten Grade möglich; am mächtigsten sind sie bei den Ctenophoren entwickelt, wo sie gruppenweise zu Ruderplättchen verschmelzen; solche Plättchen erreichen eine bedeutendere Grösse als z. B. die Ruderfüsse kleinerer Anneliden und Crustaceen. Die zur Bewegung dienenden Wimperorgane erreichen auch oft eine grössere Wirksamkeit, indem sie auf Lappen-ähnlichen oder Tentakel-ähnılichen Bildungen sich ausbreiten, so dass eine grössere Ausdehmullg der flimmernden Theile erzielt wird (Larven von Mollusken, Phoronis, Echinodermen), doch ist aucl diesen Einrichtungen eine ziemlich enge Grenze gesetzt.

Auch die Fortbewegung des Darminhaltes geschieht bei kleineren Organismen meist durch Flimmerbewegung; doch wird sie bei vielen Thieren durch Muskelarbeit (peristaltische Bewegung des Darmes) unterstützt, und endlich bei grösseren Thierformen gallz durch dieselbe ersetzt. Zur Fortbewegung von Flüssigkeit in den Coelomhöhlen, den Nieren, oder wenigstens von Schleimmassen in den Luftwegen selien wir die Flimmerbewegung selbst bei den höchsten Organisnen in Verwendung.

Früher wurde allgemein angenommen, dass die Flimmerbewegung: unabhängig vom Einflusse des Nervensystems sei; man glaubte dies besonders dadurch bewiesen, dass auch losgelöste Flimmerzellen, ja sogar Bruchstiucke von Zellen Fortdauer der Flimmerbewegung zeigen. Bei den Ctenophoren und bei den Larven von Anneliden kann aber die Innervirung nicht nur aus der Art der Thätigkeit erschlossen werden, sondern es ist auch der Zusammenhang mit Nerven histologisch nachgewiesen worden. ${ }^{1}$ )

Muskelcontractilität, welche an das Muskelgewebe gebunden ist, finden wir bei allen Metazoen; nur bei den Spongien ist es

1) Besonders instruktiv ist die Innervirung der Flimmerzellen bei den Räderthieren, welche kiirzlich in unserem Laboratorium durch J. Masius entdeckt wurde. 
fraglich, ob sie in allen Fällen Muskeln besitzen; bei einigen Arten wurden spärliche Muskelfasern in Form von spindelförmigen Zellen beobachtet.

Physiologisch ist der Gegensatz von glattem und quergestreiftem Muskelgewebe bedeutsam (es gibt aber auch Uebergänge zwischen beiden Arten). Bei der glatten Muskelfaser läuft der Vorgang der Contraction langsam $a b$, bei den quergestreiften hingegen rasch. Der Grad der Zusammenziehung ist aber bei der ersteren oft viel bedeutender. So sehen wir, dass niedere Thiere, die mit glatten Muskelfasern ausgestattet sind (Nemertinen, Anneliden, Hydroidpolypen) ihren Körper um ein mehrfaches verkürzen können, während die energische Zusammenziehung unserer Extremitätenmuskeln eine viel geringere Elongation zeigt.

Die glatten Muskelfasern setzen meist contractile Häute zusammen (z. B. den Hautmuskelschlauch bei Scoleciden und Anneliden oder die Muskelschicht des Darmes und anderer Eingeweide bei verschiedenen Thierclassen). Die quergestreiften Muskeln dagegen sind oft in der Weise verwendet, dass sie mittelst ihrer Enden an Skelettheile fixirt sind, welche die mannigfaltigsten Bewegungsapparate, meist in hebelartiger Anordnung, zusammensetzen; bei deu Wirbelthieren heften sich die Muskeln aussen an die Skelettheile, bei den Arthropoden sind sie innen an den röhrenartigen Abschnitten des Hautskeletes befestigt.

Die Muskelbewegung ist wohl in allen Fällen rom Nervensystem abhängig.

Bei den Wirbelthieren sind die willkürlichen Körpermuskeln quergestreift, die auf reflectorischem Wege reizbaren Muskeln der Eingeweide glatt, mit Ausnahme der quergestreiften Herzmuskeln.

Es ist in hohem Grade wahrscheinlich, dass bei der phylogenetischen Entwicklung der Metazoen ursprünglich die Flimmerbewegung zur Fortbewegung des Gesammtkörpers vorherrschte und erst allmählich durch die Muskelbewegung verdrängt wurde; die Flimmerapparate der Larven scheinen in der That zum grossen Theil Einrichtungen, die bei den Stammformen vorhanden waren, zu entsprechen; andererseits kommen aber doch auch viele larvale Anpassungen in dieser Beziehung vor.

\section{Empfindumg.}

Wir haben schon bei den Protozoen gefunden, dass Reize chemischer oder mechanischer Natur, die auf das Plasma einwirken, mit Bewegungserscheinungen beantwortet werden. Wir sind zu dem Schlusse gekommen, dass die Umwandlung des Reizes in Erregung, ferner die Fortleitung der Erregung innerhalb des Körpers und die Auslösung von Bewegungsphänomeuen auf den Eigenschaften des einfachen Zellplasmas beruhen; ja sogar das Unterscheidungsvermögen für verschiedenartige Reize ist diesem Plasma zuzuerkennen. Aehnlich sind wohl auch die Verhältnisse der niedrigst organisirteu vielzelligen Thiere, der Spongien, zu beurtheilen, uur dass hier auch eine Fortleitung der Erregung von Zelle zu Zelle stattfindet ${ }^{1}$ ). Bei den anderen Metazoen aber ist mit

1) Diese Organismen stehen hierin durchaus nicht in fundamentalem Gegensatz zu den höheren Thieren; denn wahrscheinlich gibt es auch bei diesen letzteren Körpertheile; wo die Erregung nur von Zelle zu Zelle fortgeleitet wird. 
dem Auftreten histologisch differenzirter Sinneszellen und Nervengewebe und Muskelgewebe eine Arbeitstheilung eingetreten, wodurch die oben erwähnten Functionen bedeutend vervollkommmet erscheinen. Die Sinneszellen besitzen eine gesteigerte Erregbarkeit, durch die Nerven werden die Erregungen viel rascler fortgeleitet und durch die Ganglienzellen in geeigneter Weise in Wechselwirkung gesetzt und endlich den Bewegungsorganen mitgetheilt. Durch die grössere Empfindlichkeit der Sinneszellen, sowie durch die gesonderte Fortleitung der Erregungen vermittelst des Nervensystems ist auch ein gesteigertes Untersc lı eid ung s vermögen bedingt ${ }^{1}$ ). Dieses wird noch bedeutend rervollkommnet durch die Ausbildung specifisch verschiedener Sinnesorgane und eines entsprechend höher entwickelten centralen Nervensystems.

Die Zustände oder Vorgänge der umgebenden Aussenwelt spiegeln sich gleichsanı in den inmeren Zuständen oder Vorgängen des Centralnervensystems der 'Thiere. Je mannigfaltiger die Simnesorgane und die zugehörigen nervösen Apparate sind, in desto zahlreichere Factoren werden aber die auf das Thier wirkenden Eindriicke zerlegt - d. h. uit desto mehr Einzelnheiten spiegelt sich das Bild der Aussenwelt in den Vorgängen des Nervensystems - und desto namnigfaltiger sind auch die Combinationen von Handlungen, mit welchen das Thier hierauf antwortet. Sinnesorgane, Nervensystem und Bewegungsorgane stehen in Bezug auf die Höhe ihrer Differenzirung, d. i. die Feinheit und Mannigfaltigkeit ihrer Ausbildung, stets in nothwendiger gegenseitiger Beziehung.

Bei allen Stufen der Ausbildung, von den einfachsten Protozoen bis zu den höchsten Metazoen, sehen wir, dass die Fähigkeit der Empfindung und die der zweckdienlichen Handlung stets in nothwendigem Zusammenhang stehen. Sie sind im Allgemeinen nicht ohne einander denkbar.

\section{Sinnesorgane.}

Die Sinnesorgane dieneu dem Unterscheidungsvermögen, insofern als sie die Reize in Erregungen umsetzen, welche auf das Centralnervensystem übertragen werden, und zwar nach folgenden Gesetzen: 1) Eine gesonderte Empfindung von Reizen kommt dadurch zu Stande, dass dieselben sowoll von gesonderten Sinneselementen (Sinneszellen) aufgenommen, als auch durch gesonderte Nervenbahnen (Nervenfasern) zum Centralnervensystem fortgeleitet werden. 2) Verschiedenartige Reize werden von verschiedenartigen (specifischen) Sinnesorganen aufgenommen.

Die specifischen Sinnesorgane sind für besondere Arten von Reizen eingerichtet, welche wir als ihre ad ä quaten Reize bezeichnen. Die Specialisirung beruht auf folgenden Punkten: a) Die Sinneszellen besitzen für die adäquaten Reize eine gesteigerte Erregbarkeit, während sie für andere Arten von Reizen wenig empfindlich sind; so haben z. B. unsere 'T'astorgane wenig oder keine Empfindlichkeit für das Licht (Lichtwellen). b) Es sind Einrichtungen vorhanden, wodurch andere als die adäquaten Reize von den Sinneszellen des Organes fermgehalten werden; so ist z. B. unser Gehörorgan so eingerichtet, dass andere Reize als Schallreize (Schallwellen) schwer zu demselben gelangen.

1) Als Unterscheidungsvermögen bezeichnen wir (im weitesten Sinne) die Eigenschaft, auf verschiedenartige Reize mit verschiedenartiger Thätigkeit zu antworten; dasselbe beruht daher auf dem gesammten Empfindungs- und Bewegungsapparat. 
Einen gewissen Grad von Empfindlichkeit besitzen diese specifischen Sinneszellen aber auch für andere als ihre adäquaten Reize. Es wird z. B. ein Druck, der auf unser Auge ausgeübt wird und auf die Netzhaut sich fortpflanzt, empfunden, und zwar als licht empfunden; ebenso ruft eine heterogene Reizung unseres Gehörorganes Tonempfindung hervor. Die subjective Art dieser Empfindungen ist im Zusammenhang mit den Vorgängen des Centrahnervensystems zu beurtheilen.

\section{Primitiv-Sinnesorgane, Organe des Hautsinnes, Tastorgane.}

Wir beobachten bei vielen niederen Thieren (z. B. Actinien, vielen Scoleciden etc.) nur eine Art von Sinneszellen, die (entweder vereinzelt oder gruppenweise) im ectodermalen Epithel sich finden. Da solche Thiere nicht etwa nur Tastempfindung haben, sondern auch Licht, Wärme, chemische Reize wahrnehmen, so werden wir ihre mit Sinneszellen ausgestattete Haut als ein primitives (nicht specialisirtes) Sinnesorg a n betrachten.

Aus diesen Primitivsinnesorganen sind durch Arbeitstheilung die speciellen Sinnesorgane hervorgegangen; unter diesen letzteren ist aber die Specialisirung nicht bei allen in gleicher Weise vorgeschritten. Den Primitivorganen am nächsten steht wohl allgemein der $\mathrm{H}$ a u tsinn, da derselbe nicht nur Tastempfindung, sondern auch Wärmeempfindung und in gewissem Grade auch chemische Empfindung vermittelt (bei vielen niederen Thieren kommt auch eine gewisse Lichtempfindung hinzu, selbst wenn sie nebstdem besondere Augen besitzen).

Nur in jenen Fällen, wo die Simneszellen an besonderen Stellen des Körpers angebracht sind, die tastende Bewegungen ausführen (Tastfäden, Tentakel etc.) kann man denselben mit grösserem Rechte Tastempfindung zuschreiben; es sind wenigstens vorwiegend in dieser einen Richtung empfindliche Hautsinnesorgane. Wir können aber, wenn wir das Wort in allgemeinerer Weise gebrauchen, auch die Tastorgane noch als Hautsinnesorgane bezeichnen.

Bei den Wirbellosen erscheinen die Elemente der Hautsinnesorgane zumeist als im äusseren Epithel gelegene Sinneszellen, mit frei über die Oberfläche des Epithels hervorragenden Sinneshärchen. Morphologisch sind zwei Haupttypen zu unterscheiden: 1) Der ursprūnglichere Typus sind isolirt stehende Sinneszellen; diese finden sich bei den Cnidariern und bei den verschiedensten anderen Thieren. 2) Die Sinnesknospen, das sind eigenthümliche Gruppen von Sinneszellen, die von einer concentrischen Zone, oft zwiebelschalenähnlich angeordneter Stützzellen umgeben werden. Die Vielzahl der Sinneszellen dient hier wahrscheinlich nur zu einer Verstärkung der Wirkung, denn sie sind wohl in gleicher Weise dem Reize zugänglich, den sie als Erregung einer gemeinsamen Nervenfaser mittheilen. Die Sinnesknospen kommen bei den meisten über den Cnidariern stehenden

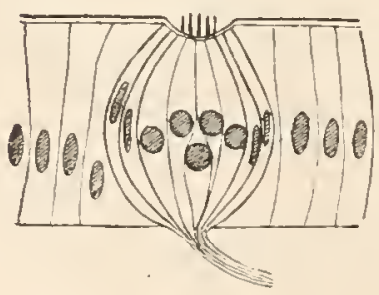
Thiergruppen vor, und zwar sind neben denselben oft auch einzelstehende Sinneszellen bei demselben Thiere vorhanden.

Fig. 179. Sinnesknospe (schematisch).

Eine Gruppe von Sinneszellen, an welche allein der Nerv herantritt, ist ringsum von Hüllzellen umgeben; daneben die gewöbnlichen Stiitzzellen des Epithels. 
Bei den Arthropoden sind in Zusammenhang nit der besonderen Ausbildung des Integumentes veränderte Verhältnisse der Tastorgane zu beobachten. Das Epithel fungirt hier bekanntlich als Matrix, welche eine dicke chitinige Cuticula ausscheidet; diese ist typischer Weise mit mannigfachen, meist beweglich eingelenkten, hohlen Borsten und Härchen

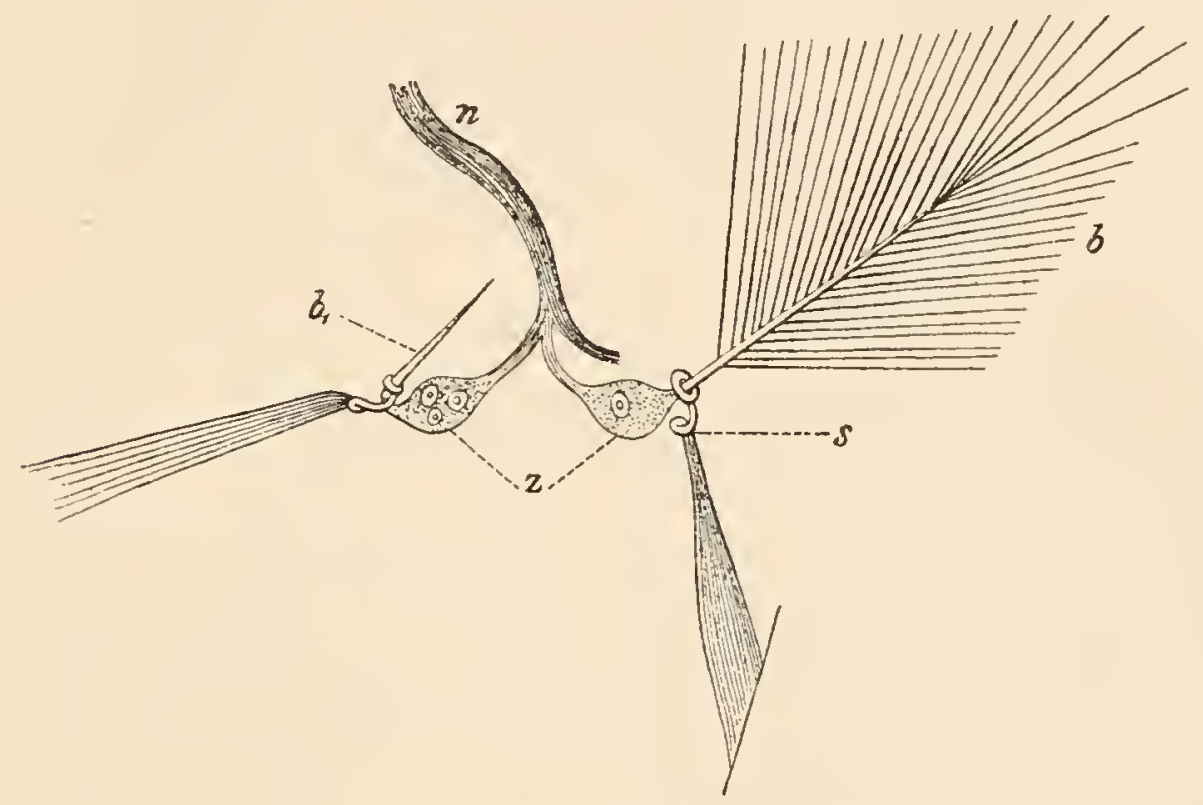

Fig. 180. Cuticulare Tasthaare einer Mückenlarve (Corethra plumicornis) nach LEYdig.

$b$ Tasthaare, $z$ Sinneszellen, $n$ Nerv, $s$ ein spiraliges elastisches Bändchen, das die Basis des Tasthaares mit einer anderen Stelle des Integumentes verbindet (die Existenz dieses Bändchens wurde wieder in Abrede gestellt).

besetzt (Trichome), welche Fortsätze der Cuticula sind ; zu denselben stehen besondere Zellen der Matrix in Beziehung, die einen dünnen Plasmafaden in das Innere des hohlen Härchens senden. Manche dieser Zellen fungiren als Tastzellen, indem sie an ihrer Basis mit einem Nerven verbunden sind; oft ist nahe von der Tastzelle eine Ganglienzelle in den Verlauf des Nerven eingeschaltet.

Bei den wasserbewohnenden Wirbelthieren sind die Hautsinnesorgane ähnlich denjenigen der Wirbellosen. Bei den Fischen, den perennibranchiaten Amphibien und bei allen Amphibienlarven finden wir Hautsimnesorgane, die nach dem Typus der Sinnesknospen gebaut sind. Die mannigfachen Modificationen derselben sind als Sinneshügel, Gallertröhren, becherförmige Organe bekannt; sie überragen die Oberfläche, oder sind in Vertiefungen des Integumentes eingesenkt. Neben solchen Organen können auch solitäre Sinneszellen in grosser Zahl vorkommen, z. B. die Stiftchenzellen bei Amphibienlarven (KöLliKer). Bei Amphioxus kommen, ausser an den Mundcirren, nur solitäre Sinneszellen vor. Auch freie Nervenendigungen zwischen den Epithelzellen werden beschrieben.

Zu dem Typus der Sinnesknospen gehören auch die eigenthümlichen "Org a n e d e r Seit tenl i n i " bei Fischen und wasserbewohnenden $A m-$ phibien, welche entweder frei all der Körperoberfläche oder in kanalartigen Differenzirungen der Epidermis eingeschlossen liegen. Man hat dieselben verschieden gedeutet: als Organe eines sechsten Sinnes, als eine Art von Gehörorgan, oder auch als Organe, welche gröbere Erschütterungen des 
Wassers (von geringer Schwingungszahl) wahrnehmen. In der That würde ein Organ, welches eine solche Art von Erschütterung oder Bewegung des Wassers anzeigt, einem Wasserthiere von grossem Nutzen sein ${ }^{1}$ ).

Bei den landbewolnnenden Wirbelthieren sind besondere Tastkörperohen vorhanden, welche unterhalb des Epithels in der Cutis liegen und aus einer eigenthümlichen Gruppe von Sinneszellen bestehen; vielleicht sind es in die Tiefe verlegte umgewandelte Sinnesknospen (dies muss erst die Entwicklungsgeschichte entscheiden). Auch Haare, an deren basaler Papille sich reichliche Nervenendigungen finden, fungiren in manchen Fällen als Tastorgane. Ferner sind feinste Nervennetze (freie Nervenendigungen) in der Epidermis selbst beobachtet.

Geschmacks- und Geruchsorgane.

Die Geschmacks- und Geruchsorgane prüfen die chemische Beschaffenheit einerseits der Nahrung und andererseits des zum Athmen dienenden Mediums, d. i. der Luft oder des Wassers.

Bei den niederen Thieren sind die Sinneszellen der Geschmacksorgane in der Regel ähnlich denjenigen der Hautsinnesorgane bei derselben Thierform. Wir erschliessen meist ihre specielle Function nur aus ihrer Lage in der Mundhöhle oder am Eingange derselben.

Die Geruchsorgane der Wirbellosen haben meist die Form von Grübchen mit lebhaft flimmerndem Epithel, welches wohl neben den Flimmerzellen auch Sinneszellen enthalten muss. Ihre lage ist in der Nähe des Nervencentrums und der höheren Simnesorgane (z. B. bei den Scheibenquallen an den Randkörpern, bei den Turbellarien, Nemertinen, Anneliden, Cephalopoden am Kopfe) oder auch in der Nähe der Athmungsorgane (Mollusken).

Bei den Arthropoden zeigen wie auch die meisten anderen Sinnesorgane, so auch die Geschmacks- und Geruchsorgane ein ganz besonderes für diese Thiergruppe charakteristisches Gepräge. Betrachten wir zunächst die Crustaceen; wir finden an dem ersten Antennenpaar (nur ausnahmsweise bei Nebalia und Cumaceen auch an der zweiten Antenne) sogenannte

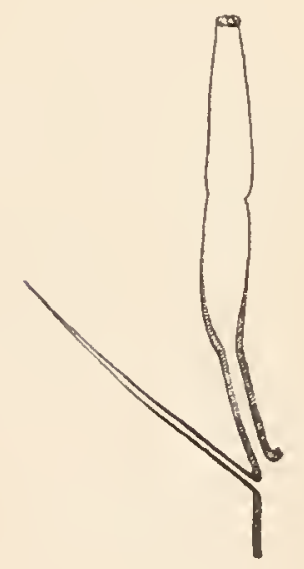
Spürhaare oder Riechhaare (auch Spïrschläuche genannt), meist büschelweise angeordnet. In der Regel sind sie bei den Männchen stärker ausgebildet. Es sind dies auf die gewöhnliche Form der hohlen Chitinhaare zurückführbare Anhänge; sie sind stets unverästelt, von mässiger Länge und cylindrischer Form. Ilre Chitindecke ist gegen das freie Ende zu meist in anselınlicher Ausdehnung sehr verdünnt; an der Spitze findet sich oft ein stark lichtbrechendes Körperchen (es wird auch angegeben, dass am freien Ende des Spürhaares eine Oeffinung bestehe [LEYDrG], doch wird von anderer Seite dieser Angabe widersprochen [CLAUS]).

Fig. 181. Riechhaar und daneben ein gewöhnliches cuticulares Haar von der ersten Antenne eines Gammariden, nach Lerdig.

1) Bei Epicrium glutinosum sind derartige Sinneshügel an der Kopfhaut zu eigenthümlichen kleinen Nebengehörorganen ausgebildet (P. u. F. Sarasin). 
Das Innere des Spürhärchens ist von einer feinstreifigen Plasmasubstanz erfüllt, welche mit einer tiefer liegenden rundlichen Zelle zusammenhängt, und an diese tritt andererseits eine Nervenfaser heran. Diese Zelle wird von den Autoren als Ganglienzelle betrachtet; sie wäre wohl zutreffen(der als Sinneszelle zu bezeichnen ${ }^{1}$ ).

Bei den Insekten sind die Geruchsorgane meist an den Antennen, die Geschmacksorgane an den Palpen der Mundwerkzeuge und in der Mundhöhle zu finden. Seltener sind derartige Organe an anderen Körperstellen ausgebildet (z. B. an den Caudalanhängen von Gryllotalpa und Periplaneta). Die Sinneselemente dieser Organe sind auch hier, bei den Insekten, auf die Grundform des chitinigen Trichoms zurückzufïhren. Es sind zarte, kurze, kegelförmige Gebilde (Sinneskegel), welche entweder frei an der Oberfläche der hier von einer Pore durchbohrten, Chitindecke oder in einem Grübchen derselben sitzen (so dass sie in letzterem Falle gegen Tastreize geschïtzt sind). Es finden sich auch Sinnes-

Fig. 182. Geschmacks- und Geruchsorgane von Insekten nach O. VOM RATH.

1. Modificationen der Chitingebilde.

$a$ zwei Sinneskegel von der Zungenspitze der Vespa vulgaris:

$b$ Sinneskegel in der Tiefe einer Chitingrube aus der Antenne von Tanessa urticae;

c zahlreiche Sinneskegel in einer gemeinsamen Chitineinsenkung von der Spitze des Lippentasters des Kohlweisslings; $d$ sehr tief eingesenkte Chitingrube mit Sinneskegel von der Antenne von Tabanus bovinus; $e$ sehr verkürzter Sinneskegel von Lobus externus der Maxille von Sialis;

$f$ Membrankanal von der Antenne von Cetonia aurata.

2. Modificationen der zagehörigen Sinneszellen.

A. Sinneszelle aus der Riechgrube an der Labialpalpe des Kohlweisslings (siehe c.).

B. Sinneskörper von der Antenne von Gomphocerus rufus.

C. Sinneskörper vom Geschmacksorgan des Rüssels von Tabanus bovinus. 1. Cuticularschicht, 2. Stützzellen, 3. Sinneszellen.
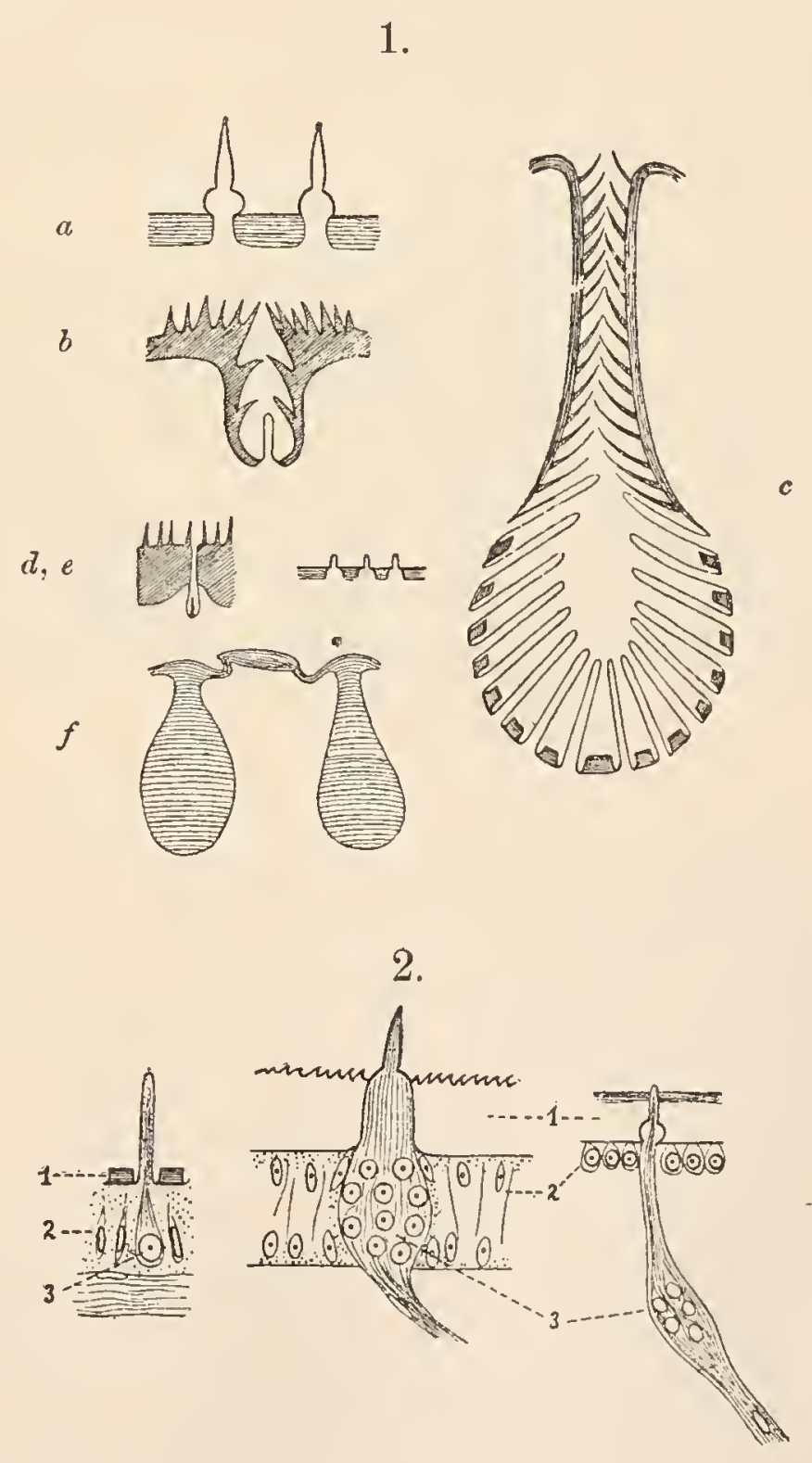

A.

B.

C.

1) Bei den Insekten hat O. том Rath in seiner schönen Arbeit über die Geruchsund Geschmacksorgane diese Bezeichnung gebraucht. 
gruben, welche eine grössere Zahl von Sinneskegeln bergen. Unterhalb der Sinneskegel findet sich seltener eine einzelne Sinneszelle, meist aber eine Simneszellengruppe, die entweder noch innerhalb der Hypodermis liegt oder auch mehr in die Tiefe gerückt ist. - An den Antennen findet sich in manchen Fällen eine besondere Modification dieser Organe, die sogenannten Membrankanäle; bei diesen ist die Trichombildung reducirt, so dass nur eine zarte Membran den Porenkanal der Chitindecke, in welchen der Fortsatz der Sinneszellen hineinragt, verschliesst.

Die Geruchsorgane der Wirbelthiere haben ursprünglich den Bau von paarigen, am Vorderende des Kopfes gelegenen Flimmergruben. Sie rücken aber dann mehr in die Tiefe und es entsteht je ein Vorraum der Nasenhöhlen, welcher nicht mit Sinnesepithel versehen ist. Bei den luftathmenden Wirbelthieren münden diese Nasenhöhlen mit je einer hinteren Oeffnung (Choanen) in die Mundhöhle und dienen als Luftwege. Das Riechepithel der Wirbelthiere besteht aus hohen Flimmerzellen und einzeln dazwischen eingeschalteten Sinneszellen mit freien Sinneshärchen. In jüngster Zeit wurde gezeigt, dass auch diese Sinneszellen ursprünglich (bei Fischen) gruppenweise nach Art von Sinnesknospen im Riechepithel angeordnet waren (BlaUe).

Man hat früher die Geruchsorgane von Wasserthieren nicht als echte Geruchsorgane anerkemnen wollen und zwar aus dem Grunde, weil unser Geruchsorgan unter Wasser gesetzt, nicht functionsfähig ist. Man wollte also strenge unterscheiden zwischen solchen Organen, welche die Beschaffenheit der Luft und solchen, welche Flüssigkeiten prüfen. Es ist aber zu bemerken, dass auch unsere Riechschleimhaut nur in feuchtem Zustande functionirt; ferner wurde gezeigt, dass, wenn man die Nasenhöhle statt mit reinem Wasser mit einer Kochsalzlösung füllt, unser Geruchsorgan die durch diese Flïssigkeit übermittelten Gerüche wahrnimmt. Der Gegensatz erscheint also bedeutend gemindert.

\section{Gehörorgane.}

Die Sinneszellen der Gelörorgane sind im allgemeinen den primitiven Tastzellen, sowohl in ihrer Form als auch in der unmittelbaren Art ihrer Function, sehr ähnlich. Die Schallwellen des umgebenden Mediums würden in den meisten Fällen als Reiz für diese Zellen nicht wirksam sein, wenn nicht Hilfseinrichtungen vorlıanden wären, um die Schallwelle in einen geeigneteren mechanischen Reiz zu verwandeln. Die Art dieser Einrichtungen ist sehr mannigfaltig.

Bei den Hydroidmedusen finden wir in der Abtheilung der Haplomorpha (od. Cordyliota) Tentakelbildungen in eigenthümlicher Weise zu Gehörkölbchen (Cordylien) umgestaltet. Dieselben sind durch Otolithen beschwert, die in den entodermalen Achsenzellen des Kölbchens entstehen. Die Sinneshaare sitzen an ectodermalen Sinneszellen, die entweder einer Epithelverdickung an der Basis des Kölbchens (Hörpolster) angehören, oder die Oberfläche des Kölbchens selbst bilden. Wenn das Hörkölbchen durch Schallwellen in Schwingung versetzt wird, so werden die Sinneshärchen angeschlagen und ein Reiz auf dieselben ausgeübt. - Solche Kölbchen können auch in Vertiefungen des Ectoderms zu liegen kommen; dadurch wird ihre Function vervollkommnet 
A.
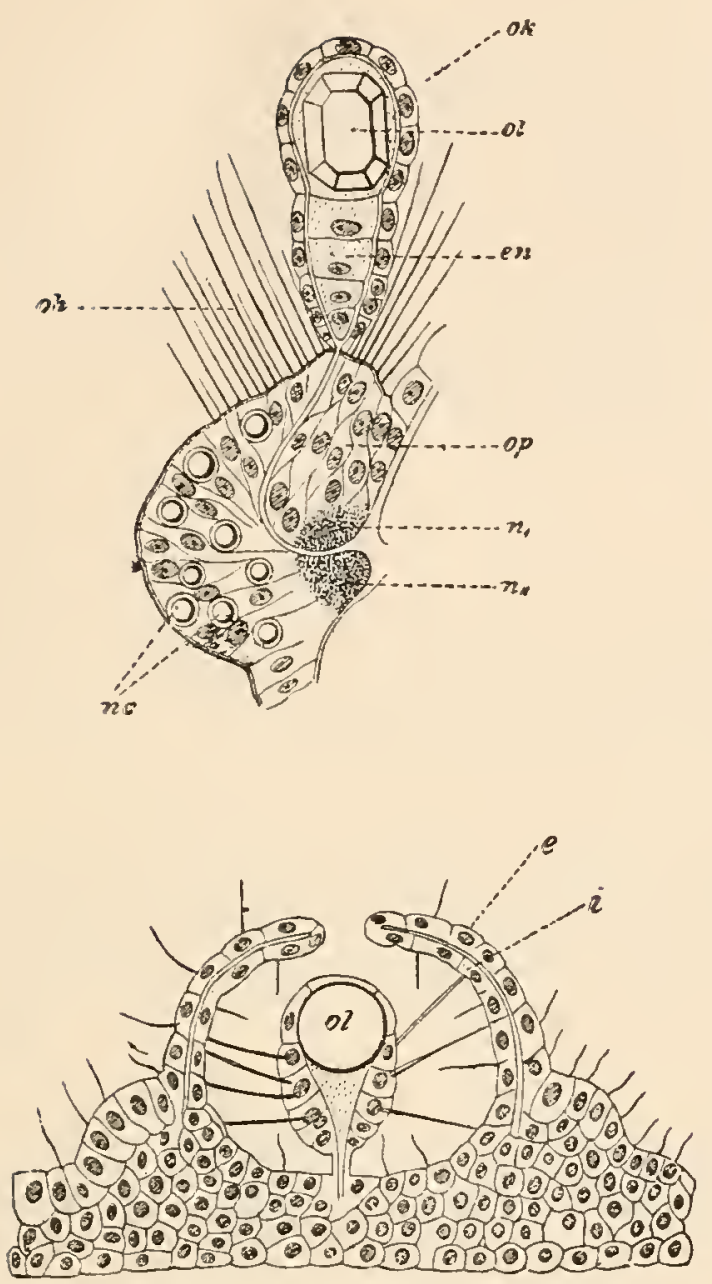

C.
B.
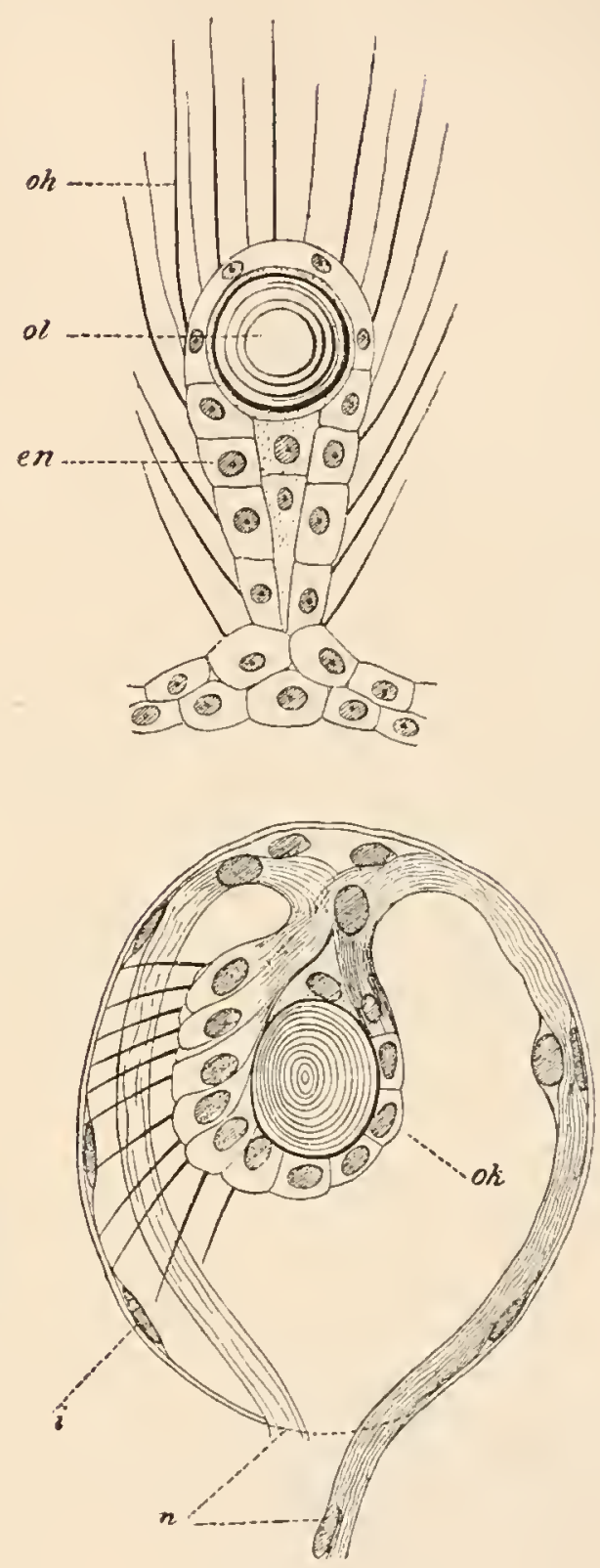

D.

Fig. 183. A. Schnitt durch den Schirmrand und ein daran sitzendes Hörkölbchen von Cunarcha aeginoides (nach HAECKEL). ok Hörkölbchen, ol Otolith, en endodermale Tentakeluchse, oh Hörbärchen, op Hörpolster, nc Nesselkapseln, $n$, $n_{\text {, }}$ Durchschnitt des inneren und äusseren Ringnerven

B. Sinneskölbchen von Pectis antarctica (nach HAECKEL). Die Hörhärchen (oh) finden sich an der Oberfläche des Kölbchens, ol Otolith, en Endodermachse (der punktirte Stricí bei en ist etwas zu kurz).

C. Durchschnitt eines Hörbläschens von Rhopalonema velatum, mit kleiner äusserer Oeffnung, in welches das Hörkölbchen eingesenkt ist; $e$ äussere Wand, $i$ innere Wand des Hörbläschens, ol Otolith des Hörkölbchens (nach HerTwiG).

D. Hörbläschen von Camarina hastata. i Wand des Hörbläschens, längs derselben tritt von zwei Seiten der Nerv $(n)$ an das Hörkölbchen (ok) heran (nach HERTwiG).

und es werden dadurch auch mit grösserer Sicherheit andere mechanische Reize (die nicht von Schallwellen verursacht sind) von den Hörkölbchen abgehalten. Endlich können die Kölbchen auch in vollkommen geschlossenen Bläschen liegen, die vom Ectoderm abgeschnürt und tief in das Innere des Körpers gerückt sind. 
Bei einer anderen Abtheilung der Hydroidmedusen, den Leptomedusen finden wir einen anderen Typus von Gehörorganen. Hier sind es selbständig ohne Beziehung zu Tentakelbildungen entstandene Gehörbläschen, die als zahlreiche Einstülpungen des Ectoderms in radiärer Anordnung längs des Scheibenrandes entstehen. Die Otolithen liegen hier in ectodermalen Zellen des Bläschens und schlagen bei ihren Schwingungen an benachbarte Sinneszellen (Hörzellen) an.

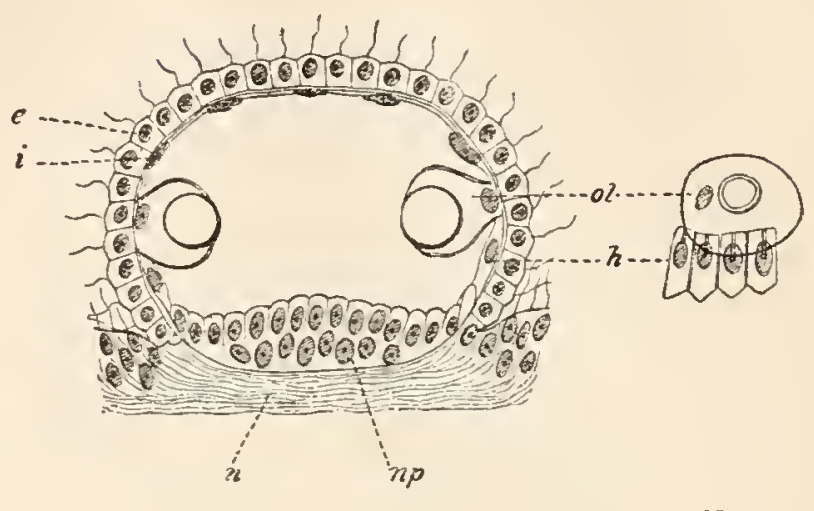

A.

B.

Fig. 184. A. Hörbläschen von Eucheilota. In Durchschnitt gesehen. $e$ äusseres Epithel, $i$ inneres Epithel des Hörbläschens, $n$ Nervenfasern, np Sinnespolster, ol Otolithenzellen, $h$ Hörzellen. B. Eine Otolithenzelle mit den benachbarten Hörzellen von der Fläche gesehen. Nach $O$. und R. Hertwig.

Der Typus von Gehörorganen, welcher bei den anderen wirbellosen Thieren am meisten verbreitet ist, sind vom Ectoderm abstammende Gehörbläschen, in deren Höhle ein grosser oder auch zahlreiche kleinere

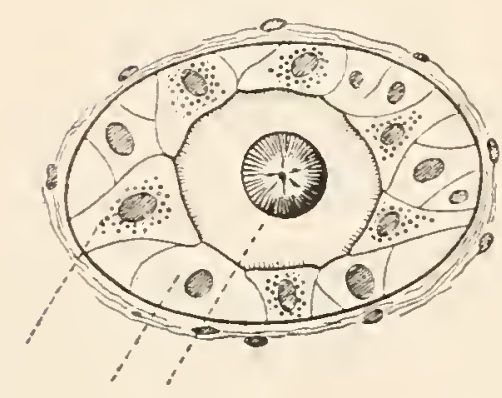

1 $2 \quad 3$

Fig. 185.

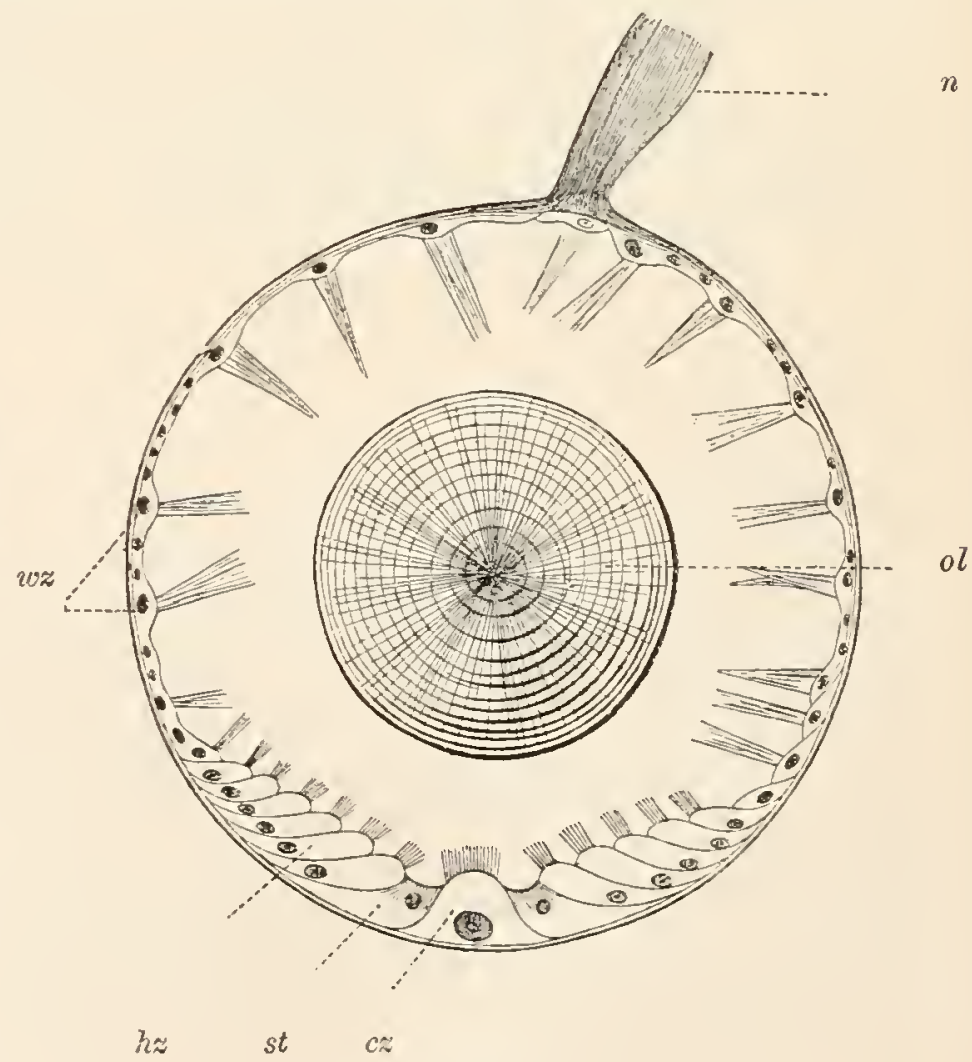

Fig. 186.

Fig. 185. Gehörorgan einer Muschel. Cyclas cornea (nach Leydig). Aussen findet sich eine Bindegewebsschichte; dann ein Epithel mit (1) Flimmerzellen und (2) Schaltzellen, innen (3) der Otolith.

Fig. 186. Gehörorgan eines Heteropoden, Pterotrachea (nach Claus). $n$ Nervus acusticus, ol Otolith im Inneren der Hörblase, $x$ Wimperzellen an der Innenfläche der Blasenwand, hz Hörzellen, $c z$ centrale Hörzelle, st Stützzellen in der Umgebung der letzteren. 
Otolithen frei liegen; dieselben sind in der Regel kalkige, geschichtete Ausscheidungsprodukte. Die Wandung des Bläschens, an welche der Nerv herantritt, enthält Sinneszellen, deren Härchen in das Lumen des Bläschens hineinragen und daneben finden sich oft auch Flimmerzellen, denen die Function zukommt, den Otolithen suspendirt zu erhalten. Solche Organe sind bei vielen Turbellarien und Anneliden bekannt und kommen den Mollusken regelmässig zu.

Bei den Arthropoden zeigen die Gehörorgane überall, wo sie uns bekannt geworden sind, sehr eigenthümliche Charaktere. Bei manchen Formen, z. B. Spinnen und Milben, sind Gelı̈rorgane nicht entdeckt. Bei den höheren Crustaceen findet sich je ein Gehörorgan in dem Basalgliede der ersten Antenne. Es ist ein nach aussen offenes Epithelsäckclıen, welches mit einem Chitinhäutchen ausgekleidet ist, das eine Fortsetzung des äusseren Chitinintegumentes ist. An der Wand des Säckchens finden wir in Reilıen längs der sogen. Hörleiste angeordnet zarte Borsten, die in ihrem Baue jenen Tastborsten entsprechen, die ganz allgemein an der Körperoberfläche (als für die Arthropoden typische Gebilde) vorkommen. Die Hörborsten unterscheiden sich von den Tastborsten besonders durch ihre grössere Beweglich-

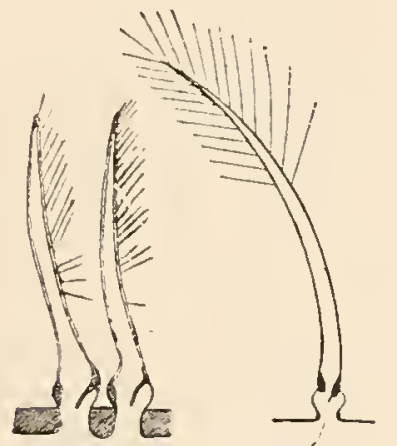

A.

B.

Fig. 187. A. Hörhaare aus dem Gehörsack eines Krebses (Crangon).

B. Hörhaare (?) von der Oberfäche des Schwanzes von Mysis (nach HENSEN). keit und durch einige Eigenthümlichkeiten der Nervenendigung. Als Otolithen fungiren Sandkörrnchen und andere Fremdkörper, die von aussen in das Hörsäckchen hineingebracht werden und an die Enden der Hörborsten ankleben. Bei Mysis findet sich ein geschlossenes Hörsäckclıen im Schwanzfächer; der Otolith ist hier ein Ausscheidungsprodukt. Auch finden sich bei vielen Krebsen freie Hörhaare an der Oberfläche der Antennen und am Schwanzfächer. V. Hensen hat experimentell nachgewiesen, dass, wenn man abwechselnd verschieden hohe Töne einwirken lässt, bald die einen, bald die anderen Hörhaare in Schwingung gerathen; für die Theorie der Unterscheidung von Tönen ist diese directe Beobachtung von grösstem Interesse.

Bei den Insecten sind nach Graber in allgemeinster Verbreitung eigenthümliche Organe nachgewiesen, die in grosser Zahl und in den verschiedensten Körpertheilen vorkommen. Es sind Zellgruppen, welche saitenartig durch die Körperhöhlen ausgespannt sind (daher als chordotonale Organe bezeichnet), indem sie an einem Ende direkt mit dem Integument verbunden an dem anderen Ende durch eine Art Ligament an einen entgegengesetzten Punkt des Integumentes befestigt sind. Dort wo sie an das Ligament grenzen, tritt ein Nerv quer an die Zellen heran; man unterscheidet in dieser Zellgruppe meist Ganglienzellen und Sinneszellen (Stiftchenzellen), welche letztere eigenthümlich gestaltete, als Hörstiftchen bezeichnete Körperchen ${ }^{1}$ ) enthalten (wo nur eine Art von Zellen vorhanden ist, sollte man sie als Sinneszellen und nicht als Ganglienzellen bezeichnen). Die saitenartig ausgespannten Sinnesorgane werden

1) Es ist sehr wahrscheinlich, dass die Stiftchen selır tief eingesenkten Sinnesgruben mit ihren Sinneskegeln entsprechen (vgl. pag. 175, Fig. 182 d). 
durch die Schallwellen in Schwingung versetzt und sind daher geeignet, als Gehörorgane zu fungiren.

Die eigenthümlichen Gehörorgane, die speciell bei den stimmbegabten Orthopterengattungen vorkommen (die Stimme wird als Lockmittel zwischen beiden Geschlechtern benutzt), sind von jenen bei den Insekten allgemein vorkommenden chordotonalen Gehörorganen abzu-

B.

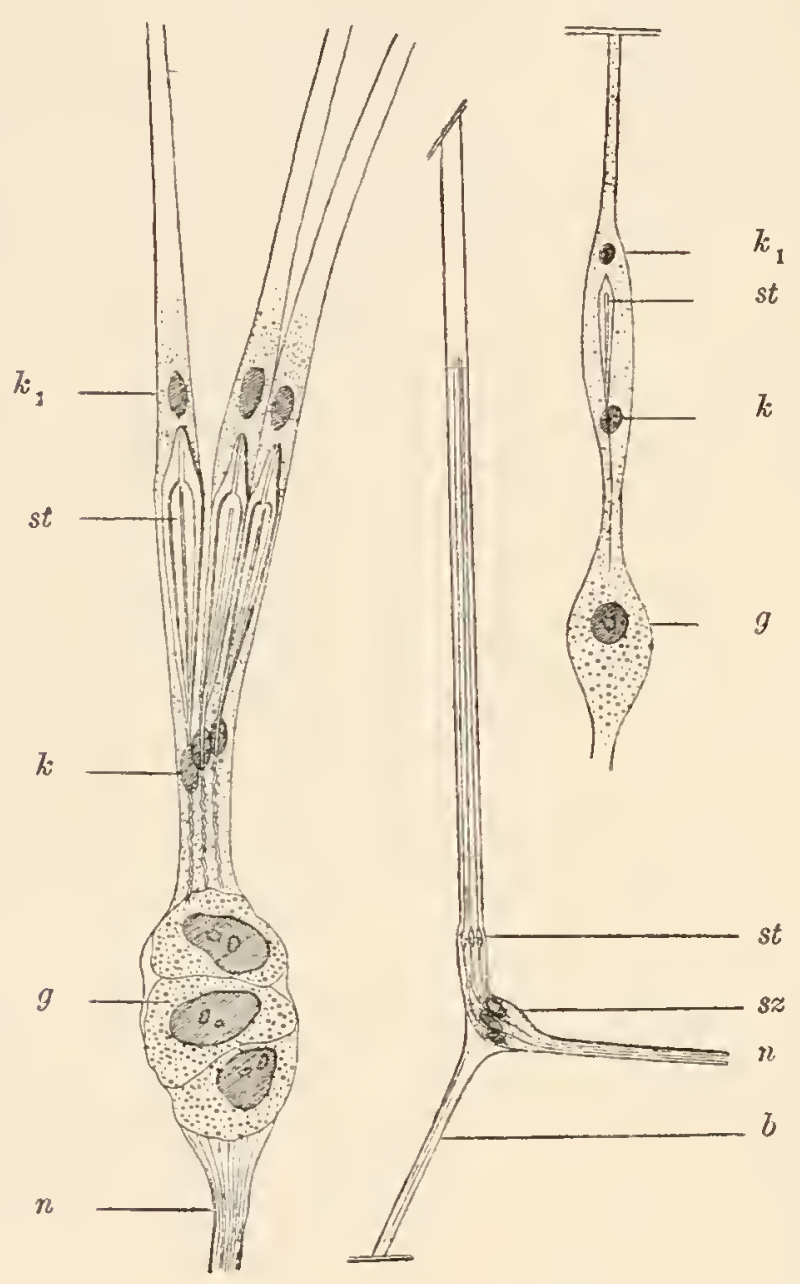

A.
C.

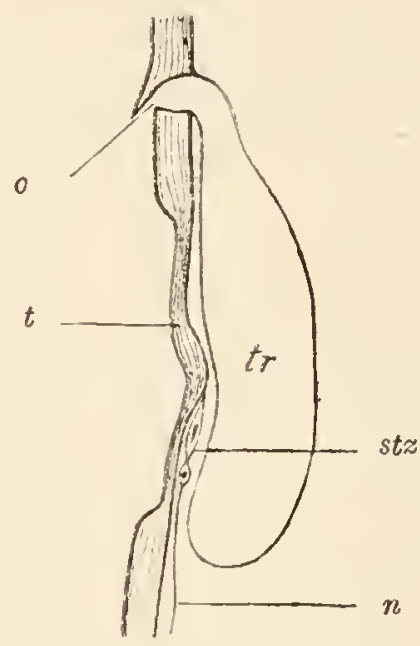

Fig. 189.

Fig. 188 .

Fig. 188. A. Ein (dreifaches) Chordotonalorgan aus der Larve von Corethra. sz Sinneszellen mit st ihren Stiften; $b$ Bändchen, durch welche die Sinneszellen gespannt werden, $n$ Nerv.

B. Ein dreifaches chordotonales Organ aus der Larve von Tabanus. $k$, $k_{1}$ Kerne der Sinneszellen, st Stiftchen, $g$ Ganglienzellen.

C. Nervenendorgan aus dem tympanalen Gehörorgan eines Acridiers. $k, k_{1}$ Kerne der Sinneszelle, st Stiftchen, $g$ Ganglienzellen.

Alle Figuren nach V. Graber.

Fig. 189. Schematische Darstellung des tympanalen Gehörorganes der Ortoptheren, im Durchschnitte gesehen. $t$ der dünne, als Trommelfell fungirende Theil der Chitindecke, tr die unterhalb des Trommelfelles liegende Tracheenblase, o äussere Oeffnung der Trachea. stz Nervenendapparat (Stiftchenzelle), $n$ Nerv. Nach V. Graber.

leiten, sie sind aber bedeutend vervollkommnet durch Ausbildung von schallverstärkenden Apparaten. Es ist nämlich die Chitindecke des Integumentes an einer Körperstelle verdüunt und ringsherum wieder in Form eines Ringes verdickt; indem dicht unter dieser verdünnten Chitin- 
membran eine Tracheenblase (blasenförmige Erweiterung des Tracheensystems) sich ausdehnt, stellt dieselbe eine über einem lufterfüllten Raume ausgespannte Membran dar, die durch Schallwellen in Schwingungen versetzt werden kann, d. i. ein Trommelfell ('T y m pa $n \mathrm{u} \mathrm{m}$, daher auch

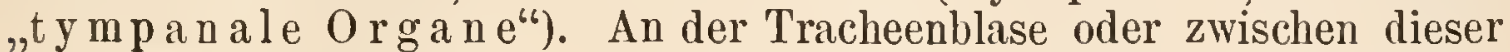
und dem Tympanum liegen die reihenweise der Grösse nach angeordneten Stiftchenzellen. Die Lage dieser tympanalen Organe ist hei den Acridiern am Thorax dicht über dem dritten Fusspaar, bei den Locustiden und Gryllodeen an den Schienen der Vorderbeine. - Andersartig differenzirte Gehörorgane (ohne Tympanum) finden sich an der Wurzel der Hinterflügel bei Käfern und der Schwingkolben bei Dipteren.

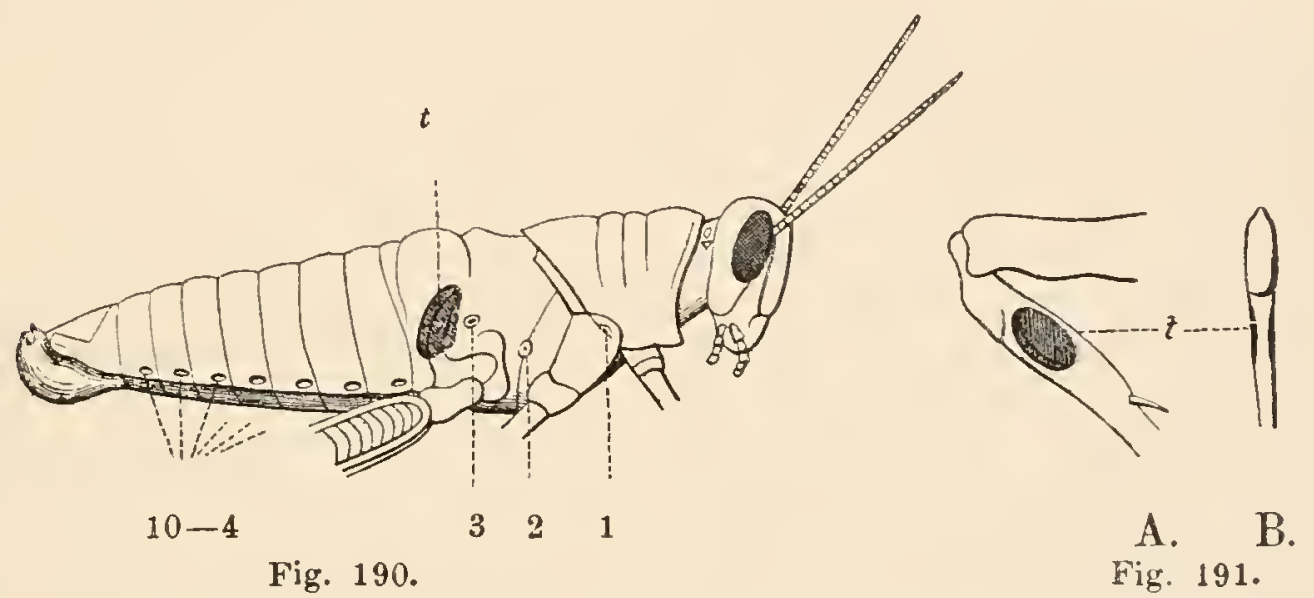

Fig. 190. Seitenansicht von Acridium, die Flügel sind entfernt. $1-10$ die Stigmenöffnungen, $t$ Trommelfell des tympanalen Organes. (Nach Fischer).

Fig. 191. Ein Stück des rechten Vorderfusses von einer Locustide, Meconema varium, mit den beiden Trommelfellen $(t)$. (Nach Fischer.)

Bei $\mathbf{A}$ ist die Tibia von der Seite, bei $\mathbf{B}$ von vorue gesehen.

Bläschenförmige Gehörorgane von besonderer Einrichtung sind bei Insecten nur in vereinzelten Fällen (im Hinterleib von Dipterenlarven, im Antennenglied von Dipteren) beobachtet.

Das Gehörorgan der Wirbelthiere ist seiner Grundform nach auf den Typus des vom Ectoderm abgeschnürten Gehörbläschens zurückzuführen. Bei der Entwicklung durchläuft dasselbe den einfachen bläschenförmigen Zustand; ja es ist sogar in diesem Stadium in manchen Fällen schon mit einem inneren Otolithen verselıen und zweifellos auch functionsfähìg (Knochenfischembryonen). Dieses Bläschen erfährt bedeutende Complicationen, indem es zum häutigen Labyrinth auswächst, welches in den einzelnen Wirbelthierclassen wieder besondere Eigenthümlichkeiten zeigt. Es kommen auch verschiedene Hilfseinrichtungen, als schalleitende und schallverstärkende Apparate hinzu (äusserer Gehörgang, 'Trommelfell, Gehörknöchelchen) und zwar speciell bei den Landthieren, bei welchen die Schallwellen dem Organe nicht mehr durch das Wasser, sondern durch die Luft zugeleitet werden. Die bedeutende physiologische Vervollkommnung, das Unterscheiden von Tönen, beruht darauf, dass verschieden hohe Töne durch Hilfsapparate (Fasern der Membrana basilaris) auf verschiedene Hörzellen als Reize übertragen werden. In Bezug auf diese Verhältnisse des Gehörorganes der Wirbelthiere wollen wir uns hier nur mit einem Hinweise begniigen, da wir an anderer Stelle noch ausführlicher hierauf zurückkommen. 
Es wurde besonders von E. MACH auf Grund zahlreicher Experimente die Theorie aufgestellt, dass ein Theil des Gehörlabyrinthes der Wirbelthiere, nämlich die Bogengänge, zur Orientirung des Körpers in Bezug auf die Schwerkraftrichtung und zur Empfindung der Bewegungen des Körpers dienen. Die Discussion hierüber ist noch nicht endgiltig abgeschlossen. Es wird aber in jüngster Zeit auch für die Gehörorgane der Wirbellosen in vielen Fällen die Frage gestellt, inwiefern dieselben ausschliesslich als Gehörorgane oder aber als Organe der Körperorientirung fungiren.

\section{A u gen.}

I. Physiologische Uebersicht.

Wir finden bei den Metazoen Augen von sehr verschiedenartiger Ausbildung, vom einfachsten bis zum complicirtesten Bau und dementsprechend von sehr verschiedener Leistung.

Wir sehen, dass die einfachste Lichtempfindung auch ohwe Augen zu Stande kommt; Thiere, welche keine Augen besitzen, können ganz wohl Hell und Dunkel unterscheiden. Wenn wir z. B. solche Thiere (augenlose Turbellarien, augenlose Larvenformen aus den verschiedenstell Classen und auch Protozoen) in unseren Versuchsaquarien beobachten, so sehen wir, dass minche Arten sich an der Lichtseite ansammeln, andere wieder diese Seite fliehen. Auch gibt es Thiere, die ihrer Augen beraubt mittelst ihres Hautsinnes noch Hell und Dunkel unterscheiden können (nacli Graber). - Wir werden daher vermuthen, dass die einfachsten Augen schon melır leisten können, als Hell und Dunkel wahrzunehmen; und in der Tlıat lässt sich dies auch aus ihrem Bau erschliessen.

\section{A. Richtungsagen (Euthyskopische Augen).}

Die einfachsten Augen bestehen aus einer geringen Anzahl von Sinneszellen (ja sogar aus einer einzigen), die von einer dunkeln undurchsichtigen Pigmentmasse becherförmig all der einen Seite eingehüllt werden, so dass das Licht nur von der anderen Seite her in einer Richtung, welche wir als $\mathrm{S}$ e h a c h s e bezeichnen wollen, in die Sinneszellen eindringen kann. Vermittelst dieser Augen kann das Thier daher auch die Richtung unterscheiden, aus welcher die Lichtwirkung kommt. Wir wollen solche Augen als Richtungsangen (eutliyskopische Augen) bezeichnen.

Das Pigment kann besonderen Zellen angehören, welche rings um die Sinneszellen angeordnet sind, oder es ist in den Sinneszellen selbst gelagert, doch in letzterem Falle wohl derartig, dass die Sehachse der Zellen
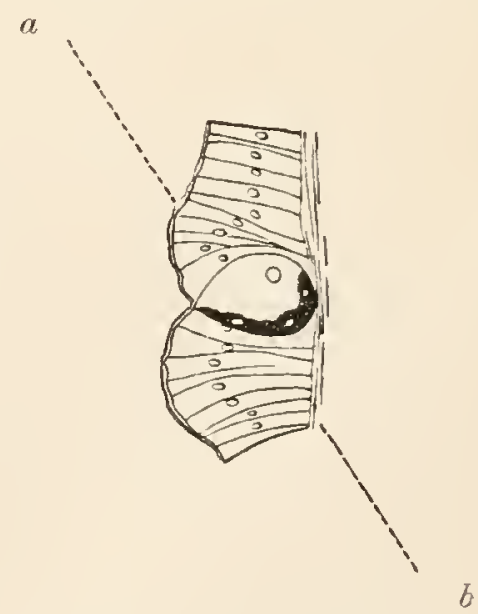
in vorderen Theile frei bleibt ${ }^{1}$ ).

Fig. 192. Querschnitt des Epithels mit eingelagerter Augendifferenzirung, vom Kopfe der Nais proboscidea (nach Carriḱre). $a b$ deutet die Richtung der optischen Achse an. Es ist fraglich, ob die grosse helle Zelle oder die pigmentirten kleinen Zellen die Sinneszellen sind.

1) Schon aus den Erörterungen JoHANnes MüLLER's zu Anfang unseres Jahrhunderts geht hervor, dass die Pigmentmassen, welche Licht absorbiren, nicht etwa zur Verstärkung 
Bei den Cnidariern finden wir kleine pigmentirte Bezirke von Sinnesepithelien, an welchen die in Mehrzahl vorhandenen Sinneszellen jede von pigmenterfüllten Stützzellen umgeben ist. Diese als Pigmentflecke oder Ocellen bezeichneten Gebilde fungiren im einfachsten Falle als Richtungsaugen; wir werden aber später sehen, dass sie durch ganz geringe Veränderungen allmählich zu bildsehenden Augen hinführeıl.

Bei den Scoleciden (Rotatorien, Turbellarien) sind meist kleine Gruppen von Sinneszellen oder auch eine einzige von einem Pigmentbecher umhüllt. Oft ist bei diesen Augen ein lichtbrechender A p p a r a t, eine Linse vorhanden, die aber hier in Verbindung mit einem so einfachen Apparat von Sinneszellen nicht zur Wahrnehmung eines Bildes, sondern nur zur Verstärkung der Lichtwirkung dient. In dem Aufbau dieser Augen gibt es übrigens mannigfache Unterschiede. Auch ihre Lagerung ist verschieden, entweder epithelial oder subepithelial, oft auch dem Nervencentrum angelagert; in letzteren Fällen ist das deckende Integument durchsichtig.

Um uns die Wirkungsweise der Richtungsaugen vorzustellen, wollen wir den Fall annehmen, dass wir in dunkler Nacht einem einzigen hell strahlenden Lichte nachgehen sollten; wenn wir dasselbe bereits ins Auge gefasst hätten, so würde uns ein einfaches Richtungsauge annähernd ebenso guten Dienst leisten, als unser hoch entwickeltes Auge. Es würde uns aber bedeutend weniger leisten, wenn der Lichtpunkt erst aufzusuchen wäre. Je kleiner die Oeffnung in der Pigmenthülle des Richtungsauges wäre, um so schärfer könnte es die Richtung sehen, um so weniger wäre es aber zum Suchen geeignet. Die Richtungsaugen besitzen in der Regel eine relativ grosse Oeffnung; was ihnen also an Genauigkeit abgeht, kommt ihnen an Fähigkeit des Suchens zu Gute.

Bei Thieren, deren Vorderende solche Augen trägt, macht dieser Körpertheil tastende Bewegungen, die auch zum Sehen in Beziehung stehen können; es kommt auch vor, dass die Augen selbst in zitternde Bewegung gesetzt werden (beides ist auch bei physiologisch höher stehenden Augen zu beobachten, z. B. die sehr auffallende zitternde Bewegung bei dem Auge der Daphnien, und hat dort ähnliche Bedeutung). Diese Berregungen haben auf das Sehen zweifachen Einfluss: 1) Wir wissen, dass ein dauernder Eindruck von den Sinneszellen im allgemeinen viel weniger empfunden wird als eine Contrastwirkung; wenn wir z. B. eine kleine Erhabenheit eines Körpers tasten wollen, so werden wir unsere Fingerspitze an demselben hin und her bewegen; auf einem ähnlichen Grund beruhen jene Augenbewegungen. (Auf Contrastwirkung ist es auch zurückzuführen, dass auch bildsehende Augen, besonders von physiologisch niedriger Stufe, einen bewegten Körper viel leichter wahrnehmen als einen ruhenden; die Wahrnehmung eines bewegten Körpers wirkt aber auch psychisch mehr ein, was nicht zu verwechseln ist mit der Leistung des Auges.) 2) Es dienen diese Bewegungen auch dazu, das Sehfeld abzutasten (gleichsam ein Bild in zeitlichem Verlaufe $z u$ sehen).

der Function dienen, sondern zur optischen Isolation. Zum Sehen gehöre; wie er hervorhebt, vor allem die specifische sensible Nervenendigung. Er wendet sich gegen Gruithusen (I s is 1820), welcher annimmt, dass jede dunkle Stelle der Haut einigermassen mit der Natur eines Sehorganes in Beziehung stehe, weil sie mehr Licht absorbirt.

Wenn ferner manche Forscher glauben, dass ein ,Wärmeauge" anders construirt sein könne, als ein Lichtauge, so liegt nur ein physikalisches Missverständniss vor. Wärmeund Lichtstrahlen unterliegen ähnlichen physikalischen Gesetzen. 
Eine bedeutende Vervollkommnung der physiologischen Leistung kann dadurch zu Stande kommen, dass die Richtungsaugen zahlreich vorhanden und so angeordnet sind,

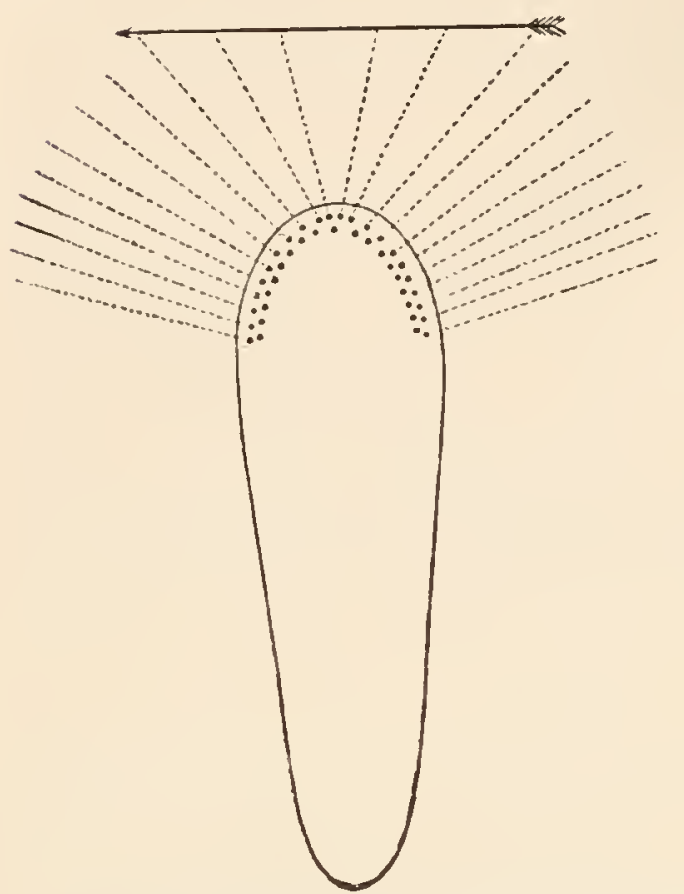
dass ihre Sehachsen divergiren. Wir können sogar sagen, dass so das Sehen eines Bildes zu Stande kommt. Wir müssen uns nur daran erinnern, dass jed es Gesichtsbild aus zahlreichen Sehpunkten sich zusammensetzt und nur um so detaillirter ist, je zahlreichere dieser Punkte auf ein gleiches Gesichtsfeld kommen. - Sehr häufig finden wir die Richtungsaugen in Zweizahl am Vorderende des Körper's (an der Oberfläche oder am Gehirn); oft sind sie dann $\mathrm{zu}$ einem sogenannten $\mathrm{x}$-förmigen Augenfleck verschmolzen.

Fig. 193. Schema, um die Wirkungsweise zahlreicher Richtungsaugen am Vorderkörper z. B. einer Turbellarie zu erklären.

Der Uebergang von Richtungsaugen zu bildsehenden Augen kann durch Vervollkommnung (Vermehrung der Sehzellen u.s.w.) eines einzigen Richtungsauges geschehen oder durch Aggregirung zahlreicher Richtungsaugen zu einem bildsehenden Auge. Es gibt mannigfache Augen, die als Uebergangsformen in diesem Sinne zu deuten sind.

B) Bildaugen (Eidoskopische Augen).

Zur Wahrnehmung eines Bildes ist eine grössere Zahl von lichtempfindlichen Elementen - Sinneszellen mit ihren specifischen Endigungen, den Stäbchen oder Zapfen - die mit gesonderten Nervenelementen verbunden sind, nothwendig. Die Sinneszellen setzen ein Sinnesepithel zusammen, das hier als Retin a bezeichnet wird. Je grösser die Anzahl der lichtempfindlichen Elemente der Retina (für ein gleiches Gesichtsfeld) ist, desto detaillirter ist das wahrgenommene Bild. In unserem Auge und dem der Wirbelthiere sind die percipirenden Elemente im Centrum der Retina (an einem kleinen Bezirke, der als M a cula lu te a bezeichnet wird) viel kleiner und daher viel zahlreicher angeordnet. Dementsprechend sehen wir in dem centralen 'Theil unseres Sehfeldes viel genauer als in der Circumferenz. - Wenn wir zwischen verschiedenen 'Thieren vergleichen, so finden wir, dass die Grösse der percipirenden Elemente sehr verschieden ist. Beim Menschen kommen 250000 Stäbchen auf einen Quadratmillimeter der Retina, beim Salamander nur 30000. Viel geringer noch ist die Anzahl der percipirenden Elemente bei den meisten wirbellosen Thieren, z. B. im zusammengesetzten Auge der Arthropoden (auf den entsprechenden Sehwinkel berechnet). Die grösste Zahl ist hier wohl 12 bis 20 Tausend für ein Auge insgesammt.

Auch die Unterscheidung von Farben ist in der Fähigkeit der Sehzellen begründet. Viele Physiologen nehmen verschiedene Arten von Stäbchen entsprechend einer Anzahl von Grundfarben an. 
Wir finden also, dass bein Auge sowie bei jedem anderen Sinnesorgane (z. B. dem Tastorgane) zur Wahrnehmung gesonderter Empfindungen vor allem gesonderte Sinneszellen oder Gruppen von Sinneszellen, verbunden mit gesonderten Nerven nothwendig sind. Wir bezeichnen dies als die nervöse Isolation der percipirenden Elemente. Zur Wahrnehmung eines Bildes ist aber noch ein zweites nothwendig, nämlich die optische Isolation der percipirenden Elemente.

Stellen wir uns vor, dass die Retina ohne Hilfsapparate den verschiedenen von aussen kommenden Lichteindrücken ausgesetzt sei; es würden so zu je einem percipirenden Elemente (Stäbchen) Strahlen von den verschiedensten Punkten der Aussenwelt gelangen, allen Retinaelementen würden dieselben zahlreichen Reize zukommen und es wäre nur eine Gesammtempfindung in Bezug auf Helligkeit und Farbe möglich. Die optische Isolation bestelit nun darin, dass die Lichtstrahlen, die von eineni Punkte der Aussenwelt ausgehen, zu einem bestimmten Elemente der Retina hingeleitet, und dass die von anderen Punkten kommenden Strahlen von diesem Punkte abgehalten werden. - Die optische Isolation kommt auf verschiedenartige Weise zustande; wir unterscheiden darnach verschiedene physiologische Typen der Augen.

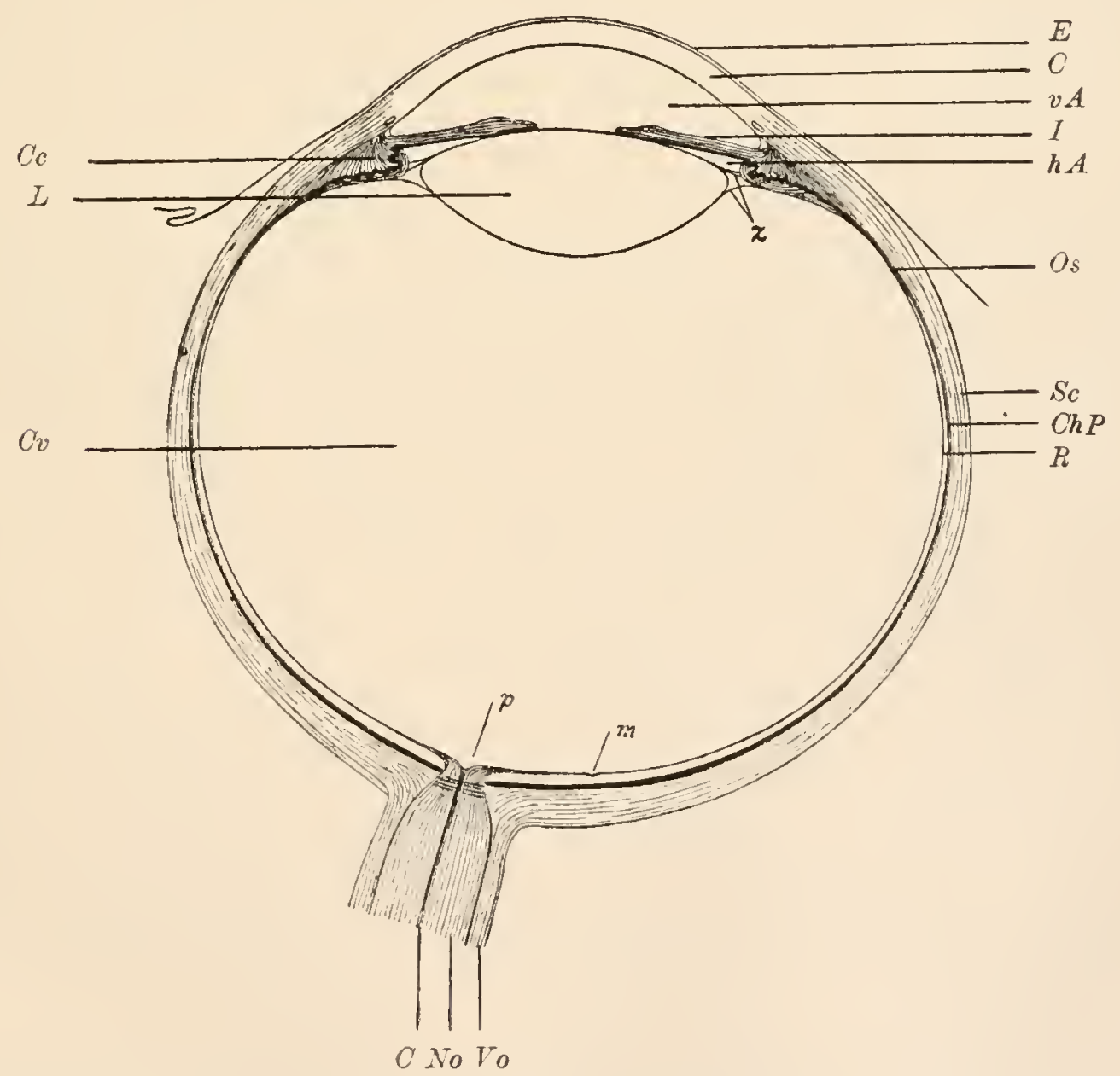

Fig. 194. Horizontaldurchschnitt durch den menschlichen Augapfel (nach ARLT).

$E$ äusseres Epithel der Cornea, $C$ Cornea, $v A$ vordere Augenkammer, $I$ Iris, $h A$ hintere Augenkammer, z Zonula Zinnii, Os Ora serrata, Sc Sklera, ChP Choroidea nebst Pigmenepithel, $P$ Retina, $p$ Papilla nervi optici, $m$ Macula lutea, Vo Bindegewebsscheide des Nervus opticus in die Sklera übergehend, No Nervus opticus, $C$ Arteria centralis nervi optici, Cc Corpus ciliare, $L$ Linse, Cv Corpus vitreum. 
a) Camera-A ugen.

Dies sind die vollkommensten Augen; hier dienen zur optischen Isolation lichtbrechende Apparate (collectiv dioptrische Medien). Zu diesem physiologischen Typus gehört z. B. das Wirbelthierauge (Fig. 194).

Am menschlichen Augapfel unterscheiden wir eine äussere feste Bindegewebsschichte als hate $\mathrm{Haut}$ (Sclera), sie geht nach vorne iiber in die uhrglasförmig gewölbte durchsichtige Hornh a u (Cornea), deren äusserstes Stratum eine ebenso durchsichtige Epithelschichte (modificirte Epidermis) ist. Innen von der Sclera folgt eine zweite Bindegewebsschichte, die blutgefässreich und dunkel pigmentirt ist, es ist dies die Aderhaut ( $\mathrm{Chor}$ ioidea), die wieder nach vorne in eine ringförmig durchbrochene contractile Membran, die Iris, sich fortsetzt. Die Wurzel der Iris bildet ein verdickter muskulöser Ring, der C i liarkörper* (Accomodationsmuskel). Die nächst innere Schichte ist das schwarze Pigmentepithel und dann folgt die glashelle Retina; unweit des Ciliarkörpers an einer als Ora serrat a bezeichneten Linie hört die nervöse Beschaffenheit der Retina auf; sie wird bald ebenfalls zu einer pigmentreichen Schichte ähnlich dem Pigmentepithel; diese beiden erstrecken sich nun als eine Doppelschichte an der hinteren Fläche der Iris bis an den freien Rand derselben. Zwischen Hornhaut und Iris findet sich ein mit Flüssigkeit ( $\mathrm{Humor}$ a queus) erfüllter Lymphraum (vordere A ugenkammer). Hinter der Iris (hintere A u g enkammer) liegt die Linse (welche ontogenetisch ein Derivat des äusseren Epithels ist). Ihre Hülle, die Linsenkapsel (eine structurlose Membran) ist durch radiäre Bindegewebsfasern (Z o nula $\mathrm{Z}$ innii) an den Ciliarkörper befestigt. Hinter der Linse erfüllt den Hohlraum des Augapfels eine schwächer lichtbrechende, durchsichtige Bindegewebssubstanz, der Glaskörper (Corpus vitreum). Der Sehnerv, der etwas einwärts von der Sehachse in den Augapfel eintritt, durchbohrt die R e tin a (MARIOTT'scher blinder Fleck) und setzt sich in deren Nervenschichte fort, die bekanntlich das rordere Stratum der Retina bildet (vergl. pag. 139), auf welche die zwei Ganglienschichten und die Sehzellen und endlich die Stäbchen folgen, welche letztere nach hinten gegen das Pigmentepithel gewendet sind.

Beim Sehen mittelst collectiver Medien wird der Lichtkegel, der von je einem Punkte der Aussenwelt auf das Auge fällt, auf je einem Punkte der Retina gesammelt (Fig. 195).

Da bei diesen Augen, ähnlich wie bei einer photographischen Camera ein objectives Bild, und zwar ein umgekehrtes Bild der Aussenwelt auf der Retina zustande kommt, so werden sie als Camera-Augen bezeichnet ${ }^{1}$ ). Wenn man sich über die Beziehung der Retinapunkte zu den wahrgenommenen Punkten der Aussenwelt kurz ausdrücken will, so pflegt man zu sagen, das auf die Retina projicirte Bild werde empfunden; eigentlich ist das Zustandekommen eines objectiven Bildes physiologisch gleichgültig:

Beim Auge des Menschen und der landbewohnenden Wirbelthiere werden die Lichtstrahlen hauptsächlich dreimal gebrochen; erstens beim

1) J. CARrik̀ne hat in seinem treftichen Buche ,Die Sehorgane der Thiere" für diese Augen die Bezeichnung "Camera obscura-Augen"6 eingefiihrt, wir wollen sie abgekürzt Camera-Augen nennen. Doch ist unser Begriff, wie aus der folgenden Darstellung ersichtlich wird, ein enger gefasster. 
Eintritt aus der Luft in die convexe Oberfläche der Cornea, zweitens beim Uebergang aus dem dünneren $\mathrm{Humol}^{\circ}$ aqueus in die dichtere Linsensubstanz, d. i. an der vorderen convexen Fläche der Linse, und

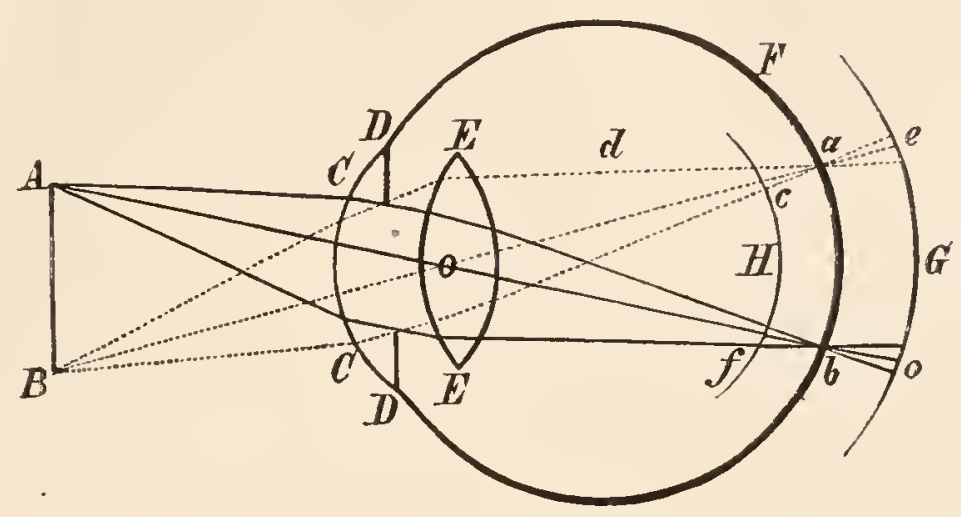

Fif. 195. Optisches Schema des menschlichen Auges. Die Strahlen der Lichtkegel von $A$ und $B$ werden bei $a$ und $b$ wieder zu Punkten vereinigt. Wenn an dieser Stelle die Retina $F^{\prime}$ sich befindet, so werden $A$ und $B$ bei $a$ und $b$ als vollkommen entsprechende Punkte empfunden. Befände sich aber die Retina nicht in $a$ und $b$, sondern vor und hinter dieser Stelle, z. B. in $H$ oder $G$, so würden statt lichter Punkte vielmehr lichte Zerstreuungskreise, für $H$ die Zerstreuungskreise $c$ und $f$, für $G$ die Zerstreungskreise $e$ und $o$ gesehen werden, denn in $H$ sind die Lichtkegel noch nicht zu einem Punkte vereinigt und in $G$ sind sie es ebensowenig, da sie nach ihrer Vereinigung in $a$ und $b$ wieder divergiren (nach JoHANNES MüLLER).

drittens, beim Uebergang aus der dichteren Linsensubstanz in das dünnere Medium des Glaskörper's, d. i. an der hinteren convexen Fläche der Linse. - Bei den Wasserthieren werden die Strahlen beim Uebergang aus dem Wasser in die Cornea sehr wenig abgelenkt, es fällt die Hauptleistung der Linse $\mathrm{zu}$, die bei diesen Thieren daher eine viel stärkere Convexität besitzt.

Man kann berechnen, durch welchen Punkt der lichtbrechenden Medien die Achsenstrahlen aller Lichtkegel (beiläufig) ungebrochen durchgehen. Wir nemnen diesen Punkt den K n o te n punkt oder Kreuzungspunkt der Achsenstrahlen. Wir können uns darnach zur Construction des Retinabildes eines vereinfachten Schemas bedienen, in welchem nur die Achsenstrahlen berücksichtigt sind. Den Winkel, welchen die Achsenstrahlen zweier Objectpunkte einschliessen, bezeichnen wir als Sehwinkel. Alles, was unter denselben Sehwinkel fällt, hat auch ein gleich grosses Netzhautbild $a b$.

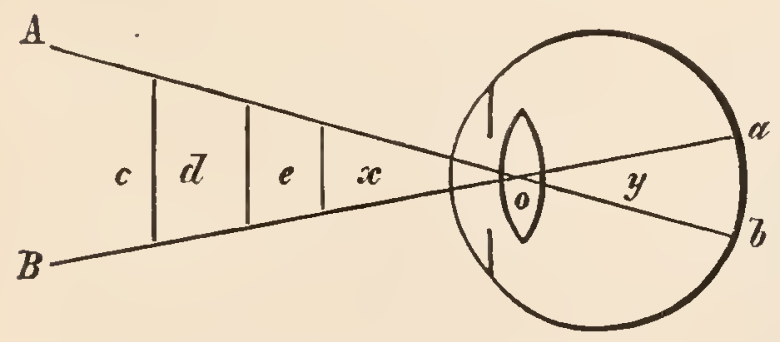
Die Gegenstände $c, d, e$ u. s. w., welche sehr verschieden an Grösse in verschiedener Entfernung liegen, haben denselben Sehwinkel und erscheinen relativ gleich gross. Wenn wir das gleiche $\mathrm{Ob}-$ ject uns näler bringen, erscheint es unter grösserem Sehwinkel, sein Bild wird auf eine grössere

Fig. 196. Schema zur Construction des Sehwinkels. Man kann diese vereinfachte Figur der vorhergehenden Figur substituiren (nach JoHaNNES MÜLLER). Anzahl von Netzhautpunkten projicirt und wir nehmen daher auch mehr Details an demselben wahr. 
Das Pigment, welches sowohl hinter der durchsichtigen Retina sich ausbreitet, als auch die innere Fläche des Ciliarkörpers und der Iris bedeckt, verliindert es, dass Licht von anderer Seite als von der Richtung des Sehens die Retina trifft; auch absorbirt es von der Retina etwa reflectirte Lichtstrahlen und bewirkt also, dass dieselben nicht zum zweiten Male zur Netzhaut gelangen und das Bild stören (Aelnnliches leistet bei unseren optischen Instrumenten die Schwärzung der Innenflïchen).

Thiere, die in der Dämmerung jagen (auch Wirbellose, z. B. Spinnen, sowie auch Pecten, Fig. 219) besitzen statt der Pigmentschichte hinter der Retina eine reflectirende Schichte (oft aus kleinen irisirenden Plättchen bestehend), die als T a petum bezeichnet wird. Das reflectirte Licht durcheilt dieselben Stäbchen zum zweitenmale und dadurch wird der Reiz wahrscheinlich verstärkt. (Bei hellem 'Tageslicht fungiren diese Augen aber schlechter). Indem wir das Licht sehen, welches aus diesen Augen durch die Pupille zurückkommt, scheinen uns diese Augen zu leuchten.

Zum deutlichen Sehen ist es erforderlich, dass sich die Retina in richtiger Entfernung von der Linse genau in Vereinigungspunkte der Lichtstrahlen befindet; wäre sie näher oder entfernter, so würden statt lichter Punkte lichte Zerstreuungskreise auf die Retina projicirt werden.

Nach optischen Gesetzen wird der Strahlenkegel, der von einem in ibestimmter Entfernung befindlichen Lichtpunkte auf eine Sammellinse ällt, in bestimmter Entfernung hinter der Linse in einem Sammelpunkte vereinigt. Wenn wir den Lichtpunkt nähern, so wird die Entfernung des Sammelpunktes grösser. Daraus geht hervor, dass für das deutliche Sehen in verschiedenen Entfernungen Veränderungen des Auges nöthig sind, die wir als A c commodation bezeichnen. Das normale menschliche Auge ist im Ruhezustand für grosse Entfernung eingestellt; die Grenze, bis zu welcher das Auge für die Nähe accommodirt werden kann, ist beim Normalauge 5 Zoll. Wir können nicht in dem Grade accommodiren, dass wir unser Auge auch im Wasser gebrauchen könnten. Ebensowenig können Wasserthiere so weit accommodiren, um in der Luft deutlich zu sehen.

Das Mittel der Accommodation ist eine For mveränderung der Linse durch Thätigkeit des Ciliarmuskels.

Für die vergleichende Physiologie ist es von Interesse zu erörtern, welche Mittel zum Zwecke der Accommodation überhaupt möglich wären. Erstens kann die Accommodation zu Stande kommen durch Veränderungen der Entfernung zwischen Linse und Netzhaut und zwar könnte entweder die Linse ihre Lage verändern oder auch die Retina (z. B. durch Formveränderungen des Augapfels) und zweitens kann sie zu Stande kommen durch Formveränderung der Linse (oder auch der Hornhaut). - Bei den Wirbelthieren im Allgemeinen spielt Formveränderung der Linse die Hauptrolle. Bei den Fischen fehlt der Ciliarkörper und hier wird durch eine andere Einrichtung (Campanula Halleri) die Accommodation besorgt, wobei wahrscheinlich auch eine Lageveränderung der Linse ins Spiel kommt.

Das Sehen eines einfachen Bildes mit beiden Augen und die daraus entspringenden Vortheile (stereoskopisches Sehen, Schätzen der Entfernungen) sind besonders beim Menschen und vielen Säugethieren ausgebildet; mit dem binoculären Sehen sind Eigenthümlichkeiten der Augenbewegung nothwendig verbunden. Schon bei vielen niedrigen Wirbelthieren sind die 
beiden Gesichtsfelder vollkommen getrennt und bei Wirbellosen kommt wohi nirgends binoculäros Sehen zu Stande (es ist schon Mangels der coordinirten. Augenbewegungen nicht möglich).

Bei vielen wirbellosen Thieren finden wir Augen, die nach demselben optischen Princip gebaut sind wie diejenigen der Wirbelthiere;

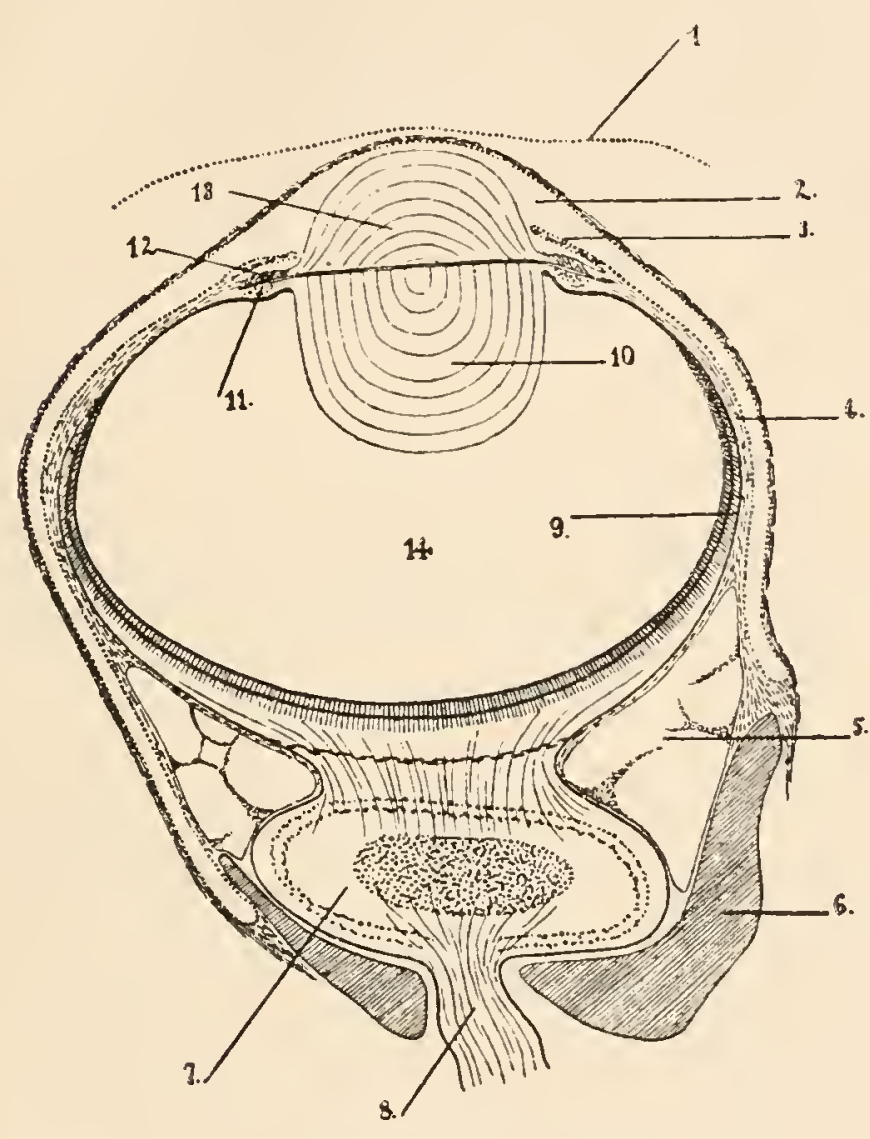

Fig. 197.

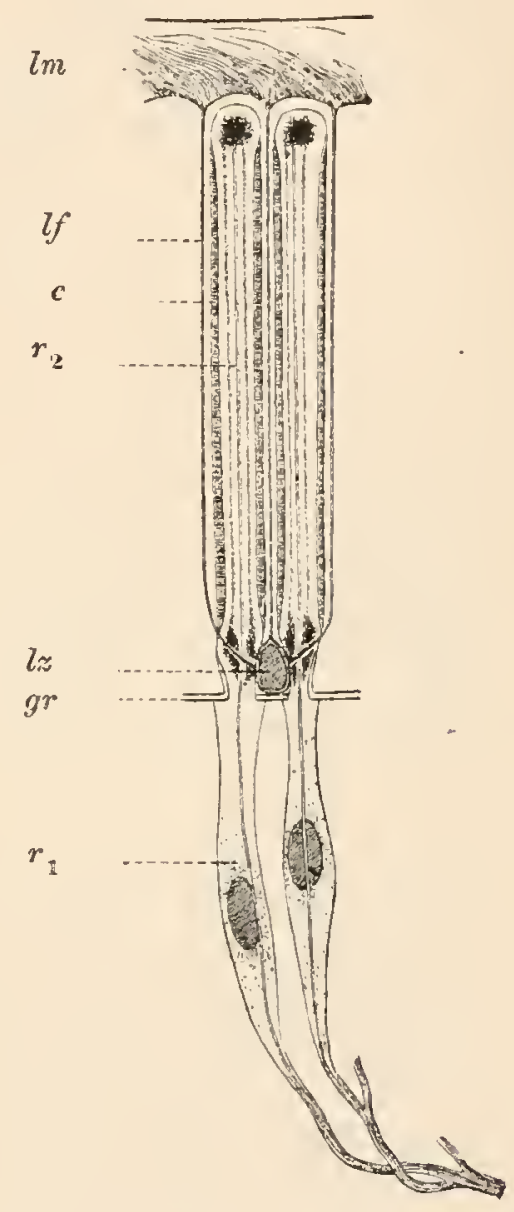

$n$

Fig. 198.

Fig. 197. Ange von Sepia im Horizontaldurchschnitt (aus mehreren Zeichnungen Hensen's combinirt). 1. äusseres Epithel der Cornea, 2. vordere Augenkammer, die von Epithel ausgekleidet ist und nach rückwärts am Bulbus weit herabreicht, 3. Iris (mit Bindegewebe, Knorpel- und Muskelfasern), 4. Sklera aus Bindegewebe, Knorpel und Muskel aufgebaut), 5. weisse Körper (von unbekannter Bedeutung), zu beiden Seiten des Augenganglions, 6. Kopfknorpel, 7. Augenganglion, der Nerv, der von demselbel zur Retina führt und an deren hinterer (d. i. äusserer) Fläche sich ausbreitet, ist von einer Fortsetzung der Argentea interna quer durchsetzt, 8. Nervus opticus, 9. Retina, 10. hintere Linsenhälfte, 11. dazu gehöriges inneres Corpus epitheliale, 12. äusseres Corpus epitheliale. 13. äussere Linsenhälfte, 14. Corpus vitreum.

Fig. 198. Schema des Aufbaues der Retina der Cephalopoden (nach Grenacher). gr Grenzmembran, $r_{1}$ hintere Hälfte der Retinazellen mit dem Zellkern und einer axialen Nervenfibrille, mit welcher $n$, der Nerv, in Verbindung tritt, $r$ vorderer Theil der Retinazellen, welchen die Nervenfibrille bis an das vordere Ende durchzielit, dieselbe ist mit Pigmentkörnchen umgeben, die besonders vorne und hinten sich häufen, $c$ cuticulare stäbchenförmige Gebilde, welche diesem Vordertheil der Retinazellen seitlich anliegen; die einander benachbarten verschmelzen mit einander, so dass ein wabenartiges Fachwerk entsteht, in welches die Vordertheile des Retinazellen hineinragen*), $l_{*}$ Limitanszellen, dieselben scheiden $l f$, die Limitansfasern, aus, welche in $l m$ die Limitansmembran übergehen.

*) Grenacher hält die zu einem Wabenwerk verschmelzenden stäbchenförmigen Gebilde für die percipirenden Retinastäbchen; doch liesse sich wohl die Meinung verthei- 
A.

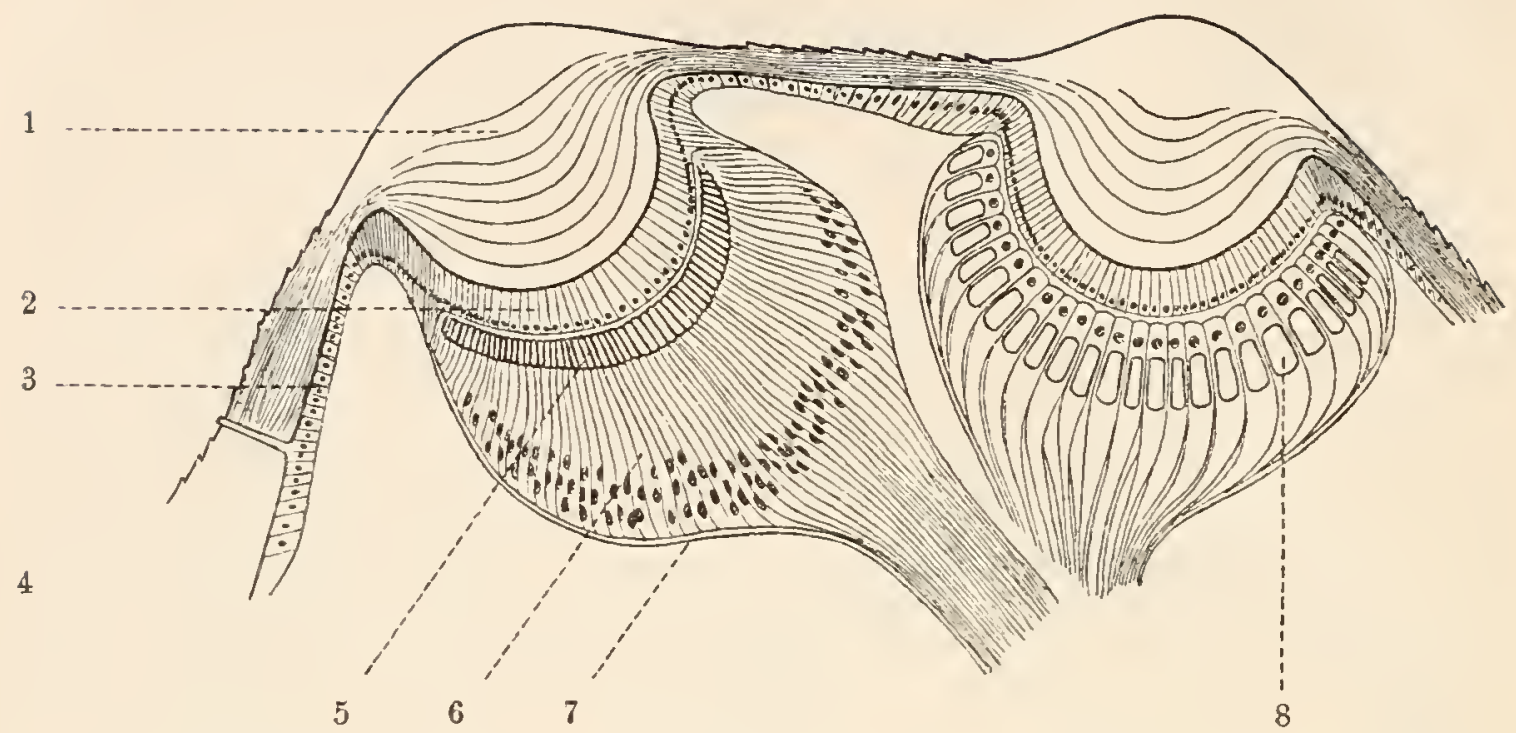

Fig. 199.
B.

Fig. 199. Durchschnitt durch A. ein vorderes und B. ein hinteres Auge der Kreuzspinne, Epcira Diadema (nach GeNacher aus CARriEre). 1 Cuticularlinse, 2 Glaskörperzellen, 3 Hypodermis, 4 Cuticula, 5 Stäbchen, 6 Retinazellen, 7 Basalmembran, die Augenkapsel bildend, 8 stäbchenartige Gebilde des hinteren Auges, welche im Innern der Retinazellen, hinter den Zellkernen liegen.

ja sie erreichen sogar bei den Cephalopoden eine ähnliche Vollkommenheit. Wir finden bei diesen eine ähnliche physiologische Einrichtung des Auges mit Linse, Glaskörper, Iris, Ciliarkörper; morphologisch ist der Aufbau aber ganz anders zu Stande gekommen, der Gegensatz ist schon darin ausgesprochen, dass die Stäbchen der Retina nach vorne (gegen die Pupille) gewendet sind.

Andere Camera-Augen sind einfacher gebaut; es fehlt die Accommodationseinrichtung (vielleicht ist sie in manchen Fällen nur unbekannt geblieben). Solche Augen sind wahrscheinlich nur zum Sehen in einer bestimmteren Entfernung befähigt. So sind die Camera-Augen bei Spinnen und Insecten (bei diesen meist neben den sogenannten zusammengesetzten Augen vorkommend) in der Regel für das Nahesehen bestimmt ${ }^{1}$ ).

Als zweiter physiologischer Typus der bildsehenden Augen sind die sogenannten musivischen Augen zu betrachten. Die optische Isolation der percipirenden Elemente ist hier durch zwei Momente bedingt, indem erstens jedes percipirende Element von einer Pigmentröhre eingehüllt ist und indem zweitens dieselben in verschiedener Richtung angeordnet sind, so dass ihre Achsen divergiren. Zwei verschiedene Arten

digen, dass dies nur Stützapparate seien, während als echte Stäbchen die Vorderhälften der Retinazellelı zu betrachten wären; in der vorderen Pigmentanhäufung müsste in diesem Falle eine axiale Lücke vorhanden sein. - Wir müssen überlıaupt bei der Frage, was als ,Stäbchen"6 zu betrachten sei, in erster Linie den physologischen Gesichtspunkt berücksichtigen; und es scheint fast, als hätte GrENACHER in seinen ausgezeichneten Untersuchungen über die Retina der Cephalopoden und auch der Heteropoden diese Frage zu viel vom morphologischen Standpunkte beurtheilt.

1) Wir schliessen dies mit grosscr Wahrscheinlichkeit aus biologischen Beobachtungen; von einer genauen physikaliscl-optischen Analyse dieser Augen sind wir noch weit entfernt; an und für sich wäre in den verschiedenen Fällen ein mannigfaches Verhalten möglich. 
von musivisch sehenden Augen sind denkbar und beide kommen auch in der Natur vor und zwar 1) convexe und 2) concave musivische Augen.

\section{b) Convexemusivische Augen (Fächeraugen).}

Dieser Typus tritt uns in den sogenannten zusammengesetzten Augen bei Crustaceen und Insecten entgegen. Die percipirenden Elemente der Retina sind hier nicht durch einzelne Zellen repräsentirt, sondern durch Zellgruppen, die als $R$ e tinula e bezeichnet werden; im Centrum der Retinula findet sich ein stäbchenförmiges Gebilde, das $\mathrm{Rh}$ abdom, welches der Anzahl der Zellen entsprechend aus $\mathrm{Rh}$ abdom eren zusammengesetzt ist; zu jeder Retimula gehören bestimmt gruppirte Pigmentzellen, welche den Pigmentmantel derselben zusammensetzen. Die Retinula nimmt nur den hinteren Theil der Pigmentröhre ein; der vordere Theil ist von dem sogenannten $\mathrm{Krystall} \mathrm{kegel} \mathrm{ausgefüllt.} \mathrm{Die}$ äussere, durchsichtige, cuticulare Chitindecke des Auges, die als Co r n e a bezeichnet wird, zerfällt meist in sehr regelmässige sechseckige Facetten, die in vielen Fällen convex verdickt sind, so dass sie eine Linse (Cornealinse) für jede einzelne Retinula darstellen. Die Wirkungsweise dieser Linse in Verbindung mit dem Krystallkegel ist die, dass nicht nur der Achsenstrahl zur Retinula gelangt, sondern ein etwas grösserer Strahlenkegel auf dieselbe gesammelt wird; es ist durch diese Einrichtung die Lichtstärke des Auges verbessert.

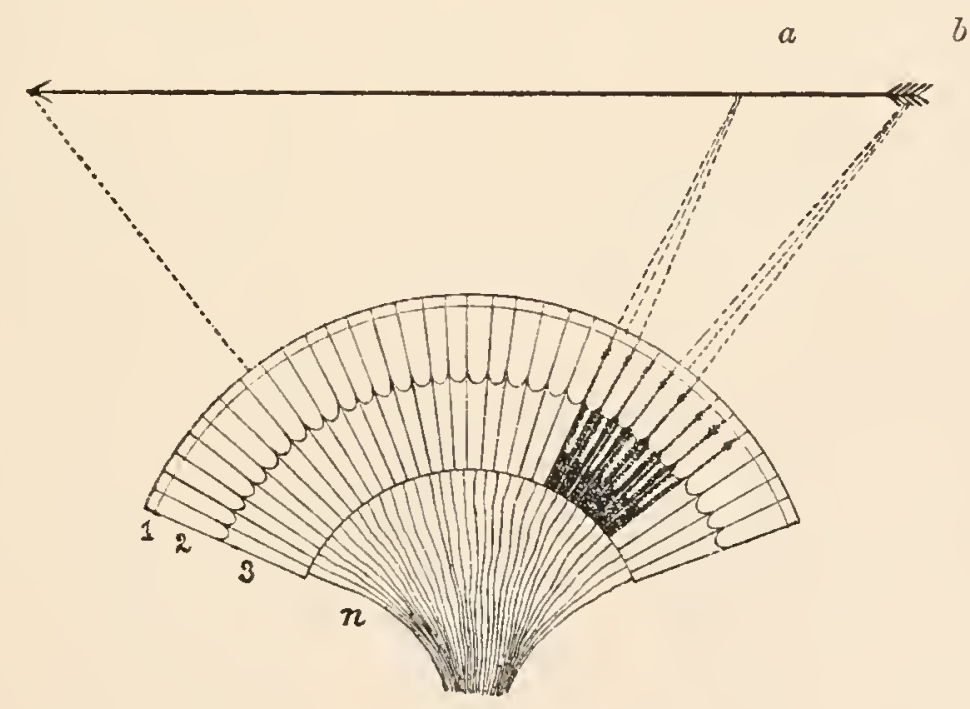

Fig. 200.

Fig. 200. Schema eines convexen musivischen Anges. Die Augenelemente (Ommatidien) bestehen aus 1 dcr Cornea, 2 Krystallkegel 3 Retinula. Auf der rechten Hälfte der Figur ist an einigen Augenelementen auch die Pigmentirung dargestellt.

Fig. 201. Ein Ommatidium vom Flusskrebs (nach Carrik̀re). 1 Cornealinse, 2 Corneazellen, 3 Krystallzellen, 4, 5 äusserer und innerer Theil des Krystallkegels, $p$ Pigmentzellen, $r$ Retinula, $R$ Rhabdom, 6 Basalmembran des Auges, durch welche die Nervenfaser hindurchtritt.

Den Sehwinkel, welcher uns die relative Grösse eines Gegenstandes anzeigt, bestimmen wir, indem wir von den Endpunkten des Objectes die Achsenstrahlen durch die betreffenden Augenkegel wach rückwärts ver-

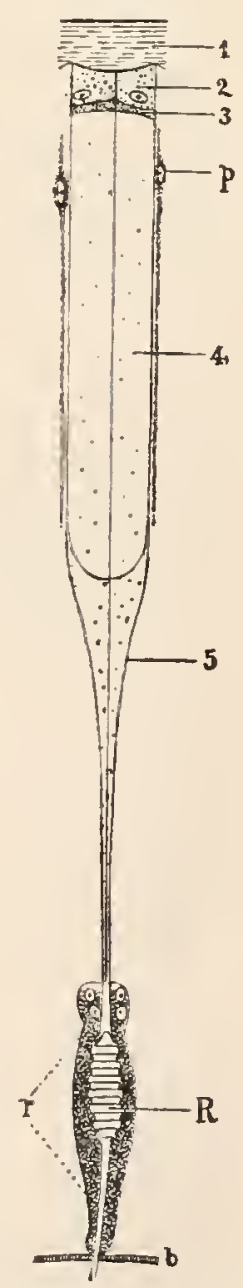

Fig. 201 . 
längern, wo sie in einem imaginären Punkte sich schneiden; der von denselben eingeschlossene Winkel (den wir in Winkelgraden ausdrücken können) ist der Sehwinkel; die Körper, welche unter gleich grossem Sehwinkel erscheinen, haben dieselbe relative Grösse. - Ein entfernterer Gegenstand wird von ebenso vielen Augenkegeln percipirt, als ein viel kleinerer aber näherer Gegenstand; mit der zunehmenden

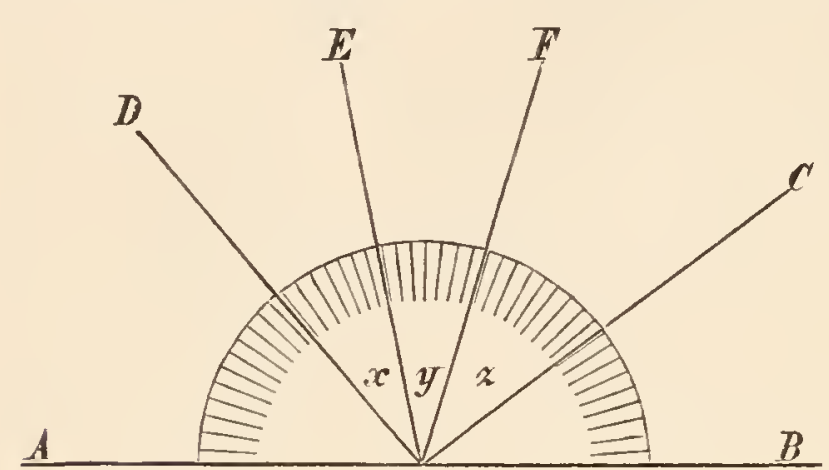

Entfernung eines Gegenstandes werden, wie bei unserem Auge, weniger Details gesehen. Wenn wir die Genauigkeit des musivischen Auges mit derjenigen eines Camera-Auges vergleichen wollen, so müssen wir berücksichtigen, wievielRetinaelemente auf denselben Sehwinkel entfallen.

Fig. 202. Optisches Schema des convexen musivischen Auges (nach JoHANes MÜLLER).

Ein von $D$ bis $E$ sich ausdehnender Körper erscheint unter dem Sehwinkel $x$; alle unter demselben Winkel $x$ gesehenen Körper erscheinen gleich gross.

Die Grösse des Sehfeldes lässt sich genau aus der Form des Auges ableiten; man muss berechnen, einem wie grossen Theile der Kugeloberfläche die Oberfläche des Auges entspricht; ein Auge von halbkugelförmiger Gestalt überblickt die Hälfte des gesammten Raunes; je flacher das Auge ist, um so kleiner - je stärker gekrümmt es ist, um so grösser ist sein Sehfeld. Die Augen beider Körperseiten beherrschen je einen Theil des Sehfeldes, da die Richtung ilırer Retinulae divergirend ist.

Es ist klar, dass dieses Auge keines Accommodationsapparates für Nah und Fern bedarf. Auch kann dieses Auge ebenso gut in der Luft als im Wasser sehen. In Bezug auf Lichtstärke steht dieses Auge weit hinter dem Camera-Auge zurück; während bei diesem von einem Lichtpunkte aus ein grosser Strahlenkegel, del die ganze Cornea trifft, auf ein Retinaelement concentrirt wird, gelangt bei dem musivischen Auge nur ein sehr kleiner Strahlenkegel zu jeder Retinula.

Die Vollkommenheit dieses Auges hängt ab 1) von der absoluten Grösse des Auges, weil mit derselben die Länge der Augenkegel wächst und damit die optische Isolirung vollkommener wird; 2) von der Zahl der Kegel, die auf einen Sehwinkel entfallen; je mehr Kegel (je geringer also die Dicke derselben), desto detaillirter ist das Bild; 3) von der Grösse des Kugelabschnittes oder der Convexität des Auges, da hiedurch die Grösse des Sehfeldes bedingt ist ${ }^{1}$ ).

1) Die von Johañes Müller aufgestellte Theorie des ,musivischen Sehens" wurde eine Zeit lang verlassen, in den letzten Jahren aber wieder vollkommen in ihr Recht eingesetzt (Boll, Grenacher, ExNer). Auch die Erklärung, der nicht geraden, sonderu gekriimmten Krystallkegel, die oft am Rande des Auges vorkommen, wurde von ExNER gegeben; die Strallen werden durch totale Reflexion an den Wänden des Kegels bis zur Retinula geleitet; für die Wahrnehmung eines geordneten Bildes ist daher nicht die bestimmte Stellung der Retinulae unbedingt nöthig, sondern nur die bestimmte Stellung des äusseren Theiles der Krystallkegel. Dagegen scheint die Anschauung ExNER's, ,dass das 
c) Concare musivische Augen.

Solche Augen sind in ihrer einfachsten Form bei Medusen und niedrigen Gastropoden beschrieben worden. Man hielt sie aber nicht für bildsehende Augen, sondern für solche, die nur Hell und Dunkel unterscheiden. Aus ihrem Bau lässt sich aber mit grosser Wahrscheinlichkeit schliessen, dass sie musivisch sehen.

Fig. 203. Schema eines concaven nusivischen Auges.

Die optischen Elemente sind derart mit Pigment ausgestattet, dass Strahlen nur in der Richtung ihrer Achse eindringen können.

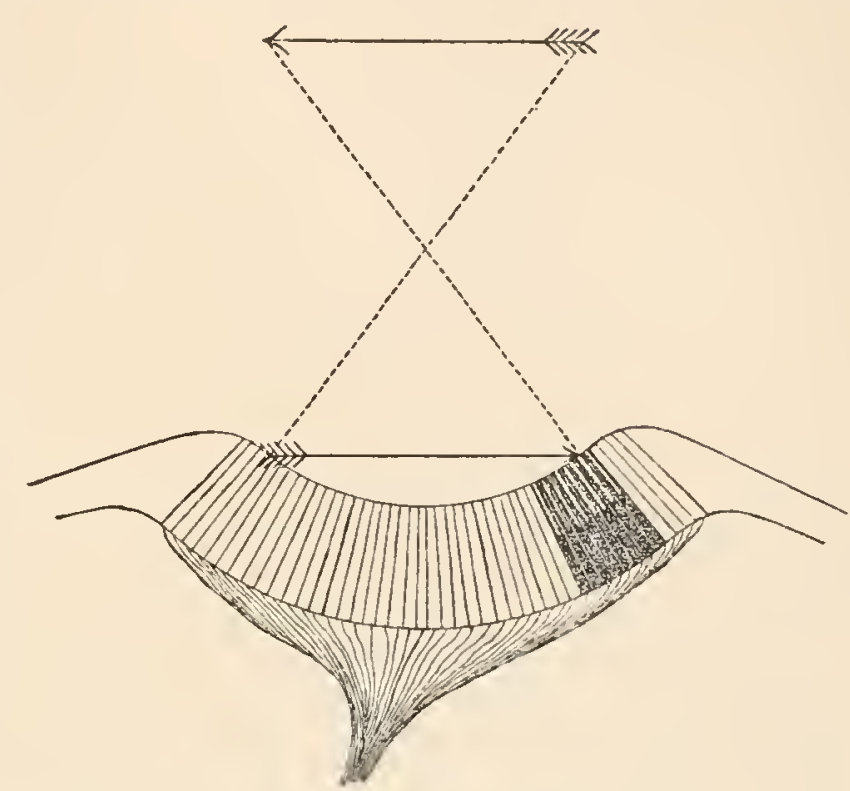

Das Princip des Sehens ist hier im Wesen so übereinstimmend mit dem Vorigen, dass wir nur auf die Unterschiede hinzuweisen brauchen. Die Achseustrahlen, welche von den äusseren Objecten zu den Retinaelementen gehen, kreuzen sich in einem ideellen Punkte, der vor der Retina gelegen ist. Das Sehen verhält sich daher so, als ob ein u mgekehrtes Bild auf die Retinafläche geworfen würde.

Zur vollkommenen Sicherheit dieser Deutung sollte wohl der Bau der Retina noch bestimmter analysirt sein. Bei der Gastropoden-Retina sind dunkel pigmentirte Zellen vorhanden, zwischen welche in regél-

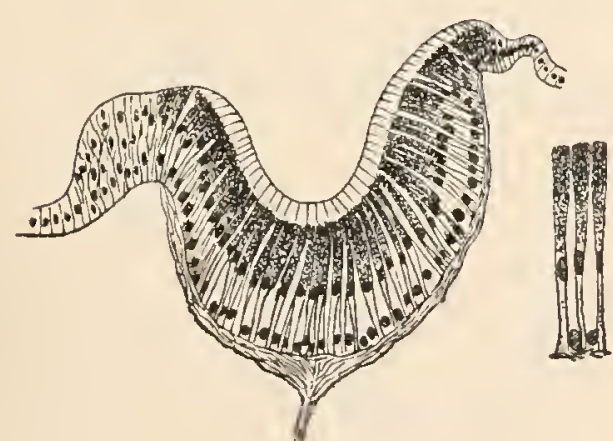

A.

Fig. 204.
A.

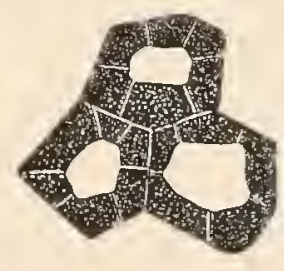

B.

B.

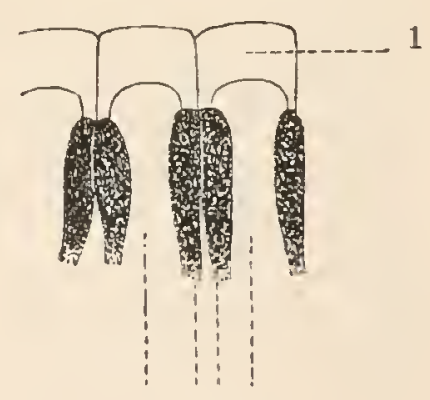

3223

Fig. 205.

Fig. 204. Schnitt durch die Sehgrube von Patella (nach CARrikire, der Nerv ist nach der Darstellung von HILGER hinzugefügt). Die Retina ist aus hellen Zellen und pigmentirten Zellen zusammengesetzt. B, Die zwei Arten von Retinazellen stärker vergrössert.

Fig. 205. A. Flächenschnitt und B. senkrechter Schnitt durch den vorderen Theil einiger Retinazellen (nach HILGER). 1 Helle Säume am vorderen Rand der hellen Retinazellen, 2 pigmentirte, 3 helle Zellen.

Facettenauge im Sehen von Bewegungen dem Wirbelthierauge $\nabla$ or a $\mathrm{s}$ is $t$, ihm aber im Unterscheiden der Gegenstände, also in der Schärfe des Sehens nachsteht" besonders mit Rücksicht anf die Art seiner Darstellung nicht begründet; auch die Annahme binoculären Sehens bei den lnsecten ist wohl irrig (vgl. pag. 183, Contrastwirkung, ferner pag. 188, coordinirte Augenbewegung).

H a t schek, I.ehrbuch der Zoologie. 


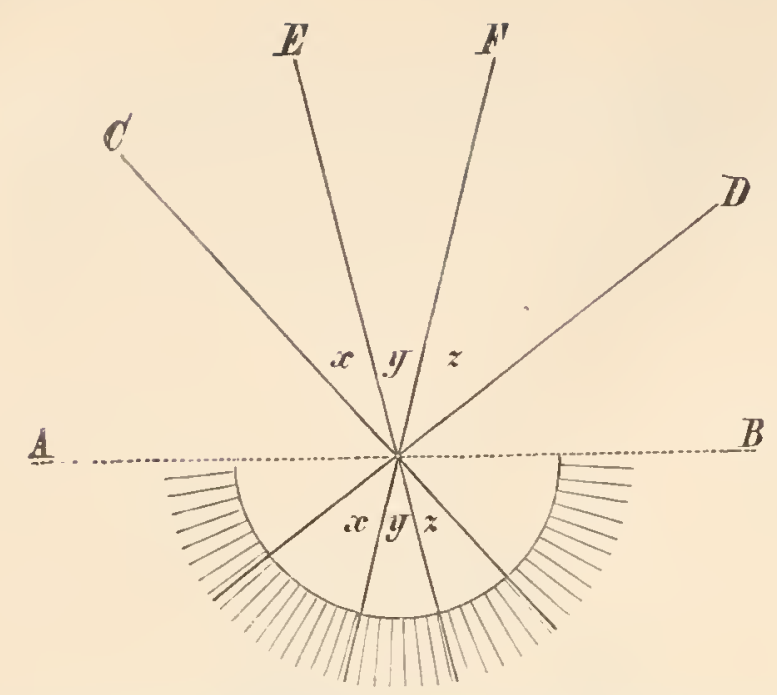

Fig. 206. 0ptisches Schema eines concav musivischen Auges. (Vergl. Fig. 202). mässiger Weise helle Zellen eingeschaltet sind. Ueber jeder Pigmentzelle ist an der freien Fläche der Retina ein heller cuticularer Saum zu beobachten; dass derselbe den Stäbchen entspreche oder dieselben einschliesse, scheint wohl wenig wahrscheinlich. Es frägt sich weiter, ob die hellen Zellen, die von Pigmentzellen umgeben sind (HILGER), oder die pigmentirten Zellen (CARRIÈre) (in welchen dieser Forscher bei Helix eine pigmentfreie Achse wahrgenommen hat), oder ob beide Arten Sehzellen sind ${ }^{1}$ ).

Den Sehwinkel, unter welchem bei diesen Augen ein Gegenstand erscheint, finden wir, indem wir von den Endpunkten des Gegenstandes gerade Linien durch den ideellen Kreuzungspunkt ziehen. Die Grösse des Sehfeldes hängt von der Stärke der Krümmung ab; sie kann in Winkelgraden ausgedrückt $180^{\circ}$ nicht überschreiten. Die Deutlichkeit des Sehens hängt von der Zahl der Retinaelemente $a b$, die auf einen Sehwinkel entfallen, die Vollkommenheit des Auges hängt ferner von der Länge der Retinaelemente (nämlich der dioptrischen Röhren) ab.

Nach Johannes Müller soll es folgende mögliche Arten von Augen geben: 1) Augen mit collectiv dioptrischen Medien (Camera obscura mit Linse), 2) convex musivische Augen, 3) Augen, die nach dem Princip der optischen Camera ohne Linse gebaut sind. Die Lichtstrahlen gehen durch eine kleine Oeffnung und die optische Isolation geschieht bei einer solchen Einrichtung auf die Weise, dass nur die Achsenstrahlen (oder vielmehr ein sehr kleiner Lichtkegel) von jedem Punkte des Gegenstandes zur Retina gelangen können und die anderen Strahlen abgeblendet werden. Die theoretische Betrachtung sowie das physikalische Experiment lehrt, dass dadurch ein objectives, umgekehrtes Bild des Gegenstandes $A$ auf einer Fläche $C$ zu Stande kommt, dessen Schärfe unabhängig von der Entfernung des Gegenstandes ist. Johannes Müller sagt, die Natur habe von diesem Mittel keinen Gebrauch gemacht, wahrscheinlich weil

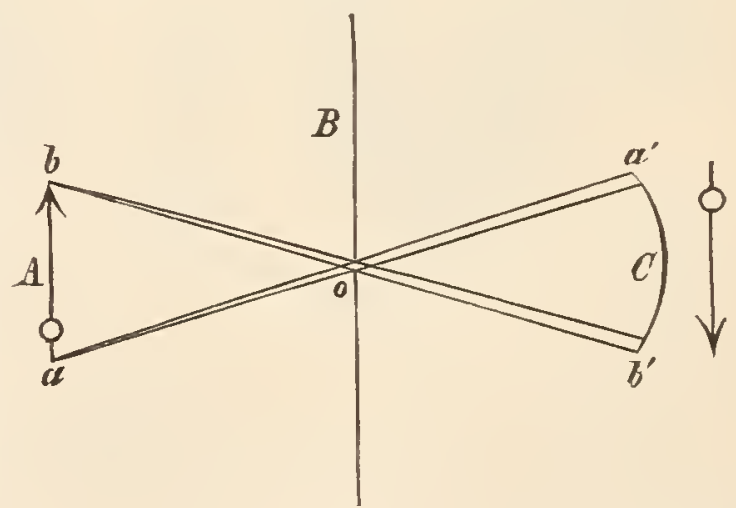

Fig. 207. Optisches Schema eines Auges, welches nach dem Princip der optischen Camera ohne Linso gebant ist. A sei der leuchtende Körper, $C$ sei die lichtempfindende Retina, $B$ sei eine zwischen $A$ und $C$ befindliche undurchsichtige, oder für das Licht undurchdringliche Wand, nur der Punkt $o$ in dieser Wand sei offen oder durchsichtig. (Nach JOHANNES MÜLLER.)

1) Nach eigenen Erfahrungen schliesse ich mich der Anschauung von CARrik̇e an. Ich kann die hellen Säume nicht für Stäbchen halten. Bei Haliotis und Patella finde ich eine helle Axe in den pigmentirten Zellen. 
die Bilder zu lichtschwach wären. Man hat später vermuthet, dass das Auge von Nautilus diesem Princip entspräche; diese Ansicht ist aber wohl irrig, denn die Oeffnung dieses Auges ist hierfür zu gross; es ist wahrscheinlich als ein concav musivisches Auge zu betrachten. Der Grund, warum solche Augen nicht vorkommen, scheint mir ein anderer zu sein, nämlich der, dass die phylogenetische Entwicklung solcher Augen schwer möglich ist, da der Entwicklungsweg viel leichter vorweg zu anderen Augenformen hinführt. 4) Die vierte mögliche Form, die der concav musivischen Augen, hat Johannes MüLler übersehen, da zu jener Zeit ihr Vorkommen in der Natur nicht bekannt war.

Es ist nun leicht einzusehen, dass die unter 2) 3) und 4) angeführten Augenformen auf gleicher physikalischer Grundlage beruhen und eine gleiche Wirkung haben müssen.

Bei dem concav musivischen Auge gelangt von je einem Punkte des Objectes ein kleiner Strahlenkegel zu je einem Retinaelement. Wenn wir anuehmen, dass in dem Kreuzungspunkt aller Strahlenkegel eine undurchsichtige Wand ausgespannt wäre, die eine Oeffnung besässe, genau von dem Durchmesser, den die Strahlenkegel an jener Stelle haben, so wäre eine Camera ohne Linse mit ebendemselben optischen Effect gegeben. Auch bei den convex musivischen Augen liegt dasselbe optische Verhältniss vor; nur dass hier wegen der divergirenden Richtung der dioptrischen Röhren die gemeinsame Oeffnung ideell zu nehmen wäre. Es ist nicht zu bezweifeln, dass in beiden Fällen, ebenso wie bei der optischen Camera ohne Linse, ein objectives Bild entworfen wird und zwar in dem einen Falle ein gerades, in dem anderen ein umgekehrtes Bild ${ }^{1}$ ).

Man hat oft hervorgehoben, dass die musivischen Augen Mosaikbilder sehen; aber auch die Camera-Augen mit Linse sehen nur feinere oder gröbere Mosaikbilder. Dass bei den letzteren ein objectives Bild auf der Retina zu Stande kommt, ist an und für sich physiologisch unwesentlich und überdies erkennen wir nun, dass dasselbe auch bei den musivischen Augen der Fall ist.

Wie bei den convex-musivischen Augen auf jertes Retinaelement durch je eine vorgesetzte Linse ein etwas grösserer Strahlenkegel gesammelt wird, wodurch diese Augen lichtstärker werden, so kann auch bei concav musivischen Augen ein ähnliches Verhältniss eintreten. Doch ist leicht einzusehen, dass hier eine Linse für alle Retinaelemente gemeinsan verwendet werden kann. Durch einen solchen lichtbrechenden Körper (der meist einfach als eine Cuticularbildung [Arthropoden] orler ein Ausscheidungsprodukt [Mollustien], des Epithels entsteht) werden nun convergirende Strahlen-

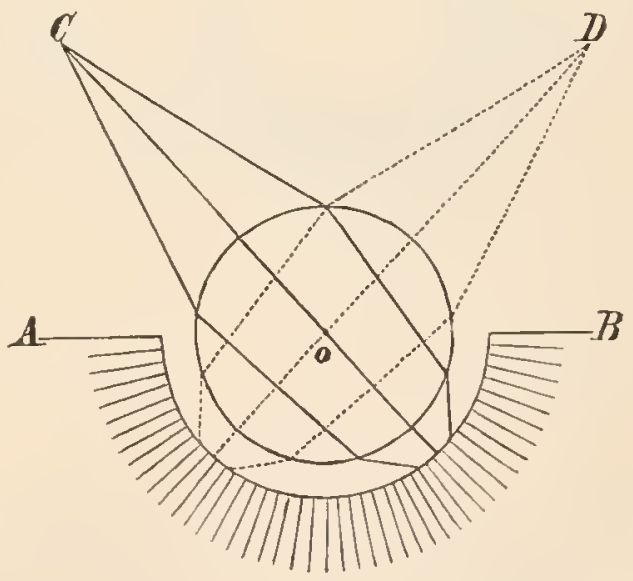

Fig. 208. Optisches Schema eines concaven musivischen Auges mit lichtverstärkender Linse (oder Glaskörper). kegel auf die Retinaelemente proji-

1) Ich schliesse mich in Bezug auf das Convex-Auge hierin ganz den schönen Ausführungen ExNER's an; in Bezug auf obige Auseinandersetzung bin ich auch meinem Herrn Collegen, dem Physiker Dr. Tumlinz für seinen Rath zu Dank verpflichtet. 
cirt; auch in diesem Falle kommen nur die centralen Strahlen zur Verwendung, während die stärker convergirenden Randstrahlen vom Pigment absorbirt werden; dennoch ist durch die Convergenz die Anzahl der in jedes Retinaelement eindringenden Strahlen viel grösser und die Lichtstärke des Auges daher sehr bedeutend verbessert. Alle Augen, bei welchen der lichtbrechende Körper (der als Linse oder Glaskörper bezeichnet wird) der Retina unmittelbar anliegt oder sehr genähert ist so dass kein Bild entworfen werden kann - und wo zugleich die Retina in ihrer ganzen Dicke pigmenthaltig ist, werden wahrscheinlich diesem physiologischen Typus zugehören.

c) Physiologische Uebergangsformen.

Es ist von grösster Wichtigkeit, dass alle Uebergänge zwischen concav musivischem Auge mit Beleuchtungslinse und vollkommenen Camera-obscura-Augen mit bilderzeugender Linse nicht nur theoretisch möglich sind, sondern auch in Wirklichkeit vorkommen. Die Linse muss allmählich in die richtige Entfernung von der Retina rücken und in Bezug auf ihre Form corrigirt werden; während sie ursprünglich nur lichtverstärkend wirkte, hat sie nun sowohl die Lichtstärke als auch die optische Isolation zu erzielen. In dem Maasse als dieselbe ein schärferes Bild auf die Retina projicirt, in dem Maasse kann das Pigment von der vorderen Fläche der Retina zurückweichen, dasselbe braucht nicht mehr eine Separathülle für jedes Retinaelement zu bilden, sondern nur eine gemeinsame Umhüllung der gesammten Retina. Mit

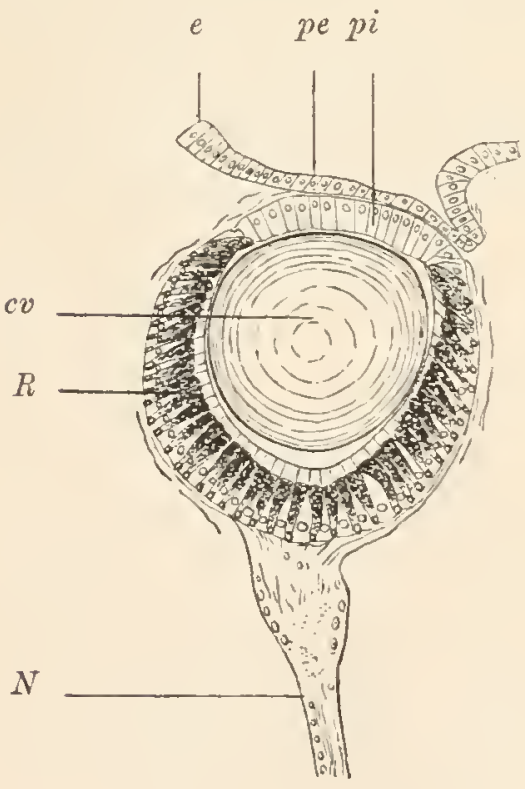
anderen Worten: in dem Maasse als die Linse auch die optische Isolirung der Retinaelemente übernimmt, in dem Maasse kann das Pigment diese specielle Function aufgeben ${ }^{1}$ ) (vergl. Fig. 209 u. 216).

Fig. 209. Auge der Weinbergschnecke, Helix pomatia (nach CARrière, etwas verändert); der lichtbrechende Körper liegt sehr nahe von der Retina.

$e$ äusseres Epithel, pe Pellucida externa, $p i$ Pellucida interna, $c v$ Glaskörper, $R$ Retina, aus pigmentirten Zellen und hellen Zellen zusammen. gesetzt, $N$ Augennerv.

\section{Morphologische Eintheilung der Augen.}

Augen von physiologisch ähnlicher Leistung können morphologisch sehr verschiedenartig aufgebaut sein. Um dies schon an einem einzigen

1) Vielleicht hat das Pigment selbst bei sehr vollkommenen Augen diese Function nicht ganz aufgegeben; wir erinnern daran, dass bei Wirbelthieren im belichteten Auge Pigmentfortsätze zwischen die Stäbchen und Zapfen sich erstrecken, die im Dunkeln wieder zurückgezogen werden (BoLL, KÜнNE). Diese Physiologen schreiben allerdings dem Vorgange eine andere Bedeutung zu. 
Theile zu erläutern, wollen wir anführen, dass z. B. die Linse des Camera-Auges in dem einen Falle eine cuticulare Bildung sein kann (Arthropoden), oder cin Sekretkörper (Mollusken), oder eine zellige, vom äusseren Epithel abgeschnürte Bildung (Wirbelthiere). Wir müssen daher neben der physiologischen auch eine morphologische Eintheilung der Augenformen treffen.

1. N a p f a ugen. Dieselben bilden eine grubenförmige Einsenkung des Epithels. Die Retina geht seitlich in die gewöhnlichen Epithelzellen über. Diese Augen fungiren in ihrer einfachsten Form (z. B. bei Patella, Fig. 210) als concav musivische Augen. In vielen Fällen kommt eine cuticulare Linse (Arthropoda), oder eine sekretartige Linse (Mollusca) hinzu (Fig. 212). Wenn die Linse in richtige Entfernung rückt, z. B. durch Einschiebung eines Glaskörpers, so kann dieses Auge von einfachstem morphologischen Charakter als Camera-Auge fungiren (Fig. 211).

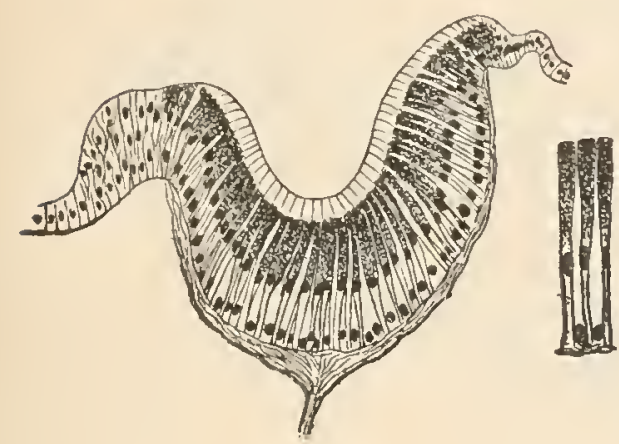

A.

B.

Fig. 210.

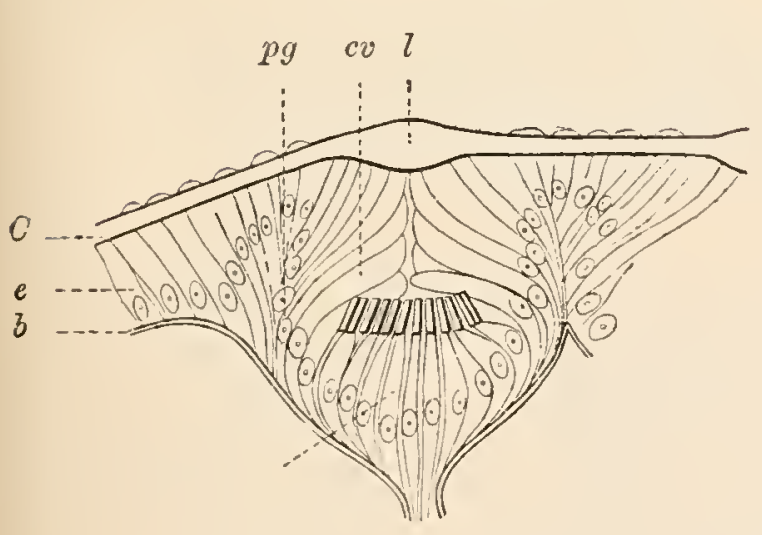

$P$

Fig. 211.

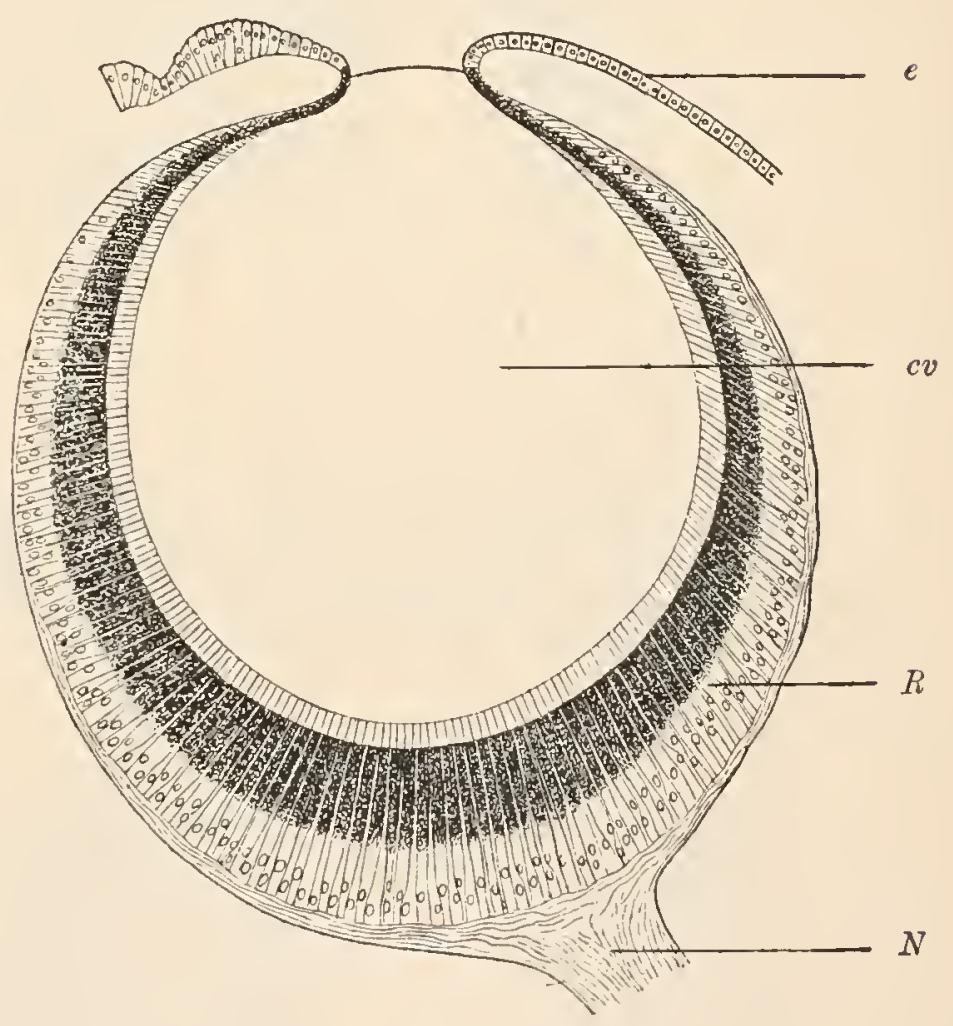

Fig. 212.

Fig. 210. Schnitt durch die Sehgrube von Patella (nach Carrì̀e, der Nerv ist ist nach der Darstellung von Hilger hinzugefügt). Die Retinn ist aus hellen Zellen und pigmentirten Zellen zusammengesetzt. B. Die zwei Arten von Retinazellen stärker vergrössert.

Fig. 211. Schnitt durch das Auge einer Käferlarve, Hydrophilus (nach GrenACHER). $C$ Chitincuticula, in $l$ die Chitinlinse übergehend; $e$ Epithelschicht, übergehend in $p g$ die Pigmentzellen, deren helle innere Enden $c v$ als Glaskörper fungiren, und weiter in $R$ die Retina; $b$ Basalmembran, übergehend in die structurlose Augenkapsel.

Fig. 212. Schnitt durch den offenen Augenbecher von Haliotis (nach HILGER).

Körperepithel, welches direct übergeht in $R$, die Retina, an deren hinterer Fläche sich $N$, der Augennerv ausbreitet, $c v$ Corpus vitreum. 
Wir finden diese Augen bei Medusen (concav musivische Augen ohne oder mit Linse) bei den niedrigsten Gastropoden-Formen und bei Tracheaten. Bei den letzteren kommt ausser der ursprünglichen Form, die als e inschichtiges Napfauge (bei Schwimmkäferlarven, Myriopoden, Seitenaugen des Scorpions) bezeichnet wird, häufiger eine höher differenzirte Form, das $z$ weischichtige $\mathrm{N}$ a p fa u ge vor ${ }^{1}$ ), Fig. 213. Dieses findet sich bei Myriopoden und Spinnen, ferner bei den Insecten neben den zusammengesetzten Augen oder auch für sich allein, nämlich bei flügellosen Insecten und Insectenlarven. Die Napfaugen bei den Tracheaten sind paarig oder unpaar und sind in der Regel in Mehrzahl rorhanden (Fig. 214).

A.

B.

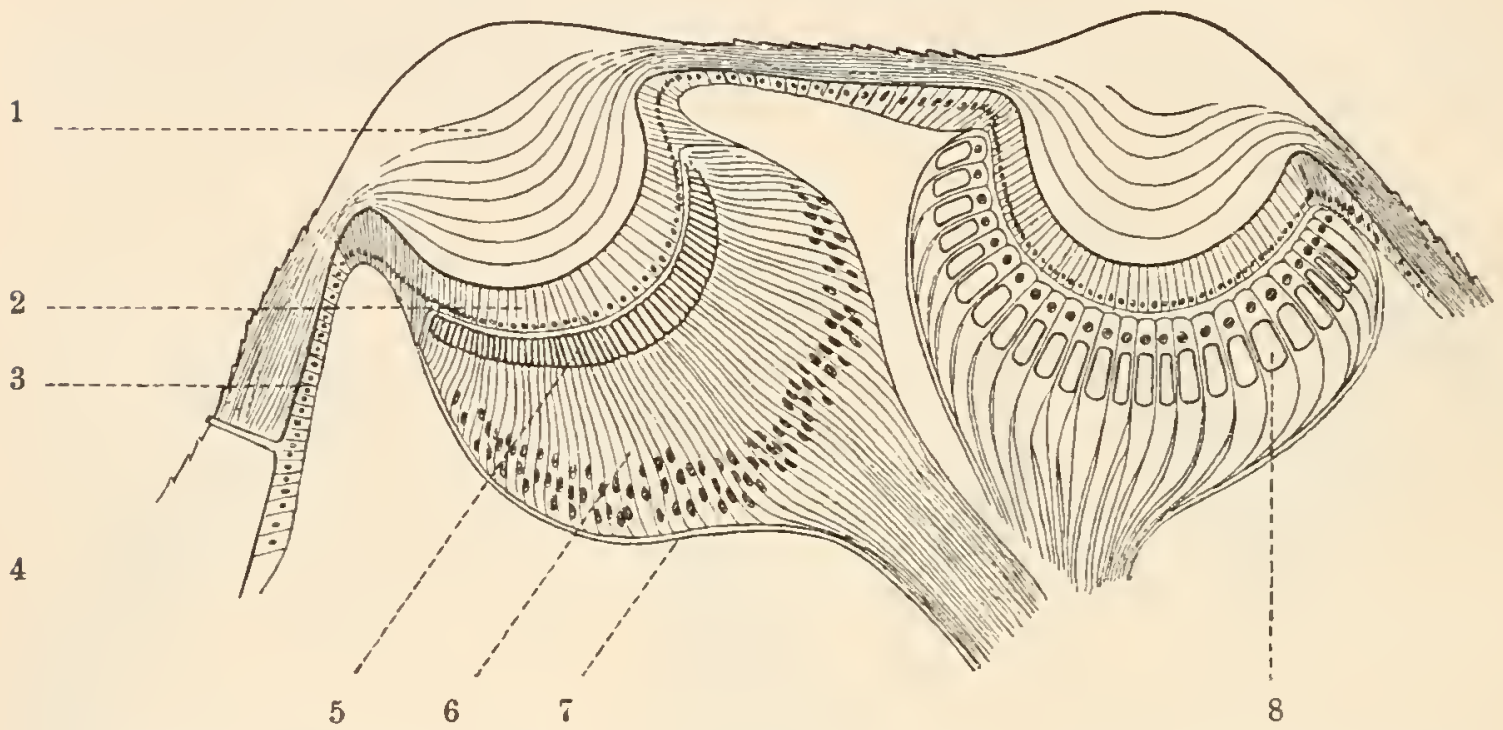

Fig. 213. Durchschnitt durch A. ein vorderes und B. ein hinteres Auge der Kreuzspinne, Epeira Diadema (nach Grenacher, aus CARriṫe). 1 Cuticularlinse, 2 Glaskörperzellen, 3 Hypodermis, 4 Cuticula, 5 Stäbchen, 6 Retinazellen, 7 Basalmembran, die Augenkapsel bildend, 8 stäbchenartige Gebilde des hintern Auges, welche im Innern der Retinazellen, hinter den Zellkernen liegen. Dies sind $z$ we is chichtige $\mathbf{N a p f a u g e n .}$

Fig. 214. a Kopf der Drohne (Apis mellifica $\delta$ ) von oben gesehen, nach Swammerdam. Man sieht zwischen den grossen zusammengesetzten Augen vorne die drei Punktaugen; $b$ und $c$ einige Augenfacetten der $\mathrm{zu}$ sammengesetzten Augen stärker vergrössert.

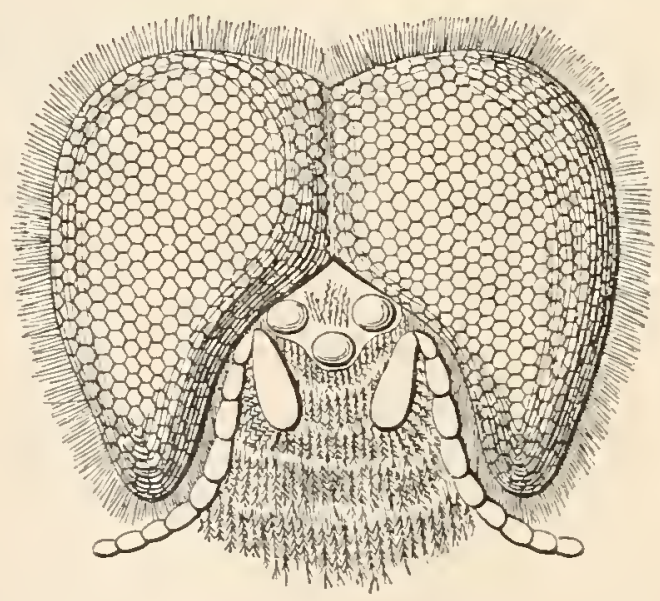

$a$
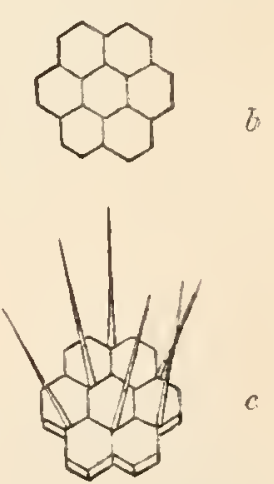

1) Man möchte wohl die Zweischichtigkeit als Delamination oder (was am wahrscheinlichsten ist) als Ueberwachsung erklären. Beide Schichten wenden ihre freie Fläcbe nach derselben Richtung. - In juingster Zeit wurden aber entwicklungsgeschichtliche Beobachtungen gemacht, aus welchen ein viel complicirteres Verhalten gefolgert wird; wir wollen aber noch weitere Aufklärung abwarten. 
2. B la se 1 a uge n. Indem sich die Sehgruben in Form einer Blase schliessen und vom Epithel vollkommen ablösen, entstehen die Blasenaugen. Die innere Fläclıe der Epithelblase ist freie Epithelfläche, die äussere Basalfläche. Der hintere Bezirk dieser Blase wird zur Retiıa, an deren äusserer oder Basalfläche sich der Sehnerv ausbreitet. Die vordere, durchVerschluss zu Stande gekommene Blasenwand ist durchsichtig und wird als in ere Pellucid a bezeichnet, das äussere Epithel, welches darüber hinweggeht, ist ebenfalls durchsichtig und bildet die äussere Pellucida. Diese Augen sind mit einem lichtbrechenden Körper versehen, der in Linse und Glaskörper sich scheiden kann; er liegt stets innerhalb der Augenblase und ist eil Ausscheidungsprodukt derselben. In manchen

Fig. 215. Auge der Weinbergschnecke, Helix: pomatia (nach CARRİ̀E, etwas verändert); der lichtbrechende Körper liegt sehr nahe von der Retina.

$e$ äusseres Epithel, pe Pellucida externa, pi Pellucida interna, $c v$ Glaskörper, $R$ Retina, aus pigmentirten Zellen und hellen Zellen zusammengesetzt, $N$ Augennerv.

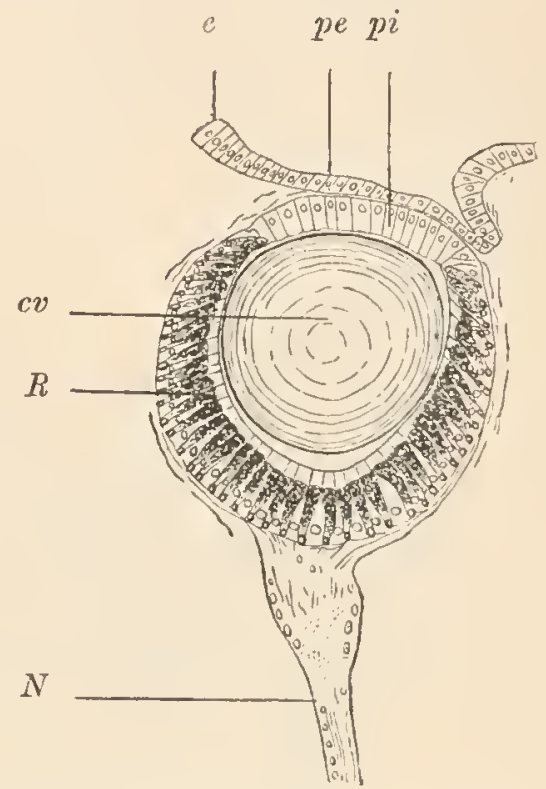

Fällen entsteht die Linse als Umbildung der inneren Pellucida (Charybdaea, Epiphysenauge der Wirbelthiere, Fig. 218).
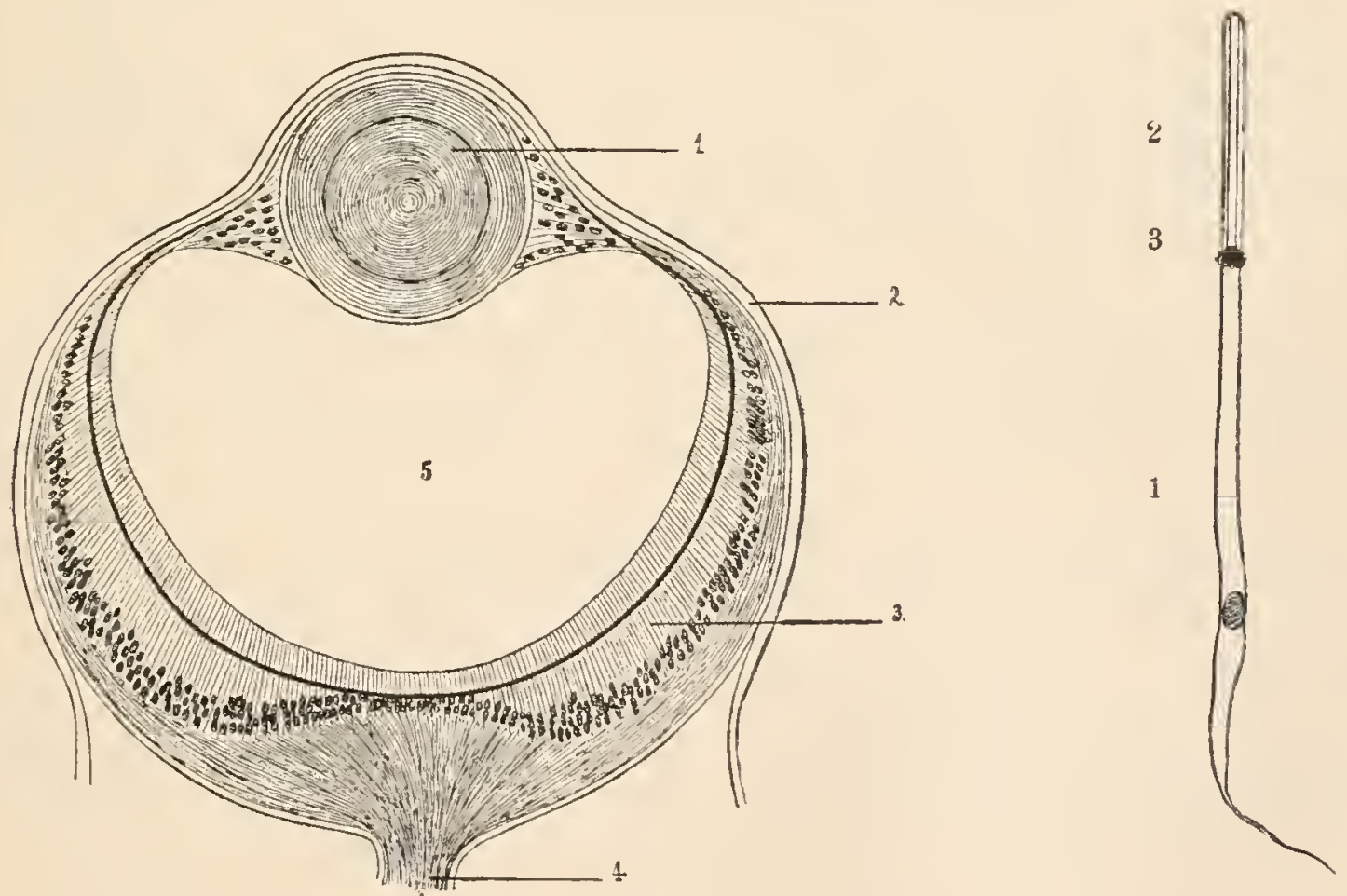

A.

B.

Fig. 216. Horizontaldurchschnitt des Auges eines pelagischen Anneliden Nauphanta colex (nach GreEFF).

A. 1 Linse, der Pellucida interna dicht angelagert, 2 äusseres Körperepithel, vor der Linse die Pellucida externa bildend, 3 Retina, von einer Pigmentzone durchsetzt, 4 Augen. nerv, 5 Glaskörper. B. eine Retinazelle; 1 der ausserhalb der Pigmentzone gelegene Zellkörper mit dem Zellkern, 2 das innerhalb der Pigmentzone gelegene Stäbchen mit dem Stäbchenmantel, 3 Pigmentzone. 


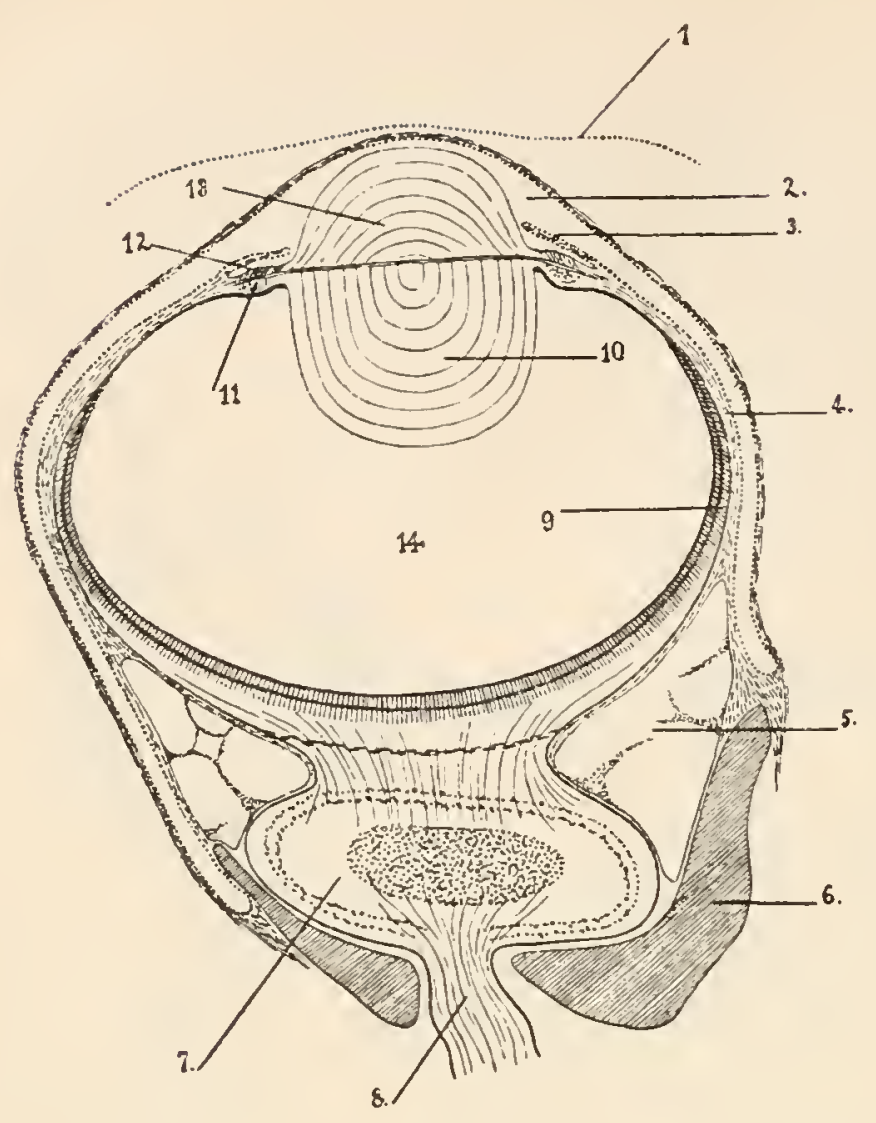

Fig. 217. Auge von Sepis im Horizontaldurchschnitt, aus mehreren Zeichnungen HENsEN's combinirt). 1. äusseres Epithel der Cornea, 2. vordere Augenkammer, die von Epithel ausgekleidet ist und nach rückwärts am Bulbus weit herabreicht, 3. Iris (mit Bindegewebe, Knorpel und Muskelfasern), 4. Sklera aus Bindegewebe, Knorpel und Muskel aufgebaut), 5. weisse Körper (von unbekannter Bedeutung), zu beiden Seiten des Augenganglions, 6. Kopfknorpel, 7. Augenganglion, der Nerv, der von demselben zur Retina führt und an deren hinterer (d. i. äusserer) Fläche sich ausbreitet, ist von einer Fortsetzung der Argentea interna quer durchsetzt, 8. Nervus opticus, 9. Retina, 10. hintere Linsenhälfte, 11. duzu gehöriges inneres Corpus epitheliale, 12. äusseres Corpus epitheliale, 13. äussere Linsenhälfte, 14 . Corpus vitreum.

Bei den dibranchiaten Cephalopoden kommen einige Complicationen hinzu. Die eine Linsenhälfte wird hier von der inneren Pellucida ausgeschieden und es fügt sich eine zweite Linsenhälfte an, welche von der äusseren Pellucida secernirt wird; ferner entsteht durch neuerliche Faltenbildung des äusseren Epithels die ringförmige "Iris" und endlich eine als "Cornea" bezeichnete Bildung, welche vollkommen oder unvollkommen sich schliessend eine vordere Augenkammer überwölbt.

Die geschlossenen Blasenaugen sind in den einfachsten Fällen physiologisch noch als concav musivische Augen mit Beleuchtungslinse zu betrachten, und von da gibt es alle Uebergänge (besonders schön bei den Mollusken bekannt) bis zu sehr vollkommenen Camera-Augen.

Blasenaugen mit einer Pellucidalinse finden sich schon bei einer Meduse (Charybdaeu). Typisch kommen Blasenaugen am Kopfe bei Mollusken (Gastropoden, Cephalopoden) vor, ferner bei polychaeten Anneliden und bei Peripalus. In jüngster Zeit wurde nachgewiesen, dass der Epiphysenanhang des Gehirns der Wirbelthiere ein mehr oder minder rudimentär gewordenes Auge vom Typus der Blasenaugen mit Pallucidalinse ist (bei manchen Sauriern vielleicht noch heute in einem gewissen Grade functionirend, nach anderer Meinung aber schon überall functionslos) (Fig. 218).

3. Inverse Blasenaugen. Diese Augen entwickeln sich aus einer blasenförmigen Anlage, die als primäre Augenblase bezeichnet wird. Bei den Wirbelthieren entsteht dieselbe als Abschnürung vom Medullarrohre und der Stiel derselben liefert den Augennerv; in anderen Fällen entsteht sie durch Einstülpung direct vom äussern Epithel. 
Fig. 218. Längsschnitt durch die Bindegewebskapsel mit dem Pinealauge von Hatteria punctata.

Schwach vergrössert. Nach Baldwin SPENCER.

Der vordere Theil der Kapsel füllt das Scheitelloch (Foramen parietale) aus.

$K$ bindegewebige Kapsel; $l$ Linse; $h$ mit Flüssigkeit gefüllte Höhle des Auges; $r$ retinaähnlicher Theil der Augenblase; $M$ Molecularschicht der Retina; $g$ Blutgefässe; $x$ Zellen im Stiel des Pinealauges; St dem Sehnerv vergleichbarer Stiel des Pinealauges.

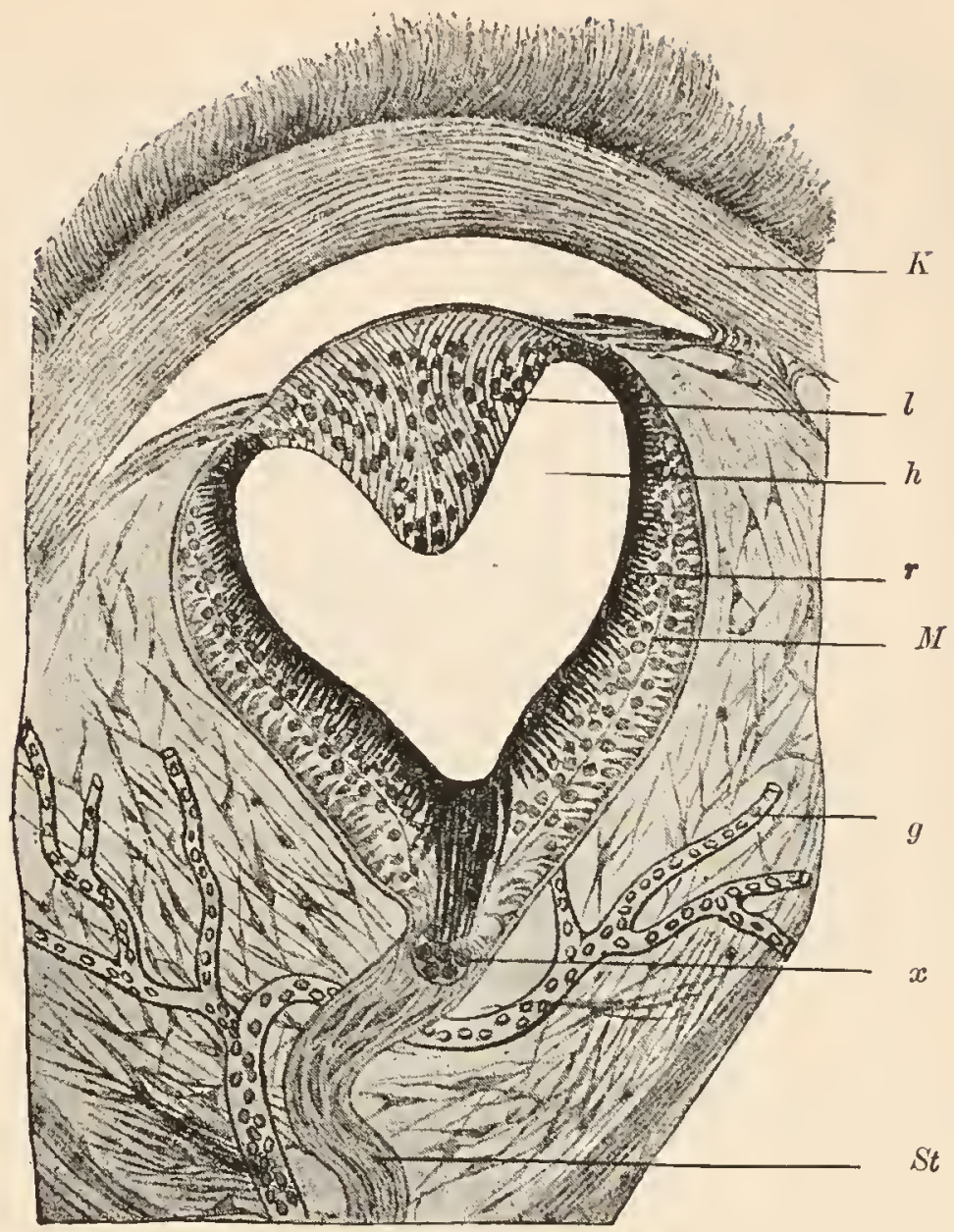

Die imnere Fläche der Augenblase ist freie Epithelfläche, die äussere ist Basalfläche. Die vordere Hälfte dieser Blase stülpt sich in die hintere Hälfte ein, so dass ein doppelwandiger Becher entsteht, der als secundärer A g enbech er (oder meist weniger zutreffend als ,secundäre Augenblase"6) bezeichnet wird. Die vordere Schichte dieses Bechers liefert die Retina, die hintere Schichte ein umhiullendes Pigmentepithel, am Umschlagsrande gehen beide Schichten in einander über. Da die "freie" Fläche der Retina dem Pigmentepithel zugewendet ist, so finden sich an dieser Seite die Stäbchen und der Nerv breitet sich an der entgegengesetzten (vorderen) Fläche der Retina aus.

Die Linse dieser Augen ist stets ein zelliges Gebilde, welches ausserhalb der primären Augenblase unabhängig entsteht; speciell bei den Wirbelthieren entsteht sie als besondere Epitheleinstülpung (Fig. 220, B, B $_{2}$ ).

Der Nerv tritt vom Rande an die Retina heran. Bei den Wirbelthieren ist dieses ursprüngliche Verhalten der Nerven nur während der Entwicklung ausgeprägt, denn der Nerv entfernt sich alsbald vom Rande des Augenbechers, es besteht aber noch eine Zeit lang eine tiefe Spalte (das "Coloboma"), die vom Rande bis zur Ansatzstelle des Nerven sich erstreckt; Spuren dieser Spalte sind bei Fischen, Reptilien und Vögeln zeitlebens erhalten (Processus falciformis, Pecten).

Diese Augen finden sich nicht nur als typische paarige Augen bei den Wirbelthieren, sondern auch in Vielzahl bei manchen Mollusken, und zwar bei der Pilgermuschel (Peclen) am Mantelrande und bei einer die Philippinischen Inseln bewohnenden Lungenschnecke (Onchidium) als Rückenaugen.

Diese Augen sind in jedem der drei Fälle phylogenetisch unabhängjg von einander entstanden. Es ist nicht zu verkennen, dass das inverse Auge 


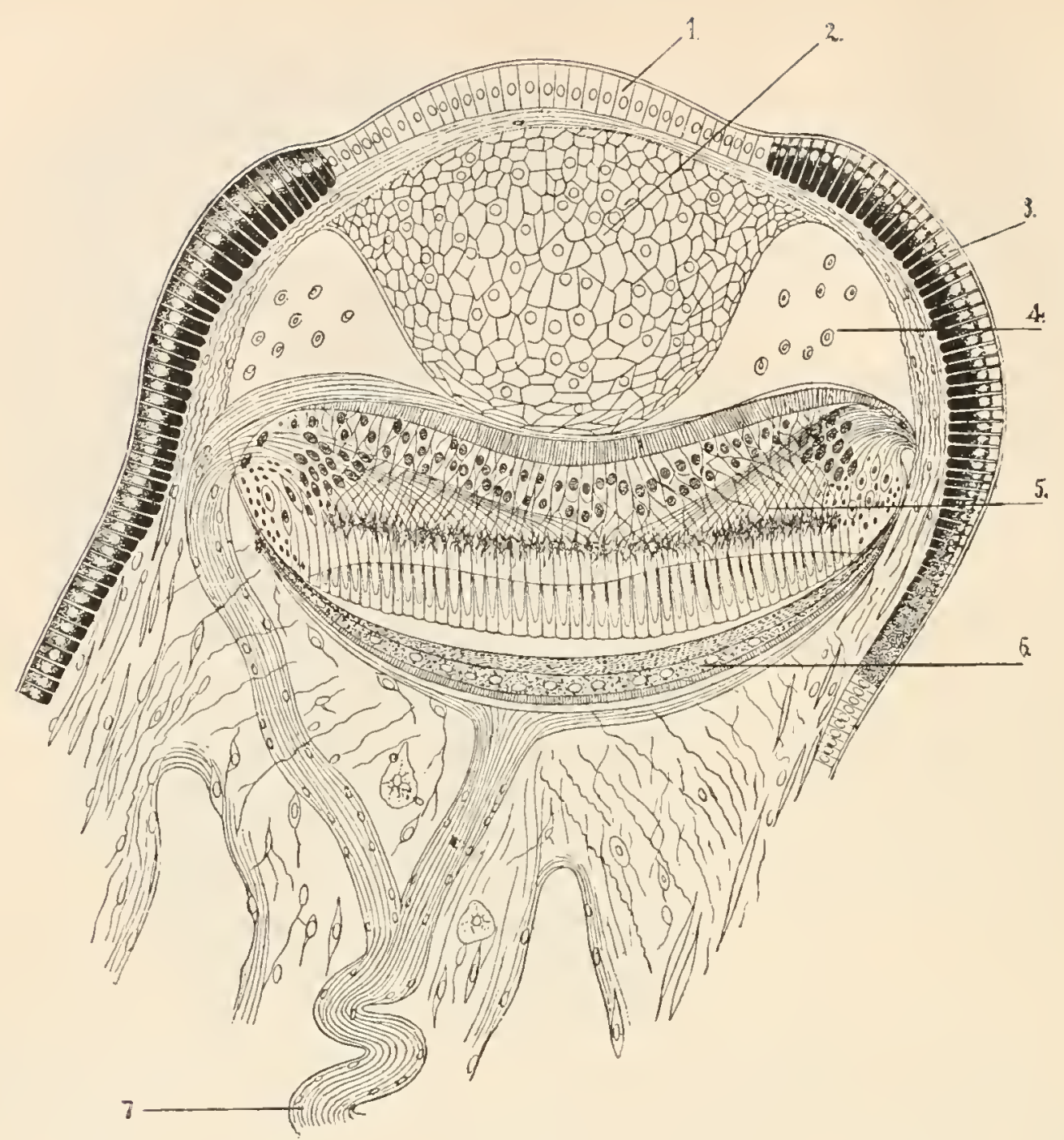

\section{.}

Fig. 219. A.
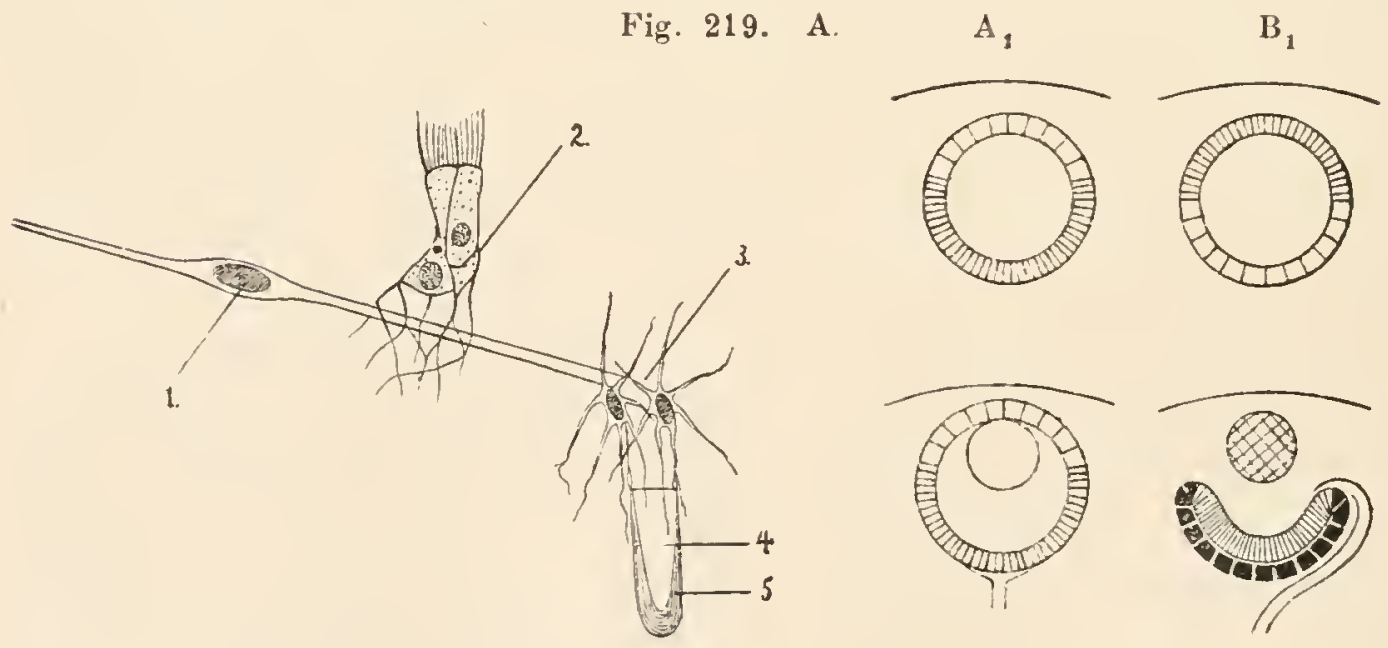

Fig. 219. B.

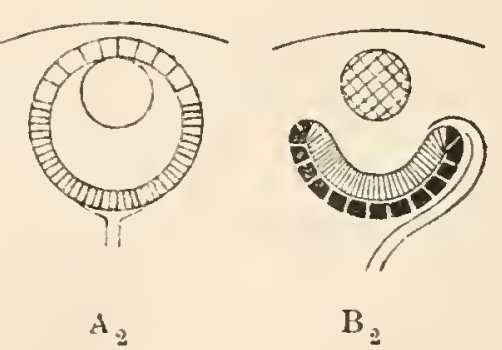

Fig. 220.

Fig. 219. A. Schnitt durch ein Auge von Pecten (nach Patten). 1. Cornea, 2. Linse, 3. äusseres Epithel, das in der Umgebung des Auges pigmentirt ist, 4. Blutsinus rings um die Linse, 5. Retina, 6. Pigmentepithel und vor derselben das T a p e t u m, 7. Augennerv.

B. Histologische Elemente, aus welchen die Retina dieses Auges zusammengesetzt ist (nach PATTEN). 1. Retinazelle, deren Endstück in der Richtung der einfallenden Lichtstrahlen umgebogen ist und (4) das Stäbchen mit (5) dem Stäbchenmantel trägt; 2 und 3 Ganglienzellen der Autoren, die aber vielleicht nur Stiitzzellen (und Limitanszellen) sind.

Fig. 220. Schema der Entwicklung des Blasenauges $\left(A_{1} A_{2}\right)$ and des inverser Blasenauges $\left(B_{1} B_{2}\right)$. 
mit dem einfachen Blasenauge in seiner ersten Anlage übereinstimmt; in dem einen Falle entsteht aber aus der vorderen Hälfte der Blase, in dem anderen Falle aus deren hinterer Hälfte die Retina. Man hat. versucht, das inverse Auge durch eine Drehung aus dem Blasenauge phylogenetisch abzuleiten; es scheint mir aber, dass dieser Deutung gewichtige physiologische Einwände gegenüberstehen.

4. Zusammiengesetzte A ugen. a) Fächeraugen bei Arthropoden. Diese Augen wurden früher in physiologischem Sinne zusammengesetzte genannt [was eigentlich seit der 'Theorie vom musivischen Sehen nicht mehr ganz passend scheint, obzwar auch Johannes MÜLler selbst sie so nennt]. Neuerdings gewinnt dieser Name morphologische Berechtigung durch die Ausführungen GRENACHER's, welcher für das zusammengesetzte Auge speciell der Insecten auf das überzeugendste nachgewiesen hat, dass jedes Augenelement [Retinula mit Krystallkörper, zusammen neuerdings als $\mathrm{O} \mathrm{mm}$ a te $\mathrm{um}$ (RAY-LANKESTER) bezeichnet] einem zweischichtigen Napfauge der Myriopoden entspreche. Durch Aggregation solcher Augen - mit Zunahme der Anzahl - sind die zusammengesetzten Augen der Insecten entstanden. Jedes Einzelauge ist in Bezug auf seine Einzelleistung zu tieferer Stufe herabgesunken, in Bezug auf das Zusammenwirken ist aber eine vollkommenere Stufe erreicht worden.

Die Entwicklungsgeschichte (CARrik̀re) bestätigt diese Ansicht. Die erste Andeutung des Auges ist durch eine schwache Verdickung des Epithels gebildet, in welcher schon die Anlage der einzelnen Ommatea sichtbar ist, welche jedes von dem anderen durch eine be-

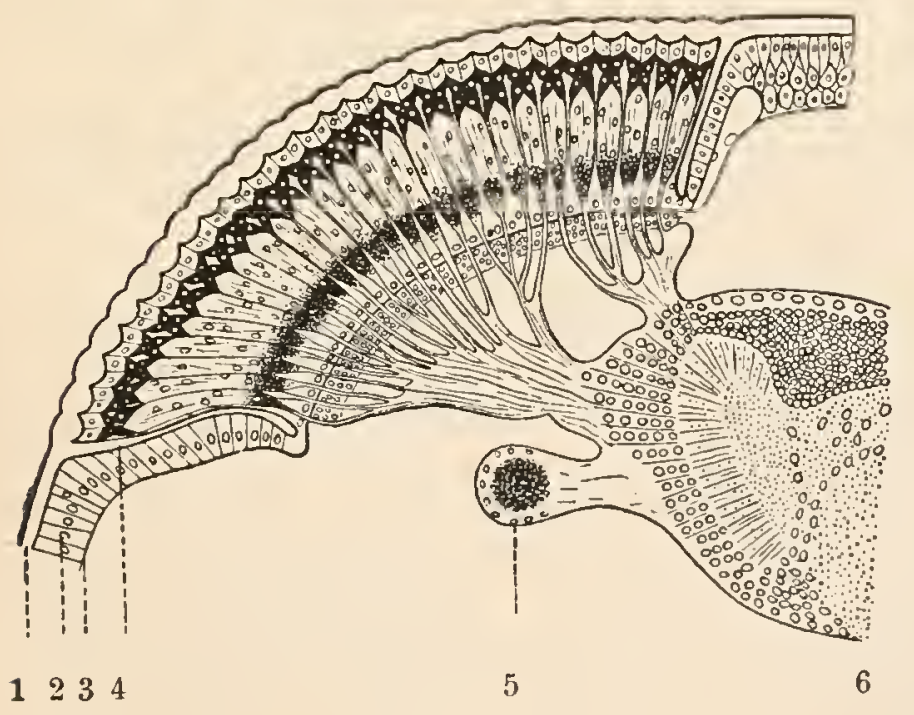

Fig. 221.

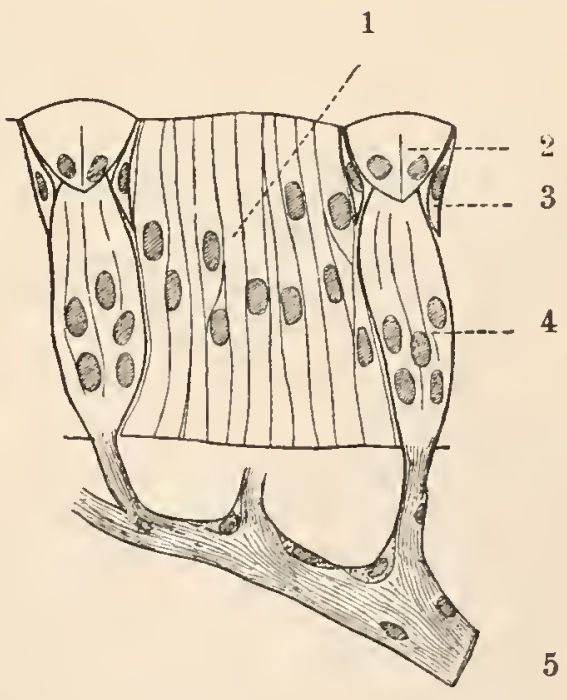

Fig. 222.

Fig. 221. Schnitt durch ein zusammengesetztes Insectenauge von Forficula (nach Carrik̀re).

1 Chitincuticula, welche über dem Auge die Corneafacetten bildet, 2 äusseres Epithel, welches direct in die Differenzirungen des Auges sich fortsetzt, 3 Basalmembran, welche in die Augenkapsel sich fortsetzt, 4 einspringende Chitinlamelle am Rande des Auges, 5 Rudiment des Larvenauges, 6 Gehirn.

Fig. 222. Schnitt durch das in Entwicklung begriffene zusammengesetzte Auge von Tespa (nach CARrik̀re). 1 Cylinderzellen, die später die Nebenpigmentzellen darstellen, 2 Crystallzellen, 3 Hauptpigmentzellen, 4 Retinula, 5 Nerv, der Aeste zu den ein. zelnea Ommatidien abgibt (nach CARriÈrE). 
trächtliche Reihe von Schaltzellen getrennt sind ${ }^{1}$ ); diese letzteren liefern die sogenannten Nebenpigmentzellen. Die Anlage des Ommateums selbst besteht aus dem oberen Stratum, das sind die Klystallzellen, umgeben von den $\mathrm{Hauptpigmentzellen}$ und dem unteren Stratum, das sind die Retinulazellen, an die ein Nerv herantritt. Die Weiterentwicklung besteht vor allem in dem sehr beträchtlichen Dickenwachstlıum der Augenanlage, wobei die Ommatea sehr hoch und schmal werden, und dann in der Ausscheidung der Cuticula (sog. Cornea), die in vielen Fällen oberhalb jedes Auges zu einer Cornealinse anschwillt. - Je nach der Differenzirung der Krystallzellen unterscheidet

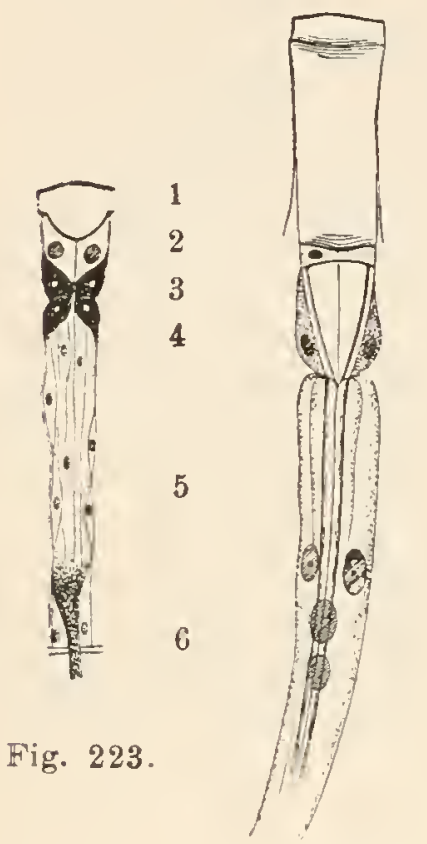

Fig. 224 . man ferner 1) A cone A ugen, wo die unveränderten Krystallzellen selbst den Krystallkörper repräsentiren (Fig. 223), 2) Eucone A u gen, wo diese Zellen basalwärts einen Krystallkegel ausscheiden (Fig. 224), und 3) P s e u doc one Augen, wo vor den Krystallzellen 4 ein durchsichtiges Produkt, der Pseudoconus, sich einschiebt (bei Fliegen).

Die zusammengesetzten Augen der Crustaceen haben sich phylogenetisch unabhängig 5

Fig. 223. Ommatidium des aconen Auges von Forficula (nach Carrière). 1 Cornealinse, 2 Krystallzellen, 3 Hauptpigmentzellen, 4 die Nebenpigmentzellen, 5 Retinula, umgeben von fadenförmgen pigmentirten Zellen, 6 Interstitielle Zellen.

Fig. 224. Ommatidium aus dem euconen Auge von Gryllotalpa (nach Grenacher) 1 Cornealinse, 2 Krystallzellen, hinter denselben 3 der Krystallkegel, 4 Hauptpigmentzellen, 5 Retinula, das Rhabdom einschliessend.

von jenen der Insecten entwickelt; sie gleichen denselben aber in hohem Grade. Sie besitzen stets besondere Cornea- und Krystallzellen und hinter den letzteren sehr anselnnliche Krystallkegel (Fig. 225).

b) Die mittleren $\mathrm{Napfaugen} \mathrm{des} \mathrm{Skorpions} \mathrm{zeigen} \mathrm{eine} \mathrm{Zusammen-}$ setzung aus Retinulae. Es wurde dies mit Unrecht als Einwand gegen die Grenacher'sche Theorie geltend gemacht ${ }^{2}$ ). - Wahrscheinlich bilden die einfachen Napfaugen der Myriopoden den Ausgangspunkt für mehrere verschiedene Entwicklungsrichtungen bei den Trucheaten. Durch Vergrösserung und Vervollkommnung lieferten sie die Napfaugen der Spinnen, die seit lichen Napfaugen der Skorpione und die einfachen Mittelaugen der Inseclen, durch Aggregirung einerseits die convexen zusammengesetzten Augen der Insecten und vielle icht auch die concaven - dann als zusammengesetzt zu deutenden - Mittelaugen des Skorpions.

1) So klar die morphologische Auffassung des zusammengesetzten Auges als Differenzirung der Epitlielschichte scheint, so ist doch durch neuere embryologische Beobachtungen bei Crustaceen eine complicirtere Deutung veranlasst worden, deren Bestätigung wir aber noch abwarten wollen.

2) RAY-LANkester hält dafür, dass die Retinulabildung der mittleren Napfaugen des Skorpions durch höhere Differenzirung der einfachen Augen abzuleiten sei (nicht durch Aggregirung). Ferner will er von diesen Mittelaugen die zusammengesetzten Augen der Insecten ableiten. Letzteres ist gewiss verfehlt, denn es wären - wie Grenacher hervorgehoben hat - die Uebergangsformen vom concaven zum convexen Auge functionsunfähig. 


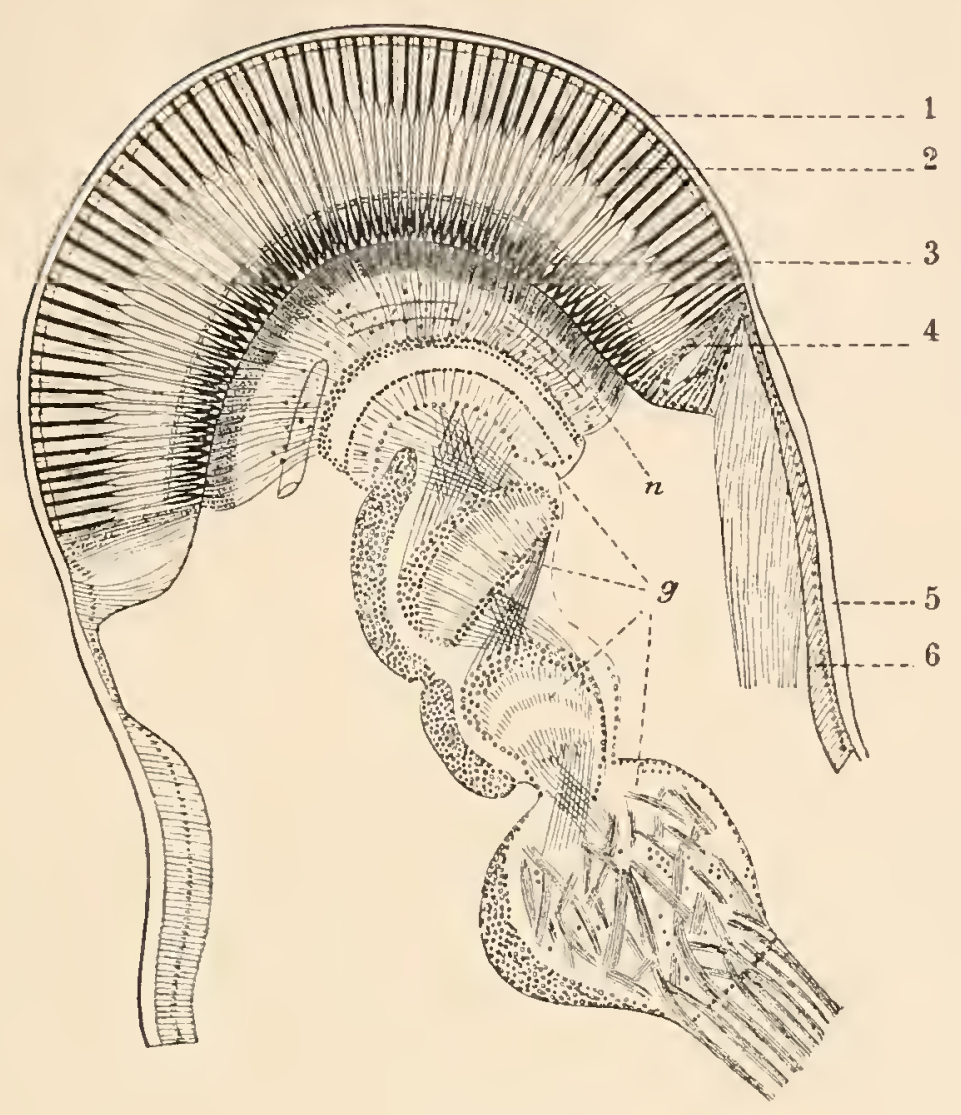

Fig. $225 \mathrm{~A}$.

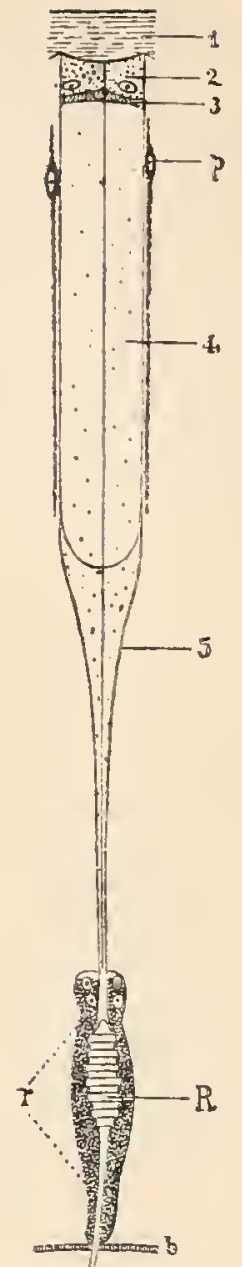

Fig. 225 B.

Fig. 225 A. Schnitt durch das Auge des Flusskrebses (nach Carrière). 1 Cornea, 2 Glaskörper, 3 Retinulae, 4 Pjgmentirte Hypodermiszellen, welche den Uebergang zwischen den Differenzirungen des Auges und dem einfachen niedrigen Epithel bilden, 5 Cuticula, 6 Epithel, $n$ Augennerv, $g \ldots g$ Augenganglien.

Fig. 225 B. Ein 0mmatidium vom Flusskrebs (nach CARrit̀re). 1 Cornealinse, 2 Corneazellen, 3 Krystallzellen, 4, 5 äusserer und innerer Theil des Krystallkegels. $p$ Pigmentzellen, $r$ Retinula, $R$ Rhabdom, $b$ Basalmembran des Auges, durch welche die Nervenfaser hindurchtritt.

Zur Morphologieder Richtungsa ge n wollen wir noch bemerken, dass hier die verschiedensten Typen vorkommen, da sie sowohl den Typus der $\mathrm{Napfaugen}$ als auch den der Blasenaugen zeigen, und da sogar inverse A u gen vorkommen (Turbellarien). Ihr Bau ist schwer zu analysiren und ihre morphologische Vergleichung gegenwärtig kaum durchführbar; in manchen Fällen sind es ursprüngliche Formen, in anderen Fällen rückgebildete. Auch ihre Lagerung ist verschieden, bald epithelial, bald subepithelial, oft auch mit dem Nervencentrum in die Tiefe verlegt. Im allgemeinen können wir hervorheben, dass der Bau der einfachsten Augen mit dem Bau der Hautsinnesorgane in den betreffenden Thierklassen oft eine gewisse morphologische Verwandtschaft erkennen lässt; und diese sind, wie früher gezeigt wurde, in dem einen Falle durch $Z_{\text {wischenzellen isolirte }}$ Hautsinneszellen, in dem anderen Falle zu Sinnesknospen aggregirte Zellen. 
Nachtrag. Noch während des Druckes des rorliegenden Buches ist eine neue Theorie über das Zustandekommen des Netzhautbildes bei dem zusammengesetzten Auge der Insecten von S. Exser veröffentlicht worden. Es soll von jedem Linsensystem (Krystallkegel mit Cornealinse) eine Art a ufrechten Bildes des Gegenstandes auf die Retina projicirt werden; aus der gegenseitigen Stellung der Krystallkegel resultirt eine Summation der Bilder. - Diese Theorie setzt ein durchsichtiges Stratum $\mathrm{zwischen}$ den Krystallkegeln und der Retina voraus und wird daher keinesfalls auf alle zusammengesetzten Arthropodenaugen Anwendung finden können. Aber selbst in dem speciellen Falle, bei Lampyris, sind nach unserer Neinung schwerwiegende Bedenken der Darstellung Exser's entgegenzusetzen. 


\section{ZEHNTES CAPITEL.}

\section{Functionen des Metazoenkörpers (Fortsetzung).}

\section{Fortpflanzing.}

Fortpflanzung ist das Endziel der Lebensthätigkeit.

In dem Wesen des Organismus liegt das Streben, immer mehr Substanz in den Kreislauf seines Lebens hineinzuziehen - zu wachsen und sich zu vermehren. Es macht daher ein Organismus dem anderen den Platz (d. i. die Lebensbedingungen) streitig und durch diesen gegenseitigen Kampf ums Dasein sind in den Zeiten alle die merkwürdigen Eigenthümlichkeiten der Organismen gezüchtet worden, welche nicht nur die Existenz des Individuums, sondern auch insgesamm in letzter Instanz zur Sicherung der Nachkommenschaft dienen.

Das Vorkommen steriler Individuen, wie wir sie z. B. als Arbeiter im Bienenstaate antreffen, steht hierzu nur scheinbar im Widerspruch. Denn diese Erscheinung ist im Grunde auf dasselbe Princip der Arbeitstheilung zurückzuführen, welches wir schon im Aufbau des vielzelligen Metazoenkörpers ausgeprägt finden. Alle die Körperzellen, welche die complicirtesten und höchsten Functionen versehen, sind vergänglich und arbeiten nur für die Existenz der Fortpflanzungszellen, die ihr Wesen dann wiedererzeugen. Ebenso sind die unfruchtbaren Arbeitsbienen mit den schönsten socialen Instinkten ausgestattet, um die Fortexistenz ihrer Geschwister und so, wenn auch indirekt, der Familie zu besorgen. Nach ähnlichen Naturgesetzen sind in der menschlichen Gesellschaft die höchsten socialen Tugenden - der Sinn für das Gemeinwohl, die Aufopferungsfähigkeit für eine Idee - entstanden; der einzelne, der für seine Nation sich opfert, hinterlässt keine oder weniger Nachkommenschaft, der Stamm aber, der solche Individuen hervorbringt, siegt über andere Stämme.

Je niedrigere Organismen wir betrachten, um so unmittelbarer und unverhüllter erscheint uns das Wachsthum und die Fortpflanzung als das Endziel aller ihrer Lebensprocesse.

Die Sicherung der Nachkommenschaft wird auf sehr verschiedene Weise erreicht. Viele niedere Thiere erzeugen bei der geschlechtlichen Fortpflanzung eine ungeheure Menge sehr kleiner Eier; die Larve verlässt in Folge dessen das Ei in sehr geringer Grösse und in sehr unvollkommenen Zustande, sie muss noch bedeutend heranwachsen und sich noch sehr bedeutend verändern, um wieder die ge- 
schlechtsreife Form zu erreichen, es werden also viele Individuen erzeugt, die Existenz des Einzelnen ist aber wenig gesichert (Entwicklung mit M etamorphose). Andere und zwar höhere Thierformen erzeugen nur wenige, aber sehr grosse und mit vielem Nahrungsdotter versehene Eier (oft vertreten secundäre Nährmaterialien denselbeu Zweck); das junge Thier verlässt das $\mathrm{Ei}$ in bedeutender Grösse und in relativ vollkommenem Zustande, es kann in den wesentlichen Eigenthümlichkeiten schon dem Erzeuger gleichen (Entwicklung o hne Metamor phose); hier werden also wenige Individuen erzeugt, deren Existenz aber in viel höherem Grade gesichert ist. Dasselbe Resultat wird in noch viel vollkommenerer Weise durch Ernährung des Embryo im Mutterleibe erreicht. Endlich kann die Fortexistenz der Nachkommenschaft noch mehr gesichert werden, indem Brutpflege (Atzung der Vögel, Säugegeschäft der Säugethiere) hinzukommt und sociale Eimriclıtungen sich entwickeln (Heerdenleben, Familienleben).

Bei sehr vielen niederen Thieren wird die oben erwähnte Massenerzeugung von Nachkommen dadurch noch gesteigert, dass ungeschlechtliche Fortpflanzung hinzukommt. Manchmal werden nur wenige Eier erzeugt und die ungeschlechtliche Fortpflanzung bietet eineu Ersatz für diese geringe Zahl (Salpen). Oft auch werden die eimmal voul der Larve aufgefundenen günstigen Lebensbedingungen durch solche rasche ungeschlechtliche Vermehrung besser ausgenutzt (Parasitell, festsitzende Thierformen).

\section{Geschlechtliche Fortpflanzung.}

Wir unterscheideu bei den Metazoen mannigfache Arten der Fortpflanzung. Bei der geschlechtlichen Fortpflanzung ist mit dem Fortpflanzungsgeschäfte eine zweite für die dauernde Existenz der Organismen überaus wichtige Function vereinigt, nämlich die Vermischung der Individualitäten. Daher fehlt die geschlechtliche Fortpflanzung bei keiner Thierart. Sie kann allein vorkommen oder neben ungeschlechtlicher Fortpflanzung, niemals kann aber die letztere ausschliesslich vertreten sein.

Es gibtgetrenutgeschlechtliche Thiere und Zwitter. Bei den Zwittern findet nicht etwa in der Regel Selbstbefruchtung statt - dies kann nur ausnahmsweise geschehen, denn dadurch ist keine Vermischung individuell verschiedenen Plasmas erreicht und der Vorgang ist nur einer ungeschlechtlichen Fortpflanzung in Bezug auf seinen Erfolg gleichwerthig; in der Regel aber findet W echselkreuzung zwischen zwei Individuen statt. Bei vielen Zwittern tritt eine ungleichzeitige Reife ihrer verschiedenen Geschlechtsprodukte ein, so dass zu einer Zeit ihre männlichen, zu anderer Zeit ilıre weiblichen Organe fungiren und dadurch schon Selbstbefruchtung verhindert wird. Dies ist ein Verhalten, wie es ähnlich bei Pflanzen sehr häufig auftritt.

Fis war früller die Anschauung allgemein verbreitet, dass das zwitterige Verlaalten das phylogenetisch ursprünglichere sei, von welchem das getrenntgeschlechtliche dadurch abzuleiten wäre, dass bei den verschiedenen Geschlechtern eimmal der weibliche, das andere Mal der männliche Theil des Geschleclitsorganes unterdruickt wäre. In jüngster Zeit aber hat Steenstrup die Ansiclit vertheidigt, dass im Gegentheil das getrenntgeschlechtliche Verhalten das ältere sei und der Zwitter- 
zustand secundär in Anpassung an besondere Lebensbedingungen sich ausgebildet hätte ${ }^{1}$ ).

\section{A uswerfen der Geschlechtsproducte (Begattung).}

Bei vielen niederen Thieren werden zur Zeit der Geschlechtsreife die Geschlechtsproducte einfach nach aussen in das Wasser entleert; das Zusammentreffen der mämnlichen und weiblichen Producte - die Befruchtung - ist in einem gewissen Grade dem Zufall überlassen; derselbe wird allerdings durch mancherlei Bedingungen paralysirt, z. B. durch das massenhafte Vorkommen der Thiere an einer Oertlichkeit.

Bei höheren Thieren ist ein ausgebildeter Begattungsprocess vorhanden, wodurch eine Ersparniss an Fortpflanzungsmaterial erreicht wird. Es gibt aber auch mannigfache Abstufungen und Uebergänge zwischen diesen beiden Fällen.

Sehr häufig kommt es vor, dass nur die männlichen Geschlechtsproducte frei entleert werden und mit dem Wasserstrome (Athemwasser etc.) in die Höhlungen des weiblichen Körpers (ja sogar bei den Spongien in das Innere der Gewebe) gelangen. In vielen Fällen werden die Eier schon innerhalb des mütterlichen Körpers befruchtet und können daselbst auch einen Theil ihrer Entwicklung durchlaufen (bei den Spongien an Ort und Stelle im Gewebe, bei manchen Quallen [Chrysaora] im Ovarium, bei Muscheln in dell als Brutraum benutztell Kiemen). In anderen Fällen wird das Weibchen erst durch den Einfluss der Spermatozoen gereizt, die Eier abzulegen.

Als ein Uebergang zum Begattungsprocess ist folgendes Verhalten zu betrachten; zur Zeit der Geschlechtsthätigkeit leben Männchen und Weibchen vergesellschaftet, wälirend das Weibchen die Eier ablegt, lässt das Männchen den Samen über dieselben fliessen, hier kommt auch schon vielfach gegenseitige Aureizung der Individuen vor. Diese Verhältnisse finden sich bei den meisten Knochenfischen (während bei den Selachiern wirkliche Begattung eintritt). Hieran schliesst sich die äussere Begattung, wie wir sie bei den Fröschen beobachten; während der Zeit der Eiablage, die oft mehrere 'Tage dauert, hält das

1) Beim Ueberblicken der Thatsachen kann man wohl hervorheben, dass festsitzende Thiere häufig $Z$ witter sind (Ascidien, Bryozoen, Cirripedien vgl. pg. 212, Spongien). Es gibt aber auch viele Ausnahmen und andererseits sind auch typisch freischwimmende Thiere Zwitter (Ctenophoren, Sagitta). - Bei den Schnecken finden wir, dass die ursprünglichen Meeresbewohner (Prosobranchier, Heteropoden) getrenntgeschlechtlich, andere Meeresbewohner (Opisthobranchier, Pteropoden) und die Land-und Süsswasser bewohnenden Pulmonaten Zwitter sind. Aehnlich verhalten sich die Anneliden, da die meisten Meeresanneliden getrenntgeschlechtlich, die Otigochaeten und Himdineen Zwitter sind. Dass der Parasitismus zur Zwittrigkeit führt, kann kaum behauptet werden; die parasitischen Plattwürmer sind Zwitter, ebenso wie ihre freilebenden Verwandten, während die parasitischen Nematoden wieder ebenso typisch getrenntgeschlechtlich sind. Wir können daher zusammenfassend hervorheben, dass gesetzmässige Ursachen für den Zwitterzustand $\mathrm{nicht} n$ a $\mathrm{ch}$ ge w iese $\mathrm{n}$ sind. Die Ansicht, dass der Zwitterzustand der secundäre sei, lässt sỉch nur für $\mathrm{manche}$ F älle mit einiger Wahrscheinlichkeit behaupten, z. B. für die Cirripedien.

Folgende Thiere sind Zwitter: Viele Spongien, Cnidarier nur ausnahmsweise (Cerianthus, Chrysaora, Hydra); die Ctenophoren, Plattwïrmer, Oligochaeten, Hirudineen; die oben angeführten Gastropoden (Pulmonata, Opisthobranchia, Pteropoda), einige Bivalven (z. B. die Auster), die Bryozoa und Phoronis, unter den Arthropoden nur die Cirripedien und die Tardigraden, unter den Echinodermen nur die Synaptiden und Molpadiden und manche Ophiuriden und unter den Wirbelthieren wenige Fische, nämlich Serranus-Arten. Als Abnormität kommt Zwitterbildung bei den verschiedensten Thieren vor.

Hatschek, Lehrbuch der Zoologie. 
Männchen das Weibchen umklammert und befruclitet die von letzterem abgehenden Eier.

Die echte oder innere Begattung kommt sowohl bei Zwittern (Techselkreuzung) als auch bei getreuntgeschlechtlichen Thieren vor; sie dient - wie schon oben erwähnt - zur besseren Sicherung der Befruchtung und führt daher zu einer Ersparung voll Geschlechtsproducten. In vielen Fällen ist sie durch gewisse Lebensverhältnisse nothwendig bedingt, wie z. B. bei allen landbewohnenden Thieren und bei Parasiten. Der Begattungsprocess ist schon für viele Abtheilungen von wirbellosen Thieren typisch, z. B. für die Scoleciden, Arthropoden, die meisten Mollusken (ausgenommen sind Bivalven, Chitonen, Scaphopoden).

Bei den Wirbellosen wird in der Regel die enpfangene Samenmasse vom Weibchen im Receptaculum seminis aufbewalırt und kommt erst während der Eiablage zur Verwendung, so z. B. bei den meisten Insecten (die meist ovipar, seltener vivipar sind).

Der Begattungsprocess steht nicht in nothwendiger Beziehung zur Entwicklung des Embryo innerhalb des mütterlichen Körpers. Dieses Entwicklungsverhältniss kommt auch vielfach ohne Begattungsprocess vor wie oben erörtert wurde; andererseits werden in jenen Fällen, wo echte Begattung vorkommt, die Eier sehr oft vor Entwicklung des Embryo abgelegt. Auch bei den Reptilien und Vögeln findet die Befruchtung zwar innerhalb des Eileiters vor Bildung der secundären Eihüllen statt, das Ei wird aber meist schon während der ersten Entwicklungsstadien abgelegt. Im abgelegten Vogelei ist die Furchung eben beendet und auf diesem Stadium bleibt das Ei bis zur Bebrütung stehen (selbst wenn diese eine Zeit lang verzögert wird, bleibt dasselbe entwicklungsfähig).

Ueberall, wo ein Begattungsprocess vorkommt, sind Begattungsorgane vorhanden, welche meist unmittelbar mit dem Endabschnitt der Ausführungswege verbunden sind. Zum männlichen Apparat gehört meist eine Vesicula seminalis, das ist ein Reservoir für die zu entleerenden Samenmassen - diese sind oft zu eigenthümlichen Gebilden, den Spermatophoren, verklebt - ferner ein Ductus ejaculatorius und meist ein vorstülpbarer Penis. Der weibliche Begattungsapparat besteht in der Regel aus einer Vagina, wozu häufig ein Receptaculum seminis kommt, das ist ein Reservoir für die aufgenommenen Samenmassen, die oft erst viel später, während der successiven Eiablage, zur Verwendung kommen.

Als Penis fungiren oft auch der männlichen Geschlechtsöffnung benachbarte heterogene Organe, z. B. bei den Krebsen benachbarte Beine, die hierzu ungestaltet sind. Auch entferntere Gliedmaassen können diesen Dienst versehen; so ist bei den Spinnen ein Maxillartaster zu einem complicirten Begattungsorgan umgestaltet. Eine der merkwürdigsten Einrichtungen kommt bei den Cephalopoden vor. Einer der Kopfarme ist in eigenthümlicher Weise zll einem als "Hectocotylus" bezeichneten Begattungsorgane umgewandelt; er nimmt die complicirten Spermatophoren auf und überträgt sie in die Mantelhöhle der Weibchen. In sehr hohem Grade ist dieser Arm bei einigen Arten (Philonexis, Tremoctopus, Argonauta) ungewandelt. Bei diesen reisst der Arm sogar beim Begattungsprocesse ab und lebt in der Mantelhöhle der Weibchen eine Zeit lang selbständig fort. Er wurde früher für einen Parasiten, dann selbst fiir ein merkwürdig gestaltetes Männchen gehalten, bis endlich der wahre Sachverhalt aufgeklärt wurde (Fig. 227). 
Dimorphismus der Geschlechter.

Männchen und Weibchen unterscheiden sich in den einfachsten Fällen nur durch die männliche oder weibliche Differenzirung ihrer'

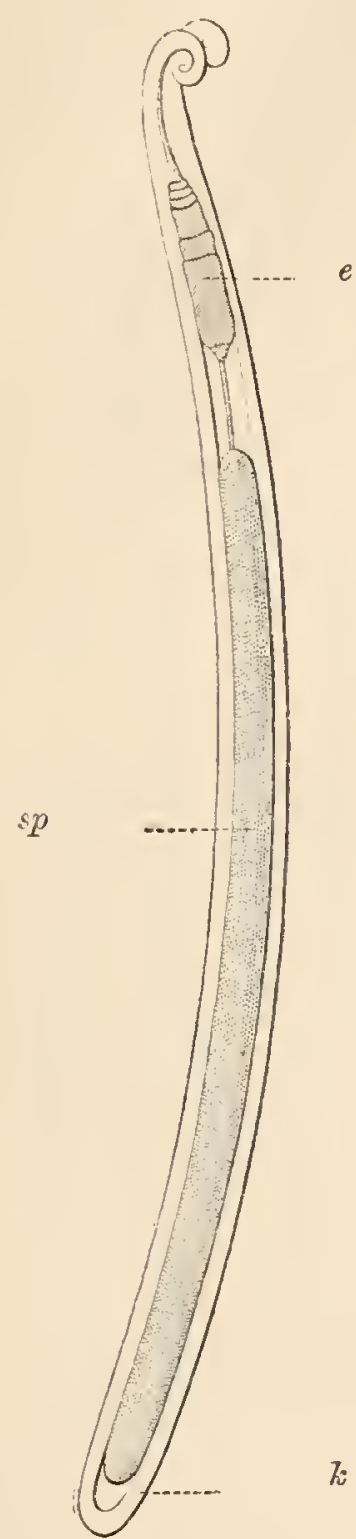
Gonaden. Oft sind aber auch andere Theile des Geschlechtsapparates (Ausführungsgänge etc.) verschieden gestaltet, und wo Begattungsorgane vorkommen, sind um so mehr auch diese ihrer Function entsprechend von einander sehr verschieden; oft sind alle Theile des Geschlechtsapparates bei beiden Geschlechtern der Anlage nach vorlianden und es kommen dann gewisse Theile bei dem Männchen, gewisse Theile beim Weibchen zu stärkerer Ausbildung, während die respectiven functionslosen Theile rudimentär werden (Wirbelthiere).

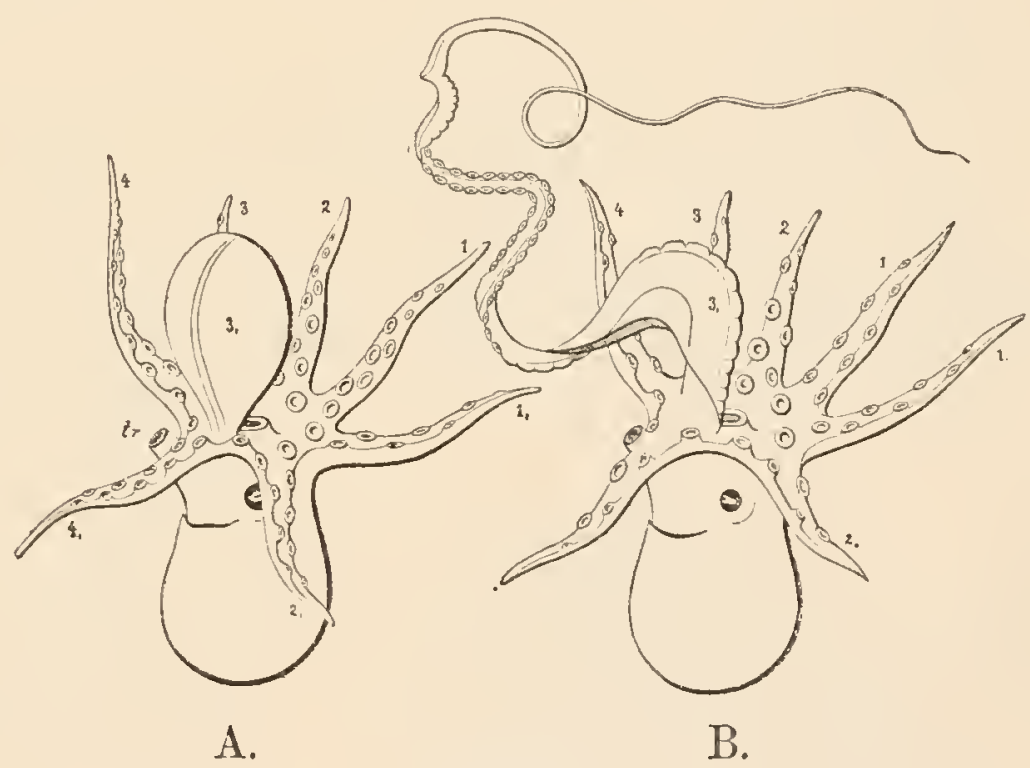

Fig. 227.

Fig. 226.

Fig. 226. Spermatophor eines Cephalopoden, Sepia officinalis (nach Milne-Edwards). 7 kapselartige Hülle, $s p$ Spermamasse, durch einen Verbindungsfaden mit $e$ dem Fjaculationsapparat zusammenhängend.

Fig. 227. Männchon von Argonauta, von der linken Seite gesehen (nach H. MüLLER.)

A. Der Hectocotylusarm ist noch in ein häutiges Säckchen eingeschlossen.

B. Der Hectocotylusarm ist bereits von dem bäutigen Säckchen befreit, welches noch als Hautfalte demselben anbängt. 1,2,3,4 Arme der rechten Seite (vom Rücken aus gezählt), $1_{1}, 2_{1}, 3_{1}, 4_{1}$ Arme der linken Seite.

Es kömmen aber auch noch andere Unterschiede zwischen Männchen und Weibchen auftreten, die oft nur in entfernterer Beziehung zum Fortpflanzungsgeschäft stehen und daher als secundär e Geschlechtscharaktere bezeichnet werden, wenn auch keine strenge Grenze zwischen diesen secundären und den zuerst genannten primären Geschlechtscharakteren sich ziehen lässt. Diese secundären Charaktere stehen ent- 
weder noch in gewisser Beziehung zur Begattung, Brutpflege etc. oder sie spielen eine Rolle bei der Bewerbung eines Geschlechtes um das andere (Schmuckfarben und andere Zierden, Ausbildung der Stimmorgane zum Lockruf und Gesang) oder auch bei den Kämpfen der Männchen um den Besitz der Weibchen (Angriffs- und Schutzorgane).

In vielen Fällen ist in der Oekonomie des Lebens eine Arbeitstheilung zwischen beiden Geschlechtern eingetreten, wodurch die Unterschiede einen sehr bedeutenden Grad erreichen können. Die auffallendsten Beispiele hierfür kommen bei einigen niedrigen Thierformen vor.

Bei den Räderthierchen (Rotatoria) sind die Männchen zwerghaft, sie entbehren des Darmkanales und haben während ihres kurzen Daseins im wesentlichen nur die geschlechtliche Thätigkeit zu erfüllen. Am auffallendsten ist wohl der von KowaLEvsky entdeckte Dimorphismus von Bonellia, einer merkwürdigen Annelidenform; die Weibchen sind mehrere Centimeter gross, die Männchen dagegen sind nahezu mikroskopisch klein, ohne Darmkanal, sie leben in Melrzahl parasitisch an den Weibchen, zur Zeit der Geschlechtsreife finden sie sich in der Vagina derselben. Bei einigen parasitischen Copepoden sind die Weibchen in Ampassung an den Parasitismus sehr verändert, wenig beweglich und von bedeutender Grösse, die Männchen dagegen sind von ursprünglicherer Gestalt, frei beweglich und viel geringer an Grösse.

Ueberaus interessante Verhältnisse wurden von DARwIN bei den Cirripedien entdeckt. Diese festsitzenden Crustaceen sind, wie bekannt, Zwitter und bilden hierdurch eine Ausnahme unter den typisch getrenntgeschlechtlichen Arthropoden. Es gibt aber, wie DARWIN entdeckte, auch getrenntgeschlechtliche Cirripedien und zwar mit ausgeprägtem

Dimorphismus der Geschlechter; die Weibchen sind von relativ ansehnlicher Grösse und festsitzend,

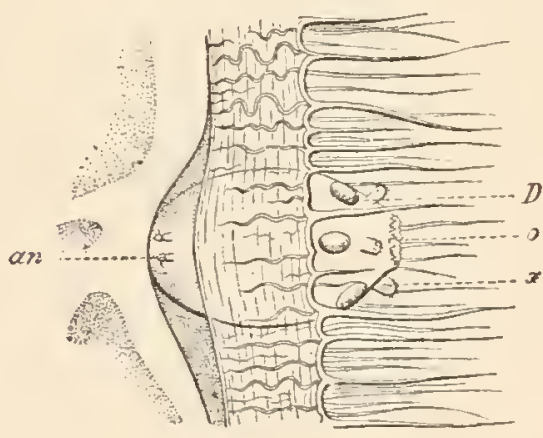

Fig. 228. Complementăres Männchen von Scalpellun vulgare, dem Körperrande (Schlussrand des Scutum) des Zwitters angeheftet (nach DARwIX). an die persistirenden Larvenantennen am vorderen Körperende, $O$ Oeffnung der sackförmigen Hülle des Männchens, $D$ rudimentäre Schalen, $x$ dornige Fortsätze am hinteren Körperende.

Es ist auch die merkwürdige Erscheinung zu verzeichnen, dass bei einer und derselben Thierart zwittrige und getrenntgeschlechthiche Generationen abwechselnd aufeinander folgen (Heterogonie). Dies kommt nämlich bei gewissen Nematoden vor. Es ist z. B. die eine Generation, die sogenannte Rhabditis-Generation, getrenntgeschlechtlich (wie die Nema- 
toden im allgemeinen), sie ist von geringer Grösse (1,5 bis $2 \mathrm{~mm}$ Länge) und lebt in feuchter Erde, die andere zwittrige Generation (mit ungleich-

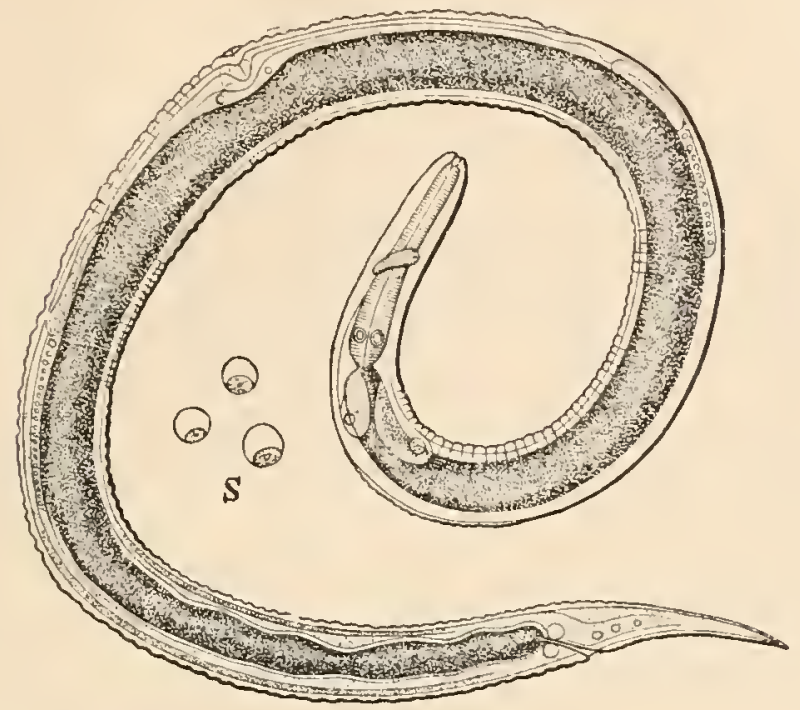

A.

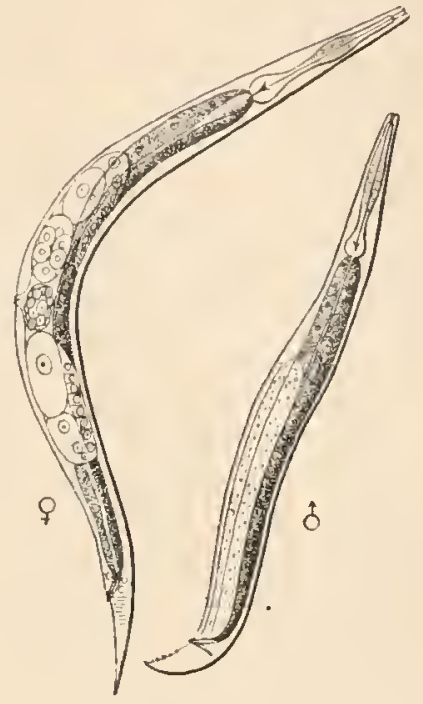

B.

Fig. 229. Die zwei Generationen, A. Rhabdonema nigrovenosum (Zwitter) und B. Rhabditis nigrovenosa (Männchen und Weibchen), die alternirend aufeinanderfolgen. $S$ einige Spermatozoen von Rhabdonema. (Aus Claus, L e hr b. d. Z.)

zeitiger Reife der Geschlechtsprodukte) lebt parasitisch in der Lunge des Frosches und ist bedeutend grösser (Länge $3,5 \mathrm{~mm}$ ), sie wird als Rhabdonema nigrovenosum bezeichnet. Aehnliche Verhältnisse finden sich bei Leptodera.

\section{Parthenogenese.}

Die Parthenogenese oder Fortpflanzung aus unbefruchteten Eiern ist aus der geschlechtlichen Fortpflanzung durch Wegfall der Befruchtung abgeleitet ${ }^{\mathbf{1}}$ ).

Da wir schon bei Volvox Parthenogenese antreffen, so möchte die Frage immerhin berechtigt erscheinen, ob dieselbe nicht schon gleichzeitig mit der geschlechtlichen Fortpflanzung aus den Zuständen, die wir bei den Protozoen antreffen, sich herausgebildet habe; es ist aber dagegen hervorzuheben, dass es nicht indifferente Fortpflanzungszellen, sondern dass es stets (auch schon bei Volvox) Eier mit allen ihren durch die Verhältnisse der geschlechtlichen Arbeitstheilung erworbenen Eigenthümlichkeiten sind, welche das Substrat für die Yarthenogenese abgeben; es ist auch zu berücksichtigen, dass die Parthenogenese immerhin nur von geringer Verbreitung im Thierreiche ist.

a) Gelegentliche Parthenogenese kennen wir bei manchen Insecten. Bei Schmetterlingen, z. B. beim Seidenspinner, wurde beobachtet,

1) Neuerdings hat Weismans hervorgehoben, dass bei Parthenogenese nur e in Richtungskörper, bei Entwicklung mit Befruchtung dagegen stets $\mathrm{z}$ wei derselben gebildet werden; dieses, "Zahlengesetz" muss noch durch ausgedehntere Untersuchungen geprïf werden und auch die Erklärungsversuche für dasselbe sind noch als provisorisch zu betrachten. 
dass Weibchen, die vom Puppenstadium an isolirt gehalten wurden, unbefruchtete Eier ablegen, aus welchen dennoch Räupchen auskriechen (in anderen Fällen werden nur die Anfangsstadien der Entwicklung durchlaufen, so dass es nicht zur wirklichen Production von Nachkommen kommt).

b) Normale Parthenogenese (Iso-Parthenogenese).

Bei vielen Insecten kommt auch $\mathrm{Par}$ thenogenese in regelmässiger Weise vor. Z. B. bei der Honigbiene entwickeln sich Königinnen und Arbeiterinnen aus befruchteten Eiern, während Drohnen parthenogenetisch d. i. aus unbefruchteten Eiern entstehen.

Die junge Bienenkönigin unternimmt, alsbald nach ihrer Verwandlung aus dem Puppenstadium, ihren Hochzeitsflug und kęhrt mit dem Begattungszeichen und von Spermatozoen erfülltem Receptaculum seminis in den Stock zurïck. Während ihrer ganzen Lebensdauer von $4-5$ Jahren reicht dieser Vorrath von Spermatozoen für das Fortpflanzungsgeschäft aus. Die Königin kann während der Eiablage Spermatozoen aus dem Receptaculum entleeren oder dies unterlassen, so dass die abgelegten Eier befruchtet oder unbefruchtet sind. Erstere legt sie in Königin- oder Arbeiterinnenzellen, letztere in Drohnenzellen. Flügellahme, zum Begattungstlug untaugliche Königinnen oder alte Königinnen, deren Receptaculum seminis schon entleert ist, können nur unbefruchtete Eier legen, sie sind „drohnenbrïtig“. - Die Arbeiterinnen sind bekanntlich reducirte Weibchen. Wenn eine Arbeiterlarve frühzeitig genug reichlicher gefüttert wird - wie eine Königinlarve - so kann sie zu einer normalen Königin sich entwickeln. Auch erwachsene Arbeiterinnen legen ausnahmsweise Eier $a b$ und zwar, da sie nicht begattet wurden, nur Drohneneier (Drohnenmütterchen).

Bei vielen niederen Süsswasserthieren, z. B. Räderthieren und kleinen Krebsthieren (Cladoceren, Ostracoden), wechselt die parthenogenetische und die geschlechtliche Fortpflanzung je nach der Jahreszeit (siehe unten), dabei sind die parthenogenetisch entwicklungsfähigen Eier von den befruchtungsfähigenverschieden (in Bezug auf Schale, Dotter etc.), an den ersteren erfolgt auch die Embryonalentwicklung schon im Mutterleibe, die letzteren werden abgelegt und überwintern als Eier.

\section{c) Hetero-Parthenogenese.}

Toch vollkommener ist die Anpassung an die Parthenogenese bei den Blattläusen (Aphiden). Bei diesen folgen in der Regel während des Sommers eine Reihe parthenogenisirender Generationen aufeinander, im Herbste dagegen treten Männchen und Weibchen auf, die sich geschlechtlich fortpflanzen. Hierbei ist folgendes zu bemerken: Es sind nicht nur die Eier je nach der Fortpflanzungsart verschieden, sondern es sind auch die parthenogenetisch sich fortpflanzenden Weibchen (sogenannte Ammen) von den begattungsfähigen Weibchen (sogen. Weibchen) zunächst in Bezug auf den Geschlechtsapparat verschieden; es fehlen den ersteren einige Theile des Geschlechtsapparates, die in Beziehung zur Begattung stehen (z. B. das Receptaculum seminis). Ferner sind sie a ch äusserlich von einander verschieden; z. B. sind bei Aphis die Ammen (sowie die Männchen) geflügelt, die Weibchen ungeflügelt, bei anderen 
Gattungelı, z. B. Phylloxera, tritt eine viel complicirtere Reihe geschlechtlicher und partlienogenisirender Formen auf.

d) Pa edo-Parthenogenese.

Dieser Heteromorphismus zwischen parthenogenisirenden und geschlechtlich sich fortpflanzenden Weibchen erreicht bei anderen Thieren einen noch löheren Grad dadurch, dass die Parthenogenese mit d e r Erscheinung der Pa edogenese, d. h. vorzeitigen (larvalen) Geschlechtsreife der Thiere, zusammenfällt. Hierher gehören die interessanten, von N. WAGNER entdeckten Fortpflanzungsvorgänge einer Gallmückenlarve Cecidomyia, sowie die ähnlichen Vorgänge bei der Puppe von Chironomus.

Wahrscheinlich sind gewisse Fortpflanzungserscheinungen der Distomeen, nämlich die Erzeugung der Cercarien in den Sporocysten und Redien, nach demselben Princip als Parthenogenese in Verbindung mit Paedogenese zu erklären (C. Grobien). - Der Embryo der Distomeen verwandelt sich nämlich, nachdem er in den Körper einer Schnecke parasitisch eingewandert ist, in eine sehr einfach gebaute darmlose S p o r o cy ste oder eine mit Darm versehene Redi e; diese erzeugt parthenogenetisch aus kleinen einfachen Eizellen (frülıer meist als Keimkörper oder Sporen bezeichnet) die nächste Generation, nämlich die geschwänzten, als Cercarien bezeichneten Distomeenlarven, welche wieder in den ersten Wirth (meist ein Wirbelthier) direkt oder durch einen Zwischenwirtl (Schnecke) gelangen und zu den Geschlechtsthieren auswachsen. Es kömmen auclı mehrere parthenogenisirende

Fig. 230. Larve einer Gallmücke (Cecidomyia) mit parthenogenetisch erzeugten Tochterlarven (nach PAGenstecher).

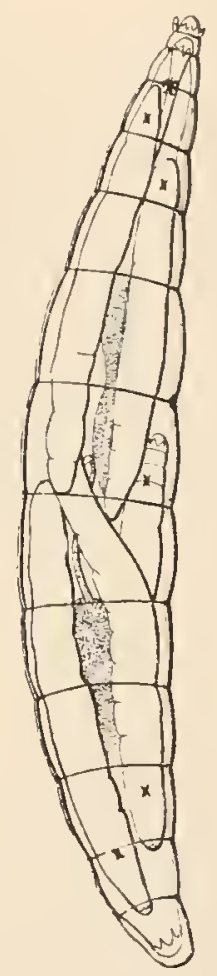

Generationen von Sporocysten oder Redien aufeinanderfolgen, deren letzte erst die Cercarienbrut erzeugt (Fig. 231).

Das Vorkommen der Partlenogenese im Thierreiche, in allen Abstufungen, von den einfachsten Fällen bis zu den vollkommenst angepassten, ist besonders in Zusammenhang mit gewissen Lebensverhältnissen zu beobachten. Die Parthenogenese findet sich vornehmlich bei niederen Süsswasser- und Landthieren, die dem Wechsel der Jahreszeiten ausgesetzt sind. In unseren Süsswässern sind es die Rotatorien, unter den niederen Crustaceen die Cladoceren und manche Ostracoden, die sich im Sommer durch Parthenogenese in rapider Weise vermehren, so dass die vorhandenen günstigen Lebensbedingungen rasch ausgenützt werden (auch ist der Wegfall der Männchen eine ökonomische Ersparung); bei Eintritt der ungünstigen Jahreszeit kommen auch Männchen zur Entwicklung und nun werden von den Weibchen zur gesclilechtlichen Fortpflanzung die meist hartsclialigen Wintereier erzeugt. Bei manchen Phyllopoden, z. B. Apus, hat die Parthenogenese sehr ïberhand genommen; die Mänmchen treten so selten auf, dass es erst nach längerem Forschen gelungen ist, dieselben zu fiuden. - Auf ähnlichen ökonomischen Principien beruht die Erscheinung der somnerlichen 
a.

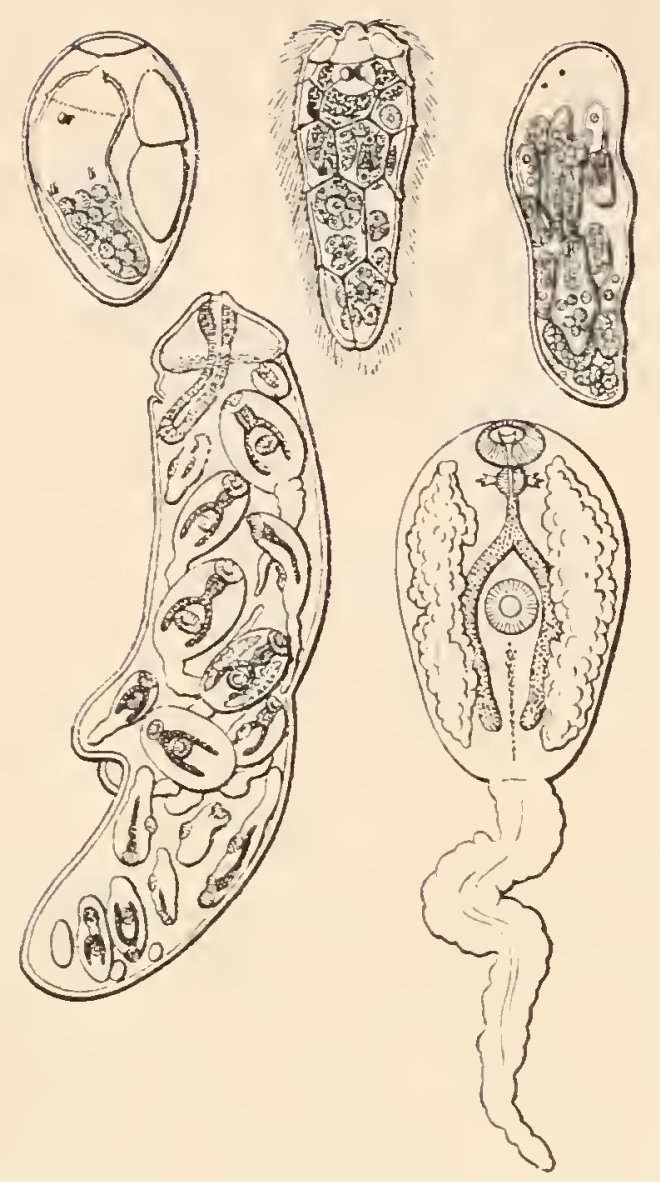

f.

$\mathrm{g}$. c.

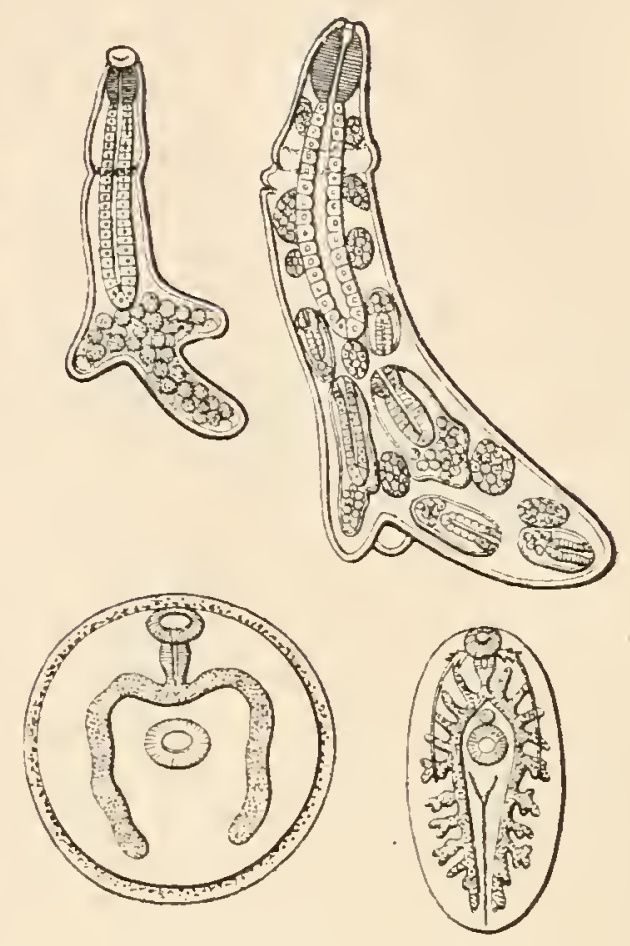

h.

i.

Fig. 231. Entwicklungscyclus von Distomum hepaticum (nach LeUckART).

a. Embryo, noch innerhalb der mit einem Deckel versehenen Eikapsel, neben demselben liegen Reste der Dotterzellen; b. Wimperlarve mit Stirnzapfen, hinter diesem ein $x$-förmiges Auge einem Gehirnganglion aufgelagert; darunter dunkelkörnige Zellen, die als rudimentärer Darm gedeutet werden; im Hinterkörper Keimzellen, z. Th. schon in Entwicklung begriffen; c. Sporocyste, die sich aus der Wimperlarve entwickelt hat; Andeutungen der Augenflecken sind noch sichtbar, im Inneren Redien in verschiedenen Zuständen der Entwicklung; d. junge Redie mit einfachem Darmkanal, im Hinterkörper Keimzellen; e. Redie, weiter entwickelt, im Inneren eine neue Redienbrut; f. Redie mit Cercarienbrut; g. Cercarie; h. dieselbe eingekapselt; i. jugendliches Distomum aus der Leber des Schafes.

Parthenogenese bei den Blattläusen und einigen anderen Insecten. Dagegen müsste die Erzeugung der Drohnen aus anderen Gesichtspunkten erklärt werden. - Nur bei den Distomeen ist es walrrscheinlich das parasitische Lebensverhältniss, welches wenigstens eine Mitursache der Parthenogenese ist.

\section{Theilung, Knospung.}

Bei vielen Metazoen kommt Fortpflanzung durch Theilung und Knospung vor. Bei der Fortpflanzung durch Theilung zerfällt der Organismus meist in zwei in der Regel annähernd gleich grosse Stücke; es werden dann an beiden Theilstücken die ihnen nun fehlenden Körperabschnitte durch Regeneration wieder ersetzt. Bei der Fortpflanzung durch Knospung wird nur eine beschränkte Stelle des Körpers zur Bildung eines neuen Individuums herangezogen; es wird dabei die Integrität des alten Körpers nicht bedeutend beeinträchtigt und die Neu- 
bildungen betreffen dann hauptsächlich die Knospe. - Wir sehen, dass diese Vorgänge viele Analogie mit den gleichnamigen Vorgängen der Protozoen zeigen, doch sind sie nicht phylogenetisch von denselben abzuleiten; in dem einen Falle handelt es sich um Vorgänge an der Zelle, in dem anderen Falle um Vorgänge am vielzelligen Körper. Das wesentliche dieses Unterschiedes wird bei genauerer Betrachtung noch mehr hervortreten, ebenso aber auch noch manche Uebereinstimmung in der Physiologie des Vorganges.

Theilung.

Regeneration im allgemeinen.

Um die Fortpflanzing durch Theilung zu verstehen, ist es nothwendig, zunächst die überaus wichtigen und interessanten Vorgänge der Regeneration ins Auge zu fassen. Regenerationsvermögen ist die Fähigkeit, verloren gegangene Körpertheile wieder zu ersetzen. Wir können z. B. beobachten, dass bei einem Wassersalamander (Triton), dem wir eine Extremität abschneiden, dieselbe wieder neu gebildet wird und zwar in einer ähnlichen Weise, wie die Bildung derselben am Embryo vor sich ging. Damit dies geschieht, müssen zuerst die Zellen nächst der Schnittstelle ihre vorhandenen Differenzirungen in einem gewissen Grade aufgeben, sich lebhafter vermehren und das Material zur Neubildung der Extremität liefern; dabei ist deren Leistungsfähigkeit beschränkt: Epithelzellen liefern wieder Epithelien u. s. w.; die Zellen greifen nicht uiber die Sphäre des Keimblattes hinaus, aus welchem sie entstanden sind (es ist aber in vielen Fällen ihre Leistungsfähigkeit auch auf ein engeres Gebiet als das des Keimblattes eingeschränkt).

Wir finden im Thierreiche die verschiedensten Abstufungen des Regenerationsvermögens. Im allgemeinen kann man den Satz aufstellen, dass, je niedriger die Differenzirung, um so bedeutender das Regenerationsvermögen der Organismen ist. Das Regenerationsvermögen soll dementsprechend auch beim Embryo nnd selbst beim jungen Thiere bedeutender sein als beim erwachsenen.

Sehr bedeutend ist das Regenerationsvermögen unseres Süsswasserpolypen Hydra. Die Versuche, welche Trembley im vorigen Jahrhundert hierüber angestellt hatte, erregten seinerzeit das grösste Aufsehen und wurden vielfach wiederholt. Weun man den Körper dieser Thiere der Quere oder der Länge nach in Stücke schneidet, so sind selbst kleine Stücke im Stande, zu einem vollständigen Individuum sich zu ergänzen; nur abgeschnittene Tentakehn können nicht mehr zu einem vollständigen Thiere auswachsen (anders lautende Angaben sind zweifelhaft). - Durch Schnitte, welche den Körper unvollständig durchtrennen, werden ebenfalls Regenerationsvorgänge eingeleitet und so köunen mannigfaltige Monstrositäten erzeugt werden.

Auch bei Thieren, die eine viel complicirtere Organisation haben, als Hydra, z. B. bei vielen Turbellarien und Anneliden, ist die Leistung des Regenerationsvermögens noch ganz erstaunlich. Wenn wir einem Thiere den Vorderkörper abschneiden, welcher so complicirte Organe, wie Gehirn, Simnesorgane, Oesophagus enthält, so sehen wir, dass dieser Körpertheil wieder ersetzt wird. Ebenso wird auch ein abgeschnittener Hinterkörper neugebildet. Es ist daher auch verständlich, dass ein querdurchschnittenes Thier sich zu zwei Individuen ergänzt, indem an 
dem vorderen 'Theilstück das fehlende Hinterende neugebildet wird und desgleichen an dem hinteren Theilstiick das fehlende Vorderende.

Bei Arthropoden und Molluslien ist das Regenerationsvermögen im allgemeinen gering; doch sehen wir beim Flusskrebs verloren gegangene Extremitäten nachwachsen; am häufigsten ist dies an den Scheeren zu beobachten, die beim Häutungsprocess leicht in Verlust gerathen; bei den Landschnecken wurde Regeneration des Augenstieles mit dem Auge beobachtet.

Bei den Echinodermen ist das Regenerationsvermögen oft sehr bedeutend; besonders bei Seesternen (vergl. unten) werden häufig Armstuicke oder ganze Arme, ja sogar Körperhälften wieder ersetzt.

Die Holothurien, welche leicht ihre gesammten Eingeweide ausstossen, sollen dieselben wieder regeneriren (dieser Vorgang wäre einer genaueren Untersuchung werth).

Bei den Vertebraten ist in den niedrigen Classen das Regenerationsvermögen in manchen Fällen noch bedeutend; so werden bei Triton noch abgeschnittene Extrenitäten oder der abgeschnittene Schwanz wieder ersetzt, ebenso bei Eidechsen der leicht abbrechende Schwanz. Aber auch den höheren Wirbelthieren fehlt das Regenerationsvermögen nicht gänzlich; sellost beim Menschen wurde beobachtet, dass bei Verlust der letzten Phalange eines Fingers in manchen Fällen an der vorletzten Phalange ein verkümmerter Fingernagel entsteht. Und endlich sind die Vorgänge der Wundheilung als bedeutsane Reste des Regenerationsvermögens $\mathrm{zu}$ betrachten.

Die Fortpflanzung durch 'Theilung beruht auf dem Regenerationsvermögen; aber nur in den ursprünglichsten Fällen ist dies ganz unmittelbar ersichtlich.

a) Theilung mit nachfolgender Regeneration.

Eine solche Vermehrung durch Theilung können wir bei vielen Thieren (Hydra, viele Turbellarien, Amneliden) künstlich herbeiführen, wie schon oben erörtert wurde. Es kommt auch in der Natur in ähnlicher Weise Selbst theilung mit nachfolgender Regeneration vor, z. B. unter den Anneliden bei Lumbriculus, Ctenodrilus; auch bei Seesternen und Ophiuriden (Ophiactis virens) ist ein älnlicher Vorgang beobachtet worden; der fünfstrahlige Körper zerbricht z. B. in zwei Stücke, deren eines dreistrahlig, das andere zweistrahlig ist; ersteres muss zwei, letzteres drei neue Radien bilden. Bei diesem ganzen Vorgange ist ein Verlust an Körpersäften unvermeidlich, ferner findet eine Durchreissung wichtiger Organe statt und es folgt eine wirkliche Wundheilung und eine zeitweilige Functionsunfähigkeit des unvollständigen Organismus.

b) Theilung mit vorzeitiger Regeneration.

Diese Fortpflanzungsart ist beispielsweise für die Annelidenfamilie der Naïdeen typisch. Wir sehen bei Nä̈s in der Mitte des segmentirten Körpers eine Wucherungszone - oder Regenerationszone - auftreten, welche alsbald durch eine scharfe Abgrenzung in einen vorderen und hinteren Regenerationsabschnitt sich sondert. Der erstere liefert eine Anzahl neuer Segmente, welche als neuer Hintertheil zur alten Vorderhälfte sich hinzufügen, der letztere liefert ebenfalls eine Anzahl neuer Segmente, welche einen neuen Vordertheil zur Ergänzung der alten Hinterhälfte liefern. Wir sehen, dass in jedes der beiden Individuen alte Segmente und neugebildete eingehen. Erst wenn die Neu- 
bildungen functionsfähig gewordeu sild, erfolgt die 'Treunumg der beiden Individuen. - Dieser Fortpflanzungsprocess ist viel vollkommener als der vorher betraclitete; vor allem ist hier die zeitweise Functionsunfähig-

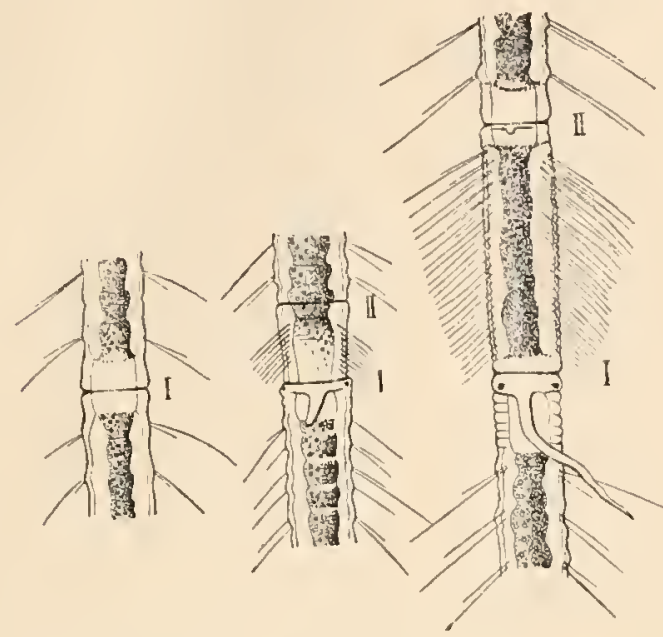

Fig. 232. Theilung von Naïs proboscidea (nach LEUCKART).

A. Die Regenerationszone ist durch eine Grenzlinie $(I)$ in einen vorderen und hinteren Theil gesondert. B. Eine neue Regenerationszone ist aufgetreten und ist durch die neue Grenzlinie $(I I)$ wieder in die zwei Abschnitte gesondert. Das $\mathrm{zwischen} I$ und $I I$ gelegene Individuum ist mithin ganz aus Regenerationsgewebe aufgebaut. C. Noch älteres Stadium. keit des Organismus beseitigt : der zusammenhängende Darm fungirt für beide Theile bis zum Zeitpunkte der Trennung und dann treten sofort die neuen Darmtheile in Function, ebenso bleibt auch die nervöse Verbindung zwischen beiden Theilen durch das alte Bauchmark hergestellt, wälırend das neue Bauclımark in der Regenerationszone schon weit ausgebildet ist, so dass es naclı der Durchreissung der 'Theile sofort in Function ist. Auch der Verlust an Körpersäften und die Wundheilung ist durch die Art der Abschnürung. nahezu eliminirt. -Dieser

Process ist phylogenetisch aus dem ersteren abgeleitet, er ist aber durch Anpassung bedeutend verbessert. Dies zeigt sich auch noch in einem anderen Punkte, nämlich in der raschen Aufeinanderfolge des Processes, die in vielen Fällen zu beobachten ist.

Bevor noch die ersten Individuen sich in der Regenerationszone von einander trennen, beginnt bereits an jedem derselben eine Regenerationszolle zweiter Ordnung sich zu bilden, ja sogar Regenerationszonen dritter und vierter Ordnung $u$. s. w. können schon auftreten, und es entsteluen so zeitweilig verbundene Individuenketten (zeitweilige 'Thierstöcke oder Cor'men). Je naclı der Art, wie die Regenerationszonen gesetzmässig aufeinanderfolgen, ist der Typus dieser Individuenketten ein mannigfach verschiedener.

Fig. 233. Individuenkette von Myrianida (nach MILNE-EDWARDS).

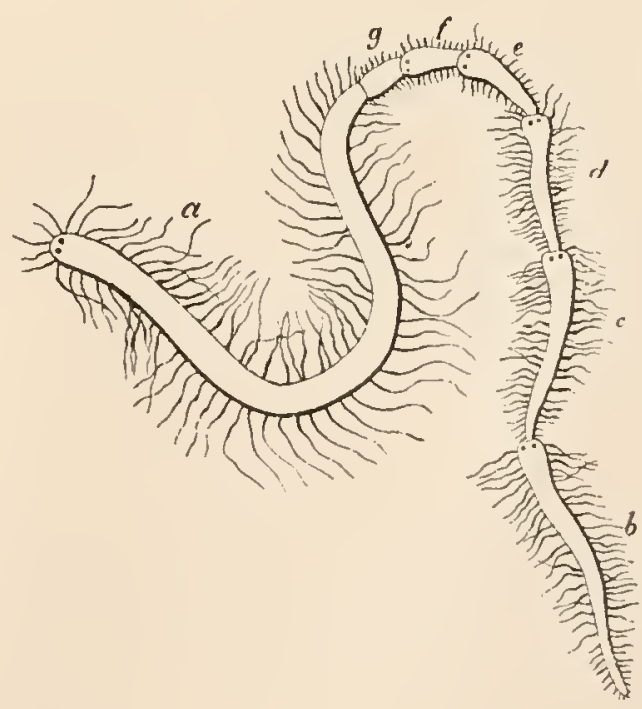

Wir wollen drei Beispiele (nach SEMPER) anführen. Erstens, es wiederholt sich der Theilungsprozess in gleicher Weise an allen Theilstuicken (regulär fortgesetzte Theilung). Zweitens, die Theilung wiederholt sich nur 

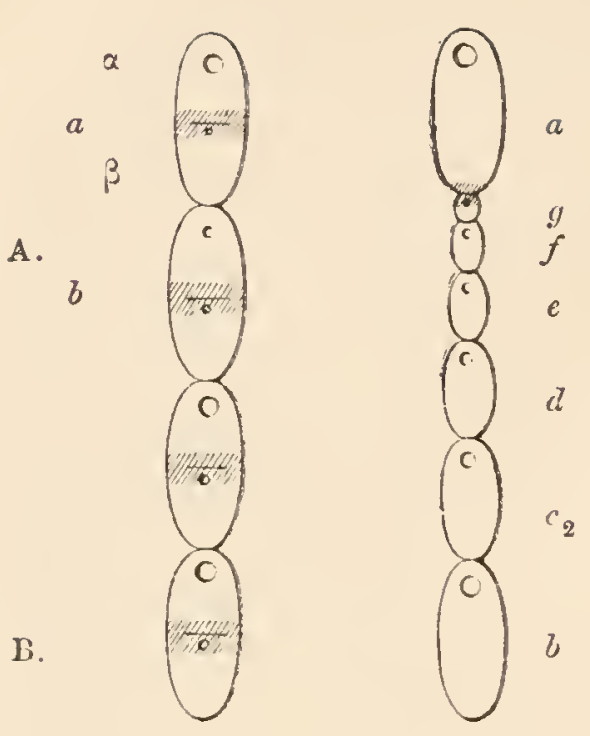

I.
II.

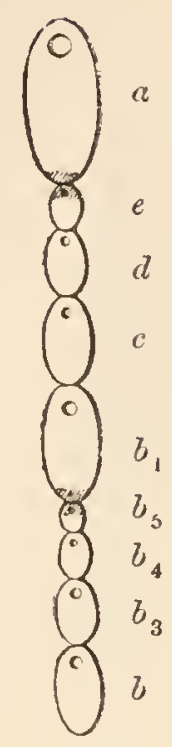

III.

Fig. 234.

1. Schema der regulär fortgesetzten Theilung (Microstomum, Chatogaster).

Il. Schema der serialen Theilung (Nais proboscidea, Myrianida).

1Il. Schema der wiederholten serialen Theilung (Nais harbata).

Diese Schemata stützen sich auf die Darstellung von SFMPER.

an dem ersten Individuum, so dass ron demselben eine Serie graduell verschiedenartiger Individuen ausgeht (seriale Theilung). Drittens, die seriale Theilung wiederholt sich und zwar zunächst an dem ältesten (hintersten) neugebildeten Individuum (wiederholte seriale Theilung.) Der zweite, von uns als serial bezeichnete Typus kann auch als Strobilatypus bezeichnet werden. Die seriale Theilung gewinnt bei rascher A ufeinanderfolge grosse Aehnlichkeit mit Knospungsrorgängeu, so dass sie oft schwer von denselben $\mathrm{zu}$ unterscheiden ist, besonders wenn das eine Theilstück des sich forttheilenden Individuums viel kleiner ist und beinahe als Neubildung erscheint.

Theilungsvorgänge kommen im Thierreiche besonders bei den niedrigeren Typen vielfach vor. Die Theilung kann eine vollständige sein oder eine unvollständige, d. h. es bleiben im letzteren Falle die Individuen in dauerndem Zusammenhang und es kommt zur Cormenbildung (siehe unten; ebenso kaun auch Knospung zur Cormenbildung führen). Bei den Spongien kommen Theilungsvorgänge häufig vor (daneben auch Knospung). - Bei den Cnidariern sind neben der typischen Knospung auch Theilungsvorgänge sehr verbreitet und zwar Quertheilung (vollständige) und Längstheilung (vollständig oder unvollständig). - Bei vielen Turbellarien und Anneliden (Naïdeen, Syllideen etc.) findet sich der oben ausführlicher geschilderte Typus von Quertheilung. Theilungsvorgänge bei den Echinodermen wurden bereits erwähnt. Im iibrigen kommt bei den höheren Thieren (über den Anneliden stehend) Fortpflanzung durch Theilung nicht mehr vor. Es wurde mit Recht darauf hingewiesen, dass sie nur bei jenen Thiergruppen sich findet, die auch sonst ein bedeutendes Regenerationsvermögen besitzen.

In jenen Fällen, wo die Theilungsvorgänge einen normalen Process im Lebenscyclus der Thiere bilden, finden sie stets an nicht geschlechtsreifen Individuen statt; mit dem Eintritt der Geschlechtsreife sistiren die Theilungsvorgänge (bei Süsswasserthieren steht oft der Wechsel auch dieser Fortpflanzungsarten in bestimmtem Zusammenhang mit dem Wechsel der Jahreszeiten). In vielen Fällen kommt es zum Dimorphismus zwischen den theilungsfähigen und den Geschlechtsindividuen. Oft kommt dies in sehr ausgeprägter Weise dadurch $z u$ Stande, dass die Theilung an Larvenstadien vor sich geht, also in den Entwicklungsgang eingeschoben ist (siehe unten bei Generationswechsel). 
c) Embryonale Theilung (mit vorzeitiger Regeneration).

Solche Thiere, die im entwickelten Zustande zu complicirt sind, um noch durch Theilung sich fortzupflanzen, können sich doch auf frïhem embryonalen Stadium, also in einem einfacheren Zustande, durch Theilung vermehren. So ist auch bei Wirbelthieren und sogar beim Menschen eine Vermehrung durch Theilung möglich. Zwillingsgeburten beim Menschen können nämlich auf zweierlei Weise zustande kommen; erstens, indem zwei Fier zur Entwicklung kommen und zweitens, indem der Embryo auf frühem Stadium durch Längstheilung in zwei Embryonen sich sondert, die sich dann beide weiter entwickeln. Solche Zwillingsbildung durch Längstheilung ist bei vielen Wirbelthieren, z. B. bei der Forelle und beim Hühnchen genauer beobachtet. Die Theilung kann auch unvollständig erfolgen, so dass zwei Köpfe an einem Rumpfe oder zwei Hintertheile an einem Vorderkörper sich finden; es gibt alle $\mathrm{Ab}$ stufungen von den ersten Andeutungen der Doppelmissbildung bis zu solchen Fällen, wo zwei Individuen nur noch durch unbedeutende Theile zusammenhängeu, oder endlich vollkommen sich trennen.

Es ist auch ein Fall bekannt, wo die embryonale Theilung als regelmässiger Fortpflanzungsact auftritt. Nach der Entdeckung von KLEINENBERG theilt sich nämlich bei Lumbricus trapezö̈des der Embryo bald nach dem Gastrulastadium in zwei Embryonen, welche beide zu normalen Individuen sich weiter entwickeln.

Ueber einige andere auf Regeneration beruhende Vor$\mathrm{g} \ddot{\mathrm{a}} \mathrm{ng} \mathrm{e}$.

Einige Erscheinungen, die nicht direct als Fortpflanzungserscheinungen zu bezeichnen sind, die aber ebenfalls auf Regeneration beruhen, wollen wir am besten an dieser Stelle besprechen.

Die sogenannte Proglottidenbildung bei den Cestoden ist keine vollkommene Fortpflanzung durch Theilung, sondern nur die wiederholte Abstossung eines Körpertheiles, nämlich des Hinterleibes, mit vorzeitiger Regeneration desselben - oder mit anderen Worten Theilung mit einseitiger volzeitiger Regeneration. Dass die abgestossenen Proglottiden nicht einem Individuum, sondern nur einem Hinterleib (also einer unvollständigen Individualität) entsprechen, lehrt die Vergleichung mit dem ungegliederten Caryophyllaeus. Bei Cestodenformen, wclche nur eine Wiederholung von inneren Organen, äusserlich aber nur wenig ausgeprägte Proglottidenbildung zeigen (Ligula), wäre nach dieser Anschauung die Proglottidenbildung secundär unterdrückt oder verwischt. - Wenn auch in der Proglottidenbildung keine vollkommene Vermehrung der Individuen vorliegt, so leistet doch dieser Process das Gleiche in Rücksicht auf die Oekonomie des Organismus.

Die Abstossung von Körpertheilen mit Regeneration derselben ist auch in auderen Fällen ein normaler Vorgang geworden. Wir wollen hier nur an die Abwerfung des Hectocotylusarmes bei manchen Cephalopoden-Männchen erinnern. Die bedeutendste Verwendung hat dieser Process aber bei der Larvenmetamorphose vieler Thiere gefunden. Theile, die bei der Metamorphose einer bedeutenden Umbildung unterliegen müssten, werden oft abgeworfen (oder resorbirt) und durch andere, morphologisch gleichwerthige ersetzt. Es werden z. B. die Tentakel der Phoronis-Larve (Actinotrocha) bei der Metamorphose abgeworfen und durch neue ersetzt, die schon 
vorher an der Basis der ersteren hervorsprossen. Wir sind der Ansicht, dass dies morphologisch gleichwerthige Organe sind und dass ein Abwerfen der Organe mit vorzeitiger Regeueration vorliege. Bei der Metamorphose der Phoronislarve wird auch der ganze Kopflappen mit dem primären Kopfganglion abgeworfen (uach Angaben besonders von CALDwLLL); wir dürften aber daraus wohl nicht ohne weiteres schliessen, dass dieses Ganglion dem entwickelten Thiere fehle, denn es könnte durch Regeueration wieder ersetzt sein. - Bei vielen Thieren geheu sehr ansehnliche Theile des Larvenkörpers bei der Metamorphose zu Grunde. Oft sind es z. B. nur geringe Theile der Leibeswand, die den Darm umwachsen und deu defiuitiven Körper liefern, während die übrigen Theile der Larve abgeworfen werden (Pilidiumlarven der Nernertinen, Larven der Seesterne, Seeigel etc.). Auch hier handelt es sich unserer Auffassung nach um vorzeitige Regeneration der abzuwerfenden Theile. Aehuliches liegt bei der Bildung der Embryonalhüllen bei Insecten und bei den höheren Wirbelthieren (Amnioten) vor, doch hier sind es nur weniger weseutliche Theile der embryonaleu Leibeswaud, die zur Bildung der vergänglichen Embryonalhüllen aufgebraucht werden ${ }^{1}$ ).

Bei der Metamorphose vieler Insecten unterliegt ein grosser Theil der Gewebe eiuem Zerfalle (Histolyse) und aus kleinen Theilen der ursprünglichen Organe findet eine Neubildung derselben statt. Auch hier ist also an Stelle einer bedeutenden Umbilduug die Regeneration getreten.

Gewiss sind auch viele andere uormale physiologische Processe aus dem Regenerationsvermögen abgeleitet, z. B. der Zahnwechsel bei Wirbelthieren, der Wechsel der Borsten bei den Anneliden. Wie weit sich dies überhaupt auf innere und äussere Vorgänge des Organismus anwenden lässt, bei welchen Zellen oder Zellkomplexe zu Grunde gehen und durch andere ersetzt werden, ist jetzt uoch kaum abzusehen.

\section{Knospung.}

A) Primordiale Knospung. Wenn wir die Knospung bei Hydra betrachten, so selien wir, dass die Knospe als eine kleine warzenförmige Erhebung auftritt; dieselbe wächst in die Länge und gewinnt die Form einer jungen Hydra, indem an ihrem freien Ende ein Tentakelkranz und die Mundöffnung entsteht; endlich löst sie sich vom Mutterthiere und stellt eine selbständige Individualität dar. Eine genauere Untersuchung lehrt, 1) dass die Knospe eine Ausstülpung der mütterlichen Leibeswand ist, so dass beide Körperschichten des Mutterthieres sich daran betheiligen und 2) dass die Differenzirungen, welche die benachbarte Leibeswand zeigt, an diesen wuchernden Schichten der jungen Knospe fehlen, und sich erst allmählich wieder herausbilden.

Diese Art von Knospung hat die grösste Verbreitung in der Abtheilung der Cnidarier (zumeist bei den Polypen, ausnahmsweise auch bei den Medusen). Die Knospen können beinahe an allen Stellen des Körpers entstehen, wo immer die zur Bildung der Knospe nothwendigen beiden Körperschichten vorhanden sind, oft sind besondere Ausläufer

1) Diese Vorgänge haben viele irrige Anschauungen veranlasst. - So wurde von manchen Forschern das definitive Thier als ein auf ungeschlechtlichem Wege (durch Knospung) erzeugter Sprössling der Larve betrachtet. - Bei Abstossung der Larventheile oder Embryonalhïllen müssen manche Theile secundär mit einander verwachsen, um die Continuität des Körpers wiederherzustellen. Es wäre nun irrig, daraus zu schliessen, dass solche Theile auch phylogenetisch aus getrennten Anlagen entstanden sind; es fehlt aber auch nicht an derartiger morplologischer Beweisfiihrung (KLEINENBERG). 
des Körpers als Stolo prolifer zur Erzeugung der Knospen bestimmt; nur manche besonders differenzirten Körpertheile sind allgemein von der Erzeugung von Knospen ausgeschlossen, so z. B. die Tentakeln. Die Kuospen lösen sich nicht immer vom Mutterthiere ab, sondern häufiger noch ist es der Fall, dass sie zur Colmenbildung verbunden bleiben. Je nach der Art und Weise, wie die Knospen gesetzmässig aufeinanderfolgen, nimmt der Cormus die verschiedenartigste Gestalt an, gerade so, wie bei Pflanzen der Wuchs und die Ramification von der Knospenfolge abhängt.

In vielen Fällen sind die knospenerzeugenden Individuen von den Geschlechtsindividuen verschieden; sie entsprechen oft persistirenden Larvenzuständen.

Aehnlich wie bei den Cnidariern spielt auch bei den Spongien die Knospung eine grosse Rolle und führt zur Cormenbildung.

B) Fortgesetzte Embryonalknospung. Bei complicirteren Organismen kann nicht mehr an irgend einer beliebigen Körperstelle durch Knospung eine neue Individualität entstehen, sondern nur an bestimmten, zur Knospung prädestinirten Körperstellen. Es muss in diesem Falle der Knospungsvorgang schon in einem Stadium beginnen, wo der ganze Organismus noch einfacher gebaut ist; es entsteht nämlich schon am Embryo eine Primärknospe, an deren Bildung sich die wichtigsten Primitivanlagen des Embryos (entweder die Keimblätter oder auch zahlreichere differente Anlagen) betheiligen, und von dieser Primärknospe spalten sich (direct oder indirect) alle späteren Knospenbildungen des Thieres ab. Die Entwicklung des Individuums aus den Knospenanlagen verläuft in ähnlicher Weise wie die Embryonalentwicklung des ersten Individuums. - Im übrigen ist die Erscheinung ähnlich der primordialen Knospung; die neuen Individuen kommen zur vollständigen Sonderung, oder sie bleiben zur Cormenbildung verbunden.

Wir findell diese Art von Knospung bei den Endoprocten und bei den Bryozoen (ectoprocta), fermer bei vielen Tunicaten. Wenn wir die Knospung mit der Theilung vergleichen, so wird uns die vielfache Uebereinstimmung beider Processe auffallell. In jenen Fällen von Theilung, wo die Theilstücke sehr ungleich sind, ist die Aehnlichkeit mit der Knospung eine seln grosse, doch ist dies wahrscheinlich nur eine Convergenz zu jener Erscheinung, nicht aber ein Uebergang zu derselben. Es ist nicht ausgeschlossen, dass einige der Fälle, welche wir als Knospung betrachteten, bei genauerer Allalyse als Theilung gedeutet werden mögen, wir neigen aber nicht zur Ansicht, dass die Knospung im allgemeinen einfach als ungleiche Theilung mit vorzeitiger Regeneration aufzufassen oder von derselbeu abzuleiten sei ${ }^{1}$ ). Wir möcliten aber hervorheben, dass Regeneration und Knospung auf ähnlichen Grundursachen beruhen. Man kann in gewissem Sinne (wie dies oft geschehen ist) die Regeneration als Knospung eines Körperstückes bezeichnen.

Die Knospung ist im einfachsten Falle (primordiale Knospung) nichts anderes als die allmähliche Isolirung einer Gruppe von Körperzellen, die sich um eine neue Achse centrirell, und ferner eine Wucherung und Neudifferenzirung dieses Materiales. (Die "Achse" ist

1) Anders ist dies bei den Protozoen; wir schliessen uns unbedingt der kürzlich von BüTsCHLI vertretenen Ansicht an, dass dort die Knospung auf ungleiche Theilung zurückführbar sei. 
ein ideeller Ausdruck für die Beziehung jeder Zelle zu ihrer Nachbarzelle und somit zum Ganzen.) Auf dieses selbe Princip sind auch die Knospungsvorgänge mit Primärknospe zurückzuführen.

\section{Generationswechsel. Individualitätslehre.}

Wir haben bereits früher hervorgehoben, dass die mannigfaltigen Arten der ungeschlechtlichen Fortpflanzung stets nur neben der geschlechtlichen vorkommen, und zwar in den meisten Fällen derart, dass die geschlechtlich sich fortpflanzenden Generationen mit den ungeschlechtlich sich vermehrenden in gesetzmässiger Weise alterniren. Wir

A.

$P$

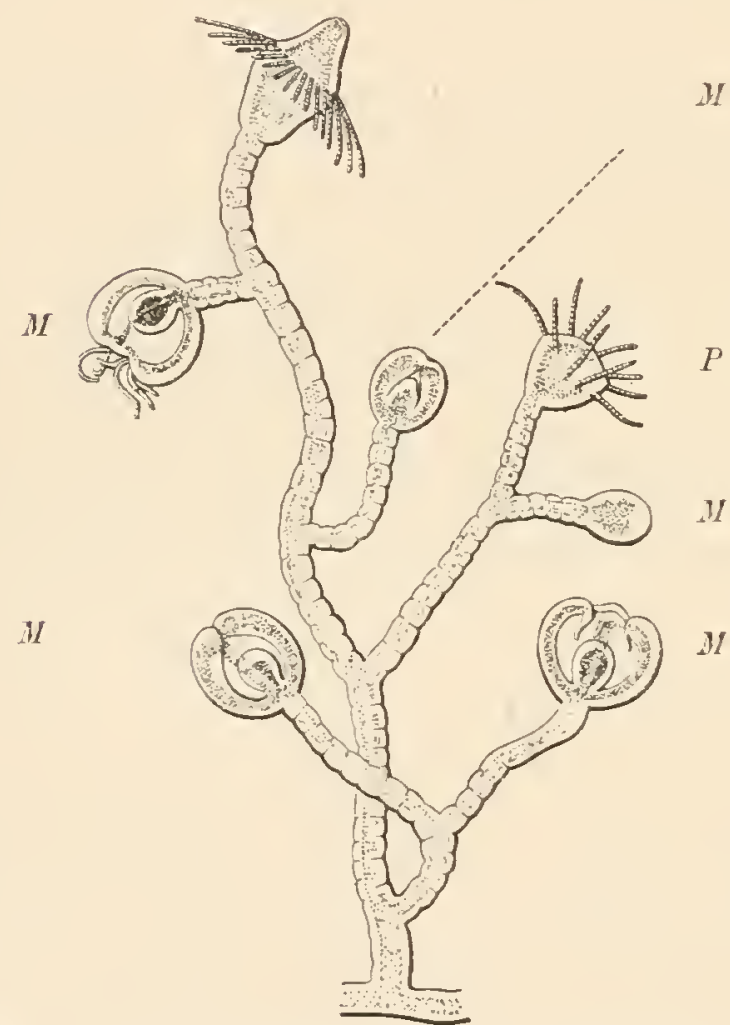

B.

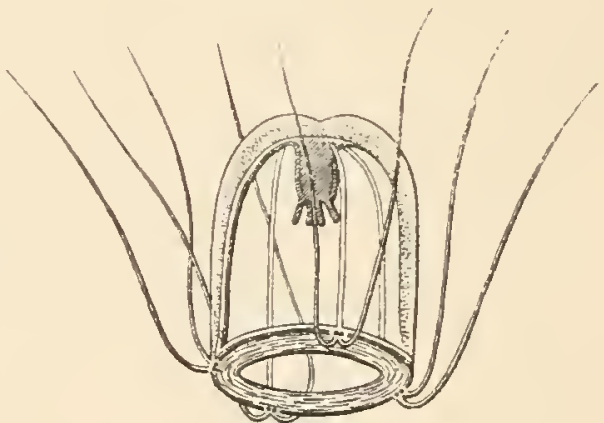

IJ Fig. 235. A. Stöckchen von Eudendrium ramosum. P Polypenindividuen, M Medusenknospen. B. Eine junge, freigewordene Meduse (Geschlechtsthier) dieses Stöckchens (Bougainvillia-Typus) (nach GEGENBACR).

haben ferner gefunden, dass in vielen Fällen bedeutende Unterschiede zwischen diesen (zwei oder mehreren) Generationen auftreten, und dass diese Verschiedenheit oft dadurch zu Stande kommt, dass die ungeschlechtliche Fortpflanzung an frühen Stadien (Larvenstadien) vor sich geht, also eine pädogenetische ist. - Wir bezeichnen als Generationswechsel die Erscheinung, dass zwei oder mehrereverschiedenartig sich fortpflanzende 11 nd auffallend verschiedenartig organisirte Generationen aufeinanderfolgen.

Der Generationswechsel wurde zuerst von dem Dichter und Naturforscher Chamisso bei den Salpen entdeckt und dies mannigfache Vorkommen dieser Erscheinung im Thierreiche wurde dann besonders von Steenstrup genauer erforscht. 
In jüngster Zeit, nachdem die Erscheinung der Heterogonie bei gewissen Nematoden entdeckt wurde, pflegt man auch die auf Parthenogenese beruhenden Vorgänge (bei Blattläusen, Distomeen etc.) vom Generationswechsel auszunehmen und zur Heterogonie zu rechnen. Es scheint aber dem Wortsinn und der historisch herkömmlichen Aus-

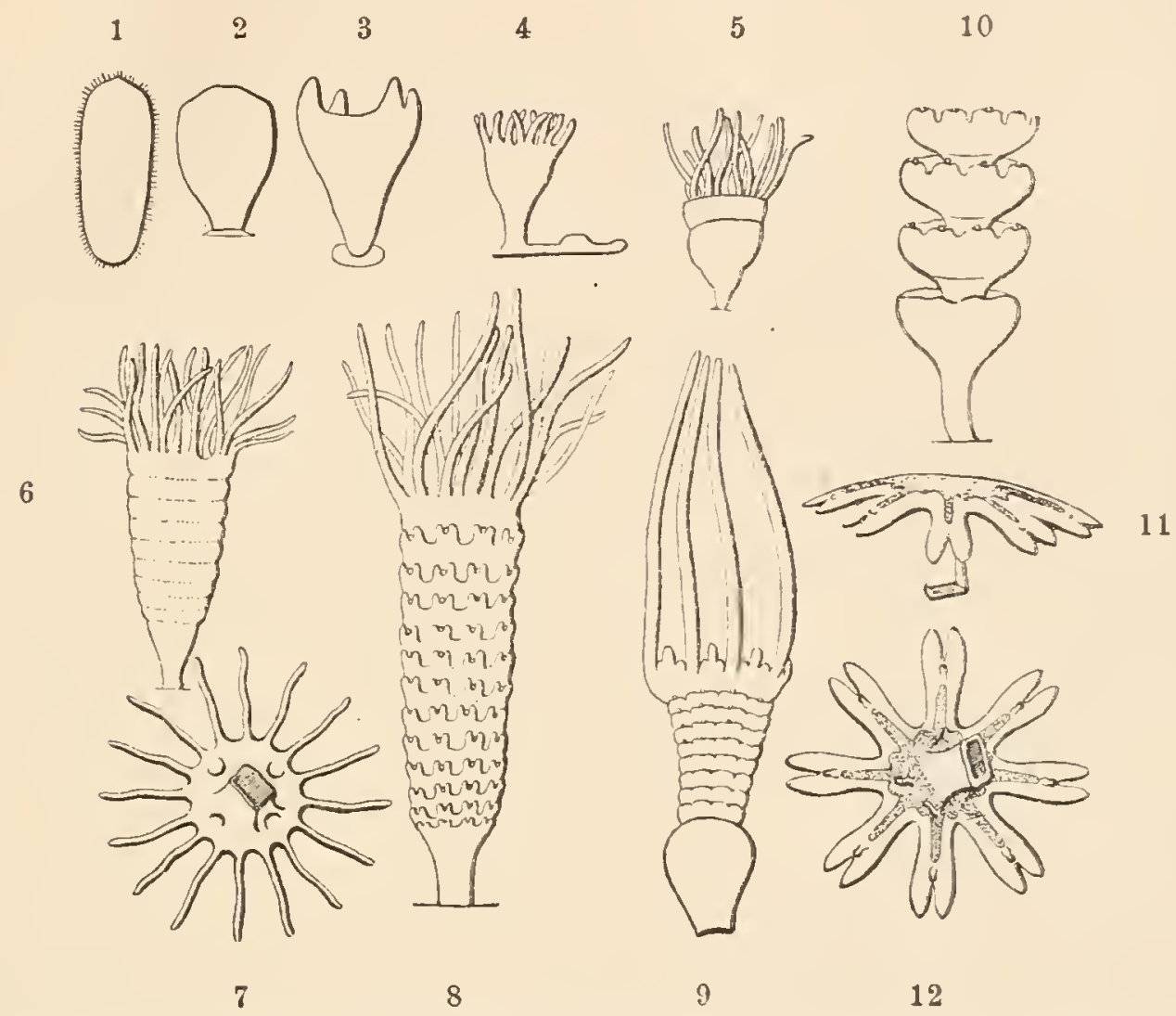

Fig. 236. Entwicklungscyclus einer Scyphomeduse (Aurelia) nach STEENsTrup und anderen. 1 Die aus dem Ei entstandene Flimmerlarve (Planula). 2 Dieselbe kurz nach dem Festsetzen. $3 \mathrm{Es}$ hat sich ein kleiner 4armiger Polyp entwickelt. 4 Es sind sechzehn Tentakel vorhanden, an der Basis des Polypen entsteht ein Stolo, aus welchem neue Polypen knospen. 5 Ein einzelner Polyp, an welchem die Quertheilung beginnt. 6 Die Quertheilung ist weiter vorgeschritten. 7 Polyp, vom Mundpole gesehen. 8, 9 Die Querstücke beginnen sich zu jungen Medusen zu bilden. 10 Die jungen Medusen (sogenannten Ephyren) lösen sich allmählich ab. 11,12 Die Ephyra von der Seite und von unten gesehen.

druckweise besser entsprechend, jede Aufeinanderfolge verschieden gebauter und verschieden zeugender Generationen als Generationswechsel zu bezeichnen; wir können in gewissem Sinne sogar die Heterogenie von Rhabdonema nigrovenosa und Leptodera unter den e rweiterten Begriff des Generationswechsels fasseu. Es handelt sich hier selbstverständlich nicht um eine verschiedene Auffassung, sondern nur um ein Uebereinkommen in Bezug auf die Benennung.

Der Generationswechsel beruht demnach in den verschiedenen Fällen:

1) auf Heterogonie (z. B. Rhabdonema nigrovenosa), (Fig. 229);

2) auf Parthenogenese (z. B. Blattläuse, Distomeen), (Fig. 231);

3) auf Theilung (z. B. Scyphomedusen), (Fig. 236):

4) auf Knospung (z. B. Hydromedusen), (Fig. 235).

Dabei ergeben sich die mannigfachsten Combinationen in der Aufeinanderfolge und den besonderen Eigenthümlichkeiten der Generationen. 
Wenn die durch Theilung oder Knospung entstandenen Individuen nicht $\mathrm{zu}$ vollständiger Trennung kommen, sondern organisch vereinigt bleibell, so entsteht ein Stock oder Cormus. Die Individuen desselben können gleichartig sein (homomorpher Cormus), oder aber im Sinne der Arbeitstheilung eine verschiedenartige Ausbildung erfahren (polymorpher Cormus). In dem letzteren Falle erscheint die ursprüngliche individuelle Bedeutung oft in hohem Grade verwischt.

Die Erscheinungen der Cormenbildung und des Polymorphismus hat vornehmlich LEUCKART, und zwar besonders an dem klassischen Beispiele der Siphonophoren, dargelegt. Bei denselben finden sich locomotorische Individuen, Nährindividuen, Fortpflanzungsindividuen etc. in einem Cormus vereinigt und die Art ihrer Thätigkeit, ihr Zusamnenwirken, ist ein derartiges, dass sie $\mathrm{physiologisch} \mathrm{nur} \mathrm{noch} \mathrm{wie} \mathrm{Or-}$ gane eines Individuums erscheinen. - Auch Hacckes hat diese Fragen eingehend erörtert. Er hat vor allem den Gegensatz von physiolog is cher und mor pholog is cher Individuali tä t hervorgehoben, und er hat eine Reihe von Graden der morphologischen Individualität aufgestellt. Einige dieser Grade haben sich aber nur als künstlich erwiesen und wir unterscheiden gegenwärtig wieder nur jene Grade der Individualität, welche schon aus den Auseinandersetzungen LEUCKART's hervorgehen. Unsere gegenwärtige Eintheilung ist: a) Individuum ersten Grades, Z ell e; b) Individuum zweiten Grades, Pers on; c) Individuum dritten Grades, Cormus. Durch weitere Zusammensetzung können auch Cormen höheren Grades entstehen. Jedes Individuum eines hölieren Grades durchläuft bei der Entwicklung stets alle früheren Individualitätsgrade.

In der Natur finden sich die verschiedensten Fälle, die nicht strenge in diese Eintheilung eingereiht werden können, z. B. die Proglottidenbildung der Cestoden (vergl. pag. 220). Die Bedeutuug des metamerischen Baues (Articulaten, Wirbelthiere) werden wir später noch $\mathrm{zu}$ erörtern haben; es ist die Frage zu beantworten, ob das metamerische Thier als Person oder Cormus, oder etwa ähnlich wie der Cestodenkörper als unvollkommen vervielfältigte Person zu betrachten sei.

\section{Vererbung.}

An die Betrachtung der Fortpflanzungserscheinungen wollen wir einige Bemerkungen über die Theorie der Vererbung anknüpfen. Aufgabe dieser Theorie ist es, den ursächlichen Zusammenhang zwischen den Erscheinungen einer Generation und den gleichartigen Erscheinungen einer nachfolgenden Generation zu erklären - oder mit anderen Worten die ganze Kette von Vorgängen zu erklären, welche zwischen diesen Erscheinungen liegen. Die Theorie hat nicht nur die Wiederholung der typischen Erscheinungen zu begründen, sondern sie hat auch auseinanderzusetzen, in welcher Weise neu auftretende Eigenschaften eines Organismus auf die nachfolgenden Generationen weiter vererbt werden (oder auch welche neu auftretenden Eigenschaften vererbt werden) und es wird mit Recht auf diesen Theil der Theorie grosses Gewicht gelegt.

Wir wollen die Vererbungstheorie zunächst nur von der einen Seite betrachten, indem wir uns zuvörderst darauf beschränken, vornehmlich die Wiederholung der typischen Erscheinungen zu erörtern. Wir sehen, dass das complicirte Individuum aus der einfachen Eizelle durch Differenzirungsprocesse sich entwickelt und dass wieder einfache Eizellen (oder Fort- 
pflanzungszellen) ron demselben gebildet werden; das Wesen dieser Processe zu erklären ist Aufgabe der D ifferenzilungstheorie. Ferner beobachten wir, dass die Charaktere zweier Individuen beim Befruchtungsprocesse vermischt werden; das Wesen dieser Vermischung soll durch die Befruchtungsthe orie erläutert werden. Dies sind die beiden Theorien, in welche die Vererbungstheorie sich gliedert.

Die Theorie der Differenzirung hat eine zweifache Aufgabe; sie hat sowohl die Entwicklung des Organismus aus dem Ei zu erklären, als auch die Wiedererzeugung von Fortpflanzungszellen im Organismus.

Die alte Präformations- (oder Evolutions-) Theorie, welche annahm, dass im $\mathrm{Ei}$ der ganze Organismus bereits vorgebildet sei und durch blosses Wachsthum und Auswickelung der Organe in Erscheinung träte, kannte eigentlich keine Differenzirung. Erst CASPar Friedrich WolfF, der uns in seiner Theoria generationis mit den Entwicklungsvorgängen im Ei des Huhnes bekannt machte (1759) hat die Differenzirungsvorgänge entdeckt und die Bedeutung derselben gewürdigt (Epigenesis-Theorie). Wir wollen nun einige neuere Theorien betrachten, welche den ursächlichen Zusammenhang der Differenzirungsvorgänge aufzudecken streben.

Es sind dies die „Pangenesis-Theorie“ von Darwin, die „IdioplasmaTheorie" von Nägeli, und Weismans's "Theorie von der Continuität des Keimplasmas". Alle diese Theorien sind als Vererbungstheorien aufgestellt; wir wollen aber an dieser Stelle zunächst jene Theile der Theorien besonders berücksichtigen, welche sich auf die Differenzirung beziehen, um so diese wesentlichen Punkte besser hervorzuheben.

Darwin nimmt an, dass von allen Zellen des Körpers, also von denjenigen der Haut, der Muskeln, der Knochen, des Gehirns, der Augen etc. kleinste Theilchen (in der deutschen Uebersetzung werden sie Keimchen genannt, man könnte vielleicht bezeichnender Keimtheilchen sagen) sich ablösen und nach den Generationsorganen transportirt werden, um dort in den Fortpflanzungszellen abgelagert zu werden. So kommt es, dass alle Qualitäten aus den verschiedensten Körpertheilen in den Fortpflanzungszellen enthalten sind - und zwar, wie wir besonders hervorheben wollen, neben e in ander vorhanden sind - und dass dieselben bei der Entwicklung nach den entsprechenden Körpertheilen vertheilt werden und dort in entsprechender Weise zur Geltung kommen. Die grosse Schwierigkeit dieser Theorie liegt darin, zu zeigen, wie alle diese Keimtheilchen, die zu den Fortpflanzungszellen gelangen, dort in eine solche Anordnung kommen, dass sie bei der Entwicklung wieder in entsprechender Weise vertheilt werden können; diese Theorie ist von DARWIN selbst als eine provisorische bezeichnet worden und hat gegenwärtig wohl nur wenige Anhänger.

NäGELI nimmt an, dass als Ursache aller Differenzirungen eines Organismus das "Idioplasma" zu betrachten sei, eine (theoretisch construirte) Bildung ron bestimmtem, complicirtem, und zwar je nach der Höhe der Organisation mehr oder weniger complicirtem Baue. Es wird angenommen, dass neben dem Nährplasma oder "Stereoplasma“ das Idioplasma einen charakteristischen und wesentlichen Theil des Zellplasmas bildet. Das Idioplasma soll in gleichartiger Beschaffenheit in allen Zellen des Körpers enthalten sein, und zwar in Form eines Gerüstes von netzartig verzweigten Fäden, welches sich mit dem der benachbarten Zellen rerbindet, so dass es ein zusammenhängendes Ganze im gesammten Körper der Pflanze oder des Thieres bildet. Das fadenförmige Idioplasma soll aus einer ungeheuren Anzahl von Elementartheilchen aufgebaut sein, die als "Micelle“ bezeichnet werden. In einem und demselben Idioplasma gibt es viele rerschiedene Qualitäten von 
Micellen und die gleichartigen sind zu einander in Längsreihen angeordnet; der Idioplasmafaden besteht daher aus einer grossen Zahl unter sich verschiedener Micellreihen. Bei der durchwegs gleichartigen Beschaffenheit des Idioplasmas ist die Mannigfaltigkeit der Differenzirungen in den verschiedenen Körpertheilen dadurch bedingt, dass in jedem dieser Theile verschiedene Combinationen von Micellreihen zur Geltung kommen (in Erregung oder Thätigkeit sind), während die übrigen Micellreihen in latentem Zustande verharren. Es sind demnach in allen Körperzellen wohl potentiell dieselben Qualitäten rorhanden, nur dass je nach den Umständen bald die einen, bald die andern derselben in Kraft treten. Die Eizelle enthält dasselbe Idioplasma wie alle Körperzellen, und so ist es erklärt, dass alle Qualitäten des Körpers schon in der Eizelle - und zwar, wie wir wieder herrorheben wollen, nebeneinander - rorhanden sind.

Auch Weisuann nimmt an, dass es ein besonderer Bestandtheil der Zelle sei, der die Differenzirungserscheinungen derselben rerursacht und beherrscht. Mit Rücksicht auf die bedeutungsvolle Rolle, die nach den neueren Forschungen der Zellkern bei der Zelltheilung und besonders bei der Befruchtung, sowie auch bei anderen Vorgängen spielt, glaubt WEIsmann in Uebereinstimmung mit vielen anderen Forschern im Kern (und $z$ war im Chromatin desselben) jenen wichtigen, die Differenzirungen beherrschenden Bestandtheil der Zelle zu finden. Er ist daher auch geneigt, den Namen Idioplasma auf jene Kernsubstanz, welcher ebenfalls eine complicirte Zusammensetzung zugeschrieben wird, anzuwenden; doch stimmen die übrigen Vorstellungen, die W. von der Kernsubstanz hat, wie er selbst auch herrorhebt, wenig zu dem Begriff des NäGEur'schen Idioplasmas; abgeselen davon, dass die Kerne getrennte Gebilde sind und nicht etwa ein zusammenhängendes Gerüstwerk im Gesammtkörper der Pflanze oder des Thieres bilden, sind sie auch nach der Differenzirungstheorie Weisnans's nicht ron gleicher, sondern von verschiedener Beschaffenheit, denn alle die rerschiedenen Qualitäten, die an den verschiedenartigen Zellen des Körpers beobachtet werden, sind begründet in den verschiedenen Qualitäten der zugehörigen Zellkerne. In dem Zellkerne der Eizelle (oder Fortpflanzungszelle) aber sind die Qualitäten jener verschiedenen Zellkerne alle nebeneinander vorhanden. Während der Entwicklung werden diese verschiedenen Qualitäten nach den rerschiedenen Zellen vertheilt und $z$ war ganz entsprechend der successice und gruppenweise erfolgenden Differenzirung der embrjonalen Zellen. Es hat demnach das Karyoplasma der Eizelle (oder Fortpflanzungszelle), welches von W. als K e i m p la sma bezeichnet wird, den complicirtesten Bau, es erfährt während der Entwicklung durch Auseinanderlegung eine successive Vereinfachung und es hat daher das Karyoplasma in den differenzirten Körperzellen den einfachsten Bau. Die Bildung von neuen Fortpflanzungszellen wird durch die „Continuität des Keimplasmas" erklärt. In gewissen Zellen des Embryo erhält sich nämlich das complicirte Keimplasma und diese Zellen liefern dann die Fortpflanzungszellen. Da dies keineswegs immer undifferenzirte Zellen sind, so wird der Vorgang als eine Versendung des Keimplamas auf dem Wege mehr oder auch weniger differenzirter Zellen betrachtet, die daher neben ihrem specialisirten Karyoplasma auch complicirtes, nicht specialisirtes Keimkaryoplasma enthalten. Also auch nach der Theorie von Weismann sollen 1) alle Qualitäten des Körpers in der Eizelle (oder Fortpflanzungszelle) n eben ein a nd er rorhanden sein. 2) Der complicirten Structur des Keimkaryoplasmas wird aber die einfache Structur des Karyoplasmas der differenzirten Zellen gegenübergestellt. 3) Es sind nach der Auffassung Weismann's alle die Arten von Karyoplasma, welche in den 
Keimzellen gesammelt, in deu differenzirten Körperzellen getrennt auftreten, an und für sich ontogenetisch unveränderliche Gebilde - in gewissem Sinne wieder ähnlich dem Idioplasma NäGELI's.

Wir wollen nun versuchen in folgendem unsere eigenen Anschauungen auseinander zu setzen. In manchen wichtigen Punkten können wir der Theorie Weismann's nicht zustimmen. Wenn wir uns gegen eine so scharfsinnige, festgefiugte und mit Berücksichtigung der verschiedensten Erscheinungen aufgebaute Theorie wenden, so wissen wir wohl, dass dies nur aus zwingenden und sehr allgemeinen Gründen geschehen darf. In vielen Punkten finden wir uns in Uebereinstimmung mit den Anschauungen von Strasburger, v. Koelliker, Th. Eimer und Grobben, es iet aber hier nicht möglich im einzelnen darauf hinzuweisen.

a) Constitution der Z elle.

Unter Constitution der Zelle wolleu wir die gesammten inneren Bedingungen (Mechanismus und Chemismus) der Zelle verstehen, welche sowohl ihre Thätigkeit, als auch - was wir hier speciell berücksichtigen - ihre Differenzirungserscheinungen verursachen. Wir unterscheiden an der Zelle jene Theile, welche stets schon an der jungen „undifferenzirten“ Zelle vorhanden sind, als primäre Theile (primäre Differenzirungen) und andere Bildungen, die später hinzukommen, wie z. B. Einschlüsse, Abscheidungen, Umwandlungsprodukte des Plasmas, als secundäre Differenzirungen. Da die letzteren von den ersteren Theilen verursacht, oder genauer gesagt, erzeugt werden, so kommen nur die primären Bestand theile als Factoren der Constitution in Betracht.

In jüngster Zeit hat sich vielfach das Bestreben geäussert, auch unter den primären Bestandtheilen der Zelle, dem einen Theile grössere Bedeutung für den Charakter der Zelle zuzuschreiben als den anderen, man hat denselben als überwiegenden, ja sogar als alleinigen Factor der Constitution hingestellt. Eine solche Tendenz liegt schon in der Aufstellung von NïgelI's Idioplasma vor. Eine greifbare Form hat die Annahme gewonnen, da man neuerdings den Zellkeru als jenen wichtigen oder alleinigen Factor der Constitution bezeichnete.

Die Function des Zellkerns ist aber noch keineswegs durch die Beobachtung genügend klar gestellt, Während wir z. B. aus den anatomischen Verluältnissen eines Organismus die Function seiner einzelnen Organe erschliessen können, ist es gegenwärtig nicht möglich, aus dem Bau des Zellkerns seine Function zu erklären; unsere Kenntnisse des Baues der Zelle sind eben noch zu unvollkommen und sie sind auch noch fortwährenden Wandlungen unterworfen.

Für die Anschauung, dass der Zellkern allein die Differenzirungen der Zelle beherrsche, lässt sich nur die eine Beobachtung geltend machen, dass bei der Befruchtung nur der Kern des Spermatozoou in die Eizelle eindringt, dass dieser also - wie man annimmt - allein die Constitution der männlichen Fortpflanzungszelle zu übertragen vermag. Hier ist aber weder die Forschung noch die Erklärung endgilıig abgeschlossen. Wenn vollkommen festgestellt wäre, dass ein Zellbestandtheil allein die Constitution der Zelle übertragen kann, so möchte man aus allgemeinen Gründen zu der Annahme kommen, dass die Verschiedenheit der typischen Zellbestandtheile nur eine actuelle und nicht eine virtuelle wäre - oder aber, dass dieser eine Bestandtheil die übrigeu Theile der Zelle aus sich wieder erzeugen könne so dass er dann eigentlich allein als der primäre Theil aufzufassen wäre.

Für die Theorie der Differenzirung ist damit nichts gewonnen, dass wir die Ursachen der Differenzirung statt in die ganze Zelle in einen Theil der- 
selben verlegen, es sei denn, dass wir auch die Art seiner Wirkung darlegen könnten ${ }^{1}$ ); sonst ist die Erklärung damit nur zurückgeschoben. Wir werden daher bei der Fortsetzung unserer Betrachtungen nur von der Constitution der Zelle im allgemeinen sprechen, es bleibt aber jedem unbenommen, die betreffenden Auseinandersetzungen auf die Constitution speciell des Kernes (des Chromatins oder des ganzen Kernes, oder dazu noch der Attractionssphäre) zu beziehen.

b) Differenzirungsvorgänge.

Die Differenzirungsprocesse, welche wir bei Protozoen beobachten, sind im Wesentlichen als Rückdifferenzirung und Aufdifferenzirung zu unterscheiden. So sehen wir z. B., dass bei der Encystirung eines Infusors seine adorale Wimperzone, seine Griffel, Borsten, Muskelfibrillen rückgebildet werden, das Infusor nimmt die Form der ruhenden (oder rückdifferenzirten) Zelle an; diese kann dann unmittelbar wieder aufdifferenzirt werden. Es kann aber auch zunächst eine wiederholte Theilung der rückdifferenzirten Zelle erfolgen und erst die Theilstücke erfahren sodann jedes für sich die Aufdifferenzirung. Wir führen diese fundamentalen Erscheinungen auf die Constitution der Zelle - d. i. auf die constant bleibenden primären Differenzirungen zurück. Wenn wir einen Theil des Infusorienkörpers entfernen, so kann derselbe durch eine partielle Aufdifferenzirung ersetzt werden (Regeneration, Theilung des differenzirten Organismus); daraus sind wichtige Schlüsse auf das Wesen der Constitution zu ziehen, auf die wir hier nicht näher eingehen können.

Die ursprünglichsten vielzelligen Organismen bestehen aus gleichartigen Zellen, deren jede durch Rückdifferenzirung zur Fortpflanzungszelle werden kann, um sodann durch Theilung und Aufdifferenzirung einen neuen Cormus zu liefern. Die Vorgänge sind hier unschwer auf diejenigen der Einzelligen zurückzuführen. Aehnlich sind die Verhältnisse bei vielen Pflanzen.

Bei den vielzelligen Organismen mit polymorphen Zellen (z. B. Metazoen) findet bei der Entwicklung aus dem Ei ebenfalls eine Aufdifferenzirung statt. Doch ist hierbei noch folgendes zu beachten. Die durch fortgesetzte Theilung aus der Eizelle herrorgegangenen Zellen erfahren nicht gleichartige, sondern verschiedenartige Differenzirung. Der ganze Differenzirungsprocess geht nicht an jeder einzelnen Zellindividualität vor sich, sondern die graduelle Differenzirung betrifft zunächst grössere und bei weiterem Fortschreiten immer kleinere Complexe von Zellen; während dessen nimmt auch die Zelltheilung noch ihren Fortgang. Die ersten Differenzirungsvorgänge sind also noch für solche Zellcomplexe gemeinsam, die später verschieden werden.

Die Bildung der Fortpflanzungszellen geschieht besonders bei den niedrigeren Metazoen durch Rückdifferenzirung von Zellen, welche schon in einem gewissen Grade differenzirt waren. Doch ist es bei keinem Metazoon der Fall, dass alle Arten von Körperzellen befähigt wären, durch Rück-

1) Man könnte liierüber mancherlei Theorien aufstellen. Wenn man dem Zellkern eine bestimmte Function zuschreiben wollte, so müsste man woll an eine der fundamentalen Functionen, Assimilatiou, Irritabilität, Contractilität denken; eigentlich ist die Assimilation die ursprünglichste derselben. Durch die Annahme, dass der Zellkern ein Organ der Assimilation (und somit des Wachsthums) der Zelle sei, liesse sich wohl die grosse Bedeutung des Zellkerns für die charakteristische Beschaffenheit der Zelle darthun, da diese ja wesentlich mit der charakteristischen Assimilation zusammenhängt. Wir werden aber besser bei unseren weiteren Ausfülırungen von einer solchen oder einer anderen Hypothese ganz absehell. 
differenzirung zu Fortpflanzungszellen zu werden, sondern es gilt dies nur für gewisse Zellen, während die anderen diese Fähigkeit eingebüsst haben. Besonders bei höheren Metazoen kommt es endlich auch vor, dass diejenigen Zellen, welche Fortpflanzungszellen liefern, von den Differenzirungen ausgeschlossen sind, so dass zwischen den Fortpflanzungszellen der einen Generation und denjenigen der nachfolgenden eine continuirliche Reihenfolge undifferenzirter oder embryonaler Zellen besteht (Continuität der Keimzellen) ${ }^{1}$ ).

Rückdifferenzirung kommt übrigens bei den Metazoen nicht nur bei Bildung der Fortpflanzungszellen in Betracht, sondern auch bei verschiedenen anderen normalen und pathologischen Vorgängen; wir sehen namentlich bei den Regenerationserscheinungen und den verwandten Processen der Theilung und Knospung, durch Rückdifferenzirung von Gewebszellen, Zellmassen von embryonalem Charakter entstehen, welche dann neue Differenzirungen in ähnlicher Weise, wie solche am Embryo erfolgen, erfahren ${ }^{2}$ ). Sie haben nicht mehr die Fähigkeit, alle Arten der Differenzirung, die in Organismus vorkommen, wieder aus sich hervorgehen zu lassen, abel es ist doch ihre Fähigkeit eine weitere, als sie in ihrem früheren Differenzirungszustande Ausdruck fand. So sehen wir z. B. bei einem Anneliden, bei welchem äusseres Epithel und Centralnervensystem wohl gesonderte Bildungen sind, dass bei der Regeneration des verloren gegangenen vorderen Körperendes ein neues oberes Schlundganglion, Schlundcommissur und ein Stuick des Bauchmarks vom Epithel aus entstehen; das äussere Epithel zeigt also jene Fähigkeit, welche beim Embryo das Ectoderm besass. Je niedrigere Metazoen es sind, die wir betrachten, um so allgemeiner können die einen Körperzellen für andere bei der Regeneration eintreten. Bei den Cnidariern sind nur noch die zwei primären Keimblätter die. Differenzirungseinheiten, die einander nicht ersetzen können ${ }^{3}$ ). Bei den Spongien sind vielleicht auch diese noch so wenig different von einander, dass eine beliebige Zellgruppe vielleicht zur Erzeugung des ganzen Körpers ausreicht, wie dies gewiss bei vielen, selbst höheren Pflanzen (Begonia) der Fall ist. Wir können also eine actuelle und eine virtuelle Differenzirung der Körperzellen unterscheiden und wir können es als eine allgemeine Regel betrachten, dass die virtuelle Verschiedenheit der Körperzellenstets wenigerweitgehend (wenigereng begrenzt) ist alsdieactuelle Verschiedenheit.

c) D ifferenzirungs - Urs a chen.

Man kann sagen, dass die Differenzirungsvorgänge, die bei der Entwicklung eines Organismus ablaufen, in der Constitution der Fortpflanzungszellen begründet sind, so dass aus der befruchteten Eizelle in dem einen

1) Es lässt sich dieser Satz selbst für die höheren Metazoen nicht im strengsten Sinne behaupten, denı in den meisten Fällen erfolgt die Sonderung der Fortpflanzungszellen erst in solchen Stadien, wo der Embryo nicht mehr aus gleichartigen, sondern aus verschiedenartigen Zellen besteht, und wenn wir uns einer tendenziösen Deutung enthalten, so miissen wir in vielen Fällen auch jenen Zellen, welche die Fortptlanzungszellen liefern, einen gewissen Grad der Differenzirung zuerkennen. Oft zeigen schon frühzeitig alle Zellen gewisse Differenzirungen, wir sehen z. B., dass bei der Blastula eines Seeigels alle Zellen Geisselzellen sind und doch kann dies nicht lindern, dass gewisse dieser Zellen direct oder durch Theilung Fortpflanzungszellen liefern.

2) Es ist dies auch so erklärt worden, dass in allen Geweben undifferenzirte embryonale Zellen zurückbleiben.

3) Die Bedeutung der Keimblätter als virtuelle Differenzirungseinheiten ist schon vielfach betont worden; man hat dieselbe aber auch dogmatisch überschätzt und übersehen, dass dieser Charakter bei den niedersten Metazoen erst allmählich sich befestigen musste. 
Falle ein Kaninchen, in dem anderen Falle ein menschlicher Organismus hervorgeht. Die Constitution jeder Körperzelle bedingt wieder ihre bestimmte Differenzirung, ihre Fähigkeit der Rückdifferenzirung u. s. f. -

Bei solchen Organismen, wo alle Zellen des Körpers Fortpflanzungszellen werden köunen, nehmen wir an, dass alle Zellen virtuell gleichartig sind und dass ihre Constitution die gleiche ist; wir werden selbst dann, wenn die Zellen actuelle Verschiedenheit zeigen, ihren Polymorphismus als rerschiedene Erscheinungsform ein und derselben Constitution erklären können. Für diese Verhältnisse, wie sie bei den Pflanzen vorherrschen, möchten die Vorstellungen NäGELI's in gewissem Sinne noch anwendbar erscheinen (aber besser noch diejenigen Strasburger's).

Bei jenen Organismen aber, wo auch eine virtuelle Verschiedenheit der Zellen auftritt, müssen wir eine verschiedene Constitution von Eizelle und Körperzellen, und auch von diesen unter sich, annehmen; hier erscheint die Theorie Nägeli's nicht mehr zutreffend. Weisuans hat in der That eine Veränderung in der Constitution der Zellen bei der Entwicklung angenommen, doch hat er sie nur als eine Auseinanderlegung der Qualitäten erklärt, welche in der Eizelle vereint, in den Körperzellen gesondert wären. Schon mit Rücksicht auf die Vorgänge der Regeneration müsste aber auch die Theorie W.'s modificirt oder ergänzt werden. Wir können aber auch aus allgemeineren Gründen seinen Ausführungen nicht beipflichten.

Es scheint mehr naturgemäss, nicht eine Auseinanderlegung, sondern eine wirkliche Veränderung der Qualitäten anzunehmen. Die Qualitäten, die in der Eizelle sich finden, verändern sich in der einen Zellgruppe in dieser, in der anderen in jener Richtung. So können wir in der Eizelle eine relutiv geringe Zahl von Qualitäten annehmen; die Summe von Qualitäten braucht in der Eizelle nicht grösser angenommen $\mathrm{zu}$ werden als in der differenzirten Körperzelle. Wir sehen überhaupt die Bedeutung der polymorphen Vielzelligkeit zum grossen Theil darin, dass trotz der beschränkten Mannigfaltigkeit der Qualitäten innerhalb der einzelnen Zelle (auch der Eizelle) doch eine viel complicirtere Gesammtleistung des Körpers durch Variirung des einen Grundthemas erreicht wird ${ }^{1}$ ). Eine solche Vorstellung erscheint im Hinblick auf die unendliche Variationsfähigkeit im Chemismus der organischen Verbindungen als wohl begründet. Es sind - um einen Vergleich zu gebrauchen - alle Anilinfarbstoffe nicht etwa im Anilin neben einander vorhanden, sondern sie sind durch geringe Veränderung aus einer Grundverbindung ableitbar ${ }^{2}$ ).

Die Entstehung der Fortpflanzungszellen erklären wir daraus, dass in jedem Organismus virtuell undifferenzirte Zellen bei der Differenzirung zurückbleiben, um die Fortpflanzungszellen zu liefern (Continuität virtueller Keimzellen). Auffallend ist es immerhin, dass z. B. bei den Cnidariern gewisse differenzirte Zellen (entweder endodermale oder ectodermale), welche nach den gegenwärtigen Anschauungen derart beschaffen sind, dass sie nicht unmittelbar für Zellen des anderen Blattes eintreten können, gleich-

1) Der Polymorphismus der Zellen ist wohl nach denselben allgemeinen Gesetzen des Polymorphismus zu beurtheilen, welche in so zahlreichen Erscheinungen bei den Organismen zum Ausdruck kommen, und welche wohl zuerst GoETHE in der "Metamorphose der Pflanzen“ erkannt hat.

2) Hier müssen wir eine gewisse Uebereinstimmung mit den Anschauungen NäGELI's Lervorheben, nämlich in Bezug auf die Annahme einer A e hnlichkeit in der Constitution aller Körperzellen, welche wir als Homoioplasie bezeichnen wollen. Dieses Princip, welches ich für den richtigen Kernpunkt von N̈̈GELI's Theorie halte, ist von grösster Bedeutung für die Erklärung zahlreicher Erscheinungen der Organismen (z. B. die correlative $A$ bänderung. 
wohl Fortpflanzungszellen liefern, aus welchen alle Differenzirungen hervorgehen. Es scheint mir aber hierin für unsere Anschauung keine principiell unüberwindliche Schwierigkeit vorzuliegen.

Es ist hier auch auf den Parallelismus der ontogenetischen uod phylogenetischen Entwicklungsweise hinzudeuten. Auch in der phylogenetischen Entwicklung sind die ursprünglich gleichartigen Körperzellen allmählich ungleichartig geworden; sie haben sich aber nicht etwa in ungleichartige Stücke getheilt (wie dies \%. B. von der Neuromuskeltheorie für einen speciellen Fall angenommen wird), sondern sie haben sich in verschiedener Richtung ausgebildet.

Man kann wohl annehmen, dass die differente Beschaffenheit der Theile schon vor der Theilung der Eizelle in derselben in gewisser Weise vorbereitet war; wenn man aber die Beziehungen von Fortpflanzungszellen und Körperzellen im Auge behält, so erscheint eine vorzeitige Ausbildung der Veränderungen in diesem Sinne nur in sehr beschränktem Grade möglich.

Wenn wir also die Frage aufstellen, warum die eine Körperzelle diese, die andere jene Veränderung erfährt, so werden wir als eine Hauptursache die Beziehung der Zelle zunächst zu ihren Nachbarzellen und weiter zum Ganzen des Körpers bezeichuen.

Dies wird uns zunächst in Bezug auf die actuelle Differenzirung klar, wenn wir die Regenerationserscheinungen in Berücksichtigung ziehen. Wir wollen versuchen, dies an einem Beispiel zu erörtern. Wenn wir eine Hydra in der Richtung I quer durchschneiden, so sehen wir, dass die Stelle $a$ einen neuen Stiel, die Stelle $b$ eine neue Mundscheibe mit Tentakelkranz liefert; wenn wir den Schnitt etwas weiter hinten, in der Richtung II, geführt hätten, so würde eben dieselbe Stelle $b$ nicht in eine Ifundscheibe, sondern in einen Stiel sich verwandelt haben. - Aehnliches gilt auch für die virtuelle Differenzirung der Zelle; hier kommen aber alle Beziehungen in Betracht, unter deren Einfluss die Zelle bei der embryo-

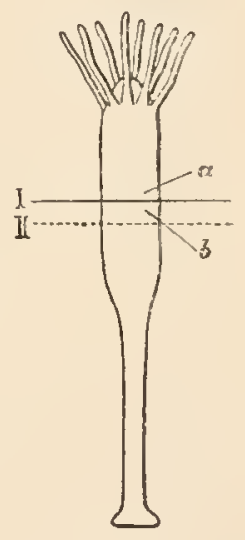
nalen Entwicklung successive sich befindet.

An dieser Stelle wollen wir darauf hinweisen, dass eine vollkommen scharfe Unterscheidung $z$ wischen actueller und virtueller Differenzirung wohl nicht möglich ist; die eine ist als Vorstufe der anderen zu betrachten. In unserer ganzen Darstellung ist der Gegensatz der Verständlichkeit wegen in etwas $\mathrm{zu}$ schematischer Weise betont.

Die Befruchtungstheorie hat in jüngster Zeit durch die umfassenden Untersuchungen des Befruchtungsprocesses von Seite zahlreicher ausgezeichneter Forscher erst ihr wissenschaftliches Fundament erhalten. Wir wissen gegenwärtig, dass die Befruchtung auf eine Conjugation der Fortpflanzungszellen zurïckzuführen ist. Es kann nun nicht mehr von einer blossen Einwirkung des Spermatozoon auf das Ei die Rede sein, sondern es ist die Fortexistenz seiner Organisation im befruchteten $\mathrm{Ei}$ und in seinen Producten erkannt worden. Dadurch ist die gleichartige Vererbung von Seite beider Eltern erklärt. Wir wollen uns hier mit diesem Hauptresultat begnügen. Man hat versucht, auch die Einzelheiten der Befruchtungsphänomene, die Bildung der Richtungskörper, Persistenz der Kernschleifen etc. in ihrer Bedeutung für die Vererbung zu erklären. Da die Forschung auf diesem Gebiete noch lange nicht zu einem Abschluss gekommen ist, so haben diese Erklärungen in vieler Beziehung noch einen mehr hypothetischen Charakter, und es ist in dem engen Rahmen unserer Darstellung nicht möglich, das Für und Wider zu erörtern. Wir wollen 
hier nur die wichtigsten Erscheinungen herrorheben, welche die Befruchtungstheorie zu berücksichtigen hat: 1) Die Constitution des Kindes ist eine Mischung der Constitutionen beider Eltern; in ihr ist zur Hälfte die väterliche, zur Hälfte die mütterliche Constitution ausgeprägt. 2) Bei den nachfolgenden Generationen (Enkel, Urenkel etc.), welche wieder durch andere Kreuzung geschlechtlich erzeugt worden sind, ist der Antheil dieser Constitution successive vermindert. Die Züchter bezeichnen gewöhnlich diesen Antheil eines Erzeugers bei der ersten Generation als Halbblut, bei der zweiten als $\frac{1}{4}$ Blut, dann als $\frac{1}{8}, \frac{1}{16}$ Blut u. s. w. - Wenn auch nicht erweisbar ist, dass die Abnahme des Antheiles genau diesem Zahlenverhältnisse entspricht, so erscheint doch die Thatsache einer successiven Abnahme vollkommen sicher begrundet. 3) Es sind die Erscheinungen, welche $\mathrm{D}_{\mathrm{ARw}}$ ix als latente Vererbung bezeichnet hat (überspringende Vererbung, Atavismus), zu erklären. 4) Es sind ferner die Erscheinungen der Bastardirung zu berücksichtigen, und zwar a) Unfruchtbarkeit der Bastarde, b) Rückschlag in Folge von Kreuzung (!), und endlich 5) die noch sehr räthselhaften und zum Theil noch zweifelhaften Erscheinungen der Pfropf-Hybride und andere verwandte, von $D_{A R w I N}$ mitgetheilte Erscheinungen.

Um nun speciell die Frage der Vererbbarkeit der individuellen Eigensehaften näher in Betracht zu ziehen, werden wir zunächst das Wesen dieser individuellen Eigenthümlichkeiten und die Ursachen derselben zu erörtern suchen.

DaRwin betrachtet als Ursache der individuellen Abänderungen die Einwirkung der äusseren Einflüsse (Lebensbedingungen) auf den Organismus ${ }^{1}$ ). Er unterscheidet 1) direkte Einwirkung, das ist solche, die den Organismus im allgemeinen betrifft und Veränderungen desselben unmittelbar hervorruft; sie kann a) den ganzen Organismus und b) nur gewisse Theile desselben betreffen; 2) indirekte Einwirkung, das ist solche, welche die Fortpflanzungsorgane afficirt; die dadurch hervorgerufenen Veränderungen treten für unsere Beobachtung erst als Veränderungen der Nachkommen in Erscheinung.

Wie sich diese rerschiedenen Fälle in Bezug auf ihre Vererbbarkeit

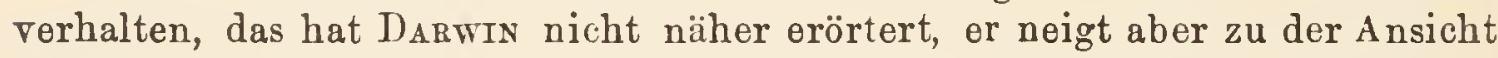
hin, dass in den meisten Fällen Vererbbarkeit anzunehmen wäre.

Darwin sucht daher in seiner Pangenesis-Theorie auch die Vererbung der direkten Veränderungen des Körpers dadurch zu erklären, dass ja während des ganzen individuellen Lebens Keimtheilchen von den etwa veränderten Körpertheilen nach den Fortpflanzungsorganen wandern sollen. - Auch Nägeli sucht die Vererbung directer Veränderungen zu erklären, indem or annimmt, dass die Einflüsse, welche an irgend einer Körperstelle eine Micellreihe treffen, sich als Erregung auf alle gleichnamigen Micell-

1) Manche Naturforscher liaben früher behauptet, dass alle individuellen Abänderungen von der geschlechtlichen Fortpflanzung herrühren, also zumeist nur auf dem immer neuen Mischungsverhältnisse der Charaktere beruhen. DARwIN hat diese Ansicht mit Hinweis auf die Knospungsvarietäten bei Pflanzen zurückgewiesen. Neuerdings hat WEISMANN diese Ansicht wieder aufgenommen, scheint aber dieselbe danı wieder verlassen zu haben. Wie auch DARwiN schon hervorhebt, können die Veränderungen zum Theil auf Kreuzung beruhen, denn die bei der Befruchtung stattfindende Einwirkung zweier verschiedener Constitutonen aufeinander ist in gewissem Sinne dem Effect veränderter Lebensbedingungen zu vergleichen (KöLREUTER). Doch ist in letzter Instanz die verschiedene Constitution immer auf die Einwirkung der Lebensbedingungen zurïckzuführen.

Man hat ferner versucht, die individuellen Abänderungen als allein aus inneren Bedingungen der Organismen hervorgehend zu erklären; auch diese Anscliauung ist irrig. Hierauf werden wir noch zurückkommen. 
reihen des Körpers fortptlanzen und überall gleichnamige Veränderungen bewirken.

Es ist ein grosses Verdienst Weismans's, diese Frage in jüngster Zeit eingehend erörtert und bedeutend gefördert zu haben. WEISMANN kommt, entgegen jenen Forschern, zu dem Schlusse, dass die directen Veränderungen des Körpers (die or als somatogene bezeichnet) nicht vererbbar wären. Er erklärt nur die indirekten Veränderungen, welche zunächst die Keimzellen betreffen (die er germogene nennt) als vererbbare. W. begründet diese Anschauung in Zusammenhang mit seiner Theorie von der Continuität des Keimplasmas. Wir wollen aber hervorheben, dass sie von derselben unabhängig auf viel allgemeinerer Basis beruht.

Es wird von W. zunächst dargelegt, dass eine Vererbung directer Veränderungen in keinem der bisher angenommenen Fälle wirklich nachweisbar sei, sondern dass ïberall eine andere Erklärung möglich oder wahrscheinlich wäre. 1) Die Vererbung $\nabla$ on Verletzungen wurde früher oft behauptet, es ist aber nun bei genauerer Prüfung noch kein einziger thatsächlicher Fall bekannt geworden. Angeborene Verstümmelungen (also indirect durch Veränderung der Keimzellen erworbene) sind vererbbar. 2) Die Vererbung von Krankheiten, welche während des individuellen Lebens erworben wurden, sind zurückzufuhren a) auf eine infectiöse Uebertragung ron Generation zu Generation, indem sogar die Keimzellen als Träger der Infectionskeime dienen können (Syphilis, Krankheit der Seidenraupen u. s. W., die Frage ist eine recht complicirte und es fehlt meist noch der direkte Nachweis der inficirenden Mikroorganismen); b) es kann in vielen Fällen angenommen werden, dass nicht die Krankheit vererbt wurde, sondern die Disposition für dieselbe, welche eine indirect erworbene (angeborene) war. 3) Die Vererbung $\nabla$ on Fähigkeiten, welche angeblich durch Uebung erworben wurden, ist anderweitig zu erklären. Wenn z. B. berühmte Musikerfamilien angeführt werden, in welchen das Talent durch viele Generationen sich vererbte, so ist einzuwenden, dass schon der Stammvater dieser Familie ein angeborenes Talent besass, welches ihn zur Wahl dieses Berufes veranlasste. - Die Rückbildung von Fähigkeiten durch Nichtgebrauch der Organe, z. B. die Flugunfähigkeit der Hausente, ist z. Th. aus dem Princip der „Panmixie", z. Th. durch die Zuchtwahl des Menschen zu erklären.

Ferner wird von WeIsManN gezeigt, dass zur Erklärung der phylogenetischen Abänderung die Annahme der Vererbung directer Veränderungen nicht nothwendig ist; ja in einzelnen Fällen, wie z. B. bei dem Instinct der Bienen, ist es überhaupt nicht möglich, mittelst dieser Annahme (Vererbung directer Veränderungen) eine Erklärung zu erzielen, da die mit dem Instincte ausgestatteten Arbeiterinnen selbst steril sind. Andererseits reicht die Vererbung der indirecten Veränderungen vollkommen zur Erklärung der phylogenetischen Abänderung aus. Ja es ist dies ganz im Sinne der Selectionstheorie, welche mannigfaltige unbestimmte Veränderungen als Substrat der Selection annimmt. Da DarwiN dem Gebrauch oder Nichtgebrauch der Organe und der directen Einwirkung des Klimas noch eine gewisse geringe Bedeutung für die phylogenetische Veränderung zugestehen wollte, so sind wir gegenwärtig durch Weismans zu einer schärferen und ausschliesslicheren Anwendung des Selectionsprincips gekommen.

Wir stimmen der von WeISMans vertretenen Ansicht vollkommen bei und wollen in unserer folgenden Darstellung dieselbe nur in einigen Punkten erweitern. 
Schon bei den Protozoen sind nicht etwa alle Veränderungen des Körpers als vererbbar zu betrachten, sondern nur diejenigen, welche in einer Veränderung der Constitution der Zelle ihren Grund haben ${ }^{1}$ ). Ueber die Natur derartiger Veränderungen werden wir uns weiterhin noch äussern.

Bei den Metazoen genügt es nicht, dass die Constitution irgend welcher Körperzellen von der Veränderung betroffen werde, sondern es werden nur jene individuellen Veränderungen für vererbbar gelten, welche auf einer Veränderung der Constitution der Fortpflanzungszellen beruhen.

Mit anderen Worten: Veränderungen in der Constitution der Körperzellen können nicht derart auf die Fortpflanzungszellen wirken, dass bestimmte, gleichnamige Veränderungen in der Constitution dieser letzteren entstehen ${ }^{2}$ ). Veränderungen des Körpers wirken gewiss auch auf die Fortpflanzungszellen, doch in mehr unbestimmter Weise, indem sie Variiren derselben veranlassen, also ebenso wie äussere Eintlïsse im allgemeinen wirken (wie wir später erörtern werden).

Aeussere Einflüsse sehr allgemeiner Natur, wie Klima, Ernährung, welche in mehr bestimmter Weise auf den ganzen Körper wirken, indem sie z. B. Veränderungen in der Behaarung, Farbe, Grösse veranlassen, werden auch in den Fortpflanzungszellen gleichnamige latente Veränderungen bewirken (in Folge der Homoioplasie der Zellen), welche erst in der nächsten Generation zur Geltung kommen. Es hat hier nun den Anschein, als ob directe Veränderungen des Körpers vererbt würden, in Wirklichkeit werden aber die gleichnamigen indirecten Veränderungen der Fortpllanzungszellen vererbt.

In Bezugauf die Naturder Veränderungen, welchedurch äussere Einflüsse in der Constitution der Eizelle hervorgebracht werden, müssen wir folgendes besonders hervorheben.

1) Schon DARwis hat gezeigt, dass die äusseren Einflüsse a) bestimmte Veränderungen bewirken können (die vorerwähnten Beziehungen von Klima, Nahrung zur Behaarung, Farbe, Grösse etc.), dass aber b) unbestimmte Tariabilität ein viel häufigeres Resultat veränderter Bedingungen sei, und er hobt hervor, dass gerade diese das wichtigste Material für die natürliche Zuchtwahl liefert. Das, was ron der unbestimmten Variabilität ausgesagt wird, scheint mir nun besonders für die indirecten Veränderungen Geltung zu haben.

2) DaRwin erklärt weiter (in Uebereinstimmung mit einer Aousserung von Wersmans), dass beim Variiren zweierlei Factoren thätig sind, nämlich die Natur des Organismus und die Natur der Bedingungen. Das Erstere

1) Wir werden dies am besten an einem wohl etwas schematischen Beispiele versinnlichen: Eine locale Veränderung z. B. am vorderen Ende eines Infusors würde bei Vermehrung desselben durch Quertheilung nur in das vordere neue Individuum direct iibergehen und nach wiederholter Theilung also nur auf einen von den zahlreichel Theilsprösslingen direkt überkommen; bei allen anderen müsste diese Veränderung neugebildet werden und dies wäre nur dann möglich, wenn sie auf der Constitution der Zelle berulite. Ebenso wird diese Veränderung bei der Encystirung aufgehoben und müsste dann wieder neu gebildet werden.

2) Die Vererbbarkeit von Verletzungen muss auch denjenigen Naturforschern unwahrscheinlich scheinelı, die im übrigen wohl eine Vererbbarkeit directer Veränderungen anzunehmen geneigt sind; denn man sieht, dass Verletzungen sehr allgemein schon am selben Individuum durch Regeneration wieder aufgehoben werden. Es ist auch schon mehrfach hervorgehoben worden, dass die negative Beobachtung weder für die eine, noch für die andere Anschauung etwas beweist. Anders wäre es allerdings, wenn die positive Beobachtung der Vererbung einer Verletzung gemacht würde, was aber bei dem gegenwärtigen Stande der Frage woll niemand mehr ernstlich erwartet. 
scheint bei weitem das Wichtigere zu sein. Die Organismen haben also selbst unter verschiedenartig veränderten Bedingungen die $\mathrm{Neigung}$, in gewissermaassen bestimmter Richtung zu variiren ${ }^{1}$ ).

3) Von grösster Bedeutung für unsere Anschaunng über das Wesen des Variirens sind die Erscheinungen des correlativen Abänderns, auf welche DaRwIN in scharfsinnigster Weise hingewiesen hat. Das Variiren der verschiedensten Körpertheile steht in gegenseitiger Beziehung. Es sind z. B. lange Beine - wie die Thierzuichter glauben - beinahe immer von einem verlängerten Kopfe begleitet; Farbe und Eigenthümlichkeit der Constitution stehen mit einander in Verbindung u. s. w. ${ }^{2}$ ).

Die Correlation des Abänderns zeigt uns wieder die Beschränktheit der Mittel, welche der Natur zur Verfügung stehen und mit welchen sie doch so grosse Erfolge erzielt. Es kann nicht der eine Körpertheil in dieser, der andere in jener Richtung variiren, sondern es herrscht eine bedeutende Gebundenheit und Begrenztheit der Variabilität. In merkwürdigster Weise machen sich die Gesetze des correlativen Abänderns in der gleichartigen phylogenetischen Veränderung homodynamer Organe geltend (mall vergleiche die Uebereinstimmung der vorderen und hinteren Extremitäten bei den verschiedenen Wirbelthieren). Die Homoioplasie gibt dem ganzen Körper sein einheitliches Gepräge.

Die Erscheinungen des correlativen Abänderns sind vorwiegend aus der Homoioplasie der Zellen zu erklären. Die Abänderung einer Qualität der Eizelle (Fortpflanzungszelle) verursacht gleichnamige Abänderungen in allen bei der Entwicklung von ihr abstammenden Körperzellen, die aber in den verschiedenen Körpertheilen in verschiedener Weise in Erscheinung treten. Eine Veränderung in der Constitution der Eizelle bedingt eine Veränderung in der Constitution jeder Körperzelle, d. i. des gesammten Körpers.

1) Dieselbe Thatsache haben auch andere Forscher beachtet (NÄGELI), doch hat dies dieselben zu der irrigen Theorie von der, phylogenetischen Entwicklung aus inneren Bedingungen" geführt (Zielstrebigkeit der Phylogenie). Thatsächlich zeigen uns diese Erscheinungen nur die engen Grenzen der Veränderlichkeit; trotz dieser Beschränkung wird der phylogenetischen Veränderung ihre ganz bestimmte Richtung durch die Selection gegeben. Diese allein kann uns die mannigfaltigen gegenseitigen Aupassungen der Organismen erklärell.

2) Man hat im allgemeinen diese scharfsinnigen Andeutungen DARwis's noch wenig beachtet. Ja ich habe sogar folgenden, allerdings aus einer vergangenen Epoche stammenden Ausspruch gelesen: „Die Hinweisungen auf unbekannte Wechselbeziehungen des Wachsthums sind unzulässig.... Es ist ein Verstoss gegen die exacte Methode und unsere Zeit rechnet nicht mit nebelhaften Wechselbezielsungen" (ScHMARDA, Zoologie, 1871). Man darf ferner das correlative Abändern nicht etwa zusammenwerfen mit dem Gesetz des bestimmten gegenseitigen Verhältnisses der Organe in Bezug auf Grösse, Ausbildung etc., welches von GeofFroY.ST. Hrarre als ,principe du balancement des organes“ und vielfach wohl auch als ,Correlation der Theile" bezeichnet wurde, denn dieses ist vorwiegend ein Resultat der beständig wirkenden Naturzüchtung (vergl. Roux', Kampf der Theile im Organismus"). 


\section{ELF'TES CAPITEL.}

\section{Cladus der Metazoa.}

\section{Spongiaria.}

Die Spongien sind Metazoen mit persistirender Primärachse; - mit obliterirtem Protostoma, - am Protostompol festsitzend; - mit einer Auswurfsöffnung (Osculum) am Apicalpol; - mitzahlreichen, verschliessbaren, an der Körperoberflächezerstreuten Poren, die mittelst wassereinführender Kanäle in das Urdarmsystem münden; - sie besitzen eine vom primären Endoderm abstammende Mesodermschichte, welche aus einer gallertigen Grundsubstanz und eingelagerten Zellen besteht; die Mesodermzellen erzeugen die Skeletbildungen und liefern die Geschlechtsproducte; - meist cormenbildend.

\section{Allgemeine Formgestaltung.}

Die Spongien sind festsitzende Metazoen von überaus mannigfacher Körperform; ihre Grösse schwankt von wenigen Millimetern bis zu etwa einem Meter.

Die Grundform des Einzelindividuums ist die eines einachsigen Hohlkörpers, der an dem einen Pole festsitzt, an dem anderen Pole mit einer Oeffnung (der Auswurfsöffnung oder O s c ul lu m) versehen ist. Zahlreiche kleinere, mit freiem Auge kaum sichtbare Oeffnungen sind über die Körperoberfläche zerstreut und stehen mit dem centralen Hohlraum in Verbindung (Einfuhröffnungen oder P o r e n). Je nachdem die Hauptachse eine langgestreckte oder verkürzte ist, erscheint die Form des Individuums als eine langgestreckt schlauchförmige, oder als die eines ovoiden oder kugeligen Hohlkörpers, oder selbst einer hohlen Platte, die mit breiter Fläche festgewachsen die jeweilige Unterlage krustenartig iiberzieht. Selten treten Andeutungen eines radiären Baues auf.

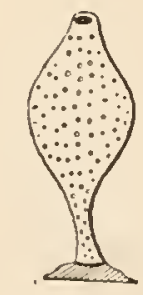

Fig. 237. Einzelindividuum eines Kalkschwammes, Ascortis (nach E. HAEckEL). 
Die Formgestaltung wird a chnoch durch die häufige Cormenbild ung beeinflusst, wobei die verschiedenartige Anordnung und die mehr oder minder ausgeprägte Sonderung der Einzelindividuen massgebend ist. Wir kennen rasenförmige orler baumförmig verästelte Cormen, bei wolchen die Einzelindividuen nur an der Basis mit einander zusammenhängen. In anderen Fällen, wo die Wandungen der Einzelindividuen nur unvollkommen von einander gesondert sind, bildet der Cormus eine compacte Masse, an der äusserlich die Vielzahl der Individuen nur durch die vermehrten Oscula angedeutet ist. Im allgemeinen könıen wir die Anzahl der Individualitäten nach der Anzahl der Oscula bestimmen; doch gibt es auch Cormen, bei welchen ein Theil der Individuen keine Oscula besitzt, wodurch die Unterscheidung derselben oft sehr erschwert wird. -

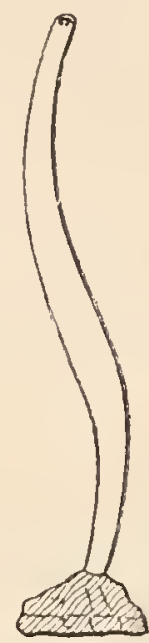

A.

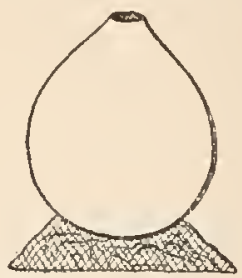

B.

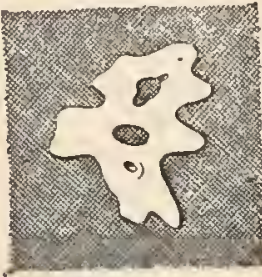

C.

Fig. 238. A. Ein röhrenartig verlängerter Kalkschwamm (vergrössert). B. Eine knollenförmige Chondrosia. C. Eine krustenartige Plalina. (Nach verschiedenen Autoren.)

Principiell ist die Anzahl der Hauptachsen für die Anzahl der Individuen bestimmend ${ }^{1}$ ). . Die Gastrallöhlen der Einzelindividuen stehen mit einander meist an der Basis in Verbindung.

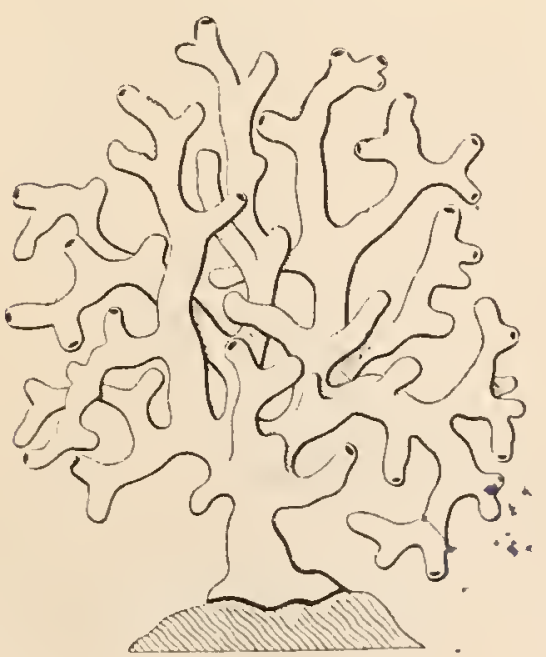

A.

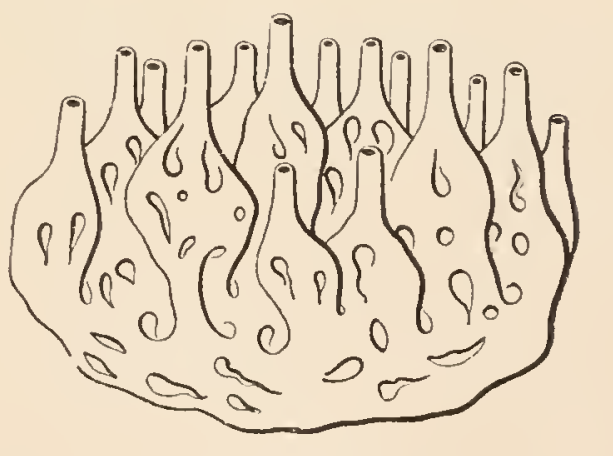

B.

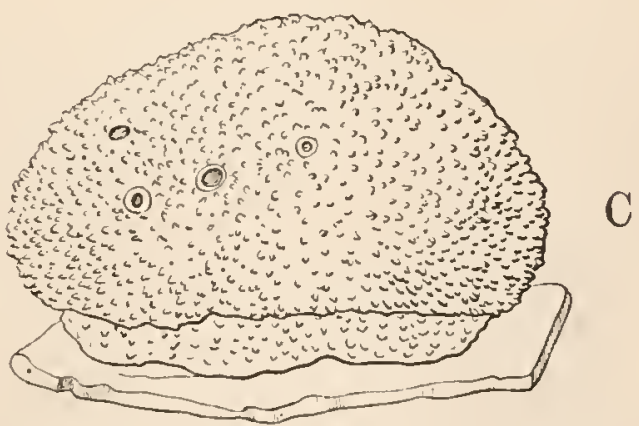

Fig. 239. A. Ein baumförmig verästelter Cormus eines Kalkschwammes, Ascyssa, vergrössert, nach HAECKEL. B. Ein rasenförmiger Cormus eines Kalkschwammes, Leucandra, vergrössert nach HAECKEL. C. Compacter Cormus mit mehreren Oscula vom Badeschwamm. Euspongia, nach F. E. ScHUlzE.

1) HAECEEL geht aber wohl zu weit, wenn er den durch tiefe Einbuchtungen zertheilten Körper mancher Kalkspongien (Nardorusform) für einen einmündigen Cormus hält. 
Sclichtenbau und histologisclie Differenzirung:

Die Wandung des Spongienkörpers ist aus drei Schichten, dem Ectoderm, Mesoderm und Endoderm aufgebaut.

Das Ectoderm ist eine einschichtige Zellenlage von seln' dünnen, platten Zellen (bei Oscarella sind diese Zellen etwas ansehnlicher und mit je einer Geissel versehen).

Das Endoderm kleidet als ein durchwegs einschichtiges Epithel die einfache oder complicirtere Urdarmhöhle aus. Im einfachsten Falle sind alle Zellen desselben gleichartig und besitzen die ganz charakteristische Form der Kragenzellen. Es sind dies hohe Zellen, die mit einer Geissel versehen sind, deren Wurzel ein eigenthümlicher protoplasmatischer Kragen umgibt. Von Interesse ist die Aehnliclikeit

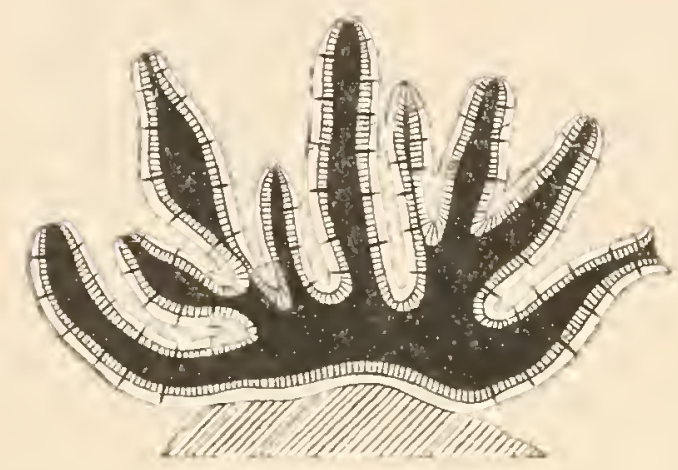
dieser Zellen mit den Choanoflagellaten. In den meisten Fällen sind diese Kragenzellen aber nur auf gewisse Stellen der complicirter gestalteten Urdarmhöhle beschränkt (Geisselkammern), während das übrige Endoderm aus dünnen abgeplatteten Zellen besteht, ähnlich denjenigen des Ectoder'ms.

Fig. 240. Schematischer Durchschnitt eines rasenförmigen Cormus (nach HAECKEL, etwas verändert).

Das Mesoderm bildet die Hauptmasse des Körper's; es besteht aus einer gallertigen Gruudsubstanz und darin eingelagerten Zellen,

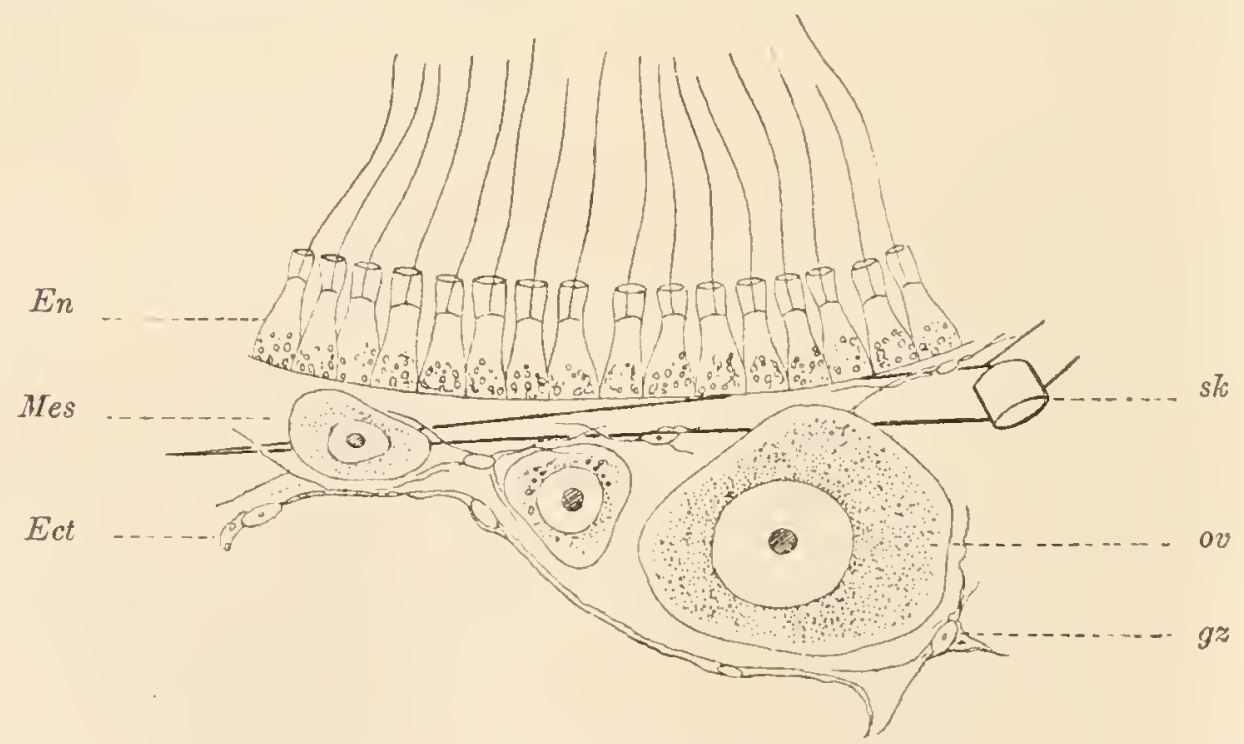

Fig. 241. Körperschichten einer Spongie (Sycon raphanus) nach F. E. SchulzE. Ect Ectoderm, Mes Mesoderm, En Endoderm (Geisselzellen finden sich nur in den Geisselkammern), $g \approx$ Bindegewebszellen der Gallertschichte, ov junge Eizellen, sk Theil einer dreistrahligen Kalkskelettnadel.

ferner speciellen, von den Mesodermzellen ausgeschiedenen Skelettbildungen und den durch Umwandlung von Mesodermzellen entstandenen Geschlechtsproducten. 
Die Mehrzahl der Mesodermzellen hat demnach die Bedeutung von Bindegewebszellen, da sie theils als Matrixzellen der Gallerte fungiren, theils auch die speciellen Skelettbildungen liefern, die in dem Spongienkörper in der Regel eine bedeutende Rolle spielen und entweder als Kalk- oder Kieselgebilde in grosser Anzahl und oft sehr bestimmter Anordnung das Gewebe durchsetzen oder als ein zusammen-

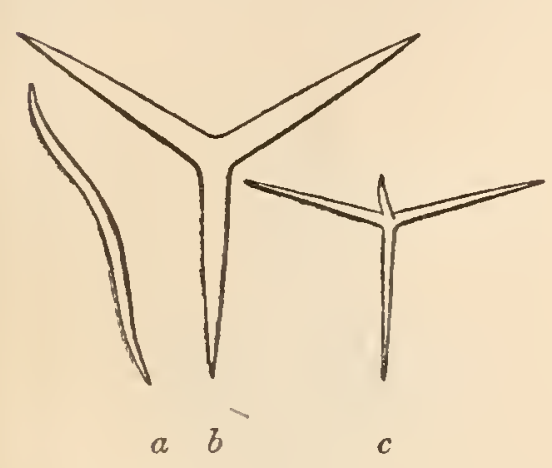

$b$

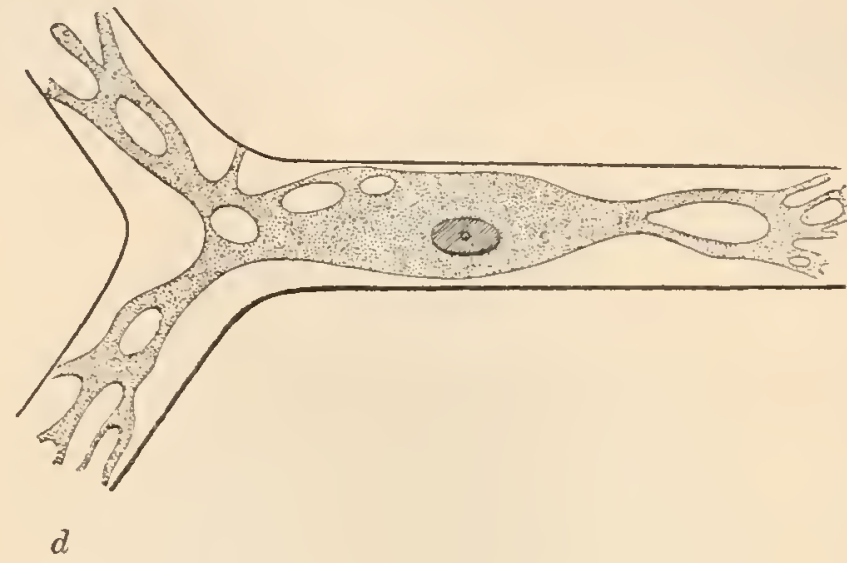

Fig. 242.

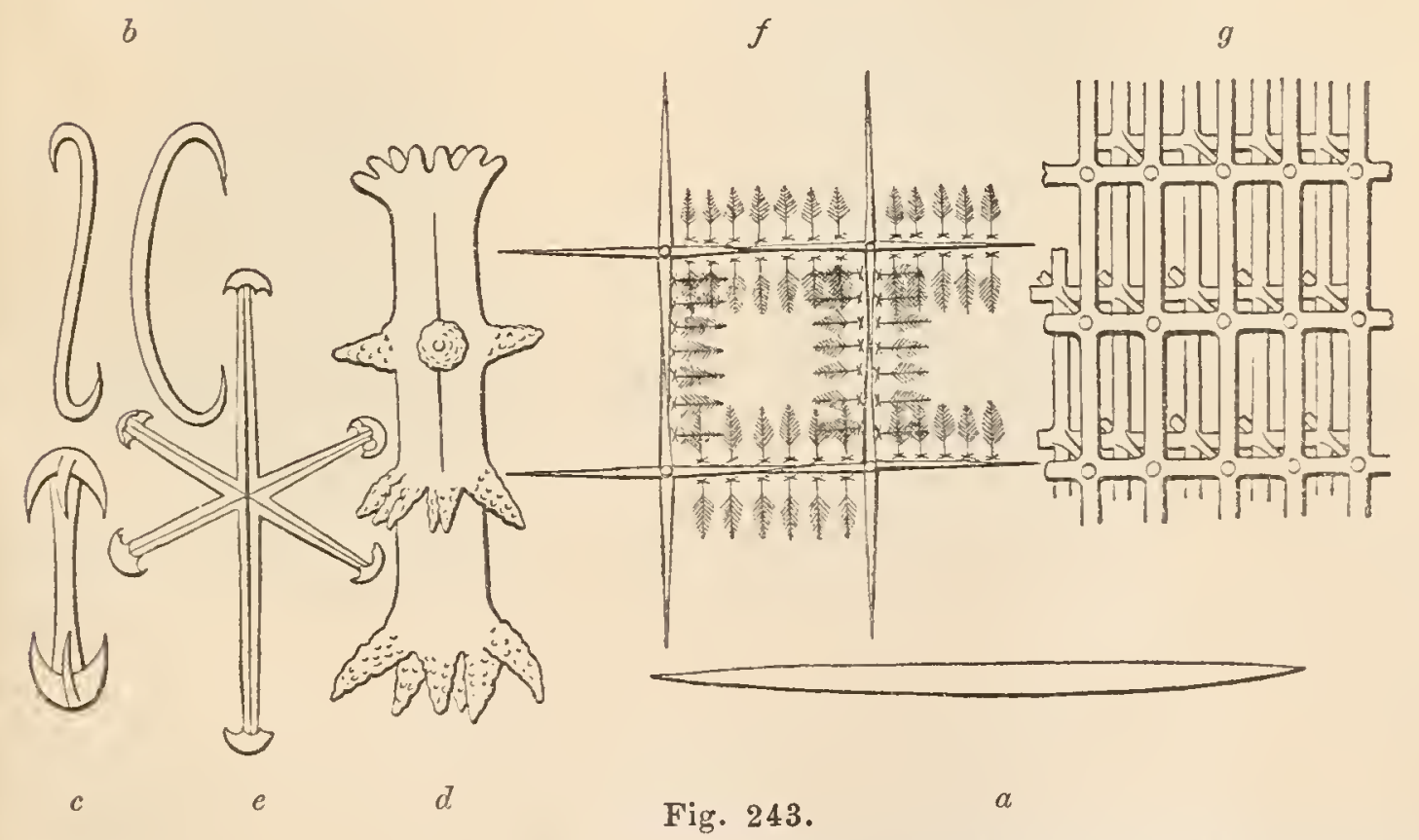

Fig. 242. Kalkspicula von Kalkschwämmen. a Stabnadeln, $b$ Dreistrahler, $c$ Vierstrahler, $d$ Stück eines Dreistrahlers mit Bildungszelle.

Fig. 243. Kieselgebild $\theta$. $a, b, c, d$ einachsige Kieselkörperchen, $e$ triaxiales Kieselkörperchen, $f, g$ nach dem triaxialen Typus aufgebaute Skeletttheile von Hexactinelliden.

Fig. 244. Stückchen eines Durchschnittes aus dem Mesoderm einer Hornspongie. Man sieht eine verästelte Spongiolinfaser, die von epithelartig angeordneten Spongioblasten umgeben ist; daneben verästelte Mesodermzellen (Fig. 242, 243 noch versch. Autoren, Fig. 244 nach F. E. SCHULZE).

Fig. 244.

hängendes Gerüstwerk von Spongiolinfasem auftreten. Bei den Kalkschwämmen finden sich sowohl einfache, als dreistrahlige und vierstrahlige Kalknadeln, die zum Theil auch die Gewebe durchbrechen und nach aussen vorragen. Viel mannigfaltiger sind die Kieselgebilde der Glasschwämme und Kieselhornschwämme, die oft im Inneren je einer Zelle gebildet 
werden. Die Hornfasernetze (Spongiolinfasern) der Hornschwämme sind von zahlreichen Spongioblasten, die um dieselbe eine vollständige Zellschichte bilden, überzogen ${ }^{1}$ ).

Gewisse spindelförmige Mesodermzellen in der Umgebung der Poren sind als Muskelzellen gedeutet worden. (In jüngster Zeit wurden auch mesodermale Ganglienzellen (?) beschrieben.)

Ein Theil der Mesodermzellen hat die Bedeutung von Fortpflanzungszellen. Die Eier entstehen, indem solche vereinzelte Zellen sich durch Wachsthum vergrössern und eine rundliche Form

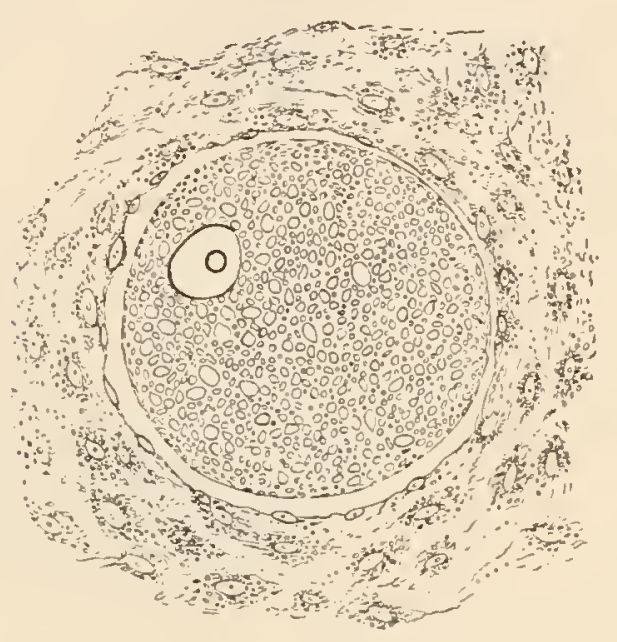

A.

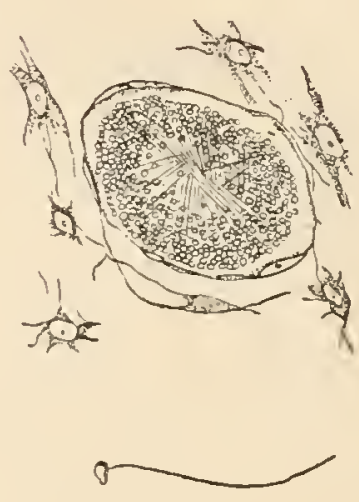

B.

Fig. 245. A. Eizelle, mit Dotterkörnchen, innerhalb des Nesoderms gelegen, von Aplysilla (nach F. E. Schulze). B. Spermaballen, der aus einer Samenmutterzelle hervorgegangen ist, innerhalb des Mesoderms gelegen, von Oscarella (nach F. E. ScHULzE).

annehmen; oft werden sie dann von der Gallerte durch eine dünne Schichte von platten Zellen abgegrenzt. Auf ähnliche Weise entstehen die Samenmutterzellen, welche Massen von stecknadelförmigen Spermatozoen liefern ${ }^{2}$ ).

Modificationen des Körperbaues.

Die wichtigsten Modificationen des Baues beruhen auf Differenzirungen der inneren Hohlräume.

Bei der Ordnung der Kalkschwämme kennen wir im wesentlichsten drei Haupttypen, die Ascon-, die Sycon- und die Leucon-Form. Die einfachste Form ist der Ascontypus. Das Einzelindividuum ist hier

1) Es drängt sich wohl die Frage auf, ob hier nicht in die Tiefe gewucherte Cuticularbildungen, also ein Epithelialskelet vorliege, ähnlich wie dies für die Skeletbildungen der Actinozoen neuerdings nachgewiesen wurde.

Zur Erklärung der so merkwürdig gesetzmässigen Formen der Spongiennadeln hat in jüngster Zeit F. E. SchulzE eine bedeutsame Theorie aufgestellt. Er hat gezeigt, dass die gesetzmässigen Achsenverhältnisse der Skeletnadeln durchaus abhängig sind von der gesetzmässigen Anordnung der von ihnen gestützten Wimperkammern bei den verschiedeneu Classen der Spongien.

2) $\mathrm{Ob}$ die Genitalzellen wirklich aus verästelten Mesenchymzellen entstehen, kann trotz der sorgfältigsten Untersuchungen wohl noch nicht mit vollkommener Sicherheit behauptet werden; es wäre immer noch an die Möglichkeit $z u$ denken, dass vergrösserte Endodermzellen in die Gallerte hinein wandern, trie dies ursprünglich von HaEckel für die Kalkschwämme angegeben wurde. 
schlauchförmig mit endständigem Osculum; der centrale Hohlraum, in welchen die Pol'en münden, ist gleichmässig mit Geisselepithel ausgekleidet. Eine zweite Hauptform der Kalkschwämme ist der Sycontypus, bei welchem die Urdarmhöhle in periphere Blindsäcke, die Radialtuben, ausgezogen ist, welche einen centralen Hohlraum umgeben. Die Kragenzellen sind auf dic Radialtuben beschränkt, während das Endoderm der centralen Höhle als ein dünnes Plattenepithel erscheint.

A.
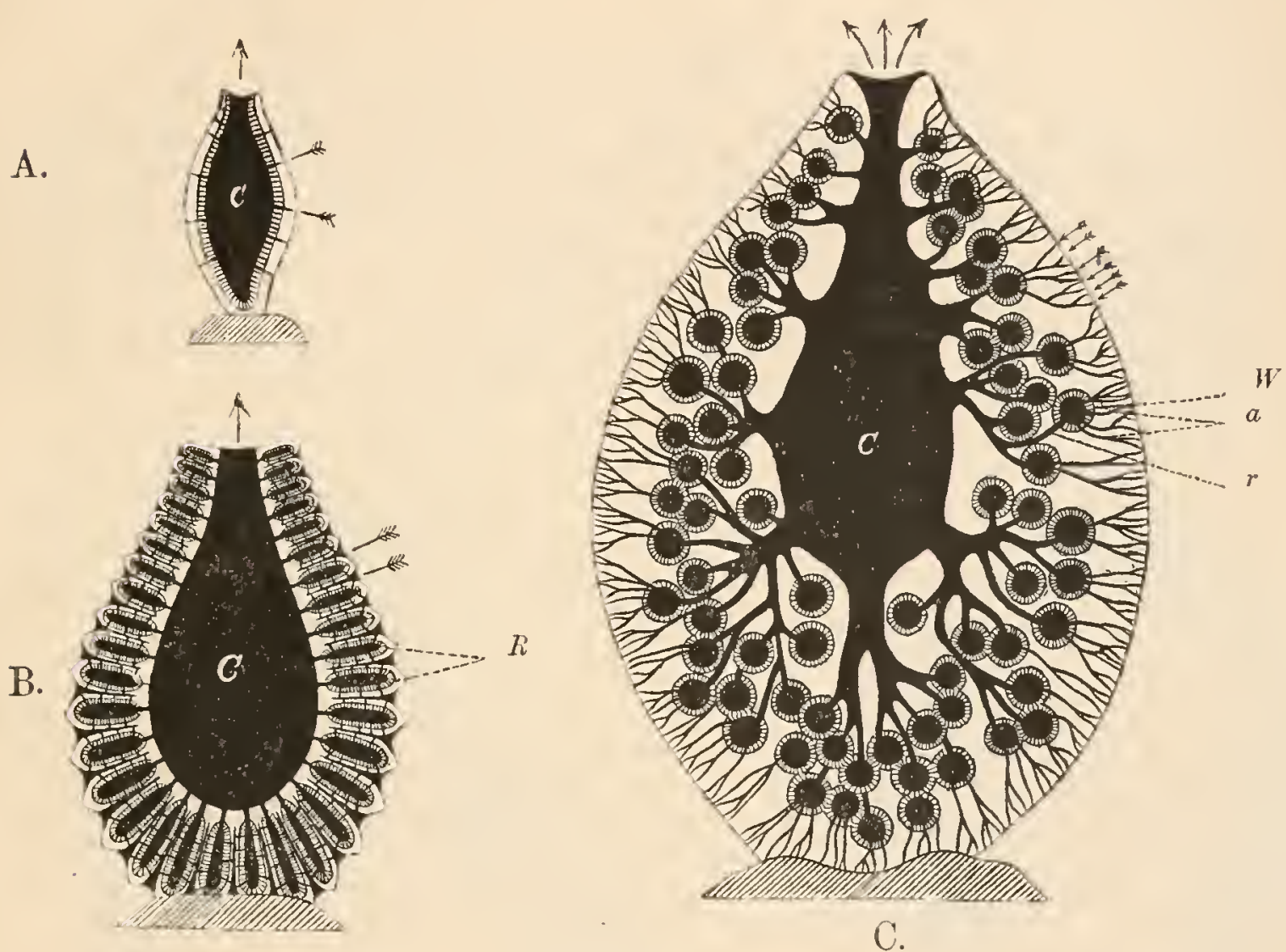

Fig. 246. Schematische Durchschnitte der drei Typen der Kalkschwämme '(nach HAECKEL, z. Th. etwas verändert). Die äussere Contour bedeutet das Ectoderm, die weisse Schichte das Mesoderm, die gestrichelte Schichte die Kragenzellen des Endoderms. Das innere Hohlraumsystem ist schwarz gehalten, die Pfeilc zeigen die Richtung des Wusserstromes an. A Ascontypus. Der innere Hohlraum $(C)$ ist ganz von Geisselzellen ausgekleidet. B. Sycontypus. Der Centralraum $(C)$ ist von platten Endodermzellen ausgekleidet und die Geisselzellen sind auf die Radialtuben $(R)$ beschränkt. C. Loucontypus. Die Geisselzellen sind auf die Wimperkammern (W) beschränkt. Die Körperobertäche sowie die zuführenden Kanäle $(a)$ sind von platten Ectodermzellen, der innere Hohlraum $(C)$ sowie die abführenden Canäle $(r)$ sind von platten Endodermzellen ausgekleidet; die Wimperkammern scheiden demnach die Ectodermzone von der Endodermzone.

Bei dem dritten Typus der Kalkschwämme, den Leuconen, finden sich die Kragenzellen auf zahlreiche kleine, kugelige Hohlräume beschränkt, die peripher um den centralen Hohlraum angeordnet sind. Jede Wimperkammer besitzt je eine zuführende und eine abführende Oeffnung. Ein System von zuführenden Kanälen, die mit ectodermalem Plattenepithel ausgekleidet sind, verbindet die Poren der Oberfläche mit den Geisselkammern, während ein System von abführenden Kanälen von diesen zur centralen Cavität führt. Die abführenden Kanäle und der Centralraum sind von endodermalem Plattenepithel ausgekleidet. 
Alle anderen Ordnungen der Spongien (die Fleischschwämme, Hornschwämme, Kieselhornschwämme, Glasschwämme), die auch als Fibrospongien zusammengefasst werden, schliessen sich in ihrem Bau dem Leucontypus nahe an. Es kommen wohl noch specielle Complicationen hinzu. So tritt z. B. häufig ein System von subdermalen (von Ectoderm ausgekleideten) Hohlräumen auf, von welchem erst die zuführenden Kanäle ausgehen. Oft ist der centrale Hohlraum von einem Gerüstwerk durchsetzt u. s. w.

\section{Fortpflanzung und Entwicklung.}

Bei den Spongien kommt ausser der geschlechtlichen Fortpflanzung oft auch Theilung und besonder's häufig Knospung vor. Bei den süsswasserbewohnenden Spongillen und einigen Meeresspongien sind auch eigenthümliche, aus eingekapselten Zellmassen entstehende Keimkörper, die sogenannten Gemmula e zu beobachten.

Die Spongien sind getrenntgeschlechtlich oder Zwitter; in letzterem Falle reifen Eier und Samen meist zu verschiedenen Zeiten.

A.

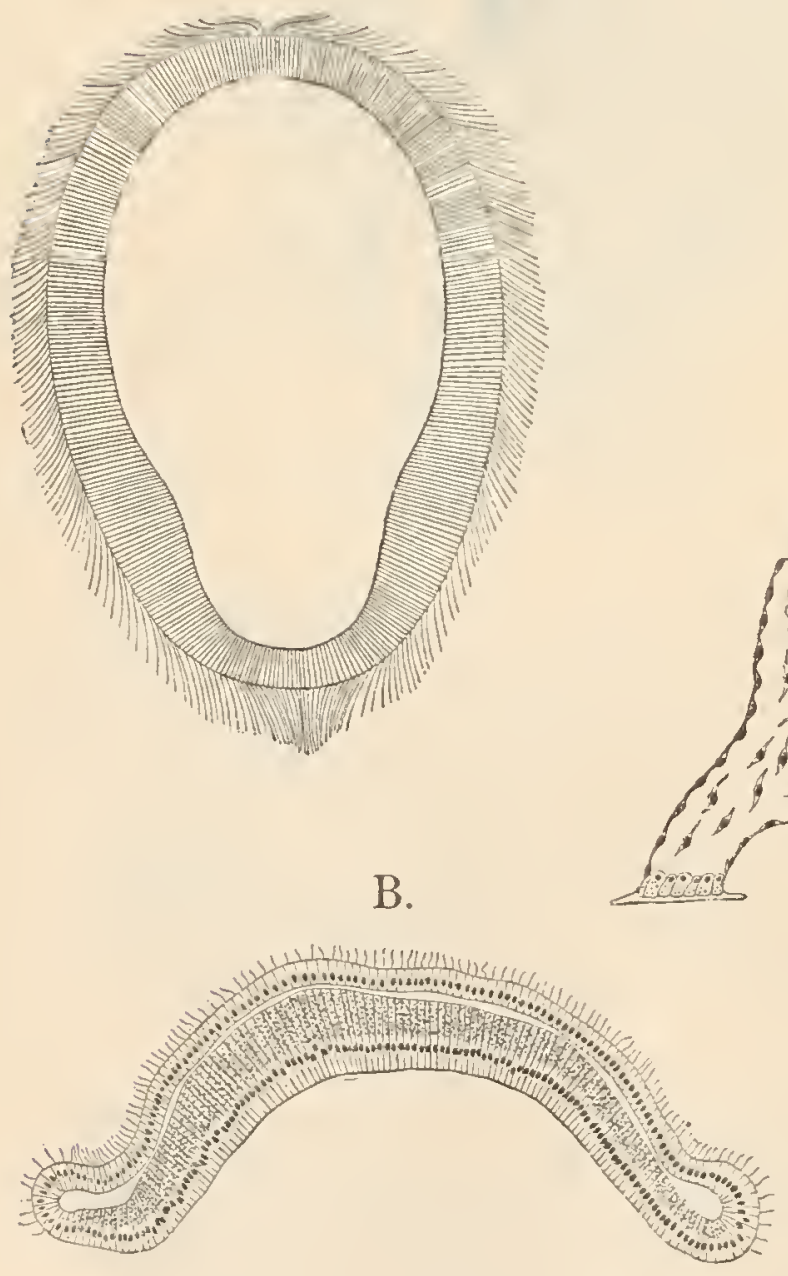

D.

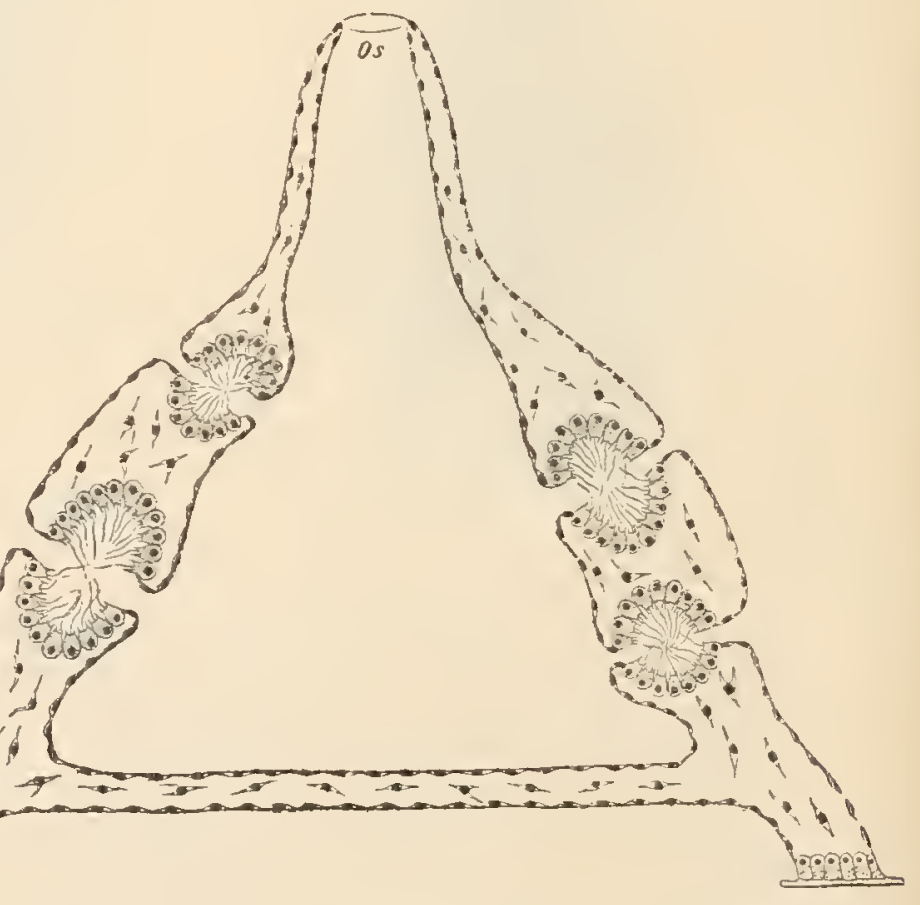

Fig. 247. Entwicklung von Oscarella lobularis, nach HEIDER. A. Blastulalarve, B. Gastrulastadium, C. Schliessung des Gastrulamundes ist weit vorgeschritten, am Rande der Protostomseite finden sich kleine, füsschenartige Fortsätze zum Zweck der Befestigung; das Endoderm zeigt Aussackungen als Anlagen der Wimperkammern, Mesodermzellen finden sich zwischen den primären Blättern. D. Junger Schwamm mit Osculum und Poren. Sämmtlich Schnitte in der Richtung der Achse. 
Die ersten Entwicklungsvorgänge an den befruchteten Eiern gehen stets innerhalb des mütterlichen Körpers vor sich und erst die bewimperten Larven werden aus demselben ausgestossen.

Wir kennen zwei Haupttypen von Larvenformen: 1. Blastulalarven und 2. parenchyniatöse Larven.

Die Blastulalarven entstehen stets durch adäquale Furchung; sie entsprechen der Grundform der einachsigen heteropolen Blastula. Als reinen Typus können wir die eiförmige Larve von Oscarella betrachten, die aus lauter hohen Geisselzellen zusammengesetzt ist. - Es ist auch die weitere Entwicklung dieser Blastulalarven genauer verfolgt worden. Die Gastrulation erfolgt erst während der Festsetzung durch Abplattung der Blastula und Einstülpung der Endodermhälfte; es ist der Protostompol, mit welchem die Gastrula sich befestigt. Das Protostoma kommt zum vollständigen Verschluss und am Apicalpol bricht später das Osculum durch. Das Ectoderm plattet sich ab. Zwischen den primären Blättern bildet sich eine Gallertschichte, in welche Zellen, wahrscheinlich aus dem Endoderm, einwandern. Bei Oscarella werden frühzeitig durch Faltung die Wimperkammern vom Centralraum abgegliedert. - Bei der Blastulalarve von Sycandra ist die eine Hälfte aus grossen, dunkelkörnigen Zellen zusammengesetzt, während die andere Hälfte aus hohen, hellen Geisselzellen besteht. Die grossen Zellen haben sich (entgegen der früheren Deutung HaEckels) als Anläge des Ectoderms, die Geisselzellen als die des Endoderms erwiesen. Diese Beschaffenheit des Ectoderms ist eine ganz specielle Eigenthümlichkeit der Sycandralarve, welche schon den nächsten Verwandten fehlt und welcher mit Unrecht allgemeinere Bedeutung zugeschrieben wurde. Auch hier wird der Gastrulamund zum Festsetzungspol, und gegenüber bricht eine neue Oeffnung als Osculum durch; hier wurde diese fundamentale Beobachtung zuerst gemacht (F. E. Schulze) ${ }^{1}$ ).

Die parenchymatösen Larven entstehen entweder durch adäquale Furchung mit nachfolgender polarer Einwucherung von Zellen in die Furchungshöhle (ganz ähnlich der Gastrulation vieler Hydrozoen), oder durch einen inäqualen Furchungsmodus, wobei eine frühzeitige Schichtung der Zellen auftritt. Sie unterscheiden sich von den Blastulalarven dadurch, dass der innere Raum ganz von Zellen erfüllt ist, die oft sogar schon ein Gewebe bilden, das in hohem Grade dem Mesoderm gleicht und sogar schon Skeletnadeln (bei den Kieselschwämmen) enthalten kann. Bei vielen Parenchymulalarven ist an dem einen Pole (wahrscheinlich der Festsetzungspol) das Epithel der Oberfläche von besonderer Beschaffenheit und oft auch zu einer Concavität. vertieft (z. B. bei den Larven der Hornschwämme Spongelia, Euspongia). Man möchte wohl die centrale Zellmasse als frühzeitig differenzirtes Mesoderm und die vertiefte Epithelplatte für die Anlage des Endoderms halten (Fig. 249 A). Doch fehlt uns die entscheidende direkte Beobachtung. über die Festsetzung und Verwandlung dieser Larven. Kurze Zeit nach

1) An die flache Gastrula der Spongien erinnert ein merkwiirdiger von F. E. Schulze entdeckter Organismus, Trichoplax adhaerens; derselbe hat den Bau einer dreischichtigen, wimpernden Platte; es wurde Fortpflanzung durch Theilung beobachtet. So lange der geschlechtsreife Zustand des Trichoplax unbekannt ist, kann seine systematische Stellung kaum beurtheilt werden. 
A.

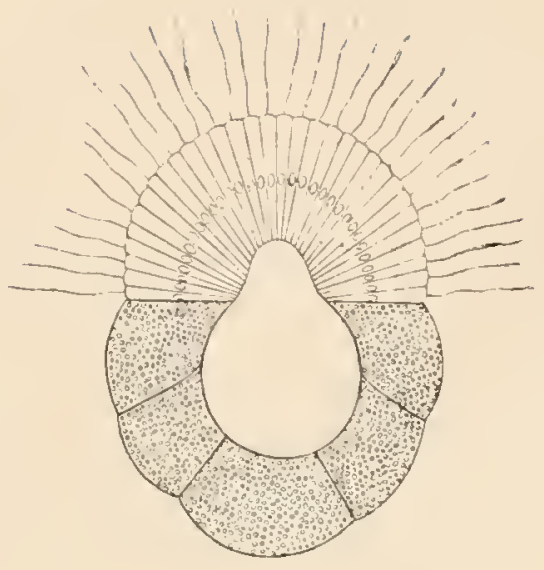

B.

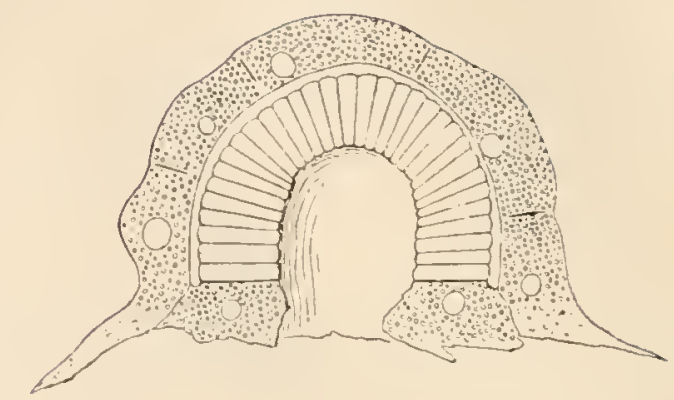

Fig. 248 .

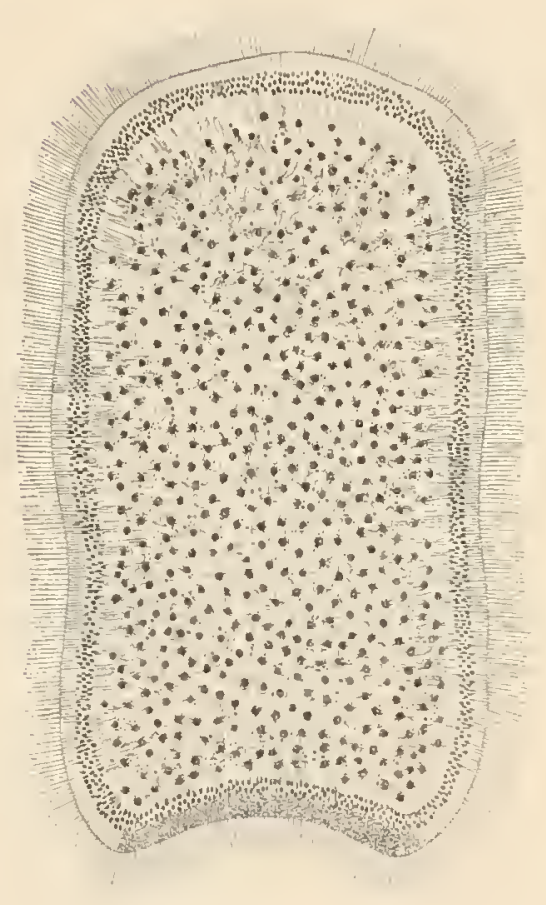

A.

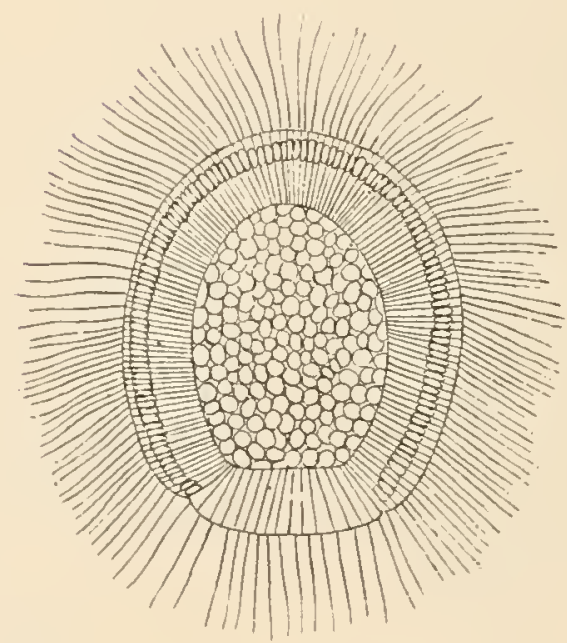

B.

Fig. 249 .

Fig. 248. Medialer Schnitt durch A das Blastrula- und B das Gastrulastadium von Sycandia rahphanus (nach F. E. SCHULzE).

Fig. 249 A. Parenchymula-Larve von Spongetia (uach F. E. Schulze).

Fig. 249 B. Parenchymula-Larve von Halisarca Dujardinii (nach Metschxikoff).

der Festsetzung ist der junge Hornschwamm der oben beschriebenen jungen Oscarella sehr ähnlich. Anders sind aber wieder einige parenchymatöse Larven aufzufassen, bei denen die innere Masse sehr wahrscheinlich der Anlage des Endoderms und Mesoderms entspricht (Leuconen etc.) (Fig. 249 B). Bei Spongilla wird nach GöтTE die äussere Schichte der parenchymatösen Larve abgeworfen und der ganze Spongienkörper entsteht aus dem Parenchym, ein Vorgang, der noch der Aufklärung bedarf. 
Die animalische Lebensthätigkeit der Spongien äussert sich vornehmlich in der Erzeugung eines Wasserstromes, welcher durch die Poren in das innere Höhlensystem eintritt und durch das Osculum den Körper wieder verlässt. Dieser Wasserstrom, der durch die Geisselbewegung der Kragenzellen verursacht wird, führt dem Thiere mikroskopische Nahrungstheilchen (organischen Detritus) zu und vermittelt auch die Athmung. Die Verdauung ist intracellulär, $d$. b. es dringen feste Nahrungstheile in die Zellen selbst ein und werden innerhalb des Zellplasmas verdaut. Als nahrungaufnehmende Zellen fungiren die Kragenzellen, doch gebeu sie noch feste Nahrungstheile an die Mesodermzellen und Ectodermzellen weiter. Den Spongien fehlt eine Gesammtbewegung des Körpers, doch sind geringe Gestaltveränderungen einzelner Theile zu beobachten, besonders das Oeffnen und Schliessen der Poren; diese Veränderungen beruhen zumeist auf amöboider Bewegung und allgemeiner Plasmacontractilität, es sind nur vereinzelte spindelförmige Zellen als Muskeln (d. h. in bestimmter Richtung contractil) gedeutet worden. Bei den Spongien herrschen demnach die niedrigeren Grundformen der Bewegung, die allgemeine Plasmacontractilität und die Flimmerbewegung vor. - Als Fähigkeit der Empfindung ist eine allgemeine Reizbarkeit des Plasmas vorhanden, die vielleicht an einzelnen Theilen eine geringe Steigerung zeigt. - Mit Ausnahme der süsswasserbewohnenden Spongilla sind die überaus mannigfaltigen Spongienformen alle Meeresbewohner.

Die Spongien werden mit Recht als die niedrigst organisirte Thiergruppe unter den Metazoen betrachtet. ES ist zwar das Verhältniss des Protostomas schon verändert und der Körper schon aus drei Schichten zusammengesetzt, doch ist innerhalb der Blätter die Differenzirung der Gewebe in Bezug auf die morphologische Ausbildung und die physiologische Leistung eine niedrigere als bei irgend einer anderen Metazoengruppe. Dies ist besonders in dem Mangel (oder doch der äusserst niedrigen Ausbildungsstufe) von Nerven und Muskeln ausgeprägt.

\section{Systematische Uebersicht der Spongien.}

I. Classe. Calcispongiae, Kalkschwämme, Skelet aus Kalknadeln bestehend.

1. Ord. Asconidae. 2. Ord. Syconidae, Sycandra raphamus. 3. Ord. Leuconidae.

2. Classe. Fibrospongiae,'Faserschwämme. Mit Kiesel oder Hornskelet, oder ohne jedes Skelet. In ihrem inneren Bau dem Leucontypus verwandt.

1. Ord. Hyalospongiae, Glasschwämme. Mit sechsstrahligen, (triaxilen), oft zu einem zusammenhängenden Gerüste verbundenen Kieselgebilden, daher auch als Hexactinellidae bezeichnet. Geisselkammern Syconähnlich angeordnet. Euplectella aspergillum.

2. Ord. Lithospongiae, Steinschwämme. Wit isolirten, deutlich vierstrahligen Kieselgebilden (daueben ankerförmige etc.), daher auch Tetractinellidae genannt. [Der Abstammung uach von den Hexactinelliden unabhängig.] Geodia, Plakina.

3. Ord. Ha lichondriae, Kieselhornschwämme. Iit einachsigen (auch kugeligen) Kieselgebilden, die oft ron Hornfasern begleitet sind; daher auch 
Monaclinellidae genannt. [Sie stammen von den Tetractinelliden ab.] Chondrosia, Reniera. Hierher gehört auch Spongilla, der Süsswasserschwamm. 4. Ord. Ceraospongia, Hornschwämme. Mit Hornskelet. [Sie stammen von den Halichondrien ab]. Euspongia, der Badeschwamm.

5. Ord. Myxospongia, Gallertschwämme. Ohne Skelet. Oscarella (Halisarca) lobularis.

Anhang. Phys emaria. Einfache, kleine, Ascon-ähnliche Formen, ohne Poren der Leibeswand, ohne Skeletbildungen, an deren statt aber Fremdkörper in die Leibeswand eingelagert sind. In der Nähe des Osculums eine spiralig angeordnete Reihe grösserer Kragenzellen. Haliphysema, Gastrophysema. 


\section{ZWÖLFTES CAPI'TEL.}

\section{Cladus der Metazoa.}

\section{Cnidaria.}

Die Cnidarier sind Metazoen mit persistirender Primärachse und von radiärem Körperbau; mit epithelialem Muskel- und Nervengewebe und Nesselzellen; ihre Keimepithelien entstehen entweder ectodermal oder endodermal. Sie sind zurückführbar auf eine polypoide Grundform (Archhydra, Haecket).

Die Archhydra, die hypothetische Stammform der Cnidarier, ist eine Gastrula-ähnliche Form, am A picalpol festsitzend, in der Nähe des oralen Körperendes mit einem Kranz von Tentakelu versehen, welche Ausstülpungen der Körperwand sind. Die Körperwand besteht aus dem ectodermalen und endodermalen Epithel und einer gallertigen, zellenlosen Zwischenschicht. In den Epithelien treten als histologische Differenzirungen Muskel- und Nervengewebe sowie Nesselzellen auf; Keimzellen werden von beiden Epithelien geliefert (vergl. pag. 252).

\section{Grundformen und Haupttypen.}

Wir unterscheiden bei den Cnidariern zwei Grundformen der Körpergestaltung, die festsitzende Polypenform und die freischwimmende Medusenform. Es gibt Cnidarier, die als Polypenform geschlechtsreif werden, andere sind nur in ihrer Jugend Polypen und im geschlechtsreifen Zustand Medusen; meist erfolgt der Uebergang zu letzterer Form nicht direkt, sondern auf dem Wege des Generationswechsels. - Auch phylogenetisch ist die festsitzende Polypenform, die u rsprünglichere Gestaltung, von welcher die Medusenform durch Anpassung an die freischwimmende Lebensweise und höhere Differenzirung abgeleitet ist.

Die Körperform des Polypen ist die eines Schlauches, der an dem einen blind geschlossenen Ende an seiner Unterlage festgewachsen ist (Basalende oder Befestigungspol), während das andere freie Ende die Mundöffnung trägt (M und po l). Diesem Ende genähert findet sich ein Kranz von beweglichen, sehr contractilen 'Tentakeln (Tentakelkranz), welcher demnach zwei Körperregionen, die orale 
oder die Mundscheibe und die aborale oder den Kelch von einander abgrenzt.

Wir haben trotz der äusseren Uebereinstimmung der Körperform zwei anatomisch scharf gesonderte Typen zu unterscheiden. 1. Typ us, Hydroidpolyp. Die Mundöffnung ist eine primäre, sie führt direct

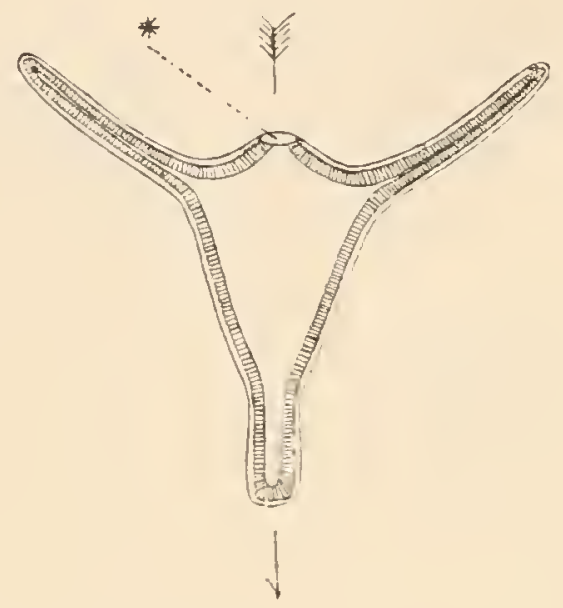

A.

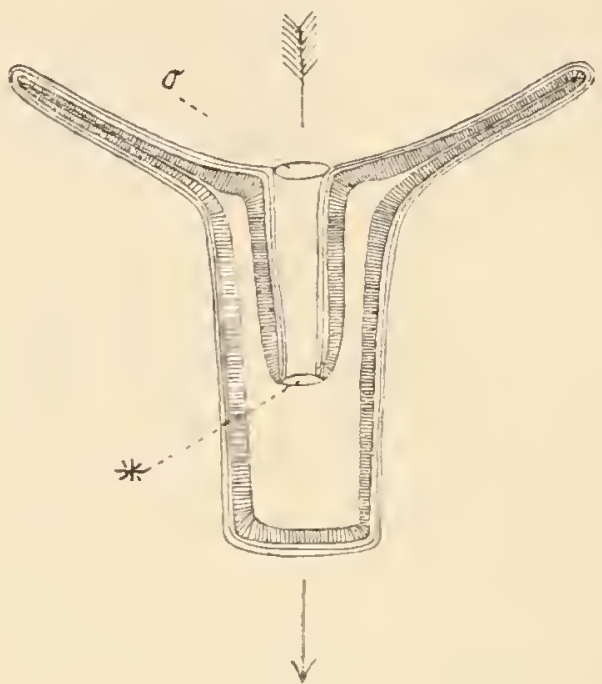

B.

F Fig. 250. A. Schematischer Längsschnitt eines Hydroidpolypen. Der Pfeil deutet die Primärachse mit ihren verschiedenen Polen an. * II undöffinung, welche mit dem Protostoma übereinstimmt.

B. Schematischer Längsschnitt eines Scyphopolypen. Der Pfeil deutet in gleicher Weise die Primärachse an. * Protostoma, welches hier als Schlundpforte in die Tiefe verlegt ist, $o$ secundäre Mundöffnung.

in die sehr einfache Urdarmhöhle, welche nur in die Höhlen der Tentakeln sich fortsetzt (in secundären Fällen sind die Tentakeln solid). Die Körperwand besteht aus dem Ectodermepithel und dem Endodermepithel, welche an der Mundöffnung in einander übergehen und einer dazwischenliegenden z ell e n freien Gallertschichte. Dieselben Schichten finden sich in den Tentakeln. 2. Typus, Scyphopolyp oder Actinopolyp. Die Mundöffinung ist eine secundäre, sie führt in ein Schlundrohr, welches - als eine Einstïlpung der Körperwand vom Ectoderm ausgekleidet ist; erst an der inneren $\mathrm{Schlundp}$ for te gehen Ectoderm und Endoderm in einander ïber. Die Urdarmhöhle (oder Gastrovascularhöhlc) ist durch einspringende longitudinale Endodermfalten (S e p te 11) complicirter gestaltet, so dass wir an derselben einen Centralmagen und peripher angeordnete Gastralrinneu

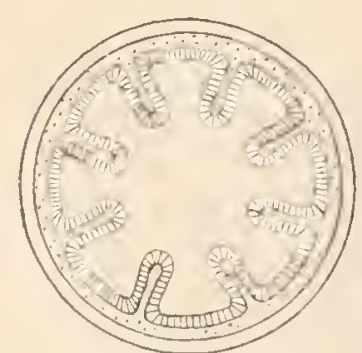

A.

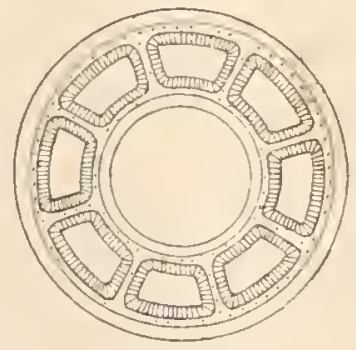

B.

Fig. 251. Querschnitte durch einen achtstrahligen Scyphopolypen (schematisch).

A. Querschnitt durch den unteren Theil.

B. Querschnitt in der Höhe des Schlundrohres. 
unterscheiden. In der Höhe des Schlundrohres sind die Septen breiter und meist an dasselbe angewachsen, so dass die Gastralrinnen hier als Gastraltasch en sich fortsetzen, welche weiter in die Tentakelhöhlen übergehen. Die Septen haben also ihre Lage zwischen je zwei Tentakeln (abgesehen von jenen secundären Fällen, wo mehrere 'Tentakeln auf eine Gastraltasche kommen). Die Körperwand ist aus den drei Schichten zusammengesetzt, doch enthält hier die Gallertschichte auch mesenchymartige Zellen (Bindegewebszellen).

Di e Körper form der M eduse entspricht im allgemeinen einer gewölbten Scheibe oder Glocke. Die convexe aborale Fläche (der Kelchfläche des Polypen entsprechend) ist nach oben gewendet, sie wird als Exumbrella bezeichnet. Am Scheibenrand findet sich ein Kranz

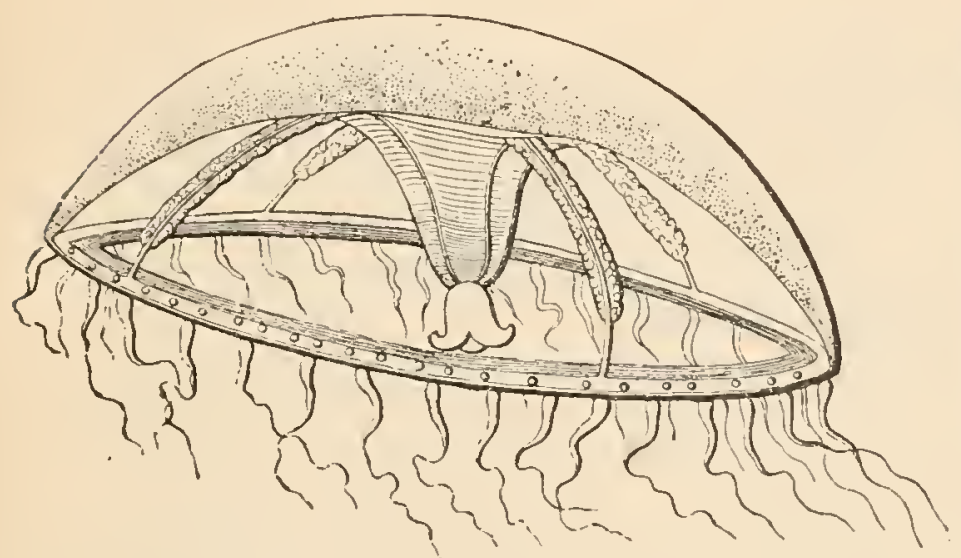

A.

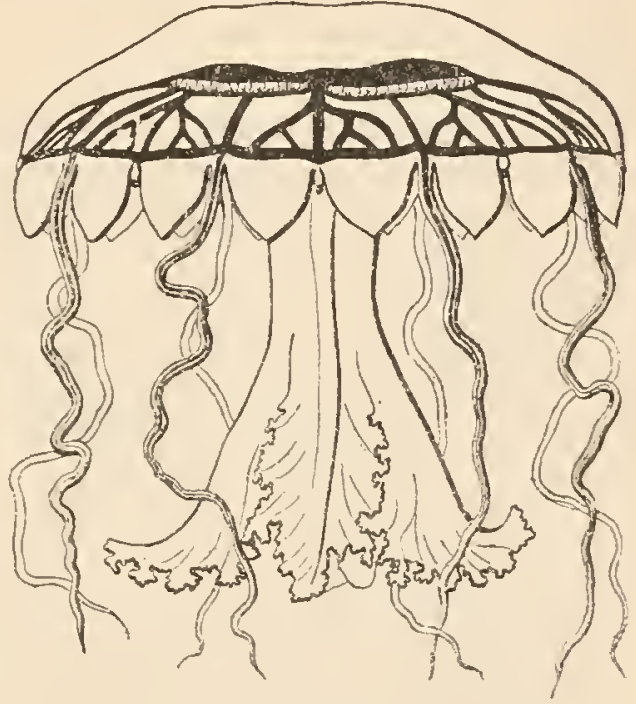

B.

Fig. 252. A. Hydroidmeduse (Irene pellucida) nach H́AEckel. Am Scheibenrande zahlreiche Tentakel und Randbläschen, ferner das musculöse Velum. Die centrale Mundöffnung führt in den kurzen Magen, der von einem kouischen Magenstiel getragen wird; an letzterem verlaufen vier Radiärkanäle, die sich an der Subumbrella bis zum Ringkanal fortsetzen. Längs der vier Radiärkanäle liegen die Gonaden.

B. Scyphomeduse (Ulmaris prototypus) nach HAECKEL. Am Scheibenrande finden sich Tentakeln und Rhopalien, das sind zu Sinneskörpern umgewandelte Tentakeln, und Randlappen. Die Mundöfnung ist von vier krausenartigen Mundarmen umgeben. Sie führt mittelst des Schlundes in den Centralmagen; von dort gehen verästelte Radiärgefüsse zu dem Ringkanal. Die bandförmigen Gonaden liegen in der Umgebung des Centralmagens.

von Senkfäden oder Tentakeln (homolog dem Tentakelkranz des Polypen). Die untere concave Fläche, Subumbrella genannt, ist homolog der Mundscheibe des Polypen, sie trägt in ihrer Mitte einen stielartigen Fortsatz (Magenstiel, Mi udsti el), an dessen unterem Ende sich die Mundöffnung findet. - Die Gallertschichte ist unterhalb der Exumbrella zu einer mächtigen Scheibe (U mbrella) verdickt. Das Urdarmsystem oder Gastrovascular'system ist dadurch in seiner ganzen Ausdehnung dicht an die Subumbrellarfläche gedrängt. In der Regel ist es in Zusammenhang mit dieser Abplattung in der Weise umgewandelt, dass nur sein centraler Theil ein einfacher Hohlraum bleibt (Centralmagen), während die peripheren Theile ein eigenthümliches System von Kanälen bilden; es sind dies meist Radiärkanäle und ein randständiger Ringkanal, in welchen andererseits die (eventuellen) Tentakelkanäle münden. 
Die Exumbrella ist von einem einfachen Plattenepithel bekleidet. Der Scheibenrand trägt nicht nur die Tentakeln, sondern es ist hier auch das epitheliale Centralnervensystem gelegen - bei den Hydroidmedusen als doppelter Gangliennervenring, bei den Scyphomedusen als eine Mehrzahl von Ganglien ${ }^{1}$ ) - und es finden sich hier die zahlreich angeordneten Sinnesorgane (Gehörorgane, Augen). Der Scheibenrand ist ferner bei den Hydroidmedusen unterhalb der Tentakeln mit einem diaphragnıaartig den Eingang der Glockenhöhle verengernden, contractilen Randsaum oder Velum versehen, bei den Scyphomedusen dagegell ist er in eine Anzahl eigenthümliclıer Randlappen ausgezogen. Die Subumbrella besitzt ein kräftiges Muskelepithel, durch dessen Contraction (bei den Hydroidmedusen durch die des Velums unterstützt) das Wasser aus der Glockenhöhle rhythmisch ausgestossen wird; durch den Rückstoss, der hierbei zu Stande kommt, wird der Körper in der Richtung des aboralen Poles fortbewegt; die elastische Gallertscheibe wirkt als Antagonist dieser Muskeln.

Wir unterscheiden, wie also ersichtlich, zwei Typen der Medusen, die Hydroidmedusen und die Scyphomedusen. So viel ähnliches auch in ihrem Bau bemerkbar ist, so zeigt doch eine genauere morphologische Erforschung, dass diese beiden Gruppen als Medusen nicht stammverwandt sind, sondern selbständig die eine von Hydroidpolypen, die andere von Scyphopolypen abgeleitet werden müssen.

Aus obigen gelit hervor, dass die Cnidarier in zwei Hauptabtheilungen zerfallen, die Hydrozoa und die Scyphozoa, deren jede ursprünglichere Polypenformen und davon abgeleitete Medusenformen enthält. Die Scheidung dieser beiden Hauptgruppen beruht auf den zum Theil schon oben erwähnten und ferner auf anderen noch genauer zu erörternden morphologischen Clarakteren; einer der wichtigsten Punkte, den wir schon hier hervorheben wollen, ist folgender: Bei den Hydrozoa sind die Keimepithelien ectodermal, bei den Scyphozoa e nd o d e r mal (O. u. R. Hertwig).

Ian kann die Verwandtschaft dieser beiden Gruppen folgendermassen darstellen. Von einer polypoiden Stammform, welche einen einfachen Hydraähnlichen Bau besass und in beiden Epithelschichten Keimzellen erzeugte (Archhydra $\mathrm{H}_{\mathrm{AECKEL}}$ ), wäre einerseits die Hydroidpolypenform mit ectodermalen Keimepithelien als Stammform der Hydrozoa abgeleitet; andererseits wäre von derselben durch Bildung des Schlundrohres und der Gastraltaschen und Beschränkung des Keimepithels auf das Endoderm jene Scyphopolypenform entstanden, von welcher die Scyphozoa abstammen.

Dieser Auffassung wird von GöTte eine andere gegenübergestellt. Er hebt hervor, dass in der Ontogenie der Scyphopolyp nicht etwa ein einfacheres Hydra-ähnliches Stadium durchlaufe (wie man nach der oben erwähnten Anschauung erwarten sollte), sondern dass die Schlundeinstülpung und die Gastraltaschen stets früher gebildet werden als die Tentakeln. Nach der ersteren Anschauung müsste man dies für Heterochronie halten; GöTte aber leitet den Scyphopolypen auch phylogenetisch nicht von der hydroidpolypenähnlichen Form ab, sondern von einer freischwimmenden "Scyphula", das ist eine tentakellose Form mit Schlundrohr und Gastraltaschen. Nach dieser Anschauung wäre die Kluft zwischen Hydrozoa und Scsphozoa eine noch tiefere; man müsste die Cnidarier in zwei selb-

1) Es werden daher von EIMER die Hydroidmedusen treffend als Cycloneura, die Scyphoredusen als Toponeure bezeichnet. 
ständige Gruppen auflöson, die keine nähere Stammverwandtschaft zu einander besässen als durch die "Gastraea". Andererseits schiene es nach dieser Auffassung eher möglich, die Clenophoren zu den Scyphozoa zu stellen, indem man auch diese vielleicht von del freischwimmenden ,Scyphula" ableiten könute.

\section{Histologischer Charakter.}

Im allgemeinen ist bei den Cnidariern das ectodermale Epithel aus plasmareichen Zellen zusammengesetzt, während die Zellen des endodermalen Epithels durch Ausbildung von Flüssigkeitsvacuolen grossblasig erscheinen, ihr Plasma ist auf eine wandständige Schichte und ein inneres Netzwerk beschränkt (vergl. pag. 140); sie sind in der Regel Geisselzellen. Diese Eigenschaften der beiden Grenzblätter sind aber nicht allein für die Cnidarier charakteristisch, sondern sie sind melır oder weniger scharf ausgeprägt auch bei vielen höheren 'Thiergruppen nachweisbar. - Die Gallertschichte ist im einfachsten Falle zellenfrei.

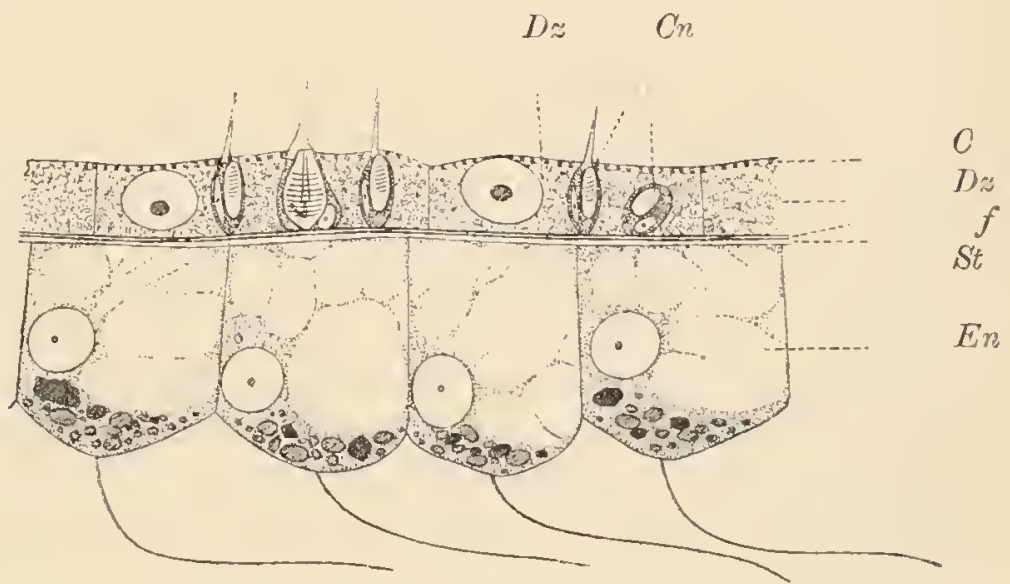

Fig. 253. Körperschichten von Hydra nach F. E. Schulze. Ec Ectoderm, mit dichterem Plasma, besteht aus grossen Deckzelle n $(D z)$, die an der freicn Fläche einen cuticula-ähnlichen Saum $(C)$ und an der Basis Muskelfibrillen $(f)$ besitzen. Dazwischen liegen an der Basalseite interstitielle Zellen, die an dem hier abgebildeten Stücke sämmtlich zu Cnidoblasten $(C n)$ umgewandelt sind, welche in die grossen Deckzellen eingeschachtelt erscheinen; die reifen Cnidoblasten sind mit einem Cnidocil versehen. St Stützlamelle. En Endoderm besteht aus grossen Vacuolen- und Körnchenreichen Geisselzellen (auch an diesen wurden neuerdings Muskelfibrillen entdeckt).

Der wesentlichste histologische Charakter, welcher speciell den Cnidariern eigenthümlich ist, liegt darin, dass die Grenzblätter E p i the $1 \mathrm{~m}$ us seln bilden (vergl. pag. 120-122); dies findet sich bei keiner anderen Thiergruppe. - Bei den Hydroidpolypen sind die Muskeln überwiegend im Ectoderm, bei den Actinozoen überwiegend im Endoderm ausgebildet; bei allen Medusenformen spielt stets die ectodermale Musculatur der Subumbrella die Hauptrolle.

Auch das Nervensystem (vergl. pag. 132) ist stets epithelial gelagert, doch ist dies eine Erscheinung, welche bekanntlich nicht auf die Cnidarier beschränkt ist. Bei den Polypenformen ist das Nervensystem, wo es überhaupt nachgewiesen ist, eil acentrisches (Actinien); bei den Medusen findet sich der Gegensatz von centralem, in naher Verbindung mit den Sinnesepithelien stehendem, und peripherem Nervensystem schon ausgeprägt; es erscheint aber auch letzteres nur in Form eines Gangliennervennetzes - regelmässig verästelte periphere Nerven von jener Al't, wie sie bei höherein Thieren vorkommen, sind nicht beobachtet. Die Nervengewebe gehören in überwiegender Weise dem Ectoderm an, doch fehlen sie auch dem Endoderm nicht gänzlich, wie $\mathrm{O}$. u. R. Hertwig bei den Actinien nachgewiesen haben.

Nesselzellen (vergl. pag. 142) finden sich bei allen Cnidariern als typische Gebilde. Sie kommen vorwiegend im Ectoderm, seltener 
im Endoderm vor; an gewissen Stellen sind sie gehäuft, z. B. an den Tentakeln, sie können sogar besondere Nesselorgane zusammensetzen (Nesselknöp fe, Nesselbat terien der Siphonophoren). Die jungen Nesselzellen entwickeln sich in der Regel aus den sogenannten interstitiellen Zellen in der Tiefe des Epithels und sie rücken bei der Reife an die Oberfäche. Die reife Nesselzelle ist durch das Cnidocil (vergl. pag. 118) und durch die Nesselkapsel (vergl. pag. 142) ausgezeichnet selten ist sie mit speciellen Muskelfibrillen zum Zwecke der Entladung ausgestattet.

Drü s enzelle n sind bei den Cnidariern als Becher- und Körnchenzellen beobachtet, dagegen kommen subepitheliale Driusenzellen nicht vor. (Eine Ausnahme bildet die "Gasdrüse" der Siphonophoren.)

Das Endoderm der Tentakeln ist in vielen Fällen, bei Polypen und Medusen, zu einem blasigen St ützgewebe umgewandelt (vergl. pag. 140); in diesen Tentakelachsen sind die Zellen stets in einer einzigen Reihe angeordnet.

Als Bindegewebe (s. str.) ist das Gallertgewebe zu bezeichnen; als Matrix desselben fungiren entweder die angrenzenden Epithelien (Hydrozoa), oder es enthält selbst specielle Bindegewebszellen (Scyphozoa). In beiden Fällen finden sich oft faserige Structuren in der Gallerte. Besonders mächtig entwickelt ist die Gallerte bei den meisten Medusen zu finden. Bei den Actinozoen kommen auch kleine Kalkkörperchen (Sklerodermiten) in dieser Mittelschichte vor.

Eigentliche, zusammenhängende Skeletbildungen sind stets ectodermalen Ursprungs. Bei den Hydroidpolypen findet sich ein cuticulares Aussenskelet, welches meist von chitiniger Beschaffenheit (Campanularien und viele Tubularien), seltener verkalkt ist (Hydrocoralliae). - In neuester Zeit wurde nachgewiesen, dass auch die massigen, hornigen oder verkalkten Skelete der Actinozoen, welche ein inneres Gerüst der Cormen bilden, ectodermale Ausscheidungen sind, die durch Einwucherung tief in das innere des Weichkörpers gelangen ( $\mathrm{KOCH}$ ).

\section{Radiärer' Typus in Bau und Wachstlum.}

\section{1) Radiärer Bau.}

Der radiäre Körperbau, welcher für die Cnidarier charakteristisch ist, beruht auf einer Wiederholung gleichartiger Organe im Umkreis der Hauptachse; die Organe sind in gleicher Weise zu einander und zur Achse gelagert, so dass in dieser Achse zusammentreffende, unter gleichen Winkeln $\mathrm{zu}$ einander stehende Radialebenen durch dieselben bezeichnet erscheinen.

Im einfachsten Falle sind es die Tentakel, welche allein den radiären Körperbau zum Ausdruck bringen ${ }^{1}$ ). Bei complicirteren Formen kommt er an zahlreichen Organen zur Erscheinung, so besonder's an den Kanälen des Gastrovascularsystems und an den Geschlechtsorganen. - In manchen Fällen wird durch ungleiche Ausbildung der Radien ein symmetrischer Bau herbeigefuihrt.

2) Wachsthum durch Intercalation neuer Radien.

Für die Cnidarier ist nicht nur ein radiärer Bau in der Vertheilung der Organe, sondern auch in Zusammenhang damit ein besonderes Tachs-

1) Bei gewissen Hydroidpolypen - Coryne, Clava - finden sich die Tentakel aber nur unregelmässig über den vorderen Körpertheil zerstreut. 
thumsgesetz charakteristisch, welches wir als Intercalation neuer $\mathrm{R}$ adi i n bezeichnen. Wenn beispielsweise ein vierstrahliger Polyp bis $\mathrm{zu}$ einer gewissen Grösse gleichmässig gewachsen ist, so wird das
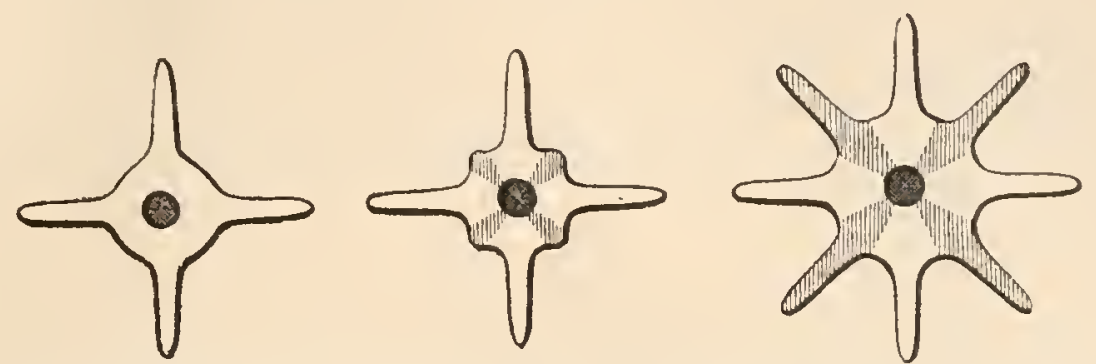

Fig. 254. Schematische Darstellung des Wachsthums durch radiäre Intercalation bei einem Polypen.

gleichmässige Wachsthum dadurch unterbrochen, dass sich zwischen je zwei Radien lebhafter wachsende Regionen bilden (Intercalation radiärer Wachsthumspunkte). Die radiären Organe werden dort neu angelegt und wachsen so rasch heran, dass sie bald denjenigen der primären Radien gleichkommen, so dass nun die Anzahl der Radien verdoppelt ist. Dieser Process kann sich wiederholen, so dass wir nach einander $4,8,16,32$ u. s. w. Radien ausgebildet sehen. Wir sprechen demgemäss von Radien erster, zweiter, dritter Ordnung u. s. w. Die Anzahl der Radien erster Ordnung nemnen wir die Grundzahl; diese ist von besonderer Wichtigkeit, da sie alle späteren Zahlenverhältnisse beherrscht. Die Grundzahl der Radien ist bei den Cnidariern meist vier oder sechs. - Der hier erörterten regulären radiären Intercalation steht die irreguläre radiäre Intercalation gegenüber, bei welcher nur zwischen bestimmten Radien eine Intercalation stattfindet. Hierbei sind die verschiedensten Combinationen der Radienfolge möglich; häufig kommt sogar eine bilaterale Symmetrie zum Ausdruck; einer der interessantesten Fälle ist die Intercalation paariger Radien von einem einzigen Radius aus (bei Cerianthus), welche wir an anderer Stelle näher erörtern wollen.

3) Bildung der Radien erster Ordnung.

Die Radien erster Ordnung treten in vielen Fällen alle gleichzeitig a uf. Doch ist dies durchaus nicht ein allgemein
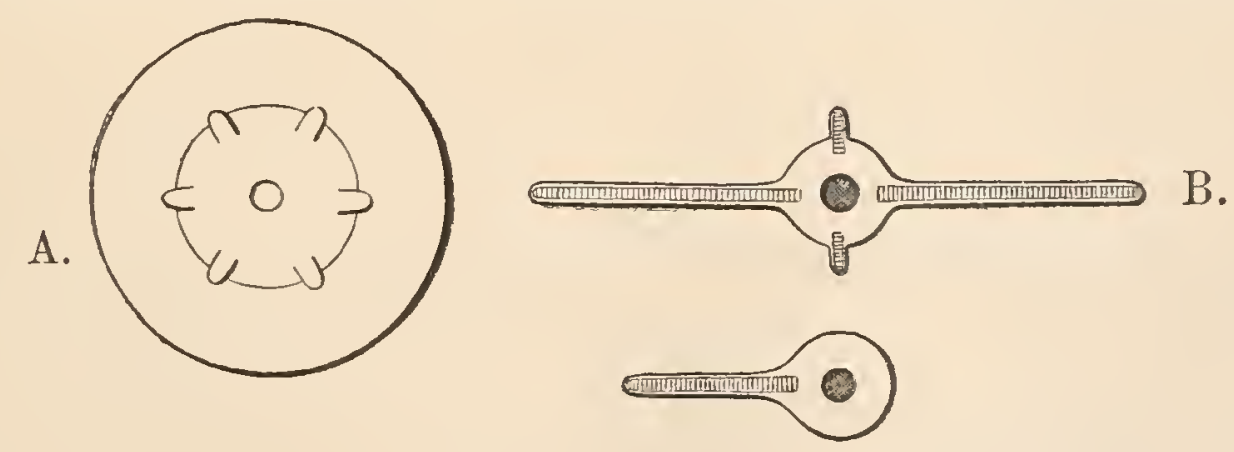

C.

Fig. 255. Bildung der Radien erster Ordnung. A. Eine junge Hydroidmeduse (Geryonia) mit sechs gleichzeitig auftretenden Radien. B. Entwicklungsstadium einer Hydroidmeduse (Polyxenia leucostyla) mit zwei primären Tentakeln. C. Entwicklungsstadium einer Hydroidmedusenknospe (Cunina rhododactyla) mit einem primären Tentakel. A, B und C nach Metschnikoff. 
giltiges Gesetz. Sehr häufig treten zuerst nur zwei einander gegenüberstehende Radien auf und die nächsten werden durch einen Process, welcher mit der Intercalation principiell übereinstimmt, eingeschoben, bis die Grundzahl erreicht ist, von da wird die Anzahl bei jeder Intercalation verdoppelt. Es ist sogar beobachtet, dass in vielen Fällen $z u$ ers $\mathrm{t} n \mathrm{r}$ ein $\mathrm{R}$ a dius a f tritt und diesem gegenüber erst dann der zweite entsteht (Cunina-Knospung). Die Erscheinung der Intercalation kann also bis auf die frühesten Stadien zurückgreifen.

Es tritt uns nun die Frage entgegen, ob die Vertheilung der Radien bei der Entwicklung schon im Ei vorbestimmt ist, oder ob nicht erst mit dem Auftreten des primären Tentakels (also des ersten Radius) die Stellung aller nachfolgenden bestimmt wird. Letzteres ist wenigstens für viele Fälle wahrscheinlich. Dadurch stünden die Cnidarier im Gegensatz zu den Bilateralthieren, bei welchen je eine bestimmte Hälfte des Eies der rechten und linken Körperhälfte entspricht. Auch bei den Ctenophoren ist schon bei der Furchung das Materiale nach den 4 meridionalen Körpertheilen gesondert.

\section{Cormenbildnng.}

Knospung und Theilung (vergl. unten) führt, wenn die neugebildeten Individuen in Zusammenhang bleiben, zur Cormenbildung. Die Cormen sind von mannigfaltigster Gestaltung; als allgemeines Gesetz ist nur hervorzuheben, dass die jüngeren Individuen an den älteren oder an dem gemeinschaftlichen Stammtleil des Cormus (Coenen chym) stets mittelst ihres Apicalpoles befestigt sind und die Gastralhöhlen dort mit einander in Zusammenhang stehen. Die Cormen sind entweder aus gleichartigen Individuen zusammengesetzt (homomorple Cormen bei Korallen-Polypen) oder aus verschiedenartigen Individuen (heteromorphe und polymorphe Cormen bei vielen Hydroid-Polypen und bei den Siphonophoren).

Fortpflanzung und Entwickluug.

Die Cnidarier sind mit wenigen Ausnahmen (z. B. Hydra, Cerianthus, Chrysaora) getrennt geschlechtlich. Die Geschlechtsproducte werden meist einfach nach aussen entleert, seltener werden die Eier während der ersten Entwicklung noch im oder am mütterlichen Körper zurückbehalten (Chrysaora, Aurelia, viele Actinozoen).

Die Eier sind in der Regel von sehr geringer Grösse und werden in sehr grosser Anzahl erzeugt (eine Ausnahme bildet z. B. Hydra). Die Furchung ist meist adäqual. Die Gastrulation erfolgt in vielen Fällen durch polare Einwucherung etc. (vergl. pag. 100), bei Scyphozoen kommt auch Invagination vor, ferner ist bei manchen Actinozoen wahrscheinlich Epibolie vorhanden. Das Resultat der ersten Entwicklungsvorgänge ist meist die sogenannte Planula, die typische Larve der Cnidarier. Es ist dies eine eigenthümliche Modification der Gastrula, welche sich von derselben durch das Fehlen des Protostoma und der Urdarmhöhle unterscheidet. Die Planula ist also eine ovale oder mehr langgestreckte, bewimperte Larve, die aus einem äusseren Ectodermepithel und einer inneren, compacten Endodermmasse besteht. Der Apicalpol bleibt dadurch kenntlich, dass er beim Schwimmen nach vorne gewendet ist. Die Eigenthümlichkeiten dieser Larve erklären sich daraus, dass dieselbe in diesem Zustande keine Nahrung aufnimmt 
and dass ilır Körperbau zur raschen Fortbewegung passend gebaut ist; die Planulalarve bikdet gleichsam die Aussaat der Thierformen.

Die Planula setzt

sich mit dem Apicalpole fest und verwandelt sich in einen Polypen, welcher entweder die bleibende Form darstellt(Actinozoa) oder von dem durch Knospung oder Theilung weiter die Medusen (Hydromedusen, Scyphomedusen) gebildet werden.- In einigen Fällen verwandelt sich die Planula direct (ohne festsitzendes Stadium) in eine Meduseuform (Haplomorpha, Pelagia).

Fortpflanzung durch (primordiale) Knospung oder durch Theilung ist bei den Cnidariern überaus verbreitet und kann in den verschiedensten Lebensstadien erfolgen; am häufigsten findet sie am polypoiden Stadium statt, doch auch schon im Planulastadium und auch an der Meduse.

Bei der Knospung entsteht durch einen regen localen Wachsthumsprocess zunächst eine Ausstülpung der Körperwand, an welcher stets sämmtliche Schichten derselbeu sich betheiligen ; aus dieser Anlage entwickelt sich die neue Individualität.

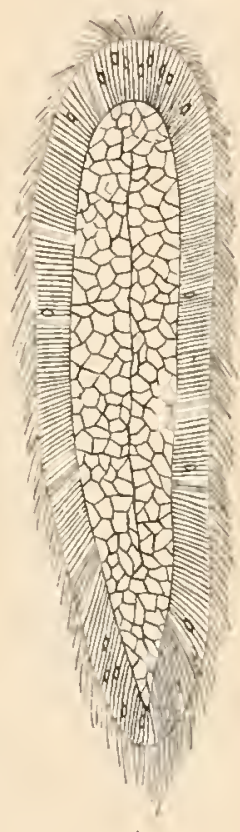

A.

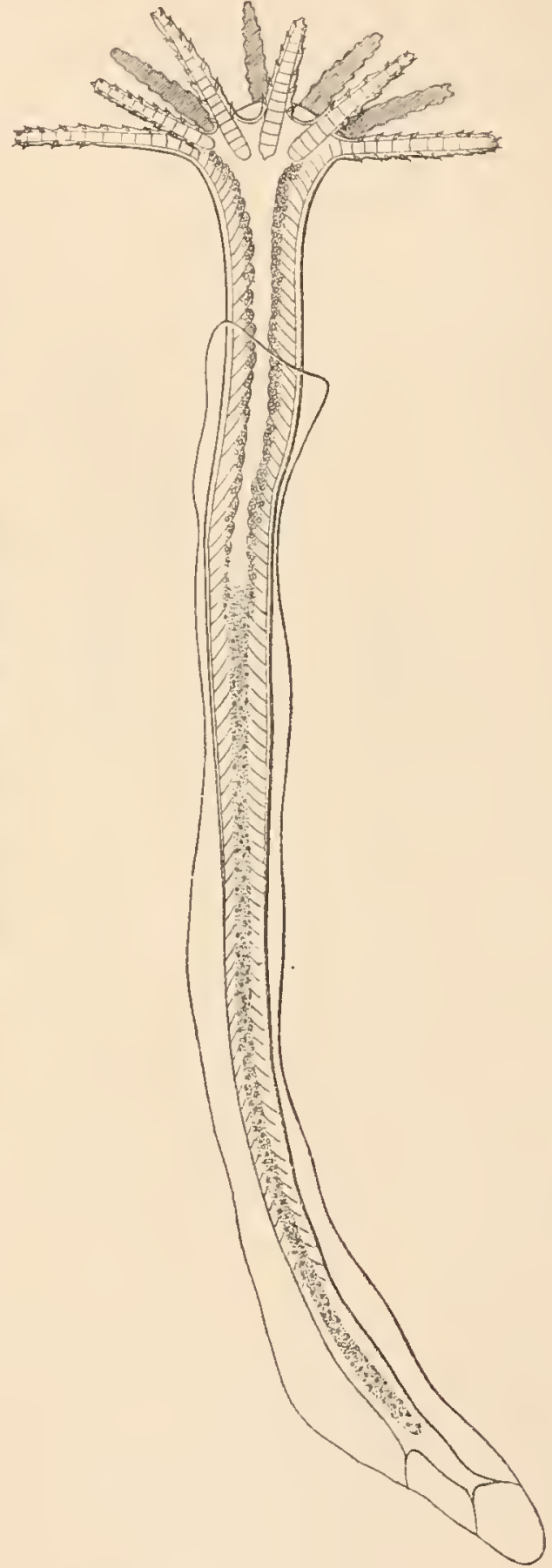

B.

Fig. 256. A. Planula einer Hydromeduse (Aequorea) nach ClaUs. Der stumpfe Pol ist der Apicalpol und ist beim Schwimmen nach vorne gewendet. Das Ectoderm ist ein cylindrisches Wimperepithel und enthält bereits Nesselkapseln. Das Endoderm ist eine solide Masse polygonaler Zellen.

B. Polyp von Aequorea kurz nach dem Festsetzen der Larve, nach MeтschNIKOFF. Die Larve hat sich mit dem Apicalpol festgesetzt, am entgegengesetzten Ende ist der Mund und Tentakelkranz entstanden. Am Hinterkörper ist eine cuticulare Röhre (Hydrotheca) zur Ausscheidung gekommen.

An einem poliferirenden Individuum entstehen entweder demselben gleichwerthige Individuen, oder solche von höherer Stufe, niemals aber solche von niedrigerer Stufe. Es knospen demnach an einem Polypeu wieder 
Polypen oder auch Medusen; an einer Meduse aber werden durch Knospung nur Medusen gebildet. - Bei der Knospung kann eine voll-

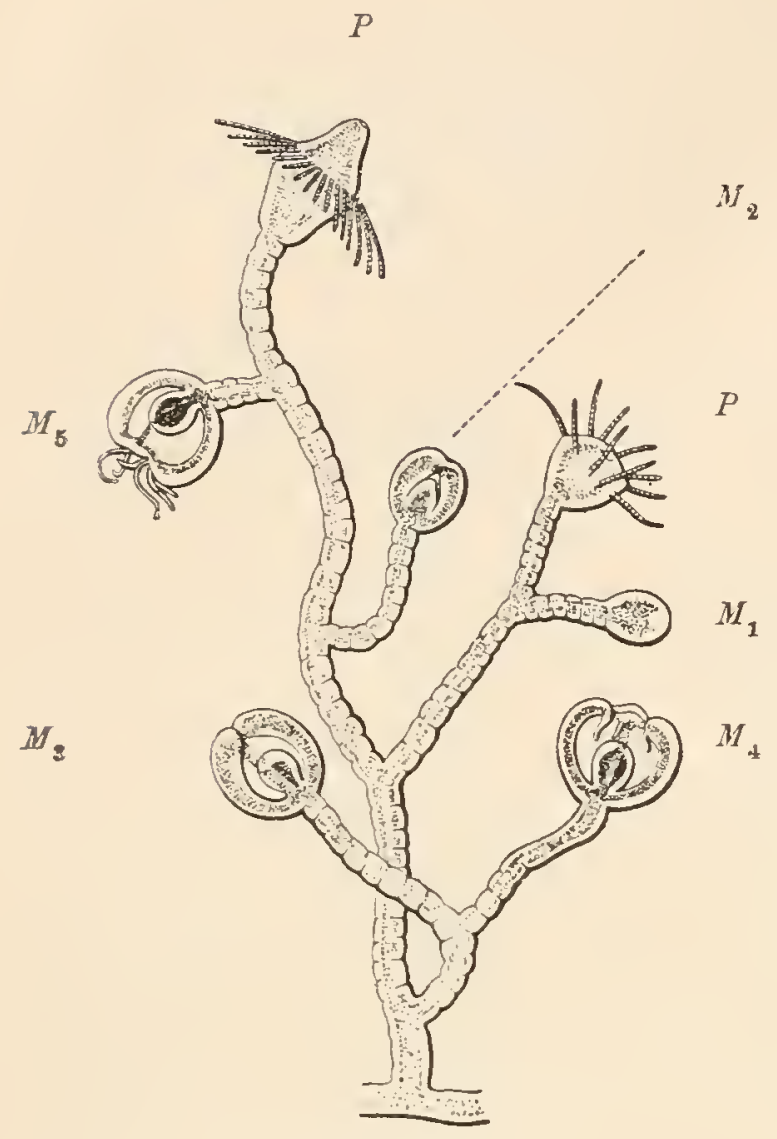

Fig. 257. A.

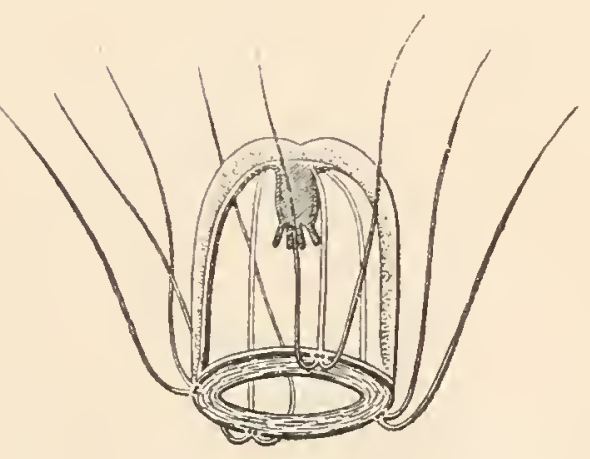

Fig. 257. B.

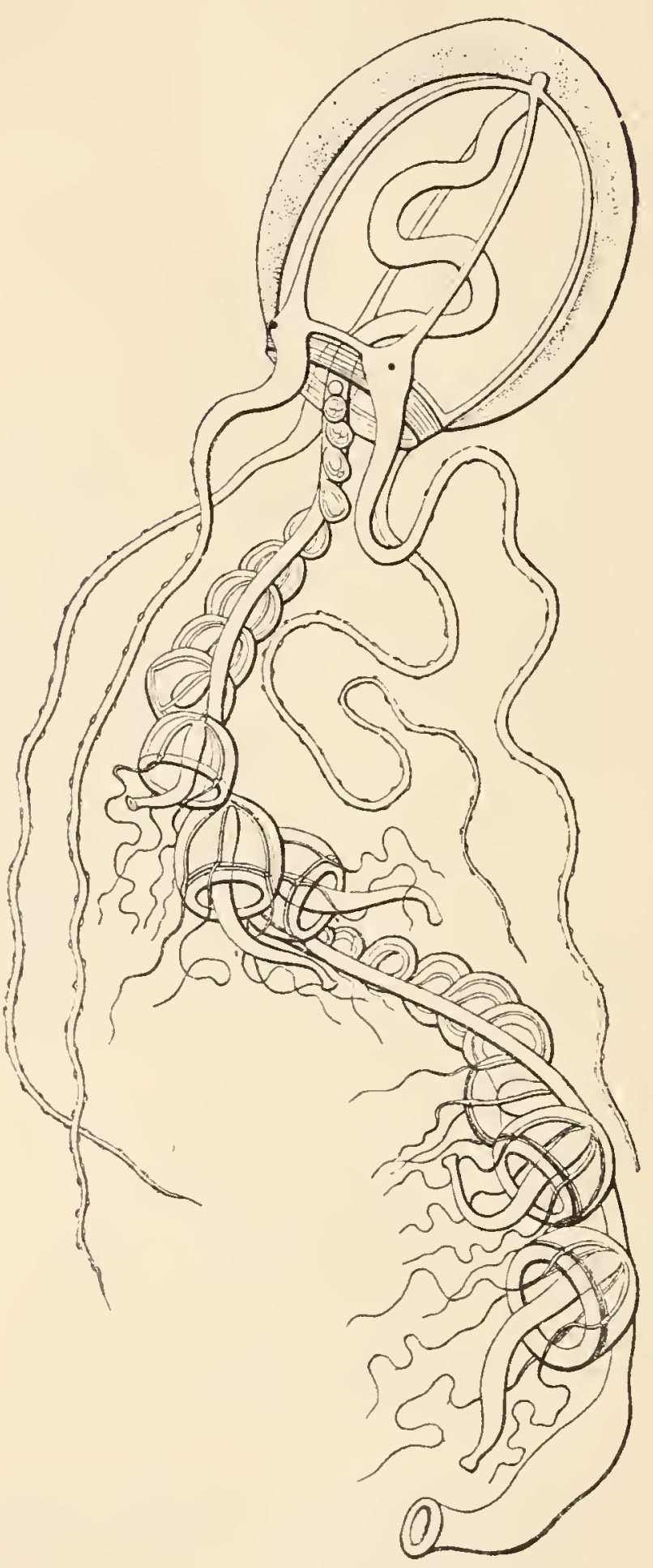

Fig. 258.

Fig. 257. Knospung von Medusen am Polypencormus.

A. Stöckchen eines Hydroidpolypen (Eudendrium ramosum) mit polypoiden Individuen $(P)$ und in Knospung begriffenen medusoiden Individuen $\left(M_{1}-M_{5}\right)$.

B. Freigewordene junge Meduse von Eudendrium ramosum (Bougainvillea-Typus) nach GegenbaUR.

Fig. 258. Knospung von Medusen an einer Meduse. Eine Hydroidmeduse, Sarsia siphonophora, an deren langem Magenschlauch zahlreiche Medusenknospen in zwei serialen Altersreihen sitzen, nach HAECKEL. 
kommene Ablösung der Individuen (Hydra, Medusen) oder Cormenbildung (Polypen, Siphonophoren) erfolgen.

Theil ung wird als Längstheilung und Quertheilung unterschieden; erstere ist eine vollkommene oder auch unvollkommene (zur Cormenbildung führende), dagegen ist die Quertheilung (Strobilabildung der Scyphistoma und mancher Actinozoen) stets eine vollkommene.

Die überaus vielgestaltige Abtheilung der Cnidarier enthält mit wenigen Ausnahmen (Hydra, Cordylophora) Meeresthiere. Die Polypen als festsitzende Formen bewohnen den Meeresboden besonders der Küsten; manche dieser Formen können bei ihrer massigen Ausbildung der gesammten Fauna ein besonderes Gepräge verleihen, wie z. B. die riffbauenden Corallenthiere in den tropischen Meeren. Die freischwimmenden Medusen und Siphonophoren bevölkern die Oberfläche des Meeres und bilden einen wesentlichen Bestandtheil dieser sogenannten pelagischen Fauna. Die Cnidarier ernähren sich von anderen Thieren, die sie trotz der Zartheit ihres eigenen Körper's mittelst ihrer nesselnden Tentakeln erbeuten.

Die Polypenformen sind in der Regel keiner Ortsbewegung fähig, doch können sie meist, zum Zwecke des Schutzes, ihren Körper stark zusammenziehen, uud denselben oft auch in das Innere schützender Röhren bergen. - Die Medusen bewegen sich, wie erwähnt, durch die Contractionen der Subumbrella; die Contractionen erfolgen beständig und rhythmisch (sie werden auch als Athmungsbewegungen aufgefasst) und dienen meistens niehr dazu, den Körper schwebend zu erhalten, als zur raschen Ortsveränderung; diese ist also im Allgemeinen nur eine langsame. Sehr contractil, wenn auch nur langsam beweglich, sind die Tentakel der Cnidarier. Ausser den Hautsinnesorganen, welche allen Cnidariern zukommen, sind bei den Medusen Augen und Gehörorgane vorhanden; vielleiclit dienen diese höheren Sinnesorgane nur zur allgemeinen Orientirung des Körpers im Raume (als Organe, welclıe die Richtung des Lichtes und die Richtung der Schwerkraft angeben).

\section{Classe der Cnidaria, Hydrozoa.}

Die Hydrozoa sind Cnidarier mit ectodermalem Keimepithel und mit zellenloser Gallertschichte. Sie sind zurückführbar auf die Grundform des Hydroidpoly pen.

Die Formtypen, die wir bei dieser Abtheilung der Cnidarier beobachten, und die sich auch innerhalb eines Entwicklungscyclus als aufeinanderfolgende Stadien finden, sind der Hydroidpolyp und die Hydroidqualle.

De r Hydroidpolyp ist eine einfach schlauchförmige Polypenform mit primärer Wundöffnung (ohne Schlundrohr und ohne echte Septenbildung in der Gastralhöhle ${ }^{1}$ ). Den ursprünglichsten Typus repräsentirt der Süsswasserpolyp $\mathrm{H}$ y dra, welcher hohle Tentakel besitzt (derselbe komint unserer Vorstellung von der Grundform der Cnidarier, welche als

1) Faltenbildungen der Gastralwand, aber ohne eigene Musculatur finden sich bei manchen grösseren Tubulariden. 
Archhydra bezeichnet wurde, am nächsten). Bei den anderen $\mathrm{Hy}^{y}$ droidpolypen bildet das Endoder'm in den Tentakeln eine einfache axiale Zellreihe, die in Folge ihrer histologischen Entwicklung als Stiutzgewebe fungirt.

Der Körper des Hydroidpolypen ist in der Regel in Stiel und Vorderkörper gesondert. Für die Gestaltung des Körper's ist auch die Tentakelstellung von Bedentıng. Bei den Coryniden und Claviden sind die Tentakel über den Vorderkörper zerstreut angeordnet, ohne einen regelmässigen Tentakelkranz zu bilden, so dass hier nicht eimmal der radiäre Typus ausgeprägt ist. Bei den Tubulariden ist nebst einem äusseren Kranz von Randtentakeln (die Yundscheibe ungebend) noch ein innerer Kranz von Mundtentakeln (unmittelbar an Mundrande entspringend) vorhanden. In den meisten Fällen ist nur der äussere Tentakelkranz ausgebildet (Campanulariae, Hydractiniae etc.). Viele Hydroidpolypen (Tubulariae, Campanulariae) bilden ein chitiniges, die Hydrocorallia sogar ein kalkiges Aussenskelett.

Die ectodermalen Muskeln der Körperwand und der Tentakeln sind stets Längsmuskeln. Bei Hydra sind auch spärlichere endodermale Muskelfibrillen beobachtet. - Das Nervensystem ist wahrscheinlich ein acentrisches Gangliennervennetz.

Nur wenige Hydroidpolypen werden in diesem Zustande geschlechts ${ }^{-}$ reif, die meisten repräsentiren die ungeschlechtliche Generation vou Hydroidmedusen; ihre Gonaden entwickeln sich in ersterem Falle (Hydra) ectodermal an der Kelchwand.

Die Hydroidmedusen sind mit einem contractilen Randsaum versehen; meist mit 4 (auch 6, 8 oder zahlreichen) eiufachen Radiärcanälen und einem Ringcanal; mit freien Randkörpern (Sinnesorganen) und doppeltem Nervenring; mit ectodermalen, an der Subumbrella gelegenen Gonaden; mit zellenloser Gallerte; meist von geringer Grösse.

Die Hydroidmedusen sind kleine Quallen von wenigen Millimetern bis zu einigen Centimetern Scheibendurchmesser (Aequorea erreicht einen Schuh im Durchmesser). Die äussere Körperform ist flach scheibenförmig bis hoch glockenförmig. Das Magenrohr beginnt entweder als ein mehr oder minder langer Schlauch im Glockengrunde, oder es liegt am Ende eines Magenstieles, der oft weit aus der Glocke hervorragt. Der contractile, mit Ringmuskelfasern ausgestattete R a n i saum (V elum), welcher vom Rande der Subrumbrella entspringend die Glockenmündnng verengt, besteht nur aus einer Ectodermfalte (Muskelepithel) und der gallertigen Stützlamelle. Die Zahl der Randtentakel ist oft auf ein vielfaches der Grundzahl vermehrt (die Radiärkanäle bleiben oft an Zahl zurïck); bei einigen Formen (Lizzia) kommen auch verästelte Mundtentakel vor. Die Tentakel sind meist hohl und sehr contractil; nur bei den Trachymedusen sind sie mit solider Endodermachse (Zellreihe) versehen und ziemlich starr; bei den Narcomedusen sind sie ebenfalls starr und vom Scheibenrande ziemlich weit gegen die Exumbrella hinaufgerückt. 'Ausnahmsweise sind nur zwei, ja sogar nur ein Tentakel (Steenstrupia) entwickelt.

Der Gastrovascularap parat besteht aus dem centralen Magen und aus 4, 6 oder 8, seltener zablreicheren (Aequorea) Radiärcanälen, die in einen peripheren Ringkanal münden; die Radiärkanäle sind meist einfacl, nur in seltenen Fällen gegabelt. Zwischen diesen Kanälen ist 
eine endodermale, ans einer Schichte platter Zellen bestehende Membran, die sogenannte, Endoderm lamelle" (oder Catham ulplat te) ausgespannt. Das gesammte Canalsystem liegt der Subumbrellarfläche genähert.

Bei jenen Formen, die einen Magenstiel besitzen, verlaufen die Radiärkanäle bis an das Ende des Stieles, wo sie erst in die Magenhöhle münden. Der Stiel ist demnach als eine untere Verlängerung der Scheibe zu betrachten (z. B. Geryoniden) und nicht etwa mit einem verlängerten Magenschlauche (vergl. Fig. 258) zu rerwechseln.

Die Aeginiden haben weite, taschenförmige Radiärgefässe, der Ringcanal ist obliterirt. - Bei den Leptomedusen finden sich am Ringcanal nach aussen mündende Oeffnungen („Excretionsöffnungen“).

Zum Verstäudniss der Morphologie des Gastrovascularsystems ist es nothwendig, die Entwicklungsgeschichte desseiben in Betrachtung zu ziehen. Bei der durch Knospung entstehenden Meduse ist diese Entwicklung genauer verfolgt worden. Wir beobachten an der Knospe eine ursprünglich einfache Urdarmhöhle, die erst durch die Einstülpung des Glockengewölbes zu einem flachen Spaltraum zusammengedrückt wird; sodann verwächst das Endoderm der exumbrellaren und subumbrellaren Seite streckenweise und bildet eine anfangs doppelschichtige, später sich vereinfachende Platte (die Endodermlamelle) und es bleibt nur im Verlaufe der Canäle und im Bereich des Centralmagens ein offenes Lumen bestehen; so wird das für die Hydroidmedusen charakteristische Verhalten hergestellt.

An der Exumbrella ist die mächtige zellenlose Gallertschichte nur von einem platten gleichförmigen Ectodermepithel bedeckt; alle wichtigeren Differenzirungen des Ectoderms sind auf die Subumbrella und den Scheibemrand beschränkt; so das Muskelsystem, Nervensystem und die Sinnesorgane.

Das Muskelsystenr besteht aus Ringmuskeln des Velums und der Subumbrella. Am Magenstiel finden sich Längsmuskeln und ebenso an den 'Tentakeln.

Das Centralnervensystem ist eine Anhäufung von Nervenelementen (Ganglienzellen und Nervenfasern), welche im Ectoderm an der Basis des Velums in Form eines doppelten Ringes (exumbraler und subumbraler Nervenring) sich findet. Der exumbrale Ring steht unmittelbar mit den Sinnesorganen in Verbiudumg, von dem subumbralen geht ein peripheres System als Nervenplexus zur Musculatur des Velums und der Subumbrella.

Die Sinnesorgane (sogen. Randkörper) finden sich im Umkreis der Scheibe. A ugen kommen als einfache Napfaugen oder als solche mit cuticularer Linse bei den Ocellaten (Augenfleckmedusen) vor. Gehörorgane finden sich erstens als Hörbläschen mit ectodermalen Otolithen bei den Vesiculaten (Randbläschenmedusen) oder als tentaculare Hörkölbchen (Cordylien, d. s. modificirte Tentakel mit endodermalen Otolithen) bei den Trachymedusen; die Cordylien sind frei oder in das Innere von Bläschen versenkt (vergl. Fig. 183, pag. 177).

Die Hydromedusen sind getrenntgeschlechtlich. Die G o n a d e $n$ sind ectodermale (oft faltenförmige) Wülste und entleeren ihre Producte direkt nach aussen; sie liegen an der Subumbrella und zwar entweder an der Magenwand (Gastralgonaden) oder längs der Radiärkanäle (Canalgonaden). (Fig. 259 u. 260, pag. 262.) 


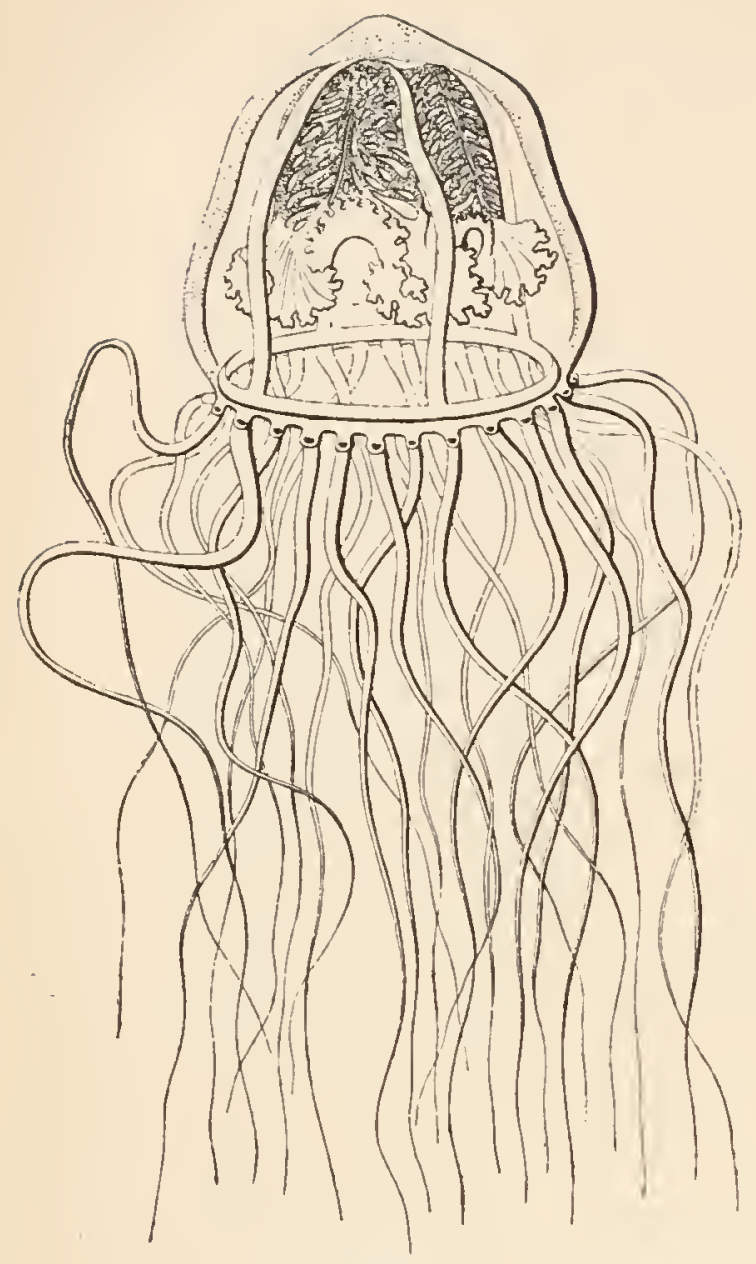

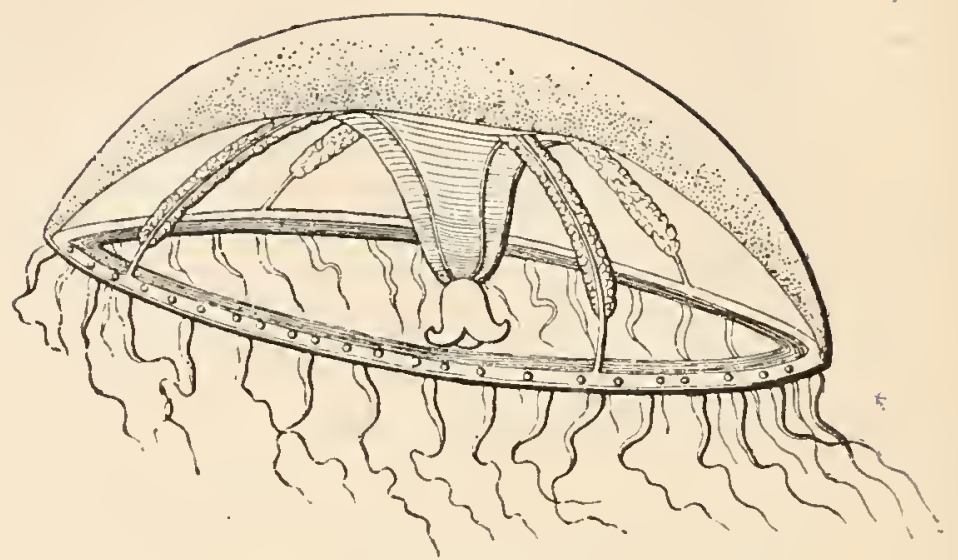

Fig. 260.

Fig. 259 Tiara pileata. Mit Augenflecken an der Basis der Tentakeln und mit gastralen Gonaden, nach E. HaEckel.

Fig. 260. Irene pellucida. Mit Hörbläschen am Scheibenrande und mit canalären Gonaden. Der Magen findet sich an der Spitze des kegelförmigen Magenstieles, nach HAECKEL.

Fig. 259.

\section{Generationswechsel.}

a) Vollkommener Generationswechsel.

Del charakteristische Generationswechsel der Hydromedusen zeigt vollständig ausgeprägt folgenden Verlauf: Aus dem Ei entwickelt sich der festsitzende, colmenbildende, geschlechtslose Hydroidpolyp; all dem Cormus entstehen durch Knospung Geschlechtsindividuen, die sich loslösen, das sind die freischwimmenden Hydroidmedusen (Fig. 257, pag. 258).

Die Hydroidmeduse entsteht niemals unmittelbar durch Umwandlung aus einem functionirenden Polypenindividuum, sondern (abgesehen von der directen Entwicklung, die wir später betrachten wollen) stets aus einer Knospe, die schon frühzeitig als Medusenknospe ron den Polypenknospen sich unterscheidet. An der Medusenkuospe tritt nämlich schon in frühen Stadien die Anlage der Glockenhöhle auf, und zwar seltener in Form einer hohlen Einstülpung, sondern meist in Form einer soliden Ectodermeinwucherung ( $\left.\mathrm{Glockenke} \mathrm{c}^{\prime} \mathrm{n}\right)$, in welcher damn eine anfangs abgeschlossene und erst secundär nach aussen durchbrechende Höhle (die Glockenhöhle) entsteht. Im Grunde der Glockenhöhle bildet sich in Form eines zweischichtigen Klöppels das Magenrohr, an welchem später die Mundöffnung durchbricht. Beim Einwuchern des Glockenkerms wird die schon früher erörterte Umwandlung des einfachen Eudodermsackes in den Gastrovascularapparat lierbeigeführt. Die 


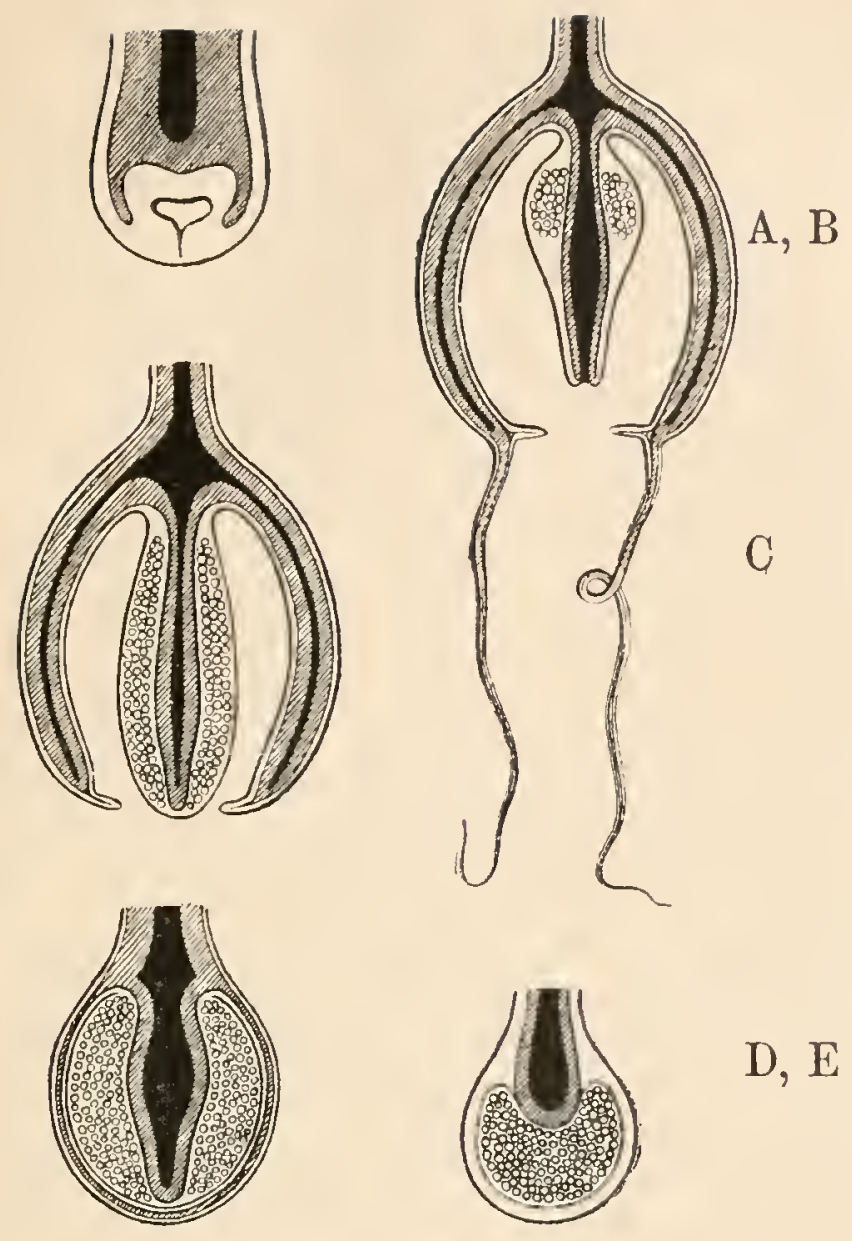

Fig. 261. Schema zur Erklärung der verschiedenen Rückbildungsstufen der medusoiden Gemmen (zum Theil nach dem älteren Schema von GEGENBAUR).

A. Frühes Entwicklungsstadium einer Medusenknospe; am freien Pol derselben entsteht als Ectodermeinstülpung die Glockenhöhle.

B. Die Meduse kurz vor ihrer Ablösung; im Grunde der Glockenhöhle ist das Magenrohr oder der Klöppel entstanden, welcher die Gonaden trägt (dieselben werden meist erst nach der Loslösung differenzirt).

C. Eine medusoide Gemme. Ohne Mundöffuung, ohne Tentakeln, aber mit vollkommenem Gastrovascularapparat in der Glockenwand.

D. Eine medusoide Gemme, deren Glockenwand (Scheibe) geschlossen bleibt, und rings um den Klöppel nur eine Hülle bildet, an welcher aber noch die Schichtenfolge der Glocke nachweisbar ist.

E. Medusoide Gemme, die unmittelbar vom Stadium A ableitbar ist; der Glockenkern liefert die Gonaden.

Gonaden werden bei dem vollkommenen Generationswechsel oft erst an der freischwimmenden Meduse im Ectoderm des Magenrohrs oder der Subumbrella ausgebildet.

Die Medusenknospen entstehen seltener unmittelbar am Hauptstamm des Polypencormus, in der Regel an der Wandung einzelner Polypen. Oft sind diese als ,proliferirende Polypen“" von den übrigen, den ,Nährpolypen", des Cormus verschieden; ihre Mundöffnumg, ja sogar ihre Tentakel können rückgebildet sein (vergl. Fig. 262 pag. 266).

\section{b) Maskirter Generationswechsel.}

Wir beobachten bei den Hydromedusen die interessante Erscheinung, dass von ganz nahe verwandten Polypenformen die einen freischwimmende Medusen hervorbringen, während die anderen nur knospenförmige, sessile Geschlechtsindividuen, sogenannte, ,medusoide Gemmen" erzeugen. Im letzteren Falle handelt es sich (wie jetzt allgemein angenommen wird) um eine phylogenetische Rückbildung der freischwimmenden Meduse, und nicht etwa (wie man frïher wohl annahm) um phylogenetische Vorstadien derselben.

An der medusoiden Gemme ist in vielen Fällen die ganze Schichtenfolge der Hydroidmeduse nachweisbar; Radiärcanäle, Ringcanal und Endodermlamelle sind vorhanden, im Ectoderm des Klöppels reifen die Geschlechtsproducte, die Glockenhöhle ist nach aussen geöffnet. In anderen Fällen bleibt die Glockenhöhle lange geschlossen und die erwähnten Schichten bilden als sehr dünne Membranen eine sackförmige Umhüllung des Klöppels. Die Gemme kamn sich noch weiter verein- 
fachen, ja sie kann auf der Stufe der zweischichtigen Knospe verharren, in deren Wandung die Geschlechtsproducte reifen (Fig. $261 \mathrm{C}, \mathrm{D}, \mathrm{E}$ ).

Durch Weismann wurde in neuerer Zeit der interessante Nachweis geführt, dass bei den medusoiden Gemmen stets ein frühzeitigeres Auftreten der Geschlechtsproducte vorkommt als bei den freischwimmenden Medusen. Dabei kommt es oft zu merkwürdigen Umlagerungen und Wanderungen der $\mathrm{Keimzellen;} \mathrm{in} \mathrm{vielen} \mathrm{Fällen} \mathrm{wandern} \mathrm{dieselben} \mathrm{aus} \mathrm{dem} \mathrm{Ectoderm}$ in das Endoderm über; im extremsten Falle entstehen die Keimzellen an ganz entfernter Stelle des Coenenchyms und wandern secundär in die medusoide Gemme ein, um dort zur Reife zu kommen. - Mit R ücksicht a uf diese Wanderungen der Keimzellen müsen wir die schwierige Frage nach der Herkunft der Keimzellen bei den Hydrozoen als noch keineswegs endgiltigbeantwortet betrachten.

Ebenso wie bei den Hydromedusen sehen wir auch bei den Siphonophoren, welche freischwimmende polymorphe Medusencormen sind, die Geschlechtsindividuen entweder als medusoide Gemmen auftreten, oder auch als selbständige, freischwimmende kleine Hydroidmedusen, die sich rom Siphonophorencormus loslösen.

Bei Hydra (dem Süsswasserpolypen) sehen wir die Geschlechtsproducte im Ectoderm des Polypen selbst entstehen. Mit Recht wird auch hier die Frage aufgeworfen, ob dies als ein ursprüngliches Verhalten aufzufassen sei, oder ob nicht etwa eine im höchsten Grade reducirte Gemmenbildung vorliege; man könnte sich vorstellen, dass die medusoide Gemme hier gar nicht mehr über die Oberfläche des Polypenleibes lervorgetreten sei. Mit Rücksicht auf die solstige sehr ursprüngliche Organisation der Hydra neigt man aber doch der ersteren Ansicht zur.

\section{c) Unterdrückter Generationswechsel (directe Entwicklung).}

Eine Unterdrückung des ursprünglichen Generationswechsels durch Abkürzung der Entwicklung ist bei den Haplomorphen eingetreten. Die freischwimmende Hydroidmedusenform hat hier die höchste Ausbildungsstufe erreicht, das Stadium des Polypencormus aber ist in der Entwicklungsreihe unterdrückt. Wohl folgt in der Reihe der durchwegs freischwimmenden Entwicklungsstadien auf die Planula eine Form, die man morphologisch einem Hydroidpolypen vergleichen könıte; doch entsteht die Meduse aus diesem nicht etwa durch Knospung, sondern durch directe Umwandlung.

\section{Polymorphismus.}

Bei den cormenbildenden Hydroidpolypen ist der Polymorphismus eine sehr verbreitete Erscheinung. Wir sehen z. B. neben den vollkommener organisirten Nährpolypen reducirte Tastpolypen, Skeletpolypen und proliferirende (d. h. Medusenknospen erzeugende) Polypen ${ }^{1}$ ). Bei den Siphonophoren erreicht der Polymorphismus und die Arbeitstheilung eine noch höhere Stufe.

1) Die Entstehung der Medusen selbst beruht wahrscheinlich auf Polymorphismus, indem sich eine immer schärfer bervortretende Differenzirung zwischen festsitzenden, polypoiden Nährthieren und freiwerdenden Geschlechtsthieren herausbildete. 
Systematische Uebersicht der Hydrozoa.

1. Ord. Authydrae.

Die Authydrae sind Hydrozoen, die im geschlechtsreifen Zustande den Bau des (vollkommenen oder reducirten) Hydroidpolypen liaben.

1. Hydrilue mit der einzigen Gattung Hydra, H. fusca, grisea, viridis. Die Hydra ist eine solitäre, nackte Polypenform mit hohlen Tentakeln und zur Zeit der Geschlechtsreife mit ectodermalen Gonaden; sie kann den Ort verändern und sich mit ihrer drüsigen Fussscheibe beliebig festheften. Den Sommer über entstehen durch seitliche Knospung Tochterindividuen, die zur vollkommenen Loslösung kommen; im Herbste bilden sich im Ectoderm hinter dem Tentakelkranz unregelmässig angeordnete Gonaden, in den weiblichen Gonaden entsteht nur ein Ei, welches mit einer chitiuigen Hülle versehen ist. Die Thiere sind Zwitter. Die Entwicklung ist abgekürzt. Die Hydra ist ein kosmopolitischer Süsswasserbewohner. Sie ist die niedrigste Cnidarierform, die uns bekannt ist.

2. Hydrocoralliae. Korallenähnliche, Cormen-bildende Hydroidpolypen mit verkalktem Aussenskelett. Coenenchym ein röhriges Netzwerk bildeud. Polymorph, mit Nährpolypen, Tastpolypen und knospenartigen Geschlechtsindividuen, an denen ein medusoider Bau nicht nachgewiesen ist. Bewohner der tropischen Meere.

Fam. Milleporidae. Millepora. Fam. Stylasteridae. Stylaster.

\section{Ord. Hydromedusae (Craspedotae).}

Die Hydromedusen sind Hydrozoen, deren Geschlechts-Individuen den Ba freischwimmender Hydroidquallen, oder an der polypoiden Amme verbleibender medusoider Gemmen besitzen.

I. Diplomorpha (= Leptolinae oder Acordyliae).

Mit polypoider Ammengeneration. Die Geschlechtsgeneration sind entweder Medusen ohne Hörkölbchen (Cordylien), dagegen mit Hörbläschen oder mit Augenflecken, und mit sehr beweglichen und extensilen, hohlen Tentakeln, oder es sind sessile Gemmen.

1. Tubulariae-Anthomedusae. Ammengeneration sind Tubulariapolypen (mit nackten Köpfchen). Geschlechtsgeneration sind entweder sessile Gemmen oder frei wordende Inthomedusen (mit gastralen Gonaden und mit Augenflecken, daher auch Ocellatae oder Augenfleckmedusen genannt) (Fig. 257 u. 258 pag. 258 und Fig. 259 pag 262).

\begin{tabular}{|c|c|c|c|}
\hline Polyp: & Podocoryne carnea & Stauridium cladonema & Polyp unbekannt \\
\hline \multirow[t]{3}{*}{ Meduse: } & Dysmorphosa carnea & Cladonema radintum & Clenaria clenophora \\
\hline & Eudendrium ramosum & Eudendrium rameum & Tubularia \\
\hline & Lizusa octocilia & m. sessilen Gemmen & $\begin{array}{l}\text { m. sessilen, trauben- } \\
\text { förmig angeordneten } \\
\text { Gemmen }\end{array}$ \\
\hline
\end{tabular}

$\frac{\text { Hydraclinia }}{\mathrm{m} . \text { sessilen Gemmen }}, \frac{\text { Clava }}{\mathrm{m} \text {. sessilen Gemmen }}, \frac{\text { Cordylophora }}{\mathrm{m} \text {. sessilen Gemmen }}$.


2. Campanulariae-Leptomedusae. Ammengeneration sind CampanulariaPolypen (die chitinartigen Skeletröhren erweitern sich an den Köpfchen zu becherförmigen Hüllen). An reducirten, von einer Chitinkapsel umgebenen Polypen-Individuen knospen die medusoiden Individuen, dies sind entweder sessile Gemmen oder Lcploinedusen (mit canalären Gonaden und Randbläschen [ausser bei Thaumanthias], daher auch Vesiculatae oder Randbläschenmedusen genannt) (Fig. 260 pag. 262).

Polyp: $\frac{\text { Cumpanularia }}{\text { Meduse }} \frac{\text { Plumularia }}{\text { Die Medusen sind Eucopiden m. sessil. Gemmen }}, \frac{\text { Serlularia }}{\text { m. sessil. Gemmen }}$,
Polyp nur in Jugendstadien bekannt
Aequorea

A.

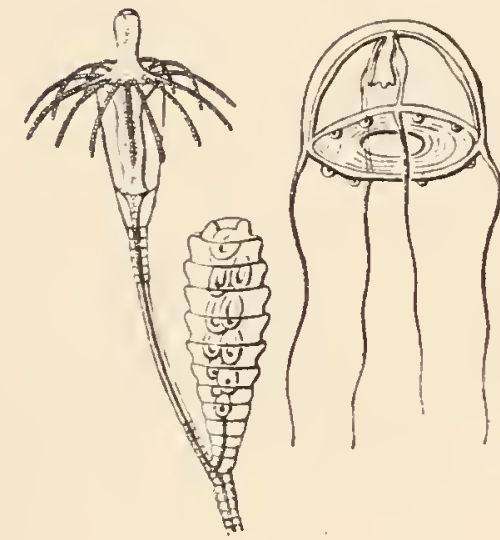

II. Haplomorpha (= Trachylinae or. Cordyliotae).

Entwicklung ohne polypoide Ammengeneration (direct). Medusen mit Hörkölbchen (Cordylien) und mit starren, wenig extensilen Tentakeln, welche meist eine solide Achse haben. Dies sind die grössten und am vollkommensten organisirten Hydroidmedusen.

\section{Narcomedusae. Cunina. Trachyined us a e. Geryonia.}

Fig. 262. Campanulariapolyp und seine Meduse.

A. Die dicke Chitinhülle ist am Stamme stellenweise geringelt, am Nährpolypen er weitert sie sich zu der becherförmigen ,Polypenzclle“, an dem mund- und tentakellosen, proliferirenden Polypoide, welches zahlreiche Medusenknospen trägt bildet die Chitinlamelle eine geringelte "Geschlechtszelle".

B. Freigewordene Meduse mit Randbläschen (Clytia bicophora) nach AGassiz.

\section{Ord. Siphonophora.}

Die Siphonophoren sind freischwimmende, polymorphe Cormen von Hydromedusen.

Trotz der physiologisch einheitlichen Leistung des Gesammtkörper's müssen die Siphonophoren morphologisch doch als Cormen aufgefasst werden, in welchen der Polymorphismus der Individuen einen sehr hohen Grad der Ausbildung erreicht hat.

Die nahe verwandtschaftliche Beziehung der Siphonophoren zu den Hydromedusen ist schon aus dem Bau ihrer Geschlechtsindividuen zu ersehen; dieselben sind nämlich, wie bei jenen, entweder medusoide Gemmen oder selbständige kleine Hydroidmedusen ${ }^{1}$ ). Wir sehen aber im Siphonophorencormus die medusoide Form nicht nur als Geschlechts-

1) Aus dem Bau dieser Geschlechtsindividuen kann geschlossen werden, dass die Siphonophoren den Anthomedusen am nächsten verwandt sind; dies soll aber für die Gruppe der Discoidea nach HAECKEL nicht gelten (?); er leitet dieselben von Trachymedusen ab. 
individuum auftreten, sondern wir finden dieselbe hier vielfach auch als steriles Arbeitsindividuum zu bestimmten Functionen angepasst.

Wir können am Siphonophorencormus der Entstehung und Anordnung nach Individuen verschiedener Ordnung unterscheiden.

Wir finden nur ein Individu um erster Ordnung, welches die Achse oder den Stamm (Hydr o som) des Cormus bildet. Der Stamm ist meist langgestreckt röhrenförmig (Agalmidae, Calicophoridae), oft aber ist er in seinem unteren 'Theile (Physophora) oder auch in seiner Gänze (Physalia) zu einem kurzen Sacke erweitert, oder er erscheint auch $\mathrm{zu}$ einer flachen Scheibe verkürzt (Velellidae). An seinem apicalen Fnde trägt er in der Regel (mit Ausnahme der Calycophoriden) eine

A.

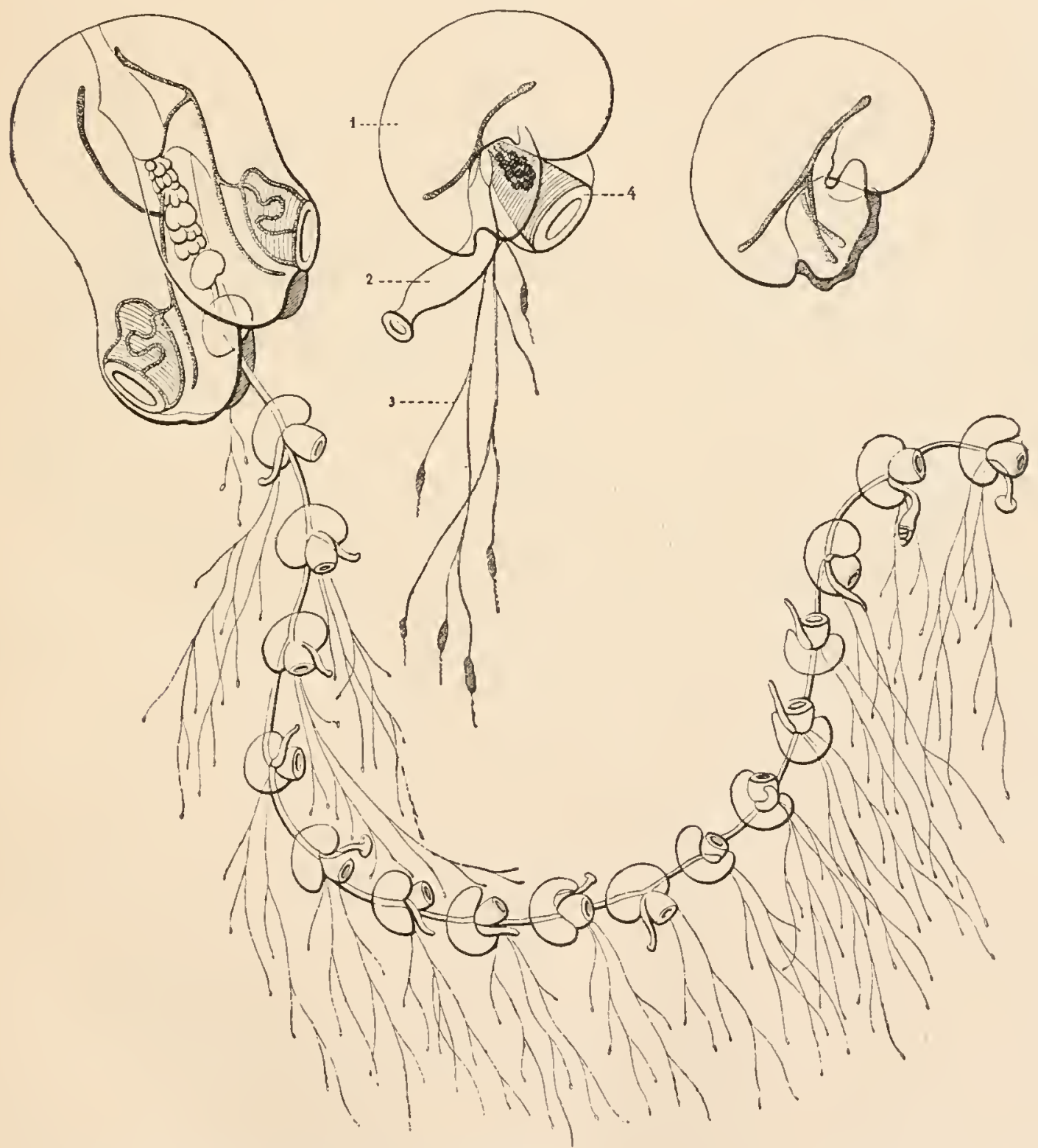

B.

C.

Fig. 263. Praya maxima nach Gegenbaur.

A. Der ganze Cormus etwas verkleinert. Vorne zwei Schwimmglocken, zwischen denselben der Beginn des Stammes mit Knospengruppen. Am Stamme in regelmässigen Abständen die Eudoxien-artigen Cormidien.

B Einzelnes Eudoxia-artiges Cormidium mit 1) Deckstück, 2) Migenschlauch, 3) verästeltem Fangfaden, 4) Genitalschwimmglocke.

C. Deckstück isolirt von der Seite betrachtet mit vier blind endigenden Endodermcanälen. 


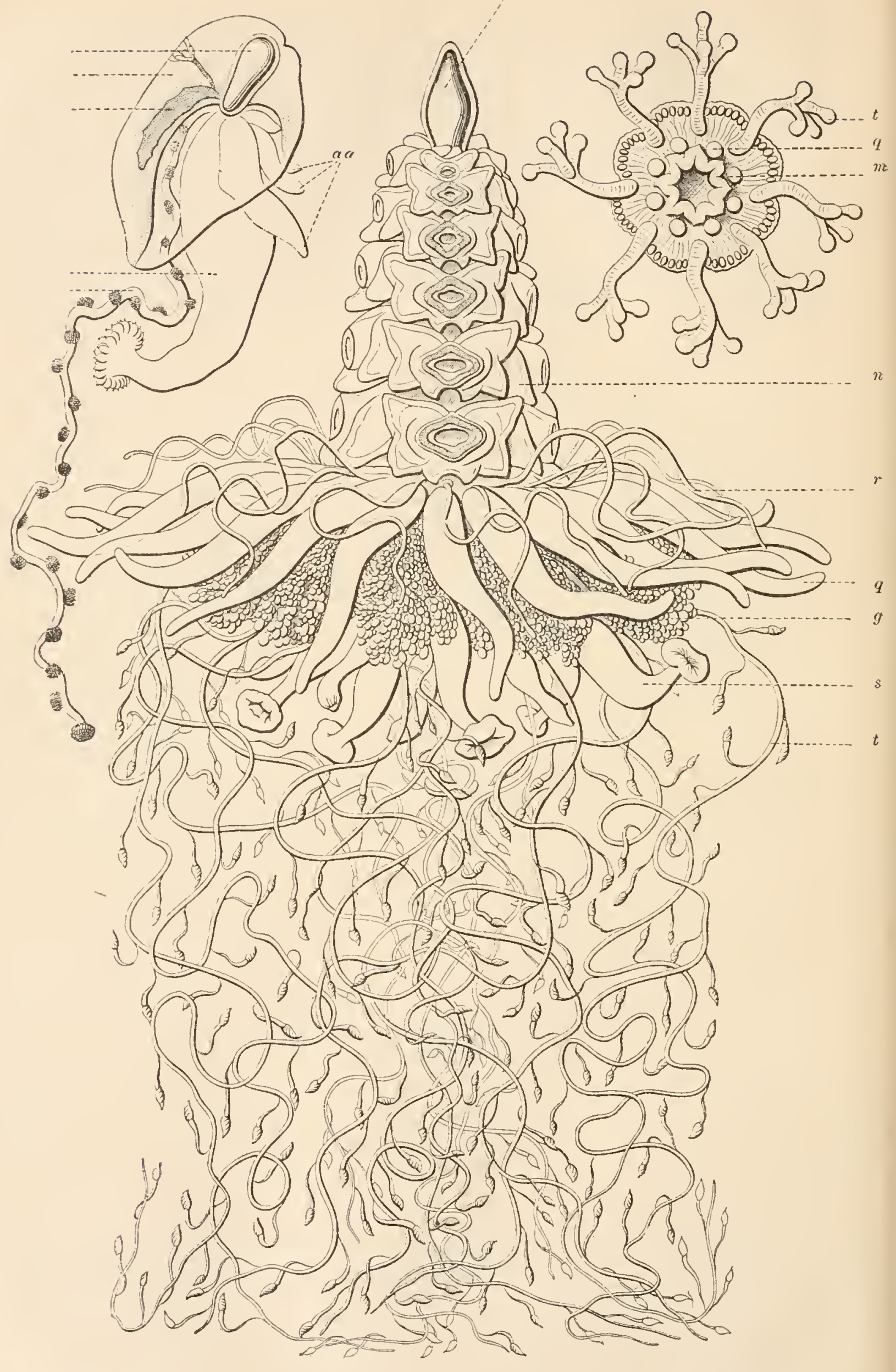

Fig. 265.

Fig. 264.

Fig. 266. 
Fig. 264. Eine Siphonophore aus der Gruppe der Physophoriden, Discolabe quadri. gata, nach HAEcket. $p$ Schwinmblase am oberen Ende des Stammes, $n$ Schwimmglocken, welche die Schwimmsäule zusammensetzen, $r$ lïhlfäden, $q$ Taster, $g$ traubige Anhäufungen von medusoiden Gemmen, $s$ Magenschläuche, $t$ Fangfäden.

Fig. 265. Siphonula-Larve von Discolabe, nach HAEckel. $b$ Deckstü k mit $b c$ endodermalem, blind geschlossenem Canal und $p$ Schwimmblase, $s$ Magenschlauch, $t \mathrm{~F}$ ang $\mathrm{fad} \mathrm{en}, a a$ bereits in Bildung begriffene secundäre Individuen.

Fig. 266. Disconula-Larve von Disconalia gastroblasta nach HAECKEL. $m$ achteckigə Mundöffnung des centralen Magenschlauches, $t$ acht randständige Tentakel, $q$ Anlage der Taster, an deren Basis später die Geschlechtsindividuen sprossen.

L u f tk a m mer (Fig. 264), die als Einstülpung der Körperwand entsteht und als hydrostatischer Apparat fungirt. Am unteren Ende des Stammes ist oft die Mundöffnung des primären Individuums vorlanden.

Als Individuen zweiter Ordnung unterscheiden wir die seitlich am Stamme in grosser Anzahl sprossenden Anhänge. Diese Individuen sind in einer ursprünglich einseitigen Linie am Stamme befestigt, doch wird meist durch eine Torsion des Stammes eine spiralige Drehung dieser Linie und somit eine allseitige Lagerung der Individuen herbeigeführt. In allgemeinen köunen wir beobachten, dass die jüngsten Individuen am Vorderende (Wachsthumspunkt) des Stammes entstehen, die ältesten daher an seinem Hinterende sich finden. Doch bilden die Schwimmglocken (vgl. unten) eine solche Reihe für sich (!), und die nachfolgenden Anhänge eine zweite solche Altersreihe. Bei diesen letzteren kann aber in manchen Fällen eine complicirtere Anordnung eintreten, indem nach einem bestimmten Gesetze (CHUN) neue Individuenreihen intercalirt werden. Anders verhält es sich bei den Velelliden, bei welchen die Individuen zweiter Ordnung an der unteren Fläche des scheibenförmigen, axialen Individuums concentrisch angeordnet sind.

Zunächst dem Vorderende findet sich meist eine grössere oder geringere Anzahl von Schwimmglocken. Es sind dies medusenähnliche Individuen mit musculöser Subumbrella und Velum, mit Radiärcanälen, Ringcanal und Endodermlamelle, denen aber das Magenrohr, die Tentakel und Randkörper fehlen (manchmal sind Andeutungen derselben vorhanden, Desmophyes). Auch ist ihre Form, im Zusammenhang mit ihrer seitlichen Stellung am Stamme, eine bilateral symmetrische. Sie fungiren als locomotive Individuen (Bewegungsorgane) des Cormus. Bei Athorybia sind die Schwimmglocken zu vorderen Deckstücken umgestaltet; bei den Rhizophysen, Physatien und Discoideen fehlen die Schwimmglocken gänzlich.

Am nachfolgenden Stammabschnitt beobachten wir verschieden gestaltete Anhangsstücke meist zu eigenthümlichen Gruppen vereinigt. Stets finden wir eine Anzahl nahrungaufnelmende Individuen, sogenannte Magenschläuche; es sind dies schlauchförmige Bildungen mit endständiger, trompetenförmig ausdehnbarer Mundöffnung; sie sind an ihrer Basis mit einem einzigen überaus contractilen Fangfaden versehen, der ebenso contractile Seitenzweige trägt, die mit complicirt gebauten Nesselbatterien (sogenannten N e s s el kn öp f e n) endigen. Oberhalb der Magenschläuche finden sich je nach der Species charakteristisch gestaltete Deckstücke, das sind gallertige Platten mit einem oder mehreren Endodermcanälen (wahrscheinlich entsprechen Deckstuick, Magenschlauch und Fangfaden zusammen einem medusoiden Individuum).

Als eine Modification der Magenschläuche sind die sogenannten Taster zu betrachten, die der Mundöffnung entbehren und an ihrer 
Basis eimen schwächeren und unverästelten Fühlfaden tragen. Auch diese kommen in Combination mit Deckstücken vor.

Bei den Calycophoriden finden sich nur Magenschläuche und keine Tastėr. Bei den Physophoriden, Rhizophysen, Physaliden und Discoideen fehlen die Deckstücke (sowie auch die Schwimmglocken).

Als Individuen dritter Ordnung (d. h. solche, die an Individuen zweiter Ordnung knospen und mit ihnen einen Cormus zweiter Ordnung, ein "Cormidium" bilden) sind die Geschlechtsindividuen zu betrachten. Sie entstehen, oft traubenförmig gehäuft, an der Basis der Magenschläuche oder der Taster. Bei den Velelliden lösen sie sich als kleine Hydroidquallen (Chrysomitra genannt) los, und es reifen erst während des freien Zustandes ihre gastralen Gonaden. Bei den Diphyiden bleiben sie sessil und entbehren der Mundöffnung, doch fungiren sie gleichzeitig als kleine Schwimmglocke (Genitalschwimmglocke) für die als „Eudoxia" sich ablösende Individuengruppe (vergl. unten). In den meisten anderen Fällen sind es stark reducirte medusoide Gemmen, in deren Klöppel die Geschlechtsproducte sich entwickeln. Die weiblichen Gemmen erzeugen meist nur je ein einziges Ei. - In der Regel sprossen weibliche und männliche Geschlechtsindividuen an ein und demselben Cormus (monöcische Cormen), seltener sind sie auf verschiedene Cormen vertheilt (diöcische Cormen).

Bei den Diphyiden lösen sich die einzelnen Individuengruppen (Cormidien), welche 1) aus Deckstück, Magenschlauch und Fangfaden und 2) aus einer Anzahl successive sich bildender Genitalschwimmglocken bestehen, vom Cormus ab und leben als sogenannte Eudoxien selbständig weiter. Eine dieser Glocken kann auch steril bleiben und eine Specialschwimmglocke für das Cormidium darstellen, welches in diesem Falle als Ersaea bezeichnet wird.

Entwicklung. Bei der Furchung mangelt die Furchungshöhle. Es bildet sich (wahrscheinlich durch Epibolie) eine Planula. Die eine Seitenfläche der Planula zeichnet sich frühzeitig durch besondere Beschaffenheit aus (die Planula ist daher bilateral

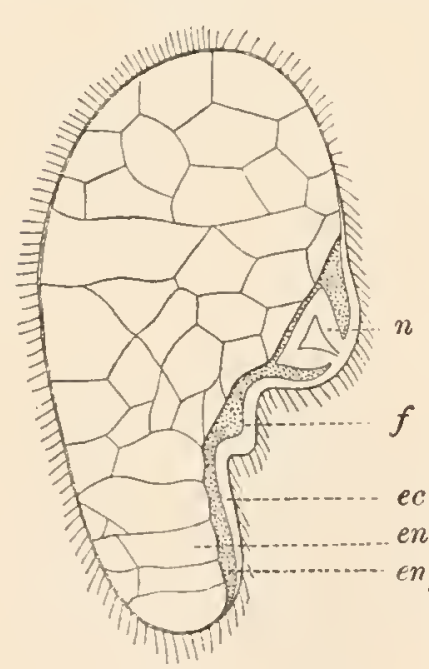
symmetrisch); das Ectoderm ist an dieser Seite verdickt und das Endoderm zeigt hier plasmareiche Bildungszellen, während es im übrigen aus grossen Nahrungszellen besteht. Diese Seite repräsentirt die spätere Knospungslinie. Am Hinterende der Planula bildet sich die primäre terminale Mundöffinung, und diese selbst wird zum Stamm (primären Magenschlauch); an demselben entsteht zunächst ein primärer Fangfaden und alsbald auch die Knospenanlagen secundärer Anhänge. In vielen Fällen ist ein vorderes p rimäres Deckstück, welches später abgeworfen wird, vorhanden. Die Deutung, dass diese aus den drei Stücken: Deckstück, primärer Magenschlauch und primärer Fangfaden bestehende

Fig. 267. Junge Larve von Epibulia, nach Metschnikoff. Das Endoderm besteht aus grossblasigen Dotterzellen (en) und an der Knospungsseite aus plasmareichen Zellen (en,), ec Ectoderm, $f$ Anlage des primären Fangfadens, $n$ Anlage der ersten Schwimmglocke.

Larve (S yphon ula, HAEckeL) einem medusoiden Individuum entspreche, hat viel Wahrscheinlichkeit für sich. - Bei der weiteren Ent- 
wicklung erfolgt oft eine Art Metamorphose, indem provisorische Schwimmglocken (bei Monophyes) oder provisorische Deckstücke (wahrscheinlich Homologa von Schwimmglocken) auftreten. [Da die Gattung Athorybia mit derartig umgewandelten Schwimmglocken versehen ist, so pflegt man die mit solchen provisorischen Deckstuicken ausgestattete Larve als Athorybiastadium zu bezeichnen.]

Die erste Entwicklung der Discoidea ist nicht bekannt, das früheste bekannte Stadium (Discon ula HaEckel's) besitzt eine radi är e, medusenähnliche Gestaltung; es ist aber möglich, dass diese Aehnlichkeit eine secundär erworbene ist.

Die Siphonophoren sind flottirende Meeresthiere. Während manche Diphyiden nur einige Millimeter gross sind, erreichen viele Physophoriden und besonders die Physalien Meterlänge. Sie fesseln unser Auge durch die Schönheit der Formen, Durchsichtigkeit und Farbenpracht. Sie zeichnen sich meist durch überaus kräftig wirkende Nesselorgane aus (besonders die Physalien).

Zur morphologischen Beurtheilung der Siphonophoren wurden verschiedene Theorien aufgestellt.

[1. Polyorgantheorie.] HuxLey erklärte die Siphonophore als ein Medusenindividuum mit vervielfältigten und mannigfach dislocirten $\mathrm{Or}$ ga n e n (Schwimmglocken, Magenschläuchen etc.).

[2. Polypersontheorie, A. Polypomtheorie.] Andere Forscher betrachten nach dem Vorgange von Vogt und LeUckart die Siphonophore als einen Hydroidpolypenstock, an welchem polypoide und medusoide Individuen sprossen und $\mathrm{zu}$ verschiedenen Zwecken angepasst erscheinen. LEUCKART deutete die Schwimmglocken, die Deckstücke, die Geschlechtsindividuen als medusoide Anhänge, die Jagenschläuche (auch Nährpolypen genannt) und die Taster als polypoide Individuen. - Schon GEGENBaUR hat aber auf manche Unzulänglichkeit einzelner dieser Deutungen hingewiesen.

[B. Medusomtheorie.] Endlich hat HaEckel eine andere bedeutungsvolle Erklärung der Siphonophore begründet, indem er dieselbe nicht auf einen proliferirenden Polypen, sondern auf eine proliferirende Meduse zurückführt, wie wir solche z. B. in Sarsia siphonophora vor uns sehen. Da eine Meduse durch Knospung nur Medusen (niemals Polypen) hervorbringt, so müssten auch alle Anhänge der Siphonophore nach dieser Theorie auf Medusen zurïckzuführen sein; und dies wird durch die scharfsinnigen Erörterungen HAECKEL's sehr wahrscheinlich gemacht. Dabei soll aber auch eine Vermehrung der Organe nach dem Princip der Polyorgantheorie vorkommen; doch eben in diesem einen Punkte, in Bezug auf die Deutung der Schwimmglocken, scheint die Theorie HAECKEL's eine Correctur zuzulassen.

Die Medusomtheorie stützt sich auf folgende wesentlichste Punkte:

1) Je eine Gruppe von Anhängen, nämlich Deckstück, Magenschlauch und Fangfaden, werden zusammen als eine modificirte Medusenperson ( $\mathrm{Me}$ dusom) betrachtet. Diese bildet mit den an ihr sprossenden Genitalglocken einen untergeordneten Medusencormus, der als Cormidium bezeichnet wird. - Bekanntlich ist eine derartige Gruppirung am augenfälligsten bei den Diphyiden ausgeprägt, wo auch diese Cormidien als „Eudoxien" sich vom Cormus ablösen und selbständig weiterleben. - Es gibt auch reducirte Medusome, bei welchen nämlich die Deckstiicke fehlen; ferner werden solche Anhangsgruppen, welche eine Mehrzahl von Magen- 
schläuchen enthalten, ron $\mathrm{H}_{\triangle \mathrm{E}} \mathrm{C}$ EEL nach dem Princip der Organvermehrung erklärt (vielleicht wären sie aber doch nur als gehäufte Medusome zu betrachten).

2) Es wird die Ueboreinstimmung des Medusoms mit der primären Si phonula larve hervorgehoben. Diese wird als primäres M edusom aufgefasst, an dessen Magenschlauch später die secundären Medusome sprossen (auch hier kommt Reduction durch Fehlen des primären Deckstückes vor).

3) In Bezug auf die Erklärung der Schwimmglocken können wir mit HAECKEL nicht übereinstimmen. H. hält dieselben für vervielfältigte und in Bezug auf ihre Lagebeziehung zum primären Magenschlauch dislocirte Medusenscheiben, welche nur wiederholte primäre Deckstücke, also wiederholte Theile des primären IIedusoms wären.

Es ist wahrscheinlicher, dass die Schwimmglocken auf steril gewordene Genitalschwimmglocken zuriickzuführen sind, welche zum primären Medusom in einem ähnlichen Verhältniss standen, wie die gewöhnlichen Genitalschwimmglocken zu den secundären Medusomen in den Cormidien ${ }^{1}$ ).

4) Die Gruppe der Discoidea hält $\mathrm{H}_{\mathrm{AECK} E L}$ für unabhängig von den anderen Siphonophoren, nach einem anderen Modus entstanden. Diese Auffassung erscheint aber nicht sicher begründet; dafür oder dawider kann erst durch Beobachtung der frühen, bisher unbekannten Entwicklungsstadien entschieden werden. Manches spricht dafür, dass die Discoidea von Physalien-ähnlichen Formen abgeleitete, am weitesten modificirte Siphonophoren wären $(\mathrm{CHUN})^{2}$ ).

1) Aus dieser Auffassung der Schwimmglocken würde sich für die phylogenetische Entwicklung der Siphonophoren folgende in einzelnen Punkten von HAECKEL abweichende Darstellung ergeben. a) Eine frühe $\mathbf{S t a m m f o r m ~ d e r ~ S i p h o n o p h o r e n ~ h a ̈ t t c ~ e i n e n ~ B a u ~}$ gehabt, welcher demjenigen eines einfachen Eudoxien-ähnlichen Cormidiums entspricht. Diese Form bestand aus einem sterilen Medusom - zusammengesetzt aus einer Scheibe, die zu einem bilateralen, primären Deckstück geworden ist, einem primären Magenschlaucb und einem primären Fangfaden und ferner aus mehreren primären Genitalschwimmglocken, welche sowoll locomotorisch fungiren, als aucb die geschlechtliche Fortpflanzung besorgen.

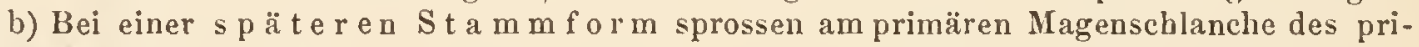
mären Medusoms secundäre Cormidien; damit in Zusammenhang werden die primären Genitalschwimmglocken steril, d. h. sie werden zu Schwimmglocken (äbnlich wie bei den als Ersaea bezeichneten Cormidien die Specialschwimmglocken). Eine solche Form existirt noch gegenwärtig in der von HAECKEL beschriebenen Mitrophyes peltifera, bei welcher das primäre Deckstück zeitlebens erhalten bleibt und daneben eine Schwimmglocke sich findet. Dies wäre also nach unserer Meinung die älteste der bekannten Siphonophorenformen.

c) Bei anderen Siphonophorenformen aber wird das primäre Deckstück nur mebr als vergängliche larvale Bildung erzeugt, oder es kommt gar nicht melır zur Entwicklung. Letzteres ist auch bei den meisten Calycophoriden der Fall, obwohl sie sonst sehr ursprüngliche Formen sind. Ich halte es daher für irrig, wenn man (wie auch HAECKEL) die erste Scbwimmglocke der Calycophoriden dem primären Deckstück anderer Siphonophoren (oder auch demjenigen von Mitrophyes) vergleicht.

Der Wecbsel der Schwimmglocken, wie er von CHUN für Monophyes beschrieben wurde und die Vielzahl derselben bei den höheren Siphonophoren scheint mir vergleichbar mit der successiven Abstossung und Neubildung von Genitalschwimmglocken an den Cormidien (Eudoxien) der Calycophoriden.

2) HAECKEL's System der Siphonophoren ist folgendes:
A. Disconanthae (Larve eine octoradiale Disconula)
B. Siphonanthae (Larve eine bilaterale Siphonula) $\left\{\begin{array}{l}\text { 1. Disconectae (= Discoidea). } \\ \text { 2. Calyconectae ( }=\text { Calycophoridae). } \\ \text { 3. Physonectae (= Physophoridae). } \\ \text { 4. Auronectae ( }=\text { Auronectae). } \\ \text { 5. Cystonectae (= Pneumatophoridae). }\end{array}\right.$ 
Systematische Uebersicht der Siplonophoren.

1. Calycophoridae. Ohne Luftsack. Mit wenigen Schwimmglocken. Der langgestreckte Stamm kann meist in einen Seitenraum der Schwimmglocke eingezogen werden. Mit regelmässigen Individuengruppen, die sich meist als ,Eudoxien" oder ,Ersaeen" ablösen.

Mitrophyes, Monophyes, Diphyes, Praya.

2. Phys ophorida $\theta$. Mit Luftsack. Meist mit zahlreichen Schwimmglocken (die bei Alhorya und Alhorybia zu vorderen Deckstücken umgewandelt sind).

Halistemma, Physophora, Forstiulia, Athorybia.

3. Aurophoridae (Auronectae). Mit grossem Luftsack, der durch ein besonderes seitliches Organ (Arophore) sich nach aussen öffnet, darunter ein Kranz von Schwimmglocken. Deckstücke fehlen.

Slephalia, Rhodalia, von HAECKEL entdeckte Tiefseeformen.

4. Pnoumatophoridae. Mit grossem, mit einer knorpelharten Stützmembran versehenen Luftsack, der eine apicale Oeffnung besitzt. Schwimmglocken sowie Deckstücke fehlen.

Rhizophysidae. Stamm langgestreckt, mit mässig grossem Luftsack. Rhizophysa.

Physalidae. Stamm verkürzt und ganz von dem grossen Luftsack eingenommen. Physalia.

5. Discoidea. Stamm zu einer Scheibe verkürzt, mit gekammertem und mit zahlreichen Oeffnungen versehenen und von einem knorpelharten Skelett gestützten Luftsack. Schwimmglocken und Deckstücke fehlen. Um den grossen primären Magenschlauch sind concentrisch kleinere Magenschläuche oder auch Palpen angeordnet, an welchen traubenförmig die Geschlechtsindividuen sprossen. Am Rande der Scheibe sind tentakelartige Bildungen angeordnet. Die medusoiden Geschlechtsindividuen werden als Chrysomilra frei. Die tracheenartigen Verästelungen der Luftkammer dienen nach CHon zur Luftathmung.

Velella, Porpita.

\section{Classe der Cnidaria, Scyphozoa.}

Die Scyphozoa sind Cnidarier mit endodermalem Keimepithel und mit zellenhaltiger Gallertschichte; sie besitzen vieroftstark modificirte oder zahlreichere Septen, deren freier Rand Mesenterial-oderGastralfilamente trägt. Sie sind $z$ ur ückführbar auf die Grundform eines vierstrahligen Scyplopolypen.

In jüngster Zeit wurde besonders durch die Forschungen der Brüder O. und $\mathrm{R}$. Herrwig sowie von Craus und HaEckel nachgewiesen, dass die Scyphomedusen und Hydroidmedusen phylogenetisch vollkommen gesondert von verschiedenen Polypentypen abzuleiten sind, und dass ferner die ersteren in naher verwandtschaftlicher Beziehung zu der Actinozoen stehen. Es werden daher die Actinozoa und Scyphomedusen als Scyphozoa vereinigt ${ }^{1}$ ). Diese Zusammenfassung stiitzt sich niclit

1) Görte fasst als Scyphozoa die Actinozoen, Scyphomedusen und die Ctenop hor en zusammen.

Hatschel, Zehrbuch der Zoologie. 
nur auf die Bildungsweise der Keimepithelien, sondern auch auf viele andere morphologische Charaktere, welche besonders die Gastralsepten betreffen; eine wichtige Vervollständigung in der Erkenntniss dieser morphologischen Uebereinstimmung ward ferner durch A. GöT'Te gegehen, welcher zeigte, dass auch bei den Scyphomedusen eill ectodermal eingestülptes Schlundrohr entsteht.

Als Grundform (Stanmform) der Scyphozoa betrachten wir eine 4 strahlige Scyphopolypenform mit Schlundrohr, welche 4 radiale Tentakel und 4 interradiale Septen besitzt. Bei den Scyphomedusen erhält sich (in der Regel) die Vierzahl der Septen, während die Zahl der Tentakel vermehrt ist. Bei den Actinozoen ist die Anzahl der Septen und der Tentakel in gleicher Weise vermehrt.

Die Septen (oder Taeniolen) und gewisse mit denselben einhergehende Differenzirungen sind für die Morphologie der Scyphozoen von besonderer Wichtigkeit. Wir wollen diese Bildungen daher zusammenfassend betrachten. Die Septen (oder Taeniolen) sind von einer Mesodermlamelle gestützte Längsfalten des Endoderms, welche in die Gastralhöhle vorspringend $\nabla$ on der Basis derselben bis zur Mundscheibe sich erstrecken. Bei den Scyphomedusen (wo sie auf die Vierzahl beschränkt sind), erfahren sie oft bedeutende Um- und Rückbildungen. Bei den Actinozoen erscheinen sie stets vollkommen ausgeprägt und in Bezug auf die Anzahl vermehrt. Bei den Actinozoen bildet der verdickte Rand des Septums ein gewundenes Band, das sogenante Mesenterialfilament; bei den Scyphomedusen treten an diesem Randwulste zahlreiche freie, fadenförmige Anhänge auf, die als Gastralfilamente bezeichnet werden. - Die Gonaden liegen paarweise an den Septen, entweder unmittelbar an den Seitenflächen derselben oder etwas mehr davon entfernt (bei den Scyphomedusen gegen die Subumbrella gelagert). Demgemäss finden wir bei den Scyphomedusen vier Paar Gonaden (die oft paarweise rerschmolzen sind). Bei den Actinozoen ist die Anzahl der Gonaden entsprechend der Vervielfältigung der Septen eine rermehrte, obzwar nicht immer alle Septen Gonaden besitzen. - In den Septen verlaufen Längsmuskeln (Septalmuskeln), welche bei den Actinozoen rom endodermalen Epithel abstammen, bei den Scyphomedusen (nämlich bei der polypoiden Jugendform Scy p hi s t o ma und bei den Stauromedusen) aber ectodermale Einwucherungen sind (nach GöTtE); es sind diese Muskeln also in diesen beiden Gruppen einander substituirende, aber nicht homologe Bildungen.

\section{Subcl. Actinozoa.}

Die Actinozoen sind festsitzende, polypoide Scyphozoen; mit tief eingestülptem Schlundrolre und wohl a usgebildeten Septen, die in vermehrter Anzahl (Grundzahl 6, 8) vorhanden und alle oder ein Theil mit dem Schlundrohre verwachsen und mit Mesenterialfilamenten versehell sind; Tentakel meist der Zahl der Gastraltaschen entsprechend; der innere Bau zeigt hilaterale Sy m etrie; solitär oder cormenbildend.

Die Actinozoen oder Korallenpolypen sind in ihrer äusseren Erscheinung den Hydroidpolypen gegenüber meist durch bedeutendere Grösse ausgezeichnet, womit auch ein complicirterer innerer Bau und 
eine reichere histologische Differenzirung einhergeht. Die Einzelindividuen sind am grössten bei den solitären Actinien, während andererseits die cormenbildenden Formen und vornehmlich die kalkabsondernden Madreporaria durch ihr festes Skelet und die Grösse der Cormen hervorragen; bei ihrem massenhaften Vorkommen spielen sie in der Fauna besonders der wärmeren Meere eine bedeutende Rolle und beeinflussen sogar die Gestaltung der Meeresküsten durch den Aufbau von Korallenriffen oder Korallenbänken, ja sie bringen sogar in Zusammenhang mit geologischen Hebungen und Senkungen festes Land (Koralleninseln) hervor.

An dem im allgemeinen cylindrischen Körper unterscheiden wir die seitliche Wand als Ma uerblatt, die untere Wand als Fuss scheibe und die obere als Mundscheibe. Am äusseren Rande der letzteren finden sich die hohlen T entakel in einem oder mehreren Kreisen angeordnet; selten kommt ein innerer Kreis von Mundtentakeln hinzu (Cerianthus). Die M undöffnung ist spaltförmig verlängert, so dass der Körper durch die entsprechende Ebene in zwei symmetrische Hälften getheilt werden kann (vergl. unten). Ebenso ist das Schlundrohr (früher meist als Magen bezeichnet) seitlich comprimirt und entweder an beiden Kanten oder nur an einer (der ,ventralen") mit einer flimmernden Schlundrinne versehen. Die verschliessbare Schlundpforte fiuhrt in den Gastral a p parat (Gastrovascularapparat), der in den Centralmagen und die Gastralfä cher (Gastralrinnen, Gastraltaschen) sich gliedert, welch letztere in die Höhlung der Tentakeln sich fortsetzen. Bei den Actiniden finden sich Oeffnungen an der Spitze der Tentakeln.

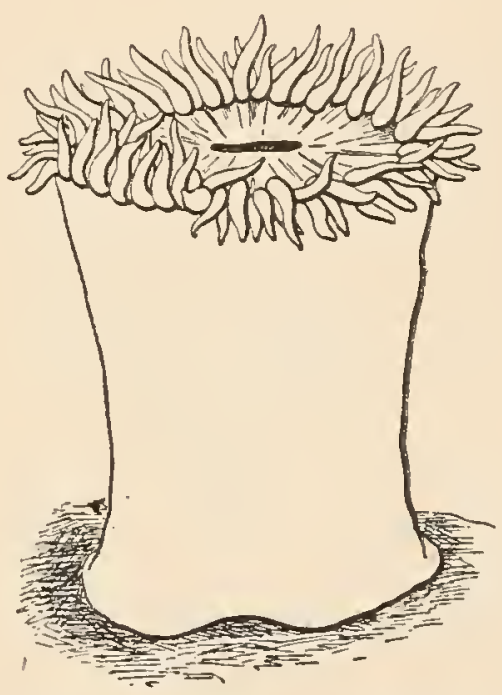

Fig. 269. Körperform einer Actinie, nach A. Andres.

Die Septen (Mesenterien), welche die Gastralfächer von einander abgrenzen, sind entweder sämmtlich mit ihrem axialen Rande an das Schlundrohr festgewachsen (Octactinien, Cerianthus, Edwardsia) oder es ist nur eine Anzahl derselben festgewachsen, während bei den übrigen der freie Rand bis zur Mundscheibe sich erstreckt (Actiniden, Madreporarien); man unterscheidet demnach in diesem Falle vollkommene und unvollkommene Septen. Die ersteren sind bei den Actiniden im Umkreis des Mundes von Septalostien durchbohrt (innerer Ring-

Fig. 270. Längsschnitt durch die linke Hälfte des Körpers einer Actinie (Tealia crassicornis), er ist so geführt, dass ein Septum mit allen seinen Differenzirungen zur Ansicht kommt. $t$ Tentakel, $s$ die eine Wand des Schlundes, $v$ Mesenterialfilament, $g$ Gonade, $l_{1}$ inneres (orales) Septalstoma, $l_{2}$ äusseres Septalstorna; ferner sind am Septum Längsmuskeln, Transversalmuskeln und Parietalmuskeln zu beobachten; $r$ Ringmuskel, quer durchschnitten. Nach Hertwig.

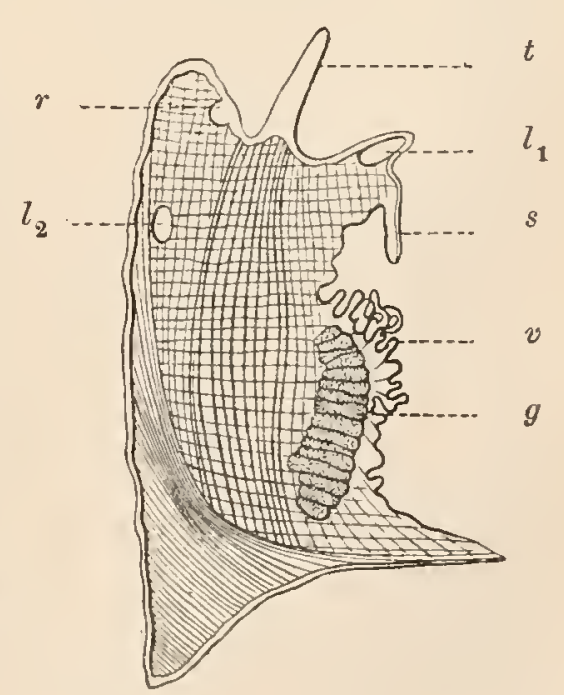

$18 *$ 
kanal), hierzu kommen bei manchen Arten noch äussere Septalostien in der Nähe des Mauerblattes (äusserer Ringkanal). - Der freie Randwulst der Septen bildet je ein vielfach gewundenes Band, welches als Mesenterialfilament bezeichnet wird. Das Epithel der Mesenterialfilamente ist reich an Drüsenzellen und Nesselzellen und bildet auch streckenweise lebhaft flimmernde Streifen. Bei manchen Actiniden (Sagartien, Adamsien) sind hier noch besondere Differenzirungen, die Acontien, ausgebildet; es sind dies lange, frei vom Septenrande sich erhebende Fäden, die mit Nesselzellen bedeckt sind und durch besondere Oeffnungen des Mauerblattes ( $\mathrm{C}$ inclides) nach aussen hervorgeschnellt und langsam wieder zurückgezogen werden können. In der Regel sind die Septen mit endodermalen Epithelmuskelzügen, Transversalmuskeln und besonders Längsmuskeln, versehen (nur bei Cerianthus fehlend). Die kräftigen Längsmuskeln sind in der

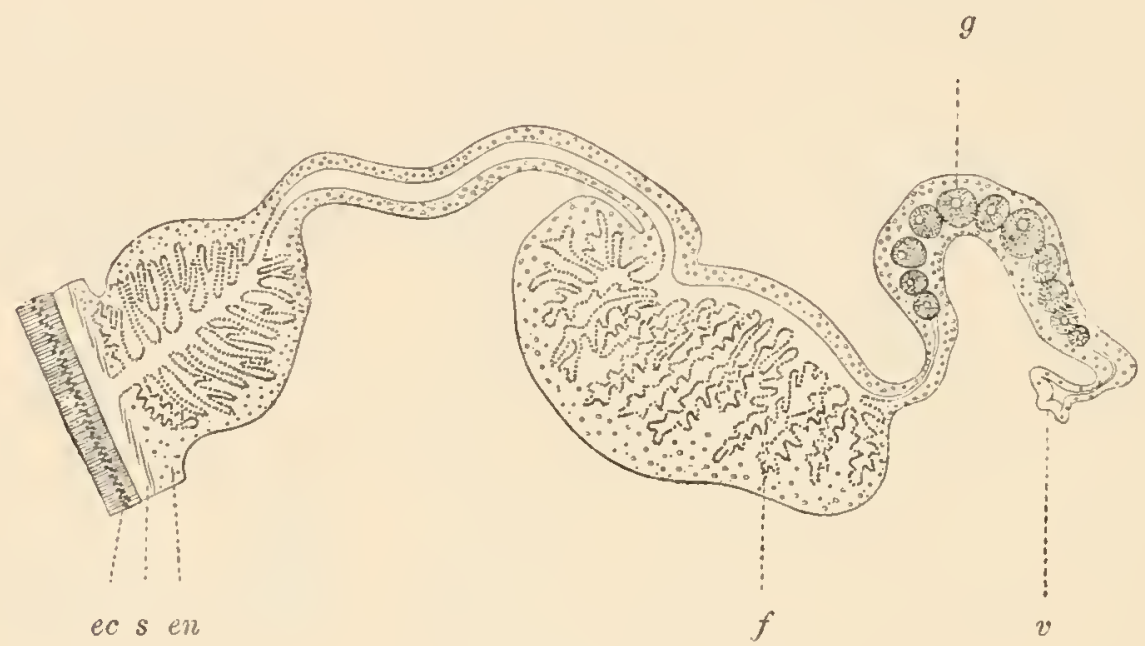

Fig. 271.

Fig. 271. Querschnitt durch ein Septum von Edwardsia tuberculata, nach HERTwIG. ec Ectoderm, s Gallertschichte, en Endoderm, an dessen Basis die Querschnitte der epithelialen Muskeltibrillen als Reihen von Pünktchen erscheinen; durch Faltungen des Muskelepithels kommt bei $f$ ein einseitiger Muskelwulst (Muskelfahne) zustande; ausserdem ist in dem vorliegenden Falle am basalen Rande des Septums ein doppelseitiger Muskelwulst vorhanden. $g$ Querschnitt des Ovariums, $v$ Querschnitt des Mesenterialfilamentes (Randwulst).

Regel einseitig am Septum angeordnet, so dass der Querschnitt das Bild einer sogenannten Muskelfahne bietet. Je kräftiger die Septalmuskeln entwickelt sind, um so unbedeutender ist die Ausbildung der ectodermalen Musculatur der Körperwand. Die Septen sind endlich auch die Träger der Gonaden, welche meist bandförmige, gewulstete Einlagerungen an denselben bilden. Die Keimzellen entstehen im Endodermepithel, rücken aber bei ihrer Reife in die mittlere Gallertschichte des Septums hinein (HerTwig).

Specifische Sinnesorgane fehlen den Actinozoen; das Nervensystem ist acentrisch, es ist als Nervenschicht des Ectoderms am stärksten an der Mundscheibe ausgebildet, es fehlt aber selbst im Endoderm nicht gänzlich. Die histologische Beschaffenheit des Ectoderms (vergl. pag. 132, Fig. 137, 138) zeigt nach HenTwig grosse Uebereinstimmung mit derjenigen des Endoderms; es ist nicht genau nachgewiesen, wo die Abgrenzung der beiden Blätter stattfindet.

Die Skeletbildungen, welche bei den cormenbildenden Formen (Octactinien und Madreporarien) den Körper stützen, sind von zweierlei 
Bedeutung. Erstens unterscheiden wil bei den Alcyonarien als mesodermale Skeletbildungen einzelne höckerige Kalkkörperchen von mannigfaltiger Gestalt (Sklerod ermiten), die in Mesodermzellen entstehen und entweder isolirt bleiben oder durch Kalksubstanz zu einer festeren, zusammenhängenden Masse vereinigt werden (Achsenskelet von Corallium rubrum, der Edelkoralle, und Röhrenskelet von Tubipora, der Orgelkoralle); bei anderen Alcyonarien kommen sie als losere Rinde neben dem hornigen Achsenskelete vor. Zweitens finden wir zusammenhängende Skeletbildungen, die bei den Alcyonarien als vorwiegend horniges, bei den Madreporariern als complicirteres, meist axiales Kalkskelet auftreten. Diese zusammenhïngenden Skeletbildungen sind nicht, wie man friiher glaubte, mesodermale Bildungen, sondern sie sind, wie in jüngster Zeit (besonders durch die Untersuchungen von Косн) nachgewiesen wurde, Ausscheidungsproducte des Ectoderms, die zunächst an der Fussscheibe beginnen, von da aber weit in das innere des Weichkörpers einwuchern und namentlich mit fortschreitendem Wachsthum des Cormus oft derart vom Weichkörper umgeben werden, dass sie als innere Skeletbildungen erscheinen. Stets sind aber sämmtliche Körperschichten mit eingestülpt und überkleiden diese basoaxialen Skeletbildungen. - An den complicirteren Skeletbildungen der Madreporarier wiederholt sich die Architektur des Weichkörpers; man unterscheidet ein gemeinsames Skelet des Cormus (Coene n chym) und das Skelet des Einzelindividuums (Polypariunı); an letzterem sehen wir ein Fussblatt, Mauerblatt, Septen, ferner oft eine axiale Erhebung, die als Columella bezeichnet wird und die auch noch von einem Kreis von Pfählchen (Pali) umgeben sein kann; überdies kann noch eine von der äusseren Körperfläche ausgeschiedene A us e n platte das Mauerblatt umkreisen. In Bezug auf das Verhältniss des Skeletes zum Weichkörper ist besonder's hervorzubeben, dass die Sklerosepten ihrer Lage nach nicht mit den Sarkosepten übereinstimmen, sondern mit denselben alterniren, also in der Richtung der Gastralfächer liegen. - Die überaus mannigfaltigen besonderen Eigenthümlichkeiteı der Skeletbildungen sind für die Systematik von grosser Bedeutung.

Die Actimozoen sind in der Regel getrenntgeschlechtlich (Cerianthus ist zwitterig). Die Entwicklung wird nur ausnahmsweise bis zu vorgeschrittenem Stadium innerhalb der mütterlichen Körperhöhle durchlaufen; meist aber finden sich freischwimmende Larven von eiförmiger Gestalt mit Schlundrohr und einer Anzahl nacheinander entstehender Septen, wozu erst später Tentakel hinzukommen. Bei den Octactinien entstehen alle diese Bildungen oft erst nach der Festsetzung der Planula-ähnlichen Larve.

Sowohl Längstheilung als Knospung führt zur Cormenbildung. Seltener kommen die neuen Individuen $\mathrm{zu}$ vollkommener Isolirung, dagegen erfolgt dies stets bei Quertheilung. Die Cormen sind aus gleichartigen Individuen zusammengesetzt, nur bei den Pennatuliden finden sich Andeutungen vou Polymorphismus.

Modificationen des radiären Baues bei den Actinozoen.

Der radiäre Bau der Actinozoen ist stets derart modificirt, dass eine Symmetrieebene, welche in der Richtung der Mundspalte liegt, den Körper in $z$ wei spiegelbildlich gleiche Hälften theilt. Stets kommt in die Richtung der beiden Mundecken je ein Tentakel zu liegen (Richtungstentakel); 
$A$

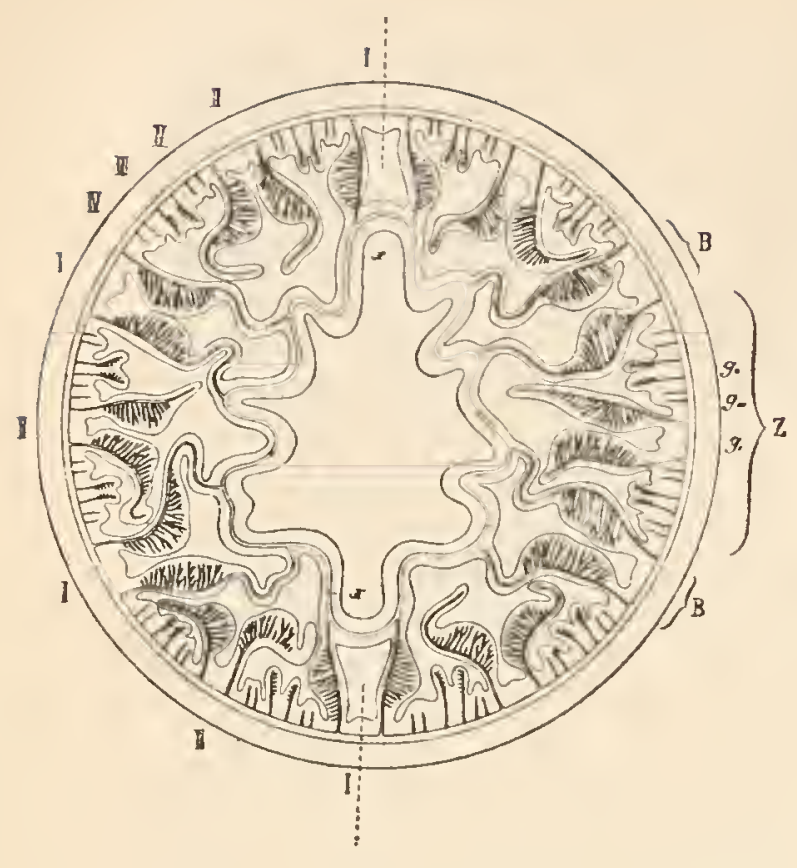

B

a.

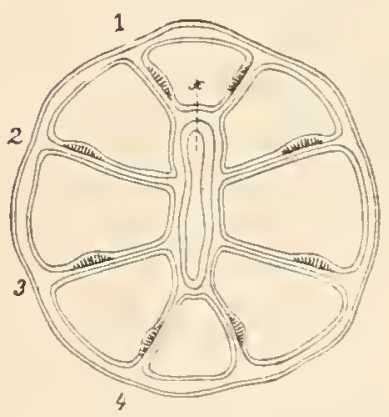

C.

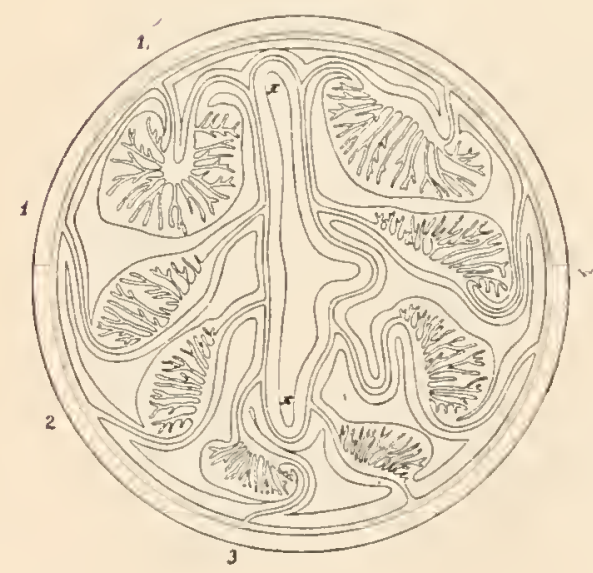

d.

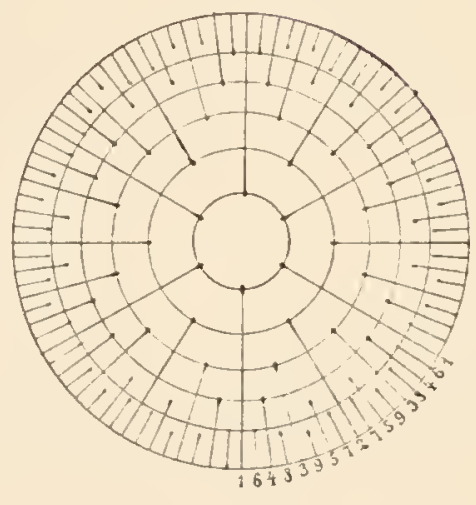

e.

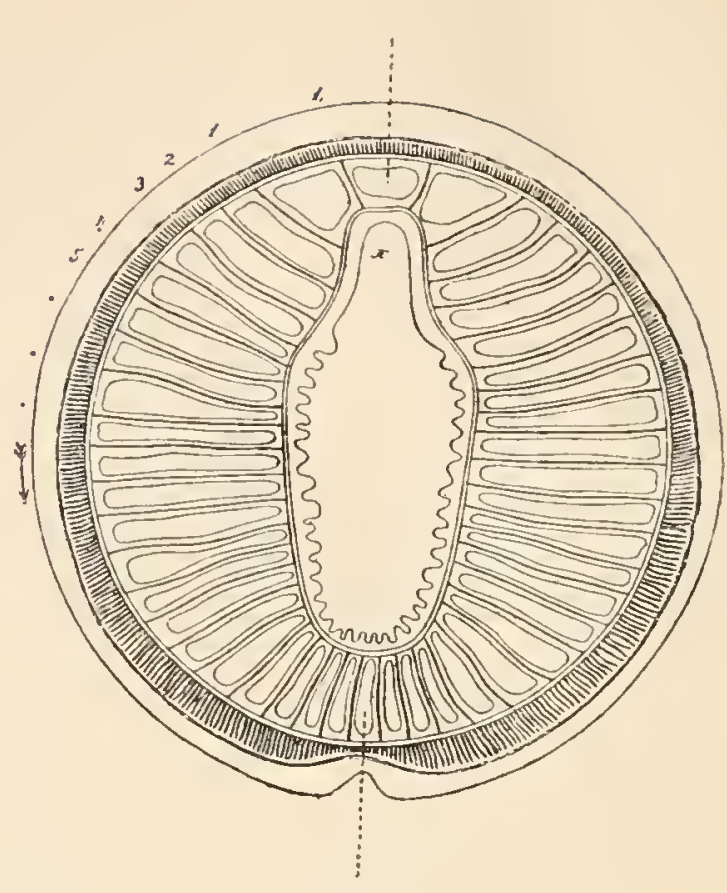

B

Fig. 272. Modificationen des radiären Baues bei den Actinozoen.

a. Querschnitt durch eine Actinie (Adamsia diaphana) (nach Hertwig). Der Bau ist zweifach symmetrisch. A und B sind die Richtungsfächer, welche die primäre Symmetrieebene bezeichnen; senkrecht darauf ist die zweite Symmetrieebene gelegen. I... sind die sechs Fächer crster Ordnung, die von den sechs Paar von Hauptsepten begrenzt sind. $I I \ldots$ sind die sechs Fächer zweiter Ordnung, $I I I$... die zwölf Fächer dritter Ordnung, $I V \ldots$ die vierundzwanzig Fächer vierter Ordnung. $B B$ sind primäre Binnenfächer, zu welchen sich $Z$ als primäres $Z$ wischenfach verhält; innerhalb des letzteren entstehen die geminalen Septen $g_{1}, g_{2}, g_{3}$; es ist leicht zu ersehen, dass die von ihnen eingeschlossenen Fächer selbst wieder die Bedeutung von Binnenfächern (2ter, 3 ter Ordnung) gewinuen.

b. Querschnitt durch Cerianthus solitarius (nach HerTwig und A. V. HeIder). A ventrales Richtungsfach, $x$ Schlundrinne, B dorsales Richtungsfach; 1 ist das primäre Septum, die Septen 2, 3, 4 sind in der Richtung des dorsalen, das Septum $1_{1}$ in derjenigen des ventralen Richtungsfaches eingeschoben. Die ectodermale Muskulatur ist sehr stark, die der Septen sehr schwach ausgebildet.

c. Querschnitt einer Octactinie (Alcyonium), $x$ Schlundrinne; die Septen 1, 2, 3, 4 sind alle gleichgerichtet (nach HERTWIG). 
d. Querschnitt durch Edicardsia tuberculata. 1 ist das primäre Septum, 2 und 3 sind in der Richtung des ventralen Richtungsfaches, 1, ist in der Richtung des dorsalen Richtungsfaches eingeschoben (vergl. b). (Nach HerTwiG).

e. Schema des Wachsthumsgesetzes des Madreporarier-Skeletes (nach MiLNE-Edwards). Die Kalksepten entsprechen der Lage nach den Fächern des Weichkörpers und stimmen in ihrer Altersfolge mit denselben überein (vergl. die Verhältnisse in Fig. a). Die Septen sind entsprechend ihrer Altersfolge von verschiedener Länge und man unterscheidet darnach : 1 sechs Septen erster Ordnung, 2 sechs Septen zweiter Ordnung, 3 zwölf Septen dritter Ordnung; 4, 5, 6 etc. je $\mathrm{n}$ u r $\mathrm{zw}$ ölf Septen 4., 5. etc. Ordnung, welche stets $\mathrm{zwischen}$ möglichst alte Septen früherer Ordnung intercalirt sind. (Dieses Gesetz erleidet mannigfache Ausnalimen.)

f. Schema des Wachsthumsgesetzes des Skeletes der fossilen paläozoischen Tetracorallier (nach KUNTH). $h$ Hauptseptum und $g$ Gegenseptum (den Richtungsfächern entsprechend), ss Seitensepten (vielleicht seitlichen „Binnenfächern" entsprechend); in den vier zwischenliegenden Quadranten (Hauptqadranten, Gegenquadranten) sind die Secundärsepten in gleichgerichteten Reilien angeordnet.

und dementsprechend findet sich in diesen beiden Richtungen auch je ein Gastralfach (Richtungsfach), und wenn es sich um skeletbildende Formen (Madreporarier) handelt, je ein Kalkseptum (kalkiges $\mathrm{Rich}$ t u n g sseptum); dagegen entspricht je ein $\mathrm{Paar}$ von fleischigen Richtungssepten den Mundecken. Zu beiden Seiten dieser Richtungsebene (oder primären Symmetrieebene) sind die Tentakeln und - was besonders bemerkbar ist - die Sarkosepten spiegelbildlich gleichartig angeordnet. Wenn dabei auch die beiden Richtungstentakel und die ihnen entsprechenden Körperhälften sich spiegelbildlich gleichartig verhalten (wobei auch zwei Schlundrinnen vorhanden sind), wonn also auch senkrecht auf die Richtungsebene eine zweite Ebene gelegt werden kann, welche ebenfalls den Körper in $z$ wei spiegelbildlich gleiche Theile scheidet, so sprechen wir von einer $\mathrm{zw}$ if ach symmetrischen $\mathrm{Anordnung}$; diese findet sich bei den Actiniden. Wenn aber die Orientirung der Septen nach den beiden Richtungstentakeln hin sich ungleich verhält (oft ist auch nur einerseits eine Schlundrinne vorhanden), so erscheint die Anordnung nur einfach s ymmetrisch; dies ist der Fall bei den Octactinien, Cerianthus, Edwardsia und den fossilen Telracorallia. Dabei sind aber, besonders mit Berücksichtigung der Muskelfahnen, noch die mannigfachsten Combinationen der Septenstellung zu beobachten. Bemerkenswerth ist das Verhalten der Octactinien, wo alle acht Muskelfahnen von dem einen Richtungsfach abgewendet und dem anderen zugewendet sind.

Für die Deutung der Architektonik ist nicht nur die Anordnung, sondern auch die Eutstehungsweise und zeitliche Folge der radiären Bildungen (Tentakeln, Gastraltaschen und Septen) maassgebend. Die Entstehung neuer Tentakeln ist aus den Gesetzen der Intercalation verständlich, mag die Einschiebung uun regelmässig radiär oder nur an gewissen Punkten erfolgen. Dagegen bedarf die Bildung der neuen Gastralfächer einer besonderen Erörterung. Nach dem einen Modus wird von einem alten Fache durch die Bildung eines innerhalb desselben neu auftretenden Septums ein neues Fach abgetheilt. Die Einschiebungen erfolgen rechts und links von der Symmetrieebene gleichartig. Jedes Fach (mit Ausnahme der Richtungsfächer) ist daher von ungleich alten Septen begrenzt. Bei Cerianthus entstehen alle neuen Septen der Reihe nach, so dass die jüngsten in dem einen Richtungsfach (dem ,dorsalen") eingeschoben werden, sie sind daher jederseits in der Reihenfolge nach diesem Richtungsfache hin zu zählen; nur ein Septum macht eine Ausnahme, da es im entgegengesetzten Richtungsfach eingeschoben erscheint. - In ähnlicher Weise sind wahrscheinlich die Verhältnisse von Edwardsia zu deuten. - Bei den 
Oclnctinien entstehen die 8 Septen gleichzeitig, doch wird vermuthet, dass dies ein abgekürter Process sei, und dass sie in der Reihenfolge von einem Richtungsfach zum anderen zu zählen wären. - Bei den fossilen Tetrucoralliern, wo wir die Architektonik nur aus den Kalksepten (die in der Richtung der Gastralfächer liegen) beurtheilen müssen, finden wir folgende Anordnung der Sklerosepten. Wir finden ein Hauptseptum und ein Gegenseptum (entsprechend den beiden Richtungsfächern), ferner jederseits ein Seitenseptum und dann innerhalb der so gebildeten 4 Zwischenräume jederseits zwei (also 4) Septenreihen, deren Septen je in gleicher Richtung und zwar nach dem Hauptseptum zu - gezählt werden.

Bei den Actiniden erfolgt die Bildung der ersten 12 Fächer ebenfalls nach dem Modus der successiven Einschiebung von Septen. Dann aber bei Bildung der nächsten Fächer tritt ein anderer Modus auf, der speciell den Actiniden eigenthümlich ist. Es werden nämlich innerhalb der alten Fächer, und zwar speciell in den sogenannten Zwischenfächern, stets Zwillingssepten (geminale Septen) gebildet, deren Muskelfahnen einander zugekehrt sind, und die je ein neues Fach begrenzen. Diese neuen Fächer sind demnach stets von gleich alten Septen eingeschlossen. - In Bezug auf die Zeitfolge der Septen ist folgendes zu bemerken. Die ersten zwölf Septen entstehen symmetrisch (d. h. rechts und links übereinstimmend) in gewisser Aufeinanderfolge. Doch werden diese ungleich alten Septen sodann in Bezug auf ihreGrösse ausgeglichen, und die anfangs wie bei den andern Actinozoen einfach symmetrische Anordnung wird zu einer zweifach symmetrischen a usgeglichen. Diese 12 ,Hauptsepten“ begrenzen 12 Fächer, von welchen man 6 als Binnenfächer (wozu die Richtungsfächer gehören), und 6 als Zwischenfächer unterscheidet. Auch die anfangs ungleichen 12 ersten Tentakel gleichen sich aus, und zwar in der Weise, dass sechs grössere Tentakel erster Ordnung (wozu die Richtungstentakel gehören, also den Binnenfächern entsprechend) und sechs kleinere Tentakel zweiter Ordnung $\mathrm{zu}$ unterscheiden sind. Alle nachfolgenden radiären Bildungen entstehen durch regelmässige radiüre Intercalation; es werden demnach, was die Tentakel betrifft, weiterhin Kreise von 12 Tentakeln III. Ordnung, 24 Tentakeln IV. Ordnung u. s. w. gebildet; ebenso verhalten sich die dazu gehörigen Gastraltaschen, welche, wie schon erwähnt, durch geminale Septenbildung

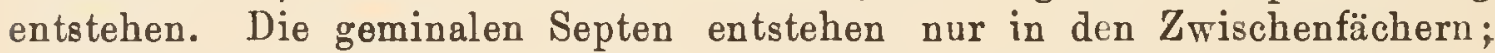
die ersten sechs geminalen Pärchen gehören zunächst noch den sechs Tentakeln zweiter Ordnung zu; die nächsten 12 Pärchen gehören dann zu den 12 Tentakeln dritter Ordnung u. s. w. (vergl. die Figurenerklärung).

In ähnlicher Weise macht sich die regelmässige radiäre Intercalation bei den Kalkskeletten der Madreporarier geltend, die sich in dem Bau ihres Weichkörpers wahrscheinlich den Actiniden anschliessen. Die Kalksepten, welche der Anordnung der Gastraltaschen entsprechen, sind regelmässig radiär nach der Grundzahl 6 angcordnet. Wir bezeichnen daher die Gruppe der Actiniden und Madreporarier als sechsstrahlige Actinozoen (Hexaclinia), wobei wir aber nicht ausser Acht lassen, dass dieser sechsstrahlige Bau durch secundäre Ausgleichung erzielt wurde (vergl. die Figurenerklärung).

\section{Systematische Uebersicht der Actinozoen.}

Alcyonaria (Octactinia) mit acht gefiederten Tentakeln und acht Septen; mit Sklerodermiten und oft mit Hornskelet. Alcyonium, Kork- 
koralle, Tubipora, Orgelkoralle, Gorgonia, Rindenkoralle, Corallium, Edelkoralle, Pennatula, Seefeder.

$R$ ugosa (Tetracorallia), fossile paläozoische Korallen.

Ceriunthidae, grosse, solitäre, skeletlose Formen, mit Randtentakeln und Iundtentakeln. Cerianthus.

Edwardsidae. Edwardsia, solitär skeletlos, mit 8 Gastralfächern und 16 Tentakeln.

Antipathidae mit sechs meist kurzen Tentakeln und sechs theilweise verkümmerten Septen, cormenbildend, mit horniger Skeletachse. Antipathes.

Actinidae, solitäre, skeletlose, grosse Formen. Grundzahl der Tentakeln ist sechs. Actinia, Adamsia.

Madreporaria. Meist cormenbildend mit festem Kalkskelet (Perforata, Aporosa). Grundzahl der Tentakeln ist sechs. Astraea, Fungia, Madrepora.

\section{Subcl. Seyphomedusae.}

Die Scyphomedusen sind Scyphozoen meist von Me dusenform (seltener festsitzend), mit Gastralfilamenten und Subgenitalhöhlen. Sie sind auf die Grundform der Scy phis toma zur ü ckführ bar.

Bei den Scyphomedusen ist das Verhältniss von Polyp und Meduse etwas anders als bei den Hydroidmedusen. Der Polyp (Scyphistoma genannt) ist das Jugendstadium; aus demselben geht die junge Meduse hervor, wobei aber, wenigstens in den bekamten Fällen, ein Qu ertheilungsprocess (Strobilation) sich einschiebt. - Bei abgekürzter Entwicklung (Pelagia) geht aus dem Ei direct eine Medusenform hervor.

\section{Scyphistoma.}

Zum Verständuiss der Morphologie der Scyphomedusen ist es am besten vou der Betrachtung der Scyphistoniaform auszugehen. Die Scyphistoma, welche wir bei vielen Scyphomedusen (Aurelia aurita, Chrysaora, Cassiopeia) als polypoides Entwicklungsstadium kennen, ist enie 16 armige Polypenform (es kommen auch Abweichungen in der Anzahl der 'T'entakel vor'), welche sicli durch den Besitz eines ectodermalen Schlundrohres und von vier gastralen Längsfalten (Taeniolen oder Septen, mit Septaltrichtern) auszeichnet.

Die Mundöffnung und rer Schlund sind in vier Ecken beziehungsweise Kanten (in der Richtung der primären Radien) ausgezogen. Letzterer liegt in dem von der Mundscheibe sich absetzenden Mundkegel oder Mundrohre. Die Gastralhöhle wird durch die in ihrer ganzen Länge sich erstreckenden Ta e wiolen in einen Centralmagen und vier periphere Rinnen, die Gastralrinnen, geschieden, welche als seichte Furchen an der Basis des Magens beginnen, gegen die Oralseite sich allmählich vertiefen und an der Mundscheibe als vier blindsackförmige Taschen (Gastraltaschen) enden; am Scheibenrande stehen die 4 Taschen durch Septalos tien (Ringkanal) miteinander in Verbindung. Innerhalb des $\mathrm{R}$ a $\mathrm{n}$ d w u l s te s der Taeniolen verläuft ein Längsmuskel, der 'Taeniolmuskel; derselbe kommt dadurch zu Stande, dass sich von der Mundscheibe aus oberhalb des 
Taeniolansatzes je eine trichterförmige Ectodermeinsenkung (S e p taltrichter, Subgenitalhöhle) bildet, deren solide strangförmige Fortsetzung bis zur Basis des Magens sich erstreckt; diese Epitheleimsenkung erzeugt den Taeniolmuskel. Dieser Längsmuskel strahlt an der Mundscheibe in Radiärmuskeln aus. Eine zusammenhängende Muskelschichte der Kelchwand wird rermisst. Die Tentakel von Scyphistoma sind mit soliden Endodermachsen versehen. Nach der Zahl der Tentakel unterscheiden wir 16 Radien, und zwar 4 Radien erster Ordnung (Gastral-oder Taschenradien), 4 Radien zweiter Ordnung (Septalradien) und 8 Radien dritter Ordnung (Nebenradien); dementsprechend nemnen wir 4 Primärtentakel (gastroradiale), 4 Septaltentakel (septoradiale) und 8 Nebententakel

A.

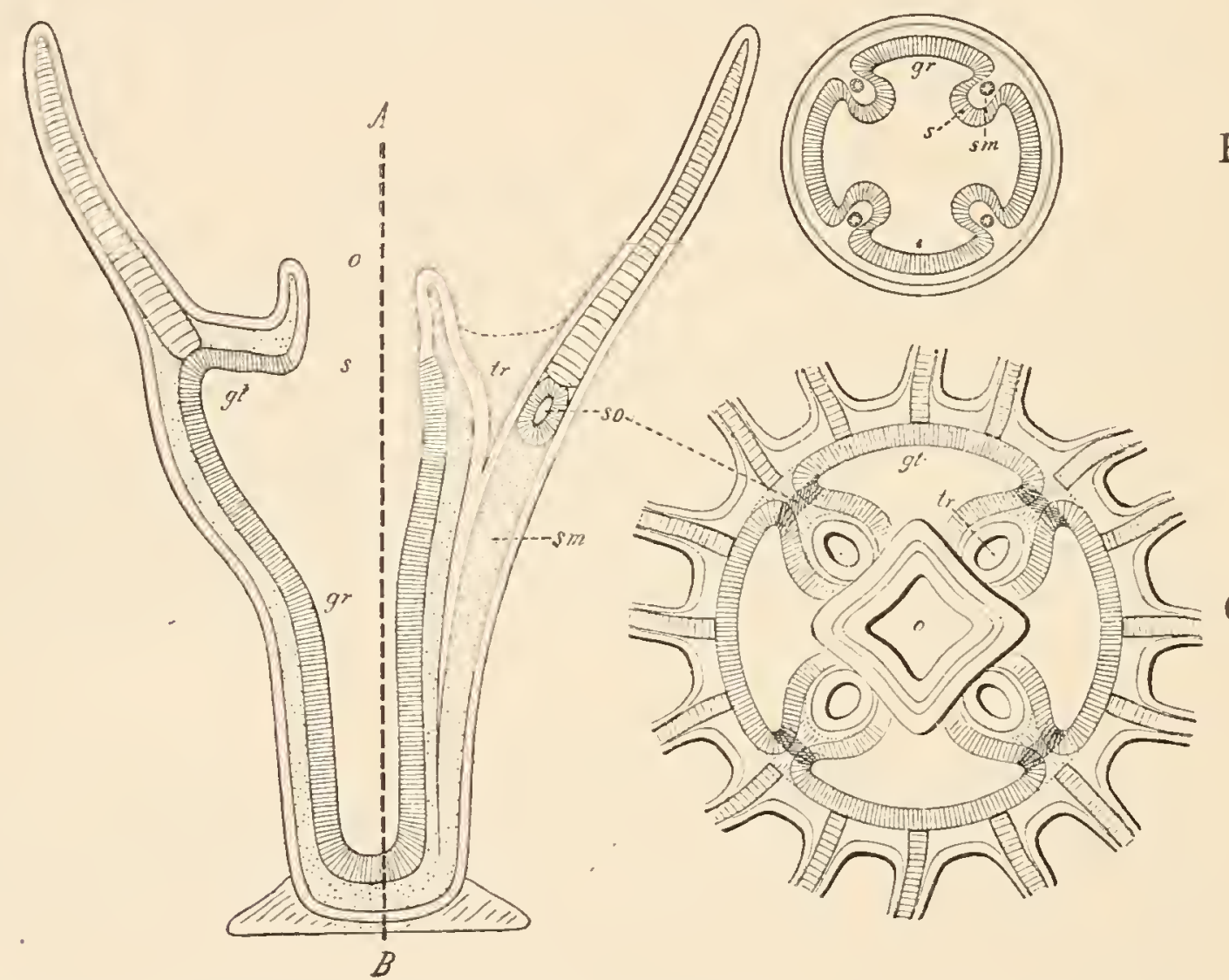

B.

Fig. 273. Schematische Darstellung des Körperbaues der Scyphistoma (combinirt besonders nach den Darstellungen von GöTTE).

A. Längsschnitt des Körpers, links ist derselbe in gastroradialer Richtung, rechts in septoradialer Richtung geführt. $A, B$ Hauptachse, $o$ Mund, $s$ Schlundpforte, gt Gastraltasche, gr Gastralrinne, so Septalostium, $t r$ Septaltrichter, sm Septalmuskel (der Strich ist etwas zu kurz).

B. Ansicht von der Oralseite oder Querschnitt in der Höhe der Mundscheibe. (Bezeichnungen wie in A.

C. Querschnitt durch den unteren Theil des Körpers, gr Gastralrinne, s Septum, sm Septalmuskel.

adradiale) ${ }^{1}$ ). Wir sehen also, dass im centralen (axialen) Theil des Körpers der vierstrahlige Bau vorherrscht, während am Rande der Mundscheibe durch die Tentakelbildung 16 Radien ausgeprägt sind ${ }^{2}$ ).

1) Hatckel nennt die Radien erster Ordnung Perradien, die Radien zweiter Ordnung Interradien, die Radien dritter Ordnung Adradien.

2) Bei dem gegenwärtigen Stande der Kenntnisse könnten wir die Scyphistoma, deren grosse Uebereinstimmung mit den einfachsten Scyphomedusen nachgewiesen ist, auch direct 


\section{Medusen form.}

Es ist anzunehmen, dass die Scyphomedusen von einer festsitzenden, polypoiden Scyphistoma-ähnlichen Stammform durch Anpassung an die freischwimmende (pelagische) Lebensweise abgeleitet sind. Den Uebergang von dem polypoiden zu dem medusoiden Körperbau sehen wir durch die Stauromedusen (Calycozoa) vermittelt, von welchen wir sowohl

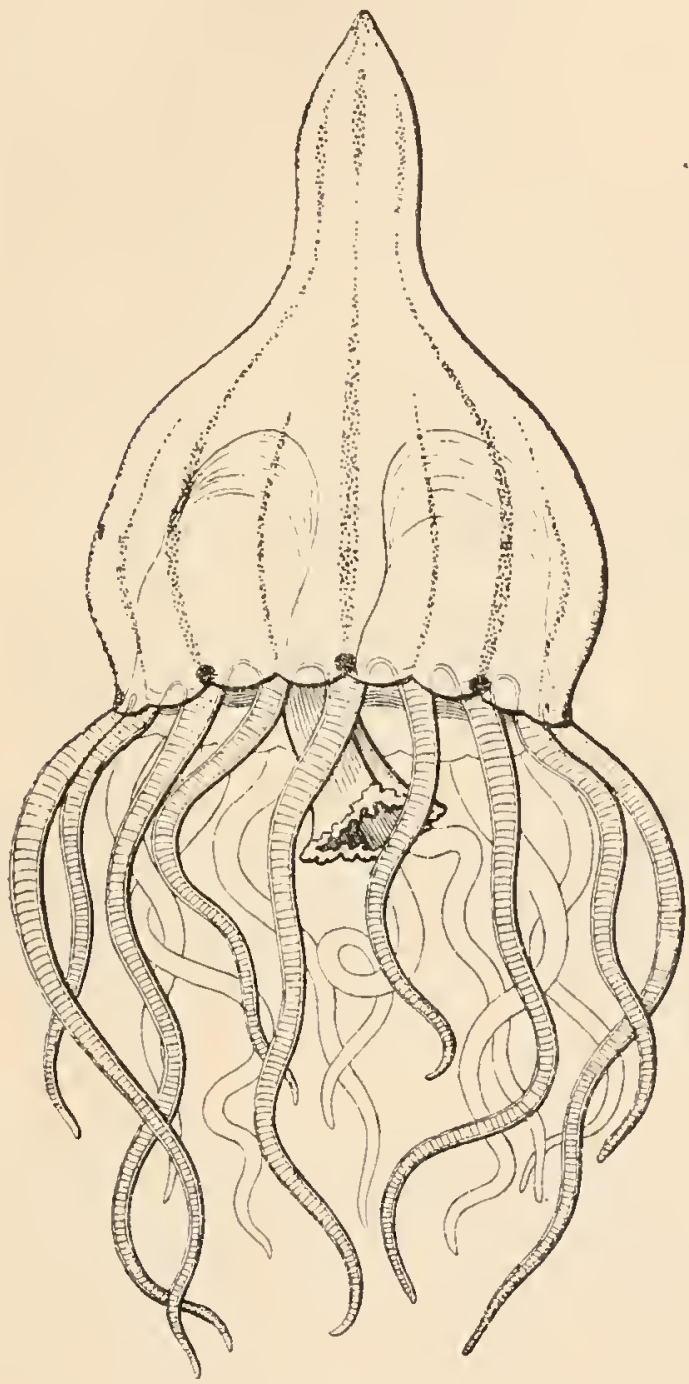

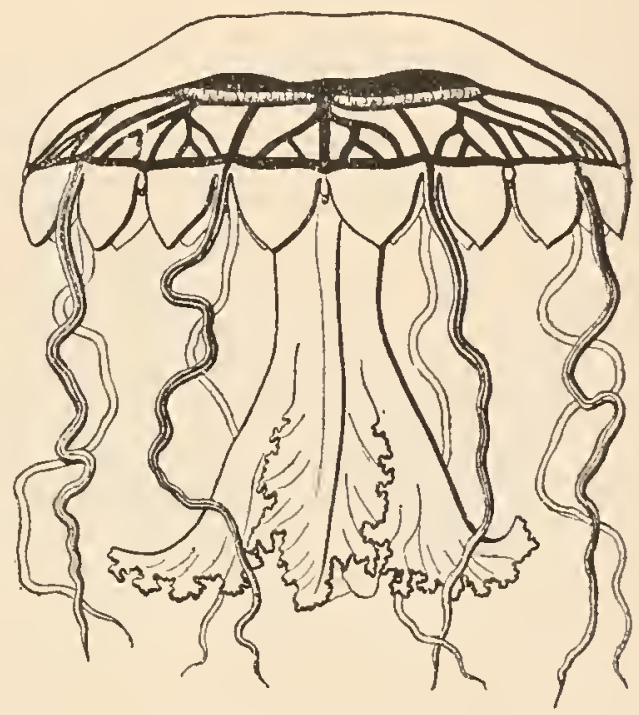

Fig. 275.

Fig. 274. Tesserantha connectens, Meduse aus der Ordnung der Stauromedusen, welche in ihrer äusseren Form und in ihrem inneren Bau der Scyphistoma noch sehr nahe steht. (Nach HAEckeL.)

Fig. 275. Ulmaris prototypus aus der Ordnung der Discomedusen. A. Von der Seite gesehen. Der Gastrovascularapparat ist schwarz dargestellt (nach HAECKEL).

Fig. 274.

festsitzende Formen (Depastrella, Lucernaria) als auch freischwimmende (Tesserantha) kennen. In ilher äusseren Form sind dieselben in der Richtung der Hauptachse noch auffallend länggestreckt und an ihrem Körper ist noch Stiel (oder Scheitelaufsatz) und Scheibe wohl zu unterscheiden. In Bezug auf den inneren Bau ist namentlich die vollkommene Ausbildung des Taeniolapparates hervorzuheben. In ähnlicher Weise verhält sich auch noch unter den Rhopaliferen die Gruppe der Peromedusen, während bei der Gruppe der Discomedusen der Stiel vollkommen in die Fläche der Scheibe aufgegangen und der Taeniolapparat stark reducirt ist.

als eine festsitzende Scyphomeduse bezeichnen. Dies hat schon vor langer Zeit STEENSTRUP ausgesprochen: ,Zufolge meiner eigenen Untersuchungen ist das polypenförmige Thier nur im Aeusseren polypenförmig, in seinem Baue aber eigentlich eine Meduse, die durch einen Stiel an feste Gegenstände geheftet ist." Seine Beweismittel beruhten aber zum Theil auf irrigen Beobachtungen. 
Bei den Rhopaliferen finden sich gewisse Differenzirungen des Scheibenrandes, nämlich die Rhopalien und die Ralld lappen, welche der Körperform ein charakteristisches Gepräge verleihen. Die Rhopalien (Sinneskolben) sind modificirte Tentakel, welche Träger der Sinnesorgane und der Nervencentren sind. Sie haben die Form kurzer Papillen oder Kölbchen, welche in einer von zwei Randlappen (s. unten)

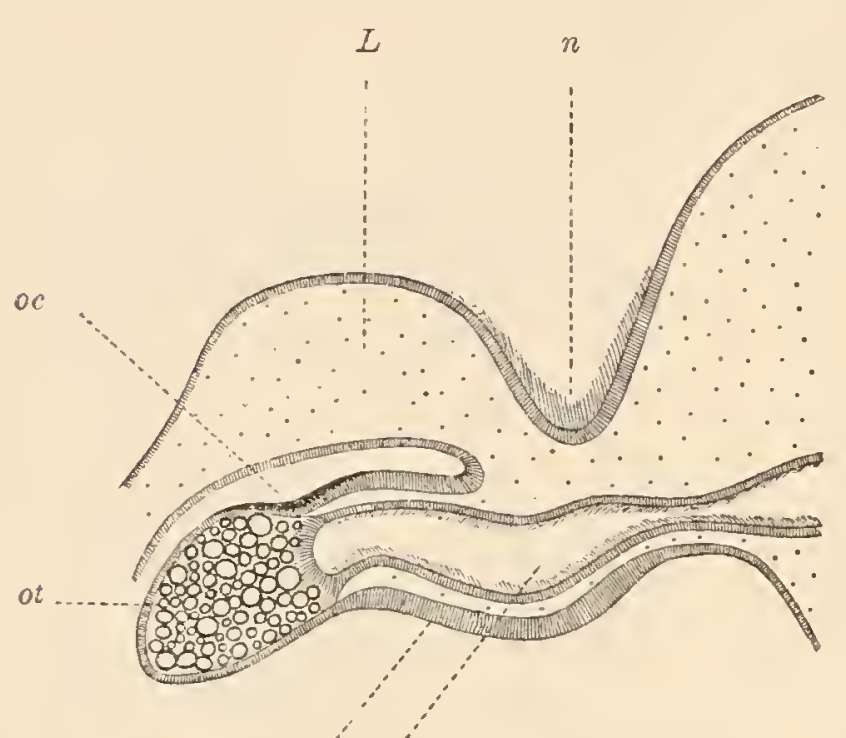
gebildeten Nische liegen und ïberdies meist von einer schuppenartigen Falte überdeckt sind; in ihrem Ectodermepithel finden sich meist mehrere A ug en in bestimmter Anordnung (die bei Charybdaea sogar eine hohe Stufe der Ausbildung erreichen); es besitzt auch Hörhaare, und es werden ferner in den Endodermzellen der Tentakelachse kalkige 0 tolithen ausgeschieden, so dass das Rhopalium zugleich als Hörkölbchen fungirt.

P v

Fig. 276. Querschnitt durch den Scheibenrand von Aurelia aurita mit dem Rhopalium (nach HERTwIG). $R$ das Rhopalium (im Längsschnitt gesehen), dessen verdickte Epithelien bilden das Nervencentrum; $v$ der Gastrovascular-Kanal, sein blindes Ende ist verdickt und enthält ot die Otolithenmasse; oc das Napfauge; $L$ Kandlappen des Schirmes, welcher das Rhopalium bedeckt; $n$ Riechgrube (diese ist nach der Darstellung von CLAUS eingetragen).

An der äusseren exumbrellaren Seite findet sich eine von Nerven-Flimmerepithel ausgekleidete trichterförmige Vertiefung, welche als $\mathrm{R}$ i ech gr ub e gedeutet wird. An der Basis des Rhopaliums liegt eine gangliöse Verdickung des Ectoderms. Diese Ganglien, deren Anzahl derjenigen der Rhopalien entsprechend 4 oder 8, seltener mehr ist, repräsentiren das Centralnervensystem. Sie stehen einerseits mit den Sinnesorganen, andererseits mit einem subumbralen Nervenplexus in Zusammenhang.

Bei Charybdaea ist auch ein subumbraler Nervenring als Commissur zwischen den Rhopalarganglien nachgewiesen.

Bei den Ephyropsiden, welche den Grundtypus der Discomedusen repräsentiren, finden sich 8 Khopalien, da sowohl die 4 gastroradialen als auch die 4 septoradialen Tentakel umgewandelt sind (selten tritt eine Vermehrung der Rhopalien mit einer Vermehrung der Radien ein). - Bei den Cubomedusen sind nur die gastroradialen, bei den Peromedusen nur die septoradialen Tentakel in Rhopalien verwandelt. Die Umwandlung betrifft also in allen Fällen nur die Tentakel 1. Ordnung oder 2. Ordnung, niemals aber die 3. Ordnung, d. i. die Nebententakel. Diese zeigen meist einen ursprünglichen Bau als hohle Fangfäden und behalten entweder ihre typische Anordnung und Zahl oder sie können auch in vermehrter Zahl zwischen die Rhopalien sich einschieben (Aurelia); selten sind sie ganz rückgebildet (Rhizostomeen). 
Die R a ll d lap pen sind lappenförmige Ausbuclitungen der Scheibe, welche ursprïnglich zwischen je zwei tentakulären Bildungen (nämlich Tentakel und Rhopalien) auftretelı. Wir finden demnach 16 Randlappen; wir können dieselben zweckmässig nach den benachbarten Hauptradien

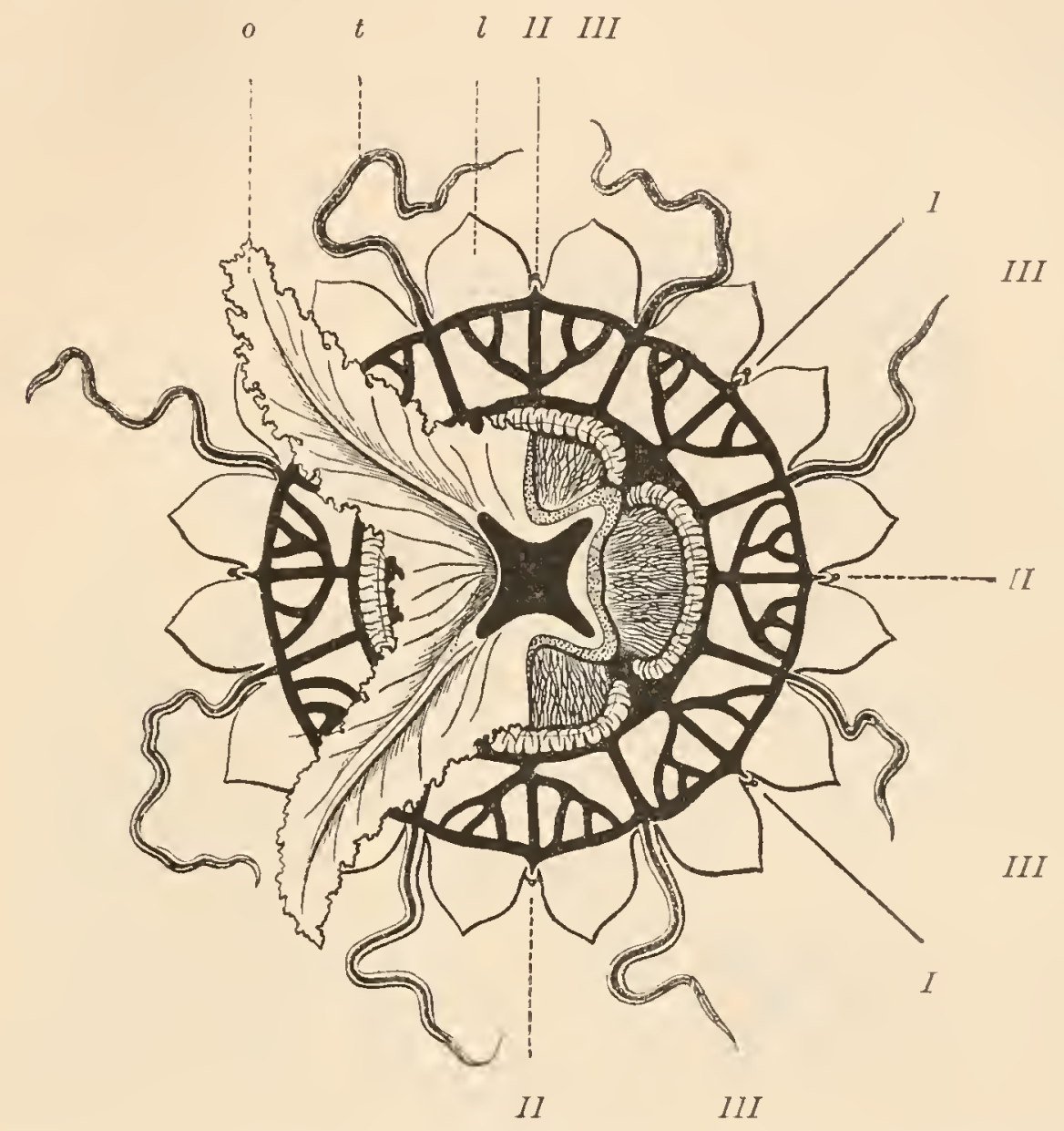

Fig. 277. Ulmaris prototypus von unten gesehen (nach HAECKEL). o Mundarme (zwei derselben sind abgeschnitten), die sich von der centralen Mundöffnung aus erstrecken, diese führt mittelst des Schlundes in den Centralmagen, der sich in das periphere Gastrovascularsystem fortsetzt. $t$ Tentakel, $l$ Randlappen. I Radien erster Ordnung, II Radien $\mathrm{zweiter}$ Ordnung, III Radien dritter Ordnung.

benennen und daher 4 Paar subgastrale und 4 Paar subseptale unterscheiden. Die Rhopalien liegen stets in tiefen Nischen zwischen einem solchen Lappenpaar. Die Beziehung zu den Rhopalien tritt um so melı" hervor, wenn zahlreiche Nebententakel zwischen die rhopalaren Lappenpaare sich einschieben (Aurelia). Die Anzahl der Lappenpaare kann auch vermehrt, sie kann aber auch reducirt sein (vergl. die radiäre Architektonik pag. 289). Bei den Cubomedusen sind 4 mächtig entwickelte Lappenpaare zu einer velumähnlichen, jedoch im Gegensatz zu dem gefässlosen Velum der Hydroidmedusen mit Gefässkanälen versehenen Bildung verschmolzen (Velarium) ${ }^{1}$ ).

Die Subumbrella ist durch den Besitz einer circulären Musculatur

1) Vielleicht sind dies die vier subseptalen (tentakularen) Paare, während die vier subgastralen (rhopalaren) rudimentär geworden wären; doch könnten auch alle acht Paare daran betheiligt sein; zu dieser Deutung möchten die Verhältnisse von Chirodropus veranlassen, wo vielleicht noch acht Paare angedeutet sind. 
im peripheren Theil der Scheibe ausgezeichnet; es bleiben aber häufig dabei auch noch die ursprünglichen radiären Nuskelzüge erhalten. Die Septaltrichter finden sich hier als sogenannte Subgenitalhöhlen wieder; sie führen diesen Namen wegen ihrer Lagebeziehung zu den Gonaden. Sie zeigen bei den verschiedenen Gruppen mancherlei Modificationen. Bei den Peromedusen sind sie trichterförmig und von solcher Ausdehnung, dass sie durch die ganze Länge des Taeniolwulstes sich erstrecken. Bei manchen Rhizostomeen (Versuriden, Crambessiden)

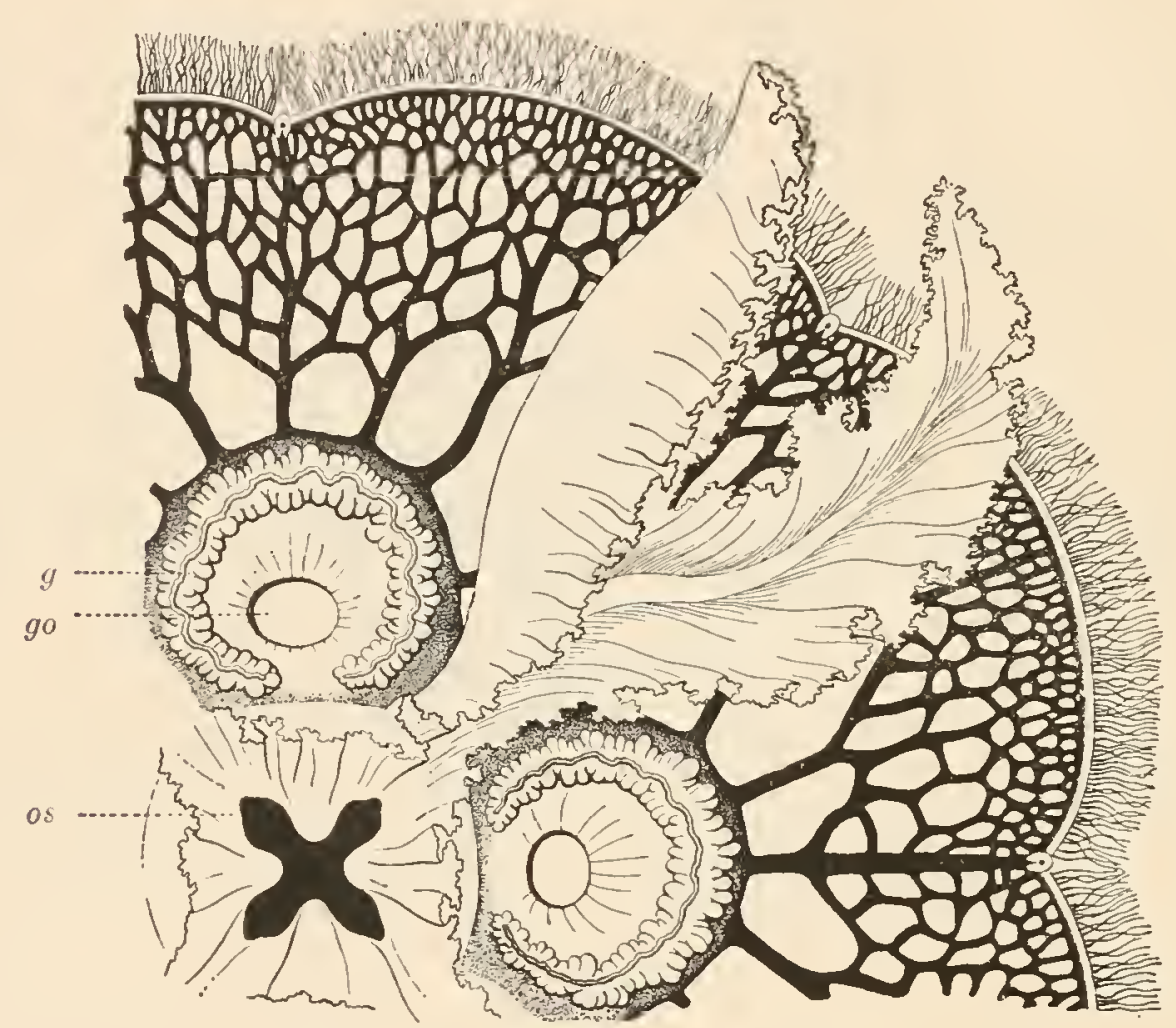

Fig. 278.

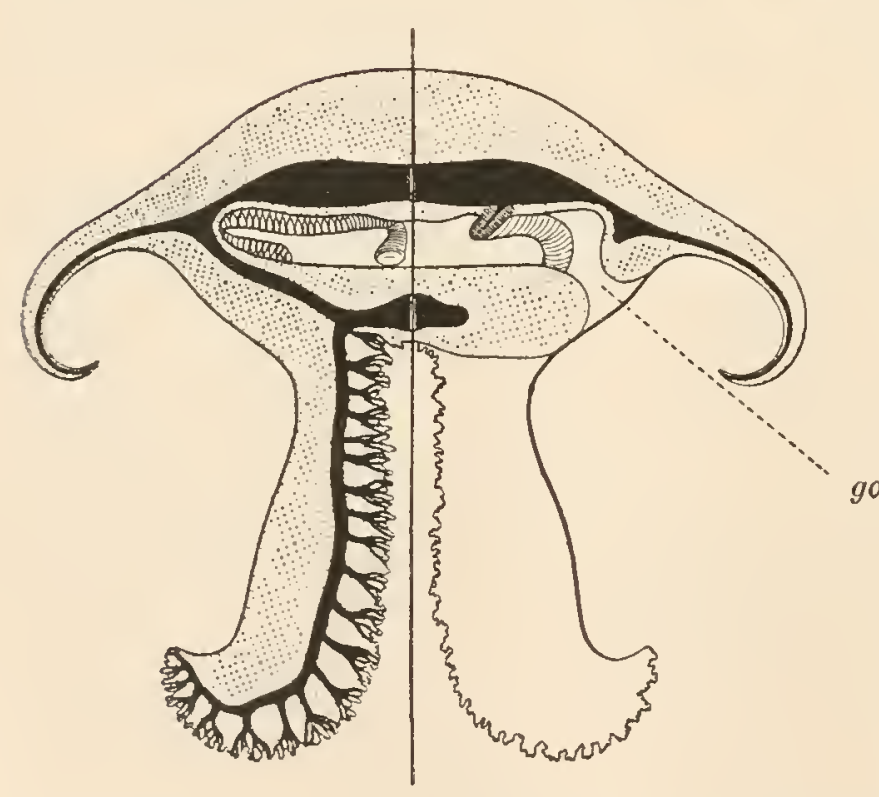

Fig. 279.

Fig. 278. Ein Quadrant von Aurosa furcata, einer Meduse aus der Abtheilung der Semostomaeen, von unten gesehen (nach HAECKEL). In gastroradialer Richtung liegen die vier gabeltheiligen Mundarme (hier ist nur einer $\mathrm{zu}$ sehen), die von dem Mundkreuze (os) ausgehen; in septoradialer Richtung liegen die vier Subgenitalhöhlen (von welchen hier nur zwei zu sehen sind) mit den vier Subgenitalostien (go) und dieselben umkreisend im Centralmagen je eine bandförmige Gonade $(g)$.

Fig. 279. Cannorhiza connexa, eine rhizostome Meduse im vertikalen Durchschnitt; links ist der Schnitt in gastroradialer, rechts in septoradialer Richtung geführt. Die vier Subgenitalhöhlen sind $\mathrm{zu}$ einem einzigen "Subgenital-Porticus" vereinigt, der durch die vier Subgenitalostien (go) nach aussen mündet. Die Mundöffnung der Rhizostomen ist in ihrem centralen Theil obliterirt und nur periphere Theile sind als zahlreiche Sangmündchen offen geblieben (nach HAECKEL, z. Th. schematisch). 
komnt durch centrale Verbiudung der vier Höhlen ein merkwiirdiger Centralraum (Subgenitalsaal) zu Stande. Nur bei den Cubomedusen und Ephyropsiden sind die Subgenitalhöhlen rückgebildet.

Am freien Ende des vierkantigen Mundrohres oder Mundstieles findet sich die Mundöffnung; diese ist entweder einfach viereckig oder sie ist, bei den Semaeosotomen, in vier lange Mundarme mit zierlich gefalteten Rändern ausgezogen; bei den Rhizostomen verwächst zunächst die centrale kreuzförmige Mundöffnung und weiter auch deren Nebenfalten, so dass nur die letzten Enden der Fältchen als za hlre i che Sa ugm ü ud chen offen bleiben. - Der ectodermale Schlund erstreckt sich im Inneren des Mundrohres bis an die Basis desselben, wo er in den Centralmagen mündet.

Von den Differenzirungen des Gastrovascularsystems wollen wir zunächst die Gonaden betrachten. Dieselben liegen an der subumbralen Wand und zwar findet sich ein Paar derselben oberhalb jeder der vier Subgenitalhöhlen; oft sind aber die beiden Theile eines Paares axial oder peripher verbunden, so dass sie je ein e hufeisenförmige, die Subgenitalhöhle umkreisende Gonade bilden. Die Gonade ist meist eine bandförmige Falte des Endorlermepithels, die oft vielfach gewunden ist und meist nur an einer Seite Keimepithel trägt; seltener ist es eine bläschenförmige Ausstülpung des Endoderms gegen die Subumbrellarwand hin (Ephyropsiden). Die dünne Wand, welche die Gastralhöhle von der Subgenitalhöhle trennt, wird in vielen Fällen mitsammt dem Genitalband in die letztgenannte Höhle als krausenförnige Bildung vorgestülpt.

Die Gastralfilamente finden sich als fadenförmige, contractile, mit Drüsen und Nesselzellen ausgestattete Anhänge in grösserer oder geringerer Anzahl längs des Taeniolwulstes. In manchen Fällen sind sie über die ganze Länge desselben zerstreut, doch am Taeniolansatz besonders dicht gehäuft (Lucernaria, Peromedusen). In anderen Fällen sind sie nur auf letztere Stelle beschränkt und dort büschelweise oder in einer Querreihe (längs der bandförmigen Gonarlen) angeordnet, oder die Anzahl derselben ist soweit reducirt, dass nur je eines an jedem Taeniolansatz sich findet.

Der Gastrovascularapparat ${ }^{1}$ ) schliesst sich bei ren primitivsten Formen in seiner Gestaltung noch sehr nahe an die bei der Scyphistoma beobachteten Verhältnisse an. So sind bei den Stauromedusen die Taeniolen noch in ganzer Ausdehnung vom Scheitelpol des Gastralraumes bis znr Basis des Mundrohres ('Taeniolansatz) wohl entwickelt und auch mit dem charakteristischen Taeniolmuskel ausgestattet. Nur erfahren die Gastraltaschen in Zusammenhang mit der Ausbildung der Scheibe eine bedeutendere Ausdehnung und auch eine grössere Selbständigkeit, so dass man einerseits den Centralmagen mit seinen vier Gastralrinnen und andererseits die vier Gastraltaschen einander gegenüberstellen kann; beide Abtheilungen stehen miteinander durch vier weite Oeffnungen (Gastralostien), welche zwischen den

1) Wenn wir in der hier gegebenen Darstellung von der Nomenclatur HAEckes's etwas abweichen, so geschieht dies, um dss Verhältniss von Taeniolansatz und Cathamnalknoten besser hervorzuheben, doch schliesst sich unsere Darstellung in der Hauptsache an die bewunderungswürdige Monographie der Medusen von HAEckel an, welche für die Kenntniss dieser Thiergruppe von epochemachender Bedeutung ist. - Das von HaEckel für die Peromedusen beschriebene Verhalten des Festonkanales soll nach CLAUs auch für die Ephyropsiden gelten; dieser Darstellung sind wir hier gefolgt. 
Taeniolansätzen liegen, in Verbindung. Die vier Gastraltaschen sind aber auch an der Peripherie mit einander in Verbindung gesetzt, indem die Taschensepten hier von deu Septalostien durchbrochen sind (Ring s in u s). Diese Durchbrechungen können eine solche Ausdehnung erreichen, dass die Taschensepten ganz aufgelöst erscheinen und die Abgrenzung der Taschen nur noch durch die Taeniolansätze angedeutet ist; der weite Ringsinus (Kranzdarm) mündet durch die vier Gastralostien unmittelbar in den Centralmagen. Bei vielen Tesseriden und den Peromedusen treten nun an Stelle der Taschensepten wieder neue (?) Ver-

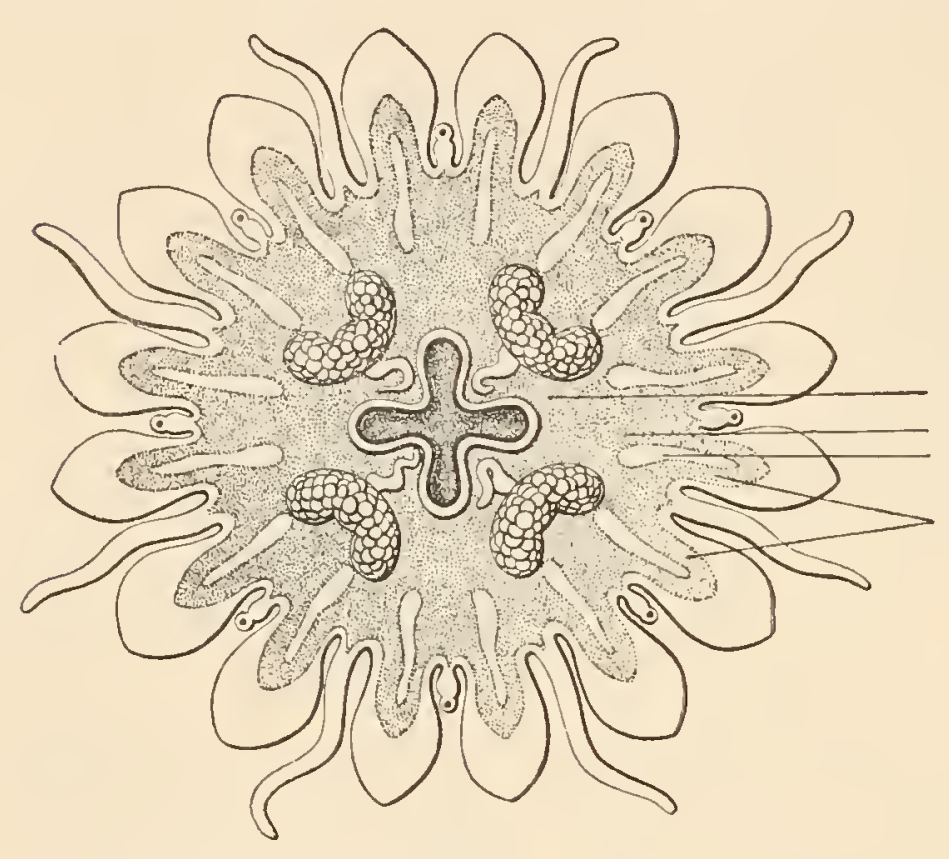

wachsungspunkte (Cathamnalknoten) auf, durch welche der Ringsinus in einen äusseren und inneren sich gliedert. - Bei den Discomedusen ist derTaeniolapparat nur noch auf ${ }_{c m}$ den Taeniolansatz berc schränkt, welcher die $s p$ Gastralfilamente trägt $f_{c}$ und auch dieser bildet nur bei den Ephyropsiden noch je eine Verbindung der Subumbrella mit der Exumbrella; bei dell Semaeostomen und Rhizostomen aber istdie Verbindung des Tae-

Fig. 280. Gastrocanalsystem einer Ephyropside (nach HAECKEL, etwas verändert nach der Darstelluug von Cuaus). Das Mundrohr ist abgeschnitten. Der Centralmagen $(\mathrm{cm})$ wird in septoradialer Richtung von den vier Gonaden und den Gastralfilamenten (hier nur je eines) begrenzt, in gastroradialer Richtung mündet er durch die vier Gastralostien in den Ringsinus $(r c)$; von diesem wird durch die sechzehn Lappenspangen $(s p)$ der Festoncanal $(f c)$ abgegliedert.

niolansatzes mit der Exumbrella geschwunden, so dass derselbe nur noch durch die an der subumbralen Gastralwand vorfindlichen Gastralfilamente gekennzeichnet ist. Das ist alles, was hier noch von der ursprünglich so mächtig entwickelten Taeniolbildung übrig geblieben ist. In diesem Falle ist nun der Ringsinưs und der Centralmagen zu einem einheitlichen Raume vereinigt. In der Peripherie des Ringsinus sind aber bei diesen Formen, sowie bei allen Rhopaliferen, neue gefässartige Differenzirungen zu beachten. Diese peripheren Gefässbildungen stehen in Zusammenhang mit der Bildung der Randlappen. Je einem Randlappen entspricht eine periphere Ausbuchtung des Ringsinus; jede dieser Ausbuchtungen ist durch einen endodermalen Verwachsungsstreifen (L a p penspange) ausgezeichnet, in der Weise, dass die 16 Ausbuchtungen in einen peripheren, regelmässig geschlängelten Ringcanal (Festoncanal) und von demselben ausgehende centripetale Radiärcanäle verwandelt sind. Dies ist der Grundtypus (Ephyropsiden, Peromedusen), von welchem die reicher verzweigten aus Ringcanal und Radiärcanälen zusammengesetzten Gefässbildungen der höheren Discomedusenformen (z. B. Auvelia, Rhizostoma) abzuleiten sein. 
Die radiäre Architektonik der Scyphomedusen ist ursprünglich von demselben Gesetze beherrscht, welches wir bei der Scyphistoma ausgeprägt fanden: Während im centralen Theil des Körpers der vierstrahlige Bau vorherrscht, sind am Rande der Scheibe durch die Tentakelbildung 16 Radien a usgeprägt.

Bei all den zahlreichen Modificationen des Körperbanes bleibt der vierstrahlige Bau der centralen Theile erhalten, dagegen kommt an den peripheren Theilen (Scheibenrand und Tentakeln) sowohl eime Vermelrung als auch eine Verminderung der Tentakelzahl vor. Die Vermehrung betrifft in vielen Fällen nur die nicht rhopalaren Zwischententakel (Aurelia, Chrysaora), selten ist sie eine regelmässigere, so dass auch die Zahl der Rhopalien zunimmt (Collapsis, manche Rhizostomen). Besonders interessant ist die Verminderung der peripheren Radien. Eine solche kommt bei den verschiedensten Abtheilungen vor und es

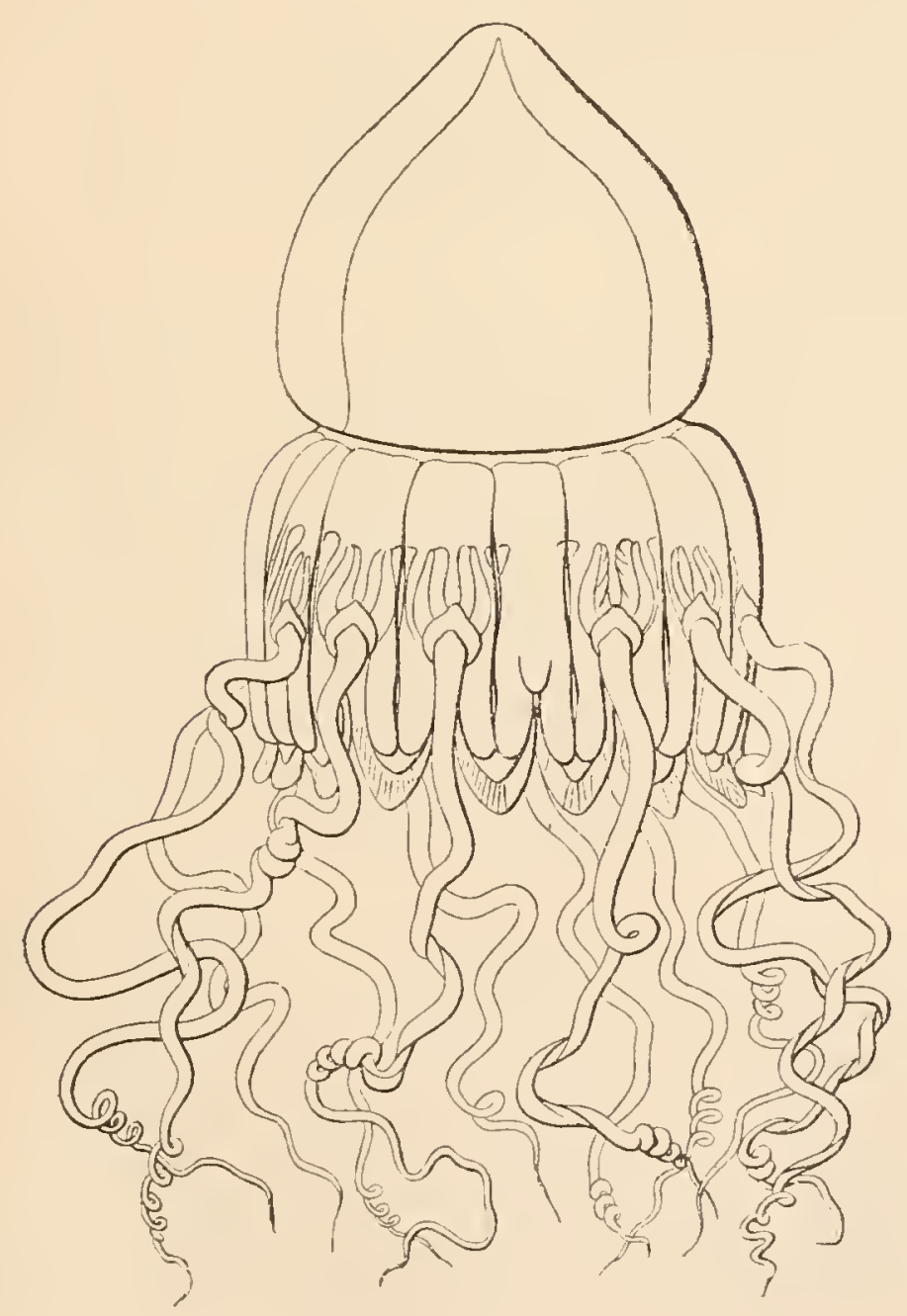

Fig. 281.

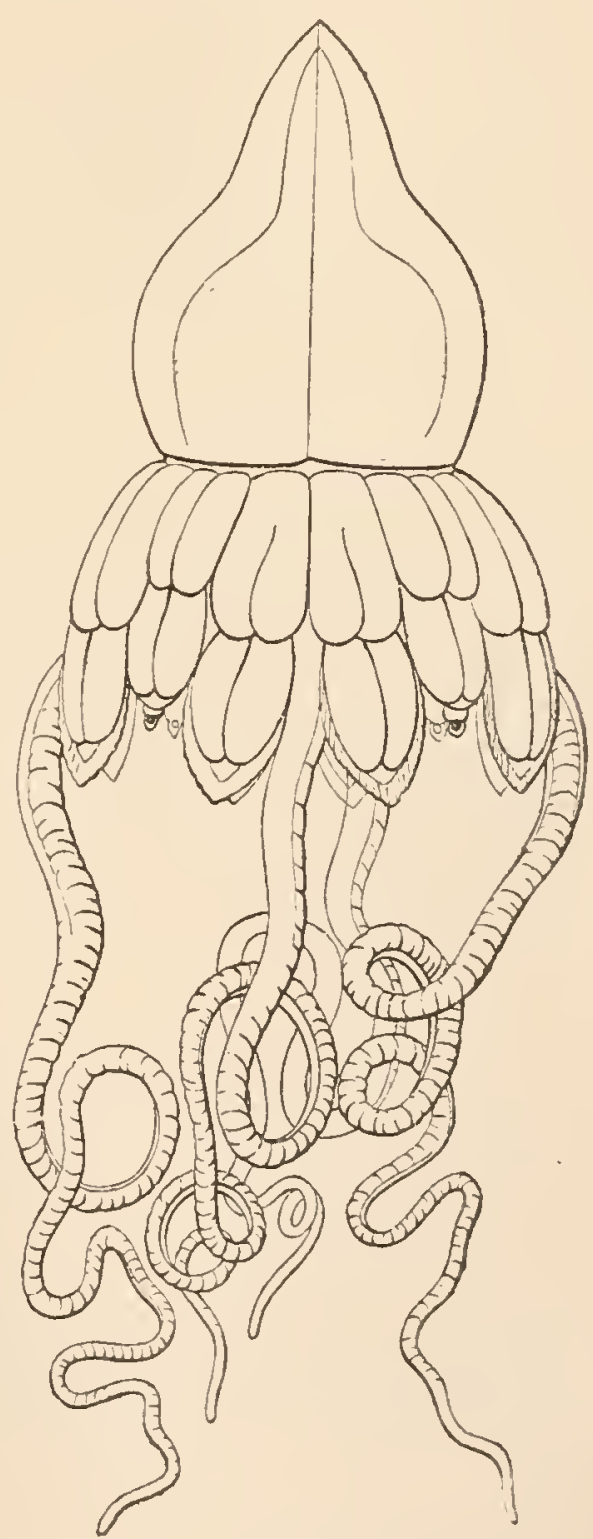

Fig. 282.

Fig. 281. Periphylla hyacinthina, eine s echzehnstrahlige Peromeduse (nach HAECKEL). Auf je drei Tentakel folgt ein Sinneskolben.

Fig. 282. Pericolpa quadrigata, eine a chtstrahlige Peromeduse (nach HaEckel). A uf je einen Tentakel folgt ein Sinneskolben. 
lässt sich erweisen, dass dies sehr wahrscheinlich eine secundäre Erscheinung ist [Tesserantha ist 16 strahlig, Tessera 8 strahlig; Periphylla 16 strahlig, Pericolpa 8 strahlig; Charybdaea ist 8strahlig, Chirodropus zeigt vielleicht noch Andeutungen eines 16 strahligen Baues]. In allen Fällen sind es die Nebententakel, die in Wegfall gekommen sind, nur bei Lucernaria verhält sich dies anders, denn hier sind die Gastralund Septaltentakel rückgebildet und die büschelförmig vermehrten Nebententakel an armartigen Fortsätzen der Scheibe erhalten. Es zeigt sich, dass alle Scyphomedusen auf dieselbe ursprüngliche Architektonik zurückzuführen sind. (Ein Gegensatz von Tetrameralia und Octomeralia, nach welchem Claus neuerdings die Scyphomedusen eintheilen will, kann nicht anerkannt werden.)

Die Entwicklung ist nur bei einigen Discomedusen zusammenhängend erforscht. Der allgemeine Typus der Entwicklung (mit Ausnahme von Pelagia) ist eine complicirte, mit Generationswechsel verbundene Metamorphose (Aurelia, Chrysaora, Cassiopeia). Aus einer regelmässigen Furchung geht eine Blastula hervor, welche durch Invagination (oder auch durch polare Einwucherung, GöтTE) eine Gastrula bildet; diese wird aber durch Obliteriren der Protogasterhöhle und des Gastrulamundes in die freischwimmende Planula form übergeführt. Nach dem Umherschwärmen setzt sich dieselbe mit dem Apicalpol fest, um sich in die Scyphistomaform zu verwandeln; dabei entstehen zuerst der Schlund und die Gastraltaschen $(2,4)$ und dann erst successive $(2,4,8,16)$ die Tentakel.

Die Scyphistoma vermehrt sich in der Regel zunächst durch Knospung, indem von dem Stiele Stolonen ansgehen, an welchen neue Individuen sprossen. - Auch die einzelne Scyphistoma verwandelt sich dann nicht direct in die junge Meduse, sondern unterliegt dabei einer Vermehrung durch Quertheilung (fortgesetzte Theilung mit vorzeitiger Regeneration), der sogenannten Strobilabildung. Durch quere Einschnürungen markiren sich hintereinanderliegende Abschnitte, von welchen der am Mundpole gelegene der älteste, die nachfolgenden successive jünger sind. Diese Abschnitte, welche an ihrer Peripherie je acht Lappenpare erhalten, kommen dann dem Alter nach zur Ablösung und repräsentiren je eine freie als Ephy ra bezeichnete Discomedusenlarve; (die Entstehung des Schlundes an der Ephyra ist noch nicht ganz aufgeklärt).

Die Ephyra ist auf die phylogenetische Form der Ephyropsiden zurückzuführen, doch zeigt sie manche secundäre Charaktere, durch welche sie von der phyletischen Stammform abweicht. So ist der 16strahlige Bau durch die provisorische Unterdrückung der 8 Nebententakel (die erst in späteren Stadien zur Ausbildung kommen) verwischt.

Die vorderste Ephyra nimmt die Scyphistomatentakel mit, die dann an der freischwimmenden Larve rückgebildet und erst später wieder durch die neu auftretenden tentakulären Bildungen ersetzt werden. Die nachfolgenden Ephyren sind von Anfang an tentakellos und zeigen daher einen relativ abgekürzten Entwicklungsgang. Der Rest des Polypen

1) Die phylogenetische Entstehung der Strobilation können wir uns folgendermaassen erklären. Zuerst lag eine directe Umwandlung der Scyphistoma in die Scyphomeduse vor (bei jenen Formen, die niedriger als die Discomedusen stehen und deren Entwicklung uns noch ganz unbekannt ist, dürfen wir jetzt noch ähnliche Verhältnisse vermuthen). - Dann folgte phylogenetisch anstatt der einfachen Loslösung der Scyphistoma eine Quertheilung derselben mit nachfolgender Regeneration beider Theile. Aus der vorderen Hälfte ent- 
kann durch Neubildung von Tentakeln sich wieder zu einem Scyphis to ma ergänzen. Aus der Ephyra entsteht durch Wachsthum und allmähliche Vervollkommnung die geschlechtsreife Discomedusenform.

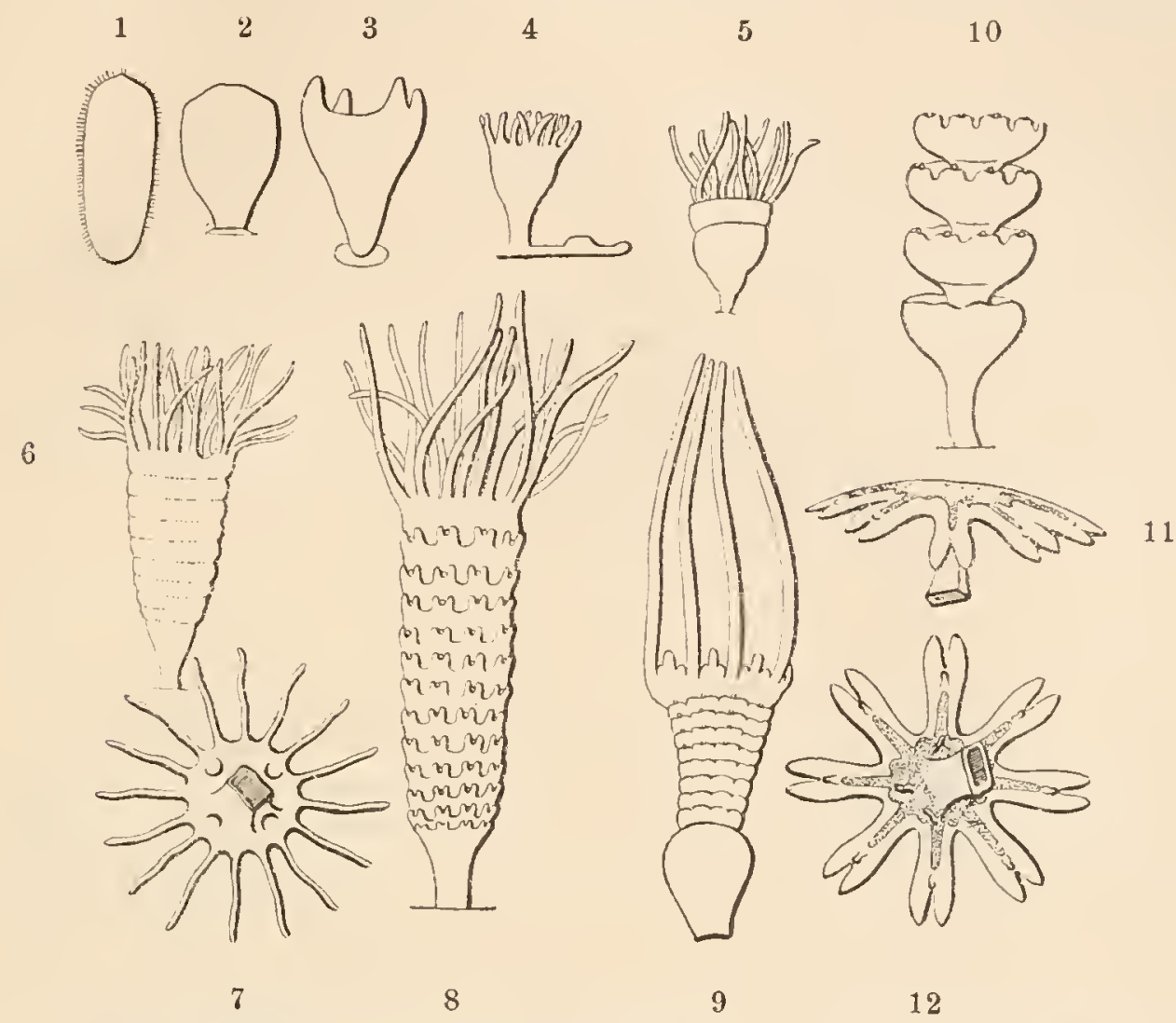

Fig. 283. Entwicklungscyclus einer Scyphomeduse (Aurelia) nach STEEnstrup und anderen. 1 Die aus dem Ei entstandene Flimmerlarve (Planula). 2 Dieselbe kurz nach dem Festsetzen. 3 Es hat sich ein kleiner 4 armiger Polyp entwickelt. 4 Es sind sechzehn Tentakel vorhanden, an der Basis des Polypen entsteht ein Stolo, an relchem neue Polypen knospen. 5 Ein einzelner Polyp, an welchem die Quertheilung beginnt. 6 Die Quertheilung ist weiter vorgeschritten. 7 Polyp, vom Mundpole gesehen. 8, 9 Die Querstücke beginnen sich zu jungen Medusen zu bilden. 10 Die jungen Medusen (sogenannten Ephyren) lösen sich allmählich ab. 11, 12 Ephyra von der Seite und von unten gesehen.

Bei Pelagia ist die Entwicklung eine abgekürzte, indem die Gastrula sich directzu der Ephyraform entwickelt.

Systematische Uebersicht der Scyphomedusen.

\section{A. Arhopalia.}

Die Arhopalia sind Scyphomedusen ohne Rhopalien, ohne Randlappen, centralisirtes Nervensystem nicht nachgewiesen.

I. Ord. Die Calycozoa (= Stauromedusae HAECKEL) sind kelchförmige Arhopalia, entweder festsitzend (mit Stiel) oder freischwimmend (mit Scheitelaufsatz); mit vollkommenem Taeniolapparat und Taeniolmuskel; Tentakel vollzählig oder zum Theil rückgebildet.

wickelte sich die Ephyra, während die hintere Hälfte durch Neubildung der Tentakel zunächst wieder zur Scyphistomaform sich ergänzte. Es wurden also nach der Bildung je einer einzigen Ephyra an dem Reste des Polypen die Scyphistomatentakel wieder ergänzt, ein Vorgang, der sich rhythmisch wiederholte. Durch Abkürzung dieses Rhythmus ist die Strobilabildung entstanden. Es wird nun an der Scyphistoma ein zusammenhängender Satz von Ephyren erzeugt; nach der successiven Abstossung eines solchen Satzes können aber an dem Rest des Polypen die Scyphistomatentakel erneuert werden. 
Die Calycozoen erweisen sich sowohl in ihrer äusseren Körperform als auch in dem Bau des Gastralapparates der Scyphistomaform noch sehr nahestehend. Auch in dem Mangel der Randlappen und Rhopalien zeigen sie sich einfacher als die übrigen Scyphomedusen.

1. Tesseridae. Scheibe einfach; Principaltentakel stets rorhanden; der weite Ringsinus durch Cathamnen in einen grösseren äusseren und kleineren inneren getheilt. Freischwimmende Formen.

Tesserantha, Scypihstomaähnlich, 16strahlig. T'essera, 8strahlig.

2. Lucernaridae. Scheibe in 8 adradiale Arme ausgezogen, welche die büschelförmig vermehrten adradialen Tentakel tragen; die gastroradialen und septoradialen Tentakel fehlen meist. Taschensepten nahezu vollständig, Ringsinus einfach und eng. Festsitzende Formen.

Lucernaria mit einfachen Gastraltaschen. Craterolophus, von den Gastraltaschen sind besondere Genitaltaschen (auch Gastrogenitaltaschen genannt) gesondert. Depastrella, mit vollzähligen Tentakeln.

A.

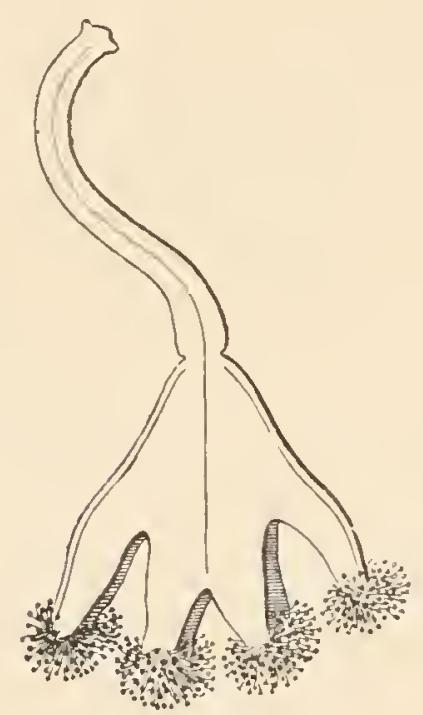

B.

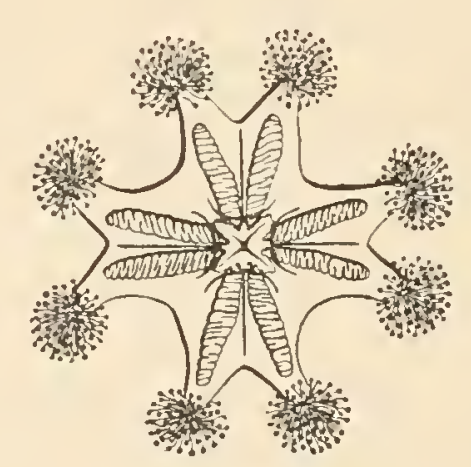

Fig. 284. Lucernaria pyramidalis. A. von der Seite gesehen, der Stiel dient zur Anheftung, B. ron dem oralen Pole gesehen, zu beiden Seiten jedes Septums liegen die bandförmigen Gonaden (nach HAECKEL).

\section{B. Rhopalifera.}

Die Rhopaliferen sind Scyphomedusen mit Rhopalien und Randlappen, mit centralisirtem Nervens y stem.

Sie sind von kelch-, glocken- oder scheibenförmiger Gestalt, mit ausgebildetem oder reducirtem Trenialapparat; oft von bedeutender Grösse.

II. Ord. Die Cubomedusen sind Rhopaliferen von glockenförmiger Gestalt mit halber Radienzahl (Nebenradien fehlen). Mit 4 gastroradialen Rhopalien und 4 septoradialen Tentakeln. Sie haben ein aus 4 (od. 8?) Lappenpaaren zusammengesetztes, mit Gefässen versehenes Velarium. Subgenitalhöhlen fehlen. Die vier Gastraltaschen sind durch vier voll-

Fig. 285. Charybdaea marsupialis von der Seite gesehen (nach CLAUS). 
ständige schmale Septen („Verwachsungsstreifen ${ }^{6}$ ) von einander geschieden. Die 8 Gonaden sind lïngs der Septen befestigte, frei in die Gastraltaschen hängende Blätter. Die Rhopalien sind durch einen subumbralen Ringnerv miteinander verbunden.

Charybdaea marsupialis, Chirodropus.

III. Ord. Die Peromedusen sind Rhopaliferen von kelchförmiger Gestalt, mit voller Radienzahl (Periphylliden) oder Rückbildung der Nebenradien (Pericolpiden). Mit nur vier septoradialen Rhopalien. Taeniolen vollkommen ausgebildet, bis an ihre Basis von den trichterförmigen Subgenitalhöhlen durchsetzt. Ringsinus durch Cathamnen verdoppelt.

Periphylla mit 16 tentaculären Bildungen (4 Rhopalien, 12 Tentakel). Pericolpa mit 8 tentaculären Bildungen (4 Rhopalien, 4 Tentakel).

IV. Ord. Die Discomedusen sind scheibenförmige Rhopaliferen mit vollständiger oder vermehrter Radienzahl. Mit 8 oder mehr Rhopalien.

1) Cannostomae, Mundrohr einfach, vierseitig prismatisch, ohne II undarme. Peripheres Canalsystem einfach, Subgenitalhöhlen fehlen.

Ephyridae. Ephyra, Ephyropsis, Nausilhö̈.

2) Semostomae. Mundrohr in 4 faltige Mundarme ausgezogen. Tentakel hohl und meist lang. Peripheres Canalsystem meist reicher entwickelt.

Pelagia mit direkter Entwicklung. Chrysaora, hermaphroditisch (Hoden an den Mundarmen!). Aurelia aurita, Vlmaris, Aurosa.

3) Rhizostomae. Mundrohr in 8 (4 gabeltheilige) wurzelförmige Mundarme ausgezogen. Centrale Mundöffnung obliterirt; statt deren zahlreiche Mündchen an den Krausen der Mundarme. Reich rerästelte Radiärcauäle durch einen Ringcanal rerbunden. 8 oder mehr Rhopalien. Tentakel fehlen. rhiza.

Cassiopeia, Pilema (Fig. 281), Canno-

Fig. 286. Pilema pulmo, stark verkleinert.

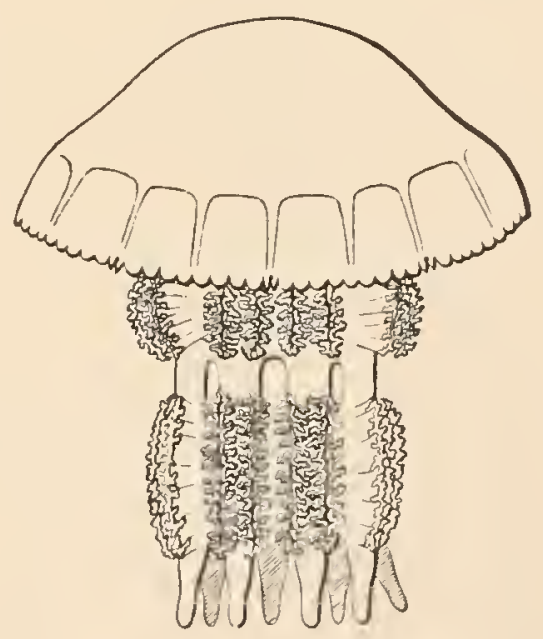




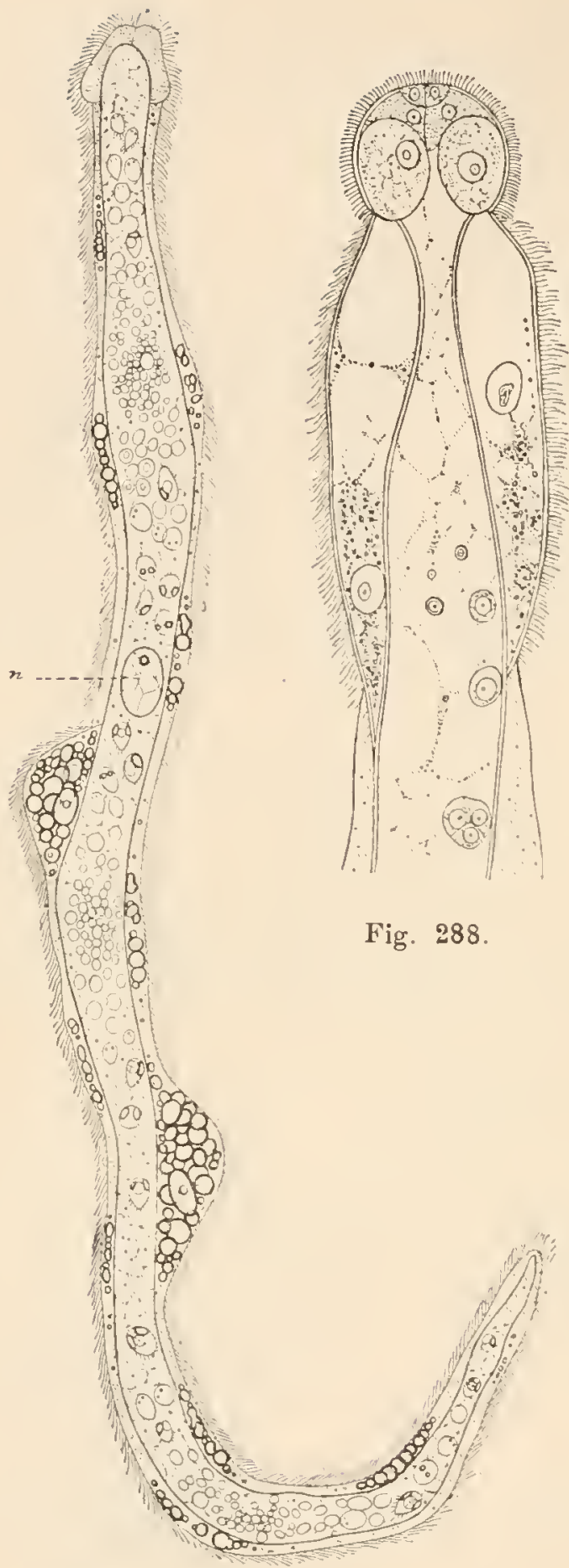

Fig. 287.

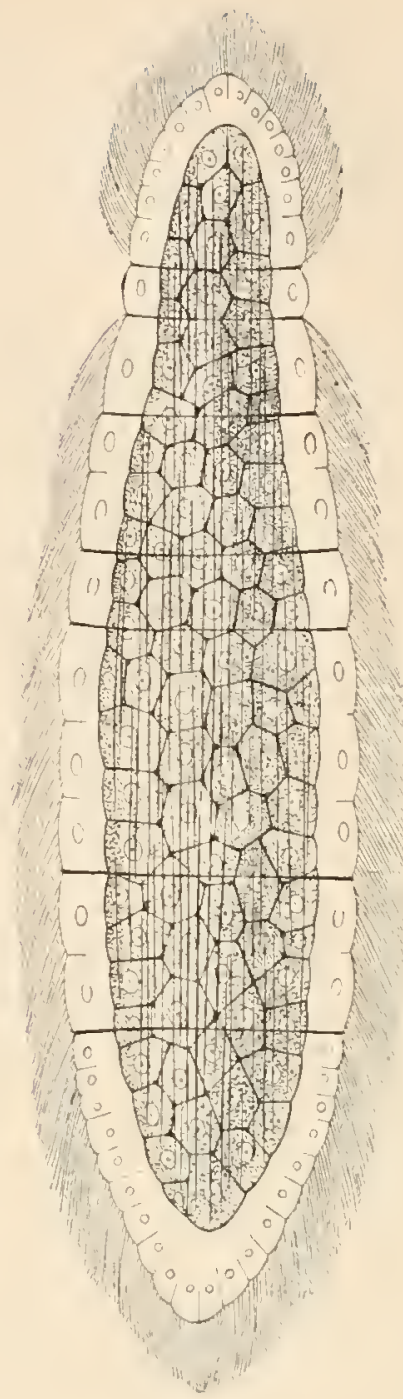

A.

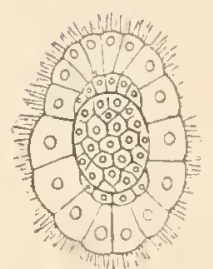

B.

Fig. 287. Dicyemella Wageneri, erwachsenes rhombigenes Individuum (nach ED. VAN BEXEDEX). Die Ectodermzellen enthalten neben dem Kern zalılreiche glänzende fettähnliche Kügelchen; an zwei Stellen sind dieselben so gehäuft, dass sie die Zellen buckelig vortreiben. Im Inneren tindet sich die grosse axiale Endodermzelle; bei $n$ deren Zellkern; sehr zahlreiche Keimzellen und Entwicklungsstadien von ,,infusorienförmigen Embryonen" erfüllen dieselbe.

Fig. 288. Vorderes Körperende von Dicyemina. Am Kopfzapfen sind die bestimmt angeordneten Ectodermzellen kleiner und plasmareicher; dahinter die parapolaren grossen Ectodermzellen, welche sich auch noch durch gewisse Eigenthümlichkeiten vor den übrigen Ectodermzellen auszeichnen. Im Inneren das vordere Stück der axialen Endodermzelle, welches einige Keimzellen einschliesst. (Nach Ed. VAN Benedex.)

Fig. 289. A. Rhopalura Giardii (Orthonectide), cylindrische weibliche Form (nach JULIN). Die Ectodermzellen sind in bestimmten ringförmigen Reihen angeordnet; darunter liegt eine Schichte von langgestreckten Muskelzellen; im Inneren findet sich eine compacte Masse von Eizellen. B. Embryonales Entwicklungsstadium von Rhopalura Giardii (nach JuliN). Aussen Ectoderm; im Centrum ein Haufen von Keimzellen; vor und hinter demselben Muskelbildungszellen. 


\section{Anhang zum Cladus der Cnidarier.}

\section{Planuloidea (= Mesozoa, van Beneden).}

Die Planuloidea sind planulaähnliche Metazoen (einachsig, lieteropol, ohne Mundöffnung, ohne Darmlumen) mit endodermalen Keimzellen; sie sind Endoparasiten.

I. Die Dicyemiden leben als Parasiten in den Nieren von Cephalopoden. Der langgestreckte wurmförmige Körper ist aus Ectoderm und Endoderm zusammengesetzt; das erstere besteht aus einer continuirlichen Schichte sehr grosser, zum Theil buckelig vorspringender Flimmerzellen; das etwas verdickte vordere Körperende ist durch besondere Anordnung seiner Zellen ausgezeichnet; das Endoderm ist durch eine einzige Riesenzelle mit grossem Kern und netzartig angeordnetem Plasma repräsentirt. Mangels einer Mundöffnung erfolgt die Eruährung endosmotisch.

Die Fortpflanzungszellen sind in die Endodermzelle eingeschachtelt, sie sind ursprünglich in Zweizahl vorhanden, vermehren sich aber stetig. Aus denselben gehen parthenogenetisch (?) zwei Arten von Embryonen hervor: 1) „Wurmförmige Embryonen". Durch Furchung und sehr" einfaclıe Epibolie (der Gastrulamund entspricht dem hinteren Körperende) entsteht ein Embryo, der durch Streckung und Wachsthum alsbald die Form des Mutterthieres gewinnt. 2) "Infusorienförmige Embryonen" entstehen ebenfalls durch Furchung und Epibolie; sie sind von gedrungener, etwa birnförmiger Gestalt und kräftig bewimpert. Das Ectoderm umgibt eine Inhaltszelle, welche wieder eigenthümliche vielkernige Zellen einschliesst, die - wahrscheinlich willkürlich - ausgestossen werden können (die ganze innere Zellgruppe wird als „Urne" bezeichnet). Interessanter Weise erzeugen gewisse Individuen nur wurmförmige, andere nur infusorienförmige Embryonen und diese zweierlei Individuen sind schon ihrer Form nach etwas verschieden (,nematogene" und, ,hombigene" Individuen). Es gibt (nach Whituax) auch Individuen, welche in der Jugend infusorienförmige und später wurmförmige Embryonen erzeugen. - Ueber das weitere Schicksal der infusorienförmigen Embryonen ist nichts bekannt; es wurde die Vermuthung ausgesprochen, dass sie die Männchen repräsentiren und dass die von der Urne ausgestossenen Zellen männliche Fortpflanzungszellen sind. Jedenfalls sind die Verhältnisse der geschlechtlichen Fortpflanzung und auch die Uebertragung der Parasiten (vielleicht durch einen zweiten Wirth) noch durch nene Forschungen aufzuklären.

II. Die Orthonectiden leben parasitisch in Ophiuriden, Turbellarien und Nemertinen. Ihr eiförmiger Körper besteht aus einer äusseren Schichte grosser Flimmerzellen, die meist in regelmässigen Ringen angeordnet sind, aus einer mittleren Schichte longitudinal verlaufender Muskelfasern, und aus einer inneren Zellmasse, welche die Fortpflanzungszellen liefert. Man unterscheidet Männchen und zwei Formen von Weibchen (cylindrische und abgeplattete). Wahrscheinlich erzeugt die eine Form wieder nur Weibchen, die andere nur Mämnchen. Zum Zwecke der Entwicklung werden die Eier entweder ausgestossen (cylindrische Weibchen) oder sie bleiben im Mutterthiere (abgeplattete Weibchen), das sich zu einem, ,Plasmodium-Sclılauche" verändert; es 
erfolgt Furchung und Epibolie, die inneren Zellen liefern die Muskelschichte und die Fortpflanzungszellen; es werden diese beiden zusammen als Endoderm betrachtet.

Von van Beneden, dem sich auch Julin anschliesst, werden die Dicyemiden und Orthonectiden als eine Gruppe betrachtet, welche eine Mittelstellung zwischen Protozoen und Metazoen einnimmt. Es ist aber

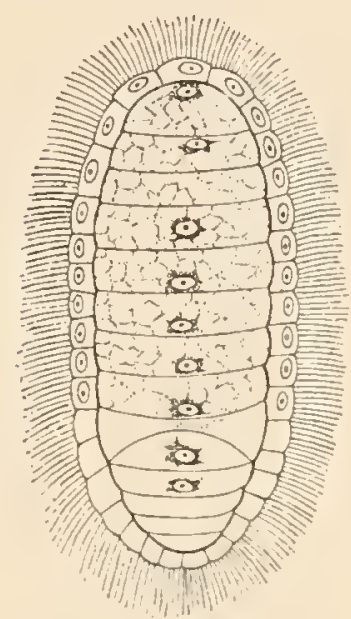
die Vermuthung begründet, dass diese Organismen durch den Parasitismus vereinfachte (rückgebildete) Metazoen sind; wenn wir auch nicht jenen Forschern folgen können, welche sie für vereinfachte Plattwürmer halten, so möchten wir sie doch als reducirte Cnidarier - und zwar als durch Unterdrückung der Endstadien geschlechtsreif gewordene Planulaformen hinstellen; man vergleiche z. B. die hier abgebildeten Planulaformen eines Hydroiden mit der Organisation einer Dicyema.

Fig. 290. Planula-Larve einer Hydroidmeduse (Aglaura hemistoma) (nach MetschnikofF). Dieselbe ist zur Vergleichung mit dem Organismus der Dicyemiden hierhergesetzt. 


\section{DREIZEHNTES CAPITEL.}

\section{Cladus der Metazoa.}

\section{Ctenophora.}

Die Ctenophoren sind Metazoen mit persistirender Primärachse und modificirt radiärem Körperbau. Sie besitzen ein ectodermales Schlundrohr und einen zum Theil radiär angeordneten Gastrovascularapparat, eine apicale Nerven-Sinmesplatte, - acht meridionale Reihen von Wimperplätchen, - meist ein Par von Fangfäden, - reich entwickeltes mesenchymartiges Muskel-und Bindegewebe; sie sind Zwitter.

Die Ctenophoren sind gallertartige, zart gefärbte, durchscheinende, mit zwei langen Senk- oder Fangfäden versehene Thiere, welche freischwimmend im Meere leben; ihre gewöhnliche Grösse ist von etwa einem Centimeter bis zu mehreren Decimetern. In ihrer ganzen zarten Erscheinung erinnern sie an die Medusen, welche mit ihnen die pelagische Lebensweise theilen; doch fällt auch schon bei oberflächlicher Beobachtung die eigenthümliche Art ihrer Fortbewegung mittelst riesiger, mit unbewaffnetem Auge wohl wahruehmbarer Flimmerorgane (Flimmerplättchen) auf, welche acht kammförmige meridionale Reihen (Rippen) am Körper der Ctenophoren bilden.

Im einfachsten Falle ist die Gestalt ei- oder birnförmig; der eine Pol wird als oraler oder Mundpol, der entgegengesetzte als aboraler oder auch apicaler oder Sinnespol unterschieden; meist ist der erstere der nach oben gerichtete. Man beobachtet am Körper eine Anzahl radiär angeordneter Organe, z. B. die Plättchenreihen und gewisse dieselben begleitende Gebilde; diese Organe sind in achtfacher Zahl vorhanden; man wird daher acht Radien - aber bei genauerer Berücksichtigung der Anatomie und Entwicklung eigentlich vier gabeltheilige Radien unterscheiden. Wenn man je ein zusammengehöriges Paar von Rippen betrachtet, so kann man die Lage des Paares als radial (4 primäre Radien) bezeichnen, wenn man aber die Lage der einzelnen Rippe berücksichtigt, so kann man sie adradial (8 Adradien) nennen. Die Ebenen, welche zwischen die vier primären Radien fallen, wollen wir als Interradien bezeichnen; da aber gewisse Organe in je zwei einander gegenüberliegenden Interradien, andere Organe in den zwei anderen Interradien sich wiederholen, so sind diese Interradien ver- 
Fig. 291.

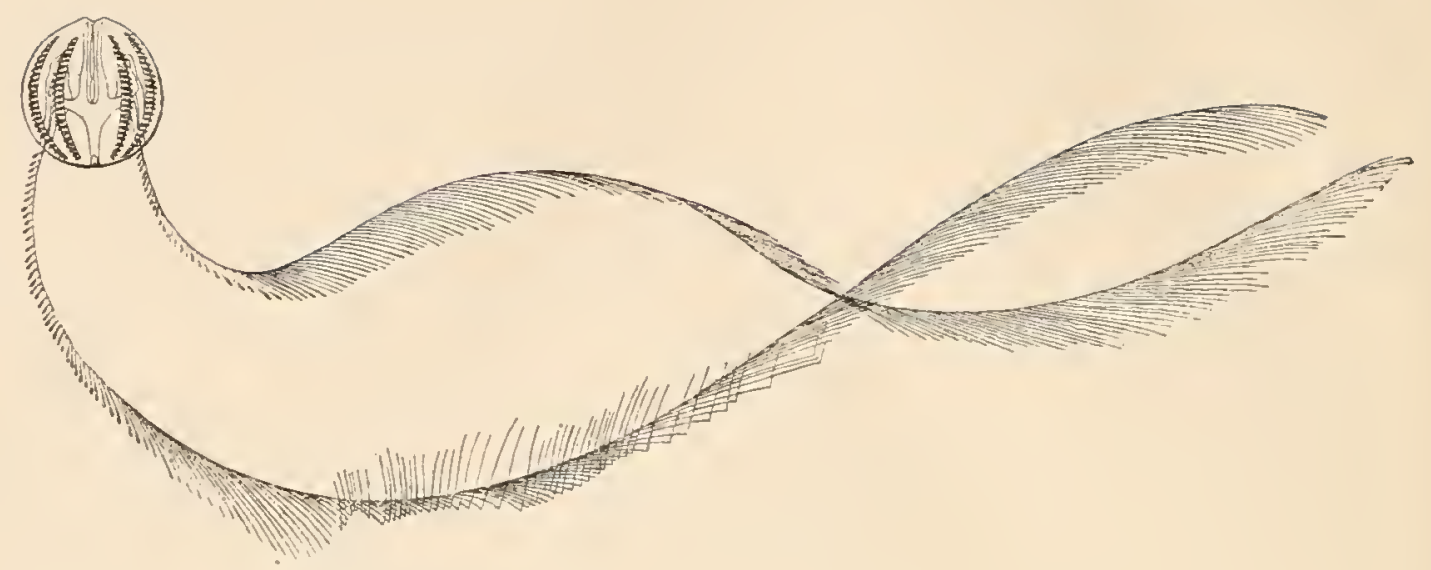

A.

B.
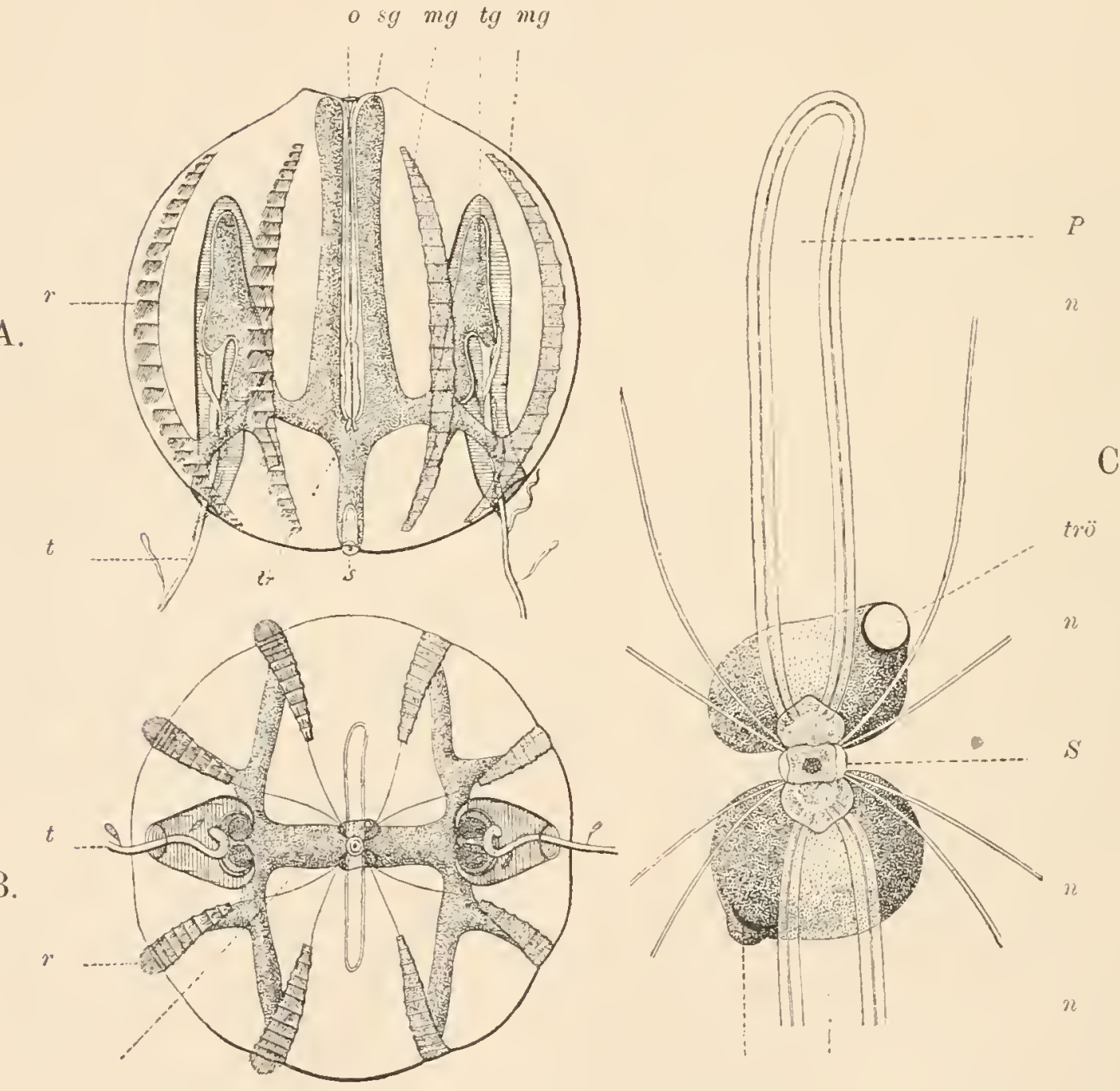

$t r$

Fig. 292. trö $P$

Fig. 291. Pleurobrachia rhododactyla, schwimmend, in natürlicher Grösse (nach AGASSIZ).

Fig. 292. A. Pleurobrachia, von der medialen Seite gesehen. o Mundöffunng, $s$ Scheitelorgan, $r$ Flimmerrippen an der linken Seite der Figur, an der rechten Seite sind sie entfernt, so dass die Meridionalkanäle $(m g)$ sichtbar sind, $t$ Tentakel, $t r$ Trichter, $s g$ Schlundgefäss, $m g$ Meridionalgefäss, $t g$ Tentakelgefäss.

B. Dieselbe, vom Scheitelpol gesehen. Rechts sind die Wimperplättchen entfernt. Bezeichnungen wie oben.

C. Das Scheitelorgan und seine Umgebung. S Scheitelorgan mit dem Otolithenhäufchen und vier Pigmentgruppen; $n n \ldots$ die 8 Flimmerstreifen, $P$ Polfeld. Unterhalb des Scheitelorganes sind die aufgetriebenen Enden der Trichtergefässe zu sehen, die mit trö, den diagonal gestellten Trichteröffnungen ausmünden. (A, B und C nach AgAssiz.) 
schieden zu benennen. Die Interradien, welche der Richtung des spaltförunig verengerten Mundes entsprechen, werden wir als die medialen, dicjenigen, welche in der Richtung der Fangfäden liegen, als die transversalen bezeichnen. Wir unterscheiden also der Lage nach radiale ( 4 fach wiederholte) und adradiale ( 8 fache), ferner mediale ( 2 fache) und transversale (2 fache) Organe. Zusammenfassend bezeichnen wir den Bau als vierstrahlig (oder vierfach gabelstrahlig) mit je zwei ungleich differenzirten Interradien. Wenn wir aber das Verhalten in mehr abstract stereometrischer Weise betrachten, so bezeichmen wir diesen Bau als zweifach symmetrisch (durch zwei Ebenen symmetrisch theilbar); wir können den Körper durch die mediale Ebene in zwei zu einander symmetrische Hälften theilen, jede dieser Hälften ist aber fül sich wieder ein symmetrischer Körper. Wir sehen hier dasselbe Verhältniss, wie weun wir z. B. zwei mit dem Rücken gegeneinandergestellte Menschen betrachten ${ }^{1}$ ).

Das äus sere Epithel des Körpers ist im allgemeinen ziemlich niedrig und ist reich an Pigmentzellen, irisirenden /ellen, sowie an Driisenzellen. An gewissen Theilen erfährt es besondere Differenzirungen, so an den Tentakeln; diese sind sehr lange, einseitig gefiederte Fäden, die in eine seitliche Vertiefung der Körperoberfläche, die Tentakelscheide, ganz zurickgezogen werden können. Die Tentakel verdanken ihre Contractilität den Mesenchymmuskelfäden, welche in ihrer Achse verlaufen; ihr äusseres Fpithel enthält nebst Sinneszellen besonders zahlreiche Klebzellen; der breite klebrige äussere 'Theil der' Zelle setzt sich in einen senkrecht gegen die Basis des Epithels absteigenden Faden fort, der als contractil gilt. - Differenzirungen des äusseren Epithels sind ferner die acht Reihen von W i m per plä t tc he n. Jedes der quergestellten Wimperplättchen entspricht zahlreichen verklebten Geisseln und sitzt je eimer queren Epithelverdickung auf, die aus zahlreichen kleinen Zellen besteht ${ }^{2}$ ). - Die acht Plättchenreihen setzen sich gegen den Apicalpol in acht schmale Flimmerstrassen (oder ,Flimmerrimnen") fort, die zu je zwei sich vereinigen, so dass sie in Vierzahl (radial) das Scheitelorgan erreichen. - Die Sinnesplatte, oder das Scheitelorgan, liegt meist in einer beträchtlichen Vertiefung: sie ist eine vorwiegend aus hohen schmalen Zellen bestehende Ectodermverdickung, die wahrscheinlich das Centralnervensystem repräsentirt, und steht in directem Zusammenhang mit verschiedenen Sinnesorganen. Zunächst ist ein sehr eigenthümliches oberflächliches Gehörorgan zu beachten; von der Sinnesplatte erheben sich nämlich radial vier hackenförmige 'Träger (zusammengesetzte Simneshare), welche gemeinsam ein Häufchen von Otolithen tragen; darüber ist eine dünne, glockenförmige Membran ausgespannt, die auf verklebte Wimperhaare zurückführbar ist, und die an ihrer Basis sechs kleine Oeffnungen besitzt, 4 zum Durchtritt der 4 Flimmerstrassen, die bis an die Otolithenträger

1) Die Medialebene wird aucl als Sagittalebene oder Magen-(Schlund-)Ebene bezeichnet; die Transversalebene heisst auch Trichterebene. Von je zwei zusammengelörigen Rippen können wir die eine admedial, die andere adtransversal nennen; liefür werden aber auch die Ausdrücke subventral und subtentacular gebraucht. - Ferner werden aber von manchen Zoologen Bezeichnungen gebraucht, zu welchen unsere Auffassung in principiellem Gegensatz stelit, indem jene in die mediale und transversale Ebene die Radien crster Ordnungverlegen und die Stellung der Rippenpaare als interradial betrachten. (CHUN).

2) Die ersten embryonalen Wimperplättchen sind das Produkt je einer einzigen Zelle 
sich fortsetzen und 2 gegen die zwei bewimperten Polfelder hin; diese letzteren Gebilde schliessen sich in der medialen Richtung an die Sinnesplatte an und werden als Geruchsorgane gedeutet. Der Sinnesplatte sind ferner mehr oder minder regelmässig vier Pigmenthäufchen eingelagert (Augen?). Epithelial gelagerte periphere Nerven ziehen, wie man vermuthet, längs der Wimperstreifen vom Scheitelorgan zu den Rippen hin.

Die Mundöffnung ist ein in medialer Richtung verlängerter Spalt; von derselben geht ein ectodermaler, überaus kräftig bewimperter Schlund (frühel meist als Magen bezeichnet, daher ,Magen-Ebene" $)$ aus, welcher von den Seiten plattgedrïckt ist, so dass seine grössere Dimension wie die Mundspalte in die mediale Richtung fällt; von der medialen Richtung blickt man also auf die schmale Kante, von der transversalen Richtung auf die breite Fläche des Schlundes; längs der letzteren verlanfen druisige Schlundwiilste. Die verschliessbare Schlundporte führt in den Gastrovascularapparat, und zwar zunächst in den Centralmagen oder , Trichter" ; auch dieser ist plattgedrickt, und zwar so, dass seine grösste Dimension in die transversale Richtung (daher auch ,Trichterebene"6), also kreuzweise zu derjenigen des Schlundes fällt. Der Trichter gibt folgende periphere Gastrocanäle ab: a) vi er radiale Canäle, die sich gabeln und so in b) aclit (adradial gelegene) meridionale Gefässe münden, die längs der Rippen verlaufen ${ }^{1}$ ); c) zw e i S chlundg e fäs se, welche längs der trallsversalen Flächen des Schlundes bis in die Nälıe des Mundes verlaufen; d) ebenfalls in transversaler Richtung $\mathrm{z}$ we i T entakelgefässe, die innelhalb der Basis der Tentakeln enden; e) eine axiale Fortsetzung des Trichters, den Trichtercanal, welcher gegen das Scheitelorgan zieht und sich dicht unterlialb desselben in medialer Richtung in zwei Gefässe (Trichtergefässe) gabelt; dieselben münden dort in der Nähe des Scheitelorganes durch verschliessbare Oeffnungen (Trichteröffnungen) nach aussen; es können dies vier Oeffnungen sein (Callianira), in der Regel sind aber nur zwei diagonal gelegene Oeffinungen vorhanden. Der ganze Gastrovascularapparat ist bewimpert; mittelst eigenthümlicher Wimperrosetten (Excretionsorgane?) öffnet er sich gegen die mesodermale Gallerte.

Die mesodermale Gallerte, welche die Stütze des ganzen Körpers bildet, enthält nebst den Bindegewebszellen überaus zahlreiclıe, verästelte, in allen Richtungen verlaufende $M$ es e $n$ c l y $\mathrm{m} m$ uskelfasern.

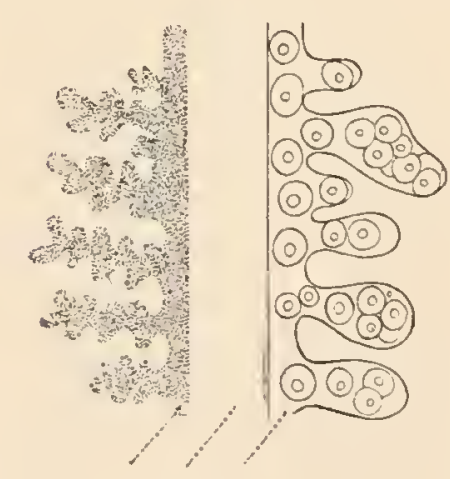

$h m g$ ov An manchen Stellen verlaufen diese Muskelfasern auch längs des Epithels, z. B. längs, der meridionalen Rippen. Von diesen Muskelfasern werden Gestaltveränderungeu des Körpers, seltener bedeutendere Bewegungen desselben (Cestus) und des Schlundes und der Tentakel bewirkt.

Fig. 293. Anordnung der Gonaden von Beroe (nach WiLl). $m g$ Meridionalgefäss, an der einen Seite desselben $h$ die Hoden, an der anderen Seite ov Ovarien.

1) Viele Autoren stellen dies so dar, dass zunächst zwei transversale Canäle vom Trichter ausgehen, die sich in die vier und dann acht radialen Canäle gabeln. Man wird aber besser diese transversalen Canäle als seitliche Theile des Trichters betrachten. 
Das Vorhandensein irgend welcher epithelialer Muskeln ist sehr unwahrscheinlich ${ }^{1}$ ). Zahlreiche feinste Fäden, die in der Gallerte verlaufen, werden als Nervenfasern gedeutet, die zu den Mesenchymmuskeln ziehen (Emer, Hertwig).

Die Ctenophoren sind Zwitter; ihre Gonaden liegen längs der Meridionalgefässe, und zwar so, dass längs der einen Seite Hoden, längs der anderen Ovarien sich finden; die Geschlechtsproducte werden durch den Gastrovascularapparat nach aussen entleert. Nach älteren Autoren sollen die Gonaden Ausstülpungen der endodermalen Meridionalcanäle sein; in neuerer Zeit hat man dagegen die Vermuthung aufgestellt, dass sie vom Ectoderm abstammen (HERTwIG), doch ist dies keineswegs sichergestellt. - Eucharis wird, wie CHuN in seiner schönen Monographie der Ctenophoren gezeigt hat, schon als Larvenform geschlechtsreif, es folgt die Metamorphose und dann eine zweite Geschlechtsreife. Chus nemnt diesen, von ihm neuerdings auch bei Bolina beobachtete Vorgang: Dis sog o n i e.

Die melurfachen Modificationen der Körperform und des Baues sind in der systematischen Uebersicht angeführt.

A.
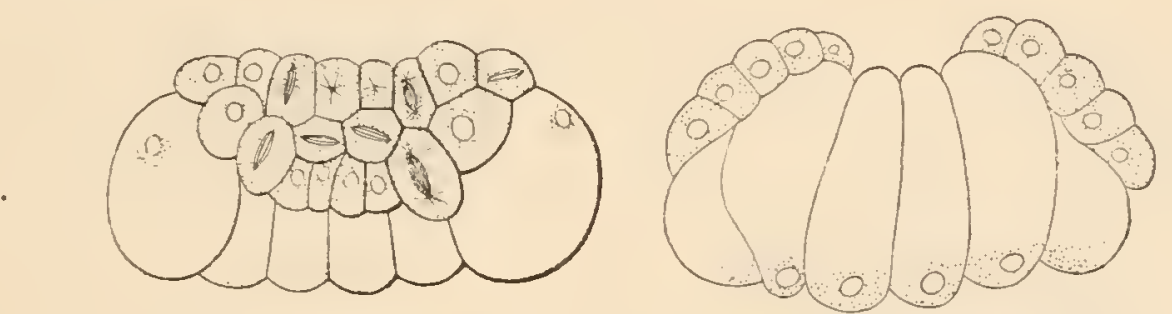

B.
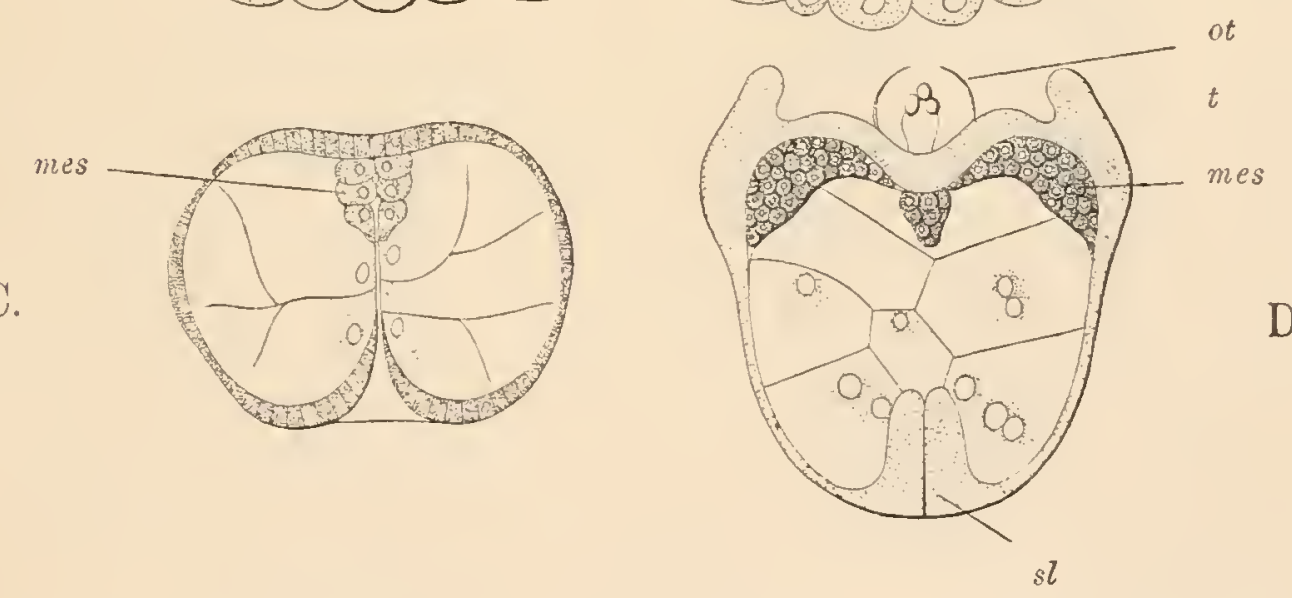

Fig. 294. Drei Stadien aus der Entwicklung einer Ctenophore (Callianira) nach Metschnikoff,

A. Vorgeschrittenes Furchungsstadium von der Seite gesehen, mit kleinen, plasmareichen Ectodermzellen (mehrfach Theilungsfiguren in denselben), und grossen, hellen, dotterreichen Endodermzellen.

B. Dasselbe Stadium im Durchschnitte gesehen.

C. Späteres Stadium im Durchschnitte gesehen; Bildung des Mresoderms (mes) am blinden Ende des Endodermsackes und Entstehung des ectodermalen Schlundes.

D. Späteres Stadium im Durchschnitte gesehen, nur das Mesoderm (mes) ist körperlich dargestellt, ot Gehörorgan, $t$ Tentakel, sl Schlund. Die acht Gruppen von Flimmerplättchen sind nicht gezeichnet.

Bei den Ctenophoren kommt ausschliesslich die geschlechtliche Fortpflanzung vor. Da beim Verlassen der Eihülle die jungen Thiere schon

1) Es bestehen noch viele gegentheilige Angaben, die aber erst des entwicklungsgeschichtlichen Beweises bedürfen; wir wollen an dieser Stelle erinnern, wie lange Zeit auch das Vorhandensein von Nesselkapseln angenommen wurde, bevor CHUN die Irrigkeit dieser Annahme nachwies. 
die Hauptzüge der Ctenophorenorganisation ausgeprägt zeigen, so kann die Entwicklung als eine directe im weiteren Sinne bezeichnet werden. - Das Ei ist klein, enthält aber demnoch nur eine dünne periphere Schichte von feinkörnigem Bildungsplasma, welches eine central gelagerte Masse von Nahrungsdotter einhüllt, der hier die Beschaffenheit einer durchsichtigen, eiweissähnlichen Substanz hat. Die Furchung ist inäqual; nach der regelmässigen meridionalen Viertheilung werden gegen den animalen Pol hin successive eine Anzahl kleiner, plasmareicher Zellen abgeschnürt, während die Zellen an vegetativen Pole gross und dotterreich sind. Die ersteren bilden als Ectoderm eine flache Scheibe von Zellen, die aber anfangs eine beträchtliche centrale Lüicke besitzt, und liegen unmittelbar den grossen unteren Endodermzellen an. Dur'ch einen Vorgang, welcher zwischen Epibolie und Embolie die Mitte hält, wird die Gastrula gebildet. Am blinden Ende des Endodermsackes wird eine Zellplatte ausgeschaltet,

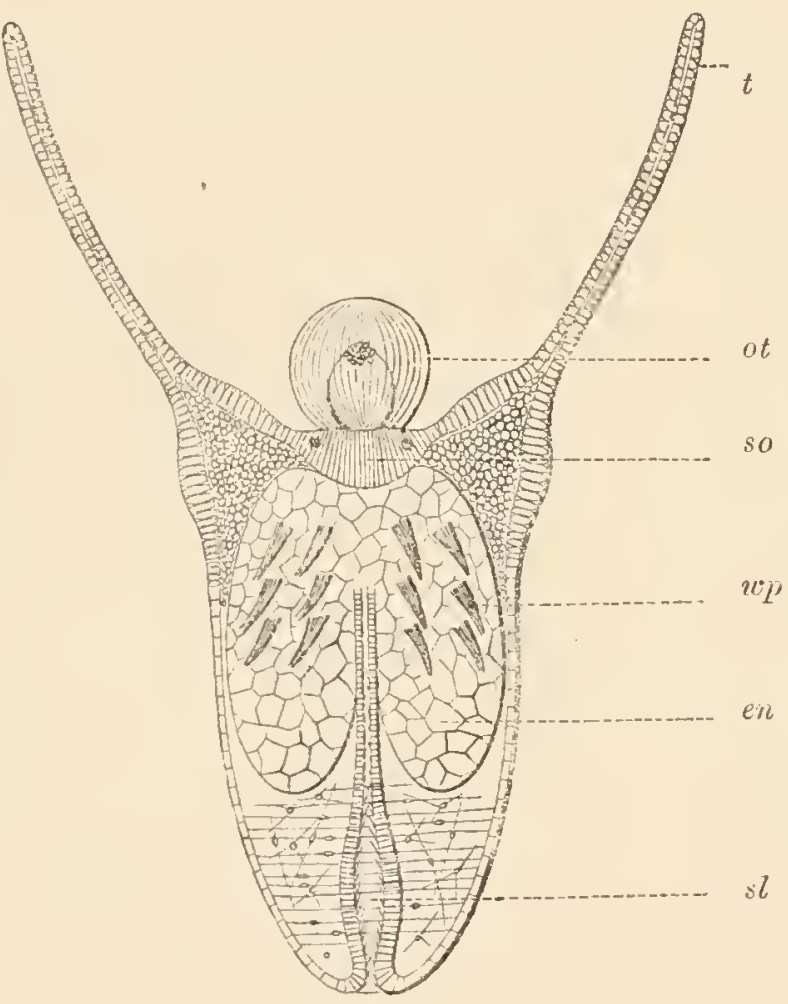
welche die einheitliche Allage des Mesoderms repräsentirt (MET'schNIKOFF). Dann bildet sich der Schlund durch Einstuilpung eines Ectodermrohres am vegetativen Pole, so dass das Protostoma als Schlundpforte in die'Tiefe verlegt wird. Der Darm bildet zunächst vier Aussackungen in der Richtung der vier primären Radien. An der Oberfläche entstehen acht Gruppen von Flimmerplättchen, am A picalpol das Scheitelorgan mit dem charakteristischen Gehörapparate, und in anfangs oberflächlicher Lage und dem Apicalpol auffallend nahe die Tentakeln (ausser bei den Beroiden).

Fig. 295. Larve einer Ctenophore (Cestus) nach KowALEvsky, etwas schematisirt. $t$ Tentakel, ot Gehörorgan, so Scheitelorgan, $u p$ die Reihen von Wimperplättchen, en die vier Endodermsäcke, sl Schlund.

Wenn wir die Gestaltung der jungen Ctenophorenlarve betrachten, so können wir nebst der auffallenden Lage der Tentakeln die geringe Ausdehnung der Flimmerrippen hervorheben; sie sind anfaugs oft nur aus je 1, 2 bis 4 Plättchen zusammengesetzt. Wir können den Körper der Larve in ein Scheitelfeld, eine äquatoriale Flimmerzone und ein Gegenfeld eintheilen. Es erfolgt erst später ein überwiegendes Wachsthum der äquatorialen Zone, und zwar wahrscheinlich stets nur durch Zuwachsen von Plättchen etc. nach der Seite des Gegenfeldes. - Bei der interessanten, von CHon genauer beschriebenen Charistephane ist dauernd jede Rippe nur von zwei Plättchen zusammengesetzt, und diese sind so breit, dass die seitlich benachbarten Plättchen zusammenstossen, so dass hier thatsächlich die acht Gruppen von Wimperplättchen eine ringförmige Wimperzone bilden. 
Systematische Uebersicht der Ctenophoren.

\section{A. Tentaculata mit Fangfäden.}

Cydippidae. Körper, nur wenig von der einfach sphärischen Form abweichend. Gastrocanäle blind endigend. Cydippe (= Hormiphora), Pleurobrachira, Callianira.

Lob a tae. Körper transversal abgeplattet, mit zwei eigenthümlichen medialen Mundlappen. Gastrocanäle anastomisirend; mit Cydippen-ähnlichen Jugendstadien.

Eucharis von bedeutender Grösse, aber äusserst zart.

Cestidae. Körper transversal abgeplattet, medial stark verlängert. Gastrocanäle anastomisirend; mit Cydippen-ähnlichen Jugendstadien.

Ceslus veneris, Venusgürtel, wird über meterlang.

Co elopla na und Cle "oplana sind in der Richtung der Hauptachse abgeplattete Formen, welche mittelst der oralen Körperfläche kriechen; sie sind ganz bewimpert und mit Tentakeln versehen.

B. Nuda ohne Tentakel.

Beroidae. Körper ohne Tentakel, in der Hauptachse verlängert, transversal etwas comprimirt. Nit sehr weitem Mund und Schlunde, ohne Schlundwülste; mit allseitig anastomisirenden Gefässverästelungen.

\section{Vergleichende Betrachtung der Protaxonia.}

Die drei Abtheilungen der Spongiaria, Cnidaria und Ctenophora werden meist als Coelenterata zusammengefasst; es wird dabei eine Reihe von Homologieen vorausgesetzt, welche durch neuere Untersuchungen aber zum Theil als irrig, zum Theil als unwahrscheinlich erwiesen wurden. Wir können $z w$ ischen diesen drei Stämmen keineanderen Homologieen mit einiger Sicherheit aufstellen, als diejenigen, welche aus der gemeinsamen Ableitung von der "Gastraea" resultiren, und die demnach allen Metazoen ge meinsam sind.

Wenn wir zunächst den Schichtenbau in Betracht ziehen, so erscheint das Mesoderm der Spongien im Vergleich zu demjenigen der anderen beiden Gruppen als eine ganz besondere Bildung, da aus demselben nicht nur Bindegewebszellen, solldern auch die Geschlechtsprodukte entstehen; den Hydrozoen fehlt ein Mesoderm, den Scyphozoen kommt ein bindegewebiges Mesoderm zu, dessen Herkunft noch nicht genügend erforscht ist; das Mesoderm der Ctenophoren zeigt diesem gegenüber einen ganz besonderen Charakter, da es aus einer localisirten Anlage entsteht (METSCHNIKofF) und vorwiegend Muskelgewebe erzeugt. Dagegen kommt bei den Cnidariern Epithelmuskelbildung vor und fehlt wieder den Ctenophoren.

In Bezug auf den Grundplan des Körpers stehen die Spongien ganz vereinzelt da; sie sitzen mit dem Protostompol fest und haben nebst zahlreichen Einströmungsöffnungen am Apicalpol eine Auswurfsöffnung, das Osculum, erhalten ${ }^{1}$ ). Der Cnidariertypus findet seinen schärfsten Ausdruck

1) Einige maassgebende Forscher nehmen sogar an, dass die Spongien ganz unabhängig von ccrmenbildenden Choanoflagellaten, die anderen Metazoen von cormenbildenden Nudoflagellaten abzuleiten seien. 
in der Zurückführnng auf eine polypoide Grundform, die am Apicalpole festsitzt. Alle höheren Differenzirungen bilden sich in Folge dessen in der Umgebung des Protostompoles, der das freie Ende oder die Nundacheibe des Thieres repräsentirt. Auch die Hledusen zeigen in ihrer Organisation den Stempel dieser Abstammung; alle bedeutenderen Differenzirungen sind an der Subumbrellarseite und am Scheibenrande zu finden. Wenn wir nun im auffallenden Gegensatze hierzu bei den Ctenophoren die meisten höheren Differenzirungen an der Seite des Apicalpoles sich ausbilden sehen, so werden wir mit Recht die Ableitung derselben von einer polypoiden festsitzenden Stammform in Zweifel ziehen, da ja auch jede Andeutung derselben in der Ontogenie fehlt. Die höhere Differenzirung des Apicalpoles liegt schon in der ursprünglichen Entwicklungsrichtung der Gastraea und ist bei den Cnidariern durch die Festsetzung unterdriickt, dagegen bei den Ctenophoren weiter ausgebildet ${ }^{1}$ ).

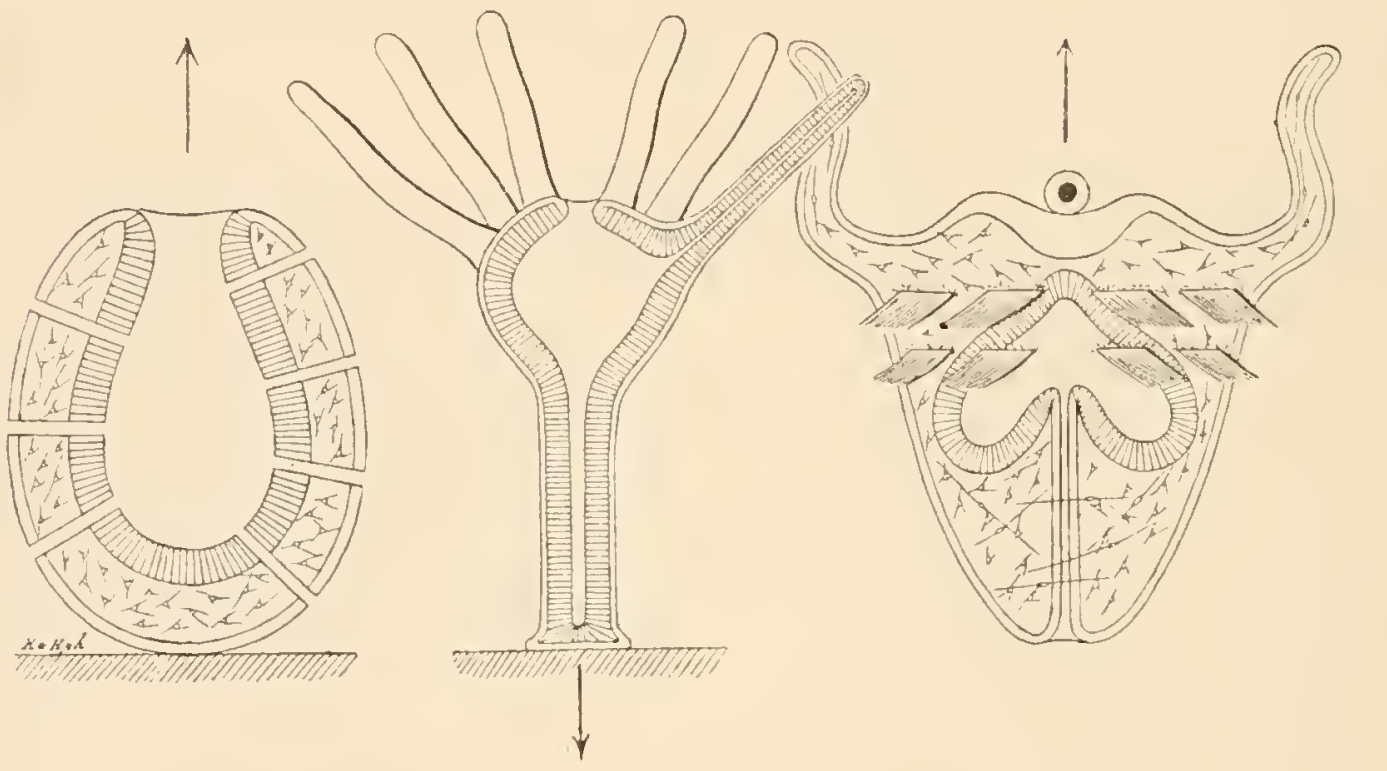

A.

B.

C.

Fig. 296. Schema der drei Grundformen der Protaxonia. A. Grundform der Spongien, B. Grundform der Cnidarier, C. Grundform der Ctenophoren. Die Pfeile bezeichnen die Richtung des Scheitelpoles.

1) Zu ähnlichen Schlüssen ist in jüngster Zeit A. LANG gekommen (Lehrb. d. vergl. Anat, pag. 72), während früher manche Forscher eine Verwandtschaft mit den Hydromedusen, andere Forscher Beziehungen zu den Actinozoen annahmen. - Man wird hier auch an die radiäre Architektonik der Ctenophoren erinnern müssen. Seit den Ausführungen von BERGMANy und LECCKART weiss man, dass die festsitzende Lebensweise radiären Körperbau veranlasst; damit ist aber nicht gesagt, dass ein solcher nicht auch aus anderen Bedingungen resultiren könne. Flottirende Seethiere (Schwebethiere) und langsam bewegliche Grundthiere neigen ebenfalls zum radiären Bau (LANG). 

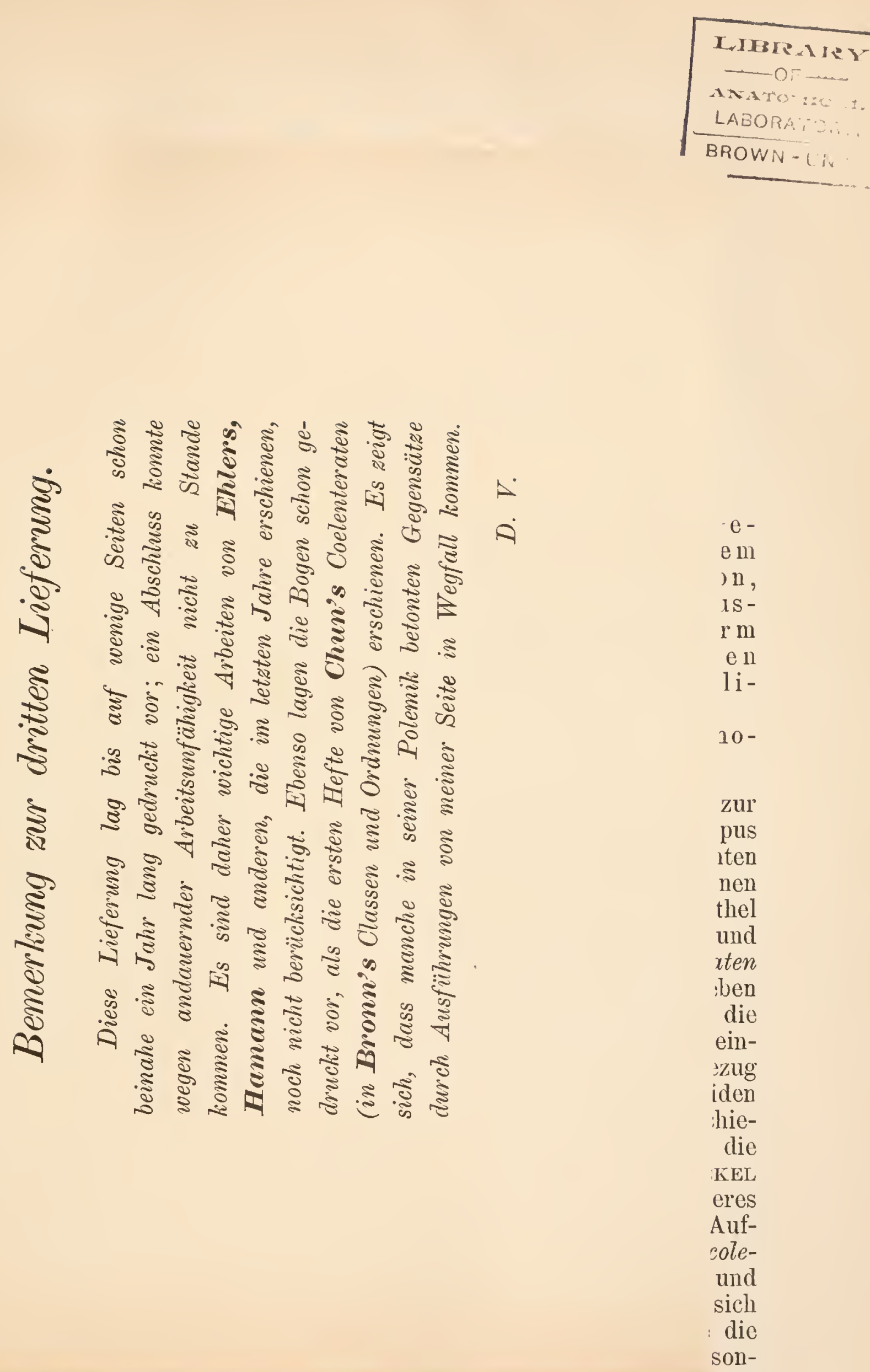

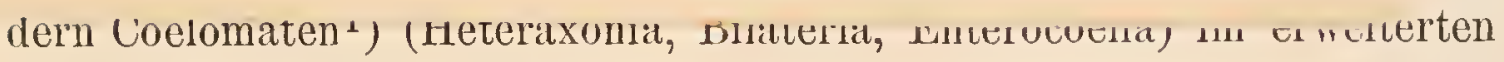

1) Bei den Scoleciden haben die coelomatischen Höhlen (Gonococl, Nephrocoel) noch nicht die Bedeutung einer Leibeshöhle; als solche fungirt hier noch das Blastocoel; Blutgefässe fehlen Wir werden dieselbcn daher passend als Procoelomaten den Euc o e lo mate $\mathrm{n}$ gegenüberstellen.

Hatschek, Lehrbuch der Zoologie. 
in der Zurückführnng auf eine polypoide Grundform, die am Apicalpole festsitzt. Alle höheren Diffarannimnman hild_. - . $m$

Um

des

den

an

im

Diff

wir

Stal

Ont

der

dari

weit

die Ric

Anat., meduse: an die von $B$ Körper anderes bewegl: 


\section{VIERZEINTES CAPITEI.}

\section{Phylum (4.-\%. Cladus) der Metazoen.}

\section{Zygoneura.}

Die Zygoneuren sind Metazoen von bilateraler Gestalt, mit ventraler Protostomregion und ventralem Schlunde; mit apical entstehendem Cerebralganglion, von welchem wenigstens ein Paar von Längsnerven ausgeht. Das (bilaterale) Mesoderm, welches rom Urdarm sich sondert, bildet Muskeln (nesenchymatöse bei den Scoleciden und nebstdem coelomatöse bei den Cephalidiern), Nephridien und Gonaden.

Die Zygoneuren sind auf die Grundform der Trochophora oder der Protrochula zurückzuführen.

Es kommt in jüngster Zeit die Anschauung immer mehr zur Geltung, dass die Coelenteraten keineswegs einem einzelnen Typus der Metazoen entsprechen, dass sie aber wohl immerhalb der gesanmimten Metazoen als die eine grosse Unterabtheilung betrachtet werden können - welche nämlich jene Thiere enthält, die mit einem einzigen von Epithel umgebenen Hohlraumsystem, dem Urdarmsystem, versehen sind - und dass denselben als andere grosse Unterabtheilung die Coelomaten gegenübergestellt werden können, jene Thiere nämlich, welche neben dem Darmkanal noch mehrere andere Hohlraumsysteme besitzen, die wir als coelomatische Bildungen bezeichnen werden, und die wahrscheinlich als Sonderungen des Urdarmsystems zu betrachten sind. In Bezug auf die Zugehörigkeit der einzelnen Stämme oder Typen zu diesen beiden grossen Abtheilungen der Metazoen herrschen aber noch sehr rerschiedene Meinungen. Die Brüder Hertwig wollten ehemals sogar die Mollusken nicht als Coelomaten betrachten und neuerdings hat HAECKEL noch die Platoden, welche er nach dem Vorgange LAxci's als besonderes Phylum betrachtet, zu den Coelenteraten gezogen. Nach unserer Auffassung besitzen aber auch die Platoden und auch die anderen Scoleciden gesonderte, von mesodermalem Epithel ausgekleidete Säcke und Röhren, welche phylogenetisch wahrscheinlich vom Urdarmsystem sich ableiten lassen, nämlich die Gonadengänge mit den Gonaden, sowie die Nephridialröhren; sie sind daher nicht Coelenteraten (Protaxonia), sondern Coelomaten $^{1}$ ) (Heteraxonia, Bilateria, Enterocoelia) im erweiterten

1) Bei den Scoleciden haben die coelomatischen Höhlen (Gonocoel, Nephrocoel) noch nicht die Bedeutung einer Leibeshöhle; als solche fungirt hier noch das Blastocoel; Blutgefässe fehlen. Wir werden dieselben daher passend als Procoelomateu den Euco el om a t e n gegenüberstellen.

Hatschek, Lehrbuch der Zoologie. 
Sinne des Wortes. Innerhalb der ganzen Abtheilung der Coelomaten unterscheiden wir wieder die drei grossen als Phylen bezeichneten Gruppen der Zygoneura, Ambulacralia und Chordonia.

Als Zygoneura fassen wir eine grosse Anzahl von Formtypen zusammen, deren nähere Verwandtschaft zu einander bei dem gegenwärtigen Stande unserer Wissenscliaft als erwiescn betrachtet I'rden kann. Es sind dies 1) die Scoleciden (d. i. Vermes mit Ausschluss der Anneliden), 2) die Articulaten (d. i. Anneliden, Onychophoren und Arthropoden), 3) die Tentaculaten (ungefähr den Molluscoideen der Autoren entsprechend) und 4) die Mollusken. Wir kömnen nicht nur die äussere Körperform dieser Thiergruppen in ihren wichtigsten Beziehungen (vorn und hinten, Bauch und Rücken) in Vergleich ziehen, sondern wir können auch die Homologie einer grossen Anzahl von Organen durch alle diese Gruppen hindurch nachweisen; dies betrifft z. B. wichtige Theile des Nervensystems, die Abtheilungen des Darmes, die Nephridien etc. etc. Ferner zeigt die Entwicklungsgeschichte eine grosse Anzahl übereinstimmender Eigenthünlichkeiten. Wir erkennen am besten die Summe der Homologien, wenn wir die gemeinsame Larvenform aller dieser Thiergruppen in Betracht ziehen.

Die gemeinsame Larvenform der Zygoneuren bezeichnen wir als T rochophora und wir vermuthen, dass sie der Stammform der Zygoneuren nahe stehe.

Die erste Anbahnung der Trochophora-Theorie rerdanken wir Hoxuex (1852), welcher die Rolatorien mit Anneliden-Larven, aber namentlich auch mit den Echinodermen-Larven verglich. Später wurde besonders von GEGENBaUr auf die Verwandtschaft der Larvenformen von Mollusken, Anneliden etc. (immer die Echinodermen-Larven mit einbegriffen) hingewiesen (1874). Bütschlt vergleicht (1876) die rou SEMPER (1872) beschriebene Trochosphaera aequatorialis mit den Anneliden-Larven und betrachtet die Rotatorien als nahe verwandt der Stammform der Anneliden und Mollusken. Weiter haben Ray-Lankester und besonders Semper viele anregende Ideen hinzugefügt, obwohl der Begriff der ,Trochosphaera"-Larve dort noch wenig präcis gefasst ist. Einen weiteren Ausbau der Theorie hatte ich in mehreren Schriften (1878-1885) versucht, welcher in der vorliegenden Darstellung noch weitergeführt wird.

\section{Trochophora (Trochosphaera).}

Die Trochophora ist die charakteristische Larvenform der Zygoneuren. Die Rotatorien stehen in ihrem Baue zeitlebens der Trochophora sehr nahe; auch die Turbellarien, welche nur das Stadium der Protrochula erreichen, bleiben dieser letzteren Form zeitlebens sehr nahe verwandt. Die Trochophora findet sich ferner als wohl ausgeprägtes Entwicklungsstadium bei den Vertretern aus den verschiedensten Gruppen der '/ygoneura, so z. B. bei Anneliden, den Tentaculaten und Mollusken. In vielen Fällen sind die Charaktere dieser Larvenform mehr oder weniger modificirt oder auch ganz unterdrïckt, dies ist besonder's bei abgekürzter Entwicklung der Fall. Der ursprüngliche Typus der Trochophora lässt sich durch Vergleichung feststellen; diejenigen Eigenthümlichkeiten, welche sich an der Trochophora sehr verschiedener Thiergruppen wiederholen, sind als typische zu betrachten. Eine ganz vollständige Vereinigung aller typischen Eigenschaften bei e in er 
Larvenform ist vielleicht nirgends erhalten, doch kommen manche Annelidenlarven dieser Vollkommenheit sehr nahe.

a) Ursprüngliche Charaktere der Trochophora (Fig. 297).

Die Trochophora ist von bilateral symmetrischer Form. Wir unterscheiden daher an derselben ein Vorder- und Hinterende, eine Bauchund Rückenseite. An der Bauchseite findet sich die Mundöffnung, nahe vom Hinterende etwas dorsal die Afteröffnung. Die Gestalt ist im Allgemeinen verkürrt eiförmig.

Die Vertheilung der Wimpern an der Körperoberfläche ist von charakteristischer Bedeutung. Am vorderen Körperende (Scheitelpol) findet sich ein Schopf von kräftigen Wimperhaaren (a picaler Wimperschopf). Ein mittlerer Wimperkranz (äquatorialer oder präoraler Wimperkranz oder Trochus) theilt die Körperoberfläche in eine vordere Hälfte (Scheitelfeld) und eine hintere Hälfte (G e g e nfeld). Derselbe liegt dicht vor dem Munde und besteht aus zwei Reihen von Wimperm, die von zwei Reihen verdickter Epithelzellen getragen werden. Hinter dem Munde liegt parallel ein éinreihiger, schwächerer Wimperkranz (postoraler Wimperkranz oder Cin$\mathrm{gulum}$ ). Zwischen diesen beiden findet sich eine Zone von zarten Wimpern, deren Bewegung nach dem Munde gerichtet ist (adorale Wimperzone); vom Munde bis an das Hinterende (den Gegenpol) erstreckt sich eine Wimperfurche oder Wimperstreif, dessen Wimperbewegung nach hinten gerichtet ist (Bauchfurche oder ventraler Wimperstreif). Ein häufig vorkommender hinterer Wimperkranz (präanaler Wimperkranz) ist eine verhältnissmässig jüngere Bildung. - Der präorale Wimperkranz dient besonders zur Fortbewegung, der postorale Wimperkranz und die adorale Wimperzone zur Nahrungsaufuahme; der präanale Wimperkranz unterstützt ebenfalls die Fortbewegung. Der apicale Wimperschopf scheint, in vielen Fällen wenigstens, ein Steuerapparat zu sein, der die Bewegungsrichtung beeinflusst; doch wurde er auch als apicales Simnesorgan gedeutet. - An der übrigen Körperoberfläche, besonders am Scheitelfeld, sind nur zartere Wimpern vorhanden, welche gegen die oben beschriebenen Wimperapparate ganz in den Hintergrund treten.

Der Köörper der Trochophora besteht aus dem Ectoderm, welches das äussere Epithel des Körper's bildet, aber auch das Epithel des Schlundes und des Afterdarnes liefert; es repräsentirt die Leibeswand, welche eine geräumige primäre Leibeshöhle oder Blastocoel einschliesst, in welcher die Gebilde der beiden anderen Keimblätter liegen; und zwar ist es das Endoderm, aus welchem das Mitteldarmepithel hervorgeht, während von Mesodermgebilden sowohl epitheliale oder coelomatische 'Theile, die besondere Höhlungen einschliessen, als auch mesenchymatöse Theile zu unterscheiden sind.

Das äussere Epithel des Körpers sondert eine deutliche Cuticula ab; es besteht aus Stützzellen, Wimperzellen und Drüsenzellen und enthält endlich als wichtige Differenzirungen das Nervensystem und die Sinnesorgane, welche beide bei der Trochophora noch eine epitheliale Lagerung besitzen.

Wir finden am apicalen Pole eine epitheliale Nervensinnesplatte, welche wir als Scheitelplatte bezeichnen; sie besteht aus einem Ganglion (Scheitelganglion oder primäres Cerebralgan- 

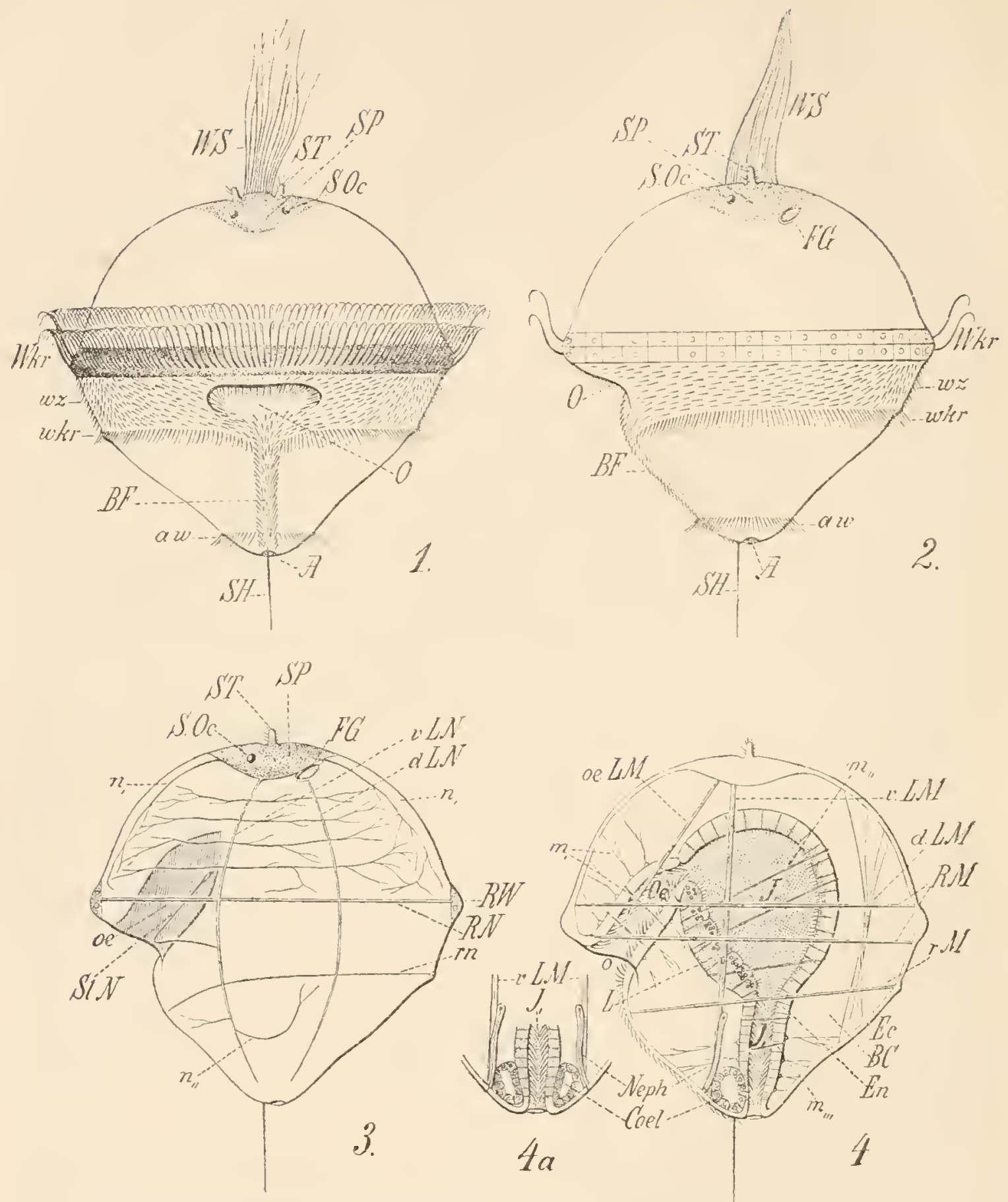

Fig 297. Schematische Darstellung des Baues der Trochophora.

1. Aeussere Form, ventrale Ansicht. $W k r$ präoralel Wimperkranz, $u k r$ postoraler Wimperkranz, wz adorale Wimperzone, WS apicaler Wimperschopf, aw präanaler Wimperkranz, $B F$ Bauchfurche, $O$ Mund, $A$ After, $S P$ Scheitelplatte, $S T$ Primärtentakel, $S O c$ Scheitelaugen, $S H$ hinteres Sinneshaar.

2. Aeussere Form, seitliche Ansicht. Bezeichnungen wie in 1. FG Cerebrale Flimmergrube.

3. Seitliche Ansicht, mit Darstellung des epithelialen Nervensystems. $S P, S T, S O c$, $F G$ wie in 1 und $2 ; v L N$ und $d L N$ ventraler und dorsaler Längsnerv, $n$, und $n_{\text {" Nerven }}$ des Scheitelfeldes und Gegenfeldes, $R n$ und $r n$ präoraler und postoraler Ringncrv, $S l N$ Schlundnerv, $R W$ Ringwulst des präoralen Wimperkranzes.

4. Seitliche Ansicht mit Darmkanal und mcsodermalen Organen. O Mund, Oe Schlund (Stomodaeum), $J$ Magen mit $L$ Leber (Mitteldarmdrüse), $J$, Darm, daran schliesst sich der Afterdarm (Proctodaeum), $v L M$ und $d L M$ ventraler und dorsaler Längsmuskel, $R M$ und $r M$ Ringmuskel des präoralen und des postoralen Wimperkranzes, $m_{\prime}$, $m_{\prime \prime}$ und $m_{\prime \prime \prime}$ Muskelu des Schlundes, des Magens und des Darmes, Neph Nephridien, Coel Coelomsäcke, Ec Ectoderm, BC Blastocoel, En Endoderm.

4a. Coelomsäcke und Nephridien, von der Bauchseite gesehen, Bezeichnungen wie in 4 
glio 11) und damit verbundenen Sinnesorganen. Die Scheitelplatte erscheint als eine Ectodermverdickung; die obersten Zellen derselben, die Deckzellen, tragen den apicalen Wimperschopf, unter diesen findet sich eine Schichte von Ganglienzellen und in der 'Tiefe die Nervenfasermasse. Die Sinnesorgane der Scheitelplatte sind: 1) ein (oder zwei) Paar von Augen (primäre A ugen oder Scheitelaugen), welche wahrscheinlich den Bau von Napfaugen besitzen; 2) zwischen diesen stehen ein Paar tentakelälnliche Tastlöcker, die mit Sinnesharen versehen sind (Primärtentakel oder Apicaltentakel); 3) es findet sich zu beiden Seiten der Scheitclplatte, oder etwas dorsalwärts, je eine Flimmergrube, die als Geruchsorgan fungirt. Vielleicht ist ursprünglich auch ein unpaares Gehörbläischen am Scheitelpole vorhanden gewesen, welches aber nur bei manchen Turbe,llarien sich erhalten liat (a picales Hörbläschen).

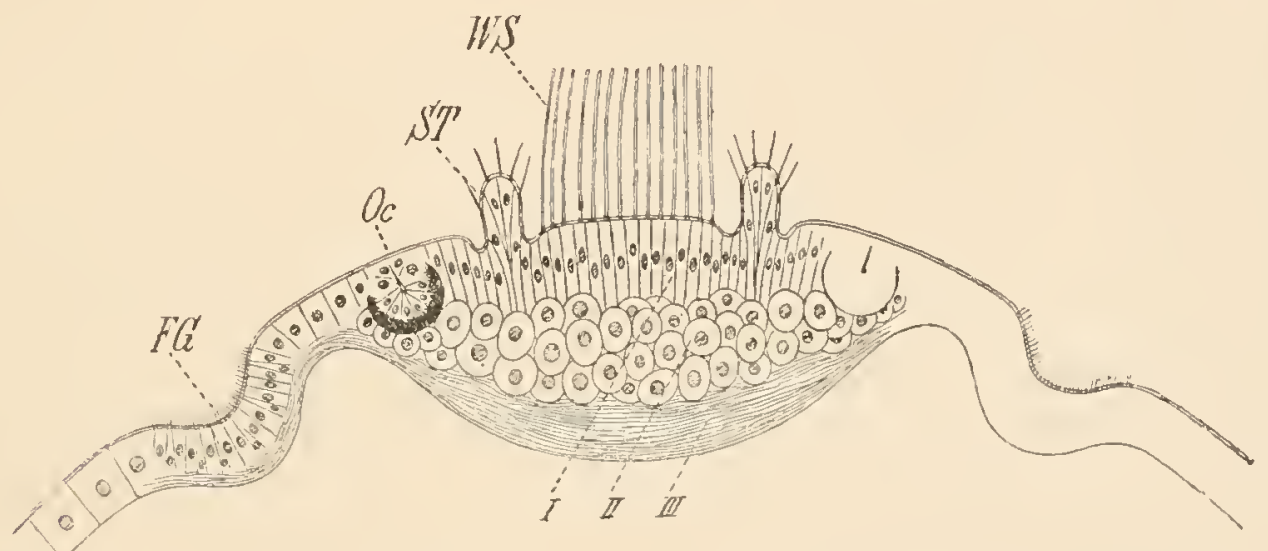

Fig. 298. Frontaler Durchschnitt der Scheitelplatte, schematisch. I Deckschicht und Sinneszellenschicht, II Ganglienschicht, III Nervensehicht, WS Wimperschopf, ST Primärtentakel, $O c$ Scheitelauge, $F G$ Flimmergrube.

Es kommen auch an anderen Körperstellen einzelne Sinneszellen und Sinnesorgane vor, namentlich ist das Scheitelfeld reich daran und zwar besonder's in der Nähe des präoralen Wimperkranzes; aucl kommen Nebenaugen des Scheitelfeldes vor, die man vielleicht zu den typischen Gebilden zählen kann, und Sinnesorgane (besonders Augen) längs des äquatorialen Wimperkranzes. Auch am Gegenfelde finden wir Sinnesorgane, wahrscheinlich ist ein ventrales und ein dorsales Paar von Sinnesorganen (Taster) am Ende der betreffenden Längsnerven als typisch zu betrachten, auch findet sich ein starres Sinneshärchen am Gegenpole ventral vom After.

Von dem Cerebralganglion geht eine Anzahl von Nerven aus, die ebenfalls epithelial in der Körperwand verlaufen. Nebst mehreren paarigen Nerven des Scheitelfeldes finden wir paarige Längsnerven, welche gegen das Hinterende des Körpers verlaufen ${ }^{1}$ ). Der Hauptnerv verläuft nahezu seitlich, doch etwas melı ventral, am Munde vorbei gegen das Hinterende des Körpers (ventrales Längsnerven pa a r), wahrscheinlich ist auch ein dorsales Längsnervenpa a r als

1) Wahrscheinlich zeigten die von der Scheitelplatte ausgehenden Nerven ursprünglich eine radiäre Anordnung. 
typisch für die Trochophora zu betrachten. Der paarige ventrale Längsnerv gibt am Scheitelfelde Aeste ab, verbindet sich auch mit dem präoralen und postoralen Ringnerven und sendet auch am Gegenfeld periphere Aeste aus; typischer Weise zweigt sich von demselben ein pariger Schlundnerv ab, der am Mundrande in das Epithel des Schlundes einbiegt und in letzterem zu je einem Buccalganglion anschwillt. Die hier genannten Nerven sind wohl an verschiedenen Stellen vou einzelnen Ganglienzellen begleitet - besonders ist der präorale Ringnerv, wie Kleinenberg, der denselben entdeckte, gezeigt hat, von zahlreichen Ganglienzellen begleitet. Das Nervensystem der Trochophora ist aber doch in hohem Grade centralisirt, da das Scheitelganglion weitaus die Hauptmasse der Ganglienzellen des Nervenapparates enthält.

Der Darmkanal der Trochophora hat einen hufeisenförmigen Verlauf und besteht aus Schlund, Mitteldarm und Afterdarm. Der Schlund, welcher von ectodermalem Epithel ausgekleidet wird, geht von der Mundöffnung aus schief nach innen und vorn; er ist am vorderen Mundrande scharf abgesetzt, am hinteren Mundrande aber geht er allmählich in die Bauchfurche ïber. Der Schlund ist kräftig bewimpert; die Muskeln des Schlundes sowie auch der anderen Darmabtheilungen werden wir später betrachten. Ein ventraler, mit paarigen Chitinkieferm versehener Schlundanhang ist eine wahrscheinlich schon der Trochophora eigenthümliche Bildung ${ }^{1}$ ). Der Mitteldarm ist vom Endoderm ausgekleidet; er hat eine retortenartige Gestalt und zerfällt in zwei Abschnitte, den weiten, zart bewimperten Magendarm, dessen ventraler Bezirk von besonderer drüsiger Beschaffenheit ist („L e be r" oder Mitteldarmdrüse) und in den schlauchförmigen, kräftiger bewimperten Dünndarm, der gegen das Hinterende des Körpers gerichtet ist. Die Structur des Mitteldarmepithels erimnert an die vacuolenreichen Endodermzellen der Cnidarier. Ein kurzer, vom Ectoderm gebildeter Afterdarm führt zur Afteröffnung. Zwischen Leibeswand und Darm finden wir die Mesodermgebilde. Dieselben sind theils mesenchymatöse Gebilde, welche in der geräumigen primären Leibeshöhle (Blastocoel) gelegen sind, theils sind es epitheliale, coelomatische Gebilde, welche für sich besondere Höhlen einschliessen.

Als Mesenchymgebilde finden wir erstens B indegewebs zelle n von verästelter Form (,freie Bindegewebszellen"), die meist vereinzelt auftreten, seltener sich häufen [in letzterem Falle können sie sogar membranartige Bildungen liefern, Echiurus-Larve, Phoronis-Larve], und zweitens Muskeln, die einzellig und dabei einfach fadenförmig oder auch verästelt sind. Wir finden erstens Muskelfasern, welche mit ihren Enden an die Leibeswand angeheftet sind und die primäre Leibeshöhle frei durchziehen; von diesen sind typisch vor allem der Hauptmuskel des Körpers, nämlich das kräftige ventrale Längsmuskelpaar, welches von der Scheitelplatte einfach oder in zwei Stiucken gegen das Hinterende des Körpers zieht, dann ein dorsales Längsmuskelpaar, welches vom Scheitelfeld zum Gegenfeld zieht, und ferner ein von der Scheitelplatte zunı Schlunde ziehendes Muskelpaar; wir finden zweitens Ringmuskeln, die der Leibeswand anliegen, zu diesen gehören Muskeln, die längs des präoralen Wimperkranzes verlaufen (p r ä or a ler Ring m ukel) und ein solcher, der den postoralen Wimperkranz be-

1) Hiervon wären abzuleiten die Kieferu der Rotatorien, der Schlundanhang der ArchiAnneliden, die Radula der Mollusken etc. 
gleitet (postoraler Ringmuskel). Von Muskeln des Darmes endlich finden wir am Schlunde zahlreiche kleine Dilatatoren, die von demselben zur Leibeswand ziehen, und circulär um den Schlund verlaufende Constrictoren; ferner am Magendarm und Dünndarm spärliche, meist circulär verlaufende Muskelfasern und endlich Dilatatoren des Dünndarmes und Afterdarmes.

'Zu den epithelialen Mesodermgebilden gehört das p a a ri ge Protonephridium; dies ist je eine längsverlaufende Röhre, welche an den hinteren Theil des ventralen Längsmuskels angeheftet ist; das Vorderende der Röhre ist durch eine T'erminalzelle geschlossen, das Kallalstü ck besteht aus einer Reihe von durchbohrten Zellen und endet vor dem After ventral mit je einer äusseren Oefinung. Die Flimmerbewegung im Inneren der Röhre ist von vorn nach hinten geliclıtet. An diesem primären Kanal kommen secundäre Verästelungen von gleicher Structur zur Entwicklung. - Endlich findet sich am Hinterende seitlicli je ein Coelo m sack, dessen epithelial angeordnete Zellen je eine Coelom öhle einschliessen, oft aber sind die Coclomsäcke durch je eine streifenartig angeordnete Zellmasse (Mesodermstreifen) mit hinterer Polzelle (Wachsthumspunkt), oder auch allein durch paarige Polzellen vertreten; die Umwandlung in Epithelsäcke folgt dann erst bei späterer Zellvermehrung.

Wir sind der Ansicht, dass nicht nur die Mesodermstreifen (wie schon die Brüder Hertwig hervorloben), soudern auch die Protonephridien als epitheliale odler coelomatische Theile des Mesoderms zu betrachten sind; die ersteren kömmen direkt vom Urdarm als Absackungen entstehen. Die ,durchbohrten" Zellen der Protonephridien können bei grösserer Zellenzahl des Organes durch gewöhuliches Epithel vertreten sein. Sowohl die Coelomhöhlen als auch die Höhlen der Protonephridien sind also von Mesodermepithel umgrenzte Höhlen und dieselben haben sich wah scheinlich phylogenetisch vom Epithel des Urdarmes als periphere Theile desselben durch Abfaltung gesondert.

\section{b) Modificationen der Trochophora.}

Wir haben hervorgehoben, dass die Trochophora bei allen Haupttypen der Zygoneura vertreten ist, doch sind nicht in allen Fällen ihre Charaktere in gleicher Vollkommenheit ausgeprägt, ja es gibt zahlreiche Fälle, wo ihre wesentlichsten Eigenthümlichkeiten ganz unterdrückt erscheinen.

Am weitesten ist die Unterdrückung der Trochophoracharaktere bei solchen Thieren vorgeschritten, deren Entwicklung ohne Metamorphose verläuft, bei welchen dieses Stadium demnach in die embryonale Lebensperiode fällt; am häufigsten sind die äusseren Charaktere veräudert, so die allgemeine Körperform und die Wimperkränze; ferner können auch die primären Muskelzüge und endlich auch das Protonephridium hinvegfallen. Manchmal sind aber selbst bei direkter embryonaler Entwicklumg noch sehr zahlreiche Trochophoracharaktere erhalten geblieben (z. B. bei der Entwicklung der pulmonaten Schnecken, bei den regenwurmartigen Criodrilus).

Auch bei larvaler Entwicklung kommen manche Modificationen vor, so z. B. in Bezug auf die Bewimperung, indem secundäre Wimperapparate auftreten oder die Larve sogar gleichmässig an der ganzen Oberfläche bewimpert ist. Unter einen besouderen Gesichtspunkt fallen 

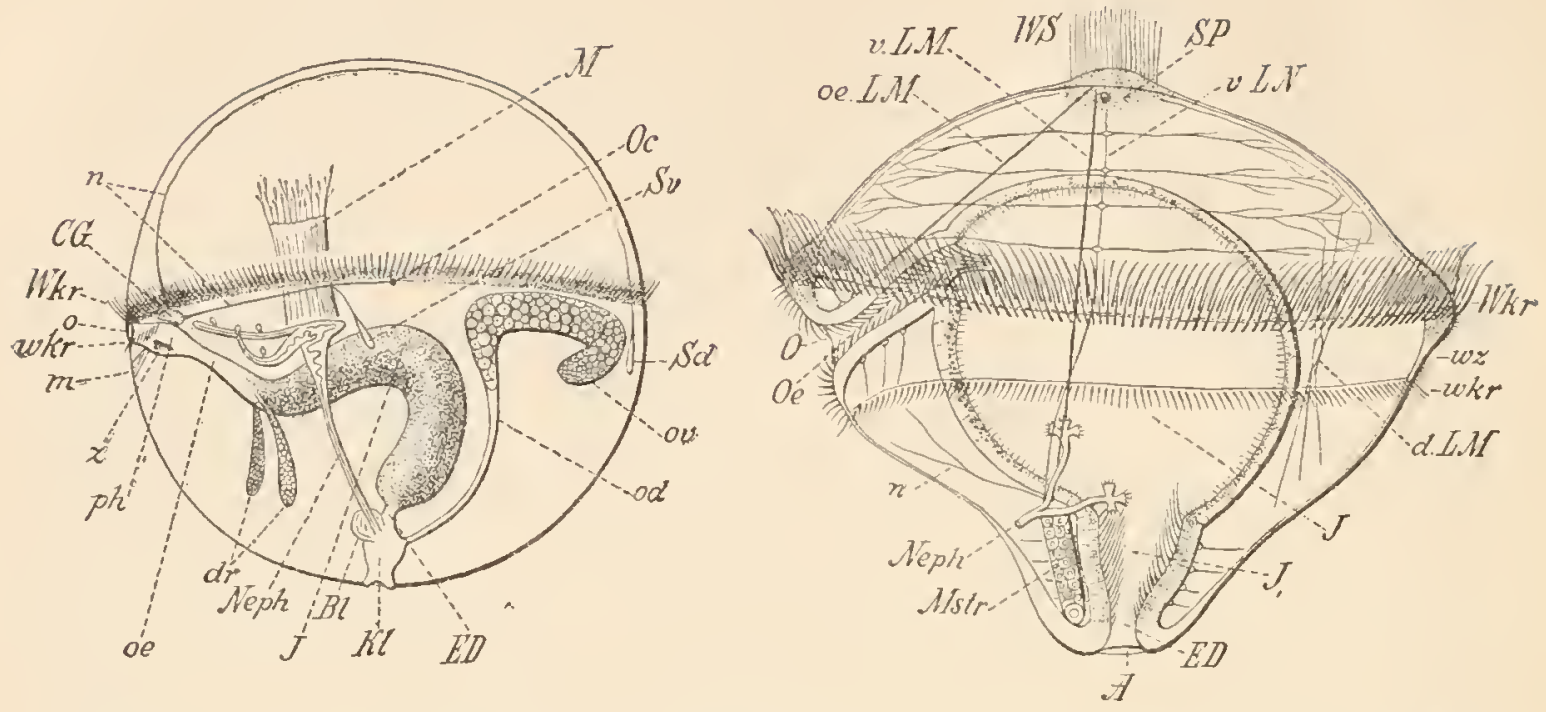

Fig. 299. Trochosphaera aequatorialis, das Kugelräderthierchen, nach SEMPER. Whr Trochus, $u k r$ Cingulum, o Mund, ph Kaumagen, mit $z$ Chitinkiefern, oe Speiseröhre, $d r$ Mitteldarmdrüse, $J$ Magendarm, Ed Enddarm, $K l$ Kloake, Neph Nephridium, $B l$ Harnblase, ov Ovarium, od Ovidukt, $M$ Muskel, $m$ Muskel des Kaumagens, $C G$ Cerebralganglion, $n$ Nerven, $S d$ dorsaler unpaarer Taster mit uupaarem Nerven, $S v$ ventraler paariger Taster, Oc trochales Auge.

Fig. 300. Trochophora-Larve von Polygordius. Wkr präoraler Wimperkranz, ukr postoraler Wimperkranz, wz adorale Wimperzone, WS apicaler Wimperschopf, $O$ Mund, Oe Speiseröhre, $J$ Magen, $J$, Darm, ED Enddarm, A After, Neph Nephridium, Mlstr Mesodermstreifen, $v L M$ ventraler Längsmuskel, dLM dorsaler Längsmuskel, oe $L M I$ Längsmuskel, der zur Speiseröhre zieht, $S P$ Scheitelplatte, $v L N$ ventraler Längsnerv (Scllundcommissur), $n$ Nerven.

jene Veränderungen, welche wir als vorzeitige Entwicklung specifischer Klassencharaktere bezeichnen kömnen. So sehen

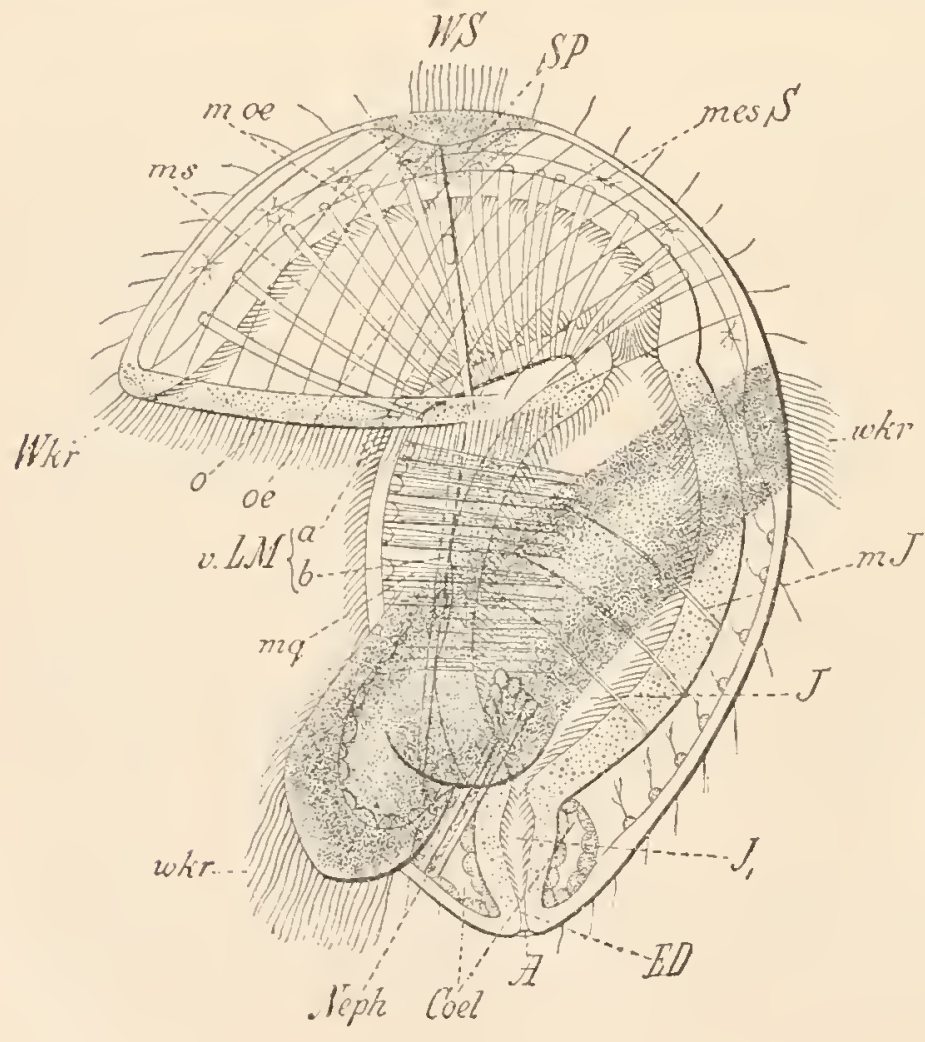

wir bei den Anneliden, für welche der metamerische Körperbau sehr charakteristisch ist, wohl in vielen Fällen die Trochophora in sehr reiner Form auftreten, in anderen Fällen aber tritt die Erscheinung der Metamerie sehr frühzeitig auf,

Fig. 301. Larve von Phoronis, sogenannte Actinotrocha. Der mächtig entwickelte postorale Wimperkranz zeigt in diesem Stadium nur erst Andeutungen der Tentakelbildung. ms Muskeln des Scheitelfeldes, moe Muskeln des Oesophagus, mesS mesodermale Membran, mq Quermuskeln, Coel Coelomsack, den Darm umgreifend und paarig vorhanden. Die übrigeu Bezeichnungen wie in Fig. 300 . 
sogar bevor noch alle 'Trochophoracharaktere ausgeprägt sind. Bei den Mollusken, die sich durch den Besitz einer Schale auszeichnen, tritt dieses Gebilde äusserst frühzeitig auf (manchmal schon während der Gastrulation) und die Troclophora ist stets schon mit der Molluskenschale versehen und zwar mit einer einfachen bei den Schnecken, mit einer zweiklappigen bei den Muscheln. Bei den Tentaculaten, die sich

Fig. 302. Trochophora einer Muschel (Teredo). Die zweiklappige Schale ist bereits ausgebildet, und es kann in dieselbe der Vorderkörper zurückgezogen werden. Schl Schlossrand der Schale, $S M v$ vorderer, $S M h$ hinterer Schliessmuskel, Mles Mesodermstreifen, $M P$ Polzellen des Mesoderms, $L$ Leber mit Fettropfen. Die übrigen Bezeichnungen wie in Fig. 300.

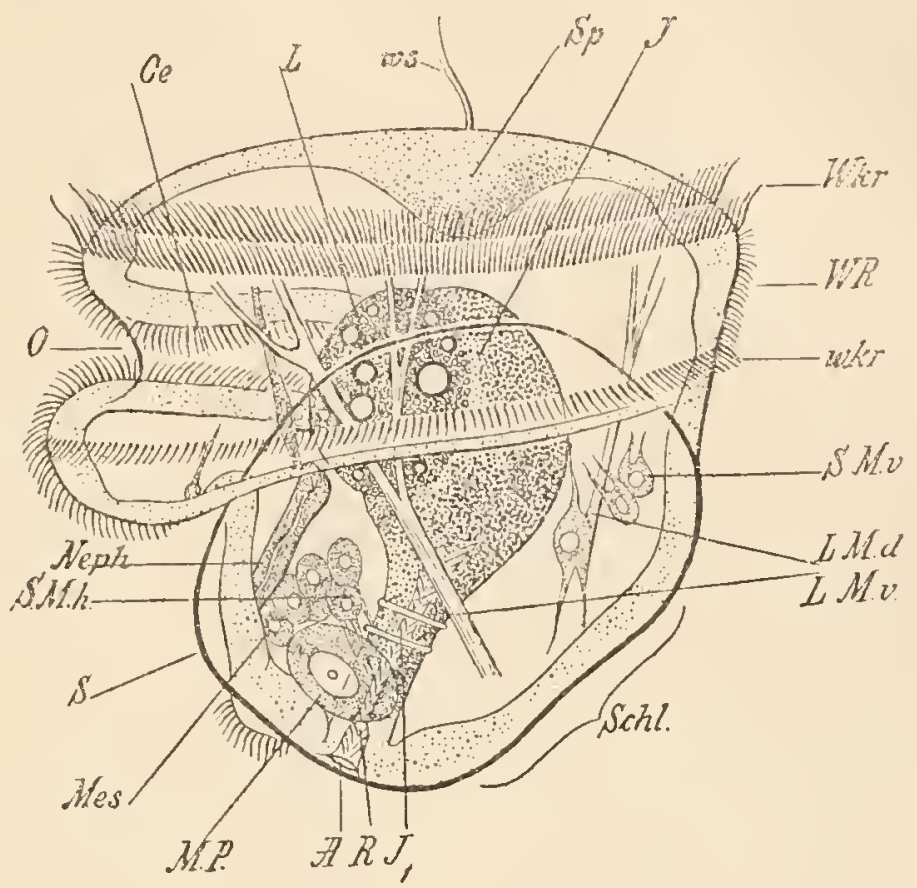

durch einen a uf den postoralen Wimperkranz zurückführbaren Tentakelapparat auszeichnen, ist derselbe schon an der Larve in ähnlicher Weise modificirt. - Auch specielle Charaktere der Ordnung, Familie, ja sogar der Species können schon frïhzeitig kenntlich sein. - Besondere Veränderungen der Entwicklung sind ferner dadurch bedingt, dass bei manchen Thiergruppen Flimmerepithelien gänzlich fehlen; dies kann mit vorzeitiger Entwicklung von Klassencharakteren und auch mit abgekürzter directer Entwicklung sich combiniren (Nematoden, Arthropoden).

c) Protrochula.

Das Stadium, welches in der Ontogenie der Trochophora unmittelbar vorhergeht, entbehrt des Afterdarmes und zeigt auch die Sonderung des Mitteldarmes in zwei Abtheilungen noch nicht ausgeprägt. Wir bezeichnen dieses Stadium als Protrochula; die Platodes erreichen nur dieses Stadium - oder, genauer gesagt, die Entwicklumg der Platodes geht schon vom Stadium der Protrochula einen anderen Weg als die der übrigen Zygoneura. Manche Forscher sind der Ansicht, dass die Mundöffnung der Protrochula (auch als Pilidiumlarve oder Protoscolex bezeichnet) noch eine ursprïngliche Lage, in der Mitte des Gegenfeldes, besitze; wir werden auf diesen Punkt noch zuriickkommen ${ }^{1}$ ).

1) In einer früheren Darstellung hatte ich die Aufstellung einer Protrochula unterlassen, da ich den mangelnden After der Platodes für eine Rückbildungserscheinung hielt; auch jetzt noch muss ich diese Möglichkeit offen halten, denn manche Erscheinungen drängen zu der Ansicht, dass vielleicht Schlund uud Afterdarm beides Differenzirungen eines Urschlundes und daher gleich alt sind (Bürschli). Die Aufstellung der Protrochula, als Bezeichnung für ein bestimmtes ontogenetisches Stadium ist gerechtfertigt, wenn auch die phylogenetische Bedeutung derselben zweifelhaft sein sollte. 


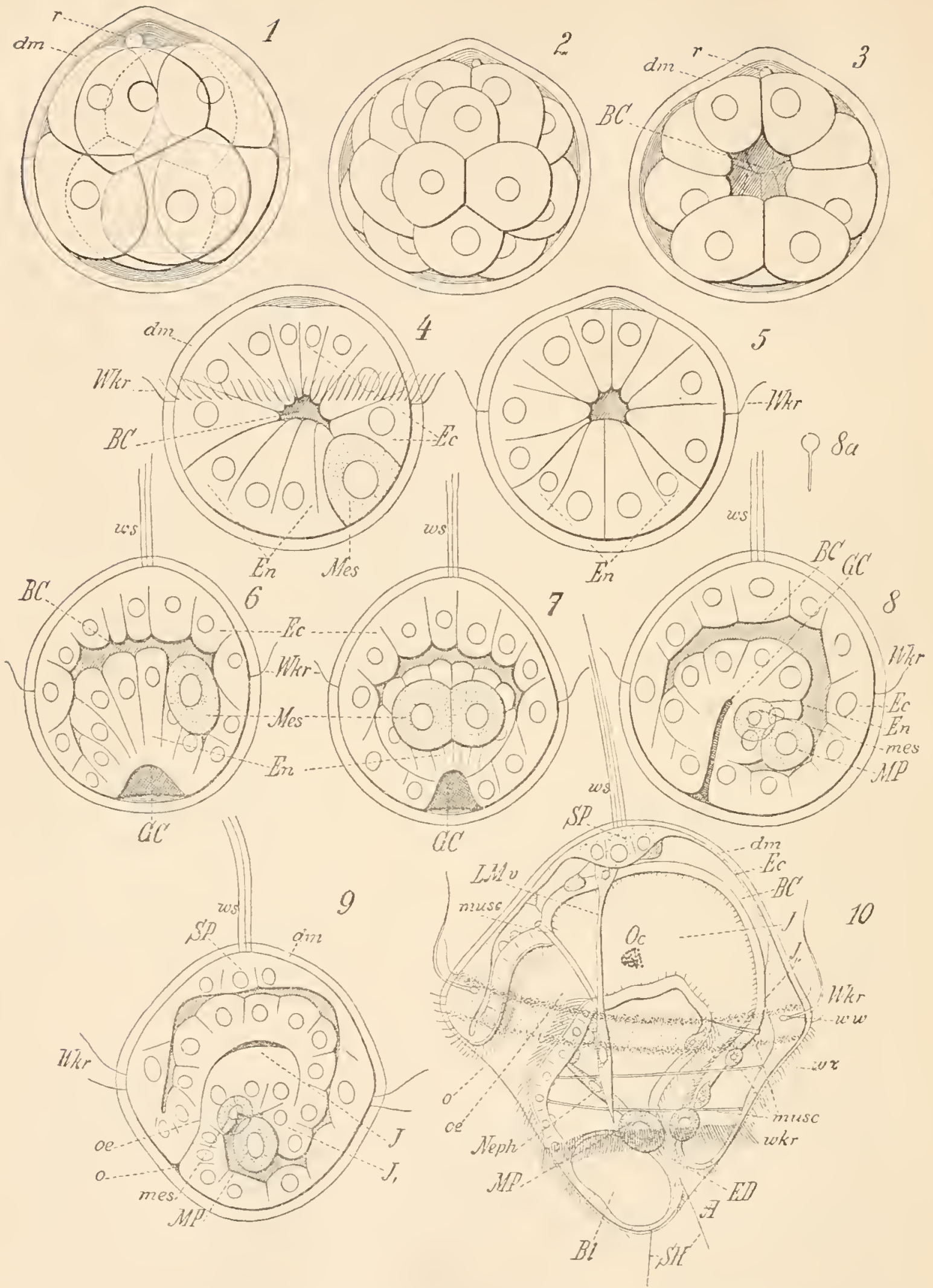

Fig. 303, Entwickinng eines Annelids (einer Serpulide) bis zum Trochophorastadium. 1 Achtzelliges Furchungsstadium. 2 und 3 Weiteres Furchungsstadium von der Fläche und im Durchschnitt gesehen. 4 und 5 Blastulastadium, schon mit äquatorialem Wimperkranze versehen, im Medianschnitt und Frontalschnitt, $\boldsymbol{6}$ und $\boldsymbol{\gamma}$ Gastrula mit Trochus und apicalem Wimperschopf. $\boldsymbol{S}$ Schliessung des Gastrulamundes. $\boldsymbol{S} \boldsymbol{a}$ Umriss desselben, von der Fläche geseben. 9 Stomodacum ist schon gebildet und die Scheitelplatte ist angedeutet. $r$ Richtungskörper, $d m$ Dottermembran, $B C$ Blastocoel, $W k r$ Trochus, Ec Ectoderm, En Endoderm, IIes die paarigen Urmesodermzellen, GC Gastrocoel, wos apicaler Wimperschopf, mes Mesodermzellen, MP Polzellen des Mesoderms, SP Scheitelplatte, 
o Mund, oe Speiseröhre (Stomodaeum), $J$ Magen, $J$ Darm. 10 Trochophorastadium; die Dottermembran ist als provisorische Cuticula nocl erhalten, aber an der Iund- und Afteröffnung durchbohrt. $\quad d m, E c, B C, J, J, W k v, w k v, w s, S P, o, o e, M P$ wie oben; ferner: ww Wimperwulst, $x z$ adorale Wimperzone, musc verschiedene kleinere lluskelfasern, $E D$ Enddarm, A After, $S H$ Sinneshärchen, $B l$ Blase, wahrscheinlich drüsiger Natur, Neph Nephridialzelle, $L I V v$ ventraler Längsmuskel.

\section{Entwicklung der Trochophora.}

Gastrulation.

Um die Entwicklung der Trochophora aus dem Ei kennen zu lernen, wählen wir als typisches Beispiel die Entwicklung der Trochophora eines Ammeliden (Eupomatus oder Serpula). Wir beobachten hier eine adäquale Furchung, eine Blastula mit kleiner Furchungshöhle und eine Gastrula, die durch einen nicht ganz scharf ausgeprägten Invaginationsprocess entsteht. Bei der Blastula und Gastrula ist eine bilateral symmetrische Vertheilung der Zellen nachweisbar und wahrscheinlich ist die Symmetrie-Ebene schon in der Eizelle vorherbestimmt. Dieses für alle Bilaterien zutreffende Verhältniss ist als vorzeitige Differenzirung der bilateralen Symmetrie zu bezeichnen. Die Bewimperung der Blastula und Gastrula ist bei Eupomatus keine gleichmässige, sondern es prägt sich schon frühzeitig die charakteristische Anordnumg der Wimpern aus, indem ein apicaler Wimperschopf am animalen Pol und ein äquatorialer Wimperkranz sich bildet. Auch dies ist eine vorzeitige Differenzirung, die es uns aber sehr erleichtert, die Beziehuugen der Gastrulaachsen zu den Achsen der Trochophora festzustellen. - Der Apicalpol der Gastrula stimmt mit dem der Trochophora iiberein; das Protostoma findet sich vorerst demselben gegenüber in der Mitte des Gegenfeldes.

M esodermbildung.

Am Protostomrande sondern sich zwei paarig angeordnete Endodermzellen von den übrigen $a b$ und rücken zwischen die primären Blätter; sie repräsentiren den Mesodermkeim oder die "Urzellen des Mesoderms". Wir bezeichnen den Rand des Protostoma, wo die Mesodermkeime sich sondern, als hinteren, den entgegengesetzten als vorderen Protostomrand (bei dieser Bezeichnung anticipiren wir das spätere Lagerungsverhältniss).

Bildung von Schlund und Bauchfurche.

Der Gastrulamund verengert sich nun, indem sein hinterer Theil sich spaltförmig in der Richtung der Medianlinie schliesst (Gastrularaphe). Ferner stülpt sich das Ectoderm in der Umgebung des Gastrulamundes ein, und zwar liefert es den tiefen Schlund in der Umgebung des offenen Protostomrestes, so dass letzterer zur inneren Schlundpforte wird, und die flache Bauchfurche längs der Gastrularaphe. Endlich erfolgt auch eine allmähliche Verschiebung der ganzen Protostomregion nach der Bauchseite, so dass der secundäre Mund bis dicht hinter den äquatorialen Ring zu liegen konmt und die Bauchfurche ihre ventrale Lage erhält und ferner das mesodermale Ende der Protostomregion mit sammt den Mesodermkeimen an den 
Gegenpol rückt, den wir nun auch als Mesodermpol bezeichnen können. Es folgt die Differenzirung der ectodermalen und mesodermalen Gebilde und schliesslich die Entstehung des Afterdarmes als blinde EctodermEinstiilyung, welche sich erst secundär mit dem Darme verbindet.

II odificationen der Entwicklung.

Diese Entwicklungsvorgänge wiederholen sich bei den verschiedensten Zygoneuren in zienlich ähnlicher Weise, es kommen aber bei anderen wieder geringere oder auch bedeutendere Modificationen vor. Wir finden dieselben in um so höherem Grade, je mehr die ganze Entwicklung eine abgekürzte oder aus anderen Ursachen modificirte ist; so z. B. wird durch Dottermassen die Formgestaltung verändert u. s. w. Gewisse Eigenthümlichkeiten sind aber doch zienlich allgemein zu beobachten, wie z. B. die Mesodermbildung an Protostomrand, die spaltförnige Schliessung des hinteren Protostomtheiles, die Bildungsweise des Stomodaeums u. s. f. Oft schliesst sich das Protostoma vollständig und das Stomodaeum entsteht als blinde Einstülpung, die erst secundär in den Mitteldarm durchbricht. Bei Paludina (einer Schnecke) soll der Rest des Gastrulamundes in die Afteröffnung direkt übergehen; auch bei Sagitta liegt der Rest des Protostoma in der Nähe des Hinterendes. Eine besondere Erörterung erfordert die Mesodermbildung. Die Bildung des Mesodermkeimes ist nicht immer auf den linteren Rand des Protostoma beschränkt (1), sondern es können (2) auch die Seitelränder des Protostoma sich daran betheiligen, oder (3) in manchen Fällen der ganze Protostomrand (Flusskrebs); der zweite Fall bildet den Uebergang zu jenen Verhältnissen, wo (4) das Mesoderm in Form seitlicher Falten vom Endoderm gesondert wird (Insecten, Sagitta, Brachiopoden). Welcher Modus unter allen diesen der ursprünglichere ist, wollen wir hier nicht erörtern und verweisen auf frühere Bemerkungen (pag. 76). - Von grossem Interesse ist die Beobaclitung, dass bei den polycladen Turbellarien das Mesoderm von vier regelmässig das Protostoma umstellenden Zellen gebildet wird, und dass vier radiär gestellte Mesodermstreifendaraus resultiren; man glaubt hierin eine ursprüngliche radiäre Anordnung zu erkennen, doch ist der ganze Entwicklungsgang noch nälier aufzuklären, um diese Auffassung sicher zu begründen.

\section{Phylogenetische Bedentung der Trochophora.}

Wenn wir als erwiesen annehmen, dass die Trochophora (oder Protroclula) die ursprüngliche charakteristische Larvenform der Scoleciden, Articulaten, Tentaculaten und Mollusken sei, so haben wir ein verbindendes Merkmal für alle diese Gruppen anerkannt. Wir können daraus auf eine gemeinsane Abstammung schliessen und zwar dürfen wir zunächst den Satz aufstellen, dass die Zygoneuren von einer gemeinsamen Stammform abzuleiten seien, welche diese charakteristische Larve als Entwicklullgsitadium besessen habe (vergl. pag. 25). - Es ist weiter die Frage zu stellen, ob etwa die Trochophora selbst die Wiederholung einer Stammform sei; das ist nun in hohem Grade wahrscheinlich, weil wir noch viele Thierformen kennen, welche in ihrem entwickelten Zustande der Trochophora sehr nahe stehen. Dies gilt vor allem für die Rotatorien. Das von 
SEMPER auf den überschwemmten Reisfeldern der philippinischen Inseln entdeckte Kngelräderthierchen (Trochosphaera aequatorialis) illustrirt diesen Satz anı augenfälligsten, doch ist hervorzuheben, dass dies ein typisches Räderthierchen ist und dass sogar viele andere Räderthierchen, trotz ihrer mehr veränderten äusseren Form, manche Trochophoracharaktere noch treuer bewahrt haben. Man hat wohl auch versucht, die Rotatorien als geschlechtsreif gewordene Larven höherer Thierformen phylogenetisch zu erklären (Unterdrïckung der Endstadien pag. 26); dies wäre principiell nicht unmöglich, doch müssen wir einwenden, dass für eine solche Hypothese keine bestimmte Veranlassung vorliegt. Es ist ferner hervorzuheben, dass auch die Turbellarien in ihren gesammten Organisationsverhältnissen ebenso der Protrochula nahestehen, nur dass ihnen im entwickelten Zustande die Wimperkränze fehlen. Die Ansicht, dass die innere Organisation der Protrochula mnd Trochophora auf Wiederholung der Charaktere einer Stammform beruhe, wird also mit Rücksicht auf die noch gegenwärtig der Trochophora ähnlichen Organisationsverhältnisse der Platoden und Rotatorien sehr wahrscheinlich erscheinen; aber auch die äusseren Flimmerapparate der 'Trochophora werden mit grosser Wahrscheinlichkeit als Charaktere einer Stammform betrachtet werden, da sie nicht nur bei den Rotatorien, sondern auch bei anderen Gruppen, z. B. bei den Endoprokten und den Tentaculaten, in definitiven Organbildungen des entwickelten Organismus sich theilweise erhalten haben.

Wir stellen demnach folgende Sätze auf: Die Protrochula ist eine Wiederholung des Protrochozoon, d. i. der gemeinsamen Stammform aller Zygoneura. - Die Trochophora ist die Wiederholung des Trochozoon, d. i. der gemeinsamen Stammform aller über den Platoden stehenden Zygoneuren. Diese phylogenetische Hypothese ist nach unserer Meinung am besten im Stande, unsere gegenwärtigen Kenntnisse von der Organisation und Entwicklung der 'Zygoneuren in begrifflichen Zusammenhang zu bringen. Mag man nun aber die phylogenetische Zurückführung der Zygoneura auf das Trochozoon (und Protrochozoon) anerkennen, oder mag man sie zuriickweisen, so ist es doch, in jedem Falle Aufgabe der Morphologie, die Organisation jeder einzelnen Gruppe in ihrem Verhältniss zu dem ontogenetischen Stadium der Trochophora zu erklären.

Die Organsysteme der Scoleciden sind direkt auf die Organe der Protrochula und Trochophora zurückzuführen. Dies gilt vom N e r vensystem, Darmkanal, Muskelı und Protonephridium; es kommt noch ein Organ in Frage, nämlich die Go naden, welche bei den Scoleciden ursprünglich paarig vorhanden sind und den Bau von Sackgonaden mit eigenen Ausführungsgängen besitzen. Ueber die Entwicklung derselben liegen nur sehr wenige Beobachtungen vor, doch

1) Manche Forscher wollen die Anneliden als Ausgangspunkt aller Zygoneuren betrachten und halten alle tiefer stehenden Formen, also vor allem die Scoleciden, tür rickgebildet. Andere wollen dies für die Rotatorien annehmen, aber nicht für die Turbellarien (LANG); die erstere Anschauung scheint mir wenigstens die consequentere.

Man könnte auch die Scolecidencharaktere der Rotatorien für ursprüugliche halten und nur die Wimperkränze als protrahirten se e u dären Larvench a rakter erklären. Wir kommen aber aus anderen Gründen zu der Ansicht, dass besonders der präorale Wimperkranz ein uraltes, von den pelagisch lebenden Vorfahren der Zygoneuren ererbtes Organ ist. 
ist es wahrscheinlich, dass die Sackgonaden und die Gonadengänge (nämlich Eileiter und Samenleiter, d. i. die proximalen Theile der Ausführungsgänge) mesodermale Entstehung haben und als coelomatische Bildungen $\mathrm{zu}$ betrachten sind.

Die Zurückführung aller dieser Organsysteme auf die der Trochophora wird, wie wir sehen werden, sich einfach gestalten bei den Turbellarien, den Rotatorien und Endoprokten, sie ist aber vorläufig ganz problematisch bei den Nematoden und Acanthocephalen, deren phylogenetische Ableitung und systematische Stellung wir daher noch als sehr zweifelhaft betrachten. Ferner finden wir bei den Nemertinen Verhältnisse, die vielleicht in manchen Punkten an die Aposcoleciden erinnern (ohne dass wir sie deshalb für eine Uebergangsgruppe halten müsstell).

Die Scoleciden besitzen also eine primäre Leibeshöhle, die von Mesenchym mehr oder minder ausgefüllt sein kann, ferner primäre Sackgonaden und Protonephridien.

Die Aposcoleciden (oder Cephalidier) besitzen eine Anzahl von wichtigen neuen Charakteren, die für alle gemeinsam sind, so die Peritonealsäcke, Mesenterien, peritoneale Gonaden, Metanephridien, Blutgefässsystem, auch meist epithelogene Längsmuskeln und meist ein Bauchmark; es ist daher ihre systematische Zusammenfassung begrïndet. In ihrer Entwicklung besitzen sie als Trochophora den Bau der Scoleciden, sie durchlaufen also ein Scolecidenstadium; es bilden sich nämlich erst nach diesem Stadium jene secundären Organe aus, welche zum Theil die primären Trochophora-Organe ersetzen, zum Theil denselben sich hinzufügen. Die ontogenetische Entstehung dieser Organe und ihre phylogenetische Ableitung bildet das Problem, welches die Morphologie hier zu lösen hat.

Eine Anzahl dieser Organe entsteht aus den Coelomsäcken; diese lieferu ferner an einer beschränkten Stelle die coelomatösen Flächengonaden. Wir stellen nun die provisorische Hypothese auf, dass die Coelomsäcke, welche bei den Scoleciden direkt zu den paarigen Sackgonaden und Gonadengängen sich entwickeln, während sie bei den Aposcoleciden nur an einer beschränkten Stelle Keimepithel bilden, nebstdem aber die verschiedenen ()rgane des somatischen und splanchnischen Blattes liefern, homologe Gebilde seien. Mit anderen Worten: die Sackgonaden und Gonadengänge der Scoleciden entsprechen den embryonalen Coelonıäcken (ler Aposcoleciden ${ }^{1}$ ).

Während wir die Ableitung aller Gruppen der Zygoneura von einer gemeinsamen Stammform, gestützt auf die Vergleichung ihrer Entwicklung und Organisation, mit einiger Sicherheit behaupten können, erscheint die Art der Verwandtschaft dieser Stammform zu den niedrigeren Typen, den Protaxoniern, als eine Frage von viel mehr hypothetischem Charakter.

Der Versuch, jene phylogenetischen Stufen, welche zwischen Gastraea und 'Trochozoon liegen, ummittelbar' aus der Embryonalentwicklung der' 'Trochophora zu construiren, hätte nur geringen Werth, wenn nicht eine Vergleichung dieser Stadien mit jetzt lebenden niedrigeren Thierformen möglich wäre. Man hat in dieser Beziehung verchiedene Hypothesen aufgestellt.

1) Eine andere Hypothese, welche die Coelomsäcke von den Protonephridien ableiten will (RAY-LANKESTER, ZIEGLER) werden wir später noch erwähnen. 
ḰLeinenberG hat versncht, die Trochophora von der Medusenform abzuleiten, indem er den präoralen Ringnerven der Annelidenlarve mit dem Ringnerven der Hydroidmedusen vergleicht; diese Hypothese erscheint aber mit Rücksicht auf die übrigen Organisationsverhältnisse kaum amnehmbar.

Viel mehr Gründe sprechen dafür, dass die Ctenophoren der Stammform der Zygoneuren selur nahe stehen; die Simnesplatte am apicalen Pole, die mesenchymatöse Musculatur, der ectodermale Schlund werden uns sofort als verwandte Züge auffallen, auch die Wimperapparate der Ctenophoren wird man vielleicht mit dem präoralen Wimperkranz der Trochophora vergleichen können. Die Hypothese der Verwandtschaft der Zygoneuren mit den Ctenophoren wurde von SELENKa und besonders von LANG ausgeführt; zur Vergleichung wurden speciell die Turbellarien herangezogen, wodurch vielleicht manche irrthümliche Auffassung veranlasst wurde. Wenn wir den Grundgedanken dieser Hypothese in seiner grossen Tragweite anerkennen, so müssen wir doch bemerken, dass wir im einzelnen vielen Ausführungen LANG's nicht zustimmen kömnen; so besonders die Ableitung der dorsoventralen Achse von der Primärachse. Wir wollen auch hervorheben, dass wir die Coelomsäcke und Nephridialkanäle der Zygoneuren (Sackgonaden der Scoleciden) von den Gastrokanälen der Ctenophoren ableiten und daher den Mitteldarm aller Zygoneuren morphologisch nur mit dem Centralmagen der Coelenteraten im allgemeinen oder speciell der Ctenophoren vergleichen möchten, nicht aber mit dem gesammten Urdarmsystem oder coelenterischen Apparat, wie Lang dies thut.

Zur Vergleichung der Zygoneuren mit den Ctenophoren werden wir die Protrochula, als die Grundform der Zygoneuren in Betracht ziehen. Der bilaterale Bau beruht auf dem Gegensatz von Bauchseite und Rückenseite und dieser Gegensatz kommt dadurch zu Stande, dass der Mund sich nicht am Gegenpole, sondern auf der Bauchseite befindet, wohin er durch eine secundäre Verschiebung gelangt ist ${ }^{1}$ ). Eine solche Lageveränderung. kann auf verschiedene Weise zu Stande gekommen sein; es könute eine Lageveränderung der ganzen oralen Körperhälfte stattgefunden haben, also eine „Knickung der Hauptachse" eingetreten sein, - oder es könute der Fall sein, dass nur der Mund und Schlund eine Verschiebung erlitt, ohne dass die Lage aller anderen Organe in gleichem Maasse beeinflusst wäre,

1) LANG hat (im Anschluss an CuUn) eine andere Ansicht über die Achsenverhältnisse der Zygoneuren ausgesprochen. Er vergleiclit die Polycladen Turbellarien mit den kriechenden Ctenophoren-Formen Coeloplana und Ctenoplana; er kommt zu dem Schlusse, dass die Hauptachse der Ctenophoren der dorsoventralen Achse der Turbellarien und weiter auch der übrigen Zygoneuren entspreche. Das Cerebralganglion soll erst sccundär von der Mitte des Riickens nach vorn gewandert sein. Der Körperrand der abgeplatteten Turbellarien entspräche der äquatorialen Zone. Wir müssen zunächst bemerken, dass Coeloplana und Ctenoplana wahrscheinlich nicht mit der aboralen Fläche kriechen, sondern mit dem ausgebreiteten Schlunde, wie dies auch andere Ctenophoren gelegentlich thun. Ctenoplana ist sogar noch eine eigentlich pelagische Form. Wir haben es hier wohl mit aberranten CtenophorenFormen aber nicht mit Uebergangsformen zu den Polycladen zu thun. Ferner spricht die Entwicklungsgeschichte der Polycladen aufs klarste gegen die LANG'sche Auffassung; der äquatoriale Wimperkranz der Polycladenlarven entspricht nicht dem Körperrande, sondern umgürtet den Körper der Quere nach und das Cerebralganglion entsteht am vorderen Körperpol. Die Lage der Tentakel auf der Rückenfläche in einiger Entfernung vom vorderen Körperrande ist wohl dadurch zu erklären, dass bei diesen Turbellarien zur Vergrösserung der ventralen Kriechfläche ein Randsaum sich gebildet hat, der auch am vorderen Körperrand über den Apicalpol hinaus sich erstreckt. Die strahlige Anordnung der Darmäste und der Nerven ist als secundär erworbene Erscheinung zu betrachten. 
es könnten z. B. die meridionalen Organe ihre Lage zumeist unverändert beibehalten haben. Ich neige mich mehr der letzteren Auffassung zu, während ich in früheren Schriften die erstere vertrat. Der axial gelagerte Urschlund (Orthostomodaeum) liefert nicht nur den Schlund, sondern auch die Bauchfurche der Trochophora. Bei dieser Verschiebung spielt wohl auch phylogenetisch ein partieller Schluss des Protostoma, d. i. der inneren. Schlundpforte, eine Rolle, ontogenetisch wenigstens kommt ein solcher Process ganz allgemein vor. Die Verschiebung des Protostoma bei der embryonalen Entwicklung der Zygoneuren erfolgt vorzeitig. Phylogenetisch ist die Bildung des Schlundes vorausgegangen ${ }^{1}$ ). Alles dies gilt auch schon für das Stadium der Protrochula.
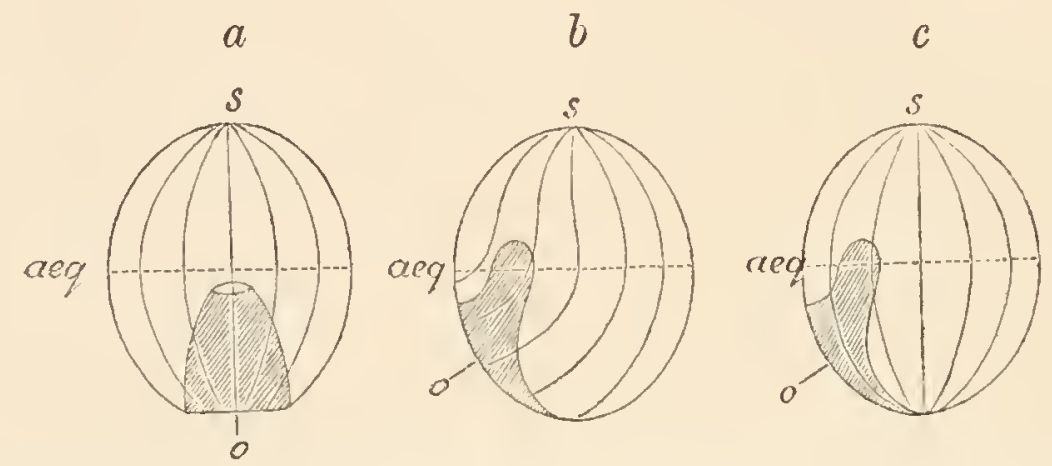

Fig. 304. Schema der hypothetischen Umwandlung des protaxonischen Typus in den heteraxonischen Typus der Trochophora. Die protaxonische Urform $(a)$ könnte verändert worden sein entweder $(b)$ durch Veränderung des gesammten Gegenfeldes oder (c) durch Verschiebung allein der Mundregion. s Scheitelpol, aeq äquatoriale Zone, o axiale Mundöffnung, welche zur ventralen Mundöffnung und Bauchfurche wird, die meridionalen Linien deuten nur die Lagebeziehungen der meridionalen Organtheile an.

Die Vergleichung des präoralen Wimperkranzes mit der Zone der Flimmerrippen bei den Ctenophoren liegt um so näher, wenn wir die Entwicklung dieser letzteren berücksichtigen, wenn wir also Ctenophorenlarven oder Formen wie Charistephane in Betracht ziehen (Fig. 305). Man könnte den Wimperkranz von acht einander genäherten Plättchengruppen ableiten, aber umgekehrt auch den geschlossenen Wimperkranz für das primäre halten; vielleicht ist es richtiger, beide Bildungen von einem gemeinsamen Grundtypus abzuleiten; wir könnten uns vorstellen, dass zum Zwecke einer geordneten Bewegungsleistung die Wimpern der Körperoberfläche zuerst derart aneinandergereiht waren, dass sie sowohl meridionale Linien als auch zugleich parallele Zonen bildeten; von diesem Zustande aus hätten durch Weiterbildung nach den verschiedenen Extremen einerseits der Wimperkranz und andererseits die meridionalen Rippen sich entwickelt. (Der Verlauf der epithelialen Nerven schliesst sich an diese Vertheilung der Wimpern an.)

Bei Betrachtung der Ctenophorententakel müssen wir uns zwei Fragen stellen: erstens, ob diese Tentakel den Primärtentakeln der Trochophora entsprechen; da nun die ersteren sehr contractile Fangarme sind, während

1) Wir möchten das ontogenetische Stadium mit axialem Urschlunde, welches aber kaum mehr in reiner Form sich erhalten hat, als Orthotrochula bezeichnen; darauf folgen die ontogenetischen Stadien der Protrochula (schon mit ventralem Schlund und Bauchfurche) und Trochopbora. Die entsprechenden phylogenetischen Stadien wären: Orthotrochozoon (den Ctenophoren nahe verwandt), Protrochozoon (afterlos) und Trochozoon (den Rotatorien nahe stehend). 
wir die letzteren von Sinneshöckern der Scheitelplatte ableiten, so möchte ich die Homologie dieser Gebilde in Zweifel ziehen. Die zweite Frage ist, ob die Ebene, in welcher die Ctenophoren-Tentakel liegen, d. i. die Trichterebene (oder sog. Trausversalebene), überhaupt mit der Trausversalebene der Bilaterien übereinstimmt, oder ob dies nicht vielmehr für die Schlundebene (sog. Medialebene) der Ctenophoren gilt; diese Frage können wir gegenwärtig kaum entscheiden.

Fig. 305. Charistephane, eine Ctenophore aus der Abtheilung der Tentaculaten. Die acht Flimmerrippen bestehen nur aus je zwei sehr breiten Plättchen, nach Chun. $s$ Sinneskörper, $t$ Tentakel, eingezogen, $o$ Mund, $s l$ Schlund, $t r$ Trichter (Centralmagen), tc Trichterkanal, slg paarige Schlundgefässe, $m g$ in Achtzahl vorhandene Meridionalgefässe, deren oraler Abschnitt die Gonaden enthält.

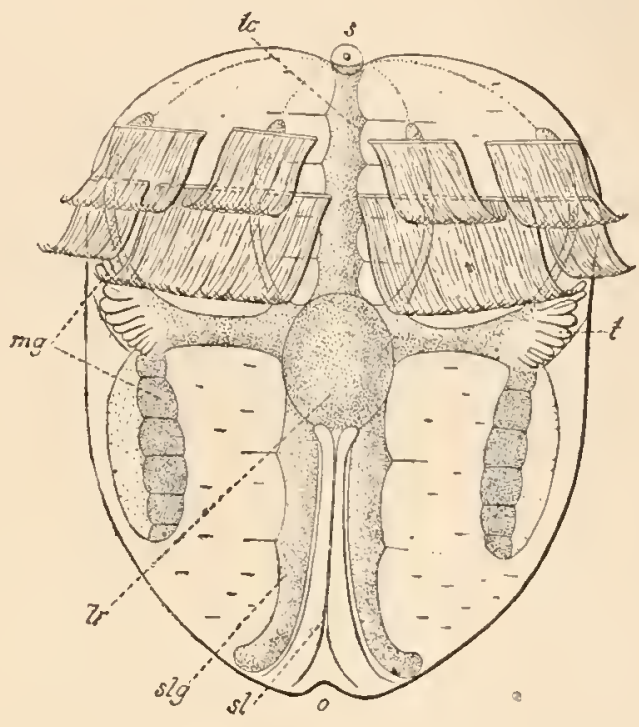

$a$

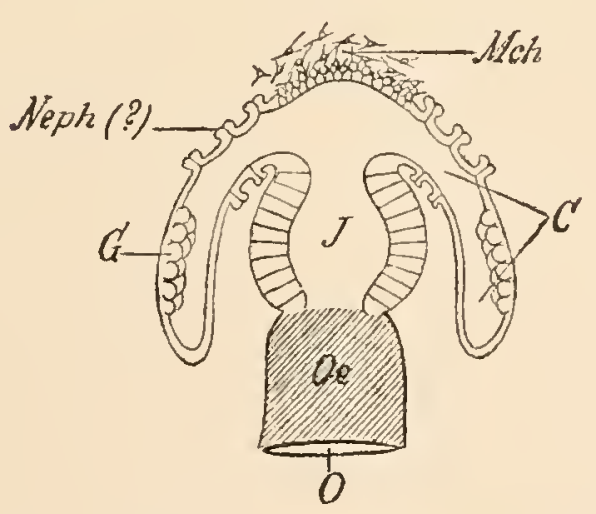

6

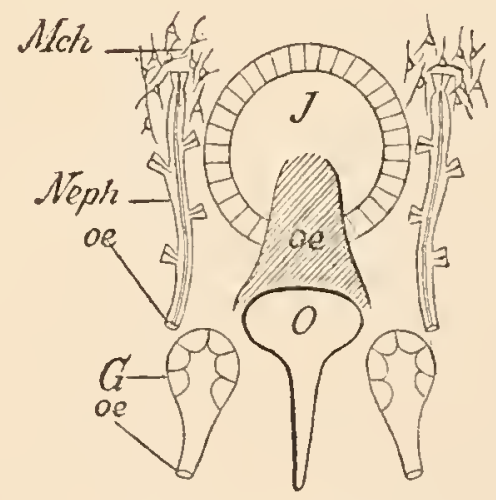

Fig. 306. Disposition des Urdarmes und seiner Derivate. a Bei den Ctenophoren ; $b$ bei der Trochophora. O Mund, Oe Speiseröhre, $J$ Ceutralmagen (Magen), Neph Nephridien, $G$ Sackgonaden; in $b$ selbständige Theile mit eigenen Oeffunngen (oe) versehen; in $a$ durch Theile der meridionalen Kanäle (c) repräsentirt; Mch Mesenchym.

Die apicale Sinnesplatte der Ctenophoren wird der Scheitelplatte der Trochophora homolog zu setzen sein; vielleicht wird sich die Homologie sogar für die einzelnen Sinnesorgane erweisen lassen. Das Gehörorgan könnte in dem unpaaren cerebralen Hörbläschen vieler niedriger Turbellarienformen wiedergefunden werden, auch die Pigmentflecken in der Sinnesplatte der Ctenophoren könnten den (ursprünglich vier?) Cerebralaugen entsprechen. Ja es wäre sogar möglich, die Geruchsgrübchen auf die Polfelder der Ctenophoren zurückzuführen, wenn die sogenannte Medialebene der Ctenophoren der Transversalebene der Trochophora entspräche.

Die acht meridionalen Nerven, die bei den Ctenophoren längs der acht Meridiane vermuthet werden, könnten wir zum Theil mit den dorsalen und 
ventralen Längsnervenpaaren der Trochophora vergleichen, da der Verlauf dieser letzteren von uns als meridional betrachtet wird.

Wir kommen nun zu der Mesodermfrage. Das Mesenchym der Clenophoren, welches am apicalen Pole des Urdarmes entsteht, vergleichen wir dem Mesenchym der Truchophora, welches besonders von dem vorderen Ende der Mesodermstreifen (Coelomsäcke) sich ablöst. Aus den Meridionalkanälen, welche bei den Clenophoren Keimepithelien erzeugen und wahrscheinlich auch excretorische Function besitzen, wären die coelomatischen Bildungen hervorgegangen, nämlich die Nephridien und Sackgonaden, die aber beide nun ihre Produkte direkt nach aussen entleeren.

Wir möchten demnach folgende phylogenetische Stufen der Mesodermbildung hervorheben: 1) Mesenchymbildung (ursprünglich wandernde Nährzellen?) allseitig vom Urdarm ausgehend, Scyphozoa; 2) Mesenchymbildung ist am vorderen Pole des Urdarmsystems localisirt, von welcher Stelle dann auch die Radialtaschen sich ausstülpen, Clenophoren; 3) Radialtaschen als Coelomsäcke abgeschnürt, Mesenchymbildung von den Coelomsäcken (von deren apicalem Pole ?) ausgehend, Zygoneura (ähnlich verhalten sich auch die Echinodermen u. s. w.) (siehe das Schema Fig. 306). 


\section{FÜNFZEHNIES CAPITFL.}

\section{Subtypus der Zygoneura: Autoscolecida.}

\section{Cladus der Metazoa.}

\section{Scolecida (= Intestina $=$ Vermes $=$ Helminthes).}

Die Scoleciden sind Zygoneuren mit primärer Leibeshöhle, mit Mesenchymmuskeln, mit Protonephridien und mit primären Sackgonaden. Das Nervensystem liegt meist subepithelial.

Die Classen der Scoleciden sind in Bezug auf ihre Organe auf die Trochophora, die Platodes auf die Protrochula direkt zur ü ckführbar.

Die Cuviek'sche Classe der Intestin a wurde besonders uach dem Vorgallge von Siebord und LeuckarT rurch Hinzuziehung der Rotatoria und der Ameliden zum Kreise der Vermes erweitert. Da wir nun aber die Anneliden - auf den Standpunkt CuviER's zurückkehrend - zu dell Articulaten stellen, eine Auffassung, die in nenerer Zeit besonders durch Sevper angebalnt wurde, so füln't uns dies wieder zur Beschränkung der Vermes auf eine Gruppe, die wir als Scoleciden bezeichnen. Den sicheren Bestand dieser Abtheilung bilden die Platoden, Gastrotrichen und Rotatorien, welche als typische Repräsentanten derselben gelten können. Die systematische Stellung der Nematoden, Acanthocephalen, Endoprocten ist dagegen noch zweifelhaft.

Die Körperform der Scoleciden bewahrt nur selten ein urspünglicheres Verhalten (Trochosphaera aequatorialis), meist entfernt sie sich durch Aupassung an die Lebensverhältnisse in mannigfachen Modificationen vom Grundtypus der Trochophora. Der Körper erscheint z. B. bei den Platoden abgeplattet, bei den Nematoden in die Länge gezogen, bei den Rotatorien ist das Vorderende in den bepanzerten Hinterleib zurückziehbar ; die Mundöffnung ist oft an das Vorderende geriickt, z. B. bei den Trematoden und Nematoden. Auch die äussere Bewimperung unterliegt vielfachen Veränderungen.

Die inneren Organe sind auf die Trochophoraorgane zuriickführbar. Das Nerveusystem ist aber stets vom Ectoderm gesondert und in die Tiefe gerückt (mit Ausnahme besonders der Nematoden); das Cerebral- 
ganglion nimmt nun meist seine Lage über dem Schlunde und wird dalier auch (wie bei Anneliden, Mollusken etc.) als oberes Schlundganglion bezeiclnet. - Der Darmkanal zeigt die charakteristischen Abschnitte (bei den Platoden ist er einfacher und ohne Afterdarm); der Mitteldarm besitzt meist nur spärlich angeordnete Muskelfasern. In einigen Fällen ist der Darmkanal rückgebildet, z. B. bei den endoparasitischen Cestoden und Acanthocephalen. - Das Mesenchymgewebe ist oft nur auf isolirte einzellige Muskelzüge beschränkt (Rotatorien, Endoprocten); bei mächtigerer Ausbildung derselben selien wir aber einen vollkommenen Hautmuskelschlauch auftreten (Platodes, Nematodes); daneben findet sich oft auch parencliymatöses Bindegewebe, entweder spärlicher ausgebildet oder auch die primäre Leibeshöhle ganz erfuillend (Platodes). - Das Protonephridium ist oft zu einem selır reich verästelten Gefässnetz ausgebildet (Platodes); bei den Nematoden ist es auf die ,Seitenkanäle" (?) beschränkt. Bei den Endoprocten findet es sich in ursprünglicher Einfachheit. Die Ausmündung unterliegt mehrfachen Variationen. - Die Keimdrüsen sind dem Grundtypus nach paarig, oft aber sind sie nur einseitig ausgebildet; sie sind stets mit Ausführungsgängen versehen, die in der Regel in der hinteren Region des Bauches in der Medianlinie münden; bei den Rotatorien münden sie gemeinsam mit Darm und Excretionsapparat in eine Cloake.

Die Eier der Scoleciden entstehen durch solitäre Eibildung und sind in der Regel klein; niemals sind bedeutende primäre Dottermassen in der Eizelle vorhanden, dagegen kommen secundäre Nährmaterialien bei den Platoden vor. Die Furchung ist daher stets eine adäquale, die Furchungshöhle ist aber in der Regel klein und die Gastrulation eine epibolische. Es kommt meist direkte Entwicklung vor oder eine secundäre Metamorphose; nur ganz ausnalimsweise finden wir typische, primäre Larvenformen (Polycladen).

Die Scoleciden sind von geringer Grösse, oft sogar mikroskopisch (Rotatorien, manche Rhabdocoelen); sie sind langsam in ihrer Bewegung, vollkommenere Sinnesorgane sind nicht ausgebildet, so besitzen sie wohl niemals eigentliche bildsehende Augen und selten Gehör- und Geruchsorgane. Sie leben meist kriechend, seltener festsitzend, im Meere oder im Süsswasser oder an feuchten Orten am Lande; viele sind Parasiten.

\section{Classe der Scolecida. Platodes.}

Die Platodes sind afterlose Scoleciden von dorsoventral abgeplatteter Körperform; ihr stark entwickeltes Mesenchym liefert den Hautmuskelschlauch, die Dorsoventral-Muskeln und die Muskeln der Eingeweide, sowie a ch das parenchymatöse Bindegewebe, welches die primäre Leibeshöhle ganz oder theilweise erfüllt; sie besitzen ein reichverzweigtes Protonephridium (Wassergefässsystem); sie sind meist Zwittermit complicirten Geschlechtsorganen.

Die Classe der Plattwürmer zerfällt in drei Gruppen: 1) die freilebenden Turbellarien, welche an der ganzen Oberfläche ihres stark abgeplatteten Körpers gleichmässig bewimpert sind; sie besitzen mannigfache Sinnesorgane, ihre Mundöffnung liegt oft noch weit hinten an der Bauchfläche;2) die Trematoden, diese sind theils ectoparasitisch, 
theils endoparasitisch lebende Thiere, sie haben im ausgebildeten Zustande eine unbewimperte Oberfläche, sie sind aber mit Haftapparaten (Mund- und Bauchsaugnäpfen etc.) ausgestattet, ihre Mundöffinung liegt ventral, aber stets nahe vom Vorderende; 3) die durchwegs endoparasitischen Cestoden, sie sind ebenfalls unbewimpert und entbehren vollkommen des Darmkanales, ihre Körperform ist durch die Vervielfältigung des mit den Geschlechtsorganen ausgestatteten Hinterleibes auffallend modificirt (Proglottidenbildung), und sie sind mit vorderen Haftapparaten (Saugnäpfen, Hakenkränzen) ausgestattet. Die Turbellarien sind die Stammgruppe, von denselben sind die Trematoden und von den letzteren wieder die Cestoden abzuleiten; dieses Abstammungsverhältniss ist voll grösster Wichtigkeit für das Verständniss der vergleichenden Anatomie und Entwicklungsgeschichte dieser Gruppen.

Das Epithel ist bei den Tubellarien ein wohl entwickeltes Flimmerepithel, bei den Trematoden und Cestoden dagegen, wo es cuticulare Bildungen ausscheidet, ist es im erwachsenen Zustande oft schwer nachweisbar, subepitheliale einzellige Drüsen sind allgemein zu beobachten.

Der charakteristische $\mathrm{Hautmuskelschlauch} \mathrm{der} \mathrm{Platoden} \mathrm{ist}$ im allgemeinen aus einer äusseren continuirlichen Ringmuskel$\mathrm{schichte,} \mathrm{einer} \mathrm{innereil} \mathrm{meist} \mathrm{in} \mathrm{Bündeln} \mathrm{angeordneten} \mathrm{Längs} \mathrm{mus-}$ kelschichte und einem innersten gekreuzten Flechtwerk von D ia go$\mathrm{n}$ a $\mathrm{lmusk}$ elf a ser n aufgebaut; unter den mannigfachen Modificationen ist besonders eine Vermehrung der Schichten (Turbellarien, Fig. 313, pag. 331) von Bedeutung. Die dorsoventralen Muskeln, welche überall zwischen den inneren Organen ihren Verlauf nehmen, sind an ihren Enden meist verästelt. Sie sind für den parenchymatösen Bau der Platoden ebenso charakteristisch wie das parenchymatöse B ind e gewebe, welches die primäre Leibeshöhle meist ganz erfüllt, oft aber auch mehr oder weniger ansehnliche Hohlräume als Reste der primären Leibeshöhle freilässt (rhabdocoele Turbellarien); zumeist besteht es aus blasigem Bindegewebe, es fehlen aber auch nicht verästelte (sogenannte ,freie ${ }^{6}$ ) Bindegewebszellen. Wir finden ferner mannigfache Muskeln der Eingeweide.

Das $\mathrm{N}$ e r ven s y t e m besteht aus dem Cerebralganglion und den peripheren Nerven und ist in allen seinen Theilen im Parenchym oder in den Muskelschichten eingebettet. Das Cerebralganglion ist von seinem Entstehungsorte, dem vorderen Körperpol (Scheitelpol) in der Regel nicht weit weggerückt (Fig. 319 C, pag. 336); es ist meist zweilappig, ja es kann sogar in seitliche Theile getrennt sein, die durch eine Quercommissur verbunden sind (Trematoden). Zahlreiche vorder e Nerven ziehen zum vorderen Körperende; nach hinten erstrecken sich die parigen Längsnerven, von welchen das ventrale Paar stets das stärkste und auch constanteste ist, es kommt aber oft auch ein dorsales Längsnervenpaar und je ein seitlicher Längsnerv hinzu (Polycladen, Acoelen, Trematoden). Ein Schlundnervensystem ist bei den Dendrocoelen nachgewiesen (Fig. $319 C$, pag. 336). Die peripheren Nerven sind oft durch Commissuren, besonders Quercommissuren in der hinteren Bauchregion, miteinander verbunden, ja es kommt sogar ein Netzwerk unterhalb des ganzen Hautmuskelschlauches zur Ausbildung. Die Hauptmasse der Ganglienzellen findet sich im Cerebralganglion, es kommen solche aber auch in den peripheren Nerven, besonders im ventralen Längsnervenpaar, vor.

Von Sinnesorgan en finden wir bei den Turbellarien ein oder 
zwei Paar A ugen, oft auch eine grössere Zahl am vorderen Kiörperende, ein umpares $H$ örbläschen, W i m perg ruben, Tentakel, sämmtlich in der Nähe des Gehirnes und am vorderen Körpertheile. Bei den ectoparasitischen Trematoden und den Larven der endoparasitischen Trematoden kommen Gehirnaugen und auch Tastorgane vor. Bei den Cestoden ist dem vorderen Körperende nur noch eine etwas erhöhte Empfindlichkeit zuzuschreiben.

Der Darmtractus der Platoden besteht aus dem Schlund und dem Magendarm; da ein Afterdarm und After fehlen, so fungirt der Mund zugleich auch als Auswurfsöffnung. Die Cestoden nehmen als Endoparasiten ihre Nahrung vermittelst ihrer Haut endosmotisch auf und der Darmkanal ist bei denselben vollkommen rückgebildet. Auch bei gewissen freilebenden kleinen Turbellarien, den Acoclen, ist der Darm nicht nachgewiesen; bei denselben tritt die Nahrung durch die Mundöffnung entweder direkt oder vermittelst eines Schlundes in das „,verdauende Parenchym" ein; dies Verhalten scheint aber noch nicht genügend anfgeklärt (Fig. 316, pag. 333).

Del' Schlund ist in der Regel in zwei 'Theile differenzirt, einen vorderen als Schlund tasche bezeichneten Abschnitt und einen hinteren muskulösen Schlundkopf (Pharynx), welcher bei den Turbellarien nach Art eines Riissels aus der Mundöffnung vorgestreckt werden kann, ähnlich verhält er sich bei den Trematoden, wo er aber auch oft als Saugpmmpe wirkt. Speicheldrüsen sind meist in die Muskulatur des Schlundkopfes eingebettet (Fig. 317, pag. 334).

Der Magendarm ist nur bei den Rhabdocoelen ein geradgestreckter, meist iiber dem Schlunde liegender Blindsack; im allgemeinen zeigt er die Tendenz zur Verästelung, er gibt Aeste ab, die selbst wieder verzweigt sein können (Dendrocoelen, Trematoden), ja sogar Anastomosen bilden; bei den Trematoden ist er durch die Ausbildung von paarigen hinteren Aesten gabeltheilig. Das Darmepithel ist meist bewimpert (intracelluläre Verdauung pag. 153).

Der Excretionsapparat (vergl. pag. 160), der als Wassergefässsystem bezeichnet wird, zeichnet sich stets durch eine reiche Verästelung aus, welche proportional mit der Grösse der Formen zunimmt. die Excretionscapillaren sind meist überaus zahlreich, auch die Sammelkanäle sind mehr oder weniger reich verzweigt, es kommt bei denselben sogar zu Anastomosenbildung. In ilner Anordnung und Ausmündung zeigen die Hauptstämme schon bei den Turbellarien mannigfaclie Modificationen; als ursprünglichster Typus sind wohl ein Paar von Längsstämmen zu betrachten, die in der Nähe des Hinterendes nach aussen münden, doch können die Mündnngen an der Bauchseite weiter vorn liegen (bei Mesostoma münden sie in den Vorraum des Schlundes [Fig. 321, pag. 338]), und sogar bis an das Vorderende rücken; auch eine mediane Verschmelzung der Hauptstämme kommt vor. Bei den Dendrocoelen sind zahlreiche Ausmündungen der beiden Hauptstämme an der Rückenfläche beobachtet; auch eine Vermehrung der Hauptstämme kommt hier vor. Bei den monogenetischen Trematoden (Polystomeen) münden die Excretionsorgane in der Regel getrennt dorsal; bei den digenetischen Trematoden (Distomeen) dagegen münden die paarigen Hauptstämme in eine hintere unpare Harnblase. Hierauf ist auch das Verhalten der Cestoden zurückzuführen, doch bildet bei diesen eine Vermehrung der Hauptstämme die Regel, auch kommen neben der Hauptöffnung zahlreiche secundäre Ausmündungen vor. 
Die Platoden sind mit wenigen Ausnahmen (Microstoma, Distoma haematobium) Zwitter. Männlicher und weiblicher Geschlechtsapparat münden an der Bauchfläche (selten asymmetrisch) hinter dem Munde, und zwar meist in eine gemeinsame Geschlechtskloake. Der männliche Theil des Apparates besteht aus den parigen Hoden und Vasa deferentia, feruer Ductus ejaculatorius, Prostatadrüse und stets auch einem vorstülpbaren $\mathrm{Pen}$ is. Der weibliche Theil ist complicirter, da das in demselben sich bildende Ei der Platoden ein zusammengesetztes ist. Die Eizelle entstammt dem (paarigen, oft auch unparen) O vari u m od e r , Ke ims to ck", zu demselben kommt je eine grössere Anzahl von Dotterzellen, die in besonderen Dotterstöcken sich bilden, und ein sekundäres Nährmaterial repräsentiren; die Eileiter und die Dottergänge führen in den äusseren Eiergang (oder zunächst in eine besonders ausgebildete Stelle desselben, das O otyp), hier wird das Ei befruchtet und mitsammt einer Anzahl von Dotterzellen von einer chitinartigen secundären Hülle eingeschlossen, welche von besonderen $\mathrm{Sch}$ al e nd r ü s en ausgeschieden wird; der Eiergang führt dann zum weiblichen Begattungsapparat, der Vagina. Meist ist auch ein Uterus zur Ansammlung der befruchteten fertigen Fier und ein Receptaculum semin is vorhanden, welche entweder Differenzirungen des Oviductes oder des äusseren Eierganges oder auch der äusseren Geschlechtskloake sind.

Die Dotterstöcke, welche für die Platoden so charakteristisch sind, werden als modificirte Theile des Ovariums aufgefasst; die Dotterzellen sind demnach abortive Eier, die zur Ernährung des Embryo dienen.

Die Polycladen zeigen ein niedrigeres Verhalten, da bei denselben typisch die Dotterstöcke fehlen; doch kommt es hier vor, dass melirere Eier in eine secundüre Hülle eingeschlossen werden, und auch, dass nur eines davon sich entwickelt, während die anderen als Nährmaterial dieuen (ähnlich wie bei manchen Schnecken, z. B. Neritina). Auch bei den Acoelen fehlen die Dotterstöcke; bei manchen Rhabdocoelen ist ein Keimdotterstock, der beiderlei Zellen liefert, vorhanden.

Die Modificationen des complicirten Geschlechtsapparates sind überaus mannigfaltig. Besonders interessant ist das Auftreten von secundären Oeffnungen; so

Fig. 307. Distomum spathulatum $(12 / 1)$, nach Leuckart. Darstellung der Körperform des Darmes und Geschlechtsapparates; am Hinterende die Excretionsöffnung. ms Mundsaugnapf, ph Pharynx, $i$ gabeltheiliger Darm, bs Bauchsaugnapf, ठ männliche, ․ weibliche Geschlechtsöffnung (nämlich Mündung des Uterus), öLg Oeffnung des Begattungsganges (Laurer'schen Ganges), $t$ Hoden, $v d$ Vas deferens, ov Ovarium, $d t$ Dotterstock, Lg LAURER'scher Gang, rs Receptaculum seminis, $u$ Uterus.

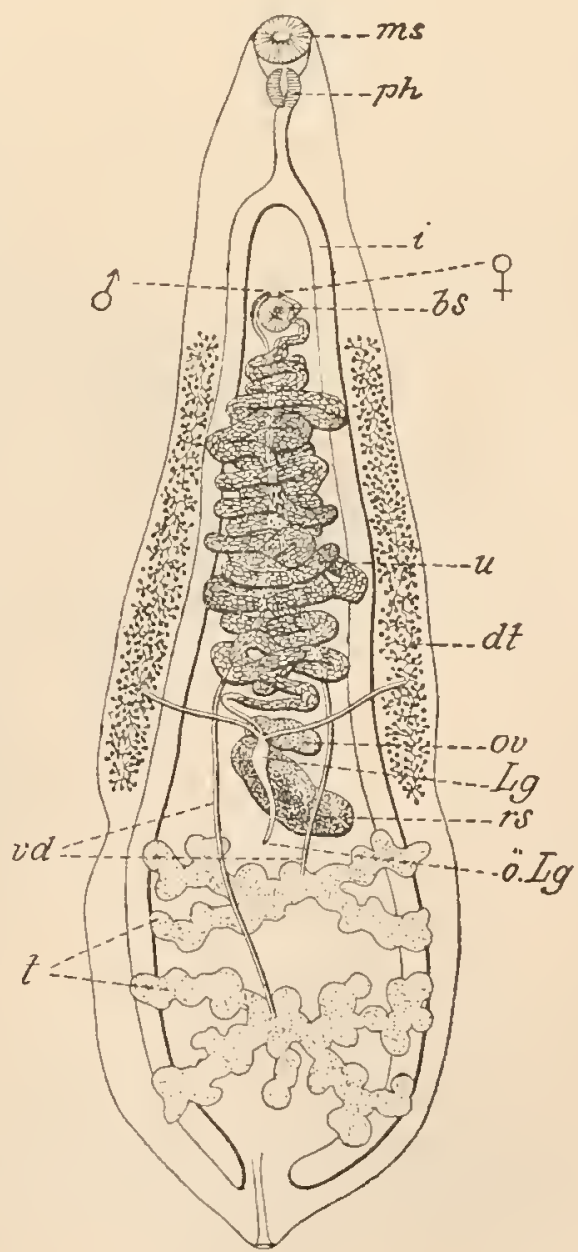


entsteht bei den Trematoden ein specieller weiblicher Begattungsgang (paarig oder einfach) und der Eiergang fungirt nun uterusartig angeschwollen nur zur Ausleitung der Eier. Bei den Cestoden dagegen fungirt der ursprüngliche Gang ausschliesslich als Begattungsgang und der besondere Uterus endigt blind bei den Taenien, oder gewinnt eine secundäre Oeffnung bei den Botriocephaliden. - Die überaus mannigfaltigen Modificationen in allen einzelnen Theilen des Apparates bilden ein wichtiges und interessantes Kapitel in der vergleichenden Anatomie der Platoden; einerseits dienen sie zur Feststellung der speciellen Verwandtschaftsverhältnisse der einzelnen Abtheilungen; andererseits ist es für den Nachweis der einheitlichen Abstammung der Platoden von grösster Bedeutung, dass eine Reihe von wesentlichen Eigenthümlichkeiten trotz aller Variationen überall sich wiederholt.

Den Grundtypus der Geschlechtsorgane können wir uns folgendermassen vorstellen: Sowohl der männliche als auch der weibliche Apparat besteht ursprünglich 1) aus zwei Paar von Längskanälen, den G o n a d e ngängen, die als periphere Ausbuchtungen die Gonaden (Hoden, Ovarien) tragen und 2) aus den Begattungsorganen (Penis, Vagina). Die ersteren besitzen ein vom Mesoderm stammendes Epithel, die letzteren haben als Differenzirungen der Haut (nach LANG) ein ectodermales Epithel.

Die Eier der Platoden sind klein, um so kleiner dort, wo ihnen secundäre Nährmaterialien beigegeben sind; die Furchung ist daher

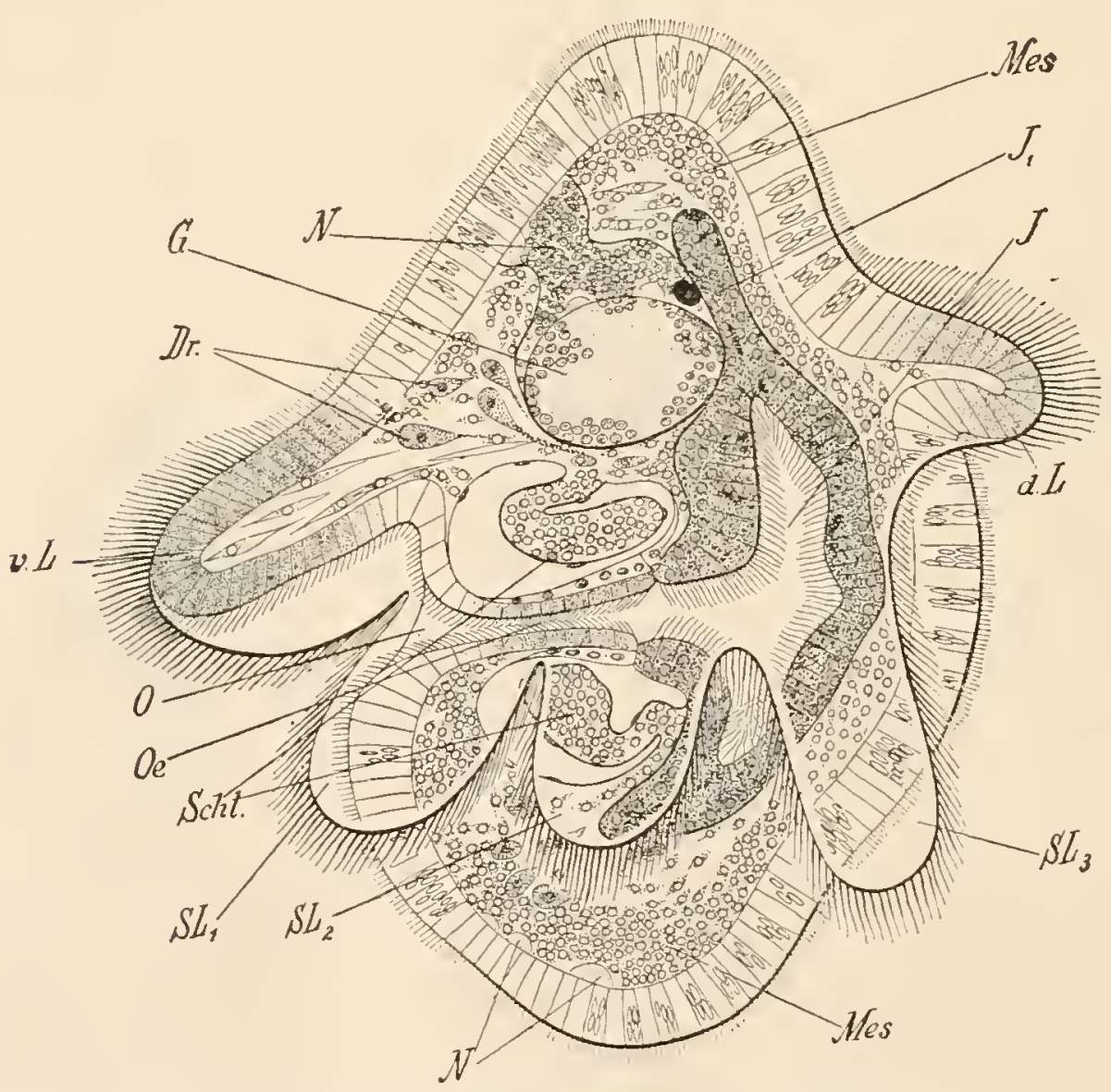

Fig. 308. Larve einer Polycladen-Turbellarie (Thysanozoon), nach LANG. Es ist die innere Organisation, im Längsschnitt gesehen, combinirt mit der Darstellung der äusseren Wimperapparate. Der präorale Wimperkranz ist auf tentakelartige Fortsätze $\left(v L, S L_{1}\right.$, $\left.S L_{2}, S L_{3}, d L\right)$ ausgedehnt. Bezeichnung der inneren Organisation wie in Fig. 323, pag. 339. 
eine adäquale, doch ist die Furchungshöhle sehr klein und die Gastrulation walıscheinlich stets eine epibolische (wie bei den Scoleciden im allgemeinen); die Differenzirung der Blätter ist übrigens noch wenig erforscht, am besten bei den Polycladen.

Das ganze Thier hat beim Verlassen der Eihülle ganz allgemein schon die Organisation eines Platoden; doch sind gewisse Modificationen, die dabei vorkommen, hervorzuheben. Nur die Larven der Seeplanarien sind durch ein wahrscheinlich palingenetisches Larvenorgan ausgezeichnet, da sie einen präoralen Wimperkranz besitzen. Die iibrigen Turbellarien haben directe Entwicklung, ebenso die ectoparasitischen Trematoden. Die Distomeen besitzen eine sogenannte infusorienförmige Larve, welche die wesentlichen Organe der Platoden (Darm, Cerebral-

Fig. 309. Wimpernde Larve von Polystomum, nach ZELLER. o Mund, oe Schlundtasche, $P h$ Schlundkopf, $J$ Darm, $S N$ Saugnapf, $O C$ Augen, Neph Nephridien, ao deren äussere, dorsal gelegene Oeffnungen.

Fig. 310. Larve von Distomum hepaticum, mit einer wimpernden grosszelligen Embryonalhülle versehen, nach LEUCKART. CQ Cerebralganglion mit $x$-förmigem Augenfleck, $J$ rudimentärer Darm, Neph Terminalzellen der Nephridien, $H Z$ Zellen der Embryonalhülle, Nuc deren Kerne; $K Z$ Keimzelle, $K Z$ ebensolche, die bereits in Entwicklung begriffen ist.
Fig. 309.

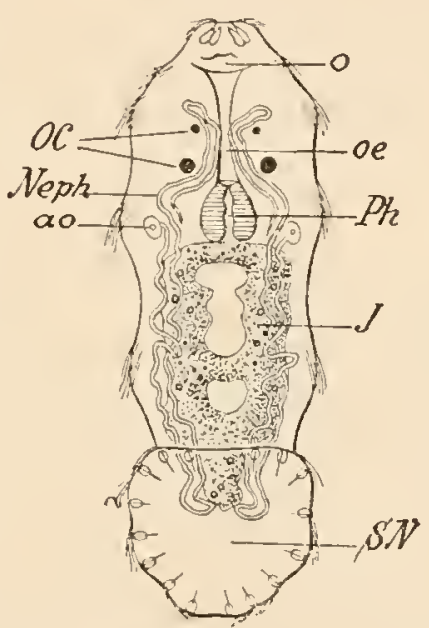

Fig. 310 .

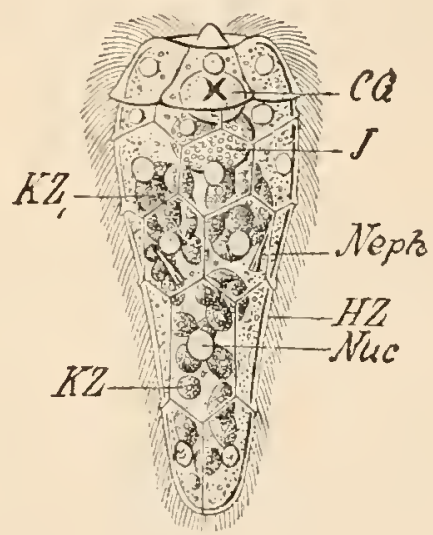

ganglion, Wassergefässsystem), wenn auch in rudimentärer Ausbildung besitzt; sie sind mit grossen Flimmerzellen bedeckt, die später abgeworfen werden; ich halte diese nicht (wie die meisten Autoren) für das gesammte äussere Epithel, sondern für einen den Körper als E m b r y onalhülle umwachsenden Theil dieses Epithels. Auch die Cestoden besitzen eine Embryonalhülle, welche entweder die junge Larve beim Verlassen des Eies als bewimperte Zellschichte bekleidet (Bothriocephaliden), oder in einen schalenartigen Apparat (Stäbchenhülle) sich verwandelt (Taeniaden); die Larve selbst ist bei den Cestoden in An-

Cestoden (Bothryo lide), nach SchauinsLAND. A Sechshakige Larve, umgehen von ihrer flimmernden Embryonalhülle. $B$ dieselbe, im Begriffe, die Hiulle zu verlassen.
$B$

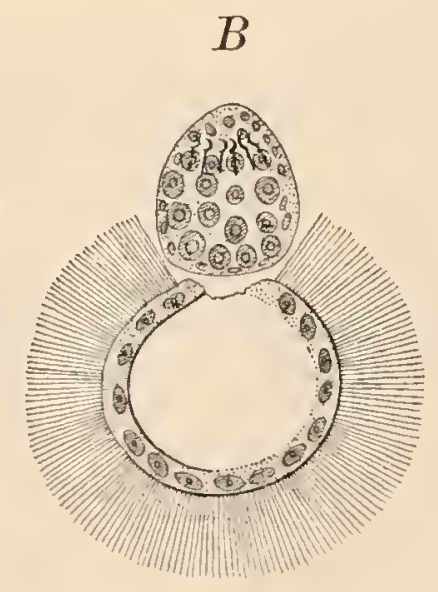

A.

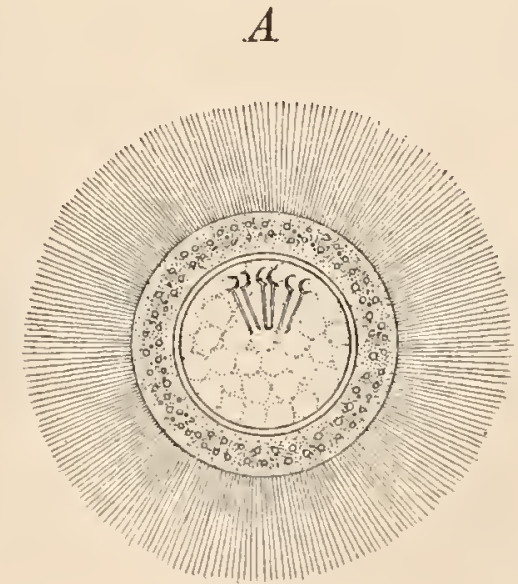


passung an ilıre speciellen Lebensaufgaben von äusserster Kleinheit und von rudimentärer Organisation, sie ist aber wohl mit jener bewimperten Distomeen-Larve, welche deutlichere Organe zeigt, in Parallele zu stellen. Sowohl bei den Distomeen als auch bei den Cestoden folgt eine merkwiirdige Netamorpliose, deren einzelne Stadien als in Anpassung an besondere Lebensbedingungen se cundär erworben e Formgestaltungen zu betrachten sind; diese Reihe wird vielfach noch durch ungeschlechtliche Fortpflanzungsvorgänge weiter complicirt. In analoger Weise finden wir durch secundäre Anpassung erworbene Larvenformen auch in anderen Thierklassen, besouders bei Insecten. Fortpflanzung durch Theilung kommt bei den Platoden in mannigfacher Weise vor. Parthenogenese findet sich bei Trematoden. Die Platoden sind durchweg kleinere Thierformen von langsamer Bewegung. Die Turbellarien leben meist kriechend im Meere und Süsswasser an Grunde und unter Stuinen; die Landplanarien besonders in der feuchten Atmosphäre der tropischen Wälder als Landthiere. Die Trematoden und Cestoden leben parasitisch an und in den verschiedensten wirbellosen und Wirbelthieren; viele interessiren uns als specielle Parasiten des Mensclien.

\section{Ord. Turbellaria.}

Die Turbellarien sind freilebende Platoden mit bewimperter Körperober fläche.

Der Körper der Turbellarien ist bei den kleineren Formen, den Rhabdocoelen, nur wenig abgeplattet, oft nahezu spindelförmig. Bei den grösseren Formen, den Dendrocoetiden, ist er stets stark abgeplattet und oval (viele Polycladen) oder mehr langgestreckt (Polycladen und alle Tricladen).

Das äussere Epithel ist bei den Turbellarien ein ansehnliches Flimmerepithel, welches auch Simmeszellen und intraepitheliale Schleimzellen (Klebzellen) enthält und meist der Sitz der Pigmentirung ist; es besitzt eine feine Cuticula; ganz ausnahmsweise kommen einzelne stärkere Chitimbildungen (Chitinhaken) vor. Subepitheliale, bis in das Parenchym ragende einzellige Druisen sind, wie bei allen Platoden, vorhanden; hier bei den Turbellarien kommen auch noch als besondere charakteristische Bildungen, drüsenartige Zellen vor, welche den Nesselorganen ähnliche glänzenrle Stäbchen (Rhabditen) oder sogar echte Nesselkapselu (bei Microstoma) erzeugen.

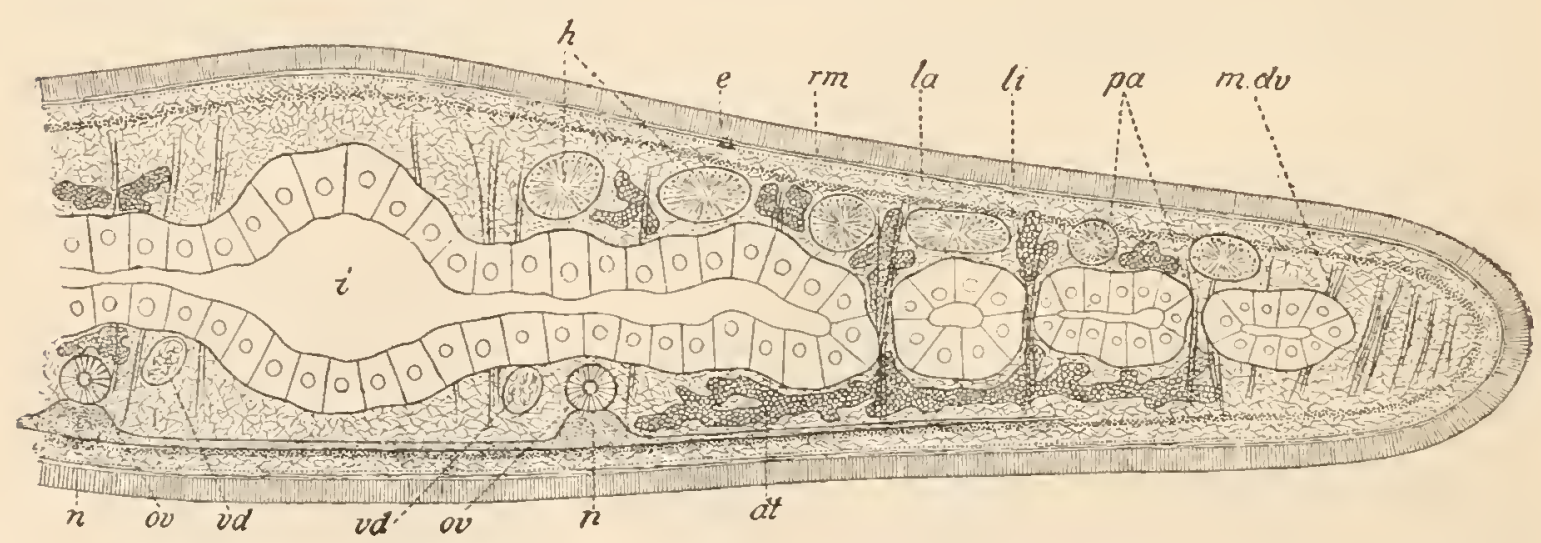

Fig. 312. Querschnitt durch den Körper einer Planarie, nach J. JiJima e Aeusseres Epithel, rm Ringmuskelschichte, $l a$ äussere Längsmuskelschichte, li innere Längsmuskelschichte, $p a$ Parenchym, $m d v$ dorsoventrale Muskelzüge, $n$ Querschnitt des ventralen Längsnerven, vd Vas deferens, ov Oviduct, $h$ Hoden, $d t$ Dotterstöcke. 
Unter dem Epithel findet sich eine Stiitzmembran, welche von bedeutender Festigkeit ist und die speciell bei den Polycladen als eine mit \%ellen versehene Bindesubstanz erkannt wurde. Dieselbe steht in inniger Verbindung mit dem Hautmuskelschlauch, der aus der äusseren Ringmuskelschichte, der imneren Längsmuskelschichte und der doppelten Diagonalfaser'schichte und stets noch einer tieferen accessorischen kräftigen Längsmuskelschichte aufgebaut ist. An gewissen Körperstellen ist der Hautmuskelschlauch zu besonderen Zwecken modificirt; so ist er in der Regel an der Bauchfläche, die als Kriechsohle fungirt, mächtiger entwickelt; bei den Seeplanarien in der Abtheilung der Cotyleen findet sich ein Saugnapf an der Bauchseite hinter dem Munde; bei einer Familie der Rhabdocoelen, den Proboscideen, kann das Vorderende des Körpers als Tastrüssel mittelst eigenthümlicher Muskeleinrichtungen eingestïlpt und vorgestreckt werden. - Dic dorsoventralen Muskeln und das parenchymatöse Bindegewebe lassen nur bei den Rhabdocoelen noch umfangreichere Gewebslücken zwischen den Organen frei. Die Muskeln der Eingeweide zeigen eine grosse Mannigfaltigkeit je nach der speciellen Leistung der Organe.

Fig. 313. Schiefer Flächenschnitt durch den Hautmuskelschlauch einer Planarie, um die Schichtenfolge der Muskeln zu zeigen, nach J. JrJiмa. rm Ringmuskelschichte, $l m$ äussere Längsmuskelschichte, $d m$ diagonale Muskelschichte, $i t m$ innere Längsmuskelsclichte.

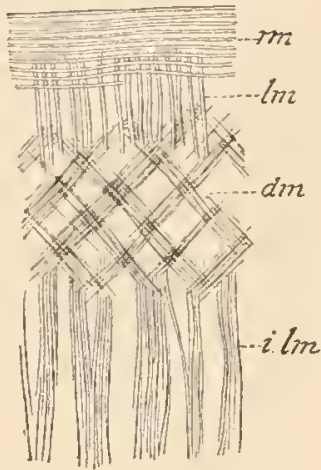

Nervensystem und Sinnesorgane sind stets wohl ausgebildet. Das oft in zwei seitliche Lappen ausgezogene Cerebralganglion liegt in der Regel in der Nähe des Vorderendes. Nur bei den Polycladen, bei welchen es vom dorsalen unpaaren Darmaste überragt wird, entfernt es sich während der Entwicklmmg manchmal bedeutend voin Vorderrande (Fig. 315). Vom Cerebralganglion ziehen zahlreiche Nerven nach dem vorderen Körperende und zu den Sinnesorganen, insofern diese nicht direkt dem Gehirn anliegen (Fig. 319). Von den hinteren Längsnervenpaaren ist bei den Rhabdocoelen und Tricladen nur das ventrale Paar beobachtet, bei den Polycladen und auch den Acoelen ist ferner ein schwächeres dorsales und ein seitliches Paar nachgewiesen; bei den Dendrocoelen ist überdies ein reicher peripherer Nervenplexus entwickelt, auch sind bei denselben Nerven im Schlundkopf beobachtet worden (Fig. 319).

Von specifischen Sinnesorganen finden wir bei den Turbellarien: Augen, Gehörbläschen, Flimmergruben (Geruchsgrübchen) und Tentakel ${ }^{1}$ ). Bei den Rhabdocoeliden finden wir meist zwei oder vier Augen dem Gehirn angefügt (Primäraugen) (Fig. 314). Die Augen der Dendrocoelen finden sich meist in grosser Anzahl (in Zweizahl bei manchen Tricladen)

1) Die Sinnesorgane kann man morphologisch in primäre Organe eintheilen, welche zum Theil in unmittelbarem Zusammenhang mit dem Gehirn sich finden, zum Theil auch am Entstehungsort des Ganglions (dem Scheitelpole) verbleiben, und in se cun d ä re Organe, die namentlich am vorderen Körperrande in grosser Verbreitung sich finden. Es sind z. B. die 2 bis 4 dem Gehirn anliegendell Augen der Rhabdocoeliden als Primäraugen zu betrachten, während die zahlreichen Augen ain vorderen Körperrande der meisten Dendrocoeliden Secundäraugen sind; zu den primären Organen zählen wir ferner die Primärtentakel, die Flimmergruben und das unpaare Gehörorgan. 
und sind stets unter der Haut gelegen (sie sind von inversem Typus!); bei den Polycladen finden wir solche meist in grosser Zahl am vorderen Körperrande, und überdies eine Gruppe übel dem Gehirn am Rücken, im sogenannten ,Gehirnhofe“, der wahrscheinlich dem Scheitelpol entspricht (letztere sind vielleicht auf Primäraugen zurïckzuführen) (Fig. 315); bei den Cotyleen kommt zudem noch ein Paar von Gehirn-

Fig. 314 .
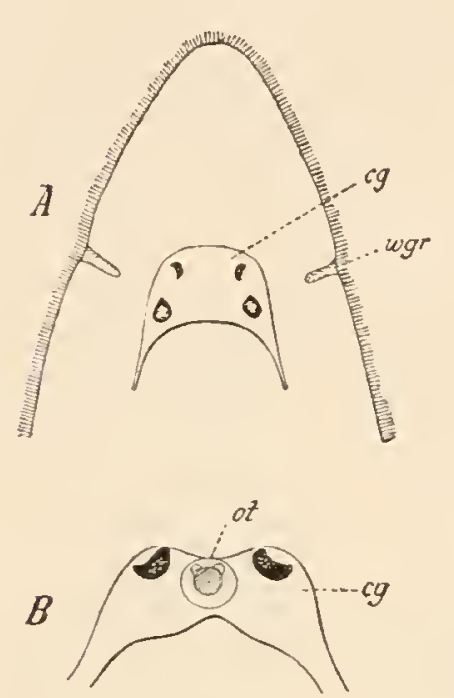

Fig. 314. A Vorderende von Allostoma (nach voN GrafF). cg Cerebralganglion mit vier Augenflecken, wgr Wimpergruben.

$B$ Cerebralganglion von Monotus, mit zwei Atugenflecken und unpaarem Hörbläschen (nach V. GrafF).
Fig. 315 .

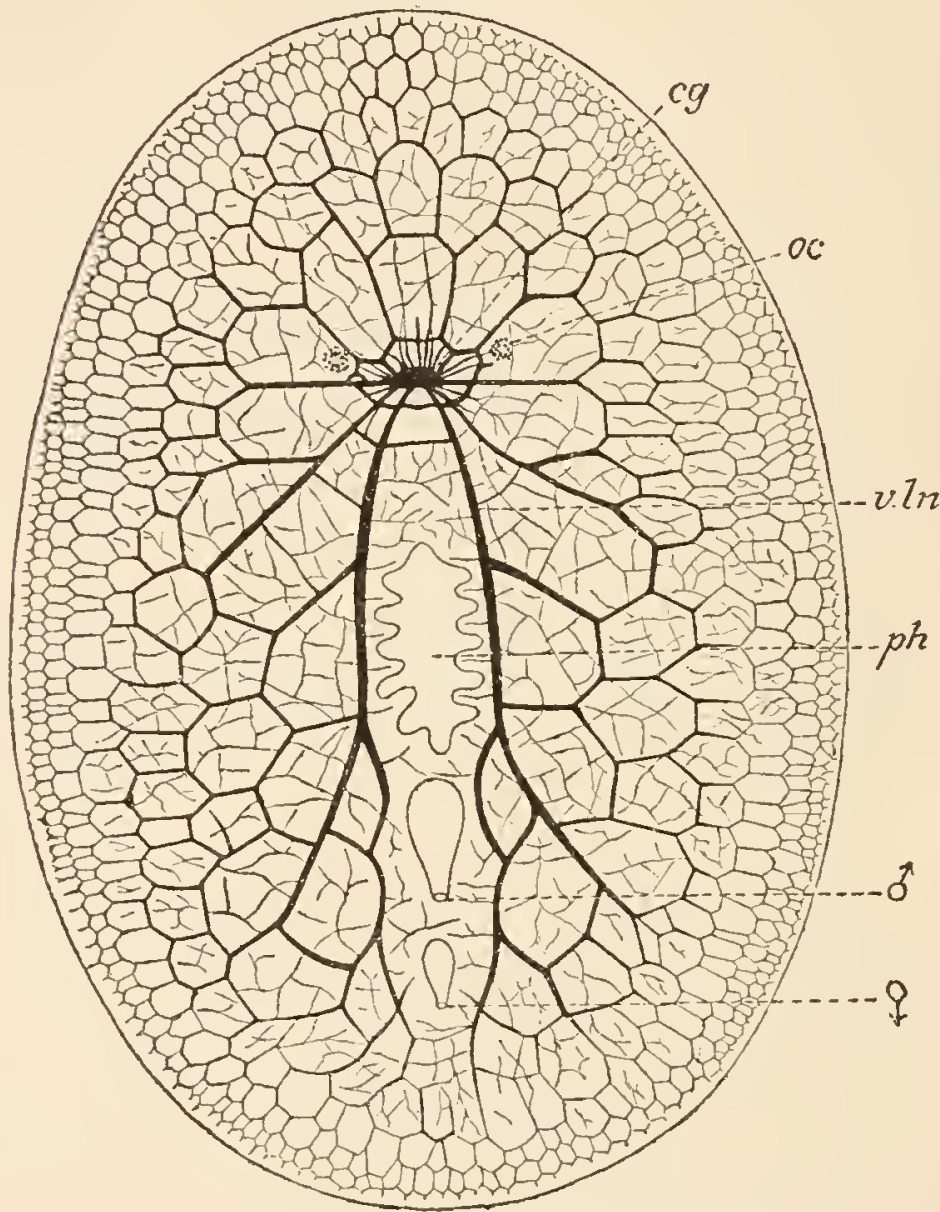

Fig. 315. Centralnervensystem und ventraler Nervenplexus einer Polyclade (Planocera), nach LANG. cg Cerebralganglion, oc Augen an der Tentakelbasis, vln ventraler Längsnerv, ph Pharynx, $\delta$ männliche, $q$ weibliche Geschlechtsöffnung.

augen vor. Ein un pares, dem Celebralganglion anliegendes, mit einem Otholiten versehenes Gehörbläschen findet sich nur bei einigen Rhabdocoeliden (z. B. den Monotiden, Otoplana und Acoelen) (Fig. 314 B); es ist dies wahrscheinlich ein uraltes Organ, das nirgends sonst bei anderen Zygoneuren sich erhalten hat. Primäre parige Flim mergruben finden sich ebenfalls nur bei manchen Rhabdocoeliden (Plagiostomiden, Microstomiden, Prorhynchiden) ${ }^{1}$ ); stärker Himmernde Stellen in der Nähe des Vorderrandes (oft in Vielzahl) sind auch bei Dendrocoelen beobachtet. Primärtentakel kommen als paarige Nackententakel nur bei gewissen Polycladen (den Planoceriden) vor; sie sind von den bei anderen Polycladen vorkommenden $R$ and te nt ake $n$ $\mathrm{zu}$ unterscheiden $\left(\mathrm{L}_{\mathrm{ANG}}\right)$, in welche oft Darmäste hineinragen. Bei den

1) Unpaares Gehörbläschen, Augen und Flimmergruben finden wir an ein und dem. selben Thier vereinigt bei Otoplana. 
Tricladen fungiren als Tentakel seitliche Ausbuchtungen des Vorderendes (die vielleicht auch Primärtentakeln entsprechen). Bei den Rhabdocoeliden fungirt das Vorderende des Körper's allgemein als 'Tastorgan und ist speciell bei den Proboscideen zu einem einstülpbaren 'Tastrüssel differenzirt ${ }^{1}$ ).

Mit Ausnahme der kleinen Acoelen, bei welchen der Magendarm, ja meist sogar der Schlund fehlen soll, sind die beiden Theile des Darmtractus stets wohl entwickelt. - Die Mundöffnung liegt an der Bauchseite (nur bei einigen Acoelen am Vorderende), sie zeigt aber dabei im speciellen ein selı wechselndes Lageverhältniss. In der Mehrzahl der Fälle - und zwar ist dies als der ursprüngliche Zustand zu betrachten - liegt sie weit linten oder in der Mitte der Bauchfläche; sie kann aber auch weit nach vorn rücken. Bei den Polycladen wird in jenen Fällen, wo die Mundöffinung nach vor'n rückt, auch die Geschlechtsöffnung mit nach vorn verschoben (Eurylepta, Prosthiotomum). Bei den Tricladen ist die Lage der Mundöffnung stets hinter der Körpermitte. Auch bei den Rhablocoelen rückt die Mundöffnung in manchen Fällen weit nach vorn (Macrostoma, Microstoma, Prorhynchus, Vortex und viele Acoelen), aber ohne dass die Geschlechtsöffinung regelmässig an dieser Lageveränderung theilnähme. - Bei mittlerer Lage der Mundöffnung ist der Schlund gerade aufsteigend, bei vorderer Mundöffnung nach hinten, bei hinterer Mundöffnung nach vorn gewendet (LANG). Der Schlund ist nur bei wenigen Rhabdocoeliden ein einfaches, innen flimmerndes Rohr mit äusserem Belage von Speicheldrüsen (Pharynx's i mplex bei Macrostoma, Microstoma). In der Regel aber ist er in Schlundtasche und vorstülpbaren Schlundkopf differenzirt. Der letztere ist eine ringförmige, in die Schlundtasche vorspringende Verdickung, welche durch besondere Differenzirung von Muskeln (Ringmuskeln, Längsmuskeln, Radiärmuskeln) und Einlagerung von Speicheldrüsen entstauden ist. Die Schlundkopfmasse ist gegen das benachbarte Gewebe durch eine vollständige Muskellamelle abgeschlossen - dies ist bei dem tonnen-

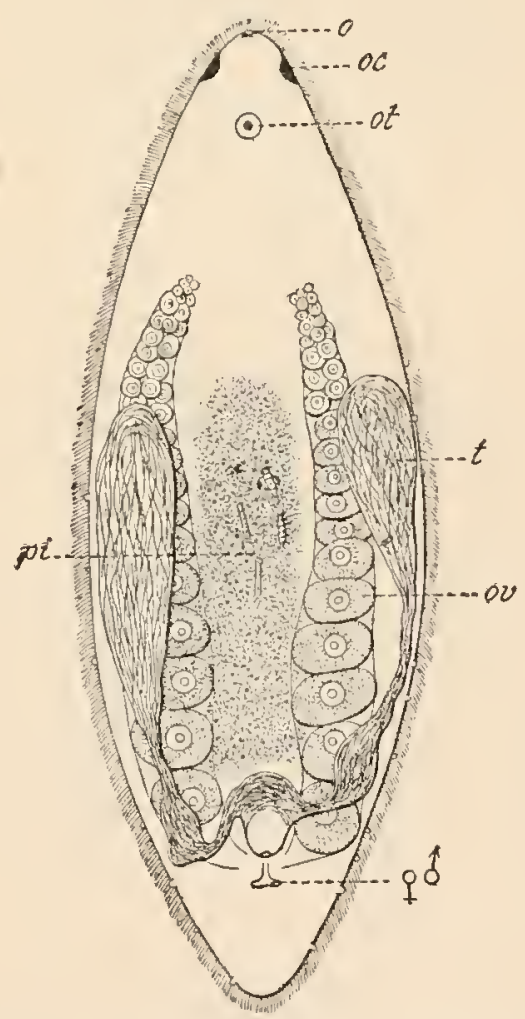

Fig. 316. Organisation einer acoelen Turbellarie (Proporus), nach L V. Graff. - Mund, oc Augen, ot unpuares Hörbläschen, $t$ Hoden, ov Ovarium, $\not \delta$ gemeinsame männliche und weibliche Geschlechtsöffnung, pi das ,,verdauende Parenchym".

1) Der Anschauung von LANG, dass die Lage des Gehirns weit hinten am Rücken die ursprüngliche sei, kann ich mich nicht anschliessen; denn der Entstehungsort des Ganglions ist das vordere Körperende. Das Lageverhältniss bei den Polycladen ist vielleicht nicht allein durch Verschiebung zu erklären, sondern durch die Ausbildung eines für die Polycladen charakteristischen Randsaumes; denn es liegen auch die Primärtentakel, die bei den Planoceriden vorkommen, und die wohl den Scheitelpol bezeichnen an der Rückenflüche in der Gegend des Ganglious. Wenn ferner LANG die radiäre Ausstrahlung der Nerven vom Ganglion nach dem Körperrande von dem ursprünglichen radiären Typus ableitet, so können wir dem nicht beistimmen, und wir müssen erinnern, dass er sich dabei-speciell auf die ventralen Nerven bezieht. Wir sind vielmehr der Ansicht, dass dorsale und ventrale Nerven als ursprünglich radiär um die Längsachse angeordnet zu betrachten sind. 
förmigen Schlundkopf ( $\mathrm{Phary} n \mathrm{x}$ bulbosus) der meisten Rhabdocoeliden der Fall —; oder es besteht ein allmählicher Uebergang der Gewebe - und das ist bei dem röhrenförmigen Schlundkopf (Pharynx plicatus) der Dendrocoeliden zu beobachten, welcher die Form eines langen, im contrahirten Zustande oft stark gefalteten Schlauches hat, der ganz in die Schlundtasche vorragt und bei der Ausstülpung weit vorgestreckt werden kann. - Der Magendarm ist bei den Rhabdocoelen ein langgestreckter, meist über dem Schlunde gelegener Blindsack (Fig. 321). Bei den Dendrocoelen besitzt er Ausläufer, die selbst wieder verzweigt sind, ja sogar durch Anastomosen-
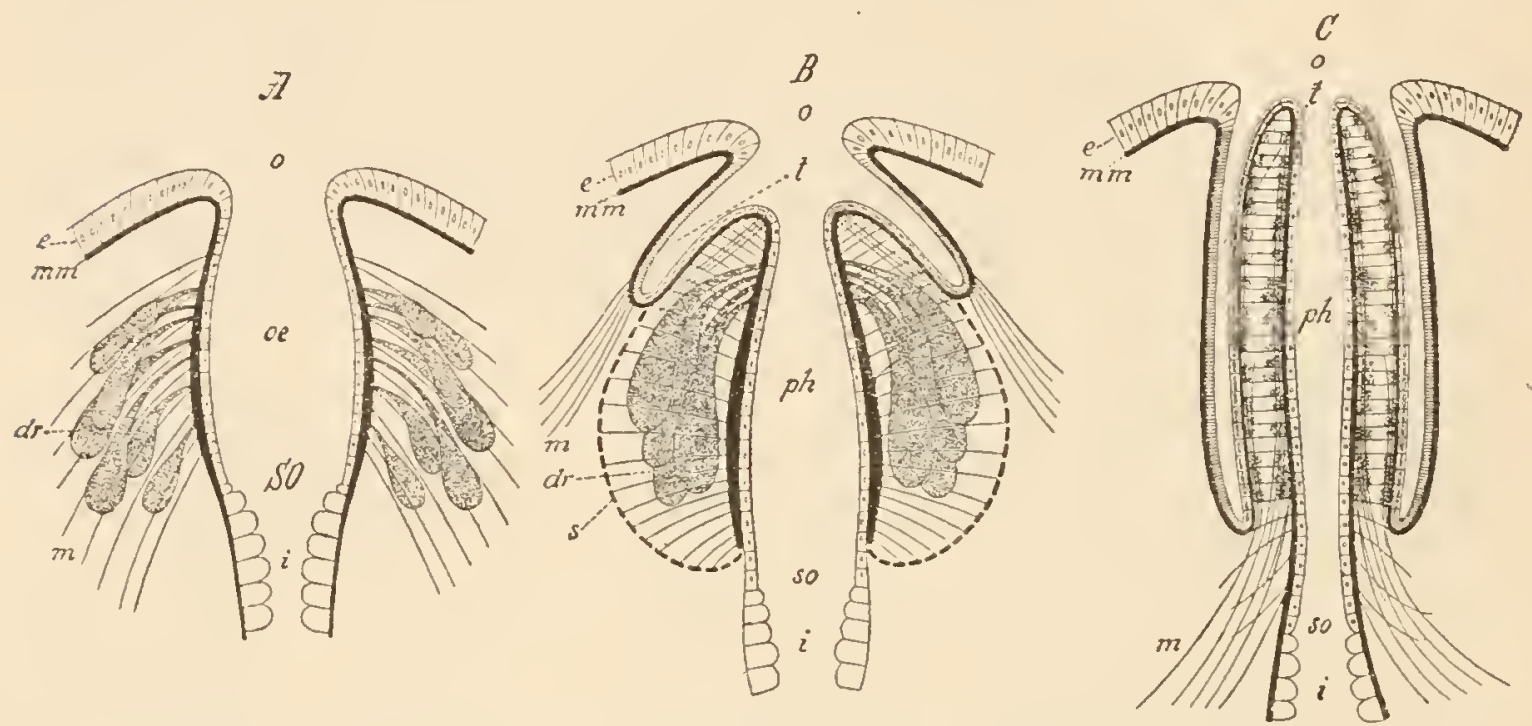

Fig. 317. Die Hauptformen des Pharynx bei den Turbellarien, nach L. v. GrafF. A Pharynx simplex (Microstoma), B Pharynx bulbosus (Mesostoma), $C$ Pharynx plicatus (Monotus).

bildung ein Netzwerk darstellen, das auch periphere Oeffinungen besitzen kann (bei manchen Polycladen); wir finden in speciellen bei den Polycladen einen vorderen unpaaren, über das Gehirn hinwegziehenden und zahlreiche paarige Hauptäste (Fig. 318); bei den Tricladen zerfällt der Dar'm schon dicht am Schlunde in drei Hauptäste, und zwar in einen vorderen unpaaren (vielleicht dem Hauptdarm entsprechenden) und je einen rechten und linken, gegen das Hinterende verlaufenden Ast (Fig. $319 \mathrm{~A}$ ); letztere können an ihrem Ende miteinander anastomosiren.

Das Wassergefässsystem besitzt in der Regel paarige Hauptstämme, die bei den Rhabdocoeliden meist an der Bauchseite durch je eine Oeffnung münden, deren Lage eine mannigfache ist, dagegen bei den Dendrocoeliden meist in zahlreiche rückenständige Poren sich öffnen (Fig. 319 A). Bei den Acoelen ist kein Wassergefässsystem beobachtet.

Die Geschlechtsorgane zeigen schon bei den Turbellarien eine so grosse Mannigfaltigkeit, dass wir hier nur die Haupttypen in ihren wichtigsten Charakteren liervorheben können. Bei den Polycladen (Fig. 318) liegen hinter dem Munde die beiden Geschlechtsöffinungen, vorn die männliche, hinten die weibliche, meistens getrennt, seltener in eine Cloake vereinigt. Die Eier werden in sehr zahlreichen Ovarien erzeugt (Dotterstöcke fehlen!) und gelangen durch zahlreiche Zweige in die Hauptstämme des Oviductes, welche als parige, uterusartig an- 
geschwollene Längskanäle erscheinen und sich in den mit Schalendrüsen versehenen unpaaren Eiergang und dic „Scheide“6 fortsetzten, welche letztere meist nur zur Ausfulur der Eier -- nicht zur Begattung dient. Die Hoden sind ebenfalls sehr zahlreich und ilı'e Ausführungsgänge (Vasa deferentia) bestehen aus den verzweigten Aesten und den

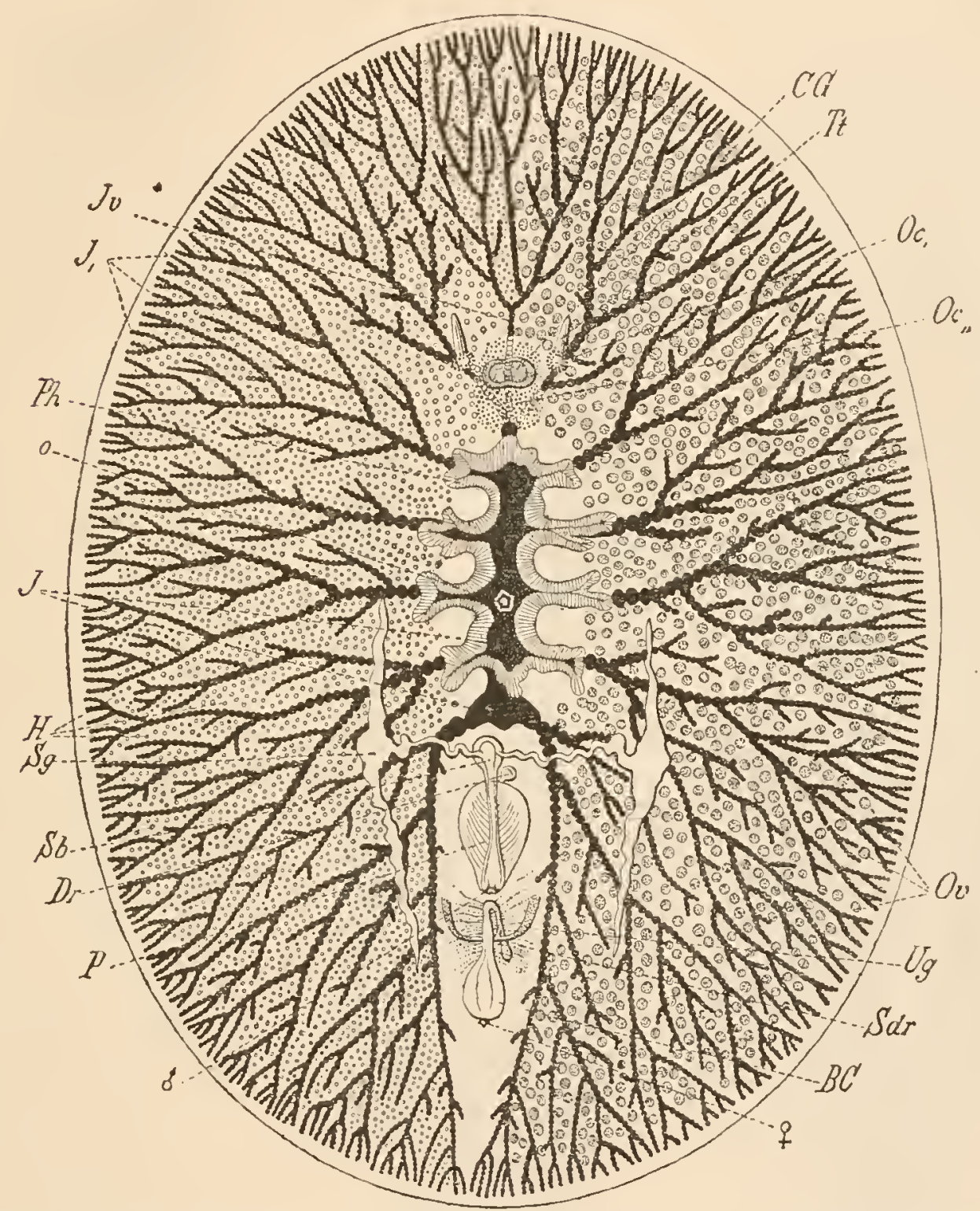

Fig. 318. Organisation einer Polyclade (Planocera), von der Bauchseite gesehen; die rückenständigen Tentakel $(T t)$ sind aber durchschimmernd dargestellt; links sind nur die Hodenbläschen $(H)$, rechts nur die Ovarien $(O v)$ eingetragen, nach LANG. o Mund, Ph Pharynx, $J$ Darm, $J$, periphere Darmäste, $J v$ vorderer, über das Gehirn hinwegziehender Darmast, $C G$ Cerebralganglion, $T t$ Rückententakel, $O c$, Hirnhofaugen, $O c$, Tentakelhofaugen, $O v$ Ovarien, $U g$ Uterusgänge, $S d r$ Schalendriisen, $B C$ Bursa copulatrix, ㅇ weibliche Geschlechtsöffnung, $H$ Hoden, $S g$ Samengänge, $S b$ Samenblase, $D r$ drüsiger Anhang, $P$ Penis, $\delta$ männliche Geschlechtsöffuung.

paarigen Hauptstämmen, in welchen die Samenmassen sich anhäufen; es schliesst sich ein Begattungsapparat mit Prostatadrüse und vorstülpbarem Penis an, letzterer findet sich meist in Einzahl, seltener vielfach, und ist oft mit chitinartiger Spitze versehen, die bei der Begattung in die verschiedensten Stellen des Körpers eines anderen Zwitterindividuums 
eingestossen wird, um dort die Samenmassen oder auch Spermatophoren abzusetzen.
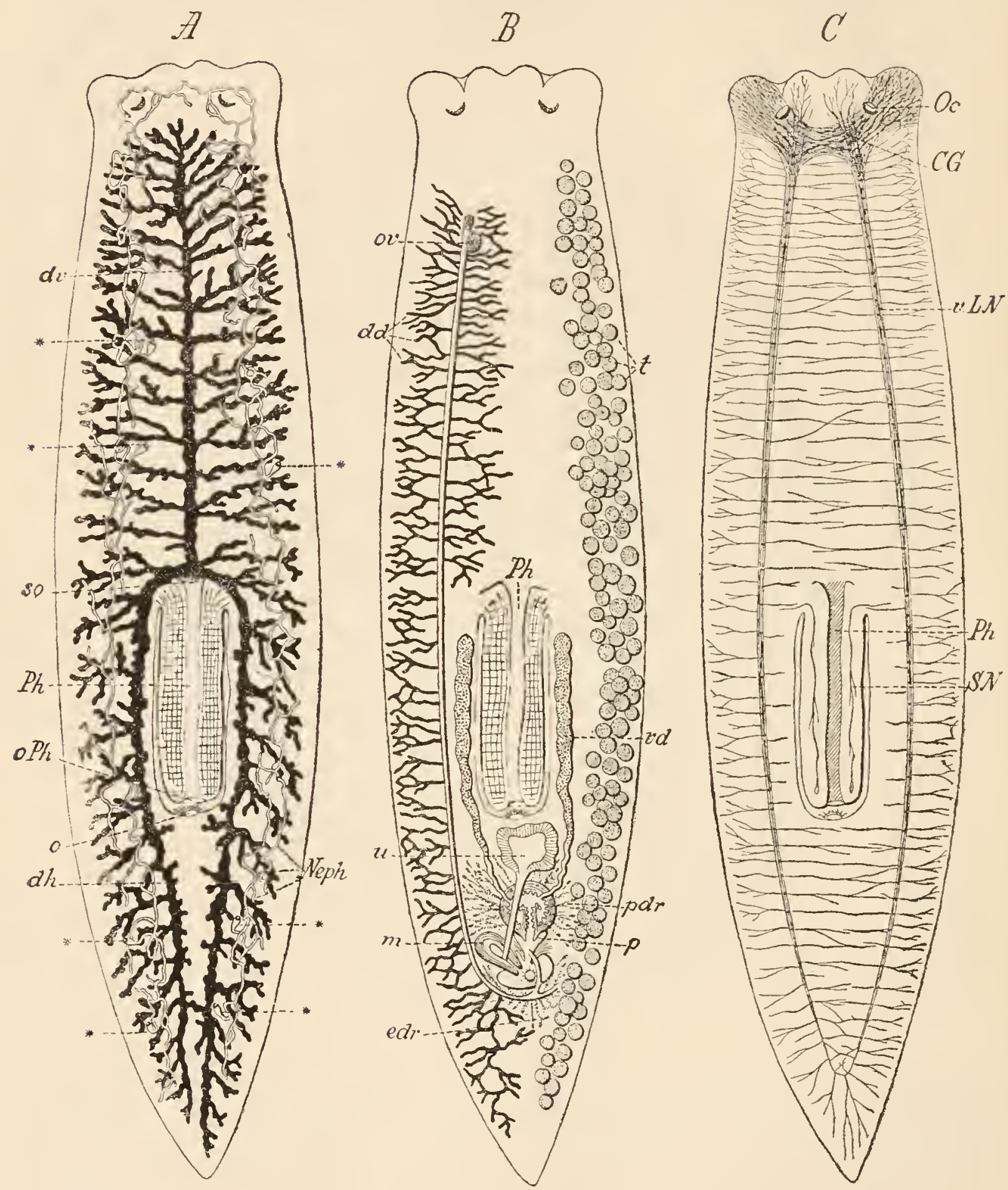

Fig 319 Organisation von Planaria, nach J. JiJiMA.

$A$ Darmkanal und Excretionsapparat. $O$ Mund, $P h$ Pharynx, oPh dessen äussere Mündung, so dessen innere Mündung (Schlundpforte), dv vorderer unpaarer Darmschenkel, dh hintere paarige Darmschenkel, Neph Nephridien in ihren Hauptrerästelungen, * deren äussere rückenständige Mündungen.

$B$ Geschlechtsapparat, rechts ist nur der Hoden, links nur Ovarium, Dotterstöcke und deren Ausführungsgang dargestcllt. ov Ovarium, $d d$ Dotterstöcke, $u$ Uterus, $m$ muskulöser Sack, $t$ Hoden, vd Vas deferens, $p d r$ Prostatadrüsen, $p$ Penis.

$C$ Nervensystem. $C G$ Cerebralganglion, $O c$ Cerebralaugen, $v L N$ ventraler Längsnerv, $S N$ Schlundnerv. 
Bei den Tricladen findet sich hinter dem Munde der männliche und der weibliche Ausführungsgang in eine gemeinsame Kloake mündend. Die Oviducte sind paarige, longitudinale Kanäle, von welchen jeder an seinem Vorderende nur ein kleines Ovarium, seitlich aber zahlreiche verästelte Dotterstöcke trägt; es folgt der unpaare Eiergang mit Schalendrüse, die Scheide und der mamnigfach gestaltete Cterus. Der männliche Apparat ist ähnlich dem der Polycladen, doch mit unbewaffnetem Penis (Fig. $319 \mathrm{~B}$ ).

Bei den Rhabdocoeliden sind die Geschlechtsöffnungen meist vereinigt, seltener getrennt, und sind meist in der hinteren Bauchregion gelegen. Die grösste Mannigfaltigeit herrscht besonders in den secundären Theilen des Geschlechtsapparates (Samenblase, bewaffnetem oder unbewaffnetem Penis, Scleide oder Bursa copulatrix, Receptaculum seminis, Uterus). Die Ovarien sind stets nur in einem Paare oder auch nur umpaar vorhanden; Dotterstöcke (oft mit den Ovarien als Keimdotterstöcke vereinigt) sind vorhanden oder fehlen; die Hoden finden sich zahlreich (,folliculär"6) oder nur in einem Paar. Es werden folgende drei Typen (nach v. GRAFF) unterschieden: 1) die Acoelen haben nur Ovarien (keine Dotterstöcke!) und folliculare Hoden, 2) die Alloiocoelen haben Ovarien, Dotterstöcke und folliculäre Hoden, 3) die Rhabdocoelen besitzen Ovarien, Dotterstöcke und nur ein Paar von compacten Hoden.

Die Fortpflanzung der Turbellarien ist vorwiegend geschlechtlich (durch Wechselkreuzung der /witter). Bei manchen Rhabdocoeliden des süssen Wassers werden dünnschalige Sommereier und hartschalige Wintereier erzeugt; bei ersteren soll Selbstbefruchtung des Zwitters stattfinden. - Fortpflanzung durch Teilung kommt mehrfach vor und ist besonders ausgebildet bei den Microstomiden; sie führt zu einer Art von Segmentirung bei Alaurina.

Die Entwicklung der Turbellarien ist meist eine direkte; nur einige Polycladen besitzen Larvenstadien mit präoralem Wimperkranz. - Die Embryonalentwicklung ist bei den Polycladen am besten erforscht. Meist werden die Eier vor der Entwicklung als Laichmassen abgelegt. Die Furchung ist zumeist mässig inäqual, die Gasstrulation erfolgt durch Epibolie; vier Urmesodermzellen, die das Protostoma radiär umgeben, sollen vier Mesoderm-

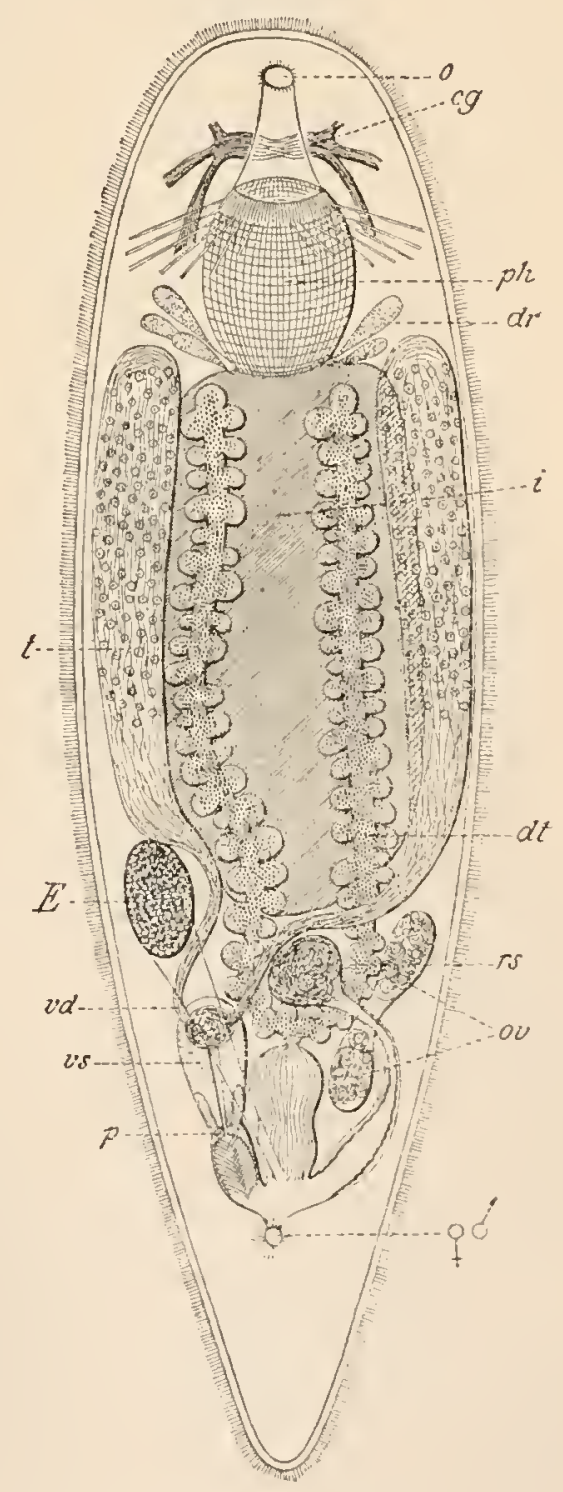

Fig. 320. Organisation von Vortex viridis, nach Max Schultze. o Mund, $c g$ Cerebralganglion, ph Pharynx, $d r$ Speicheldrüsen, $i$ Darm, $\{d$ gemeinsame Mündung der Geschlechtskloake, ov Ovarien, $d t$ Dotterstock, rs Receptaculum seminis, $E$ Ei im Uterus, $t$ Hoden, $v d$ Vas deferens, vs Vesicula seminalis, $p$ Penis. 

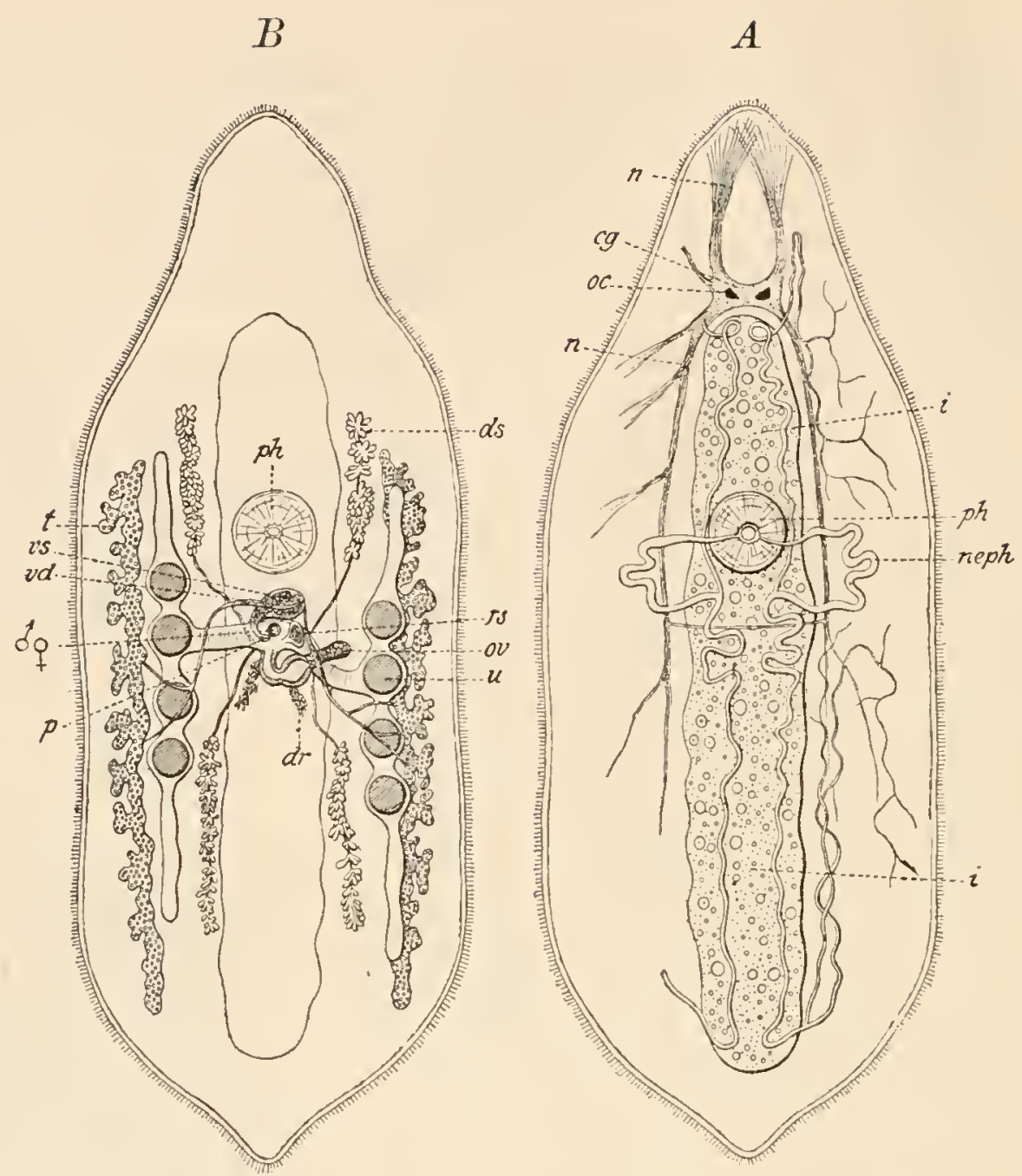

Fig 321. Organisation von Mesostoma Ehrenbergii, einer Rhabdocoelen-Turbellarie, nach $R$. LEUCKART (etwas verändert).

A Nervensystem, Darm und Excretionsapparat. cg Cerebralganglion, oc Augen, $n$ Nerven, ph Pharynx, $i$ Chylusdarm, neph Nephridien.

$B$ Geschlechtsapparat $\delta q$ Gemeinsame Oeffnung der Geschlechtskloake, ov Ovarium, $d s$ Dotterstock, $d r$ Schalendrüsen, $r$ Receptaculum seminis, $u$ Uterus mit Eiern, $t$ Hoden, $v d$ Vas deferens, vs Vesicula seminalis, $p$ Penis.

streifen bilden; der Gastrulamund schliesst sich spaltförmig und rückt vom Gegenpol nach der Bauchseite und es folgt die Bildung des ventralen Schlundes; das Cerebralganglion entsteht als paarige Ectodermverdickung des Scheitelpoles ${ }^{1}$ ); der äquatoriale Wimperkranz, der den Körper quer — von der Bauchseite nach der Riickenseite - umgürtet, ist in vier bis acht Lappen ausgezogen. Die Larve nimmt beim Wrachsthum eine gestrecktere Form an und die innere Organisation wird vervollkommnet. Die Metamorphose erfolgt durch Schwinden des Wimperkranzes und durch Abplattung des Körpers.

Bei den Tricladen werden grössere Cocons einzeln abgelegt, die nebst den Eizellen eine bedeutende Masse von Dotterzellen enthalten. Die Entstehung der Keimblätter ist noch nicht vollkommen aufgeklärt. Der Embryo schluckt mittelst eines Embryonalschlundes Dottermassen

1) Die Ersclieinung, dass mediane unpaare Organe entwicklungsgeschichtlich verschieden entstehen, nämlich bei den einen Thieren aus unpaarer, bei anderen nahe verwandten Thieren aus pariger Anlage ist schon von vielen Autoren hervorgehoben worden. 
und blälit sich in Folge dessen hohlkugelförmig auf; es erfolgt bedeutendes Wachsthum, sodann scliwindet der Embryonalschlınd und an derselben Stelle entsteht der definitive, anfangs nach aussen nicht geöffnete Schlund; endlich erfolgt eine Streckung und bedeutende Abplattung der Körperform ; beim Verlassen des Cocons besitzt das junge Thier schon die charakteristische Organisation einer Planarie.

Fig. 322. Polycladenlarven, nach LANG. Mit Rücksicht auf ihre äussere Körperform und Bewimperung; Cerebralganglion $(c g)$, Augen $(o c)$ und Mund (o).

$\boldsymbol{a}$ Junge Cotyleenlarve, $\boldsymbol{b}$ ältere Cotyleenlarve, $c$ Planoceridenlarve mit Tentakel $(t)$.

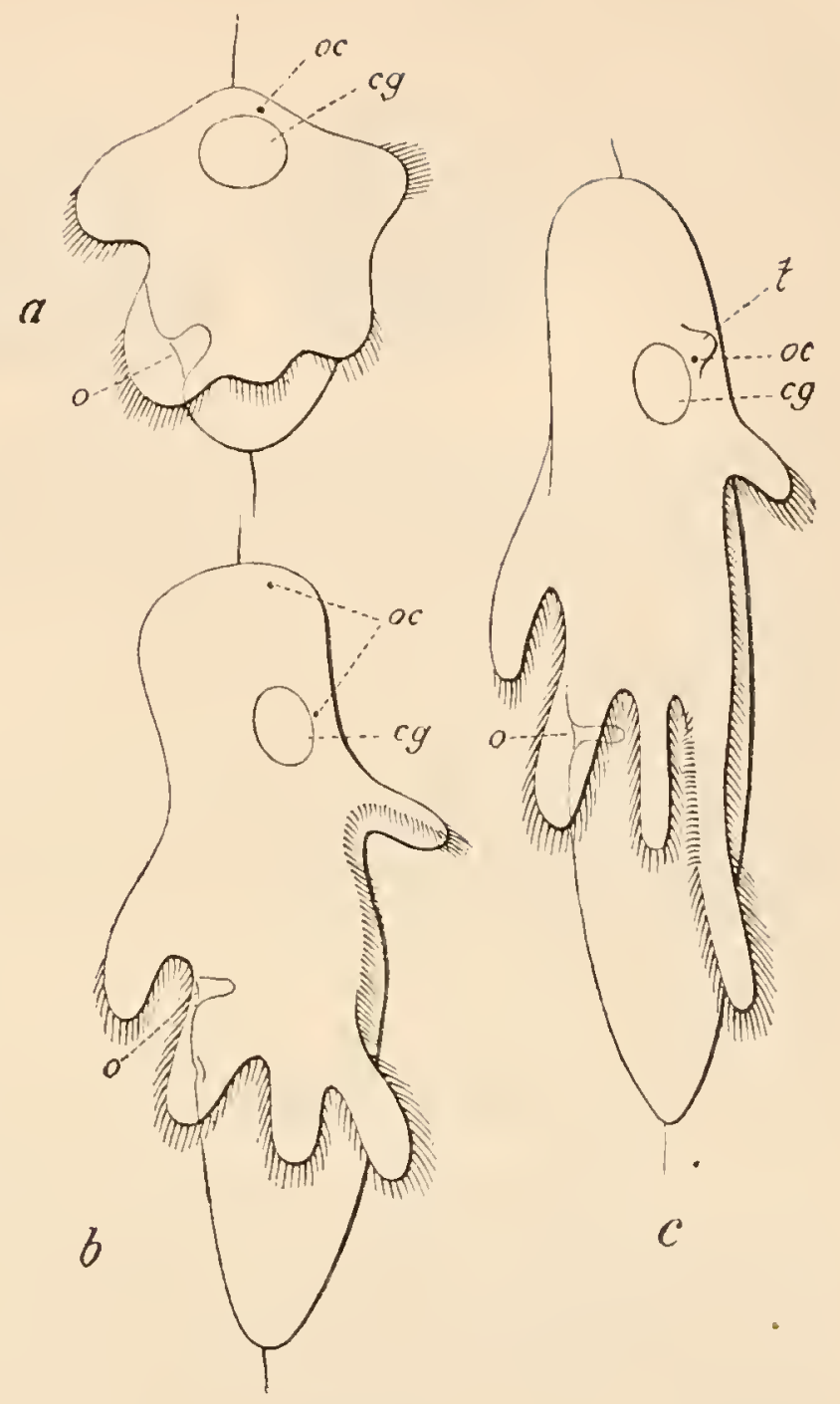

Fig. 323.

Längsschnitt durch eine junge

Cotyleenlarve (Thysanozoon) (anch LANG). $O$ Mund, $O e$ speiseröhre, Schl Pharynx, $J$ Chylusdarm, $J$, dessen vorderer, das Gehirn überdeckender Ast, $G$ Cerebralganglion, $N$ Nerven, Mes mesodermale Gebilde, Dr Drüsen.

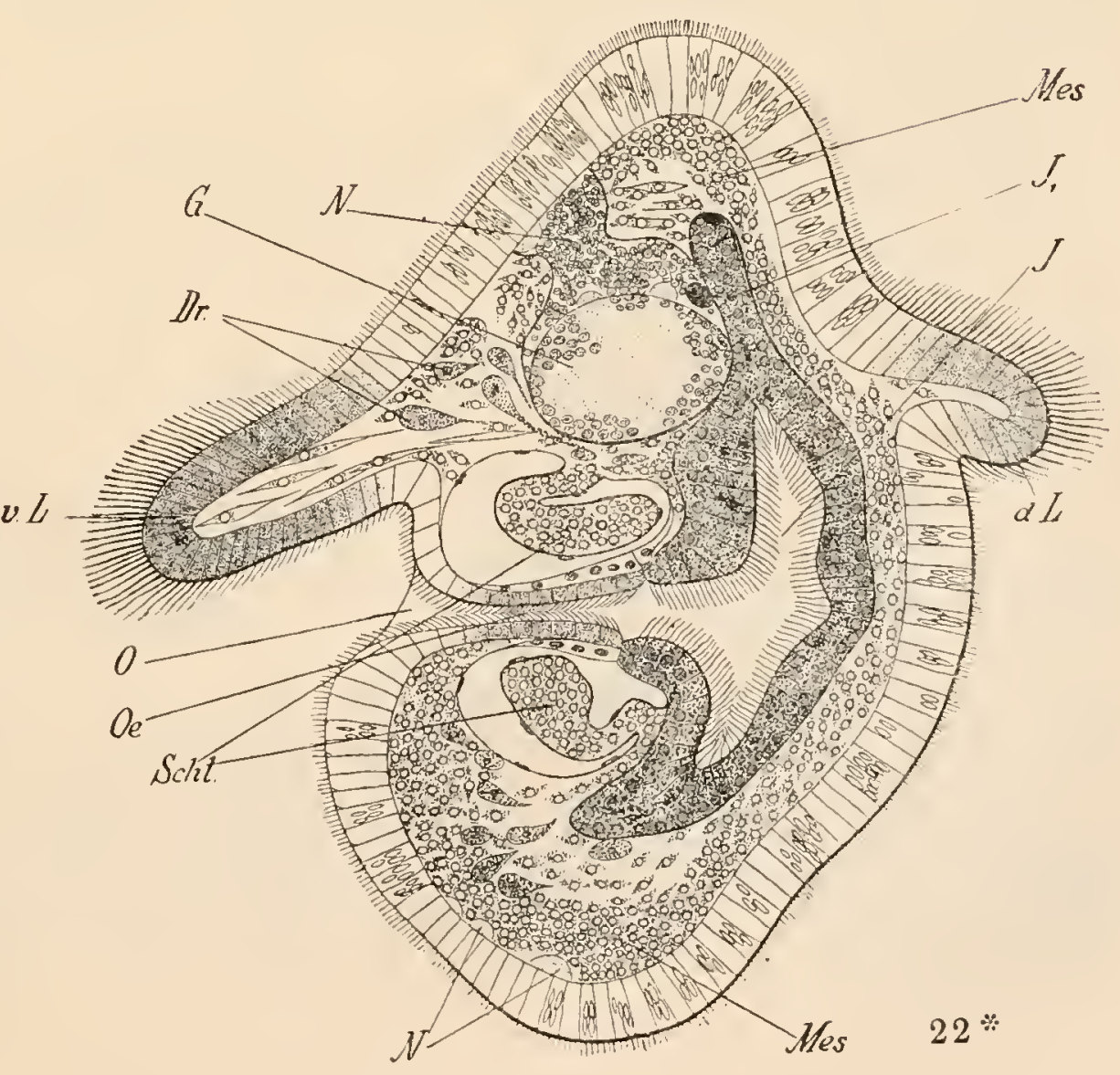



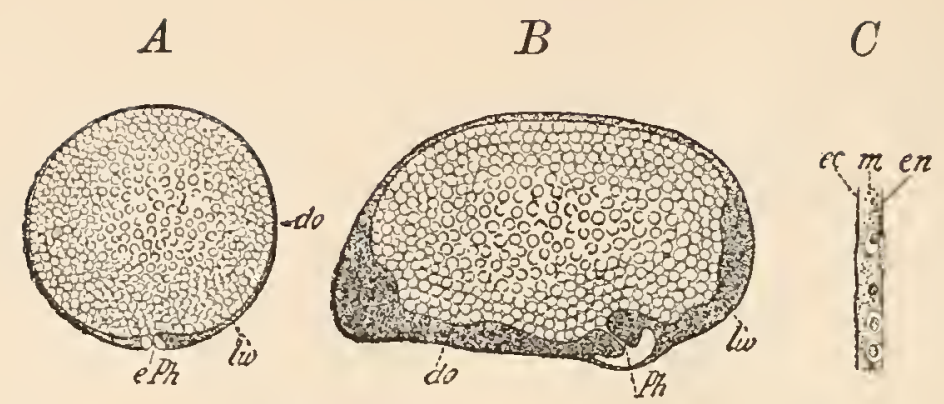

Fig. 324. Entwickelungsstadien von Planaria, nach J. JiJimA.

$A$ Ein Embryo, welcher durch Schlucken von Dottermassen kugelförmig aufgebläht ist. lw Leibeswand, do Dotter, der die Darmhöhle erfüllt, ePh embryonaler Pharynx.

$B$ Ein älterer Embryo, der sich zu strecken beginnt; der definitive Pharynx $(P h)$ ist angelegt.

$C$ Die drei Schichten der Leibeswand. ec, en das platte Ectoderm und Endoderm, $m$ Mesoderm.

Die Rhabdocoeliden haben wahrscheinlich alle direkte Entwicklung; die Eier werden abgelegt, oder es kommt der Embryo schon im Uterus zur Entwicklung.

Systematische Uebersicht der Turbellaria.

I. Dendrocoelidae. Grössere, stark abgeplattete Turbellarien, mit röhrenförmigem Pharynx und mit verzweigtem Magendarm.

1. Polycludidea (Digonopora), Se eplanarien. Körper meist blattförmig breit, Mund in verschiedener Lage, Hauptdarm mit zahlreichen Aesten versehen, Geschlechtsöffnungen meist getrennt, Entwicklung oft mit Metamorphose.

a) Acotylea ohne Bauchsaugnapf: Planocera, Stylochus, Leptoplana. b) Cotylea mit Bauchsaugnapf: Thysanozoon, Eurylepta.

2. Tricladidea (Monogonopora). Körper platt und länglich, Mund hinter der Mitte, Magendarm zerfällt in drei Hauptäste, Geschlechtsöffnung einfach.

a) Planariidae, Süsswasserplanarien. Planaria, Dendrocoelum; Gunda lebt im Meere. b) Geoplanidae, Landplanarien; leben als Landthiere meist in den feuchten tropischen Wäldern. Geoplana; Geodesmus, europäisch, in feuchter Erde.

II. Rhabdocoelidae. Kleinere, weniger abgeplattete, oft spindelförmige Turbellarien, mit einfachem oder meist mit tonnenförmigem Pharynx und mit geradem, selten gelapptem Magendarm, oder darmlos (? Acoela).

1. Allococoela, meist Seethiere, ihr Magendarm ist oft gelappt. Monotus mit Gehörbläschen; Plagiostoma mit Wimpergrübchen.

Otoplana intermedia (G. DU PLEssrs) besitzt ein frontales Gehörbläschen und ein Paar von Wimpergrübchen, die Geschlechtsorgane stimmen mit denjenigen der Monotiden überein, der Darmtractus gleicht dem der Tricladen; scheint einen sehr ursprünglichen Typus unter allen Turbellarien zu repräsentiren. 
2. Rhabdocoela, Seethiere und Süsswasserthiere, meist mit deutlicher primärer Leibeshöhle. Vorlex, Mesostoma; Microsloma zeichnet sich durch Theilungsvorgänge aus.

3. Acoela, Seethiere, ihr Magendarm ist ohne Höhlung und vom Parenchymgewebe nicht unterscheidbar, mit Gehörbläschen. Convoluta.

\section{Ord. Trematodes.}

Die Trematoden sind parasitische Platoden, im erwachsenen Zustande unbewimpert, mit olalen und ventralen Saugnäpfen, mit gabeltheiligem Magendarm.

Die Trematoden stammen von Turbellarien ab. Ihre besonderen Eigenthümlichkeiten sind von der parasitischen Lebensweise abzuleiten und bestehen besonders in dem Mangel der Bewimperung und dem Besitz von Haftapparaten; auch die merkwürdigen Entwicklungsverhältnisse (Generationswechsel der Distomeen) sind in Anpassung an den Parasitismus entstanden.

Die Körperform der Trematoden ist meist stark abgeplattet, blattförmig; seltener ist der Körper mehr langgestreckt und von rundlichem Querschnitt, oder sogar kurz und gedrungen. Die Mundöffnung ist beinahe ausnahmslos ganz nahe an das Vorderende gerückt. Die ventral gelegenen Haftapparate (Mundsaugnapf, Bauchsaugnapf etc.) verleihen dem Körper ein charakteristisches Gepräge.

Die Körperoberfläche entbehrt bei dem entwickelten Thiere der Bewimperung, dagegen ist eine ansehnliche $\mathrm{Cuticula}$ ausgebildet, die von feinen Poren durchsetzt und oft durch besondere sehr regelmässige Sculpturen, z. B. reihenweise angeordnete Härchen oder derbere Borsten und Häkchen, ausgezeichnet ist; auch die grösseren Chitinhaken an den Haftapparaten der monogenetischen Trematoden sind als Cuticularbildungen zu betrachten. Die subcuticularen Epithelzellen sind beim erwachsenen 'Thiere nicht nachweisbar; die Meinung einiger Forscher aber, dass die Epidermis während der Entwicklung überhaupt abgeworfen werde, und dass die vermeintliche Cuticula eine Basalmembran sei, möchten wir nicht theilen (vergl. pag. 329). Einzellige tiefer gelegene Hautdrüsen sind vielfach nachgewiesen. Der Ha u muskelschla u ch besteht aus den typischen drei Schichten, äusserer Ringmuskelschichte, innerer Längsmuskelschichte und innerster gekreuzter Diagonalfaserschichte, doch ist die letztere in der Regel nur am Vorderkörper ausgebildet. Auch die typischen, das Parenchym durchziehenden dorsoventralen Muskeln („Parenchymmuskeln ${ }^{6}$ ) sind vorhanden. Als besondere Differenzirungen des Hautmuskelschlauches sind die Saugnäpfe zu betrachten, welche aus circulären und radiälen Muskeln aufgebaut sind und durch besondere Muskelgruppen als Ganzes bewegt werden. Die Distomeen besitzen einen Mundsaugnapf und einen in der Mitte der Bauchfläche (oder auch weiter vorn) gelegenen Bauchsaugnapf. Bei den Polystomeen kann der Mundsaugnapf fehlen oder es können in der Umgebung des Mundes auch mehrfache Saugnäpfe vorhanden sein, und es findet sich bei denselben ferner am Hinterende eine complicirtere, meist mit mehrfachen kleineren Saugnäpfen und mit 
Chitinhaken ausgestattete Haftscheibe (vielleicht dem Bauchsaugnapf entsprechend). - Die Zwischenräume der inneren Organe sind stets von parenchymatösem Bindegewebe ganz erfüllt.

Der Darmtractus ist bei den Tre-

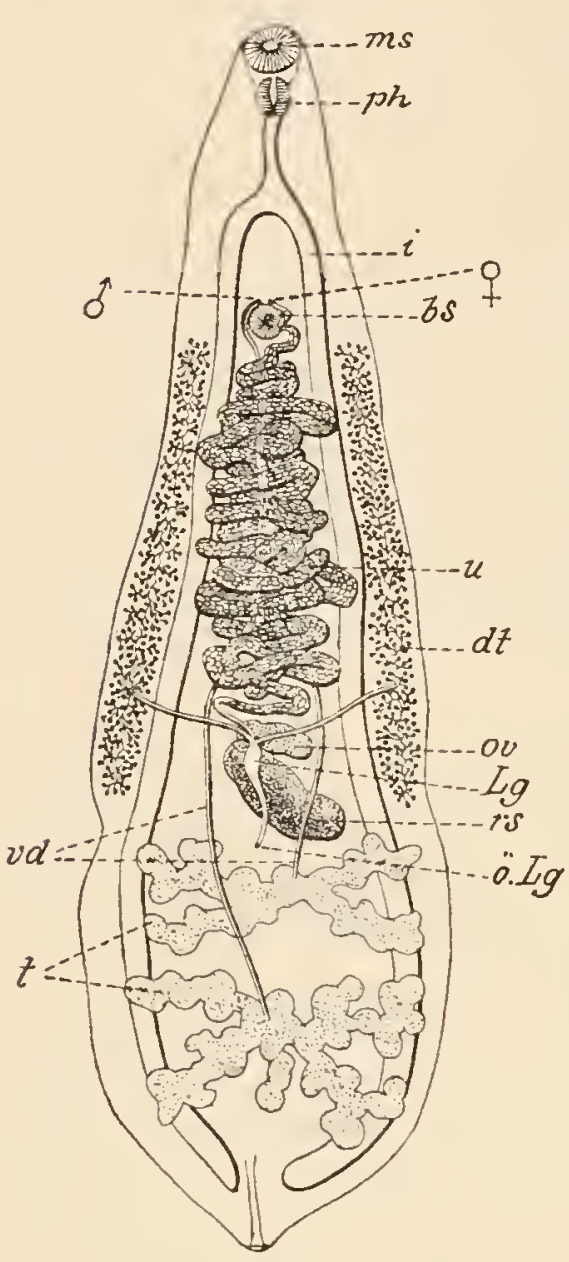
matoden, wenige Fälle ausgenommen, wohl entwickelt. Die Mundöffnung gehört der Bauchseite an und ist ganz nahe an das Vorderende gerückt (mit Ausnahme von Gasterostomum); oft ist sie, wie erwähnt, von einem Mundsaugnapfe umgeben; die Schlundröhre oder Schlundtasche führt zu dem tonnenförmigen Schlundkopf (eingelagerte Speicheldrüsen fehlen), der als Saugpumpe fungirt und oft auch vorstülpbar ist. Auf diesen folgt der Chylusdarm, der aus einem unpaaren, oft nur sehr kurzen Anfangsstücke (sog. Oesophagus) und paarigen Gabelästen besteht, welche letztere bei den grösseren Formen auch verzweigt sein können (Fig. 328 A).

Fig. 325. Distomum spathulatum $(12 / 1)$, nach LEUCKart. Darstellung der Körperform des Darmes und Geschlechtsapparates; am Hinterende die Excretionsöffnung. ms Mundsaugnapf, $p h$ Pharynx, $i$ gabeltheiliger Darm, bs Bauchsaugnapf, ठै männliche, ㅇ weibliche Geschlechtsöffnung (nämlich Mündung des Uterus), $\ddot{L} \mathrm{Lg}$ Oeffnung des Begattungsganges (Laurer'schen Ganges), $t$ Hoden, $v d$ Vas deferens, ov Ovarium, dt Dotterstock, Lg LAUren'scher Gang, rs Receptaculum seminis, $u$ Uterus.

Der typische Excretionsapparat mündet bei den Distomeen am hinteren Körperende mittelst einer contractilen Harnblase, bei den Polystomeen sind die paarigen Mündungen der Excretionskanäle in der Regel dorsal gelegen.

Das Nervensystem besteht aus den durch Auseinanderüucken paarig gewordenen Cerebralganglien, welche durch eine dorsale Commissur verbunden sind, wozu oft auch eine den Schlund ventral umgreifende Commissur hinzukommt. Von den Cerebralganglien ziehen wenige kleinere Nerven nach vorn und mehrere Längsnervenpaare nach hinten; es sind nämlich nebst dem ventralen Paare auch seitliche und dorsale Paare beobachtet worden. - Die Sinnesorgane sind in Folge der parasitischen Lebensweise und langsamen Beweglichkeit sehr reducirt. Doch kommen bei den ectoparasitischen Polystomeen sowohl im Larvenzustande als auch am erwachsenen Individuum zwei bis vier Gehirnaugen und ferner Tastorgane in der Umgebung des Mundes vor. Bei den endoparasitischen Distomeen findet sich nur bei der infusorienförmigen Larve ein x-förmiger Augenfleck.

Die zwitterigen Geschlechtsorgane zeigen die für den Platodentypus charakteristischen Complicationen. Das getrenntgeschlechtliche Verhältniss bei Distomum haematobium erscheint als ein secundär erwor- 


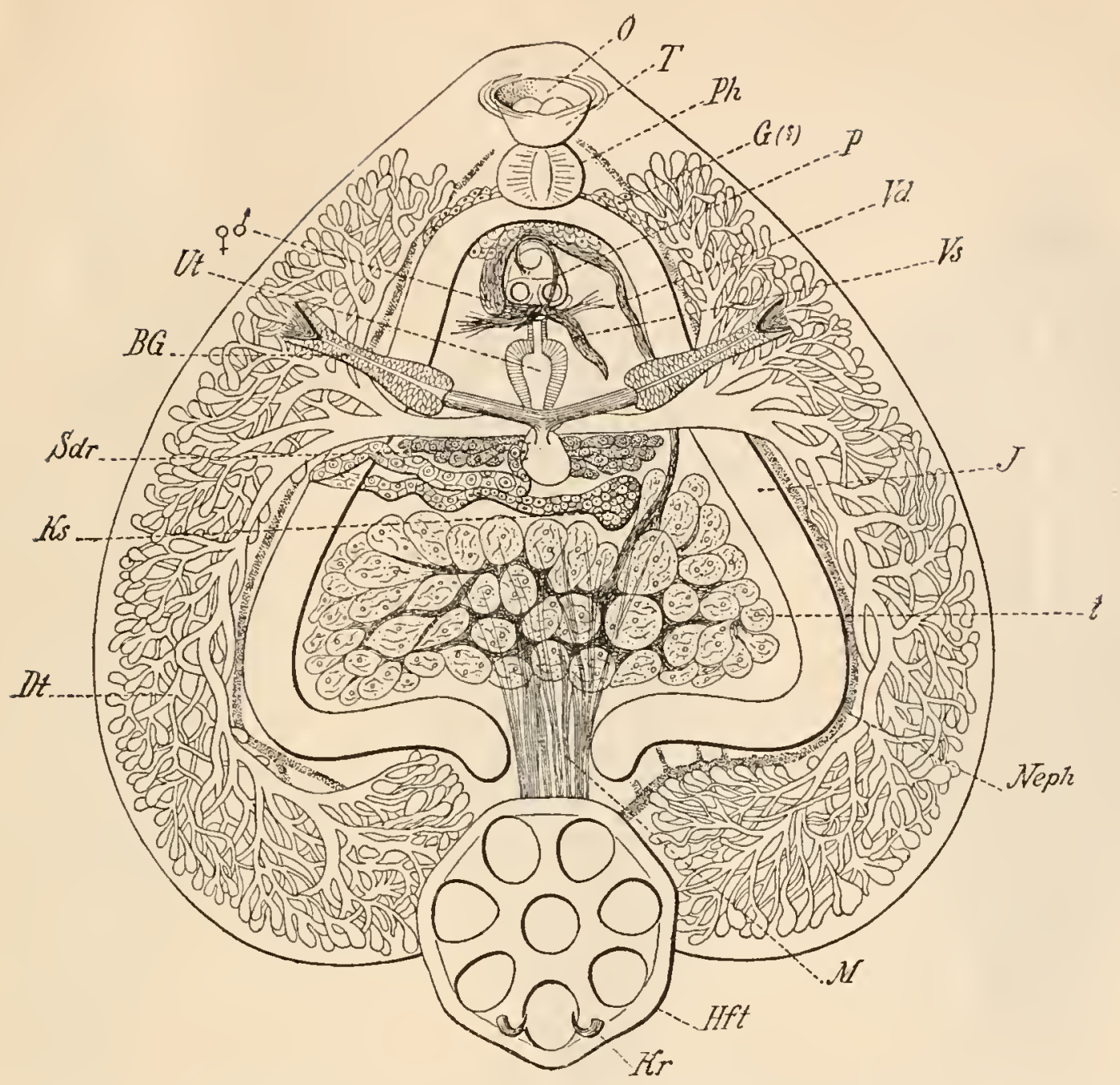

Fig. 326. Uebersicht der Organisation einer Polystomee (Calicotyle Kroyeri), nach WrerzeJskr. Hft Haftapparat mit $K r$ Chitinhaken, $O$ Mund, $T$ Schlundtasche, Ph Schlundkopf, J Darmschenkel, G Ganglienzellen (oder Drüsen?), Neph Hauptstämme der Nephridien, $M$ Muskeln des Haftapparates, $\Varangle \delta$ gemeinsame Geschlechtsöffoung, $t$ Hoden, $V d$ Vas deferens, $V s$ Vesicula seminalis, $P$ chitiniger Penis, $K s$ Keimstock (Ovarium), Dt Dotterstock, $S d r$ Schalendrüse, $B G$ pariger Begattungsgang, Ut Uterus.

bener Zustand. Im allgemeinen betrachtet erfüllen die massigen Dotterstöcke, Keimstock (stets in Einzahl) und Hoden den Hinterleib und die Ausführungsgänge ziehen nach vorn, wo die männlichen und weiblichen Begattungsorgane entweder nahe bei einander oder noch häufiger in eine Geschlechtskloake vereinigt in der vorderen Bauchregion median (seltener seitlich und asymmetrisch) ausmünden. Merkwürdig sind gewisse Nebenkanäle, die vom Ootyp ausgehen. Dazu gehört der LaURER'sche Kanal der Distomeen, der an der Rückenfläche ausmündet; seine Function ist noch nicht klar erwiesen, vielleicht ist er als accessorischer weiblicher Begattungsgang $\mathrm{zu}$ betrachten. Bei Polystomum findet sich nebst dem primären weiblichen Ausführungs-

Fig. 327. Distomum haematobium. Männchen, welches an der rinnenförmig vertieften Bauchfläche das Weibchen trägt (aus LEUCKART). $s$ Bauchsaugnapf des Männchens und Weibchens.

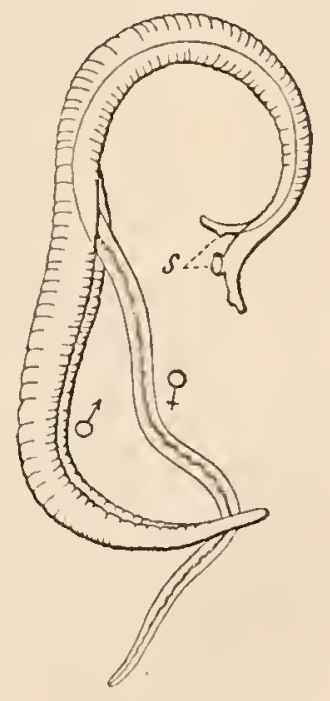



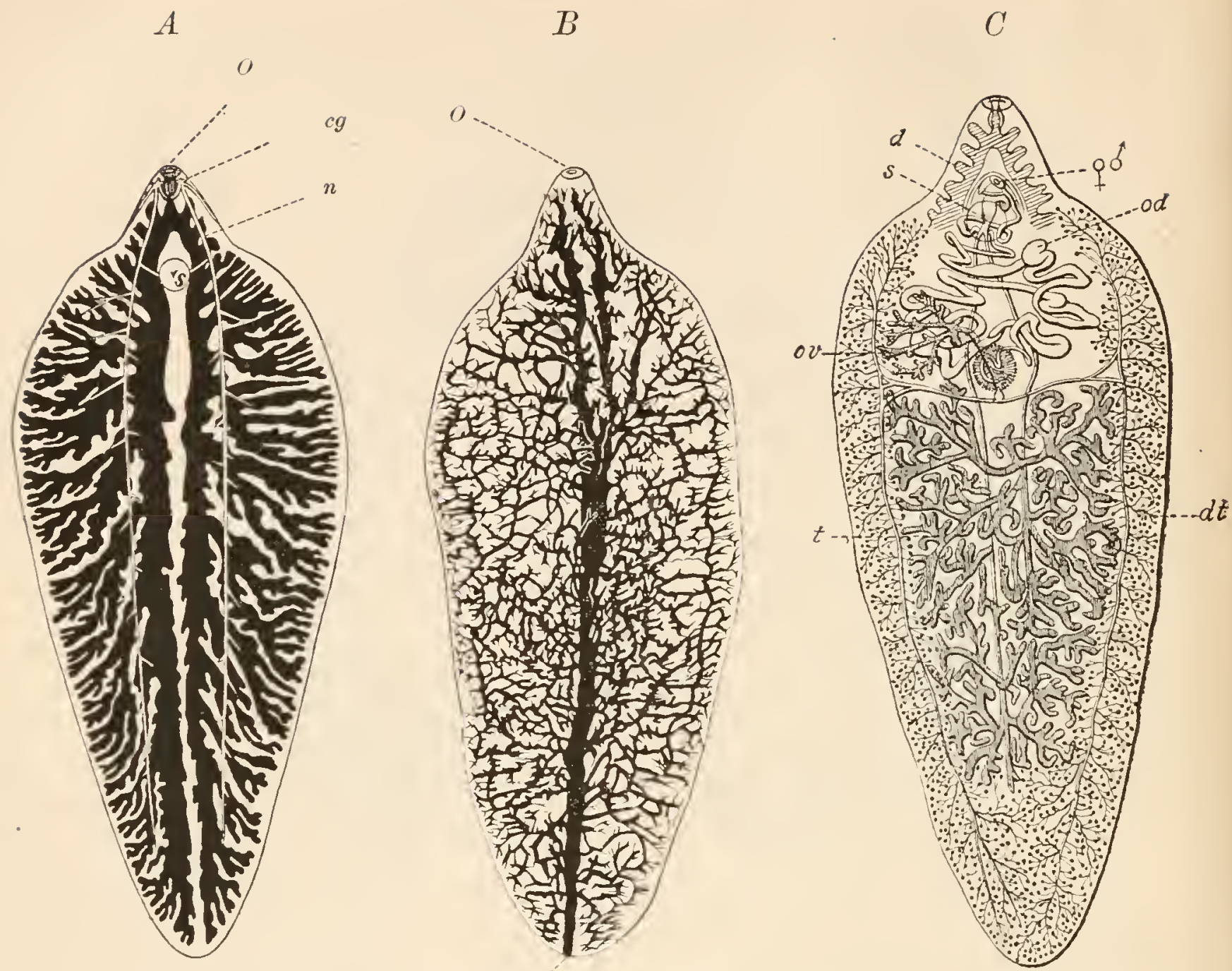
$d t$

$p$

Fig. 328. Organisation des Leberegels (Distomum hepaticum), nach SoMMER.

$A$ Darmkanal und Nervensystem. O Nundsaugnapf mit der Mundöffinung, welche vermittelst eines kurzen Schlundes mit Schlundkopf in den gabeltheiligen, reich verästelten Chylusdarm führt, s Bauchsaugnapf, cg Cerebralganglien, welche dorsal und ventral vom Schlunde durch Commissuren verbunden sind und nebst kleineren Nerven besonders je einen starken Längsnerven $(\boldsymbol{n})$ nach rückwärts senden.

$B$ Excretionsapparat, in seinen Hauptverzweigungen dargestellt. $p$ Mündung des Excretionsapparates, $o$ Mundsaugnapf.

$C$ Geschlechtsapparat. $d$ Darm, $s$ Bauchsaugnapf, $q \delta$ gemeinsame Mündung der weiblichen und männlichen Organe, ov Ovarium, dt Dotterstöcke, od Oviduct (Uterus), $t$ Hoden (vergl. Fig. 329).

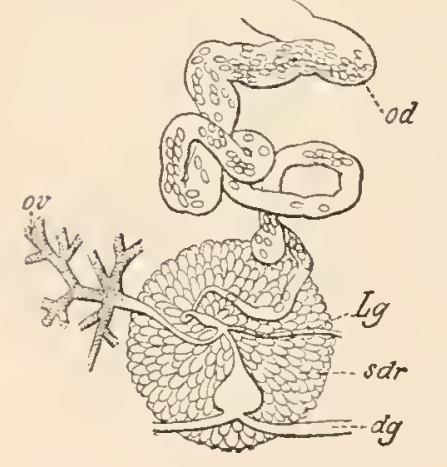

gang, der als Uterus und Oviduct fungirt und dem LAUReR'schen Gange noch ein paariger, rechts und links mündender weiblicher Begattungsgang; auch bei Calicotyle und anderen ist letzterer beobachtet.

Fig. 329. Distomथm hepaticum, mittlerer Theil des Geschlechtsapparates, wo die Eier gebildet werden. ov Ovarium, dg Dottergänge, welche von den Dotterstöcken ausgehen, $L g$ LAURER'scher Gang (Begattungsgang?), sdr Schalendrïse, od Oviduct (Uterus). 
Nebst der geschlechtlichen Fortpflanzung findet sich schon bei manchen Polystomeen Parthenogenese, z. B. bei Gyrodactylus, wo der noch im Mutterleibe befindliche Embryo schon wieder einen solchen nächster Generation, einen Enkel, und dieser einen Urenkel enthält; bei den Distomeen ist ein auf Parthenogenese beruhender complicirter Generationswechsel vorhanden, indem auf die geschlechtliche (zwitterige) Generation partlienogenetisch sich fortpflanzende Generationen von sehr reducirtem Baue folgen.

Die Entwicklung ist bei den Polystomeen eine direkte. Die Larve besitzt schon die wesentlichen Organe des entwickelten Thieres, sie unterscheidet sich von diesem nur durch die geringe Grösse, den Mangel der Geschlechtsorgane und den Besitz eines Flimmerkleides.

Fig. 330. Wimpernde Larve von Polystomum, wach ZELLER. - Mund, oe Schlundtasche, $P h$ Schlundkopf, $J$ Darm, $S N$ Saugnapf, $O C$ Augen, Neph Nephridien, ao deren äussere, dorsal gelegene Oeffinungen.

Fig. 331. Larve von Distomum hepaticum, mit einer wimpernden grosszelligen Embryonalhülle versehen, nach LEUCKART. $\quad C A$ Cerebralganglion mit $x$-förmigem Augenfleck, $J$ rudimentärer Darm, Neph Terminalzellen der Nephridien, $H Z$ Zellen der Embryonalbïlle, Nuc deren Kerne, $K Z$ Keimzelle, $K Z_{1}$ ebensolche, die bereits in Entwicklung begriffen ist.
Fig. 330.

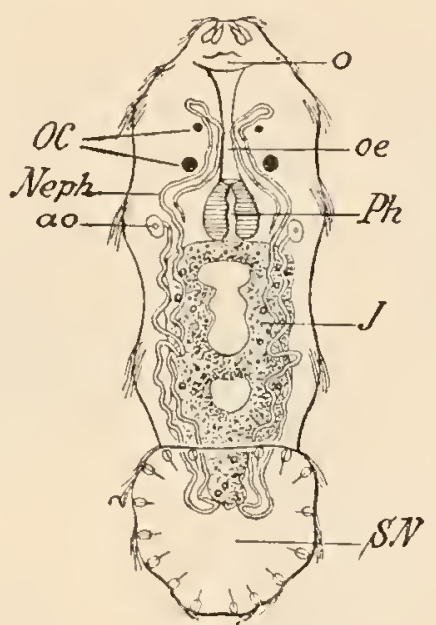

Fig. 331.

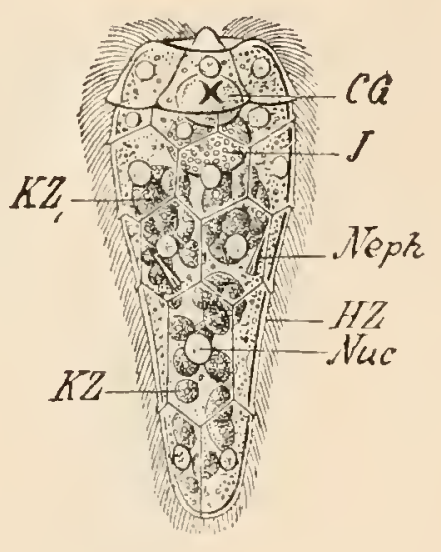

Bei den Distomeen sondern sich nach der Furclung gewisse Zellen zur Bildung voll Embryonalhüllen ab; die erste (äussere) Hülle umwächst nicht nur die übrigen Embryonalzellen, sondern auch zugleich die dem Ei beigegebenen Dotterzellen. Auch die Flimmerzellen, welche die ausschwärmende Larve bedecken, sind wahrscheinlich als eine zweite, innere Embryonalhïlle zu betrachten. Auch diese Larve zeigt dic charakteristischen Organe des Platodentypus (aber ohne speciellere Bildungen, wic Haftapparate etc.), jedoch sind dieselben zum Theil nur in rudimentärer Form vorhanden, was mit dem darauffolgenden Generationswechsel ursächlich zusammenhängt; ein rudimentärer Darmkanal, ein Cerebralganglion mit $\mathrm{x}$-förmigem Augenfleck und Excretionsorgane sind nachgewiesen worden; ferner sind im Hinterlzörper schon Massen von Keimzellen vorhanden. Diese Larve verwandelt sich, wenn sie in den passenden Wirth gelangt, nicht direct in ein Distomum, sondern sie wächst nach Abwerfen der Flimmerzellen zu einem parthenogenetisch sich fortpflanzenden Keimschlauch (Sporocyste) aus, welcher eine sehr reducirte Organisation zeigt. Die dünne Leibeswand desselben enthält wohl Excretionsorgane, es fehlen aber Darmkanal, Nervensystem, Haftapparate etc.; die geräumige Leibeshöhle ist von Keimzellen und daraus sich entwickelnden Embryonen erfüllt. Es folgt meist eine Reilie ähnlicher parthenogenetischer Generationen auf einander, die sich auch 
durch Theilung fortpflanzen können; zunächst kommen Sporocysten und dann Redien, welche letztere durch den Besitz eines einfachen Schlundes und schlauchförmigen Darmes sich von ersteren unterscheiden. Endlich werden in den Redien Distomeenlarven erzeugt, deren Körper den Bau eines Distomum zeigt, aber mit einem Ruderschwanze und mit Bohrstachel versehen ist; diese als Ce rcarie bezeichnete Form gelangt durch mehr oder weniger complicirte Wanderung in den ersten Wirth und wächst nach Abwerfen des Ruderschwanzes zu dem Geschlechtsthier aus. Besondere Beachtung verdienen die mit diesem Generationswechsel verbundenen biologischen Verlhältnisse, auf die wir noch zurückkommen werden.

Die Trematoden sind Parasiten, welche als solche die merkwürdigsten und mannigfaltigsten Anpassungserscheinungen an die Verhältnisse

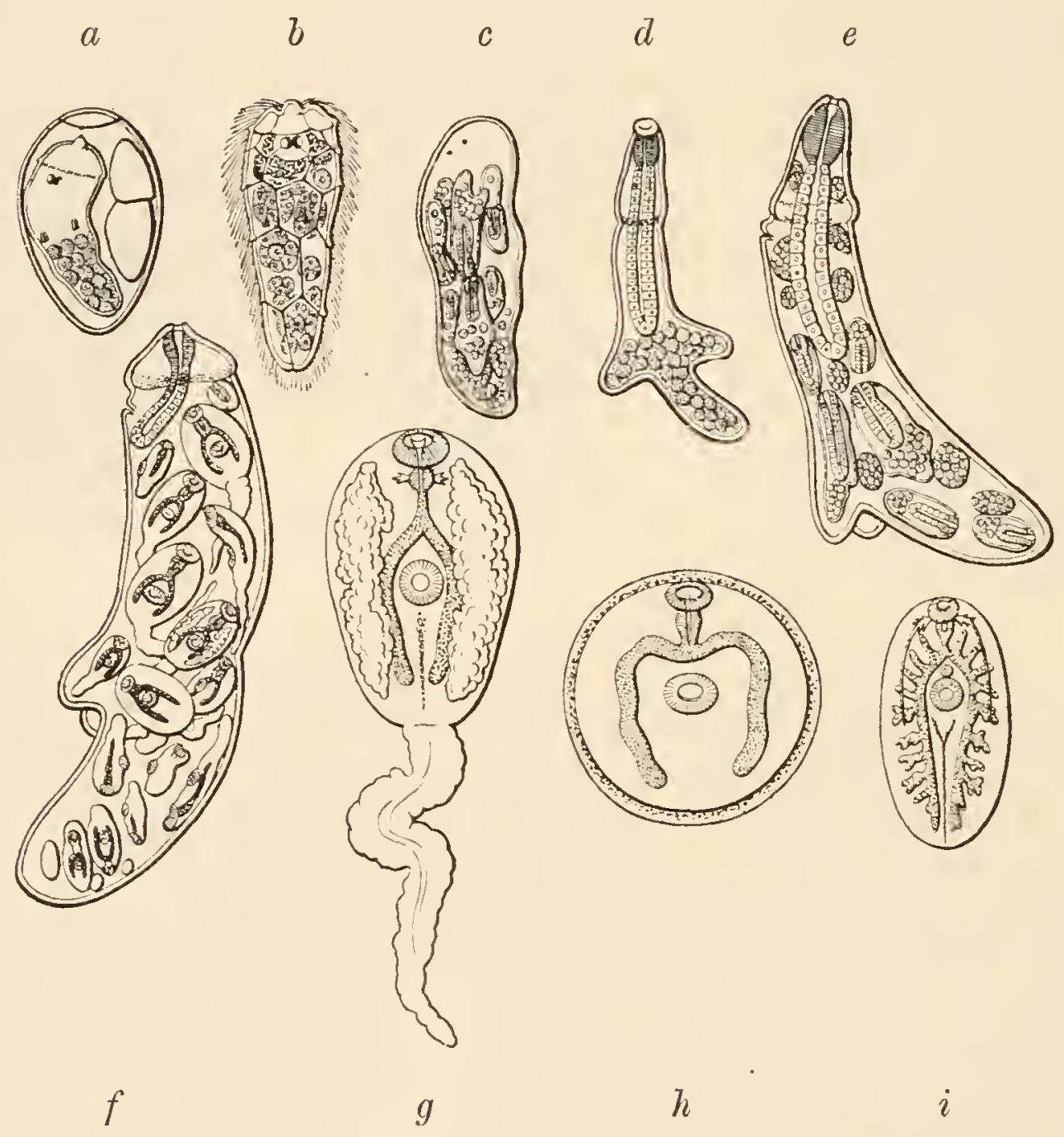

Fig. 332. Entwicklungscyclus von Distomum hepaticum (nach LeuckarT).

a Embryo, noch innerhalb der mit einem Deckel versehenen Eikapsel, neben demselben liegen Reste der Dotterzellen; $b$ Wimperlarve mit Stirnzapfen, hinter diesem ein x-förmiges Auge einem Gehirnganglion aufgelagert; darunter dunkelkörnige Zellen, die als rudimentärer Darm gedeutet werden; im Hinterkörper Keimzellen, z. Th. schon in Entwicklung begriffen; $c$ Sporocyste, die sich aus der Wimperlarve entwickelt hat; Andeutungen der Augenflecken sind noch sichtbar, im Inneren Redien in verschiedenen /uständen der Entwicklung; $d$ junge Redie mit einfachem Darmkanal, im Hinterkörper Keimzellen; e Redie, weiter entwickelt, im Inneren eine neue Redienbrut, vorn ventral die Geburtsöffnung; $f$ Redie mit Cercarienbrut; $g$ Cercarie mit seitlichen Drüsenmassen, zur Bildung der Cyste; $h$ dieselbe eingekapselt; $i$ jugendliches Distomum aus der Leber des Schafes. 
ihrer Wirthe zeigen. Die Polystomeen leben ectoparasitisch zuneist an der Haut oder den Kiemen von Fischen. Nur wenige finden sich endoparasitisch, wie z. B. Polystomum integerrimum in der Harnblase des Frosches; die Larven dieser Form wandern an die Kiemen der Kaulquappen; die Fortpflanzungszeit des Parasiten ist jener des Wirthes angepasst. - Die Distomeen leben im geschlechtsreifen Zustande endoparasitisch in den verscliedensten Organen von Wirbelthieren. Die Flimmerlarve gelangt in das Wasser und wandert in bestimmte Schneckenarten (und zwar in deren Leibeshöhle, Leber etc.) ein, um dort die Generationen von Sporocysten und Redien zu erzeugen. Die Cercarien verlassen wieder die Schnecke und wandern meist activ in eine zweite Schneckenart ein, wo sie nach einiger Zeit in den Geweben sich einkapseln und in einem Ruhezustand verharren, bis die Schnecke von dem ersten Wirth, der, wie erwähnt, stets ein Wirbelthier ist (z. B. Sumpfvogel, Säugethier), verzehrt wird; dort verwandelt sich die Cercarie in die geschlechtsreife Form. In manchen Fällen (bei Distoma hepaticum) wandert aber die Cercarie nicht in eine zweite Schnecke ein, sondern kapselt sich im Freien an Gräsern oder Wasserpflanzen ein, die dann von dem ersten Wirthe (z. B. dem Schafe) gefressen werden. Der hier beschriebene Wirthwechsel, der auch bei anderen parasitischen Thierformen beobachtet wird, ist eine höchst merkwürdige Anpassung des Parasiten an die Lebensverhältnisse anderer Thiere; er ist darin begründet, dass die Parasitenbrut nothwendigerweise neue Nährthiere aufsuchen muss, um die Lebensbedingungen nicht zu erschöpfen; im einfachsten Falle sind diese Wirthe vielleicht von gleicher Art und dies führt erst zu den Fällen eines vollkommenen rhythmischen Wirthswechsels.

Systematisclie Uebersicht der Trematoden.

I. Monogenea $=$ Polystomeae, meist mit complicirteren und zahlreicheren Haftapparaten. Ectoparasitisch zumeist an Fischen. Mit direkter Entwicklung ohne Wirthswechsel.

1. Tristomeae mit einem grossen hinteren und zwei kleinen vorderen Saugnäpfen, an Seefischen. Tristomum, Calicotyle.

2. Polystomeae s. str. mit grosser hinterer Haftscheibe, die zahlreiche Saugnäpfe und Chitinhaken trägt.

Polystomum integerrimum in der Harnblase von Fröschen, die Larven in der Kiemenhöhle der Kaulquappen. - Diplozoon paradoxum, durch kreuzweise Verwachsung zweier Larven (Diporpa) entsteht das $\mathrm{x}$-förmige Doppelthier, an den Kiemen von Süsswasserfischen. - Gyrodactylus elegans; das im Uterus befindliche Tochterindividuum enthält schon ein Enkelindividuum und dieses wieder ein Urenkelindividuum. Aspidogaster im Herzbeutel der Teichmuschel.

II. Digenea $=$ Distomeae, mit höchstens zwei Saugnäpfen, endoparasitisch in Wirbelthieren (die ungeschl. Generationen in Schnecken), mit Generationswechsel und Wirthswechsel. 
1. Distumidae mit Mundsaugnapf und Bauchsaugnapf. Distoma hepaticum. Länge bis $3 \mathrm{~cm}$. Vorderleib verschmälert. Körper mit schuppenförmigen Cuticularstacheln besetzt. Darmkanal verästelt. Uteruswindungen dicht hinter dem Bauchsaugnapf gelegen. Eier oval, gedeckelt, 0,13 mm lang. Lebt in den Gallengängen und im Darm der Schafe, seltener bei anderen Säugethieren, über die ganze Erde verbreitet. Als Zwischenwirth ist nach der Entdeckung von Levcirart besonders Limnaeus minulus zu betrachten. Die Cercarien kapseln sich an den Blättern ron Pflanzen ein. Die Schafe werden durch den Besuch inficirter, feuchter Weideplätze im Spätsommer von dem Parasiten befallen und erkranken an der sog. Leberfäule (gestörte Gallensekretion, Abmagerung, Anämie, Fieber), die Krankheit steigert sich im Winter, ganze Herden kommen zum Aussterben; die überlebenden Thiere genesen im Frühjahr durch Auswandern der Leberegel. - Dieser Parasit kommt auch gelegentlich im Menschen vor, nur im Narentathal in Dalmatien ist die Krankheit endemisch; Symptome beim Menschen in der Regel gering; durch Wanderung aber können die Würmer grössere Schädlichkeit hervorrufen, ja sogar Abscesse erzeugen. - D. lanceolatum, Länge bis $1 \mathrm{~cm}$, Eier $0,04 \mathrm{~mm}$ lang, Darm unverästelt, Uteruswindungen im Hinterkörper. Aehnlich verbreitet wie die vorige Art bei Säugethieren; beim Menschen sehr selten. - D. ophthalmobium, Jugendform ohne Geschlechtsorgane, im Auge eines Kindes gefunden. - D. haematobium ist getrenntgeschlechtlich, das Männchen hält an seiner rinnenartig vertieften Bauchtäche das Weibchen dauernd fest. Länge des Männchens bis $14 \mathrm{~mm}$, des Weibchens bis $19 \mathrm{~mm}$. Kommt in Aegypten als Parasit des Menschen vor und zwar in der Pfortader und deren Aesten (Venen der Milz, der Mesenterien, des Dickdarmes, der Harnblase); bewirkt Blutharnen und Bleichsucht (Distomen-Haematurie); es werden besonders Knaben befallen. Zwischenwirth unbekannt. - Andere exotische Formen von Distomum leben in der Leber, der Lunge, dem Darme des Ilenschen (China, Japan, Indien). Bei Thieren sind sehr zahlreiche Arten bekannt.

2. Monostomidae, mit einem Saugnapf am Vorderende, besonders in Vögeln schmarotzend. Monostoma lentis wurde einmal in mehreren Exemplaren in der Linse beim Menschen gefunden.

A nhang: Gasterostomum, Mundsaugnapf in der Mitte der Bauchfläche im Darme ron Süsswasserfischen.

\section{Ord. Cestodes.}

Die Cestoden sind endoparasitische Platoden, unbewimpert, ohne Darmtractus, mit Haftorganen am Vorderende, in der Regel mit Proglottidenbildung.

Die Cestoden sind von den Trematoden abstammende und durch die endoparasitische Lebensweise noch weiter veränderte Formen, was z. B. in den ausschliesslich vorderen Haftapparaten und dem Mangel des Darmes sich ausprägt. Die auffallendste - aber nicht ausnahmslos vorhandene Eigenthümlichkeit ist die Proglottidenbildung. Es ist dies eine Vervielfältigung des Hinterleibes, welcher mit allen seinen charakteristischen Organen, namentlich dem Geschlechtsapparate, sich 
derart wiederholt, dass er eine Reile von Gliedern oder Proglottiden bildet, in welcher die ältesten am Hinterende liegen und dort successive abgestossen werden, wälırend unmittelbar hinter dem Kopfe fortgesetzt neue Proglottiden entstehen. Wir betrachten diese Erscheinung als eine fortgesetzte Abstossung eines Körperabschnittes mit vorzeitiger Regeneration desselben. Es erfolgt hier nur eine Vervielfältigung eines Körpertheiles, also nur eine unvollständige Verviel-

Fig. 332.

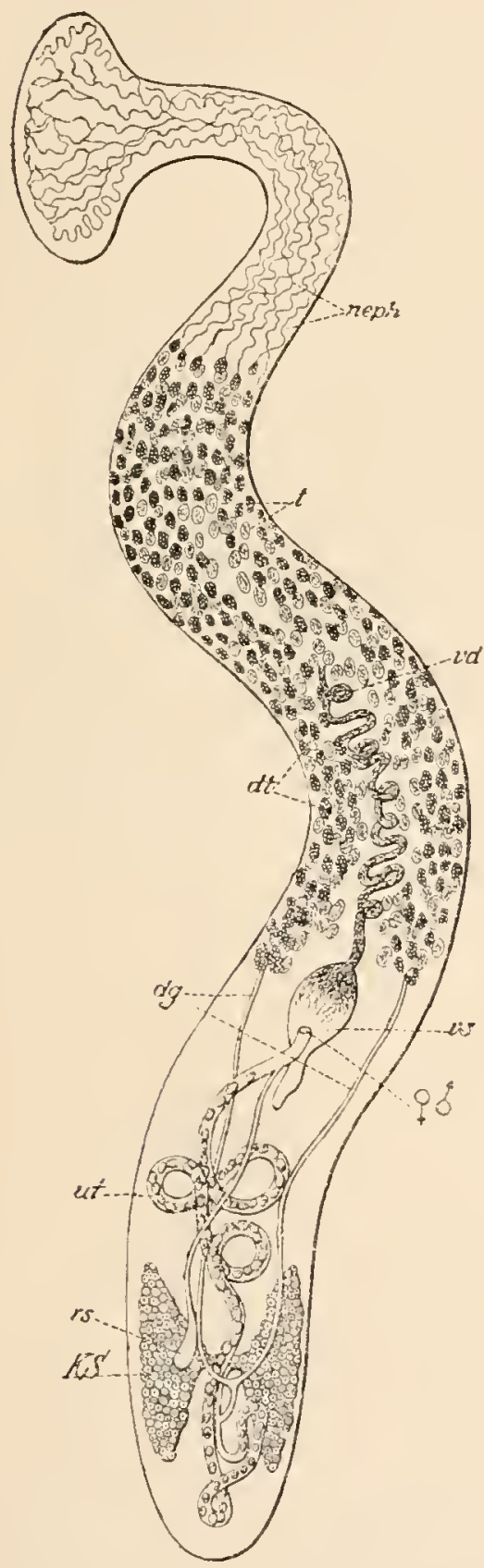

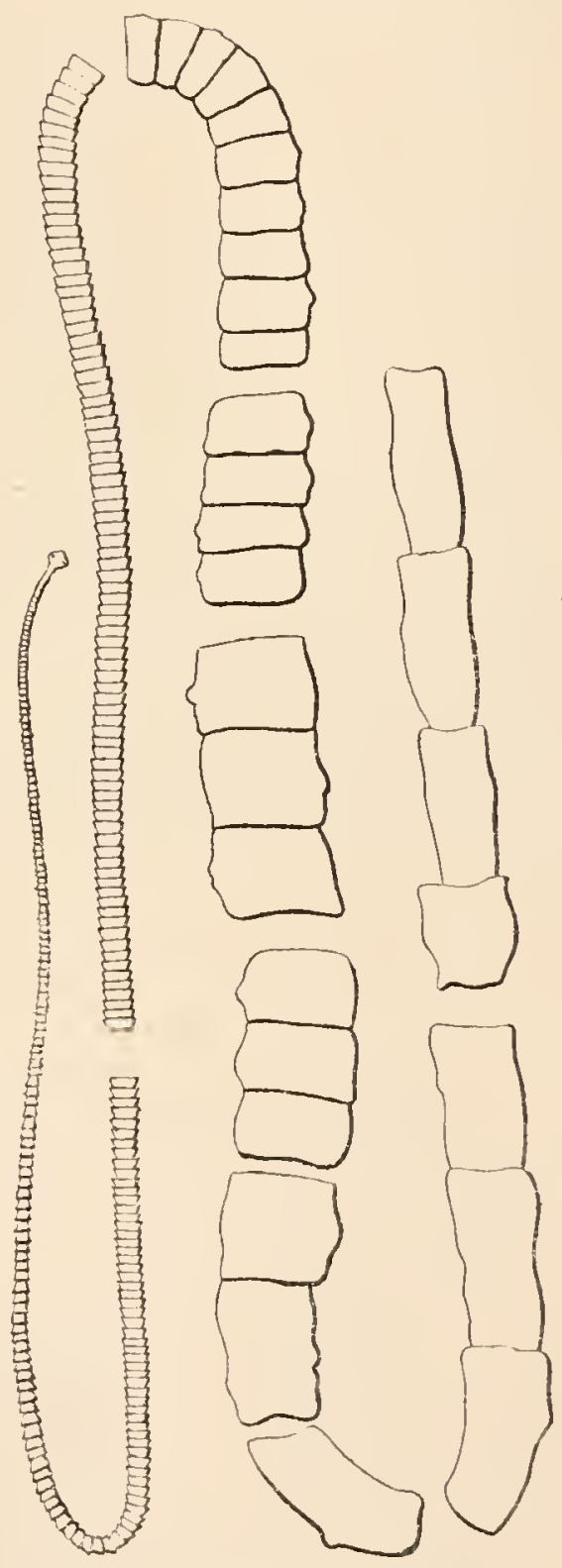

Fig. 333. Caryophyllaeus mutabilis, nach Srein (stark vergrössert). neph Excretionskanäle im Scolex, $\$ \delta$ gemeinsame Geschlechtsöffnung, $t$ Hodenbläschen (hell), vd Vas deferens, vs Vesicula seminalis, $K S$ Keimstock (Ovarium), dt Dotterstöcke (dunkelkörnig), $d g$ Dottergänge, ut Eileiter (Uterus), rs Receptaculum seminis.

Fig. 334. Taenia mediocanellata (saginata), nach Leuckart. Es sind Stücke aus den verschiedenen Regionen der Bandwurmkette dargestellt. 
fältigung der Individualität (nämlich der Person) ${ }^{1}$ ). In dem ursprünglichen Verhältniss, welches wir jetzt noch bei manchen Formen antreffen, ist der Hinterleib mit allen seinen Organen nur einmal vorhanden (Caryophyllaeus). Als nächstes phylogenetisches Stadium müssen wir jenes betrachten, wo die successive Abstossung der einzelnen Glieder am vollkommensten erfolgt, dieselben können in solchen Fällen sogar noch lange nach der Ablösung fortleben und wachsen. Bei sehr rascher Production der Glieder gehen dieselben auch serienweise ab und oft bleiben sie sogar in festerem Zusammenhange (verschiedene Bothriocephaliden); endlich sind jene Erscheinungen, wie bei Ligula und Triaenophorus, wo die Proglottiden sich äusserlich gar nicht scharf von einander absetzen und nur in der inneren Wiederholung der Organe angedeutet sind, als am weitesten modificirte Zustände $\mathrm{zu}$ betrachten.

Wir unterscheiden demnach an dem Körper der Cestoden einen bedeutend verschmälerten Vorderkörper oder Scolex, dann eine sogenannte Halsregion, wo die Bildung der Proglottiden stattfindet und ferner die Reihe voll Anfangs kleinen, gegen das Hinterende an Grösse bedeutend zunehmenden Proglottiden. Der Scolex ist mit Haftapparaten ausgestattet, welche je nach den verschiedenen Abtheilungen der Cestoden verschiedene Charaktere zeigen. Bei Caryophyllaeus (Fig. 332) ist der Scolex unbewaffinet; bei den Bothriocephalen trägt er zwei längliche Saugnäpfe, bei den Taeniaden sind vier radiär angeordnete Saugnäpfe und ein meist mit einem doppelten Hakenkranz versehenes Rostellum vorhanden; die Tetraphylliden besitzen vier complicirtere, oft mit Haken versehene Haftscheiben, wozu bei Tetrarhynchus sich noch vier in Taschen zurückziehbare rüsselartige Gebilde gesellen. Die Proglottiden sind stark abgeplattet und von viereckiger, oft in die Länge oder in die Quere ausgezogener Gestalt.

Bei den Cestoden ist die Körperoberfläche wie bei den Trematoden unbewimpert und mit einer ansehnlichen Cuticula bedeckt, die oft diclit

$A$

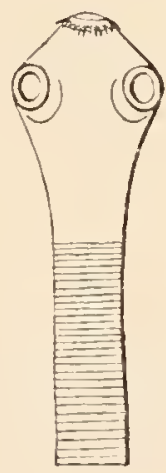

$B$

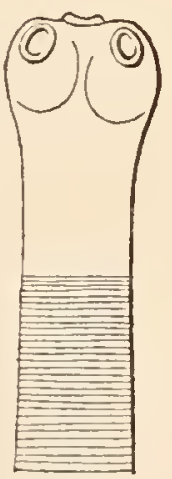

$C$

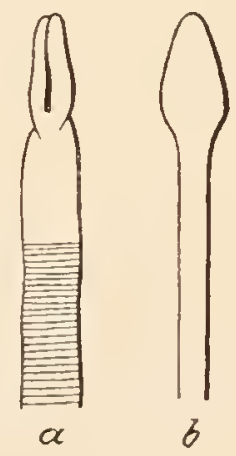

$D$

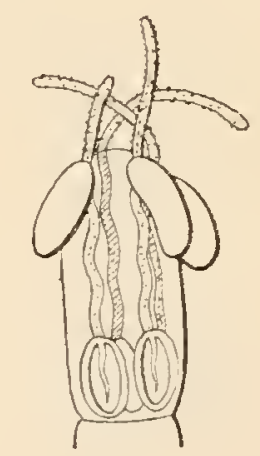

Fig. 335. Scolex von verschiedenen Cestoden. (nach Leuckart). A von Taenia solium, $B$ von Taenia mediocanellata, $C$ von Bothriocephalus latus, $a$ von der Fläche, $b$ von der Kante, $D$ von Tetrarhynchus.

1) Die in jüngster Zeit oft discutirte Frage nach dem Individualitätsgrade der Cestodenkette findet in dieser Fassung wohl ihre richtigste Beantwortung. Der Cestodenkörper ist also weder eine Person noch ein Cormus und er ist in das übliche Schema der Individualitätsgrade nicht obne weiteres einzureihen. Für die Oekonomie des Organismus hat der Vorgang den Werth einer vollkommenen Fortpflanzung durch Theilung. 
mit zarten cuticularen Härchen besetzt ist. Die Deutung dieser Membran als Cuticula ist nicht sicher, da die zugehörige Epithelschicht nicht bestimmt nachgewiesen ist; manche Forscher halten sie (wie bei den Trematoden) für die Basalmembran eines frühzeitig abgestossenen Epithels. Die Gewebe, die unterhalb dieser Cuticula sich finden, sind noch nicht endgiltig aufgeklär.t; zunächst folgt ein System ron Quermnd Längsfasern, die viele Forscher für Muskeln halten, darunter eine senkrecht faserige (bindegewebige?), auch Drüsenzellen enthaltende Zellschichte. Dann folgen die Schichten des Hautmuskelschlauches, nämlich eine Ringmuskel-, eine Längsmuskelschichte und eine transversale Muskelschichte (diese Muskelschichten werden auch als Parenchymmuskeln gedeutet); endlich finden sich dorsoventrale Parenchymmuskeln. Differenzirungen des Hautmuskelsclilauches sind die Haftapparate, d. i. die Saugnäpfe; in der Gruppe der Taeniaden kommt hier ferner das vorstülpbare, meist hakentragende Rostellum in Betraclit; an diesem fun-

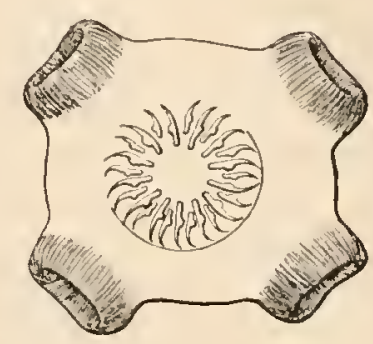

Fig. 336. Scolex von Taenia solium, vom Scheitelpol gesehen (nach LEUCKART). giren im einfachsten Falle im Innern verlaufende Längsmuskeln als Rückzieher und ein sackförmiger, das Rostellum von hinten umgebender Muskel, der auf ein Bindegewebspolster wirkt, als Ausstülper des Rostellums; bei den grösseren Arten kommen auch radiäre Muskeln und ein zweiter Muskelsack hinzu, sowie auch Muskeln, welche das Rostellum als Ganzes bewegen. - Das Bindegewebe des Körpers enthält allenthalben, besonders in der äusseren Leibesschichte, concentrisch geschichtete Kalkconcremente. - Der Darmkanal fehlt den Cestoden gänzlich und die Nahrungsaufnahme erfolgt durch die äusseren Bedeckungen, die aufzunehmende Nahrung ist hierzu durch den Verdauungsprocess des Wirthes in hohem Grade vorbereitet. - Der Excretionsapparat zeigt besonders deutlich einen Gegensatz von gröberen, oft mit anastomosirenden Aesten versehenen Ausführungsgängen und sehr reich entwickelten Excretionscapillaren; die ersteren münden in Längskanäle, die oft in Vierzahl oder aber durch Reduction des einen Paares in Zweizahl den Körper nahe den Seitenrändern durchziehen, sie sind durch Querkanäle an dem vorderen und hinteren Rande jeder Proglottis verbunden und besitzen Klappenapparate (vergl. Fig. 339); im Scolex bilden sie oft eigenthümliche Schlingen; sie münden am Hinterende der ältesten Proglottide durch eine gemeinsame contractile Endblase, in vielen Fällen sind auch zahlreiche Ausmündungen an der Körperfläche vorhanden; naclı Ab-

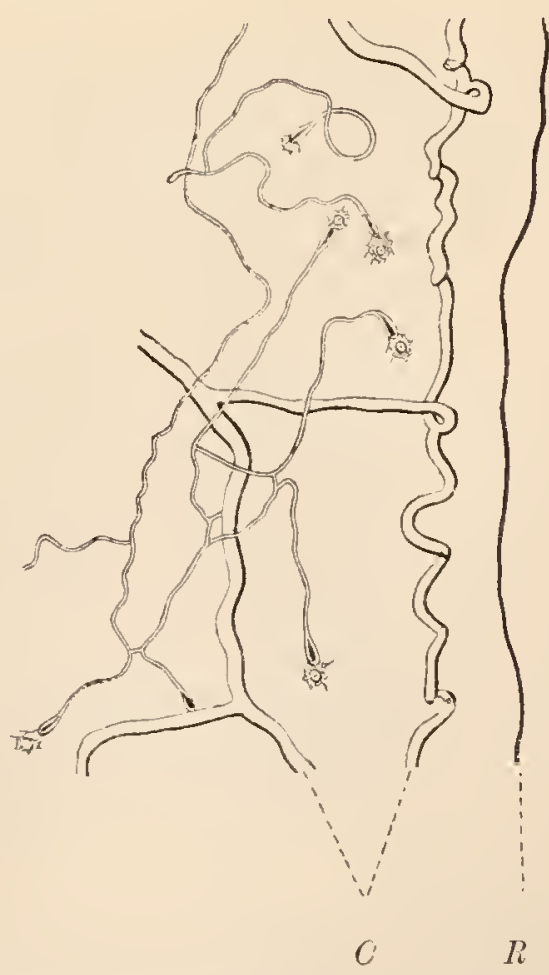

Fig. 337. Ein kleiner Theil des Excretionsapparates einer Taenie (nach PrNTnER). $R$ Rand des Körpers, $C$ grössere Sammelkanäle, in welche die capillaren Kanäle einmünden. 
stossung des Endgliedes münden die Längskanäle in der Regel gesondert.

Das Nervensystem besteht zunächst aus dem vorn im Scolex gelegenen Cerebralganglion, welches oft quer ausgezogen ist. Von diesem gehen Nerven nach vorn zu den Haftorganen; nach hinten geht ein Längsnervenpaar, welches alle Proglottiden durchzieht, es liegt seitlich von den Excretionsstämmen und entspricht wahrscheinlich dem ventralen Nervenpaar der Trematoden; dazu kommen aber noch eine Anzahl feinerer dorsaler und ventraler Längsnerven (bis 18), welche nur eine Strecke weit vom Cerebralganglion nach hinten zu verfolgen sind; diese Nerven sind vorn durch mannigfache Commissuren mit einander verbunden; bei den Taenien sind auch die vorderen, zu den Haftapparaten ziehenden (8) Nerven durch eine Ringcommissur verbunden. Specifische Sinnesorgane sind nicht bekannt.

Die zwitterigen Geschlechtsorgane der Cestoden, die sich in jeder Proglottis wiederholen, zeigen die tür die Platoden charakteristischen Complicationen in voller Entfaltung; hierbei kommen verschiedene besondere Eigenthümlichkeiten in Betracht. Bei Caryophyllaeus fungirt der weibliche Ausführungsgang noch ähnlich wie bei den Trematoden als Uterus. Bei den Bothriaden dagegen ist nebst dem weiblichen nur als Scheide fungirenden Gange ein besonderer schlauchförmig gewundener Uterus vorhanden, der durch eine eigene Oeffinung nach aussen mündet. Auch bei den Taeniaden ist ein besonderer Uterus als Aussackung des weiblichen Apparates vorhanden, der aber der äusseren Mündung entbehrt, so dass die Eier erst durch Zerfall des Proglottidenleibes frei werden. Die zwitterige Geschlechtsöffinung, die bei Caryophyllaeus und den meisten Bothriaden noch an der Bauchfläche sich findet, ist schon bei manchen Bothriaden und bei den Taeniaden an den

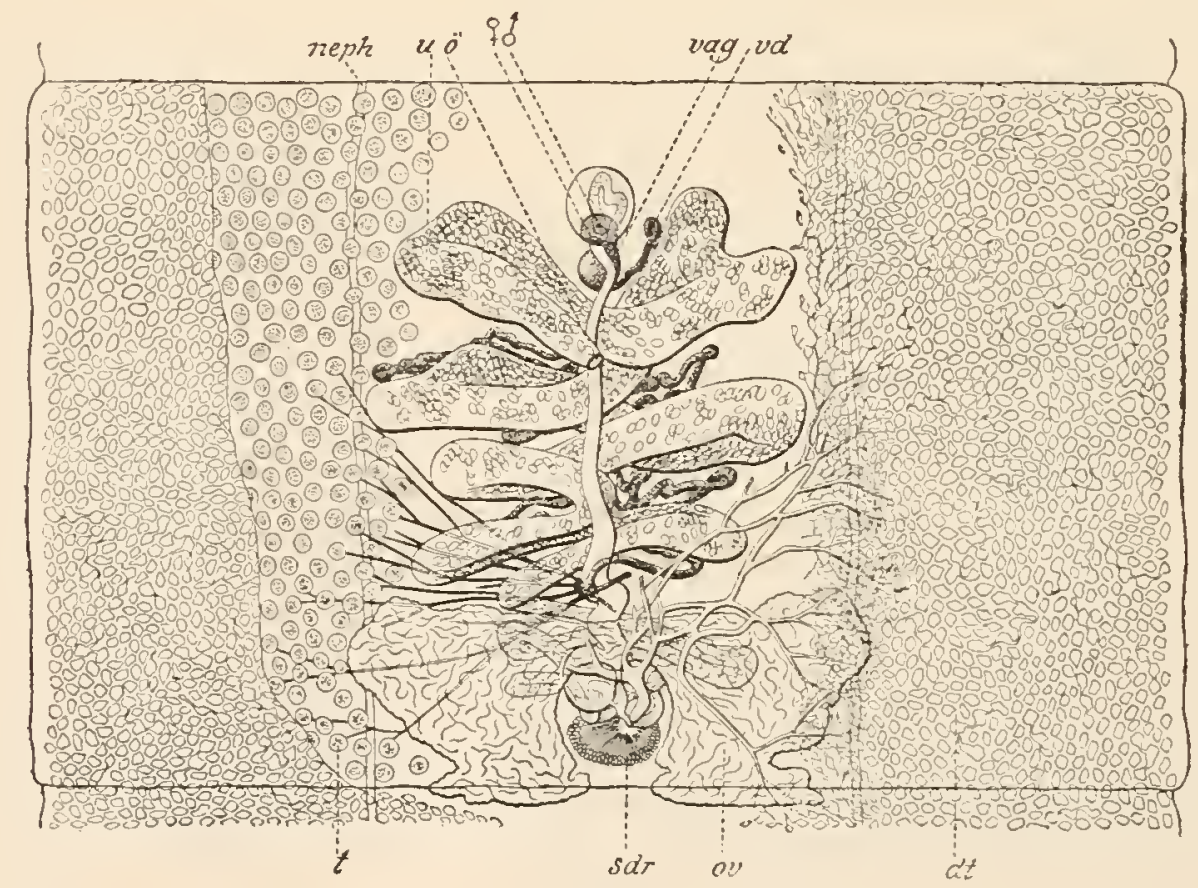

Fig. 338. Geschlechtsapparat einer Proglottis von Bothriocephalus latus (nach SoMMEr). $\bigcirc^{\circ}$ gemeinsame Geschlechtsöffnung, $\ddot{o}$ Uterusmündung, ov Ovarien, $d t$ Dotterstöcke, an beiden Flächen in der Rindenschichte gelegen, sdr Schalendrüse, vag Begattungsgang, $u$ Uterus, $t$ Hoden, in der Mittelschicht gelegen, um dieselben zu zeigen ist ein Theil der Dotterstöcke entfcrnt, $v d$ Vas deferens, neph Hauptstämme des Wassergefässsystems. 
Seitenrand der Proglottiden gerückt; oft ist sie abwechselnd rechts und links gelegen. Bei manchen Taeniaden sind die Geschlechtsorgane innerhalb jeder Proglottis symmetrisch verdoppelt und es finden sich Gesclıleclıtsöffurungen an beiden Rändern des Körpers (T'aenia cucumerina); dies ist wohl als eine eigenthümliche, normal gewordene Doppelbilluulg zu betrachten.

Wir wollen nun als Beispicl den mehr modificirten 'Jypus der Geschlechtsorgane von Taenia solium genauer kemnen lernen. Die Geschlechtsöffiung, die sich bald an der rechten, bald an der linken Seite der Proglottiden fundet, führt in die von einem Wulste umrandete Geschlechtskloake, in welche die weiblichen und männlichen Gänge nünden.

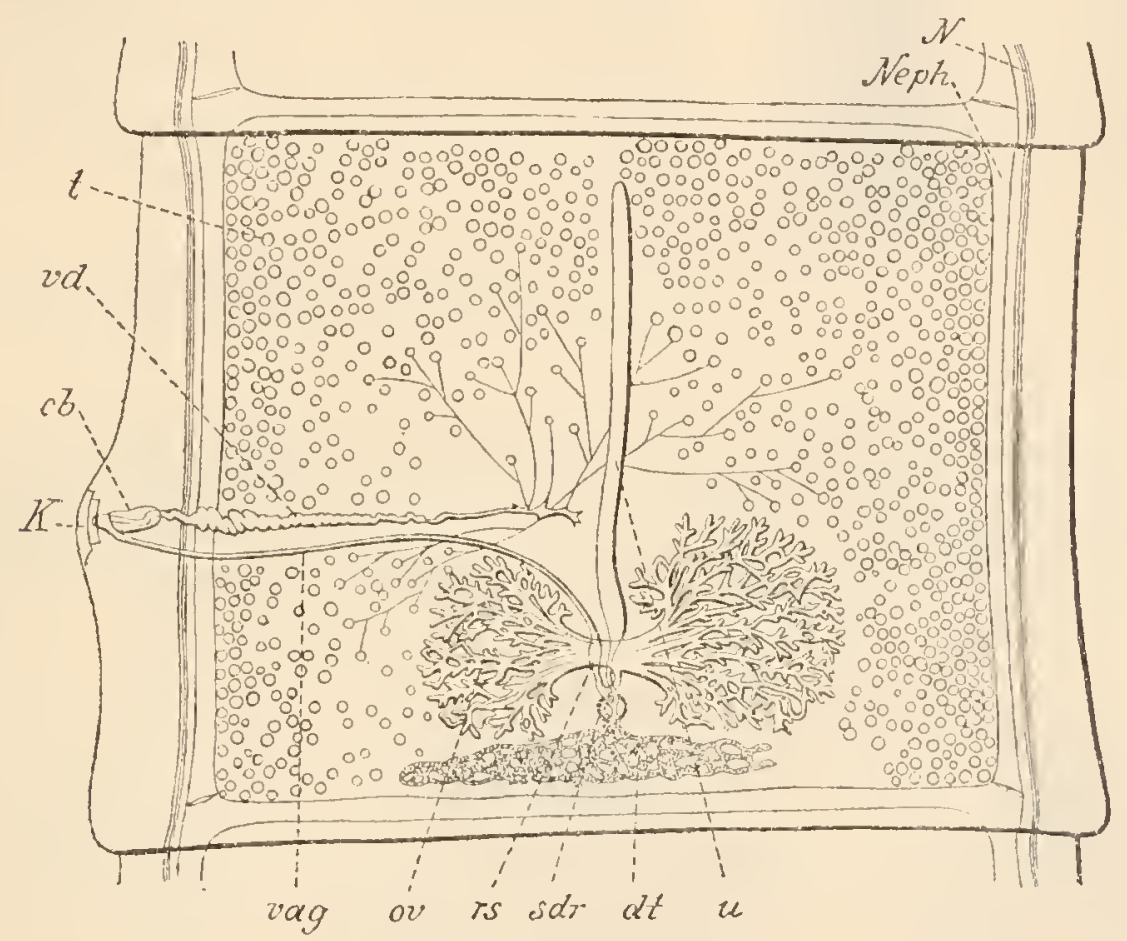

Fig. 339. Proglottis mit Geschlechtsapparat von Taenia mediocanellata (nach Sommer). $K$ Gesehlechtskloake, ov Ovarium, dt Dotterstock, sdr Schalendrüse, vag liegattungsgang mit is Receptaculum seminis, $u$ Uterus, $t$ Hoden, $v d$ Vas deferens, $c b$ Cirrusbentel mit Cirrus, $N$ seitlicher Längsnerv, Neph Hauptstämme des Excretionsapparates.

Der männliche Apparat besteht aus den sehr zahlreichen Hodenblüschen, die über die ganze Proglottis vertheilt sind, den verzweigten Samenkanälchen, die zu einem quer verlaufenden Vas deferens sich vereinigen, welclies samenblasenartige Erweiterungen besitzt und in einen fadenförmigen, mit Häkchen besetzten Penis oder Cirrus mündet, der in eincn muskulösen Cirrusbeutel zurückziehbar ist. Der weibliche keimbereitende Apparat besteht aus parrigen Ovarien und einem bei den Taenien an hinteren Rande der Proglottis liegenden unpaaren, netzförmig verzweigten Dotterstocke (bei den Bothriaden, Fig. 338, liegen die parigen, viel umfangreicheren Dotterstöcke in den seitlichen T'heilen der Proglottis). Keimzellen (Eizellen) und Dotterzellen gelangen in das Ootyp, wo die Befruchtung der Eizelle stattfindet und wo von den umgebenden Schalendrüsen die Eischale gebildet wird. Ku den Ootyp fülnt von der Gescllechtskloake her die Scheide, die an einer Stelle zu einem Receptaculum seminis angeschwollen ist, und andererseits erstreckt sich nach vor'n der Uterusschlauch, in welchen die fertigen Eicr gelangen. - 
Der Geschlechtsapparat kommt in den jüngeren Proglottiden erst allmällich zur Entwicklung; in den mittleren Proglottiden ist er in voller Entfaltung, hier erfolgt die Begattung, die oft eine Selbstbegattung fler Proglottis ist, oft auch von einer benachbarten Proglottis desselben 'Thieres erfolgt; diese Fïlle haben wohl für die Oekonomie des Orgauismus keine grössere Bedeutung als eine parthenogenetische Fort-
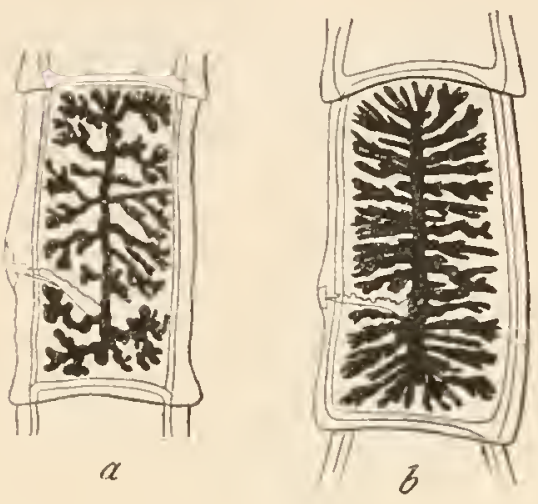
pflanzung und es ist gewiss auch eine Begattung verschiedener Individuen nothwendig, wenn auch in längeren Intervallen. - In den hinteren ältereu Proglottiden veröden alle Theile des Geschlechtsapparates mit Ausnahme des Uterus, der hier erst strotzend von Eiern erfüllt zur Höhe seiner Function gelangt und durch Ausbildung zahlreicher Seitenäste sich vergrössert.

Fig. 340. Reife Proglottiden von T'aenia soliun (a) und Taenia mediocanellata (b), mit gefülltem Uterns

Dic ersten Entwicklungsvorgänge, welche schon im Uterus vor sich gehen, sind jenen del Distomeen sehr ähnlich. Es gehen aus der furchung der sehr kleinen Eizelle nicht nur Zellen zum Aufbau des Embryo hervor, sonder'n auch zur Bildung von zwei embryonalen
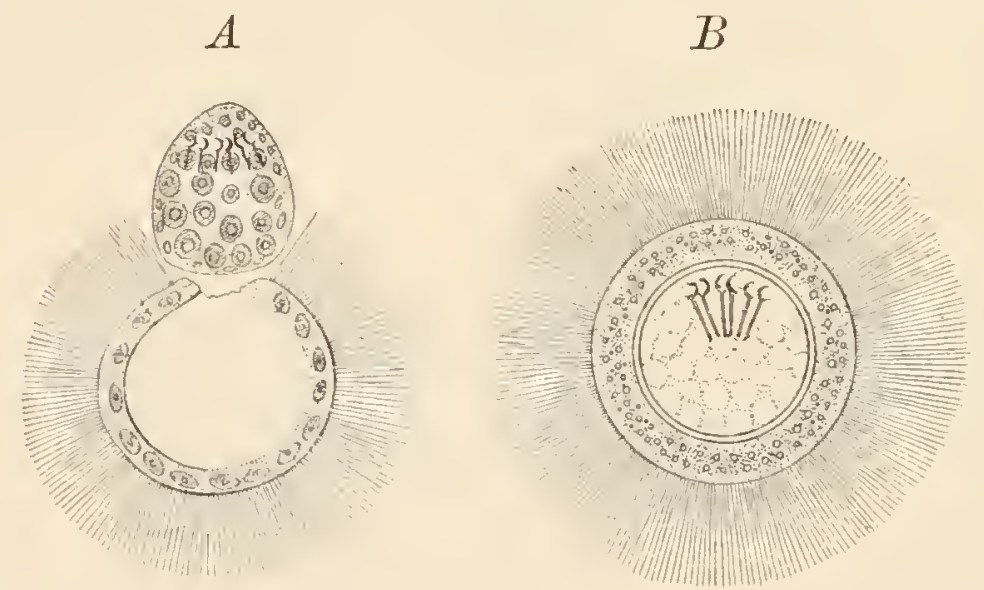

Fig. 311. Larve eines Cestoden (Bothryocephalide), nach SchaunsLAND. A Seclıslakige Larve, ungeben von ihrer flimmernden Embryonalhiille. $B$ dieselbe, im Begriffe, die Ilïlle zu verlassen.

Hïllschichten. Bei den Bothriaden umwächst die äussere Embryonalhülle, zugleich auch die secundïren Dottermaterialien, die innere Embryonalhülle lagegen ist mit äusserst langen, zarten Wimperhaaren um-

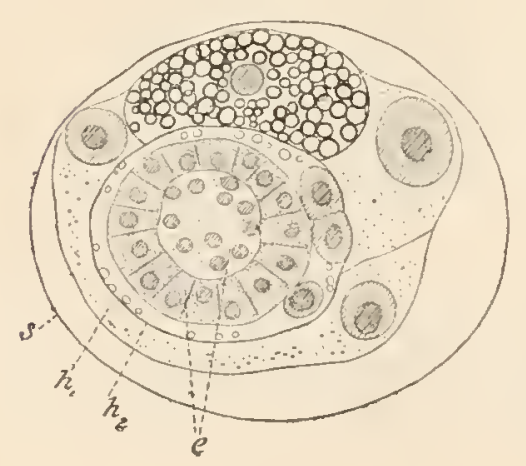
geben, sie bleibt auch nach dem Verlassen des Eies eine Zeit lang erhalten und dient zum Umherschwärmen der Larve im Wasser. Bei den Taeniaden wird von der äusseren Embryonalhülle eine dunkelkörnige /elle (Dotterreste?) mit umschlossen; die innere

Fig. 342. Embryonales Entwicklungsstadium von T'aenia (nach ED. VAN BENEDEN). $s$ Eischale, $h_{1}$ äussere Embryonalhülle mit einer grossen, von glïnzenden Körnchen (Dotterkiimchen?) erfiillten Zelle, $h_{2}$ innere Embryonalliille, e die zwei Schichten des Embryonalleibes. 
Hiille bildet sich sodamı rurch Verkalkung zu einer Eubıyonalschale um, welche aus radiür gestellten stibchenartigen Gehilden besteht.

Der Fubryo selbst, dessen Aufhan aus zwei Schichten (Ectoderm und Mesodern?") nachgewiesen wnde, ist in beiden Fillen rundlich mol mit sechs chitinigen Embryonalläkchen versehen, die ilın später zum Einbolnen in die Darmwandung seines Mirthes dienen.

Fig. 343. Entwicklungscyclus von Taenia solium (uach LEUCKART). a Embryo mit Stäbchenhiille, $b$ der sechshakige Embryo, $c$ die bildung des Scolex an der Wand der Finne, $d$ eine Finne mit ausgrebildetem, eingestiilptem Scolex, $e$ mit ausgestiilptem Scolex.

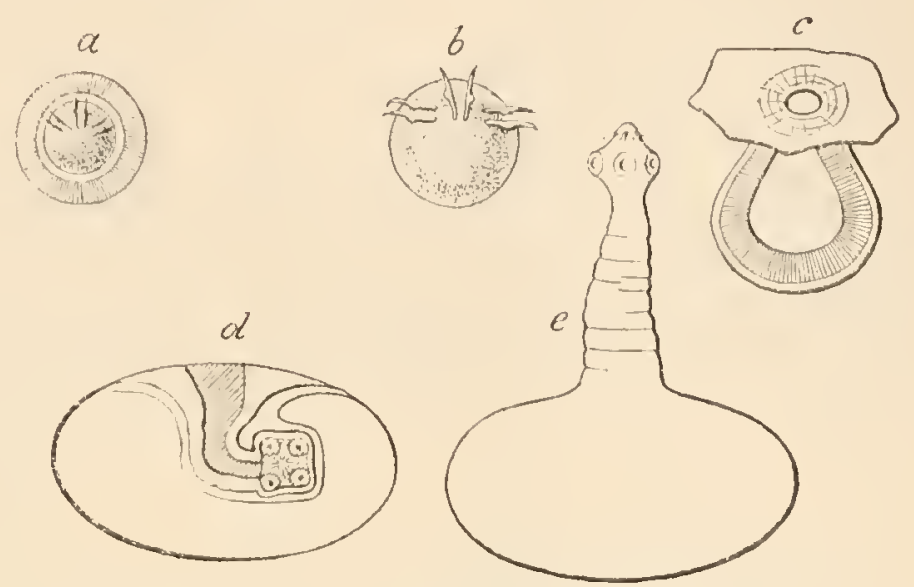

Diese sechshakige Larve entspricht morphologisch schon dem Platoden-Organismus, der aber hier von sehr reducirtem Bau ist. Dic merkwürrlige Reihe von Stadien, die nun zu dem entwickelten Bandwurm hinführt, ist daher als eine secundäre - durch Anpassung an die besonderen Lebensverhältnisse erworbene - Metamorphose zu betrachten. Die sechshakige Larve (,sechshakiger Embryo" ${ }^{6}$ ) muss, um sich weiter entwickeln zu können, in einen zweiten Wirth gelangen, bei welchem sie durch den Darm in die Gewebe eindringt ${ }^{1}$ ) und sich dort in eine Finne (Cysticercus-Stadium) verwandelt. Diese hat den Bau einer hohlen Blase, deren Wandung sich an einer Stelle und zwar gegenüber ren noch erhaltenen Embryonalhäkchen zur Bildung des S colex oder Bandwurmkopfes verdickt; derselbe entsteht aber zunächst nicht als Auswuchs, sondern in Form einer Einstülpung; seine Schichten erhalten dadurch eine ungekehrte Anordnung, so rlass die Saugnäpfe und das Rostellum an der Innenfläche seiner eingestülpten Höhle liegen; es ist dies als eine provisorische Einrichtung zu betrachten, wir sehen, dass bei älteren, reifen Fimmen der Scolex abwecliselnd aus- und eingestülpt werden kann ${ }^{2}$ ). Bei kleineren Finnen ist der Blasenhohlraum nur unbedeutend (Cysticercoid) und kann

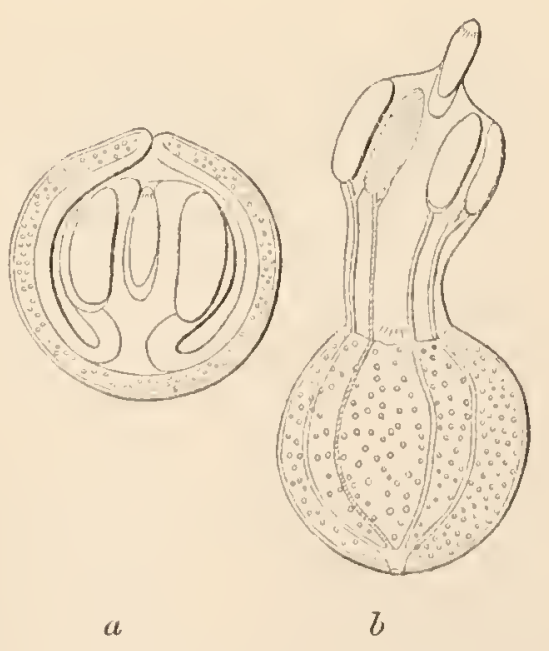

Fig. 344. Ein Cysticercoid (aus Braun, Parasiten). a jm eingestiilpten, $\zeta$ im allsgestiilpten Zustand.

1) Bei den Wirbelthieren erfolgt die Weiterverbreitung der sechshakigen Larve innerlıalb des liöpers dureh den Blutstrom.

2) Man hat dic Blasenwand, die an dem vorgestiilpten Scolex nur als ein Anlang erscheint, mit dem Cercarienschwanze verglichen, dieser Vergleich scheint aber nicht begrïndet 
auch ganz fehlen (Plerocercus); auch kann bei solchen die Einziehming des Scolex ohne vollkommene Umstülpung erfolgen oder ganz unterbleiben. Wem die Finne mit dem Fleische des Finnenwirthes in den Bandwurmwirth gelangt, so siedelt sie sich dort im Dünndarme an und verwandelt sich unter Verlust der Endblase und durch Ausbildung der Proglottiden in das Geschlechtsthier. - Ausnahmsweise sehen wir hei Archigetes Sieboldii das Thier schon im Finnenwirthe geschlechtsreif werden und zwar ohne wiederholte Proglottidenbildung durch Lintwicklung eines einzigen Geschlechtsapparates; die Blase bleibt hier als Anhang dauernd erhalten.

Dieser Entwicklungsgang des Bandwurmes wurde von früheren Forschern als eine Form von Generationswechsel aufgefasst, insofern als man annahm, dass der Scolex ein ungeschlechtlich erzeugter Abkömmling der Cysticercusblase sei; ebenso wurde die Proglottis als eine heteromorphe, vom Scolex erzeugte Individualität betrachtet. Gegenwärtig erklärt man allgemein wenigstens alle erstgenannten (der Proglottidenbildung vorherge-

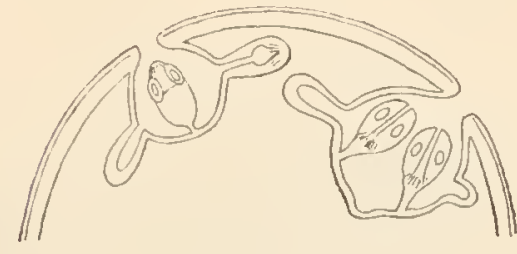

$a$

Fig. 345. a Schematische Darstellung der Echinococcusblase mit den Brutkapseln und ihren zahlreichen Scolices; 6 Taenia echinococcus. (Nach LELCKART.)

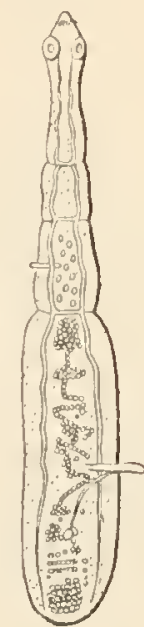

b henden) Vorgänge nur als Metamorphose. Anders ist dies aber in jenen Fällen, wo eine ungeschlechtliche Fortpflanzung auf dem Finnenstadium erfolgt; dies ist nämlich bei den Fimnen vom Echinococcustypus (Echinococcus, Coenurus) der Fall, bei welchen nicht nur die Finne durch

Theilung eingeschachtelte Tochter- und Enkelblasen erzeugt, sondern wo auch schr zahlreiche Scolices an je eincr Blase entstchen, ein Vorgang, der ebenfalls als Theilung (oder

Ḱnospung) zu betrachten ist. Die zu dieser Finne gehörigen Bandwurmformen erzeugen im Gegensatz zu dieser reichen Fimnenknospung nur eine geringe Zahl von Proglottiden.

Die Lebensgeschichte der Cestoden zeigt eine grosse Mannigfaltigkeit der merkwürdigsten Anpassungen an den Parasitismus. Nicht nur die äusserst cinfachen Lebensäusserungen, mit welchen der Mangel der Simnesorgane und des Darnes zusammenhängt, kommen hierbei in Betracht, sondern auch namentlich der sehr ausgeprägte Wirthswechsel, welcher darin besteht, dass der Parasit an zwei Wolnnthicre angepasst erscheint, die stets wieder untereinander in gewissen Lebensbeziehungen stehen müssen. Das Geschlechtsthier bewohnt stets den Darm cines Wirbelthieres - Fisch, Säugethier etc. - , welches wir daher als Bandwurnwirth bezeichnen; die sechshakige Larve wandert in einen zweiten IIirth, wo sie zur. linne sich entwickelt; dieser Finnenwirth kamm auch ein I'irbelthier sein, oft aber ist es auch ein wirbelloses Thier, z. I3.

zu sein, denn das Wassergefässsystem miindet oft am Hinterende der Schwanzblase; cs wäre sogar mörlich, dass die an der Blase befindlichen Embryonalhäkchen auf die hinteren Haftapparate von Trematoden zu beziehen wïren. Die Zurickführung des Rostellums auf das Stomodaenm der Trematoden scheint auch sehr gewagt. 
ein Insekt, cinc Schnccke etc. In der Regel ist der Finnenwirth ein pflanzenferessendes oder onnivores 'I'hier', das dem Bandwnmwirtl _ der meist ein Fleischfresser ist - zur Nahrung dient; so kommt die Uebertragung der Finne zu Stande, die also passiv geschicht. lis lebt z. B. die Tacnia solium in Dünndarm des Menschen, die reifen, mit Fierı erfüllten Proglottiden gelangen auf die Dungstätten, wo sic von dem Schweine verzehrt werden, welches als Finnenwirth dient; durch den Genuss von finnigem und nicht genügend gekochtem Schweinefleisch acquirirt der Mensch wieder den Bandwurm. Für dic Taenia mediocancllata ist Bandwurmwirth der Mensch, Finnenwirth das Rind. $T$. serrata lebt im Jagdhunde, die Finne in der Leber des IFasen und Kaninchens, T. erassicollis in der Katze, die linne in der Hausmaus, T. crassipes im Fuchse, die Finne in del Feldmaus, T. in den Mäusen und Ratten, dic Finne in Mehlwurm, T. cucumerina in Hunde, dic Finne in der Hundelaus (Trichodectes eanis), Tacnia echinococcus lebt in Ilunde, die Finne (Echinococcus) im Menschen, Taenir coenurus in Hunde, die Fimne (Cocnurus cerebralis) im IIirn der Schafe etc. ete.

Systematiscle Uebersicht der Cestoden

(mit besonderer Berücksichtigung der menschlichen

Parasiten).

A. Bothriadue, Haftapparate des Scolex mannigfacl verschieden; Genitalölfnumg flächenständig oder seitenständig, Uterusmiundung Hächenständig; Dotterstock in der Rindenschichte gelegren, parrigr; Larven nit winupernder Enbryonalhülle; Finne plerocerc. Dic meisten hierher gohörigen Formen leben in Fischen.

Ungegliedert sind: Amphilina mit einem vorderen Saugnapf', 'l'rematoden-ïhnlich, lebt in der Leibeshöhle ron Störeu. - C'aryophyllaens.s ohue Haftapparate, lebt im Darme von Fischen (Cyprinoiden). - Aichigeles mit zwei schwachen Sauqgruben ist Finnen-ähnlich, da die Blase mit den Embryonalhäkchen zeitlebens als Schwanzanhang erhalten hleibt; wird in dem Finnenwirth, und zwar in limicolen Oligochnelen, auch geschlechtsreif.

Tetrarhynchidae mit vier Sauggruben und vier hakenbesetzten Rüsseln, die retractil sind; Tetrarhynchus. - Telraphyllidac mit vier oft hakentragenden Saugnäpfen; Acantobolhrium, Phyllobolhrium ctc. - Diphyllidne mit zwei Saugnäpfen und zwei hakentragenden Stirnzapfen, Echinobolhrium. - Alle diese Gattungen leben in Rochen und Haien.

Ligulidae mit zwei schwach angedeuteten Sauggruben, sind nur innerlich gegliedert, leben als Jugendform in der Leibeshöhle ron Süsswasserfischen, geschlechtsreif in Wasservögeln; Ligulu.

Bothriocephalidae. Scolex mit zwei länglichen, Hächenständigen Saugrnäpfen, Proglottiden sind breiter als lang. Zahlreiche $A$ rten leben in Raubfischeı, Wasservögeln und Säugethieren. Hierher gehört: Bothriocephalus latus, breiter Bandwurm des Menschen, ist der grösste Bandwurm des Menschen, Länge 5-9 m. Scolex mit zwei länglichen, flächenstäudigen Sauggruben. Hals lang und dünn. Zahl der Glieder 3000-4000, dieselben sind breiter als lang, im lebenden Zustande aber mehr gestreckt; das letzte ist hinten abgerundet. Die mittleren Theile des Geschlechtsapparates bilden in der Mitte jeder Proglottide eine etwas vorspringende rosettenähnliche Figur (Wappenlinie). Geschlechtsöffnung und Uterusöffnung flächenständig. 
Die Eier sind oval, 0,07 mm lang, mit gedeckelter Schale. - Der Bandwurm lebt im Darme des Menschen, kommt aber nur in gewissen Ländern regelmiissiщ vor, und zwar: Westliche Schweiz, nördliches Russland und russische Ostseeprovinzen, Schweden, Finnland. - Die bewimperte Larve gelangt in das Wasser und wandert in Fische,

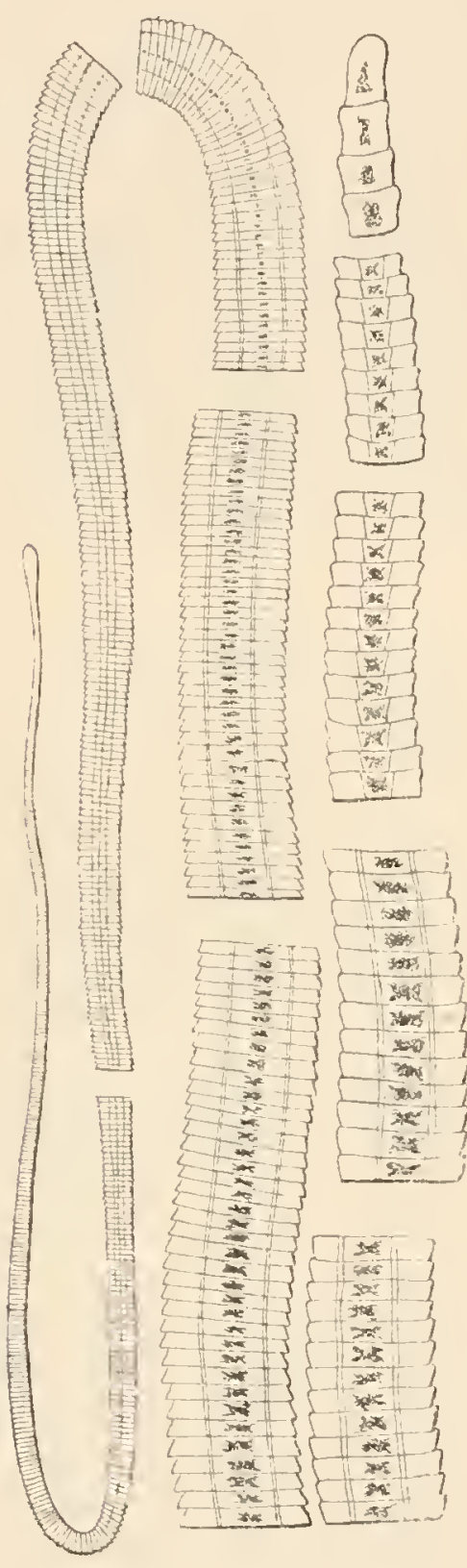

Fig. 346. Bothriocephalus latus (nach LEUCKART). Es sind Stücke aus den verschiedenen Regioneu der Bandwurmkette dargestellt. nämlich Hecht und Quappe (Lola vulgaris), ein, wo sie im Muskelfleisch zu einer plerocercoiden Finne, von länglicher Gestalt, mit nicht einstülpbarem Scolex, sich entwickelt. Die Verwandlung derselben in den Bothriocephalus latus des Menschen ist durch M. Bradn experimentell erwiesen. Die Infection erfolgt also durch Genuss von ungenügend gekochten Hechten oder Quappen. Die pathologisohe Bedeutung des Wurmes ist wicht sehr bedeutend; auch ist derselbe leicht abzutreiben.

B. Taeniadae. Scolex mit vier Saugnäpfen und einem Rostellum, welches meist einen mehrreihigen Hakenkranz trägt. Geschlechtsöffumng seitenständig, Uterus blind geschlossen; Dotterstock in der Mittelschicht gelegen, unpaar. Embryonen mit Stäbchenhülle (unbewimpert). Jugendforn sind meist echte Finnen (Cysticercus, Cysticercoid). Die Geschlechtsform lebt nur in Vögelı und Säugethieren.

Die einzige Gattung Taenia mit vielen Arten, die man in zwei (oder drei) Gruppen scheiden kann:

a) Cystoideae. Die Finnen sind cysticercoid oder plerocerc und finden. sich meist in wirbellosen Thieren; die Bandwürmer sind kleinere Formen und leben im Darme von Vögeln oder Säugethieren. - Taenia cucumerinc lebt im hinteren Theile des Dünndarmes ron Hunden und Katzen in grosser Anzahl; wird manchmal auch bei Kindern gefunden. Die Finne ist plerocerc und lebt in der Leibeshöhle der Hundelaus (Trichodecles camis). Die Länge des Bandwurmes ist 15 bis $20 \mathrm{~cm}$; reife Glieder blassröthlich, bis $1 \mathrm{~cm}$ lang. Geschlechtsorgane und Geschlechtsöffnungen sind in jedem Gliede doppelt vorhanden. Die Eier des Bandwurmes bleiben an den Haaren namentlich der Gesässtheile hängen und werden von der Hundelaus verzehrt; diese beherbergt die plerocerce Finne; dadurch, dass die Hunde ihr Ungeziefer verzehren, erfolgt die Rückinfection. Die Infection des Menschen erfolgt wohl durch zufällige Verunreinigung; die pathologische Bedeutung ist gering, da hier nur wenige Exemplare gleichzeitig vorkommen.

b) Cystotaeniae. Die blasenförmigen echten Finnen (Cysticercus) leben nur in Säugethieren (Nagern, Wiederkäuern); die Bandwürmer sind meist grössere Formen und finden sich ebenfalls nur in Säugethicren (Raubthieren 
etc.). - Als besondere Gruppe (Coccotaeniae) köunte man endlich diejenigen Tacnicn sonderu, deren sehr grosse blasenförmigre l'iunen zahlreiche Scolices erzengen (Eehinococeus-'Iypus), und deren Geschlechtsthiore kleine bis sehr kleine Formen mit meist nur wenigen Gliedern sind.

$A$

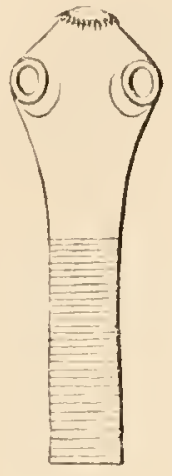

$a$

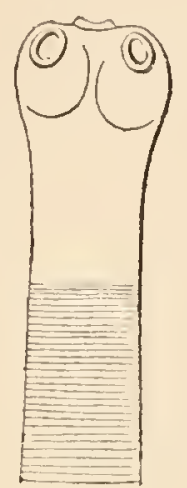

$b$
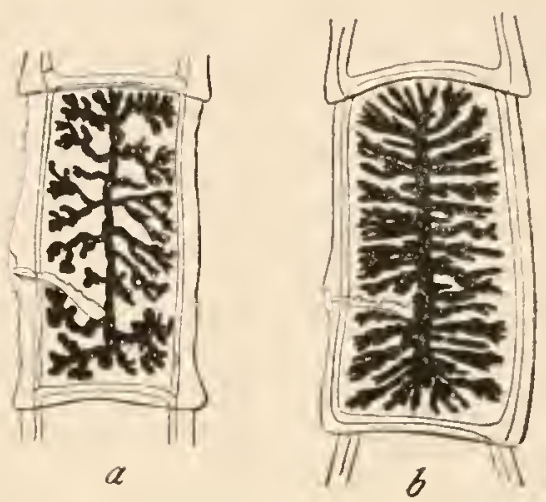

Fig. 347. A Scolex von Taenia solium (a) und von T. mediocanellata $(b)$. B Reifo Proglottis von $T$. solium $(a)$ und von $T$. mediocanellata (b). (Nach LeuckarT.)

Taenia solium, bewaffineter Bandwurm des M enschen. Liiuge $2-3,5 \mathrm{~m}$. Scolex mit einem stark vorspringenden, mit doppeltem Hakenkranz versehenen Rostellum und mit vier grossen, aber weniger muskulösen Saugnäpfen (im Vergleich mit $T$. mediocanellata). Hals dünn und lang. Zahl der Proglottiden 800-900; dieselben sind mässig dick; die länglichen reifen Glieder werden in der Regel einzeln abgestossen und sind ungefähr $1 \mathrm{~cm}$ lang; an diesen zählt man jederseits $7-10$ verästelte Seitenzweige des Uterus. Die Eier mit radiär gestreifter Embryonalhülle sind $0,03 \mathrm{~mm}$ gross. - Der Bandwurm lebt ausschliesslich beim Menschen im Dünndarme, er entwickelt sich aus der Finne in $11-12$ Wochen und producirt dann Jahre lang neue Proglottiden; er ist über die ganze Erde verbreitet, soweit das Schwein als Hausthier gehalten wird. Doch ist die Verbreitung ungleich und hängt auch von localen ökonomischen Verhältnissen $a b ;$ so ist dieser Bandwurm in Norddeutschland ungleich häufiger als in Süddeutschland, Oesterreich, Italien. Die Finne, der sogenannte Cysticercus cellulosae, dessen Zugehörigkeit zu T. solium zuerst KücheNMFISTER experimentell nachgewiesen hat, ist rund oder oval, ungeführ von der Grösse einer Erbse, manchmal auch etwas grösser; sie lebt meist beim Schweine, vorzüglich in dem intermusculären Bindegewebe, aber auch in anderen Organen, z. B. Unterhaut, Gehirn, Auge; die Finne kommt ausserdem beim Reh, Schaf, Hund und vielen anderen Säugethieren vor, und ferner auch beim Nenschen, welcher Umstand von besonderer pathologischer Wichtigkeit ist; im Schweine bedarf der Cysticercus zu seiner Entwicklung die Zeit von $2^{1 / 2}-3$ Monaten und bleibt dann Jahre lang in gleichem Zustande. - Die pathologische Bedeutung der Taenie ist an und für sich eine geringe und von der individuellen Beschaffenheit des damit behafteten Nenschen abhängig. Der Parasit kommt selten in grösserer Zahl vor, und von einem einzelnen Exemplar werden kräftige oder weniger reizbare Personen wenig oder gar nicht belästigt; bei reizbaren Personen aber kommen mannigfache Störungen zunächst des Darmes vor; die Dia- 
guose ist hauptsächlich durch Nachweis der regelmässig mit den Fäces abgehendeu Proglottiden und Bandwurmeier zu begründen. Trotz der meist nur geringen pathologischen Bedeutung des Bandwurmes selbst, ist doch die Abtreibung desselben dringeud geboten, da die zugehörige Finne auch im Menschen sich entwickeln kann und daher das Vorhandensein des Bandwurmes eine fortwäbrende Gefahr nicht nur für die damit behaftete Person, sondern auch für die Ungebung derselben bedeutet. Es ist daher auch wichtig, auf Grund der abgehenden Proglottiden diese Taenie von der ungefihrlichen T. mediocanellata zu unterscheiden (vergl. Fig. 347). Die Abtreibung von T'. solium ist wegen der schwächeren Saugnäpfe viel leichter and sicherer, doch sind dabei brechenerregende Mittel zu vermeiden und etwa eintretender Brechreiz zu stillen (z. B. durch Schlucken ron Eispillen), da hierdureh Finnen-Infection entstehen könnte. Bekanntlich ist die Abtreibung des Wurmes nur dann vollkommen gelungen, wenn auch der Kopf mit abgeht, da sonst die Bandwurmkette wieder heranwächst. - Finnen (Cyslicercus cellulosae) kommen im Menschen einzeln oder zahlreich, ja sogar zu 'Tausenden vor. Die pathologische Bedeutung ist je nach der Zahl und dem Sitz der Parasiten verschieden; einzelne Finnen in der Unterhaut verursachen nur geringe Schädlichkeit, anders aber, wenn sie im Muskelfleisch des Herzens, im Auge oder im Gehirn vorkommen, wo sie die schwersten functionellen Störungen jener Organe verursachen können; die Diagnose ist meist schwierig; im Auge sind die Finnen direkt zu beobachten und werden extrahirt, doch verbleibt eine dauernde Schädigung des Organes. Da von einem Bandwurm-Kranken fortwährend reife Proglottiden abgehen und die Eier auf die verschiedenste Weise die Wäsche, Kleider, Gebrauchsgegenstände verunreinigen können, so ist die Gefahr einer FinnenInfection auf dem Wege des IIundes nicht nur fuir ihn selbst, sondern auch für die nächsten Personen vorhanden; viel gefährlicher ist aber eine innerliche Selbstinfection, welche dadurch zu Stande kommen kann, dass durch antiperistaltische Darmbewegungen reife Proglottiden in den Magen gelangen und unter dem Einflusse der Magensäure zerstört werden, wobei die Embryonen massenhaft frei werden und in die Magenwand sich einbohren; daher rührt auch die Gefährlichkeit der Brechbewegungen beim $\Lambda$ btreiben des Wurmes. - Zur Vorbeugung der Infection ist eine regelmässige amtliche Fleischbeschau empfohlen; ferner ist der Genuss ungenügend gekochten Fleisches oder Würste zu vermeiden. Den Schweinen soll der Zugang zu den Dungstätten und Aborten verwehrt sein; abgehende Bandwürmer sind zu verbrennen; endlich ist als allgemeines Mittel gegen alle Parasiten strenge Reinlichkeit geboten.

Taenia mediocanellata (= saginata), unbowaffneter Band wurm des II enschen. Grösser als die vorhergehende Art, Länge 4-8 m. Scolex mit wenig entwickeltem, flachem, hakenlosem Rostellum und mit vier kräftig muskulösen Saugnäpfen. Hals kurz und breit. Zahl der Proglottiden 1200-1300; dieselben sind feist; die reifen Glieder werden gewöhnlich zu mehreren gleichzeitig abgestossen und wandern oft selbstthätig aus dem Darme aus (ohne Stuhlgang); sie sind bis $2 \mathrm{~cm} \mathrm{lang,} \mathrm{man}$ zählt an denselben $17-30$ verästelte Uteruszweige. Die Eier mit radiär gestreifter Embryonalhülle sind $0,03 \mathrm{~mm}$ gross. Der Bandwurm lebt ausschliesslich im Dünndarm des Menschen und ist mit der Rindviehzucht über die Frde verbreitet; besonders häufig ist er in Indien und Abyssinien, wo der Genuss rohen Fleisches Sitte ist. Die Infection erfolgt durch den Genuss finnigen Rindfleisches, welches in ungenügend gekochtem oder ungenügend gebratenem Zustande genossen wurde. Der Bandwurm entwickelt 
sich aus der Finne in etwa drei Monaten, er stösst dann täglich bis 12 Proglottiden ab. Die Finne lebt in geringer Zahl in Fleisch des Rindes. Dieser Bandwurm verursaeht mehr Beschwerden als $T$. solium, da er grösser ist und auch rascher wiichst. Er ist auch wegen seiner kräitigeren Suugniiple schwerer abzutreiben. Doch ist er ungefährlich, da die zugchörige Finne im Menschen nicht vorkommt, also eine Finneninfection nicht zu befürchten ist.

Taenia echinococcus, Ech in o c oc cus-Band w u r m. Ein sehr kleiner Bandwurm von etwa $1 / 2 \mathrm{~cm}$ Länge, mit nur 3-4 Proglottiden. Scolex mit hinfälligem doppeltem Hakenkranz. Er lebt, oft in grosser Zahl, im Dünndarm des Hundes. Die zugehörige Finue lebt in der Leber und anderen Organen beim Schwein, Rind und anderen Säugethieren (Echinococcus veterinorum) und auch beim Menschen (Echinococcus hominis). Die Echinococcusblasen werden mehrere Centimeter gross, aber auch darüber bis zur Grösse eines Kindskopfes; sie sind meist rund, seltener ausgebuchtet oder gelappt. Dieselben liegen in einer vom Wirthe gebildeten Bindegewebskapsel; ihre eigene Wandung besteht aus einer sehr charakteristisehen dicken, geschichteten Cuticula und einer darunter liegenden „Parenchymschicht"; aus letzterer entstehen zahlreiche Brutkapseln oder Tochterblasen, die in die Höhlung jener dickwandigen Mutterblase hineinragen und selbst zahlreiche Köpfchen erzeugen (das Schichtungsverhältniss ist aus der schematischen Fig. 345 a zu ersehen). Die Köpfchen werden durch Platzen der Brutkapseln frei und fallen in die Höhlung der Mutterblase. In manchen Fällen kommen, keine Köpfchen zur Entwicklung, die Echinococcusblase bleibt steril (Acephaloeysten). Die Entwicklung der Echinococcusblase dauert mehrere Monate und dieselbe lebt jahrelang fort. - Die Echinococcuskrankheit ist über die ganze Erde verbreitet, besouders häufig, geradezu endemisch tritt sie in Irland auf (Hydatidenseuche). - Pathologis che Bedeutung. Die Echinococcusblasen kommen beim Menschen in den versehiedensten Organen, am häufigsten aber in der Leber vor; meist vereinzelt, in auderen Fällen aber sogar zu Hunderten. Der Echinococcus, weleher zwar langsam wächst, kann doch bedeutende Functionsstörungen orzeugen; auch kommen Perforationell und Abscessbildungen vor; wemn solche in das Blutgrefässsystem erfolgen, so kommt es zu gefährlichen Embolien. - Die Diaguose (Hydatidensehwirren) des Echinococcus ist oft schwierig; sie ist nur dann zweifellos, wenn bei Probepunctation in der entleerten Flüssigkeit Köpfchen oder Häkchen nachgewiesen werden. Zur Heilung wird Entleerung der Echinococcusblase durch Punctation vorgenommen, welche oft zur Verödung derselben führt. - Da die Infection durch die Eier der T'aenia echinococcus des Hundes und zwar auf dem Wege des Mundes erfolgt, so ist zur Vermeidung derselben Vorsicht beim Umgang mit Hunden zu üben und besonders Verumreinigung der Hände etc. hintanzuhalten.

Trıniu coenurus ist ein etwas grösserer Bandwurm, von etwa $40 \mathrm{~cm}$ Länge, der in dem Dünndarm des Schäferhundes lebt. Die zugehörige Finue erreicht die Grösse eines Hïhnereies und erzeugt ebenfalls zahlreiche Köpfchen, sie kommt im Gehirn der Rinder und Schafe vor und verursacht die Drehkrankheit der Schafe. Thiere, welche an dieser Krankheit zu Grunde gehen, sind sorgfiiltig zu verscharren; keineswegs aber darf das erkrankte Gehirn, wie dies früher oft geschah, den Hunden vorgeworfen werden, denn bei diesen entwickelt sich dadurch der Bandwurm, durch dessen Eier sodann die Weideplätze verseucht werden. 


\section{Classe der Scolecida. Gastrotricha.}

Die Gastrotrichen sind Scoleciden mit parigem velltralem Wimperstreif, meist mit gabeltheiligem Schwanzanhang, in it terminaler Mundöffnung und Nematoden-artigem Schlunde.

Diese Thiergruppe wird meist anhangsweise zu den Räiderthieren gestellt. Es ist aber richtiger, wie neuerdings Zeuinka hervorgehoben hat,

$a$

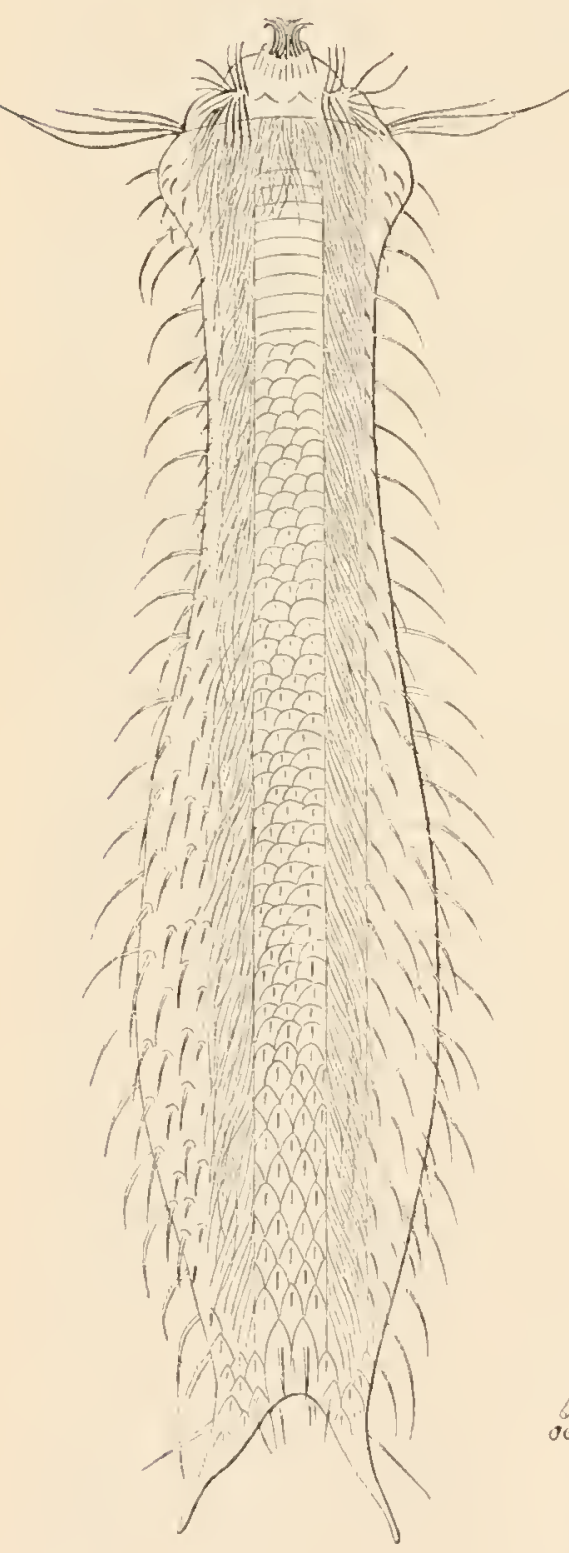

$b$

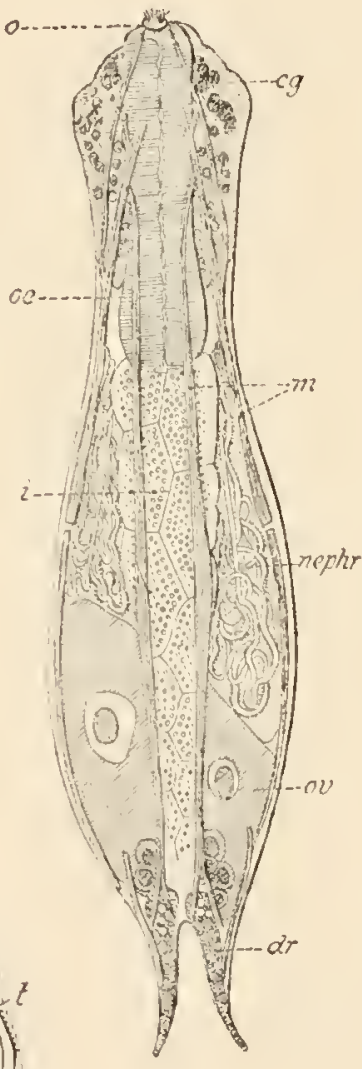

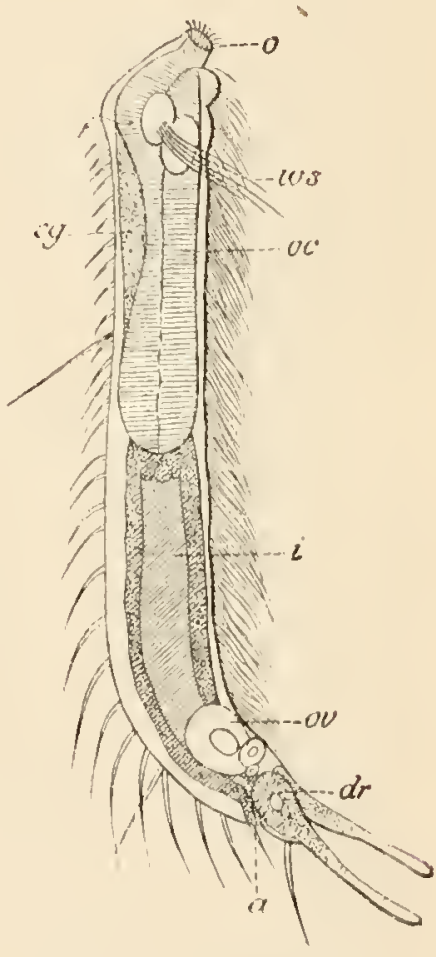

Fig. 348. Organisation von Chaetonotus maximus (nach ZkLINKA).

a Chaetonotus maximus, von der Bauchseite gesehen. b Ventrale Ansicht, Uebersicht der Anatomie. o Mund, cg Cerebralganglion, oe Oesophagus, $i$ Darm, $m$ Iängsmuskeln, neph $r$ Nephridien, ov Ovarien, $d r^{\circ}$ Schwanzdrïsen. $c$ Seitliche Ansicht, Uobersicht der Anatomie. a After $d$ Nephridium. $t$ Terminalapparat, oe äussere Mündung. $e$ Cuticulares Schūppchen mit Stachel. 
sie als besondere Classe der Scoleciden zu betrachter, welche solbständig vou der 'Trochophora abzuleiten ist. Die oralen Wimperkränze, welche den Iholalorien zukommen, fehlen hier; auch liegt die Mundöffnung vollkommen terminal und die Scheitelplatte ist dorsal verschoben. Dagegen haben sich andere Trochophoracharaktere, die den lolatorien fehlen, erhalten; so der rentrale Wimperstreif und die Wimpergruben.

Die Gastrotrichen sind Süsswasserthiere von mikroskopischer oder nahezu mikroskopischer Grösse $(0,06-0,4 \mathrm{~mm})$. Thre Gestalt ist spindelförmig mit abgeplatteter Bauchseite. Das Vorderende ist verdickt; das Hinterende trägt meist einen gabeltheiligen Anhang (Fuss, Schwanz), der mit Drüsenzellen ausgestattet ist. Del Körper ist von einer festen Cuticula bedeckt, deren Aussenschichte in der Rt gel zu einem eigenthümlichen Besatz von Stachelschuppen differenzirt ist. Die Bewimperung ist auf einen paarigen ventralen Wimperstreif beschränkt, sowie auf mehrere Gruppen von Tastwimpern all der vordersten Körperregion, die zum Theil vielleicht den cerebralen Wimpergruben des Zygoneurentypus entsprechen. Das Cerebralganglion steht noch in inniger Verbindung mit dem Epithel des Vorderendes und besonders mit den dort befindlichen Sinneswimperzellen, und liegt dorsal vom Schlunde; es entsendet nach hinten zwei ventrale Längsnerven. - Das Muskelsystem ist erst in jüngster /eit nachgewiesen (/LLINRA), es sind paarige, seitliche und ventrale Lïngsmuskeln, welche aus je zwei hintereinander gereihten Muskelzellen bestehen. - Die Excretionsorgane bestehen jederseits aus einem einfachen, aufgeknäulten Rohre mit flimmerndem Terminalapparat, und sie münden ventral in der Mitte der Körperlänge. - Der geradgestreckte Darm verläuft in einer deutlichen Leiboshöhle. Die Mundöffnung liegt am Vorderende und ist mit einem Kranze gekrümmter Greifborsten bewaftinet. Sie fïhrt in eine Speiseröhre, welche an jene der Nematoden erinnert, da sie ein dreikantiges Lumeu und in die Wandung eingelagerte Radiärmuskeln besitzt ${ }^{1}$ ). Der aus grossen Zellen zusammengesetzte Mitteldarm verläuft gerade nach hinten; ein kurzel Afterdarm mündet dorsal vom Schwanzanhang. Dic Thiere sind nach einer Ansicht getrenntgeschlechtlich, nach anderer' sind sie 'Zwitter mit protandrischer' Geschlechtsreife; dies ist deshalb ungewiss, weil die männlichen Organe überhaupt noch nicht sicher nachgewiesen sind. Das Ovarium liegt ventral am Hinterende als eine Anhäufung kleiner '/cellen; dieselben wachsen einzelweise heran zu relativ sehr grossen, nit einer derben, oft stacheligen Dottermembran versehenen Eiern. Dieselben werden vor der Entwicklung abgelegt; diese ist eine direkte, die ausschlüpfenden Jungen besitzen die charakteristische Organisation und eine relativ schon bedeutende Grösse.

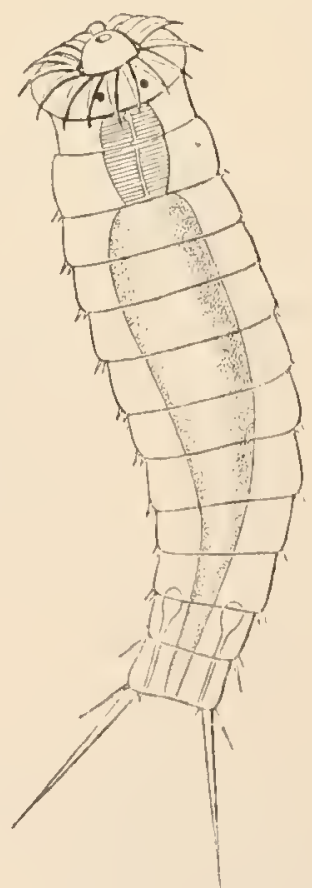

Fig. 349. Echinoderes Dujardinii (nach CLAPALÈDE).

1) ZELINkA hält die radiären Muskeln für Differenzirungen des Vorderdarnepithels selbst; es ist möglich, dass diese (allerdings noch zweifelhafte) $\Lambda$ uffassung auch auf die Nematoden ausgedehnt werden kann; dies wäre nun eine sehr eigenthimliche Art von Epithelmuskeln bei Zygoneuren 
Clncelonotus, Ichlliydium leben im Süsswasser.

An hang: Echinoderidae. Dius sind kleine Meeresthiere mit segmentirtem Chitinskelett und mit entspreehend scomentweise angeordueten Muskelzürren; mit vorstülpbarem Hakenapparat an Mundende; mit einfaclien parigen wimpornden Excretionskanälen. - Sie sind wahroheinlich den Gastrotrichen verwandt; ein neuerer Bearbeiter (RinHARD) widerspricht aber dieser Anschauung; er will sie eher als reducirte Anneliden betrachten.

\section{Classe der Scolecida. Rotatoria.}

Die liotatorien sind Scoleciden mit persistirenden (als retractiler Räderapparat mehroder weniger modificirten) W imperkränze 1 , ohne Hautmuskelschlauch, mit reräumigem Blastocoel; mit Kaumagen und nit einer Kloake, in welche Darm-, Geschlechts-und Excretionsa pl)arat münden; meist mit ventralen Fussanlang; sie sind getrenntgeschlechtlich.

Die Rotatorien sind unter allen Zygoneuren jene, welche in ihrer gesanmuten Organisation den Trochoplioratypus noch am näclısten stehen. Diese Beziehung tritt aber in Folge der mannigfachen Modificationen der äusseren Körperform bald mehr, bald weniger deutlich hervor. Als wesentlicle neue Charaktere sind besonders hervorzuheben die vollkommene Sonderung des Nervensystems vom Epithel, der Kaumagen ') und dic Kloake.

Sie sind der grossen Mehrzahl nach Süsswasserthicre von mikroskopischer oder nahezu mikroskopischer Grösse. - Ihre Körperform zeigt in den meisten Fällen gewisse Eigenthümlichkeiten, welche nit der Ausbildung eines festen, cuticularen Chitinpanzers in Zusammenhang stehen. Der Vorderleib mit den Wimperapparaten (Kopf) ist !ämlich einstülpbar in den Mittel leib (Rumpf), dessen Cuticula einen mehr oder minder starren Panzer bildet; ferner findet sich eine ventrale, scliwanzartige, bewegliche Verlängerung des Körpers, der sogenannte Fuss, der meist zwei Zehen trägt, an welchen mehrere einzellige Drüsen ausmünden, und der oft ebenfalls in den Panzer zurückzichbar ist; der After liegt dorsal von demselben. In einigen Fällen ist der Panzer in eine Anzahl beweglicher, hintereinander liegender Ringe gegliedert, und dies kann auch den Fuss betreffen; diese ,äussere Gliederung.6 ist in Anpassung an die Bewegung entstanden und ist keineswegs von einer inneren Wiederholung von Organen (Metamerie) begleitet. Bei den festsitzenden, rölrenbewohnenden Rotatorien ist der Fuss zu einem langen contractilen Stiel ungewandelt; der After, der stets dorsal vom Fusse gelegen ist, rückt dadurch weit nach vorn. In manchen Füllen kann die Körperform vereinfacht erscheinen, namentlich durch Fehlen des Fusses (z. B. bei Anuraea, manchen Arten ron Asplanchna etc.). Anı weitesten geht die Vereinfachung der Körperform bei Trochosphnera aequatorialis, wo der Räderapparat nicht retractil ist, und wo der präorale Wimperkranz (Trochus) im Aequator des

1) Es ist möglich, dass auch der Kaumagen auf eine schon dem Trochozoon eigentbümliche Differenzirung des Stomodaeums zurückzufïhren ist; von derselben wäreu auch die ventrale Pharyngealbildung bei Auneliden und die Radula der Mollusken ableitbar. 
kugelförnigen Körpers verläuft ${ }^{1}$ ). Zn den auffallendsten Complicationen der Körperform gehört die Ausbildung iusserer, durch Muskelı beweglicher Anhänge des Nittelleibes bei Hexarthra und Triathra²).

Fin. 350. Brachianus plicatilis, Uebersicht der Organisation von der Dorsalseite (nach MöruUs). $W$ Räderorgan, $h$ Leibeswand, ans Cuticula und II ypoderuis bestehenu, $f$ Fuss, * zehenartige Anlü̈ıge, $m$ Nundhöhle, $k$ Kanmagen mit Zahıapparaten, oe Oesophagus, $m d r$ Mitteldirmdruisen, $i$ Darm, kl Kloake, a After, musc Muskeln, cg Cerebralganglion mit Augenfleck, sd und sv dorsaler und veutraler Taster, neph Nephridien, ol Blase, ov Ovarium.

Für die Körperform der Räderthiere kommt auch die Gestaltung der Wimperkränze (Räderapparat) in ihren mannigfachen Modificationen besonder's in Betracht. Der präorale Wimperkranz (Trochus) und der postorale (Cingulu m) sind in vielen Fällen deutlich ausgeprägt; der ersterc dient vorzüglich zur Schwimmbewegung oder bei festsitzenden Formen zur Erzeugung eines Wasserstromes, der letztere mehr zur Zuleitung der Nahrungstheilchen zum Munde. Das von den Wimperapparaten umsäumte Scheitelfeld ist selten vorgewölbt, meist flach, ja sogar trichterförmig eingezogen; die Wimperkrünze können in vollstän-

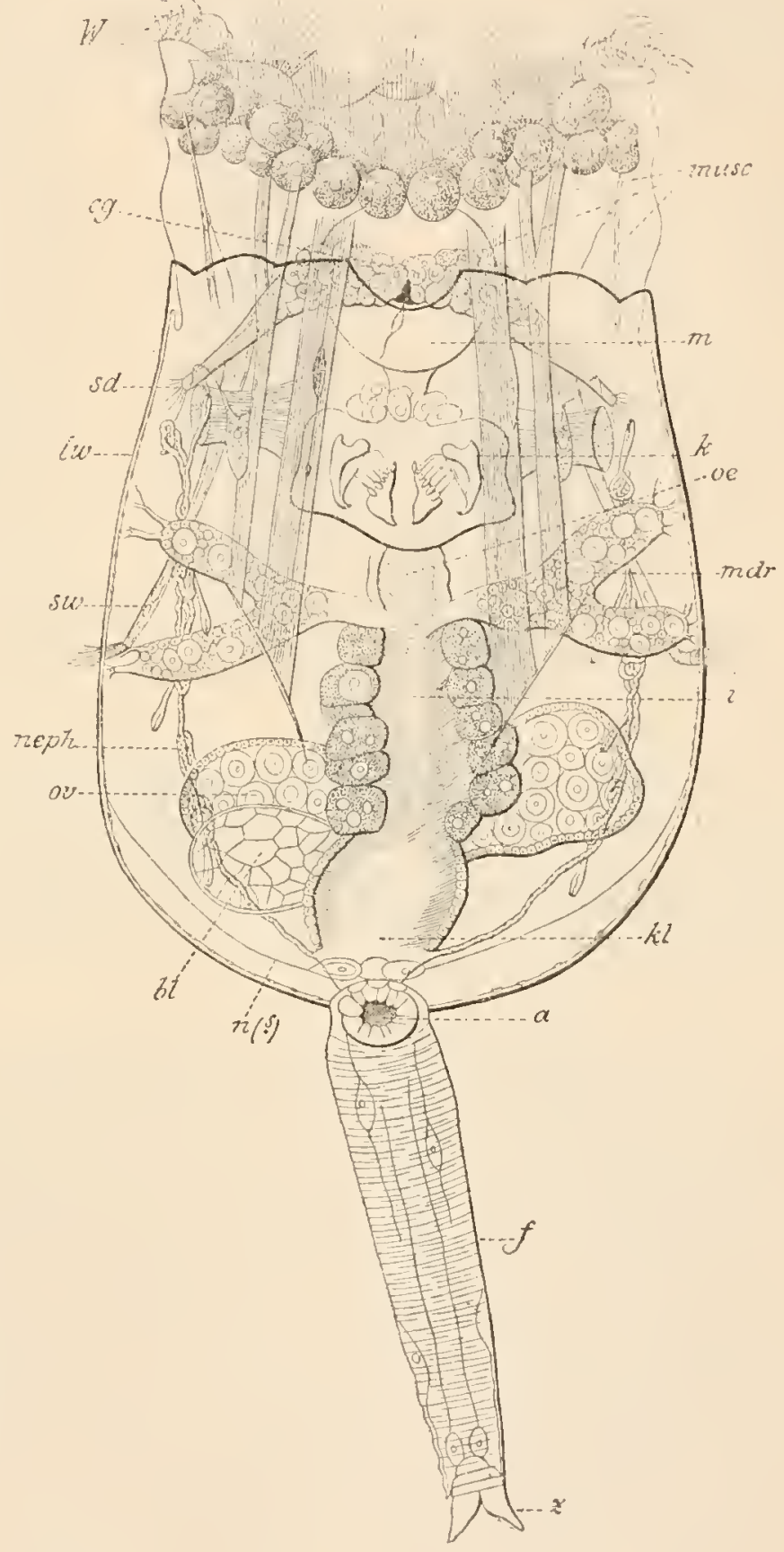

1) Wenn auch diese Körpergestalt derjenigen der Trochophora-Form selır ähılich erscheint, so dürfen wir dies doch nicht ohne weiteres für ein ursprüngliches Verhalten elklären, sondern wir müssen an die Möglichkeit einer sccundïren Vereinfitchung denken; denn es sind in dem Besitz der Magenkiefer und der Kloake schon wanz typische lintiferencharaktere vorhanden, ja es finden sich hier sogar manche Eigenthïmlichkeiten, die weniger ursprünglich erscheinen als bei anderen Rotiferen, so del Mangel des postoralen Wimperkranzes, der unpaare dorsale Taster, das unpare Ovarium

2) Die früher von einigen Forschern (zucrst LEYDIG) vertretene Anschaung, dass die Rotatorien mit den Crustaceen verwandt wären (sie wurlen geralezu als Wimpcrkrebse bezeichnet), möchte gewiss in der Nauplius-Aehnlichkeit ler Ilexarthra eine Stütze finden; wir betrachten diese Aehnlichkeit alser nur als eine Convergenzerscheinung. 
diger For'm das Scheitelfeld umsïumen, dabei gewimnen sie oft durch lappenartige Ausbreitung eine grössere Entfaltung (Lacinularidae); oft aber sind dieselben in der dorsalen und ventralen Mittellinie unterbrochen und der Mund kam dam tief zwischen diese seitlichen W'imperlappen des 'Trochus hineinrücken; in anderen Fällen wieder ist der Apparat in noch zahlreichere Wimperlappen getheilt; die Eimrichtung kam sich endlich auf eine Bewimperung in der Umgebung des Mundes

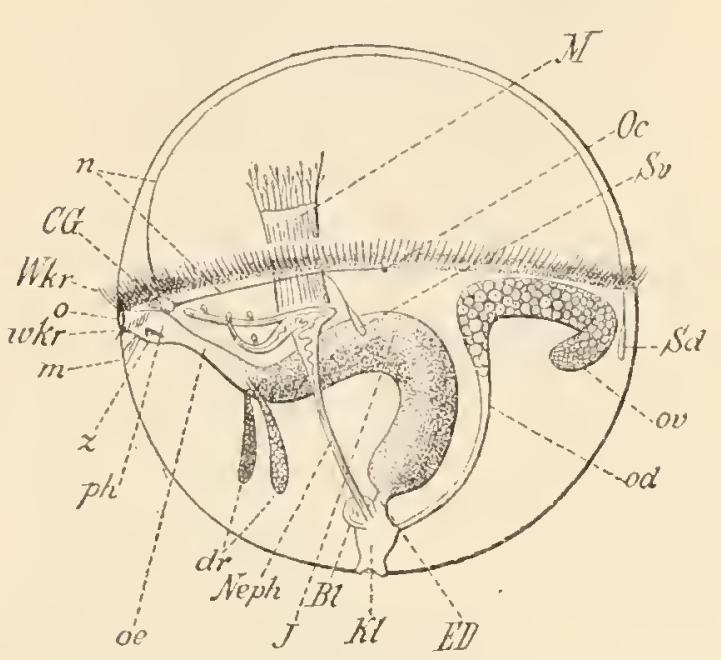
beschränken oder sogar bei dem entwickelten Thiere ganz in Wegfall kommen. Bedeutend modificirt erscheint der Vorderleib bei Stephanoceros und Floscularia; hier ist der postorale Wimperkranz (Cingulum) in fünf Arme ausgezogen, die mit borstenartigen, wenig beweglichen Wimpern versehen sind; zwischen diesen $\mathrm{Ar}$ men liegt der tiefe Mundtrichter, an welchem vielleicht noch Reste des Trochus in der Anordnung der Bewimperung zu erkennen sind.

Fig. 351. Trochosphaera aequatorialis, das Kugelräderthierchen, nach SEMPER. Wh Troehus, $x k r^{*}$ Cingulum, o Mund, ph Kiaunagen, mit $\approx$ Chitinkiefern, oe Speiseröhre, dr. Mitteldarmdrüse, J Magendarm, Ed Fnddarn, Kl Kloake, Neph Nephridium, Bl Harnblase, ov Ovarium, od Ovidukt, $M$ Muskel, $m$ Muskel des Kaunagens, $C G$ Cerebralganglion, $n$ Nerven, $S d$ dorsaler unpaarer Taster mit unpaarem Nerven, $S v$ ventraler paariger Taster, Oc troehales Auge.

Die Leibeswand besteht zunächst aus der äusseren Cuticula, welche besonders am Mittelleib kräftiger entwickelt ist, und sodann aus der Hypodermis, die zumeist aus sehr dünnen, abgeplatteten Zellen zusanmengesetzt ist. Die Muskeln der Leibeswand (glatte oder auch quergestreifte Fasern) bilden keine zusammenhängende Schichte; manchmal finden sich vereinzelte Ringmuskelfasern, die in regelmässigen Abständen der Leibeswand anliegen : constanter ist das Vorkommen von einzelligen Längsmuskeln, die frei durch die Leibeshöhle ziehen und nur mittelst ihrer Enden der Leibeswand angeheftet sind, und die zur Einziehung des Vorderleibes, zur Bewegung des Fusses u. s. w. dienen. Die meist sehr geräumige Leibeshöhle (Blastocoel) enthält die Eingeweide, die durch vereinzelte Bindegewebszellen oder auch verïstelte Muskelzellen in ihrer Lage erhalten werden. Besondere Zellen der Hypodermis sind mächtiger entwickelt, so als Wimperzellen an den Wimperapparaten, ferner an gewissen Stellen (vergl. unten) als Simneszellen; ferner kommen Drüsenzellen, welche in das Körperinnere einragen, besonders am Fusse vor, und dienen hier zur vorübergehenden oder dauernden Befestigung.

Der Darmkanal, der meist geradegestreckt, bei eimigen Tubicolen aber hufeisenförmig' gekrümmt verläuft, zeigt charakteristische Complicationen. Die Mundötfnung liegt ventral oder rückt auch mehr an das Vorderende des Körper's; der postorale Wimperkranz setzt sich meist direkt in die Bewimperung der Mundhöhle fort. Der von ectodermalem Epithel ausgekleidete Vorderdarm (Stomodaeum), in den sich auch die 
$a$
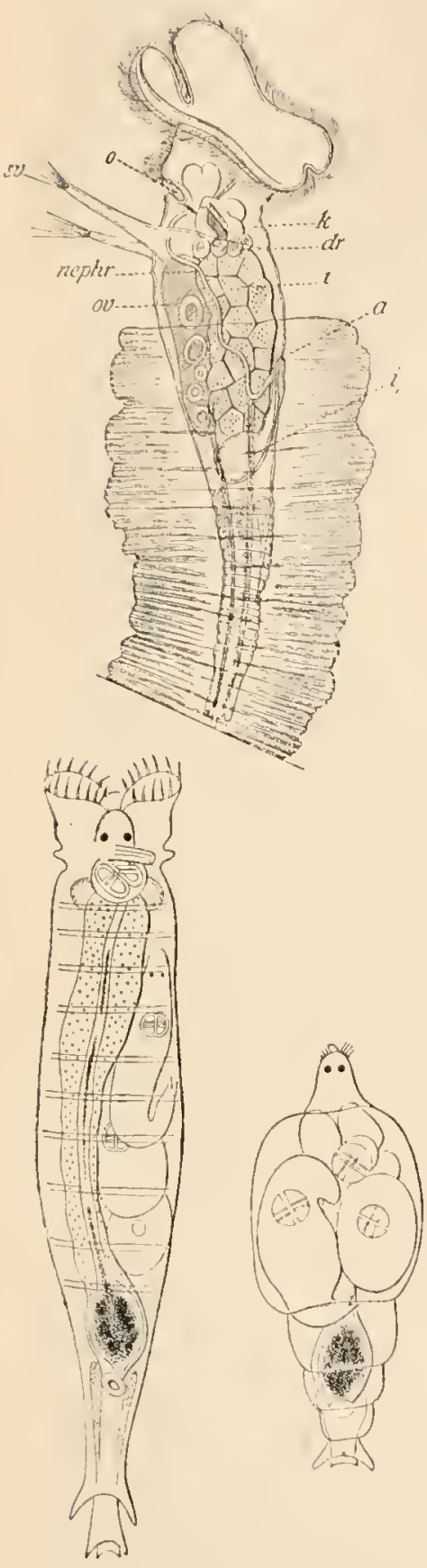

$e_{1}$ $b$

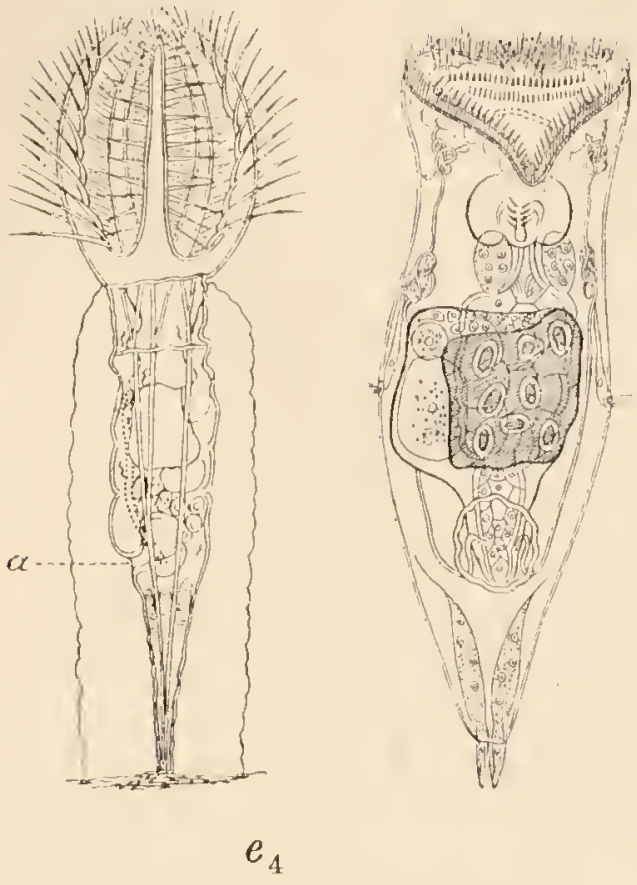

l
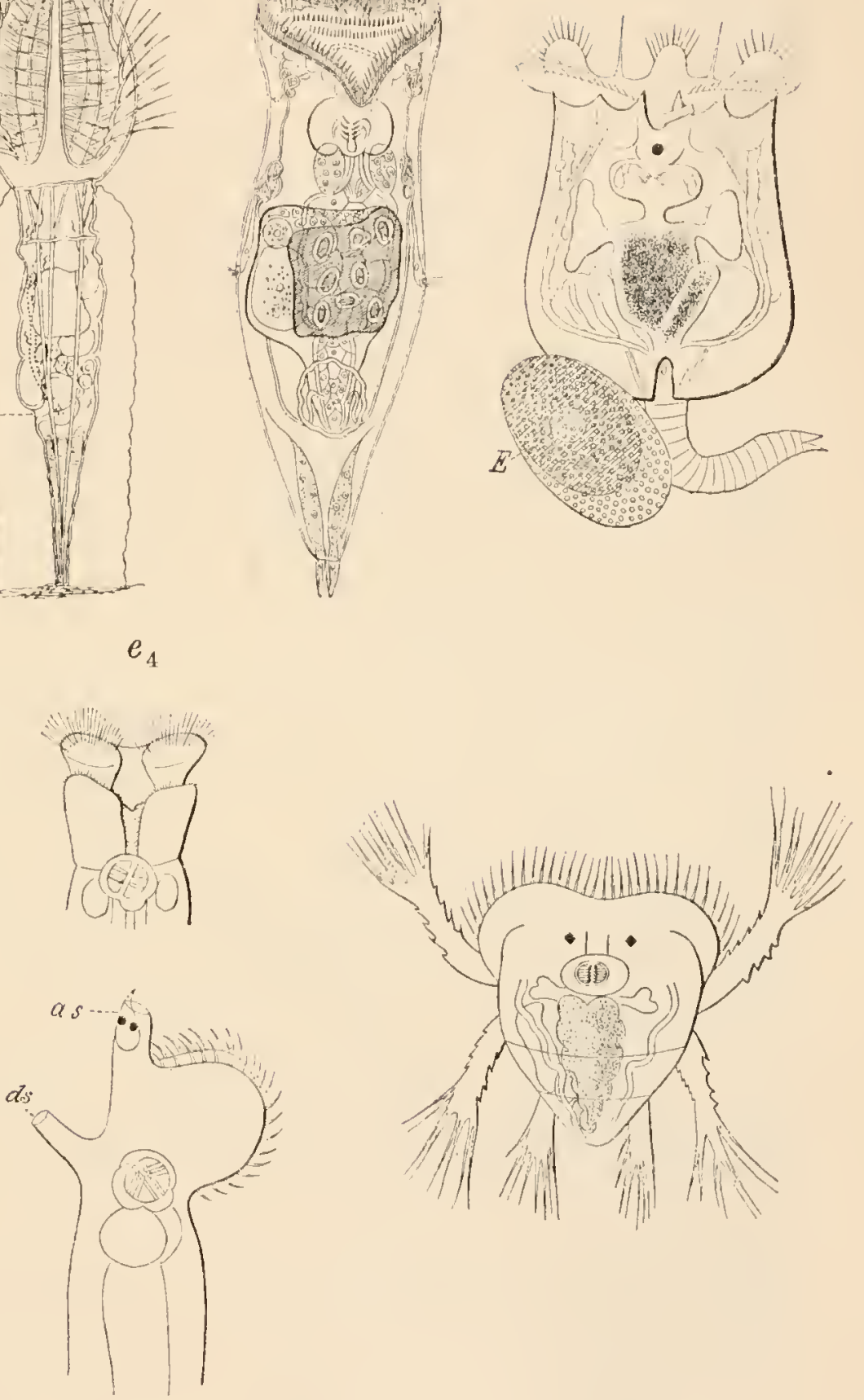

$e_{3}$

Fig. 352. Verschiedene Rotatorienformen. a Tubicolaria (nach Lerdig). o MIund, F Kaumagen, $d \cdot$ Nitteldarmdriscn, $i$ Dam, $i$, Endarm, a After, so ventraler Taster, nephr Nephridium, ov Ovarium. \& Stephanoceros (nach IfTrDlG). a After. c Hydatina (nach Plate). $d$ Brachianus (nach linknista). F Fin Ei, welches bis zum Ausschlipfen vom Mutterthicre getragen wird. $e_{1}$ Rotifer mit Embryoncn (nach Enreniserg). $\boldsymbol{e}_{2}$ Derselbe, contrahirt. $e_{3}$ Vorderende, von der Seite gesehen. as Apicales, ruisselartiges Simnesorgan, ds dorsaler, unparer Taster. $e_{4}$ Vorderende voll der Ventralseite, mit Trochus und Cingulum (nach BLocumanN). $f$ Hexarthra (nach Scumarda).

Körpercuticula fortsetzt, ist in zwei Abschnitte differenzirt, die Mundhöhle und den Kaumagen; der letztere enthält als cuticulare Differenzirungen seiner ventralen Wand einen chitinigen Kanapparat, der sehr 
häufige klappende Bewegungen ausführt. . Er ist aus complicirten paarigen Kieferstücken zusammengesetzt; meist sind ein Paar stärkere Aussenkiefer und ein Paar schwächere Innenkiefer vorhanden, deren specielle Gestaltung für die Systematik wichtig ist. - Auch der vom Endorlerm ausgekleidete Mitteldarm ist in mehrere Abtheilungen gegliedert; zunächst auf den Kaumagen folgt der dünnwandige, innen wimpernde, meist mit mehreren Muskelfasern versehene Oes o phagus; an seinem Ende münden paarige Anhangsdrüsen in denselben ein, welche als Mitteldarmdrüsell oder wohl auch als Pankreas bezeichnet werden; hierauf folgt der Magen, der aus grossen wimpernden Epithelzellen, die grünlich oder bräunlich gefärbt sind und meist Fetttropfen enthalten, zusammengesetzt ist, und in der Regel gar keine Muskeln besitzt; daran schliesst sich ein engerer, wimpernder Enddarn, der in dic Kloake einmündet; es ist fraglich, ob derselbe eine ectodermale oder eine endoderniale Bildung ist. Die Kloake, in welche auch der Excretions- und Geschlechtsapparat führt, ist meist unbewimpert; sie muss als Ectodermbildung betrachtet werden; ihre äussere Mündung findet sich dorsal vom Fusse.

Der Excretionsapparat (Wassergefässsystem) zeigt den typischen Bau des Protonephridiums. Er besteht aus drüsigen Längskanälen, die bis in den Vorderleib sich erstrecken, und oft stellenweise aufgeknäult erscheinen; sie tragen kleine Seitenästchen, die mit je einem 'T'erminalorgan (Wimperflanme, Kitterorgan) versehen sind; sie münden mittelst einer unpaaren contractilen Blase in die Kloake; oft münden sic auch direkt in dieselbe und es ist die Blase dann ein selbständiger Anhang der Kloake. Selten fehlt die Blase gänzlich (Philodiniden).

Das Centralnervensystem besteht aus einem rundlichen oder quer ausgezogenen Cerebralganglion, welches dem Schlunde dorsal aufgelagert ist; sein ursprünglicher Entstehungsort ist noch nicht durch Beobachtung eruirt. - Von Sinnesorganen sind zunächst sehr einfach gebaute Augenflecke zu erwähnen, von welchen wir der Lage nach verschiedene Arten unterscheiden. Am häufigsten findet sich ein dem Cerebralganglion anliegender x-förmiger Augenfleck (Doppelauge), welcher wohl den prinären Cerebralaugen der 'Trochophora entspricht; in einigen Fällen finden sich auch Augenflecke im Epithel des Trochus (aus trochalen Sinnesorganen hervorgegangen), so z. B. bei Trochosphaera und bei Asplanchna; bei den Philodiniden findet sich ein apicaler rüsselähnlicher Fortsatz, der ein paar von Augenflecken trägt. Ferner kommen Hautsinnesorgane (Sinnesknospen) ror, die aus Gruppen von Simneszellen bestehen, die an der freien Fläche mit einem Büschel von Simnesharen ausgestattet sind und nach innen, wosellst der Nerv an sie herantritt, weit in die Körperhöhle vorspringen (in der Literatur werden sie nach dem Vorgange von LEYDIG meist als periphere Ganglienzellen bezeichnet). Solche Organe finden sich zunächst als paarige Stirntaster am Scheitelfelde; diese entsprechen vielleicht den primären apicalen 'Tentakeln. Sehr' charakteristisch für' die Rotatorien ist ferner der Besitz eines dorsalen und eines ventralen (anch als laterales bezeichneten) Paares von Tastern am Mittelleib; dieselben sind in manchen Fällen an besonderen Fortsätzen des Körpers angebracht; das dorsale Paar ist oft zu einem unparen Nackenorgane ')

1) Es ist fraglich, ob alle als Nackenorgane oder "Naekenröhren" bezeiehneten Gebihle den vereinigten dorsalen Tastern entsprechen. Wenn wir z. l3. die Nackemrihre, die sehr 
vereinigt. - Auch am Trochus kommen Sinneszellen vor (trochale Sinnesorgane). - Das periphere Nervensystem besteht aus Nervenfasern, welche vom Cerebralganglion zu den Simnesorganen, zu den Winperkränzen und zu den Muskeln ziehen'). Wir kïmnen die peripheren Nerven eintheilen in a) Nerven des Vorderleibes, wolche er'stens nach vorn $\mathrm{zu}$ den Stirutastern und zweitens allseitig voin Cerebralganglion ausstrahlend zu allen Zellen der Wimperkränze zielıen, und in b) Längsnerven, welche als dorsales und ventrales Paar zu den beziiglichen Tastern ziehen; entsprechend der Verschmelzung der dorsalen Taster kann auch der zugehörige Nerv unpaar werden (z. B. Lacinularia). Vou diesen Längsnerven (besonders vom ventralen) zweigen sich auch die Nerven der Muskeln ab. Ein Schlundnerv ist noch nicht beobaclitet $\left.^{3}\right)$.

Die Rotatorien sind getrenntgeschlechtlich. Die Weibchen besitzen paarige oder auch ein unpaares Ovarium, dieselben liegen an der ventralen Seite des Darmes und enthalten neben den eigentlichen Keimzellen grosse, zu einer gemeinsamen Masse verschmolzene Nährzellen. Der kurze Oviduct, der oft auch als Uterus fungirt, mündet in die Kloake. - Die Männchen, welche nur zu gewissen Zeiten auftreten, sind meist zwergartig und von rudimentärer Organisation, besonders in Bezug auf den Darmapparat. - Die meisten Räderthierchen pflanzen sich den grössten Theil des Jahres parthenogenetisch vermittelst dünnschaliger sog. Sommereier fort; jene Sommereier, aus welchen sich Männchen entwickeln, sind kleiner. Die hartschaligen Wintereier werden (vielleicht nicht immer) befruchtet. - Der Embryo entwickelt siclı nach der Ablage des Eies oder noch in dem als Uterus fungirenden Eileiter. Die Entwicklung ist eine direlite, da der Embryo beim Ausschlüpfen schon im wesentlichell die definitive Organisation zeigt, ja sogar an Grösse nicht mehr bedeutend zunimmt. Eine Ausnahme bilden die Tubicolen, deren junge Thiere im Vergleich zu den erwachsenen einen noch wenig entfalteten Räderapparat besitzen.

Die Furchung der kleinen, dotterarmen Eier ist adäqual oder mässig inäqual, von oligomerem 'Typus; die Gastrulation ist epibolisch; die Mesodermbildung und die weitere Organbildung ist noch nicht befriedigend erforscht.

Die meisten Räderthiere sind Süsswasserbewohner und in mannigfacher Weise an dieses Verhältniss angepasst; viele Arten widerstehen der Austrocknung und bewohnen sogar das Moos an Bäumen, Dachrinnen $u$. s. w.

vielen Loricaten zukommt, mit dem dorsalen Tasterpaare, das speciell bei Brachionus plicatilis ansgebildet ist, der Lage nach vergleichen, so erscheint in diesem Falle die Zurïckfiihrung zweifelhaft. (NB. Die letztgenannte Art, die sich durch den Besitz von dorsalen Tastern und den Mangel einer Nackenrölıre auszeichnet, wäre wohl von der Gattung Brachiomus zu trennen und etwa als Brachionidium zu bezeichnen.)

1) Die Darstellung des Nervensystems und der Sinnesorgane stützt sich zum Theil auf ncuere Untersuchungen von Masius, die in unserem Laboratorium vorgenommen wurden.

2) Periphere Ganglien, die mehrfach beschrieben wurden, scheinen noch zweifellaft; es können leicht Verwechselungen mit Bindegewebszellen vorkommen. Bei Discopus synaptre ist ein reicher Ganglienplexus von ZELINKA beschrieben worden; dies ist aber eine merkwiirdige Form, deren systematische Stellung weniger sicher erscheint.

3) Bei Asplanchna wurde ein Schlundnerv von Masius geschen, docl sind lierüber uoch ausgedchntere Untersuchungen zu crwarten.

4) Die Arbeitstheilung der Zellen, welche sonst als folliculare Eibildung auftritt, hetrifft hier das Ovarium als Ganzes; die Rezeichnung Keimstock nnd Dotterstock für liese Theile des Ovariums scheint mir aber lier nicht zu passen. 
Systematische Uebersicht der Rotatoria.

A. Vagantia, freischwimmend oder kriechend.

1. Trochosphaeridne. Trochosphaera nequatorialis, das kugelriiderthierchen, von SғмPer auf überschwemmten Reisfeldern der Philippinischen Inseln entdeckt.

2. Ilyatimidae, rielgestaltige Gruppe, welche zum Theil auch schr ursprüngliche Formen enthält; Panzer wenig entwickelt. Asplanchna, mit bliudgeschlossenem Darme; Nolomula, Ilydalima, Ilexarlhra.

3. Loricala, Panzer wohl ausgebildet, oft mit charakteristischen Siculpturen und Fortsätzen. Bruchionus.

4. I'hilodinilae, langgestreckt wurmförmig; Fus: gegliedert; rom Räderorgan nur der rentrale Theil als paarige Lappen ausgebildet; dorsal vou diesen ein (apicaler?) rüsselartiger Fortsatz, der oft mit zwei Augen versehen ist. Rotifer, Philodina.

B. Tubicola, festsitzend, meist mit Gallerthülse.

1. Lacimlaridae, Räderorgan vollkommen und von schr ursprünglichem Typus, dabei aber in Lappen ausgezogen. Lacimularia sociulss, T'mbicolaria, Melicerta.

2. Flosculuridue, Räderapparat in fünf Arme umgewandelt. Flosculuria, Stephunoreros.

Aberrante Typen sind Seison an der Haut eines Krebses (Nebalia); Discopus synaplae an der Haut von Synapta; beides Meeresthiere.

\section{Classe der Scolecida. Endoprocta.}

Die Endoprocta sind Scoleciden (?), die mit einer st ielartigen Verlängerung des Scheitelfeldes festsitzen; der' 'T rochus ist $z$ u e inem wimpernden 'Tentakelkranz ungebildet, das Gegenfeld istzur Bildnngeines Atriums eingezogen, in nerhalb dessendemnachdie Mundöffnung, die Afteröfnung, sowie die Oeffnung der Sackgonaden und der Exeretionsorgane münden; hier findet sich auch Zwischen Mund und After (ventral) ein Ganglion; dagegen ist das larvale Scheitelganglion (?) rückgebildet; Fortpflanzung geschlechtlich und durch Knospung.

Die Endopructen sind kleine Meeresthiere - nur Urnatella lebt in nordamerikanischen Süsswässern; sie sind festsitzend und von polypomorpher Gestalt ${ }^{1}$ ); sie bilden Knospen, die selbständig werden (Loxosoma), oder zur Cormenbildung vereint bleiben (Pedicellina, Urnatella). Besonders durch letzteres Verhältniss tritt eine Aehnlichkeit mit den Bryozoen, die auch in anderen Organisationseigenthümlichkeiten vorhanden ist, auffallend hervor. Die Endoprocten werden daher meist zu den Bryozoen gerechnet; Nitsche hat sie aber allen anderen "Ectoprocten"-Bryozoen als ,Fndoprocta" gegenübergestellt. Wenn wir noch weiter gehen und sie von den Bryozoen vollkommen trennen, so geschieht dies mit Rücksicht auf eine ganz verschiedene phylogene-

1) Als polypomorph bezeichnen wir festsitzende Thierformen mit Tentakelkran\%, die bei den verschiedensten Typen durch Anpassung an die festsitzende Lebenswrise sich ansbilden, z. 13. bei den Cnidariern, Anneliden, Teutaculaten, Echinorlermen. 
tische Ableitung dieser beiden Gruppen. Unsere morphologische Auffassung der Endoprocta, die wir allerdings nur als eine provisorische betrachten, stützt sich auf die Vergleichung der Endoproctenlarve mit der 'Trochophora; die Richtigkeit dieses Vergleiches muss aber durch neue embryologische Forschungen noch geprüft werden.

Die Endoproctenlarve besitzt einen äquatorialen Wimperkranz, welchen wir dem Trochus vergleichen; das eine, gewölbte, Feld des Körpers, welches wir als Scheitelfeld betrachten, besitzt am apicalen Pole ein von Sinneshärchen umgebenes und weiter ventral ein retractiles bewimpertes Gebilde; eines von beiden dürfte der Scheitelplatte entsprechen (das ventrale hielt ich ehemals für eine primäre Knospe, eine Vermutliung, welcher auf Grund neuerer Untersuchungen widersprochen wird). An dem ganz bewimperten Gegenfeld findet sich die Mundöffnung, die Afteröffnung und die Oeffinung des einfach gebauten Protonephridiums in typischer Lage. Die Mundöffnung führt in einen hufeisenförmigen bewimperten Darmkanal, der aus den typischen Theilen, ectodermalem Oesophagus, Magen mit ventralem Drüsenfeld (sog. Leber), Darm und ectodermalem Enddarm, besteht. Die Leibeshöhle ist eine primäre; es finden sich mehrfache einzellige Muskelfasern ${ }^{1}$ ). - Die Larve besitzt die Fähigkeit, das Gegenfeld einzustülpen, so dass es die Form eines Atriums einnimmt, an dessen Eingang nun der Wimperkranz liegt. Die

$A$

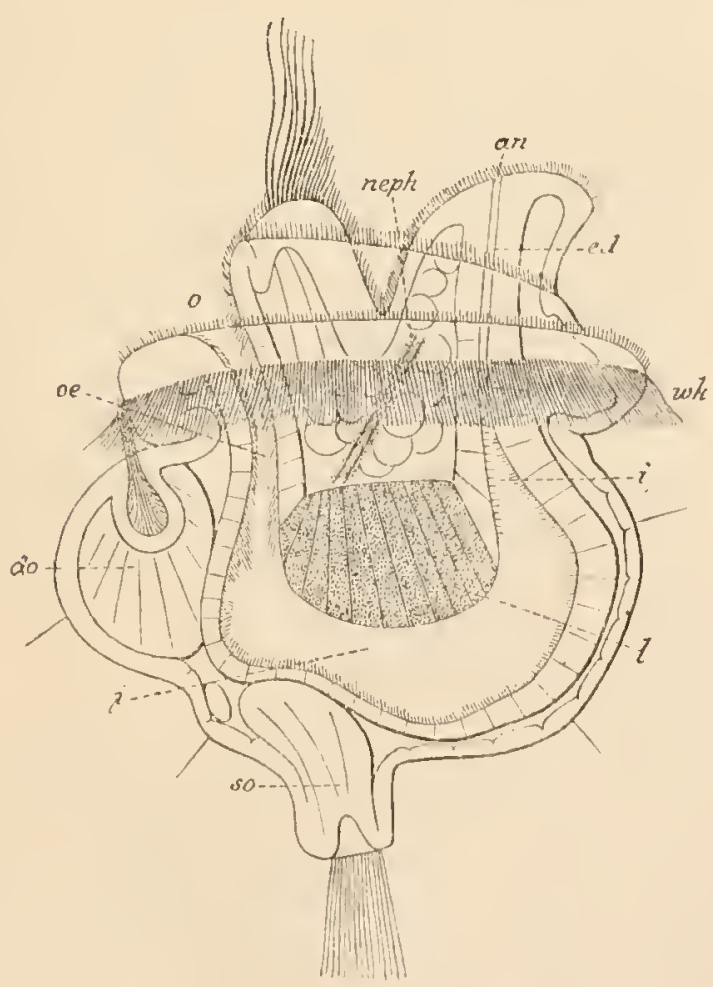

$B$

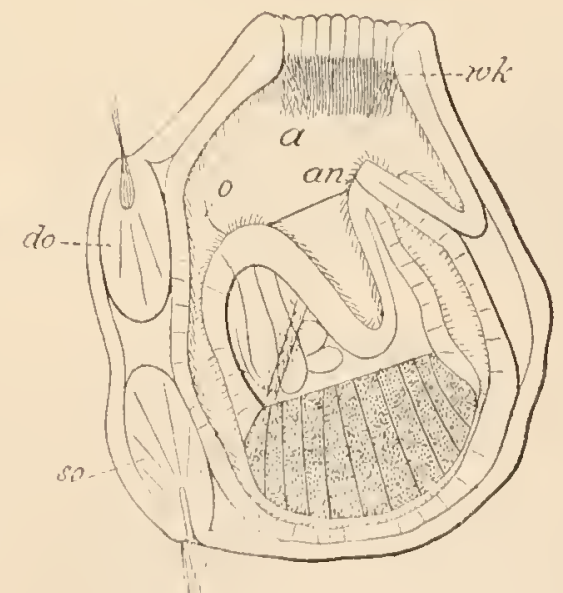

Fig. 353. Larve von Pedicellina. A im ausgestreckten Zustande, schwimment; $B$ im eingestülpten Zustande. wh Wimperkranz, do dorsales Organ, so Scheitelorgan, o Mund, oe Oesophagus, $i$ Magen, $l$ Leber, $i$, Darm, ed Afterdarm, an After, neph Nephridium, $a$ Atrium (in Fig. $B$ ).

1) Man künnte wohl die Larve auch anders aufaufassen versuchen, indem man die Region zwischen Mund und After fïr das verkürzte Scheitelfeld, die übrige Fläche fiir das ausgedelınte Gegenfeld hielte; es wärc dann an eine nähere Verwandtschaft mit den Bryozoen eher zu denken; die l,arve müsste aber in diesem Fallc nicht als eine ursprüngliche, sondern als eine stark modificirte Form lietrachtet werlen. 
Lagerung der Organe entspricht dann vollkommen derjenigen bei dem entwickelten Thiere, nur dass letzteres an Stelle des Wimperkranzes einen Kranz von wimpernden Tentakeln (d. i. eine in Tentakeln ausgebuchtete Wimperschmur) besitzt und am Scheitelfeld mittelst einer stielartigen Verlängerung befestigt ist. Bei der Metamorphose der Larve sollen zwar merkwürdige Verlagerungen (nämlich eine Drehung des

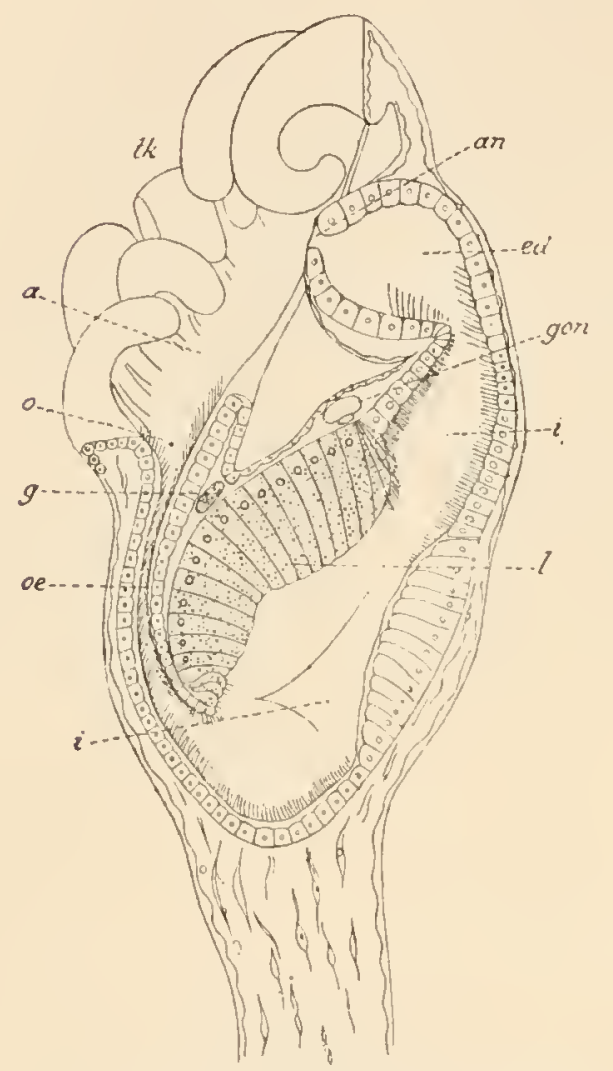

Fig. 354 Längsschnitt des Kelches von Loxosoma (nach Nitschk). $t k$ Tentakelkranz, gon (ionaden. l)ie ïbrigen Bezeichnungen wie oben. gesammten Eingeweidecomplexes, deren morphologische Bedeutung nocli nicht aufgeklärt ist) erfolgen, dessen ungeachtet ist aber der hier erwähnte morphologische Vergleich der Larvenorganisation und der definitiven Organisation als ein vollkommen gesicherter zu betrachten. - Wir unterscheiden daher am entwickelten Thiere einen mit Längsmuskelfasern versehenen Stiel und einen Kíelch, welcher die Körperorgane enthält; an diesem finden wir ein Atrium, welches von einem Kranze von T'entakeln umstellt ist; dieselben können in das A trium eingekrümmt werden, dessen contractiler Rand sich sodann über ihnen schliesst. Darmkanal und Excretionskanäle entsprechen jenen der Larve. Ein Scheitelganglion, das an der Kelchwand zu suchen wäre, wird vermisst, dagegen findet sich ein Ganglion zwischen Mund und After, von welchem Nerven zu den Tentakeln und zu einem Paar von Tasthügeln an den Seiten der Kelchwand ziehen. Es gibt getrenntgeschlechtliche und auch zwitterige Formen; die parrigen, über dem Magen gelegenen Hoden und Ovarien sind Sackgonaden und münden durch einen unpaarell Ausführungsgang vor dem After. Das Atrium dient als Brutraum. - Neben der geschlechtlichen Fortpflanzung erfolgt eine Vermohrung durch Kinospung. Die Knospen entstehen bei Loxosoma au der Aussenwand des Kelches, und zwar rechts und links an der oralen Seite desselben; sie kommen zur vollkommenen Ablösung als selbständige Individuen. Bei Pedicellina und Urnatella bilden sie sich am Stolo, der an der Basis des Stieles an der oralen Seite auswächst und nur wenig verästelt ist; die Individuen bleiben zur Bildung eines Cornus vereinigt; die Knospen entstehen successive an den freien Enden des Stolo, welche die Wachsthumspunkte des Stolo darstellen. Interessant ist es, dass bei Pedicellina die Kelche von den Stielen abfallen und durch Regeneration ersetzt werden können (ein Process, der von SkEuIGER genauer untersucht wurde). Bei der Knospung soll nicht nur das Atrium, sondern auch der Darmkanal aus dem äusseren Epithel der Knospungszone entstehen.

Die Knospungsvorgänge sind ron allgemeiner theoretischer Bedeutung. Nitsche leitet die ganze Knospe (bei L.orosuma) rom iusseren Epithel ab. 
Fig. 355.

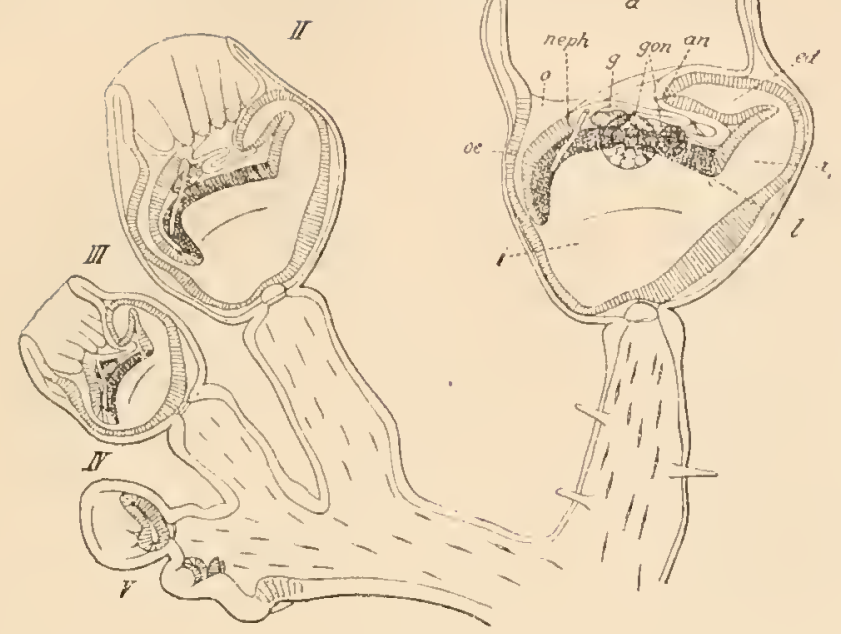

Fig. 356.

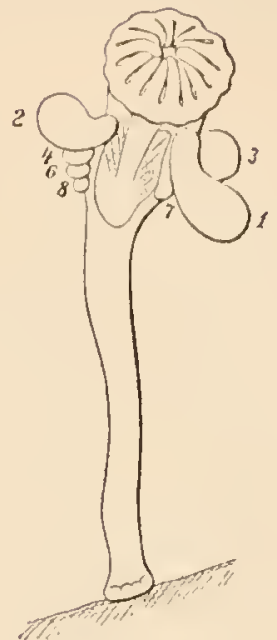

Fig. 355. Knospung von Pedicellina. $I$ die älteste, $V$ die jüngste der Kinuspen, die an Stolo prohifer entstehen. Die anderen Bezeichnungen wic oben.

Fig. 356. Knospung von Loxosoma (nach Nitschk). Lie Knospen, deren Altersfolge durch Ziffern bezeichnet ist, entstehen am Kelche und kommen als selbständige Individuen zur vollkommenen Lostrennung.

Ich selbst stellte die Knospung (bei Pedicellina) so dar, dass von einer Primärknospe, an deren Aufbau alle drei Keimblätter sich betheiligen, alle späteren Knospen sich abspalten. Durch neuere Untersuchungen erscheint dies zweifelhaft. Seeriger leitet bei Pedicellina den Darm der Knospe vom äusseren Epithel, die Mesodermgebilde rom alten Mesoderm ab und weist ein gleiches Verhältniss bei Regeneration des Kelches nach. Dies wird eine Aenderung in unserer Auffassung der allgemeinen Gesetze der Knospung nöthig machen, indem wir uns dem früher von Nissche vertretenen Standpunkte wieder nähern ${ }^{1}$ ).

Loxosoma, Kinzelthiere, of mit einer Fussdrüse versehen, Knospen werden selbständig, leben oft an Spongien, Wurmröhren u. dgl.; Pedicellina, kormenbildend; Urnatella lebt im Süsswasser in Nordamerika.

\section{Classe der Scolecida. Nematodes.}

Die Nematoden. sind Scoleciden (?) von langgestreckt spulrunder Körperform, mit vorderer Mundöffnung und ventraler, nahevom Hinterendegelegener A f teröf nung. Bewimperung fehlt der Gesammtorganisation in allen Lebensstadien. Die äussere Cuticula ist mächtig entwickelt und wird periodisch erneuert. Subcuticula mit seitlichen Verdickungen (Seitenlinien), längs welcher die einfachen seitlichen Wassergefässkanäle liegen und mit einer dorsalen und ventralen Verdickung (Medianlinien), in welchen Längsuervenfasern verlaufen. Vier

1) Ich komme auch bei den ectoprocten Bryozoen neuerdings zu einer Bestätigung der von Nitsche vertretenen Darstellung. 
Längsmuskelfelder; deutliche (primäre) Leibeshöhle; Mitteldarm nur vom Endodermepithel aufgebaut. Centralnervensystem in Form eines Schlundringes. Getrenntgeschlechtlich, mit schlauchförmigen Gronaden. Entwicklung direct. Zum grossen Theil parasitische Thiere.

Die Organisationseigenthümlichkeiten der Nemaloden sind in dieser ganzen Classe ziemlich einförmig, sie zeigen aber viele merkwürdige Besonderheiten den anderen Scolecilen gegenüber; so ist z. B. die Zurückfüihrung des ringförmigen Centralnervensystems auf dasjenige der Scolecill'"l ganz unsicher; ja dies gilt sogar in Bezug auf die übliche Auffassung von Bauch- und Rückenseite der Nemarolen, welche nur in der Lage der weiblichen Geschlechtsöffuung eine Begründung findet; diese Körperseiten sind bei den Nematoden sowohl äusserlich als auch innerlich auch nur sehr wenig ron einander verschieden. - Die Zuordnung der Nematoden zu den Sculeciden ist noch durchaus nicht sicher begründet, da die Beurtheilung ihrer Leibeshöhle und Körperschichten noch unklar ist. - Es ist fraglich, ob die parasitischen oder die freilebenden Nemuloden dem Ausgangspunkte der Gruppe näher stehen. Man möchte wohl der ersteren Vermuthung den Vorzug geben und annehmen, dass viele Eigenthümlichkeiten dieser aberranten Thiergruppe durch den Parasitismus erworben worden sind, doch spricht manches auch für die zweite Theorie. - Unter den vielen Möglichkeiten, die in Bezug auf die Verwaudtschaftsbeziehungen der Nemaloden ausgesprochen wurden, möchten wir die eventuellen Beziehungen zu den Gastrolrichen und die zu den Amneliden besonders hervorheben. In ersterem Falle wäre nebst anderen Modificationen eine riesige Grössenzunahme auf Grund des Parasitismus erfolgt, in letzterem Falle dagegen hätte eine sehr bedeutende Vereinfachung der Organisation, sogar in Bezug auf die Schichtung des Körpers, stattgefunden. Der in jüngster Zeit ( erörterten Ableitung der Nemaloden von den Plattwürmern und zwar den Tremalorlen möclsten wir mit Rücksicht auf die bedeutende Verschiedenheit des Geschlechtsapparates nicht das Wort reden.

Die Körperform der Nematoden ist in der Regel spulrund und mehr oder weniger langgestreckt und an beiden Enden verjüngt. Das Vorderende, wo die Mundöffinung liegt, ist abgestutzt, das Hinterende meist zugespitzt. Der After liegt meist ventral in der Nähe des Hinterendes, seltener terminal. Viele Nematoden sind nahezu mikroskopisch klein, andere erreichen den Umfang eines grossen Regenwurmes (menschlicher Spulwurm, Pferdespulwurm) und noch darïber.

Bewimperung fehlt nicht nur vollständig an der äusseren Körperoberfläche, sondern auch in der ganzen inneren Organisation, und zwar nicht nur am entwickelten Thiere, sondern auch in allen Entwicklungsstadien. Der Körper ist an seiner ganzen Oberfläche von einer mächtigen chitinartigen, durchsichtigen $\mathrm{Cnticula} \mathrm{bedeckt,} \mathrm{welche} \mathrm{durch}$ Häutung periodisch abgeworfen und erneuert wird, und welche besonders bei den grösseren Formen eine bedeutende Dicke und einen complicirteren geschichteten Bau erreicht. Die äussere Schichte derselben ist in der Regel mit einer mikroskopisch feinen Querstreifung (Ringelung) versehen, die an den Seiten des Körpers durch eine zackige Längslinie unterbrochen ist. Die innere Schichte ist oft durch gekreuzte diagonale Fasersysteme ausgezeichnet. In manchen Fällen finden sich 
Stacheln und IIaken als Differenzirungen der Cutienli. Verschieden datron sind wohl die feinen Borsten, die an Vorderende freilebender Nematoden (der sog. Cirriferen) sich finden, dil diese die Cutiena durchbohren und wahrscheinlich in Bezichnng zu Sinneszellen stehen.

Fig. 357 .

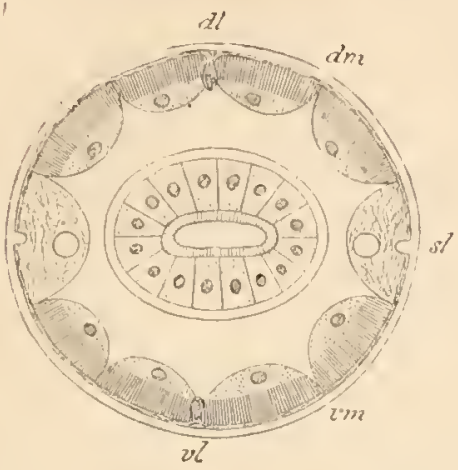

Fig. 358.

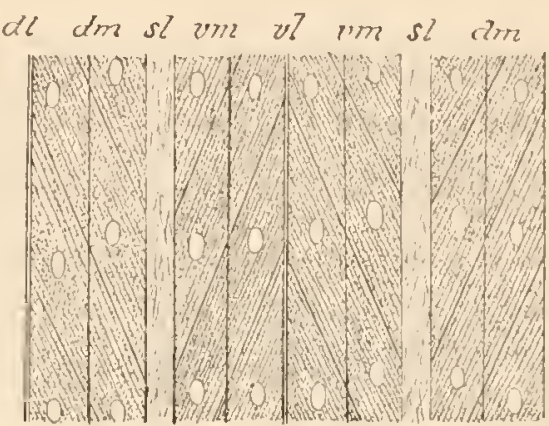

Fig. 357. Querschnitt durch den Körper eines Nematoden, vom Typus der Mero-

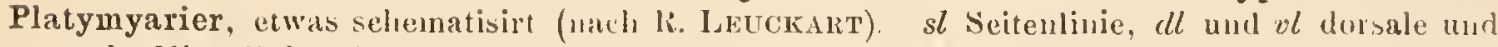
ventrale Mittellinie, dm und $v m$ dorsales und ventrales Muskelfeld.

Fig. 358. Ein Stück der Leibeswand eines Meromyariers, längs der dorsalen Linie aufgeschuitten und ausgebreitet (nach LEUckArT). Bezeiehnumen wie oben.

Fig. 359

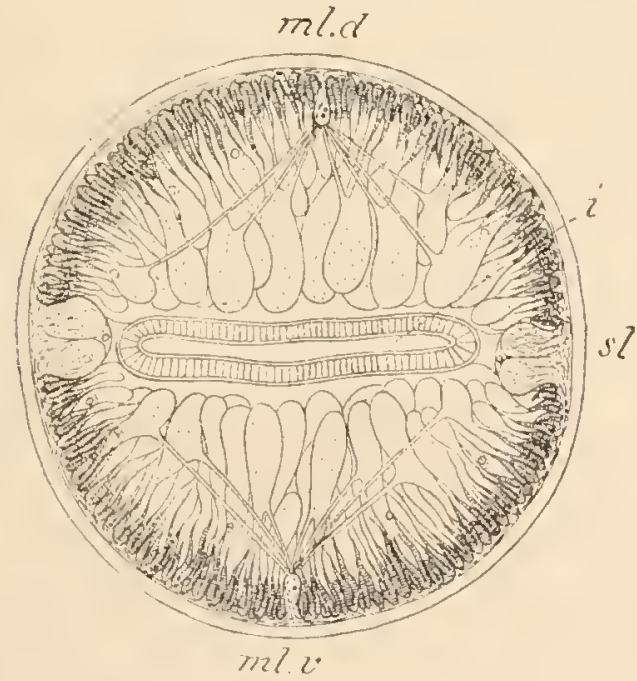

Fig. 360 .

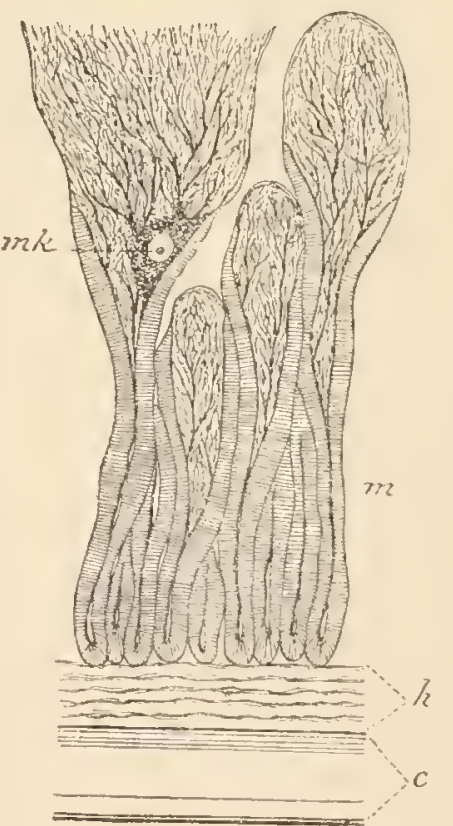

Fig 359. Querschnitt durch den Körper eines Poly-Coolomyariers (Ascaris lumbricoides), naeh LEUCKART. mld und mlv dorsale und ventrale Medianlinie, sl Seitenlinie, i Darm.

Fig. 360. Ascaris lumbricoides, Querschnitt der Leibeswand, zun Theil nach LeUck.1RT. c geschichtete Cutieula, h Hypodermis (Fasergewebe mit Kernen, in welchem dieke Gallertcylinder verlaufen), $m$ Muskelzellen, $m k$ Zellkern des Muskelkörperchens.

Die unterhalb der Cuticula befindliche Hy poder m is, welche hier meist als Snbcuticula bezeichnet wird, besitzt an erwachsenen 'Thiere selten mehr den Charakter eines Epithels, sondern erscheint als ein faserig körniges Gewebe, in welches Zellkerne eingebettet sind. Diese 
Subcuticula zeigt besondere Differenzirungen in den vier "Lüngslinien“" des Körpers. Von diesen sind die beiden seitlichen als Seitenlinien bezeichneten Bildungen mächtige wulstartige Verdickungen der Subcuticula ${ }^{1}$ ); längs (lerselben verlaufen, wenigstens im Vorderkörper, die Excretionskanäle. Die sogenannte dorsale und ventrale Medianlinie dagegen ist je eine schmale, leistenartig nach innen vorspringende Verdickung der Subcuticula, innerhalb welcher einige Nervencylinder verlaufen.

Der Subcuticula dicht anliegend folgt nach innen eine Muskelschichte, welche die innerste Schichte der Leibeswand (Hautmuskelschlıuch) darstellt. Es sind dies ausschliesslich Längsmuskeln; dieselben sind in Form von vier gleichartigen Längsmuskelfeldern und zwar als ein dorsales und ein ventrales Paar - angeordnet und erstrecken sich in den Zwischenräumen der vier Längslinien durch die ganze Länge des Körpers. Der Bau dieser Muskeln, welcher zuerst von SchNeiden richtig erkannt wurde, ist äusserst merkwürdig und gleicht dem Typus eines Epithelmuskels. Bei den meisten Nematoden bestehen die Muskelfelder aus eigenthümlichen rhombischen Zellen (Muskelzellen oder Muskelfasern), von welchen nur zwei auf die Breite eines Muskelfeldes kommen (daher ,Meromyarier"6); dieselben sind derart regelmässig angeordnet, dass sie nicht nur Längsreihen, sonderı zugleich auch kurze diagonale Reihen bilden, die in den benachbarten Feldern gegen einander in spitzem Winkel convergiren. Die Muskelfibrillen verlaufen entsprechend dieser diagonalen Richtung. Wie der Querschnitt lehrt, bilden die bandartigen Fibrillen, dicht an einander gereiht, eine einfache äussere Schichte der Muskelzelle (daher "Platymyarier"6), während der plasmareiche Rest jeder Zelle, der als Muskelkörperchen bezeichnet werden kann, gegen die Leibeshöhle bauchig vorspringt. Besonders bei den grösseren Nematodenformen finden sich aber veränderte Verhältnisse, indem erstlich von den viel langgestreckteren Muskelzellen eine grössere Anzahl auf die Breite jedes Muskelfeldes entfällt (daher „Polymyarier“") und indem ferner die Fibrillenschichte an jeder Zelle nicht mehr eine einfache Platte bildet, sondern seitlich an derselben emporsteigend eine gefaltete Platte darstellt, in deren Höhlung das Plasma des Muskelkörperchens sich fortsetzt (daher "Coelomyarier"). Dadurch ist eine grössere Massenentfaltung der Fibrillen ermöglicht. Bei dieser letzteren Form von Muskelfasern sendet das riesige, blasenartige Muskelkörperchen je einen strangförmigen Fortsatz zu der entsprechenden Medianlinie, welcher mit den dort verlaufenden Nerven in Zusammenhang steht. (In Gegensatz hierzu scheinen die Muskelfelder der Anneliden stets von der Aussenfläche her ihre Innervation zu empfangen.)

Die Leibeswand schliesst eine deutliche Leibeshöhle ein, in welcher der Darm und die Geschlechtsorgane liegen. Zwischen Leibeswand und Eingeweiden finden sich vielfach bestimmt angeordnete Balken und Platten einer structurlosen Bindesubstanz, welche keine Zellen enthält. Da der Mitteldarm nur aus einer äusseren structurlosen Basalmembran und einer inneren Epithelschichte besteht, so sehen wir auf dem typi-

1) Ich finde in dem Fasergewebe von Ascaris lumbricoides quer verlaufende, dicht aneinandergcreihte Gallerteylinder, die in den Seitenlinicn in mächtigc längsverlaufende Stränge ïbergehen. Aehnliche Beobachtungen hat vielleicht HaMANN gemacht, der von einem Gefässsystem der Subcuticula berichtet (scine ausfïhrlichen Nitheilungen sind zu erwarten). 
schen Querschnittsbild den Körper aus drei '/ellschichten aufgebaut, der äusseren Epidermis (Subcuticula), der epithelähnlichen Muskelschichte und dem Darmepithel.

Der Darmka 11 a l verläuft gerade gestreckt durch den Körper. Der Mund, welcher stets terminal liegt, ist in der Regel von Lipjen umgeben und führt in eine Mundhöhle, die von einer festen, oft mit zahnartigen Gebilden versehenen Cuticula ausgekleidet ist. Manchmal mïnden hier grosse Speicheldrüsen (Dochmius). Lippen und Kälnne zeigen bestimnte Charaktere, die uns zur Unterscheidung der systematischen Hauptgruppen von Tichtigkeit sind. - Der eigentliche Darm zerfällt in Oesophagus (Stomodaeum oder Schlund), Mitteldarm und Hinterdarm (Proctodaeum). Del Oesophagus, welcher meist als Saugapparat fungirt, besteht aus einer äusseren structurlosen Membran (Propria), einer dicken Muskelschichte, die nur aus Radiärfasern besteht, welche zur Erweiterung des Oesophagus dienen, und einer inneren stalken elastischen Cuticula, die ein typisch dreistrahliges $\mathrm{Lu}$ men einschliesst und als Antagonist der Muskeln fungirt; eine dazu gehörige Subcuticula ist kaum nachweisbar. Der Oesophagus endet meist mit einer besonderen, oft mit Kieferu versehenen Anschwellung (Bulbus, Muskelmagen), die oft auch Drüsenzellen in ihrer Wandung enthält; anstatt dieses Bulbus kann auch ein ausschliesslich drüsiger 'Theil sich fnden; und dieser ist bei den Trichotracheliden ausserordentlich lang und nur von einer einzigen $/$ sellreihe gebildet. Der Chylusdarm besteht aus einer ansehnlichen äusseren,

Fig. 361 .

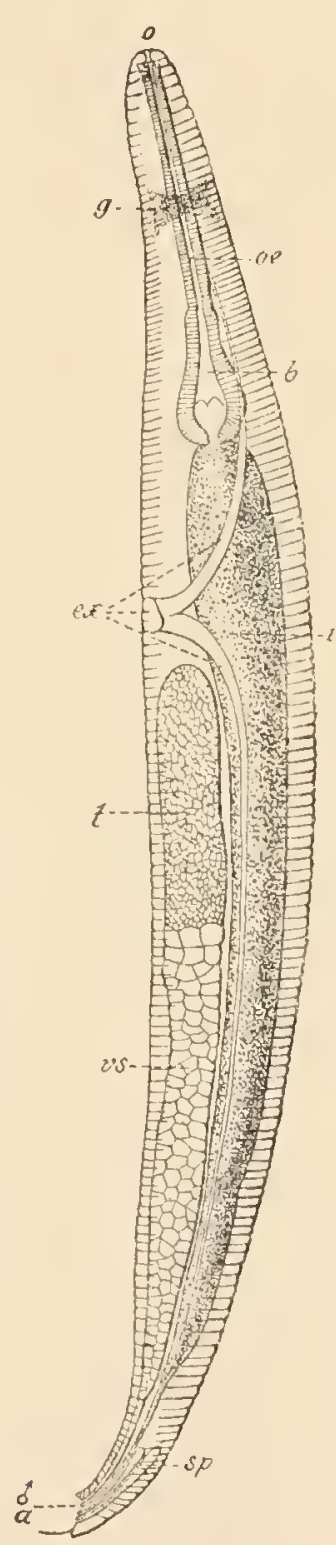

Fig. 361. Uebersicht der organisation von Oxymis Diesingii, Männchen, aus der Kiichenschabe (nach IBÜTSCHLI). o Mund, oe Oesophrigus, $b$ dessen liulbus, $i$ Darm, бa After und mänuliche Genitalöffnung, $g$ Ganglienring, $e x$ Excretionskanäle, $t$ Hoden, vs Vesicula seminalis, $s p$ Tasche für das spiculum.

\section{Fig. 362}

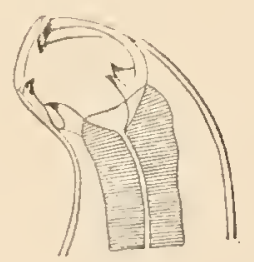

1'ig. 362. Mundkapsel von Nockmius, wit Chitiuzähnen (nach LEUCKarT). structurlosen Basalnembran

(Propria), einer Epithelschichte und einer inneren, von senkrechten Poren durchsetzten Cuticula (Stäbchensaum). - Der Enddarm ist aus innerer Cuticula, Epithelschichte und äusserer Muskclschichte aufgebaut. Neben dem ventral, seltener terminal gelegenen After münden meist mehrere einzellige Drüsen.

Als Excretionskanäle werden zwei Schläuche gedeutet, welche den Seitenlinien dicht anliegend, wenigstens in der vorderen Körperhälfte gefunden werden, und dic unweit des Schlundringes in kurze Querkanäle übergehen, dic durch eine gemeinsame unpaare ventrale 
Oeffnmmg nach aussen münden. Nach den bisherigen Untersuchumgen nuuss us noch zweifelhaft erscheinen, ob dies selbständigc Gebilde oder $11 \mathrm{r}^{\circ}$ Differenzirungen der Seitenlimien sind. Neben dem Excretionsporus münden manchmal zwei grosse einzellige Drüsen aus (besonders bei den Strongyliden).

Das Nervensystem, welches besonders bei den grossen Ascariden gemauer erforscht ist, besitzt eine epitheliale Lagerung, d. h. es längt iulberall innig mit der Subcuticula zusammen. Der centrale Theil findet sich in einiger Entfernung vom Vorderende des Körpers als eine l’ingförnige Bildung, welche die Speiseröhre eng umschliesst (Schlundring); derselbe kanm als eine ringförmige Epithelverdickung betrachtet werden, welche aber von den vier Längsmuskelfeldern durchbolnt wird,

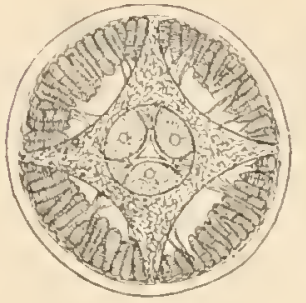

Fig. 363. Querschnitt durch den Schlundring von Eustrongylus (nach LEU. CKART). so dass ein Zusammenhang mit der Subcuticula nur in den vier Längslinien erhalten bleibt; die Ganglienzellen sind aber an diesem Schlundring nicht gleichartig vertheilt, sondern sind an gewissen Stellen gehäuft, z. B. beim Spulwurm an den Seiten und ventral. Von diesem Schlundring gehen nach vor'n sechs Nerven aus, nämlich zwei Nerven in den Seitenlinien und vier längs der vier Zwischenfelder in der Subcuticnla verlaufende Submediamnerven; diese vorderen Nerven versorgen besonders die papillenartigen Sinnesorgane in der Umgebung des Mundes; hinter den Mundlippen stehen sie mit zahlreichen Ganglienzellen in Verbindung, die wohl auch als Centralapparate zu betrachten sind; nach hinten gehen vom Schlundring ebenfalls vier Submediannerven ab, die aber nur eine Strecke weit zu verfolgen sind, wälnend ein dorsaler und ventraler Nerv in den beiden Medianlinien die ganze Länge des Körpers durchzieht und zu den entsprechenden ventralen und dor'salen Muskelfelderu in Beziehung steht; stellenweise sind diese beiden Nerven durch Ringfasern, welche in der Subcuticula verlaufen, mit einander verbunden. Bei den grossen Ascariden ist auch ein vor dem After gelegenes Analganglion, ja beim Männchen sogar ein vollständiger präanaler Nervenring (d. h. ein Ringganglion) nachgewiesen, der ferner mit Nerven und Ganglienzellen des Enddarmes und hinteren Körperendes in Verbindung steht. - Nebst den oralen Tastpapillen finden sich solche auch am Hinterende; sonstige Simesorgane sind rur bei freilebenden Nenatoden erkannt, und zwar krommt ein dorsaler x-förmiger Augenfleck in der Gegend des Schlundringes und Tastborsten besonder's an Vorderkörper vor.

Bei den Nematoden kemmen wir nur geschlechtliche Fortp f l a n z u n g (und Parthenogenese?). Sie sind typisch getrenntgeschlechtlich. Es gibt nur wenige Ausualmen (secundärer Natur), wo in den Genitalsäcken neben Eiern auch Spermatozoen erzeugt werden (Pelodytes hermaphroditus, von ScHNiner in faulenden Schnecken entdeckt); bei Rhabdonema nigrovenosum findet sicl Heterogonie, es wechselt nämlich die kleinere getremutgeschlechtliche Rhabditis-Generation mit der grössercn zwitterigen als Rhabdonema bezeichneten ab. - Die Männchen sind in der Regel etwas kleiner als die Weibchen und zeigen ein ventral umgelinimmtes Hinterende, welches meist durch besondere Tastpapillen ausgezeichnet ist. - Die Geschlechtsorgane sind in beiden Geschlechtern älnulich gebant; auffallend ist aber die verschiedenartige Ausmündung. - Die weibliclien Organe nünden in der Mitte der 
Bauchfläche aus; es sind paarige lange, oft vielfach gewundene Schläuche; in der Regel ist der eine Schlauch nach vorn, der andere nach hinten gelagert; in den verjingten blinden Ende jedes Schlauches findet sich das Keinepithel, es fungirt dieser Theil demnach als Ovarium, die darauffolgenden Abschnitte werden als Oviduct und Uterus bezeichnet und fülıren zu der kurzen unpaaren Vagina. - Der männliche Genitalschlauch ist in der Regel unpaar, seine Abschnitte fungiren als Hoden (in welchem die cigenthümlichen, kegelför'migen, amöboiden Spermatozoen sich bilden), Vas deferens und Samenblase, er mündet ventral in den IIinterdarm, der demuach beim Männchen als Kloake zu bezeichnen ist. Mls männlicher Begattungsapparat finden sich meist paarige, durch besondere Mnskeln vorstülpbare, chitinartige Spicula, die an der Dorsalseite des Hinterdarmes in besonderen taschenartigen Anhängen desselben liegen. Oft ist anch der Endtheil der Kloake selbst vorstïlpbar (Trichina). Bei den Strongyliden ist das Hinterende des Männchens von einer schirm- oder glockenförmigen Bursa copulatrix ungeben.

Fig. 364 .

Lig. 364. Hinterende des Männchens von Ascaris lumbricoides, in Iängssochnitt (nach LEUCKART). a Kloakenöfnung, $i$ Darm, de Ductus ejaculatorius, $s$ spiculumtasche

Fig. 365. Bursa copulatrix des Männchens von Sclerostomum (nach LEUCKART).
Fig. 365

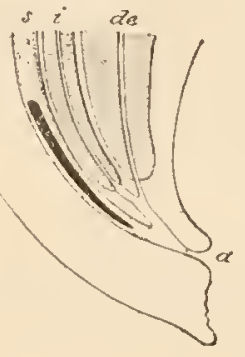

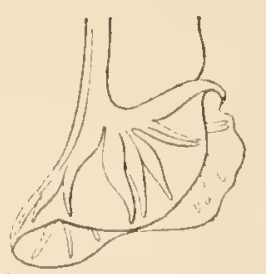

Dic Entwicklung ist eine directe. Die befruchteten Eier, dic nnit ciner ansehnlichen Dottermembran versehen und meist von ovaler Gestalt sind, häufen sicl in manchen Fällen nur in geringerer Anzahl, in anderen Fällen aber in sehr bedeutender Menge in Uterus all. Dio Entwicklung erfolgt meist nach Ablage der Eier, bei vielen Arten aber schon im Uterus. Die Furchung ist adäqual, aber ohne Furchungshöhle, die Gastrulation erfolgt durch Epibolie, del Gastrulamund entspricht der Ventrallinie; es sonder'n sich zwei Urmesodermzellen, von welchen zwei Mesodermstreifen geliefert werden, dic sodann in die Anlage der vier Muskelfelder, der Excretionskanäle und die Genitalanlage sich sondern (GöTTE), welche letztere bei den jungen Nematoden typisch durch zwei Embryonalzellen repräsentirt wird. Stomodacum und Proctodaeum entstehen als Ectorlermeinstülpungen. Der Embryo ist nach Bildung dieser Anlagen oval, el streckt sich sodann in die Läinge und liegt endlich spiralig gewunden innerhalb der Eihïlle. Das junge Thier zeigt schon die typischen Nenatodencharaktere, ist aber von relativ sehr geringer Grösse. Oft sind diese Jngendformen auch mit besonderen Einrichtungen für ihre parasitischen Wanderungen ausgestattet (Bohrstachel); sie erfahren melirfache Häutungen.

Es gibt zahlreiche kleine Nematoden, die freilebend sind, aber gleichwohl meist von organischen /ersetzungsplorlukten sich nähren. Sie finden sich in Meere, seltener im Schlamm der Süsswässer. Ferner in Pflanzen und in faulenden vegetabilischen Stoffen (Anquillutiden). Aber auch bei den parasitischen Formen findet sich eine grössere Mannigfaltigkeit der biologischen Verhältnisse, namentlich in Bezug auf 
die Art der Einwanderung, als bei anderen parasitischen Thiertypen. In vielen lällen leben die jungen Thiere frei als sogenannte Rhabditiden im Wasser oder in feuchter Erde (Dochmius, Sclerostomum). Alldere Fornen werden frühzeitig, oft schon im Ei, durch Nalıungsmittel wieder in ihren Wirth übertragen (Oxyuris vermicularis). In einen anderen Falle lebt nicht nur der geschlechtsreife Parasit in seinem Wirthe, sondern es verbleibt auch die junge Brut in demselben bis zu eincr gewissen Lebensperiode, die durch Einkapselung als Ruhezustand charakterisirt ist; es muss dann eine Uebertragung in einen zweiten Wirth, der aber auch von derselben Art wie der erste sein kann, erfolgen, damit dort derselbe Cyclus durchlaufen werde (Trichina). Nur in einigen Fällen ist ein typischer Wirthswechsel, der sonst so allgemein bei Parasiten vorkommt, ausgebildet, indem nämlich die Jugendfor'm den einen Wirth, die geschlechtsreife Form den anderen Wirth bewolnt. So wandert bei der abyssinischen Filaria medinensis, welche geschlechtsreif in der Unterhaut des Menschen lebt, sowie bei Cucullanus elegans, der geschlechtsreif im Darme des Barsches sich aufhält, die junge Brut in dic Leibeshöhle gewisser kleiner Süsswasserkrebse, nämlich Cyclops-Arten ein, wo sie nach einiger \%eit sich cinkapselt. - Parasitische Nematoden finden sich bei den verschiedensten Wirbelthieren und Wirbellosen; da sie getrenntgeschlechtlich sind, so leben sic stets in Mehrzahl oft in grosser Menge in einem Wirthe.

Systematische Uebersicht der. Nematoden (mit besollderer Berücksichtigung der menschlichen Parasiten).

1. Enoplidae. Speiseröhre ohne Anschwellung; häufig mit Augen versehen; oft mit Schwanzdrüsen; kleine freilebende Thiere, meist im Isere. Enoplus, Dorylaimus.

2. Anguillulidae. Speiseröhre mit zwei Anschwellungen, kleine Formen, theils freilebend, theils in Pflanzen oder auch in Thieren schmarotzend. Tylenchus scandens, W e i z enäl c he n, verursach tie Gicht der Weizenkörner; Sphuerularia bombi; Heterodera Schachtii, Rübennematode, verursacht die Riibenkraukheit; Anguillula aceti, Essigälchen an Pilzen im Kleister oder Essig u. s. w. Rhabditis, zahlreiche Arten leben in faulenden Substanzen, andere sind wenigstens zeitweilig parasitisch; $R$. (Rhabdonema) nigrovenosa. zeigt die Erscheinung der Heterogonie, die getrenntgeschlechtliche Generation lebt in feuchter Erde, die grössere Zwitterform lebt in der Lunge des Frosches.

R. stercoralis intestinalis (Rhabdonemn strongyloides) ist ein Parasit des Menschen in den wärmeren Ländern der alten Welt; zeigt ebenfalls Heterogonie, die eine Generation (intestinalis) lubt im Darme in grossen Mengen, die andere (stercoralis) im Freien als Zwischengeneration. Erzeugt schwere Erkrankungen.

3. Mermithidae. Mund mit 6 Papillen, lang fadenförmig; leben als Larven in der Leibeshöhle fon Insecten, geschlechtsreif in feuchter Erde. Mermis.

4. Filariadae, lang fadenförmig; $\delta$ mit eingerolltem Hinterende und mit zwei ungleichen oder nur einem Spiculum; Schmarotzer.

Filaria (Dracunculus) medinensis, II e d in a w u rm, Parasit des Menschen in den Tropenländern der alten Welt; bis $80 \mathrm{~cm}$ lang und nur etwa $1 \mathrm{~mm}$ dick, mit verkümmertem Darme, lebt im Unterhaut- 
bindegewebe und erzeugt dort Geschwüre, die autbrechen; die in ungeheurer Anzahl erzeugten Larven gelangen ins $W$ asser und wandern in kleine Siisswasserkrebse (Cyclops) ein, diese werden wahrscheinlich mit dem Trinkwasser rom Menschen aufgenommen. - Filaria sanguinis hominis in den 'Tropenländern; die sehr kleinen Larven leben in grosser Zahl im Blute des Menschen; erzeugen Nierenentzündung. Die geschlechtsreife Form (F. Bancrofil) ist mehrere cm lang und lebt in lymphatischen Geschwülsten. Die Larren gelangen auch in Mosquitos, doch ist es fraglich, ob dies ein Zwischenwirth ist.

5. Trichotrachelidae. Vorderende verdïnnt, Oesophagus lang und dünn, mit einreihigem Zellstrang; $\delta$ mit nur einem oder ohne Spiculum; Parasiten.

Trichocephalus dispar, Peitschen w um, 4-5 cm lang, das Vorderende lang und dünı, enthält nur den Oesophayus, der kürzere und dickere Hinterleib aber den Darm und die Geschlechtsorgane. Eier tonnentörmig, dickschalig. Der Parasit bewohnt das Coecum des Mlenschen, der dünne Vorderkörper ist in die Nichleimhaut eingebohrt; selten kommen mehr als 10 Exemplare gleichzeitig vor; die pathologische Bedcutung ist daher gering. Die Infectionsweise ist unbekannt; doch ist es wahrscheinlich, dass die längere Zeit im Freien ausdauernden Eier wieder direct in den Menschen gelangen.

Trichina spiralis, Trichine. Das geschlechtsreife Thier lebt im Darme des Menschen etc. (Darmtrichine); ơ 1,5 mm lang, 오 $3 \mathrm{~mm}$ lang; am Hinterleibsende des Männchens zwei Papillen, die Kloake desselbon ist vorstülphar, Spicula fehlen; beim Weibchen liegt die Geschlechtsöffnung weit vorn, die Embryonen entwickeln sich schon im Uterus. - Die sehr kleinen Jungen $(0,01 \mathrm{~mm})$ durchbohren die Darmwandung und wandern selbstthätig in die quergestreifte Musculatur, und zwar in das Innere der einzelnen Muskelfasern ein. Die Muskelfasern degeneriren, die junge Trichine wächst auf deren Kosten und kapselt sich dann spiralig eingerollt ein (eingekapselte , $\mathrm{M}$ uskeltrichine"). Durch Uebertragung in einen anderen Wirth kann die Trichine geschlechtsreif werden und es kann ein neuer Cyklus beginnen. Die Trichine lebt nicht nur im Menschen, sondern auch im Schwein, in der Ratte, im Kaninchen und vielen anderen Säugethieren, seltener in Vögeln, so z. B. im Huhn, in der Taube, Ente etc. Pathologische Bedeutung. Die Trichine wurde als eingekapselte Muskeltrichine von dem englischen Studenten der Medicin PaGET entdeckt (1835). Trotzdeln blieb die Bedeutung derselben als Krankheitserreger lange unbeachtet und wurde erst erkannt, als durch LEUCKarT und ZnNKer anlässlich eines in Dresden durch Trichinose erfolgten Todesfalles der ganze Entwicklungsgang der Trichine festgestellt wurde. Bald darauf wurde die Aufmerksamkeit durch mehrere Trichinenepidemien (Epidemie von $\mathrm{H}$ a dersl e be n) noch mehr auf die grosse Bedeutung der Trichinenkrankheit gelenkt. - Die Gefährlichkeit der Trichine beruht darauf, dass ihre Brut nicht wie bei anderen Nematoden nach aussen entleert wird, sondern in die Gewebe und zwar die Muskelfasern desselben Wirthes einwandert. Die Infection des Menschen erfolgt in der Regel durch den Genuss ron trichinösem, ungenügend gekochtem Schweinefleisch; erst eine Temperatur von $+55^{\circ} \mathrm{R}$, auch im Inneren des zubereiteten Fleischstückes, tödtet die Trichinen. Die Trichinen siedeln sich im Darme an; sie verursachen dort schon Darmerscheinungen, welche aber nur bei grösserer Menge der Parasiten sehr heftig werden. Schon nach einer Woche beginnen aber die von den Darmtrichinen erzeugten Larren die Darmwand zu durchbohren, um 
Fig. 366

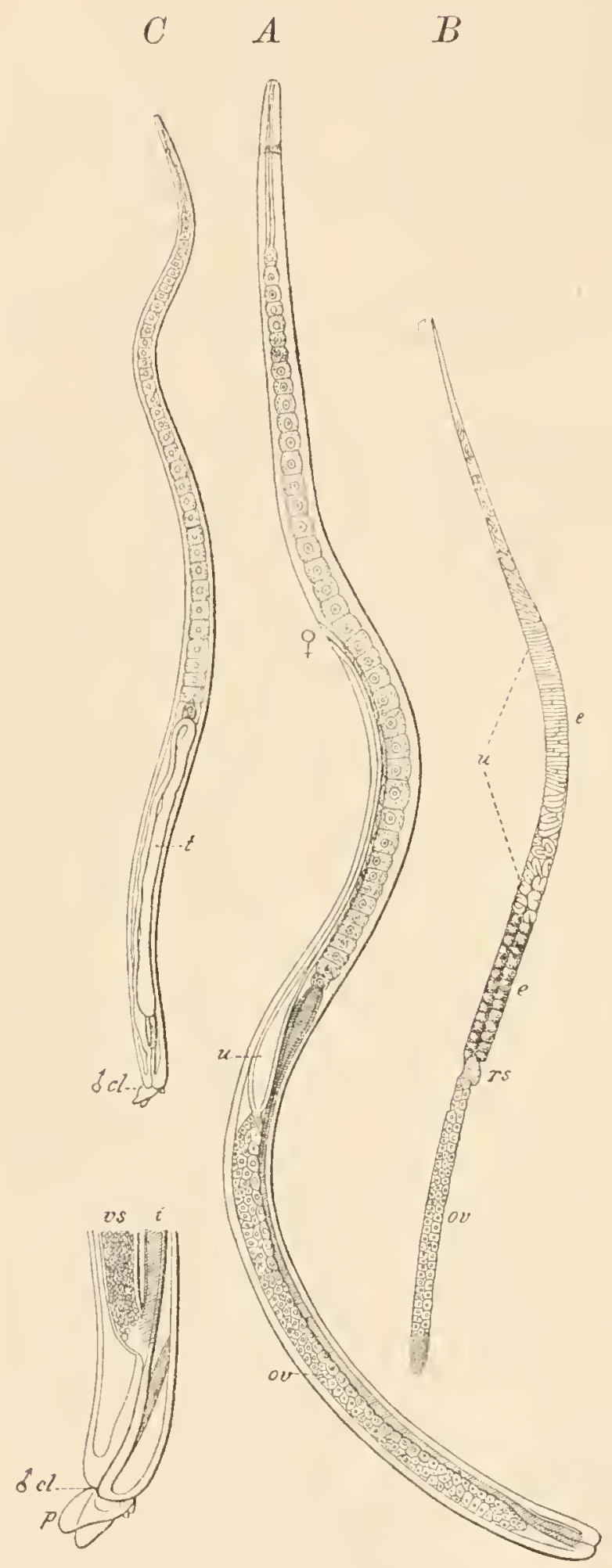

$D$
$A$

Fig. 367 .

$B$

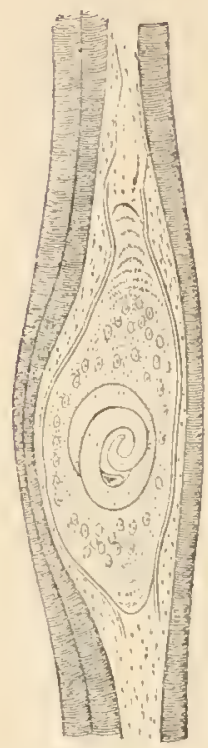

Fig. 366. Trichina spiralis (1):ch LevCKArT), $A$ Weibchen kurz vor der Geschlechtsreife. $Q$ weibliche Oetrnung, $u$ Uterus, $o v$ Ovarium. $B$ Genitalapparat eines geschlechtsreifen Weibchens. ov Ovarium, rs Receptaculum seminis, $u$ Uterus, mit $(e$,$) jün-$ geren und $(e)$ älteren Embryonen. $C$ Männchen. $t$ Hoden. $D$ Hinterende des Männchens, noch mehr vergrössert. $\delta c l$ Kloake, $p$ Papillen neben derselben, vs Vesicula seminalis, $i$ Darm.

Fig. 367. A Wandernde Trichinenlarve (sogenannter ,Embryo"). B Muskeltrichine, in einer degenerirten Muskelfaser eingekapselt, daneben mehrere unveränderte Muskelfasern (nach LEUCKART).

in die Gewebe einzuwandern; die Darmerscheinungen steigern sich bedeutend und können selbst zum Tode führen (Cholera trichinosica). Die wandernde Brut erzeugt Oedeme im Gesicht etc., und sobald sie in den Muskeln angelangt ist, Entzündungen und heftige Schmerzen und mannigfaltige andere Störungen. Die Nachschübe von Larren rom

Darme aus dauern 4-5 Wochen und führen zu einer fortwährenden Steigerung der Symptome. Wenn die Kranken dieses Stadium überdauern, so kann eine allmähliche Heilung eintreten. - Die Muskelfasern, in welche die Trichine einwandert, gehen zu Grunde, denn ihre Substanz wandelt sich in eine körnige Masse um; später erhält die spiralig eingerollte Trichine eine längliche Kapsel, die allmählich in 5-8 Monaten verkalkt, und es verharrt der Parasit im Ruhezustand. - Die Di a g n o se der Trichinenkrankheit 
ist meist erst in vorgeschrittenem Stadium, nach Einwanderung der Brut in die Gewebe, festzustellen; am sichersten ist der Nachwois der jungen Trichinen in harpunirten Muskelfasern. - Heilmittel können dann nicht mehr den Parasiten bekämpfen, sondern nur gegen die Begleiterscheinungen sich richten. Prophylaktisch wird gegen die Trichinose rorgegangen: 1) Durch mikroskopische Fleischbeschau, die in Norddeutschland obligatorisch eingeführt ist; man hat nur mehrere Proben ron Muskelfasern des geschlachteten Thieres zu prifen. 2) Ferner durch genügendes Kochen oder Braten des Fleisches. 3) Durch sorgfältige Reinlichkeit beim Halten der Schweine; die Schweine selbst werden nämlich dadurch inficirt, dass ihnen etwa Sihlächtereiabfälle vorgeworfen werden, orler auch, indem von ilnèn liatten angegriffen und angefressen werden. Die Ratte beherbergt nämlich schr häufig Trichinen und da diese Thiere Leichen ihrer eigenen Art benagen, so ist Gelegenheit zur fortwährenden Erhaltung der Trichinose bei denselben grgeben. Nach Leuckart sind die Ratten als die eigentlichen Trichinenträger und Verbreiter zu betrachten; dieselben sind daher sorgfiiltig von den Stallungen der Schweine fernzuhalten.

6. Strongylidae. Mit Mundpapillen und grosser, mit Zähnen bewaffneter Mundkapsel, o mit Bursa. P'arasiten.

Eustrongylus gigas, Männchen $40 \mathrm{~cm}$, Weibchen bis $1 \mathrm{~m} \mathrm{lang,}$ röthlich. Dieser grosse Nematode kommt im Nierenbecken des Menschen vor, ist aber sehr selten. Ebenso bei verschiedenen Säugethieren. Entwicklung und Infectionsquelle unbekannt.

Dochmius duodenalis, of $1 \mathrm{~cm}$ lang, $q 1,8 \mathrm{~cm}$ lang; kenntlich durch die Mundkapsel und die Bursa des Männchens; lebt im Dünndarm des Menschen in Italien, Schweiz, Aegypten, Brasilien. Dieser Parasit lebt in grossen Massen im vorderen Theil des Dünndarmes; er ist mit seinem Mlundende in die Darmwand eingegraben, aus welcher er Blut saugt. Er verursacht schwere Erkrankungen (Blutarmuth, Abmagerung etc.), die selbst zum Tode führen. Die Krankheit ist als "äg yptische Chlorose“ bezeichnet, da sie zuerst in Aegypten genauer beobachtet wurde. In jüngster Zeit ist dieselbe auch in Südeuropa, Ungarn, Schweiz aufgetreten, z. B. bei den am Bau des Gotthardtunnels beschäftigten Arbeitern. Die Eier werden nach aussen entleert, die jungen Thiere leben frei im Wasser; die Infection erfolgt durch das Trinkwasser (Letckart). Es werden Wurmabtreibungsmittel angewendet und Wechsel des Aufenthaltes empfohlen.

7. Ascaridae. Mund mit drei Lippen (eine dorsale, zwei ventrale); meist mit Oesophagusansehwellung; Parasiten.

Oxyuris vermicularis, Hade $\mathrm{nw} \mathrm{ur}$. If $4 \mathrm{~mm}$, 우 $10 \mathrm{~mm}$ lang; Hinterende des Männchens stumpf, eingerollt; das des Weibchens lang zugespitzt. Am Vorderende eine dorsale Auftreibung, längs derSeitenlinie eine niedrige Leiste. Eier oval, 0,05 mm lang. Der Madenwurm gehört zu den häufigsten menschlichen Parasiten, besonders bei Kindern; er kommt meist in Hengen im Dickdarm vor. Kur Abendzeit verlassen die Würmer den Darm und wandern in der Gesässkerbe, bei Mäßchen sogar in die Vagina und den Uterus; sie veranlassen sehr lästiges Jucken und Nervenreiz, welcher bei den Kindern manche Störungen verursacht (Anlass zur Onanie, frühzeitige Erectionen und Pollutionen bei Knaben). Man findet junge und alte Oxyuren neben einander; dennoch ist es unwahrscheinlich, dass sie an Ort und Stelle sich fortpflanzen, sondern es ist die Annahme nahezu erwiesen, dass die Kier, welche schon den Embryo enthalten, stets den Darm verlassen und im Freien eine Keit verbleiben und dass die Infection immer wieder durch Aufnahme ron Eiern auf dem Wege durch den Mund 

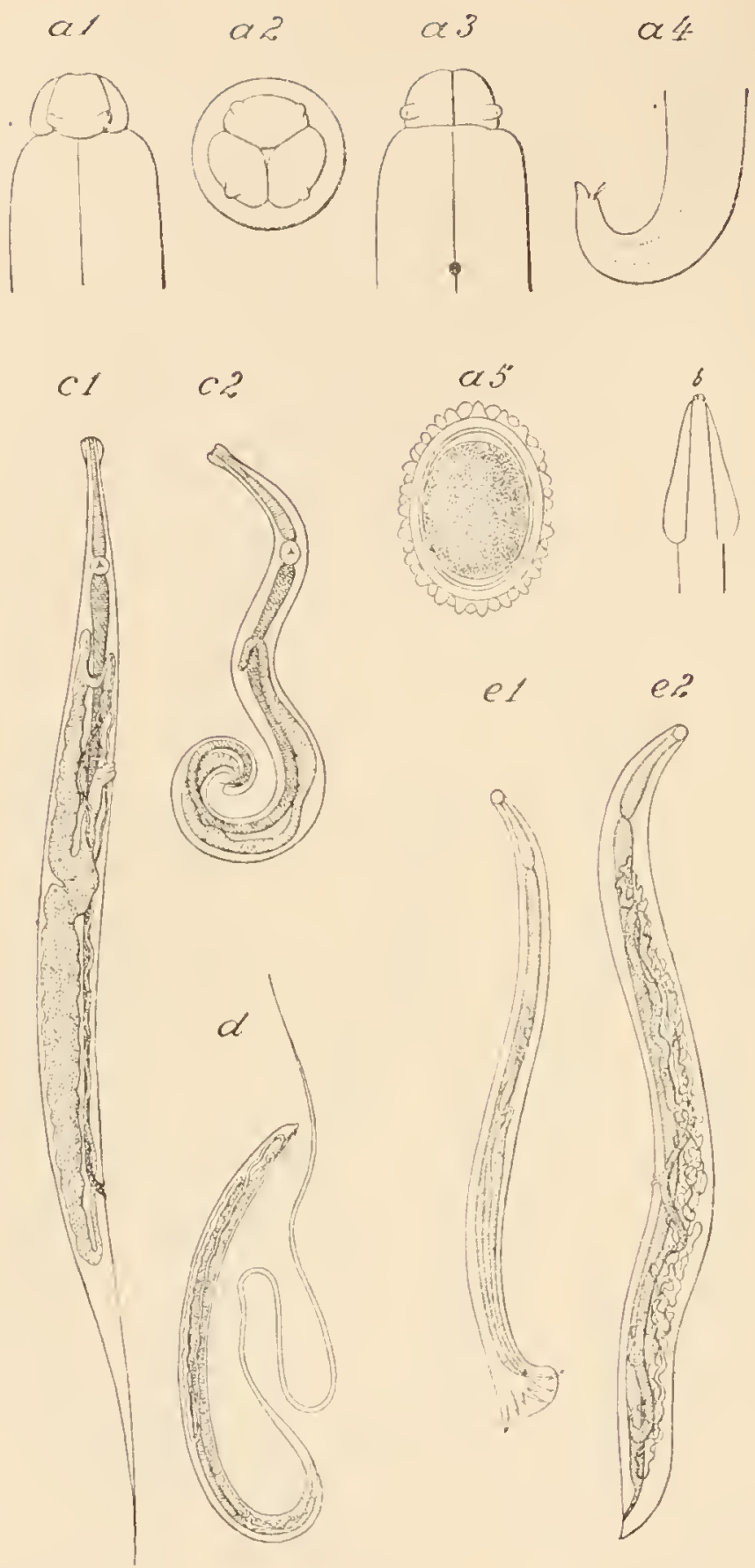

Fig. 368. Ascaris lumbricoides. $a_{1}$ Vorderende von der Rückenseite gesehen ; $a_{2}$ dasselbe vom vorderen Pole; $a_{3}$ dasselbe von der Bauchseite; $a_{4}$ Hinterende des Männchens, von der linken Seite; $a_{5}$ Li, mit der Dottermenbran und dem eiweissartigen Ueberzug. $b$ Ascaris mystax, Vorderende mit flügelartigen Verbreiterungen. $c \mathbf{0 x y -}$ uris vermicularis ; $c_{1}$ Weibelen ; $r_{\mathrm{g}}$ Männehen. $d$ Trichocephalus dispar 9 , nur selwwach vergrössert. e Dochmius duodenalis; $e_{1}$ Männehen mit Bursa eopulatrix; $e_{2}$ Weibehen. Alle Figuren nach LEuckart.

erfolgt. Da die Eier auf mannigfache Weise die Gebrauchsgegenstände verunreinigen, ist eine fortwährende Neuinfection ermöglicht; manche Kranke köunen daher die Oxyuren durch viele Jahre nicht los werden; auch erklärt es sich, dass diese Parasiten oft epidemisch, besonders in Pensionaten, Kascrnen auftreten. - Die Diagnose ist leicht, da mit den Fäces meist zahlreiche Oxyuren entleert werden. Zur Heilung werden Wurmmittel gegeben, aber auch mancherlei Mittel in Form ron Klystiren etc.

\section{Ascaris Tumbri-}

coides, gemeiner

$\mathrm{Spulwurm}$. ठ bis $25 \mathrm{~cm}$,

$q$ bis $40 \mathrm{~cm}$ lang. Vorderende allmählich rerjüngt, Hinterende rascher zugespitzt. Lie dorsale Mundlippe trïgt zwei, die rentralen Lippen je eine Papille; der innere Rand der lippen ist fein gezähnelt. Eier oval, 0,05 mm lang, durch einen höckerigen Eiweissüberzug ausgezeichnet. — Gehört zu den hïufigsten menschlichen Parasiten, beim Erwachsenen und besonders bei Kindern. A uch bei Thieren kommt dieser Spulwurm vor, so beim Rind und Schwein (der grosse Spulwurm des Pferdes repräsentirt eine andere Art, 4. mepalocephula). Die Eier gelangen mit den Fäces des Wirthes nach aussen und entwickeln sich nach einer Ruhepause langsam weiter; der eingerollte Embryo bleibt lange Zeit lebensfähig, doch ist sein nächster A ufenthalt nicht bekannt; durch direkte Aufnahme dieser Eier in den Darm des Menschen erfolgt keine Infection; so ist der Entwicklungsgang für diesen gewöhnlichsten Parasiten trotz zahlreicher Bemïhungen noch uner- 
forscht. - Pathologische Bedeutung: In geringer Anzahl vorhanden erzeugen die Spulwürmer kaum besondere Störungen. Anders aber, wenn sie in grosser Zahl, selbst zu Hunderten, vorkommen; sie verursachen Entzündungen des Darmes, Krämpfe, Verstopfungen. Die Spulwärmer können in selteneren Fällen auch die Darmwand perforiren, in andere Organe eindringen, ja selbst durch Abscesse der Körperwand nach aussen gelangen. - Die Diagnose ist leicht durch mikroskopische Untersuchung der Fäces festzustellen, da die sehr charakteristischen Eier stets in Menge entleert werden. Es werden zur Abtreibung verschiedene Wurmmittel empfohlen; die abgetriebenen Würmer sollen verbrannt werden, um die Weiterverbreitung der Eier zu vermeiden.

Ascaris mystax, Katzenspulwurm, viel kleiner, durch zwei flügelförmige Leisten längs des Vorderendes ausgezeichnet, ist häufig bei Katzen und Hunden und kommt selten auch beim Menschen vor.

An hang zu den Nematoden: Gordiidae. Mit der Gattung Gordius. Diese langen, spulrunden, nematodenälınlichen Thiere zeigen so viele besondere Organisationseigenthümlichkeiten, dass ihre '/ugohörigkeit zu den Nematoden fraglich erscheint. So sind ein Cerebralganglion, Schlundring und Bauchstrang als Theile des Centralnervensystems gedeutet worden. Seitenlinien fehlen. Dic paarigen Genitalsiicke erstrecken sich in der ganzen Länge des Körpers und sind derart mit der Längsmuskelschichte des Leibes verwachsen, dass sie an die paarigen Peritonealsäcke der Coelomaten erinnern, um so mehr, da die licimepithelien nur als locale Differenzirungen in denselben erscheinen (nach den Untersuchungen von VEJdovsKy); die Genitalorgane münden sowohl bei dem $\delta$ als auch bei dem $q$ durch besondere Ausfïhrgänge aml Hinterende; dieses ist beim Männchen gegabelt und mit Papillen versehen. Bei den geschlechtsreifen 'Thieren ist der Darm reducirt nurl nicht functionirend, obzwar dieselben frei im Wasser leben. Die kurzen Larven, die mit einem hakentragenden einstülpbaren Vorderende versehen sind, wandern in die Leibeshöhle von Wasserinsecten ein, diese werden von auderen Insecten (oder auch von Fischen) gefressen, in deren Leibeshöhle die Gordien damn zu bedeutender Länge heranwachsen; zum Zwecke der Geschlechtsthätigkeit wandern dieselben in das Wasser aus.

\section{Classe der Scolecida. Acanthocephali.}

Die Acanthocephalen sind Scoleciden (?) von endol) arasitiscle er Lebensweise; der Darmkanl fehlt, Bewimperung mangelt der gesammten ()rganisation in allen Lebensstadien; der längliche spulrunde Körper ist vorn mit einem einstülpbaren hakentragenden Rissel versehen, hinter welclem cin Ganglion liegt; die Leibeswand besteht auseiner dünnen Cuticula, einer nuchtigen Subcuticula mit eincm System von Unterhautkanälen, einer äusseren Rings- nud einer inneren L ängsnuskelschichte; paarige keulenfälnige Wucherungen der Leibeswand (Lemnisci) ragen vorn in die geräumige Leibeshöhle; sie sind getrenntgeschlecht- 
lieh, die complicirten Genitalorgane münden am Hinterende; Entwicklung mit eigenthümlicher Metamorpliose.

Die Verwandtschaftsverhältnisse dieser merkwürdigen Thiergruppe sind noch ganz unklar. Die Beziehungen zu den Nematoden, die von vielen Forschern angenommen werden, sind sehr zweifelhaft; wir wollen besonders die nur zarte Cuticula und die fadenförmigen Spermatozoen als Eigenthümlichkeiten hervorheben, welche gegen jene Annahme sprechen ${ }^{1}$ ). Zweifellos haben diese Thiere durch Anpassung an den Parasitismus ihre eigenthümliche Organisation erworben; auch scheint es mit Rïcksicht auf die merkwürdigen histologischen Verhältnisse, besonders die riesenhaften Zellelemente, nicht unwahrscheinlich, dass sie von kleineren Thierformen abstammen und dass sie erst durch den Parasitismus eine bedeutende Grössenzunahme erfahren haben.

Fig. 369 .

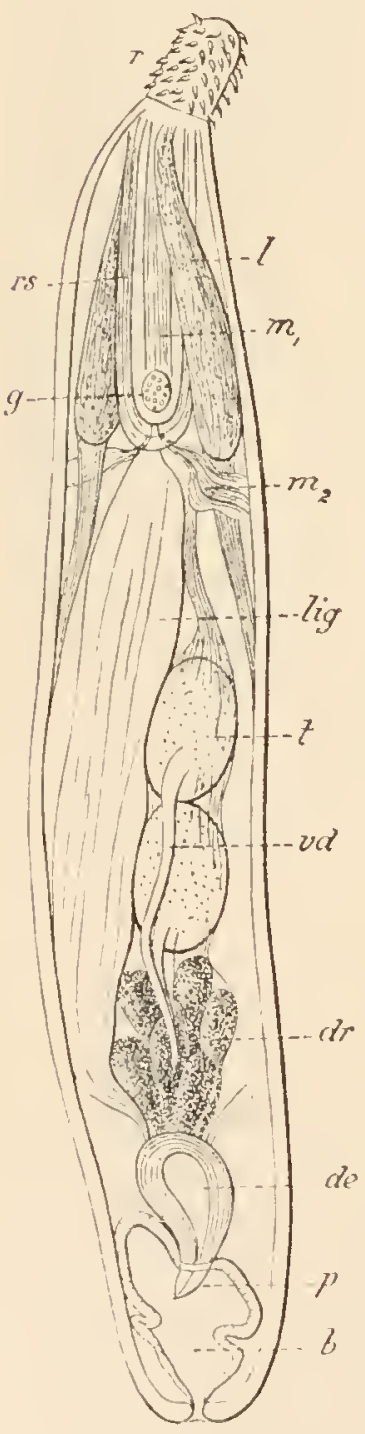

Fig. 370 .

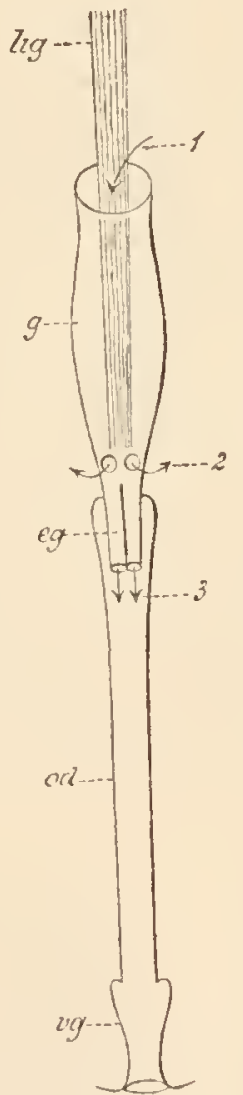

Die Grösse der meisten Acanthocephalen beträgt kaum einen oder nur wenige Centimeter; Echinorhynchus gigas aus dem Schweine erreicht aber bis $50 \mathrm{~cm}$ Länge. - Die Körperform ist länglich spulrund, Rücken und Bauchseite sind nur wenig verschieden und auf jene Regionen bei anderen Thieren nicht sicher zurücktührbar; das Vorderende ist durch den einstülpbaren, mit Haken besetzten Rüssel ausgezeichnet, mittelst dessen die Parasiten in der Darmwand ihres Wirthes befestigt sind. Diese chitinigen Widerhaken sind, sowie die Cuticula, von der darunter befindlichen Subcuticula oder Epithelschichte erzeugt; im Inneren des Rüssels verläuft sein Rückziehmuskel; hinter dem

Fig. 369. Echinorhynchus angustatus, Männchen (nach LEUCKART). $r$ Rïssel, $r s$ Rüsselscheide, $g$ Ganglion, $l$ Lemniscen, $m_{1}$ Retractor des Rüssels, $m_{2}$ Retractor der Rüsselscheide, lig axiales Ligament, $t$ Hoden, $v d \mathrm{~V}$ as deferens, $d r$ Drüsen (Prostata), de Ductus ejaculatorius, $p$ Penis, $b$ vorstülpbare Bursa copulatrix.

Fig. 370. Schema des weiblichen Geschlechtsapparates von Echinorhynchus. lig axiales Ligament, $g$ Uterusglocke, eg Eiergang, orl Ovidukt, vg Vagina, die Pfeile bedenten bei 1 den Eingang in die Glocke, bei 2 die Wege, welehe zuriick in die Leibeshöhle fïhren, bei 3 die Wege, welche weiter in den Eileiter fiilıren.

1) Durch neuere Uutersuchungen ron HAMAN, deren ausfülurliche Mitheilung zn erwarten ist, soll die Verwandtschaft mit den Nematoden eine sichere Begründung erfahren 
Rüssel befindet sich ein sackförniger, nach riickwärts in die Leibeshöhle hineinragender Muskel, der als Rüsselscheide den eingestülpten Rüssel aufnimmt und durch seine Contraction denselben wieder ausstülpt; die Rüsselscheide selbst ist wieder durch seitliche Rückziehmuskeln und das axiale Körperligament an der Leibeswand befestigt. - Am Grunde der Ruisselscheide liegt ein Ganglion, von welchem Nerven theils zu dem Rüssel und den Genitalorganen, theils auf dem Wege der seitlichen Rückziehmuskeln der Rüsselscheide zur Leibeswand verlaufen. - Die $K \ddot{0} \mathrm{r}$ e r w a n d, welche eine geräumige Leibeslıöhle einschliesst, bestelıt aus einer äusseren dümmen $\mathrm{C}$ u ti c ula, dann ciner sehr mächtigen Sub cuticula, die von senkrechten Fasern und zahlreichen Körnchen durchsetzt ist und in ihrer tiefen Schichte ein eigenthümliches Gefässnetz, das System der Unterha u tkanäle entlı̈̈lt, in welchem eine körnchenreiche Flüssigkeit fluctuirt; walırscheinlich stehen diese Gefässe in Beziehung zur Nahrungsaufnalıme, welche durch die ganze Körperoberfläche stattfindet. Die äussere Ringsund die innere Längsmuskelschichte sind aus kolossalen, merkwürdig gebauten Muskelzellen zusammengesetzt; zwischen denselben findet sich eine structurlose (zellfreie) Bindesubstanz, welche auch dic Leibeshöllle begrenzt und auch alle inneren Orgaubildungen überkileidet. -. Die L e m n is ci, welche neben der Rüsselscheide als parrige keulenförmige Körper weit in die Leibeshöhle hineinhängen, sind continuirliche Fortsetzungen der Subcuticula, sie haben dieselbe Structur und auch ein reich entwickeltes Gefässnetz; wahrscheinlich dienen sie dazu, die Nahrungsflüssigkeit an die Leibeshöhle weiter zu geben; die Muskelschicht des Körpers setzt sich ebenfalls faltenförmig auf die Lemnisci fort. - Die Acanthocephalen sind getrenntgeschlechtlich. Die weiblichen und männlichen Geschlechtsorgane sind wenigstens der Anlage nach von ähnlichem Typus. Sie sind einem axialen Ligament eingelagert, welches von der Rüsselscheide zu dem hinteren Körperende zieht; dasselbe besteht aus structurloser Bindesubstanz, es kann aber auch Muskelfasern enthalten. Am männlichen Apparate finden sich vor'n ein Paar Hoden, in welchen die langen fadenförmigen Spermatozoen entstehen und die mittelst paariger Samengänge (vasa deferentia) in einen unpaaren, mit Drüsen (Prostata) versehenen Ductus ejaculatorius und Penis münden, welch letzterer in der 'Tiefe einer glockenförnig vorstülpbaren Bursa copulatrix liegt. - Der weibliche Apparat besteht zunächst aus dem Ovarium, welches ursprünglich vorn in dem Ligament eingelagert ist, bei seinem Wachsthum aber in eine grosse Menge von Zellballen sich umwandelt, die sich ablösen und in del Leibeshöhle flottiren; in dieser finden sich auch die isolirten heranreifenden Eier. Der ausführende Apparat beginnt mit einem trichterartigen Organ („Glocke"6, ,Uterusglocke" , dic aus einigen colossalen Kellen zusammengesetzt ist), dessen vordere grosse Oeffinung mittelst fortwïhrender Schluckbewegungen Eiermassen aufnimmt; die unreifen Eier werden durch weiter hinten gelegene paarige, ,dorsale" Oeffnungen wieder in die Leibeshöhle entleert und nur die reifen, schmal spindelförmigen Eier können durch paarige hintere, enge Kanäle (Eicrgänge, Glockenschlundgänge) in den Eileiter (der auch als Uterus bezeichnet wird) gelangen; dieser fülnt zu der am Hinterende ausmündenden Vagina. - Die Entwicklung zerfällt in zwei Perioden, die Embryonalentwicklung und die sehr eigenthümliche Metamorphose. Diese ist mit einem typischen Wirtliswechsel verbunden; die Geschlechtsthiere halten 


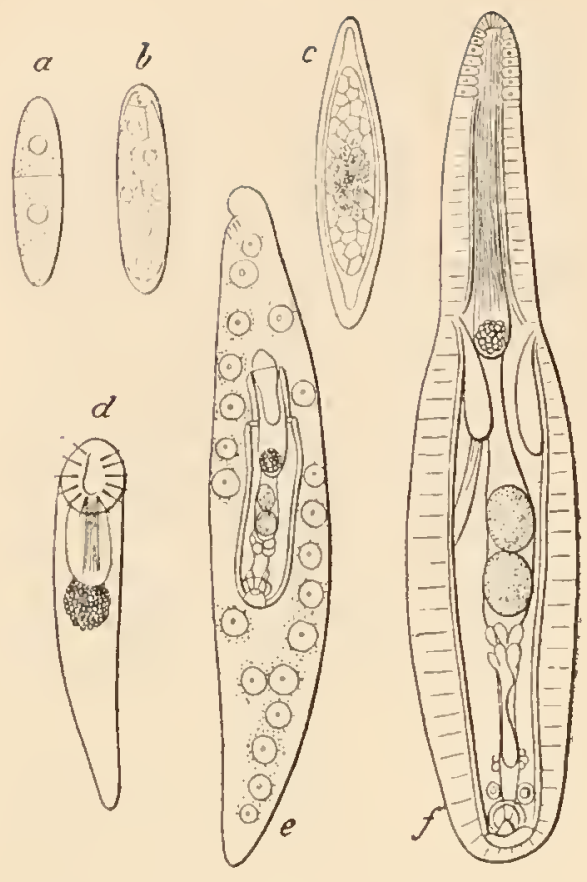

Fig. 371. Entwicklung von Echinorhynchus proteus (nach LAUCKART). $a$ und $b$ Furchungsstadien; $c$ Sonderung der Schichten; $d$ die junge Larve init bilateralem Hakenapparat, mit einem Muskel und einem hellen elastischen ['olster, dalinter dunkelkörniger Zellhaufen; $e$ aus den dunkelkörnigen Zellen entwickelı sich alle Organe mit Ausuahme des Epithels; $f$ weiteres Entwicklungsstadium mit männlichen Organen.

sich stets im Darme bestimmter Wirbelthiere (meistens Fische) auf. Die Eier, welche mit dem Kothe des Wirtlies nach aussen gelangen, enthalten schon den reifen Embryo; sie werden von Arthropoden (Insecten, Krebsen) gèfressen; die Larve verlässt die Eihüllen und gelangt nach Durchbohrung des Darmes in die Leibeshöhle. Hier verwandelt sie sich in den jungen Echinorhynchus und verbleibt in einem Ruhezustande, bis sie wieder passiv in den ersten Wirth übertragen wird, wo sie erst die Geschlechtsreife erreicht. So lebt Echinorhynchus angustatus in Darme von Süsswasserfischen - als Larve im Flohkrebs, (Gammarus pulex); E. polymorphus im Darme von Enten und Wasservögeln - als Larve in der Wasserassel (Asellus aquaticus); E. gigas im Schweine, vielleicht auch im Menschen - als Larve im Engerling (Larve des Maikäfers) und in Cetonia.

Es gibt nur die eine Gattung, Echinorhynchus, mit vielen Arten. Im Menschen ist mit Sicherheit nur einmal eine kleine, noch unreife Form beobachtet ( $E$. hominis von $\mathrm{I}_{\text {AAMBL }}$ in Prag in der Leiche eines Kindes gefunden).

Die merkw ürdigen Entwicklungsvorgänge wurden besonders von LEucKaRT erforscht. Die Embryonalentwicklung wird schon in der Leibeshöhle durchlaufen; erst während der Entwicklung (Furchung u. s. w.) entstehen mehrfache cuticulare Hüllen (als „Eihüllen" bezeichnet), das nun spindelförmige $\mathrm{Ei}$, welches durch die Leitungswege ausgestossen wird, enthält bereits den reifen Embryo, welcher aber erst im Darme des Larvenwirthes die cuticularen Hüllen verlässt; die Larve ist länglich, hat vorn einen provisorischen bilateralen Hakenapparat, der mit provisorischen Rückziehmuskeln versehen ist, und besitzt eine provisorische Cuticula; die äusserst dicke, grosszellige, helle Epithelschichte umgibt einen kleinen centralen, dunkelkörnigen Zellhaufen, aus dem später die Muskelschichten und alie inneren Organe des Echinorhynchus entstehen; diese inneren, bedeutend heranwachseuden Bildungen erscheinen bei der Entwicklung als das wesentlich formbestimmende. 


\section{Anhang zum Cladus der Scolceiden: Nemertini.}

Die Nemertinen sind Kygoneuren mit kopfartigem Vorderleib (Prosoma?) und Ianggestrecktem, metamerisch gebautem Hinterleib (Gollosoma, Metasolla?). Mit bewimpertem äusserem Epithel und Dermalschicht; in it II a tmuskelschlauch (i. e. somatischer Muskulatur), mittler Parenchymschicht und innerer, dem Darme zugehörender Muskelschichte (i. e. s planchnischer Muskulatur). - Mit Protonephridium (?). - Mit metamer angeordneten Sackgonaden; mit Blutgefässsystem. - Mit Cerebralganglion und Seitensträngen; mit cerebralen Flimmergruben. - Mit einem am Vorderende desKörpers ausstülpbaren Rüssel, der in der Höhlung (Rliynchocoel) einer muskulösen Rüsselscheide liegt.

Die Nemertinen wurden bis in die jüngste Zeit meist als Nächstverwandte der Turbellarien betrachtet und daher zu den Plattwürnerı gerechnet. Manche Forscher stellten sie aber in die Nähe der Amneliden (Mc Intosh, Semper), eine Anschauung, die durch neuere Untersuchungen immer mehr Stützen gewinnt; so durch die ausgedehnten Arbeiten von Hubrecnt, der uns auch die ursprünglichere Organisation der Palaeonemertinen kennen lehrte, und durch die neuesten vortreftlichen histologischen Untersuchungen von BüRGER.

In Deutschland hat zuerst Semper die Anschauung nachdrücklich vertreten, dass die Nemertinen von den Plattwürmern zu trennen sind. - Es ist in der That nicht nur das Vorhandensein eines Afters, sondern auch der stets sehr einfache, in der Regel nicht zwitterige Geschlechtsapparat, wodurch sie typisch von den Plattwürmern sich unterscheiden. Andererseits ist sowohl in der Metamerie als auch in dem Besitz des Blutgefässsystems und der Schichtung des Körpers eine so grosse Annäherung zu den Anneliden gegeben, dass zu einer vollständigen Uebereinstimmung nur noch in gleicher Weise ausgebildete Coelomhöhlen und Metanephridien (Segmentalorgane) fehlen. Doch muss auch noch die Entwicklungsgeschichte beweisen, inwieweit die Uebereinstimmung in der Schichtung des Körpers auf Homologie beruht. Auch die Metamerie könnte entweder auf gleichu Weise zu erklären sein wie bei den Anneliden (ja sogar als unterdrückte Theilungserscheinung), sic könnte aber auch auf andere Weise und phylogenetisch von jener unabhängig sich ausgebildet haben. Wir sind veranlasst, den Nemertinen vorläufig eine Mittelstellung zwischen den Scoleciden und Cephalidiern zuzuschreiben.

Der Körper der Nemertinen ist langgestreckt, manchmal sogar in extremer Weise, indem er bei einer Dicke von einigen Millimetern eine Länge von mehreren Metern erreicht (Lineus); er ist mehr oder weniger abgeplattet. Durch die äussere Bewimperung und die weiche Körperbeschaffenheit ähneln sie den Turbellarien. Als verschieden gebaute 'Theile des Körpers können wil' unterscheiden: den Vorderleib oder Kopf, der durch das Cerebralganglion, die Wimpergruben, die Mundöffnung und Rïsselöffnung ausgezeichnet ist, und den Hinterleib oder Rumpf, in welchem gewisse Organe - die Darmsäcke, Go- 
naden etc. - sich metamerisch wiederholen, und welcher bei der Larve von geringer Länge erst später bedeutend heranwächst (wahrscheinlich durch terminales Wachsthum). Die Metamerie ist aber bei manchen Formen nicht vollkommen regelmässig und symmetrisch ausgebildet').

Die Schichtung des Körpers zeigt gewisse Unterschiede bei den drei Ordnungen der Nemertinen. Das ursprïunglichste Verhalten findet sich bei den Palaeonemertinen s. str. (Carinelliden). Das äussere Epithel ist Sitz der mannigfachen Pigmentirung und besteht aus Stiitzzellen (sog. Fadenzellen), einzelligen Drüsenzellen und Packetdrïsen und wahrscheinlich auch Sinneszellen. Darunter liegt dic d e rmale Schichte (weniger passend als Basalmembran bezcichnet), d. i. cine Bindesubstanz mit eingelagerten Zellen. Darauf folgt die somatische Muskulatur, bestehend aus äusserer Ringmuskel-

Fig. 372

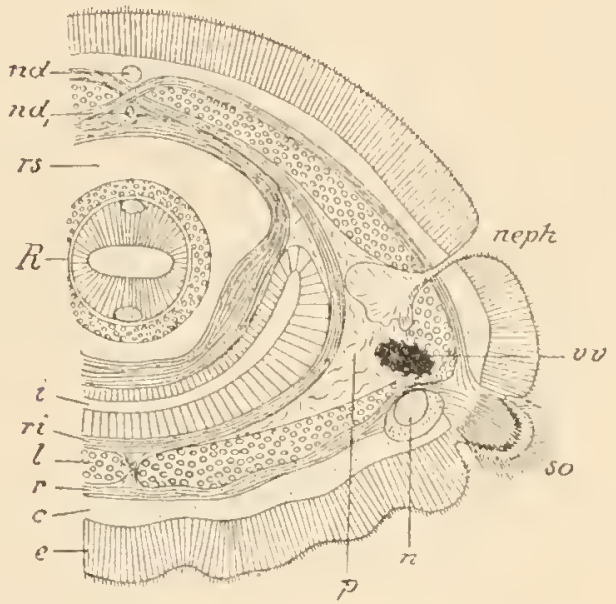

Fig. 373.

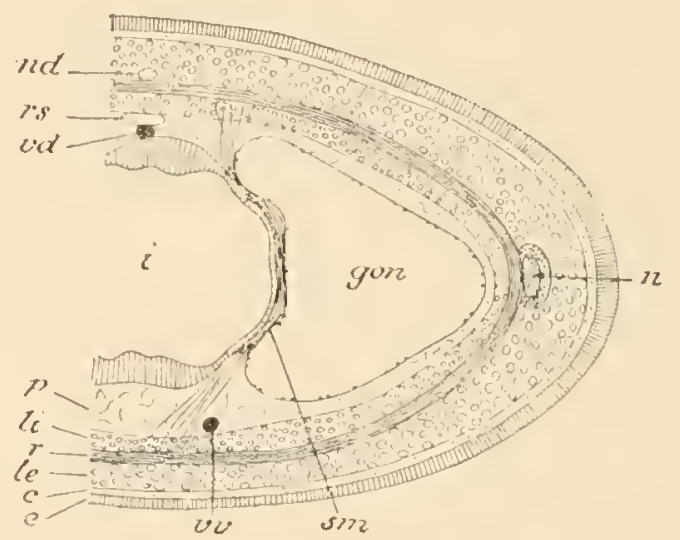

Fig. 372. Carinella annulata, Querschnitt aus der Region der Nephridialporen (nach O. Bürger). $e$ Epithel, $c$ Dermalschichte, $r$ Ringmuskelschicht, $l$ Längsmuskelselicht, vi splanchnische Muskelschichte, $i$ Darm, $r$ 's Höhle der Rüsselscheide, $R$ Rüssel mit Muskelschicht, Epithelschicht und Riisselnerven, nd und nd, grosser und kleinel Rückennerv, $p$ Parenchymschicht, $\leadsto$ Seitenstränge, so seitliche Sinnesorgane, vv laterales Blutgefäss, neph Nephridialmündung.

Fig. 373. Cerebratulus marginatus, Querschnitt aus der Mitte des Körpers. Die Rüsselschcide ist hier schon sehr eng, es ist ein Genitalsack getroffen (nach O. BükGER). $e$ äusseres Epithel, $c$ Cutis, le äussere Längsmuskelschicht, v Ringmuskelschiclıt, li innere Längsmuskelsehicht, $p$ Parenchymschicht, sm splanchnischer Muskel, $i$ Darm, gon Genitalsack, $n$ Seitenstrang, vv ventrale Blutgefässe, vd dorsales Blutgefäss, $r s$ Rüsselscheide, nd Rückennerv.

schichte und innerer Längsmuskelschichte; letztere ist durch radiale Muskelfasern in Fächer abgetheilt, welche zahlreiche Muskelfascrbündel enthalten; die Anordunng dieser selbst ist eine röhrenartige, da die Fasern die äussere Hülle des Bündels bilden und die Muskelkörperchen in die Achse desselben zu liegen kommen (die Entwicklungsgeschichte mïsste noch entscheiden, ob dies in der That Muskclfaserbündel oder etwa vielkernige Muskelfasern sind). Sodann folgt die Parenchymschichte, sie scheidet diese somatische Musculatur

1) Auch beim Regenwurn (Lumbricus terrestris) kommt als abnorme Bildung asymmetrische Metamerie vor, z. B. zwei linke Metamerhälften einer rechten Hälfte entsprechend; auf diese Erscheinung hat mein Assistent Herr Dr. CoRI mich aufmerksam gemacht. 
von einer inneren Ringmushelschichte, die (wie Bühask zeigte) dem Danne zugehört und daher als splanchmische Muskelschichte zu bezeichnen ist. Das Parenchyn besteht aus einer Bindesulstanz mit eingestreuten /ellkürperchen; diese /ellen aber sind rings un cinzche Organc -- die Blutgefässe etc. - gehäuft und dort geradezu cpithelälmlich angeordnet. In der dorsalen und ventralen Mittellinie, wo die Längsmuskelschichte unterbrochen ist, gehen dic Muskelfasern der äussercn Ringmuskelschichte in gekreuztem Verlaufe in die splanchnische Ringmuskulatur über und sie bilden eine Art muskulöses dorsales u ud ventrales Mesenterium (nur bei den Carinelliden). Die splanchnische Muskulatur schliesst nicht nur das Epithelrohr d es Darmes ein, sondern es ist auch innerhalb derselben dic Imuskulöse R iis s e lsch e id e eingeschoben, welche das Rhynchocoel und in diesem den $\mathrm{R}$ üs sel mit allen seinen Schichten enthält (vgl. unten). In der Parenchymschichte liegen die parigen Sackgonaden, die vom Kímepithel ausgekleidet sind (vergl. unten). Von den Blutgefässen sind die seitlichen Gefässe stets zwischen somatischer Muskulatur und Parenchymschichte gelegen (bei den Carinelliden kommen nur diese vor, das dorsale Gefäss, welches nebstdem bei den anderen Nemertinen vorkommt, verläuft zwischen Darm und Rüssclscheide). Das Centralnervensystem, welches in Rumpfe in Form von cinem Paar von Seitensträugen verläuft, liegt bei den Palaeonemertinen stets ausserhalb der Muskelschichten und zwar bei Carinella innen von der dermalen Schichte, bei Carinina sogar noch epithelial (Hubrecu't).

Die Schichtung der Hoplonemertini ist eine äusserst ähnliche, nur liegen die Neiven-Seitenstränge nicht mehr aussen, sondern innen von der somatischen Muskulatur und statt der vollkommenen splanchuischen Nusculatur finden sich nur dorsoventrale Septalmuskeln, die segmentweise zwischen den Darmtaschen auftreten.

Bedeutend verschieden und zwar complicirter ist die Schichtung der Schizonemertini; auch zum Verständniss dieser Verhältnisse ist es nothwendig, von einer Vergleichung mit den Palaconemertinen auszugehen. Wir sehen dann, dass die complicirten Verhältnisse nur darauf beruhen, dass nach aussen vou der Ringmuskelschichte neue Schichten und neue Differenzirungen aufgetreten sind; zumächst ist eine mächtige ä ussere Längs muskelsch ich te hervorzuheben, welche ähnlich wie die primäre innere Längsmuskelschichte gebaut ist; sie geht nach aussen allmählich in die sogenannte $\mathrm{Cu}$ tis über, welche zum Theil noch Längsmuskelı, ferner Bindegewebe und Packetdrüsen enthält; es haben nämlich letztere hier das Epithel verlassen und eine subepitheliale Lagerung gewonnen; hierzu kommen noch dünne subepitheliale Muskelschichten (dicht unterhalb des Epithels). Es ist nicht unwahrscheinlich, dass alle diese neuen Schichten aus einer Differenzirung der dermalen Schichte hervorgegangen sind. Die splanchnische Schichte ist auch hier nur durch Septalmuskeln vertreten. Die Seitenstränge liegen stets noch ausserhalb der Ringmuskelschichte.

Der R üssel, welcher durch eine Oeftnung am Vorderende des Körpers ausgestülpt werden kann, ist eine für die Nemertinen typische Bildung; er ist als eine Einstülpung ler Körperwandung zu betrachten, deren Schichtung sich an ihm oft in vollkommener Weise wiederholt (am eingestülpten Rüssel in ungekehrter Reihenfolge). Der Rüssel der Palaeonemertinen und Schizonemertinen ist weniger stark ausgebildet, oft nur kurz und auf das Vorderende des Körpers beschränlit (sowie 


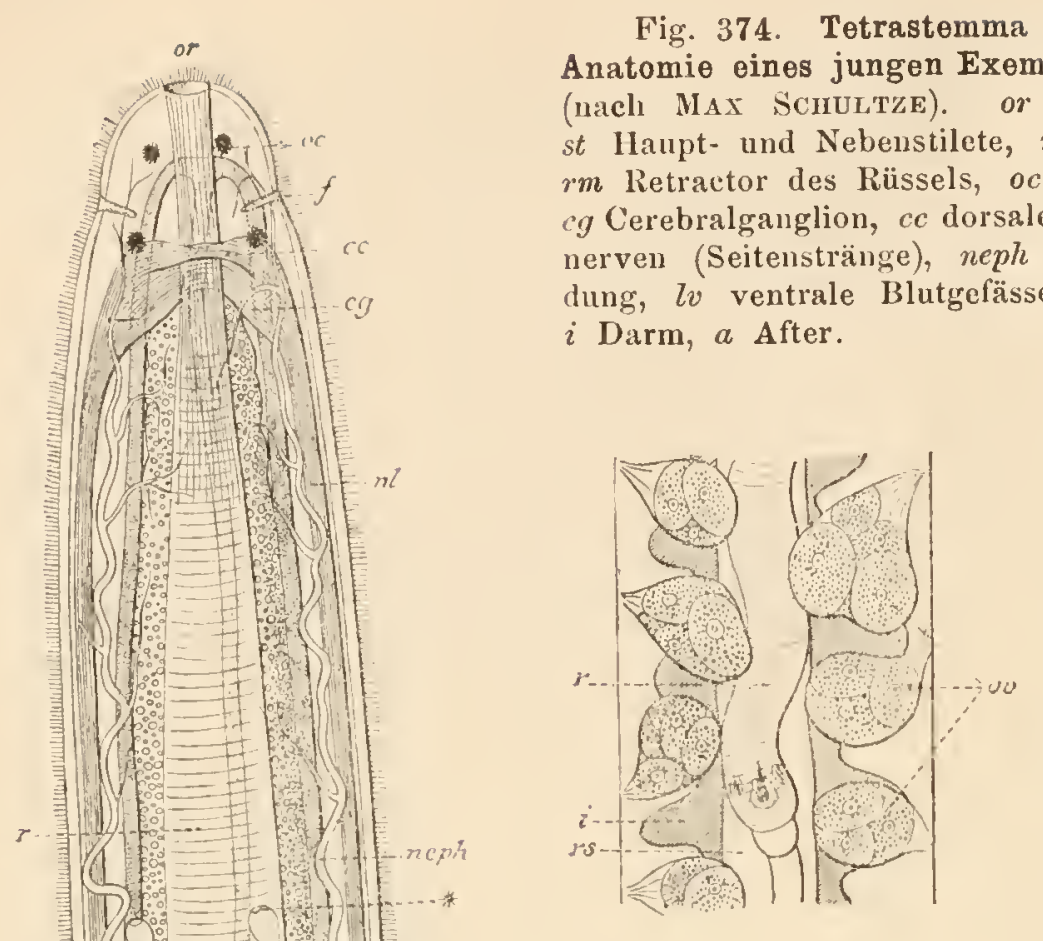

Fig. 375. Ein Stück des Körpers eines geschlechtsreifen Thieres (Tetrastemma), nach MAX Schultze. $r$ Rüssel, $r s$ Rüsselscheide, $i$ Darmtaschen, $o v$ mit diesen alternirende Ovarialsäcke.

auch die Rüsselscheide); er ist mit Nesselorganen (Rhabditen) ausgestattet. Der mächtig entwickelte, meist gewundene Rüssel der Hoplonemertinen besitzt eine bedeutende Länge, welche oft die des Körpers uibertrifft; er gliedert sich in mehrere Regionen, die vordere stellt den ausstiilpbaren Theil dar, welcher in seinem Grunde mit bestimmt angeordueten Stileten (Hauptstilet, Nebenstilete) versehen ist, die bei der Ausstülpung an die Spitze zu liegen kommen; es folgt eine drüsige Region (Giftdriise) und der Retractormuskel, welcher den ausgestülpten Rüssel wieder einziehen kanı. Im Ruhezustand liegt der Rüssel in der über dem Darme verlaufenden Rüsselscheide, die aus einer Muskelschichte und einer inneren, das Rhynchocoel auskleidenden epithelähnlichen Schichte besteht. - Oberhalb der Rüsselöffnung mündet manchmal eine eigenthümliche Kopfdrüse aus (Eupolia).

Das Nervensystem ist mächtig entwickelt, es besteht aus dem Cerebralganglion und den Seitensträngen (oder „Seitenstämmen“), welche durch die ganze Iänge des Körpers sich erstrecken und oft über dem After sich vereinigen. Das Cerebralganglion besteht aus mehreren Ganglien, nämlich aus einem paarigen ventralen und einem paarigen dorsalen Ganglion; das ventrale Ganglienpaar geht nach hinten direct in die Seitenstränge über, es ist durch eine unterhalb der Rüsselscheide gelegene Quercommissur (die "ventrale Gehirncommissur") verbunden; das dorsale Ganglienpaar ist durch eine über der Rüsselscheide verlaufende Quercommissur („dorsale Hirncommissur") verbunden, die 
Rüsschüundung ist daher vom Cerebralganglion ringförmig umgeben; es besitzt einen mehr oder weniger deutlich gesonderten hinteren Lappen (Ricchlappen), welcher in nähere Beziehung zu den cerebralen finmmergruben tritt; bei den $\mathrm{Hop}$ o 0 n e m e r ti n e $n$ ist aber cin diesen hinteren Lappen entsprechendes, ganz sclbständiges Ganglion vorlıanden. - Dic Seitenstränge sind in ilner ganzen Länge mit Ganglienzellen versehen und zwar mit einer lateralen und einer medialen Gangliensäule; der histologische Aufbau stimmt in hohem Grade mit dem des Bauchmarkes bei den Anneliden iiberein (äussere Gliahülle oder Neurilemm, innere Gliahülle, centrale Fasermasse, Gangliengruppen, colossale Achsencylinder oder Neurochorde, colossale Ganglienzellen oder Neurochordzellen). - Vom Gehirn gehen erstens Nerven aus, die zu den Sinnesorganen des Kopfes ziehen, ferner aber die Schlundnerven und besondere Rüisselnerven, endlich ein grosser und ein kleiner me-

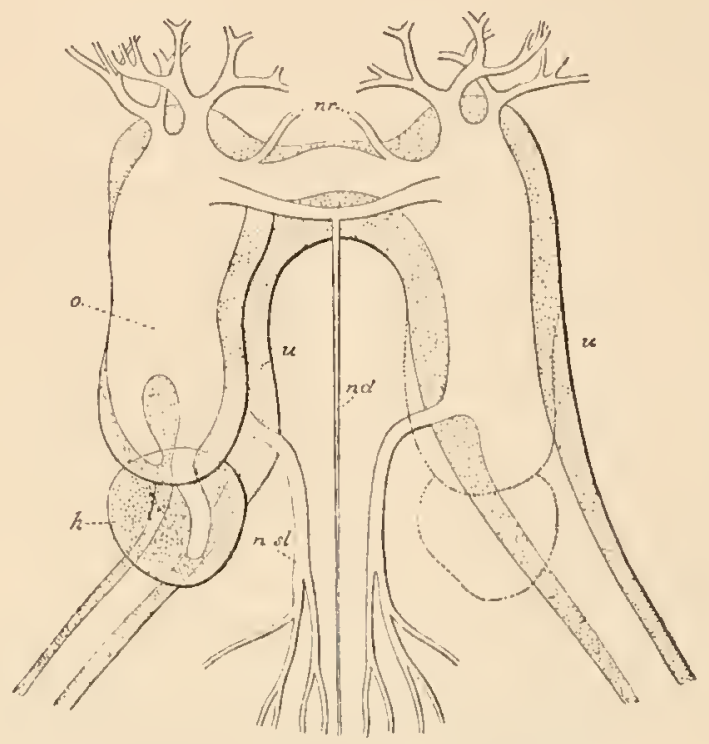

Fig. 376. Cerobralganglion von Cerebratulus (nach HubrechT), schematisch. $u$ unteres Ganglion (Commissuralganglion), o oberes Ganglion, $h$ binteres Ganglion (Riechlappen), $n s l$ Schlundnerv, $n r$ Rüsselnerv, nd Rückennerv. diancr Rückennerv, der durch

die Länge des Rumpfes sich erstreckt. Von den Seitensträngen gehen metamere Ringnerven ab, die auch mit dem Rückennerven sich verbinden; statt dieser ist zwischen den Schichten der somatischen Musculatur oft ein reicher Nervenplexus als eine förmliche Nervenschichte entwickelt.

Von Sinnesolganen finden wir am Kopfe: A ugen, von inversem Typus (ähnlich denjenigen der Turbellarien) in verschiedener Kahl. Paarige, dem Gehirn anliegende $\mathrm{Hörbläschen} \mathrm{kommen} \mathrm{bei}$ Oerstedtia vor. Sodann dic cerebralen Flimmergruben, meist ,Seitenorgane" genannt, welche - wie Dewolexzky nachgewiesen hat - die Function von Geruchsolganen haben; diese Organc, welche innig mit dem Riechlappen des Gehirns sich verbinden, sind typisch für die Nemertinen und besitzen bei denselben eine höhere Ausbildung als bei irgend welchen anderen Thieren, nur bei den Palaeonemertinen sind es einfachere Flimmergruben; meist münden sie mittelst eines Flimmerkanales nach aussen; bei den Schizoncmertinen öffict sich dersclbe in der 'Tiefe der sogenannten seitlichen Kopfspalten; sic besitzen ausser den Sinnesepithelien Drüsenmassen und sind mit sackartigen und schlauchartigen Frweiterungen verschen. Sinnesgrübchen (Simnesknospen) finden sich besonders am Kopfe. Carinella besitzt ein Paar von seitlichen Sinnesorganen in der Nähe der Nephridialmündungen.

Der D armkanal ist durchaus bewimpert und verläuft geradegestreckt durch den Körper. Die Mundöffinung liegt an der Ventralseite (entweder hinter der Hirnregion oder auch vor derselben), selten ist sie mit der Rüsselöffnung vereinigt (Malacobdella, Prosadenoporus); 
sie fühnt in den einfachen Oesophagus; der nächste Abschnitt ist der Mitteldarm (Cliylustarn), der mit seitlichen, oft streng metaner angeordneten 'Taschen versehen ist, die mehr oder weniger' ausgeprägt vorkommen und nur bei den Carinelliden gänzlich fchlen; die Hoplonemertini besitzen ferner einen unparen, vorderen, ventralen Dirnbindsack. Ein kurzer Enddar'n muindet direet in die am Hinterende dus Körpers gelegene Afteröffnumg (ohne Vermittlung eines nachweisbaren ectodermalen Afterdarmes).

Das Blutgefässsystem besteht aus einem unpaaren dorsalen Gefäss, in welchem das Blut von hinten nach vorn strönt (dasselbe fehlt bei Carinella) und paarigen seitlichen Gefässen, in welchen die Riclitung des Blutstromes die umgekelirte ist (bei Vog'r und Jung finde ich eine entgegengesetzte Angabe). Dieselben sind im einfachsten Falle durch vordere und hintere Gefässbogen verbunden; oft kommen auch sugmentale Quergefässe und ein reiches Gefässnetz des Kopfes hinzu. Die Gefässe sind mittelst eigener Muskelschichte contractil; sie besitzen eine innere epithelähnliche Auskleidung; das Blut enthält meist grosse gefärbte Bluthörperchen.

Der Excretionsapparat wurde in einer älteren Arbeit von Max Schultze bei dem kleinen durchsichtigen Tetrastemma als gauz ähnlich dem Wassergefässsystem der Platoden dargestellt. Neuere Untersuchungen haben jedoch bei den grösseren Formen nur in der Region des Oesophagus je einen seitlichen kurzen wimperıden Kanal nachgewiesen, der an seinem Hinterende nach aussen mündet. Kurze Seitenäste desselben stehen mit dem seitlichen Blutgefüss in inniger Verbindung (es wurde auch eine Communication mit demselben behauptet). In manchen Fällen kommen mehrfache äussere Mündungen vor (metamer?).

Der Geschlechtsapparat der Nemertinen, welche meist getrenntgeschlechtlich, selten Zwitter sind, ist äusserst einfach. Die paarigen Gonaden liegen seitlich innerhalb der Parenchymschichte; sie wiederholen sich metamerisch, indem sie mit den Darmtaschen alterniren ${ }^{1}$ ), meist kommt nur ein Paar, oft aber auch mehrere auf ein Segment; sie besitzen jede ihren besonderen Ausführungsgang, der seitlich odel mehr dorsal nach aussen mïndet und meist erst bei vollendeter Geschlechtsı'eife zur Entwicklung kommt. Bei den Palaeonemertinen sind die Gonaden ihrer Anlage nach compacte, dem Parenchyn

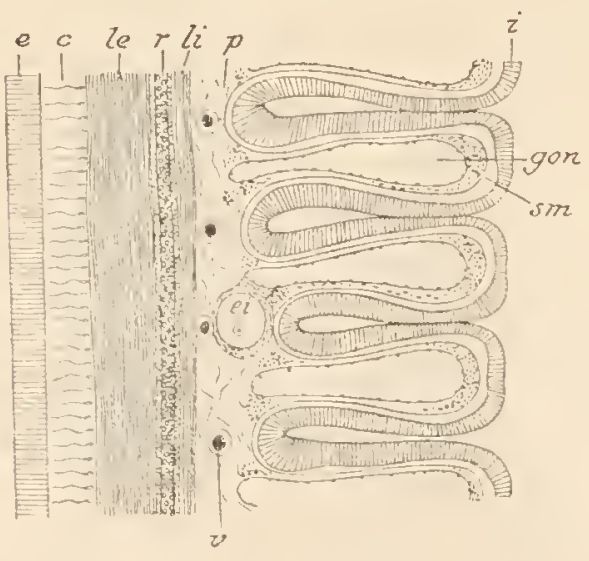
eingelagerte \%ellhaufen, die crst mit der Reifung der Geschlechtsproducte zu Sïcken sich erweitern; bei den anderen

Fig. 377. Cerebratulus marginatus, Hälfte eines frontalen Längsschnittes aus der Mitte des Körpers (nach O. BürGER). $e$ äusseres Epithel, c Cutis, le äussere Läugsmuskelschicht, $r$ Ringmuskelschicht, $l i$ innere Längsmuskelsehieht. p Pcritonealschicht, $v$ quere Blutgefässe, gon Genitalsäcke, die mit den Darmtaschen alterniren, ei ein Ei, das sich in einem Follikel entwickelt, sm splanchnische Musken, $i$ Darmepithel.

1) Die Darmtascheu und die Blutgefässschlingen liegen septal, die Genitalsäcke und die dorsoventralen Muskelbündel dagegen interseptal (vergl. Fig. 377). 
Nemerlinen aber tinden sich schon trüher goräunige Säcke, von einem Epithel ausogkleidet, welches erst später die Geschlechtsporoducte liefert (ähnlich dem Peritoncalepithel, welches dic Leibeshöllle bei deı Amneliden auskleidet).

Die Frage, welche Bildungen der Nemerlinen utwa dem Peritoneum und der Leibeshöhle der Anneliden entsprechen mögon, kmn noch nicht endgiltig beantwortet werden. Das Khyuchocoel, welches manchinal segmentale Aussackungen besitzt, wurde erst neuerdings wieder in dieser Bezichung hervorgehoben; doch ist diese Anschaunng auszuschliessen, denn die Rüsselscheide ist phylngenetisch wohl erst mit der Rüsselbildung aulgetreten und hat sich wohl zugleich mit dem Rüssel erst allmählich nach hinten zwischen die anderen Schichten eingeschoben; sie kommt daher für die Vergleichung der typischen Körperschichtung nicht in Betracht. Ilan hat ferner das Parenchym als Homologon des Peritoneums betrachtet, und es ist daran zu erinnern, dass die Parenchymzellen rings um gewisse Organe schon eine epithelähnliche Anordnung zeigen. Ich neige aber mehr zu dor Ansicht, dass speciell das Epithel der Sackgonaden dem Peritonealepithel zu vergleichen sei.

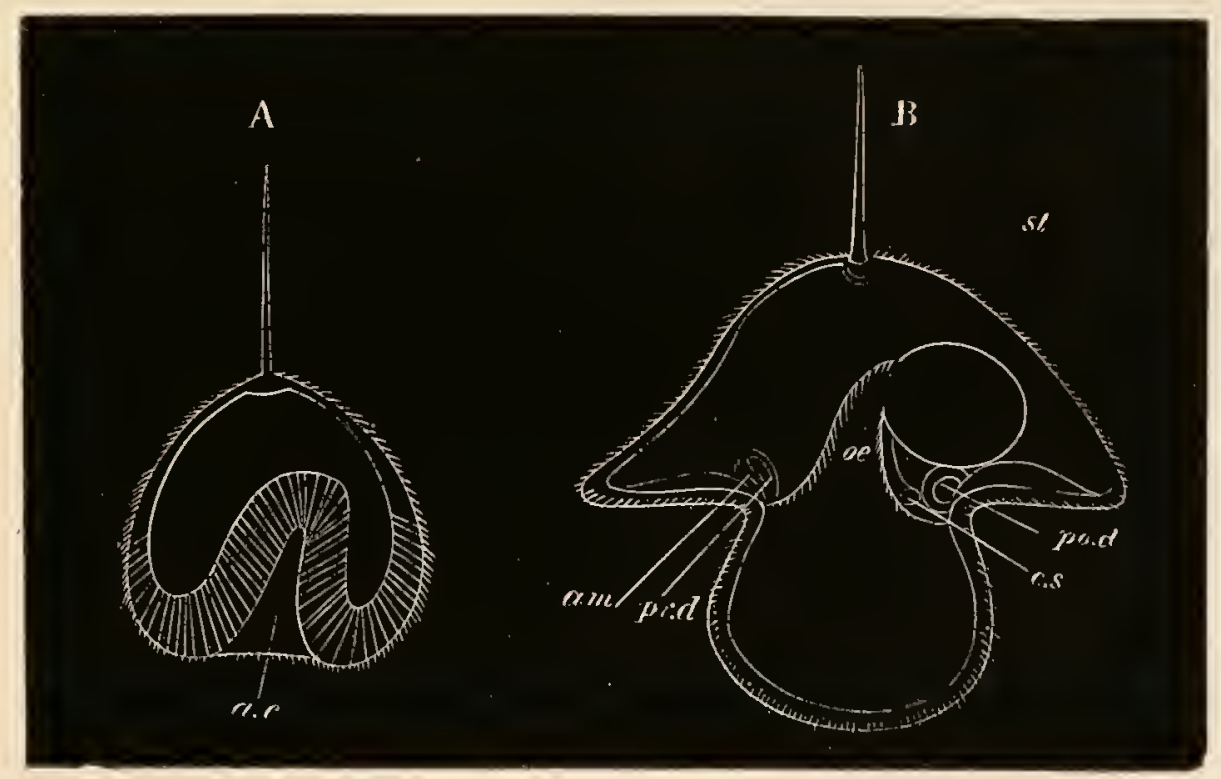

Fig. 378. Zwei Entwicklungsstadien von Pilidium (Hach METSCHNIKUEF aUs BALFUUR's Ilandbuch). ae Urdarm, oe Oesophagus, st llagen, ane Amnion, prod und pod vordere und hiutere Embryonalscheibe, cs Flimmergrube.

Die Nemertinen legen ihre kleinen dotterarmen Eier meist in unfangreichen Laichmassen ab; einige sind lebendig gobärend. Die En tw icklung erfolgt nach drei verschiedenen Typen: 1) En twicklung mittelst Pilidium-Larve (Lineus, Nenertes). Durch adäquale Furchung entsteht eine Blastula, an welcher frühzeitig das Mesoderm auftritt: durch Invagination bildet sich die Gastrula. Diese entwickelt sich wciter zu ciner Larve, die morphologisch der Protrochula entspricht; sie wird als Pilidium bezcichnet und zeigt gewisse Besonderheiten ihrer Gestalt, welche mit der eines Fechterhutes verglichen wird. Es ist nämlich das gewölbte Scheitelfeld mit einem ITimperschopfe versehen; der präorale Wimperkranz (der nach SALEssky einen Ringruerven besitzt) ist in melrere Lappeu, und zwar einen dorsalen, einen ventralen und in ein seitliches Lappenpaar ausgezogen, das Gegen- 


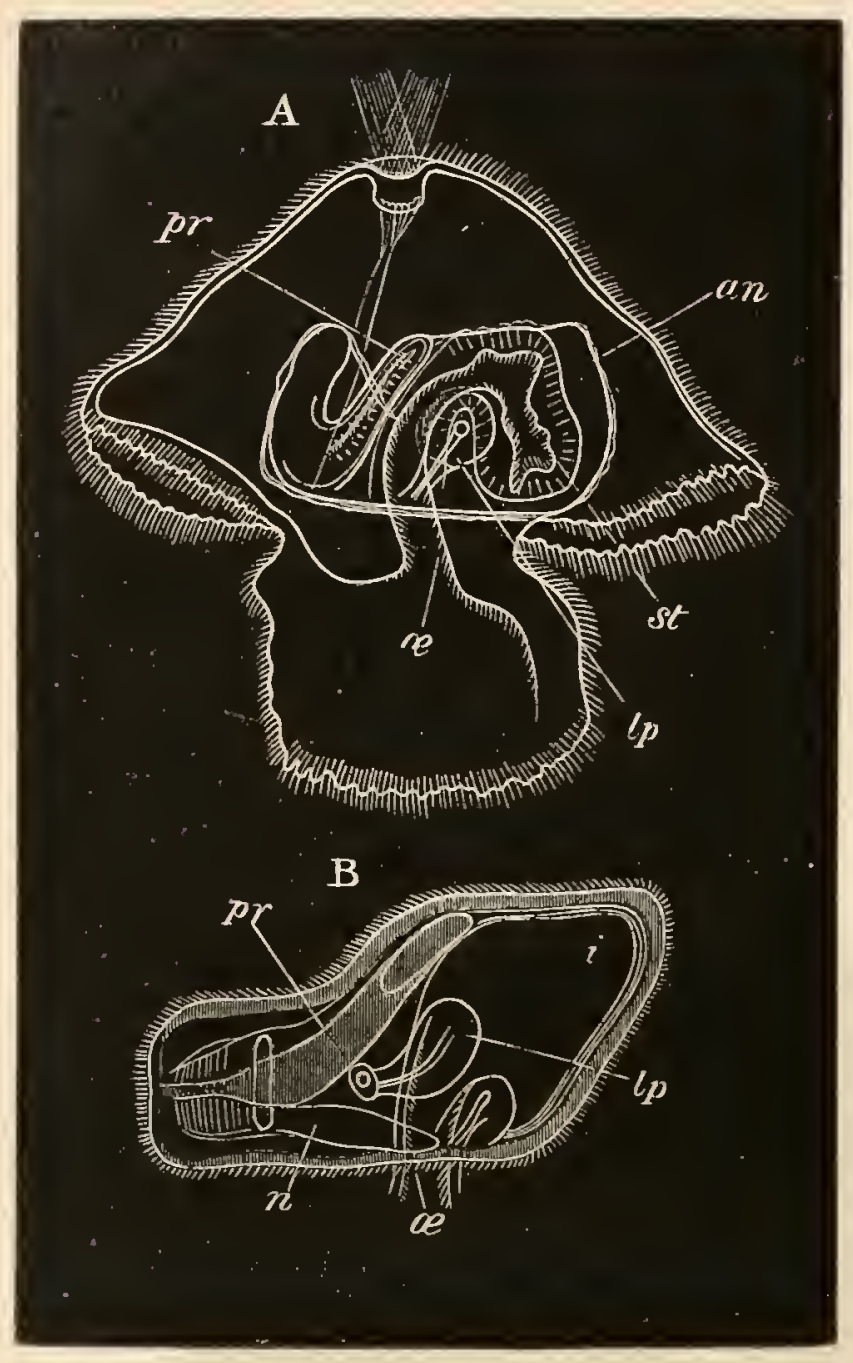

Fig. 379. A Pilidium, mit einem bereits ausgebildeten $\mathrm{Ne}$ mertinenembryo. $\boldsymbol{B}$ Reifer Embryo von Nemertes in der Lage, welche or innerhalb des Pilidiums einnimmt. oe Oesophagus, st Magen, $i$ Darmkanal, $p r$ Rüssel, $l_{p}$ Seitengrube, an Amnion, $n$ Nervensystem. (Nach Bǘtschli aus Balfour's Handbuch.)

feld ist nicht vorgewölbt, sondern zwischen diesen Lappen eingezogen; der Mund liegt nur wenig excentrisch, die wimpernde Speiseröhre führt in einen rundlichen, blindgeschlossenen Magendarm; von der apicalen Ectodermverlickung (Scheitelplatte) zieht ein paariger Muskelstrang nach hinten. - Dic Entstehung der Nemertine aus der Pilidiumlarve geschieht unter bemerkenswerthen Vorgängen. Es bilden sich am Gegenfeld zwei Paar verdickte Ectodermplatten, ein vorderes Paar vor dem Munde und ein hinteres Paar hinter dem Mundle. Diese vier Eubryonalplatten (oder Körperplatten), an welchen sich auch indiffer'ente Mesodermzellen häufen, werden durch einen Einstülpungsprocess in die Tiefe verlegt und repräsentiren die Anlage der Körperwand der Nemertine; dazu kommt noch ein mittleres Paar, welches die Flimmergruben liefert. Das Umschlagsblatt, mittelst dessen die Embryonalplatten mit der Leibeswand des Pilidiunıs zunäclist noch in Zusammenhang bleiben, wird als Amnion bezeiclınet. Die ursprünglich getrennten Fmbryonalplatten verwachsen miteinander zu einem kahnförmigen Gebilde, welches den Pilidiumdarm umgibt und damn über demselben sich schliesst. So entsteht im Inneren der Amnionhölıle rlie junge Nemertine; an derselben bildet sich ferner der Rüssel als eine vordere Finstiilpung ihrer Leibeswand und das Cerebralganglion als eine Abschnürung vom Ectoderm, die weiter in die Seitenstränge auswächst ${ }^{1}$ ). Die alte Körperwand des Pilidiums und auch die Amnionhülle wird dann abgeworfen, wodurch ein rascher Uebergang von der freischwimmenden Larve zu der kriechenden Nemertinenform stattfindet. Dabei ist es auffallend, dass umfangreiche und anscheinend bedeutungsvolle Tlıeile, wie z. B. die Scheitel-

1) Bei dem späteren andauernden terminalen Wachsthum der Nemertine wachsen auch die Seitenstränge an ilırem Hinterende fort; währeud bei den Anneliden aı dem wachseıden Hinterende nur drei Primitivanlagen, das Ectoderm, Endoderm und Mesoderm sich betheiligen, sind hier die Wachsthumspunkte der Seitenstränge als selbständige gesonderte Anlagen vorhanden; vielleicht sind schon die ersten Bildungsvorgänge der Seitenstränge in ähnlichem Sinne aufzufassen. 
platte verloren gehen, so dass das Cerebralganglion ganz unabhängig von derselben sich bildet. Nan hat daraus geschlossen, dass dasselbe nicht den Cerebralganglion der Anneliden entspreche (an dessen Bildung sich die Scheitelplatte betheiligt); wir lialten diesen Schluss abcr nicht für herechtigt, da wir die Vorgänge der Fntwicklung hier als embryonale Abstossung eines Körpertheiles mit vorzeitiger Regeneration desselben erklären; älnlich sind die Vorgänge bei Echinodermen, Sipnnculnes etc. zu beurtheilen und auch die Bildung der Fmbryonalhiillen bei Insecten und bei Wirbelthieren.

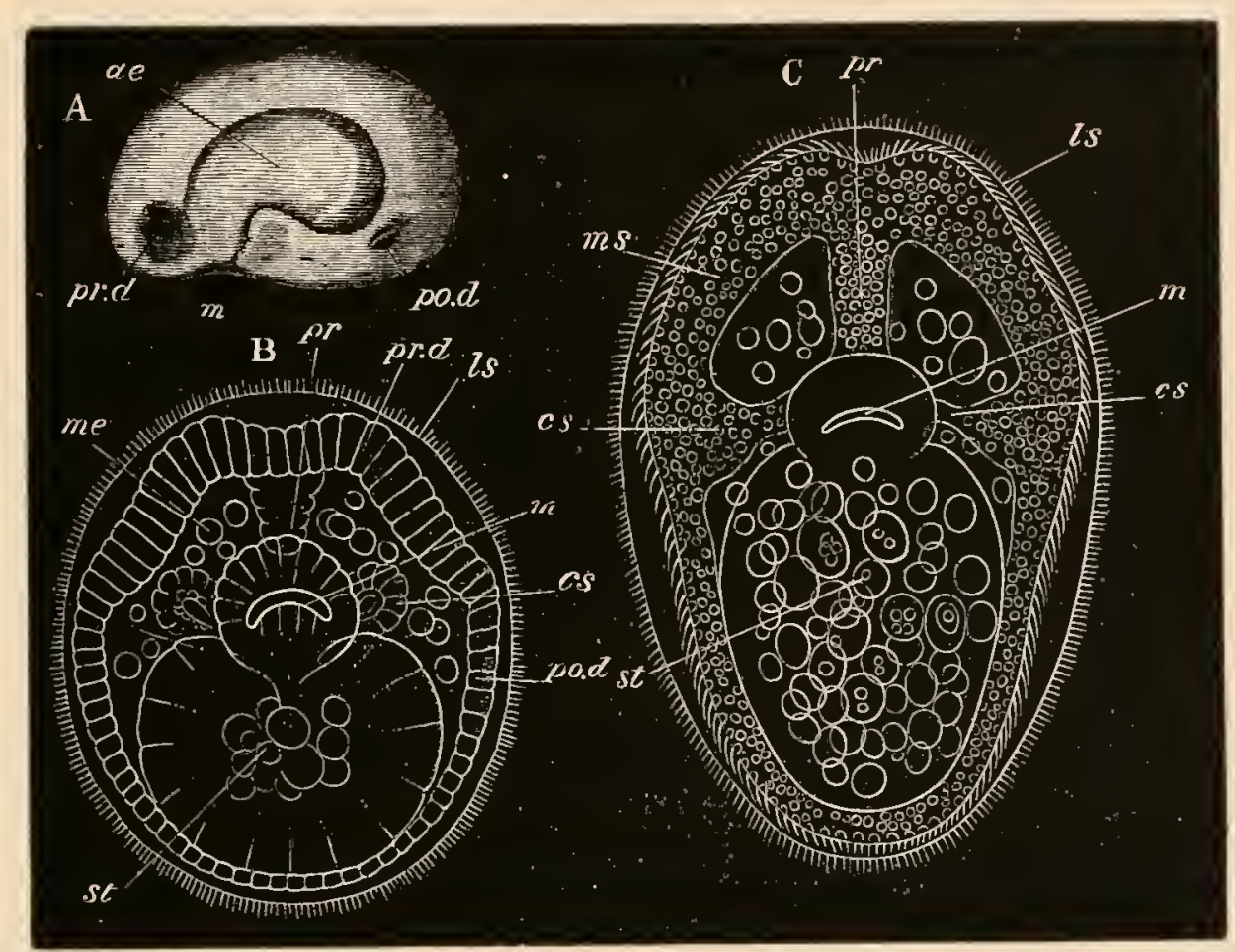

Fig. 380. Drei Entwicklungsstadien von Lineus (nach BArroIs aus BALFour's Handbuch). $\boldsymbol{A}$. Seitliche Ansicht des Enbryos anf einem sehr frihen Stadim. $\boldsymbol{B}$ und $\boldsymbol{C}$ Zwei spütcre Stadien, von der Bauchfläche gesehen. ae Urdarm, $m$ Mund, prd und pod vordere und hintere Embryonalscheibe, cs Flimmergrube, $p v$ Rüssel, me Mesoderm, $l s$ Embryonahülle, ms Muskelschichte, st Magen.

2) Entwicklung nacli dem Desor'schen'Typus(Lincus); die ganze Entwicklung wird hier innerhalb der Laichmassen vor dem Verlassen der Eihülle durchlaufen; eine ausgeprägte Pilidiumlarve ist hier nicht vorhanden, doch sondert sich auch hier das Ectoderm in eine :iussere wimpernde Embryonalliüle und eine Mehrzahl von Embryonalscheiben, welche letztere durch eine Art von Einstïlpung in die Tiefe verlegt werden und durch Verwachsung die Leibeswand der Nemertine billen. Die äussere bewimperte Embryonalhülle ist als reducirter Pilidiumleib zu betrachten (das Umschlagblatt, oder Amnion, fehlt hier).

3) Directe Entwicklung (bei verschiedenen Nemertinenformen). Bei diesem Typus entsteht aus dem gesammten Zellmateriale die junge Nemertine. In einigen Fällen wurde aber auch hier die Abstossung einer äusseren wimpernden \%ellage beobachtet, so dass dieser Entwicklungstypus vielleicht doch noch enger an die vorerwähnten sich anschliesst. 
In allen Fällen besitzt die junge Nemertine nur einen ganz kurzen Hinterleib, der den Vorderleil an Länge laum übertrifft; erst durch das spätere Wachsthum macht er ein vielfaches desselben aus.

Man hält die Pilidiumentwicklung für den ursprünglichsten, den Desor'schen Typus für den abgeleiteten und die directe Entwicklung für den am meisten modificirten Typus. Dies ist mit den Verwandtschaftsverlıältnissen der einzelnen Gattungen bis jetzt noch nicht in Uebereinstimmung zu bringen. - Die Pilidiumlarve entspricht, wie erwähnt, der Protrochula. Eine speciellere Vergleichung aber mit jüngeren Polycladen-Larven (Stylochus pilidium) ist nicht in der von GöT"re versuchten Weise durchführbar (LANG).

Die meisten Nemertinen leben im Meere in Schlupfwinkeln, unter Steinen u. S. w. ; nur wenige Arten sind Land- und Süisswasserbewohner. Sie ernähren sich räuberisch von Würmern, Mollusken u. dgl.; wenige sind Parasiten (Malacobdella, Carinella galateae).

\section{Systematische Uebersicht der Nemertinen.}

I.'Palaeonemertini (s. str.). Olnne äussere Längsmuskelschichte; Seitenstränge ausserhalb der Muskelschichten (dermal oder sogar epithelial) gelegen. Mund hinter den Cerebralganglien, Riissel unbewaffnet, ohne Kopfspalten.

Carinina, Carinella. (Polia ist zu der nächsten Ordnung zu ziehen, die Stellung von Cephalollirix und Valencinia ist noch unbestimmt.)

II. Schizonemertini. Mit äusserer Längsmuskelschichte; Seitenstrïnge zwischen dieser und der Ringmuskelschichte gelegen. Mund hinter den Cerebralganglien, Riüssel unbewaffnet; meist mit Kopfspalten.

Polia ohne Kopfspalten; Lineus, Cerebralulus etc. mit Kopfspalten.

III. Hoplonemertini. Ohne äussere L:ingsmuskelschichte; Seitensträuge innerhalb von den Muskelschichten (im Parenchym) gelegen. Mund in der Regel vor den Cerebralganglien, Rüssel bewaffnet.

Irepanophorns, Tcirastemma, Oersledtia, Nemerles itc.; Malacobdella, parasitisch in der Kiemenhöhle ron Muscheln, der kurze Körper mit einem hinteren Saugnapf, liüssel unbewaffnet. 


\section{SECIIZEHNTES CAPITEL.}

\section{Subtypus der Zygoneura (5., 6. und \%. Cladus der Metazoa).}

\section{Cephalidia (= Aposcolecida).}

Die Cephalidier sind Zygoneuren mit secundären () rgansystemen, nämlich mit parrigen Peritonealsäcken, mit Metanephridien, mit Blutgefüsssystem, meist mit epithelogenen (vom Coelomepithel abstammenden) Muskeln nnd meist mit Bauchmark. - Der Gegensat\% zweier Körpertheile, des Prosoma mit den primären Trochophora-Organen, die zum Theil nur als provisorische ()rgane dienen, und dem Metasoma mit den secundïlen ()rgansystemen ist in der Entwicklung oft deutlich ausgeprägt, in anderen Fällen aber durch Unterdrückung der provisorischen Organe mehr verwischt.

Wir vereinigen hiermit mehrere grosse Abtheilungen, welche man wohl vielfach auch ,höhere Wirbellose" genannt hat, die wir aber nach unserem System genauer" als "höhere Zygoneuren" bezeichnen würden. Eine systematische Zusammenfassung dieser Gruppen wurde schon von iilteren For'schern, besonders von Lamarck und von LATTLEILLe versucht, begegnete aber später ernstlichem Widerspruche ${ }^{1}$ ) und ist aus den neueren Systemen ganz verschwunden. Wenn wir jetzt auf Grmul mancher neuer Gesichtspunkte dieselbe Aufstellung vorliehmen, so be-

1) LEUCKART schreibt in seiner berühmten Sehrift (,Ueber die Morphologie der niederen Thiere" 1848): „Die Aehnlichkeit der Arthropoden und Würmer ist nach meiner Ansicht ohne allen ticferen Zusammenhang." _ _ _ _ _ ,Immerhin aber beruht die Vereinigung der Wiirmer nnd der Gliederfuissler auf ciner bestimmten Achnlichkeit in der äusseren Form, auf einer Aehnlichkeit, welche durch die - nach der typischen Bedeutung allerdings etwas differirende - Verwendung eines gleichen morphogenetischen Vorganges bedingt ist. Aus diesem Grunde mag denn auch jenes Verfahren bis zu einem gewissen Punkte immer noch vertheidigt werden kömnen. Wenn aber LAMARCK, LATreille und Carus den Arthropoden und Anneliden noeh die Mollusken hinzufigen und aus diesen drei Gruppen eine einzigc gemeinschaftliche Abtheilung (Animaux sensibles I_AM., Cephalidia IAstr., Corpozoa Car.) bilden, so wird daraus ein blosser irrationaler Haufen von Formen, dessen innere Gelialtlosickeit zu offen am Tage liegt, als dass noch cin Wort dariber zu verlieren wäre" (l.c. p. 78, 79). 
trachten wir dies als eine Restitution, und wir wollen den von LATRELLAE gebrauchten Namen Cephalidia als den passendsten vorziehen.

Der Zusammenhang der Cephalidier mit den Seoleeiden ist dadurch sicher begründet, dass bei viclen derselben die Trochophoraform als Larve vorkommit; die Cephalidier durchlaufen demnach ein ScolecidenStadium. Wir sehen sodann eine Anzahl secundärer, für die Cephalidier charakteristischer Organe auftreten. Die Frforschung der ontogenetischen Entwicklung dieser Organe und die phylogenetische Ableitung derselben, d. i. ilre Beziehungen zu den primären 'Trochophoraorganen, bildet den Inhalt des hier vorliegenden morphologischen Problems, welches gegenwärtig aber noch leineswegs vollständig und endgiltig beantwortet ist.

\section{Primäre und secundäre Organe der Cephalidier.}

Bei der Entwicklung der Cephalidier finden wir die primären oder 'Trochophoraorgane (welche wir als solche in einem früheren Capitel charakterisirt haben), dieselben sind aber zumeist anf einen vorderen Körperabschnitt beschränkt, den wir als Prosoma bezeichnen. Einige dieser Organe gehen nicht in die definitive Organisation über, sondern dienen stets nur als Larvenorgane und werden später rückgebildet; dies gilt besonders von dem Protonephrirlium (welches wir auch als Kopfniere oder Prosomniere bezeichnen) und wohl auch von den primären Längsmuskeln. - In einem hinteren Liörperabschnitt, dem Metas o ma, entwickeln sich eine Anzahl s e c und ärer Organe. Die meisten der hier in Frage kommenden Gebilde sind Differenzirungen der paarigen, zunächst auf das Metasoma beschränkten Coelomsäcke und diese sind es, die wir zuerst betrachten wollen.

Das Perito nealepithel, welches direct von dem Coclomepithel gebildet wird, unschliesst die Leibeshöhle oder Coelomhöhle; es berleckt nicht nur die innere Fläche der Leibeswand und die äussere Fläche des Darmes, sondern auch die Mesenterien (dorsales und ventrales), welche den Darm suspendirt halten; es sind dies longitudinale Scheidewände, welche durch die paarige Anlage der Coelomsäcke bedingt sind; ebenso verhält sich das Peritonealepithel auch zu den queren Scheidewänden oder Dissepimenten, welche besonders die hinter einander sich wiederholenden Coelomhöhlen der Anneliden von einander scheiden.

Das K eimepithel der Gonaden ist in ursprünglichen Fällen, z. B. bei vielen Anneliden, nur eine besondere Stelle des Peritonealepithels.

Fig. 381. Schema der Entwicklung eines Cephalidiers. $m v_{1}$ und $m d_{1}$ primärer ventraler nud dorsaler Längsmuskel, $m v_{2}$ und $m d_{2}$ secundiirer ventraler und dorsaler Längsmuskel, $p n$ Prosomniere, $m n$ Metasomniere, sc Schlundeommissur, bm 13anchmark, pe Peritonealepithel, gon Keimepithel.

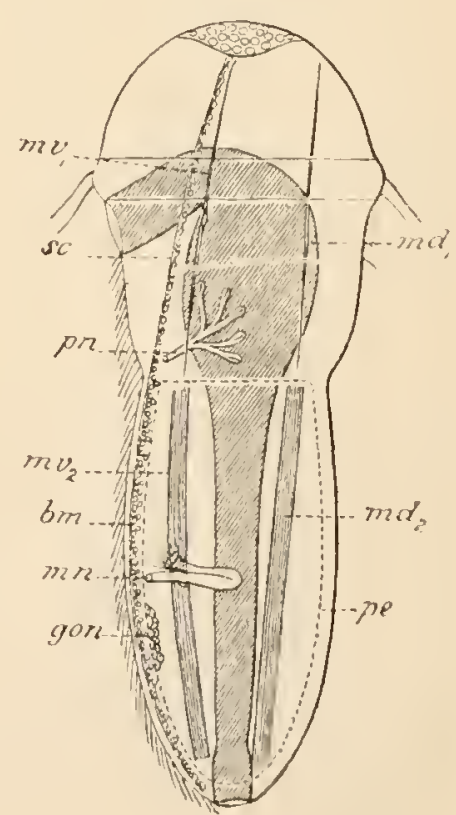


Die Metanephridien sind paarige Röhren, welche einerseits mit den Coelomhöhlen durch je einen offenen Trichter zusammenhängen, welcher eine direkte Fortsetzung des Peritonealepithels ist, und andererseits durch eine ziveite Oeffnung an der Körperoberfläche nach aussen münden. Sie fungiren nicht nur als Nieren, sondern werden vielfach auch zur Ausführung der Geschlechtsprodukte aus der Leibeslıöhle verwendet; ja es ist eine immer wiederholte Frage, inwiefern die directen Ausführungsgänge der Gonaden, die wieder bei den höheren Typen der Cephalidier, z. B. bei den Arthropoden und Mollusken sich finden, etwa durch Umbildung von Metanephridien entstanden sind. - Die morphologische Ableitung der Metanephridien ist noch nicht endgiltig aufgeklärt; nach der einen Ansicht sind dieselben als Wiederholungen oder als Abgliederungen der Protonephridien entstanden, welche aber durch die secundär vom Peritonealepithel entwickelten Flimmertrichter mit der Coelomhöhle in neue Verbindung getreten sind (HATSCHEK, E. MEYER); nach einer anderen Anschauung sind sie in ihrer Gänze als Ausstülpungen des Peritonealepithels, die nach aussen durchgebrochen sind, zu betrachten (O. und R. HerTwig, Sengwick, EISIG, BERGH).

Als epithelogene, vom Coelomepithel abstammende Muskeln müssen (wenigstens bei den Articulaten) beträchtliche Theile der Körpermuskeln betrachtet werden, und zwar sind dies vornehmlich die Längsmuskeln des Körpers. Bei Polygordius sollen schon an dem einschichtigen Peritonealepithel Muskelfibrillen an der Basalseite der Zellen entstehen, und später erst eine Sonderung von Muskelzellen und Peritonealzellen erfolgen; über dieses wichtige Verhältniss bestehen aber nur erst vereinzelte Beobachtungen.

Es ist wahrscheinlich, dass diese Muskeln coelomatische Bildungen sind, welche als secundäre substituirende Organe für die ursprünglich auch in das Metasoma sich erstreckenden primären (mesenchymatischen) Längsmuskeln eintreten. Es wäre aber auch denkbar, sie als Wiederholung der primären Längsmuskeln des Prosoma zu erklären; in diesem Falle müssten aber die primären Längsmuskeln einer veränderten Auffassung unterliegen; man müsste etwa auch diese für epithelogene Gebilde halten, die sich aber von ihrem coelomatischen Mutterboden schon frühe vollkommen emancipirt hätten; dies würde ferner auch in Bezug auf die Morphologie der gesammten Scoleciden zu einer veränderten Auffassung führen.

Sowohl die äus s e ren Muskelschichten der Körperwand - und zwar sind dies besonders Ringmuskeln - als auch die Muskeln der Mesenterien, Dissepimente und des Darmes scheinen als mesenchymatische Gebilde den coelomatischen Muskeln mehr fremdartig gegenüber zu stehen (die äussere Längsmuskelschicht des Darmes ist aber vielleicht eine epithelogene Bildung), obzwar sie als Mesodermgebilde doch auch in weiterem Sinne mit den Coelomsäcken genetisch verknüpft sind. Diese Muskelschichten sind wahrscheinlich von den primären Muskelbildungen der Scoleciden ableitbar.

Das Blutgefässsystem, dessen Vorhandensein für die Cephalidier (sowie für alle über den Scoleciden stehenden eucoelomatischen Thiere) typisch erscheint - wenn es auch bei manchen Formen secundär unterdrückt ist, tritt in den ursprünglichsten Fällen als ein geschlossenes, d. h. in sich zurücklaufendes System von Röhren auf, in welchem die Blutfiüssigkeit durch Contraction der Gefässe in Circulation 
versetzt wird. Als typische Theile des Gefässsystems unterscheiden wir ein dorsales, über dem Darm gelegenes Gefäss, welches contractil ist und in welchem das Blut von hinten nach vorn getrieben wird und ein Bauchgefäss, in welchem das Blut in umgekehrter Richtung strömt; diese Gefässe sind durch zwei Systeme von Gefässen verbunden, durch ein viscerales, am Darme verlaufendes Gefässnetz und durch somatische, längs der Körperwand verlaufende Quergefässe. Von den Modificationen, welche dieser Grundtypus erfährt, ist besonders hervorzuheben die Umwandlung des Dorsalgefässes in ein Herz, welche bei den höheren Typen (Arthropoden, Mollusken) eintritt. - Das Blutgefässsystem wird von vielen Forschern nach dem Vorgange von Butschli auf die primäre Leibeshöhle, welche durch die bedeutende Entwicklung des Coeloms eingeengt ist, zurückgeführt: die Muskehn der Gefässe sind Mesenchymmuskeln; nach dieser Auffassung müsste man aber auch die innere epithelartige Auskleidung der Gefässe, die in vielen Fällen zweifellos vorhanden ist, als ein ebenfalls vom Mesenchym abstammendes Pseudoepithel erklären, eine Anschauung, die aber vorläufig durch keine Beobachtung gestiitzt ist; hierüber muss erst die Entwicklungsgeschichte der Gefässe Entscheidung bringen, von welcher wir jetzt noch sehr wenig wissen.

Das B a u chmark, welches rom Ectoderm abstammt, ist ebenfalls $\mathrm{zu}$ den secundären Organen $\mathrm{zu}$ rechnen, dasselbe ist aber zurückzuführen auf eine Fortsetzung der ventralen Längsnerven; diese bilden im Bereich des Prosoma getrennt verlaufend die Schlundcommissuren, im Metasoma aber rücken sie meist näher zusammen und sind durch Quercommissuren verbunden und stellen so das Bauchmark dar.

Dasselbe fehlt bei Phoronis und den Bryozoen, doch beruht dies vielleicht auf. Rückbildung.

\section{Prosoma und Metasoma.}

In allen Fällen, wo die Entwicklung eine ursprüngliche, nicht abgekürzte ist, bildet das Prosoma anfangs den überwiegend grössten Theil des Körpers und das Metasoma stellt einen nur unbedeutenden Anhang desselben vor; bei der weiteren Entwicklung erfährt letzteres aber ein dermassen überwiegendes Wachsthum, dass es später den weitaus grösseren Körperabschnitt bildet. Die primären Organe des Prosoma kommen zuerst zur Ausbildung, die Organe des Metasoma aber werden erst später differenzirt. Einige Organe des Prosoma - die Protonephridien und die primären Längsmuskeln - werden sodann rückgebildet und es erfolgt (bei den Anneliden) ein secundäres Einwachsen von coelomatischen Organen des Metasoma, und zwar besonders der secundären Längsmuskeln, in das Prosoma.

Bei allen Articulaten erfährt das Metasoma eine Vervielfältigung, nämlich eine Wiederholung in der Längsachse, welche typisch durch eine Wiederholung der Coelomsäcke (,Ursegmente“) eingeleitet wird, und die wir als Metamerie bezeichnen. Die Molluscoideen (Tentaculaten) und Mollusken sind ungegliederte Formen, d. h. sie besitzen ein einfaches Metasoma.

Die Metamerie des Körpers.

Die Metamerie der Articulaten, welche wir hier zunächst in Berücksichtigung ziehen wollen, besteht in einer Wiederholung gleichartiger, in der Längsrichtung des Körpers auf einander folgender Körperabschnitte, die als Metameren oder Somite bezeichnet werden; es wiederholt 
sich in jedem Metamer die ganze Summe von Organen in gleicher Art und Anordnung, es wiederholt sich daher auch das Verhältniss von Vorn und Hinten in jedem Metamer (C. E. V. BAER).

Wir finden am Körper der Thiere sehr häufig die Erscheinung, dass gewisse gleichartige Organe in Vielzahl sich wiederholen - z. B. Haare, Federn, Zähne bei Wirbelthieren; wir wollen solche Organe als homoioplastische bezeichnen (ihre Uebereinstimmung und auch ihr correlatives Abändern beruht auf der Homoioplasie des Körpers, vergl. pag. $232 \mathrm{u}$. 237); diese Wiederholung ist unabhängig ron der Metamerie, es kommen solche Organe auch innerhalb eines Metamers in Vielzahl vor. Die Metamerie selbst besteht aber in der Wiederholung der gauzen, bestimmt angeordneten Summe von Organen, die ein Metamer ausmachen; wenn wir vorher von homoioplastischen Organen sprachen, so könnten wir nun die Metameren als homoioplastiche Körperabschnitte bezeichnen; man wendet hier aber eiue speciellere Bezeichnung an, indem man diese Körpertheile und ihre einzelnen sich wiederholenden Organe als homodynam bezeichnet.

Die Metameren sind nicht gleich alt, sondern entstehen derart, dass das vorderste als ältestes und die darauffolgenden der Reihe nach als jüngere sich bilden; man pflegt zu sagen, dass das jüngste Metamer stets vor dem undifferenzirten Endsegment, und zwar von diesem sich abtheilend, eingeschoben wird, doch kann man sich auch so ausdrücken, dass das undifferenzirte Endsegment sich fortgesetzt theilt, und zwar in einen vorderen Abschnitt, der sich dann weiter ausbildet, und in einen hinteren Abschnitt, der als undifferenzirter (, unsegmentirter" ${ }^{6}$ ) Rest zurückbleibt. Dieses Endsegment bleibt in der Regel auch dann, wenn die Metamerenbildung einen Abschluss erfährt, von rudimentärer Organisation. Das Endsegment trägt meist auch den After mit seiner Umgebung (Periproct). Der gesammte Körper der metamerisch gebauten Articulaten besteht aber nicht nur aus einer Reihe gleichartiger Metameren, sondern es findet sich vorn das Prosoma als ein Körperabschnitt, der in vielen besonderen Eigenthümlichkeiten von den Metameren abweicht. Wir können demnach den Körper der Articulaten eintheilen 1) in das Prosoma, an welchem wir ein Prostomium und ein Metastomium unterscheiden und 2) in das Metasoma, welches aus einer Reihe von Metameren besteht, deren letztes (rudimentäres) Endsegment meist das Periproct trägt.

In den ursprünglichsten Fällen sind die Metameren nicht nur der Anlage nach, sondern auch im ausgebildeten Zustande vollkommen gleichartig; wir bezeichnen dieses Verhalten als homonome Metamerie. Dieselben sind aber in anderen Fällen nur der Anlage nacl gleich, sie übernehmen nach dem Princip der Arbeitstheilung verschiedene Leistungen und gewinnen dem entsprechend auch eine verschiedene Ausbildung; wir nennen dieses Verhalten heteronome Metam e rie. Die Heteronomie kann bloss die innere Organisation betreffen (innere Heteronomie), oder auch im äusseren Bau zum Ausdruck kommen (äussere Heteronomie, oder Heteronomie im gewöhnlichen Sinne;) wenn dies nicht ausdrücklich anders bemerkt ist, so verstehen wir unter Heteronomie nur das letztere Verhalten. Wir finden die verschiedensten Ausbildungsstufen der Heteronomie; dieselbe ist schon bei den Anneliden vielfach angedeutet und bei den Arthropoden immer scharf ausgeprägt. In der Regel sind Gruppen von Metameren in gleicher Weise modificirt, so dass die Heteronomie zur R egionen- 
b ild ung des Körpers führt. Wir unterscheiden z. B. bei den Insecten als Kopf einen Köpertheil, der aus dem Prosoma und mehreren vorderen Metameren hervorgegangen ist, und welcher die höheren Sinnesorgane, die bedeutendsten Theile des Centralnervensystems, den Mund und die Mundwerkzeuge trägt, - a als Thorax die nachfolgenden Segmente, welche Bewegungswerkzeuge tragen, - und als Abdomen die hinteren Segmente, welche vornehmlich die Organe der vegetativen Sphäre, d. i. Darm, Herz und Geschlechtsorgane enthalten. Doch sind diese Regionen nicht immer nach demselben Princip ausgebildet; so finden wir beim Flusskrebs Herz, Leber, Geschlechtsorgane im Thorax, und das Abdomen dient als schwanzartiges Bewegungsorgan. In anderen Fällen, z. B. bei den Myriopoden, ist nur der Kopf als die eine Region ausgebildet und der Rumpf als zweite Region besteht aus ziemlich gleichartigen Segmenten.

Die Bildung des Kopfes ist eine für die Articulaten äusserst wichtige Erscheinung; sie wird durch eine Umwandlung der vordersten Metameren ganz allmählich eingeleitet. - Nur in wenigen sehr ursprünglichen Fällen, so bei Protodrilus und Polygordius, sind noch alle Metameren gleichartig; das Prosoma, dessen Metastomium hier noch von ansehnlicher Grösse ist, repräsentirt allein denjenigen vorderen Körpertheil, welcher von den nachfolgenden gleichartigen Metameren sich unterscheidet (Mangel der Gonaden, der Mesenterien, der Nephridien, welche letztere als Prosomnieren bei der Larve vorhanden waren, aber dann geschwunden sind). Wir können daher mit Recht das Prosoma als den primären Kopf der Articulaten bezeichnen. Auch bei den Protochaeten (Saccocirrus) findet sich noch ein ähnliches Verhalten, wenn auch das Metastomium hier schon an Ausdehnung reducirt ist; alle Metameren sind äusserlich homonom, wenn auch eine Anzahl der vordersten, in welche der Schlund hineinrückt, hier schon wie bei den höheren Anneliden keine Gonaden zur Entwicklung bringen. - Bei den Polychaeten und Oligochaeten ist das Metastomium meist reducirt und mit dem ersten Metamer zu dem sogenannten Mundsegment (auch Peristomium genannt) verschmolzen. Dieses erste Metamer zeigt beinahe immer Veränderungen, insofern als seine Borstenbündel in der Regel reducirt sind, meist aber ganz in Wegfall kommen. Man pflegt auch das Prostomium und Mundsegment als Kopfmundsegment zusammenzufassen und wohl auch als Kopf zu betrachten; derselbe ist aber nicht scharf gegen die nachfolgenden Metameren abgesetzt ${ }^{1}$ ). Erst bei den Arthropoden ist die Kopfbildung scharf ausgeprägt und kann als typisch für dieselben bezeichnet werden; hierbei kommt die Verwendung der zu den Kopfmetameren gehörigen Gliedmaassen als Mundwerkzeuge in Betracht. Bei den Crustaceen besteht der Kopf aus Prosoma und vier Metameren, bei den Tracheaten nach unserer Auffassung ebenfalls aus Prosoma und vier Metameren (nach der Auffassung der meisten Autoren nur drei Metameren).

\section{Entwicklung der Metameren.}

Die Metameren entstehen durch eine schärfere Abgrenzung von einzelnen Abschnitten aus den Primitivanlagen des einfachen, noch un-

1) Die hier erörterten Beziehungen wurden schon in einer früheren Publication auseinandergesetzt, wenn auch die Terminologie erst hier neu eingefiihrt ist; E. MEYER hat diese Termini in einem anderen Sinne gebraucht, was mit seinen zum Theil abweichenden theoretischen Anschauungen zusammenhängt. 
differenzirten Metasoma; die Primitivanlagen, welche dasselbe enthält, sind 1) das äussere Epithel oder Ectoderm, 2) die paarigen Coelomsïcke, die auch durch solide Mesodermstreifen vertreten sein können, 3) das Darmepithel oder Endoderm und ferner 4) die Mesenchymzellen, die zwischen diesen Blättern sich finden. Die Abgrenzung der Metameren tritt nicht an allen diesen Primitivtheilen zu gleicher Zeit deutlich hervor; zuerst und am ausgeprägtesten tritt die Theilung an den Mesodermstreifen oder Coelomsäcken in Erscheinung, welche in eine Mehrzahl hinter einander liegender Säcke oder hohler Plättchen, die sogenannten "Ursegmente", sich theilen; an Ectoderm kommt die Gliederung erst später zum Ausdruck mit der Ausbildung seiner Organe (Bauchganglienkette etc.) und durch segmentweise Einschnürungen; zuletzt erst wird das Endoderm von der Segmentirung betroffen, und sie tritt an diesem, wie es scheint, mehr passiv und in manchen Fällen gar nicht einmal deutlich auf. Die Bildung der Ursegmente ist bei der Bildung der Metameren nicht nur der einleitende, sondern auch der vor allen anderen charakteristische Process.

Die Bildung der Metameren beginnt bei vielen Anneliden an del freischwimmenden Trochophoralarve; sie wird in ursprünglicheu Fällen auch nach der Metamorphose zeitlebens fortgesetzt; die vorderen Segmente können schon reife Geschlechtsproducte enthalten, während hinten fortwährend noch neue Segmente erzeugt werden; es findet ein fortgesetztes Wachsthum des Hinterendes statt. Hier ist demnach die Zahl der Segmente nur eine in gewissen Grenzen bestimmte; doch ist hervorzuheben, dass die ursprünglicheren Formen stets polymetamere sind. Andere Anneliden besitzen jedoch im erwachsenen Zustande eine ganz bestimmte Segmentzahl; oft wird dieselbe mit Abschluss der larvalen Metamorphose, also zugleich mit der definitiven Gestaltung, oft erst mit der Geschlechtsreife erreicht; in anderen Fällen, wo eine Metamorphose fehlt (bei Oligochaeten, Hirudineen), wird oft sogar schon bei der embryonalen Entwicklung die volle Zahl der Segmente ausgebildet. - Bei den Crustaceen werden stets einige Segmente schon während der Embryonalentwicklung angelegt - und zwar sind es wenigstens z w e i, die nämlich schon bei der sogenannten Naupliuslarve der Crustaceen auftreten - und die übrigen Segmente werden dann in bestimmter Anzahl im Verlaufe der Metamorphose gebildet. Bei vielen Crustaceen aber, und namentlich bei den höheren, ist die Metamorphose unterdrückt und die successive Entstehung der Metameren fällt schon in das embryonale Leben. Analoge Verhältnisse finden wir bei den Tracheaten; die Tausendfüsser vermehren ihre Segmentzahl immerhin noch bedeutend nach Verlassen der Eihülle, bei den Insecten wird die volle Segmentzahl stets schon am Embryo gebildet. Bei letzteren ist der Process auch insofern noch mehr abgekürzt, als die Altersfolge der Segmente bei deren Bildung kaum mehr nachweisbar ist; der langgestreckte Embryonalleib zerfällt sofort in die volle Siegmentzahl (die merkwürdigen Erscheinungen, die hierbei vorkommen, nämlich die Projection der Segmentationsvorgänge auf äusserst frühzeitige Entwicklungsstadien, werden wir an anderem Orte noch würdigen).

Die phylogenetische Entstehung der Metamerie ist ein Problem, in Bezug auf welches zahlreiche Theorien aufgestellt wurden; von diesen sind folgende besonders herrorzuheben:

1. Theorie: Ableitung der Metamerie von der locomo- 
torischen Segmentation. Man findet bei manchen Thieren, z. B. bei den Rotatorien, eine äussere Segmentirung in Anpassung an die Bewegung; dieselbe ist aber nicht von einer inneren Wiederholung von Organen begleitet. Eine ähnliche Gliederung kann auch an Körpertheilen, z. B. den Beinen und Fühlern der Arthropoden auftreten. Einige Forscher vertreten nun die Meinung, dass auch die Metamerie der Articulaten von einer solchen äusseren Gliederung den Ausgang genommen habe und erst später in vollkommener W Cise auf die innere Organisation sich erstreckt hätte; diese äussere Gliederung soll zunächst in einer Ringelung Ausdruck gefunden haben oder auch darin, dass in Vielzahl vorhandene, aber ursprünglich dismetamer angeordnete äussere Bewegungsorgane eine regelmässige metamere Anordnung gewonnen hätten.

Die Mehrzahl der Forscher aber widerspricht dieser Anschaung besonders mit Rücksicht darauf, dass die Metamerie in ursprünglichen Fällen eine vollkommen homonome ist und dass sie gerade in diesen Fällen in der inneren Organisation am deutlichsten zum Ausdruck kommt. Wenn später bei höheren Formen eine Anpassung des metamerischen Körpers an die Bewegung immer mehr sich ausbildet, so tritt gerade hier die innere Metamerie wieder mehr zurück und statt der homonomen Metamerie erscheint die heteronome.

2. Theorie: Ableitung der Metamerie von der „Pseudometamerie". Eine in gewissem Sinne der ersterwähnten verwandte Anschauung wurde in jüngster Zeit von LANG aufgestellt, indem er annimmt, dass in nere, in Vielzahl vorhandene, aber ursprünglich dismetamer angeordnete Organe - wie Gonaden, Darmblindsäcke, Nephridialäste - erst allmählich eine streng metamere Anordnung gewonnen hätten; aus einem solchen Verbalten, welches bei Polycladen, manchen Tricladen sich findet, hätte sich durch allmähliche Uebergänge (Nemertinen) der bei den Anneliden herrschende Befund herausgebildet. Das terminale Wachsthum - d. i. die successive Vermehrung der Segmente und die vorausgehende Differenzirung der Prosomorgane (Trochophoraorgane) - also jene Züge der Entwicklung, welche wir als hervorstechende bei den metamerischen Thieren erkannt haben, werden von LANG als secundäre (caenogenetische) Anpassungen der Entwicklung betrachtet. Im Einklang mit dieser Theorie wird die Ableitung der Anneliden-Organe von den Organen der Turbellarien versucht.

3. Theorie: Die Metamerie als Cormenbildung. Die Metamerenbildung wird als ein Theilungsprocess aufgefasst, der metamerische Körper wird als ein Cormus, das einzelne Metamer als niedrigere Individualität betrachtet; diese Theorie wurde - im Anschluss an die durch SteEnstrop begründete Auffassung des Bandwurmkörpers als Cormus - von den meisten Forschern angenommen und besonders von HAECKEL (generelle Morphologie) in klarer Weise dargelegt. - Sowohl die Proglottidenbildung, als auch die Metamerie wäre auf jenen Theilungsmodus zurückzuführen, welchen wir als seriale Theilung (oder Strobilabildung) bezeichneten; in der Mehrzahl der bekannten Fälle (und ähnlich auch bei der Proglottidenbildung) ist es das vorderste Individuum, welches fortgesetzt durch ungleiche Theilung neue Theilstuicke liefert; in der dadurch entstehenden Individuenkette ist das vorderste Individuum das älteste, das hinterste das zweitälteste und auf dieses folgen $\mathrm{nach}$ vorn die jüngeren in abgestufter Altersreihe („prosthioseriale Theilung"). Nur selten, z. B. bei der Strobilabildung der Scyphomedusen, ist es das hintere Theilstück, an welchem die Theilung sich stetig wiederholt; es ist daher das vorderste Individuum das älteste und es folgen $\mathrm{nach}$ hinten die jüngeren in abgestufter Altersreihe („opistho- 
seriale Theilung" oder eigentliche Strobilabildung); auf diese letztere Theilungsart wäre die Metamerie der Articulaten zurückzuführen.

4. Theorie: Ableitung der Metamerie ron dem tcrminalen Wachsthum der Scoleciden. Ich selbst erklärte mich gegen die oben erörterte Cormentheorie, und zwar auf Grund der Verschiedenheit des vordersten Körperabschnittes (Cerebralganglion, unpaare Leibeshöhle des Prosoma) den Metameren gegenüber - einer Verschiedenheit, die nicht nur anatomisch, sondern auch entwicklungsgeschichtlich hervortritt. Nur das Prosoma enthält das Cerebralganglion und die anderen wesentlichen Trochophoraorgane, während die Metameren sich sehr abweichend verhalten. Ich erklärte daher die Metamerie aus der Wiederholung nicht der ganzen Individualität, sondern nur eines Körpertheiles (des Gonosoma), welche nach Art einer Doppelbildung aufzufassen sei. - Später aber modificirte ich diese Ansicht und suchte die Metamerie auf eine Wachsthumserscheinung zurückzuführen, welche wir schon bei vielen Scoleciden beobachten; es ist dort nämlich das Wachsthum des Körpers kein gleichmässiges, sondern es ist oft schon ein überwiegendes Wachsthum des Hinterendes (Wachsthumspunkt) vorhanden, woraus eine relative Längenzunahme des Körpers während des Wachsthums resultirt. Indem sich dieses terminale Wachsthum steigert und zu einem absatzweisen wird, kommt es zum metamerischen Bau und Wachsthum (man vergl. andere ähnliche Wachsthumsvorgänge, z. B. das Wachsthum des Tentakelkranzes bei den Tentakulaten). Die Entwicklung des Prosoma wurde als vorzeitige Ausbildung eines Körpertheils gedeutet. Ich will aber hervorheben, dass ich, wie weiter unten erörtert werden soll, neuerdings zu der Cormentheorie zurückkehre.

5. Theorie: Ableitung der Metamerie von dem radiären Bau der Scyphozoen. Die besonders von O. und R. Hertwig angebahnte Ableitung der Coelomhöhlen von Aussackungen des Urdarmes hat einem anderen Forscher SeDgwick zu einer Theorie Veraulassung gegeben, uach welcher der metamerische Bau der Articulaten direkt von dem radiären Bau der Scyphozoen abzuleiten wäre. - Die Altersfolge der Metameren wird folgendermaassen auf diejenige der Radiomeren zurückgeführt; bekanntlich findet sich bei den Cnidariern eine Intercalation neuer Radien; dieselbe kann eine streng radiäre sein, indem zwischen je zwei alten Radien je ein neuer eingeschoben wird; sie kann aber auch nur an bestimmten Punkten, ja sogar nur von einer einzigen Seite aus erfolgen (Cerianthus), so dass in letzterem Falle eine bilaterale Symmetrie angedeutet ist und die Altersfolge der zu beiden Seiten einer Symmetrieebene angeordneten radiären Stücke (biseriale Intercalation) an die Altersreihe der bilateralen Metameren orinnert. - Die Organisation der Articulaten wird in folgender Weise von derjenigen der Scyphozoen (Actinien) abgeleitet. Durch Streckung der Oralseite und theilweise Verwachsung des Mundes wird die langgestreckte Bauchseite gebildet; der orale Ringnerv wird zu dem ventralen Längsnervenpaar; die Tentakeln werden zu den segmental angeordneten Extremitäten; die inneren Gastraltaschen liefern die Coelomsäcke. - SEDGWrcK nimmt an, dass die ungegliederten Mollusken, sowie die Scoleciden durch Reduction von metamerischen Thieren abgeleitet seien. Die Trochophora wird als eine secundäre (caenogenetische) Larvenform betrachtet.

Wir müssen S. gegenüber hervorheben, dass bei den Actinien stets auch unpaare Tentakel und entsprechende unpaare Gastraltaschen in der Richtung der Symmetrieebene selbst vorhanden sind. Ferner ist wohl gegen die von S. angedeutete Zurückführung der Organe im einzelnen vieles einzuwender. 
Wie vorhin schon erwähnt wurde, bin ich geneigt, die Wachsthumstheorie wieder $\mathrm{zu}$ verlassen, um $\mathrm{zu}$ der von HAECKEL und anderen vertretenen Cormentheorie zurückzukehren, da diese Theorie am ungezwungensten die typischen Entwicklungs- und Wachsthumserscheinungen der Articulaten erklärt. Die Schwierigkeit in Bezug auf das abweichend gebaute Vorderende erscheint geringer mit Rücksicht auf unsere neuere Auffassung der Proglottidenbildung bei den Cestoden (pag. 349, vergl. auch LaNG u. a.); wir seben, dass auch dort nur die Vervielfältigung eines Körpertheiles vorliegt; dieselbe kann aber ganz wohl auf einen Theilungsprocess mit einseitig unterdrückter Regeneration zurückgeführt werden, wobei allerdings nur ein unvollkommener Cormus (den wir etwa als Hemicormus bezeichnen können) zu Stande kommt. Es liegt nun vahe, auch bei der Metamerie eine ähnliche Theilung mit unvollkommener oder unterdrückter Regeneration anzunehmen. Allerdings ist bei den Cestoden, wo die abgeschnürte Proglottide ihre Lebensaufgabe nahezu vollendet hat (und die Gewebe überreif sind), die Unterdrückung der Regeneration leicht begreiflich; bei den Anneliden dagegen kann ein Grund hierfür nur in dem innigeren, bleibenden Zusammenhange der Theilstïcke gesucht werden. So kommt es dazu, dass ein vorderer Körpertheil mit dem Cerebralganglion nebst seinen Sinnesorganen und dem Munde, den wir etwa als "Prosthion“ bezeichnen können, nur einmal vorhanden ist. Nur das vorderste Theilstück besitzt ein Prosthion und entspricht annähernd einer vollkommenen Individualität, bei den nachfolgenden Metameren fehlt das Prosthion, die Regeneration desselben ist unterdrückt; diese entsprechen daher nur virtuellen Individualitäten. Es muss übrigens bemerkt werden, dass auch ein anderer Körpertheil, nämlich das Periproct, als „Opisthion“ nur einmal und zwar am Endsegment vorhanden ist.

In Bezug auf die sehr wichtige Frage, welches Körperstück der vorderen vollständigen Individualität entspräche, wären zwei Möglichkeiten ins Auge zu fassen; entweder könnte man das Prosoma als Prosthion betrachten und dieses nebst dem ersten Metamer für die erste Individualität halten oder es könnte auch das Prosoma allein schon als vollständige Individualität gelten. Wir halten letztere Deutung für die richtige; doch bedürfen dann gewisse Eigenthümlichkeiten des Prosuma noch einer näheren Erklärung, so vor allem der Mangel der Coelomsäcke; wir begründen dies hypothetisch dadurch, dass das vorderste Individuum steril wurde und der Gonaden (Coelomsäcke) entbehrte ${ }^{1}$ ).

Wir wollen nun unsere theoretischen Anschauungen zusammenfassen, indem wir die phylogenetische Entwicklung der Metamerie folgendermaassen darstellen. Zuerst erfolgte an einem Trochophora-ähnlichen Organismus eine Fortpflanzung durch Theilung und Regeneration und zwar nach opisthoserialem Typus; die einzelnen Individuen kamen zur vollständigen Trennung. Später kam es dazu, dass die Individuen zu einem Kettencormus vereinigt blieben, und zugleich kamen gewisse Modificationen zur Ausbildung; das vorderste Individuum blieb als "Amme" steril, die folgenden Individuen wurden durch Unterdrückung der Regeneration je ihres Prosthions verlustig, dagegen erfuhren sie eine secundäre weitere Ausbildung ihrer Organsysteme (besonders der epithelogenen Muskeln der Coelomsäcke). Wir können die

1) Die endgiltige Beantwortung der ganzen Frage hängt noch von zukünftigen Untersuchungen ab. Sie steht im Zusammenhang mit der morphologischen Beurtheilung der Nephridien; ferner ist die Bildung des vordersten Metamers und seine secundären Beziebungen zum Prosoma noch näher zu prüfen, u. s. w. 
hierdurch erfolgende Verschiedenheit von Prosoma und Metameren als die primäre Heteronomie bezeichnen. - So kommen wirzu der Anschauug, dass die Ausbildung der Metamerie zugleich auch die erste Ursache wurdefürdie Entstehung der secundären Organe, die für die Cephalidier charakteristisch sind ${ }^{1}$ ).

Fig. 382. Schema zur Ableitung der Metamerie von der Vermehrung durch Theilung. $A$ Opisthoseriale Theilung mit vollkommener Regeneration. $\boldsymbol{B}$ Derselbe Modus mit unterdrïckter Regeneration und sterilem vordersten Individuum. cg Cerebralganglion, o Mund, $₫$ Längsnerveu, $g$ Gonaden (Coelomsäcke).

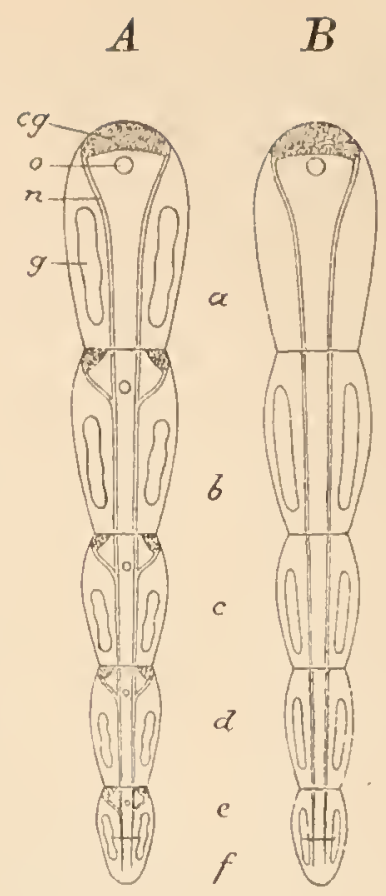

Unsere Betrachtungea über die Metamerie beziehen sich nicht nur auf die Articulaten, sondern sie gewinnen auch Bedeutung für die Beurtheilung der Mollusken und Tentaculaten.

Da wir das Prosoma für die vorderste Individualität halten, welche in dem Metasoma in unvollkommener und veränderter Weise wiederholt wird, so können wir auch die Mollusken und Tentaculaten, bei welchen der Gegensatz von Prosoma und Metasoma besteht, nicht für ungegliedert halten. Es wären zwei Möglichkeiten zu beachten: 1) Die Zusammensetzung des Metasoma aus mehreren Metameren könnte verwischt sein, oder 2) das Metasoma bestünde nur aus einem einzigen Metamer. Ich halte letzteres für wahrscheinlicher; ich vermuthe, dass diese Thiere von polymetameren Formen abstammen, indem eine Reduction der Metamerenzahl auf ein einziges stattgefunden hat, welches aber nun eine um so complicirtere und höhere Ausbildung erreichen konnte.

Die Erscheinung der Metamerie kommt auch bei anderen Thiertypen vor, z. B. bei den Wirbelthieren und bei den Echinodermen, bei den letzteren an jedem der fünf Radien des Körpers. - Die Metamerie muss nicht in allen Fällen auf gleiche Weise entstanden sein - bei den Echinodermen ist sie wahrscheinlich auf eine Wachsthumsform zurückzuführen - und wir werden daher jene Erscheinungen nicht mit Nothwendigkeit mit jener der Articulaten in genetische Beziehung bringen müssen; bei den Wirbelthieren aber spricht vieles für eine solche Annahme.

1) Dieser Satz kanu seiue Geltung behalten, auch wenn eine andere Theorie der Metan merenbildung anerkant wird, z. B. die Wachsthumstheorie. 


\section{SIEBZEHNTES CAPITEL.}

\section{Cladus der Metazoa.}

\section{Articulata.}

Die Articulaten sind Cephalidier mit ausgeprägter Metameriedes Körpers; mit meist deutlich gegliedertem B a uchmark. Für die Entwicklung ist die Ursegmentbildung und das Auftreten einer Bauchfurche charakteristis ch.

Die Einheit des Articulatenstammes, welche schon von Cuviek erkannt war, wurde von LEUCKART wieder in Zweifel gezogen, und auf seine Autorität gestützt haben sich lange Zeit die meisten Zoologen seiner Anschauung angeschlossen. LEUCKART hielt die vielfache Uebereinstimmung zwischen Anmeliden und Arthropoden nur für eine Convergenzerscheinung, die also nicht auf wirklicher Verwandtschaft beruhe. Es sollten auch fundamentale Unterschiede vorhanden sein; besonders hob er hervor, dass das obere Schlundganglion der Arthropoden nur als vorderstes, vor dem Munde gelegenes Ganghion der Bauchganglienkette $\mathrm{zu}$ betrachten wäre, während das obere Schlundganglion der Anneliden auf ein dorsales Ganglion zurückzuführen sei. Gegenwärtig ist wohl die phylogenetische Ableitung der Arthropoden von den Anneliden allgemein anerkannt; das obere Schlundganglion der Arthropoden ist zum Theil auf dasjenige der Anneliden zurückführbar, nur dass hier wahrscheinlich noch gewisse 'Theile, so z. B. secundäre Augenganglien, als neue Cerebraltheile hinzukommen. Auch in ihren übrigen Organisationsverhältuissen erweisen sich die Arthropoden trotz ihrer viel höheren Differenzirung als Abkömmlinge der Anneliden, welche demnach als die Stammgruppe der Articulaten anzusehen sind.

\section{Classe der Articulata. Annelides.}

Die Anneliden sind Articulaten von vorwiegend homonomer Segmentirung (ohne typische zusammengesetzte Kopfbildung); mit Hautmuskelschlauch; meist mit segmentirter Leibeshöhle; meist mit typischen Segmental- 
organen; meist mit geschlossenem Blutgefässsystem; Wimperepithelien sind oft noch stellenweise an der Oberfläche und stets an inneren Organen vorhanden.

Von den Anneliden stammen nicht nur die übrigen Classen der Articulaten, sondern wahrscheinlich auch die Tentaculaten und Mollusken $\mathrm{ab}$, und wenn auch für diese letzteren die Art der Ableitung bisher noch weniger bestimmt erwiesen ist, so ist doch für ihre morphologische Erklärung die Vergleichung mit dem Organismus der Anneliden schon jetzt von grösster Wichtigkeit. Auf die Befunde bei den Anneliden stützt sich demnach unsere Auffassung der gesammten Cephalidier.

Viele Forscher gehen noch weit ïber diese Annahme hinaus und sehen in den Anneliden auch den phylogenetischen Ausgangspunkt für die Enteropneusten, die Echinodermen und die Chordonier. Vom morpliologischen Standpunkte betrachtet, stehen daher gegenwärtig die Anneliden im Mittelpunkt des Interesses.

Wir werden aus diesem Grunde der Morphologic und auch dem System der Anneliden eine etwas eingehendere Behandlung widmen. In Bezug auf das System der Anneliden sind die Anschauungen der Zoologen noch keineswegs übereinstimmend. Unsere eigene Anschauung geht dahin, dass Protodrilus und Polygordius, welche wir als Archianneliden bezeichnen, der ursprünglichen Stammform der Anneliden noch am nächsten stehen; von diesen einfachsten Formen führt der Stammbaum aufwärts zu den Chaetopoden, und zwar durch die Protochaeten und Spiomorphen zu den am höchsten entwickelten Vertretern des Annelidenstammen den Rapacien; daneben gibt es aber zahlreiche secundär vereinfachte oder modificirte Formen (Drilomorpha, Terebellomorpha, Serpulimorpha), und von solchen leiten sich auch die Oligochaeten und weiter die Hirudineen ab; als ein ebenfalls stark modificirter Seitenast des Annelidenstammes sind die Echiuriden zu betrachten. Die von uns angenommene ursprüngliche Bedeutung der Archianneliden wird aber von einigen Forschern (KLeINenberg, EIsig, E. MEYER) mit grosser Heftigkeit bekämpft und es werden von ihnen die Rapacia als Ausgangspunkt der Anneliden betrachtet, so dass alle anderen Gruppen als rückgebildete Formen anzusehen wären.

Unsere oben angedeuteten Anschauungen haben wir in der vorliegenden Darstellung festgehalten und im einzelnen noch weiter ausgeführt und begründet. Wir wenden uns daher zunächst zur Betrachtung der Archianneliden, um uns so zugleich eine Vorstellung von der Grundform der Anneliden zu verschaffen.

\section{Unterclasse der Anneliden. Archiannelides.}

Die Archianneliden sind kleine Anueliden von sehr ursprünglicher Organisation; mit umfangreichem, wohlgesondertem Metastomium, mit vollkommener (äusserer und innerer) Homonomie der Metameren, mit langen (spionidenartigen) Primärtentakeln; mit epithelialem Nervensystem; Bauchmark ungegliedert; ohne Borsten, ohne Cirren, ohne Parapodien; Entwicklung mit larvaler Metamor phose. 
Wir bezeichnen als Archianneliden die Gattungen Protodrilus und Polygordius; die Zugehörigkeit einiger anderer Gattungen, die von manchen Forschern hierher gestellt wurden, ist mehr oder minder. zweifelhaft, wie weiter erörtert werden soll.

Die Gattung Protodrilus betrachten wir als diejenige, welche der Stammform der Anneliden am nächsten steht und uns den Typus der Anneliden in seiner einfachsten Form erkennen lässt. Die Körperform ist langgestreckt und von rundlichem Querschnitt; gegen das Hinterende, wo die jüngeren Segmente sich finden, wird der Körper allmählich dünner. - Die Metamerie ist äusserlich nur wenig angedeutet, sie ist dagegen in der imneren Organisation vollkommen ausgeprägt. Wir unterscheiden als vordersten Körperabschnitt das Prosoma, welches aus dem Prostomium mit einem Paar langer Tentakel (spioniden-

Fig. 383 .

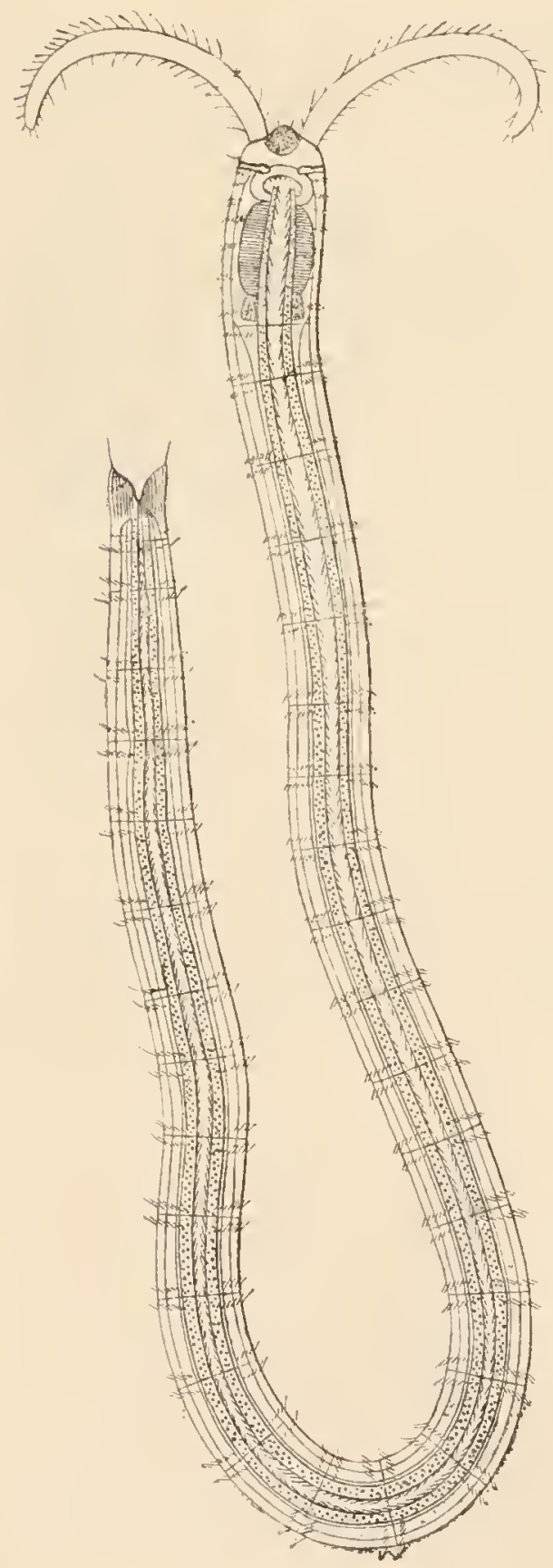
artige Primärtentakel) und dem umfangreichen Metastomium besteht; darauf folgt die Reihe der Segmente, die vollkommen, äusserlich und innerlich, homonom sind (alle Segmente besitzen Gonaden); die Segmente vermehren sich stetig, so dass im Hinterende immer noch in Entwicklung begriffene Segmente zu finden sind; das Endsegment trägt neben dem After ein Paar von drüsigen Zacken. -- Vom Munde bis zur After-

Fig. 384 .
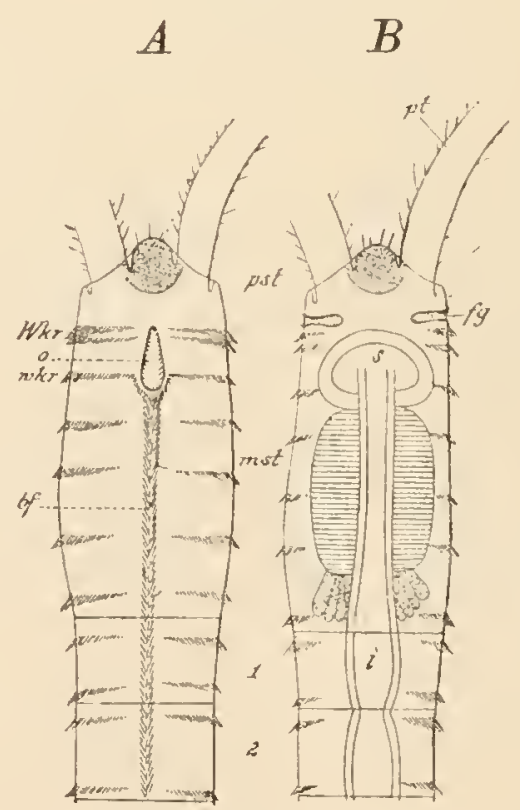

Fig. 383. Protodrilus Leuckartii, vom Kücken geseheu.

Fig. 384. Vorderende von Protodrilus. $\boldsymbol{A}$ vom Bauche, $\boldsymbol{B}$ vom Rücken gesehen. pst Prostomium, mst Metastomium, 1 und 2 erstes und zweites Metamer, o Mund, Wkr präoraler, wkr postoraler Wimperkranz, bf Bauchfurche, pt Primärtentakel, $f g$ Flimmergrube, $s$ Schlund, dahinter der Schlundanhang und die Schlunddrüsen, $i$ Darm. 
region erstreckt sich eine ventrale Wimperrinne, deren Flimmerung mit zur Kriechbewegung dient. Ferner finden sich zahlreiche Wimperkränze, und zwar im Prosoma ein doppelreihiger präoraler und ein postoraler und noch zwei folgende Wimperkränze; sodann segmentale Wimperkränze, je einer vor und hinter jeder Segmentgrenze.

Die Schichtung des Körpers ist folgende: 1) Die epitheliale Schichte besteht aus einer äusseren Cuticula und aus dem Epithel, welches Stützzellen, Drüsenzellen, Sinneszellen und auch Gewebe des Nervensystems enthält; das epitheliale Bauchmark besteht aus den Seitensträngen, die zu beiden Seiten der Flimmerrinne liegen. ¿) Der Hautmuskelschlauch. Eine Ringmuskelschichte fehlt (eine solche

$A$

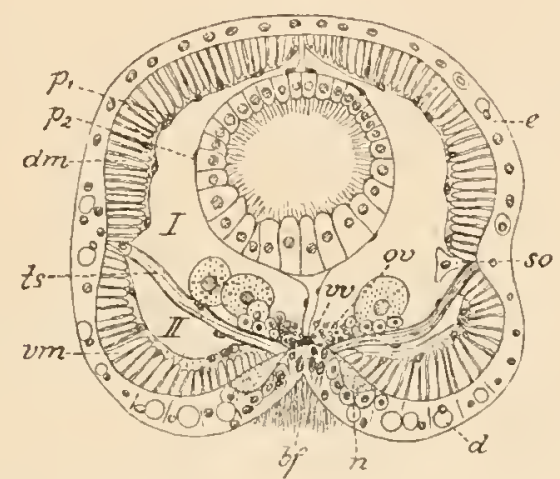

$B$

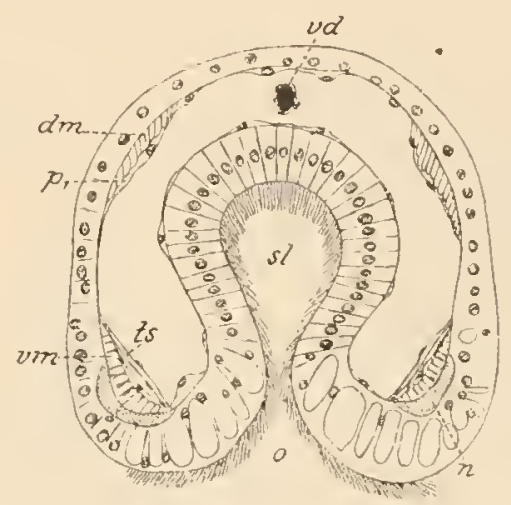

Fig 385. Querschnitt durch den Körper von Protodrilus. $\boldsymbol{A}$ durch ein Metamer, $\boldsymbol{B}$ durch die Mundregion. e Epithel, $d$ Drüsenzellen, $n$ Bauchmark, Schlundcommissur, bf Bauchfurche, $d m$ und $v m$ dorsales und ventrales Muskelfeld, $t s$ transversales Septum, $p_{1}$ und $p_{2}$ Somatopleura und Splanchnopleura, $I$ und 11 Hauptkammer und Seitenkammer der Leibeshöhle, ov Ovarium, vv Bauchgefäss, o Mund, sl Schlund, vd Rückengefäss.

kommt den meisten Anneliden zu, und der Mangel derselben ist hier wohl nicht als ursprünglicher Charakter, sondern als eine Vereinfachung $\mathrm{zu}$ betrachten). Die Längsmuskelschichte ist in der dorsalen und ventralen Mittellinie und in den Seitenlinien, wo sich die verschiedenen Mesenterien und deren Muskeln inseriren, unterbrochen, sie besteht daher aus vier Längsmuskelfeldern, nämlich einem dorsalen und einem ventralen Paar. Der Bau der Muskelfelder ist ein sehr einfacher; die bandförmigen Muskelfasern sind mit ihrer Kante -senkrecht gegen die Haut gerichtet, sie sind wie die Blätter eines Buches aneinandergereiht, ihre Zellkerne liegen an der inneren Kante. 3) Die nächste Schichte (genetisch eng mit der Längsmuskelschichte verknüpft) ist die Somatopleura, welche die Leibeshöhle auskleidet. Die Leibeshöhle selbst ist nicht nur segmental gekammert und durch ein dorsales und ventrales Mesenterium in eine rechte und linke Hälfte getheilt, sondern auch beiderseits durch ein transversales Septum, das von der Seitenlinie zu deren Bauchmark zieht, in eine Hauptkammer und eine Seitenkammer geschieden. - Diese transversalen Septen bestehen aus den regelmässig angeordneten transversalen Muskeln und dem sie bedeckenden Peritonealepithel; letzteres bildet an der Seite, welche der Hauptkammer zugewendet ist (nur an dieser?) das Keimepithel. Die transversalen Septen sind in dem vorliegenden Falle gitterförmig durchbrochen. Die Excretionsorgane (Segmentalorgane), welche längs der Seitenlinie retroperitoneal liegen, und das Blutgefässsystem 
(Darmsinus, ventrales Gefäss) sind zur Vervollständigung des Querschnittbildes zu berücksichtigen, ebenso der Darmtractus, welcher aus Peritonealschichte oder Splanchnopleura, Muskelschichte und Epithelschich te besteht.

Im Prosoma ist die Schichtung eine ähnliche, nur dass die Muskelfelder und auch die transversalen Septen viel schmäler werden; es fehlen hier aber stets die medianen Mesenterien, welches Verhalten durch die Entwicklungsgeschichte seine tiefere Begründung findet.

Wir wollen nun die einzelnen Organsysteme in Betrachtung ziehen, zunächst den Darmtractus. Von der längsgerichteten Mundöffinung geht der kurze, im Prosoma gelegene Schlund aus; derselbe ist mit Schlunddrüsen und einem eigenthümlichen ventralen Schlundanhang (Schlundkopf) versehen. Der Chylusdarm, welcher schon im Prosoma beginnt, verläuft geradegestreckt durch den Körper, als ein einfaches bewimpertes Rohr, welches nur im Zustande der Contraction segmentweise eingeschnürt ist.

Das Blutgefässsystem ist sehr einfach; den Chylusdarm umgibt ein Blutgefässsinus (zwischen Pleura und Epithel); erst hinter dem Schlunde geht derselbe in ein contractiles, herzartiges Rückengefüss über; an Vorderende gabelt sich dasselbe, seine beiden Aeste gehen zunächst schleifenförmig in die Tentakeln und ziehen dann längs der Schlundcommissur zur Bauchlinie, wo sie zum einfachen Bauchgefäss sich vereinigen, welches bis an das Hinterende verläuft [eine Verbindung mit dem Darmsinus (?) ist nicht beobachtet].

Die Segmentalorgane finden sich in allen Metameren. Sie bestehen aus dem Flimmertrichter, der vor dem Dissepiment in der Leibeshöhle des vorhergehenden Segmentes sich öffnet (der Trichter des ersten Segmentalorganes ragt in die Prosomhöhle), ferner dem Kanal, der ausserhalb des Peritoneums, in der Längsrichtung verlaufend, an der Seitenlinie nach hinten zieht und in dem hinteren 'Theil des Segmentes durch eine ectodermale Oeffnung nach aussen mündet.

Das Centralnervensystem besteht aus dem Cerebralganglion (Scheitelganglion) der Schlundcommissur und dem Bauchmark; letzteres ist ungegliedert; es hat die Form paariger Seitenstränge, deren Ganglienbelag in der ganzen Länge gleichmässig vertheilt ist; dieselben verlaufen epithelial zu beiden Seiten der Bauchfurche.

Die Geschlechtsorgane sind zwitterig. Eine Verwendung der Segmentalorgane zur Ausfuhr der Geschlechtsproducte aus der Leibeshöhle ist hier zweifelhaft.

Die Entwicklung (vergl. Entw. d. Chaetopoden) verläuft mit Metamorphose.

Die Gattung Polygordius unterscheidet sich in einigen Punkten. Der Körper ist unbewimpert, ohne Bauchfurche. Der Schlund ist einfach, ohne Schlundanhang und Drüsen. In der Nähe des Hinterendes findet sich ein Papillenkranz (bei $P$. appendiculatus zwei lange Schwanzfäden). Das Bauchmark ist eine mediane, ungegliederte strangförmige Epithelverdickung. Es findet sich in der ganzen Länge des Körpers ein contractiles Rückengefäss (nebst Darmsinus?); dasselbe ist mit dem Bauchgefäss durch vordere und hintere Gefässbogen und segmentale Quergefässe verbunden. Diese Thiere sind getrenntgeschlechtlich.

Von einigen Forschern werden mehrere unzweifelhaft rückgebildete Annelidenformen zu den Archianneliden gezählt. Histriobdella, welche auf Hummereiern schmarotzt, scheint mir aber eine rückgebildete Euniciden-Form 
zu sein, worauf die Schlundkiefer und die neben zwei kurzen Primärtentakeln vorhandenen fuinf Cerebralcirren hindeuten. - Dinophilus ist vielleicht eine rückgebildete Archiannelidenform, wenigstens sind die Anhangsorgane des Schlundes jenen von Protodrilus ähnlich; die ventrale Bewimperung kann wohl als ein allgemein larvaler Charakter gelten, ebenso die Wimperkränze, deren Vertheilung nicht mit jener bei Protodrilus übereinstimmt. eher noch mit jener von Ophriotrocha, einer larviformen Eunicide. Die Segmentalorgane von $\nu$. sind ohne Trichter (larval?); Dissepimente und Mesenterien, sowie Blutgefässe fehlen; Bauchmark (Seiteustränge) und Längsmuskeln sind schwach entwickelt; die Geschlechter sind getrennt, bei manchen Arten dimorph mit Zwergmännchen.

Fig. 386. Dinophilus, Weibchen, vom Rücken gesehen (nach E. MEYER). Der Körper ist mit zwei cerebralen Wimperkränzen, die vor der Flimmergrube liegen, und segmentalen Wimperkränzen versehen. $s g$ Cerebralganglion, "g Flimmergruben, o Mund (von der Bauchseite durchschimmernd), $p h$ Pharynx, $d r$ Schlunddrüsen, $i$ Darm, neph Nephridien, ov Ovarium.

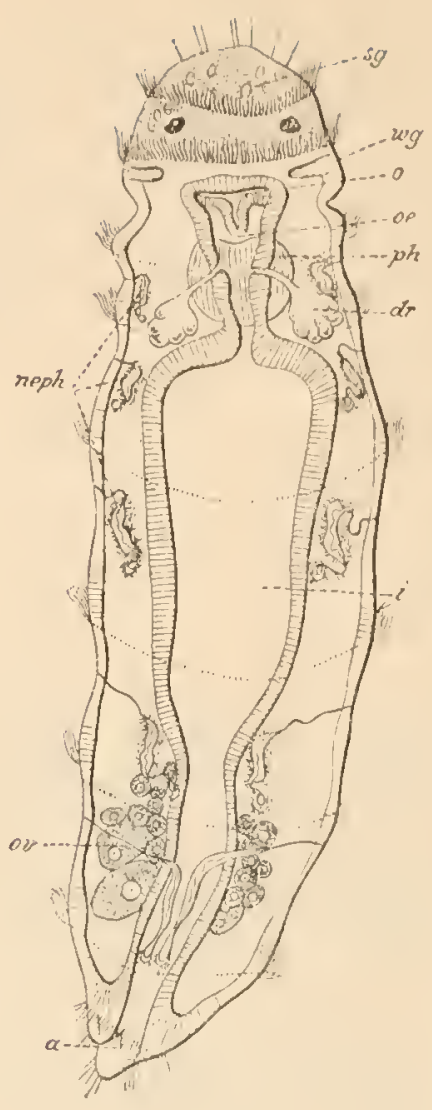

Systematische Uebersicht der Archianneliden.

1. Protodrilidae. Protodrilus, im Meere, im Sande.

2. Polygordiidae. Polygordius, im Meere, Strandregion.

A nhang: Dimophilus; selbst in kleineren Seeaquarien lange andauernd und sich daselbst fortptlanzend.

\section{Unterclasse der Anneliden. Chaetopoda.}

Die Chaetopoden sind Anneliden mit Borstensäcken; wit deutlicherinnerer und äusserer Metamerie.

Die Borsten sind für die ganze Gruppe del Chaetopoden charakteristische Gebilde und fehlen nur ausnahmsweise (Tomopteris, Anachaeta, Branchiobdella); sie werden als cuticulare Bildungen betrachtet, nicht nur wegen ihrer chitinähnlichen Beschatfenheit, sondern auch wegen ihrer Entstehung. Ihre Bildung geschieht in Follikeln (Säcken), welche auf Einwucherungen des äusseren Epithels zurïckgeführt worden sind; jede Borste wird von einer einzigen Bildungszelle ausgeschieden, bei ihrem Wachsthum durchbricht sie den Follikel und ragt durch den Follikelhals über die Oberfläche der Haut empor; die Borsten werden zeitweilig abgestossen und es treten neue Ersatzborsten für sie ein. - Die Follikel ragen tief in das Innere des Körpers ein und erhalten einen Peritonealüberzug; dieselben sind ferner mit speciellen Muskelgruppen versehen, die zur Bewegung der Borsten oder Borstengruppen dienen. 
Fig. 387 .

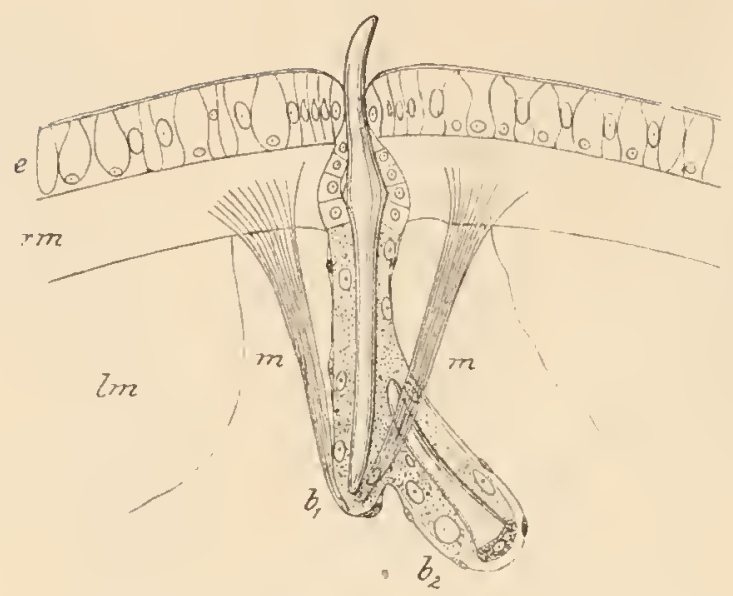

Fig. 388.

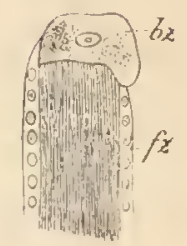

Fig. 387. Querschnitt der Körperwand mit Borste von einem regenwurmartigen Anneliden (nach VEJDorskY). $e$ Epithel, $r m$ Ringmuskelschichte, $l m$ Längsmuskelschichte, $b_{1}$ Borstenfollikel, $m$ dessen Muskeln, $b_{2}$ Ersatzfollikel mit Ersatzborste, an deren Basis noch die Bildungszelle sichtbar ist.

Fig. 388. Borstenbildung bei einer Eunicide (nach Spengel). fz Zellen des Borstenfollikels, $b z$ Bildungszelle an der Basis des Follikels, von dieser ausgehend die faserige Substanz der Borste.

Die Borsten bestehen, sowie die äussere Cuticula, aus einer chitinähnlichen Substanz, sie sind von faseriger Structur und in der Regel solide (bei den Amphinomiden sind sie oft hohl, kalkig und von spröder Beschaffenheit). Die Mamigfaltigkeit ihrer Form ist uns für die systematische Betrachtung von Wichtigkeit. Man unterscheidet A) einfache Borsten, die aus einem Stück bestehen; die wichtigsten Formen derselben sind die linearen oder Harborsten (Setae lineares), welche geradegestreckt und lang sind (haarförmige, gesäumte, lanzettförmige, meisselförmige), ferner die Hakenborsten (Un cin i), die entweder sanft oder auch scharf S-förmig gekrümmt sind; die ersteren mehr gestreckten Haken endigen oft mit zwei umgebogenen
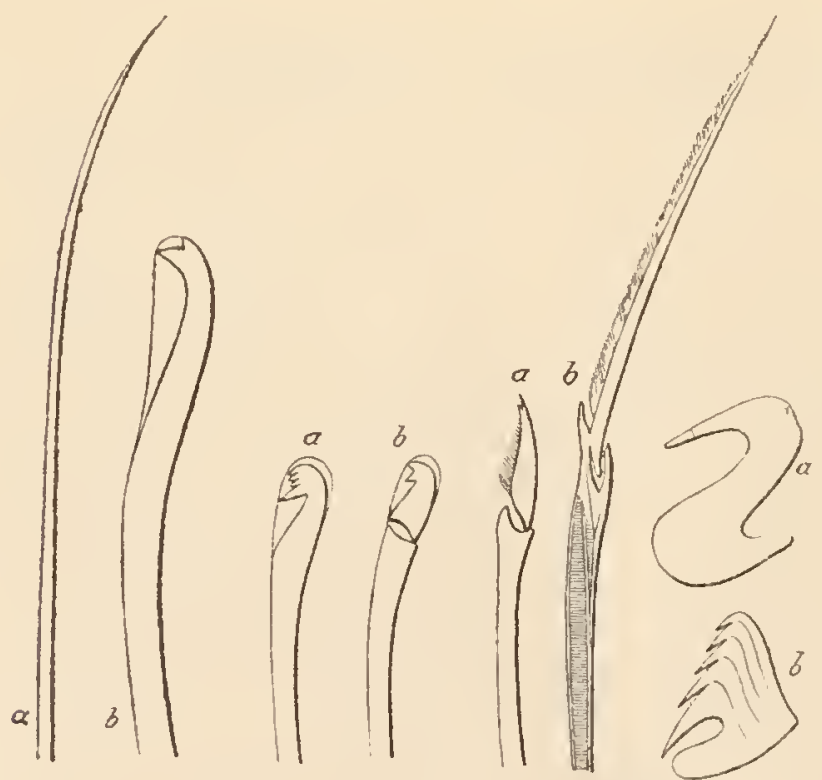

$A$ $B$
C
Fig. 389. Grundformen der Borsten bei den Polychaten. $\boldsymbol{A}$ Einfache Borsten von Spio. a Haarborste, $b$ gestreckte Hakenborste. $\boldsymbol{B}$ Uebergangsformen von der einfachen gestreckten Hakenborste (a) zu der zusammengesetzten Borste (b) von Lumbriconereis Nardonis. $C \mathrm{Zu}$ sammengesetzte Borsten von Nereis cultrifera. Zwei Formen $(a, b) . \quad D$ Einfache kurze Hakenborsten. a S-förmiger Haken von Laonome, $b$ gezähnter Haken von Serpula. (Alle Fig. nach Clapark̀de.) 
Zälmen. Die Plattenborsten oder Paleen sind an ihrem Ende stark verbreitert und durch lebhaften Glanz ausgezeichnet. Als N a d e ln oder Aciculae werden die starken Stützborsten bezeichnet, die im Inneren der Parapodien sich finden und nicht oder nur wenig iiber die Oberfläche hervorragen. Von den gestreckteren Haken sind, wie uns gewisse Uebergänge beweisen, B) die z 11 sammenges etzten B orsten abzuleiten, welche aus zwei Stücken, dem Stiel und dem beweglichen Anhang bestehen, nach dessen mannigfaltiger Form man viele Typen unterscheidet (Spiessborsten, Sichelborsten, Besenborsten etc.); die zusammengesetzten Borsten kommen nur bei den Rapacien vor. Die Borsten sind in bestiminter Weise angeordnet; sie sind bei den Polychaeten meist büschelweise an besonderen Anhängen des Körpers, bei den Oligochacten, wo sie in geringerer Zahl vorkommen, einfach der Haut eingepflanzt (vergl. unten) zu finden.

Di e Körperform der Chaetopoden ist meist langgestreckt, wurmförmig, seltener breit nnd gedrungen, im Querschnitt entweder rundlich oder auch ventral abgeplattet. Für dieselbe ist zunächst die Zahl und auch die Form der Segmente maassgebend; dieselben sind melı länglich oder auch kurz und breit; sie sind meist durch tiefe Furchen von einander abgegrenzt, seltener sind sie selbst durch secundäre seichtere Furchen geringelt (Glycera, man vergl. auch die Hirudineen). Von besonderer Wichtigkeit für die Formgestaltung sind auch die äusseren Anhänge des Körper's, und zwar 1) die der Segmente, 2) die des Prostomiums (des „Kopfes") und 3) die des Endsegmentes.

I. Die segmentalen Anhainge, welche wir hier zunäclist betrachten wollen, zeigen die mannigfachste Ausbildung und Zusammensetzung, sie können auch der Reduction anheimfallen und nur noch durch die Vertheilung der Borsten angedeutet sein.

A. Protopodium. Bei den Protochaeten (Sacocirrus) sind eigenthümliche einfache retractile Fussstummel vorhanden, die ein einfaches Bündel von langen (meisselförmigen) Haarborsten enthalten; sie sind nahe der hinteren Segmentgrenze etwas dorsal gelagert.

B. Parapodium. Als Parapodien bezeichnen wir die segmentalen borstentragenden Anlänge der Polychaeten. Es ist eine Anzahl heterogener Gebilde, die in den Aufbau des Parapodiums eingehen. Wir unterscheiden an einem gemeinsamen Basaltheil je einen dorsalen und ventralen borstentragenden Ast; diese Aeste sind wohl durch Tlieilung aus einem ursprünglichen einfachen Fussstummel hervorgegangen. Hierzu kommt je ein dorsaler und ventraler Cirrus, das ist ein fadenförmiges, von einem Nerven durchzogenes Tastorgan; diese Cirren sind wohl durch Weiterbildung von Tastpapillen entstanden, welche - worauf manches hindeutet - ursprünglich in Kreisen an den Segmenten des Annelidenkörpers angeordnet waren; wir bezeichnen sie als Parapodialcirren zum Unterschiede von den ähn-

Fig. 390. Retractiles Parapodit von Sacocirrus, vom Rücken gesehen. $p$ Parapodit, $s$ Sinneshügel, $b$ eine einzelne meisseliörmige Borste.

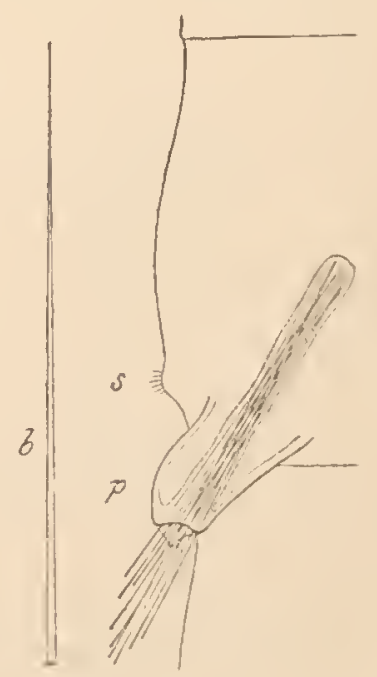


lichen Cirren des Prosoma und Endsegmentes ${ }^{1}$ ). Es kommen endlich als dorsale Anhänge der Parapodien Kiemen vor, welche im einfachsten Falle fadenförmig, oft aber durch Verästelung complicirter gestaltet sind (kammförmig, gefiedert, baumförmig, strauchförmig etc.); sie sind ilırer Function gemäss mit Gefässen versehen, doch gibt es auch Lymphkiemen, und zwar bei den Glyceriden und Capitelliden, welche keine Gefässe besitzen. Die Parapodialkiemen sind morphologisch bestimmte Gebilde und sind wohl zu unterscheiden von kiemenartigen, ja sogar verästelten

$A$
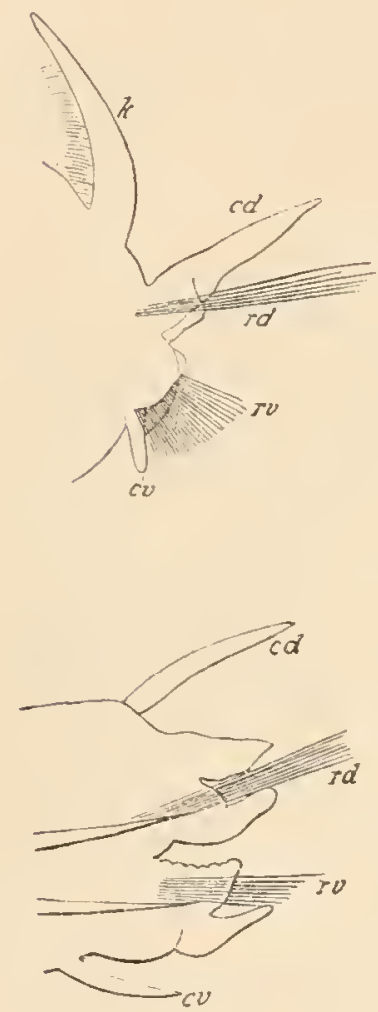

$C$
$B$
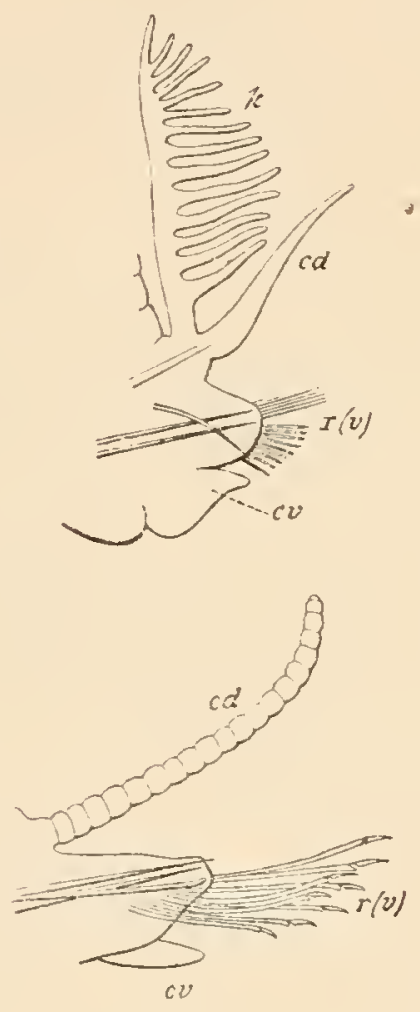

$D$

Fig. 391. Verschiedene typische Formen von Parapodien. A Completes Parapodium von einfacher Gestaltung, von einem Spiomorphen (Theodisca liriostoma), nach Claparìde. $\boldsymbol{B}$ Incompletes Parapodium, der dorsale Ast ist rückgebildet, von einer Eunicide (Eunice gigantea), nach EHLERs. $C$ Incompletes Parapodium, ohne Kieme, $\nabla$ on einer Nereide (Heteronercis Malgreni $\sigma^{3}$ ), nacl CLAPA- $_{\text {LAP }}$ Rède, $D$ Incompletes Parapodium, ohne Kieme und ohne dorsalen Ast, von einer syllidee (Syllis fumensis), nach E. V. MARENZELLER. k Kieme, $r d$ und $r v$ Ramus dorsalis und Ramus ventralis, $c d$ und $c v$ Cirrus dorsalis und Cirrus ventralis.

dorsalen Cirren (Fig. 392). - Wir können die Parapodien als c o mple te bezeichnen, wenn sie alle genannten Theile besitzen, und als incomplete, wemn auf Kosten einiger stärker entwickelter Theile andere unterdrückt sind. - Durch Verkürzung des Basaltheiles verwandelı sich die Aeste des Parapods in unabhängige Gebilde, die als Borsten-

Fig. 392.

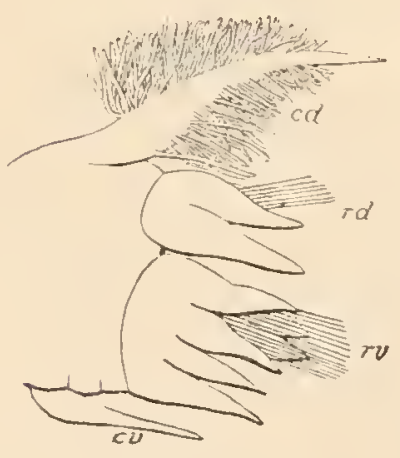

Fig. 393.

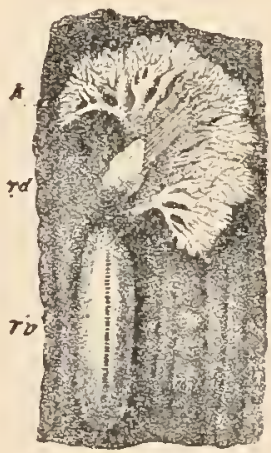

Fig. 392. Incompletes Parapodium, ohne Kieme, dessen dorsaler Cirrus aber kiemenähnlich gestaltet ist, von einer Nereide ( $D \in n$ dronereis arborifera), nach EHLERS.

Fig. 393. Ein Körpersegment von Arenicola, in seitlicher Ansicht (nach MILNE-EDwARds). $k$ Kieme, rd dorsaler Borstenhöcker, $r v$ ventraler Borstenwulst.

1) Zu blattförmigen Deckplatten, „Elytren“, sind die Cirren an einem Theil der Segmente bei den Aphroditeen umgewandelt. 
höcker und Borstenwïlste unterschieden werden; wenn solche Gebilde dorsal und ventral vorhanden sind, so nennen wir die Anordnung zweizeilig, wenn eines von beiden unterdrückt ist, einzeilig; daneben können auch die Kiemen selbständig auftreten oder fehlen. Bei den Oligochaeten endlich fehlen die Kiemen und auch die Höcker und Wülste sind derart reducirt, dass wir nur noch in die $\mathrm{Haut}$ e ing e p flanzte Borstenbündel unterscheiden.

Wir betrachten als Ausgangspunkt dieser mannigfachen Parapodienformen der Polychaeten das complete Parapodium; dasselbe ist zweiästig, mit dorsalem und ventralem Cirrus und mit dorsalerkieme. Es findet sich in einfachster Ausbildung schon bei den Spiomorphen; der dorsale Ast enthält meist Haarborsten, der ventrale meist gestreckte Hakenborsten, oft in deutlich fächerartiger oder querer Anordnung; der dorsale und ventrale Cirrus ist nur schwach entwickelt; die Kieme ist einfach fadenförmig. - Eine viel höhere Ausgestaltung dieser charakteristischen Theile finden wir bei den Rapacien (s. str.); die Parapodien sind hier mächtig entwickelte Anhänge, sie sind stets mit Aciculae versehen (solche kommen sonst nur noch bei Aricia vor), es finden sich neben einfachen Borsten stets auch zusammengesetzte Borstenformen, und zwar vorwiegend im ventralen Aste (nur bei Nephthys fehlen meist die zusammengesetzten Borsten); die dorsalen und ventralen Cirren sind hier stets besser ausgebildet; Kiemen können grösser und complicirter auftreten. Mit der höheren Differenzirung und Ausgestaltung des einen Theiles stellt sich sehr häufig aber eine Reducirung des anderen ein, so dass wir bei den Rapacien selten die complete Form der Parapodien finden (Nephthys, Glycera); wir beobachten hier vielmehr zumeist incomplete $\mathrm{Parapodien}$ in den mannigfachsten Modificationen. Bei den Euniciden ist die kammförmige Kieme wohlentwickelt, der dorsale Ast aber reducirt. Bei den Nereiden sind die zwei Aeste stark ausgebildet, es fehlt aber die Kieme, und bei den Syllideen und Phyllodoceen ist zudem noch der dorsale Ast reducirt. Bei Tomopteris fehlen die borstentragenden Aeste gänzlich und es sind an dem basalen Stummel nur noch die beiden blattförmig ausgebildeten Cirren vorhanden.

Getheilte Parapodien (Meropodien). Nach einer anderen Richtung finden wir das Parapod bei den übrigen Polychaetengruppen (Drilomorpha, Terebellomorpha, Serpulimorpha) und zwar durch Rückbildung verändert. Der Stamm des Parapods ist hier derart verkürzt, dass die beiden Aeste als selbständige Anhänge des Körpers erscheinen, ebenso auch die Parapodialkjeme, wenn eine solche vorhanden ist. Der dorsale Ast ist in der Regel zu einem kegelförmigen „B orsten hö cker" mit einem fächerförmigen Bündel von Haarborsten verwandelt, der ventrale Ast in einen quer ausgezogenen „Borstenwulst", der eine oder zwei Reihen ron Hakenborsten trägt; es kann aber auch die umgekehrte Anordnung statt haben; merkwürdig ist das Verhałten der Serpuliden, die im Vorderkörper dorsal Borstenhöcker, ventral Borstenwülste besitzen, am Hinterkörper aber die umgekehrte Anordnung zeigen. Diese getheilten Parapodien sind nie complete, indem hier die Cirren stets fehlen oder nur angedeutet sind (Seitenorgane der Capitelliden); die Kiemen können wohlausgebildet sein oder fehlen; die dorsalen und ventralen borstentragenden Anhänge können beide rorhanden sein ( $z$ weizeilige Anordnung), oder es ist nur eines von beiden ausgebildet (einzeilige Anordnung).

Fehlende (rückgebildete) Parapodien. Bei den Oligochaeten finden wir weder Cirren noch Kiemen, und statt der Höcker und Wülste 
finden wir nur einfach in die Haut eingepflanzte Borstengruppen. In manchen Fällen erinnern die zweizeilig angeordneten Gruppen noch vollkommen an das Verhalten der Drilomorphen, indem wir ein dorsales fächerförmiges Bündelchen von Haarborsten und ein ventrales quer ausgezogenes von Hakenborsten beobachten (Naiis). Bei den regenwurmartigen sind die Bündelchen weiter getheilt, so dass wir jederseits zwei Doppelreihen von Borstenfollikeln' finden, die nur je eine einzige Borste enthalten. Endlich sind die kranzförmig über einen grossen Theil des Umfanges des Segmentes vertheilten Borsten von Perichaela zu erwähnen (man vergleiche auch die hinteren Borstenkränze bei Echiurus).

Die parapodialen Anhänge sind nicht immer in der ganzen Ausdehnung des Körpers gleichartig ausgebildet. Abgesehen davon, dass sie zuweilen an den hintersten Segmenten rudimentär werden, was oft zur Ausbildung eines scliwanzartigen Hinterendes führt (z. B. besonders bei den Terebellomorphen), können sie auch in den aufeinander folgenden Körperabschnitten eine verschiedene Differenzirung erfahren, so dass eine deutliche Regioneubildung des Körpers auftritt (z. B. Serpulimorpha). Am wichtigsten aber ist die Umbildung, welche in der Regel das vorderste Körpersegment erfährt, indem dieses in nähere Beziehung zum Prosoma tritt und mit dessen reducirtem Metastomialtheil verschmilzt; wir bezeichnen dasselbe nuı als $\mathrm{M} u \mathrm{ndsegment}$ oder Peristomium; die Erscheinung tritt besonders bei den Rapacien typisch auf; die Borstenbündel (und auch die Kiemen) des Peristomiums werden meist rudimentär (sie können angedeutet sein, z. B. Aphroditeen, oder auch ganz fehlen, z. B. Euniceen [Fig. 397], etc.), die Parapodialcirren dagegen erfahren an diesem Segmente häufig eine bedeutendere Ausbildung, so dass sie mit als tentakelartige Gebilde des Vorderendes neben jenen des Prosoma fungiren (Fig. 395, etc.); wir wollen sie als Peristomialcirren bezeiclnen (in der Literatur wurden sie bisher Fühlercirren oder kurz Cirreıs s. str. genanıt). In einigen Fällen sind es auch mehrere der vorderen Segmente, an welchen die Parapodialcirren vergrössert erscheinen und die Borstenanhänge geschwunden sind, wobei oft ein gewisser Uebergang zu den folgenden Körpersegmenten stattfindet (viele Phyllodoceen, Euniceen etc.); bei den Nereiden aber sind typisch

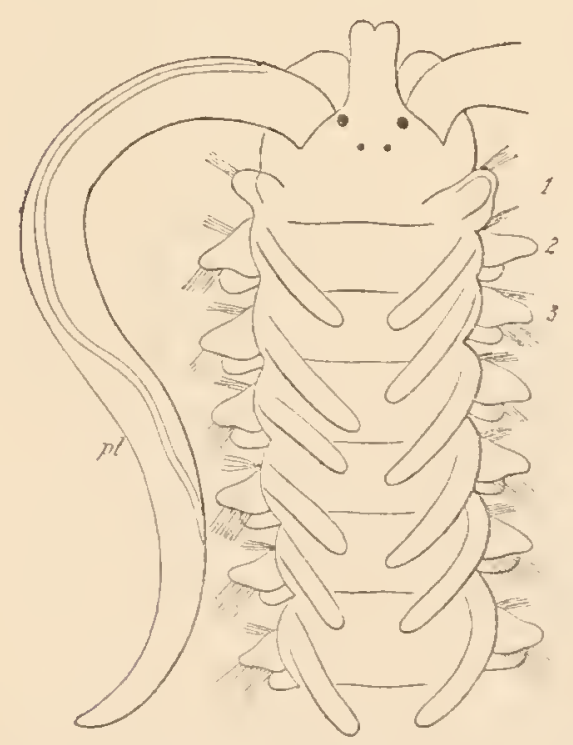
zwei Segmente mit Unterdrückung ihrer Borstenbündel und besonderer Ausbildung ihrer dorsalen und ventralen Cirrenpaare in die Bildung eines Peristomiums eingegangen, welches scharf gegen die nachfolgenden Segmente $a b-$ gesetzt ist (Fig. 396). Dies ist entwicklungsgeschichtlich durch E. Meyer erwiesen; einen phylogenetischen Uebergang zu diesem Verhalten zeigt die Gattung Stephania.

Fig. 394. Vorderende von Spio Mecznikowianus, nach Claparìde, pt Primärtentakel. 1 Erstes Segment (Peristomium) mit Borstenbündel, ohne Kieme; 2. 3 die nachfolgenden Segmente. 


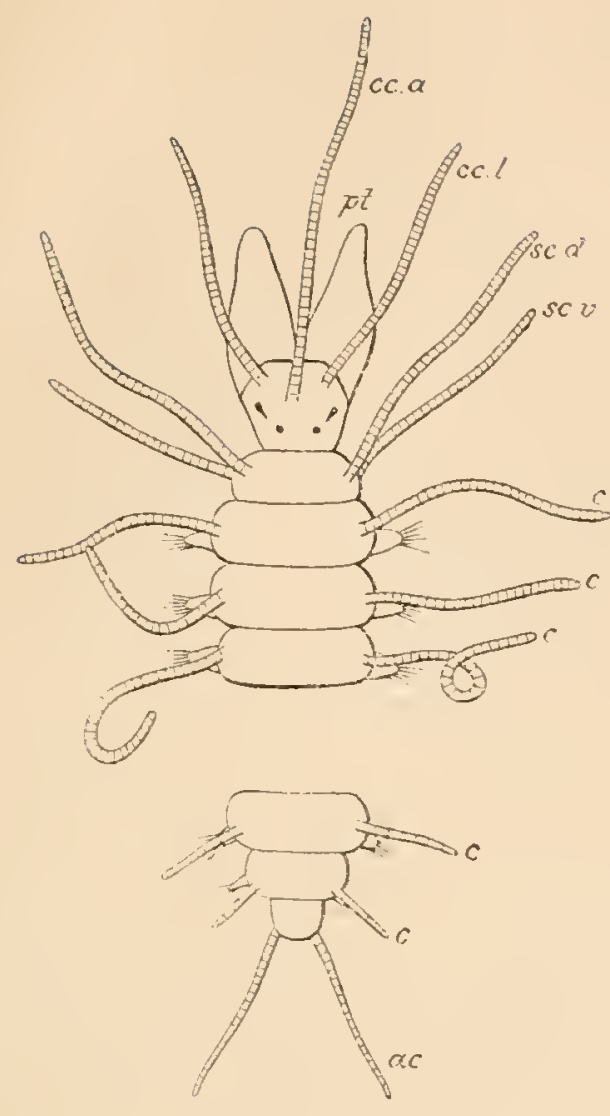

Fig. 395.

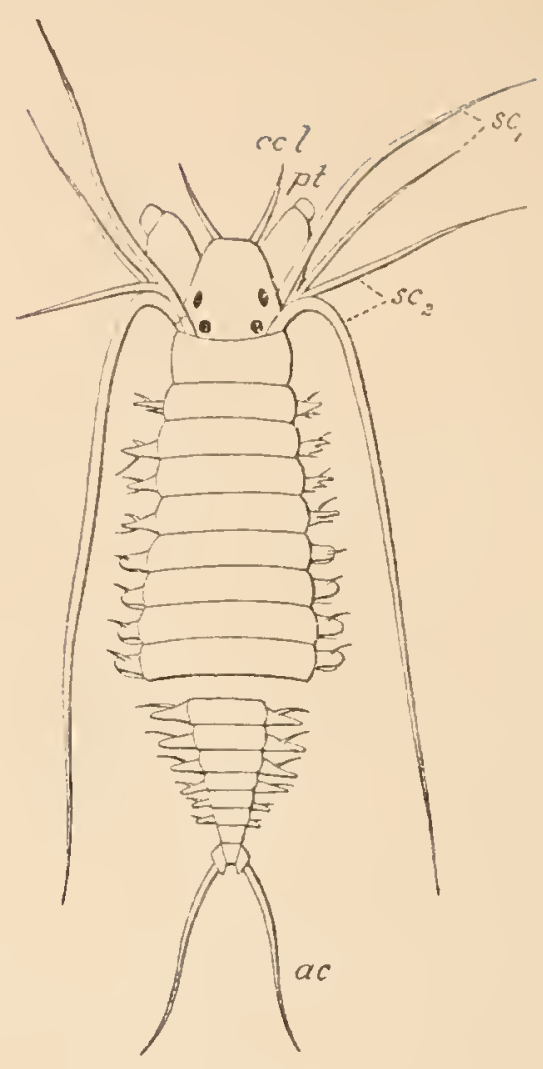

Fig. 396 .

Fig. 395. Vorder- und Hinterende von Syllis fiumensis, nach EuLEns. $p t$ Primärtentakel (Palpen); cc.a apicaler, und cc.l pariger Cerebralcirrus; sc.d, sc.v dorsaler und ventraler Cirrus des Peristomiums, dessen zugehörige Borstengruppe ganz in Wegfall gekommen ist; $c$ dorsale Cirren der übrigen Segmente; ac Analcirren.

Fig. 396. Vorder- und Hinterende von Nereis rubicunda, nach EhLERs. pt Primärtentakel (Palpen); $c c_{.} l$ Cerebralcirren in einem einzigen Pare vorhanden; $s c_{1}$, $s c_{2}$ peristomiale Cirren am vorderen Rand des Peristomiums zusammengedrängt; ac Analcirren.

II. Die Anhånge des Prostomiums. Am vorderen Körperende finden sich bei den meisten Polychaeten mehrfache tentakelartige Anhänge, und zwar in sehr wechselnder Zahl und Anordnung, je nach den verschiedenen Familien. Gleichwohl lassen sich die mannigfachen Verhältnisse auf einen gemeinsamen Grundtypus zurückführen. Wir werden am Prostomium zweierlei Anhänge unterscheiden: 1. Primärtentakel, die nur in einem Paar vorhanden sind, und 2. Cerebralcirren, deren Zahl oft fünf (Grundtypus), oft aber auch durch Reduction geringer ist.

Die morphologische Beurtheilung dieser Anhänge ist in der bisherigen Literatur meist sehr unklar durchgeführt. Bei den Rapacien werden die von uns als Primärtentakeln bezeichneten Gebilde als "Palpen", die von uns als Cerebralcirren bezeichneten Anhänge dagegen als "Tentakeln" unterschieden. Die Homologisirung mit den entsprechenden Gebilden in den Annelidenordnungen ist aber nicht immer richtig erkannt worden. Am weitesten ist in der morphologischen Erkenntniss in jüngster Zeit E. MeYer vorgedrungen, der die Primärtentakeln als „neurale (d. i. ventrale) Tentakeln“, die Cerebralcirren als "haemale (d. i. dorsale) Tentakeln" bezeichnet. 
A. Primärtentakel. Jenes Paar von charakteristischen Tentakeln, welche wir schon bei Protodrilus, Polygordius und ebenso bei Saccocirns fanden, bezeichnen wir als Primärtentakel; sie sind bei den genannten Thieren langgestreckte, sehr contractile Anhänge, die meist von einer Blutgefässschlinge durchzogen sind, und deren Epithel reich mit Sinneszellen ausgestattet ist. Auch bei den Spioniden sind dieselben in ähnlicher Weise stets als „Fangfühler" ${ }^{66}$ ausgebildet (hier wurden sie oft irriger Weise als "Cirren" [Peristomialcirren] bezeichnet); sie besitzen hier eine charakteristische Längsfurche und ein blind endigendes Blutgefäss (Fig. 394). Sie kommen ebenso auch den Chactopteriden zu, fehlen aber den Aricieen. Bei den Rapacien (Fig. 395, 396 , etc.) sind sie in den meisten Fällen vorhanden, doch sind sie hier kurz stummelförmig („Palpen“6) und sind an die Ventralseite des Prostomiums gerückt; bei manchen Syllideen u. a. sind sie zu einem unpaaren Anhang verschmolzen. - Bei den Drilomorphen fehlen sie meist; vielleicht sind sie auch hier in manchen Fällen zu einem unpaaren Kopfzapfen verschmolzen (Cirratulus). - Bei den Serpulimorphen (Fig. 408) sind sie in Zusammenhang mit der festsitzenden Lebensweise zu der Tentakelkrone ausgebildet (wie besonders E. Merer nachgewiesen hat).

B. Cerebralcirren. Am Prostomium finden sich ferner Anhänge, die zu den segmentalen Cirren der Parapodien in Beziehung zu bringen sind, wie durch die in vielen Fällen ganz übereinstimmende Struktur unzweifelhaft bewiesen wird (besonders lehrreich sind in dieser Frage die mannigfachen Formen der Syllideen [Fig. 395], deren grosse und bei den verschiedenen Arten sehr chrarakteristisch gestalteten dorsalen Parapodialcirren bei aller Mannigfaltigkeit stets mit den Cerebralcirren übereinstimmen. Bei den Archianneliden und Protochaeten, bei denen die Parapodialcirren nicht ausgebildet sind, fehlen auch die Cerebralcirren. Auch bei den Spioniden, deren Parapodialcirren nur schwach entwickelt sind, spielen ebenso die Cerebralcirren nur eine geringe Rolle; bei einigen Arten sind sie aber nachweisbar; man wird daher ihr Fehlen bei anderen Arten als Rückbildung erklären können. Bei den Rapacien, bei welchen auch die Parapodialcirren am besten entwickelt sind, finden ebenso die Cerebralcirren ihre höchste Ausbildung; es scheint, dass sie hier functionell für die mehr reducirten Primärtentakel eintreten. Die An-

Fig. 397.

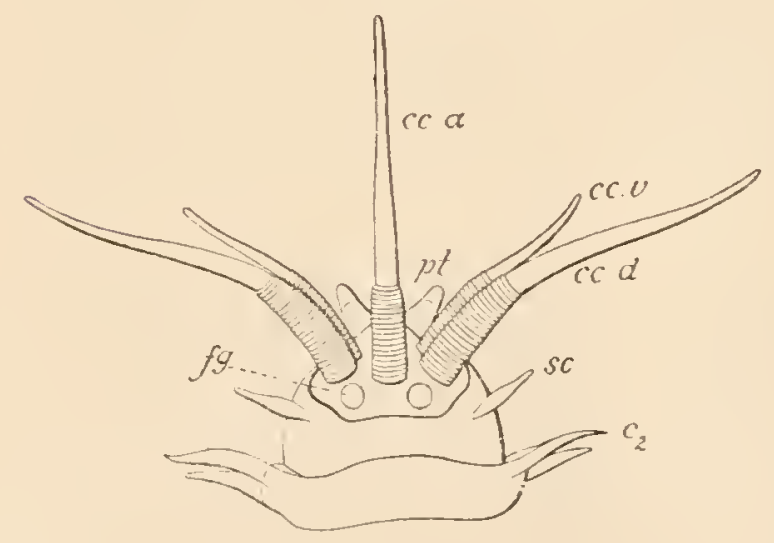

Fig. 398

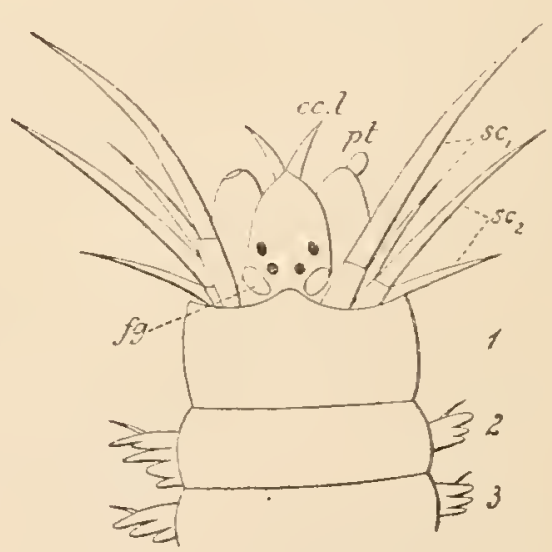

Fig. 397. Vorderende von Diopatra, nach SPEnGEL.

Fig. 398. Vorderende von Nereis, nach ClAPARÈDE. pt.Primärtentakel, cc (cc.a, cc.v, $c c . d, c c . l)$ Cerebralcirren, $s c$ Peristomcirren, $f g$ cerebrale Flimmergruben. 
ordıung der Cerebralcirren ist folgendermassen aufzufassen: Die vier Längsreihen voll Cirren, welche an dem segmentirten Körper durclı dic dorsalen und ventralen Paare von Parapodialcirren gebildet werden, setzen sich auch auf das Prostomium fort, insoferne als wir auch hier ein dorsales und ein ventrales Paar von Cerebralcirren beobachten; ihren Abschluss findell diese vier Reilien in dem umparen oder apicalen Cerebralcirrus. Diese fünf Cerebralcirren sind aber in Zusammenhang mit einer Lageveränderung des gesammten Prostomiums (vergl. unten bei Nervensystem) auf die Rückenseite verschoben. Die volle Fünfzahl der Cerebralcirren ist bei manclien Rapacien ausgebildet, z. B. bei vielen Euniceen (Fig. 397); bei anderen ist eine Reduction eingetreten, so haben die Syllideen (Fig. 395) stets nur drei, die Nereiden (Fig. 398) nur zwei Cerebralcirren u. s w. Auch bei den Amplinomeen ist meist noch die Fünfzahl vorhanden. In der Gruppe der Dilomorpha sind ebenso wie die parapodialen, so auch die cerebralen Cirren (und auch die Prinärtentakel) rückgebildet. - Dagegen erscheint bei den Terebellomorphen die Anzahl der Cerebralcirren bedeutend vermehrt, dieselben bilden hier die eigenthümlichen Büschel von Fangfäden.

Das Fehlen jeglicher Prostomialanhänge, welches schon bei den Drilomorphen zu bemerken ist, sowie auch aller Parapodialanhänge, wird in der Gruppe der Oligochaeten typisch; ebenso auch bei den Echiuriden.

III. Die Anhänge des Hinterendes (Periprocts) sind mannigfach, und ihre morphologischen Beziehungen sind noch nicht vollkommen aufgeklärt. Bei vielen Archianneliden und ebenso bei Saccocirrus finden wir ein Paar mit Drüsen- und Sinneszellen ausgestattete „Afterzacken"; nebstdem kommt bei einigen Polygordius-Arten nocls ein Kranz von Papillen oder Simneshöckeru vor (ein Paar langer, fadenförmiger Anlänge besitzt Polygordius appendiculatus); auf . diesen Papillenkranz sind vielleicht die zahlreich um den After angeordneten Analcirren zurückzuführen, die für die Spiomorphen charakteristisch sind und auch bei den Opheliaceen sich wiederfinden. Bei den Rapacien ist dagegen am Hinterende stets nur eine geringere Anzahl, aber desto grösserer Cirren vorhanden; seltener sind es vier und zwar ein dorsales und ein ventrales Paar, so dass sie als Abschluss der am Körper verlaufenden vier Längsreihen von Cirren elscheinen meist aber nur zwei sehr stark ausgebildete (Eunice, Nereis, etc.) (Fig. 395, 396). Nur ausnahmsweise ist auch ein unpaarer Analcirrus vorlianden (Ophriotrocha), der auch in anderen Annelidengruppen siclı findet. Auch bei den Amphinomeen sind meist zwei grosse Aftercirren vorhanden. Bei den übrigen Anneliden fehlen die Aftercirren.

Die Organisationsverhältnisse der Chaetopoden lassen sich auf einen gemeinsamen Grundtypus zurückführen, der sich ummittelbar an jenen der Archianneliden anschliesst, in den einzelnen Fällen aber mehr oder weniger bedeutende Modificationen erfährt.

Das äussere Epithel scheidet stets eine deutliche $\mathrm{Cu}$ ticula aus, innerhalb welcher unter rechtem Winkel sich kreuzende diagonale Faserstrukturen nachweisbar sind. Bei den Rapacien erreicht die Cuticula eine bedeutende Mächtigkeit und feste Consistenz, sowie eine lebhaft metallisch irsirende Färbung; eigentliche Pigmentstoffe (von abgelagerten 
Sekreten gebildet) kommen nur selten in derselben vor. - Flimmerhaare finden sich an der äusseren Körperfläche nur an gewissen beschränkten Stellen, so z. B. an den Kiemen, an der Bauchfurche (Serpula), seltener als Wimperkränze (Ophriotrocha).

Das Epithel selbst (Subcuticula, Matrix) ist meist in charakteristischer Weise aus Stützzellen, welche die Cuticula ausscheiden, und Drüsenzellen, die durch besondere Poren der Cuticula nach aussen münden, aufgebaut. Die Stützzellen haben in einigen Fällen eine merkwürdige, faserige Structur (Fig. 140). In den Drïsenzellen werden bei vielen Polychaeten auch stäbchenartige Gebilde erzeugt. Eine besondere Ausbildung erfahren die Drüsenzellen in Clitellum der Oligochaeten. In die Tiefe verlegte subepitheliale Drüsen kommen nur in manchen Fällen vor; sie können, auf gewisse Körperstellen beschränkt, eine mächtige Entwicklung und besondere functionelle Bedeutung gewinnen; so dienen sie z. B. zur Auscheidung der pergamentartigen, kalkigen etc., oft auch durch Fremdkörper oder Faeces verfestigten Wohnröhren, welche von vielen Anneliden (besonders den sogenannten Sedentarien) erzeugt werden. Hierher gehören auch die Parapodialdrüsen vieler Anneliden; in einzelnen Fällen sind diese letzteren aber auf umgewandelte Borstensäcke oder Borstendrüsen zurückzuführen (bei Polyodontes nach EIsIG).

Das Nervensystem zeigt bei den Chaetopoden in Bezug auf seine Lagerung sehr interessante Verhältnisse, insofern als hier alle Uebergänge von vollkommen epithelialer Lagerung bis zur vollständigen Sonderung angetroffen werden. In einigen Fällen ist bei ein und demselben Thiere im Vorderkörper und Hinterkörper hierin ein verschiedenes Verhalten zu beobachten (abgesehen von der Neubildung am fortwachsenden Hinterende). Das vollkommen gesonderte Nervensystem kann nach innen vonı Hautmuskelschlauch bis in die Leibeshöhle rücken; es ist aber in letzterem Falle stets mit einem Peritonealuiberzug versehen ${ }^{1}$ ). Bei den Polychaeten herrscht noch zumeist die epitheliale Lagerung des Nervensystems vor; bei vielen derselben ist die Zugehörigkeit des Nervensystems zun Epithel erst in neuerer Zeit besser erkannt worden, da nachgewiesen wurde, dass gewisse bindegewebsartige Hüllen (Neurilemm) des Nervensystems auch nur als modificirte Epithelgewebe zu betrachten sind und mit der Subcuticula noch continuirlich zusammenhängen (RHODE). Die vollkommene Sonderung vom Epithel, die bei den Polychaeten seltener vorkommt, ist bei den Oligochaeten die Regel.

Die typischen Theile des Centralnervensystems sind: das Cerebralganglion, die Schlund commissur und das Bauchmark.

Das Cerebralganglion ist, wemn es noch seine epitheliale Lagernng besitzt, stets im Prostomium zu finden, dessen Inneres oft ganz von demselben erfüllt wird (viele Polychaeten). Vom Epithel gesondert rückt es in der Regel weiter nacls hinten und ist in diesem Falle meist dem Schlunde aufgelagert (Oligochaeten). Der Aufbau des Cerebralganglions aus einer Anzahl besonderer Ganglien ist mehrfach betont worden (Spengel, E. Meyer u. a.).

Nach unserer Auffassung sind drei Hirnabschnitte zu unterscheiden: 1) Ein unpares I ittelhirn, welches sich oft noch in mehrfache Lappen

1) Hierzu kommen oft noch besondere Längsmnskeln oder eine vollkommene Muskelschichte (Lumbricus) am Bauchmark. 
gliedert und auch insofern eine (innere) Zusammensetzung zeigt, als es zu mehrfachen Sinnesorganen, nämlich den Cerebralaugen und den Cerebralcirren in Beziehung steht; es ist von einer queren Fasermasse durchzogen, die ventral in die seitlichen Schlundkommissuren übergeht. 2) Ein vorderes Ganglienpaar (Tentakularganglien), welches in Beziehung $z u$ den Primärtentakeln steht, und 3) ein hinteres Ganglienpaar (Riechlappen), welches zu den Riechgruben gehört. In der Regel ist schon bei den Polychaeten das Mittelhirn mitsammt dem ganzen Prostomium und dessen

Fig. 399.

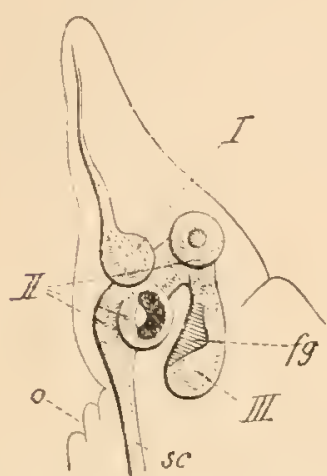

Fig. 400
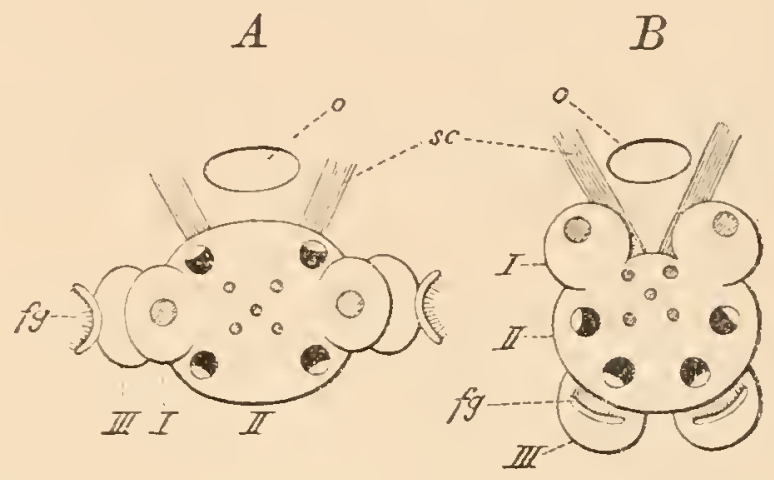

Fig. 399. Vorderende mit Gehirn von Cirratulus, nach E. MEYER. I Vorderhirn (Tentekularganglien), II Mittelhirn aus mehreren Theilen bestehend, III Hinterhirn (Riechganglien), $f g$ Riechgrube.

Fig. 400. Schematische Darstellung des Cerebralganglions vom vorderen Körperpol gesehen. A Ursurüngliche Lagerung. $B$ Verschiebung der Ganglien. I Tentakularganglien mit Andeutung der Wurzel der Tentakelnerven. II Mittelhirn mit Andeutung der Lage der 5 Cerebralcirren und den vier Augen. $I I I$ Riechganglien mit den Wimpergruben. - Mund, sc Schlundkommissur. (Die ursprüngliche Lage der paarigen Cerebralcirren wäre vielleicht richtiger ausserhalb der Cerelıralaugen anzunehmen.)

Anhängen etwas dorsal verschoben, dabei sind aber die vorderen oder Tentakularganglien zugleich mehr ventralwärts, die hinteren oder Riechganglien mehr dorsalwärts gerückt. Das Verhältniss dieser Verschiebung zu der hypothetischen ursprünglichen Lagerung ist in der schematischen Fig. 400 dargestellt. - Die Hirntheile sind in vielen Familien uur undeutlich gesondert oder auch theilweise reducirt; dies geht parallel mit der Rückbildung der prostomialen Sinnesorgane; besonders bei den Oligochaeten ist dies die Regel; die zahlreichen, oft knotig vorspringenden Ganglienpakete entsprechen dann keineswegs den ursprünglichen Hirnabschnitten.

Die peripheren Nerven, welche vom Cerebralganglion ausgehen, versorgen dlas vordere Körperende und dessen Simnesorgane, die zum 'Theil aber dem Ganglion unmittelbar verbunden sind.

Die Schlundcommissur, welche zu beiden Seiten des Mundes vom Cerebralganglion zum Bauchnıark hinzieht, besteht in der Regel nur aus Nervenfasern und deren Hüllgewebe; von der eigentlichen oder primären Schlundkommissur (s. str.), welche dem Metastomium zugehört, sind zu unterscheiden die vorderen Theile des Bauchmarkes, die in manchen Fällen (z. B. Amphinomeen) noch in Form von seitlich auseinandergerückten Strängen den Mund zwischen sich fassen, aber dennoch wohl den vordersten, auf das Metastomium folgenden Metameren zuzurechnen sind, wie aus ihrer Entwicklung, ihrem Aufbau und der Anordnung der peripheren, von ihnen abgehenden Nerven zu erweisen wäre. 
Das Bauchmark, welches sich durch alle Metameren erstreckt, dem Endsegment aber nicht zukommt, zeigt bei allen Chaetopoden eine deutliche Gliederung, dadurch bedingt, dass die Ganglienzellen in keinem Falle mehr einen gleichmässigen Belag bilden, sonderu segmentweise gehäuft erscheinen. (Ich finde, dass dies auch schon bei Saccocirrus nachweisbar ist.) Dazu kommt die regelmässige Wiederholung der Quercommissuren, d. i. querer Nervenfaserzüge, welche die Ganglienhälften der beiden Körperseiten miteinander verbinden, und endlich auch die regelmässig sich wiederholenden (meist drei Paar in jedem Segmente) peripheren Terven, die in der Regel nur von den Ganglienknoten ausgehen. - Man unterscheidet zwei Hauptformen des Bauchmarkes, die Bauchganglienkette und das Strickleiterbauchmark - je nachdem die Seitenstränge des Bauchmarkes nahe aneinandergerückt oder aber weit voneinander entfernt und dementsprechend durch lange Quercommissuren verbunden sind.

Die typische Bauchganglienkette besteht aus den segmentalen Ganglien (selten in jedem Segmente in melurere aufeinanderfolgende Kuoten zerfällt) und den intersegmentalen Längscommissuren. An dem Querschnitt des Ganglions sehen wir, dass die längsverlaufenden Nervenfasern in zwei seitlichen Hauptmassen und oft auch einem mittleren Strange angeordnet sind; meist sind drei oder mehrere sogenannte colossale Nervenfasern gesondert gelagert (vergl. pag. $135 \mathrm{ff}$.) ; die Nervenfasermassen bilden den dorsalen Theil des Ganglions; sie sind durch quer verlaufende Nervencommissuren verbunden. Die Ganglienzellen sind an der ventralen Seite des Ganglions in je zwei lateralen und zwei medialen Paketen angeordnet, die vorn und hinten an jedem Ganglion sich wiederholen (diese Anordnung ist zurïckführbar auf rier ursprünglich continuirliche Ganglienzellsäulen). Das epithelogene Stützgewebe bildet sowohl eine äussere (Neurilemm) als auch eine mediale Stützlamelle des Ganglions. - Die Läugscommissuren zeigen denselben Aufbau, nur dass die Ganglienzellen und auch die queren Faserzüge hier fehlen. - Das Strickleiterbauchmark ist, wie schon erwähnt, nur durch das Auseinanderrücken in zwei seitliche Stränge, deren Ganglienknoten durch längere Quercommissuren verbunden sind, gekennzeichnet. Der histologische Aufbau dieser beiden Formen des Bauchmarkes zeigt aber bis ins einzelue die grösste Uebereinstimmung, und àer Gegensatz erscheint daher morphologisch geringfügig, besonders wenn die epitbeliale Lagerung des Nervensystems noch erhalten ist.

Die peripheren Nerven, die vom Bauchmark ausgehen, und im Epithel selbst oder subepithelial gelagert sind, erstrecken sich oft bis zur Rückenlinie, um sich dort ringförmig zu vereinigen. An der Basis der Parapodien ist meist ein ansehnliches Parapodialganglion zu finden; auch sonst sind in den Verlauf der peripheren Nerven oft Ganglienzellen eingeschaltet, so dass ein förmlicher Nervenplexus (epithelial oder subepithelial) zu Stande kommen kann. Diese Nerven versorgen sowohl die Sinnesorgane der Haut, als auch den Hautmuskelschlauch.

Ein Schlundnervensystem mit Schlundganglien, welches mit den Schlundcommissuren und auch mit dem Cerebralganglion zusammen häugt, ist allgemein nachgewiesen; auch dieses kann eine vollkommen epitheliale Lage im Schlundepithel bewahren, welches daher als dessen Entstehungsort $\mathrm{zu}$ betrachten ist. Ein sympathisches Nerven- 
ga n gli en-Geflech t für den Mitteldarm ist nur bei den verwandten Hirudineen genauer erforscht.

Die Siln esorgane sind bei den Rapacien am höchsten entwickelt, bei den festsitzenden Polychaeten-Formen und bei den im Schlamm und Humus lebenden Otigochaeten mehr verkümmert.

Als Hautsinnesorgane finden sich seltener einzelne Sinneszellen; allgemeiner kommen Simnesknospen über die ganze Körperoberfläche zerstreut vor; besonders gehäuft sind sie am vorderen Körperende, an den Tentakeln und an allen Cirren. Die sogenannten Seitenorgane der Capitelliden werden als verkürzte Parapodialcirren betrachtet (KLEINenberG, Eisig), sie mögen durch Vergrösserung einzelner oder durch Vereinigung zahlreicher Simnesknospen entstanden sein.

Fig. 401. Centralnervensystem der vorderen Körperendes und Schlundnervensystem von Nereis, nach QuAtrefages. Cerebralganglion $(\mathrm{cg})$; Schlundcommissur (sc); die 4 ersten Ganglien des Bauchmarkes $(b m)$; Schlundnervensystem $(s n)$.

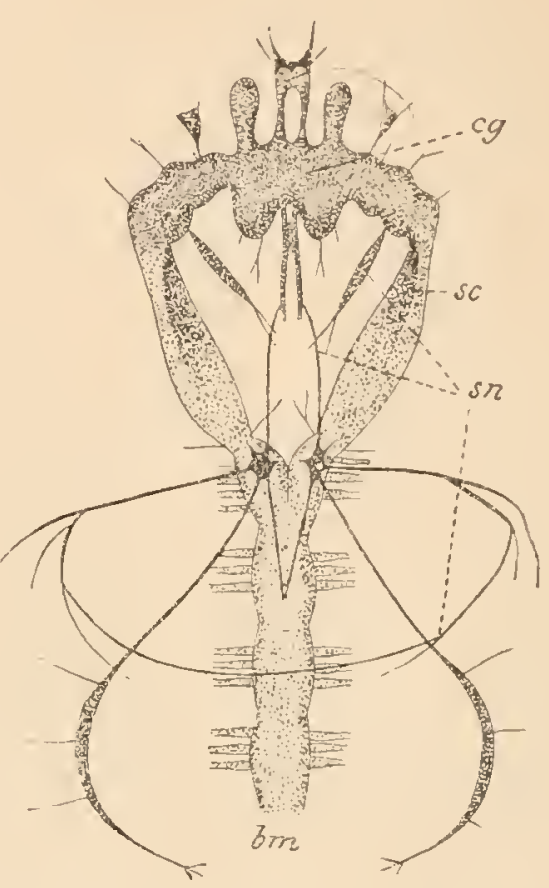

Aehnliche Sinnesknospen, welche im Schlunde sich finden, sind als Geschmacksorgan e zu deuten.

Als Geruchsorgane werden die parigen Flimmergruben betrachtet, welche mit den hinteren Hirnlappen innig verbunden sind. Sie sind als kräftig bewimperte, meist vorstülpbare Taschen bei den Polychaeten sehr verbreitet, fehlen aber den Otigochacten. Sie gehören ihrer Entwicklung nach dem Prostomium an.

Gehör bläschen kommen nur selten (so bei Serpuliden und Arenicoliden) meist in einem Paar, der Schlundcommissur anliegend, vor; sie sind wohl der metastomialen Region zugehörig.

A ugen kommen bei den Polychaeten in der Regel am Prostomium vor (Cerebralaugen); sie sind nach dem Typus des einfachen Blasenauges gebaut und stehen in inniger Beziehung zum Mittelhirn. Bei vielen Familien finden sie sich in Vierzahl, und zwar ist ein grösseres vorderes und ein kleineres hinteres Paar zu unterscheiden. [Wir vermuthen, dass dies von einem ursprünglicheren Verhalten abzuleiten sei, wo vier gleich grosse Augen, als ventrales und dorsales Paar, regelmässig um den Apicalpol vertheilt waren, und dass hierin Beziehungen $\mathrm{zu}$ einer primären radiären Anordnung vorlagen.] Oft ist nur noch das vordere Paar erhalten und erreicht dann oft eine um so bedeutendere Grösse (Phyllodoceen); den Höhepunkt der Ausbildung zeigen die zwei den Kopf weit überragenden Augen bei den pelagisch lebenden Alciopiden (vergl. pag. 199). Seltener sind zahlreiche kleine Augen am Prostomium zu finden (Capitelliden etc.). Bei einigen Serpuliden kommen Augen an den zahlreichen Fäden der 'Tentakelkrone vor. Bei Polyophthalmus wiederholen sich seitliche, augenartige Organe an allen Körpersegmenten. Nur wenige Oligochaeten (Nä̈deen) besitzen A ugen, und zwar ein rudimentäres Augenpaar im Epithel des Prostomiums. 
Die somatische Muskulatur besteht aus der äusseren Ringmuskelschichte und der inmeren Längsmuskelschichte; letztere ist nach innen gegen die Leibeshöhle vom Peritonealepithel bedeckt, zu welchem sie in genetischer Beziehung steht; fernel gehören hierher' die queren Muskeln, die in den transversalen Septen verlaufen, und endlich die Muskeln der Borstenbündel, die von der Basis der Borstenfollikel in verschiedener' Richtung zur Leibeswand ziehen. Die Längsmuskelschichte ist im einfachsten Falle in vier Linien unterbrochen, in der Bauch- und Rückenlinie und in den sogenannten Seitenlinien, welche letztere vou den Parapodien eingenommen werden; man unterscheidet da also ein dorsales und ein ventrales Paar von Längsmuskelfeldern. Es kommen aber oft noch accessorische Längsmuskelfelder hinzu, so z. B. ein medioventrales, oft auch seitliche Felder, welche letztere zwischen den dorsalen und ventralen Borstengruppen verlaufen (bei den Drilomorphen und besonders bei den Oligochaeten). Der histologische Aufbau und speciell die mannigfachen Faltungsprocesse der Längsmuskelschichte wurden schon an anderer Stelle (pag. 123) erwähnt. - Die transversalen Septen (zusammenhängend oder gitterförmig durchbrochen) sind bei den meisten Polychaeten vorhanden; den Oligochaeten scheinen sie zu fehlen ${ }^{1}$ ).

$\mathrm{V}$ iscerale M uskeln finden sich nicht nur am Darm, sondern auch an anderen inneren Organen (Blutgefässe, Excretionsorgane etc.); auch die Muskeln der Dissepimente, aus gekreuzten Fasersystemen bestehend, sind hier zu erwähnen.

Die drei Abtheilungen des Darmes, Vorderdarm, Mitteldarm und Hinterdarn, zeigen mannigfache Differenzirungen.

Der ectodermale Vorderdarm oder Schlund erstreckt sich stets durch eine Anzahl der rordersten Körpersegmente (ausser bei Aeolosoma), in welchen keine Gonaden zur Entwicklung kommen. Er ist häufig durch einen ausstülpbaren Theil, den Schlundkopf, ausgezeichnet; mit diesem Namen werden verschiedenartige Bildungen bezeichnet, deren specielle Homologie noch dahingestellt sein mag. Schon bei einigen Archianneliden fand sich ein eigenthümlicher vorderer, ventraler Schlundanhang. Bei Saccocirrus und den Spiomorphen fehlt ein solcher, doch ist in einigen Fällen der Schlund selbst vorstülpbar (Theodisca). Für die Rapacien ist es charakteristisch, dass der Schlund oder 'Theile desselben vorstülpbar und bewaffnet sind; dabei ist aber' ein mannigfaches Verhalten $\mathrm{zu}$ constatiren. Bei einigen wird der Schlund einfach nach aussen vorgestülpt, wobei ein am Hinterende des Schlundes befindlicher Kranz von weichen Papillen (Nephthys) oder' auch von chitinigen Zähnen, sogenannten Kiefern, vorgestreckt wird; letztere sind bei Glycera in der Zahl 4 regelmässig rings um die Schlundöffnung gestellt. Bei den Phyllodoceen, Syllideen etc. liegt der vorstülpbare Theil (röhrenförmiger Schlundkopf) in Form eines röhrenförmigen Gebildes (Duplicatur) im Schlunde und ist bei den letzteren mit einem unpaaren Chitinzahn versehen; bei den Nereiden finden sich ein Paar grosse, seitlich gestellte Schlundkiefer. Die höchste Stufe del Ausbildung erreicht der Schlundkopf bei den Euniciden; er bildet einen

1) Bei Lumbricus kommen kleine quere Muskelbänder vor, die zwischen den dorsalen und ventralen Borstengruppen sich erstrecken und vielleicht als letzte Reste der transvirsalen Muskeln zu betrachten sind, worauf mein Assistent, Herr Dr. CorI, mich aufmerksam machte. 
vorderen ventralen Anhang des Schlundes und ist mit einer ansehnlichen Reihe von oberen likeferpaaren und einem kleineren unteren Kieferpaare ausgestattet. In mancheli Fällen ist ein besonderer hinterer drüsiger Abschnitt des Schlundes vorhanden (z. B. Syllideen), und sehr oft finden sich an seinem Hinterende paarige, drüsige Anhänge. - Bei den Drilomorphen, Serpulimorphen und Terebellomorphen ist keine Schlundbewaffnung vorhanden, doch ist oft ein schwach entwickelter, vorderer, ventraler Schlundanhang angedeutet. Die Oligochaeten besitzen einen kurzen Schlund ohne Schlundkopf und Bewaffnung.
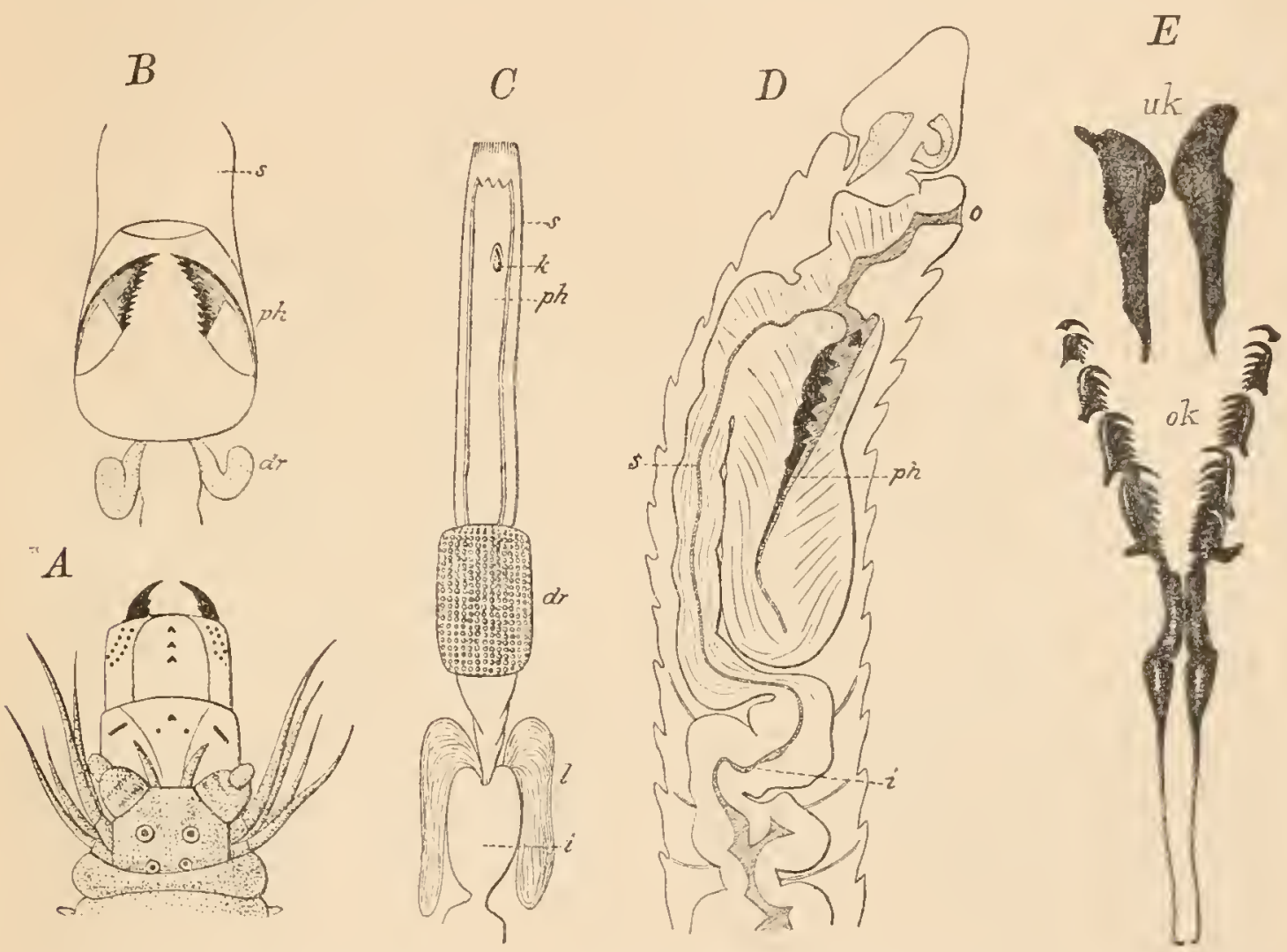

Fig. 402. A Nereis cultrifera. Vorderende mit vorgestulptem Schlund. An demselben 2 grössere Chitinkiefer und zahlreichere kleinere Zähnchen. $\boldsymbol{B}$ Vorderdarm einer Nereis in eingestülptem Zustande. $s$ Schlund (Tasche); $p h$ Schlundkopf; $d r$ Anhangsdrüsen. $C$ Vorderdarm von Syllis sexoculata. $s$ Schlund (Tasche); $p h$ Schlundkopf, $k$ unpaarer Chitinzahn; $d r$ drüsiger Abschnitt; $l$ paarige Drüsenanhänge ; $i$ erste Kammer des Mitteldarmes. $D$ Medialer Längsschnitt durch das Vorderende einer Eunicide (Lumbriconereis.) o Mund; s Schlund; $p h$ ventraler Schlundkopf; $i$ Mitteldarm. E Chitinkiefer aus dem ventralen Schlundanhange einer Eunicide. $u k$, of Unter- und Oberkiefer. $A, C, D, E$ nach Ehlers, $B$ nach Claperìde.

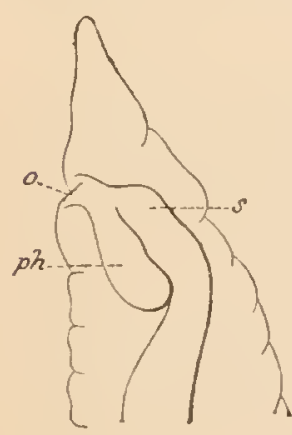

Fig. 403. Vorderende von Cirratulus, nach E. MErFr. o Mund; s Schlund; ph ventraler Schlundanhang.

Der Mitteldarm ist nur im Larrenstadium deutlicher in Magen und Dünndarm geschieden; er ist meist durch die Dissepimente regelmässig intersegmental eingeschnürt und daher segmental erweitert; oft steigert sich dies Verhalten derart, dass ansehnliche seitliche Darmtaschen in jedem Segment zu Stande kommen, die bei den Aphroditeen endlich zu ansehnlichen Blindsäcken auswachsen. Eine sehr merkwürdige Bildung, der ventrale Nebendarm, der als dünneres Rohr den Mittel- 
darm begleitet und nur an beiden Enden in denselben mündet, ist bei Capitelliden und Rapacien beobachtet; dieses Gebilde ist vielleicht auf eine typische ventrale Flimmerrinne des Darmes zurückzuführen. Beim Regenwurm dient eine ansehnliche dorsale, in das Darmlumen vorspringende Schleimhautfalte (Typhlosolis) zur Vergrösserung der resorbirenden Innenfläche. Bei den Oligochaeten ist der auf den Schlund folgende Theil des Mitteldarmes zu einem Oesophagusabschnitt ausgebildet, der bei den Regenwürmern noch weitere Differenzirungen (Kropf und Muskelmagen) erfährt. Der Mitteldarm besteht im allgemeinen aus der Peritonealschicht, äusserer Längs-, innerer Ringmuskelschicht, Gefässschicht und der inneren meist bewimperten Epithelschicht.

Der Enddarm, welcher von ectodermalem Epithel ausgekleidet ist, hat meist nur eine sehr geringe Ausdehnung.

Das Blutgefässsystem der Chaetopoden zeigt die typischen Theile in mehr oder weniger bedeutenden Modificationen. In einigen Fällen fehlen die Blutgefässe gänzlich (Capitelliden, Glyceriden). In der Regel ist es als ein geschlossenes System vorhanden, welches eine besondere gefärbte (rothe oder auch grüne, gelbe) Blutflüssigkeit meist ohne Blutkörperchen enthält. In der Regel ist das Rückengefäss contractil, oft auch alle oder nur einige der somatischen Gefässbogen, seltener auch andere Gefässe. - Bei kleineren Formen finden sich nur die typischen Hauptgefässe (splanchnisches Gefässnetz, Rückengefäss, vordere Gefässbogen, segmentale somatische Gefässbogen), bei grösseren Formen kommen neue Gefässe (z. B. Längsgefässe am Bauchmark von Lumbricus und Nephthys, seitliche Längsgefässe im Vorderkörper von Serpulaceen etc.) und zahlreiche Gefässverästelungen besonders in den Kiemen und in der Körperwand hinzu. - Das Rückengefäss ist meist einfach, in einigen Fällen aber paarig (Eunice); es kann auch zum grössten 'Theil fehlen und durch einen Darmblutsinus (zwischen Darmepithel und splanchnischem Blatte an Stelle des splanchnischen Gefässnetzes) ersetzt sein (Serpuliden, Ciratulus); bei den Terebelliden ist das herzartig erweiterte Rückengefäss auf das Vorderende des Körpers beschränkt. Im Rückengefäss findet sich oft ein eigenthümlicher pigmentirter Zellkörper (Herzkörper). - Das Blut gelangt meist durch die vorderen Gefässbogen in das unter dem Darm gelegene Bauchgefäss. - Durch die segmentalen somatischen Gefässbogen, in deren Verlauf die Gefässe der parapodialen Kiemen eingeschaltet sind, fliesst das Blut meist vom Bauchgefäss wieder zum Rückengefäss. Besondere Kiemenherzen finden sich an den Gefässbogen bei Eunice (Fig. 404). Seltener strönt das Blut vom Rücken-

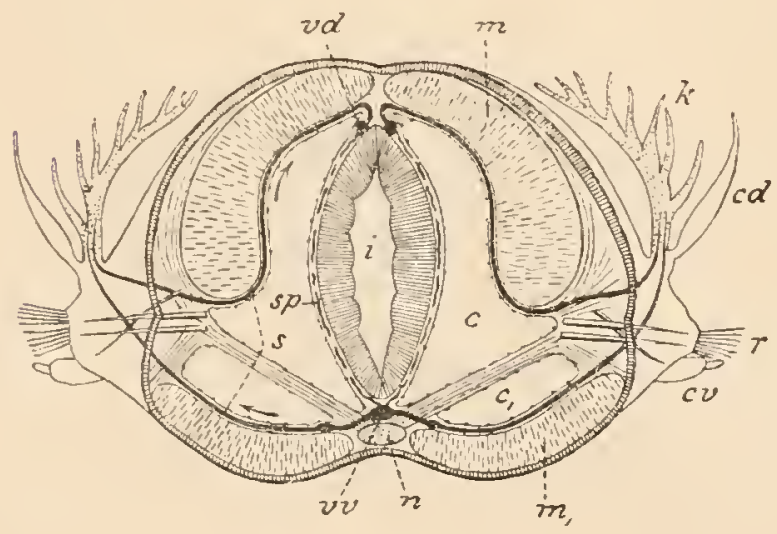

Fig. 404. Querschnitt durch ein Segment mit der Blutgefässvertheilung desselben von Eunice, nach EHLERs. to Kieme; $c d$ Cirrus dorsalis; $r$ ventrales Ruder; $c v$ Cirrus ventralis; $m$ dorsales; $m$, ventrales Muskelfeld; $c$ Hauptkammer; $c$, Bauchkammer der Leibeshöhle; $i$ Darm; $u$ Bauchmark; $s p$ splanchnische Gefässe; vd Riickengefäss (paarig); vv Bauchgefäss; s somatischer Gefässbogen. 
gefäss zu den Kiemen und von da zum Bauchgefïss, so z. B. bei den am Vorderkörper befindlichen ' Kiemen der Terebelliden. In einigen Fällen, so bei vielen Oligochaeten, sind ein oder mehrere in der vorderen Körperregion gelegene somatische Gefässbogen besonders contractil und sackartig erweitert und entbehren jeder Gefässver'weigung, sie sind in seitliche Nebenherzen umgewandelt, welche das Blut rom Rückengefäss zum Bauchgefäss fülıren.

Die Leibeshöll le ist durch die typischen medialen (dorsales und ventrales) Längsmesenterien, die segmentalen Septen und die transversalen Längssepten in mehr oder weniger vollkommen von einander abgeschlossene Kammern getheilt. Ganz allgemein ist aber bei den Chaetopoden durch das Hineinrücken des Schlundes in die vorderen Segmente eine Rückbildnng der Dissepimente und medialen Mesenterien in dieser Region eingetreten. - Es kommen ferner mannigfache Modificationen vor. Bei den Oligochaeten fehlt wohl durchweg das dorsale Mesenterium; auch fehlen denselben die transversalen Septen. In einigen Fällen, z. B. Terebelliden, sind in einer Körperregion bestimmte Dissepimente stärker ausgebildet und andere unterdrückt in Kusammenhang mit gewissen Umbildungen des Nephridialsystems (siehe unten). In höherem Grade ist eine Rückbildung der Dissepimente bei den Glyceriden (u. a.) eingetreten, so dass der Darm eine freiere Beweglichleit besitzt.

Die Leibeshöhle ist allseitig von einem peritonealen Epithel ausgekleidet (auch im Prosoma, trotz der dort andersartigen Entwicklung); dieses Epithel zeigt manchmal an bestimmten Stellen eigenartige Differenzirungen, von denen man vermuthet hat, dass sie zur Excretion in Beziehung stehen; besonders sind hier die grünlichen, körnigen Chlorogogenzellen hervorzuheben, die das splanchnische Gefüssnetz, das Rüickengefäss und einen Theil der Seitengefässe bei den „Oligochaeten" überziehen. Die Leibeshöhlenflüssigkeit enthält in der Regel Lymphzellen, in einigen Fällen gefärbte, an farbige Blutkörperchen erinnernde Zellen (bei den Blutgefässe entbehrenden Glyceriden). Auch mit Excreten beladene Zellen werden darin angetroffen.

Als Excretionsorgane finden sich die typischen Segmentalorgane, deren Trichter meist das Dissepiment durchbohrend in das nächstvordere Segment hineinragt; bei vielen Polychaeten ist dieses Lagerungsverhältniss des Trichters nicht ausgesprochen; bei Chaetogaster fehlen die Trichter. - Bei den Polychaeten sind die Segmentalorgane meist kurz und weit; oft sind sie in jedem Segment noch ziemlich gerade gestreckt nach hinten verlaufend zu finden, oft auch nur schwach gekrümmt, in anderen Fällen aber schon schleifenförmig ausgebildet; sie sind meist ausserhalb der Leibeshöhle retroperitoneal gelegen. Bei den Oligochaeten sind sie stets schleifenförnig und überdies noch mehrfach aufgeknäult und sie sind unter Mitnahme eines Peritonealüberzuges in die Leibeshöhle gerückt; ihr Kanal ist oft in verschiedenartige Abschnitte differenzirt, und oft schliesst sich ein ansehnlicher ectodermaler, mit einer Muskelschicht versehener Endabschnitt an denselben. Das Lumen ihres Excretionskanales ist enge und im Querschnitt von nur einer "durchbohrten" Zelle umgeben. - Von den mannigfachen Morlificationen der Segmentalorgane ist hervorzuheben das Vorkommen mehrerer Organe in einem Segmente und zwar hinter einander bei $\mathrm{Ca}$ pitelliden (EISIG) (auch kommen da Segmentalorgane mit mehreren Trichtern vor) und neben einander, den vier oder mehreren Borstengruppen entsprechend, bei manchen exotischen Lumbriciden (Acantho- 
drilus, Perichaeta); bei exotischen Lumbricidengattungen kommt auch in Zusammenhang mit den Segmentalkanälen ein reich verästeltes, durch viele Segmente zusammenhängendes Netzwerk von Flimmerkanälen vor. - Eine ungleiche Ausbildung der Organe in den verschiedenen Körperregionen ist mehrfach beobachtet. Bei den Capitellinen schwinden die

Fig. 405 .

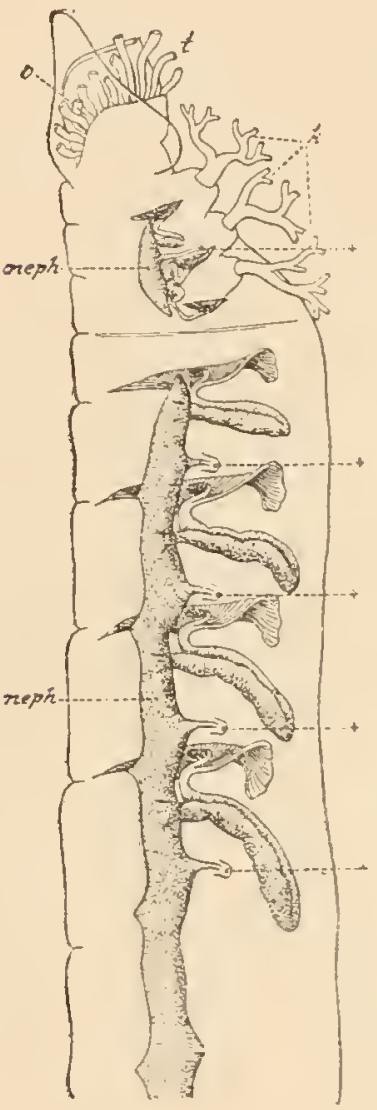

Fig. 406.

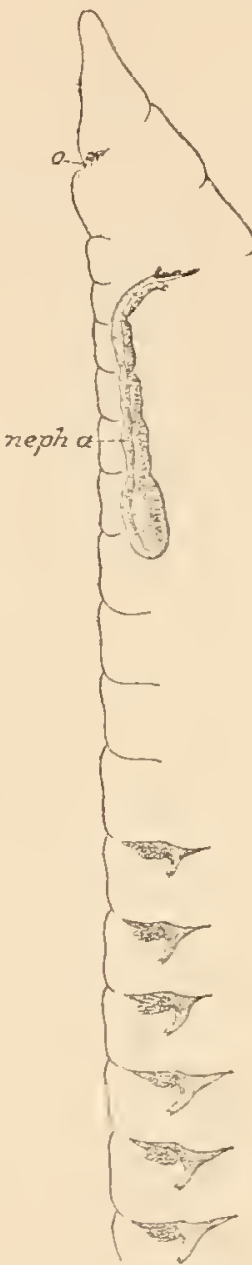

Fig. 407

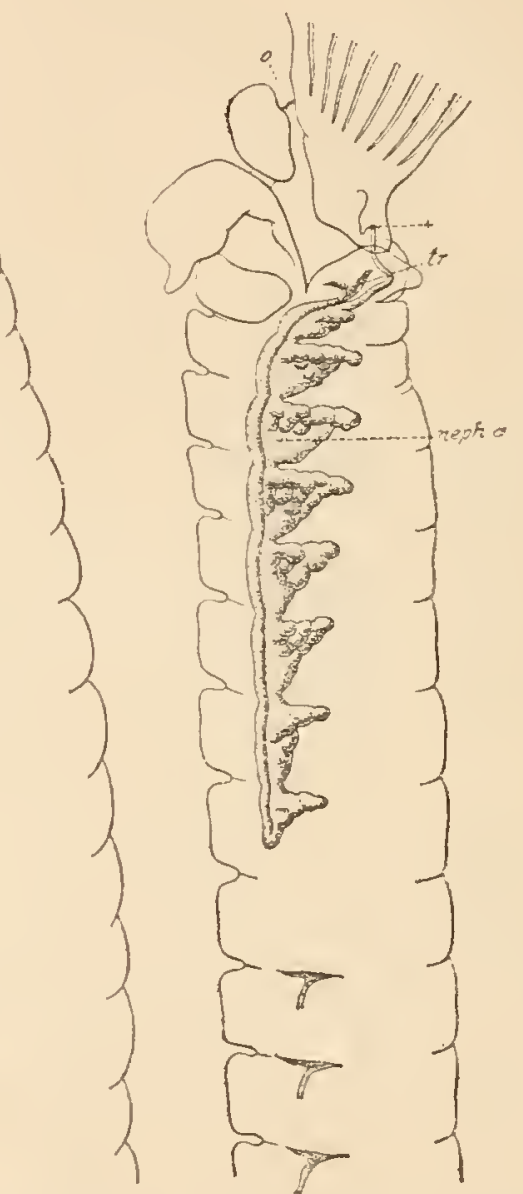

Fig. 405. Vorderende von Lanice conchilega, nach E. MFxER. Die Kopfcirren $(t)$ und Kiemen (k) sind abgeschnitten; o Mund; neph die drei verb. Nephridien der vorderen Thoracalkammer; neph, die Nephridien der hinteren Thoracalkammer; der die letzteren verbindende Kanal erstreckt sich noch durch zahlreiche folgende Segmente; die äusseren Mündungen sind durch + bezeichnet.

Fig. 406. Vorderende eines Cirratuliden (Chaetozone), nach E. MEYER. neph.a vorderes excretorisches Organ.

Fig. 407. Vorderende von Spirographis. nach E. MErER. neph a vorderes excretorisches Nephridium; + dessen Mündung; $t r$ Wimpertrichter.

Segmentalorgane meist in den vorderen Körpersegmenten, in welchen die sogen. "Genitalschläuche" sich bilden (ähnlich wie bei den limicolen Otigochaeten). Bei den Terebelliden finden sie sich nur in dem vorderen Theil des Körpers, dessen Leibeshöhle durch ein besonders entwickeltes Dissepiment bei Schwund der übrigen in einen vorderen und hinteren ,Thoracalraum" getheilt ist; die Segmentalorgane des vorderen Thoracalraumes fungiren als Excretionsorgane, die des hinteren als Ausführgänge des Geschlechtsapparates. Bei Lanice conchilega sind jederseits mehrere solcher Organe durch einen Längskanal in Verbindung 



